\title{
The American Veterinary Profession
}


$3 x^{3}=i+c^{2}$

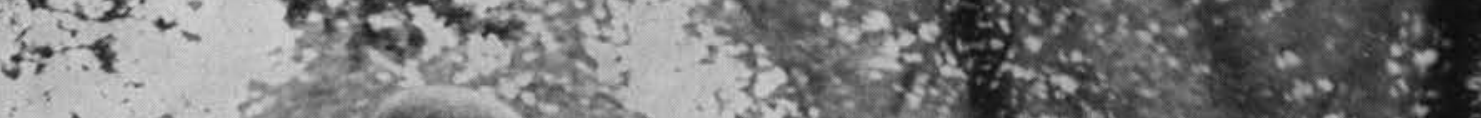

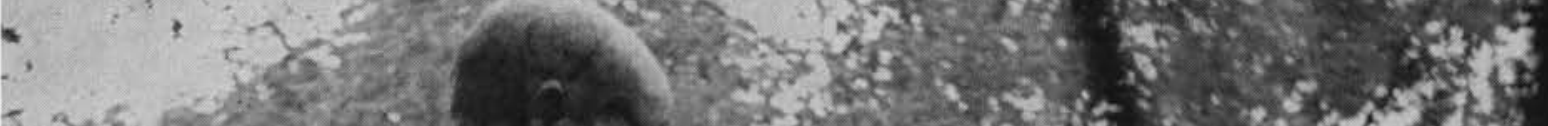
a

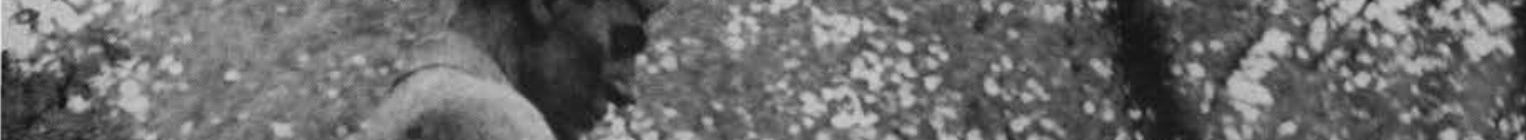

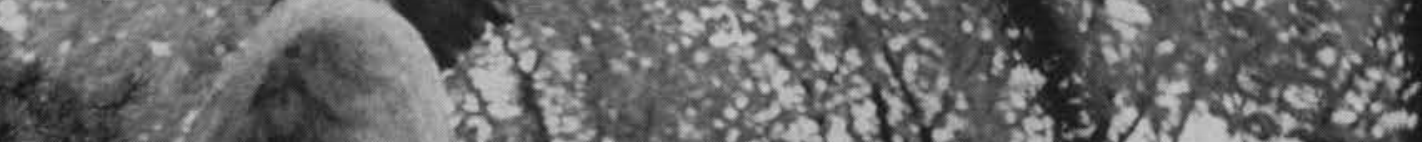

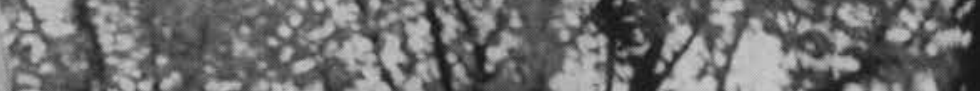

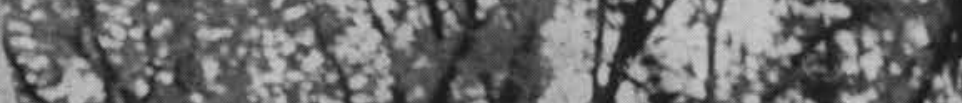

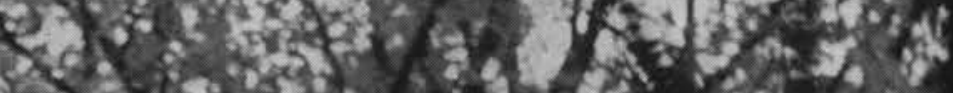

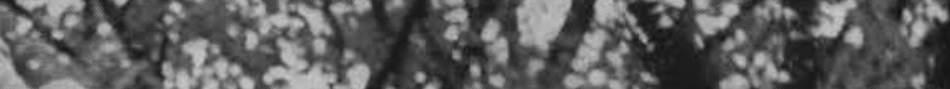

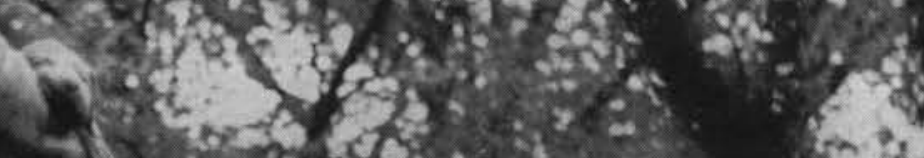

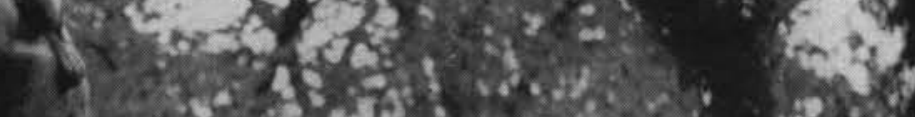

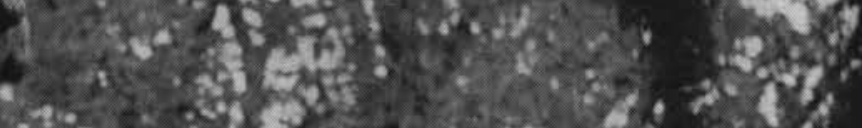

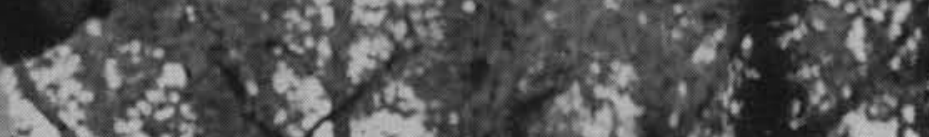
No 0 : 3 \%

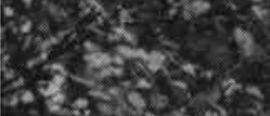
4052 S.

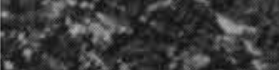

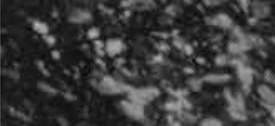
B. 5 . ar.

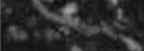

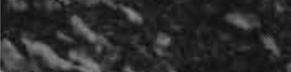

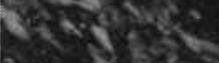

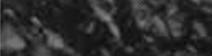

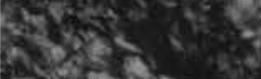

arcestor

$303 x+25$

Bes?

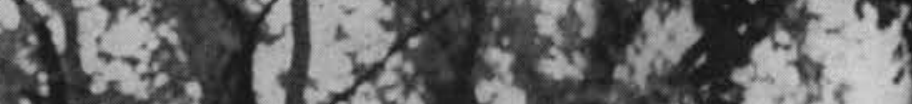

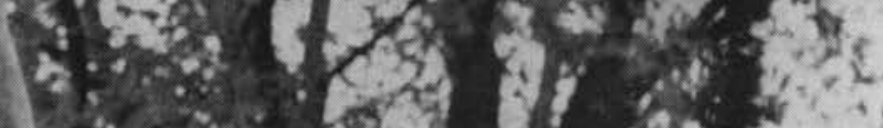

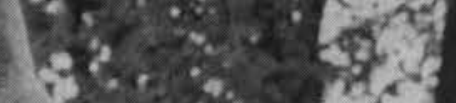
in fis

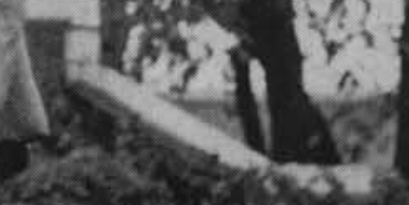

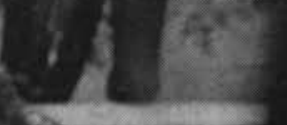

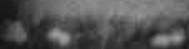

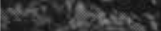

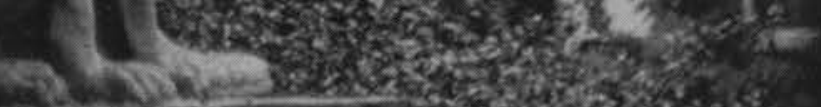

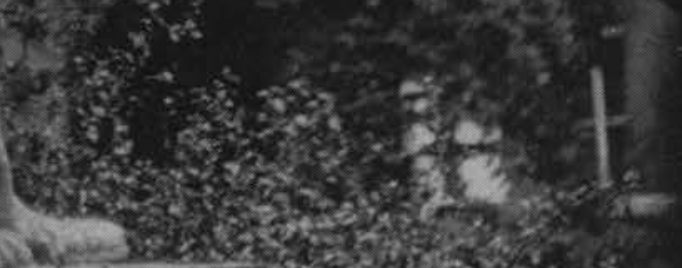

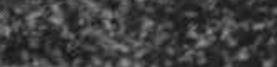




\section{The American \\ Veterinary Profession \\ Its Background and Development}

J. F. Smithcors, D.v.M., ph.D.

lowa State University Press

Ames, lowa, U.S.A. 


\section{About the Author}

J. F. Smithcors is a past president of the American Veterinary Historical Society and a member of the Council of the American Association for the History of Medicine. His collection of veterinary historical books, dating from the sixteenth century, is one of the finest of its kind.

$\mathrm{He}$,formerly was Associate Professor of Anatomy and Lecturer in Veterinary History, College of Veterinary Medicine, Michigan State University, where most of the research and writing of this work was done.

Besides this book, he is author of Evolution of the Veterinary Art and of numerous historical articles in veterinary and medical journals of the United States and England.

Dr. Smithcors holds a bachelor's degree from Rutgers University and a doctorate from Michigan State University. He obtained his master's and doctor of veterinary medicine degrees from Cornell University. $\mathrm{He}$ is editor of American Veterinary Publications, Inc.

FronTISPIECE: The professional concern and care of the veterinarian are conveyed by Christian Petersen's sculpture in the Veterinary Quadrangle at Iowa State University.

() 1963 by the Iowa State University Press.

All rights reserved.

Composed and printed by the Iowa State University Press, Ames, Iowa, U.S.A.

Library of Congress Catalog Card Number: 63-16672 
SF 63

$\cdots, 1, \cdots, 2$.

e. 1

\section{To The Veterinary Profession}

of the United States and Canada whose heritage has afforded me

many hours of pleasure - this volume

is dedicated - in the belief that:

"the orderly contemplation

of its own history is a proper

and profitable pursuit for any

profession -

which takes pride in its

ancestry and entertains

some hope for posterity." 



\section{PREFACE}

The year 1963 marks the centennial of the American Veterinary Medical Association and immediately follows that of the Ontario Veterinary College. Although it may not have been apparent at the time, the founding of these two institutions coincided with the ushering in of a century of unparalleled progress in veterinary medicine. Earlier attempts to form veterinary schools and associations had met with from little more than moderate degrees of temporary success to complete frustration. The reasons for success being elusive earlier were, perhaps, not fully appreciated at the time, and these same circumstances prevailed for years following the founding of the Toronto Veterinary College (now OVC) and - to an even greater extent - the United States Veterinary Medical Association (now AVMA).

Both institutions, however - each under an aegis indicative of a broader sphere of influence - have lived a hundred years. This in itself is worthy of note. But more important is the fact that each has brought in its wake other schools and associations which together have formed the backbone of the American veterinary profession.

Not all veterinary institutions established during this period have met with unqualified success, however, nor have all the problems facing the veterinary profession been solved. And what is more to the point, many of these relatively recent - and some still existent - shortcomings are deeply rooted in the more remote past. Thus the knotty and persistent problems of professional ethics, of promotion of veterinary services, of public appreciation of the role of veterinary medicine in human welfare, of lay encroachment into the veterinary domain -these and other problems not only have interrelationships within the 
existing scheme, but are related to circumstances and events of long ago.

Perhaps with the resurgence of equine practice, but more likely with the increasingly cosmopolitan view of the profession being taken by veterinarians in recent years, there no longer need be any hesitation in considering the past for fear of finding the skeleton of a horse doctor in the medicine chest. In fact, it is becoming more and more apparent, inasmuch as today's problems are not all of recent vintage, that an awareness of past shortcomings - as well as accomplishments - can be utilized as a steppingstone to future greatness.

Thus the do-it-yourself mania - as in mastitis treatment, for example - can be related not only to the apparent success of empiric methods, but to a deeply-rooted tradition in these matters. The colonial farmer can hardly be blamed for attending his stock as best he could, for not only were there no bona fide veterinarians in America before 1800 , there were but a precious few until well near the end of the century. The rash of "everyman his own farrier" type of work, and the farm papers that advertised "a free horse doctor with every subscription," made capital of this penchant of the home handynian.

To a large extent it appears to have been the influence of these agencies that convinced the American animal-owning public that the services of veterinarians were essentially an unessential luxury. This had the unfortunate consequence of delaying the emergence of a veterinary educational system for a century beyond its beginnings in Europe - and of favoring the short-term trade school type of institution once a need for educated veterinarians was realized. And in all too many instances, even the better-educated practitioner of more recent times fell into the snare of giving away his precious heritage - the art of diagnosis - while making a living on what he could dispense.

With the above in mind, I have considered it essential to delve deeply into our more remote past - the background of the American veterinary profession (Part I). Previous writings on American veterinary history have largely written off the colonial period; in fact, with few exceptions the material on colonial veterinary medicine presented in books and articles to date can be summarized but briefly: there was no veterinary service in colonial America.

However, too little attention has been given to the rather obvious fact that - in all ages - when men and animals have coexisted there have been problems which properly fall within the veterinary domain. A major thesis of this book is that this very lack of a veterinary service compounded problems once the veterinary profession began to take 
shape. The deceptively apparent immunity of animals to disease for a century or more - occasioned in part by lack of numbers - beclouded men's minds into believing that animals could continue to thrive without much attention - until long after the great animal plagues threatened the very existence of the burgeoning livestock industry.

The second part of the book deals with the development of the veterinary profession in America, together with some consideration of the interplay of other agencies in this development. For several reasons, the largest part of the story is based upon events which have occurred within the framework of organized veterinary medicine on a national basis, i.e., the AVMA. While it is obvious that many developments worthy of note have originated with individuals or groups more or less apart from AVMA influence, it has been expedient - even necessary - to limit consideration to those events which have reached the national level. Thus, however valid, the topics reported as being of interest to the profession at any given time are largely selected from those receiving attention at national meetings. By the same token, primary attention has been given to men who have reached prominence through the national association.

Several topics, however, have been considered more or less apart from the main thread of the story, including the epochal achievements of the Bureau of Animal Industry, the veterinary public health movement, and the American Veterinary Review. In addition, the section on veterinary education has been written by Dr. George C. Christensen. Lt. Col. Everett B. Miller, VC, had nearly completed a section on veterinary military history for inclusion in this book when unforeseen circumstances prevented his finishing it. At the suggestion of General Russell McNellis, VC, the introductory part of Colonel Miller's United States Army Veterinary Service in World War II (Office of the Surgeon General, 1961) has been included here as an abbreviated version of this most important aspect of our veterinary history. To both of these individuals I am indebted for making this a better book than it would have been otherwise.

As presented, the book represents the distillation of several thousand volumes - by conservative estimate, somewhere between one and two million pages of material - most of them turned page by page. As the work draws to a close, it is obvious that the best part of six years' research and writing - one year of it full-time - has been inadequate to achieve the consistency and balance a work like this should have. 
Specialists in particular fields will undoubtedly find errcrs of omission and commission; and to those who might want to go further into any particular subject, a note about the documentation of this work - or lack thereof - is indicated. My books and papers - some 3,000 pounds of them - were shipped west in 55 boxes; 54 arrived: the one with my lists of references apparently is still somewhere between East Lansing and Santa Barbara. As far as the book proper is concerned, however, all is not lost, for much internal documentation is included - enough to give an adequate entry into the pertinent literature. The early agricultural and veterinary journals are well-indexed, and there are relatively few specific items mentioned in the text that could not be found with reasonable facility.

Acknowledgements: The study on vet rinary medicine in colonial America was supported by a grant from the American Philosophical Society, much of this work being done from original source materials at the Clements Library of the University of Michigan. Much of the later study was supported in part by a major grant from the American Veterinary Medical Association, with most of the work being done at the Michigan State University Library. To these agencies, and to the many individuals who have helped me in many ways, I am deeply grateful.

I am especially indebted to Marty my wife for doing the final typescript, and for her patience in enduring a somewhat ascetic life for lo these many years. I would be remiss in not mentioning my former students - several hundred of them - who over several years compiled several thousand subject matter and biographical references from the early agricultural and veterinary literature; these are on file in the Veterinary Medicine Library at Mighigan State University. A grant from the Michigan State University All-University Research Fund was used to defray the cost of preparing the illustrations, and a fair portion of the book represents the fruits of research, the bread and butter for which was supplied by Michigan State University while I was a staff member there.

I would also acknowledge the special assistance of Bert W. Bierer of South Carolina for the help derived from his monograph on American Veterinary History (mimeo, Baltimore, 1940), and of David L. Cowen of Rutgers University for his critical reading of a portion of the manuscript. Also to Mary Ellen Haggerty of Detroit for the original paintings from which the illustrations on page 2 are reproduced and to Charles Packard for the frontispiece photograph; and to W. W. 
Armistead of Michigan State University for his active support of veterinary history as a discipline, and for the quotation which appears with the dedication of this book.

A special word of thanks is due Marshall Townsend and the Iowa State University Press for help with problems incident to publication, and for the technical excellence and format of the book.

Finally, a word about the style of the work. My Evolution of the Veterinary Art has been both criticized and commended for its lapses from matter-of-fact reporting. Since it is manifest that I cannot please everyone, I have chosen to continue writing in my own style. The very selection of materials requires at the outset a philosophy of some sort, and I would hope that my own commentary, implicit or otherwise, will stimulate rather than stifle thoughtful consideration of the matters presented. 


\title{
Contents
}

\author{
Part One
}

\section{Background of the American Veterinary Profession}

1. Livestock in the New World . . . . . . . . . . 3

Indian Agriculture-The Spanish Colonies-The Virginia Colony-The New England Colonies-Care of Livestock-Pennsylvania Pioneers-Veterinary Public Health in Colonial America

2. Witchcraft Vs. Animal Medicine

Superstition and Sorcery-The Mark of Markham

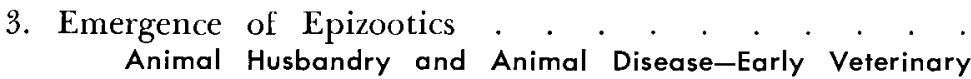
Literature-The Recording of Animal Disease-Veterinary Medicine in the Writings of Washington-Thomas Jefferson, Good Shepherd

4. The First Friends of Veterinary Medicine

Richard Peters, Judge-Benjamin Rush, Physician-James Mease, Epidemiologist--Peter Browne, Professor-Other Philadelphia Friends-William Carver, Practical Horse FarrierJames Carver, Professional Farrier

5. Veterinary Medicine in the Agricultural Press . . . .

Periodical Literature and Professional Development-The American Farmer-New Diseases and Old Needs-The Turf Register-The American Agriculturist-The Enlarging Sphere of Reporting Animal Disease

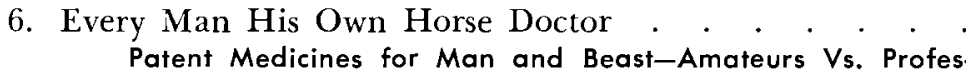
sionals-The Need for Veterinary Education-Humanity and Homeopathy

7. George Dadd and Veterinary Journalism - . · . Modern Horse Doctor-American Veterinary Journal-George Dadd, Veterinary Educator-Veterinary Science and Agriculture

8. Dissatisfaction With the Status Quo . . . . . . .

Veterinary Journalism After Dadd-The Livestock Journals -End of an Epoch: Robert Jennings 
Part Two

\section{Development of the American Veterinary Profession}

9. USVMA: The First Quarter-Century

Organization: 1863-Constitution and Bylaws: 1863-The Formative Decade-Emergence of a Leader-An Expanded Sphere of Influence-Silver Jubilee

10. American Veterinary Review

Mission of the Review-The Quest for Status-Legislation and Education

11. Veterinary Public Health ca. 1880 spection

12. The Animal Disease Problem and the Bureau of Animal

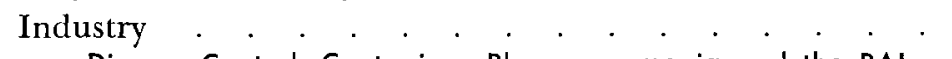

Disease Control-Contagious Pleuropneumonia and the BAI-

Texas Fever-Hog Cholera-Foot-and-Mouth Disease-Rabies and Vivisection-Bovine Tuberculosis-The Federal Meat Inspection System

13. Union of East and West. $\cdot$ Rebirth in the Nineties-Emphasis on Education-Exit USVMA;
.

Rebirth in the Nineties-Emphasis on Education-Exit USVMA;
Enter AVMA-The Association in Canada-Crossing the Continent-Golden Jubilee-Debut of the Journal

14. Toil in the Twenties . . . . . . . . . . .

A Search for Stability-Emblem of the Association-Hard Times Ahead-The Man, Merillat-Curtailment of the Colleges -Prospects for Preventive Medicine

15. Thinking in the Thirties

Professional Ethics and Public Relations-Veterinary Economics-Small Animal Practice and AAHA-Veterinary Medicine: Agricultural or Medical?-Retrospect and Prospect-Diamond Jubilee

16. Changing Times: The Forties and Fifties

Life Begins at Forty-The War Years-Television in the Fifties -Into the Sixties

17. What's Past Is Prologue
Axioms of History-Image of the Profession-A Look at the Record-A Glimpse of the Future-Continuum

18. Education for the Veterinary Profession by G. C. Christensen, D.V.M., Ph.D.

Need for. Research Recognized-The Turn of the Century-An III Wind-World War I-Postwar Period-The Low Point-An Upward Trend-The Great Depression-Postdepression Years - World War II-Postwar Educational Expansion-The Modern Period-A Look to the Future

19. Military Veterinary History

$$
\text { by Lt. Col. E. B. Miller, VC, USA }
$$

Evolution: 1775 to 1916-Development: 1916 to 1940-Mission and Responsibilities-Administration

Appendix: Constitution and By-laws of the United States Veterinary Medical Association: 1863 
PART ONE

\section{Background of the American Veterinary Profession}




\section{The roots of animal disease in colonial America}

Animals brought into the relatively disease-free environment of the colonies thrived at first. But later dependence upon this deceptively apparent immunity to disease, coupled with increasing lack of concern over the physical well-being of animals, contributed to the animal disease problem toward the end of the colonial period. Famine and filth were major factors in the increasing toll of animal plagues, and our colonial heritage had demonstrable effects upon the development of the veterinary profession in America.
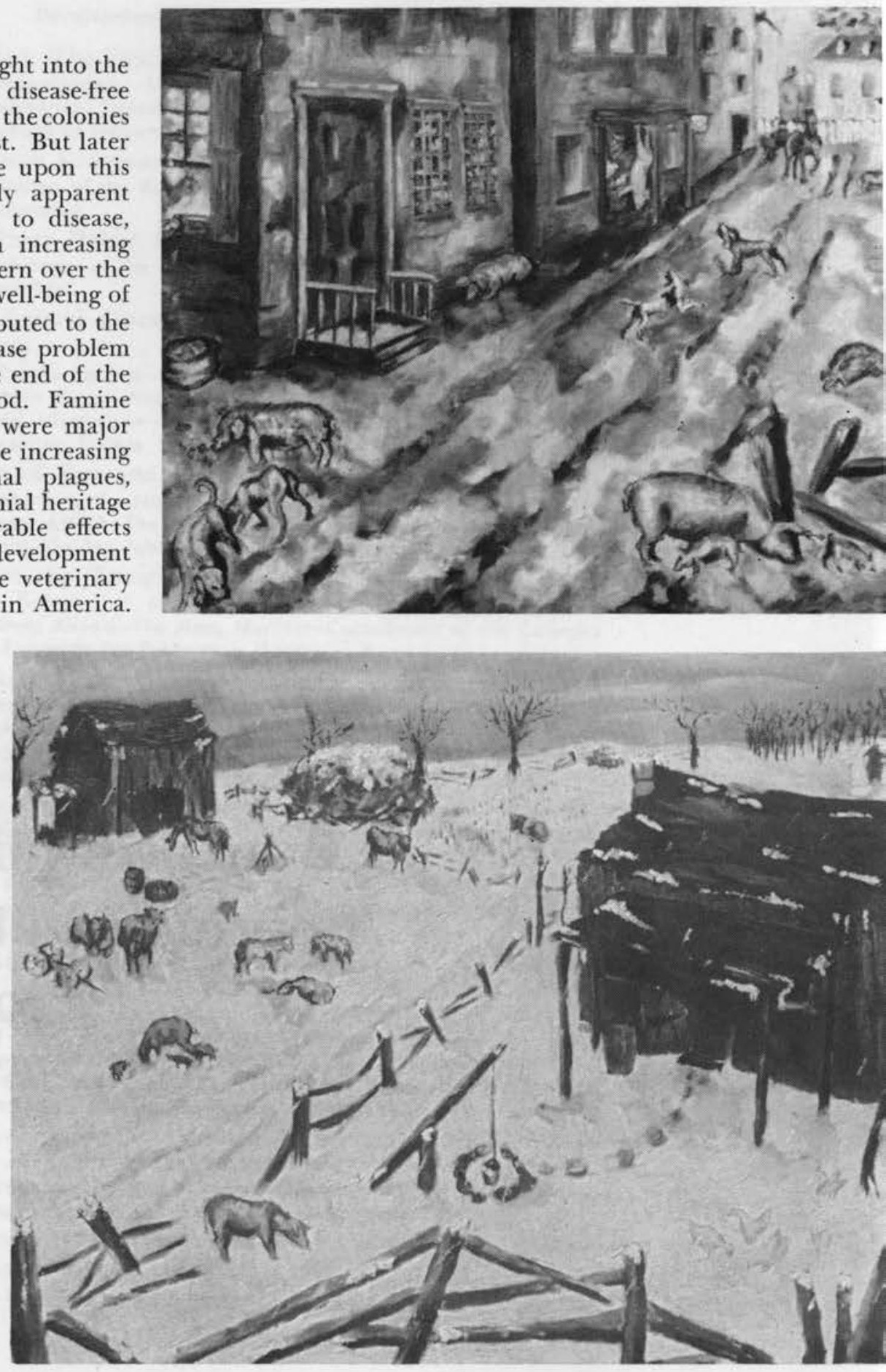

Reproductions from paintings in oil by Mary Ellen Haggerty presented at the 30th annual meeting of the American Association for the History of Medicine, Williamsburg, Virginia, 1957. 


\section{Livestock in the New World}

THE NORTH AMERICAN INDIANS had no domestic livestock prior to the coming of the white man, with the possible exception of a few motley dogs descended from wolflike ancestors, and used by a few tribes for light draft purposes, food, or hunting. The bison was undomesticable, for draft purposes at least, and the great numbers of these animals in the Plains regions would have made domestication as meat animals an unnecessary chore. Nor was animal milk a necessary adjunct to the raising of the younger generation as in more civilized nations. The Aztecs of Central America had a species of dog they revered as a sacred or sacrificial animal, and may have had occasion to attend its accidents and ills, but unlike early civilizations in Asia and Europe, the North American Indian had no need for veterinary medicine.

\section{INDIAN AGRICULTURE}

The Indians, however, were better agriculturalists than they are frequently credited with being, for the cultivation of corn extends to prehistory, and the several species the Indians used cannot be maintained in a wild state. They recognized good land, passing by areas unfit for cultivation, and used good tillage practices - considering the primitive tools they had - along with the use of fertilizer. The abundance of good land, however, made the clearing of new land more profitable than the continued use of old land once its fertility had been lowered to a point of diminishing returns. Although they had no steel axes, the practice of the Indians of girdling trees and waiting for the limbs to fall off has been cited as a prime example of their proverbial laziness. But it might be argued that the early settlers-even with their steel axes-were tilting at windmills in challenging the forest primeval, and they had the blisters to prove it.

Even with abundant game in the forests and on the prairies, Indian agriculture was limited by the lack of draft animals. Practically all field labor was performed by women, and Champlain termed squaws "the Indian's mules." Being essentially a nomadic culture, little thought was given to the accumulation of surplus crops against hard times. Dogs, which the Indians accumulated in numbers after the coming of the white man, were eaten when other food was scarce. The traditional succotash as made by the Indians included squash and dog meat in addition to the familiar corn and beans. The colonists in adopting this dish left out the squash and substituted pork for the dog meat. Agriculture was closely related to religious ritual, and while animal disease was not an immediate concern, plant pests and diseases were thought to be sent by evil spirits as a penalty for wrongdoing. The belief in disease as a punishment for sin appears to have been 
a fundamental concept among primitive peoples - in the old world as well as the new.

"Primitive" does not connote a lack of astuteness, however; Indian medicine men called upon to deliver their tribes from scourges of caterpillars apparently knew that their incantations would be potent only when it was time for the caterpillars to pupate. And one Indian chief, accused of killing colonists' livestock, in turn accused the English of killing the Indian's deer. When told his deer could not be distinguished because they were unmarked, the chief suggested the colonists kill only marked deer - those unmarked belonged to the Indians.

\section{Discreet Indians}

The Indians were not all the veritable giants they may have seemed to the settler facing the business end of a tomahawk, and even in their native habitat they suffered from a number of infectious and dietary diseases. And the diseases introduced through the white man killed more Indians than were slaughtered in all the Indian wars. Of an estimated 15,000 Indians in Pennsylvania at the time of William Penn in 1682 , only 1,500 were left a century later. The Indians practiced a species of domestic medicine that like any other empirical practice had some noteworthy features, but with the publication of native American medical and veterinary works, the prowess of the Indian in these matters was greatly overrated. Thus many homegrown medical works touted secret Indian remedies, as did the patent medicine peddler who later charmed a mint of money from the pockets of a gullible populace. One widely circulated veterinary work of the late eighteenth century claimed authorship in part by "discreet" or "experienced" Indians.

If the Indians had had occasion to practice any form of veterinary medicine, it undoubtedly would have been of the same nature as their medical rituals. Captain John Smith, writing of his Voyages and Travels in 1612, describes these:
Every spring they make themselves sicke with drinking the juice of a root they call wighsacan, and water; whereof they powre so great a quantity, that it purgeth them in a very violent maner; so that in 3 or 4 daies after, they scarce recover their former health.

Sometimes they are troubled with dropsies, swellings, aches, and such like diseases; for cure wherof they build a stove in the form of a dovehouse with mats, so close that a fewe coales therein covered with a pot, will make the pacient sweate extreamely. For swellings also they use smal peeces of touchwood, in the forme of cloves, which pricking on the griefe, they burne close to the flesh, and from thence draw the corruption with their mouth. With this root wighsacan they ordinarily heal greene wounds: but to scarrifie a swelling or make incision, their best instruments are some splinted stone. Old ulcers or putrified hurtes are seldome seene cured amongst them.

They have many professed Phisitons, who with their charmes and Rattels, with an internall rowt of words and actions, will seeme to sucke their inwarde griefe from their navels or their grieved places: but of our Chirurgians they were so conceipted, that they beleeved any Plaister would heale any hurt.

\section{THE SPANISH COLONIES}

Columbus brought several species of domestic stock to the West Indies on his second voyage in 1493; turned loose, these multiplied at a great rate, and served as a source of foundation stock for the Spanish colonies in Mexico. Despite other hardships, the Spanish colonists never suffered the "starving times" experienced by the English settlers of North America, who at times reputedly were forced to turn to cannibalism. Despite the riches in precious metals taken from New Spain, the value of the agricultural products of the colonial plantations far exceeded the output of all the mines. Much of this wealth was in cattle; Richard Hakluyt observed in 1572:

There is in New Spaine a marvelous increase of Cattel, which dayly do increase and they are of greater growth than ours are ... some one man hath 20,000 head of cattel of his owne . . They have great increase of sheepe in like manner. ... They have many horses, mares and mules which the Spaniards brought thither.

In 1587, some 35,000 hides were shipped from St. Domingo, and 64,000 from New Spain. This trade is of some interest in the 
later history of animal disease in North America, for Texas fever is presumed to have been introduced to the southeastern United States through tick-infested hides from a Spanish vessel wrecked along the Carolina coast.

\section{Prolific Pigs}

Cattle - a few heifers at least - were brought to Florida by Ponce de Leon in 1520. Although none of these appear to have survived, and while the mythical quest for the "fountain of youth" is now considered a flight of fancy of a later historian, Ponce probably little realized just what a vitalizing element cattle were to be in the economy of the new world. The first horses introduced into this country were landed in Florida in 1527. This importation was likewise unsuccessful; all 42 animals soon perished or were destroyed, whether as a result of accident or disease is not known. Swine, along with horses and cattle, were introduced by De Soto in 1539 from Cuba. Packs of bloodhounds and Irish greyhounds were brought along to pursue the Indians, but they appear to have been used chiefly to herd the everincreasing swine population on the 4,000 mile march to the Mississippi and back. Unlikely as it may seem, the progeny of the original 13 sows increased to over 700 in less than three years. This expedition also marked the first successful importation of horses into the continental United States, but these animals fared less well than the porcine fraternity.

Some idea of the hardships suffered by horses may be had from the ferocity of certain of the engagements between the Indians and De Soto's band of 600. On one occasion, 2,500 Indians were slaughtered, with the loss of 18 Spaniards, but the Spaniards who remained alive suffered an average of five arrow wounds each. Of the hundred horses belonging to the Spanish entourage: "Twelve horses died and seventy were hurt." And on another encounter: "There died in this affair, eleven Christians, and fifty horses." Additional horses either escaped or perished in an at- tempt to get the remnant across the Mississippi River, and upon De Soto's death in 1542 only three remained of the original one hundred. Some of those which escaped in the river crossing fared rather well, for it appears that they joined a small band of the progeny of horses brought to Mexico by Cortez. Within 40 years the Indians along the Mississippi had an ample supply of horses originating from this band of Mexican migrants and defectors from De Soto's camp.

The original 13 sows landed by De Soto in 1539 had increased to 300 in a year or so, and evidently to a considerably greater number within another year, for along with the 12 horses lost in one engagement, 400 swine reportedly were lost also. And along with the later loss of 50 horses, all but 100 of the remainder of the pig population were lost. This was in March, 1541; yet in May, 1542, upon De Soto's death, these had increased to 700. Thus is it evident that pigs were admirably adapted to life in the new world; wherever swine were introduced, they soon overran the confines of the settlements and took to the woods. In some areas the Indians gave up deer hunting, and for settlers on the fringe of civilization, boar hunting became a favorite pastime.

\section{Virgin Territory}

Cattle also increased and in some areas ran wild, but conditions in Florida were inimical to the survival of any but the hardiest of stock. Swarms of horseflies killed hundreds of horses and cattle, and those which escaped were kept in poor condition. Indian attacks and the raids of pirates and rustlers further reduced the livestock population about the settlements, and as late as the early eighteenth century the Augustinian friars were never able to supply their own needs for beef. It is reported that at times they were forced to eat horses, cats, and dogs to keep alive. The Indians became the first large herders in Florida, and in the mid-eighteenth century cattle and horses were plentiful and sold for trifles. Oxen were used for draft 
rather than horses or mules because they were better able to withstand the continual attacks of flies. On large ranches herds of as many as 5,000 cattle were observed huddled in masses, switching their tails in unison to drive off the murderous insects - flies by day and mosquitoes by night. As more land was cleared, flies became less of a problem, and today Florida is one of the major cattle raising areas in the United States.

Other than the Spanish importations, major attention has been focussed upon the stock introduced by the English into Virginia and Massachusetts in the early 1600's. The Portuguese, however, brought cattle and swine to Nova Scotia and Newfoundland in 1553, where despite the radical change in climate, they increased rapidly. Thirty years later the English explorer, Sir Richard Gilbert, was wrecked on the shore of Newfoundland in an attempt to land there to secure provisions of cattle and swine.

As indicated below, these phenomenal increases in livestock populations, other than under conditions such as obtained in Florida, undoubtedly were due, in part at least, to the relatively disease-free environment into which they were brought. Moreover, in most settlements, the slaughter of any part of the foundation stock was forbidden during the formative years of the settlement - not infrequently upon the pain of severe penalty, including that of death. The slaughter of diseased animals, however, was sometimes permitted, and except for summary justice meted out to cattle rustlers, it may be doubted that the death penalty was ever enforced-except in the case of one man who killed and salted his wife during the "starving time" at Jamestown.

\section{THE VIRGINIA COLONY}

The details of these early importations are clouded with obscurity; not so with those of the Jamestown settlement in 1607 , however. Earlier, Sir Richard Grenville had brought horses, cattle, sheep, goats, and swine to Roanoke Island in 1585 , but no evidence of any surviving stock was found by the Virginia settlers. The otherwise favorable conditions would suggest that these animals fell prey to the Indians, for whom the hunting of domestic animals on an island would have been like shooting ducks on a pond. Concerning the small supply of stock imported in 1607, the Rev. W. Simmonds wrote: "3 Sowes, in one year increased 60 and od Pigges; and neere 500 Chickens brought up themselves, without having any meat given them."

Other animals apparently were imported in 1608 , and by the fall of 1609 , when Captain Smith left Jamestown, they had "six Mares and a Horse; five or sixe hundred Swine; as many Hennes and Chickens; some Goats and some Sheepe." Smith himself later noted: "There were few countries where overgrowne women became more fruitful."

\section{Starving Times}

Evil times fell upon the new settlement, however, and the misfortunes of these early colonists are well documented. Many were impoverished gentlemen in search of a fortune, and not being inclined to the new life by experience or temperament, many of their efforts were misdirected. With provisions already low, and their few crops blighted by a severe drought in 1609 , in the absence of the strong hand of Smith the colonists turned to eating their precious foundation stock of animals. Simmonds, an eyewitness, states: "as for our hogs, hens, goats, sheepe, horse, or what lived; our commanders and officers did daily consume them: some small proportions we tasted, till all was devoured." And Lord Delaware declared upon his arrival in 1610:

Our people, together with the Indians, had the last winter destroyed and kild up all our hoggs, insomuch as of five or six hundred (as it is supposed), there was not above one sow, that we can heare of, left alive; not a henn nor a chick in the forte (and our horses and mares they had eaten with the first) .

The historian, Fiske, states:

After the last basket of corn had been devoured, people lived for a while on roots and 
herbs, after which they had recourse to cannibalism. The corpse of a slain Indian was boiled and eaten. Then the starving company began cooking their own dead. One man killed his wife and salted her, and had eaten considerable of her body before he was found out. This was too much for people to endure; the man was tied to a stake and burned alive. . . . No wonder that one poor wretch, crazed with agony, cast his Bible into the fire, crying "Alas! there is no God."

Vegetarianism to the contrary, the desire for good red meat appears to be a fundamental clrive of most peoples, and cannibalism as such may be prompted less by a craving for human flesh than by a lack of another source of meat. At any rate, a Father Cobo declared that the spread of Spanish cattle in New Spain during the sixteenth century "had a great deal to clo with ending the cannibalism of the Chiriguana of Los Charcas and of the Carib." Horses also increased at a prodigous rate; the Indians blessed them for having relieved them of burden-bearing, and horses became so cheap that they were hunted rather than bred. Priestley states:

Pedro di Mendoza, abandoning Buenos Aires, where he settled in 1535, turned loose five mares and seven horses; by the end of the century their progeny overran the country down to the Straits of Magellan. . . By 1508 the people of $\mathrm{La}$ Espanola were given royal permission to hunt for a pastime the droves of wild descendants of the first hogs which had been brought.

Returning to the desperate colonists of Virginia, only 60 persons of some 500 in the colony in October were alive in May, and these had "the gleam of madness in their eyes." Fortunately, some of those who survived lived to see better times; few, perhaps, would have envisioned how much better these were to be, especially with regard to the increase of livestock.

\section{Increase of Cattle}

With the arrival of Sir Thomas Dale as governor in 1611 , things took a turn for the better; the indolent colonists and the new arrivals found themselves under a strict disciplinarian, but one who forced them to help themselves. Indian methods of tillage were adopted, and adequate provisions were made for the 100 or more cattle and 200 swine brought over. Dale designed and had erected the first stable in Virginia, and ordered that hay be put up for the winter. This was wild grass; the culture of grasses was not begun on any scale for another 150 years, and in the meantime many cattle starved to death in the more severe winters. Nor did the colonists, who had traditionally provided little winter shelter for their animals in England, continue to provide shelter for their stock beyond what the woods had to offer, once the restrictions of the settlement were behind them.

Reference has been made to the phenomenal increase in numbers of livestock. The hundred or so cattle imported in 1611 had barely doubled in number by 1616 , but by 1620 they had increased to 500 ; to perhaps 5,000 by 1627 despite the massacre of most livestock by Indians in 1622, and to 30,000 by 1640 . While there undoubtedly were more animals imported than are on record, it is obvious that other factors must account for this increase. In the first place, except for a few oxen for draft, only heifers (and the necessary number of bulls) were brought over, primarily because of the great expense of transport. It may be presumed that an attempt was made to select only healthy animals in England, for a heifer landed in Virginia represented an investment of $\$ 250$ in Virginia currency. The conditions on shipboard probably were better for the animals than for persons, for the former were housed above deck on caraval type ships, which because of their resemblance to Spanish vessels, often caused concern when they first appeared on the horizon.

While sanitary conditions were good, the decks being cleaned by washing the offal into the sea, many animals were lost through injuries incurred during storms at sea. Of 52 head on one trip, 10 were lost in this manner, but the loss was in part made up by the birth of 10 calves while still at sea. Moreover, by comparison with 
the colonists themselves, scurvy, the dread killer of men aboard ship, was not a problem. Many persons who survived scurvy were landed in such a vitiated state that they fell ready victims to any of a host of diseases during their first few months in the new world. For this and other reasons, although over 100,000 persons had emigrated to Virginia by 1670 , there were only about 75,000 inhabitants at this time. Although, as pointed out by Captain Smith, women were extremely fertile in the new country, they were outnumbered by men five to one among those who came from England. While few remained widows for long, and there are many records of families of a dozen or more children, this continual childbearing undoubtedly led many women to early graves and may actually have tended to depress the net population.

Cattle also were prolific once they had become acclimated, and their increase was practically guaranteed by the severe prohibitions against their slaughter once an agricultural economy had been established. In a determination to avoid a return of the "starving time," stringent laws, apparently including the death penalty, were enacted to preserve the precious animals with which the colony was restocked. It may be doubted, however, that the death penalty was ever inflicted for cattle killing in the Virginia colony, but even with a substantial increase in numbers, the laws against slaughter remained strict. In 1619 a decree promulgated by the Virginia Company stipulated:

No man, without leave of the Governor, shall kill any Neat cattle whatsoever, young or olde, especially kine, Heyfurs or cow-calves, and shal be careful to preserve their steers and oxen, and to bring them to the plough and such profitable uses, and without having obtained leave as aforesaid, shall not kill them, upon penalty of forfaiting the value of the beast so killed.

Apparently excess males were killed from time to time, and by 1627 animals permitted to be slaughtered included females which "had ceased to breed, or were stricken with a disease or infirmity that would inevitably end in death." If the idea of eating animals which were about to die of disease seems esthetically offensive, the British had a long tradition in this department. Earlier, sheep dying of anthrax were fed to farm laborers, and as late as 1865, when asked by a German colleague what Britain did with her diseased meat, the eminent John Gamgee answered: "Eats it."

Still concerned with the need for further increases in livestock, the Virginia Company sent orders to the Governor in I621:

for ye making all due provision for ye Encrease and preservation of ye bread [breed] of all sorts of cattle, And in particular Kyne: whereof wee thinke it most unfitt, that any should bee as yett killed, and requier your vigilent care for ye Inhibiting thereof.

There are conflicting reports concerning the economy of the colony at this early period; some of the more glowing ones undoubtedly were circulated by the London Company in an attempt to secure more settlers. Thus in 1620 the counsel for Virginia stated:

The Cattle which we have transported thither, being now growne neere to five hundred, become much bigger of Body, then the breed from which they came: The Horses are also more beautifull, and fuller of courage. And such is the extraordinary fertility of that Soyle, that the Does of their Deere yeelde two Fawnes at a birth, and sometimes three.

This was written to refute rumors of poverty spread back home by letters of the colonists, but it is of some interest to note that the fertility of the soil was related at this early time to the reputed increase in size of stock. While more probably there was some basis for reporting a size increase in animals, and much of the land was very fertile, some of the earliest farms were established upon land already abandoned by the Indians as unproductive. Forage was short at times, and in 1618 Governor Argall ordered: "no man to take hay to sweat tobacco because it robs the poor beasts of their fod- 
der." Yet this same governor in the winter of 1617-1618 killed some of the public cattle for personal profit.

\section{Decrease of Cattle}

At this time there was said to be some 300 cattle in Virginia, and: "Cattle that springe all brought forth another yeares increase." But in the Indian massacre of 1622, much of the livestock on the settlements was destroyed, and some that survived had to abandoned to the Indians, the rest being brought back to Jamestown. Stock which already ran wild in the woods fared better, the wild cattle being referred to as "Indian deer," and wild swine were so abundant that the Indians apparently gave up deer hunting. Yet in the famine that followed the massacre, the settlers were unable to hunt in the woods for fear of the Indians. The number of cattle salvaged by the settlers was reported to be 192 by actual count, and according to one settler:

Some of theis 192 dyed by the way and many dyed as wee have Crediblie heard for want of good lookinge to. Many alsoe have been slayne by the Indians since the last Massacre. . . . How manie more these might have beene encreased had not soe many persons beene unfortuatelie and inconsideratelie sent over to Consume the fruits of the former labour and another abuse latelie crept in of killing the bull Calves wch was not suffred before their last 4 Yeares.

Letters from various colonists leave little doubt as to the condition of the colony at this time, especially with reference to their lack of livestock. One wrote in 1623:

This yeare we live hard by reason of the Indians and gett little or no meate. ... We lack about halfe our kine and most of these are dead this Winter. Here hath been a generall death of men and Cattle. ... [ Another wrote ]: for as well our people as our Cattle have dyed, that we are all undone ... [ and another ]: Many of our yong Cattle are dead for there hath ben a generall mortalitie of man \& beast this yeare \& the last.

Still another elaborated:

As you know this land hath felt the affliction of Warr, sense of sicknes and death of a great nomber of men, likewise among the Cattle for doggs have eaten this winter more flesh then the men: And he that had 40 hoggs about his house hath one or two: and a hundredth henns hath now 3 or $4 \ldots$ The woods are so dangerous we dare not goe abroad: And for tame Cattle there have so many died and ben killed otherwayes that there is no more to be had.

Some cattle appear to have been left, however, for in 1623 the death penalty was provided for cattle stealing.

During these early times there are few specific references to measures taken for the care of livestock other than desultory attempts to gather native grasses for hay, and protection of animals from the Indians. Some thought for the medical care of animals may have occurred to a few settlers, however, for in 1620 Records of the Virginia Colony indicate: "Markhams and Googes books . . . are now sent," and an invoice of goods sent from England includes among agricultural tools: "a bras serine [syringe] for a glister [clyster, or enema] pipe." It might be noted that there were few worthwhile books on animal disease extant in England at this time, and Markham's work, probably his notorious Maister-Peece (1610) alluded to below, was no exception. Barnaby Googe's Foure Books of Husbandrie (1577) was a translation of an earlier work by the German, Conrad Heresbach.

Googe was a poet with no pretensions to competence in the veterinary field, and except for what is abstracted from the ancient Roman authors on contagious diseases, the work is a prototype for many of the worthless works which followed, first in Britain and later in America. Thus while he advises separation of the sick if "murrain" appears, he repeats the centuries-old superstition of keeping swine away from cattle because their dung is poisonous and breeds pestilence and murrain. "Wolf in the tayle" is described, together with the approved manner of slitting the tail and putting in salt and soot. "Sickness of the loonges" is treated with a pint of salt in a quart of cham. berlye (urine). On the other hand, calves 


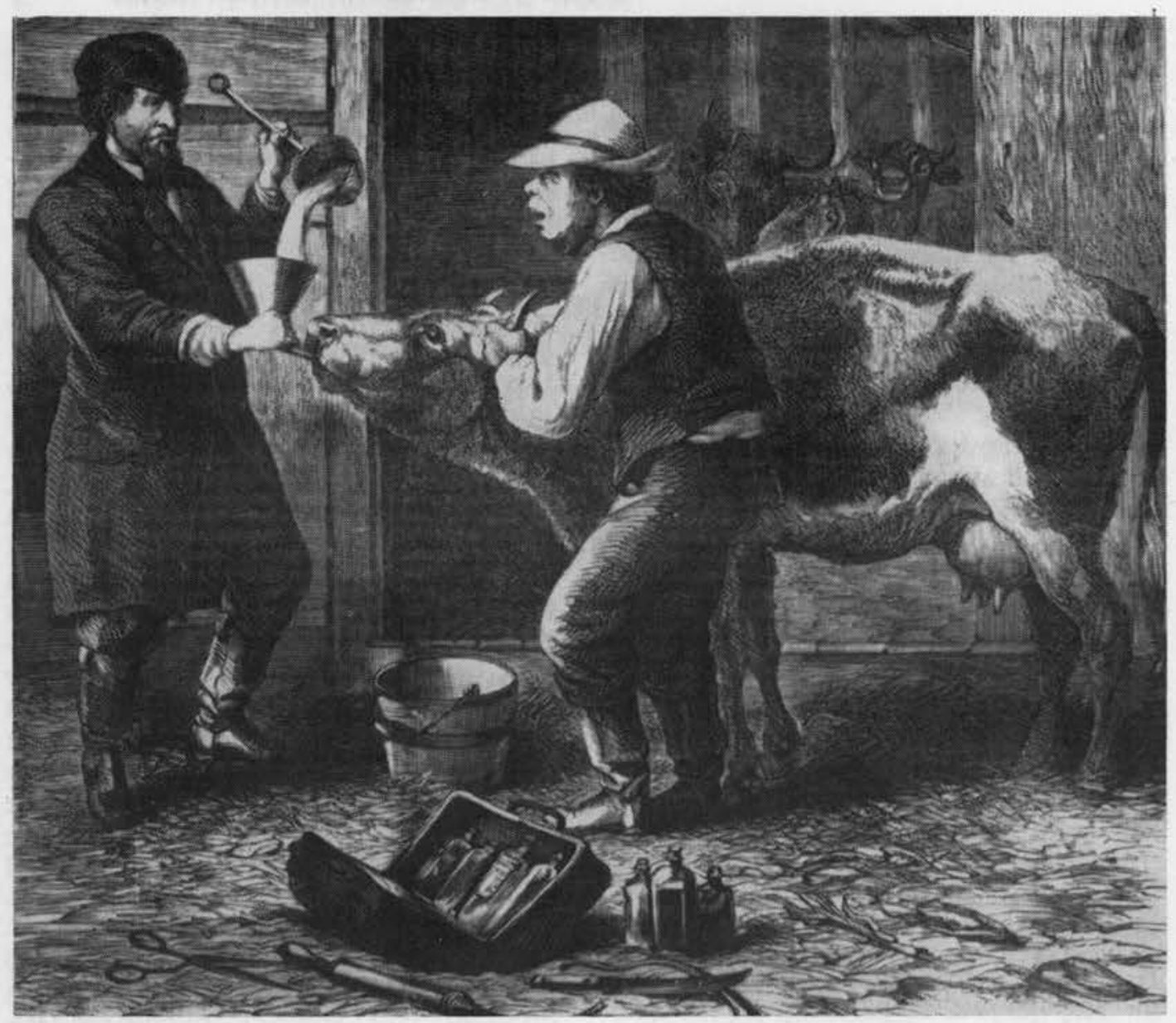

with dysentery are to be given milk to which rennet has been added. One affection of some interest is "gargyse," a swelling about the eye, for which surgical intervention is prescribed. The term employed for this swelling actually refers to the throat, as in gargle, and later was used to denote a swelling on any part of the body. Thus "gargyse of the udder" eventually came to be known as "garget," a not uncommon designation for mastitis even today.

Those who followed Googe's recommendations at least had an authority of sorts for failing to house their cattle. Googe states: "You shall have them foddered abroad all the winter; they can abide the cold." He, of course, was referring to the milder winters of England, where this practice was common. It did not occur
"The Cow Doctor" of rural America in the mid-nineteenth century (above) differed little from his colonial counterpart two centuries earlier, either in knowledge of animal disease or his medical and surgical armamentarium. The type of drench. ing pipe and funnel used by the cow doctor is depicted at right. American Agriculturalist

to most of the Virginia settlers - or even to many in Massachusetts - that circumstances alter cases, and countless numbers of cattle succumbed to the cold and starvation of the harsh winters.

With the importation of replacement stock following the hard times of 1622- 
1623 , conditions in Virginia were greatly improved. As new ground was broken, a large measure of the fertile promise of the new world was realized, and livestock increased more in the proportions dreamed of by the more enthusiastic earlier settlers. Although stock was still neglected by present standards, its care did improve, and by 1625 there was at least one "cow-doctor" in the colony, and a few years later Virginia began exporting cattle to New England.

\section{Competent Cow Doctor}

While it must be supposed that animals suffered more from disease than is on record, it is evident that few plagues of newsworthy proportions occurred prior to 1700 . Except for large-scale deaths of animals in the severe winters, some 50,000 cattle being said to have perished in Virginia alone in the winter of 1673, "the hardest season experienced in the history of the Colony," few records of animal diseases, sporadic or otherwise, exist.

What may be the first record of veterinary services in America is recorded by the medical historian Blanton who states: "in colonial Virginia the services of veterinarians were sought and valued." He refers to a William Carter as: "an expert veterinarian or cow doctor, who lived in James City in 1625." The designation of "veterinarian" was unknown at that time, however; the term was not introduced in any English writing until 1646 by Sir Thomas Browne, and was not in general usage until well into the nineteenth century. How expert a cow doctor Carter may have been is open to doubt if his testimony in a lawsuit is representative of his prowess. It is of interest that he establishes the presence of a second man who had some reputation for treating cattle. As recorded by Blanton from the court record:

... he drest a Cow for Mr. Allnutt in May lasst ... for wch demandinge 10s. Mr. Allnutt did not pay him, And the last springe there was a Cow ... with a fistula uppon the Eye ... and about Easter last he offered Mr. Allnutt ... to cure ye cow wth ye fistula for 20 s. in money soe as he might be satisfied for the former cure, wch Mr. Allnutt refused saying he had rather give another man forty shillings then him 20s. and so put the Cow to goodman Tree's man to Cure, who not beinge to cure her Mr. Allnutt offered this deponent to give him content if he would Cure her . . . [Carter] used his best skill, yett at length she dyed.

In 1642 the York County (Virginia) court awarded Thomas Spilman 400 pounds of tobacco from a John Smith who had hired Spilman: "to use the best of his skill for the cure of the horse," but which had died. Inasmuch as the owner was present "at the opening of the horses wound," and brought no charges of lack of skill, the court decided he was liable for the cost of treatment.

\section{Pest-free Haven}

A factor of considerable importance was the environment into which these animals were brought. Inasmuch as no domestic animals existed in the new world prior to the coming of the white man, America at the outset provided a practically pest-free haven. Only by this factor can the lack of animal plagues of any consequence for a century or more be explained, for while the abundant feed caused animals to grow larger than those in England for a while, as the population increased, feed became scarce. Many animals died during the winters, and nearly all were left in a weakened condition in the spring, ripe for the invasion of plagues had they been lying dormant. This eventually did occur as a concomitant of generations of degenerate breeding and management.

From prehistoric times, cattle have been considered as synonymous with wealth, and Virginia was no exception. In 1630, Captain Smith relates that there were: "about five thousand people, and five thousand kine, calves, oxen, and bulls; [and] for goats, hogs, and poultry . . . they have so much more than they spend."

Yet at this time cattle were worth about $\$ 375$ in terms of purchasing power in Virginia. About this time Virginia began exporting cattle to Massachusetts, which, to- 
gether with relaxation of slaughter laws, helped account for a decrease in the cattle population from 30,000 in 1640 to 20,000 in 1649 , but at this latter date there were only 15,000 inhabitants. Sheep had increased to but 3,000 at this late date, primarily because of the depredations of wolves. Hogs, the most prolific of the lot, had so increased by 1627 that the settlers were obliged to palisade the settlements to keep them out.

Few horses were brought to the colonies in the early days. It was early learned that they were unsuited for plowing, and they required much more attention in winters than did oxen. It 1647 only five horses were enumerated in Lower Norfolk County for tax purposes; at this time four pounds of tobacco were levied on cattle while 32 pounds were levied on horses. While there were only 200 horses in all of Virginia at this time, many of these were of blooded stock, and horseracing was the coming sport. Before the end of the century wild horses were so numerous they were hunted as sport, frequently with dogs. These animals were so fleet that many good horses were ruined in the chase. Horses were introduced to New France in 1647, where they soon became a pet luxury, and they thrived surprisingly well despite the harsh winters. Tail docking was universal.

Evidently conditions in Maryland were much the same as in Virginia at this time, although the eyewitness account of Lord Baltimore in 1633 might be somewhat exaggerated inasmuch as it was intended as a prospectus for colonists:

There are such numbers of swine and deer that they are rather an annoyance than an advantage. There are also vast herds of cows, and wild oxen, fit for beasts of burden and good to eat. . . Sheep, as well as asses and mules, have to be procured either from our country or from the Canaries. The nearest woods are full of horses.

The latter statement, of course, simply was not true.

\section{THE NEW ENGLAND COLONIES}

While the Mayflower had dogs, and possibly goats and chickens aboard on her maiden voyage, no cattle or horses were brought over in 1620. Of the first importation of cattle in 1624, William Bradford wrote that Edward Winslow brought over: " 3 heifers and a bull, the first beginning of any catle of the kind in ye land." These were allowed to increase for four years, and were then apportioned by lot. Other importations were made, and animals were kept on the town commons under the care of keepers much as had been the custom in England. Here, too, the absence of disease was in great contrast to what had been the situation in England. There are no records of widespread animal disease in the early days of the colony. The importance of animals in the economy of the colony is demonstrated by the numerous ordinances passed regulating the keeping and slaughter of livestock; the events of veterinary importance are considered in the section dealing with public health matters in the colonies.

Some items from Governor Winthrop's Journal for 1630 undoubtedly are representative of events in the early days of the Massachusetts colony:

July l: The Mayflower and the Whale arrived safe in Charlton harbor. Their passengers were all in health, but most of their cattle dead (wherof a mare and a horse of mine). Some stone horses [stallions] came over in good plight . . .

Sept. 30: The wolves killed six calves at Salem, and they killed one wolf . . . The wolves killed some swine at Saugus. A cow died at Plimouth and a goat at Boston, with eating Indian corn ...

Oct. 29: The Handmaid arrived at Plimouth having been twelve weeks at sea, and spent all her masts and of twenty-eight cows she lost ten.

Captain Smith relates concerning a shipment of cattle from Virginia to Massachusetts in 1630: "Of two hundred Cattell which were so tossed and brused three score and ten died."

Despite an increase of animls more or less commensurate with that in Virginia, the value of cattle skyrocketed in Massachusetts as it had done in the South. Bradford stated in 1638: 
Kine were sould at 20 pounds and some at 25 pounds a peece, yea, sometimes at 28 pounds [ over $\$ 500$ purchasing power]. A cow-calfe usually at 10 pounds."

That these prices were artificially high is demonstrated by the fact that in 1642 prices fell in one week from 22 pounds to 6 or 8 . Sheep also were valuable animals in the North; while they were harried by wolves as they were in Virginia, there were few diseases, which in the South made sheep raising a doubtful enterprise from the early days of the colonies. Wool, of course, was a premium product in the rigorous northern climate.

The loss of animals being transported was a matter of some economic importance, for Governor Winthrop relates that in 1630:

The passage of the people in the Eagle and nine other vessels to New England came to 9500 pounds. The swine, goats, sheep, neat and horses cost to transport 12,000 pounds, besides the price they cost.

By 1633 the population of the Massachusetts Bay Colony numbered 4,000, with 1,500 cattle, 4,000 goats and "innumerable" swine.

The Dutch brought 103 head of animals, including horses, cattle, sheep, and swine, to New Amsterdam in 1625; only two died on the voyage. The floors of the pens aboard ship were sanded to prevent injury from falling. The animals were kept on farms ("bouweries" - whence the Bowery) outside a stout palisade wall (whence Wall Street) at the edge of the settlement. Many pigs, however, were kept within the town limits, and slaughterhouses were built over the ditch outside the wall. These wastes, which found their way to the East River, were the first of an apparently never-ending series of offenses to the olfactory senses of the Gothamites. In an article entitled "The Butcheries of New York," in the American Agriculturist for 1849 the writer says with much feeling: "It is quite time our city fathers proceeded efficiently for the removal of these intolerable nuisances. The stench from these yards is perfectly unsupportable."
Most of the sheep brought to New York in 1625 fell prey to wolves and dogs; 20 years later there were only 16 sheep left in the colony. The sheep introduced into Massachusetts in 1633 were of a coarsewooled relatively unprofitable type. Finewooled sheep were not imported until 1793; the first such animals, brought from Spain, came to an untimely end - the caretaker, not realizing their value, ate them. Later importations early in the eighteenth century resulted in an outbreak of "Merino fever," prices for rams reaching $\$ 500$ to $\$ 1,000$ before the rash subsided.

\section{Sheep May Safely Graze}

Unlike the situation in New York, the 88 sheep brought to Massachusetts in 1635 had multiplied to a thousand or more by 1642 , had again tripled in a few years, and were reputed to number nearly 100,000 by 1660. While wolves, bears, and dogs harassed sheep in Massachusetts as elsewhere, the provident Puritans took measures to reduce the inroads made by these predators. Flockmasters were appointed to attend their grazing on the town commons, and laws were enacted to reduce the population of sheep-killing dogs and wolves. In 1648 an ordinance was passed requiring:

If any dogg shall kill any sheepe, the owner shall either hange his dogg forthwith, or pay double dammages for the sheepe; if ye dogg hath bene seene to course or bite any sheepe before... then he shall both hange his dogg and pay for the sheepe.

This principle was reaffirmed numerous times and, in effect, is the law today in most states. Likewise, a system of bounty for wolves undoubtedly was effective in reducing the population of predators, but the inherited bounty system still existing in many states is considered illogical by many conservationists because it upsets the balance of nature.

\section{Pioneers and Providence}

Sporadic deaths from accident and disease, and losses from marauding Indians and wolves, undoubtedly were relatively common. While they did not interfere with the net increase in livestock popula- 
tion, nor, perhaps, were they particularly serious in the communal herds, on the fringe of civilization they were a threat to existence itself. Here the thin veneer of civilization depended upon the labor of the ox, the milk of the family cow, and the meat of the pig. Callous though it may seem, the loss of one of these animals was possibly a harder blow than the death of a child, although infant mortality was a matter to be reckoned with, for children also constituted a form of wealth. The pioneer certainly mourned the passing of his child as much as the man in town, but a child was replaceable, whereas frequently an animal was not-even if he happened to have the price of one; most often he likely did not.

The observations of De Crevecoeur made about 1770 are applicable to any pioneer community at any time. The early American colonist, he says:

finds himself suddenly deprived of the assistance of his friends, neighbors, tradesman, and all those inferior links which make a well organized society so beautiful and pleasing. What is he to do in all possible cases of accidents, sickness, and other casualties which may befall his family, his cattle and horses ... Has he a cow or an ox sick, his anxiety is not less, for they constitute a part of his riches. He applies what recipes he possesses; he bleeds; he foments; he has no farrier at hand to assist him.

A cow, perhaps a few sheep, a couple of poor horses must be housed, must be fed through the inclement season. If the least accident happens through droughts, sickness, carelessness or want of activity happens, a general calamity ensues. The death of any one of these precious animals oversets the well being of the family. Milk is wanting for the children; wood must be hauled; the fleeces of sheep cannot be dispensed with. What providence can replace these deficiencies?

All too frequently the answer was, "None."

Yet despite this knowledge, the lack of attention to animals upon the pioneer farms was a primary cause of loss. It would seem as if it were a reaction to being freed from the relatively severe restrictions of communal life under the town fathers. There, not only was the manner of keeping animals legislated, but such items as who might be entertained in a citizen's house and for how long. Obviously, it was more often the citizen who-whether he liked it or not-was appointed cow-keeper or garbage-overseer or fence-mender, than it was the town fathers, who migrated to the fringe. More likely it was a reversion to traditional ways of life once the authority of the town was removed, coupled with the probability that there always seemed to be something more pressing than building a cow house or mending fences.

\section{CARE OF LIVESTOCK}

The care of livestock by the colonists left much to be desired, and, in fact, remained a matter for reproach. Two centuries later, the editor of the Country Gentleman (1866) comments upon this inertia in an article entitled "Shelter for Animals." Noting that some improvements had been effected lately, he states:

We can well remember when nothing was more common than feeding cattle and sheep from stacks in the open field throughout the entire winter . . . exposed to every snow storm and every sharp cutting wind .... it was necessary that one-third of their entire food should go towards restoring the animal warmth swept away by the furious winds. This, however, it did very imperfectly; and the feeling of many farmers for their cattle on entering winter and emerging from it, was like that of a general on

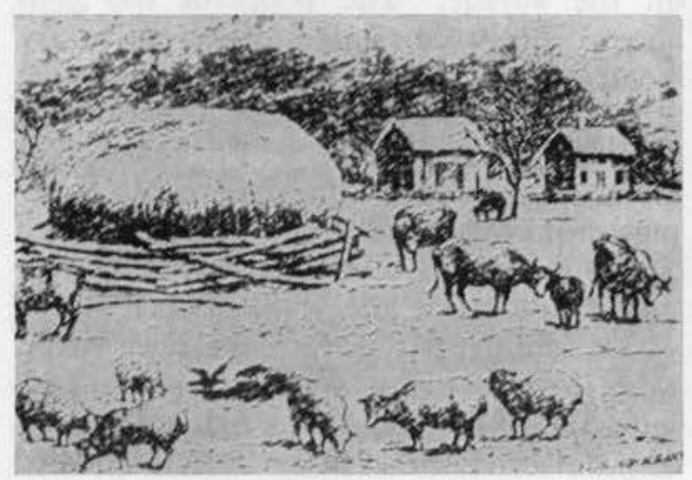

Protection against the elements had been less a problem in the relatively mild climate of England, but even in the most severe weather it was not unusual for the colonists to leave their stock to fend for themselves. This apathy toward animal needs persisted to the point of becoming traditional. American Agriculturalist 
taking his men into battle and coming out of the conflict - he expected to lose many of his men as an unavoidable calamity ... the degree of success or failure was sometimes measured by the distance at which an animal's ribs could be counted when viewed across the field.

In many areas the situation was not much different from that in Virginia two centuries earlier. Concerning the loss of some 50,000 cattle during the harsh winter of 1673, the historian, Bruce, states that even at a much later date:

The habit of furnishing but little food to cattle in winter still prevailed, the provender which they received, when it was supplied at all, being the shucks of Indian corn, to which occasionally a small quantity of wheat straw was added.

Shelter was provided for the cattle that grazed upon the town commons in the Massachusetts settlements, frequent reference being made to "cow-houses" in the early records of the colony. Animals were well guarded, and the best meadow land reserved for grazing. Cattle represented real wealth, for with the wages of laborers being fixed at one shilling or less per day in 1630 , and cattle worth up to 25 pounds - of which 10 pounds represented the cost of transport from England - one cow was worth a year's labor or more. Although grazing on the commons was practiced until 1800 in some areas, the arrangement must have been far from satisfactory, and may have been a factor in the urge for men to head for farms of their own as soon as they could raise the capital necessary to stock one. The owner paid for a full season's grazing regardless of how long the animals grazed: "What Catle shall be put to the neatherd shall pay for the whole tyme, except in case any should miscarry, and then yts loss enough." Evidently abortion was not unknown in 1630 , but there are no suggestions that the disease was a great problem at this time.

\section{The Town Bulls}

A more serious concomitant of the com: mons system was the fact that all cattle had to be bred to the town bulls, and it may be doubted that the town fathers were particularly astute in choosing the best stock. Inasmuch as only female cattle were imported after the foundation bulls were brought in, the quality of male stock must have steadily deteriorated because of the indiscriminate breeding. The English cattle were mostly Devonshires, which thrived well at first, but: "with neglect, hardship and miscellaneous crossings the breed deteriorated and, big-boned, rangy and tough, were known as the red or native stock." Nor was the increase in Massachusetts as great as in Virginia, for in 1634 there were but 1,500 cattle for a population of 4,000 . On the other hand, sheep increased by 100 fold in 20 years, there being over 100,000 in Massachusetts by 1660 .

The almost total neglect of the veterinary art as such during the colonial period must be charged to this curious attitude toward the keeping of animals. And, as indicated above, despite the defects of the commons system, matters deteriorated once the bulk of the livestock population was removed to individual farms and the pioneer fringe. That conditions did not change during the entire colonial period may be appreciated from the (possibly prejudiced) observations of a Britisher, Dr. John Mitchell, in his work on American Husbandry (London, 1775):

Most of the farmers in this country are, in what concerns cattle, the most negligent ignorant set of men in the world. Nor do I know of any country in which animals are worse treated. Horses in general, even valuable ones, are worked hard and starved: they plough, cart, and ride them to death, at the same time that they give very little heed to their food; after the hardest day's works, all the nourishment they are like to have is to be turned into a wood, where the shoots and weeds form the chief of the pasture; unless it be after the hay is in, when they get a share of the after-grass. A new Englander (and it is the same quite to Pennsylvania) will ride his horse full speed twenty or thirty miles; tye him to a tree, while he does his business, then re-mount, and gallop back again. This bad treatment extends to draft oxen; to their cows, sheep, and swine; only in a different manner, as may be supposed. 
Small wonder then that little thought was given to the need for a veterinary profession until long after the introduction of large-scale animal plagues which threatened the entire livestock industry.

\section{Crazed Cattle}

The period from 1650 to 1700 includes the pioneer years for a number of the colonies. The events in Pennsylvania, for example, were not materially different from those in the other colonies, and little that can be considered new transpired in the older settlements. One notable exception - a sidelight so far as veterinary medicine is directly concerned - was the extension of witchcraft and sorcery to animals and their diseases. But as is all too well known, unreasoning superstition plays at least a subtle role in animal treatment even today, if only by the laity. Certainly it played a major role in some areas until very recently. But while much of the discussion of this period (Chapter 2) relates to this subject, it should not be supposed that in all respects the colonies had reverted to the Middle Ages.

In 1682 contemporary reports mention the great increase of livestock in the Carolinas, one stating that sheep: "thrive very well; the Country being so friendly to their natures, that it's observed, they are neither liable or incident to any known Disease or Distemper."

Another writer the same year observes: "The Cattle are not subject to any Disease as yet perceiv'd, and are fat all the Year long." As might be expected, however, all reports dating to this time do not agree; some observations undoubtedly were valid on a purely local basis, others may have been overenthusiastic.exaggerations. Thus a Virginia historian dealing with the late seventeenth century states:

Cattle at this period suffered even more than the horses from the hardships and privations to which they were exposed in the winter, many perishing in the spring, because, having ventured after the young grass in the marshes, they were too weak to extricate themselves from the quagmires into which hunger had led them. The wealthiest planters, from this cause, sometimes lost as many as thirty head apiece. Among the horned cattle a curious habit was observed as soon as the spring tides began to pour their floods into the rivers and estuaries; and irrestible impulse taking possession of them, they would make for the salt water, travelling twenty and thirty miles to reach it. . . The opinion prevailed among a large number of planters that to feed livestock in winter was to prepare the way for their destruction. . . . No hay was now produced in the Colony as a cultivated crop.

Since no specific mention appears to have been made of providing animals with salt - anymore than with the other amenities of daily life - it may be that these cattle were crazed for salt and instinctively knew where to find it. This particular event is too well documented to be an isolated happening, or due to mere happenstance.

The first great epizootic among cattle, but one not too well substantiated, apparently occurred in "the South" in 1695, when, it is said, over 100,000 cattle were carried off. Mention is also made of a "recently published and handy little pocket volume": The Countryman's Companion, or a New Method of ordering Horses and Sheep so as to preserve them both from Diseases and Casualties, and to recover them if fallen Ill (London, 1680) finding its way to the mantel-corner of many colonial farm homes. Books, other than those on theological subjects, were relatively rare in the colonies, and none dealing even remotely with animal diseases appear to have been published in America before 1710.

\section{PENNSYLVANIA PIONEERS}

Pennsylvania was settled in 1647 by Swedes, who despite the neglect of their livestock, soon produced an excess that was eagerly bought up by other settlers. About 1700 , Pastorius, a German, in what may be a biased account of the Swedes states:

The old inhabitants are poor agriculturalists. Some of them have neither barns nor stables ... and allow their cattle, horses, cows, swine, etc. to run in the woods summer and winter, and so derive little profit from them.

And as late as 1759 , another observer reports: 
Stables and cow-houses are seldom seen on farms. The animals endure the severity of the winter which, along with rain, frost and snow, is sometimes intolerable.

Still another traveller reports in 1749 an account - probably gotten from an overenthusiastic old settler-concerning the stock of the early Swedes. Of the animals brought over by the settlers, he says:

The hogs propagated so much that, there being so great a plenty of food for them, they ran wild in the woods, and the people were obliged to shoot them when they wanted them. ... The horses ran wild in the woods in some places. . . . Food for all kinds of cattle was so plentiful and abundant that the cattle were extremely fat. A cow at that time gave more milk than three or four do at present [ 1749], but she got more and better food at that time than three or four get now.

While the truth generally lies somewhere between the extremes, it is evident that livestock was at a premium during the time of William Penn, and for some time prior. In 1676 a law was passed making it unlawful "for any man to kill any Cow, Ox or Bull or such like Cattle," without a permit. And Penn stipulated in 1682 that no one "shall within three years kill or cause the same to be killed, any Cow, Calf, or Ewe-lamb, whose dam shal not dye by casualty," upon penalty of forfeiting five pounds. In 1701 this was amended to the effect that "no person shall kill or sell to kill above one half of theer growing neat Cattle." Hogs were also protected in the early days of the colony. In 1672 the penalty of ear-cropping was decreed for pig stealing. In 1682 Penn substituted 29 lashes and banishment.

The English, perhaps, were the most notorious offenders in the matter of neglect of livestock, primarily because the mild climate of England required less attention to housing. Fletcher, in his work on pioneer agriculture in Pennsylvania, states:

The reluctance of most English immigrants to build barns was due, in part, to their background of experience... many cattle died from exposure and hunger. Others were "on the lift" in the spring - so weak and emaciated that they had to be lifted to their feet. Eventually farmers of English stock built tight barns.
The Pennsylvania Germans, however, who settled at the same time as the English, early became famous for their handsome barns. In 1787 Benjamin Rush observed:

They always provide large and suitable accomodations for their cattle before they lay out much money in building a house for themselves.

According to Fletcher, livestock raising in Pennsylvania was more or less incidental until about 1790, and animals were indeed left to fend for themselves in the forest, in in part because of the abundance of game. He states:

The cattle of early colonial days were small, scrawny and unproductive. This was due not only to insufficient and unbalanced feeding and promiscuous breeding but also to the character of the stock imported; only the smallest animals could be kept alive during the long voyage. . . The inevitable result of poor feed, poor shelter and promiscuous breeding of livestock running at large was degeneracy. By 1750 the stock was much smaller and less productive than the animals first imported from Europe . . . Frequently cattle died of starvation or by eating, in desperation, laurel, wild cherry and hemlock. Credulous farmers tied a dogwood bough about the neck of a cow that staggered from starvation - this was supposed to be a tonic! Cows lost in the woods might not be milked for several days, hence they dried up quickly.

\section{Pugnacious Pigs}

While it undoubtedly was true that semiferal hogs soon populated the woods of Pennsylvania, as they had earlier in Virginia, Fletcher says of them:

The swine of early colonial days were razorbacks. They had a narrow body, long snout, arched back, large bones. They were better qualified to serve as subsoilers than to fill the pork barrel. Running wild, swine degenerated toward the wild boar type of Europe from which they had sprung-lean, swift, fierce. They could outrun and sometimes outfight most of their forest enemies.

Nor was any improvement in the breed to be noted a century or more latter. The eminent British veterinarian, William Youatt, in his book on The Pig (1846) says of the American hogs: 


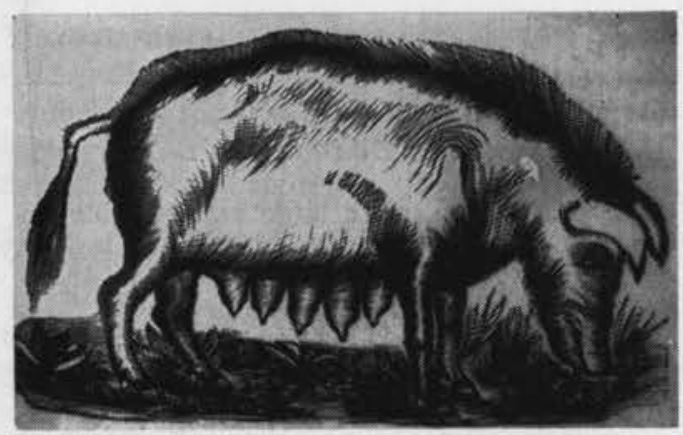

Hogs allowed to run wild soon reverted to ancestral prototypes, and in some areas the "prairie ranger" was hunted as a sport. The fact that many of these feral hogs were found in supposedly virgin territory led to the belief that they were native. Perriam and Baker: Stock Doctor

They have long-peaked snouts, coarse heads, thin chests, narrow shoulders, sharp backs, slab sides, meagre diminutive hams, big legs, clumped feet, the hide of a rhinoceros, the hair and bristles of a porcupine, and as thick and shaggy as a bear's; ... . No reasonable fence can stop them; but, ever restive and uneasy, they rove about, seeking for plunder, swilling, grunting, rooting, pawing - always in mischief and always destroying.

And Charles Dickens, in his American Notes (1842), describes the "swinish multitude" of the large cities:

They are the city scavengers, these pigs; ugly brutes they are, having for the most part scanty brown backs, like the lids of old horse-hair trunks, spotted with unwholesome black blotches; they have long gaunt legs, too, and such peaked snouts, that if one of them could be persuaded to sit for his profile, nobody would recognize it for a pigs likeness ... he is in every respect a republican pig, going where he pleases, and mingling with the best society, on an equal if not superior footing, for every one makes way when he appears.

Despite the almost universal practice of letting hogs roam at large, and the ravages of weather, wolves, bears, and Indians, pork early became an article of export from several colonial ports. Pennsylvania soon established her supremacy in the swine trade, exporting both pork and live hogs within a decade of the founding of the colony, in part because of the better care given their animals by the Germans and
Quakers. Some of these hogs topped 200 pounds at slaughter.

Virgina and Massachusetts also carried on an extensive trade. Smithfield hams, still the epicure's delight, were already famous before the Revolution, and pork exports from Virginia exceeded 20,000 barrels annually before 1750 . Practically all of this was raised in the woods, and an exceptionally hard winter undoubtedly was reflected in a lessened supply the following season. During the winter of 1694 it is reported that in excess of 60,000 hogs and 25,000 cattle died in Virginia of cold and starvation.

The indispensable part played by the ubiquitous razorback in the settling of America, however, should not be underestimated. For a century and a half, agriculture was primarily subsistence farming; hogs, which were highly successful in fending for themselves, were an important hedge against hard times. This is particularly true of the early pioneer times on the western fringe. Quite correctly, one traveller about 1700 notes: "These hogs suffer hardships as no other animal could endure." Here, neglect was understandable, but at times it exacted a heavy toll. The

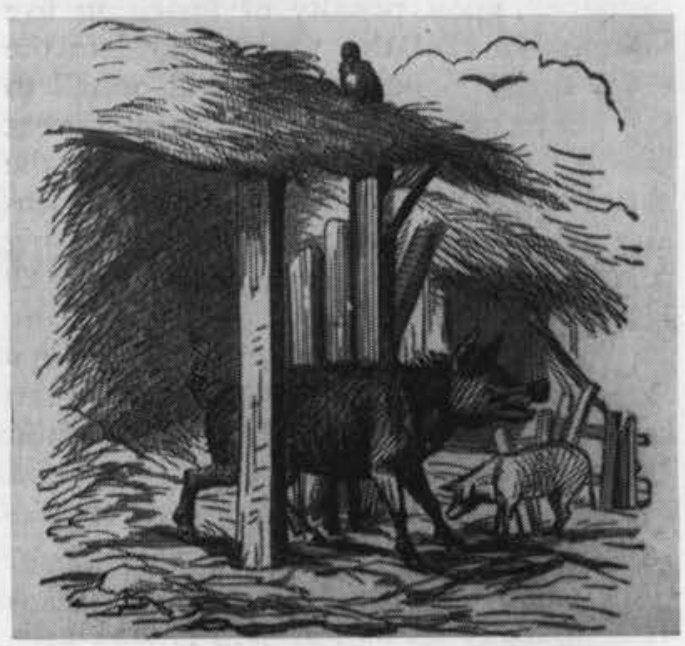

The "razorbacks" kept by many poor farmers who made no effort to breed toward any standard differed little from swine that roamed the woods. Perriam and Baker: Stock Doctor 
German Prince Maximilian, visiting in Indiana in 1843, writes:

We observed them in our excursions, in the depth of winter, when the young ones often perish with cold; and we also saw them eaten by the mothers. Dead swine were lying about in all directions, partly devoured by others. The negligence and want of feeling with which the animals are treated, are very great.

\section{VETERINARY PUBLIC HEALTH IN COLONIAL AMERICA}

The most superficial study of the colonial town records of any of the settlements clearly demonstrates that livestock played an important part in everyday life. The earliest concern was over the manner of handling the animals which grazed upon the town commons. Grazing on the commons in England had been a fertile source of contagion, but this apparently was not a problem in this country until late in the colonial period, when the practice was being superseded by an agricultural rather than a town economy. But, as the livestock population increased, so did animal disease and, with the latter, a number of problems of a public health nature inevitably arose.

That these problems relating to animal and human health were not considered as being in the veterinary domain is not surprising, for the American colonies had no veterinary profession - nor did they recognize the need for one. The injuries and ailments of animals were attended by the owner as best he could or, occasionally, by the relatively scarce self-denominated farrier or cow-leech - who likely as not often added to the misery of his patients.

The nature of some of these worthies may be deduced from a contemporary description of one who appeared in a New York City parade in celebration of the ratification of the Constitution. Several thousand people were in the line of march, arranged by trades and professions. A newspaper account, reprinted in the Pennsylvania Journal for August 20, 1788, informs us:

Walter Gibbons, Horse-Doctor, dressed in an elegant half shirt with a painted horse on his breast; a balling iron in the horse's mouth, and the Doctor putting a ball of physic down his throat, with implements of farierry [sic] ready for use. Over the horse, written "Federal Horse Doctor;" at bottom; "physic." On his back a horse skeleton, the Doctor examining the head; over his head, "Federal Horse Doctor," at bottom dissection.

Under such conditions, it is perhaps obvious that the earliest records of problems now considered to be wholly, or in part, in the veterinary domain should have been those in which there is an interrelation between animal and human health. But what we would today consider as veterinary public health matters were not recognized as such in colonial times. If the colonist neglected the control of his animals which fared surprisingly well despite the seeming lack of attention - the colonial town fathers were considerably more astute in framing measures to protect the populace, whether from Indians, animals, or epidemics. More or less in the order in which action was taken, these public health problems can be categorized as follows: (1) restrictive measures against livestock; (2) regulation of slaughter and disposal of animal wastes; (3) food hygiene, including inspection of foods of animal origin; (4) control of animal diseases transmissible to man.

\section{Restraint of Animals}

Almost from the very beginning of the Massachusetts settlements, town ordinances regulating the herding and movement of livestock were put into effect. Cows belonging to private citizens, along with the town bulls, grazed on the commons under the care of keepers as late as 1800 , and apparently occasioned relatively little trouble. Pigs were kept at first in the same manner but, pigs being pigs, they proved troublesome from the outset, and many families simply let them roam. Apparently free from disease themselves, they soon became a menace to the community as indicated by the following excerpt from the town records of Boston for 1658: 
Whereas by long and sad experience very many and greatt damages have accrued to this towne by swine, besides the many dangers that children have beene in of loss of life and limb, and elder people also of greatt hurt, by the unruliness and ravenousnes of swine, and notwithstanding the law in that case provided by the Gen. Court that requires the making and constituting effectuall orders to prevent all harmes by swine. And although yearely endeavours have beene to attaine the end aforesaid and yett fruittles.

Itt is therefore ordered that hence forth every inhabitant in this towne that shall keepe any swine within this towne after the first of next month they shall constantly keepe up such swine in their owne ground . . . yett shall so keep them ... [without] the annoyance of any neighbors or travellers through the comon streetes or high wayes, upon the foresaid penalty [ two shillings, six pence] for every offence.

But in 1671, this law required restatement:

This town haveing lately many and greivous complaints of greate suffringes by ... swine in this towne, and alsoe consideringe the many inconveniencies by the aboundinge of these creatures, in a towne soe populous as this is in respect of sicknesses \& the like.

And in 1701, not only was it illegal to allow swine to go at large upon the town:

nor shall any person keep any hogg or swine in any hoggstey within twenty foot of any highway, street, lane or alley within this neck of Boston, or the dwelling house or shop of any Neighbour.

Legislative acts such as these failed in their purpose, however, and swine continued to roam the streets long after towns had become cities. One of the first reforms urged by the New York Evening Post upon its establishment in 1801 was the clearing of pigs from the streets.

\section{Destructive Dogs}

Dogs, too, had their day in court; as early as 1635 , the town of Salem passed a dog ordinance requiring, among other stipulations, that they "be tyed up in the day tyme \& if any doggs there spoile fish ... they also shall either be sent away or killed." And at Ipswich, in 1644, dogs were required to have one leg tied up to pre- vent their digging up fish in the cornfields. (A fish was placed in each hill of corn as fertilizer - a practice learned from the Indians.)

The cow keepers of Boston town, in 1692, were given liberty to: "destroy and kill any dog or dogs they shall find to seize upon any cow or cattle." In 1696:

Noe person whatsoever shall keep more than one Dogg, or Bitch in the Town ... [ [and] noe Hounds or Hunting Doggs shall be suffered to Goe at Large in the Town . . . It shall be lawfull to any of the inhabitants of the Town to kill and destroy any Dogg so kept [ contrary to these orders ].

Although the wisdom of allowing any person to act as judge and jury in such cases may be open to question, in 1701, it was ordered further that after notifying the owner, any inhabitant could

cause the Town to be rid and discharged of [any] unruly Dogg or Bitch, that ... hath been known to bite seiz upon worry or do harm to man or beast.

Wolves, and dogs - many with the demeanor of wolves - were a powerful deterrent to the sheep industry of the colonial period, and for some time after. In 1794, a traveler through southeastern Pennsylvania wrote:

Sheep are not well understood, little attended to, are very often destroyed by the wolves \& few People therefore except of good Capital keep them.

The wolves were slowly decimated by a bounty system and by the encroachment of civilization but, as the wolf was pushed into the hinterland, the semiferal dog took his place - and with a vengeance. Pennsylvania attempted to counteract these depredations with a dog law in the early 1800's, but how effective this may have been is a moot question.

The broad aspects of this problem are clearly stated in an exchange of letters, in 1811, between Thomas Jefferson (after his retirement from public life) and a Peter Minor. While their thoughts on the matter may appear harsh, it should be recalled 
that Jefferson was an astute farmer as well as an able public servant, and his correspondent seems to have been equally well versed in agricultural and legal matters. Minor had proposed a dog law for Virginia patterned after the one in effect in Pennsylvania, adding:

Since the introduction of the Merino \& other valuable breeds of Sheep, I think it particularly behoves us to guard against their destruction by dogs. But Independent of their propensity to destroy Sheep, why should we not endeavor to diminish a race of Animals which to make the best of them are a nuisance, but when considered in a state of madness are certainly as great a curse as can visit us.

\section{To this Jefferson replied:}

I participate in all your hostility to dogs, and would readily join in any plan of exterminating the whole race. I consider them as the most afflicting of all follies for which men tax themselves, but as total extermination cannot be hoped for let it be partial. I like well your outlines of a law for this purpose: but should we not add a provision for making the owner of a dog liable for all the mischief done by him?... The average of what they get fairly and unfairly of the food fit for man, would feed a man ... [ [and] are there not as many sheep and hogs annually lost to the owners by dogs, or with their aid, as there are dogs in the state?

\section{Regulation of Slaughter}

In the first days of the colonies, the slaughter of meat animals was not a problem. The first few animals brought over were intended for foundation stock and, while hogs in Virginia soon became so numerous that the Indians reportedly gave up deer hunting, the killing of cattle was made a capital offense.

With most of the meat supply being wild game killed in the woods, the public health problems attendant upon the establishment of slaughterhouses did not exist. But as towns grew in size and the livestock population increased, slaughtering became a regular industry. A particularly revealing series of entries is to be found in the town records of Boston in the 1640's:
[ 1642 ] It's Ordered that the Constable shall give speedy notice to Robt. Nash, Butcher, that with all speed he remove the Stinking garbage out of his yard, nere the street, and provide some other remote place for slaughter of Beasts, that such loathsome smells might be avoyded, which are of great annoyance unto the neighbours, and to strangers.

[ 1647 ] It is ordered that the annoyance that is made bye Robt. Nash in his slaughterhowse, by his killinge of beasts in the street now layd out, that hee shall remove that annoyance on penalty of $19 \mathrm{~s} 6 \mathrm{~d}$. for evry defect justly complayned of.

[ 1649 ] Robert Nash is fined 19s 6d. for his leavinge his slaughter howse with noyesome smells, to the offence of the Towne.

Mr. Nash may have been the only butcher in Boston at this time, for the ordinance framed for the relief of the town from this specific nuisance was not extended to all until 1652, when it was ordered:

that noe person inhabiting within this Towne shall throw forth or lay any intralls of beast or fowles or garbidg or Carion or dead dogs or Catts or any other dead beast or stinkeing thing, in any hie way or dich or Common within this neck of land of Boston, but ar injoyened to bury all such things that soe they may prevnt all anoyanc unto any.

Whether convenient burying ground became scarce, or the town fathers felt that an easier method might result in greater compliance, they decreed in 1666:

for the prevention of annoyance to the Town, all garbidge, beast entralls \&c. are to be throwne into the Mill Creek over the Mill Bridge upon penalty of 20 shillings for every default.

Later it was stipulated that not more than three slaughterhouses should be erected over the Mill Creek; it was not until 1798 that one of the duties of a newly appointed health officer was "to prevent dead carcasses and other nuisances being thrown in to the Mill Pond."

The appointment of a health officer for Boston town followed closely upon a law of the Commonwealth providing for similar services, and later the same year the 
town fathers broadened this concept by establishing a Board of Health:

The Duty of the Board of Health shall be to examine into all Nuisances \& other causes injurious to the health of the Inhabitants whether the same shall be caused by stagnant Waters, drains, common sewers, slaughter Houses, Tan Yards, Fish Houses, Docks, Necessaries, putrid animal or vegetable substances or any other cause of whatever kind, which may be injurious to the Health of the Inhabitants as aforesaid, with power to search all houses, stores, cellars, ships \& vesells where they may have reason to suspect any of the causes aforesaid to exist.

\section{A Wholesome Food Supply}

As mentioned above, the British forbears of the American colonists had generally given little thought to the wholesomeness of their food supply, especially as it related to the lower classes. It is not surprising, therefore, that few references should be found relating to food hygiene in the early days of the colonies.

The town records of Boston for 1654 indicate that two men were chosen for "Searchers and packers of Flesh and Fish," but subsequent appointments do not in. clude the term "searcher," and it would appear that the duties involved mainly supervision of weight and the adequacy of the containers. The first specific reference to matters of food hygiene in Boston appears in the regulations for the town market in 1733:

if any Person or Persons Shall Presume to Expose to Sale in the Said markets or Either of them unholsom or Stale victuals, Blown meat, Leprous, or measly Swine, He She or they so offending Shall forfeit and pay in Proportion to the Offence.

The legality of this ordinance was confirmed in 1742, and orders were given to prosecute offenders. Nothing appears to have been stated concerning the authority for determining when an offense had been committed but, in 1742, this matter was placed in the hands of the clerk of the newly erected Faneuil Hall Market, who:

shall suffer no unwholsome or putrid Meat, or otherwise unfit for Sale, to be Sold there; and if any such be Offered to Sale, in the said
Market, he shall be obliged to prefer a Prosecution against the Offender ... [ and ] no Meat shall be left in the Market after it is shut up.

In a relatively short time after its settlement, Pennsylvania began to export considerable quantities of beef. In an act of 1727, there was appointed: "an officer for viewing, searching, packing or repacking and branding all beef and pork intended for exportation." While it may be presumed that this law was based more upon economic necessity than altruistic motives, it is at least an early recognition of the need for food inspection.

\section{Military Food Hygiene}

A major source of information on almost any aspect of colonial affairs is the writings of George Washington (42 large volumes). It is from these writings that we obtain a good picture of the problems of food hygiene in the military campaigns of the French and Indian and the Revolutionary wars. In 1755, Washington mentions the procuring of salt beef, some of which had to be condemned upon receipt. Because of the problems involved in storage and transportation of processed meat, it was preferred to drive live cattle behind the armies for slaughter as needed. Washington's passion for detail is demonstrated by his diagrams for battle lines in certain static campaigns in which the position of grazing fields and slaughterhouses for the army are indicated. The scarcity of transport emphasized the advantages of keeping slaughter cattle nearby. But in a fast moving campaign, the cattle could not be driven fast enough, and in a forced retreat they frequently had to be left behind, to the obvious advantage of the enemy forces. "Grass guards" were posted to protect the grazing cattle, but frequently cows were lost to the enemy or even to noncombatant Indians.

In a communication to Commissary Charles Dick, in 1755, Washington directed:

You are, so soon as you arrive here, to give such directions as you shall see necessary about driving the Cattle to Fort Cumberland. You 
are to send up Doctor Walker, or go yourself there, to see them properly killed and salted.

And later the same year, he wrote Commissary Thomas Walker:

I am sorry to find the Carolina Beeves are so unfit for Slaughtering ... [ Colonel Stevens is ] to assist you with his advice, either to kill and salt, or feed them this winter. ... Provender is very scarce in this Colony, however. . . . As I am unacquainted with the proper methods to cure provisions, I must desire you will consult the principal Officers at the Fort; and if their opinions corroborate with yours, let some of the Beef be dried, as you propose. . . . I am informed, that meat will lie sometime in bulk without salt. I think you should not delay slaughtering the Beeves one moment .... for the Cattle lose flesh every hour ... [ and to Robert Dinwiddie ]. Many of the Carolina beeves are dead, through absolute poverty; and the chief part of them too poor to slaughter.

It might be noted that Washington was only twenty-three years old at this time, but was already a formidable military disciplinarian. His order: "You are to send up Doctor Walker, or go yourself there, to see them properly killed and salted," meant exactly what it said. While it must be assumed that supervision of slaughter and processing by a medical officer was a fortuitous exception rather than the rule, it is evident that Washington insisted upon the best food hygiene at his command. His concern did not stop with matters of supply, but carried down to the welfare of all of his soldiers. Although Washington insisted on maintaining an aloofness even with his officers, as a good commander he was attentive to the needs of his men. In 1756, he wrote:

The Soldiers have made some complaints of their provision being very bad. The Commissary is ordered to inspect all that he can have the least doubt of and if there is any that can be saved, to put it into fresh pickle; what can not, must immediately be thrown away.

In a similar vein, one of Washington's first general orders as Commander in Chief of the colonial forces in the Revolutionary War (1775) reads:

Next to Cleanliness, nothing is more conducive to a Soldiers health, than dressing his provisions in a decent and proper manner. The Officers commanding Companies should therefore daily inspect the Camp Kitchen, and see the Men dress their food in a wholesome way.

And in 1777 , he issued a general order requiring:

A fatigue party of an officer and twenty privates, to be employed to bury all the Offals in and about the Slaughter House, dead horses, dogs, or any kind of Carrion in and about the town; also to remove all the filth about the Gaol . . . otherwise as the weather grows warm, the consequences may be fatal, as well to the Soldiery, as the Inhabitants . . . [also ]: The Commissary General to have his Slaughter-house, at least a mile in the rear of the camp, and to be very careful to have the offals, of what he kills, buried, a sufficient depth under ground .... [and]: The Slaughter pens are to be removed from the brooks which afford water for the army. The offal is to be buried once a day.

It was not until 1783, the last year of the war, however, that official provisions for civilian inspection of meat destined for the army were made. In a general order, Washington directed:

The Contractors for the Army having desired, that agreeably to Contract, a person might be appointed to inspect the Cattle destined for the Army, Henry Wykoff, esquire of Fishkill is appointed for that purpose . . . he was recommended by Mr. Parker [ one of the contractors ] who, himself, previous to the appointment, had condemned a large quantity of Beef wch. had been slaughtered and was ready to Issue.

These selections, culled from nearly 20,000 pages of the writings of Washington, are a representative sample of his thinking on military food hygiene and reflect his sagacity in all matters relating to military operations. From the above it is evident that, in principle at least, the fundamental basis for an adequate system of safeguarding the meat supply for the army had been evolved by the end of the Revolutionary War. How well the tenets of Washington were carried out in subsequent wars, in the nineteenth century at least, is open to suspicion - considering the "embalmed beef" scandals of the SpanishAmerican War. 
Returning to civilian matters, a bill framed by Thomas Jefferson and enacted by the Virginia legislature, in 1786, became the prototype of similar measures in other states. This was:

A Bill Prescribing the Punishment of Those Who Sell Unwholesome Meat or Drink. - Be it enacted by the General Assembly, that a butcher that selleth the flesh of any animal dying, otherwise than by slaughter, or slaughtered when diseased, or a baker, brewer, or distiller, who selleth unwholesome bread or drink shall, on conviction the first time, be amerced; the second time he shall suffer judgement of the pillory, and the third time he shall be imprisoned and make fine; and every time after he shall be adjudged to hard labour six month in the public works.

\section{Rabies Rampant}

While it must be supposed that animals suffered more from disease during the colonial period than is on record, nevertheless, it is a fact that animals in the New World enjoyed an immunity from largescale plagues - an immunity unknown for centuries in Europe. Not until the end of the colonial period did it become apparent that this immunity was a deceptive one, and that the furies were gathering to be unleashed in the nineteenth century. The one disease that reached alarming proportions prior to 1800 was rabies.

Although rabies had been the scourge of both dogs and man from the beginning of historic time, Noah Webster, in his History of Epidemic and Pestilential Diseases (1800), states that this disease did not appear in America until 1769, at first in and around Boston. Webster says: "Rabies in dogs commenced in this part of the world at this time" (1769). But on July 5 of the same year, George Washington noted in his diary:

A Dog coming here [ Mount Vernon] which I suspected to be Mad I shot him, Several of the Hounds running upon him may have got bit. Note the consequences.

While no "consequences" were mentioned in his diary, the fact that Washington should have recorded the occurrence in a rather perfunctory manner, and that he an- ticipated some untoward consequences, suggests some familiarity with the disease. As a matter of fact, rabies is first mentioned in the Archives of Virginia in 1753.

While reports of human infection are surprisingly scarce in the early reports from Boston, swine, which had the run of the streets, were bitten in large numbers, and foxes in the rural areas became infected. It seems that dog ordinances were ineffective in controlling the disease for, in addition to it remaining a problem in New England, rabies was reported to be "common" in Philadelphia and Maryland by 1779 , and "raging" over all the northern states during the 1780's.

The town fathers of Boston were disturbed over the dog menace, and in 1784 it was recorded:

The Committee Appointed to consider of the danger the People at large are continually exposed to, by the large number of Dogs, going at large in this Town, have attended that service - And as many Persons, not only in the Town, but in other parts of this Commonwealth, have been bit by that Animal, and some have lost their lives, \& others in great Danger - therefore your Committee apprehend it of great consequence to the People, at large that some effectual method be taken to prevent, the growing evil complained of.

The committee requested instructions for framing a dog law, but it is not clear just what action may have been taken at this time.

In 1786 Washington wrote in his diary:

A Hound bitch which like most of my other hounds appearing to be going Mad and had been shut up, getting out, my Servant Will, in attempting to get her in again, was snapped at by her at the Arm. The Teeth penetrated through his Coat and Shirt and contused the Flesh, but he says did not penetrate the skin nor draw any blood.

Thus in his usual vein, Washington was more concerned with the apparently unharmed individual than with his cherished dogs. His matter-of-fact observation that most of his hounds appeared to be going mad undoubtedly belies his concern over them, but perhaps suggests that the situation was by no means uncommon. 
Human rabies had become a major problem during this decade; Webster states that the gazettes of 1785 "abound with accounts of its dreadful effects," and during the following year, "many cases of hydrophobia were observed in the Southern States."

Some of the newspaper accounts of human deaths from rabies during this period are hardly more than vital statistics; others portray graphic and unusual cases. In 1789 the Connecticut Courant mentions the case of a man who: "died in July of that dreadful malady, taken as was supposed, by skinning a cow that died of the disorder in the April preceding." And in 1796 the same paper records the death of a man bitten five weeks prior by his own dog when disengaging it from combat with another. The dog died three weeks later; meanwhile:

He suffered the dog afterward to lick the wound . . . It did not occur to Mr. Eger all this time that the animal could have been infected with the hydrophobia; on the contrary, he supposed him to have been poisoned, and employed a negro man to open his body with a view to ascertain the fact, but no symptoms of poisoning appeared.

The Philadephia physician, James Mease, published a work: On the Disease Produced by the Bite of a Mad Dog (1792), in which he rejected the commonly held concept of spontaneous generation of the disease in man or dog, insisting that the only mode of transmission was the wound produced by the bite of an infected animal. His illustrious contemporary, Benjamin Rush, in his Observations Upon the Nature and Cure of the Hydrophobia (1805), recognized the bite of a rabid, or merely "angry," animal as a cause, but listed twenty other causes, including fear, thirst, heat, cold, worms, dysentery, and typhus.

\section{Prevention Versus Cure}

Responsible physicians and quacks alike professed to "cure" rabies. In the former category was a Dr. Henry Stoy of Lebanon, Pennsylvania, who was "celebrated for curing persons bitten by mad animals." In

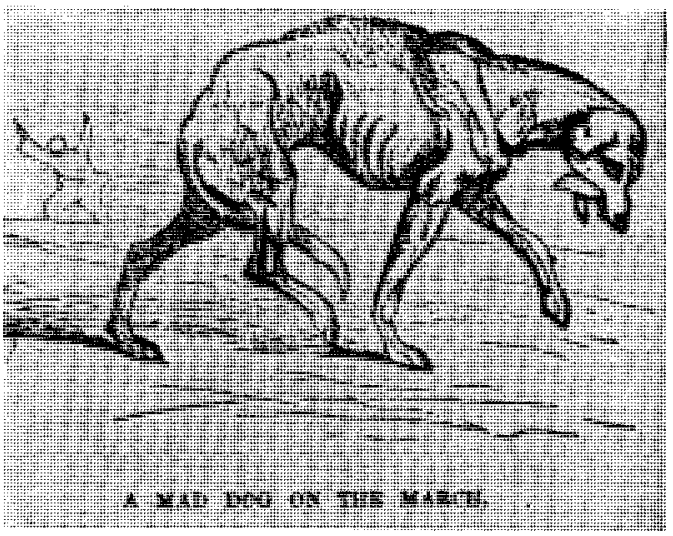

The colonies appear to have been free of rabies until about 1750 when the disease appeared in dogs and spread to wildlife. The cry of "mad dog" became increasingly frequent and was the occasion for much talk but relatively little effective action. Forester: The Dog

1797, Washington gave a servant, who had been bitten, $\$ 25$ for expenses for a trip to Lebanon for treatment. The physician's fee was $\$ 5$. Concerning the "cure" of his servant Christopher, Washington notes:

he derived so much aid from the medicine he took as to have remained perfectly well ever since; and has placed such confidence in his Doctrs. skill, that he wou'd not again despair of being cured of the bite of a mad dog; if the Hydrophoby was strong upon him.

Stoy's method was communicated to the Senate of Pennsylvania in the early 1800's as "a sure remedy for the bite of any kind of mad animals." The informant, Valentine Kettering:

from motives of humanity . . . says that his ancestors had already used it in Germany 250 years ago, and that he had always found it to answer the purpose, during a residence of fifty years in the United States.

This remedy, he says, is said to be the same through which the late Doctor William Stoy effected so many cures, and consists of chickweed. The weed must be gathered in June when in full bloom, and dried in the shade, after which it is pulverized:

The dose of this for a grown person is a small tablespoonful in beer or water. For children the dose is the same, yet it must be 
administered at three different times. In applying it to animals, it must be used green, cut to pieces, and mixed with bran or ther feed. For the hogs the pulverized weed is made into little balls by mixing it with flour and water. It can also be put on bread and butter, or in honey.

The Rev. Henry Muhlenberg is quoted to the effect that in Germany:

30 grains of this powder are given four times a day, the first day, then one dose a day for a whole week; while at the same time the wound is washed out with a decoction of the weed, and then the powder strewed in it.

If the theory that more of a good thing is better than a little be admissable, the latter regimen would seem more promising than a single shot.

Not all those who professed to cure rabies were as magnanimous as Doctor Stoy, however. As related by Merillat and Campbell, in 1811 the New York legislature appropriated $\$ 1,000$ to pay one John $M$. Crous for a rabies cure and received the following prescription:

Take one ounce of the jaw-bone of a dog, burned and pulverized, or pounded to fine dust. Take the false tongue of a newly foaled colt; let that be also dried and pulverized; and, Take one scruple of the verdigris which is raised on the surface of old copper by lying in moist earth; the coppers of George I. or II. are the purest and best.

It would, perhaps, be invidious to note that another century was to elapse before sound rabies control programs were worked out by responsible public health officers. And it is all too apparent that, for various reasons, the problem is not yet one of the past.

\section{Anthrax Epizooty}

One other disease common to man and animals which became a problem during the period under consideration was an- thrax, but this appears to have been confined, in epizootic proportions at least, to the West Indies. Fleming, in his work on Animal Plagues, states that in 1769:

An epizooty of anthrax on St. Domingo resulted in famine, compelling the colonists to salt or smoke the flesh of all their cattle-dead or dying from the anthracoid malady. The consequence was, that a carbuncular epidemy appeared, and in less than six weeks more than fifteen thousand black and white people had perished. The plague did not cease until the consumption of the poisonous flesh or "tassau" was interdicted.

The disease appeared again in epizootic proportions on the Island of Grenada in 1783, and in Barbados in 1795. Fleming quotes a contemporary report which records that:

On those plantations where care was taken to burn the carcases of the diseased cattle, no further consequences resulted. But they unhappily were few. On those where this precaution was not used, and, indeed, it is surprising that it should be used in any, seeing that the disease was new, and its effects unknown, the flesh of the cattle that died being dug up and eaten by the negroes, proved most dreadfully septic, producing a pestilential carbuncle, attended by a malignant fever. There were not wanting instances of the iniquitous practice of offering the flesh of the diseased cattle for sale, and on these occasions, such was the highly septic nature of this poison, that even touching the flesh, in such manner as that part of the sanies adhered to the finger, produced the same fatal consequence.

One instance of infection in a child who drank milk from a diseased cow was recorded, and Fleming suggests a possible relationship between anthrax and the outbreaks of "milk-sickness" in America in the nineteenth century. While this, of course, was due not to anthrax but to white snakeroot poisoning, it seems likely that the West Indies remained a reservoir of infection. 


\section{Witchcraft Vs. Animal Medicine}

IN THESE DAYS of "miracle" drugs it has become commonplace to expect a little magic in most medicines. Recognizing that an antibiotic armamentarium sometimes may be used indiscriminately as a substitute for the powers of nature and good nursing care, it may be possible to take a more dispassionate view of colonial charms and witchcraft than all too frequently has been done.

\section{SUPERSTITION AND SORCERY}

The idea that certain persons are endowed with supernatural powers is deeply rooted in the philosophies of most civilizations, perhaps as a logical projection of the observation that some individuals seem to have unusual qualities. In like manner, certain herbs, minerals, and animal products - some undoubtedly useful as medications - came to have magical powers imputed to them. It is, therefore, a not too illogical development to find these same powers transferred to inert objects, and charms and incantations substituted for medical services. That it should have been women who were attributed with these powers - once they had been determined to be evil - comes as no surprise, for colonial society, perhaps to a greater extent than in the mother country, was a man's world. Moreover, witchcraft frequently had medical connotations, and it was the women who, in the absence of a bona fide medical service, performed most of the domestic medicine.

\section{Enchanted Oxen}

With disease still looked upon as punishment for sin as a legacy from the past, and preached by the omnipresent pastor, those who had no doubts concerning their own righteousness found it convenient to look to their neighbors as the source of their ills. Thus in 1692 at the height of the witch fever, as related by Marion Starkey in The Devil in Massachusetts:

There was the tale of the Enchanted Oxen of Salisbury Beach. Fourteen head that John Allen had put out to fatten on the salt grass had one day been goaded by the devil into swimming to Plum Island. When Allen traced them there and tried to round them up, the oxen ran from him "with a violence . . . wholly diabolic" and plunging into the water swam straight out to sea. . . . Faced with so ruinous a disaster a good Puritan searches his conscience to see "what sin unrepented of" God is punishing him for. Allen may have started such a search, but he was interrupted by a memory ringing in his ears like a spiteful echo of the shrill voice of Susanna Martin, "Your oxen will never do you much service!"

It came back to him now. Just before he turned his oxen out to grass he had refused to hitch his oxcart to haul her some staves, and in those words had Susanna mocked him. . . . Who but Susanna had sent the devil into his cattle? 
On the basis of this and other similar stories, including one of some phantom puppies, Susanna Martin and four other women were convicted of witchcraft and hanged. As to what really had happenend to the cattle, we of course will never know. It has been suggested they may have been poisoned from eating Jimson weed, which had been introduced from the West Indies early in the century, and now thought to be a possible explanation for some actual hysteria and other symptoms of persons suspected of being "possessed." Other explanations of the crazed cattle may have been simply a craving for salt, or there may have been some actual disease of the nervous system.

It was something in the nature of poetic justice that the pastor-prosecutor of the five women died of hemorrhage some years later, perhaps with the dying words of one ringing in his ears: "God will give you blood to drink." In evaluating the Salem witch trials, Miss Starkey asks:

Heaven forgive us, "demoniac possession" is with us still, even if the label is different, and mass mania, and bloodshed on a scale that the judges of old Salem would find incredible.

Whatever stand one may wish to take today regarding witchcraft in colonial times, there is no denying the fact that this phenomenon had the stamp of high legal recognition. Some who might take issue with the philosophies of Cotton Mather on various grounds might be surprised that no less a personage than the benevolent William Penn presided over the trial of an alleged witch in 1684 .

\section{Bewitched Bovines}

Being slow to think evil of their neighbors, this one instance of a witch trial in the Quaker colony is something of a curiosity, and one of some interest in that it involved a Margaret Mattson, who was accused of having bewitched her neighbor's cows. She was declared not guilty "in manner and forme" as indicted (an unusual verdict in such cases), but was reprimanded for "haveing the Comon fame of a witch."
A much stronger case, however, was made against Grace Sherwood of Princess Anne County in Virginia. In 1689 she and her husband brought suit for slander against one neighbor who had openly declared she had bewitched his hogs and crops, and against another for declaring she had, in the form of a black cat, slipped through his keyhole. The jury found her guilty on both counts on the basis of the traditional trial by water and an examination for "witch marks."

Although the witch-hunting mania had cooled down considerably by the end of the seventeenth century, it should not be supposed that all prospective witches immediately flit from the scene. A New York correspondent to the Albany Cultivator in 1839 states:

The last time I sat on a grand jury, a woman of Duanesburgh applied for protection from her neighbors, who called her a witch. They sought opportunities to attack her when passing in the street, and attempted to draw blood from her head by striking her, believing that if they were successful, it would protect them from her witchcraft. . . She was Scotch, and ... some of her neighbors believed she had lately made a pass to Scotland, over the ocean in a wash-tub. . . .

About three or four years ago ... a descendent of German parents, in Rotterdam, adjoining our city, stopped at our store, and said he was on his way to the adjoining town of Glenville, to expel the witches from the cattle of a Dutch farmer there, who had sent for him for that purpose. Shortly after, that farmer stopped at the store, and we attempted to admonish him for such folly. He answered with great pathos, that when his cows all slunk their calves, it was time to do something for them. ... If grand juries would indict, and the courts would condemn to be hanged those convicted of witchcraft, as they formerly did, witches would be as numerous now as then, notwithstanding the boasted light and knowledge of the age.

Judgement upon witchcraft cases involving ecclesiastical matters are perhaps best left to those qualified to evaluate the evidence. In medical matters, however, qualified physicians and quacks alike added fuel to the fire. Even by seventeenth-century 
The so-called "Hex Book," numerous editions of which were published from 1820, was a compilation of ancient and mystic remedies for man and beast.

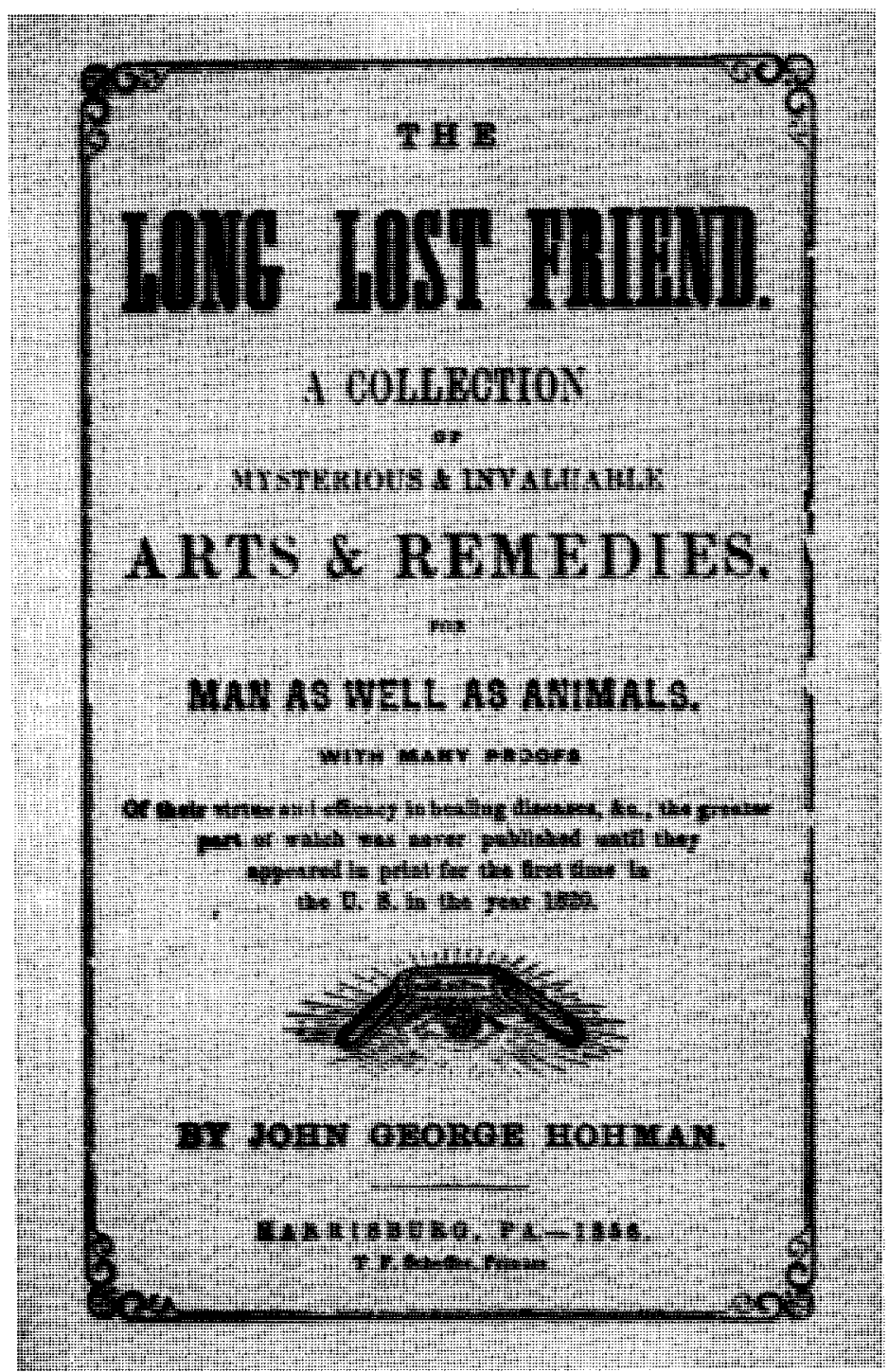

standards, the quality of the medicine practiced in the colonies left much to be desired. It is reasonable to suppose that relatively few competent physicians, who enjoyed a comfortable income and good social standing in England, would have left the mother country for the uncertainties of colonial life. The skill of those who possessed some qualification in medicine was such that it was complained: "Shoemakers, Weavers and Almanack makers ... have laid aside the proper business of their lives to turn Quacks." While laws regulating the practice of medicine were passed in Massachusetts in 1649, and in Virginia as early as 1639 , these appear to have had little effect.

While it might be supposed that the medical profession would have been first in discounting or combatting a belief in witchcraft, all too often medical men promoted it as a convenient means for concealing their own deficiencies. It was an easy thing to say that a person who failed 
to respond to medical treatment - all too often little more than bleeding, blistering, or purging - obviously was bewitched. Insanity or epilepsy quite obviously was "demoniacal possession." The ancient physicians had a better appreciation of the nature of nervous afflictions than any doctor of the seventeenth century. It was not until nearly 1800 that the eminent colonial physician and signer of the Declaration of Independence, Benjamin Rush, made substantial contributions to the understanding of nervous diseases in America, and so helped spell the doom of the devil in disguise. That the medical practices of any time must be viewed in perspective, however, may be appreciated by considering the probable reaction of the town fathers of colonial Boston or Salem to the sudden appearance of a white-coated physician with syringe of penicillin in hand. If he had been given the opportunity, the magical results would most certainly have convicted him of sorcery or worse.

Among intelligent and educated peoples, belief in witchcraft can perhaps at best be dismissed as a misdirected means to an end. But among settlers on the fringe of civilization, without books, doctors, or educated neighbors (the etymology of "neighbor" is nigh boor), that they might turn to for answers to puzzling questions, reliance upon superstition is a universal practice. In a recent work on Folk-lore from Adams County Illinois, some 10,000 superstitious practices are detailed, many relating to animals and medicine. As practiced by individuals, many of these "charming" bits of lore can be dismissed as traditional nonsense; but if anyone were to engage in even a few of these practices professionally, he would be lucky even today to escape with much less than the brand of "witch" or "wizard." When a belief in witches actually was in vogue, it was much simpler to attribute the loss of milk or sudden death of a cow to witches than to find-or even search for - the real cause. And to doubt that there were persons who could "bewitch" cattle amounted to rank heresy.

\section{A Hex on Your House}

Hex signs may still be seen on the houses and barns in eastern Pennsylvania; some of these may have been primarily decorative, but others had more mystic meaning. Less well known is the body of medicomagical folklore which thrived in this region. Much of this is detailed in a curious little book entitled The Long Lost Friend, by John George Hohman, first published in 1819, and printed at Harrisburg, Pennsylvania, as late as 1856 . More magical than medical, this work is known as "The Hex Book" in the antiquarian book trade, and is something of a rarity. The author avers:

Whoever carries this book with him, is safe from all his enemies, visible or invisible; and ... cannot drown in any water, nor burn up in any fire, nor can any unjust sentence be passed upon him. So help me.

As a charm "to gain advantage of a man of superior strength," one has but to repeat:

I, (your name), breathe upon thee. Three drops of blood I take from thee: the first out of thy heart, the other out of thy liver, and the third out of thy vital powers; and in this I deprive thee of thy strength and manliness.

Obviously, if this were to be translated into action, it undoubtedly would achieve its purpose. It should be kept in mind that charms such as this were not used idly, but with conviction of their efficacy - and often with malice aforethought. If said by a person reputed to have some success in these matters, this might indeed cast gloom upon the gullible.

In like vein, words could be substituted for deeds in dealing with animals. Thus as a remedy for the bots in horses:

You must stroke the horse down with the hand three times, and lead it about three times holding its head toward the sun, saying: "The Holy One saith: Joseph passed over a field and there he found three small worms; the one being black, another being brown, and the third being red; thus shalt thou die and be dead."

This particular charm utilizes the magic 
of the number three (three times), the sun, and the deity, but perhaps credits the "worms" with an ability to realize their number was up.

That this particular remedy is an ancient one is evident from the fact that a similar charm appears in the writings of Albertus Magnus, the cleric-philosopher of the thirteenth century. As a charm against "the Worms in the Body," one should repeat:

God went upon an acre field. . . He made three furrows, and found three worms. The first was black, the other was white, the third was red; forthwith (name) all thy worms are dead.

To augment the power of the spoken word: "Move three times with the finger around the navel, while pronouncing the three holiest names." This charm was used for both man and beast; if the latter, the animal's name was spoken.

Other remedies for worms given by Albertus include: rubbing the parts with fresh hot ox gall; rubbing the mouth and tongue of cattle with salt and serpentinetree bark; a mixture of vinegar, egg shells, chimney soot and pepper for horses; or simply cut a piece of elderwood "on a Good Friday, before sunrise . . . without making a noise."

Hohman prescribes a mixture of white hellebore and linseed powder - the only medical treatment included-but offers several other charms, one being:

Worm, I conjure thee by the living God, that thou shalt flee this blood and this flesh, like as God the Lord will shun that judge who judges unjustly, although he might have judged aright.

Hohman states that his book is partly derived "from a work published by a Gipsey, and partly from secret writings, and collected with much pain and trouble, from all parts of the world." He mentions Albertus Magnus as a source in several instances. He also states that his reason for publishing the book is:

my compassion for my suffering fellow-men. . . Besides that I am a poor man in needy cir- cumstances, and it is a help to me if I can make a little money with the sale of my books.

\section{Potent for Poll Evil}

Hohman makes it clear that he is a deeply religious man, but appears to have reservations about what his clerical friends might have to say about certain of his cures:

I am willing to follow the preacher in all reasonable things, yet when $I$ am in danger and he advises me not to use any prescriptions found in this book, in such a case I shall not obey him. ... I am willing that my books should be seen by every body, and I shall not secrete or hide myself from any preacher.

His cure for poll evil perhaps falls into this category:

Break off 3 twigs from a cherry tree; one towards morning, one towards evening, and one towards midnight. Cut three small pieces off the hind part of your shirt, and wrap each of those twigs in one of these pieces; then clean the pollevil with the twigs and lay them under the eaves. The ends of the twigs which had been in the wound must be turned toward the north; after which you must do your business on them, that is to say, you must [defecate] on them; then cover it leaving the rags around the twigs. After this the wound must be again stirred with the three twigs, in one or two days, and the twigs placed as before.

This, presumably, is what is known as the businessman's cure. The remedy following this is "to stop pains or smarting in a wound," and the provident businessman might well have provided himself with the essentials at the same time he was preparing to combat the poll evil:

Cut three small twigs from a tree - each to be cut off in one cut-rub one end of each twig in the wound, and wrap them separately in a piece of white paper, and put them in a warm and dry place.

It might be surmised that if the condition were not particularly painful, the paper for the latter cure might be put to a better use.

\section{Verhext}

The emphasis placed upon livestock by the early settlers of Pennsylvania, particu- 
larly those of German ancestry, resulted in the logical development that most of those accused of witchcraft were suspected of harming livestock. Any antisocial old woman was a likely suspect, and in most cases such individuals were ill-equipped to defend themselves. The Germans in particular had a penchant for reviving and embroidering stories which had survived from the days when Germany had been the world's capital for witch hunters. Cattle were verhext by witches who milked them by squeezing on a towel, or "shot" them with hairballs, or afflicted them with "the murrain." The ever-provident Germans, of course, had their own ways of counteracting these evil influences. Some of the "hex" signs on Pennsylvania barns were made with the avowed intent of circumventing witches. If the identity of the witch were known, a silver bullet fired at a crude picture of her would transfer the spell to the witch. (Television fans are aware of the power of a silver bullet in restoring law and order.) The signs of the zodiac were faithfully consulted before crops were planted or calves castrated, and thus the almanac became second in importance only to the Holy Bible. The appropriate charm, handed down as a family secret, would suffice for any emergency, however great.

In an attempt to cut down the monster his predecessors had propagated, the editor of the Farmers' Almanac in 1830 wrote:

Signs and omens and prognostics continually fill the minds of some. . . . Farmer Bluejoint has nailed an Ass's shoe to his hogsty to keep the evil spirit from his herd of swine; for, it is said, that old Splitfoot has always hated Asses since the affair of Balaam. The rats by thousands destroyed his grain. So, he got his daughter, Dolly, to write them a threatening letter, which he placed in his corn crib. The consequence was that every varment of them immediately evacuated the place.

The latter superstition was very common. A note often was placed in a rat hole; if the rats took it away it constituted their acceptance of the "terms," and reputedly they were frequently observed leaving in droves
- often to a neighbor's place suggested in the note.

Once an animal had been verhext, strenuous measures were often required. Witch-doctors were consulted, who for a fee would employ the appropriate countercharm. In the 1670's this consisted of burning affected cattle or dogs on the forehead with a branding iron-precisely as had been done in the Middle Ages. Or if the animal had died, it was carefully cremated to insure its complete immolation - perhaps a more potent charm against plague than was appreciated. Later the Braucher, or "pow-pow" doctor, relied upon incantations; to be effective these had to be learned from one of the opposite sex, and administered by the healer only to individuals man or beast - of the opposite sex. The formula for "schwinde," or tetter, was:

Go out of the marrow into the bones,

Out of the bones into the flesh.

Out of the flesh into the blood,

Out of the blood into the skin,

Out of the skin into the sky,

Out of the sky seven yards deep in the ground.

From the folklore of various corners of the country come measures to prevent sickness in livestock: make three crosses in the doorsill of the stable, keep a goat running with horses or cattle, or be sure the stable has many cobwebs. Pennyroyal in the stable will keep flies from molesting stock. If a calf or colt is castrated in the sign of the "private parts" it will die. Cow manure rubbed on a caked udder will cure it. Feeding a cow a stolen dishrag will cure indigestion. Feeding a hornet's nest to a horse will cure distemper. Tie a live hoptoad to the withers of a horse to cure sweeny. Rub bacon fat on the instrument that causes a wound, and the wound will heal in a few days. For a nail prick, carry the nail in your pocket, and the wound will not become infected; or cast the nail into a fire to prevent blood poisoning. A dog that licks the blood of a dead man will go mad ... etc., ad infinitum. But let him who has no skeletons in his closet cast the first stone. 


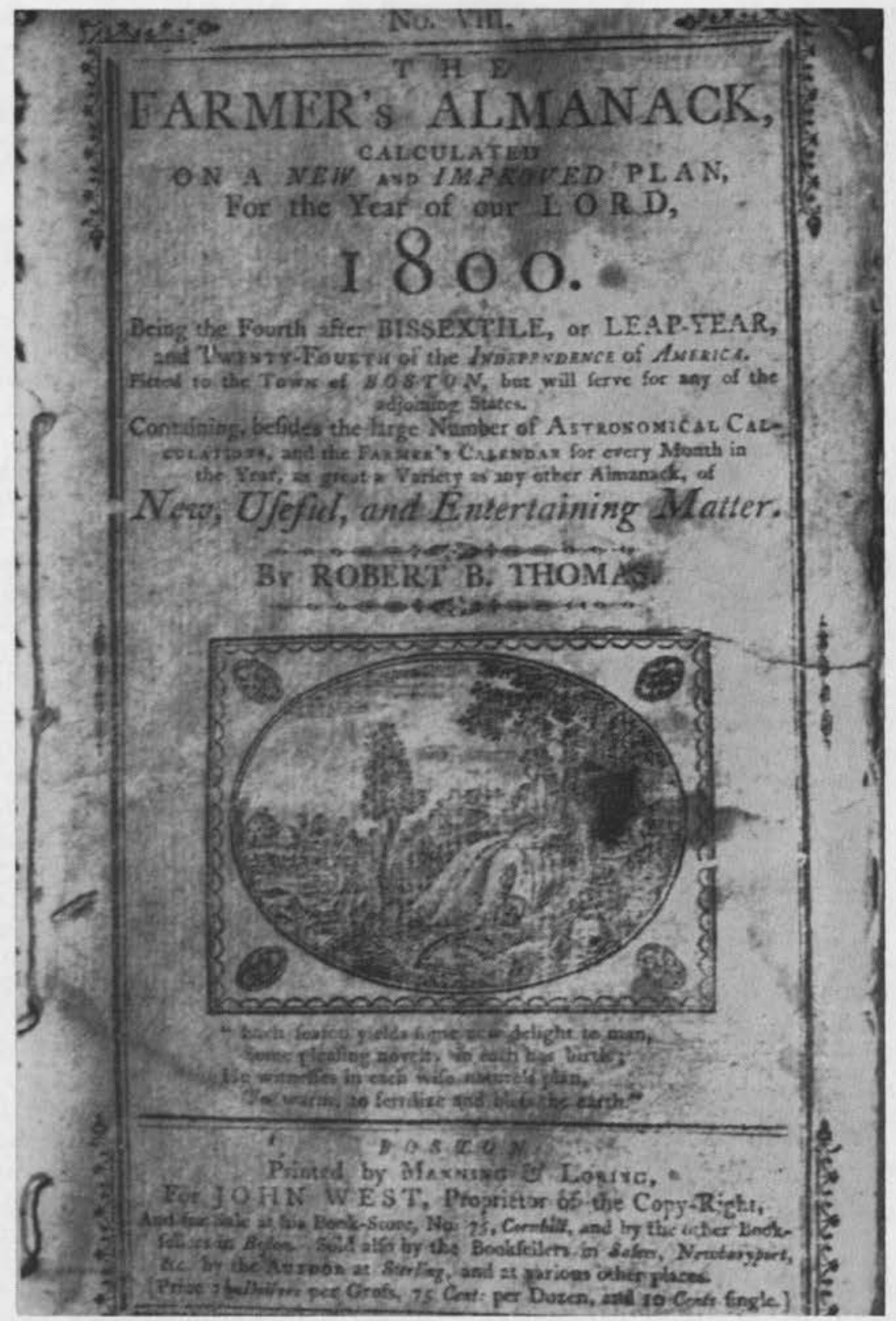

Beginning in 1793, the Farmer's Almanack gave directions for castrating animals according to "the signs," as it did for planting seeds, and the like. 


\section{THE MARK OF MARKHAM}

Some of the quaint practices of superstitious folk undoubtedly did harm - if only by depriving the affected animal of proper attention. More often, perhaps, these simple practices saved the hapless animal from real harm at the hands of countless self-denominated experts, professional or amateur, who killed and maimed more often than they cured. Countless works on animal disease, professing humanity to the horse, remain as morbid examples of the barbaric butchery that was performed under the guise of farriery for a century or more. Worse, the veterinary profession, once it became a reality, labored long under the disadvantage it inherited from the likes of these. One particular work, if taken in chronological sequence would be discussed much later; in actuality, however, it belongs to the Middle Ages, and did more harm than all the witchcraft ever practiced in America.

The Citizen and Countryman's Experienced Farrier (1764), by J. Markham, G. Jeffries, and Discreet Indians, was one of the first veterinary works published in America (Wilmington, Delaware) to achieve a wide circulation. In this, and the second edition (Baltimore, 1797) the Indians were identified as "Discreet"; in the third edition (Baltimore, 1803) they had become "Experienced," but their contributions, if any, are not specifically identified. In true Markhamian manner, we are assured on the title page that the book contains:

a valuable collection of the best receipts in the known world for the cure of all maladies and distempers incident to horses of what kind soever, with directions to know the ailment, or disease.

The "J. Markham" is none other than the redoubtable Gervase (Jarvis) Markham, whose Maister-peece (London, 1610, and innumerable later editions) was the bete noire of reputable veterinary writers in Britain for nearly two centuries.

Jeffries appears to have been a farmer of Chester County, Pennsylvania; other acknowledged contributors are Matthew
Hodgson, a British farrier long since dead, and a Nathaniel Shaw, whose identity is not clear. Also, a committee of four "revised and examined the copy and manuscripts" of the first edition, and were "of opinion that it [the second edition] will be of great service to the public in general." The third and fourth (Chambersburg, Pennsylvania, 1839) "editions" are only reprintings of the second.

The word "proved" appears after many of the receipts given, suggesting they had been tried - as undoubtedly they had but about all that the entire work proves is that those responsible for it lacked astuteness in choosing a source from which to copy. Markham himself had "proved" these same remedies nearly two centuries earlier; William Gibson's New Treatise on the Diseases of Horses, London, 1751, would have been a much more fortunate choice-particularly for the horse. In 1610 , Markham's Maister-peece was at least excusable as a product of the times; not so, however, is the case of his copyists two centuries later. At least five editions of the Farrier as such - and inumerable imitations - appeared to 1850 .

The Farrier begins with "choice secrets" for preparing the horse for racing; the sport of kings being a serious business in colonial and post-Revolutionary America, the book undoubtedly was in great demand for this advice alone. In fact, the scarcity of this work today, and the poor condition of most copies extant, suggests that many of them were literally worn out by long use. At the time, a strict regimen of six months duration was usually considered necessary to bring a horse "fat and foul" to his peak condition. These trainers, says the Farrier, "rob their noble masters of half a year's pleasure," and in so doing, "devour up an hundred pound wager." The shorter regimen of two months of purging, bleeding, sweating, and exercise recommended undoubtedly was more than adequate. For example, if the horse showed signs of sickness, "let blood instantly, and for the three following mornings, the horse being fasting." The latter is a concession to the 


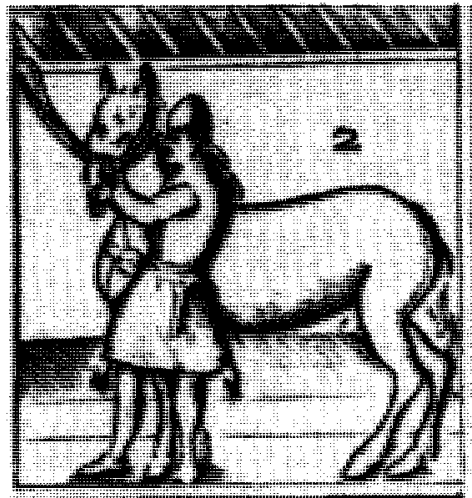

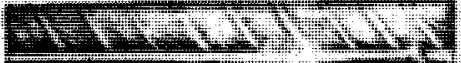
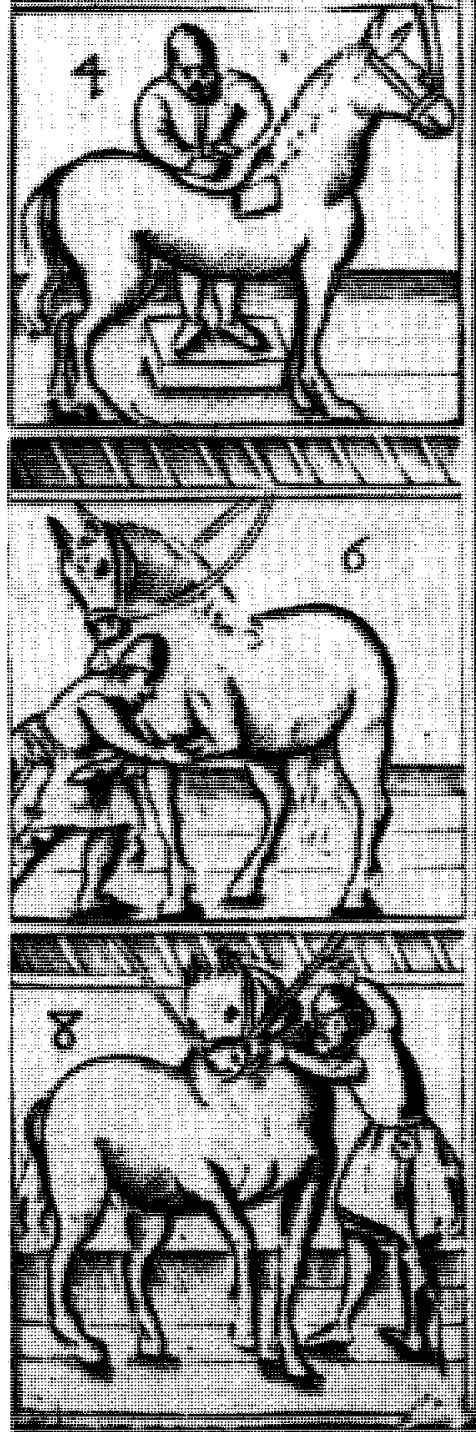

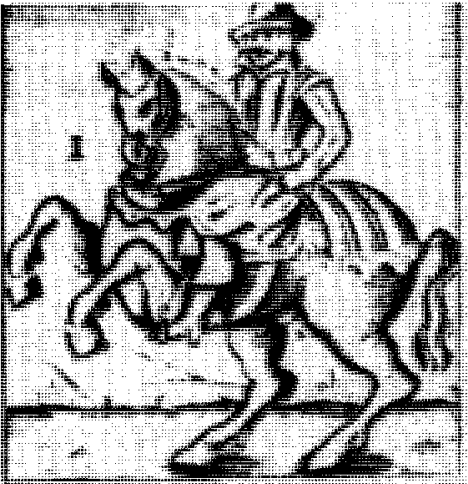

7 MARKHAMS

\section{Manter inter}

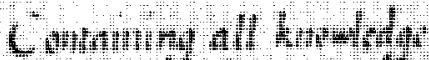

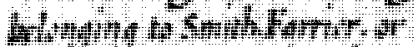

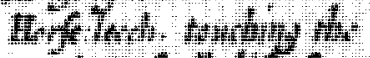
minit of all deft

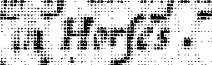

Devilu nutu two horatus

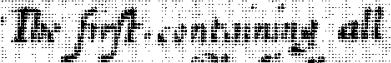

$$
\text { intwh }
$$

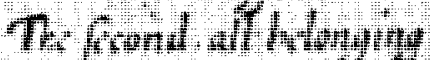
4) chatwey

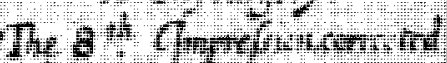

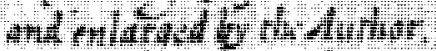
Grumale Mutham

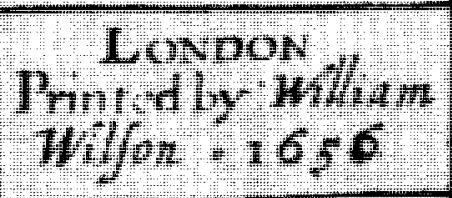

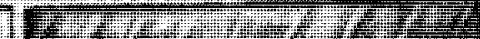

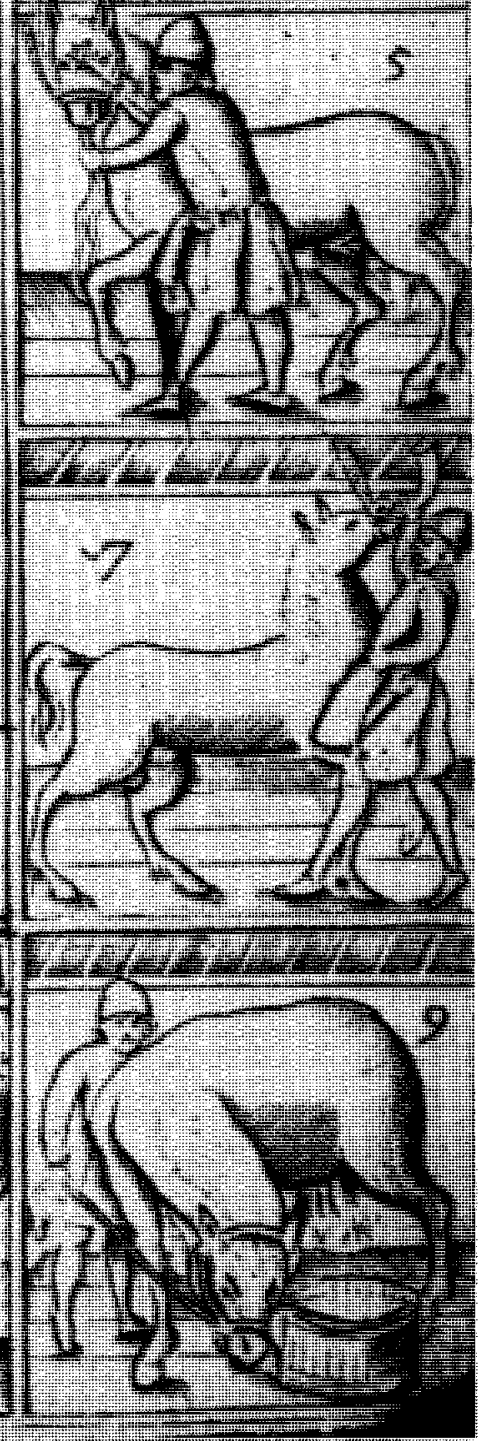

Markhams Maister-peece (London, 1610), although never reprinted in America, was the prototype of many worthless American works when better books were available for source material. 


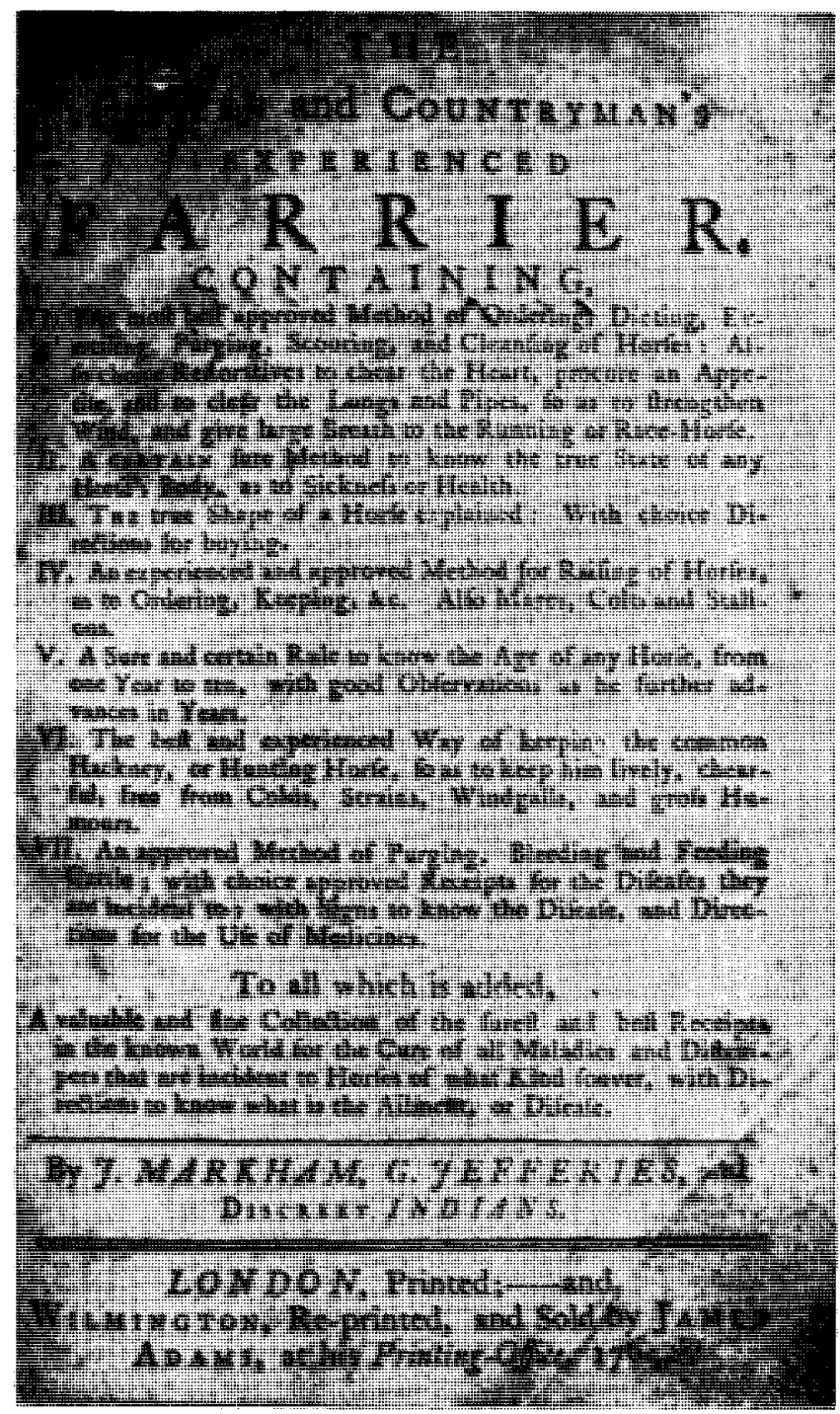

A wretched compilation, in part from Markham, The Citizen and Countryman's Experienced Farrier (Wilmington, 1764) went through at least five editions. Most copies extant show evidence of hard usage, and many subsequent works show evidence of wholesale pilferage from these poor productions.

superstitious practices of the ancient Romans, who would render treatment only if the animal wcre fasting, but the Farrier was not the last in this country to observe this and many other practices in the same category.

In treating of this work in some detail, it must be remembered that most of it is copied from the worst possible British source. While the American editors presumably selected those sections which were more applicable to conditions here, their choice of Markham itself demonstrates their inability to make any contribution of value. The wide distribution and evidence of actual use of this work, however, makes it apparent that the practices advocated were characteristic of actual practice at the time, and indeed for long decades before and afterward. The brutality and incredible ignorance of later generations of fearless farriers may be traced to this one polluted wellspring. It is painfully evident that the section containing "the experienced receipts of George Jeffries," which he says, "may, in some measure, be ac- 
counted more natural, as the productions are of this climet," does not differ from Markham's muddled discourse first offered in 1610 .

\section{The Black Drink for Glanders}

While glanders probably was not the serious problem in colonial America that it was in Britain, it is likely that some horses were affected, for the disease had become a major problem by Civil War times. For glanders, the first disease considered by the Farrier, nothing is said of the cause or of diagnosis - as is the case with most other complaints - only cures, most of them "infallible," are given. Thus it is likely with the "cure" for glanders being convenient, many horses were treated for it willy-nilly. Of the medicine-composed of vinegar, honey, alum, and salad oil:

give your horse six spoonfuls in each nostril, with a little horn ... at 9 different times, being 3 days between every drink, every second time .. give him chickens-guts warm, rolled in beaten bay-salt, and put them down his throat.

On the other hand: "To stop the glanders until you sell your Horse," it was necessary only to give bruised elder bark in a quart of ale on three successive mornings.

Another "infallible cure in three or four times giving," was "the black drink for the glanders." This required preparation of the horse by purging and fastening a goose feather annointed with sulfur and butter up each nostril: "to purge his head and lungs, and cause him to send forth much filthy matter." The "black drink" was composed of "new-made urine, and strongest white wine vinegar, of each half a pint," with three spoonfuls of mustard, given, "at the mouth, except two small hornfuls which must be poured into his nostrils." Any comment would be superfluous, except, perhaps, that whether the condition being treated was glanders or not, one "cure" would have been as effective as the other. ders:

For farcy, the cutaneous form of glan-

Take rue ... garlic ... aqua vitae ... and a little black wool, and put it in the ears equally, then sew up the ears together: afterwards cut the horse's forehead, and put into the cut the inner rind of an elder, about an inch long.

Elsewhere one sensible statement concerning this disease complex appears:

If an horse hath the farcion, and his breath smells strong, and stinks, do not meddle with him, for his lights are rotten, and there is no cure for him, for he is as full of them within as without .... [also] separate the sound from the sick, for this disease is infectious; they will take it of one another.

But "if his breath be sweet, there is no doubt of the cure," which consists of drenches containing various herbs, and an ointment of alum made with "fasting spittle."

For "an approved cure for the botts, and all kind of worms whatever," give a quart of new milk sweetened with honey, followed by black soap dissolved in white wine; "let him fast two hours after it, and the worms will void in great abundance." Or:

Take the soft downy hairs which grow in the ears of an horse . . mix them well with half a gallon of sweet oats, and give them to the horse. There is nothing that will kill worms more certainly.

There is no question that bots were a major problem in colonial America; nor is it likely that the measures above abated the problem much. Perhaps the effectiveness of these cures was recognized, for in "extream cases," a liquor made from:

about four or five lumps of the white dung of a hen, and three pints of good ashes, as much chimney soot. . . Will perfectly cleanse his stomach, kill the worms, and cause him to rope at the mouth abundantly.

Jeffries advises bleeding from the palate, allowing the horse to swallow the blood, which will be ingested by the bots - causing them to loosen-following which a pint of linseed oil "will kill them instantly." Inasmuch as he does not specify boiled linseed oil, it is perhaps not clear whether "them" refers to the bots or the horses. 


\section{Mastiff Medicine}

For a "back-sinew" (plantar ligament) strain, or "numbness of joints," we are directed: "Take a fat mastiff whelp, slay it and gut it, then fill the body with grey and black snails, and roast it." The drippings are to be made into an ointment with oil of spike and oil of wax, and applied hot. Or:

Take a live cat, cut off her head and tail, then split her down the chine, and clap her hot, bowels and all, upon the strain, and let it stay there for forty-eight hours.

Other more moderate remedies, such as hog's grease, are prescribed, but these dog and cat atrocities appear to have fascinated the plebeian public since ancient times: the mastiff medicament was prescribed for rheumatism in man by a Doctor Carter of Kentucky in 1825. These vulgarities were at least harmless to the horse, and mav have served to reduce the depredations of packs of dogs that wrought havoc upon flocks of sheep and spread rabies throughout the colonies beginning about 1770 . But for sheer brutality, a "proved" cure for "shoulder strain" is as unconscionable as the devil himself could devise:

First tie up his sound-leg very sure with a list or garget, then walk or drive him on three legs that he may lay the weight of his body upon the lame leg till he begins to sweat at the ears and cods with the pain. ... Let him bleed. . . . Tie his forelegs together as close as possible ... drive a wedge about the breadth of a six-pence, between the toes of his shoes, and the toes of his feet . . . annoint the strain once with oil of turpentine and beer, and once with blood and salt. . . . It is a speedy cure.

And if this is not enough, consider the plight of the hapless horse that might also be treated for a splint at the same (or any other) time:

You must cast the horse, then beat the place with a stick until it is soft, and fleam it in three or four places upon the splent, and squeeze out the blood. . . . Melt some black pitch in an iron pan ... and dab it on close all over the splent ... a and the splent will come out. . . . It makes a great blemish, and takes away the hair and flesh, and sometimes the hair comes no more.

And "for a foundered Horse" we are directed:

Take out the soles of his feet. . . Cut the middle of the sole just at the frush's [frog] end, in the shape of an hen's tongue, and raise it a little with the point of your knife ... prick the vein until it bleeds. . . . Let him stand in the stable ... the bottom of the hoof, being thus festered, the sole will come out easier by a great deal, and with less danger of pulling away the veins with the sole of the foot. ... Take your drawing knife, and draw the hoof to the quick ... then raise the sole at the toe, and take hold of it with a pair of pincers and pull it upward to the heel, and so pull it quite out, then apply hare's-wool to stop the blood ... then wash the sole of the foot with urine, and set on the shoe, and put in pitch, turpentine, and hog's-grease. . . . You must never take out the soles of both fore-feet at one time, for then he will not be able to stand.

\section{For Staggers and Stumbling}

Diseases of the nervous system appear to have been common if the number of conditions mentioned is a criterion, and the drastic remedies used would suggest they

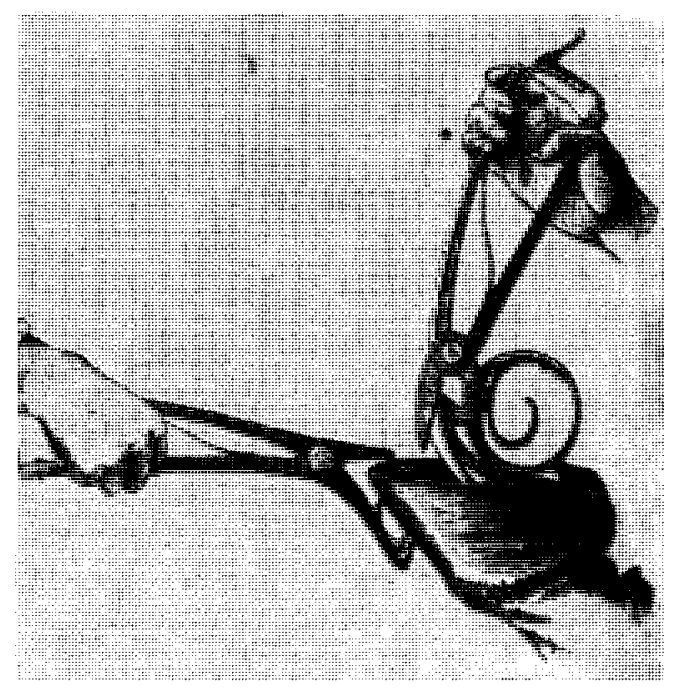

The practice of unsoling the foot for founder was commonly advocated from the dawn of printing to the late nineteenth century, despite the protestations of more humane horsemen and veterinary practitioners. Manger: Facts for Horse Owners, 1894 
were little understood. For the mad staggers:

Let him blood in both veins of the neck, and in the third furrow of the palate ... run an awl into the gristles of his nose, above his nostril, the bleeding at his nose and mouth will ease the pain in his head ... [ [ or ]: Take a long straight stick ... run it up to the top of his head [via the nostril! ], jab a little hard, turn the stick and draw it out, and he will bleed freely. . . . To cure, take an handful of rue ... garlic ... salt, vinegar ... aqua vitae, ... put it equally into each ear ... then tie or stitch the ears shut. ... Give wild poppy-seed in half a pint of beer, up his nostrils ... he will appear as if dead for a time, and this sleeping will much refresh him.

The treatment for a "stumbling" horse antedates the machinations of Markham, and may be attributed to Leonard Mascall (late sixteenth century), whom Markham barely managed to deprive of the distinction of being the greatest rogue in veterinary history. The operation, performed as a preventive as well as a cure, consisted of cutting the conjoined tendon of the levator muscles of the upper lip, and was known as "cutting the cords." The Countryman's Farrier directs:

Tie him close to a post . . cut a hole lengthway down to his lips, endwards, in the midst of his nose, between his nostrils, the length of your thumb. . . You will see a white flat sinew; put the point of your cornethorn under it, and raise it above the skin, then pull it hard out with your cornet-horn and turn your cornet-horn about [three times]: in thus doing you will see him bring his hinder legs to his fore-legs. ... Cut the sinew ... and put a little butter and salt into the wound ... and the horse will go well, and never stumble afterwards.

Lest it be thought that all the "choice re. ceipts" should be like those above, the remedies for mange, however unpleasant the preparation and administration of some may have been, undoubtedly had some beneficial effect. Thus, "for any mange, scab, or leprosy whatever," we are directed:

First let blood, then take a quart of old urine or vinegar, and break into it a quarter of a pound of best tobacco ... let it stew all night; then strain it, and with the water wash the infected place.

Another remedy consists of ale, tobacco, alum, salt, and mercury. Nothing is said in this particular treatment of the infectious nature of the disease, but directions are given for washing the manger with scalding water and fumigating the saddle with burning sulfur. The precautionary note Jeffries adds is probably the most sensible writing in the entire book:

Let not your saddle or collar that was upon a mangy horse go on any other, for it will quickly give it a sound horse, being an infectious disease.

\section{Generation of Vipers}

What, then, is to be our evaluation of this work? Despite an occasional sensible remedy, and others which at least did no harm beyond depriving the animal of better treatment, the Countryman's Farrier is an utterly wretched and abominable anachronism. In addition to subjecting innumerable animals to unnecessary tortures for the century or more the several editions were in vogue, it created an additional generation of vipers that plied their trade in like manner for another half century. Truly Markhamian throughout, the evaluation of Markham by an English country gentleman, John Lawrence, in his Treatise on Horses (London, 1810) will bear repeating:

The redoubtable Gervase Markham was for more than a century the oracle of sapient grooms, the fiddle of old wives, and the glory of booksellers. .. . The mischiefs which have been occasioned by the extensive circulation of this man's books are incalculable. They brought almost as many evils and cruel inflictions upon poor helpless animals as the opening of Pandora's box did upon the human race.

Lawrence advises the owners of horses to purchase any of Markham's works their grooms or farriers may have, and "put them to more harmless and necessary purposes than to those which ignorant people would most probably apply them." 
The evil influence of Markham was accentuated by the dearth of good veterinary works, there being only about two dozen titles, including British reprints, published in America to 1800. Even George Washington succumbed to the wiles of Markham, for in 1759 he mentions setting a horse's leg "according to Markham." This undoubtedly was the Maister-peece itself, imported from England. Probably many settlers brought their favorite work on farriery with them - all too often, perhaps, their choice was no better than that of Washington. Copies of the Maister-peece in the original are far more common today than its hybrid offspring.

\section{Antidotes for Markham}

It should not be supposed that no respectable veterinary works had been published in America to this time, however, for Bartlet, Burdon, Taplin, and James Clark had all been reprinted here before 1800. Clark's Treatise on the Prevention of Disease (London, 1778, Philadelphia, 1791) in particular still contains much that is worthwhile, but it seems to have had a relatively small circulation and less influence upon American veterinary practice. An even more obscure little Modern Practice of Farriery, or Complete Horse Doctor, published in Philadelphia in 1793, is as sensible an epitome of practice as might have been expected at the time. The author, J. Thompson, a Britisher, states that his book is "the result of 37 years practice and experience." Actually, as he states himself, it is primarily a distillation of the best offered by the leading British writers whose works were also available in this country. This little work deserved greater acceptance than it received; indeed it is practically unknown to bibliographers - in America or Britain.

Bleeding is recommended in most conditions; it would be too much to expect anyone at the time to question the practice, but Thompson at least is moderate, and specifies that the blood be measured to avoid excessive bleeding. Likewise, purg- ing is frequently resorted to, but with moderation; like Clark, the author notes that horses are too easily killed by strong purgation. Considerable space is devoted to the causes of disease, diagnosis, and prevention. His treatment stands in strong contrast, for the most part, with the absurdities of Markham, as may be seen by comparing the remedies offered for the same conditions reviewed above from the Countryman's Farrier.

On glanders, Thompson gives an account of the practice of the eminent Frenchman, LaFosse, who recommended trephining the nasal cavity and using irrigations and fumigants. Thompson, however, says:

Trepanning ... is not only a most painful operation, but also attended with such trouble and expence, it must be an extraordinary horse to compensate the account ... the first loss will be ultimately best in a resignation of the hide to the collar-maker, and the remains to the hounds.

The relation of farcy to glanders is not recognized, but the condition is well described, together with an acknowledgement that it frequently is not amenable to treatment. Various astringents are used for the local eruptions, but if these do not suffice, the owners are advised to: "save themselves unnecessary expence and trouble in their endeavours to obtain a cure." When the symptoms "denote the distemper to have penetrated internally ... it is most probable . . . irremediable by art."

For bots, calomel and savin or wormwood are recommended. Various liniments and poultices are used for strains, and with the addition of blisters, for splints or spavins. He disapproves of firing, and says purging may be adopted by those "whose credulity can conceive that a course of purgatives and diuretics will contribute to the removal of corns and warts from the feet and hands of the human species." For staggers, rapid bleeding to the extent of three or four quarts is the first recourse: "if he survives the fit," purgatives and alteratives are given. It is of some interest that he recognizes the similarity of various nervous disorders, and gives precise directions for 
differential diagnosis: on the wholly imaginary matter of "stumbling" as an entity, he is discreetly silent. Mange is recognized as infectious, and sulfur or mercurial ointments are recommended. There would be little point in enlarging upon the merits of this little gem, for it would appear that it fell into few hands, and still fewer appreciated its merits.

\section{Buchan's Bungling}

By contrast with Thompson's work, a book which found its way into many homes was Buchan's Domestic Medicine, issued in America as a dual purpose Every Man his own Doctor, with an appendix "Containing a Complete Treatise on the Art of Farriery" (not attributable to Buchan). Buchan was an English physician whose treatise achieved a wide circulation, many editions being published in both Britain and America beginning in the late eighteenth century. The section on farriery, some 100 pages, was first added to the American edition published in New Haven in 1816. Medical historians quite understandably have been hypercritical of Buchan's medical writing for the layman, but while any "do-it-yourself" manual is potentially dangerous, this does contain much that would appear to have been useful. Less can be said, however, for the section on farriery, for much of it is straight out of Markham and others of his stripe, including: "original discoveries adapted to our own country," furnished by friends of the publisher.

The cures for mad staggers and for stumbling, for example, are taken directly from Markham, as given above. To cause a mare to clean after foaling:

Take a quart of old strong beer, and boil in it an handful of fennel, with a fourth part of the best oil of olive, and mix well together. Give this to the mare milk warm, by pouring it into her nostrils ... and it will presently give her ease.

And to provoke lust in mares: "with a bush of nettles pat her hinder parts." For "Cramps, or Convulsions of the Sinews or
Muscles" (tetanus), which is stated to be of frequent occurrence:

First sweat him, by burying him all, save the head, in a dunghill. . . . But if the convulsion comes accidentlly, as by the prick, or half cut of a sinew, then search for the wounded sinew, and with a pair of scissars clip it asunder, and the convulsion will cease.

The practice of using a dunghill to sweat a horse dates to the Byzantine veterinarians (fourth century); a medium less suitable for treating tetanus would be difficult to imagine.

The usual remedy: salt, soot, and garlic, is prescribed for "the distemper called the Tail," and we are informed:

The distemper called the Gargyse is a swelling on one side of the eye in manner of a boil, botch, or buboe. This is as dangerous a distemper as any that can attend cattle.

It is necessary to lance the swelling "to prevent its falling into the muzzle of the beast, which will certainly happen, if not timely prevented by this method, and prove mortal." The wound must be dressed with fresh human urine and salt. For scab, a remedy taken directly from an English work of 1729 is given:

Of old human urine a quart, in which mix a handful of hen's dung, or half a handful of pigeon's dung, and give it to the beast to drink.

And for a cow with blood in her urine: "Put a frog down her throat, and drive her next day into water, and she will directly [urinate] clear."

The diseases of swine are handled in like manner. One item of some interest is the mention of "the Choler in Hogs," which is taken from a British work of a century before. The lethargy and loss of appetite described resemble the symptoms of hog cholera; thus this description may have furnished a precedent for the inept naming of the disease when it was first reported in America in the 1830's.

\section{Retrospect and Prospect}

In any historical account it probably is desirable that some sort of chronology be 


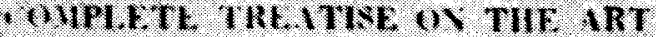

a.

\section{F I R R I E R Y,}

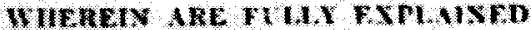

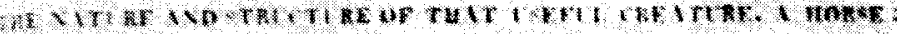

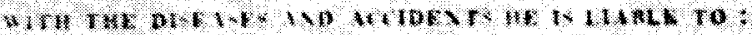

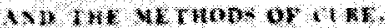

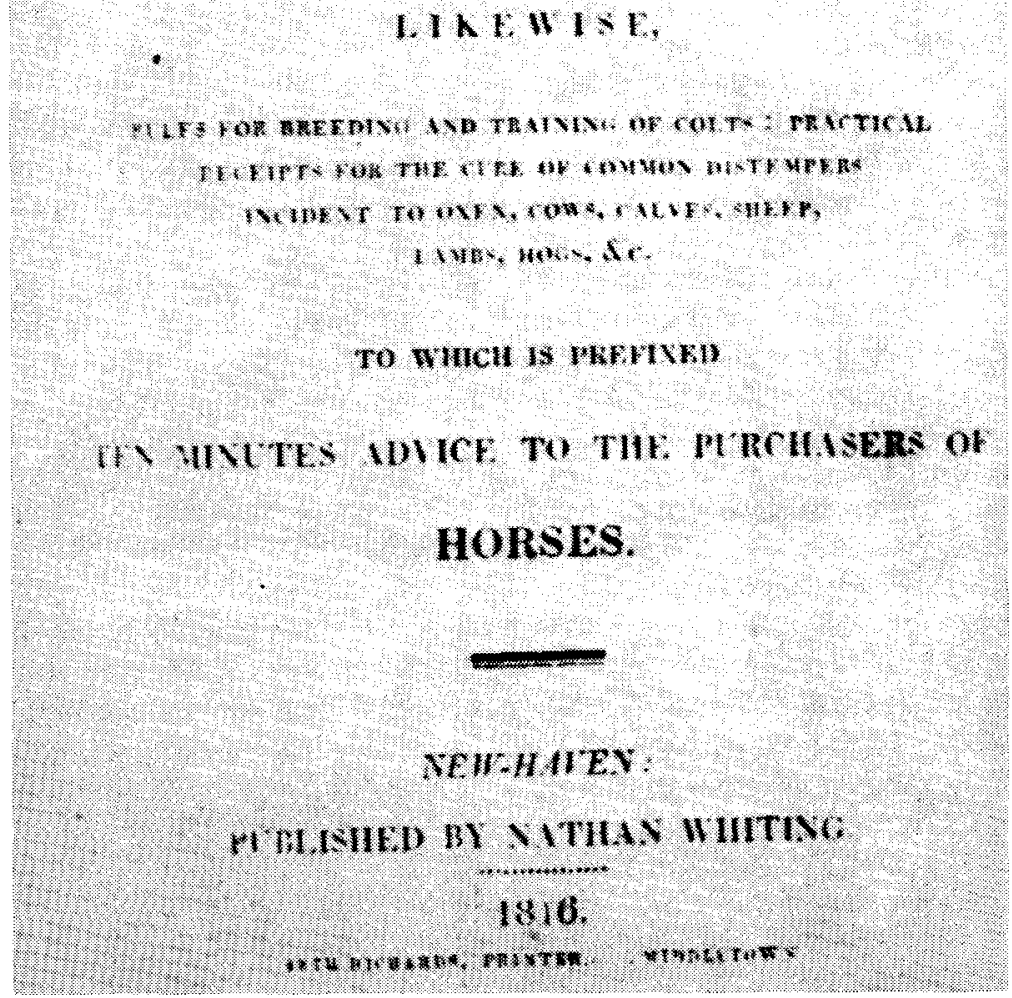

A section on Farriery was added by the American publisher of Buchan's Every Man His Own Doctor (New Haven, 1816), a version of Buchan's Domestic Medicine, numerous editions of which were published in England and America. 


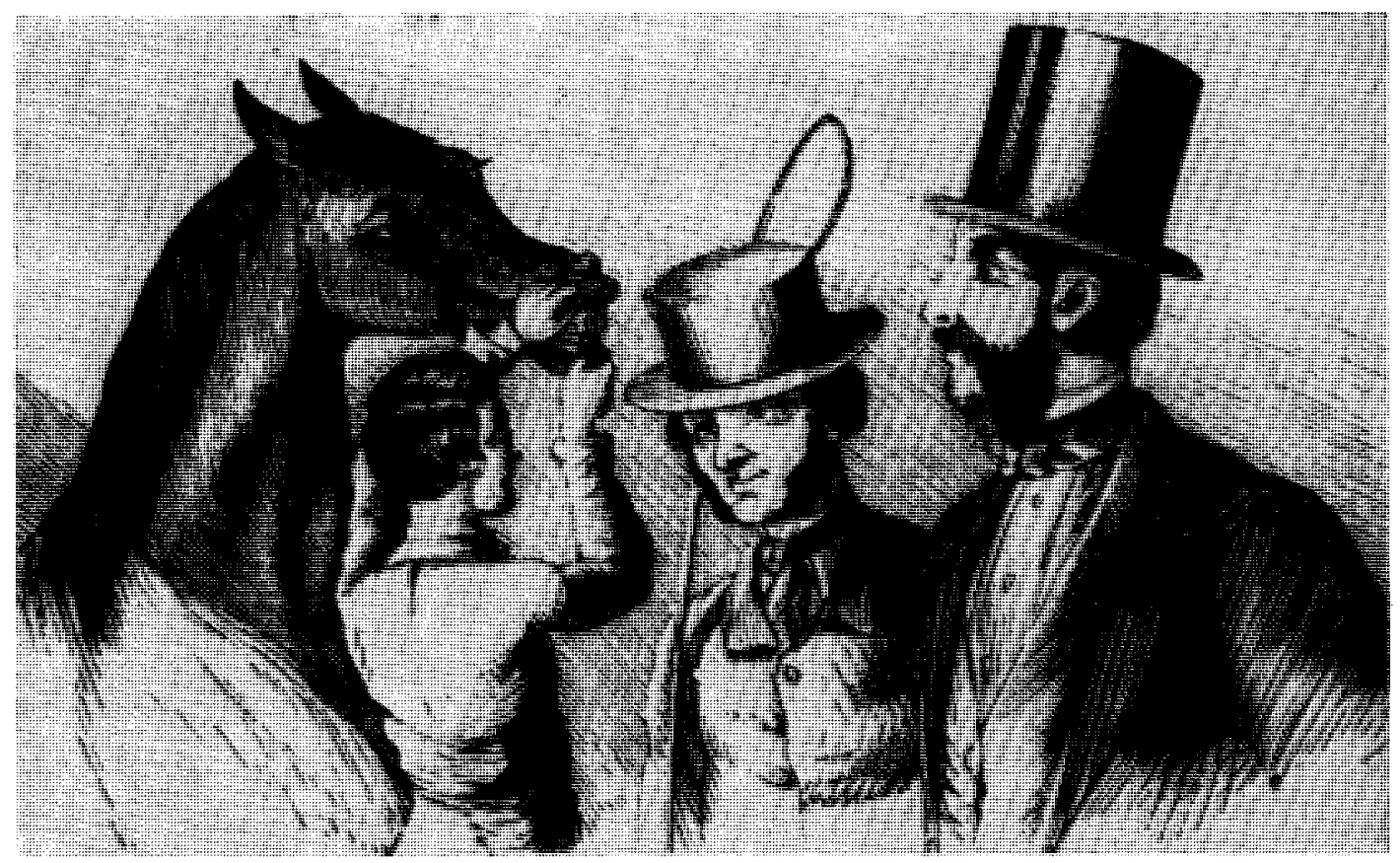

Settling on the age of a horse by examination of the (sometimes "doctored") teeth has been an ageless contest between seller and buyer, and some of the earliest writings of veterinary interest in colonial times included this subject. Mayhew: Illustrated Horse Doctor, 1865

adhered to. With military or political history this is not overly difficult. Veterinary medicine practiced a la Markham in 1850 , however, quite properly belongs to another century-except that the anachronism must be acknowledged at this later date. Certainly, those who used American versions of Markham and others of his stripe were doing little more than extending this baleful influence beyond what might have been expected from the British versions of a century or two earlier. Another obvious problem relates to the fact that veterinary medicine as such had no standing-nor any advocates - in America prior to 1800. But problems which would be recognized today as being of a veterinary nature, of course, existed from early colonial times as they have at any time in history when men and animals have co-existed.

The attention paid by our colonial forefathers to what we would chose to call matters of veterinary public health interest is perhaps the brightest chapter in the story thus far. Inadequate as some of the meas- ures taken may have been, these at least form the earliest record of continuing overt thought and action being applied to matters with veterinary overtones. That little attention should have been given to veterinary problems per se prior to 1800 is not surprising; little enough thought had been applied in Britain - where the problem of animal disease had been very real for long enough. The real nature of the animal disease problem in America had not yet manifested itself, and there were all too few persons by 1800 - and for some time afterward-capable of synthesizing anything approaching an adequate appraisal of the situation from the fragmentary data available.

In the discussion which follows on veterinary medicine during the eighteenth century, it is evident that parts of the story already have been told. Much of the story is best told in retrospect and prospect in terms of the influence of one period upon another. Certainly, many of the veterinary problems of the nineteenth century had 


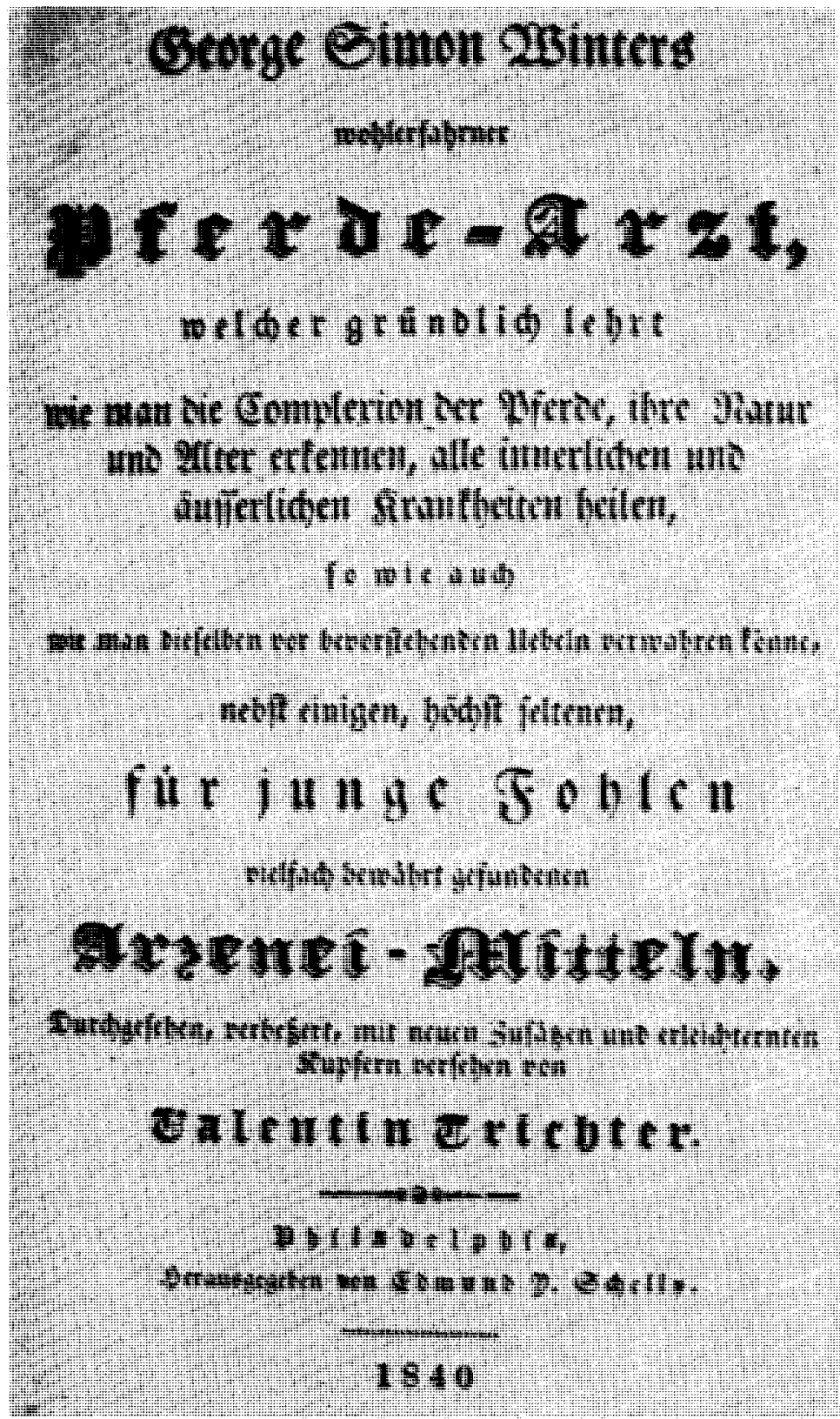

Winters" Pferde-Arzt ("Horse Doctor"), Philadelphia, 1840, was a faithful copy of the original German work of 1678. roots extending back a century or more; moreover, few of our problems of today have been created de novo by events of the immediate past.

Thus the stage was set for countless later "Domestic Medicines" which dealt indiscriminately with man and beast. On any appreciable scale at least, these were an American innovation. While very few such works had been published in Britain, the cost of books in America apparently made these dual purpose works attractive.

\section{Veterinary Publishing Ventures}

Philadelphia early took the initiative in the publishing field, and more veterinary works were issued with a Philadelphia imprint before 1800 than from any other 


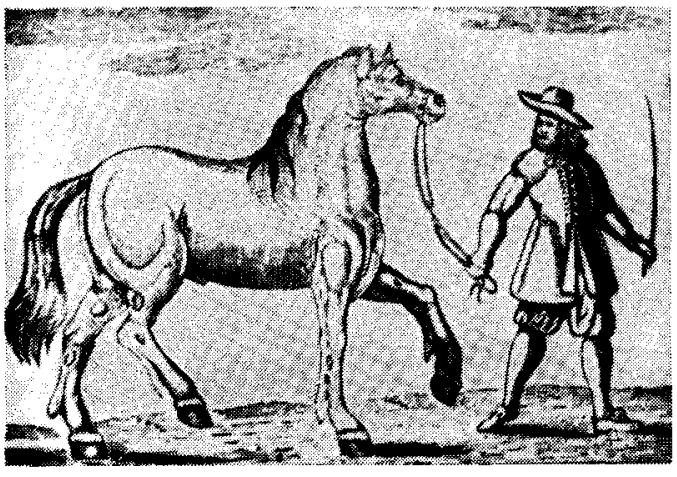

Blemishes of the limbs of the horse, from Winters' Pferde-Arzt (1840). The earlier German ancestry (1678) of the book is clearly evident from the man's costume.

place. In 1735, William Burdon's Gentleman's Pocket Farrier (London, 1730) was published by Benjamin Franklin. The choice of Burdon's little work as his first and unfortunately last - veterinary venture, undoubtedly reflects the sagacity of Franklin, for Burdon was a cavalry captain who deplored the brutal treatment of horses common in England at the time. Had the American horse-owning public been willing to accept him as a guide, there would have been little call for the muddled writings of Markham and his tribe.

Franklin began publication of the Pennsylvania Gazette in 1728; while this was primarily a newspaper and literary journal, occasional articles on animals and animal disease were reprinted, from British sources, the first being in 1729 on determination of the age of the horse. Others followed; one in 1735 gives the best account of bots published in America for many years to come, but these articles were too few and far between to be of significance. Poor Richard's Almanac, which Franklin started in 1732 , created a precedent for many such publications in presenting information on the proper time for castrating animals, and on the treatment of various ills. Because of the scarcity of information on animal disease in Franklin's time, his publication undoubtedly served some purpose in this area. Dependence upon this type of information, however, kept better and more ample writings from reaching hands that needed them; in fact, the simplicity of the almanac led many to distrust anything more complex.

Little more appears to have been published until Markham's retrograde work appeared in new guise in 1764. Nor is it likely that the series of works in German, published for Pennsylvania German consumption beginning in the 1770 's, added much that was new to the veterinary art. These were mostly reprints of earlier German works - how much earlier may be appreciated from the fact that a pferde-Arzt ("Horse-doctor") by George Simon Winter, published in Philadelphia in 1840, is an exact copy of a work by this author in 1678 . Two of the early works were Nachrichters, Germantown (Pennsylvania), 1770, 1771, by Johann Deigendesch, and a Vieh-ArzneyBuch (Cow-Doctor-Book), Philadelphia, 1771. As German colonists migrated westward, stock books in German with midwestern imprints made their appearance in the early 1800's. And at least one American work, The American Farmer's Horse Book, (Cincinnati, 1867), was translated into German - Das Pferdebuch des amerikanischen Farmers - and published in Milwaukee.

Late in the century a series of reprints of works by English veterinary writers ap-

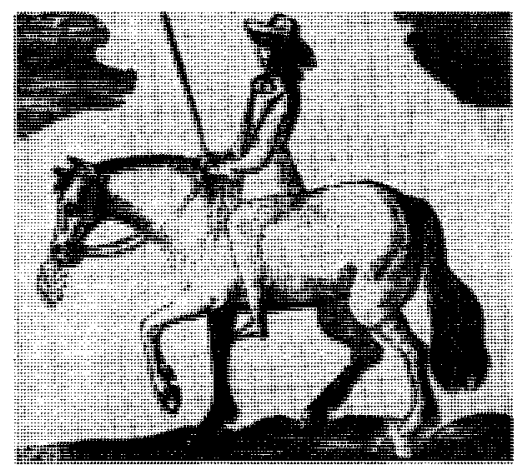

Horse with nasal discharge suggesting glanders, from Winters' Pferde-Arzt (1840). Although early works, including British reprints, warned against the danger of glanders to man and its incurable nature in animals, numerous "cures" were propagated, and the disease was allowed to become widespread following the Civil War through the sale of surplus infected Army horses. 


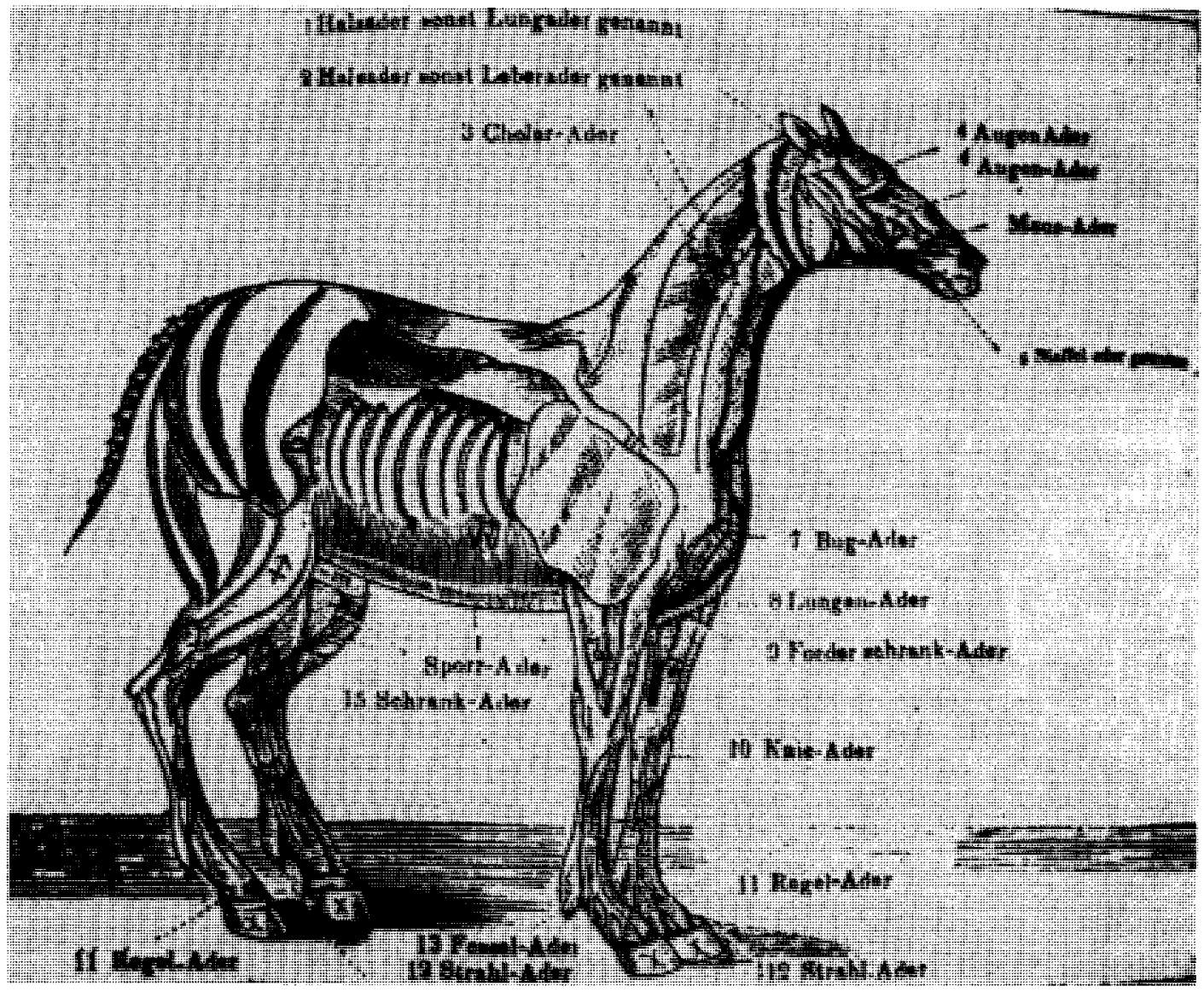

Bloodletting diagram with signs of the zodiac, from Winters' Pferde-Arzt (1840). For the three centuries or more that bleeding of animals and man "according to the signs" was popular, veterinary and medical works carried such diagrams showing when and where phlebotomy should be performed.

peared in American editions. These included:

Gentlemen's Farrier Repository (London, 1753), Philadelphia, 1775, 1787, 1790, 1791 , by J. Bartlet, a surgeon who had turned to veterinary writing, but who did not practice. His eloquent plea for greater humanity toward the horse, and for simplification of remedies, probably fell upon deaf ears in America as it had in Britain.

Gentleman's Pocket Farrier (London, 1735), Baltimore, 1796, 1797, by Henry Bracken, M.D. This is a version of Captain Burdon's work, issued by him in 1730, and edited by Bracken, who was a physician as well as a surgeon - an unusual combination for the times in Britain, where surgeons were looked upon as inferior to physicians. Like Bartlet, Burdon - via Bracken - advocates more rational practice, in particular he deprecates the universal practice of excessive bleeding of horses. But again, contemporary and later practice in America would suggest that this plea was largely unheeded.

Farriery Improved (London, 1737), Philadelphia, 1794, 1796, 1798, by Bracken was one of the better works of the time, but is infected with much medical philosophy not particularly applicable to the horse. None of these works is as valuable as the New Treatise on 
the Diseases of Horses (London, 1788), Philadelphia, 1794; and $A$ Compendium of Practical and Experimental Farriery (London, 1796), Philadelphia, 1797, by William Taplin. Taplin, also a surgeon, was a bombastic writer who was the prototype of that fraternity each of whom claimed to have "the largest practice in the world," and to have "never lost a case." Two years after establishing an "equestrian receptacle," Taplin boasted that not a single horse had ever left his premises dead.

An anonymous work, attributable to Taplin, was published in Charleston in 1799 , and is of particular interest inasmuch as it is the first American work devoted entirely to the dog. This is the Method of Raising and Training pointers: "An account of the several disorders to which they are subject, and the proper treatment and medicines in such cases." Earlier, however, The Modern System of
Illustration from Bracken's Farriery Improved, Philadelphia, 1794 (London, 1737), an early protest against barbarous treatment of the horse. Although the methods of graduate veterinarians of the time were not overly gentle, those of blacksmiths and farriers were notoriously harsh. Michigan State University Library

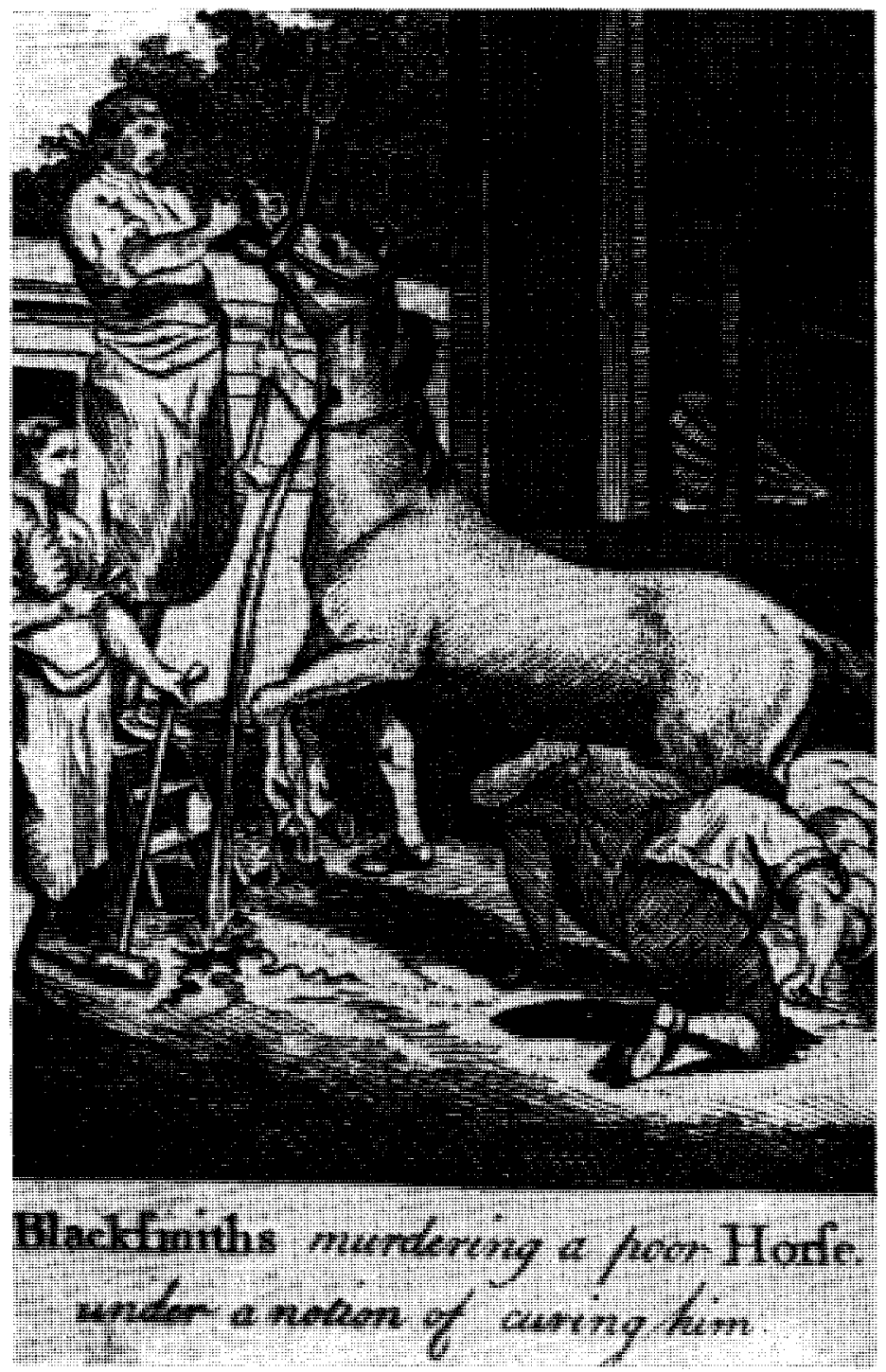




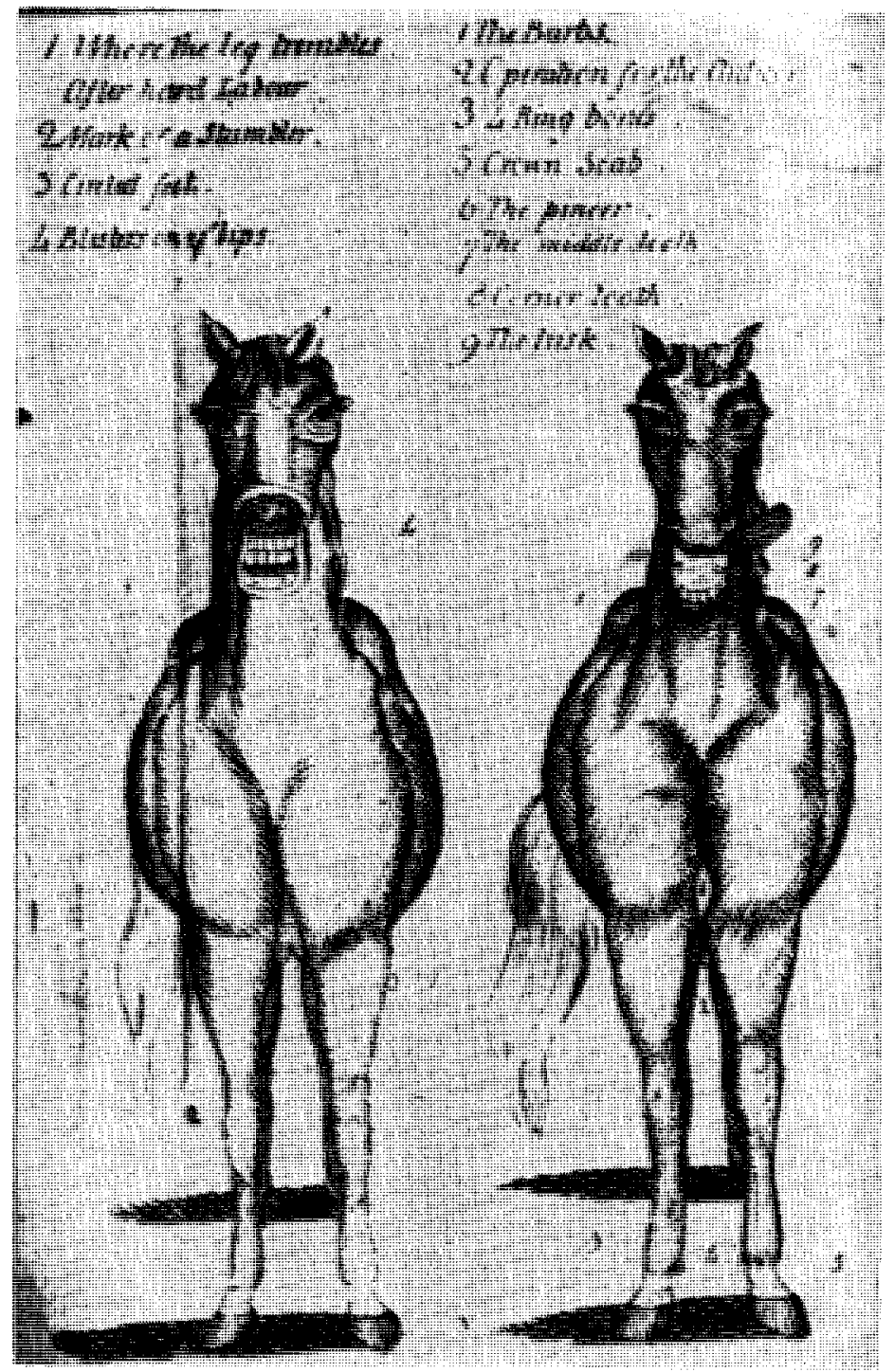

Illustration from Bracken's Farriery Improved, 1794, one of a series of plates which attempted to depict points of anatomy and sites for operative procedures. This device was used and enlarged upon by innumerable later "Stock Doctors." Michigan State University Library
Farriery, Boston, 1796, by John Mills, included "a successful method of treating the canine species in that destructive disease called the distemper."

\section{Auf Deutsche}

The impact of German culture upon American customs and manners has been greater, perhaps, than is generally realized - outside of Milwaukee or eastern Pennsylvania. In the veterinary field the number of German publications, beginning about 1770 and extending over a century or more, might seem surprising to one unacquainted with the numbers of Germans and their nature. In 1740 there were about 40,000 Germans in Pennsylvania, and perhaps 120,000 by 1790 ; by the time of the Revolution they comprised about one-third of the state's population, and there was agitation to make German the official language of the state. In the entire United States there were perhaps 400,000 Germans, about a tenth of the total population. Mere numbers, however, do not tell the story; as agriculturalists the Germans 
undoubtedly were superior to the English, and many were skilled artisans. The latter probably included a higher proportion of printers during the eighteenth and early nineteenth centuries than among any other group. The press at Ephrata, Pennsylvania, was the third colonial press in America.

The veterinary press had flourished in Germany since early sixteenth century, and undoubtedly many German immigrants brought their favorite stock remedy books with them. By comparison with those of other European countries, these usually included more on the diseases of other domestic animals, rather than dealing only with the horse. When the concept of veterinary education became a reality in 1761, the Germans espoused this development with characteristic vigor, and by 1800 had established no less than ten veterinary schools - nearly as many as in the rest of Europe. Thus it is not surprising that the Germans in America should give thought to the production of veterinary books. Some of these, like those in English,
The more elaborate "Stock Doctors" of the nineteenth century used a drawing depicting individual ailments as an aid in diagnosis. The poorer productions, as this one from an advertising pamphlet (ca. 1880), tried to encompass all problems in one diagram.

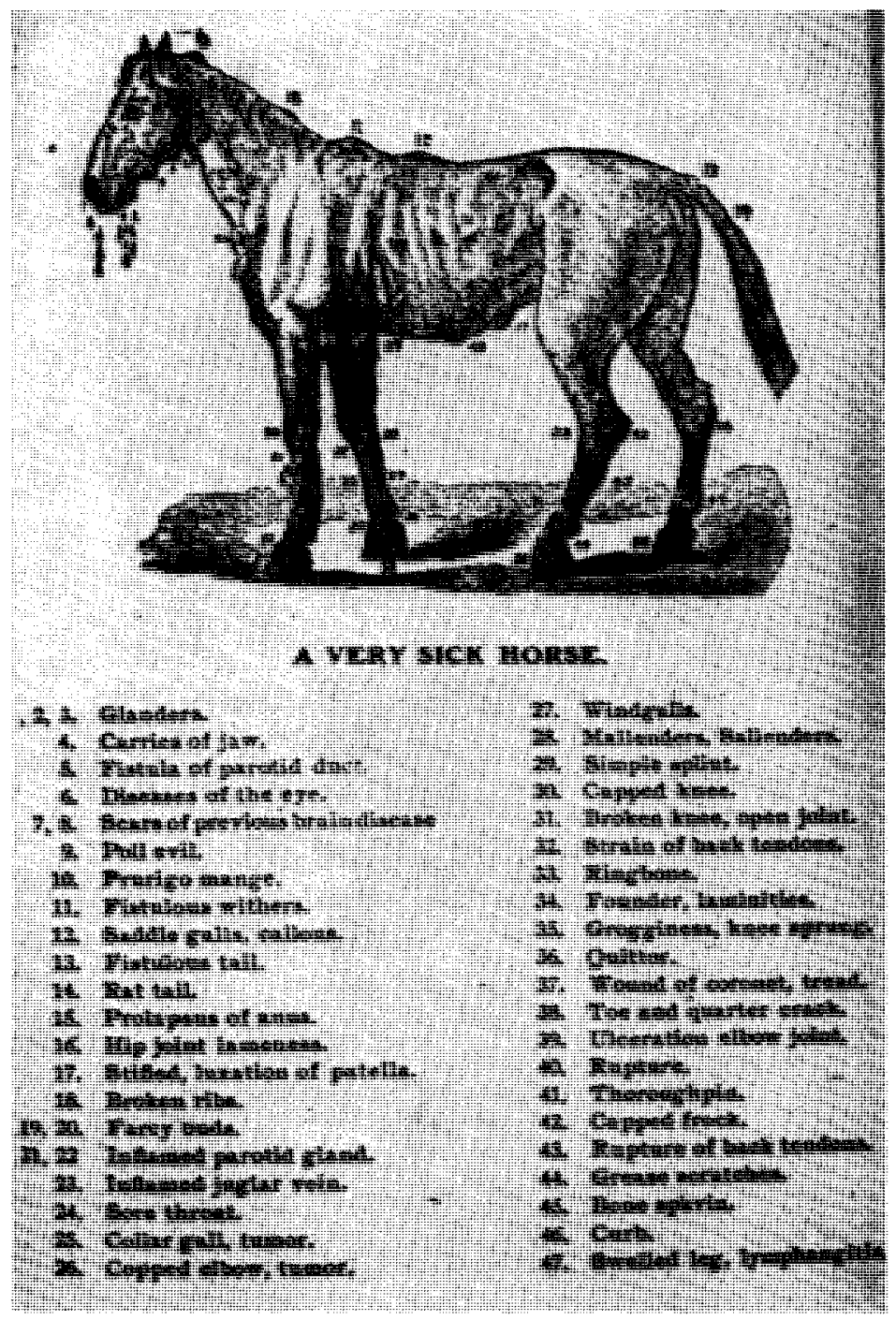




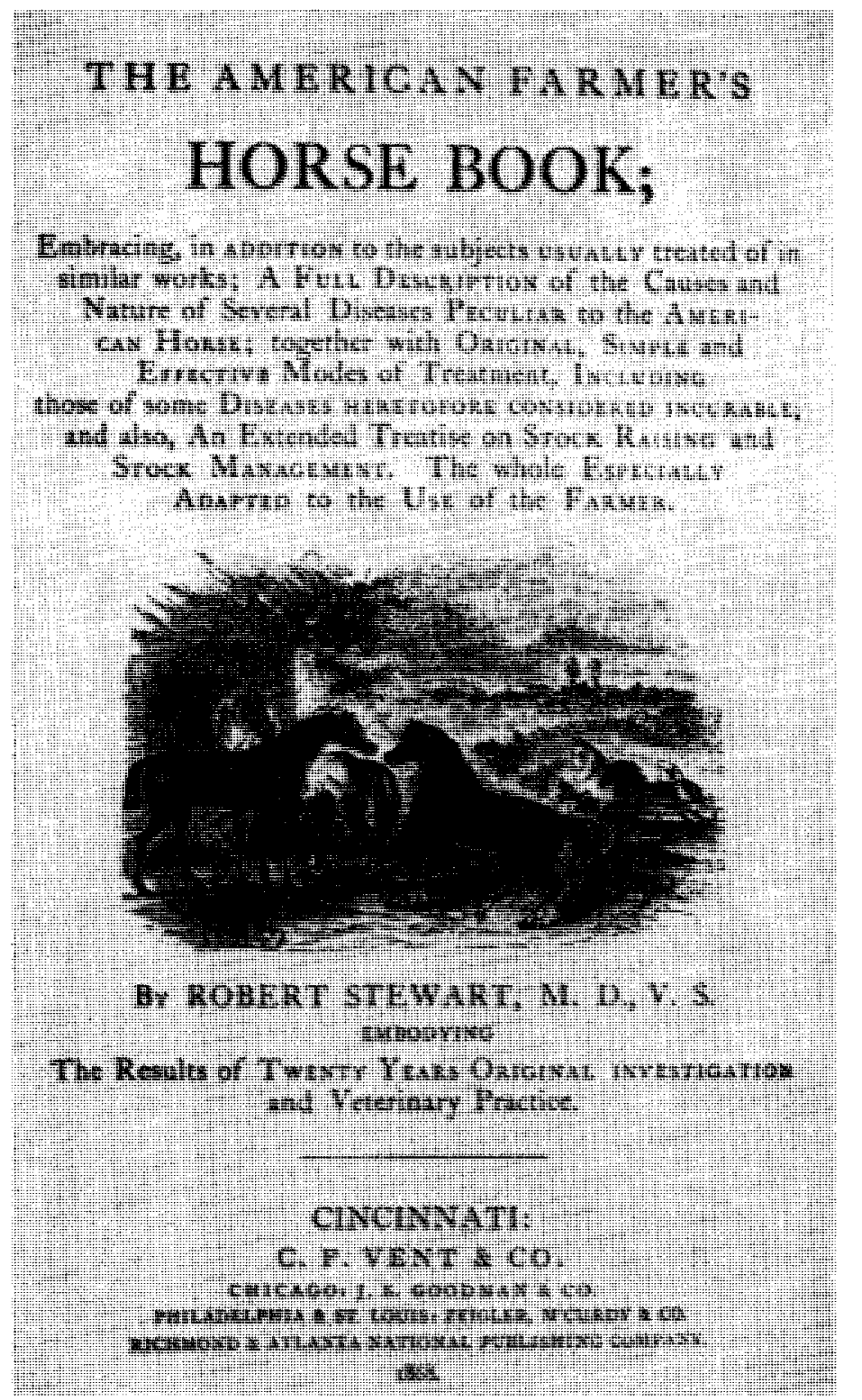

Stewart's American Farmer's Horse Book, Cincinnati, 1867, was one of few (and perhaps the first) native works to be published in a German language edition (Milwaukee). Reprints of earlier German works and the original writings of immigrant German veterinarians were more popular in the Pennsylvania German community.

were reprints of works which were popular in the homeland; a relatively greater number of the German-American books, how. ever, appear to have been of local origin. Conversely, with the demand for veterinary texts in the late nineteenth century, a substantial number of the more widely used works were translations of German veterinary texts. This, of course, is a reflection of the pre-eminence of German veterinary science at the time; the fact that many individuals on our recent and present teaching staffs - or their preceptors - learned veterinary medicine from these texts suggests that the German influence may still be stronger than might be suspected.

Most of the early German veterinary works published in America were homely Iittle books of stock remedies which presupposed some ability to diagnose the condi- 
tion being treated, and while it may be supposed that the German-American had more ability in this area than his English cousins, it is obvious that these had more informational than instructional value. While most advocated gentler methods than those of the Markhamian stripe, a number were infected with superstition, in some cases to a minor degree, but others perpetuated the penchant of the German mind for seeking out witches and goblins. And while more of these works than those in English dealt with animals other than the horse, it is evident that the information on these other animals came from elementary sources rather than from the hochschule of veterinary medicine.

\section{Der Doktor Vom Friederick-Stadt}

Some of these works combined the medicine of man and his animals. One such was a New Expert, American Home and Stable Doctor (title translated), published in 1794 in Friederich-Stadt, Maryland (now Frederick, settled by Germans in 1733). This work devotes 35 pages to the "stable doctor," of which 6 are devoted to a rambling preface; 20 to the horse, detailing remedies for some 50 diseases; 5 to the cow (12 diseases); 2 to sheep ( 8 diseases); 1 to swine ( 2 diseases plus spaying); and 1 on the $\operatorname{dog}(3$ diseases).

The first disease taken up, and at some length, is yellow water (jaundice) of horses, which was at least timely, for the disease is considered to have been seen first in America about 1793. This anononymous work was decidedly ahead of its time, in America at least, in stating that a confirmatory diagnosis of this condition could be made by taking some blood and noting the "especially yellow" color of the "watery" part of the blood. A mixture of pulverized cherry, oak and dogwood bark was prescribed; if unavailing, a mixture of equal parts of copperas (iron sulfate), antimony, saltpetre, and rosin, or a decoction of senna leaves (a purgative cholegogue), in addition to the inevitable bleeding.

For founder: open a neck vein, mix a pint of the blood with a quart of salt water, and give it to the horse. Also: "lead him in flowing water for 15 minutes morning and evening," and give laxatives.

Contrast this with Markham's directions: "draw the hoof to the quick... then raise the sole at the toe, and take hold of it with a pair of pincers . . . and pull it quite off"; or with the Horseman's Friend (!) of 1871 , who advocated bleeding until the horse falls and pouring boiling lard over the hoof. On the other hand, the German "stable doctor" advises for a wrenched shoulder, tying the affected horse to another and forcing him to exercise until he sweats: "then take much blood from him."

If a horse will not eat: "smear his teeth with onion, or cook a half-ounce of asafetida ["devils-dung" in German] in a pint of wine and give it to him." And "when one does not know what is the matter with a horse: It is much easier, said a very wise man, to give a horse-doctor-remedy than to know what ails him." A general medicine composed of hartshorn, goat's blood, saffron, olive oil, and hops is advised in this case. And an easy remedy for a horse that cannot urinate: "Take a seemly number of childlice, and put them in the horse's genitals. He will soon urinate." Or to stop bleeding: "Take grass which grows on a grave, pulverize it, and put it on the wound." The prescribing of arsenic for poll evil or fistula, however, has a familiar ring; but for lampas: "Let him be burned by a smith."

\section{Superstition vs. Science}

As suggested above, the remedies for animals other than the horse are more steeped in superstition, or at best, folklore. Thus for difficult calving, give the cow lampblack and salt "and after calving, a piece of the afterbirth." When a cow gives bloody milk: "Give her blood to drink." For all "inner sicknesses," and for worms: a good handful of wormwood cooked in beer. When a cow does not ruminate: "Lance her under the tongue, smear it with honey and salt; or give her the cud 


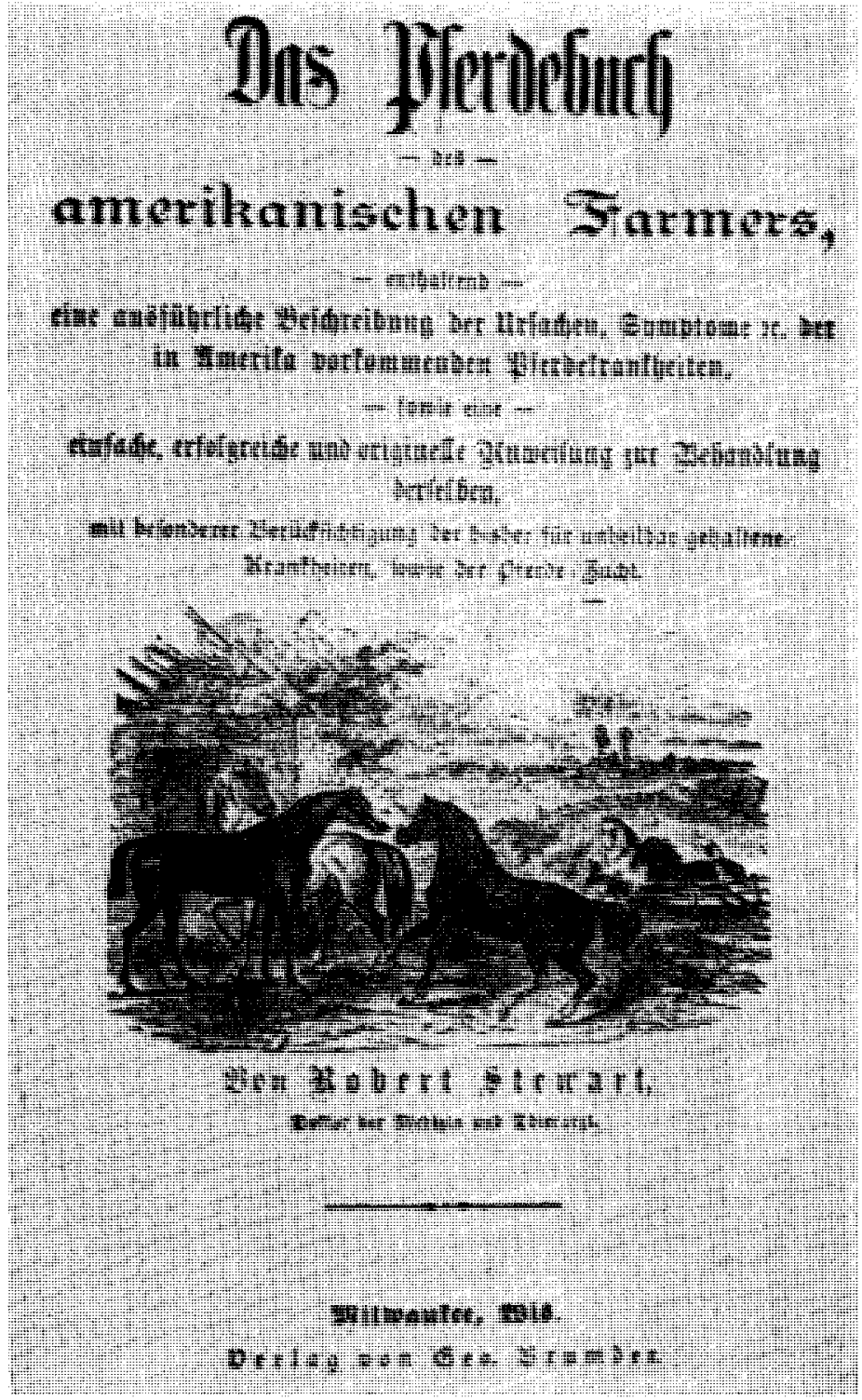

Das Pferdebuch des amerikanischen Farmers was a full translation of Stewart's Horse Book. Around the mid-century several midwest farm journals published editions in German.

of another cow; then put her to fresh grass." And when a cow has the worm in the tail: "Then must one cut it off."

It is evident, however, that some attempt was being made to free the mind from murky practices; for wildfire (probably erysipelas) of sheep:

It is of no use, from fear, that the whole flock might be affected, to bury the first sheep that dies under the sheepfold gate. Take caroway, beat in old beer, make a salve and smear it on the sheep.
But to get female lambs: "Tie the ram on the right side, or cut out the right testicle." From the time of the ancient Romans, femaleness has been associated with the sinister parts.

For spaying swine, directions are given "how a farmer can cut his own sows"; the details of the operation would meet with approval by the do-it-yourself fraternity. For measled swine, bruised snails are prescribed, and against the "swine-death," pul- 
verized wood in wine is given "and bury a root under the trough that the pigs eat from."

Relatively little had been written in America on the diseases of dogs to this date; nor does the little this work has to offer remedy the situation. To keep a dog from going mad: "On hot days give all his food in water or milk in which pigeon or hen dung has been mixed." For a dog or man which has been bitten, a complex regimen of complex remedies is prescribed. For fleas and lice, smear the animal with olive oil, followed by a vinegar rinse. And when a dog has painful eyes, we are to chew ivy, "and spit it in his eyes morning and evening."

\section{Pferde-Arzt}

Considerable improvement can be noted in the Complete Horse-Doctor-Book (title translated) by Joh. Nicol. Rohlives, published in Reading (Pennsylvania) in 1817. The subtitle indicates that this gives: "fundamental information so the farmer and horse-owner can recognize and cure all illnesses... together with a treatise on the diseases of dogs." The book contains 65 pages devoted to 47 diseases of the horse, followed by a 35-page summary of the preceding, and 6 pages on the $\operatorname{dog}(9$ diseases). In the Preface the author states:

There is such an increase in the United States of German receipt books of every kind, that it is difficult to determine which are of real benefit. ... When a farmer lives alone and at a distance, or a traveller has misfortune, his horse is very sick, the receipt book that gives only remedies cannot help, without instruction how to determine each illness, or the variations it may have. ... This book teaches how one can recognize the various diseases of horses.

The author is fairly faithful in carrying out his announced intentions; thus in colic:

The horse will not eat, and paws the earth with his forelegs. At the beginning of the disease he does not lie long, but springs up; when it progresses, he remains down, striking with all limbs.

We are directed to let a quart of blood, and give a decoction of chamomile flowers, linseed oil, and saltpetre every two hours, with a clyster every half hour until the symptoms abate. The remedies for practically all diseases are free of superstition, and are quite moderate; how much good some may have done might be open to question, but at least most of them would have done little harm - which, perhaps, is the best we can say for some conditions today. On fractures, he says:

When a horse breaks a bone, it is best that you should immediately put him to death, as the healing of the bone is unlikely in most cases.

On dogs in particular, this work stands in bold contrast to that preceding. "The dog," says the author, "is unquestionably a domestic animal. He lightens the work of many men, protects his master against thieves, [etc.]." For ulcers of the mouth: "Take a spoonful of honey, mix with 4 spoonsful of vinegar, tie some linen cloth to a stick and swab the mouth three times daily." For diseases of the eye: give Glaubers' salts, and bathe the eye with cold water. If the eye appears hurt, rub grease on it. If a dog cannot hear, drop onion juice in the ear to loosen the wax. Also:

Flesh wounds which suppurate, and the dog licks, heal themselves. ... If a limb is broken, bring the bones together and bind with cloth over four sticks. ... Mix a quarter ounce of camphor in a quart of brandy and wet the bandages. It will soon heal.

For burns: "smear the burned place with fresh cow manure ... or olive oil and cold water shaken together is a good remedy." And for fleas: "Take green walnut shells, steep in water, and wash the dog often, so will the fleas leave."

On coughs and catarrh: "Dogs kept in rooms get colds, start coughing and get a slimy nasal discharge. Take licorice and beer, mix with honey and give daily." The "dog-plague," says the author:

is a nerve fever that settles in the stomach and intestine. First there is a quivering of the muscles, the dog is dull, frisks little, later not at all. There follows a discharge from the nose, the hinder parts become lame and the eyes run. 
Liver of antimony as an emetic, and Glaubers' salts as a laxative are prescribed. In madness:

The dog is dull, frisks not and seeks solitude, he barks no more, and harks no more to the voice of his master. Soon ... a white foam runs from the mouth. He bites all that get in his way, and runs down the road, tail between his legs, and he has runny eyes. As soon as this happens, the dog must be killed. If a $\operatorname{dog}$ is bitten by a mad dog, burn the wound. If the wound is entirely fleshy, cut out the part; place a half ounce of beef tallow over the fire, and mix with an eighth ounce of Spanish fly powder and a half ounce of oil of turpentine; let cool and smear the salve on the wound.

Perhaps with tongue in cheek, he adds: "There is yet another remedy against madness; one must use foresight to prevent the cur from biting his dog." 


\section{Emergence of Epizootics}

IN THE VETERINARY DOMAIN, the eighteenth century in America differed but little from that which preceded it. Both Europe and America were in a political and military ferment during much of the century, and great changes had been wrought in economic life by the century's end. The more or less communal life of the colonial town slowly gave way to an expanding rural economy, but except for a broadening of the agricultural horizon, few large scale changes in the fundamental philosophy of the farmer occurred. The cultivation of grasses as a hay crop beginning about 1765 had a greater potential insofar as the welfare of animals was concerned than was realized for some time. Except for the Pennsylvania Germans, little thought as yet was given to providing housing or the other amenities of good management of animals.

\section{ANIMAL HUSBANDRY AND ANIMAL DISEASE}

In the older settlements continual cropping of the land, especially by such demanding crops as tobacco, led to progressive diminution of yields with the result that forage and feed for animals became more scarce. Animal starvation continued to exact a heavy toll, undoubtedly accentuated by the complications of nutritional deficiencies resulting from soil depletion even when feed was adequate. Old pas- tures and barnyards (more often yards without barns) became reservoirs of infection: the sanitation of a generation or so previous, or lack thereof, was considered adequate - and why not? - it sufficed for grandfather. If a crude stable had been erected, disposal of manure was only an occasional problem - on those occasions when the barn had to be moved off the accumulation of several seasons to prevent the horns of the cattle from further damaging the already leaky roof. Obviously, those doors which were still on hinges opened outward. While some of the apparent increase in outbreaks of animal disease may be attributed to better reporting, that an actual increase did occur can hardly be doubted. In the newer settlements, and especially upon the pioneer fringe, the events of the previous century were repeated.

In Europe the ravages of rinderpest and other cattle plagues became so violent that drastic action was called for. In the half century beginning with 1711 , some $200,000,000$ cattle died in Europe. Intelligent attacks upon the problem had been made by medical men at the behest of their governments, but little progress of a continuing nature occurred until the establishment of the veterinary schools of France in the 1760's. The success of these schools, and the organization of a veterinary profession that logically followed, led to the establishment of twenty schools in a dozen 
countries before the end of the century. Not all of these immediately fulfilled their avowed purpose, but the concept of a veterinary service had come into being. The London school in particular, for a half century after its establishment in 1791, failed to deliver the bright promise it might have had, and the impotence of the British veterinary profession had repercussions in America.

With a predominantly British heritage, it is not surprising, therefore, that little or no overt thought was given to the need for a veterinary profession in America before the end of the eighteenth century. Not even George Washington, who, as one of the most advanced agriculturalists in colonial America, was in touch with foreign developments, left any indication that he had considered the need for professional veterinarians. This, in spite of a neverending concern for the welfare of his animals which - he leaves no doubt - were often in need of better care than they received. The story of animal diseases as they affected his Mt. Vernon stock is the most substantial record given us by any individual during the eighteenth century. Yet these observations were merely incidental to the everyday interests of Washington, and a major gap exists for the war years when more pressing matters engaged his attention.

\section{Problems in Pennsylvania}

Pioneer life in Pennsylvania was beset with the same problems that faced settlers in the other colonies. Heavily wooded, few rural areas were without oppressive swarms of flies, mosquitoes, gnats, and punkies which attacked cattle and horses even more than they did man. A contemporary report states:

The chief plague to horses and cattle was the large horse fly which drove them in from the woods every clear day about eight or nine o'clock. Exposed horses died under the infliction by pain and loss of blood. We made fires of rotten wood and chips and the cattle would run in as the morning advanced and hold their heads and necks in the smoke.
These "gnat fires" were not only necessary, but aided in clearing the forests; as land was cleared the problem lessened as it had in Florida a century earlier.

The woods also harbored many predators; wolves were a major deterrent to sheep raising; bears killed swine; foxes and wildcats claimed poultry. In the mountainous areas rattlesnakes endangered man and beast alike, except perhaps for hogs - at least it was reported "hogs are immune to their poison." The hogs themselves killed many; others were killed by dogs. As late as 1792 one farmer in Pennsylvania reported killing a thousand rattlers in two days. The bounty system claimed many wolves, and these predators were driven westward with the expansion of agricultural land, but their legacy was inherited by packs of feral dogs which, in eastern Pennsylvania at least, probably destroyed more sheep than the wolves ever had.

With the woods serving as both pasture and shelter, and doing neither well in the harsh winters, cattle in droves died of starvation, or by poisoning from laurel, wild cherry, or hemlock which they had eaten in desperation. Already poor as milk producers, cows lost in the woods for a few days would dry up quickly from not being relieved of what little milk they had to offer - and the loss of this little was hardship enough even if the animal itself was not lost to wolves or Indians.

Where sheep could be protected from predators, they were reported early in the century:

in considerable numbers, which are generally free from the infectious diseases which are incidental to these creatures in England, as the rot, scab or maggots. They commonly bring forth two lambs at once, some twice in one year, and the wool is very fine and thick.

But by the end of the century, the situation, perhaps attributable to inbreeding, was such that:

A continued diminution of size takes place; perhaps, however, the greatest defect is want of increase, arising both from the barrenness of the ewes and the lambs being so weak and sickly as to die in great numbers. 
In the first communication of the Massachusetts Society for Promoting Agriculture founded in Boston in 1796 by a group of public-spirited citizens, we find a growing dissatisfaction with the state of affairs. Concerning sheep husbandry in the region, it is stated:

The management of sheep is said to be a science in England: It is certainly not one here in America; and the inference is that our sheep well deserve the attention of spirited improvements, since they are so profitable.

The Lincolnshire rams recently imported by a few who apparently had given some thought to the matter, however, were "ill flavoured, not very healthy, and ill adapted to the short sweet food of our hills." On cattle, the publication goes on to charge:

It is very careless and stupid to go on rearing the calves from poor cows ... their good or bad qualities are doubtless hereditary ... the bull is to be chosen with no less care than the cow.

Nor were all the Pennsylvania Germans of the eighteenth century the paragons of perfection in farming that legend has made them out - at least those "economical Germans" observed by one traveller in eastern Pennsylvania in 1794. This Englishmen, Davy by name, notes that no bedding was used for horses: "their Stables having all boarded floors are clean and dry," but finds it:

extraordinary that amidst this System the Farmers are so inattentive to the making or saving of Manure \& instead of a regular Court yard their Stables \& Barns are plac'd in a Waste where the Dirt and Dung collect until the Building is almost buried. . . . Their Cattle are turned into the Woods... [ [and] are induced very regularly to return to their Homes by being fed with Salt which they are all so fond of that they may be effectually tamed with small Quantities frequently given to them and given once a week is wholsome \& considered absolutely necessary to their Health.

\section{Monster Mania}

About this time there was a notable upsurge in livestock farming, possibly as a subconscious reaction to a growing spirit of nationalism. In the 30 years following 1765 , the livestock population per farm in eastern Pennsylvania had more than doubled, and there were more farms. According to Fletcher:

This is one of the most important events in the history of Pennsylvania agriculture. It is especially significant in its relation to the maintenance of soil fertility and the development of a permanent agriculture.

This renewed interest in animals, however, produced some less than logical overtones. In particular, there was ushered in an era when it became more fashionable to vie with one's neighbors to produce the biggest rather than merely the best. An advertisement in 1791 may be considered the herald of this monster mania:

To the Curious: To be seen at Jeremiah Bullfinch's, near the Mill-Bridge, a live HOG, That is thought to be the biggest ever raised in this Country, weighing upwards of 1000 weight. The price for viewing of said quadruped is 4 pence.

This craze was not confined to one place or time; it raged throughout much of the nineteenth century, and indeed is not completely a dead issue today.

Horses were not shod until after 1750 , even for heavy hauling. Despite a generally stony soil, Penn himself states that an unshod horse would go 50 miles a day without damage to his feet. But for various reasons-flies, cost of transport, and greater cost of keeping, plus the fact that they were less useful than oxen in breaking new ground - few horses were kept during the early days. Ear-cropping or branding on the settlement, or summary justice by hanging in frontier areas was the fate of the horse thief. To improve the breed, Penn had directed in 1682 that no person shall "suffer any Stone horse [ungelded] to run at large after two years old, under thirteen and one half hands high." Later the proclivities of some of the inferior "stone horses" caused the age for gelding to be reduced to 18 months. 


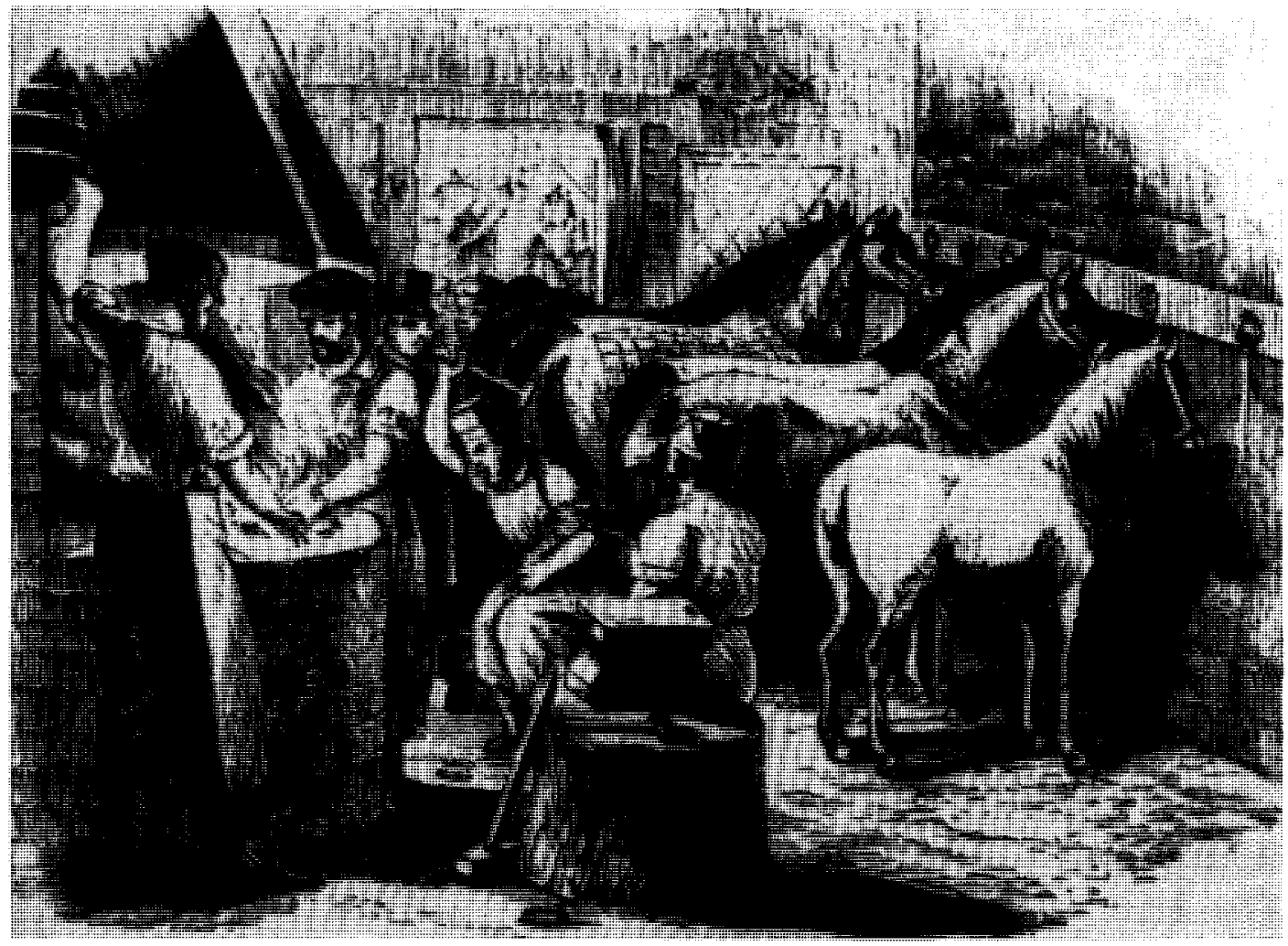

Shoeing of horses did not become common until after about 1750 , due in part to the cost of imported iron. Although at first blacksmiths did little in the way of farriery, their increasing business in shoeing may have accounted for many paying increasing attention to the ailments of horses. Mayhew: Illustrated Horse Doctor

\section{The Village Blacksmith}

The blacksmith had always stood at the head of the tradesmen in the colonies, and after 1750 shoeing of both horses and oxen is frequently mentioned as a common activity of the smith. Little is said of the practice of farriery by blacksmiths, and during the Revolutionary war the practice of these two groups is clearly demarcated. Probably the primary reason for horses not being shod during the early colonial period was the scarcity and cost of iron.

Farrriers apparently did shoe horses, however, for in 1779 - price ceilings being imposed during the Revolution - there was decreed a maximum price allowable: "Farriers for Shoeing a Horse all round $£ 6$ and for shifting a set of Shoes 48 shillings." At this time the cost of an ordinary felt hat was four pounds, and of the best beaver hat 35 pounds. Refined iron was set at $£ 37$ per hundredweight. Dependence upon imported artisans and materials, of course, has always resulted in high prices. In 1842 , it was stated:

The price of shoeing a horse in Iowa is \$5, and it takes a load of corn to pay for it . . a man who knows how to hammer iron, can make more money than a member of Congress.

And a note in a newspaper in 1958 stated that hayrides were becoming a thing of the past because, among other reasons, the price of shoeing horses had risen to $\$ 25$.

In the breaking of new ground, oxen were preferred to horses because of their slow steady gait, and when worn out - or in times of extreme adversity - they could be eaten; horsemeat, and still less customary items of food, however, more than 
once graced the pioneer table. The shoeing of oxen, at least the heavier ones, required a frame with a wide belly band to support the animal, for many were unable to stand on three feet. Ox pulling contests were popular events at fairs. There was never enough animal power to supply the demand, however, and those who may have been critical of the red man for having his women do all the agricultural work perhaps little realized that the average farmwife daily did more than a dozen squaws - and raised a large family in her spare time. Small wonder, then, that many farmers buried three or four wives! Dogs, too, did their duty; in taverns they were used to turn the spits by putting them on a treadmill with a live coal so placed as to discourage them from stopping. Frequently it required several hours to roast a large chunk of beef.

\section{Medical Capital of America}

Philadelphia early became the medical capital of the colonies, the first medical school in America being founded there in 1765 , but elsewhere physicians frequently were held in low repute. It was generally safer to let nature take its course; if the "leech," as the doctor was known in rural areas, was in doubt he drew a pint of blood - if he was sure of his diagnosis, he drew a pint of blood. While good medical training was available to those who could afford to go to England, the compensation for medical services was so low, except for "fashionable physicians" in the cities, that foreign study was out of the question. Despite this, there were some 3500 medical men in the colonies at the outbreak of the Revolution, of which about 400 were graduates of foreign universities, the majority being trained locally via the apprentice route or not trained at all. The establishment of medical schools in the late eighteenth century was a prime factor in elevating the practice of medicine in postRevolutionary America. Unfortunately, the new country was to wait another century for its first veterinary schools to exer- cise a similar salutary influence upon animal medicine.

Considering the times, an impressive number of books was published in colonial America. Few of these, however, were for farmers; probably few farmers read much, either for lack of time or inclination for books. Books were expensive, and farmers came to consider them as unnecessary luxuries. When Benjamin Franklin, impatient with the conservatism of his farmer friends, purchased 50 copies of Jared Eliot's Essays on Field Husbandry to distribute among them, many declined his gift, saying in effect: "We want no information on husbandry; we know all about it. Give us labor." And when agricultural societies were formed, somewhat belatedly in the late eighteenth century, some doubting members still insisted that the best way to improve agriculture was to "lay your hands on the plough-handles and urge on your horses." Those farmers who did want books had to turn to England; of 71 titles added to the library of the Philadelphia Society for Promoting Agriculture in 1811I814, only seven were native works.

\section{EARLY VETERINARY LITERATURE}

Books dealing with animal disease were even more scarce in colonial America than those on agricultural matters. By 1710 , when the first American work touching upon animal diseases was printed, farming, of course, had been a fact for two centuries in the colonies. While some books on farriery undoubtedly had been brought from England, it is painfully evident that those who had animals, or professed to treat their ailments, were even less anxious for book learning than were dirt farmers. For the sake of animals, however, this may have been just as well, for few of the books published in England prior to 1750 could have done much but heap more misery upon an already miserable brute creation. And by the time veterinary works did become available, public taste in these matters had become so degraded that despite the fact that there were a few good works that might 
have been lifted from the British, those of the stripe of Markham held the most appeal.

\section{First in the Field}

The first work published in the colonies to touch upon animal disease appears to have been an anonymous little Husbandman's Guide (Boston, 1710; New York, 1712). In less than 50 small pages this covered: "Directions for Husbandry. . . . Choice Physical Receipts for divers dangerous Distempers in Men, Women and Children. . . . [and] Useful Rules of Arithmetick." A dozen pages are devoted to:

The experiened Farrier, containing many excellent and profitable Receipts for the curing of Diseases in Horses, Sheep, Cows, Oxen and Hogs.

The entire work is taken from or patterned

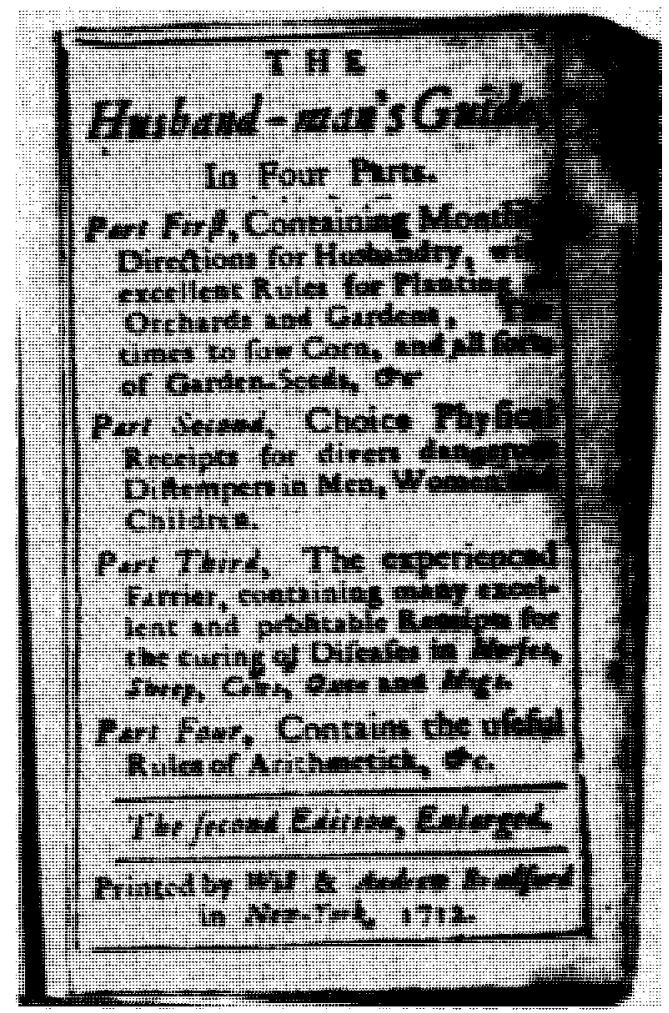

The Husband-man's Guide, Boston, 1710, New York, 1712, was the first American work to deal with animal diseases - in a wretched Markhamian fashion. University of Michigan Library after Markham - whose various writings encompassed all aspects of domestic life.

Two examples of typical Markhamian nastiness are found in the treatments for spavin and farcy:

For the blood Spavin: Tye up the vein, and let blood below the tying, fry Cow-dung in linseed oyl, and apply it. . . . For the Farce [sic]: Take Hogs grease \& the juice of Rue, each 2 ounces, stop the quantity of a Walnut in either Ear of the horse, stop it in with Cotton, and sow up the ear for 24 hours.

At this time, however, there were few other British works that would have been much better to copy from, and while the ancient writers on husbandry would have been good sources, these were not yet available in English translations. Although it seems difficult to reconcile writings like this "Experienced Farrier" with reason at any time, the continued popularity of various versions of Markham for another century or more is still less defensible, for by 1750 several fairly $\cdot$ respectable veterinary works had been published in Britain.

\section{Pater's Errors}

This Husbandman's Guide, a second edition of which apparently was required only two years after its first appearance, was the progenitor of an interminable series of such omnibus works on domestic matters. One such, The Book of Knowledge (Albany, 1794), by Erra Pater, and "treating of the Wisdom of the Ancients," includes such diverse subjects as astronomy, medicine, palmistry, meteorology, and "the whole Mystery of Husbandry." Thirteen pages are devoted to:

The compleat and experienced Farrier and Cowleech, containing above an hundred approved receipts and medicines, for the cure of all distempers in cattle, as horses, kine, sheep, and hogs; with directions how to find and know what their diseases and infirmities are.

While some of these "approved receipts" are taken from the ancient writers - who had their share of harsh and dirty treatments - the more rational aspects of earlier practice are overlooked. 


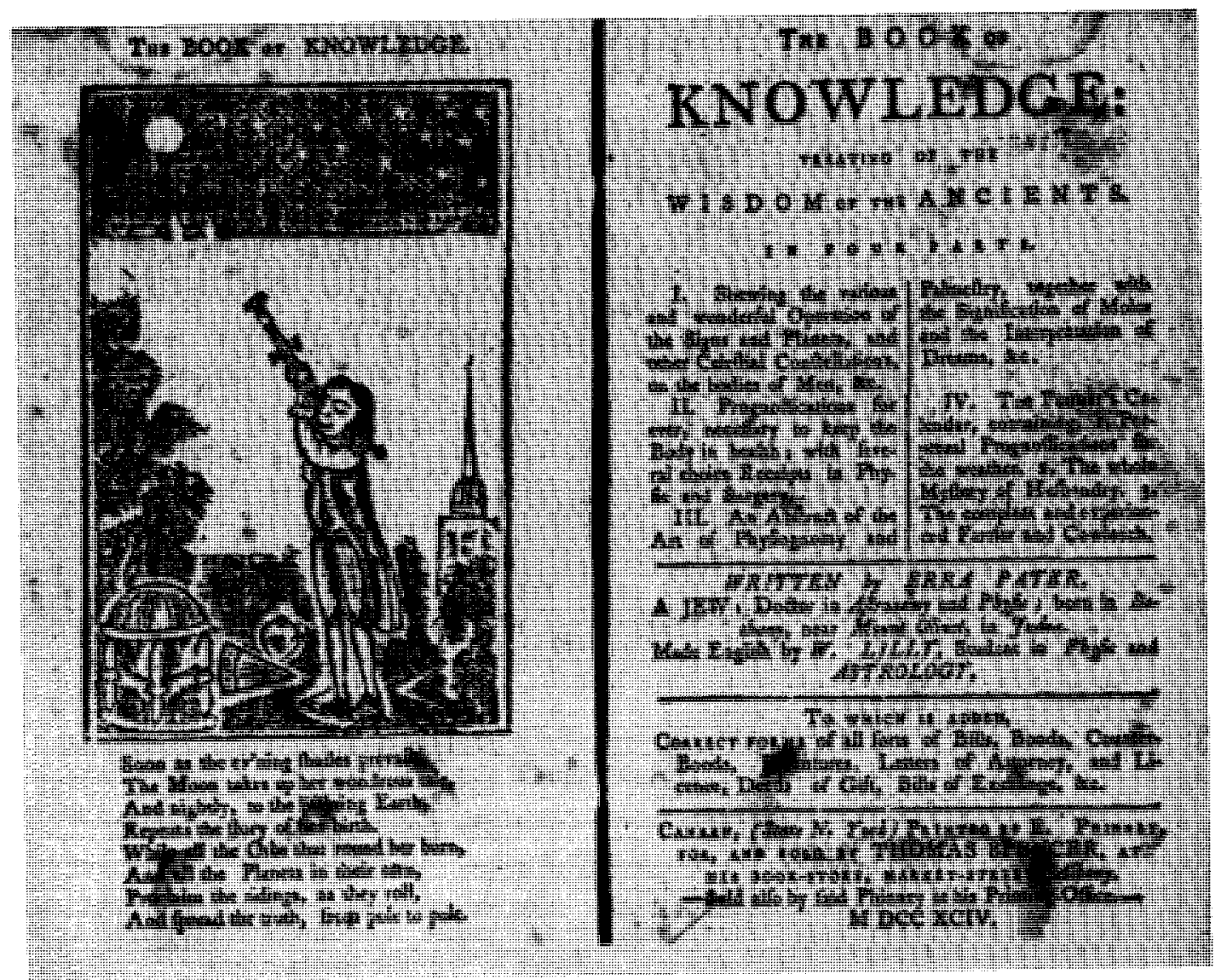

An example of the mystic omnibus household works which enjoyed some popularity, Erra Pater's Book of Knowledge, including "The compleat and experienced Farrier and Cowleech," did little to advance the veterinary art of the times. University of Michigan Library

The relative simplicity of some of these measures undoubtedly had some merit in a country where apothecary shops were not abundant and drugs were expensive when available. At the opposite extreme was Gibson's Farrier's Dispensalory (London, 1721, Philadelphia, 1724?), in which prescriptions calling for 20 to 30 ingredients are the rule, and those with 50 or more are not uncommon. Needless to say, one edition of Gibson's work would be sufficient to meet the demand in America (and there is some doubt as to whether this work was published here at all). Some examples of Erra Pater's rough and ready treatments include:

For a bruised back: dip a wad of hay in water, lay it on the sore, and keep on an old saddle. . . For a broken wind: take boar's dung, and powder it, and pour a good quantity of it into milk lukewarm; give the horse a quart every third day. ... For a festered sore: take lime, tow, and horse-dung, temper them well together with pepper, and the white of an egg, lay it to the sore. ... For a fistula in the head: take the juice of housleek, and dip a lock of wool in it, put it in his ear, and bind it fast.

For the ringbone or spavin: burn it with an hot iron, and annoint the hair about it with neat's-foot oil. . . For the staggers: take a spoonfull of aqua vitae [brandy] and a spoonful of salt, put it in to one of his ears, and so likewise in the other ear, and bind them up. .. Against [urinating] blood, or bloody flux: take a frog, and cut off his left leg, and so put him alive into the beast's mouth; have ready a handful of salt mixed with a pint of good strong ale; and soon as you can, after the frog, give the beast to drink. 
Pater's surgery is equally rough and ready:

For the haw, or horn in the eye, if you cannot have a farrier to do it, take a cord with a stick, and twist his nose very hard, and hold him fast, then take the upper lid of each eye, and with needle and thread give it a stitch to the top of the horse's ear, and underneath the eye-lid you shall see a skin with a hard gristle or horn, which with a sharp penknife, you may cut out; but be careful in cutting it too much; then take a little small beer or ale, and spurt it in to wash it, and it will help him.

\section{And superstition rears its ugly head:}

To cure any swelling in the leg: Mark the ground where the said leg or foot doth stand, and with a knife or other thing dig up a turf or piece of earth just where the leg or foot did stand, hang the same on a white thorn ... and as the turf drieth, so shall the swelling cease.

What would seem a practical suggestion "For a sow that eateth her pigs," is to take the poorest piglet, annoint it with the juice of stonecrop, and give it to her to eat, "She will never do the like again."

\section{Preventive Medicine}

Of the several veterinary works published in America prior to 1800 - or indeed for some time after - the one we should like to have seen set the pattern for practitioners was James Clark's Treatise on the Prevention of Diseases Incidental to Horses (Philadelphia, 1791). First published in Edinburgh in 1788, this valuable little work was not fully appreciated in Britain, although it did go through four editions to 1805. One edition appears to have sufficed for America; unfortunately it was Markham whose heavy hand was felt from the grave for two centuries or more. That Clark's work made little impression upon American thought may be appreciated from the statement of Merillat and Campbell concerning failure of the Army in the 1890 's to recognize the need for veterinary hygiene:

Although Clarke's "Preventive Veterinary Medicine" had been published in Philadelphia a century earlier there were none who proclaimed the advantages of preventive veterinary medicine to the army.
It is something of continuing injustice to Clark that the market value of his book is yet today substantially less than those of Markham. The later editions of Markham today command two or three times the price of Clark's 1791 work, and the 1764 Markham would buy ten copies of Clark. The reason for this is not difficult to comprehend: the few copies of Markham extant today are dog-eared and shabby from long use, while comparatively handsome copies of Clark are obtainable. Mortality in the stable obviously is greater than on the library shelf.

Clark's work, however, does deserve some consideration - if only to see "what might have been." His motto, taken from Lucan: "to hold the golden mean, to keep the end in view, and follow Nature," is literally the golden key to his philosophy. Clark says:

The propriety of this excellent maxim is, perhaps, in few cases more applicable than in the following subject, relating to the Management of Horses. . . . There is no subject, of equal importance, in which people are more apt to be led by prejudice in favour of certain established modes and customs. ... The health and soundness of horses depend greatly on the manner in which they are treated; and it ought always to be observed, as a general maxim, that the nearer we approach in the management of horses, to that which is most agreeable to their nature, they will be in the greater perfection. . . Health is the faculty of performing all the functions of animal life in the most proper and perfect manner.

Clark was a strong detractor of the common practice of regular bleeding and purging as prophylactic measures, for:

In order to preserve horses in this healthful state, it is not necessary to have recourse to medicine or blooding, \&ec. \&ec. by way of preventing diseases, or preserving them in health.

The latter, he insists, can be accomplished by providing clean and airy stables, good feed, moderate exercise, and good grooming. He rails:

Many of the hovels at present used as stables do not even deserve the name. . . Surely there can be nothing more hurtful than keeping a number of them [ perhaps 30 or 40 horses] shut 
Clark's Treatise on the Prevention of Diseases Incidental to Horses, Philadelphia, 1791, a reprint of the British edition of 1788, was the first truly meritorious veterinary work to be published in America. However, it did not achieve the popularity of many less deserving works.

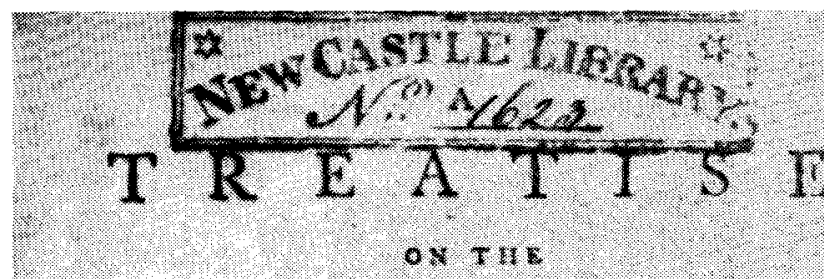

PREVENTION OF DISEASES

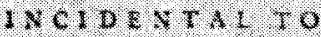

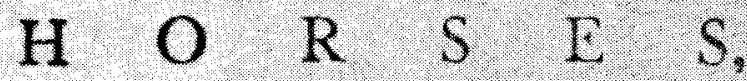

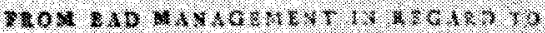

STA B L. E S. F O OD,
W A T L R

A IR, $\wedge * 0$ EXTRCISE.

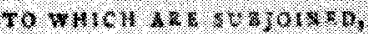

\section{O B S E R V A I I ONS}

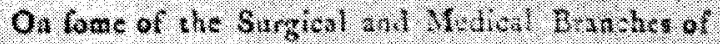

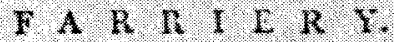

\section{Bv IA M E C L A R K,}

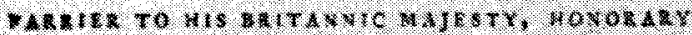

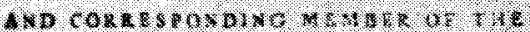

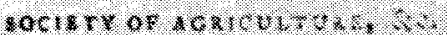

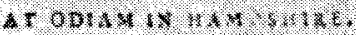

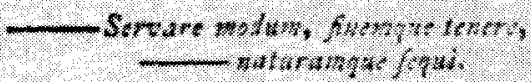

$20.6 \%$

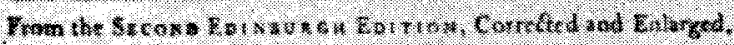

P II A D E I P II IA.

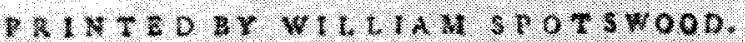

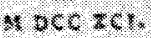

in a close warm stable, where they must constantly breathe a hot foul-air which, at the same time, is strongly impregnated with the putrid steams of their own dung, wind, and urine.

\section{Clark on Contagion}

At a time when the nature of contagion was little understood - or generally not believed in, for the concept of spontaneous generation of disease was still paramount in the minds of most - Clark states:

Large crowded stables contribute greatly to communicate contagious or infectious diseases. ... Those epidemical diseases amongst horses which have appeared in Britain ... raged with most violence in those stables where a great number of horses were confined together in one large stable, whilst its effects, in small well 
aired stables, was more mild and less destructive.

On the fundamental unity of disease processes in the several species, Clark says those of the horse:

have a great analogy to those of the human body .... if the symptons attending any one of the diseases to which horses are liable were faithfully related to a physician, although he never saw a sick horse, yet he could from thence name the disease. . . . The cure of the diseases in horses must depend upon the same principles as those of the human body.

Clark was insistent upon good nursing care of the sick horse - a concept practically unknown in his time and he substituted simple medicines for the fantastic faragoes of the farrier: "It is amazing what different kinds of compositions are forced down horses throats on these occasions." While it would be too much to expect that he would advocate doing away with bleeding entirely, Clark asks:

Why let blood from them on every trifling occasion, unless there may be such symptoms as may require it? . . i it impairs their constitutions, subjects them to diseases, and hastens a premature old age.

Farriers, both professional and amateur, of Clark's time were more interested in cures than causes, and thus pharmacy was of more concern than pharmacology or physiology. Clark, who later wrote a textbook on Veterinary Physiology and Pathology (1806), gives a detailed and accurate account of the anatomy and physiology of the heart and the circulation. To this he adds:

some observations on the pulse of horses, a due attention to which is of the utmost consequence to practitioners in farriery, and which, in the general practice, seems either to be not understood, or not attended to, for, without a proper knowledge of the pulse, we neither can form a right judgment of diseases, in which the vascular system is affected. . . Young practitioners ought there to make themselves well acquainted with all the variations that take place in diseases, together with the changes that happen when deviating from the healthy state to the morbid or diseased.

For the benefit of "young practitioners" - apparently he knew it would be folly to attempt to teach old dogs new tricks Clark gives four pages on the pulse in health and disease.

These were the times when horses had to undergo their semiannual purges to keep them in health; so drastic were these that many animals were unfit for work for several weeks afterward. Moreover, the aloes ball was the first recourse in any form of disease. Concerning this practice, Clark says in derision:

Many people... whose heads are fuller of humours than their horse ... are but too fond of giving purging medicines, and frequently prescribe them whether the case may require them or not. . . It ought always to be remembered, that great evacuations weaken an animal body, and, if they are repeated too frequently ... or, if they are carried to excess ... the powers of life are quite overcome, and death follows of course. . . Mild purges are much safer at all times, and of more benefit to the constitution.

While Clark does give specific directions for the symptomatic treatment of disease, his work was understandably the despair of the farrier who "played it by ear" in diagnosing disease. Frequently the diagnosis may have depended upon the diseases for which the farrier may have had drugs to dispense. Clark says in his introduction:

My design is not to advance or support any extravagant hypothesis respecting medical theories, or to recommend insignificant nostrums, as infallible remedies for this or that disease or lameness; but to make some general remarks and observations upon the common methods at present in use in the management of horses.

His principal philosophy is summed up in a chapter on "Observations on Giving Medicines as Preservatives or Preventatives" in which he attacks those who believe their main mission in life is to meddle with nature:

If a man or a horse is in a state of health, what more is required, or how can they be made better; health is the most proper state of an animal body, and it is not in the power of medicine either to make it better, or to preserve it in this same state. 


\section{Home-grown Herbs}

The American Academy of Arts and Sciences, founded in Boston in 1780, had among its objectives: "improvements in agriculture, to promote medical discoveries, etc." On the latter, it is noted:

Many important discoveries in pathology, as well as in the animal economy, have been in great measure useless to this part of the world, in consequence of a situation so remote from ancient seats of learning and improvement.

One means taken to correct this deficiency was the publication, in the first volume of the Academy Memoirs (1785), of a lengthy article on indigenous herbs of medical value, including applications to animal medicine. A few examples of the latter follow.

Roots of the yellow water flag "have been mixed with the food of swine bitten by a mad dog, and they escaped the disease, when others, bitten by the same dog, died raving mad." Mezeron "is used with success in discussing indurated tumors. Farmers apply it to swellings in cows' bags." Pyrola, or falsevine:

if it be eaten in large quantities, will occasion abortion in all kinds of herbivorous animals $\ldots$ in some instances it has deprived farmers of almost all the increase of their flock in the spring.

The root of garget, or pokeweed, which later became a favorite remedy for mastitis (garget): "Farriers give a decoction to drench cattle, and apply them in the form of a poultice, for discussing tumors." Concerning cowslips:

It has been supposed that the remarkable yellowness of butter in the spring is caused by this plant: but ... it will occasion such inflammation, that they generally die.

The juice of ground ivy in wine "will destroy white specks upon horses eyes," but is hurtful to horses if eaten in large quantities. The oil of origanum "is used by farriers as a caustic" (and is still used in strong liniments). Mountain cranesbill "is given to cattle when they make bloody water."

\section{THE RECORDING OF ANIMAL DISEASE}

Records of animal disease during the eighteenth century are noticeably lacking, particularly before 1750 . This may have been due in part to a still slow buildup of reservoirs of disease, but more animals, undoubtedly, died of disease than are on record. Although animals continued to be concentrated around the larger settlements - many still on the town commons - increasing numbers became scattered on farms at or beyond the fringe of town. Physical separation, together with poor transportation, provided a sort of insular segregation of individual groups of animals; thus while individual flocks or herds may have been decimated from time to time, epizootic disease had not yet become a problem.

Another factor, however, may have operated to conceal to some extent the proportions of the disease problem that must have existed. Relatively fewer outbreaks of disease appear to have been reported during the first half of the eighteenth century than in the century preceding when the animal population was much less. The higher concentration of animals - frequently within the confines of the town would have predisposed to disease at this earlier time: Moreover, the incidence of disease under these conditions would have been more apparent as well as more real, and thus more likely to be a matter of record. As settlers moved to the fringe of civilization they left behind their principal medium of communication, the small town newspaper which had become a distinct feature of colonial life.

The loss of any given number of animals beyond the confines of the settlement would have been more keenly felt, but would less likely have been a cause for concern in town - even when the facts became known. The early newspapers are full of notices of strayed or stolen animals - for whicl there was some hope of return. Anything approaching an adequate concept of contagion, however, did not exist, and the loss of animals under conditions that otherwise might have stimulated an 
inquiry into the cause more often than not may have been accepted as one of the risks to be hazarded.

Taking the early reports at face value, it would appear that extremes of climatic conditions took a larger toll of animal life than did disease. In these cases, however, the death of animals might be considered as an observable result of a cause which was all too apparent - to the journalist in town as well as to the farmer who sustained the loss. In addition, seasonal alterations of the atmosphere, as well as major meteorological phenomena per se, were considered as one of the principal causes of disease. This idea, which is a legacy of the ancient concept of air as one of the four elements having a fundamental relation the production of disease, was a strong deterrent to rational investigation of the causation of disease until well into the nineteenth century. Concerning the increasing occurrence of animal disease in America toward the end of the eighteenth century, Noah Webster, in his History of Epidemical and Pestilential Disease (1799), says, "These phenomena indicate an unhealthy state of the elements."

\section{Webster and Fleming}

Webster's work constitutes one of the best sources of information on contagious diseases of both man and animals in early America. That it can be considered authoritative may be adduced from the fact that it has been called the most important medical work ever produced by a layman. In attributing contagious disease to elemental conditions, Webster may have fallen short of the mark made by some of his predecessors, but it should be considered that he has given us an educated estimate of the consensus of the "experts" of his time. Both this and his record of the occurrence of disease make his work an invaluable reference.

Another major chronology of animal disease in eighteenth-century America - taken in part from Webster - is the work on Animal Plagues (1871), by the British veterinarian, George Fleming. That the rec- ord as compiled by these two authors gives us but a disconnected picture of the animal disease situation is all too apparent, however. This fact was noted by Cotton Tufts in the Memoirs of the American Academy of Arts and Sciences for 1785. Writing on "the Horn-Distemper in Cattle," a disease which was to become widespread in the mind of man during the ensuing century, Tufts opines:

Beasts of the forest, guided by the dictates of nature, and uncontrolled by man in their food, air, exercise and rest, are seldom affected with any disease, whilst in almost all countries, the domestic kind, that are more immediately under the government of man, are subject to a variety.

He goes on to state however, that "scarcely an instance in this country of reigning sickness among tame or wild beasts, has been noted by its historians."

The first epizootic to attract the attention of historians was that of catarrh, or influenza, of horses. Fleming records the presence of "horse catarrh in America" in 1699, and again in 1732. The latter outbreak began in New England, prior to a major epizootic in Great Britain, and spread southward to the West Indies, and Central and South America. The course of the disease is said to have been very much like the English outbreak, which is well documented by William Gibson, the noted surgeon-farrier, in his New Treatise on the Diseases of Horses (London, 1751). Gibson, who draws upon his personal experiences during this outbreak, gives a faithful account of the disease.

Fleming picks up the thread in 1766, when:

Horses and horned cattle died in great numbers in America, especially in New England and New Jersey. ... This autumn [1767] has been fatal to the horses in America, as well as England and Holland. The distemper there has been attended with fatal effects; in the province of New Jersey, it has carried off almost all their young horses and colts; and in New England the havoc it has made is also very ruinous.

And in 1768: "horses were generally affected with a disorder of the head and 
throat, which proved fatal to many, and much injured the serviceableness of those that survived." Beyond a heavy mortality among horses in Maryland in 1789, nothing further is noted on this disease until 1808.

Webster records much the same information regarding this "epidemic catarrh," and by inference relates the one outbreak to the fact that "the summer of 1768 was hot." $\mathrm{He}$ gives frequent accounts of severe drought, floods, cold, heat, and "blasting" of corn, all of which must have had some effect upon livestock - which for the most part were left exposed to the elements - but he has little to say on this matter. Inasmuch as even relatively mild outbreaks of animal disease in England and on the continent are frequently mentioned, it seems likely that Webster would have recorded similar occurrences in America if data were available. He does mention that in 1789 , "In Maryland, the autumn was distinguished by an unexampled mortality among horses."

On the matter of the elements, Webster notes that the winter of 1717 "was terribly severe, and remarkable for prodigious storms of snow." In Connecticut a flock of 100 sheep was buried under 16 feet of snow for 28 days; two were alive when dug out. And the winter of 1740-1741 "was of the severest kind. Many cattle perished for want of wood." Not only was this of sufficient moment to merit notice in the Journal of the New York Assembly, but Benjamin Franklin, in The General Magazine for 1741, published an account of the winter in Maryland:

There has been the hardest winter that ever was known here by the oldest person. ... In the Country, some have been froze to Death: One Man near the Town, was much eaten by the Hogs ... . and it was imagin'd that the Hogs got foul of him before he was quite dead ... [an] abundance of Cattle, Hogs and Sheep have perished already, and more daily are perishing.

A major crop failure in 1788, mentioned by both Fleming and Webster, reduced the hardy Vermonters "to the necessity of feeding on tad-poles boiled with pea-straw.
.. Cattle perished in considerable numbers." Webster further notes:

The winter of 1798-9 was very long and severe. . . This long duration of cold exhausted all the barns of hay and other fodder, and multitudes of cattle perished in various parts of the country.

\section{Dog and Cat Distemper}

According to Fleming, the first occurrence of distemper in dogs anywhere in the world was in South America in 1735, but the disease appears to have been known earlier. The date of its introduction in the American colonies can only be approximated: Cotton Tufts, writing in the $\mathrm{Mem}$ oirs of the American Academy of Arts and Sciences for 1785, states: "About twentyfive years past an epidemic distemper prevailed among dogs, and occasioned a great mortality." This would place the date about 1760. About the same time the disease broke out in Europe, apparently following a path from Spain to England. In 1767, Fleming states, "The distemper in dogs was so violent in Louisiana, that the greater part of them died."

Cat distemper, which Fleming calls "an extraordinary epizooty ... which appears to have been developed in America," made its first appearance in 1796 in New York City, where some 4,000 cats are said to have died. The following year 5,000 cats perished in Philadelphia. As described by Fleming:

The animal ... usually lost its appetite, but drank a great deal, slept much, looked very ill, and many began to grow emaciated. Some died in a kind of stupor; others, on the contrary, towards the termination of the disease, became mad, vomited, and foamed at the mouth.

The disease spread rapidly over most of Europe, where cats also died by the thousands. Concerning its spread in America, Webster states:

The cat-distemper appeared in Philadelphia, as early as June [1797] and proceeded northward and eastward, like the catarrh of 1789 . In August it was very fatal in New York, and in the course of the summer and autumn, it spread destruction among those animals over the Northern States. 
Certain of these outbreaks coincided with the appearance of yellow fever in man, and attempts were made to link the two diseases by incriminating the cat as the reservoir of the disease in man. Nor were dogs exempt from suspicion, for Fleming states: "Also among the dogs, at the beginning of the yellow fever, there was a sickness of which many died." And during an outbreak of yellow fever at New Orleans in 1822: "it was observed that the dogs suffered from the black vomit." The epidemiology of yellow fever, of course, was a mystery at the time, and remained so for many years.

\section{Gallinaceous Gapes}

Gapeworms in poultry evidently became well established during the late eighteenth century, for in 1798, a Dr. Wiesenthal, Professor of Anatomy at Baltimore, wrote:

There is a disease prevalent among the gallinaceous poultry called gapes, which destroys eight-tenths of our fowls and occurs in the greatest prevalence among young turkeys and chickens bred upon old established farms. Chicks and poults in a few days after they are hatched, are found frequently to open their mouths wide and gasp for breath, at the same time sneezing and attempting to swallow. At first the affection is slight, but gradually becomes more and more progressive until it ultimately destroys. Few recover: they languish, grow dispirited, droop and die. It is generally known that these symptoms are occasioned by worms in the trachea. I have seen the whole wind pipe completely filled with these worms and have been astonished that the birds could breathe under such conditions.

In severe cases, Dr. Wiesenthal recommends surgical removal of the worms; in others, insertion of a feather into the trachea may dislodge them. The parasites removed, he cautions, must be destroyed to prevent further contamination of the ground, and chicks and poults should be raised on ground to which fowl had not had access for at least a year. Unfortunately, for many decades poultry raisers poked feathers down the throats of birds without realizing the greater wisdom of this early observation regarding area sanitation.
During the nineteenth century "the gapes" became one of the most perplexing problems of farm folk, whose flocks - large and small - were decimated by this parasite. What appears to have been another disease caused great mortality among geese and other fowl in the 1790's, concerning which Webster says, "I have not been able to obtain a particular description of the symptoms, but it was observed the transition from apparent health to death, was very rapid." The symptoms of gapeworm infection, of course, are quite apparent, and were known at this time. The Maryland Journal and Baltimore Advertiser in 1779 carried an advertisement for:

The Poulterer's Friend: A certain preventive of Gapes in chickens and turkeys ... [it] will stimulate the growth of young Fowl, and will prove very beneficial in preventing the ravages of chicken cholera. It is estimated that $3 / 4$ of the young chickens die of Gapes, which has hitherto baffled every effort to cure. Ask for the "Poulterer's Friend" and take no other article. Already half a dozen worthless imitations have been put on the market.

\section{Mad Dog}

The first notice by Webster of disease in dogs is mention of "some cases of canine madness" in 1769 - so far as Webster could discern - the first occurrence of rabies in America. The historical archives of Virginia, however, indicate the presence of the disease in the colonies as early as 1753 . Two centuries earlier rabies spread by vampire bats reputedly spread havoc among the conquistidores of New Spain. And, as noted elsewhere, the casual reference of George Washington to rabies in 1769 suggests some familiarity with the disease. Fleming notes that rabies was "very com. mon" in Philadelphia and Maryland in 1780. Webster makes no further reference to rabies until 1785 , when:

In America canine madness began to rage and spread in all parts of the northern states. The gazettes of 1785 abound with accounts of the dreadful effects of this singular disease. It will be remarked that epidemic madness of dogs is one of that series of diseases which belong to every pestilential period. Whenever the 
human race are generally afflicted with epidemics, the canine species rarely escape the effects of the general principles; and not infrequently foxes, wolves and other wild animals, experience its malignant effects, and run mad.

Sporadic cases in man, and rabies in epizootic proportions among animals are mentioned by Webster several times between 1785 and 1800 , who argues:

These phenomena indicate an unhealthy state of the elements. ... What I denominate a pestilential principle, does, at certain times, pervade not only the element of air, but the water also. The proofs of this are abundantly numerous and convincing. . . . The pestilential principle has extended to every species of life. The beasts of the field perish with deadly epidemics; the fish die on the bottom of rivers and the sea ... while corn is blasted on the most fertile plains.

These phenomena excite the astonishment of men, who have not attended to the history of pestilence, in which they might have found the means of solving the difficulty; for similar facts have marked the progress of pestilential diseases, from the days of Moses to this hour.

To illustrate his thesis, Webster quite correctly states:

In the long sieges, bad food is often a powerful cause of disease ... [and] whenever grass is defective in wholsome, nutritious qualities, horses, horn-cattle and sheep are sure to suffer by mortal distempers.

\section{Public Health Pundit}

On the subject of public health, Webster was considerably ahead of his time. Among several suggestions for improved sanitation in cities, he suggests that the privies-outdoor plumbing, of course, being the rule - be placed at the back line of lots where they might be connected to a conduit to lead the wastes away. Also:

All dead animals in a city or its vicinity, should be buried or burnt; as cats, dogs and horses. The indecency alone of suffering their carcases to putrefy before the eyes of mankind ought to make it a strict article of police, to remove them. But they should be buried; not one should be permitted to offend the eyes or nostrils of a citizen. They are offensive to decency, to moral sentiments and to health.

He states that in New York City, "from twenty to thirty worn-out cart horses die and putrefy in the suburbs of that city, every year."

Concerning a matter more directly related to veterinary public health, Webster continues:

If animals, which constitute a part of the food of men, are subject to epidemic distempers, they cannot be eaten with safety, while affected by disease. When fish or fowls are sickly and many of them die, or become lean, the fact should be ascertained by the faculty or a board of health, and public notice should be given, that people might avoid using them as food. In some instances, fish are so sickly as to excite nausea; in which case the use of them should be forbidden.

In a similar vein, the colonial physician, Benjamin Rush, urged in 1807:

It is our duty and interest to attend in a more especial manner to the health of those domestic animals which constitute a part of our aliment, in order to prevent our contracting disease by eating them.

\section{The Suffering South}

Animals in the deep South had their share of troubles during the eighteenth century. Of the first cattle - a few heifers - brought to Florida in 1520 by Ponce de Leon, it has been noted that there is no trace of their increase, if any. More than likely they were eaten by the exploring party or lost to the Indians. Nor is there any assurance that those brought by De Soto in 1539 enjoyed any better fate. St. Augustine, the oldest city in the United States (1565), early became a center of missionary work among the Indians - who returned the favor by almost continual harassment of the colonists and their cattle for the two centuries Florida remained under Spanish rule. Dacy, in his story of Four Centuries of Florida Ranching, speaks of the precarious position of the brotherhood because of Indian attacks from one side, and pirate raids on the other:

Apparently the beef produced by the dons never supplied the home demand, as in 1712 the St. Augustinians were forced to eat horses, cats, and dogs to keep alive. 
The stock liberated by the Indians from the colonists became the foundation of large herds; indeed, the Indians became the first large ranchers in Florida. By the 1750 's, cattle and horses had become plentiful and sold for trifles.

Bartram, in his Travels Through South Carolina, Florida and Georgia in 1774, noted:

Indian riders herd large lots of cattle. . . Though the horned cattle and horses bred in their meadows are large, sleek, sprightly, and as fat as can be, they are subject to mortal diseases. I observed several of them dreadfully mortified, their thighs and haunches ulcerated, raw, and bleeding, which, like the mortification of slow cancer, at length puts an end to their miserable existence. The traders and Indians call this disease water rot or scald, and say that it is occasioned by the warm water of the savannas during the heat of summer and autumn when the creatures wade deep and feed on water grasses of which they are immoderately fond; whereas the cattle which only feed and range in the high forests and pine savannas are clear of this disorder.

The Iberville colony of Louisiana, found. ed about 1700, imported cattle from Santo Domingo, and by 1708 had increased its holdings to about 1,500 , and to 10,000 by about 1750 when most of the cattle died of a "mysterious malady." Slaughter of beef was subsequently prohibited until there had been an adequate increase, as was traditional upon the founding of a new colony.

In all too many instances, the identity of these "mysterious maladies" is destined to remain as unknown to us as to those who were troubled by them, for all too often nothing is said concerning symptoms or course of the disease - except for its termination. Thus the nature of "the distemper" or "murrain" often can only be surmised, although these terms were usually reserved for frankly contagious or infectious diseases. At times such diseases were alarming enough to warrant legal interdiction. A proclamation of the governor of South Carolina in 1744 was issued:

Ordering and commanding all persons whatsoever in this province, who have any black cattle amongst which any appearance of this distemper hath been, or shall be, to keep all their cattle within their enclosed grounds.

This "distemper" apparently raged for some years, for data from the files of the Charleston (South Carolina) Library Society indicate that in 1741 there was "great mortality among cattle," and in 1744 "infectious distemper in cattle in various parts of the Province. . . . Whole herds destroyed ... large boils full of corruption near kidneys in opened carcasses." The proclamation above most likely was in consequence of "An act to prevent the spread of infectious distemper," in 1744. During 1745 and 1746 numerous cures and means for control of the disease appear in the newspapers; there were those who were sure they could "stop further spreading of infection," or cure it with such items as "a snuff of leaves of the broad-leaved Heart Snake Root." How long the disease raged, or how far it was spread, is not indicated, but in 1762 it is noted: "Murrain has recently appeared in cattle in Va.," and in 1773: "The murrain has appeared in several parts of S.C." On November 13 of the latter year, Wm. Bull, Lt. Gov., issued a proclamation: "announcing the appearance of murrain and cautioning against purchase of infected cattle and against driving from infected ranges."

Nor were the horses of South Carolina exempt; in 1767 it was noted: "Distemper among horses seems to be the same as appeared in the Northern Provinces." This apparently was influenza, which was widespread about this time throughout the colonies. "Cure" of the disease could be effected:

by bleeding plus a ball of brimstone and saltpetre; inject sharp vinegar into the nostrils and bathe the outside of the throat with vinegar, hogs lard and camphor. Tar on bridle bits is a good preventive.

Rabies appears to have invaded South Carolina in 1772; on February 20 there was "a fatal case of hydrophobia in a mulatto boy in Savannah," which occasioned the statement that the disease was "until now almost totally unknown in the Southern 
Provinces." Acting with alacrity, on February 25: "Gov. James Habersham issued a proclamation that all in Savannah keep their dogs confined." The report in 1790 of "a recent fatal case in a white lad of 14 , six weeks after he was bitten," suggests that rabies was not unknown during the interim. A week after this last incident a city ordinance was passed "placing a tax on dogs." How effective this may have been, or for how long, is a moot point, for in 1800 there are reports of "several persons bitten by mad dogs in the streets."

Thus it is likely that if the full details were available, the record of animal disease in one part of the country at this time would not have differed greatly from that in any other. A thorough search of colonial documents undoubtedly would do much to enlarge the presently rather scanty records of the incidence of infectious disease among the animal population. In some areas at least, the apparent immunity to animal disease might well be related to the inadequate reporting - or failure to ferret out all that has been recorded. But the colonial period is not unique in this respect.

A "Bill for Preventing Infection of the Horned Cattle" was introduced in the General Assembly of Virginia in 1785 and passed the same year. This stipulated that cattle could not be driven into or through the commonwealth without a bill of health signed by two disinterested freeholders, who: "shall have viewed the cattle and reported them to be free from distemper." Infected cattle were to be impounded; if they escaped or were removed without proper certification, they were to be slaughtered and

their carcases, with the hides on, but so cut or mangled that none may be tempted to take them up and flay them, to be buried four feet deep.

Failure to comply made the owner liable to a fine of 20 shillings per head. This "distemper" may well have been Texas fever; although nothing in the bill suggests it, this disease was already present in the South. Other legislative acts more obvi- ously aimed at halting spread of this disease are considered elsewhere.

\section{Hollow Horn vs. Hollow Belly}

No account of animal disease in the eighteenth century would be complete without mention of the so-called "hollow horn" of cattle, also termed "horn distemper," or "horn ail." This "disease," which seized the imaginations of the intelligent as well as the gullible, seems to have made its first appearance about 1770. For nearly a century the literature on animal disease was replete with methods of diagnosis and cure of this affliction. In 1785 it was deemed of sufficient importance to be given space in the Memoirs of the American Academy of Arts and Sciences, but the learned Cotton Tufts could offer nothing not already known by every farmer. A traveller in Pennsylvania in 1794 notes:

Horn'd Cattle in this Country are very subject to have rotten Horns, always the cause of speedy decay \& death unless soon healed. As a remedy they either cut them off, or bore a large hole \& pour into it Brine, or Vinegar, with Pepper \& Salt in it. This passes down through the Nostril \& generally cures. They now burn the sprouts of Calves horns when two Months old \& then the Horns will not grow.

By inference, at least, this latter measure appears to have been an excellent preventive; but more important, this casual observation dates this practice - for whatever the reason.

References to this disease, once an agricultural periodical literature was established in 1819, would fill a fair sized volume - one that would delight the soul of a gimlet-maker. It was not until about 1850 that reason prevailed, and it was realized that this notorious scourge coincided with a period when poor feeding and general neglect of cattle were as notorious but less well recognized than the easily detectable consequence. In 1847, the noted agriculturalist, Lewis Allen, in his little book on Domestic Animals, opined that hollow horn was "usually hollow stomach due to hard work, poor food, or exposure to cold." Some comfort was afforded the gimlet-wielding fra- 
ternity, however, for if it were a "true" case of hollow horn, the customary boring, with the salt, soapsuds, or vinegar treatment was advised. It is of some interest that in a recent discussion (1958) of the "downer-cow" syndrome, it was stated, "our main problem with 'downer' cows is from 'hollow belly," " and, (with tongue in cheek), in Georgia, "cows become puny and have hollow horns and tails from the causes mentioned."

That hollow horn was related to poor winter feeding is suggested by a letter from a Civil War soldier to his wife in Michigan. Datelined "Camp near Alexandria, Va., Jan. 31, 1863," the pertinent passage reads:

You may do as you think best about selling Pink. But I bleave I would sell her before next winter that is if she is going to have the hollow horn every winter.

While hollow horn appears to have been indigenous to America, the equally notorious "wolf in the tail" had its roots in Britain, and earlier in Germany where Wolf meant an ulcer. How much improvement had occurred in the handling of this condition in three centuries of thought - or lack thereof - upon the matter may be adduced from the rustic doggerel of Thomas Tusser in 1576 :

Poor bullock with browsing and naughtily fed, Scarce feedeth, his teeth be so loose in his head; Then slice ye the tail where ye feel it so soft With soote and with garlicke bound to it aloft.

The Practical Stock Doctor, in 1920, directs:

When a cow or steer gets sick and begins to lose flesh, examine the tail, and if at the end of the tail bone it seems hollow or flabby, split the hollow and fill it with common salt, then wrap with a rag saturated with turpentine. This will be all the attention necessary.

The equally apocryphal "loss of cud" caused numerous animals to have anything from dung to dirty dishrags forced down their throats.

In the same category as the above was the commonly diagnosed "black teeth" of hogs. Speaking of pioneer conditions in Pennsylvania, a historian notes:
Hogs were starved in winter and the result was considered a disease and called "black teeth." The remedy was to knock out the teeth with a hammer and a spike; if the critter recovered, the remedy was the right one; if it died, the reason given was that the remedy was too late. A far better remedy would have been a bucket of warm slop, a tight stable and plenty of hay.

Little appears to be on record concerning the activities of farriers as such during the eighteenth century - and in many cases perhaps the less said the better. One item of particular interest may be the first record of a woman carrying on this trade, usually reserved for stout-hearted men. The following advertisement appeared in the Boston Gazette in 1767:

This is to give notice that the Widow Hendry, having had her Workshop destroyed in the late Fire in Paddy's Alley, carries on the Farrier's Business on Scarlet's Warf, at the North End, where she hopes her Customers will continue their Favors to her, in her deplorable Circumstances.

\section{VETERINARY MEDICINE IN THE WRITINGS OF WASHINGTON}

The writings of George Washington are a rich source for the historian in almost any area: political, social, cultural, economic, and agricultural, to name but a few. The paucity of veterinary writings as such during colonial times makes the references of Washington to veterinary matters an especially valuable source for the historian of veterinary medicine. As an astute agriculturalist, the thoughts of Washington upon the care of animals may be taken as representative of the best thinking of the times.

There being no graduate veterinarians in America during Washington's time, and few competent self-taught farriers or cowdoctors, most of the ailments of livestock were attended, or at least supervised, by the owner - or, as was frequently the case, left unattended. Washington makes no reference to professional attention of any sort upon his stock at Mount Vernon - other than horseshoeing - but does mention having his animals treated for various illnesses 
while on the road. Of particular importance is the fact that his writings establish the presence of farriers in the Continental Armies; it has usually been considered that farriers were not provided for cavalry troops until reorganization of the Army in 1792. Another subject of veterinary interest is Washington's provisions for military food hygiene.

Throughout his writings, it is evident that Washington expected much of his horses, but at the same time was very solicitous of their welfare. This was true during his youth as well as in his more mature years. On his mission to the French in 1753 , he wrote in his diary:

Our horses were now weak and feeble, and the Baggage so heavy ... that we doubted much their performing it; therefore myself and others ... gave up our Horses for Packs, to assist along with the Baggage. ... The Horses grew less able to travel every day.

And in 1755 during the French and Indian War he lamented:

surely no man ever made a worse beginning, than I have; out of 4 Horses which we brought from home, one was kill'd outright, and the other 3 render'd unfit for use.

On several occasions he mentions the difficulty of getting horses, wagons, and forage, and the poor condition of those few horses that were available. On a trip to Winchester in 1755 , he wrote:

I met with no other Interruption than the difficulty of gettg. Horses after I found... [mine] for want of Shoes grew lame, I was oblig'd to get a fresh horse every 15 or 20 Miles, which render'd the journey tiresome.

And later the same year:

I have been now 6 days with Colo. Dunbar's Corps, who are in a miserable Condition for want of Horses, not having more than one half enough for their Wag'ns. . . . I believe shortly he will not be able to stir at all ... there has been vile management in regard to Horses.

\section{Mashd Leg a la Markham}

On a visit to his home at Mount Vernon in 1760 , Washington wrote in his diary:
Upon my return found one of my best Waggon horses with his right foreleg mashd to pieces, which I suppose happend in the Storm last Night by Means of a Limb of a tree or something of that sort falling upon him. Did it up as well as I coud this night. . . . [the day following]: Had the Horse Slung upon Canvas and his leg fresh set, following Markham's directions as near as I coud. ... . [but two days later]: The Broken legd horse fell out of his Sling and by that means and struggling together hurt himself so much that I order'd him to be kill'd.

With a limb "mashd to pieces" it is very unlikely that the horse would have escaped dying from infection, or if it did, that it would have had the use of its leg - a serious matter for a wagon horse (i.e., more serious than for a brood mare). It is also curious that Washington should have shown what must be considered something less than the best judgement in electing to use Markham as a guide - or even to admit owning this particular work. In a footnote to this entry, the editor of Washington's works states:

None of Markham's writings were in Washington's library, but William Gibson's Treatise on the Diseases of Horses (London, 1751) had been purchased in 1759, and Jacques de Solleysell's The compleat Horseman, or perfect Farrier (London, 1729) is in the inventory of the library.

Either of these would have been a better choice, and it is perhaps significant that Washington appears to have gotten rid of the Markham. The work referred to undoubtedly is Markham's Maister-peece (London, 1610). Despite other shortcomings, however, Markham's section on broken bones is acceptable in some respects. Although he gives appropriate directions for slinging the horse, once this is done, all he says about setting the limb is "then you shall put the bones in the right place," following which bandages and splints are to be applied. Inasmuch as Markham admits that most farriers did not have the skill to set a broken limb on a horse, it may be doubted that much could be expected of an amateur. 
It is of some interest that in addition to the copy of Gibson, which Washington ordered from Robert Carey \& Co. of London in 1759, he also specified six bottles of Greenhow's Tincture (probably a horse liniment), and "2 pr good Horse Scissars." And later he ordered:

40s. Worth of Medicines for Farriery, among wch let there be

4 lb. flower of Brimstone

$4 \mathrm{lb}$. Anniseeds

4 lb. Carthamus

5 lb. Syrup of Colts foot

2 lb. Diapente

5 lb. black Soap

5 lb. Cummin Seeds

4 lb. Fenugreek

2 lb. juice of Liquorace

4 lb. long Pepper

These were among the more common ingredients of most animal medicines; it is a commentary on the times that 40 pounds of drugs could be had for as many shillings. While this list does not prove that Washington compounded his own remedies, for each of these was used singly also, he at least showed good judgement in buying simple drug ingredients rather than some of the fantastic compound remedies popular at the time. Some of these contained from 50 to 100 ingredients; the diapente ordered by Washington, as the name implies, contained five.

In 1762, Washington wrote to George William Fairfax concerning the death of a mare belonging to the latter that apparently had been sent to Mount Vernon for breeding. The mare had been well when let out of the stable in the morning:

but before Night was swelled to a monstrous size and died in a few hours. Bishop (my old Servant) opened her but coud perceive no hurt, bruise, or other apparent cause of so sudden a death, which Inclines me to think it was occasioned by eating blasted Corn. ... She had no Foal in her, which assures me she never would Breed, as I am convinced she had a competent share of Ariel's performances.

This occurred during Washington's absence; evidently his servant had been sufficiently well instructed to proceed with a post-mortem examination without specific directions. While not much, perhaps, might have been expected under the circumstances, it is at least significant that such examinations of animals which died apparently were done as a matter of course. Washington's surmise over the probable cause is certainly as good as any that might be made, and shows that he had some familiarity with the digestive troubles of horses.

\section{Hard on Horses}

As an owner of fine horses, Washington insisted upon the best care possible for them. As a rider, he was solicitous of the well being of his mounts, but it is apparent that he expected much of them, for he makes frequent mention of having foundered his horses while on a journey $-\mathrm{a}$ serious matter when horses were so depended upon. Thus in 1769 Washington notes that he: "Got to Eltham, after foundg my Horse," and listed: "Expences of my Sick Horse 15s." And in 1770:

Began a journey to the Ohio ... and lodgd at. Leesburg distant from Mount Vernon abt. 45 Miles. Here my Portmanteau Horse faild in his Stomach.

After traveling another 30 miles the day following, he notes: "My Portmanteau Horse being unable to proceed, I left him at my Brother's." Again, in 1771 he was forced to make: "some considerable stop at Ruffin's Ferry, occasioned by a Sick Horse," and lists expenses of $10 / 3$; and upon another occasion in 1772 , the self-accusation "Foundered two of My Horses," appears. While a good horseman might consider himself at fault if his horse were to be foundered, not infrequently this trouble would be a direct result of the poor condition of a borrowed horse, or poor facilities for care on the road. The inconvenience occasioned by lamenesses is suggested by a note from Washington to the Reverend Jonathan Boucher in 1772:

I send my Carriage up but cannot undertake to promise for the Horses bringing you down .. . with my lame Horses not being return'd from Williamsburg.

Some idea of the attention Washington paid to his horses en route may be had from his diary for 1791 : 
At the Red Lyon we gave the horses a bite of Hay - during their eating of which I discovered that one of those wch. drew the Baggage waggon was lame and apprd. otherwise much indisposed - had him bled and afterwards led to the Buck-tavern. . . . [and the day following]: The lame horse was brought on, and while on the Road apprd. to move tolerable well, but as soon as he stopped, discovered a stiffness in all his limbs, which indicated some painful disorder. I fear a Chest founder. My riding horse also appeared to be very unwell, his appetite had entirely failed him.

The self-imposed schedule Washington made for himself upon a trip explains much of the trouble he had with his horses. In fact, until the relatively recent combination of good automobiles and good roads, his schedule would not have been an easy one to follow by car. At the age of 59 on a journey from Augusta to Columbia (Georgia) in 1791 (today a distance of 74 miles via U.S. Route 1), Washington travelled a distance of 49 miles on May 21, and 48 the following day-21 miles of which were made before Sunday breakfast. This day he wrote:

The whole Road from Augusta to Columbia is a pine barren of the worst sort, being hilly as well as poor. This circumstance added to the distance, length of the stages. want of water and heat of the day, foundered one of my horses very badly.

At Columbia on the twenty-fourth he added: "The condition of my foundered horse obliged me to remain at this place, contrary to my intention, this day also." On the twenty-fifth he resumed his trip: "the foundered horse being led slowly on," and on the thirtieth: "This day I foundered another of my horses." And on another trip in 1795 a horse overcome with heat was led for a day, following which, "My sick horse died."

\section{Eminent Agriculturalist}

On agricultural matters, Washington may be considered one of the first experimentalists in America, and he conducted his farming enterprises at Mount Vernon in a manner quite unknown to the great majority. His philosophy is summed up in a letter to Arthur Young, editor of the Annals of Husbandry:

The System of Agriculture (if the epithet can be applied to it), which is in use in this part of the United States, is as unproductive to the practitioners as is ruinous to the landholders. Yet it is pertinaciously adhered to. To forsake it; to pursue a course of husbandry which is altogether different and new to the gazing multitude, ever averse to novelty in matters of this sort, and much attached to their old customs, requires resolution: and without a good practical guide, may be dangerous; because, of the many volumes which have been written on this subject, few of them are founded on experimental knowledge, are verbose, contradictory, and bewildering.

With regard to experimental animal husbandry, Washington is best known for having introduced the breeding of mules. While at least a few mules had been brought over from Europe, apparently no serious attempts to breed them here had been made. Writing to a shipowner friend in 1784 , Washington requested him to secure a good Spanish jack: "whose abilities for getting Colts can be ensured." Washington expressed concern over a story he had heard that jacks exported from Spain:

very frequently have their generative parts so injured by squeezing, as to render them unfit for the purpose of begetting Colts, as castration would, when from a superficial view no imperfection appears. Whether the latter is founded in truth, or mere report, I do not vouch for; but as I would have a good Jack or none, I am induced to mention the circumstances.

It was the custom in Spain to crush the testicles of jacks considered unfit for breeding, and apparently there was some suspicion that the same was done to those exported to prevent other countries from obtaining foundation stock from their justly famed breed.

\section{Royal Gift}

Pursuant to Washington's request, a jack fulfilling his requirements was secured, but delivery was refused because of the exhorbitant price. The following year two jacks were sent to Washington as a gift from the King of Spain; one was lost in a storm at 
sea, the other arrived after a hazardous journey from New York and was named Royal Gift. Four months after arrival Washington wrote his brother that Royal Gift, "seems too full of Royalty, to have anything to do with a plebean race; perhaps his Stomach may come to him, if not, I shall wish he had never come from his Most Catholic Majesty's Stables." In 1786 Washington received a gift of a jack and two jennets from the Marquis de Lafayette. The jacks were used extensively at home and about the countryside, but the mulebreeding business was not without its pitfalls. In 1788 Washington mentions that many foals were lost by abortion, which he attributed to scanty feed as a result of a poor crop year.

That the loss of his foals may have been due to contagious abortion, however, is indicated by frequent reports of losses. But this disease had not been recognized as an entity at this time; thus it is not unusual to find the losses attributed to a variety of causes. In 1793 Washington had no doubt that excessive riding at night was:

the primary cause of my loosing a number of horses; the poverty of others, and the slinking of foals which happens so frequently that I make a miserable hand of breeding Mules.

Later he states: "almost all the Mares had slunk their foals." Nor were animals immune from various other troubles; in 1797 he lamented:

I am unlucky in the loss of Mules; not less than five or Six within two, or at most three years, have died by violent means. . . . [And earlier]: I believe no man is more unlucky in the deaths, or in the accidents to Horses than I am; for I am continually loosing them by one means or another.

\section{Suffering Sheep}

Sheep, which Washington considered "that part of my stock in which I most delight," also suffered, primarily as a result of his enforced absenteeism from Mount Vernon. This Washington well knew, for he stated in 1798:
My Stock of all sorts has been much neglected during my eight years residence from home, and will take more time than in the usual course of Nature will be allowed me, to improve them much.

His sheep, however, had been subject to various troubles over a long period. In 1772 he wrote the Reverend Jonathan Boucher:

I find upon enquiry that, it will not be in my power to supply you and Mr. Calvert with the Weathers you want; the Rot, or some other distemper among my sheep swept off near an Hundred, in the Space of a Month, this Spring for me.

During the war years his stock deteriorated greatly, but Washington had little time to devote to his farming operations, and only one reference, to the possibility of distemper in his cattle in 1778, appears in his writings. During his tenure as President, much of his contact with Mount Vernon had to be by correspondence.

In November, 1793, Washington wrote his overseer:

I am sorry to find that scarcely any report comes to hand without mentioning the death of several Sheep. If the Overseers begin thus early to report deaths, what may I not expect to receive between this and May?... [and later]: Let $\mathrm{Mr}$. Crow know, that I view with a very evil eye the frequent reports made by him of Sheep dying. When they are destroyed by Dogs it is more to be regretted than avoided perhaps, but frequent natural deaths is a very strong evidence to my mind of the want of care, or something worse.

To counteract this evil, Washington requested reports on every lamb dropped, and on: "every one that dies; that I may be able to form a just opinion of the care and attention they pay to this business." And in 1794:

As I am constantly loosing Sheep I wish, this year, you would cull them closer. The flock would be benefitted thereby, whilst I might get something for the refuse; instead of the frequent reports of their deaths.

To his overseer again in 1797, Washington wrote: 
I hope, at your last shearing, there was a complete cull, separation of all the old, scabby and disordered Sheep. I do not know how to account for the weekly loss you sustain, in this species of Stock, unless it be by keeping such poor and diseased sheep in the flocks as to contaminate others.

Thus, although he was not notably successful in achieving the desired results, Washington recognized the necessary steps to be taken to reduce his losses: adequate records, culling of poor animals likely to become diseased, and avoidance of contagion by removal of those suffering from disease.

\section{War Horses}

During the Revolutionary War fewer horses than might be supposed were used in combat. Those officers who had private mounts usually had to provide them for themselves, and frequently forage was too scarce to support even those horses which were required to haul provisions. Thus in 1776 Washington wrote to Colonel Thomas Seymour:

There is not more forage on hand or to be had than is absolutely necessary for the Use of our Working and Artillery Horses, and ... it is my desire your Men may be halted some way in the Rear of this place, and their Horses sent back, otherways the Men can only be a stop and a check to the service, as they cannot act as Horse Men in case of Action, or if they could forage would not be found to support them.

This scarcity of forage was equally a disadvantage to the British; in 1777 Washington wrote:

The Enemy's want of Forage compells them to send out very large Parties to secure it, those are always beat in, with some Loss. Their draft and Artillery horses die fast; and now that I have brought all the useful ones from their neighborhood I think they will meet with much difficulty in advancing.

Want of forage was not the only trouble. Despite a series of orders directing proper shoeing, feeding and usage of horses, mismanagement appears to have been the rule. Military horses were used for nonmilitary purposes, and were misused in the service. In 1777 Washington issued a general order:

The Horses belonging to the Artillery are not to be used under any pretence whatsoever, but for the purpose for which they are designed. ... The commanding Officer of Artillery is to take care that their horses Shoes are kept in good order.

And in a letter to Major General Thomas Mifflin: "It is more than probable that, in the course of service, many horses will be so worn down as to render it beneficial to the public to have them sold. On one occasion General Putnam reported the death of 25 artillery horses from bad usage and the expected death of more.

Despite a continual shortage of wagon horses, the teamsters used them badly, riding them hard when they were not in draft, which caused Washington to issue a general order: "to the Quarter-Masters and Waggon-Masters, to give strict orders against such practices in future." And later:

The Commander in Chief has reason to believe, that it has been owing to the carelessness and inattention of the waggon-masters, in not seeing the horses properly fed and managed, that such great numbers of them have foundered and died.

Of the unavoidable hardships at Valley Forge, Washington wrote that by comparison with the suffering of his men "could the poor Horses tell their tale, it would be in a strain still more lamentable, as numbers have actually died from pure want."

\section{Revolutionary Farriers}

Of particular importance in the history of military veterinary medicine is the littleknown fact that official provisions were made for including farriers in cavalry troops during the Revolutionary War. Merillat and Campbell state: "Available records do not show any veterinary surgeon as being on duty with the military forces of the United States during the Revolutionary War." Moreover: 
The first provision made for mounted troops was by Act of Congress, March 5, 1792, which provided for the organization of one squadron of light dragoons of four troops. For each troop was authorized one farrier.

This is usually considered the beginning of our military veterinary arm.

As Commander-in-Chief of the Continental Army, however, the decisions of Washington were as binding at the time as the acts of the Congress were later. On December 16, 1776, Washington appointed Colonel Elisha Sheldon commandant of the Connecticut Regiment of Horse, and directed:

Your Regiment is to consist of One Major, an Adjutant, Surgeon and Mate, and Six Troops; to each Troop, One Captain, One Lieutenant, One Cornet, One Qr. Master, two Sergeants, two Corporals, One Trumpeter, One Farrier, and thirty four privates.

And in 1777 Washington directed the formation of "a Company of Artificers enlisted during the War, to be attached to the Artillery in the Field." This company of sixty men skilled in various crafts included a master blacksmith and 15 smiths, and two farriers. The number of smiths would suggest that horseshoeing was to be in their province (as it was at Mount Vernon), and that the farriers were to be employed more as veterinary practitioners. However, in the recommendations drawn up by Washington in 1798 for reorganization of the Army, he suggested one blacksmith per troop of dragoons, but made no mention of a farrier - already provided for by Act of Congress in 1792.

As evidence that farriers actually served during the Revolution, in a communication to the Pennsylvania Board of War in 1777, Washington mentions one Joseph Fox, identified as a Light Horse farrier. In regard to a Mr. Hughes, suspected of being connected with spying activities, Washington wrote, "I shall enquire into his political Conduct for some time past, and if I find the least Grounds for a belief, that Fox's testimony is true, I shall have him apprehended."
That other veterinary practitioners served in the Revolutionary War is indicated by a correspondent to the American Farmer in 1830, who in offering a remedy for bots in horses, states that it is one he has used, "for more than half a century with invariable success." The remedy, consisting of a drench of milk, salt water, and linseed oil, is of less interest than its source. He says:

I received it from a German veterinarian, who came to this country with the Baron Steuben, and was attached, as farrier, to the general staff of the main army, in the years 1778 and 9 . He may be remembered by some of the military gentlemen of that day, under the dignified appellation of Count Saxe, a nom de guerre, given him by the Baron, on his entering our service. He was a man of great skill and celebrity in his profession.

Of even greater interest from the standpoint of military veterinary medicine is Washington's attention to food hygiene, considered in an earlier section.

It is evident that Washington's passion for detail extended to matters which would today be considered in the veterinary domain. There is no inference, however, from his writings that he gave any overt thought to these matters as being the concern of anyone other than a good farmer or a military commander. The concept of a veterinary profession was unthought of in America during Washington's lifetime; nor can it be considered that he was particularly obsessed with problems of a veterinary nature. The selections quoted represent a large part of all his thoughts on these matters, gleaned from nearly 20,000 pages of his writings. What is important is that collectively these form the most extensive body of first-hand observations on veterinary matters made by any American prior to 1800 , and as such they represent an invaluable addition to the fragmentary history of colonial veterinary medicine.

\section{THOMAS JEFFERSON, GOOD SHEPHERD}

Jefferson's writings on animal disease extend beyond the eighteenth century, but are considered here because they form a 
natural sequel to those of Washington. Like Washington, Thomas Jefferson was a good farmer, and showed much interest in the welfare of his livestock. And like Washington, he appears to have been more interested in his sheep than other species, if the volume of his writings on this subject is any criterion. This, in part at least, may have been generated by the tidal wave of interest in the Merino sheep, which had been introduced from France early in the nineteenth century. The "Merino fever" resulted in fabulous prices being paid for foundation stock, rams frequently bringing a thousand dollars or more. But like other financial schemes, this bubble broke - for some sooner than might have been surmised.

In 1810 Jefferson wrote to a Joseph Dougherty:

I am confident that sheep will be found to be profitable as soon as you can get a proper stock. The late importation of Merinos will of course reduce the extravagant prices at first given; but they will steadily maintain a price of good profit.

\section{But only two years later, he again wrote:}

the Merino fever has so entirely subsided in this part of the country that the farmers now will not accept of them, because they produce less wool \& less suitable for the coarse manufactures they want, than the sheep they possess, and there is no market for the wool in this state.

One reason for sheep being unprofitable at this time appears to have been the introduction of scab, and much of Jefferson's correspondence relating to his sheep during 1811-1812 concerns this problem. In March of 1811 he wrote George Jefferson:

The two last Merino ewes have brought the scab into my flock of sheep, which is now generally infected with it. The oil of turpentine is the principal ingredient in the remedy for it, but it would take more than our apothecaries could furnish here, and at their exhorbitant prices. Will you be so good as to send me a gallon.

To this, George Jefferson replied:
I really am beginning to apprehend that the introduction of Merino sheep into the Country may prove more injurious than beneficial, as I understand they have communicated the scab to the flock of almost every person who has them. There is danger I suppose of its spreading as other diseases have done, so as never to be eradicated.

Mr. Graham of this place [Richmond] informs me that he thinks he has lately cured it in his Merinos by steeping one pound of Tobacco in a gallon of boiling water, \& rubbing the parts affected well, as soon as it cooled. As this remedy must be perfectly innocent (except perhaps with pregnant ewes) would it not be well to make the experiment.

Jefferson mentions that he had lost several sheep from scab, and had:

tried mercurial ointment with no effect. Repeated annointings with brimstone \& fat have eradicated it, except in a single subject, now separated. . . The falling off of the wool and scabs in it's place is the indication, \& the ointment immediately rubbed in effects the cure at once.

\section{One of his correspondents suggested:}

$\Lambda$ strong decoction of Tobacco mixed with some soft soap, \& rubbed on them, I think the best mode of killing or curing the Scab: better even than mercurial ointment. Livingston gives a Receipt for it in his Book on sheep.

The book referred to is An Essay on Sheep, by R. R. Livingston, the American minister to France. First published in London in 1809, and here in 1810, Livingston's work was instrumental in popularizing the fine-wooled Merino which had been introduced in the United States by Livingston in 1802. While his work presumably deals with sheep and their diseases in America, the section on disease presents nothing new, being taken entirely from older English works. It would, perhaps, be too much to expect an original veterinary work from the hands of a statesman; how the net effect of his book must be accounted is open to speculation. It undoubtedly awakened a new interest in sheep, but by presenting an overly enthusiastic picture of the value of the Merino, it was the undoing of many who became infected with the "Merino fever." 


\section{Lunatics in Love}

Jefferson himself appears to have been only mildly affected, for he mentions that he had only one ram and three ewes, one of which died of scab. The other two, he complains mildly: "for two years have brought me only ram lambs, so that I remain still with only 2 ewes." Hearing of this, a William Thornton wrote from Washington:

I am sorry you have not been more fortunate in raising Merinos. I informed Judge Cranch, that, if the Ram be put to the Ewes in the increase of the moon, the Lambs would be more generally males, if in the decrease females. $\mathrm{He}$ tried this with our joint flock of common Ewes, amounting to about $400: .$. . by which he found my statement right in the proportion of 4 to $5 \ldots$ \& this appears to be more the case in other Animals. . . This if true generally, would tend to prove that all animals are lunatics in love.

Jefferson gives no indication as to his concern, or lack of same, over this "lunacy," but he was concerned over other problems of breeding.

Something of an experimentalist like Washington, he had imported a pair of African broad-tailed sheep, which he seems to have preferred for table purposes. He had found, however, "the ewe would never breed, her massive tail never admitting the commerce of the ram." He had, therefore, instituted a program of inbreeding with the ram, and found the same trouble with the ewes when they carried $7 / 8$ of the original blood. To get around this obstacle:
I had the tails of my young Ewes cut off, and only lost one, which I am confident was by inattention after the operation. I directed them to be laid on their Backs, and the skin of the tail being clipped toward the root, the tail resting on a Block a broad and sharp axe was applied near the root of the tail and by a stroke of a mallet the tail severed at one blow, the skin was then drawn over the stump \& sewed to the other on the upper sides, so as to protect the stump, \& leave the parts exposed, and thus they are prepared for any cross. This being done in cool weather subjects the animals to very little if any risk.

In addition to the physical obstacle presented by the broad tail, Jefferson states: "A Merino I suppose would be alarmed at such an unnatural mass."

Jefferson's mention of the diseases of other animals is only incidental. On one occasion a horse "became all but blind in both eyes. After about 10 days or a fortnight however they mended, and tho' they are still weak, yet he sees pretty well again." And another horse:

has been occasionally subject to a spasmodic affection like the Thumps which I once thought alarming but am now induced to believe that it is nothing more than Hickup, as it always succeeds a hearty meal or draught of water.

It is evident that Jefferson is describing periodic ophthalmia and heaves. Jefferson's thoughts on the dog problem are discussed elsewhere, as are his legislative efforts to prevent the spread of "Infection of the Horned Cattle." 


\section{The First Friends of Veterinary Medicine}

IN CONSIDERING THE SOURCES of information on animal disease prior to 1800 , it is evident that these were at best intermittent, desultory, or merely incidental. In the absence of a regular medium for the reporting of disease-animal or human - this is not so surprising as it is unfortunate. The reports of travellers, undoubtedly honest souls at heart, frequently are colored by imagination, or distorted by inadequate observation. Most of the books on veterinary subjects were either frank British reprints, or "tainted" by British thinking in the sense that they did not reflect the actual situation in America. And while some altruism can be ascribed to the authors of native works, none are entirely devoid of commercialism. No single writer, George Washington excepted, produced any substantial volume of first-hand observations on animal disease and related matters, and it must be accepted as fact that he did not give overt thought to veterinary medicine per se as a necessity in the expanding economy of the New World.

Credit for the first recognition of veterinary medicine as an essential force in America, and for the first conscientious reporting of animal disease, must go to the Philadelphia Society for Promoting Agriculture. This group, which numbered among its membership such luminaries as Washington, Franklin, Noah Webster, and Benjamin Rush, was founded in 1785 , but it is not until the publication of the first volume of its Memoirs in 1808 that we have any record of its advocacy of veterinary medicine. It is significant that practically all of the pioneer advocates of veterinary medicine in America were members of, or associated with, the Society. In particular, three of its members, Judge Richard Peters, and the physicians, Benjamin Rush and James Mease, can be accounted the first staunch friends of the yet unborn veterinary profession. The contributions of each of these men, therefore, will bear examination at some length.

\section{RICHARD PETERS, JUDGE}

Richard Peters, a prominent patriot, lawyer, and country gentleman, was the first public figure to call for the establishment of a veterinary profession in America. In 1805 he became president of the Philadelphia Society for Promoting Agriculture, and a year later was responsible for the Society offering a gold medal:

for the best essay and plan, for promoting veterinary knowledge and instruction, both scientifically and practically, under the circumstances of our country. . . . Aid to schools and establishments for this, among other agricultural purposes, ought to be given by the national and state legislatures. . . . Animals are abandoned, when diseased, to all the calamities attended on ignorance of their maladies, or cure. Pretenders and empirics, of the most contemptable character, prey on the necessities 
and credulity of those who are compelled to apply to them on this subject. . . . If it [veterinary medicine] has held an inferior rank in the classification of science and knowledge, it is entirely owing to the unmerited neglect with which it has been unaccountably treated. It is time it should be rescued from obscurity, and placed among the most commendable and necessary branches of medical education.

How much earlier he had this interest is suggested by his statement in 1807 , at the age of 37 :

For a great portion of my life, I have occasionally endeavored to prevail on professional men, to assist the business of agriculture, by devoting part of their time and talents to veterinary subjects. It is truly unfortunate, that veterinary knowledge is so rare, and so little valued by medical characters, that necessity compels, and accident alone favours experiments, in the hands of those, who have no assistance from professional attainments.

Until Benjamin Rush responded to the Society proposal, Peters commented, concerning his own efforts:

I have never succeeded. ... Whatever may be thought by others, of this first compliance [by Rush], with my long continued endeavours, I deem it the cornerstone of some future valuable building.

Rush's lecture delivered before the Society in 1807, calling for medical men to pay more attention to veterinary medicine, however, evoked no immediate response. Commenting on a paper on sheep diseases by a Dr. Petrikin in 1811 , Peters noted:

until this communication we have had no instance of the good effect produced on medical men, by the important example set in that lecture. So our domestic animals are either, from necessity placed in the hands of ignorant and fraudulent quacks, and low pretenders to veterinary knowledge, or abandoned to their fate. The latter is in most cases, the safest alternative.

\section{Hoven Cattle}

Peters himself, however, did not sit idly by, expecting others to provide the material he called for. In fact, in addition to being a pillar of the Philadelphia Society, he may be considered the first substantial contributor of first-hand observations on veterinary matters. In 1805 he read a paper "On Hoven Cattle," in which he attributed the recent increase of this ailment to the replacement of "worn out and sterile" pastures with clover. The latter, he considered good for agriculture, but when hungry cows are turned into lush pastures, it is "most productive of this disease." After recognizing the symptoms, Peters directs:

Immediately stab the animal, on the left side, between the hind rib and the hip bone ... be not nice as to this. The disease will certainly be mortal, unless instantly relieved, therefore think not any remedy too daring. ... I can vouch on my own experience, for the efficacy and little danger of the operation. Let nature cure the wound.

Other remedies he suggests include: forcible withdrawal of the tongue: "raking the beast . . . often practised by farriers"; and drenching with oil or salt water. He warns:

Some will suppose the beast poisoned . . . some, astonished at the suddenness, hideous symptoms and rapid progress of the malady, will pronounce, very gravely, that it is the effect of madness, or secret mischief and witchcraft. However absurd they may appear to persons of intelligence, I have been present when such causes have been seriously assigned. . . . The knife is the surest remedy for, and antidote against, this imaginary poison. It instantaneously dissolves the fancied spells of the ideal practitioner in witchcraft. It banishes from the brains of those who prove themselves no conjurors, all apprehensions on this score; more decidedly and promptly than even the old horse shoe, nailed on the door sill.

A case of "croup" in a calf in 1812 gave Peters the occasion to extol the virtues of post-mortem examination - something for which his treatment, if carried on extensively, would provide ample subjects. Peters relates:

I had the calf copiously bled; and directed castor oil to be thrown down the throat, through the neck of a bottle; after opening the passage of the windpipe with a flexible twig. . . I It finally died, by suffocation, in a spasmodic, or convulsion, fit. ... I had it dissected (not very neatly) by my old farmer ... a sort of ill digested greyish pus, filled up the passage. 


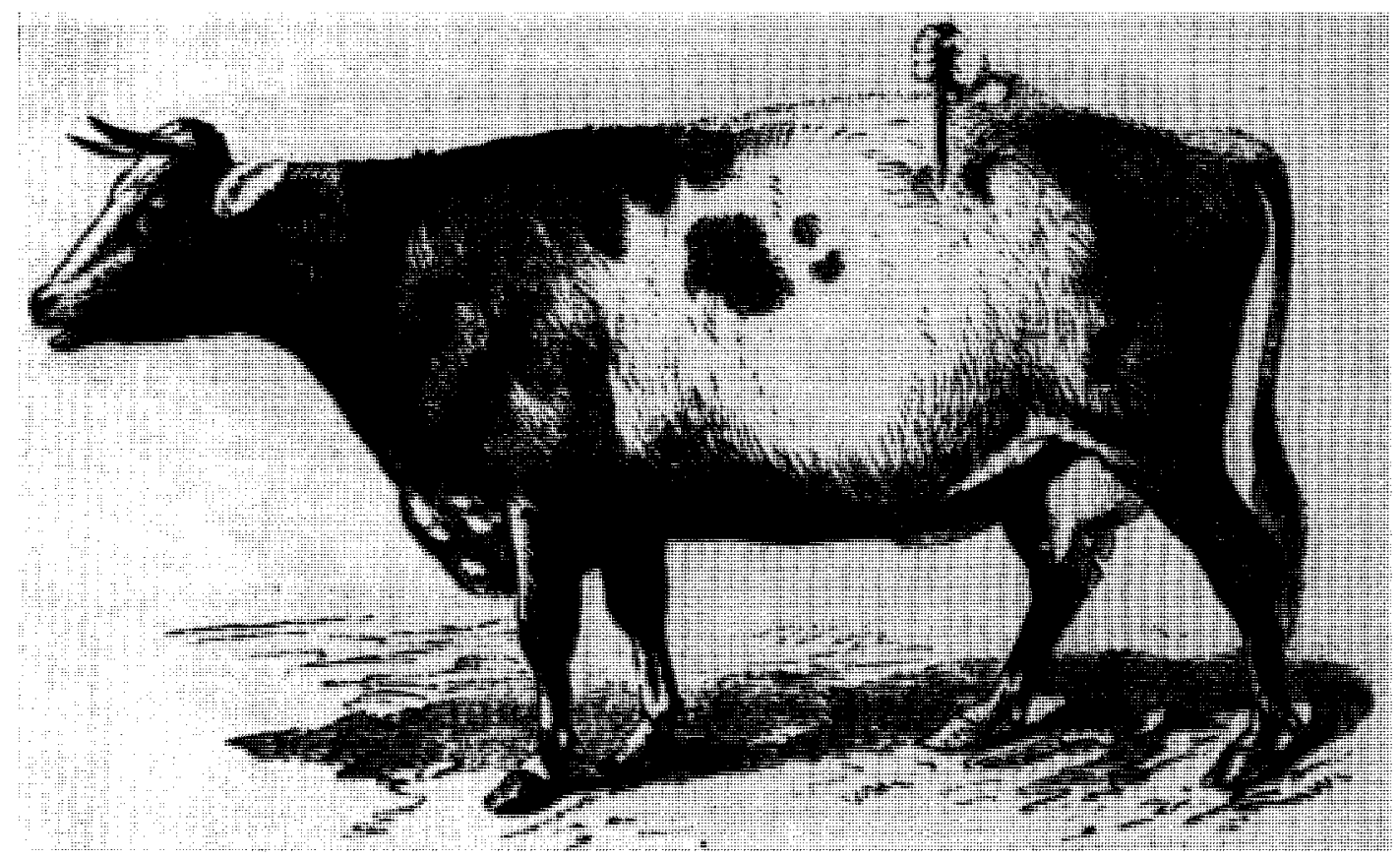

The trocar was recommended for bloat (hoven) in cattle as early as 1805 by the prominent agriculturalist and Philadelphia judge, Richard Peters, who also was the first proponent of veterinary education in America. American Agriculturalist

On the subject of post-mortem examination, Peters urges:

Every fact relating to accidents or diseases of our stock, is interesting, in the present dearth of veterinary information. Those who neglect to attend to such facts, deeming them trifling and unimportant, are either culpably careless, or reprehensibly fastidious. Let every farmer and owner of stock, inform of any uncommon occurrences or diseases in domestic animals, happening under his observation; and a body of facts and information will be accumulated, which may, by men of medical science, and intelligence on such subjects, be turned to the greatest advantage. It has always been my habit to cause to be opened, and examined, every beast which could furnish instruction, for my own, or the benefit of others, when, on my farms, the animal had died by disease, or accident. Every farmer should follow this prac. tice; and note the appearances, or probable causes, occasioning, or supposed to have produced, the loss of the animal. A knowledge of disease will point to remedies; and both himself and his neighbours may derive future advantages from his present misfortune.

\section{Haws in Horses}

In a paper "On the Haws, or Hooks, (so called) in Horses," in 1813, Peters blames much of his misfortunes with horses on: "a conceited driver of my carriage, who believed himself exclusively acquainted with the management of the affairs of the stable." This wretch:

stopped every crevice in the stable, through which air could be admitted; and fed unsparingly, contrary to my frequent injunctions. The consequences were, that several of my horses were seized with violent fevers, and particularly in morbid affections of the eyes. . . My servant knew, as he believed, effectual remedies. "My horses had the hooks," as the haws are vulgarly denominated. - "These must be cut out of the eyes."

But Peters, who earlier had had a horse ruined in this manner, would not permit the operation (excision of the third eyelid), and substituted bleeding and purging. Peters also mentions lampas, or congested 
palatal mucosa, for which "burning is usually practiced ... but I never suffer it to be done."

On the subject of servants, Peters blames himself for:

unusual remissness in frequent visits to my stables. Such negligence every owner of horses should cautiously avoid. True, we cannot control or command servants in this country; in which Saturnalia are celebrated every day in the year. Among the ancients, the servants were satisfied with one annual, but short, term of equality.

He mentions the exemplary conduct of George Washington, who:

commenced every day with a visit to his stables: in which he minutely examined and directed every necessary arrangement: and no person of his day knew better how to treat the horse.

In a paper "On Sheep-killing Dogs," read in 1810 , Peters urges:

We owe to the community, to be assistant in every way; and particularly to the execution of the laws on the subject. . . . Death is the only effectual remedy. . . . If numbers were lessened, those retained would be well fed; and few or none compelled to wander in search of prey. ... It should be made disgraceful and uncivic . . [to] keep supernumerary, worthless, or starved dogs.

Commenting on the recently enacted Pennsylvania dog law, Peters says: "Our dog law is a good one." This imposed a light tax on one dog, but increasingly heavier assessments on additional dogs kept by one owner as "a check on the unreasonable multiplication of the numbers of dogs." Owners of dogs which had killed sheep were required to kill the dog, and indemnity was paid the owner of the sheep from the tax funds in proportion to the value of the sheep.

\section{Yellow Water}

From the veterinary standpoint, the contribution of Peters that merits him lasting recognition is his article: "On the Yellow Water of Horses," read before the Philadelphia Society in 1807. Peters had lost three of four horses affected with the disease in 1799; the constitution of the fourth horse "vanquished both his disease, and the remedies," and was living 20 years later. Although he admits: "I am not scientifically informed," he is satisfied that a "violent remedy must be pursued." This included bleeding - a gallon at first, and half a gallon daily for several days " Few know the great quantity of blood, a tolerable sized horse can lose, without injury.") and strong purges. A drench of three or four ounces of nitre daily, injections of snake root and peach leaves, with shad pickle, salt, soap, and molasses in various combinations, brewers yeast, rowelling, blistering, and back-raking "are very efficacious."

A friend who had used "immediate and plentiful bleeding and nitre," had lost none, "though the horses, very generally, through the neighboring country, died of this disease. He took, at various times, from 6 to 8 gallons of blood from an horse." And while it is evident that Peters is convinced of the utility of copious bloodletting, he says:

I shall not enter the lists, for or against plentiful blood letting. The lancet is held by some, in human subjects, to be the magick wand of Hygaeia; and by others, the minister of death. So may they deem the fleam, applied to horses.

On the matter of contagion, in which he notes disagreements of opinion, he says: "The wisest course, is not to risque a well horse, among the sick."

On symptoms, which he says he cannot accurately describe, Peters is quite precise: these include dullness of the eyes, with the whites being jaundiced; pendant ears; tail projected horizontally; inclination, but incapacity to eat or to stool; flanks tucked and hollow; frequent shivering; and high fever, as indicated by a pulse rate above 45 - the pulse was neglected by most farriers. Also: "The hind legs are stiff, and straddling wide; but finally all the limbs fail," whereupon the horse writhes in circles on the ground: "hence some country people call the disorder 'the circles.' " Only the livers were seen to be affected: 


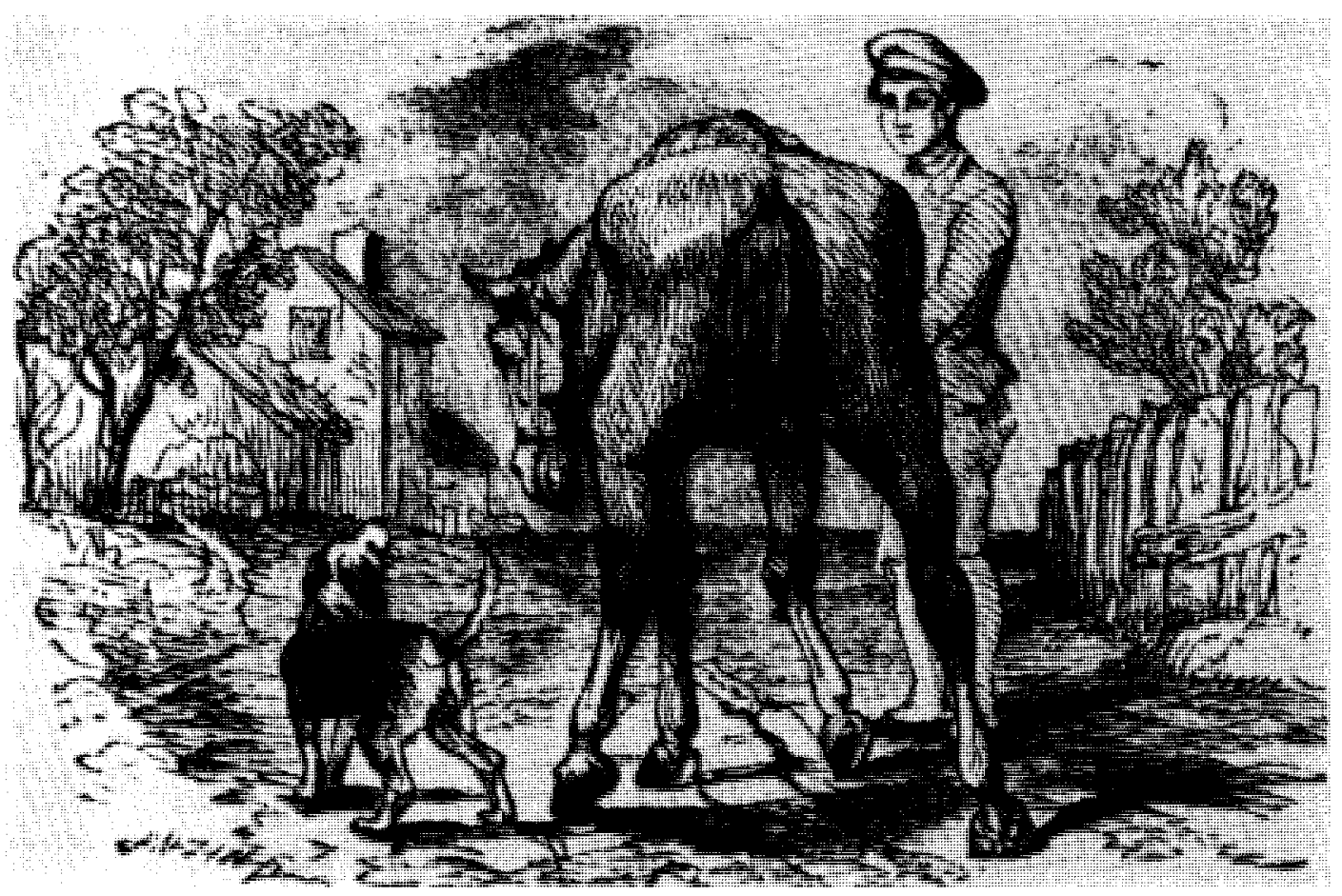

Urinary problems were common - or at least frequently diagnosed - throughout the nineteenth century, "yellow water" of horses being a common complaint during the first decade. The straddling posture was considered an unfailing diagnostic sign. Manning: Stock Doctor

parts of the liver were hard and scirrhous... dry and friable. ... The disease appears to be an highly malignant bilious fever. The secretion of the bile is obstructed by the morbid state of the liver and the gall is retained in the blood: and thus tinging that and the urine, possibly gave the name to the disease, of the yellow water.

Peters continues with full details of feeding, and notes that "exercise excited the lurking disease." The disease, he feels, is much the same as the yellows, or jaundice, described in British works. He states:

It is an hepatic affection; and as a farrier who attended my anatomical theatre, and had opened many horses with this disease, called it the "liver disorder" for want of a more appropriate term.

More or less in summary, he suggests:

At any rate, this almost resistless destroyer, should add to our motives for using more oxen, and fewer horses, on our farms.

This disease apparently was diagnosed frequently toward the end of the eight- eenth century and later, for a Dr. F. B. Sayre, in the Medical Repository for 1800 , entitles a communication: "Observations of the Disease Commonly Called YellowWater in Horses." According to Sayre, the disease was first seen in New Jersey in 1793, and was characterized by loss of appetite, highly colored urine, and swellings about the throat. It was believed to be contagious: "Therefore, the farmers assiduously separated the disordered from the sound." The common treatment-bleeding and purging - Sayre considers to have been inadequate, and rowelling to be of no significance. In his own experience he effected cures by bleeding to faintness and using strong calomel purges.

\section{Peters' Legacy}

Peters' account is of considerable interest from several standpoints. It is perhaps the first full description of any animal disease in America; and in all too many in- 
stances for another century or more emphasis was upon treatment alone-especially in those cases which terminated successfully. The treatment administered by Peters can be considered only as reflecting contemporary thinking - or lack thereof upon the subject of animal disease. He at least admits: "The remedies are by no means well ascertained," and, "I have no theory to establish." He displays to perfection the enlightened interest of the landed gentry in the welfare of animals, and was among the first few to consistently call for greater attention to veterinary matters. Not only did he have relatively complete necropsies made, but evidently a number of farriers also did this as a matter of course. At this time there were no graduate veterinarians in America, the first having come to these shores in 1800 .

Peters again pleads for greater attention to veterinary medicine in his eulogy on the horse:

It is to be earnestly wished, that intelligent medical characters here, would turn their attention to the disease of that noble animal, the horse - The companion, the faithful servant, and friend to man, - he deserves our grateful attention, and care. He shares and lessens our toils, promotes our health, administers to our comforts and amusements, fights with us our battles, and contributes largely to our wealth and prosperity.

Peters' final plea appears in his comments on an article in the final volume of the Memoirs of the Philadelphia Society (1826), on the death of a horse from worms:

This and a thousand other misfortunes occurring to our domestic animals, loudly impress the indispensable usefulness of veterinary knowledge. . . Many years have passed away since our Society, and myself individually, have warmly and feelingly recommended a veterinary institution, and that it should be part of the education of medical men, to know how to treat the diseases of the animals composing our stock. Let this part of the acquirements necessary for those who practice in the country, be rescued from the low state in which it now is; by being made essential to the education of medical men; and countless advantages will accrue to our farmers and breeders of stock. It is vain to raise valuable animals, without ensur- ing, (so far as human means can accomplish it,) their safety, when attacked by diseases, or injured by accidents too frequently occurring; and often fatal through the want of skill in their treatment.

Peters' advocacy of veterinary medicine did have palpable results, if only in the contributions of Benjamin Rush and James Mease. The continuity of the work of this triumvirate, however, ceased with the suspension of the Society Memoirs in 1826, and none of the three lived to see their aspirations materialize. How much impact Peters may have had beyond his intimate circle is perhaps a moot question, but his writings leave no doubts about the merits of the claim of his being the first friend of the veterinary profession in America.

\section{BENJAMIN RUSH, PHYSICIAN}

Even a casual study of the life and work of Benjamin Rush reveals hardly a facet of colonial and post-Revolutionary culture in which he did not demonstrate some interest. Among his manifold medical interests was his advocacy of veterinary education, a sidelight of his rich life which has received only the briefest notice by medical historians. In urging the study of the diseases of domestic animals by medical students and physicians, Goodman, his biographer, credits Rush with being "the earliest proponent of the study of veterinary science in America." It is obvious, however, that this writer was unaware of the endeavors of Richard Peters. Rush's principal veterinary contribution was his response to the request of the Philadelphia Society for a "Veterinary Essay and Plan." While Rush is something of a controversial figure with regard to his contributions to medicine, there need be no doubt that his advocacy of veterinary medicine can be taken at face value.

Colonial America had its physicians, and had asserted its independence in medical education by the establishment of the Medical School of the College of Philadelphia in 1765. Despite the interruptions of war, several additional schools of medicine had been founded to 1800 . Beginning with scattered contributions in the eighteenth 
century, an impending voluminous medical literature found its fountainhead in the Medical Repository in 1797. A number of colonial physicians already had become world figures in medicine. Colonial America early recognized its need for physicians, and, whether graduate or nongraduate, the doctor was an important man in the New World.

In Europe, it is understandable that veterinary medicine should have been a subject beneath the notice of the average physician or surgeon. While veterinary and human medicine had flourished side by side in ancient times, the separation between the two disciplines had become absolute during the twilight of the Byzantine era. With animal medicine securely in the rough-and-ready hands of the farrier and cow-leech, there was little left of the once fundamental identity of veterinary and human medicine. In America however, many rural physicians forgot their hereditary antipathy for animal medicine and treated animals and man without discrimination. Undoubtedly many of them came to grips with the unescapable fact that a medical education did not always supply them with the necessary weapons for this guerilla warfare. What is remarkable is the number of eminent physicians, foremost among them Benjamin Rush, who recognized the need for veterinary education at a time when livestock owners did not see beyond the confines of their own barnyards and pastures. Undoubtedly there were occasions when they lamented the lack of qualified medical care for their stock, but none had raised the issue of how this problem should be met.

In compliance with the request of the Philadelphia Society, on November 2, 1807, Rush addressed the medical students of the University of Pennsylvania upon: "The Duty and Advantages of Studying the Diseases of Domestic Animals, and the Remedies Proper to Remove them." It is perhaps more than a little significant that Rush expected veterinary medicine to develop at first along with human medical study. While he did "lament the want of a veterinary institution in this country," he apparently acted in accordance with the desires of the Society for a "practical" approach to the problem by urging medical students to study the diseases of domestic animals, for:

In vain will be the efforts of public bodies and private individuals to disseminate veterinary knowledge in our country, without a provision for regular and oral instruction upon it.

\section{A Veterinary Chair}

Rush apparently did envision the establishment of a veterinary curriculum as such, for he adds:

From the public spirit of the trustees of our University, and particularly from their disposition to promote every branch of science connected with medicine, there is reason to believe, that it is only necessary to lay before them the advantages of a veterinary chair, in order to insure its establishment. . . .

I have lived to see the medical school of Philadelphia emerge from small beginnings, and gradually advance to its present flourishing condition; but $I$ am not yet satisfied with its prosperity and fame, nor shall $I$ be so, until I see the veterinary science taught in our university.

The University of Pennsylvania did establish a school of veterinary medicine, but not until 1884, 71 years after the death of Rush. In keeping with the tradition Rush might have wished to father, the school was established largely through the efforts of a lineal descendent, the eminent Philadelphia physician, Rush Shippen Huidekoper, who became its first dean.

While Rush also foresaw the possibility that veterinary medicine might develop in conjunction with agricultural education, and not without profit to both, it is in some respects unfortunate this did become the pattern for the development of most of our veterinary schools. Beginning as veterinary science departments of agricultural colleges, and designed to render a necessary service to agricultural interests, most of our veterinary schools had to evolve without the guidance of experienced medical edu- 
cators and the salutary stimulus of a medical climate. Rush states:

Should the subject of the diseases of domestic animals be connected with instruction upon the principles of agriculture ... it would form a still more useful branch of education, not only for physicians, but for private gentlemen.

Although his "veterinary" lecture is not included in his Selected Writings, nor does it appear as such in an extensive bibliography of his works, Rush did include it in a volume of Introductory Lectures published in 1811, and it appears in the form of fragmentary lecture notes in his Autobiography. It would, therefore, be unjust to conclude that he had stepped outside his sphere, if that were possible, in complying with the request of the Philadelphia Society. While he mentions this request "being impressed upon me with peculiar force by the enlightened and patriotic president of that society, that I was led to select the interesting subject of our lecture," it seems most unlikely that his compliance was anything but one of sincere interest in the matter. Few men in any walk of life have before or since demonstrated so cosmopolitan and enlightened an interest in the affairs of man.

\section{The Science of Medicine}

That his convictions on the subject of veterinary medicine were not of a neoplastic nature is demonstrated in Rush's earlier writings. He had studied comparative anatomy at Edinburgh under Alexander Monro, Secundus, and in his "Lectures on Animal Life" in 1799, he had expounded upon the values which medicine might derive from the lower forms of animal life. Along the lines of his own philosophy, Rush stated in his "veterinary" lecture:

The science of medicine is related to everything. A mere physician, that is a plysician who knows nothing but the sciences which are supposed to belong exclusively to his profession, is a non-entity. To deserve that title in its extensive import, it is necessary for us to know something of the principles and practice of every art and pursuit of man.
That Rush understood the differences as well as the similarities of human and animal diseases is evident from his lengthy description of specific symptoms of certain animal maladies. An advantage in studying the diseases of animals is that:

the number of their diseases is more limited, and their symptoms are more obvious, for they are not multiplied, nor complicated by intemperance in eating or drinking, nor are they under the influence of passions which suspend or alter them, and in some instances, to prevent their evolutions. The seats of their diseases, moreover, are more perfectly known from the greater facility of dissecting and examining their bodies after death.

\section{Domestic Duties}

In keeping with the title of his lecture, Rush mentions the moral obligations as well as the practical advantages of a study of the diseases of animals. Thus he urges:

We are bound in the first place, to discharge the important duties to domestic animals which I have mentioned, by the relation that has been established between them and us by the author of nature. . . They live only for our benefit ... so that there is constantly due, to them, an immense balance of debt from us.... By studying the diseases of domestic animals, we may rescue them from the hands of quacks, who add, to the mischievous and unsuccessful efforts of nature, the evils of absurd, painful, and destructive remedies.

Concerning the practical advantages to be derived from a study of the diseases of clomestic animals, Rush says:

It is our duty and interest to attend in a more especial manner to the health of those domestic animals which constitute a part of our aliment, in order to prevent our contracting clisease by eating them. A few years ago, a farmer in New Hampshire, who had overworked a fat ox in the time of harvest, killed him and sent his flesh to market. Of four and twenty persons who ate it, fourteen died, and chiefly with diseases of the stomach and bowels.

Rush's statement in this regard appears to be the first public recognition, by an eminent American, of the interrelation of certain human and animal diseases which included a practical solution to the problem. 
In a sense, he anticipated a function of boards of health to which little thought, and less action, had been applied. It was not until 1884, when the Bureau of Animal Industry was established as an adjunct of the Department of Agriculture, that Rush's concept was ready for implementation upon a national basis.

Rush also urged the study of animal disease from a sense of duty to the nation and its citizens, saying:

The products of agriculture and commerce are often lessened by a fatal epidemic, brought on by diseases which blast the character of animal provisions; and many poor families have been left to suffer all the evils of penury and famine, by the death of a single horse, upon whose labor, of a cow upon whose milk, or of a hog upon whose flesh, they had relied exclusively for subsistence; all of whom perhaps perished by diseases that might have been cured.

A plague which killed large numbers of animals in a frontier community was a real calamity which stripped away the thin veneer of civilized comfort afforded by the work or food potential of the wealth represented by domestic animals.

In speaking to a group of medical students, it is logical that Rush should include a reference to the advantages accruing to medicine itself from a study of animal disease, a subject he had alluded to in his previous writings:

By extending our knowledge of the causes and cures of the diseases of domestic animals, we may add greatly to the certainty and usefulness of the profession of medicine, as far as it relates to the human species ... there is scarcely a form of disease mentioned in our systems of nosology, but what is to be met with in domestic animals. . . By acquiring this kind of knowledge, you will add to the resources of medicine as far as it relates to the human body and by disseminating it gratuitously in your neighborhood, you will become the benefactors of your country.

\section{Modus Operandi}

Rush adds:

For a while your knowledge in this branch of science, must be acquired by reading, observa- tion and experiments; for as yet no societies or schools have been established for cultivating, or teaching it in the United States.

Regarding such societies Rush states:

In st. Domingo [Dominican Republic], a society called the "Philadelphians," was established many years ago, consisting chiefly of physicians, whose principal business was to investigate and cure, what they called epizootic diseases, that is the diseases of domestic animals.

The society, however, had gone out of existence.

Rush concludes his lecture, saying:

I have then gentlemen, laid before you a brief detail of the obligations we owe to our domestic animals, and the reciprocal advantages to be derived from extending to them, the benefits of the science of medicine. In performing this task, I have endeavored to become the organ of speech for the dumb, and a suppliant for creatures that are unable to plead for themselves. Permit me to recommend the subject to your attention in your future studies. . . . Take care of the health of domestic animals.

What the impact of Rush's plea for the study of veterinary medicine may have been is perhaps too subtle to determine. Certainly nothing as concrete as his determination to see veterinary science taught in "our university" came about in his lifetime, nor for long years afterward. As influential as he was in the affairs of the university, and the nation as well, public opinion had been too long one of indifference to the necessity for veterinary education. On the other hand, Rush's address apparently did stimulate the thinking of leading agriculturalists. John Skinner, editor of the American Farmer, not only reprinted Rush's address, but made repeated pleas of his own for the establishment of veterinary schools. Like Rush, he advocated the inclusion of veterinary instruction in the medical curriculum until veterinary schools should come into being. In addition, he fostered the reprinting in America of the leading veterinary works of Britain. In 1846 an unacknowledged summary of Rush's address, in his own words, appeared in the American Agriculturalist. 
Rush's colleague, James Mease, delivered the first of "A Course of Lectures upon Comparative Anatomy and the Diseases of Domestic Animals" before the Philadelphia Society in 1813. Mease actually worked in the field of comparative pathology for some thirty years, and is noted for his pioneering work on Texas fever of cattle. Perhaps as an indirect result of the efforts of Rush and Mease, Robert Jennings, a student at the Pennsylvania Medical College of Philadelphia, delivered a series of veterinary lectures to his fellow students from 1846 to 1850. And in 1850 , with the aid of a group of medical men of Philadelphia, Jennings organized the short-lived Veterinary College of Philadelphia.

\section{JAMES MEASE, EPIDEMIOLOGIST}

One of the results of Rush's lecture appears to have been: "A Course of Lectures upon the Comparative Anatomy and the Diseases of Domestic Animals," by James Mease, M.D., who was secretary, later a vice-president, of the Philadelphia Society. The introductory lecture of Mease's course, which was given in the winter of 18121813, was published in the Memoirs of the Society for 1814 and as a separate publication.

Mease (1771-1846) was a younger contemporary of Benjamin Rush (1745-1813), and while the two were friends and comembers of the Philadelphia Society, Mease did not hesitate to differ with his colleague when the occasion arose. Thus Mease's concept of rabies in 1792 was far more advanced than that of Rush in 1805. At the time, and for logical reasons, rabies was considered to be entirely a medical problem. Mease not only rejected the current concept of the spontaneous generation of the disease, but held advanced views on the contributions to the problem that might be made by a study of comparative pathology. On the other hand, Mease and Rush held almost identical views upon the need and means of increasing veterinary knowledge. Rush's manifold interests undoubtedly prevented his making more than passing observations upon animal disease. Mease, perhaps stimulated by Rush's plea for investigation of animal disease on the part of physicians, actively worked in the field of comparative pathology for more than thirty years. In addition to his contributions in this area, Mease also published papers in the Society Memoirs on such diverse subjects as pine forestry, smut in wheat, manures for clover, varieties of wheat, and thorn hedges, but his contributions of greatest interest and value are those on animal disease.

\section{Veterinary Medicine vs. Farriery}

In his introductory lecture upon comparative anatomy and diseases of animals, Mease thought it "very probable that a part of my hearers are entirely unacquainted with the subject upon which I am to lecture, and even with the meaning of the words "Comparative Anatomy." In explaining his subject, he says that one of his objects is "to point out its intimate connexion with Veterinary Medicine." The more widlely read veterinary writers of the time had done little to enlighten their readers upon comparative anatomy; most of these works were little more than farriers' guides which placed primary emphasis upon cures. Little or no thought was given to the anatomy of the principal subject, the horse, much less to physiology or pathology, or to the diseases of other animals.

That Mease intended to approach his subject in an entirely different manner, a manner largely unknown in America, is evident from his statement:

A distinction must be made between veterinary medicine and farriery. The first is founded upon science, whereas farriery disclaiming any connexion with science, proves itself a mere practice, habit or routine, and as it rests on nothing regular or solid, so it must ever be variable. The course of veterinary medicine and farriery are indeed the same, but with this difference, that the former condescends to admit a guide, while the latter prefers to ramble at risk and hazard.

Among the advantages which have resulted 
from a study of comparative anatomy, Mease mentions the elucidation of the structure and function of man, and the improvements in surgery resulting from experimental investigation. And:

Comparative anatomy is as essential to the successful practice of veterinary medicine, as a knowledge of the structure of the human body is to the cure of the diseases and accidents incident to mankind. It is owing to a want of this knowledge of their structure, that our useful domestic animals are so mismanaged by farriers, and pretenders to animal medicine; and that diseases, trivial in their nature, or that slight surgical cases often end in death, or lameness, which might have been easily prevented by a scientific treatment.

Such ignorant practices as giving the horse when sick "the drench from a horn, whether the disease be pleurisy or colic," will:

necessarily continue so long as veterinary medicine is not studied scientifically, or until medical gentlemen cease to think it beneath their notice; and I may add, until the owners of fine horses will by pecuniary rewards, encourage men of respectability and knowledge to engage in its practice.

The proper plan of study, he adds:

requires a leisure and education, far beyond the capacities and circumstances of those to whom the care of our animals has been hitherto abandoned ... we might suppose, that a greater degree of judgement and penetration are requisite for the physician of animals than of mankind.

\section{Status, Then and Now}

Mease points out that in ancient times: "Veterinary medicine was esteemed among the most important objects, and worthy of the consideration of an inquiring mind." Not only did eminent physicians of times past practice upon man and beast without discrimination, but later, when veterinary medicine had been far outstripped by its parent science, the leading medical minds were less apt to disparage the values of animal medicine than were the lesser lights in surgery and medicine. Even so, it was not until long after the establishment of schools of veterinary medicine in late eighteenthcentury Europe that public opinion toward veterinary medicine began to be more favorable.

Recognizing that a separate system of veterinary schools could not come into being before there was a public acceptance of the distinction between farriery and veterinary science, both Rush and Mease urged the acquisition of veterinary knowledge by medical men. Mease says:

If we consider the present state of animal medicine in this country, under its appellation of farriery, we see it in as deplorable a situation, as was the art of medicine, during the barbarous ages, when the gross ignorance of its professors brought disgrace upon the art itself, and when many diseases, which now yield readily to judicious treatment, raged without control; yet that the veterinary art, like human medicine, in the hands of a judicious person, is made respectable, we may see by the example of ancient times, and by the present example of several nations of Europe. . . .

It remains for this country . . to follow those examples; and by advancing the art to a height as yet unattained, to make amends for the neglect we have hitherto shown it. Indeed I am persuaded that in a short time the public attention will be called to the subject, and that men of education will think it no derogation from their medical character, to become acquainted with the diseases of cattle, or to lend their aid in the removal of them when required.

In recommending the study of animal disease to the rural practitioner, Mease says, "The veterinary science offers a new and respectable means of employment to its professors," and this will not only be the means of "extending the sphere of his utility, but his personal consideration" as well. As a practical example of the debt of medicine to such study, he cites the case of John Hunter, who not only fostered the establishment of the Veterinary College of London (1791), but also attended the practice of the college infirmary upon occasion. It was his observation of phlebitis following the bleeding of horses, and the dissection of the veins of affected subjects, that led Hunter to the seat of the condition in similar cases in man. 
In response to an inquiry, Mease wrote in 1816 :

I cannot recommend any book on the diseases of cattle. I have read every one that ever was published in English, and am disgusted with the absurdity and inhumanity of the practice they advise. In the northern states our cattle are, fortunately, healthy, if justice be done to them. In the southern states, the chief diseases they are subject to arise from shameful neglect and poverty; and until a planter makes up his mind to house his cattle in storms, and supply them with plenty of wholsome juicy food, it is better that he should not have medical books, as he will pester the animal with drenches instead of good hay, pumpkins, turnips, potatoes, and corn meal. In the winter of 1813, I gave a course of lectures on the diseases of domestic animals, with the hope of exciting the attention of medical gentlemen to the subject. . . . I hope the trustees of the University will establish a professorship of Veterinary Medicine, when I will furnish the person appointed, if desired, with the result of my researches on the subject.

\section{Mease on Mad Dogs}

On the subject of rabies, Mease, who had in 1792 made the first real contribution to this problem in America, stated: "it still continues to humble the pride of the medical profession." Mease rejected all of the commonly accepted causes of rabies in the dog, particularly that of spontaneous generation and the redoubtable "worm under the tongue" (lyssa) claimed by innumerable authors since Pliny. Concerning the latter cause, Mease states: "The iclea of a worm is utterly false, no such thing exists." While Mease's statement leaves some doubt that he knew of the existence of the fibrous lyssa in the tip of the dog's tongue, the history of rabies would have been saner had this structure escaped notice altogether. Generations of hardy practitioners had removed the lyssa from healthy dogs as a preventive, and from rabid dogs as a "cure."

Unlike some of his medical brethren who claimed to cure human hydrophobia, Mease states emphatically that the disease has never been cured, but

We must not despair; for I cannot think that Providence has determined to permit this disease to be forever incurable, and can any more powerful argument be adduced for investigating the diseases of domestic animals, than the knowledge of this fact, that all of us are every day of our lives liable to the attack of an awful and incurable malady from one of them?

Mease gives a summary of the important outbreaks of epidemic diseases among domestic animals in America, and suggests that by a greater knowledge of them we might be led to anticipate fatal epidemics and provide the means of guarding against them.

\section{"I shail demonstrate"}

There seems to be no record of the other lectures delivered by Mease, other than evidence that he did advertise: "lectures will be given every Tuesday, Thursday, and Saturday afternoon at half past three o'clock" during the winter of 1812-1813. In his introductory lecture, he states that it is his intention to adopt the following plan:

1. I shall demonstrate the structure of different animals.

2. Explain the use and functions of the several parts, and compare them with those of the human body.

3. Point out the causes, nature and symptoms of diseases in our domestic animals, with the method of cure.

4. Give the natural history, operations, and closes of medicines.

In summary, he says:

From this plan it will be seen, that farriery, strictly so called, or what relates to the fashionable operations on a horse, makes no part of the course. By thus separating the scientific from the merely mechanical part, the veterinary science will be at once put in a condition to go hand in hand with human medicine.

Mease recognizes the propriety of teaching the proper methods of shoeing the horse, but his insistence upon the separation of the scientific from the mechanical aspects of the art was largely forgotten by later veterinary educators until long after the heyday of the horse.

What the immediate effects of Mease's lectures may have been would be difficult 
to determine. Certainly they were the first efforts in this direction in America. There would seem to be little doubt that his lectures stimulated a continuing interest in animal diseases on the part of members of the Philadelphia Society. Inasmuch as practically all of the early promoters of a veterinary profession in America were associated in some way or another with the Society, it would seem a safe assumption that Mease's lectures had some influence in moulding veterinary perspective.

\section{Texas Fever}

In his introductory lecture of 1813, Mease mentioned the fact that he had investigated a fatal cattle disease in 1796 , the particulars of which "I shall hereafter detail." The one fact, and an important one, he mentions in the body of his lecture is that the reservoir of the disease was a small area of South Carolina, and that apparently healthy cattle from this area infected all others with which they mixed in being driven north. He says:

A singular fact attending this disease is, that the cattle alluded to, have the power of infecting others with which they associate, while they themselves are in perfect health.

The existence of the disease, later designated as Texas fever had been reported as early as the 1760 's, and in 1766 the colony of North Carolina had passed laws to control the movement of cattle from South Carolina or Georgia. Mease's investigation of 1796 and his report of 1814, however, are the first scientific contributions on the subject.

While Mease did not identify the tick as a vector in spread of the disease, his identification of immune carrier cattle was largely forgotten until scientists of the $\mathrm{Bu}$ reau of Animal Industry began a frontal attack on the problem in the 1880's. In the open-minded spirit characteristic of the true investigator, Mease did not discount the value of observations made by those closest to the problem; his identification of immune carriers was based upon informa- tion which had been told him "by an intelligent drover." In a similar vein it was the faith of the veterinarian, Fred Kilborne, in cattlemen's observations on the tick that led him, in spite of professional ridicule, to the final incrimination of the tick.

In an article in 1826 on "An Account of a Contagious Disease Propagated by a Drove of Southern Cattle in Perfect Health," Mease reported his earlier observations on symptoms and epizootology in great detail, thus providing an invaluable first chapter in the written history of Texas fever. By this time the disease was widespread in eastern Pennsylvania, and was commonly denoted as the "bloody murrain" inasmuch as "some discharged bloody urine, others bled at the nose." Mease continues:

Upon being opened, the kidneys were found inflamed, and sometimes in a state of suppuration, and the intestines filled with hard balls. I prescribed strong purgatives. To one I gave two ounces of calomel, in sweet oil, on the second day of the disease, but without producing any evacuation. Bleeding was tried, without success. The blood was in a state of decomposition, and did not coagulate. As a preventative I recommended smearing the nose, horns, forehead, hoofs, and tail with tar, to counteract the contagion of the disease, by creating an artificial atmosphere around the animal, and also the obvious expedient of an entire separation of the old stock from the strangers. None of the southern cattle died.

The useful deduction of which the foregoing statement admits, is a caution in respect to the mixing northern and southern cattle, without the performance of a kind of quarantine by a strange drove, before they are permitted to associate with the stock already on the farm.

Mease makes it clear that the southern cattle were confined "for one night in a ploughed field," and that the northern cattle which became affected "had no intercourse with the drove." With additional observations of similar instances, it might be supposed that a logical thinker such as Mease might have arrived at the deduction that some intermediary agent, in this case the cattle tick, must have been operative in producing the contagion. At this time, 
however, the tick had not been recognized as more than a minor depredator in its own right. In the absence of knowledge of the real cause of the disease, it is not surprising that Mease's treatment of affected animals, although based upon accurate post-mortem finding, would avail little, particularly in arresting the contagion. As health officer of the port of Philadelphia, however, Mease had demonstrated sound principles of quarantine in dealing with yellow fever; segregation similar to but more stringent than that suggested by Mease was the only effective means of arresting the spread of Texas fever before the role of the tick was fully elucidated.

\section{Ergotism}

In addition to having made the first scientific observations upon rabies and Texas fever, Mease also may be credited with being the first American to identify ergot poisoning among domestic animals. While Mease in his report of 1826 "On the Hoof Disease from Eating Hay Affected with Ergot," credits a Dr. Arnell with having made a similar observation in 1820, Mease's own observations go back to 1803 . He states that cattle which ate hay infested with ergot "became affected with a disease in their hoofs, causing them sometimes to drop off." Concerning Arnell's description of the disease, Mease says:

The facts detailed by him, leave no doubt of the deaths of numerous cattle in his vicinity being caused by their eating hay made from some grass that was affected with the species of ergot, observed in the produce of the meadows before mentioned.

Had the observations of James Mease been made during a time of great activity in the field of veterinary investigation, not only would he still have been a giant among men, but his contributions would have received just recognition. Because of the lack of interest in animal disease during Mease's lifetime, and for some decades later, no appropriate vehicle for the reporting of observations upon animal dis- ease existed. Due largely, perhaps, to the increasingly metropolitan character of the city of Philadelphia, publication of the Memoirs of the Philadelphia Society for Promoting Agriculture was suspended with the volume of 1826 . Thus the veterinary contributions of Mease were buried in a once respected, but later little-remembered tomb, until they were resurrected recently by Bert Bierer in his Short History of Veterinary Medicine in America (1955).

\section{PETER BROWNE, PROFESSOR}

In 1837, Peter Arrell Browne, a lawyer and professor at Lafayette College, Easton, Pennsylvania, published:

An Essay on the Veterinary Art; Setting Forth its Great Usefulness, Giving an Account of the Veterinary Colleges in France and England, and Exhibiting the Facility and Utility of Instituting Similar Schools in the United States.

This essay formed the basis of an address to the Philadelphia Society on January 23, 1838 and was published in the Cultivator the same year. He also sent the essay to the president of the British Veterinary Medical Association, and abstracts from it were published in the Veterinarian in 1839 , in connection with which the editor stated:

This, indeed, is erecting a veterinary school on a noble foundation. That it may fully answer the expectations of those to whom it owes its birth, is our ardent wish.

This implies, as did Browne's pamphlet, that the school-Rittenhouse Collegewas in operation. While such a school was chartered in 1850 , this had no connection with Browne's scheme, and it is evident that Browne's institution existed only on paper. His concept of what constituted an adequate system of veterinary instruction, however, is worth reproducing at some length. Browne states that while the college was formed to give instruction in literature and science:

there is now attached to it a separate department for teaching, theoretically and practically, 
the following branches of useful knowledge:

1. The different species and various races of the domestic animals.

2. The breaking, educating, training, and fattening certain domestic animals.

3. Commercial Jurisprudence as regards domestic animals.

4. The study of the outward forms of domestic animals ... [and] the indications of their age.

5. The internal structure of domestic animals - their anatomy-their comparative anatomy, and the most humane and economical use of their strength and speed.

6. The various medicines used for the nourishment of different domestic animals.

7. The various medicines required for domestic animals - the most approved methods of raising, curing and preserving those that are botanical - a general knowledge of those that are mineralogical, together with the manner of mixing, preparing, and administering both.

8. The most effectual methods of preserving domestic animals from disease, and curing those that contract disease, together with the methods used to prevent contagion and infection.

9. The accidents and injuries of domestic animals, and the surgical operations that are required.

10. The most approved methods of shoeing, either generally, or when the animal is diseased or lame.

For these purposes, Browne says, "there is ... a theatre for lecturing, a museum, a library, a dissecting room, a forge, hospitals, sheds, \&c." In addition to a director, there were listed four professors - anatomy; botany; chemistry and pharmacy; and pathology, surgery, and farriery - in addition to four other teachers, a head farrier, librarian, and attendants. Inasmuch as Browne remained active in civic affairs for another twenty-five years, it may be presumed that he had ample time to reflect upon his somewhat premature announcement.

Although the agricultural journals had been alluding to veterinary medicine rather than farriery - for a number of years, the editor of the Cultivator in printing Browne's essay in 1838 observes:

As it is not generally understood what is implied by the term veterinary art, we make the following quotation from Dr. Brown's essay by way of explanation.

After defining "Science" and "Art," Browne had explained:

The VETERINARY is a SCIENTIFIC ART in the strictest sense of the term. . . Veterinary comprehends a knowledge of the external form, as well as the internal structure and economy of domestic quadrupeds, the appropriate management of them, and the nature, causes and cure of their diseases.

In giving the subjects detailed by Browne as belonging to the veterinary art, the editor states: "Such are among the important and useful studies which would be taught in an agricultural school." To support the veterinary department of his school, Browne proposed to raise a subscription of $\$ 50,000$ in shares of $\$ 50$ each, and to extend certain privileges to the subscribers, as had been done by the London Veterinary College. Those who have recently opened new schools of veterinary medicine will be interested to know how Browne expected to spend the $\$ 50,000$ :

He estimates the cost at $\$ 47,500$, viz. 125 acres of land, at $\$ 100$, making $\$ 12,500$, buildings $\$ 30,000$, and library and apparatus $\$ 5000$.

Thus a tidy $\$ 2,500$ would be left for unanticipated expenses.

\section{New Venture in New York}

There is little doubt that the editor of the Cultivator (Albany), Jesse Buel, who was an eminent agriculturalist, expected veterinary medicine to develop as an appendage to agricultural education. In addition to his remark above, an article printed the same year concerning a proposed agricultural school for New York State leaves no doubt on this issue: "The chief object of the school should be to form practical mechanics ... veterinary surgeons and practical agriculturalists." One of six professorships was to be "Comparative Anatomy and the Veterinary Art"; liberal studies were to be the province of the preparatory schools. At the end of the 
second year of more general studies, six of "the most distinguished pupils," apparently one for each professor, should be selected to serve as "adjunct professors." In return for free tuition, these were to assist the professor and coach the dullards. During the third year of "special" studies, the students:

should be actively engaged in the kinds of business for which they design to prepare themselves ... . under the direction of the professors of the branches they pursue.

The library should include: "books on the veterinary art," and the farm should have: "an hospital for the reception of sick animals and for veterinary practice." Whether these student veterinarians were to be turned loose on the countryside is not made clear, but it is possible that such a system would produce a fair number of hospital cases within its own fences. Later it is stated:

There are more quacks in the veterinary art, than in the profession of surgery; and it therefore stands the intelligent breeder in hand, to qualify himself to become, in some measure, his own cattle doctor.

In fairness to Buel, however, in reference to an inquiry about animal disease, he states:

We are not skilled in the diseases of cattle; and we are satisfied that we are suffering immense losses annually, in the death, by diseases, of our domestic animals, which might be avoided, had we schools, like those of Europe, to teach and promulgate correct knowledge in the veterinary art.

And elsewhere he prints a contribution from a Britisher, who states: "The cure, it has been hinted, must generally be left to the veterinary practitioner in the complicated diseases of the horse." With precious few qualified veterinarians in the United States at this time, it is likely that the plan espoused by Buel would at least have been some improvements on the status quo.

\section{OTHER PHILADELPHIA FRIENDS}

A number of scattered articles on animal disease in addition to those mentioned above appeared in the Memoirs of the Philadelphia Society in the five volumes published from 1808 to 1826 . The irregularity of publication, however, would suggest that the time was not ripe for a bona fide agricultural journal. In the first volume there was reported a method of "Cutting off the horns of Bull Calves" by means of a sharp gouge "when a calf is about a month old, and the horns have risen above the skin."

In an article "On Sheep and their Diseases," a correspondent reports that he had observed "the worm in their head," which he supposed to be caused by the "sheep bee," and for which: "I know no cure." To prevent the condition he smeared their noses with tar. On intestinal worms, he mentions:

I frequently find the tape worm, to the number of four or five, in one sheep, and four or five yards long. I lately killed a lamb with eleven: the animal was fat: these seem to be least injurious to sheep, as those in which I have have found them have the fewest knobs on their bowels.

Those which cause "knobs," he says are more injurious, but less so than the "small round worms, about one inch long." $\mathrm{He}$ notes: "sheep are much more healthy here, than in England," but reprimands American farmers for not docking their sheep, "hence they often dislocate their spines, and render their limbs paralytic, by the violence with which they frisk their tails when affrighted."

In 1814, a physician, who apparently did not disdain attending livestock, necropsied several sheep belonging to a patient, who had lost 30 of 300 . He found "an effusion of water around the lungs," together with "considerable inflamation of the membrane lining the thorax." He prescribed bleeding and purges, which apparently resulted in the recovery of a number. He also mentions "an inflammatory sore throat was epi- 
demic among the horses throughout this country," and attempted to relate it to an epidemic of "hooping cough" in man.

\section{Sheep Problems}

In a lengthy communication "On Merino Sheep" in 1814, a correspondent from New Jersey states that he has had experience with worm in the head, prolapse, abortion, cholera, and foot rot. The worm in the head, he says:

did not come into much notice, until the last summer, when a considerable alarm was excited among merino-men by its discovery, but their fears were chiefly groundless, for they are now found to exist in a greater or less degree, in the heads of almost all sheep, producing for the most part but little inconvenience and very rarely death.

He suggests trepanning the frontal sinuses and picking the grubs out with tweezers, which he says is neither difficult nor dangerous, or causing the animal to sneeze by blowing sulfur fumes up the nostrils.

A New York correspondent to the American Farmer in 1823 says, "It has been but a few years since worms have been discovered to breed in the heads of sheep, though it is probable they have, from time immemorial." Unlike his New Jersey compatriot, however, he contends: "these grubs do more injury to the sheep of our country, than all the diseases with which they are afflicted." He gives a good summary of the life cycle of the sheep bot, and recommends injecting a suspension of snuff and asafetida up the nostrils.

On a related matter - that a parasite with a life cycle as simple as that of the common horse bot should have defied identification of its adult form and the mode of infection for so long, is perhaps less surprising than the fact that a considerably longer time was required for this information to become common knowledge. As late as the early nineteenth century, there were those who had had the opportunity to learn differently who believed in the spontaneous generation of bots in the stomach of the horse - despite a proper appreciation of the facts of life concerning the sheep bot. The concept of spontaneous generation of lower animal forms, of course, was not dealt a final death blow until the work of Pasteur and others in the late nineteenth century was accepted.

\section{Dunghill Dialectic}

It is of some interest, therefore, to note an article in the Cultivator for 1841. Being unsigned, it presumably is authored by one or both editors, Willis Gaylord and Luther Tucker, but the information is taken from other sources. The article concerns the "eyeworm," Filaria, of the horse, a specimen of which had been found by a Dr. Lee of New York. After giving a good description of the parasite, a number of other parenteral forms are mentioned, following which there is a lengthy dissertation on their origin:

Perhaps the origin of these parasitic animals is one of the most difficult questions to solve, belonging to animal physiology. ... Writers on this subject are at this time divided into three classes, those who advocate the doctrine of spontaneous generation; those who maintain that these worms, \&c. "are produced by some living process or function of the organism" [flukes were still held by some to be the result rather than the cause of sheep "rot"] ... and those who attribute the origin and presence of worms, whether intestinal or visceral, in all cases to ova.

The writer discounts either of the former theories as: "admission that we do not know how else it could be produced." And if spontaneous generation were a reality:

We should expect occasionally to see a man, a quadruped, or a bird, spring up from some dunghill or fermenting vat. . . The old doctrine then, which attributes the origin of all vitality, to an egg or germ, is not likely to be falsified in this case. . . It is probable that ... by circulation in the blood, the ova of the filaria reached the eye of the horse, where, finding suitable food, it remained until it reached adult size. 
Prolapse of the vagina, as a concomitant of difficult parturition, the Jersey sheepman says, is "oftentimes very troublesome," and while there had been many cases in his flock, he had lost only one - in which "the cesarean operation was successfully performed by killing the ewe to save the lamb." Prolapse prior to parturition:

may generally be reduced by raising the animal up by the hind legs, and shaking her well ... and to use a few sutures to prevent a recurrence. . . I have recourse always to the lancet, both as a remedy and preventive.

Prolapse of the uterus he associates with abortion. The latter he attributes to high feeding, having lost lambs from 15 of 25 ewes suffering from "too much blood." Following this loss, he practiced bleeding to the extent of a half-pint taken from the external jugular vein.

"A new and most alarming disease," causing purging and loss of appetite, and which for lack of a better designation he called "cholera" was traced to overfeeding on corn, but was confined to ewes which had recently lambed. Death was rapid: "the unexampled rapidity of its progress allowed no time for the operation of remedies." Another "new" disease in his flock was foot rot, which he says, "is certainly not contagious, [and] may safely be attributed to wet pastures." He says he has never known it to affect native sheep, or foreign coarse-woolled sheep; nor were either affected with scab.

\section{Other Matters}

On the matter of urine, Peters states in 1818:

It is asserted, that it is preferred by Horses and Cattle to Salt; and is, to them, salutary as a medicine, as well as a condiment, promotive of health, and consequent profit. . . . Many years ago, a German woman kept Cows, in a town in Maryland ... [which] were remarkable for their goodly appearance. ... Envy was excited: and she was narrowly watched. At length it was discovered, by her rivals, that she daily emptied the contents of the Urinal, into the food of her Cows. She acknowledged this to have been the magical cause of the superiority of her Butter and Cream. But when the secret was discovered, she could sell no more of the celebrated articles.

Several articles on "Hoven Cattle" appeared at various times, following that by Peters in 1808 . In 1811 a correspondent takes Peters to task for supposing that the gas was contained in the abdominal cavity - a common fallacy perpetuated since the days of John Fitzherbert's Boke of Husbandrie (1523). The advantages of the trocar and cannula are given in detail in the same volume, and of the stomach tube in 1818 .

An early experimental approach to the problem of excessive salivation in horses, later a cause of great concern, was reported in 1811. The writer, believing the spotted spurge plant to be the cause "of the salivation that has occurred so frequently among horses," fed some on repeated occasions to his horse, whereupon:

A preternatural discharge of saliva took place in less than half an hour... I think it extremely probable, that the plant in question is the general cause of the salivation in horses.

In the final volume of the Memoirs (1826) there is an account of the "Dissection of a horse, whose death was occasioned by perforation of the Aorta by worms," by Richard Harlan, M.D. The abdomen of a year-old colt, the body of which was sent to Harlan by a friend, was found to contain two bucketfuls of blood, which had come from a ruptured sac surrounding the aorta. In this early report of verminous aneurism, the doctor states:

We discovered the cause of the whole mischief, viz. a great number of small worms, from a quarter to three quarters of an inch in length, attached to the internal coat of this portion of the artery; giving it truly a worm-eaten appearance.

In the one article on diseases of swine appearing in the Society Memoirs (1811), the author notes that this is a subject: 
that few writers have thought worth while to notice. . a subject on which it has either not been fashionable to treat, or perhaps from the mistaken idea "that the hog like the miser, can do good only when he dies."

Among his hogs, of which he kept up to 250 , he says the "staggers" was most troublesome, causing death of several at a time, and in less than a half-hour after symptoms appeared: " They were immediately bled under the ear and at the tail ... a few recovered, but a greater number died." This was until 1803, when an acquaintance gave him a British work of 1706, which advised cutting a "bare knob in the roof of the mouth," allowing it to bleed, and then giving the hog urine to drink. The success of this procedure was such that "where I used to lose six I do not now lose more than one." And in 1807:

an epidemic.. raged among the swine throughout this part of the country ... the people in the neighborhood called the disorder the sore throat. - A hog would come up to the trough, eat, apparently in good health, and in ten minutes after, be dead.

Nothing could be found on post-mortem examination. By accident it was discovered that feeding on clover would prevent the disease: "in consequence there was neither staggers or sore throat among them; no sickness and no deaths."

\section{WILLIAM CARVER, PRACTICAL HORSE FARRIER}

In 1818 William Carver published his Practical Horse Farrier; or, The Traveller's Pocket Companion (Norristown, Pennsylvania). The title continues:

Shewing the best method to preserve the horse in health; and likewise the cure of the most prominent diseases to which this noble animal is subject, in the United States of America. The whole being the result of nearly forty years' experience, with an extensive practice.

Except for the reference to the United States, the title page reads much like any of a number of previous works, British or
American, which promised much, but delivered little beyond a rehash - or outright reprinting - of what had been offered before. Frequently a claim to years of experience might be deduced to mean experience in digesting other men's works; many were armchair compilations. Carver, however, appears to be a notable exception, for there seems to be no question that his book is literally the product of long experience, and while he acknowledges the influence of a number of British writers, much of his writing is in the first person in the form of his experiences in American practice. This latter feature makes the book doubly valuable in the present instance, for many early American works give no indication of the prevalence in this country of the conditions treated in the text.

In his preface, Carver says:

The author... is aware that his work will meet with objections, on account of there having been many large volumes published on Farriery by men of science, who were acquainted with the dead languages ... [but] those languages only serve the purpose of those who wish to keep the world in ignorance. . . . The reader may think that $I$ am an enemy to science and $a$ friend to ignorance-but the case is otherwise. I should feel myself happy to see science flourish, stripped of her garb of mystery and quackery. . . I I have been an eyewitness to the dreadful effects of the ignorance of those who have undertaken to doctor the horse, both in this country and England. ... I am certain that there are persons in this city [New York], who undertake to doctor the horse, that cannot either read or write their own names - and consequently know nothing of the quality or power of medicine ... they cannot consult the state of the blood of the horse ... or know how many times the pulse beats in a minute, in order to judge of the state of the animal, they pretend to cure.

\section{On shoeing, he continues:}

I have attempted to describe the best method that I have discovered, in thirty years' practice. ... I have witnessed the dreadful, and the most evil consequences, of horses being placed in the hands of unexperienced shoers in this city. I have known smiths to open shops, and undertake to shoe horses, who never had shod a horse in their lives; and the result has been, 


\section{PRACTICAL}

\section{MORSE PABRIEB9}

on,

\section{The Traveller's Pocket Companion.}

SHEwIXe

TAE BEST METHOD TO PRESERVE THE HOR

IN HE ALTH:

$\times \mathrm{No}$

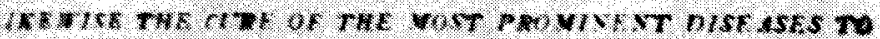

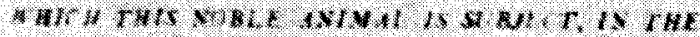

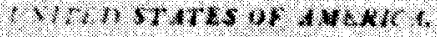

The whole being ties result of nearli forty years' experience. with an externuve prictue.

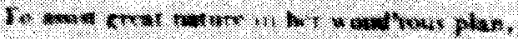

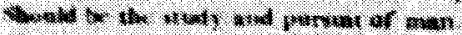

$m$

SFCOND FWTHTOX.

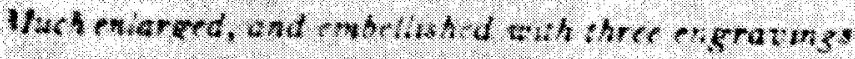

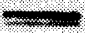

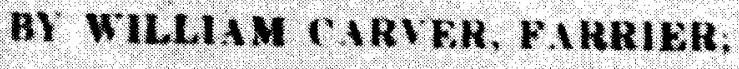

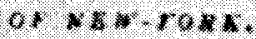

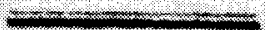

PIII. $41 \mathrm{FI.VMII.}$

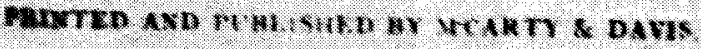

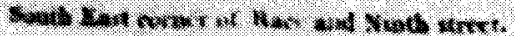

1820.
Carver's Practical Horse Farrier, Norristown, 1818, was an early work based on broad experience, keen observation, and sound judgement. 
that the feet have been ruined. . . . I would not permit three fourths of the smiths, of this city, to take off a single shoe from my horse's foot, was I not present at the time.

\section{Critic Carver}

On the matter of criticism of others, of course, Carver did not differ from his predecessors; most works of the time were fair subjects for criticism. But most of these overly censorious critics had little real basis for their criticism - having little better to offer in its stead. Undoubtedly, many had a base motive in doing so - the sale of their own work. On this matter, however, Carver says:

I have not written this small treatise with a view of deriving any pecuniary advantage, as I am now arrived at an advanced period of life ... my only object is that of being useful to those who are in possession of that useful animal, the horse... Although there are a great number of horses kept in this city, I do not find one citizen that makes the economy or welfare of the horse so much his study that he might examine this work, or to whom I might dedicate it. I therefore dedicate it to the public at large, leaving them to judge of its merits, and my experience or veracity.

Unfortunately, Carver was quite correct in his appraisal of the numbers of men in his fair city who had made an adequate study of the horse. Moreover, his writing vindicates his claims concerning his own experience and veracity. On the matter of practitioners unable to read or write, when nongraduates were permitted to register under the first practice act in New York in 1886 , more than one, of necessity, did so by "making his mark."

Little is known of Carver's personal life beyond what is contained in incidental passages in his book. It is obvious that he had experience in both England and America; it is apparent that he was British-born and came here some considerable time before authoring his book. Just when he might have come to New York - which he calls "this city" - cannot be determined with any degree of accuracy; he speaks of cases he had attended in "this city" in the past few years, but his residence probably dates to some time earlier, perhaps to the turn of the century. He speaks of "a Mr. Clements, a farrier in this city," and mentions referring cases to him "on hearing of his presence in the city." This individual undoubtedly was J. Clements, a London graduate, who came to New York in 1804. Carver's wording strongly suggests he was in practice here before Clements arrived. What may be a more precise indication is his statement that he had attended several horses belonging to a gentleman who "arrived in this country about twenty years ago" (ca. 1800).

\section{The Carver Clan}

The name of Carver is most closely associated with the person of James Carver, a London graduate of 1815, who published two issues of his ill-fated Farrier's Magazine in 1818, and conceived the idea of a veterinary college in Philadelphia. James was the son of another William Carver, whom the author identifies as "a countryman of mine, from England, and one of the best farriers that ever came to this country ... a man of sound judgement, and long experience. We went hand in hand in all difficult cases." The author also states:

Attempts have been made to establish a Veterinary College in the United States, but all to no purpose. An institution of this kind could not fail to be of the utmost utility and importance, in cultivating that valuable science, veterinary surgery; but at this time, it appears to me impracticable. Mr. Carver [father of James], some time since attempted to effect the establishment of one in New York, but failed in the accomplishment of his object; I presume his son recollects the circumstances and the futility of his efforts.

\section{Author Carver also speaks of:}

my friend, Mr. James Carver, veterinary surgeon, from the Farrier's college at London ... I have perused, with considerable interest ... [his] work on Farriery, and am clearly of opinion that his doctrines are sound. He reasons like a man of experience and sound judgement. I should like to hold a correspondence 
with him [James resided in Philadelphia]. His father and myself were as intimate as brothers, and I regret the loss of his friendship and associations.

This digression may serve to place the name of Carver in proper perspective in the annals of American veterinary history. As an examination of the Horse Farrier should suggest, it is its author, rather than the other William Carver - or even his son - that perhaps is the more deserving of lasting recognition for having made a definitive contribution to American veterinary medicine. At least William Carver, the author, has been more or less the forgotten member of the Carver clan.

\section{Colleg'd Idiots}

Something of Carver's character can be gathered from his writing, in particular, the principles which guided his practice. If he appears to be disdainful of graduate veterinarians, probably he had cause, for few of the early graduates of the London school distinguished themselves. Also, it may be presumed that it was the less, rather than the more, distinguished that would give up a lucrative practice in England for the uncertainties of America. In speaking of his unsuccessful attempts to treat bone spavin, Carver says:

I have many times since been applied to, for to cure the bone spavin, but declined the attempt. But on hearing of a Mr. Clements . . who, it is said, is in possession of a diploma from the Veterinary College of London, and that he could cure the bone spavin, I advised those who applied to me, to take their horses to him: although I confess, that I did not place any more confidence in the talents of $\mathrm{Mr}$. Clements, on account of his diploma, or his knowledge of the dead languages - as neither of these can give experience. During the course of my life, I have conversed with many collegebred gentlemen, who in my opinion, were colleg'd idiots. ... If I myself am in possession of any diploma, it is a grant from the college of nature, and the credentials are, experience, reason, and common sense.

Mr. Clements, says Carver, pursued the same methods other practitioners used - "and the horses still remained lame." Elsewhere he says:

There are many others who profess to have a thorough knowledge in veterinary surgery; overstocked with diplomas of which they boast, like coxcombs with their fine coats, and a little knowledge of the latin language; but I never saw them perform cures equal to this good old friend of mine [his namesake, William Carver].

As late as 1870, M. H. McKillip of Chicago said he had never seen a London graduate who was a proficient practitioner; they were "gropers and itinerants seeking new pastures, invariably banking on the M.R.C.V.S. rather than ability and character to distinguish them from the rabble." It should be emphasized that McKillip and, to a lesser extent, Carver had reference only to those graduates who had emigrated to America.

Nor should it be supposed that Carver was prejudiced against college training in veterinary medicine as such. As mentioned above, he thought, "an institution of this kind could not fail to be of the utmost utility and importance... but at this time, it appears to me impracticable." In retrospect, we would have to agree with Carver on the latter point; America was simply not ready to accept the idea of a veterinary college in 1818 - nor in 1850 . Carver adds:

It has often occurred to me, that if a few young men in this country would turn their attention to the cultivation of this important branch of science, and make the veterinary art their study, they might become useful to the community and rise to opulence, by the profession. There are many who have good educations, and although there are no veterinary colleges in this country they might derive the necessary information from the study of the most celebrated authors. . . By a proper application to these works, a young man, even of ordinary capacity, might in a short time become a proficient in Farriery . . . and acquire an ample fortune. It is by the study of those books, and an extensive practice that I have obtained a knowledge of the horse.

\section{A New Broom}

Like other intelligent men of the time, Carver had long since disposed of the buga- 
boo of superstition. Hobgoblins, however, ran rampant in the minds of many of the less enlightened. Carver relates:

I recollect, a few years past, to have been called by a respectable Dutchman in this city, to see his horse, that had the mad staggers. He said to me, Mr. Carver, mine horse is bewitched - I suspect the person who has done it - I have some very bad neighbors. I laughed at the ignorance of the man, and his belief in ancient superstition! For my own part, I have long since discarded from my mind, witches, hobgoblins, and ghosts of all kinds: having swept them away from my brains, with the besom [broom] of thought! I drove the old lady, the witch, out of my employer's horse-but the poor animal lost the sight of one eye. This I clid not attribute to my friend's old witch, but to the malignity of the disorder.

Carver's work follows the typical pattern of most others of the time with regard to the subjects treated. In general, his methods of treatment can be considered simple and moderate, certainly less contrary to nature than those of most of his contemporaries. His rationale obviously is influenced by James Clark, a worthy preceptor, and one of few practitioners fit to be followed. Carver says:

It should be observed to give horses as few medicines as possible, and not to follow the ridiculous custom of frequently bleeding and purging, when the horse is in perfect health. Proper dressing, feeding, and exercise will alone cure many disorders, and prevent most. . . . Having visited many stables in this city, I have found many stalls where horses have stood in their dung, to the thickness of six or seven inches, which I could attribute to nothing but the indolence of those that had the care of horses committed to them.

The custom of driving horses with blankets on them, he likewise says, is a pernicious practice: "If nature ... had destined the horse to wear blankets, she would have sent him covered with them!"

\section{Local Diseases}

While it may be supposed that Carver's writing is directed principally toward diseases as he has seen them in America, it is those which he specifically mentions as being frequent here that are of greatest interest. Obviously, many of the descriptions of conditions in British reprints, or British inspired works published in America, had some utility, but there is no way of knowing to what extent these conditions prevailed here. Thus Carver states:

Pleurisy, and inflammation of the lungs, is a disorder that horses are much subject to in this country. I have frequently found, by examining the carcasses of dead horses, different kinds of inflammations on the pleura.

His treatment for the condition, for which he gives symptoms adequate for diagnosis, is the commonplace bleeding, blistering and purging - with reasonable restraint. And:

Strangles is a distemper to which colts and young horses are very subject . . [but] I have known horses, in this country, that have been eight or nine years old, to have this disorder, which I never saw in England.

Vegetable poultices on the throat and purging are recommended: nothing is said of the contagious nature of the disease. Glanders and farcy, contrary to the teaching of the London school, he recognizes as contagious; in glanders:

The horse should be dispatched as quick as possible, for fear of the contagion spreading: besides, no other horse should be permitted to stand in the same stable with a horse in this situation.

Upon being applied to for a cure:

I have recommended the owner immediately to give the horse a leaden ball through his heart or brains; and I always looked on it as folly for an author even to write on it, or prescribe any cure.

Farcy, however, which he has been highly successful in treating: "is also a distemper to which horses are much subject to in this country; and which perhaps has called forth as much, or more of my practice, than 


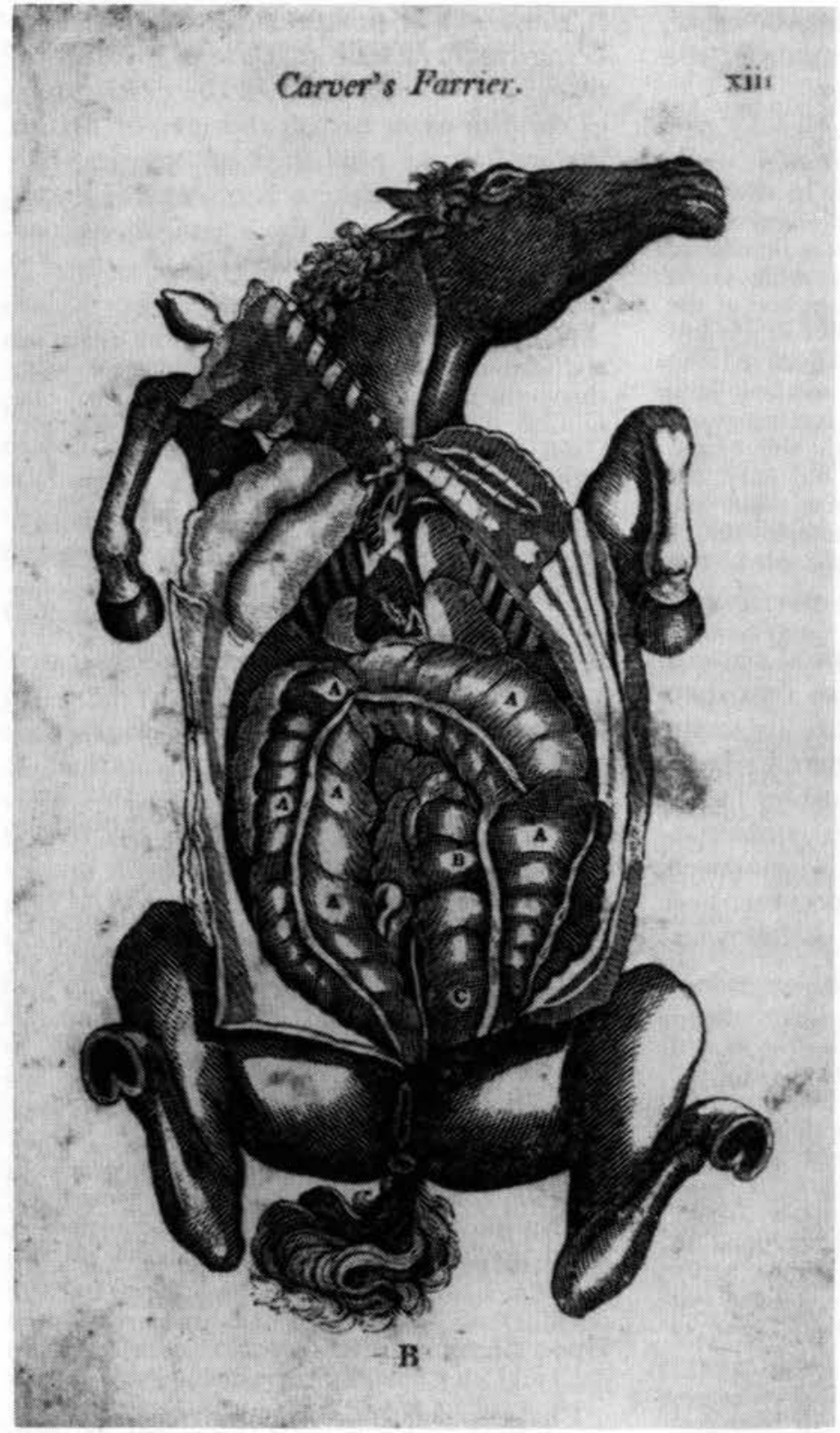

Illustration of the viscera of the horse, from Carver's Farrier (1818). The original plate is from Ruini's Anatomy of the Horse, 1598, much copied by later authors.

any other disorder." A major difficulty, he finds, is with horses at some distance:

as proper regimen, exericse, and good nursing, are very essential in performing a cure. The practitioner also has other evils to encounter, as he is seldom applied to until a variety of nostrums have been given the horse, which he has to encounter and counteract, as well as the disease. . . . Besides it is expected that he be almost possessed of supernatural powers, so as to raise the dead to life - or perform an instantaneous cure. And his employer is not acquainted with the danger to which he is exposed, at the time he is practising on this powerful animal. Neither is he acquainted with the quantity of medicine that the horse requires, or the expense of those medicines. . . . On account of the high price of drugs ... I have been obliged to substitute medicine of a 
cheap quality, and to omit those that would have had a far better effect: for gentlemen in this country do not pay that respect to a valuable horse, that the gentlemen in England do.

These woes of the large animal practitioner, as many of this brotherhood could attest today, were not peculiar to the early nineteenth century.

With regard to bots, one of the major problems at the time, Carver urges:

It would be both needless and useless to insert all the nostrums that have been recommended to destroy worms and bots, that reside in the stomach (and intestine) of the horse.

For bots, which he says are the most mischievous, he gives milk and molasses followed by a purging ball - " in some cases with good effect." He censures Clements for claiming - as taught at London - that:

a horse was never known to die with the bots . . almost every superannuated old woman knows that the bots destroy numbers of fine horses... so much for theory and a diploma.

\section{“Locked jaw," says Carver,}

is a disorder, that has hitherto baffled the art of the physician, and also the power of medicine to cure, either on man or beast. ... In the course of my practice, I have had a great num- ber of horses under my care, that have had, what is generally called the stag evil [from the arching of the neck], or lock jaw - but performed a cure on two only.

He ridicules those authors who recommend giving balls of various sorts to horses with lockjaw, saying:

I would ask those gentlemen, how a single ball is to be given, when not so much as a shilling piece can be put between his teeth; and his jaw cannot be pried open, even with an iron bar.

\section{Sane Shoeing}

The shoeing of horses, Carver insists:

is an operation of far greater importance than is generally imagined... [and] I am well aware, that what I shall here advance will meet with opposition, from the ignorant and prejudiced shoers of horses ... three fourths of them are as ignorant of the structure of the foot, as the horse is of then. But I shall appeal to the understanding and judgement of the experienced few, both in this city and elsewhere, for the justness of the statement. . . A most pernicious custom is practised in this city, by many pretended shoers, which is to make presents to gentlemen's coachmen, grooms, or negroes, in order to obtain horses to shoe.

The conscientious Carver, upon being asked by these leeches what he would offer,
Strangles was a common problem from colonial times, treatment of which - including vigorous use of the twitch changed little until the advent of chemotherapy and tranquilizers. Manning: Stock Doctor

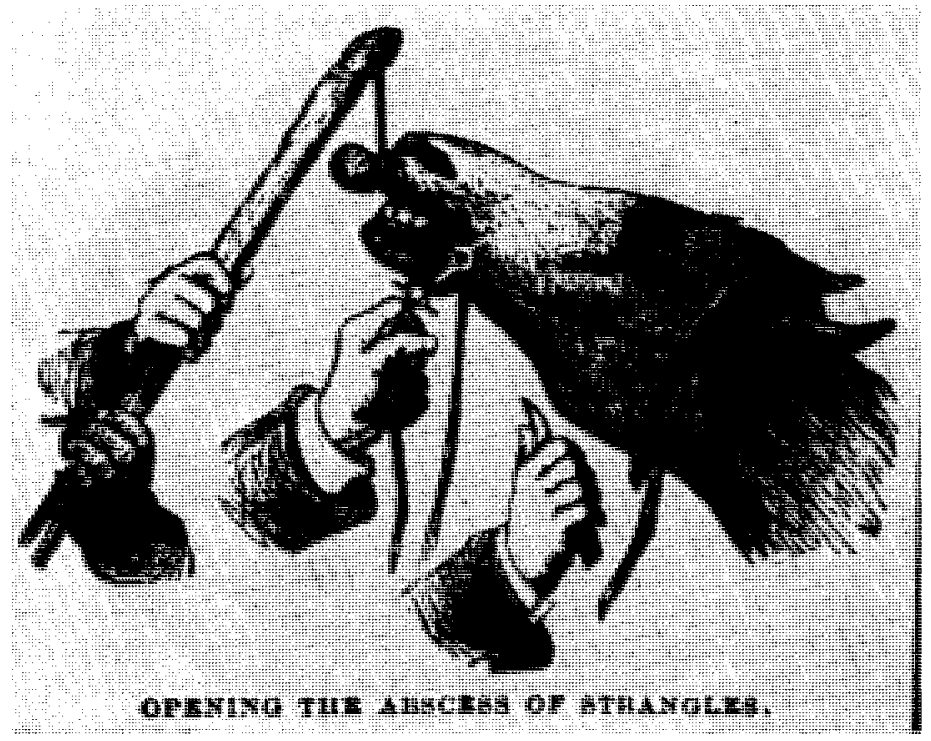


says: "My reply was, that I should give nothing." They told him that the common practice was to remove and apply the same shoes, and charge as for new shoes, and some owners:

told me that they believed there were more horses shod for bribes and grog, than by experienced workmen; and when they discovered the fraud, they immediately ordered the horses back to my shop.

Additional light is cast upon the character of the common shoeing smith of the time. Of "old and experienced" shoeing smiths, Carver says:

There are a few such characters in this city, and but few. The greater part of them have never made the anatomy of the foot their study. 'They are generally employed as journeymen, and like birds of passage, are here to-day and gone to-morrow. Talk to them of the internal structure of the foot, of the coffin, and coronet, and you will find them entirely ignorant, and know no more about the matter than the horse knows about them. ... They are so tenacious of their own opinions, and so perverse, through ignorance that they will not be taught. Since I have given up the business of horse shoeing, I have frequently, at the solicitation of gentlemen, gone to smith's shops and shod their horses, in order that they might travel sound. In many instances I have endeavoured to instruct smiths in the principles of shoeing ... but the next time they attempted to shoe, they would still cut down the heels, frogs, and bars of the feet, against which I have so much protested.

\section{Mange, Carver states:}

is a disorder that horses are subject to in all countries. .. . This distemper is contagious and is frequently caught by infection. I have known men who have taken care of horses with the mange to have caught the itch from them... . When a horse is labouring under this disease, by taking a microscope and looking at him [?] through it, you may discover a number of small live insects in the pustules.

Carver apparently did not use the microscope himself, but his reference to identification of the mange mite by use of the microscope (hand lens?) is an early one in veterinary literature, perhaps the first in America.

\section{The Doctor on Docking}

Carver appears to have had strong humanitarian instincts; he laments:

The docking and nicking of horses is a cruel practice, and ought to be abandoned by the whole race of mankind . . . but that creature called man, attempts thus to mend the works of his almightly wise Creator, and in the execution of which, he frequently spoils and disfigures them.

Carver admits to having performed these operations a few times at the insistence of clients, and he details what he considers the best methods to save the horse from some of the barbarities perpetrated upon this hapless animal. He says, however:

Contrary to my pecuniary interest ... if I can prevent one owner of a horse from performing this brutal practice on the animal, my wishes, in some measure, will be gratified.

More or less as a valedictory, Carver states:

As the first edition of this work [1818] was disposed of in the course of eight months, it was thought advisable to publish a second [ 1820$]$, under the impression that the first met the approbation of the public ... this may probably be the last time they may hear from me on the subject of that most excellent and noble animal the horse; wishing that my fellow beings called man, may perform their duty through life as well as the beautiful creature I have just mentioned, and long admired, and endeavoured to relieve when in distress, and to protest against the brutality of the worst of all animals, Man. . . Hoping this work may prove of utility to the owners and lovers of horses, the author takes his leave of the public and subscribes himself-Their obedient servant, William Carver.

It appears, however, that Carver did not take his leave for some time. An item by him on the management of horses appears in the New York Enquirer in 1830, in which he says, "I presume none of my fellow-citizens will doubt but I have some knowledge of the structure and economy of horses, after years of extensive practice."

What, then, is to be our evaluation of this man and his work? Every man to some degree, of course, is a product of his times, 
and the Practical Horse Farrier is not without its faults, either of omission or commission. But judged against the backdrop of his own time - the only fair criterion it is obvious that William Carver was far in advance of his contemporaries, and the over-all tenor of his writing is acceptable even today. A little immodest at times, he was less so than most of his fellow practitioners and authors, and it may with good reason be said that he had more cause to have a good opinion of his practice than others had of theirs. What is of greatest consequence to the historian, he has given what appears to be an honest and conscientious picture of conditions as he found them in practice - rather than in the writings of others. Certainly, veterinary medicine in America, and thus the public, would have benefitted if this second edition of his work had not been "the last time they may hear from me on the subject."

\section{JAMES CARVER, PROFESSIONAL FARRIER}

As indicated above, it was James Carver, a London graduate of 1815 , who is the best known of the Carver clan, primarily because bibliographers of Americana give his ill-fated Farrier's Magazine (1818) perhaps greater recognition than it deserves. At least from a veterinary viewpoint it is less revealing of conditions as they exisited here than is William Carver's Farrierwhich as a book is dismissed rather lightly, being presumed to be of the same genre as others. Actually, Carver's Magazine, while apparently intended to be issued serially (only two issues appeared), was more in the nature of a repository which could just as well have been published as a book. There is no intention, however, to detract from its value as an historical item; considerable insight is offered on Carver's intentions to see veterinary medicine raised to a more proper status.

In the introduction to Part II of his Farrier's Magazine, Carver states:

It is only within these last thirty years that reterinary medicine has been placed on the footing of a science. The institution of the
Royal Veterinary College of London is the great era from which this improvement may be dated, and the sequence of this has been, that ignorance and error have been detected, so as to establish what may be termed the difference between random routine and scientific practice; and the first professor, M. St. Bell, a Frenchman, showed (as I may be doing for this country) what now might be done during the short time he possessed the appointment. . . .

The greatest skill is requisite to form a judgement on the diseases of brutes . . . can there be a greater burlesque, than the supposition of a man's ability to give physic for a horse, excepting in very common cases, merely because he knows how to groom and shoe him? The plea of experience is futile; for the utter inability of illiterate and uninformed men to investigate the principles of science, and their total want of opportunity to acquire, even by rote, a rational system of practice. The whole stock of medical knowledge of these practitioners usually consists of a number of receipts, handed down from Tom and Dick to Harry, with which they continually ring their charges in all cases, right or wrong, hit or miss; and so fiercely are they bigoted to their own particular nostrums, they are totally incapable of all advice or improvement, the common and unavoidable fate of confirmed ignorance, since it is the highest point of knowledge to know and feel that we still need information. . . . Into such hands do men commit their distempered animals, who have it not in their power to reproach their masters with their accumulated sufferings. Mankind, from prejudice, indolence, and want of feeling, neglect those creatures which they can purchase with their money; and the progress of veterinary medicine, grounded, as it necessarily must be, on a proper knowledge of the anatomy, physiology, and pathology of disease, will in this country, as it was in Europe, be rapid or slow according to the diligence of those enlightened practitioners which the college has sent forth. ... .

The number of horses annually lost in all the public cities of the United States, and particularly in the mail stage departments, either from evils attendant bad shoeing or other mismanagement, is incalculable, and calls aloud for the attention and interference of government. . . In endeavoring, therefore, to obviate this defect, I trust I am performing a most useful and acceptable task to the community.

Among Carver's essays in this publication is one addressed to Judge Peters and several medical men of Philadelphia, among others, on the importance of veterinary science. In this: 


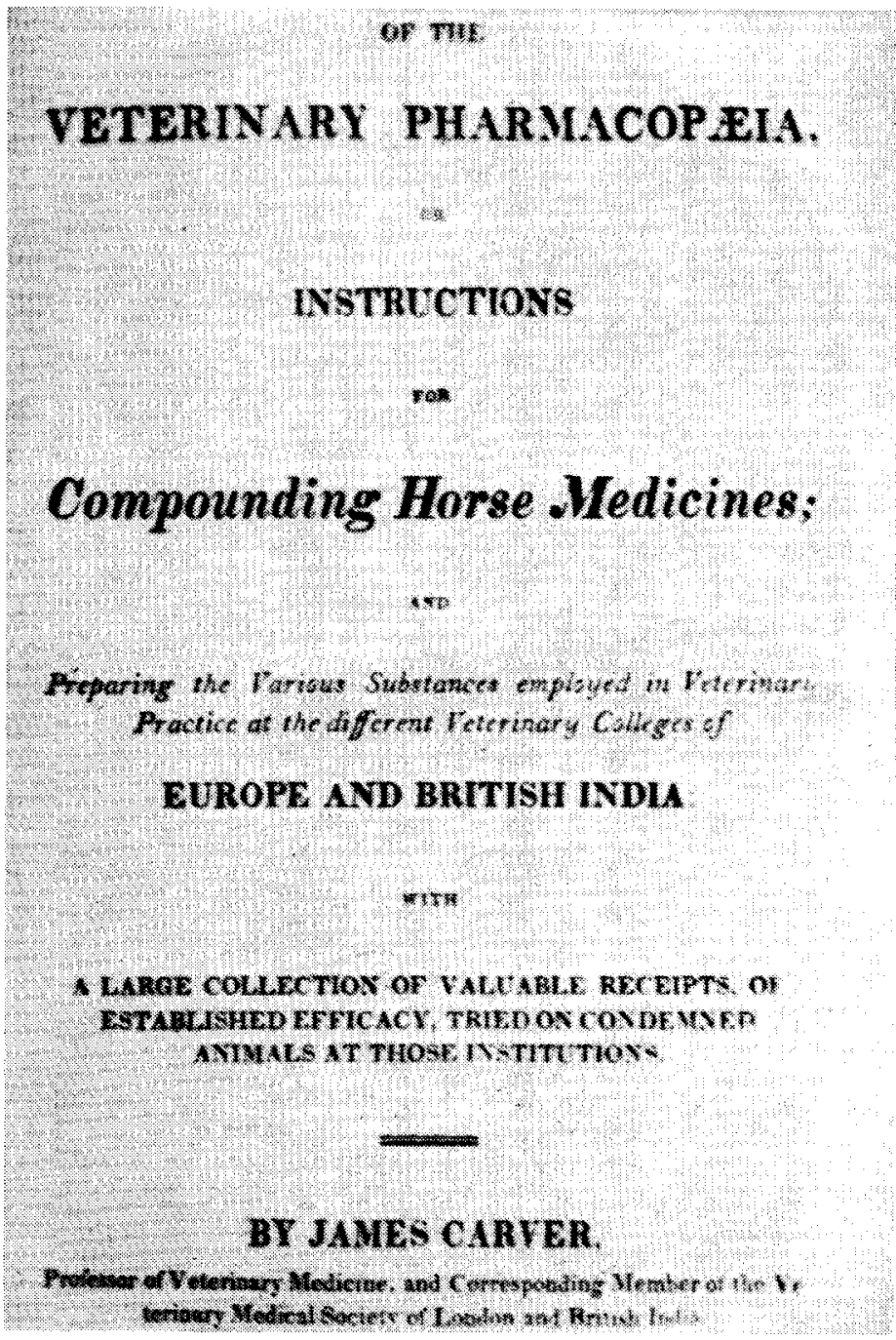

Internal title page from James Carver's Farrier's Magazine, 1818, a collection of essays on veterinary subjects. Although serial publication appears to have been intended, only two issues were published. $\mathbf{R}$. $\mathbf{R}$. Shomer collection
I cannot forbear offering scme remarks respecting the Veterinary profession, independent of the subject of the new Veterinary Forges I am now establishing in this city, with a view of laying the foundation stone for ameliorating the Diseases of Quadrupeds in general, and in order to give encouragement to those who may still feel a want of confidence in not knowing its having assumed the form of a science, as if it were a derogatory and hopeless profession . . to accomplish this, however, some time must be allowed.

Some disappointment has, without doubt, arisen, from unfounded expectations of relief in desperate and hopeless cases, where human art could not avail; and some, not finding their interest served in this respect, have become rancorous enemies to the establishment of the
New Forges, as well as to the profession... . Still there can be no doubt, that if human medicine and surgery have been aided by public establishments, the Veterinary art must admit of improvement by the same means; and that cloud of imbecility that has so long obscured and stigmatized the profession in this country, now promises gradually to be dispelled; and no doubt that in a few years, there will not be a city, a town, or a country village in the United States, but will have to boast a practitioner, whose abilities may do honour to a great national institution.

\section{Forging Ahead}

Following this, Carver inserts an "essay" promoting his proposed forges: 
Cities, Country Towns, and Villages, and Proprietors of Mail and Stage Coach Establishments, will find it an object of great commercial, as well as domestic importance to their own interests in obtaining smiths, and inviting them to receive instruction, and to establish themselves on their different lines. . . The following gentlemen, therefore, seeing the ignorance and incompetency of farriers, and others, who have hitherto practised on the diseases of horses in this city ... have cheerfully stepped forward to sanction and support it.

Among the several patrons listed by Carver are Drs. Chapman and Hewson, Professors of Anatomy, and Dr. Mease. He continues:

Country smiths, respectable young men desirous of emulating in this branch of the Veterinary Art, as well as to learn the surgical, operative parts of the profession, will do well to apply before the ensuing winter. And every person being so instructed, and found qualified, will receive a proper certificate, signed by the medical patrons, gentlemen and professor of the aforesaid establishment, as being better qualified to practise with advantage to themselves and to the public.

Carver adds that he has established a small laboratory, where:

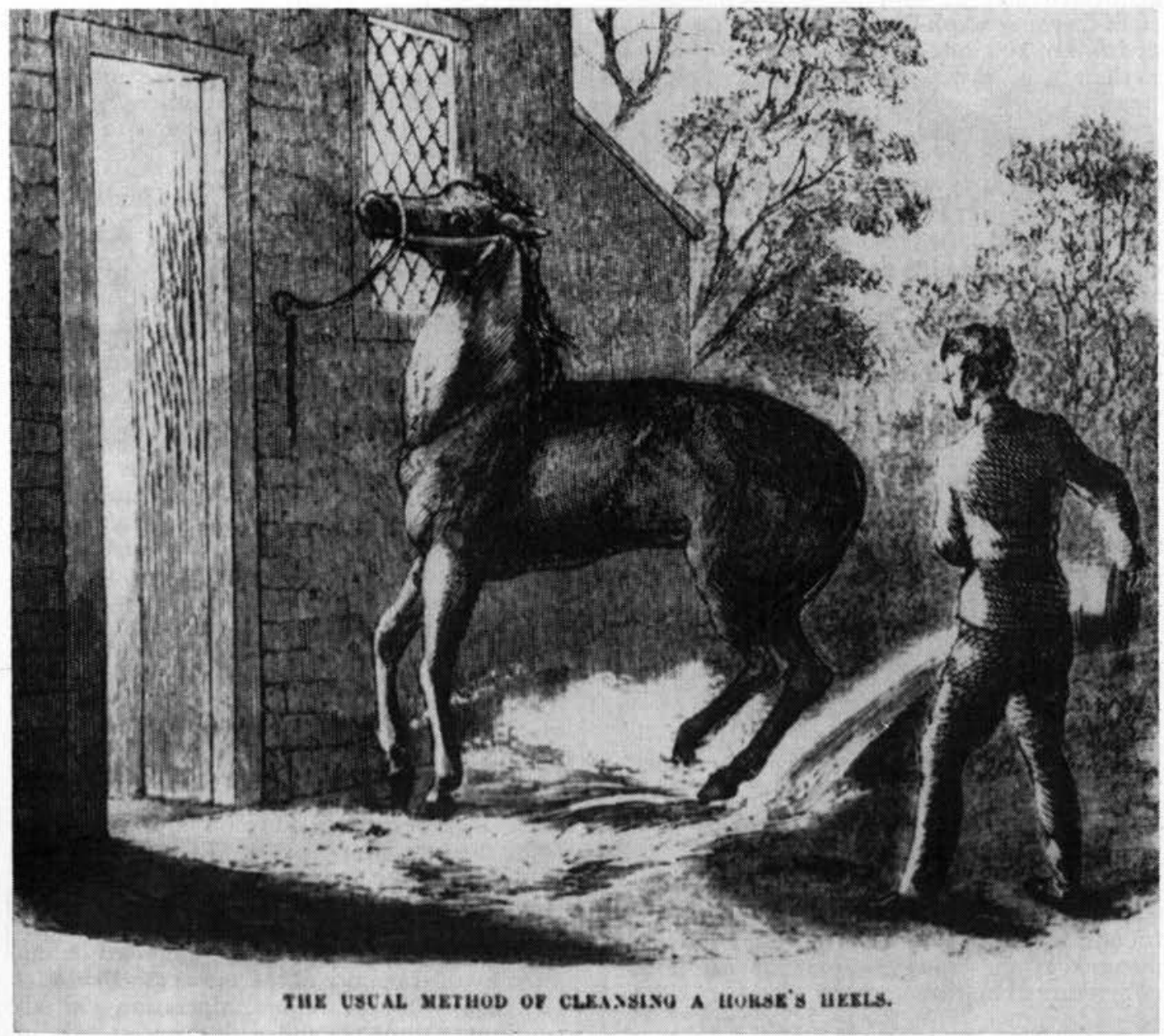

Although the aphorism "No foot, no horse," had been repeated since ancient times, few horsemen paid heed - but paid in terms of horses made useless before their time. Mayhew: Horse Doctor 


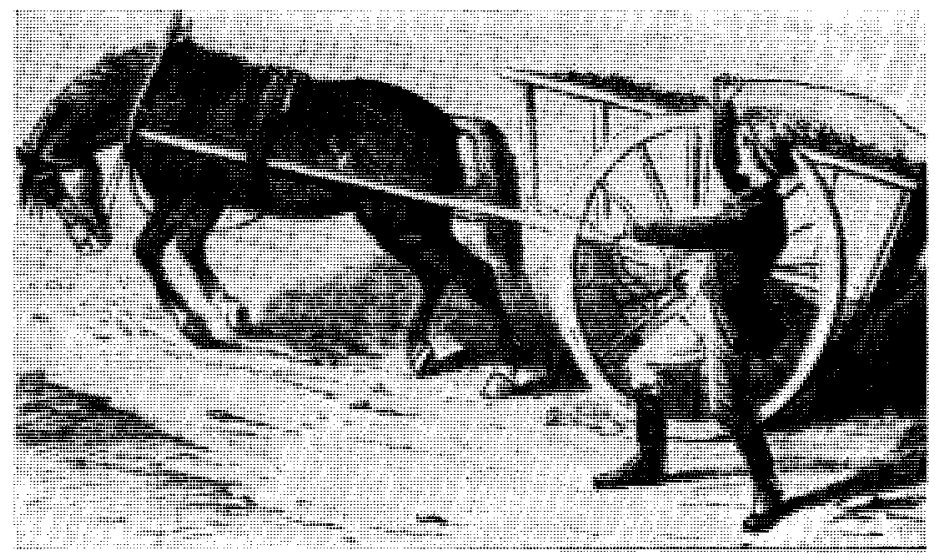

Overwork of horses, especially on stony streets, was often cited as a cause of foot troubles. American Agriculturalist

gentlemen may be supplied with what Medicines they may want. City and country druggists, desirous of retailing . . . may be supplied also. Each article containing a regular practical treatise on the complaint intended to be removed.

\section{Carver then lists some twenty-eight}

Subjects which will be taught and demonstrated to every smith on receiving instruction at the New Veterinary Forge ... [concluding with] how and why the shoeing art has for so many ages been involved in a cloud of darkness. With conclusions how this branch of the Veterinary Art may be drawn from contempt to respectability.

In an "Advertisement to the Faculty, Gentlemen, Farmers, and Graziers of Pennsylvania, and the United States in General," Carver gives a concise history of the veterinary art in antiquity, and an outline of the history of the schools of France. In this he states:

Dr. Rush, whose heart was ever warm for the introduction of any new branch of science, which might tend to promote the welfare of the animal creation, conversed much with me on Veterinary subjects, and laboured hard to prevail upon me to establish that pursuit in this city-but not having then obtained it scientifically, I proposed to Dr. Rush and other friends, already mentioned, my then intended pursuits at the college,-from whence I am now returned and commenced practice.

In a history of the London school, he mentions that one of its promotors, Granville Penn, is of the Penn family of Pennsylvania . . strange it is, that the very man who laid the foundation of the London Veterinary College, should be an American. . . May we not, therefore, hope, ere long, to see another Penn rise up and lay the foundation stone of a Veterinary institution in this country?

Carver's statement about the family ties of Granville Penn is correct, but it may be doubted that this made him an American.

\section{Professional Qualifications}

Carver then speaks of "The Character of a Veterinary Surgeon," saying:

There is, undoubtedly, no profession in which greater natural qualifications are required than our own. The more liberal nature has been in her gifts, the more carefully the first impressions have been cultivated by rational education - by so much better will a man be fitted for the practice of it. Youth, firmness, dexterity, acute sensation, sound judgement, and humanity, are the qualifications which may be considered as necessary for a surgeon, whether his patient be a man or a quadruped.

In elaborating on these, he says:

He that begins to study on the brute ... from the earliest period of life, will be most likely to acquire reputation ... Firmness... implies resolution to go through his operations, however hazardous or severe, undisturbed by any accidental circumstances - unmoved or unawed by the presence of spectators ... Dexterity ... enables him to finish an operation with all convenient dispatch, and with the least pain to the patient. ... Acute sensation ... is necessary to distinguish the true state of the pulse ... Sound judgement. . . enables him to form 
judicious prognostics... Humanity ... is the cardinal qualification of all; it reflects a lustre on the rest, and completes the true character of the man, as well as the surgeon.

Of the "acquired knowledge necessary to make a good Veterinary Surgeon," Carver says the most important are "a knowledge of the power and properties of medicines
... [and] a complete and thorough knowledge of Comparative Anatomy."

Carver's publication closes with a listing of his qualifications and testimonials as to his abilities; an invitation to the students of the University of Pennsylvania "to attend a Course of Lectures on the Foot of the Living Horse; and the various diseases
In his Farrier's Magazine (1818) James Carver gives a good description of the horse's eye and of the operation for cataract, learned while he was a student at the London Veterinary College. R. R. Shomer collection

\section{DIFERERT STAGKS OF CATKRACT}

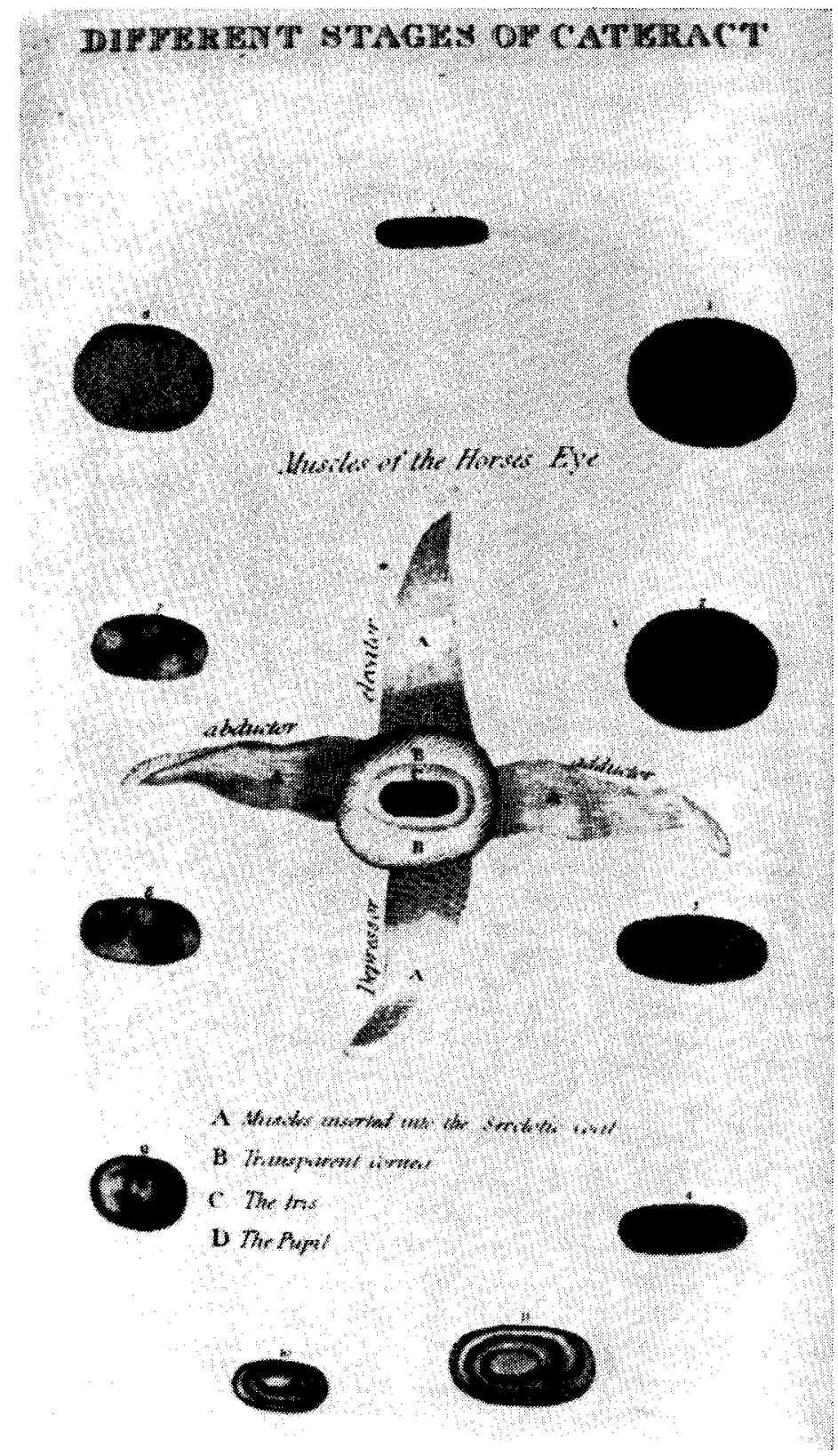


attendant on Quadrupeds in general" and an advertisement for his "Veterinary Bath." Finally, he gives: "Heads of Subjects to be treated of in Dr. Carver's proposed Publications," which is essentially what might pass for the table of contents of any standard work on farriery. Thus it would appear that Carver had intended to continue his magazine "In order that the public may be put in possession of all of the necessary information in Veterinary Science."

\section{Manure Factories}

The second issue of the Farrier's Magazine contains several essays on the eye of the horse and its diseases, some sixty-eight pages in all, undoubtedly some of the best veterinary writing that had appeared to this time in the United States. It would appear that this is primarily the substance of what was taught on the eye at the London school. Carver does, however, add some comments from his own experience. His belief, reinforced by teachings at the London school, was that ophthalmia and other affections of the eye were due largely to poorly ventilated stables, which he says, are converted into "storehouses and factories of manure." One of his objects is:

to point out and expose whatever I may have seen and witnessed, particularly on Long Island and among the Pennsylvania farmers, as well as in the city of Philadelphia, what I know to be so productive of causing so much blindness, as well as every way prejudicial to the general health of that noble animal. For, on Long Island, it is notorious, that three horses out of every five through the island, is blind with cataract; and if any one will only take the trouble for the space of one week, to walk up and down Market-street [Philadelphia], he will, I believe, find that I am not very far out of my calculation, as respects this state and city ... if people are determined to continue on, in their old way of stable deception, by suffering their horses to stand literally on hot beds of manure, and are determined to give no ventilation to their stables, certainly, as a veterinary practitioner, the more grist will continually be coming to my mill.

Carver is especially harsh on some of the practices of ignorant practitioners, as that of blowing powdered glass into the eye to cure "moon blindness." And in decrying the practice of farriers in cutting out the frog, he says:

In order to show the evil tendency which this abominable practice at one time produced in the British army, the officers of the regiment were obliged to pass a martial law, that every farrier who was found guilty of this crime, was branded on his posteriors with a hot iron in front of his regiment. And if some of the sons of Erin, at the south end of the town, were to have this operation performed on them a few times, I am confident there would not be so many lame horses in Philadelphia as there now are; for I have been witness to the abominable practice, and stood by and seen them deprive the frog of large slices, which I am confident it was not in the power of nature to replace in as many months.

In several articles on "The Epidemic Fever, or Influenza ... in and about the City of Philadelphia," Carver leaves no doubt that he had correctly identified the disease, but gives no satisfactory evidence as to how extensive it was. He says:

The cases in and about the city, from every account that I could collect, have been numerous, and I have this day learnt that it is still prevailing very much about Darby, Chester, and Wilmington.

Most of his material, however, relates to the history of the disease in Europe, and to a number of cases he had personally attended. 


\section{Veterinary Medicine in the Agricultural Press}

ONE OF THE MOST ACCURATE INDICATIONS of the state of development of a profession is the caliber of the professional journals. The accelerated flow of new developments in recent times makes it all the more apparent that the best interests of the veterinary profession could not be served adequately by books alone, however excellent these might be. This premise was equally valid in times past; in 1835, the medical historian, Bostock, attributed the superiority of Scottish medicine, in large part, to the excellent medical journals of the Scots: "a circumstance which has materially contributed to the improvement of the knowledge of practical medicine." It is a well established fact that major credit for the first real improvement in veterinary education and practice in England belongs to the Veterinarian, which began publication in 1828. Blaine, in his Outlines of the Veterinary Art (1841), enjoined students and practitioners to read all the veterinary journals.

\section{PERIODICAL LITERATURE AND PROFESSIONAL DEVELOPMENT}

The development of the veterinary profession in America to its present high status is closely paralleled by that of the professional journals. The present status of both could be recognized by the most disinterested observer; what is truly remarkable is that this has come about during the lifetime of a substantial number of still-active veterinarians. Prior to the publication of the American Veterinary Review in 1877, there had been only two abortive attempts at professional veterinary journalism. The Farrier's Magazine in 1818, published by James Carver, lasted for only two issues; the American Veterinary Journal, published sporadically by George $H$. Dadd in the 1850 's, terminated with the fourth volume. Obviously, neither had any appreciable influence upon the development of the veterinary profession. For nearly a century after this nation had asserted its independence, America remained largely dependent upon Britain for its supply of graduate veterinarians and most of its professional literature, both books and periodicals. Of the works published in America to 1860 or later, a large majority were reprints or digests of British works, or were by men whose training and writing was decidedly British. The only truly native works were those of self-educated veterinarians or by medical men who had interested themselves in the disease of animals. A substantial proportion of those published from 1860 to 1900 were also of foreign origin.

In examining the array of veterinary writings prior to the establishment of a professional veterinary periodical literature, it is painfully evident that what was available 
did not begin to attack the problems of livestock disease which were peculiar to America. To fill this void, the agricultural press, whose publications mushroomed from one in 1819 to more than 30 by 1840 , began printing articles on animal disease, and by 1850 more agricultural journals were published in America than in all other countries of the world together. Many reported on animal disease only incidentally; others conducted regular veterinary departments, some advertising: "a free horse-doctor with each subscription."

An adopted custom soon assumes the proportions of an inherent prerogative, and thus a number of the agricultural journals still are in the veterinary business - diagnosing and prescribing, rather than limiting their scope to the broader aspects of animal disease which are within their proper province. Had there been a thriving veterinary press at the time, the problem might never have developed, but under the circumstances which prevailed, it is doubtful that even a heavily endowed professional journal could have served its intended purpose until there was a substantial number of well-trained graduate veterinarians to make proper use of the information provided. Today the chief endowment of the veterinary press, as regards both association and independent journals alike, is the relatively small group of dedicated men in editorial offices who give continuity to the fundamental philosophies of the veterinary profession.

\section{THE AMERICAN FARMER}

The first agricultural journal, or at least the first to wield any considerable influence by virtue of its circulation and continued publication, was the American Farmer, founded in 1819 by John S. Skinner, a prominent agriculturalist in his own right. While it is true that a small number of publications, chiefly those of agricultural societies, containing articles on animal disease and the need for better veterinary information, had appeared before this time, these appear to have had but little influence outside their own limited spheres.
The Memoirs of the Philadelphia Society for Promoting Agriculture, first published in 1808 , is perhaps the most notable of this group, but only five volumes were published, the last in 1826, and its circulation presumably was chiefly among the members of the society. An examination of the early volumes of the American Farmer, therefore, should prove of interest in tracing the evolution of veterinary journalism in the agricultural press.

No veterinary contributions appear in the first five numbers (forty closely printed pages) of volume one. The first mention of any animal disease occurs in a digest of a British article: "On Draining," passing reference being made to the fact that sheep are less liable to "the rot" (liver flukes) on drained land. In the first of a series of unsigned articles "On the Murrain of Horned Cattle," the author says this is a subject: "not unworthy of attention," and that physicians are more capable of dealing with the problem than any other group, since "there is no treatise on brute diseases deserving even that name; nor can there be, in the present state of that art of healing." This science, he says, is a century behind all others.

Later, he expresses doubt that "the murrain" can be the cattle plague (rinderpest) of Italy because of its sporadic nature, and suggests poor food and muddy water as the most probable causes (the symptoms fever and bloody diarrhea - suggest Texas fever). The correspondent admits he is a novice, but feels qualified to give a number of remedies. These include diuretics; bleeding; purging with salts, calomel, and aloes; and enemas of linseed oil and salts: "taking care in using the pipe not to poke it in the gut." Also recommended was scalding the belly with hot water, and giving hot whisky toddy with juniper berries boiled in it. To advance the study of animal disease he suggests a medical board be attached to each agricultural society; the veterinary schools of England and France, he says, having received "only incidental aid from professional [medical] men ... are comparatively inefficient." 


\section{The Veterinary Art}

The first use of the term "veterinary art" appears in a letter from "A Rough Farmer," who relates:

I was informed by an old gentleman who practiced the veterinery [sic] art in Baltimore for several years before his death, that he believed that most complaints of the cows in Baltimore originated from the feeding on slops.

Under "Notices for a Young Farmer" the initiate is advised to teach himself:

by reading and observation, at least the outlines of VETERINARY KNOWLEDGE, and promote its encouragement. ... Do not depend on charlatans, or servants, for what a little attention on your part might avoid or remedy. ... When any of your livestock die of disease, or invisible casualty, have them opened, for discovery of the cause, and future instruction.

In an earlier "Notice," the young farmer was advised that human urine "is preferred by horses and cattle to salt; and is to them, salutary as medicine, as well as a condiment promotive of health.'

Another feature, continuing irregularly for several volumes, was the reprinting almost in toto of $A$ Compendious Dictionary of the Veterinary Art, by the Britisher, James White, although the name of the author is not mentioned. Some of the items inclucled in the first volume are: abortion, which may result from falls, or the smell of blood or carrion, bleeding being the only remedy; abscesses, which should be poulticed and opened; age - of the horse by its teeth, and cattle by their horns; blackleg, in which the emphysema and great mortality is noted, bleeding and salts being the only recourse; bloodletting (In England, White was known as "bleed 'em White."); and calving, in which a good description of normal and abnormal presentations is given. A prominent characteristic of most of the agricultural journals was the reprinting of British works serially, and of articles from British journals. This put a considerable amount of information at the disposal of farmers, although much of it did not pertain to local problems, and some undoubtedly created local problems.

A number of articles appeared on hydrophobia in man, together with a number of "cures," which would appear to have been most successful in treating those bitten persons who most likely would not have developed the disease. A good description of the rabid dog is given, but there is no suggestion that rabies might be other than a purely medical problem. That rabies was a serious problem at this time may be adduced from the writings of a number of physicians in the medical press.

\section{Burnt Tongue}

Several issues carry articles on a disease of cattle, horses and hogs which the observers term "burnt tongue" or "sore tongue," the symptoms of which are practically identical with aphthous stomatitis as described by Udall. One writer reports he saw the disease as early as 1801. Opinion was divicled as to whether or not it was contagious; all agreed it was fatal if not treated. Treatment ranged from astringent mouthwashes to purging and the inevitable bleeding. One report states that asafetida tied to the bridle as a preventive was "used with success."

This disease brought to the American Farmer the first contribution by a veterinary surgeon, John Haslam, a graduate of the London school, who had come to America in 1803, and who subsequent to 1819 contributed many articles to the agricultural journals. He reports: "I have had a great number of horses and horned cattle under my notice, labouring under the present epidemical disease," but later he says the disease is "neither contagious nor infectious." He claims to have cured all of his cases with a mouthwash of alum, saltpetre, vinegar, and honey, and by administering a pint of linseed oil daily. Bleeding, he says, has no effect, and "the cause of the disease is enveloped in mystery."

Thus in the space of one year, the American Farmer, at first devoid of any information on animal disease, began reporting the observations of amateurs, and finally attracted the attention of one of the inore 
capable graduate veterinary practitioners of the time. This increasing interest in animal disease problems led the editor in subsequent volumes to call for the establishment of veterinary schools; until these were established, he suggested the addition of regular lectures on the veterinary art to the curriculum of medical schools.

\section{Me Too}

That other agricultural journals should follow the pattern set by Skinner was a logical development; their success in this venture into veterinary journalism undoubtedly was a factor in keeping the circulation of the ill-fated American Veterinary Journal below a profitable level. On the other hand, it would seem doubtful that America was ready for a professional veterinary journal as early as 1850 . According to the editor, George H. Dadd, there were only 15 graduate veterinarians in America in 1847. Thus the field was wide open for the establishment of full-fledged veterinary departments in the agricultural journals. A number of these were conducted in a professional manner by competent veterinarians; others, like the deluge of the "every-man-his-own-horse-doctor" type of work, probably exerted a powerful delaying action upon the development of a strong veterinary profession.

The first appearance of a "Veterinary" column in the American Farmer was in 1830; this, however, was a reprint from Skinner's American Turf Register, which had a Veterinary Department from its inception in 1829.

Concerning one function of an agricultural paper, the editor of the Michigan Farmer suggested in 1845:

Suppose a disease to appear among ... domestic animals, and to produce serious damage. All set to work to discover the cause, and devise the most efficient remedy. Their joint efforts will be more likely to be successful, than those of any single individual. At length the investigations of one of their number is crowned with the desired success. He has discovered the cause and the remedy, and straightway communicates his discovery to his neighbors. The ravages of the disease are immediately stayed, and perhaps thousands of dollars are saved to that single community.

The scheme may have seemed Utopian at the time, but like other well laid schemes of mice and men, this too "gang aft a-gley." Animals - some of them at least-persited in getting well despite the machinations of man, and thus given sufficient animals for "experimentation," every man, and his little brother, found infallible cures for everything, and willingly communicated these to less forturnate mankind. Most editors, unfortunately, lacked discernment in matters relating to animal disease, and while many worthwhile contributions were published, so were many atrocities.

The present high status of veterinary practice is in no small part attributable to the efforts of the professional veterinary journals, both in fighting for proper recognition of the work of the veterinarian, and in seeing to it that the practitioner has the tools essential to waging the good fight. As the bellwether of the profession, the veterinary journals of today serve as the means of giving continuity to the fundamental philosophy that enduring values are built upon service. The agricultural journals, insofar as they call attention to disease problems and the need for adequate professional care, undoubtedly serve to extend the sphere of veterinary service.

\section{Smooth as Glass}

Volume two of the American Farmer offers excerpts from a sporting pamphlet which "contains many directions for the cure and management of horses and logs." The author, a Col. George Hanger, advises:

When a dog looks unkindly in his coat, though he has been physicked, give him three doses of powdered glass, as much as will lie heaped up on a shilling to each dose. This will make his coat very fine, and he will look well in his skin; besides it is a very great cleanser. The powdered glass must not be made of the green glass bottles, but from broken decanters and wine-glasses, powdered and ground in an 


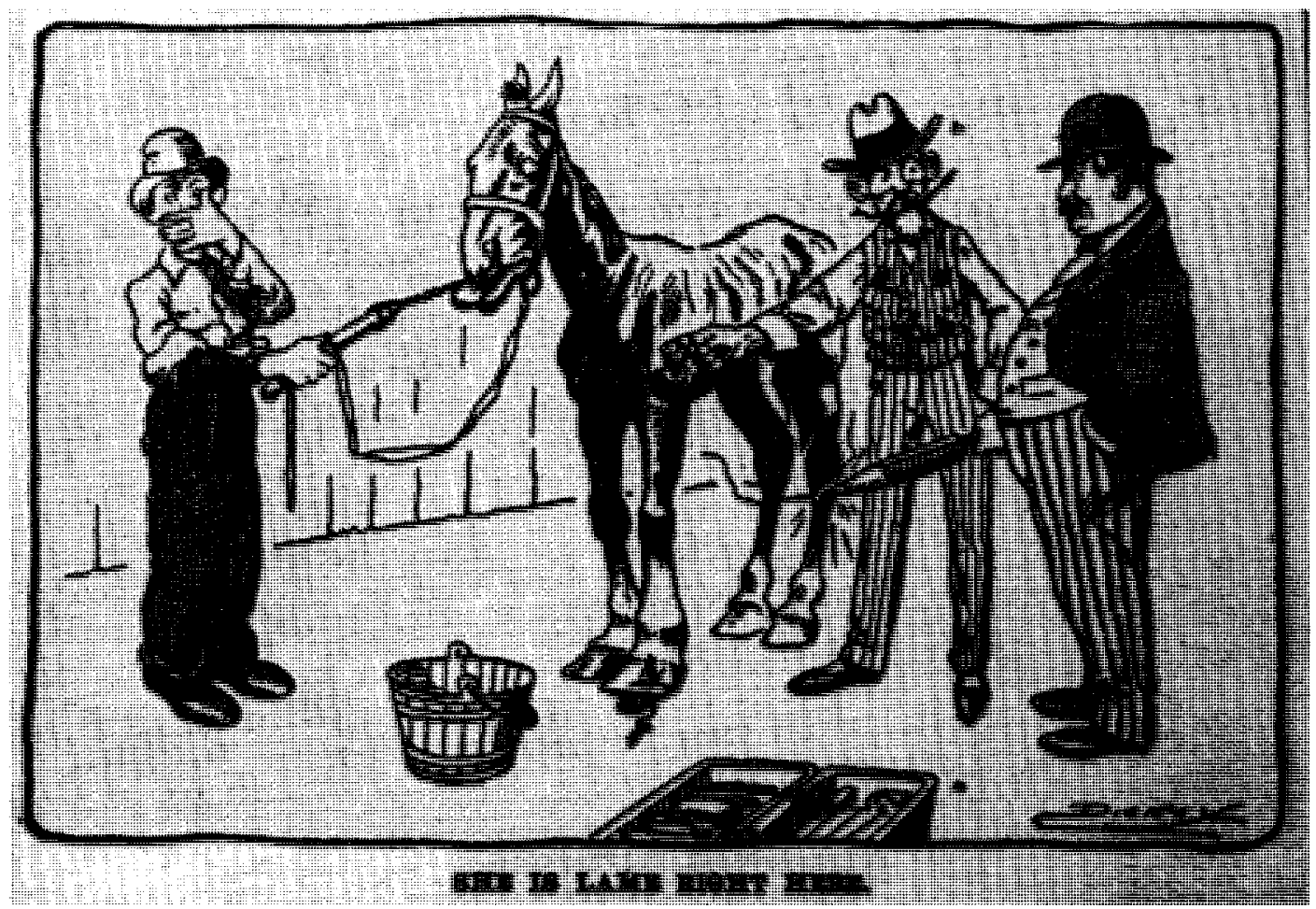

Cartoon lampooning the all too common diagnosis of "shoulder lameness" - frequently despite obvious indications to the contrary. Note the outsize firing iron. From a late nineteenth century satire on "horsey characters." Howe: Stable Conversations

iron mortar, then sifted through a fine muslin sieve.

On the other hand, for lameness in horses:

If the cause of lameness be not very visible to the eye, you may rest assured it lies in the foot or fetlock joint; in this case, send for a veterinary surgeon; for to cure it, great skill and practice is necessary, and a thorough knowledge of the anatomy of the foot, and fetlock joint. Wise John Grooms and the farrier, provided they know not where the lameness really lies, swear the horse is lame in the shoulder, whereas the lameness is in their heads.

Under the heading: "An old Story and a new Invention," a correspondent suggests:

squeezing to death, between the thumb and forefinger of the right hand, the insect that causes the gapes in young chickens ... the windpipe, being a soft tube admits of sufficient squeezing to kill the worms without any injury to the chicken.
Another reader had suggested the most common treatment at the time-extracting the worms by means of a feather. Gapeworms of poultry already were a major problem, and editors of the agricultural journals, who apparently at first published every letter sent them (and perhaps wrote a few themselves), eventually had to call a halt on those pertaining to gapeworms.

In response to a correspondent in 1824 , who was of the opinion that in gapes "the disease produces the worm," Skinner opined that the reverse was more likely the case, and observed:

among poultry women, it is an axiom, not to let young poultry go abroad very early in the day - it may be that, if the worms are picked from the earth, the sun drives them below the surface. That there is something in old dunghills, unpropitious to the rearing of barn-door fowls, is well known, for it is invariably found, that they succeed best, where new establishments are made on new ground. 


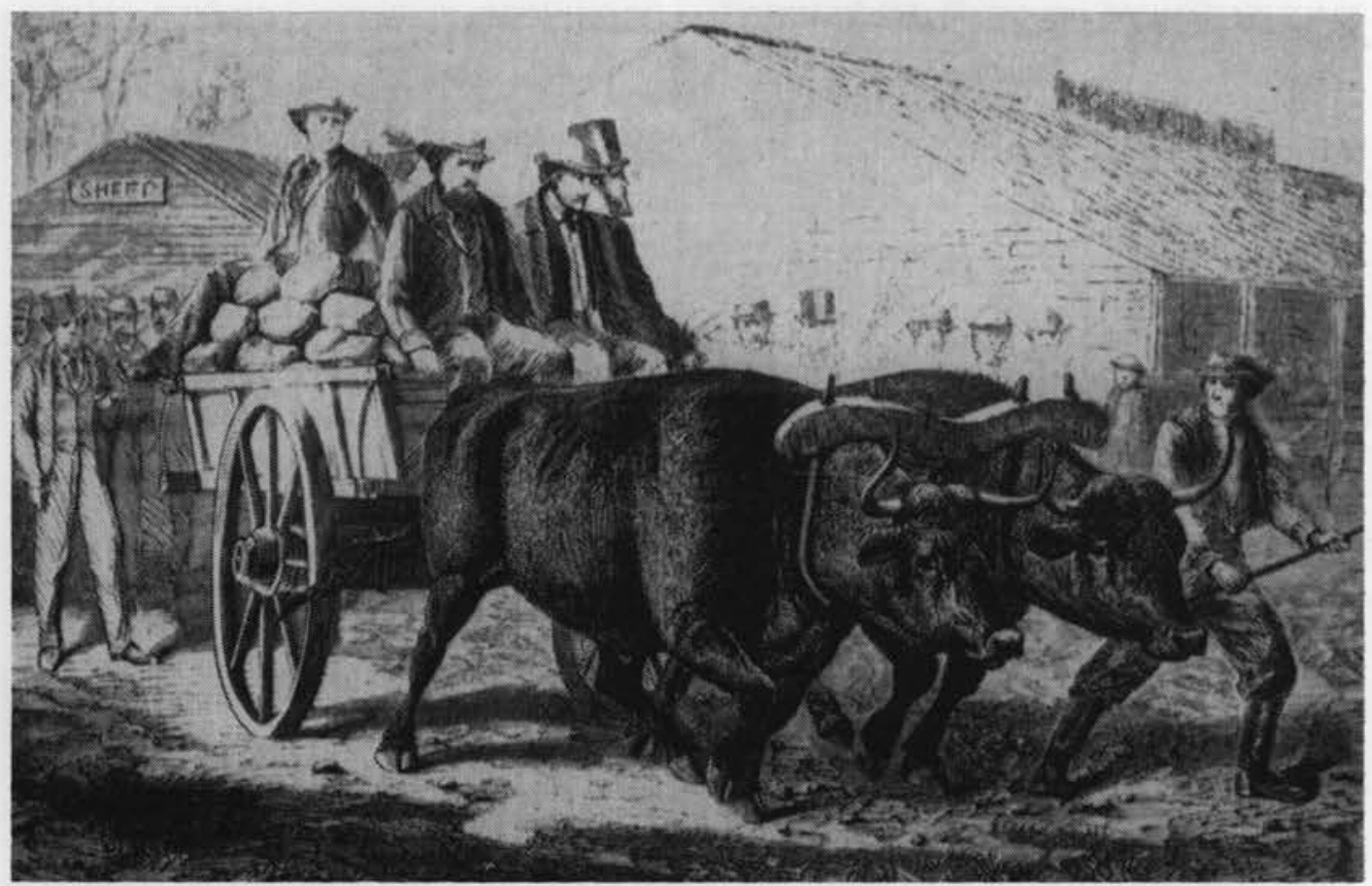

Weight pulling, at first by oxen and later by horses, has been a favorite and hotly contested sport at fairs since colonial times-only recently supplanted by rather less romantic tractor trials. American Agriculturalist

It may have taken some time for poultrymen to appreciate the axioms of poultrywomen, but communication between members of the gentler sex appears to have something of the nature of a party line. A "Cousin Tabitha"-had observed that a negro woman of her acquaintance, who raised chickens in the woods and burned over her poultry runs to get rid of leaves, had little trouble with disease. Tabitha relates:

I have found that burning over my fowl yards, with leaves or straw, white washing the chicken house, and ploughing the yard and digging up the floor of the house, usually has the effect of lessening the number of small vermin and insects, and may in other ways have been salutary.

\section{Horses vs. Oxen vs. Mules}

A lively discussion of the relative merits of horses vs. oxen developed in the second volume of the American Farmer, occasioned apparently, by a recommendation of
President Madison that the use of oxen should be encouraged in preference to horses. Timothy Pickering, the former quartermaster general of the Continental Armies added his weight to the argument by asserting that without oxen to move heavy ordnance the siege of Yorktown would have been attended with "great delay and difficulty." $\mathrm{He}$ had turned to the use of oxen in the winter of 1780 because of "the considerable destruction of horses in the operations of the way, and the great expense of procuring and supporting them." Some farmer-friends of his, he relates, had turned to the use of oxen for ploughing and other draft because their horses frequently were sick when needed, or they became mired too easily on the muddy spring roads. He quotes a letter from one:

This spring all my horses became sick, and I was forced to buy a pair of oxen. I supposed I should be tired of them; but on the contrary, I am tired of horses. 


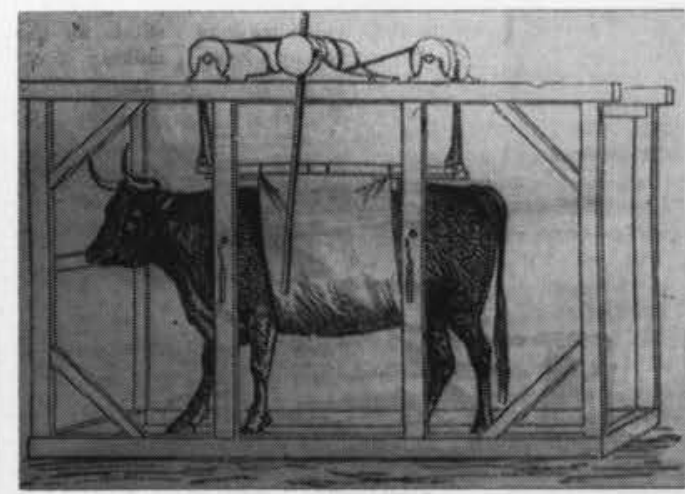

In most areas, oxen were the principal draft animals, and shoeing was essential for road work or work on stony ground. Stocks were necessary for supporting heavier animals which could not maintain their balance on three legs. American Agriculturalist

In a letter "On Shoeing Oxen," a correspondent states:

A great objection to the use of Oxen for draft in Virginia is, that during a considerable part of the winter their feet become so lacerated by the ice and frozen ground, that they are rendered unfit for service. The only effectual remedy for this evil is shoeing; - but owing to the supposed difficulty attending the operation, it is seldom resorted to.... Shoeing is a very simple operation and may be performed by any smith ... but the apparatus for confining the ox is unknown here. ... In Massachusetts, it has been in use from time immemorial, and it is considered a necessary appendage to every smithery.

The same difficulty was observed in western Pennsylvania, where "our blacksmiths do not know how, and will not learn because they think it degrading to shoe an ox." Oxen, unlike horses, usually cannot support their weight on three legs; thus the need for stocks with a broad belly band.

The subject of economical farm power later evoked paeans of praise from proponents of the mule. Thus it was claimed that mules could be worked twice the number of years a horse could, and at half the expense of keep. Also:

The contrast in the mule's freedom from malady or disease, compared with the horse, is not less striking, indeed, it is not improbable, but a farmer may work the same team of mules above twenty years, and never be presented with a farrier's bill, or find it necessary to exercise the art himself. . . . If by hard fare, or hard work, he is reduced to a skeleton, two or three weeks rest and good keeping will put him in flesh and high condition for labour. I have witnessed several such examples with subjects twenty years old; so much cannot be said of a horse half that age. The expense of shoeing a mule, the year round, does not amount to more than one-third that of a horse.

Another enthusiast, who had been "in the habit of observing mules ever since I was a boy," insists:

I never saw one sick; nor have I ever seen one foundered, nor have I ever seen a dead one. I believe they seldom die but from old age, and we have not been using them long enough for many to have died in that way. I do not believe they are subject to the distemper, glanders, staggers, or any of the common complaints of horses.

Mules may not be made like this any more, much less horses, but one horse with the tenacity of a mule was mentioned by a correspondent in 1825 . This remarkable animal was known to be 63 years old at the time:

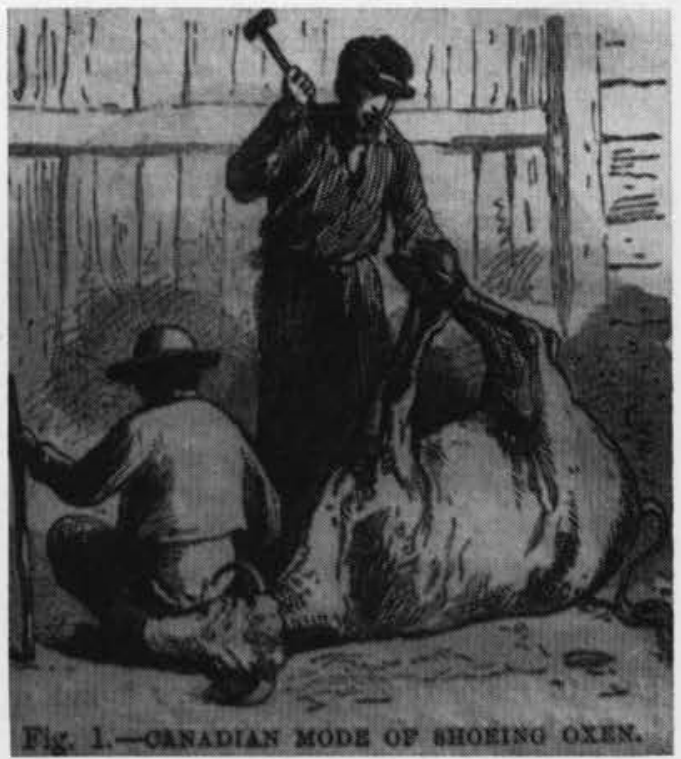

An alternative to using stocks for shoeing oxen was developed by Canadians, but this method was little used in the United States, perhaps because it was believed that cattle would die if placed on their backs. American Agriculturalist 


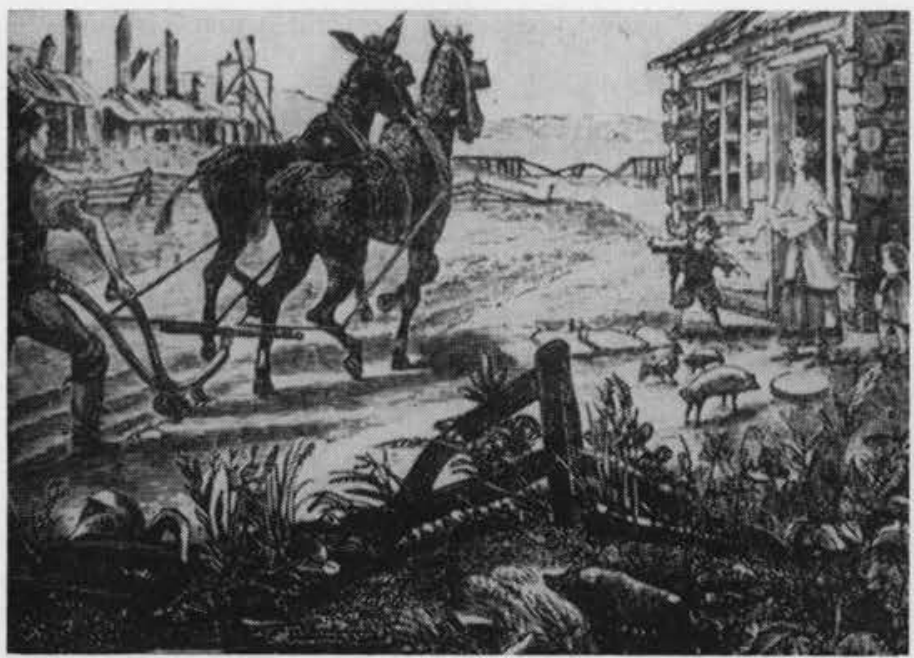

\begin{abstract}
"Poor farmers," who took pride in getting the last ounce of energy from their animals with the least input found the mule admirably adapted to their methods. Manning: Stock Doctor
\end{abstract}

When young, and, indeed, till he reached the age of 50 , he manifested an extremely vicious disposition. . . . Thirty years of his life, it seems, were spent in a gin, and the remainder ... in towing boats. . . . This extraordinary animal is healthy, and manifests no symptoms whatever of approaching dissolution.

Some men, however, found the secret of killing mules, for a Florida correspondent to the American Agriculturalist in 1846 inquires about "the cause of so many of our mules and horses dying with the colic." He says:

We are the most unfortunate people in the world as regards our stock. I lose three, and sometimes five mules every year by the colic; every day there is a mule brought to me from the field sick with the colic.

His admission: "We plow them hard; [and] give them as much water as they can drink when they are taken out to be fed," caused the editor to remark: "No treatment ... would be more sure to induce colic." Another correspondent adds to this:

Mules are but little subject to disease, except by inflammation of the intestines, caused by the grossest exposure to cold and wet, and excessive drinking of cold water after severe labor. ... .

No opinion is more erroneous than that mules can thrive on brambles and briars. They may live, but cannot thrive, if treated inhumanely, they will treasure up their revenge for years, until an opportunity offers to gratify it.
They are called obstinate by mulish drivers, and by none else.

\section{Spayed Stock}

The matter of the deterioration of dairy stock in America occupied the attention of a number of agriculturalists around 1820 . A major problem was:

The young cattle are, with few exceptions, without any kind of shelter during the whole of our severe winters. They are foddered with poor hay, straw and husks, and suffered to browse in the woods, and in the spring become so feeble that they can barely crawl up the hills to crop the honey suckle clover; this luxuriant herbage soon restores them ... but they are to undergo another pinching winter! ... Can it be expected, under such a course of treatment of the race, for nearly two centuries, but that the organs for the secretion of milk, will become diminutive?

The writer mentions that a number of heifers which were slaughtered prematurely would afford greater profit if they were spayed, either to fatten for meat or as work animals. Spaying of heifers, which British veterinarians later considered to have been an American innovation, is mentioned as being commonly done in Yorkshire, from whence it was introduced to New York by an English farmer.

A quotation from a French veterinary journal, appearing in the Michigan Farmer for 1864 , credits: 
a land owner in the United States, Mr. Winn ... [with] the first practice in spaying cows. The object of the operation was to maintain in the cow, without interruption, a supply of the same quantity of milk that she gave at the time of spaying.

The editor states:

Comparatively few stock raisers or farmers in Michigan, fully understand either the art or advantages of spaying cows; still we have among us one of the most successful operators in the country, in the person of Mr. William Wallington, of Ann Arbor, he has practiced this for a number of years ... operating on full one hundred cows in different parts of the State, and the demand for his services have increased to such a degree that he has continual calls from all points. Every operation without any exception has been successful in securing the object aimed at, and no injury has in any case happened to the animals treated.

The spaying of sows, of course, had been practiced for centuries; the sixteenth century sow-gelder, Jakob Nufer, achieved immortality by (reputedly) successfully performing a cesarean section on his wife. Also, the operation is described in a number of British and colonial American works of farriery. In response to a request for the method of operation, a Maryland correspondent to the American Farmer in 1822 obliges with one "practised by a very expert hand in this part of the country." With the hog strapped to a board, a flank incision was made, through which:

the pride and the bag is to be drawn ... after cutting the pride off, the greatest care must be taken to return the bag to its former situation ... more are lost for want of attention in that particular, than any other.

Spaying of ewes never became common, but one spayed ewe mentioned by this correspondent was "the fattest he ever beheld." The spaying of sows, however, apparently was a novelty in some circles, for a Massachusetts pig farmer in 1824 wrote, "I never spay sows, because we have no one who knows the mode, which is to be regretted." It would seem likely, however, that he would have regretted it all the more had he had the services of a character who in 1850 reported on spaying sows by a "new process," which according to this innovator:

I tried with success, and with less pain to the animal, than when done with the knife. It is, to inject with a small syringe, up the uterus, about a wine-glassful of sulphuric acid. This destroys, on the part of the sow, all desire to take the boar.
Some pig problems have changed little-and the method of handling them less than the attire of the practitioner. Clater-Armatage: Cattle Doctor

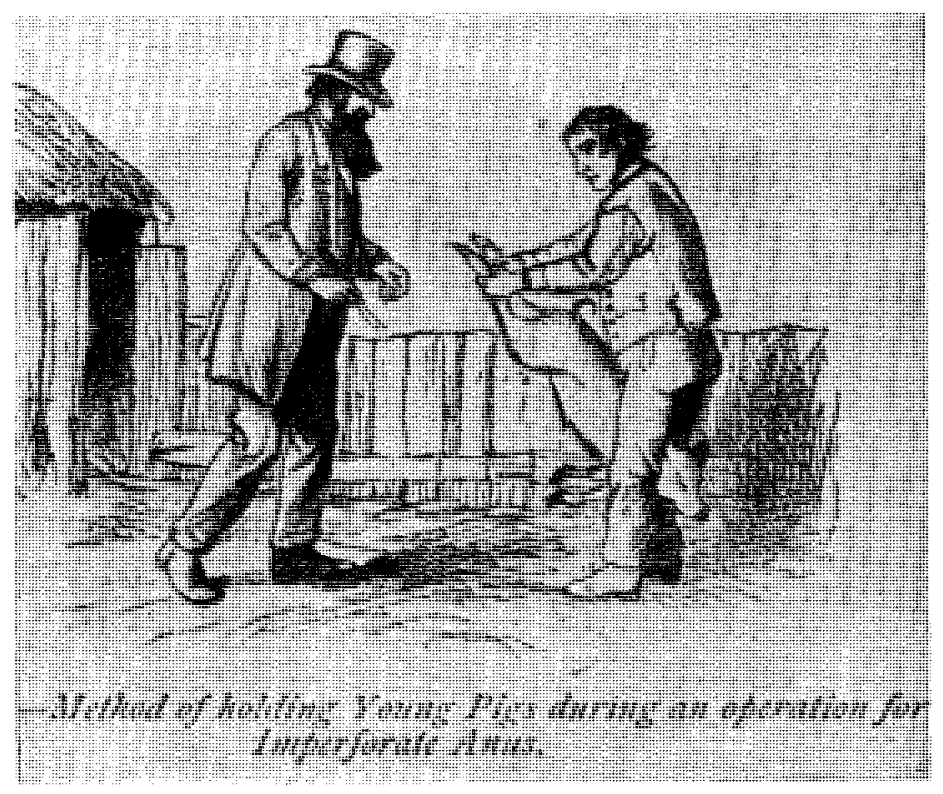


Offhand, it would seem more likely that it would have been more accurate to have said simply, "This destroys part of the sow."

Equally curious is the "Substitute for Spaying" offered by a correspondent to the Cultivator in 1838 who says:

The old method of gelding sows is not only very cruel, but quite disagreeable to the operator, as well as dangerous to fat animals . . . the modus operandi in this neighborhood, as practised by myself lately, but much longer by others, is simply this: . . pass the small end of a common goose quill down the vagina two inches or more ... through which drop six or seven shot, and your work is complete.

A reader who later inquired about the efficacy of "bulleting" was told by the editor, "the practice... has been a failure... spaying is to be preferred."

If "elastration" should be thought a recent innovation, the editor of the American Farmer in 1823 notes: "Many farmers emasculate their lambs by a ligature made on the spermatic chord, which soon occasions the testicles to rot off."

\section{Horn Distemper}

The ever-present "horn distemper" is mentioned as an inevitable accompaniment of the system of cattle keeping - an early recognition of this relationship:

My experience tells me the cattle poorly fed become feeble, and when severly pinched with the cold, their blood being weak, is driven from the extremities, which, becoming thus defenseless are of course frozen, and I believe it is here proper to state also that the horns become hollow in proportion to the poverty of the creature that wears them.

Another correspondent, however, through "accurate observation," finds that any softness in the tail:

is proof of tendency to hollow horn. . . . In New England, they all cut off the tails. . . I I have seen an a nimal on her side, which, within half an hour, was led to rise and after eat, merely by cutting off three inches of the tail.

In 1824 an "agriculturalist" disputes the idea that it is only animals in poor condi- tion that are subject to hollow horn, and while the disease is to be diagnosed with the gimlet, "cattle without horns are quite as subject to it." Some, he says, rely on the feel of the horn, but this is uncertain, as it may be either hot or cold:

A very small gimblet will, however, remove all doubts ... if the disease does exist ... little or no blood will follow the boring; whereas if the disease does not exist, you will find blood immediately upon entering the horn. The gimblet used for boring, should be well washed and greased after using; for if it is not, and should be used to try the horn of an animal not actually affected with the disease, it will most generally give it to them.

Comment upon the latter would seem superfluous.

The subject of horn-ail attracted the attention of Joseph Fiehrer, Veterinary Surgeon, lately of France and a resident of Harrisburg in 1841. He notes that the disease "is so very prevalent in America," and that the common treatment: "is entirely wrong in principle. .. Boring the horns is at most curing symptoms and not the disease." Bleeding and purgatives were his mainstay. The "disease" apparently was better understood by at least one Ohioan, who gives the following preventive for "Winter-kill" of cattle and other stock:

R. Good shelter-um, q.s.

Corn-meal-um q.s.

Clear water-um q.s.

The "corn-meal-um" is to be made into a poultice, and kept constantly applied to the mucous membrane of the stomach. For the benefit of strictly professional men, he suggests the above may be given as follows:

$\begin{array}{ll}\text { R. Refug. opt. } & \text { q.s. } \\ \text { Zea pulv. } & \text { q.s. } \\ \text { Aq. font. } & \text { q.s. }\end{array}$

One adequate explanation of the deterioration of livestock may be found in the experiences of a farmer of upper New York State who apparently had caught the Merino fever in 1814 , and

had all the disadvantage of inexperience to encounter - which proved almost fatal. I win- 
tered my sheep in the open air, without sheds; my lambs came in February, and mostly all died; and those that survived were poor little nurly things, and mostly all died the next winter. I also lost about one-fifth part of my old sheep, which I think was mostly owing to their being constantly exposed to the cold rains and snow; for they were well fed.

One solution, although an expensive one, was to import new foundation stock from England. An invoice for 12 head of cattle shipped to Kentucky in 1817 shows the cost on board ship in England to be (in round figures) $\$ 1,500$; freight and expenses to Baltimore, \$1,500; insurance to Baltimore, $\$ 1,100$; freight $\$ 500$, and insurance $\$ 1,650$ from Baltimore to Kentucky. Together with incidental expenses, and the fact that one animal had died, and another left lame in Maryland, this meant that animals costing about $\$ 125$ in England were worth about $\$ 700$ delivered in Kentucky. The accepted wage for farm labor at the time was seventy-five cents per day.

\section{Prodigious Porkers}

In the same issue of the American Farmer there is a lengthy article by James Mease: "On the Principles of Improving the Breed of Domestic Animals." To refute the idea that all American stock was of inferior size, he gives the weights of a number which were on record - this was early in the craze for huge stock. Several oxen mentioned exceeded 2,500 pounds, two in excess of 3,000 . One weighing 2,800 pounds at seven years brought $\$ 1,000$ for slaughter. Most of these animals were worked for several years, then fattened for meat. Numbers of pigs ranging from 700 to 1,000 pounds are also mentioned; one in Virginia reached 1,200 pounds, and one in New Jersey, 1,350 pounds while yet under three years of age. In the 1840 's several weighing 1,400 pounds are mentioned.

In 1827 "the great ox Columbus, weighing 4,000 pounds, probably the largest in the world," was placed on exhibition, and

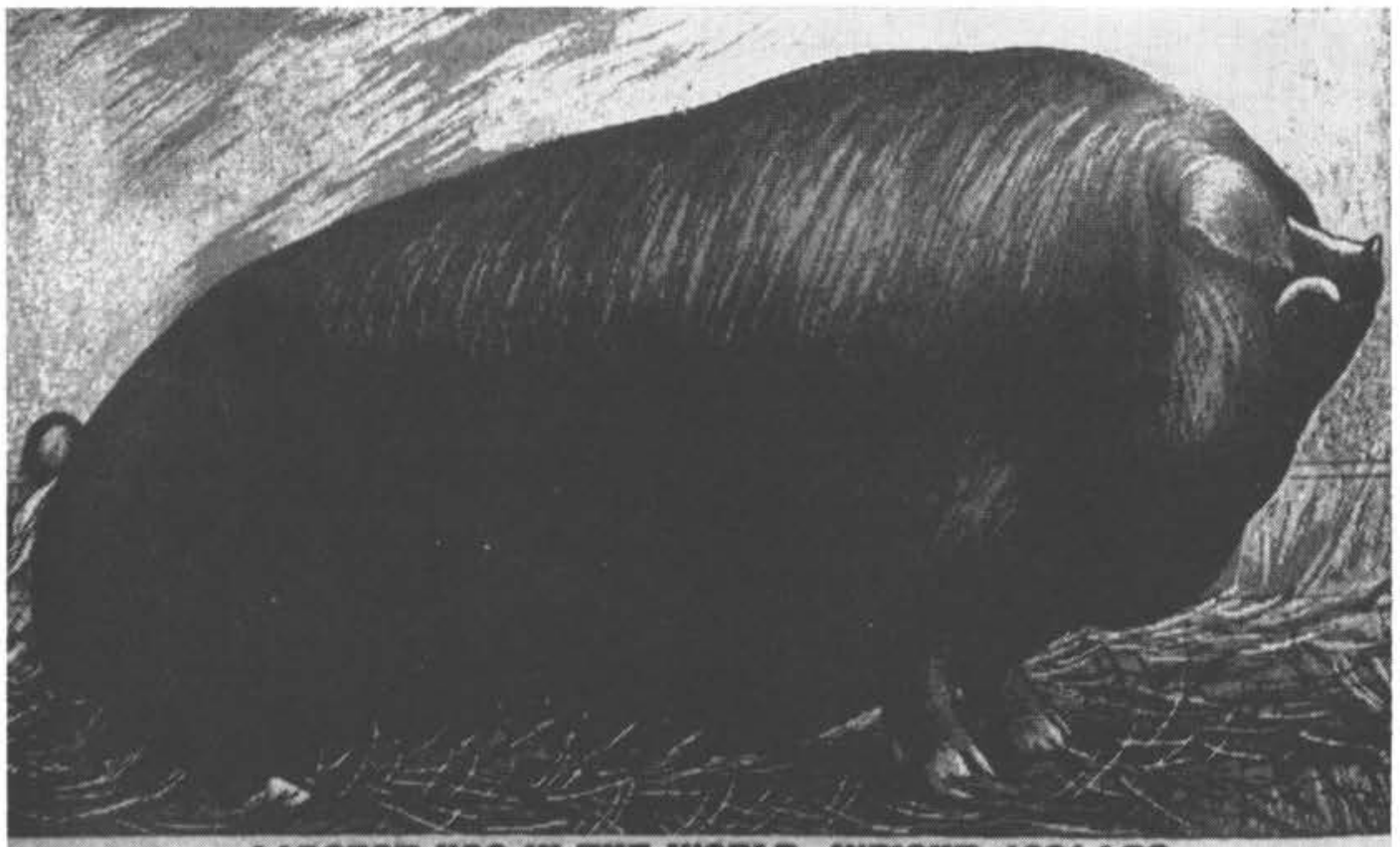

LARGES HoQ in THE WORLD. WEIAT, 1621 LBS.

Stock food companies used pictures such as this to suggest what their wares would do. This beast - if depicted with any degree of accuracy - suggests those of ancient Roman times which, reputedly, had to be wheeled to pasture. Contemporary advertisement 


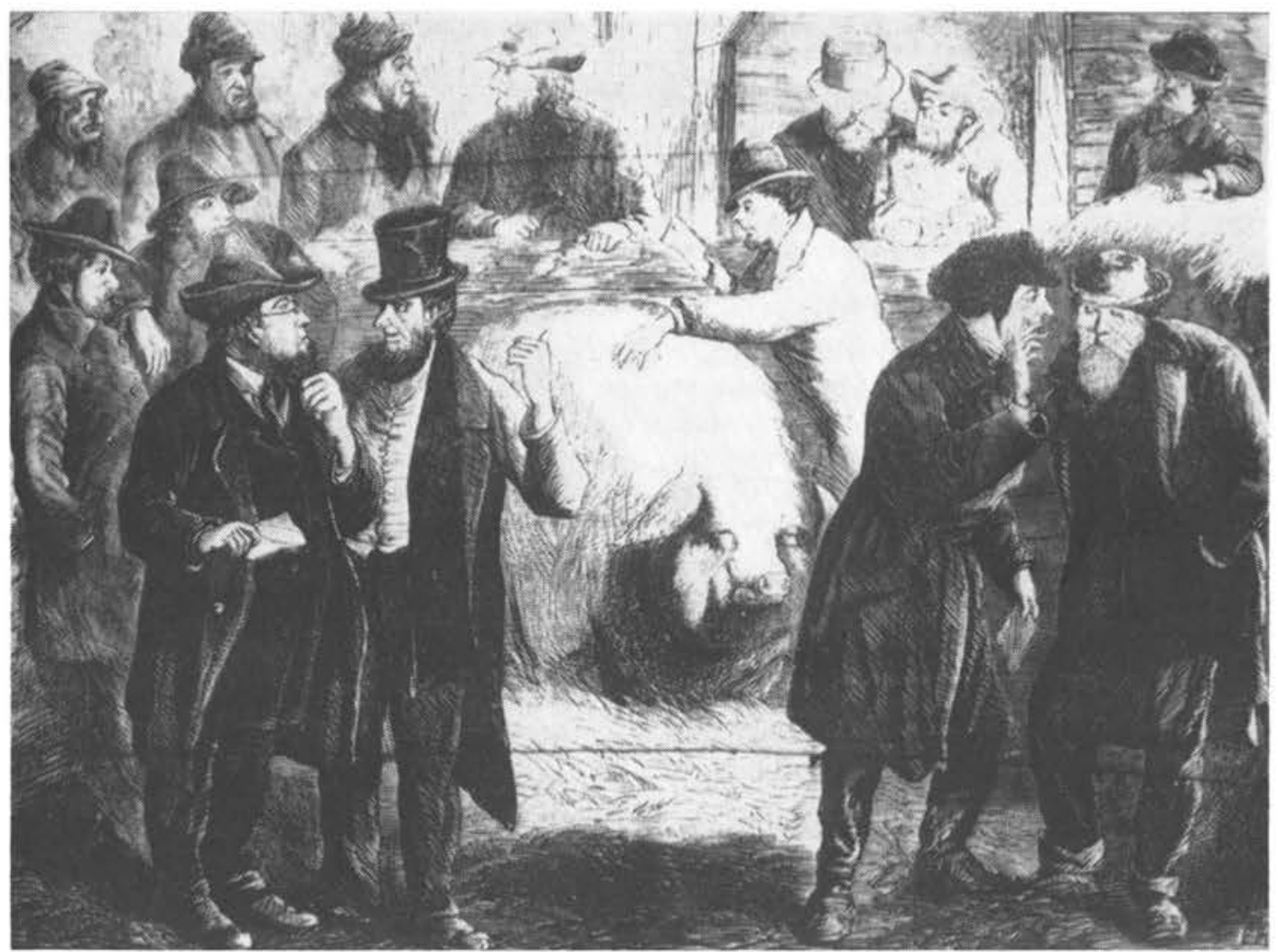

The mania for huge animals had a natural concomitant in the pastime of guessing their weight at fairs. Agricultural editors lampooned both the mania and the methods for determining weight - said by some to consist of balancing the hog against a number of rocks and then guessing the weight of the rocks. American Agriculturalist

was viewed by more than 40,000 persons in Boston, New York, and Philadelphia. Although seven years old, "he has not arrived at his full size, but may be made to weight 1,000 pounds more . . all pronounce him the most noble and extraordinary animal ever exhibited." The following year he had been "exhibited in all the principal cities from Maine to Virginia, and has been viewed by more than 60,000 persons." In quite another category: "There is also the extraordinary Small Cow, that measures only two feet ten inches in length. She is nine years old and well proportioned." Admission to see Mutt and Jeft was 12 cents - children half price.

In the former category was an Ohio hog weighing 1,260 pounds, on which the owner had realized some eight or nine hundred dollars in exhibiting it at $61 / 4$ cents a view, and for which he was offered $\$ 2,500$ delivered in New York: "The purchaser, it is expected, will undertake its transportation to the eastern cities, to show the Yankees what kind of hogs we raise in Ohio." Yankees, of course, would not likely ignore such a challenge, and with the turning of the wheels of progress we find in 1840:

an account of a very extraordinary hog raised in Wallingford, Vt. and sold for two hundred dollars to a gentleman who designs to transport him over the country as a show. He weighs, it is said, 1600 pounds and is three or four years old!

The accuracy of some of these weights, however, might be open to suspicion if a device of certain westerners about this time was in widespread use:

In Iowa they weigh pork by putting a plank across a rail with the hog on one end and then 
piling stones on the other end to balance. They guess at the weight of the stones, and thus come to the weight of the pork.

Probably more accurate is the record of a 138 pound kidney from a cow weighing 600 pounds: "The beef was very poor, almost the whole nutriment seeming to have tended to this enormous kidney." Since there seems to have been no aversion to at least trying the beef, think of the prodigious kidney pie that might have been made!

More or less in the same category as this craze for mammoth animals was the "hen fever," which reached its height about the mid-century. The editor of the American Agriculturalist in 1850 noted:

Few are aware of the extent to which the hen fever is now raging among our amateur farmers... \$3 and even \$4 per dozen is by no means an uncommon price for eggs of a choice kind. . . . The yellow fever and cholera may be more fatal . . but the "hen fever" is making the most fools. . . Breeders who live upon the gullibility of the public keep this fever alive, by means of publications, in such papers as will lend themselves to the henhusseys ... to assist them to sell their great, overgrown, longlegged, crane-necked, big-headed abortions. ... We understand that from $\$ 20$ to $\$ 100$ a pair is the asking price of these "great poultry breeders." . . . Respectable agricultural papers ... could be much better occupied than in such humbugging and foul foolery.

Later in the century there developed a passion for small animals (beyond that of small animal practice by a few veterinarians), and reports of the "smallest horse in the world" continued to be printed. By 1906 this honor had been bestowed on "Speck," a miniature mustang of Delaware, standing 6.2 hands high and weighing 62 pounds at six years of age.

Mease, however, in another of his frequent contributions to the American Farmer is obviously displeased with the popular clamor for excessively large animals. Commenting on an exhibition of fat stock in Philadelphia in 1821, entitled: "Pennsylvania against the World," the alleged object of which was "the improvement of the breed," Mease asks:

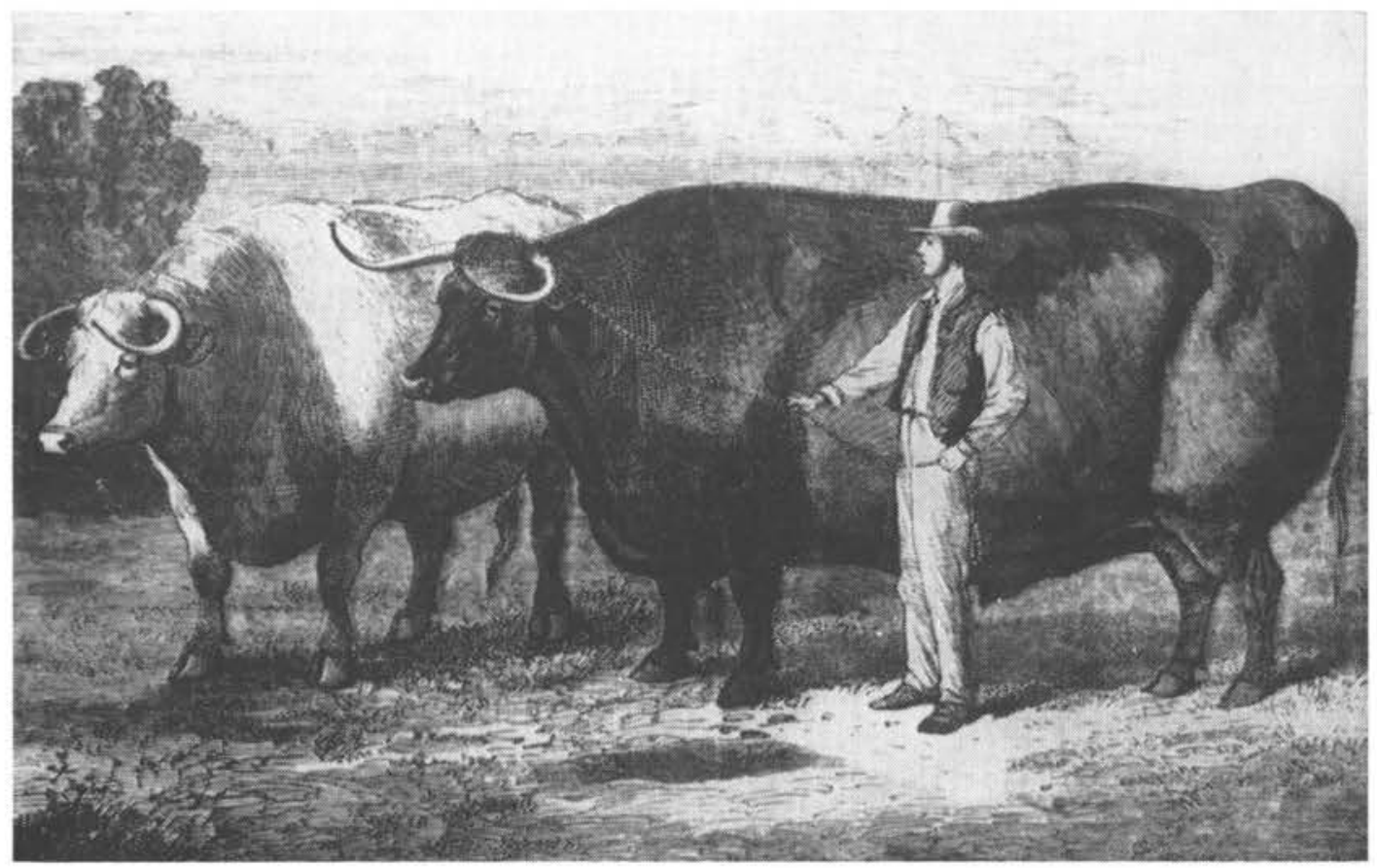

Although of seemingly dubious proportions, some apparently honest observers of the mid-nineteenth century reported cattle more than ten feet long and standing over six feet high. There is one apparently authentic report of an ox weighing 4,500 pounds. American Agriculturalist 
Did any of these crammed beasts leave their progeny behind them? ... Where, moreover, is the utility of such overfeeding? . . . The difficulty is to find lean enough in the cattle and sheep to eat: as to the hogs, nineteentwentieths of their weight will be consigned to the manufacturers of soap.

British oxen generally topped most that America could produce at this time, however; at least five animals from 3,900 to 5,000 pounds were recorded from 1810 to 1821 .

\section{Hydrophobia and Hysteria}

Numerous articles on hydrophobia in man and various domestic animals appear in the early volumes of the American Farmer; the accuracy of diagnosis in some of these, however, is open to suspicion. Such is likely in a lengthy case report in 1820 , in which it is purported that the herb scullcap, or scutellaria "was successfully employed in the cure of said disease." A girl, bitten by a dog which later was shot as mad, ten months later developed symptoms of hysteria in which she simulated the actions of a rabid dog including trotting in a circle about the room. A witness stated that he "once had eight sheep bit by a mad dog, and that they were every one affected in precisely a similar manner."
The editor reports a novel mode of curing hydrophobia in 1824, which he thinks may supersede the use of scullcap. The case concerned a Frenchman "who manifested the utmost horror for liquids," and upon whom:

The surgeons of the hospital determined to try ... an experiment which had been found successful when applied to animals. The operation consisted in the introduction of water into the veins, by means of an incision above the wrist. The experiment fully succeeded, as the patient now takes liquids without aversion.

A correspondent relates in 1822 that he knew of a dog supposed to be mad, and which a servant had been instructed to take to the woods and shoot. The servant, however, observing that the dog seemed "to have something in his throat," investigated and found a tumor under the tongue, lancing of which effected an immediate cure. This led the writer to suggest that someone in each village should be capable of using the lancet "as there are many parts in this extensive country where medical aid cannot be procured." He also recalls that as a boy in England he had "learnt to worm dogs, which it was said did not prevent their going mad ... but disabled them from biting anything. . . . I afterwards wormed a number of dogs." He could not

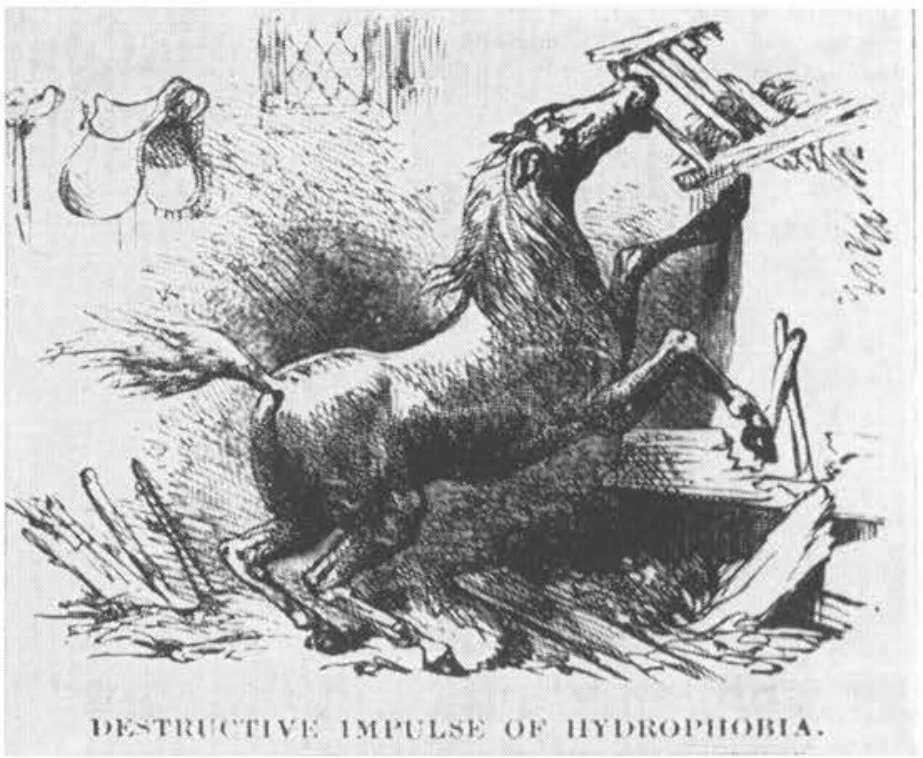

That rabies was incurable was long obscured by the fact that not all victims of bites, even by known rabid animals, developed the disease, and many persons subjected themselves to danger in useless treatment of frankly rabid livestock. Manning: Stock Doctor 
recall whether this had the supposed effect "but as the custom was general, there must have been something in it." This practice of removing the fibrous lyssa from the tongue stems from ancient times, and continued in vogue until late in the nineteenth century - long after its efficacy should have been a matter of common knowledge. Fleming, in 1872, states that the practice was still common in England, and:

The operators justly deserve the punishment which will be awarded them, should they come within the cognizance of the Royal Society for the Prevention of Cruelty to Animals.

In an article on "Hydrophobia in Sheep," the writer states that in 1810 a dog had bitten 15 or 20 sheep with only trifling injury, but had attacked two cows with such ferocity that he was shot as being mad. Several of the sheep lambed soon after, and their wounds had healed in two weeks, but about this time they demonstrated "incessant libidinous actions," and all died of rabies within six weeks. All were skinned:

without inconvenience - a proof that the blood of the infected animal cannot be injurious ... the skins were taken from several hogs, which died of hydrophobia, the same time, and the bodies eaten by the others, with entire impunity.

Another correspondent in 1824 relates an attack of a dog which bit a cow, a horse, his dog, and several pigs. After the latter died with symptoms of rabies in about ten days, the dog was "put out of harm's way; and the cow developed rabies two months later." The horse, however, was bitten only on the nose; recalling an "experiment," the owner "by careful amputation removed all the wounded part, and he never was affected."

In 1828 , by direction of the Secretary of War, agents in the Indian country were to "ascertain the Indian's remedy against the effects of bites of mad-dogs and snakes ... for it is most certain they possess them." One agent was:

often amused at their statements of the charms they used ... and I saw some white men who believed in all this, as if it had been part of the holy Gospel. . . . I am of the opinion that bandaging and suction, are their great resorts, together with some application, but of what, they were too superstitious to tell me. They think a disclosure of a secret of this kind breaks the power of its enchantment.

Another agent, however, was more successful, for:

The offer of pay was an inducement to them to disclose the secret. . . . The cure for hydrophobia is a plant resembling the tobacco plant, which is made use of by the Indians as a substitute for tobacco. ... When a dog is afflicted, it is moistened and tied round his neck, and the dry tobacco put in a pipe and smoked by a person into his nostrils. . . . They never knew persons to be mad, though they have been frequently bitten by mad-dogs, because they apply the remedy immediately ... [and] a mad-dog was never known to die when they applied the above remedy.

\section{The Experienced Sportsmen}

In a series of articles: "On the Management of Horses and Dogs" in volume five of the American Farmer, an "experienced sportsman" divulges, "the most useful medicine for horses," consisting of a pound of nitre, and a half pound of sulfur, made into a mass with molasses. This medicine "is perfectly innocent, and so mild and gentle in its operation, that it acts insensibly on him, and is not to be perceived, but by the cure" - for practically everything in the book. On the other hand: "With spavins and ring-bones I will have nothing to do. Send for a skilful veterinary surgeon." On the subject of worms, he says:

I have often read, in farrier's works, and in those of veterinary surgeons, of worms in a horse's stomach - for my own part, I cannot credit it; for the peristaltic motion of the stomach is so powerful ... that worms may as well live between two millstones, or in a hot baker's oven, as in a horse's stomach.

Dogs, he avers, "in the distemper, absolutely die for want of nourishment. . . I have saved the lives of several, by drenching them, three or four times a day, with 
strong beef or horse broth." While he had never had a dog go mad, he says:

Provided a dog went mad in my kennel, I would discharge the person who looks after them; for no dog goes mad without first rejecting his food. The moment a dog refuses his food, or feeds very sparingly, he should be taken from the others, and chained up in some safe place.

\section{Benevolent Bots}

A number of articles on bots of horses, some suggesting they did considerable harm, led John Haslam, in 1823

to lay before the public, some facts, which I have noticed, in the course of twenty-four years experience. ... People imagine bots kill more horses than any other disease. If we reverse this opinion, we shall perhaps come nearer to the fact; for in all probability there is no disease that destroys so few. . . . That bots never kill I will not assert, though there are eminent veterinarians in England who say they never do. It is a common opinion, that a few bots are essential to the health of the horse. . . But in the many hundreds that I have opened, there have been some in which not a bot was to be seen; and not one of these may be supposed to have died for the want of bots.

Haslam, a graduate of the London Veterinary College, and the first graduate veterinarian in America, obviously alludes to the opinion of his preceptor, Edward Coleman, who taught that a few bots were essential to proper nutrition by acting as gravel in triturating the horse's food. The English veterinarian, Bracy Clark, even proposed feeding bot larvae to young horses for this purpose. For the benefit of "such persons as would rather give something to facilitate their discharge," Haslam recommends an ounce of powdered savin daily for three days; they will be "very much astonished at the quantity of bots brought off by it." In 1828 a "subscriber" states: "In our southern country more than half the horses die of botts or cholick; yet you seidom find two men agree in the mode of treatment of either."

In response to a request by a correspondent for information on glanders in 1823 , the editor inserts a lengthy article on the subject, taken from British sources. It is unfortunate that the tenets of Coleman that the disease was spontaneously generated - continued to be propagated by his graduates, rather than the enlightened views of this writer. In addition to giving a good description of the disease and its natural and experimental transmission, he says:

I have not been so fortunate as to discover a remedy for glanders; nor has it ever come to my knowledge that any other practitioner has been more successful. . . . The most effectual mode of prevention consists in separating a suspected horse from others.

This conmunication, however, led a subscriber from Pennsylvania to write, "I consider the glanders to be a neglected or violent case of the distemper." Glanders, he says, is incurable, "But take the distemper, or strangles, in time, cure it effectually and you prevent the glanders." In offering his cure for strangles - bleecling, salts, and sassafras tea - he concludes, "If thee thinks this prevention better than a cure, thee may give it a place in thy paper."

Glanders, however, is mentioned but seldom during the first half of the nineteenth century, and it may be supposed that some of the cases reported were more likely strangles. In 1844 an Alabama correspondent to the Cultivator states: "More than 30 years since the glanders of the most virulent kind, was amongst the horses of the neighborhood in which my father lived. Great numbers died off." A strong decoction of tobacco juice, given internally, he says, was effective in curing one animal. A considerably more cogent note appears in 1846 in response to the request of a correspondent for information on glanders. The editor states, "We would refer you to Dr. George Wright, of this city [Albany], veterinary surgeon, for the information you want."

In a notice of $A$ Compendium of Cattle Medicine, by James White (Philadelphia, 1824), the editor of the American Farmer says: 
The fashion for "bobtails" resulted in tail docking being widely practiced by horse fanciers, farriers, and veterinary surgeons alike, although those who professed to the title of "V.S." preferred the more professional-appearing tail cutters to the cleaver. Liautard: Surgery

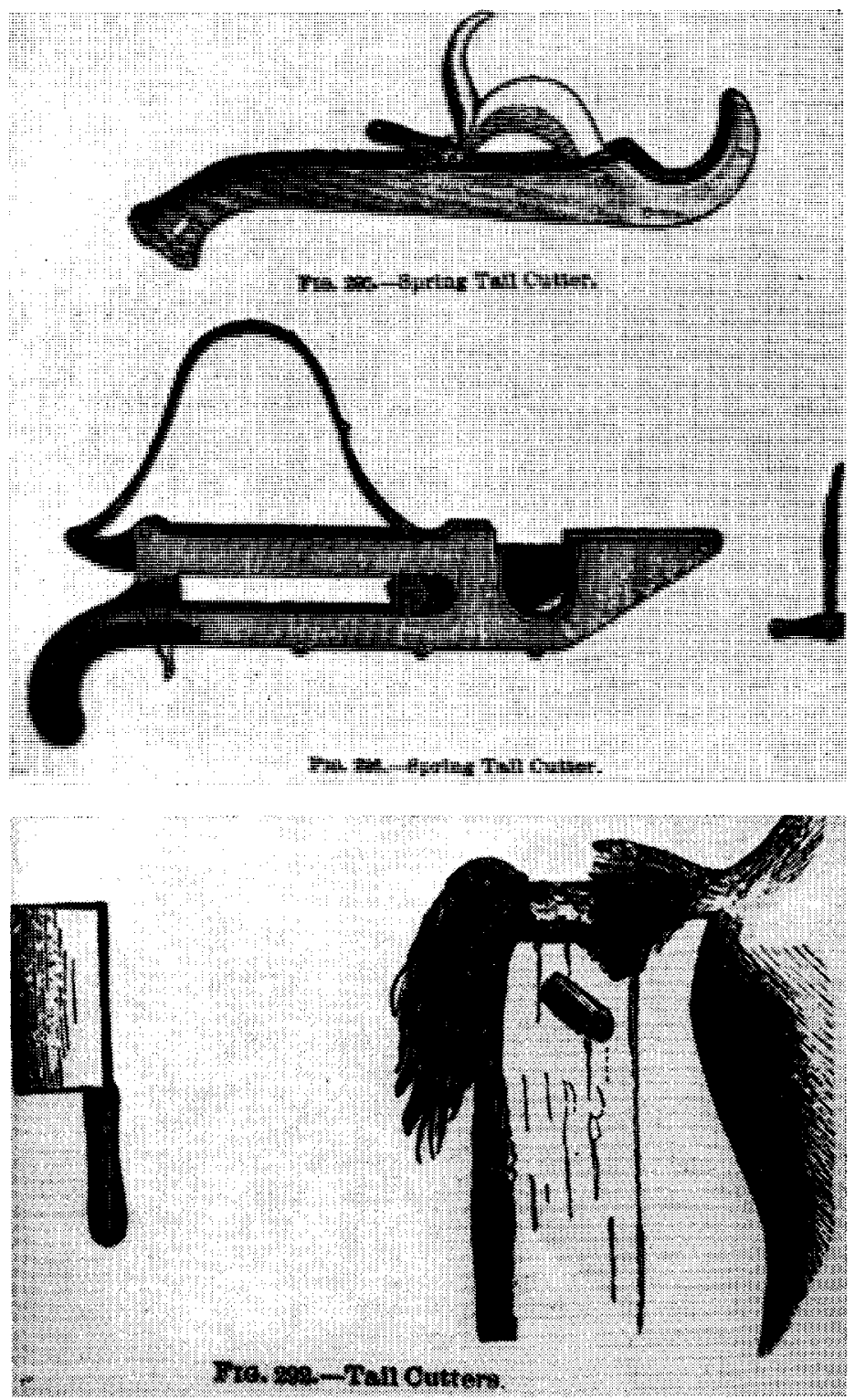

The book in question, would necessarily make part of every farmer's library. At all events, there is on every farm, such frequent occasion to treat cattle, sheep and hogs for various $\mathrm{di}$ seases and accidents, which if not soon removed, are sure to destroy - that every one should have this volume within his reach, at a moment's warning.

The price of the work was $871 / 2$ cents.

\section{To Lessen the Miseries}

Under "Advice to Young Farmers" in 1824, an anonymous writer, in speaking of docking horses, states:

The English have been ridiculed by foreigners, for "making curtails", both upon their kings and their horses. As to those made upon the latter, I think there can be no doubt of the 
utility. Long tails, for which some people are such warm advocates, setting aside the incommodity to the rider, of being fanned by them, dirty or clean, do not in their appearance convey that idea of expedition upon which our affections are so bent in this country. . . .

It has ever been my favourite study . . . to lessen the miseries of animals. ... I had heard of many accidents, some of them fatal, from horses being docked at too late a period, and by bungling blacksmiths; and indeed I had seen several operations of the kind which made me sick. It occurred to me, that colts ought to be docked early, whilst the tail is tender and gristley; which operation I ever afterwards performed, upon my own, myself, with a good sharp kitchen knife, with all possible success, and which $\mathbf{I}$ wish to recommend as a general custom. ... The stroke . . . curtailed them in an instant; and with so little pain, that they scarcely left their carrots. ... If a flux of blood be not desired, a ligature may be made, previously to the operation: but in case of plethora, dulness, or heaviness about the head and eyes, it may be presumed that bleeding will benefit the colt, and the wound may be entirely neglected. ... No twitching, trammelling, searing with hot irons, nor any of the barbarous Vulcanian apparatus is required; and what will weigh more than all the rest, with certain of my readers - no farrier's bill.

The "Vulcanian apparatus" referred to is undoubtedly the "docking machine" used on adult horses.

Revulsion against another barbarism impelled the veterinarian, John Haslam, to write a long article "On the Haws or Hooks" in 1824. In so doing, he says:

I am fully aware of the prejudice that may be excited against me, but nevertheless, as it is under full conviction that I have truth on my side, I proceed with courage to state such facts as will, if adhered to, not only produce a more humane treatment of domestic animals, but also advance the interests of their owners.

Opinions that have existed for ages, though the most absurd, commonly pass from father to son, with the sanctity of truth; antiquity giving weight to them; and so much respect is paid to ancient notions by the bulk of mankind, that for a man to contest the truth of them, is to put his character at stake.

Markham, and other English writers, he says, call this a disease. Of this group: "Taplin . . . loses all credit as a veterinary writer, by speaking of the gall bladder of the horse." The haw, or nictating membrane, Haslam contends: is a useful appendage to the eye, and is as natural to the horse, as it is for him to have two ears. ... By taking this membrane away, I have known horses to go blind, that before had good eyes.

Haslam apparently had the courage of his convictions, for he relates that to one farmer who insisted on the operation for fear his horse would die of the "disease," he promised:

that my head should be given for a football if he died or went blind, with the existing disease; he recovered perfectly although the reputed tumour was not cut away.

In speaking of Blaine, and other contemporary English veterinary writers, Haslam says:

It is acknowledged that within the last thirty years, greater improvements have been made in the veterinary art than at any former period; and it was about that time in England, that men of learning began to think that branch of the healing art worthy of their notice. It is to characters like these, we are indebted for that investigation which taught the true diseases, to which the horse is subject, and expunged such as were only imaginary.

"Another imputed disease," says Haslam, is the lampas:

All young horses either have this enlargement, or it has been taken away; this being the fact, how is it possible that it can be a disease? We may as well charge the creator with a universal defect in the order of creation.

He admits, however - as numbers of veterinarians have had to since - that on occasions he has had no alternative but to perform the operation of burning or lancing the palate. Haslam continues:

It is many years since I first began to deny the existence of the hollow horn as a disease, and was induced to go to the slaughter house, in order to know the state of the healthy subject.

He had convinced himself that "as in the most healthy state the horn is hollow, it must be absurd to treat it as a disease." And on diagnosis of the condition by feeling the horns and finding them cold, Has- 
lam says: "With equal propriety may it be said, a man's leg is hollow because his extremities are cold in sickness."

\section{NEW DISEASES AND OLD NEEDS}

One of the major services performed by the early agricultural journals was the recording of "new" diseases for the information of their reaclers at the time - and, perhaps unwittingly, for the gratification of later historians. One such report in 1824 concerns "Observations on a Remarkable Disease Among Cattle, and Its Propagation to the Human Species," by J. Kercheval, M.D., of Kentucky. This "singular and fatal disease," he reports, "first made its appearance among the cattle of this neighborhood during the summer of 1819 , and its fatality was so great that horses, cows and sheep, were alike the victims of its fury." Death was sudden, the external signs being swellings from the throat to the flanks, which

upon post mortem examination, were found to contain extravasations of grumous blood... . The blood in some instances was so dissolved that it transuded through the pores of the skin. ... Alike novel in its character and unique in fatality, it is viewed here, as a new disease; nor is my knowledge of veterinary pathology sufficient to enable me to assign its appropriate rank among the many maladies of our domestic animals.

Anthrax, of course, had been long known in both animals and man, but perhaps a provincial physician on the fringe of civilization might be forgiven for his failure to recognize it. He continues: "In the human subject this disease, or at least one derived from it, commenced in a small and circumscribed vesicle," and he goes on to describe faithfully the malignant carbuncle, and "wool sorters' disease."

$\mathrm{He}$ adds:

No one was affected with it, who had not been previously engaged in flaying or otherwise handling and touching the carcase of an animal that had died of the distemper described.

Nor was the nature of anthrax much better understood in 1840, when a cor- respondent to the New England Farmer reported an "epizooty" in Massachusetts, which "carried off many animals." $\mathrm{He}$ gives a good description of the disease, particularly among those who skinned some of the dead animals, after which "the animals were buried without flaying." The disease was quite properly compared to one of the Biblical plagues of Egypt.

Blackleg in cattle likewise was not reported, or more likely, recognized, with any frequency until the 1840's, when numerous references to it may be found in the Cultivator. In 1844 a Vermont farmer, however, states:

We have met with some loss every year since my remembrance, in this neighborhood, from this disease, and some years to quite an extent. We have generally practiced bleeding in the fall as a preventive.

This he found effective for several years, but finally some calves which had been properly bled died, whereupon "a strong dose of lobelia" saved one of his best calves, which he had counted "as good as dead." This led a Kentucky Irishman to recall, "my own sufferings, and those of my father, from that dreadful disease for many years" in Ireland, until it was found that inserting a clove of garlic under the skin of the cow's tail was a sure preventive:

The effect is surprising. As quick as the person performing the operation can step from the tail to the mouth of the calf, the smell of garlic is perceptible on the breath of the animal! . . . from that time to the present I never lost one.... I never heard as yet of a case of the black leg in calves in this country; but if such a disease ever makes its appearance, you may rest satisfied that the above is a sovereign remedy.

The same remedy appeared in the Country Gentleman for 1853, and specified the under side of the tail as the proper site for implanting the garlic. This brought the caustic comment from a physician that it

like many prescriptions for the human species, seems superlatively ridiculous; misleading the credulous and wonderloving, without contributing to science or proving efficacious in the re- 
moval of disease. We would like to inquire if the upper side of the tail would not answer? ... Is the rapid traveling of the medicine from the tail headwards a sure indication of its happy remedial action? If so, we trust that if this man should be attacked with mortification of the hand, he will not complain if his surgeon should cleave a toe and introduce a garlic. . . What is science in the one case is so in the other. We have no remedy to suggest, but enter our decided protest against quack prescriptions, and mysterious and wonder-working manipulations, whether designed to be carried out on man or beast.

\section{The Rubbing Disorder}

In this category of reports of "new" diseases is an account of: "The Rubbing Disorder in Cattle," in the American Farmer for 1824. The correspondent, apparently a farmer, notes that an incurable disease which had broken out in Maryland for the first time in 1822 was

very similar, if not the same, which I have occasionally witnessed the ravages of, amongst the cattle of Tennessee, some eight or ten years past. . . . It was usually denominated the rubbing distemper, because cattle when attacked, would rub their heads and necks against the trees and other firm objects, until their horns would sometimes drop off, or their eyes be rubbed out of their heads, before they were carried to such heights by the itching of their skins.

He attributes the disease to sudden overloading of the stomach upon being turned into

fresh cornstalk fields ... when a great portion of the stalks abound with saccarine juices. ... Upon dissection, the contents of the paunch are found to be as dry as ashes. . . The distemper is not contagious [but] . . . I I have known eight or ten die of it on one plantation, and all nearly about the same time, and always in the fall of the year.

This is a good description of "mad itch," or pseudorabies, supposedly first described in 1902.

This communication caused a man in Ohio

to transcribe from my notebook, an account of what appears to me to have been a similar disease amongst the cattle in this county, in the year 1813.
A farmer near Marietta lost several cows during one week in September. The onset was rapid, and "the hair and scarf skin, was in a few hours entirely rubbed off from the side of her neck and head"; death occurred in 12-14 hours. No unusual postmortem appearance of the viscera was noted, nor was the feeding indicated. One animal was subjected to bleeding two gallons, cutting off the end of the tail, strong purges, burning with a hot iron over the poll - which "appeared to give the cow ease" - and trepanning the cranium which "did not appear to afford any relief." A considerable quantity of bloody serum escaped from uncler the dura mater when it was punctured: "So far as I have heard, the disease has in every instance proved fatal .. . the disease appears to have been in some measure contagious." A few cases were noted the following year, but none since to the date of writing (1824). Some idea of the baffling nature of the condition can be appreciated from the writer's concluding remarks:

I have often thought it was a fortunate thing for the illnatured and ugly old women, any where in the neighborhood of this disease, that the belief in witchcraft has been banished from our land, or I fear, that many a harmless old soul would have had this sin laid to her charge.

By the 1840's, mad itch was attributed to feeding on dry cornstalks. In the Cultivator for 1844 it is stated that the cause has been

hitherto considered unknown, and medical treatment almost useless . . . the disease appears, so far as we have learned, only where cattle have been fed on stalks, or where that is almost their only food, as in the west. . . . Separate your cattle from your hogs in cornstalk chewing time, and you will separate your cattle from the mad itch.

For affected cattle: "Open the second stomach and extract the cornstalks." Later in the same volume, however, the editor states: "We do not know that the cause of what is called mad itch has ever been discovered." Deaths of stalk-fed cattle in Iowa the following year were attributed to constipation, although: 
The death of the animals was so sudden that cows which gave a good mess of milk at night, were dead the next morning; and oxen which worked well as ever in the morning, died in the afternoon.

\section{In 1848 in Michigan:}

A great many cattle were dying off in that region, from some terrible malady, and it was observed, that only those which had been turned into cornfields, had been the victims ... the same fatal effect, from turning cattle into cornfields, had followed, in other parts of the country.

With the statement: "the cause and treatment of the complaint seems to be pretty well understood," purging and bleeding are prescribed.

\section{What's in a Name?}

It would be difficult to determine exactly when any particular "new" disease first became a problem, and even more so when it actually first appeared. In sense, a disease can hardly be said to exist, at least so far as awareness of it as an entity, until there are persons capable of diagnosing it. But not all the diseases diagnosed were actually entities in themselves - or even diseases, as in the case of the so-called hollow horn. In a few instances, descriptions antedating an identification of a condition as a disease entity, but adequate to diagnose it, may be found in the early literature. These generally can be found only accidentally, i.e., it is difficult to make a search for something that has no name. Frequently the earliest date of publication may have little bearing upon the dating of the disease, for many of these early communications to the agricultural journals are in the form of recollections of events that preceded the establishment of the journals.

Some of these descriptions of events of years or decades earlier may be open to suspicion as to their accuracy, but many give unusually lucid details. In most cases it seems logical to presume that the first reporting of a disease is not necessarily coincident with its earliest appearance. Even a positive statement with regard to time may be suspect - without needing to question the veracity of the writer - for many individuals at this time were born, lived, and died within a radius of a few miles, and there may have been few events that could be used to "date" a disease. Those who would take the trouble to write of their experiences, however, may have been somewhat more cosmopolitan characters. At any rate, it seems likely that most diseases existed in at least a sporadic - and likely unrecognized - form for some considerable time prior to their "discovery."

\section{Big-head}

Osteoporosis, the so-called "big-head" of horses, was first reported from Georgia in the American Farmer in 1822. This correspondent infers that the disease was common but, beyond a description of it, knows nothing of its nature. He asks:

Is this the disease described under the name of Glanders? Is it contagious? Are mules liable to be affected by it? Is it curable, and by what means?

An answer, from one who says, "I am no farrier," was shortly forthcoming. This man from South Carolina had seen "a number of horses that were afflicted," and had cured one:

I had him thrown and tied, then run an hot iron through his head, inserting it into the lump on one side, and carrying it through the lump on the other [!] The horse never after had any symptom of the disease. . . . It differs very much from the glanders. I think it certainly is not contagious. I have never heard of a mule to have it.

A correspondent from North Carolina in 1824, says, however: "About twelve or fourteen years since, it was very prevalent in this part of the country, but is now rarely heard of." He gives an excellent description of the disease, and states:

The disorder does not appear to be contagious, yet when it commences in a large stock of horses many of them are apt to be affected ... and horses brought from a distance to supply the place of those which die, or be- 


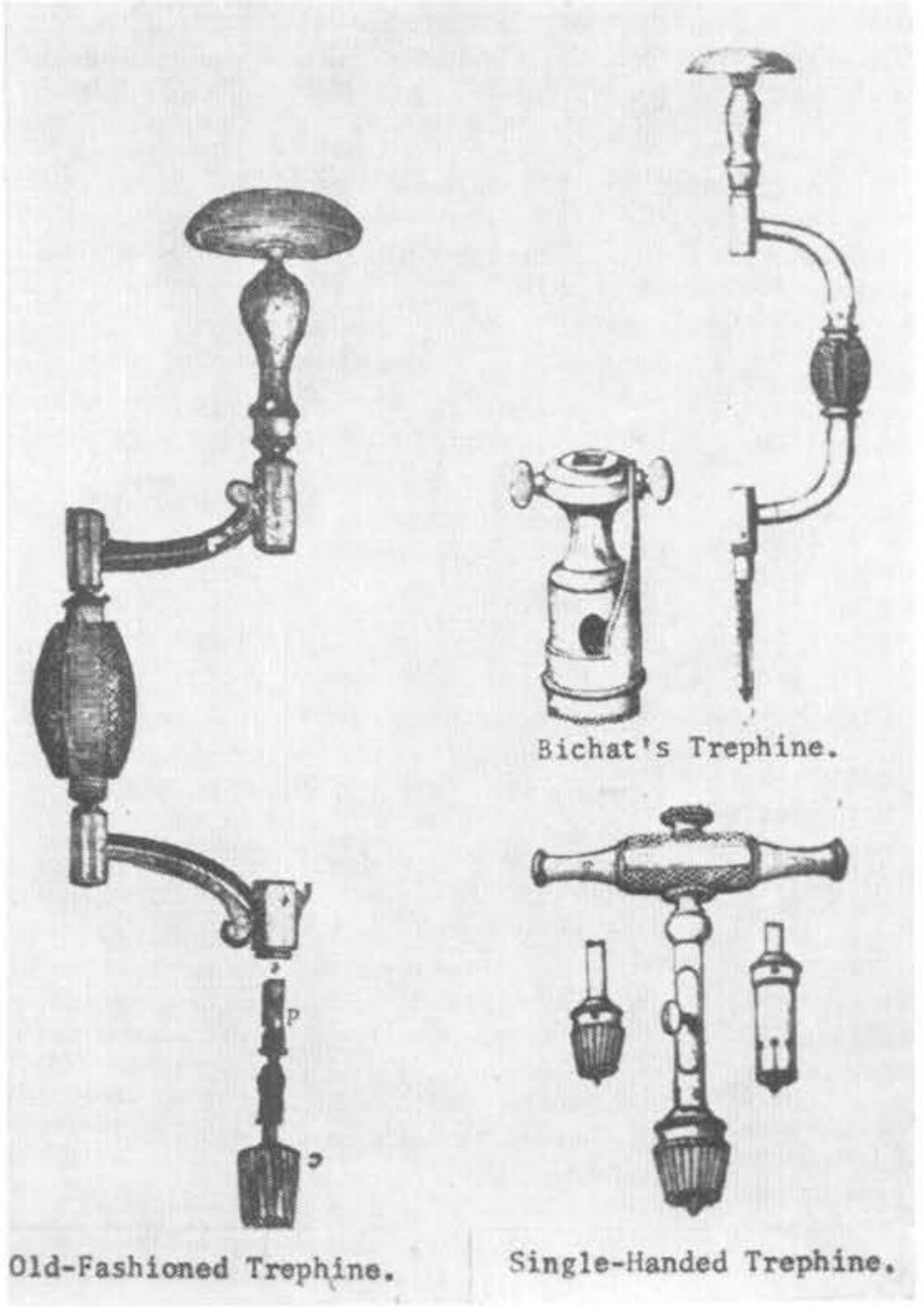

Types of nineteenth-century trephines, used primarily in repelling cheek teeth of horses via the maxillary sinus. Liautard: Surgery come useless, are equally subject to the complaint.

Of numerous treatments - trepanning, setons, cautery, tooth extraction, hot fomentations, etc. - tried on his father's horses, "I have known none of them succeed well...my father lost many horses." That is - until he tried a remedy suggested "by a traveller." All this required was a hot iron, whereupon:

Search out a gristle or ligament which extends from near the eye of a horse to near his nostril. ... Apply the edge of the heated (until it is quite red) iron across this ligament, about midway between the eye and nostril, and sever it by burning entirely in two, to the bone ... on both sides of the head. . . . Let the wound then do for itself.

This is but a variation of the ancient cure for a stumbling horse, which required cutting "the cords," the conjoined tendon of levator muscles of the upper lip, and is a good example of the traditions against which the veterinarian John Haslam protested.

An example of the local nature of some of these outbreaks - or of the local nature of knowledge in a provincial society - is found in the American Farmer for 1830. Another North Carolinian, only one county removed from his fellow correspondent in 1824, states that big head was 
common "about 12 years ago," i.e., about 1818. His neighbor says it was prevalent about 1808 or 1810 , but "is now rarely heard of." If it had been common in his area as late as 1818 , it seems likely he would have mentioned it. In this second outbreak, the writer states: "Before a remedy was found out, many losses were sustained.... One of my neighbors lost horses to the value of 6 or 7 thousand dollars." Despite all the remedies in the book:

in every case that I saw, or heard of, the disease terminated in the death of the animal. At length white arsenic was recommended... I have known the arsenic exhibited in at least twenty cases, in all of which it effected a cure, and $I$ think I can say, that it is an infallible remedy.

The cure consisted of a piece of arsenic:

the size of a common field pea ... wrapped in fine paper... make an incision in the skin ... insert the arsenic - or the paper containing it - and with a needle and thread make one suture ... bleed the horse, and turn him out alone in a good pasture.

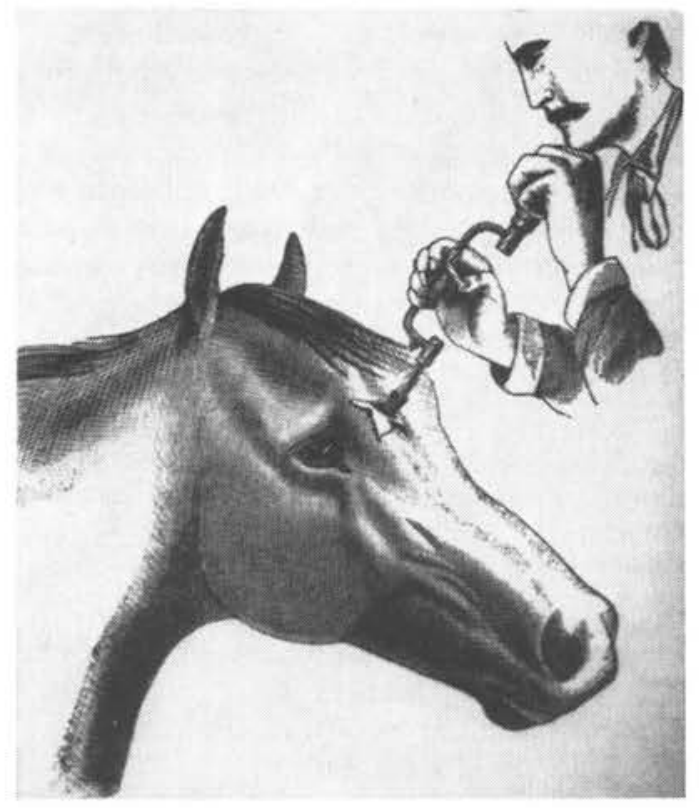

Method of trephining, still used-with refinements - in opening the sinuses. Early farriers trephined the skull to insert caustics and other agents for treatment of conditions of the head. Liautard: Surgery

\section{Slobbering Horses}

"Salivation" of horses was first reported in 1822 by a correspondent from Pennsylvania who says, "I have for some years been endeavouring to discover the cause of an excessive discharge of saliva, (or what is commonly termed slobbering)." The disease was serious enough for him to conduct some experiments, which led him to suppose the cause was a gastric disturbance from some herb, but he adds: "For the three last summers, the horses have suffered but very little, in this part of the country." The year following, a Virginian expresses the idea that the cause is a mold or fungus, and editor Skinner suggests it is "an evil of comparatively modern date ... aggravated by wet weather, when vegetation is more luxurient." The horses in his native Calvert County, Maryland, he notes, "are slobbering at a degree, that one would suppose would exhaust them unto death."

In 1828 this disease attracted the attention of C. S. Rafinesque, Professor of Botany and Natural History at Transylvania University, Kentucky. He writes:

This disorder frequently attacks horses in many parts of the United States. ... Various conjectures have been formed on the cause of this morbid affection, some of which ascribes it to a spider swallowed by the horses!

No one, he says, has published the real cause - which he is now enabled to point out, it being due to the eating of either Euphorbia or Lobelia mixed with the forage. This being the case: "It will be easy to prevent the disease... by pulling them up, or by burning the pastures."

Rafinesque undoubtedly was honest in his belief that he was the discoverer of the cause of salivation in horses. But a William Young, in a paper: "On the Salivary Defluxions in Horses," published in the Memoirs of the Philadelphia Society for Promoting Agriculture for 1811, had incriminated Euphorbia, the spotted spurge plant. On the basis of some precise and carefully controlled experiments, he concluded, "I think it extremely probable, 
that the plant in question is the general cause of the salivation in horses."

\section{Distempered Meat}

A good example of the type of animal disease reporting which leaves considerable to the imagination is a communication to the American Farmer in 1826. A correspondent from Georgia, writing on the Distemper, admits:

I am but little acquainted with the symptoms of the disease, but am informed that the animal is obstinately constipated. . . . I presume not one in an hundred recovers. ... Instances occur of whole stocks being swept off in a week or two; and so convinced are the poor farmers of the incurable nature of the disorder and its aptness to go through a whole stock, that so soon as one is attacked, he gives up the whole lot for lost.

This report, of course, conveys little except the apparent fact that some epizootic of considerable proportions existed. He mentions that northern cattle were particularly susceptible, which might suggest Texas fever. Of more interest is his inference that these cattle "given up for lost" were probably sold for slaughter:

Our lovers of "old Georgia roast beef" have their pleasures considerably marred by the unwelcome intrusion of the idea that they may be feasting on distempered meat, which is not only disgusting to a delicate stomach, but really dangerous, as alarming are the consequences of feasting on such beef.

In commenting on this communication, Skinner suggests:

Our correspondent would render a publick service by getting some respectable physician to write for the American Farmer, a memoir on this formidable disease.

The matter also offers an opportunity for him to promote the suggestion:

All the medical schools should give lectures on comparative anatomy, and the outline of the veterinary art, until we can get regular veterinary schools established.
"Sore tongue" of horses, known as early as 1801 and reported in the first volume of the American Farmer, continued to cause concern. A correspondent from Maryland in 1826, who feared this "will destroy all our horses," was reassured by a Virginian:

This disease ... known with us by the name of the sore tongue .. has for several years been prevalent in this section of the country, and when it first made its appearance, excited much alarm with the farmers, but from experience in its treatment is now considered so simple a disease, that we take little or no care in keeping separate, the diseased horses, from those that are not.

Cattle, he says, frequently contract the disease "from eating about the stable where our horses have the disease." Turpentine as a cure, or tar as a preventive, mopped on the tongue was found to be highly effective in combatting the disease.

\section{Trembleweed}

The first report on "Trembles," or milk sickness, appeared in the American Farmer in 1827. However, the celebrated pioneer physician, Daniel Drake, had studied this condition in 1810, and diaries of travellers to the West indicate its presence as early as 1800. Of course, the "reservoir" of the disease, the white snakeroot plant, had been present all along; all that was required was animals to eat it. This "singular disease" was a complete mystery for many years after it first attracted attention; indeed it was not until relatively recently (ca. 1920) that its real nature was elucidated to the satisfaction of all.

In 1827 a Kentuckian petitioned his legislature to offer a reward "for the discovery of the cause of the disease, which, for many years, in that section of the country, had been fatal to man and beast." The now-familiar details of the disease are worth giving at some length:

The disease appeared first in cattle early in the spring, and late in the fall. It was supposed to originate from some herb eaten by them in 
those seasons. A beast apparently in perfect health, will suddenly be seized with a trembling and sickness, which will carry them off in a few hours.

Dogs, hogs, or any other animals, that eat the flesh, are immediately taken with a puking, after which they fall into a stupor, and die in an hour and a half or two hours. Persons drinking the milk of a cow that is infected, are taken in the same manner, and immediately die... within [a radius of] five miles... 500 dollars worth of stock die annually, and that part of the country had been almost stripped of cattle . . a as many as thirty to forty persons had lost their lives by this fatal poison.

Mr. Yancey stated, that the same disease prevailed in the neighbourhood of Goose Creek, in Tennessee, where he had been, and it was said, even the buzzards which ate of the carcase of cattle that had died with it, immediately perished.

In 1839 the New England Farmer reported:

A gentleman at the west has announced, that he has discovered the cause and cure of this formidable disease, which has been so destructive in some parts of the western states, and las, in some few instances, destroyed or driven the inhabitants from some of the most fertile sections of the country. He is claiming considerable sums from the state legislatures for the promulgation of his specific, and should there be no humbuggery about it, he will certainly be entitled to a handsome reward.

The editor of the Cultivator, however, thought differently; in an item headed "Quackery" in 1845, he grudgingly acknowledges:

a long and almost unreadable letter; the purport of which, so far as we can make out, is to inform the public that he thinks he has found a cure for milk-sickness, and is willing to "sell a knowledge of it to all that wish to purchase, who appear in person."

An article in the same issue doubtfully attributes the disease to the eating of poison oak.

The New England Farmer goes on to state that the disease is unique to the United States, and confined principally to Tennessee, Kentucky, Ohio, Indiana, and Illinois, and in a few instances has appeared in Wisconsin and west of the Mississippi and:
There is scarcely a poisonous mineral or plant to which it has not in turn been attributed. . . . Whatever the poison may be, it causes cattle to quiver, stagger, and die within a few hours. If cows eat of it, the milk is poisoned, the butter is also poisoned, and those who partake of either, are as surely injured, as if they had partaken of the original cause itself. . . . Dogs and wolves who feed on animals that have died with this disease share the same fate, and to prevent the extending of the evil to dogs and swine, cattle that die with the poison are buried carefully to avoid such results.

In districts where the disease prevails, great care is necessary in killing beef animals, as sometimes the beef will produce vomiting, when the animal is so little affected as to escape notice. To test the presence of the disease, some butchers are in the habit of driving the animal a mile to heat its blood; when if it is poisoned it will exhibit that peculiar trembling so certainly indicative of the presence of the complaint.

\section{The Puking Complaint}

On the formidable nature of the disease, a writer from the West is quoted as saying:

I have seen many farms with comfortable buildings and improvements, entirely abandoned, and their owners fled to other quarters, to avoid this dreadful curse.

Others apparently were more hardy - or foolhardy, as the case may be - for a Col. Hinde of Illinois is quoted as saying:

Calling to see a friend on Darby Creek, Ohio, whom I had not seen for twenty years, he pointed to his wife and remarked - "She is my third wife; I am her third husband; and in yon graveyard lie fifteen members of our families taken off by that dreadful disease, the puking complaint!"

The editor makes further comment unnecessary in stating, "Surely there must be some unusual fascinations in any place that would lead an individual for so many years to encounter so fatal an enemy to life."

In 1856 a North Carolina correspondent to the Cultivator inquired about the cause of milk sickness, which was troublesome in that state. With no knowledge of the probable cause, he says:

It is confined here entirely to rich coves with a northern exposure, and does not affect cattle 
if kept up till the dew is gone. Its limits are so well defined that it can be pointed out with accuracy, and is often fenced up so as to prevent cattle from running on it. . . The flesh of cattle is so poisonous when they are affected with it, that $I$ have known hogs and dogs killed by eating it before they were able to leave the place. Another peculiarity of this disease is, that the butter is poisonous, whilst the buttermilk is harmless, and is used with impunity.

Butchers exercised suspicious animals to bring on the typical trembling, which, he says, "causes all conscientious persons to refrain from slaughtering." In response to this item, a physician from Iowa states concerning:

this distressing malady which so far has proven itself one of the opprobria of the profession $\ldots$ to a certainty ... the agents that cause this disease are Copper and Arsenic.

\section{Snakeroot in the Grass}

An Illinois correspondent to the Ohio Cultivator in 1858 asks for information on milk sickness, saying it "troubles us considerably." The editor replies that it "is generally supposed to be caused by the cattle eating some foul herb, which some suppose to be the plant known as white snake root." A man brought him specimens of the plant "some years ago, and said that wherever Milk Sickness prevailed, this was found growing in the pastures where the cattle fed. Clean pastures are a great preventive of disease in cattle." As is often the case, one such item frequently brings on a flurry of letters pro and con; thus a "con" man states that the cause "is a mold that gathers near the roots of grass, and along low, wet places." He likens it to toadstools, which grow in the same places, and which "I have known children to gather, and eat them, and die in a short time."

This in turn elicits a positive statement from another, who says:

The alleged cause seems to me to be entirely erroneous. . . . I don't believe that any man can produce a case of Milk Sickness or Trembles without the weed known as white snakeroot. . . This weed will grow on dry land as well as wet, but is more abundant on low land. I have seen fields that were partly cleared, so full as to look like a field of rubbish. and get it well seeded down, this weed dies out. I had a field, two years ago, that killed four head of horses, and several cattle. I did nothing but to clean the field of logs and brush, and seed it to grass, and my stock thrives well, and no signs of Trembles, and not a weed of this kind can be found in the fields. I have a field now that would make nice pasture for some of those men that believe mold to be the cause .... A female is easier cured of the Trembles. than a male ... as the part of the animal that is affected by the Trembles, is of different form in the male and female.

The "mold man" tangles with the "snakeroot man" with the observation: "I do not say that the gentleman's writing is an absurdity, but I think he is mistaken." In claiming that it is bad water that is really at fault, being the "cause" of both mold and toadstools, he says:

Let the gentleman rid his pasture of weeds, logs and bad water, and put good tame grass in his fields, then he may make a decoction of snake root for a physic for his horses in the spring season, and I feel confident that he will have better luck with them. As I have used the weed known as white snake root to physic horses and cattle, I cannot believe that this is the cause of trembles. . . When our stock gets the trembles, we give a gallon of alcohol and four ounces of sulphuric acid ... it has proved a sure cure in all cases. [!]

The man whose horses died of trembles in January asks, "How could they get the weed in the winter season?" and was disposed to incriminate another type of mold. Another, "living in an infected district, where probably there has been some twenty deaths since the first settlement," states that there has been only one death this season, but "four out of five of my family have been afflicted," one for the third time. While

snake root... grows very plenty in all our timber lots. . . I am of the belief that it is a miasma that rises from the river, which is inhaled, causing sickness. This fog, or whatever it is, settling on grass, causes Trembles in horses, cattle and sheep. 
Later, the editor states:

We feel that we have already published enough on this subject in its present form of supposition, but justice to Mr. Miller [proponent of snakeroot] requires us to give his final argument.

Thus William Miller, of Clyde, Ohio his arguments make his name worthy of perpetuation - answers his detractors:

Wherever the disease is known, the weed will always be found. Take some of those weeds, bruise them in your hand and then go to an animal that is down with the trembles, and you will find that the breath of the animal smells exactly like the weeds. . . In August, 1858 , I turned a healthy calf, three and one half months old, into a field of three acres of these weeds, and watered it from an Artesian well, which is as pure water as any in the State, and in three weeks it died with the trembles. I saw him eat the weeds, and no mold or water could be got in the field. . . .

If the gentleman has no better physic than tremble weed, I advise him to get one. I suppose that snake-root can be given the same as arsenic or calomel, that is, in such proportions as not to kill.

And regarding the horses killed in winter:

When frost comes, the weed trinkles down among the grass, but mind you the strength is there yet, and thus you see how your colts could get the weed. It could also be got in hay. ... I would like to know why this miasma or fog will not settle on good tame feed where cattle have no access to weeds; and why people that never use milk, butter or meat, are never known to have the milk sickness.

A North Carolina correspondent to the Country Gentleman in 1856 asks for information on milk sickness, and hopes his inquiry "may interest Dr. Cuming and others who may be willing to benefit mankind." M. A. Cuming, V.S., of St. John, New Brunswick, had contributed a number of highly intelligent articles to several of the farm journals in the United States, and apparently was looked on as something of an authority on animal disease. Cuming replies to this communication primarily because his name was mentioned, for he had never seen the disease, and asks, "Is the disease so obscure and uncer- tain that those affected by it cannot be known in order that their products may be avoided as food?" He suggests:

two distinct fields of investigation . . . by those whose studies and experience properly qualifies them for doing so. The effects of the milk and flesh of the sick cattle on the human beings partaking of them, belong appropriately to the medical physiologist and pathologist to examine, and it is only in so far as the cattle themselves suffer, that the science and experience of the veterinarian can be applied.

Except for a few men like Cuming himself, there were all too few veterinarians at the time who would have been capable of conducting an adequate investigation of the veterinary aspects of the problem, and hence the practical logic of his distinction of the two fields of inquiry. Cuming, however, evinces a little too much conservatism on the matter; it is likely that he might have turned in a better performance on the problem than many a medical man of the day. A few farmers had made a correct diagnosis long before medical investigation finally incriminated the white snakeroot as the culprit.

\section{Lockjaw and Blind Staggers}

Tetanus undoubtedly had been a problem of some proportions since the early days of the colonies. A physician, writing in 1826, states:

This disease much more frequently occurs in that useful animal [the horse], than farriers, and those who pretend to know something about it, are willing to allow. . . . Ignorance of a disease will ever lead to mischievous and destructive practice.

He states that injuries to the feet, and docking, are the most frequent causes, that protrusion of the third eyelid is merely a symptom - and deplores its removal - and that he had cured three of five cases with calomel. Of the two that died, one had had the "haws" removed; the other "was one of those desperate cases."

The New England Farmer for 1831 reports: 


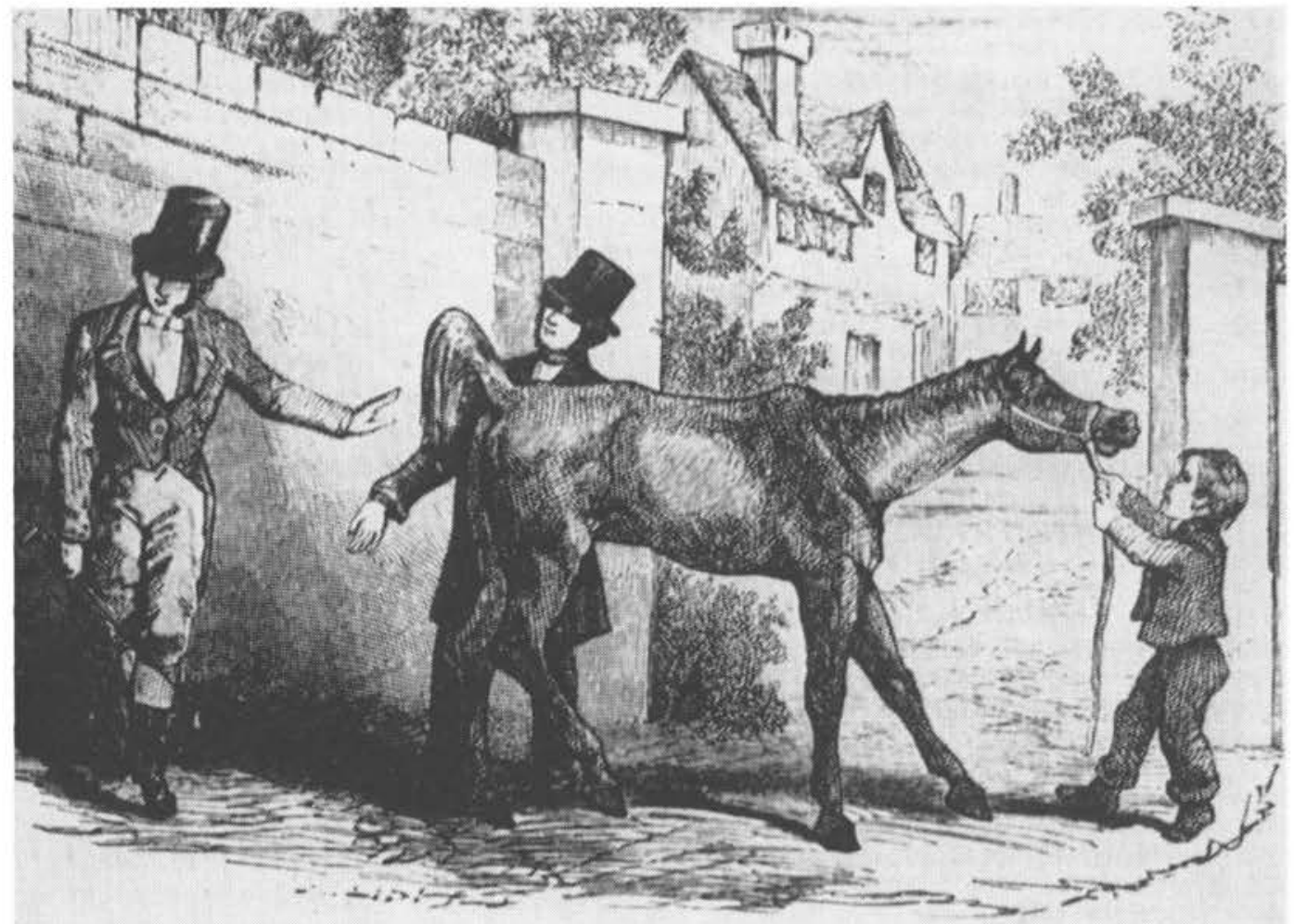

SHOWING IIOW FAR AN ANIMAL WITII TETANUB I8 CAPAPLE ON MOJUN.

The "sawhorse" attitude has long been recognized as being diagnostic of tetanus, but early claims of successful medical treatment of this condition would cast suspicion on claims of success in other conditions. Today, tetanus is much easier to prevent than to cure. Mayhew: Horse Doctor

In Plymouth county [Massachusetts] a disease called the "blind staggers," is prevailing to a considerable extent among the horses, and large numbers have died within a short period. In the town of Middleboro the number that have died is estimated from 70 to 100 .

The editor requested the eminent physician, James Thatcher, to investigate the outbreak, who in turn secured a lengthy description from a Dr. Thompson. The latter says he is "in no measure qualified to write on the epidemic... [and] I shall not make any attempt at veterinary style." The disease began in August 1831; 50 horses died in the first three weeks, and another 25 to the end of September, with about 25 animals recovering from the disease in this time. The only pathology found was an inflammation of the brain and stomach, except that he notes the ab- sence of the "natural rugae" over half of the stomach lining (but he begins with the premise, "I am unacquainted with the anatomy of the horse"). Although the disease is commonly called "blind staggers," a number he examined were not blind, but all exhibited the typical gyrations, pain, and delirium. Treatment by the farmers, he says, "was wholly empirical," and included "filling the ears with various substances."

Regarding his recommendations for treatment, the disease being:

a high grade of inflammation. ... Blood would be drawn, not by quarts, but gallon upon gallon. In the early stages from three to four gallons should be drawn; if it is borne without fainting, the operation should be repeated according to the severity of the case, in 8,12 . or 18 hours. 
Another physician, in giving a lengthy analysis of a single case, states he has not had the leisure "to ascertain what is already made public in books on veterinary medicine." His conclusions are essentially the same as Thompson's.

At a time when so little was known about the specific nature of animal disease, it is not surprising that a practice like bleeding should have been so universally depended upon. As stated by a horseman in 1832:

For almost every sudden attack of disease to which horses are liable, bleeding, if immediately effected, is a most excellent remedy and the only one which in all cases can at once be employed. ... In the course of the last season my grooms bled by my direction from fifty to one hundred different horses, some of them repeatedly at different times until they fainted, taking from the jugular vein through a large orifice from 10 to 12 quarts of blood, and in no single instance have I known any accident or injury to arise from the practice.

Regarding a "new" pig disease in 1841, the Cultivator reported:

In the West and South ... great losses have been sustained within a year or two by a dis- ease which has not, so far as we have learned. yet appeared in the North. It is called the thumps, from a violent internal action or beating, which destroys the animal in a few hours or days. It has been hitherto found very difficult, if not impossible to cure.

But a Dr. Shelby of Tennessee had found the use of calomel promising, and a correspondent from Indiana in 1844 thought the disease was an inflammation of the lungs, and suggested bleeding as the proper remedy. In this the editor concurred, but added: "The hog is a bad subject to bleed, (except with a butcher-knife) though cutting off the tail and ears may answer the purpose."

\section{Rot in Sheep}

Diseases of sheep were given considerable attention during this period, but most of the material is taken from British sources. One article by a Massachusetts sheepman in 1824 appears to relate personal experiences with a number of diseases - at least he omits "a great variety of other diseases which I have had no opportunity of attending personally." Those
During the eighteenth and nineteenth centuries, "mad stag. gers" was a common diagnosis probably for several conditions with central nervous manifestations. Manning: Stock Doctor

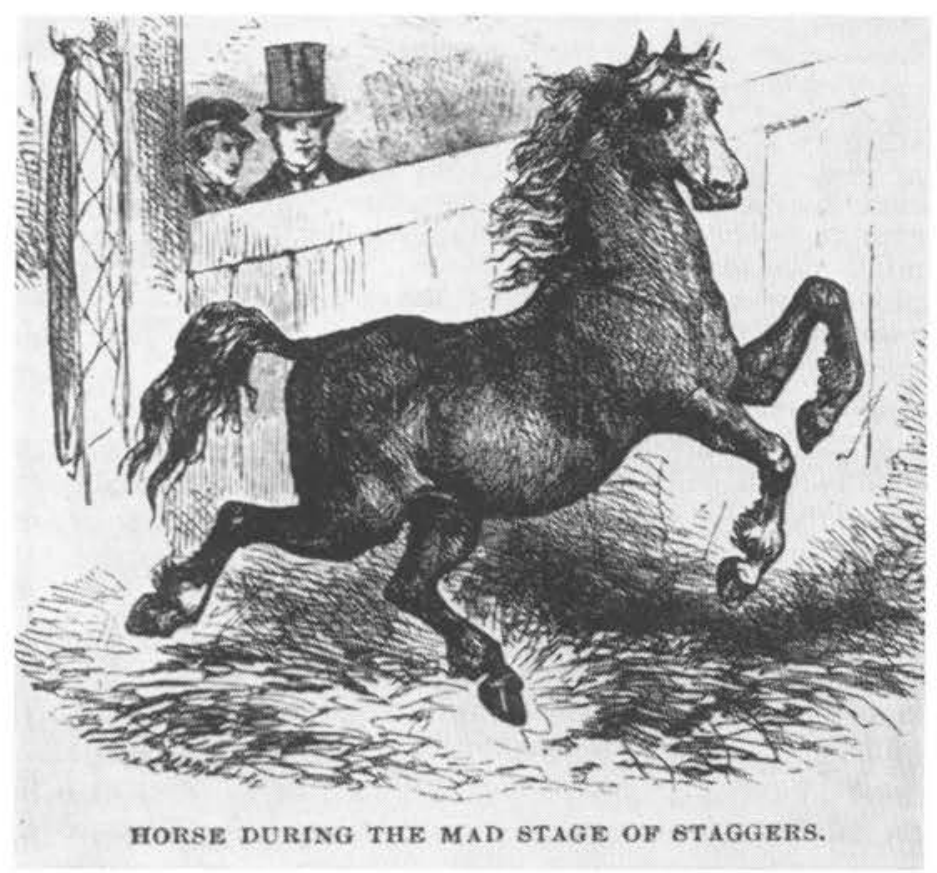


he mentions are "the rot [liver flukes], the mouth and hoof distemper, the itch or scab, the sheep-pox, the reeling sickness, and swelled paunch." Reports of other farmers are silent on the matter of "mouth and hoof distemper" and sheep-pox, and more confidence might be placed in this report had the author related it in the first person. The rot, he says, "is unquestionably caused by feeding in swampy grounds... [and] is certainly not infectious." He details the symptoms and postmortem appearance, but missed finding liver flukes. By the time "a common observer may notice the symptoms, [it] is probably incurable," but earlier it can be managed by moving the sheep to high ground (away from snails, the intermediate host of the fluke).

The "mouth and hoof distemper... is not only contagious but also infectious in the highest degree," but nothing is said of segregating the diseased. Local treatment of the feet and mouth are advised. The "itch or scab is a disorder more dreaded than any other ... is certainly contagious ... [and] often seems to be epidemic." A decoction of tobacco is used as a remedy. The sheep-pox

is contagious . . . if it appears in a neighbouring flock, care should be taken to mitigate its effects by a general careful inoculation, since it is certain that the disorder is less violent if taken by inoculation than in the natural way . . . the operator introduces the matter, from a pustule five or six days old, in two or three places between the legs or on the tail ... under the skin about an eighth of an inch.

The "reeling sickness is never infectious, but generally incurable." Affected animals show weakness of gait, seek seclusion, and carry the head to one side; "the animal then begins to turn round, always in one direction, - stumbles and falls repeatedly, sometimes with the head under the body, then ceases to feed and soon dies." He says the cause is unknown, but his description of the lesions of the brain, "one or more blisters ... filled with a watery secretion," suggests echinococcosis, or tape- worm hydatids. Trephining, he says, will sometimes effect a cure. "Swelled paunch" may be relieved by driving the sheep rapidly, or with the trocar and cannula. On the matter of trephining for hydatid, the editor of the New England Farmer exclaims:

In the name of all that is merciful, we would inquire if there is no other remedy known for this disease in sheep. ... Sooner than subject the a nimal to such a surgical operation ... we would prefer to deprive it of life at once.

An avid sheep breeder, and frequent contributor to the American Farmer, was George Washington Parke Custis, stepgrandson of George Washington, whom the latter adopted after the death of his stepson (whom he did not adopt). In 1826 , G. W. P. Custis relates the contents of a letter he had received in 1808 from James Carver, who at the time was in India. In this, Carver states that after a severe flood, the peasants of India lost many sheep from the rot, and "from the pleasure which I had always taken, in showing humanity to domestic animals," he (Carver) tried several remedies without effect. Apparently recalling Jenner's work on the relation of the "grease" of horses ("greasy heel") to cowpox, he inoculated a cow with virus from a horse's heel, “and as soon as I was able I inoculated several of the sheep, and thereby effected perfect cure.... I was afterwards successful in all the attempts which I made." Custis merely passes on Carver's experience for what it might have been worth.

\section{Canine Killers}

Innumerable correspondents lament the depredations of sheep-killing dogs. Some states had enacted dog laws, but how effective these may have been is open to question. In 1825, a correspondent from Tennessee, who says, "This State Legislature has not as yet thought the matter of protecting sheep from dogs worth legislation," reports that farmers within a two-mile radius of him had lost "about six hundred" sheep in the past two or three years. Most 
persons thought that a tax should be levied on all clogs, usually doubled for "sluts," and some an increasing levy for each additional dog. Thus it was recognized that while nearly every man had a dog, poor men usually had two or more. Slaves in particular were singled out as offenders in this regard; most of them, it was alleged, not having more than enough food for their families, forced the dogs to forage for themselves.

Another correspondent in 1825, noting:

with some astonishment . . . the different communications relative to the preservation of sheep ... would think that the dogs had been depredating more, the last few months, than formerly; or that our sheep are now worth more care.

He states that he had never lost a sheep to dogs because he kept them penned with his cattle, which ". . . will not permit dogs to enter the pen and destroy the sheep." Not only did he think dog laws unnecessary, but:

As to taxing dogs, it is of little use, for man will have his amusement according to his taste; and nothing is more reasonable than for a man to take his dog and gun, and amuse himself about his farm; deprive him of this, he may roam from his wife and family to public places for amusement, where, it is likely, he will not engage in amusements as innocent as he would at home, with his dog and gun.

Sporadic reports of losses of sheep from marauding dogs - even if by the hundreds - do not make for reliable statistics. A "roll call" of counties in Ohio in 1859 gives a total of just under 100,000 sheep killed or injured by dogs that year, the total loss being given as $\$ 146,748$. This number is in excess of 2 per cent of the sheep population, but in several apparently sparsely settled counties, the loss was more than 10 per cent.

The depredations of sheep-killing dogs and the transmission of rabies by dogs continued to be a sore point which led to the eventual passage of reasonably strict doglaws in a number of states. The American Agriculturalist for 1860 printed recently enacted statutes of Rhode Island, Massachusetts, and $W$ isconsin. Noting the death of a prominent farmer from rabies, the editor muses:

We never pass his house or remember his lonely widow and orphan children, or think of his loss to the country, without estimating how much greater the value of that one life, than of all the dogs in the land. We grant that sometimes a life has been saved by a dog, but such instances are so rare, when compared with the deaths by hydrophobia, that they are not worth taking into account. ... If farmers fully appreciated the actual condition of things - if statistics could be gathered of the loss suffered by dogs during the last dozen years alone, and the public were aware of the fact that the number of sheep in our country could be doubled during the next dozen years, were there perfect security against dogs, we have no doubt there would be such a general excitement that our State Legislatures would be compelled to pass the most stringent laws that could possibly be enforced.

Appended to this article is the Rhode Island law, which provided for registry of all dogs, and the right of any citizen to kill dogs without collars, or any dog molesting a person or animal, together with stipulations as to the liability of owners for damage done by their dogs. Yet the editor, Orange Judd, says: "The law is good so as it goes, but is not half stringent enough." This apparently led a subscriber, "the owner of a big dog we suppose," to ask:

if we "haven't got an attack of the dog-o-phobia." To which it is answered: we have, and you would have it too, had your experience been like our own. ... We yet carry abundant scars of an unmerciful "chewing up" received from a dog that attacked us when a boy. . . . We make frequent sacrifice to these scars by furnishing free doses of strychnine or lead to dogs that wander upon our premises.

He mentions a recent case near Paterson, New Jersey, in which:

A single dog bit a large number of cattle ... of which twenty one have been attacked with hydrophobia, and twenty of these are already dead. Besides these, a number of others are supposed to have been bitten by the same dog. . . The positive loss already experienced 


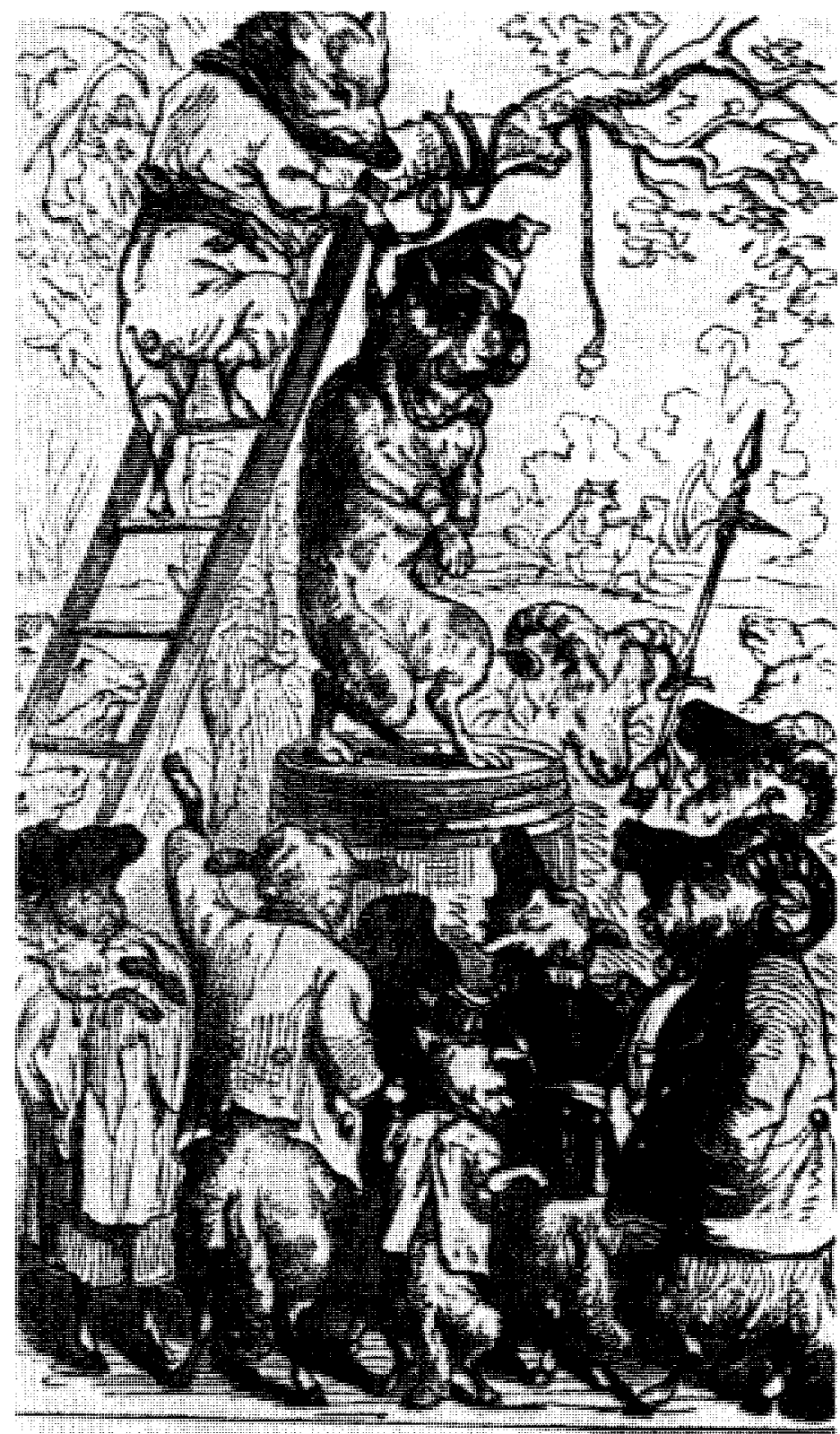

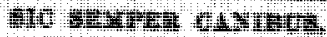

From colonial times, packs of wild or semiferal dogs ravaged sheep herds but evoked more acid controversy than overt action over the merits of dog taxes and destruction of unlicensed animals. Agricultural editors suggested that plagued livestock might have wished for more decisive means for protection. American Agriculturalist from this one dog is estimated at not less than sixteen hundred dollars. . . We have got the "dog-o-phobia," and the disease is getting worse.

\section{Mastitis and Milking Tubes}

Mastitis, more commonly denominated "garget" at this time, seems to have been mentioned less than perhaps was warranted.
An article in the New England Farmer for 1834, however, states:

It is well known that the Garget prevails among cows in this State [Maine] to a very serious degree; and I believe in general the best cows are the most liable to have it, which often renders them as to milk, partially or wholly valueless. 
The writer suggests planting Garget, the common poke-berry, in the barnyard, for, "In the incipient stages of the disorder the cows will instinctively crop the leaves of the plant, and thus become their own physicians."

No reports of mastitis, or garget, appear in the first ten volumes of the American Farmer. Whether the disease was not a problem, or simply was ignored, cannot be determined. Probably all too few cows gave enough milk to make udder diseases particularly common; later the journals are replete with this problem.

A curious item appeared in the Farmer in 1824, under the heading of "Important Discovery - A new and expeditious method of Milking Cows," to which the writer, none less than the noted Dr. James Thatcher, was witness:

A rye straw was introduced into the orifice of each teat, through which the milk flowed spontaneously in a full and interrupted stream, until the udder was completely emptied. In exactly five minutes, between 5 and 6 quarts were thus drawn off. . . The discovery of this novel process was reserved for a simple rustic boy . . . [who] always dreaded the milking as a very laborious and fatiguing task. . . . Whether the habitual employment of the tube will tend to impair the retentive power of the teat or otherwise prove injurious, must be determined by experience; but I am inclined to the opinion, that no injury will be produced.

Thatcher lists the advantages to be derived from this discovery:

The whole business [of milking] may be performed in one third of the time. . . . We may be relieved from the unpleasant apprehension of dirty hands employed in milking. ... When the udder is in an indurated or diseased state, or the teats tender and excoriated, the animal may be milked without pain.

In a postscript which accompanies the article, Thatcher adds that this cow (which was a hard milker) was still being milked with straws without difficulties: "But in other instances... serious difficulties have ensued; such as obstructions in the teat, and diminished quantity of milk."

Two weeks later, the inevitable occurred: a correspondent, who says this discovery "is going the rounds," had tried it on his cows, and thinks it his duty to report:

I found on the day following, that inflammation had taken place in their udders, the milk was clotted, unfit to use, and the quantity diminished one half; and although it is now ten days since I tried the experiment, they have not yet got over it, or come to their milk.

Such is the power of the press!

The matter of milking tubes came up again in the 1860's. One man used silver tubes made in Mexico, where, he says:

They are in general use, and answer well with the half wild cattle of that country, which give but little milk, and that unwillingly. . . Whether constant use would work injury, I do not know.

This drew a quick response from another correspondent to the Country Gentleman, who says these are

an old thing in a new form. Long years ago. ... We used a short piece of straw. ... But if the practice was continued many days, it opened the orifice so that the milk would waste when the udder became distended.

In the late 1870's an "improvement" on the milking tube was introduced in the form of four tubes connected by rubber tubing. The tubes were inserted and the common orifice of the tubing placed over the pail. The editor of the American $A g$ riculturalist states that he had some reservations concerning its use, but:

After a personal trial we must admit that we have been forced to modify our previous opinions ... it acts with apparently much ease and comfort to the cow ... a large pail, holding 14 quarts, being filled in 7 minutes; the process is perfectly clean, and the milk gathers no impurities.... Of the future effect upon the cow we aren't prepared to say . . . but there is evidence that the machine has been used in a noted Scotch dairy for 8 years ... we shall continue to use it, and take whatever risk there may be.

Later he says: "They cannot be entrusted to the ordinary run of milkmen," and recommends that "careful, skillful owners" 


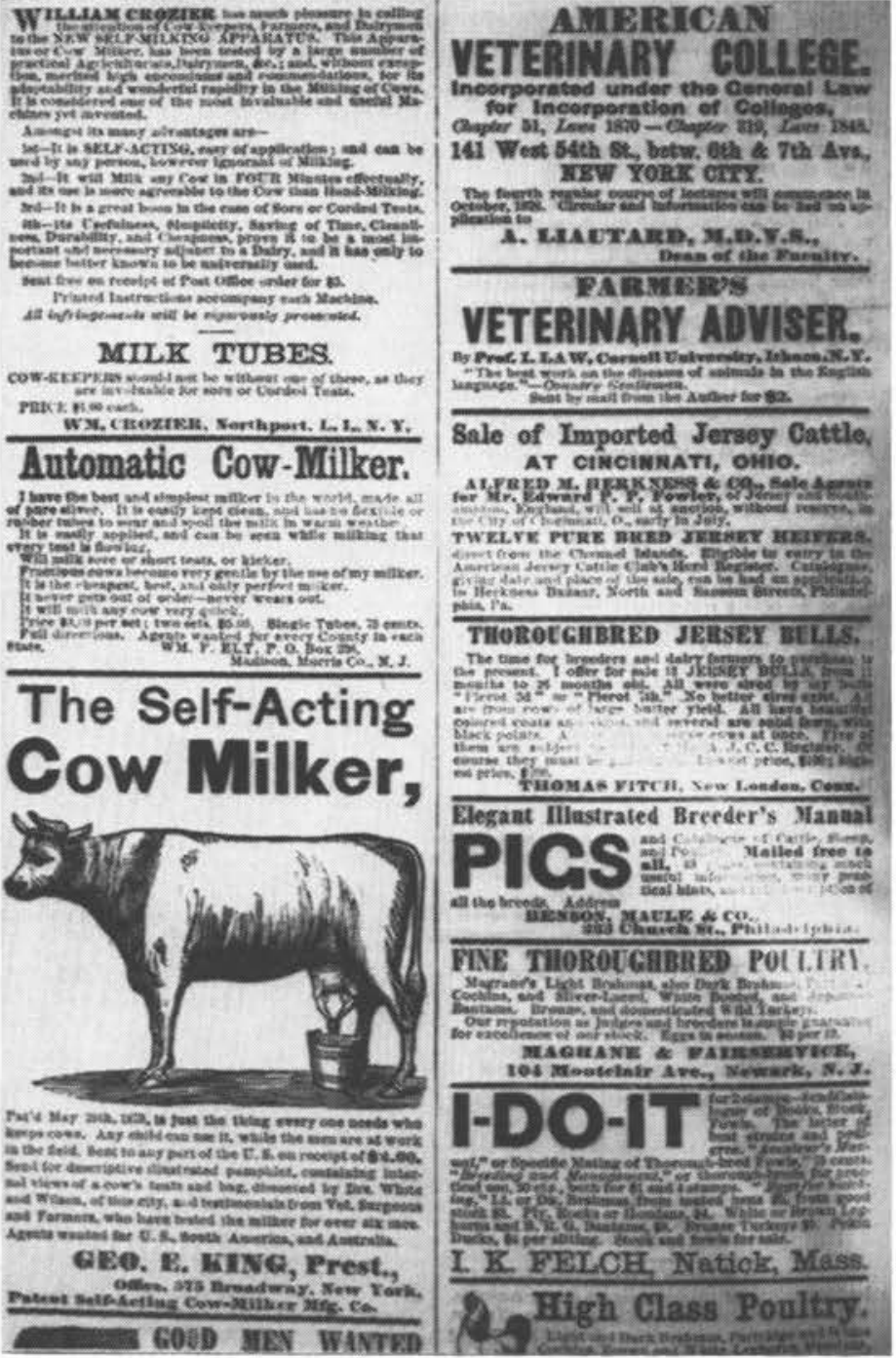

Teat tubes, in the guise of "automatic milkers," enjoyed a splurge of popularity during the mid-nineteenth century until it was realized that thes were a potent source of udder trouble. American Agriculturalist keep a set on hand "for temporary use for badly sore, or cracked teats." It is probably safe to surmise that many who tried this innovation were forced to give up its use perhaps by going out of the milk business.

\section{Veterinary Education and Veterinary Practitioners}

The publication of items such as the above, or of brutal or ridiculous remedies for disease, undoubtedly did more to retard veterinary progress than perhaps was realized. As editor of the American Farmer, Skinner might be accused of occasional lapses of judgement in selection of what he printed, but it is likely that he had little from which to choose. There can be no question, however, but that he was sincerely interested in advancing the veterinary art; the columns of his journal carry numerous references to the need for veterinary education - mostly from his own pen.

In 1822, Skinner had reprinted Rush's essay on veterinary medicine in which Rush called for the establishment of a veterinary 
school and urged that physicians pay some attention to it until the school became a reality. In 1825 , John Haslam prepared an extensive statement of the objects and organization of the London Veterinary College, apparently at the request of Skinner, who adds a long preface to the article. Skinner states:

We are not aware that any attempt has been made to establish a Veterinary College, but projects have been started and some have been executed for founding Agricultural Schools, with which the veterinary science is essentially connected. We should suppose that in our largest cities, a separate college might now be instituted and supported, on a plan somewhat similar to the one in London. At all events the time for it may soon arrive if it be not now at hand; and we therefore embrace the opportunity which now presents, of recording, for reference, and as far they may be found to suit, for precedent, the plan and regulations of the VETERINARY COLLEGE in London.

Skinner does not enlarge upon the means that might be employed toward this end except to say that there are enough comparatively rich men in America "who ought to contribute more freely to publick Institutions which might be founded for publick utility and benevolent purposes." Later the same year, however, in an editorial on "The Value to Farmers of The Veterinary Science," Skinner details a case which responded to the prompt use of "the phleme and stick, which every farmer should have in its proper place." This case, he says:

inculcates the obligation and the advantage upon every one to make himself familiar with the rudiments of comparative anatomy and the veterinary science - that he may be ready to perform to the brute creation those offices of kindness which are dictated equally by the injunctions of religion and the spontaneous suggestions of enlightened humanity.

In mentioning Haslam's son, who was a student at the London school in 1829, Skinner remarks:

It is gratifying to believe that our young men begin to seek honour and prosperity by other roads than the brief and the gallipot. - The bar is so crowded that they are literally treading on each other's toes, and the wonder is how they all exist - and if it were not that they do not harmonise so well, the disciples of Esculapius would soon be riding double through the country. There are surely other occupations that demand quite as much talent, and which are equally entitled to be honoured by sensible men ... more useful to the country than studying law as a stepping stone to some precarious and servile public employment - or putting them to study medicine for the honour of being called Doctor Polyglot or what not.

On the matter of agricultural education, the Farmer for 1827 printed a letter from Anthony Morris in which he stated his intention of establishing an institution on the farm of his son, "called Bolton Farm ... distant twenty miles from Philadelphia." The year following he states that his son has "put such parts of it as I may select at my disposition .. . for the first agricultural institute." In 1830, Skinner observed "with pleasure, that Anthony Morris, Esq. is about commencing his long contemplated institution for agricultural education." While nothing was stated about instruction on the diseases of animals, and the farm itself was physically removed from the present Bolton Center of the University of Pennsylvania, the suggestion of familial descent is a matter of some interest.

\section{Practitioners, Veterinary and Medical}

In 1825, the first "business card" of a veterinarian appeared in the pages of the American Farmer:

RICHARD WEAVER, VETERINARY SURGEON, respectfully informs his friends and the public in general, that he has commenced practising in the above profession; assuring them that all animals intrusted to him will be attended with all possible attention and care. $\mathrm{He}$ flatters himself, with the practice that he has had in London and different parts of Europe, to have a share of public patronage.

R.W. by means of his surgical system, castrates horses in a manner which has been allowed to be the easiest and safest ever acted on horses - in training they may take their regular exercise in three days after the operation has been performed, which is strong proof of the excellence of this method over any other now in practice.

He may be consulted at all hours in the day at No. 9, German-lane [presumably Baltimore]. 
Whether Weaver was a graduate veterinarian or not is unknown. Certainly there were few graduates in America as early as 1825, nor does Skinner's reference to "professional veterinary surgeons" (below) prove they were graduates - most likely they were not, for there was nothing to prevent anyone from claiming what he wished. Weaver's announcement, however, is the only one of its kind to appear in the American Farmer for a number of years.

In reply to an inquiry in 1830 concerning bighead in horses, Skinner regrets:

It is not in our power to say any thing very satisfactory, with regard either to the nature or the treatment of this disease. It appears to be peculiar to our country; as, by reference to the English and French Farriery books we find nothing stated in them analogous to it. Our inquiries from several professional veterinary surgeons in our city [Baltimore] have been equally unsatisfied. In one case only, we learn, from Dr. Haslam, that by checking it in its very incipient stage . . . the animal has been cured by administering ... stramonium . . . with his feed. ... A careful anatomical inspection, after death, would no doubt throw some useful light upon the subject, which is important; since we are told, that the disease is very common in the western portions of our country.

The existence of "several professional veterinary surgeons" in one city at this early date is of some interest; Baltimore, New York, and Philadelphia, however, were the only cities so well supplied. John Haslam who qualified at the London Veterinary College in 1801 and came to America in 1803 , is the only known graduate in Baltimore as late as 1830 . Numbers of nongraduate practitioners were available at this time; some unblushingly proclaimed their abilities; others were as able as the better qualified veterinarians.

Another type of practitioner at this time was the physician who attended his own stock, if not that of clients. One such, who identifies himself as "M.D.," writes in the American Farmer for 1830 on a "Caesarean Operation Performed on a Mare." The physician had bought a pregnant mare with a deformed pelvis, hoping to get the foal which had been sired by a famous horse. He performed a ventral section; the foal was dead, and the mare died. Undaunted, the physician states that he has given the details of the operation:

because it is a case of some novelty, and that other persons meeting with similar cases may be induced to try the same experiment; for from the circumstances, of this case, (although unsuccessful), I am satisfied, had the operation been performed at an earlier period, I would certainly have saved the colt, and perhaps the mare also.

The more common situation in 1830 , undoubtedly, was that alluded to by another correspondent, whose contribution was reprinted from the Virginia Literary Museum by the American Farmer. This writer contends:

The diseases of the horse are too much neglected by scientific inquirers in this country. In Britain and in continental Europe, especially in the latter, there are veterinary colleges where the anatomy, physiology and pathology of that useful animal are regularly taught and investigated, by professors of eminence not only in veterinary but in human medicine. Here there is no instruction of a scientific nature to be obtained and the poor animal is handed over to the illiterate farrier or left to the sole efforts of nature - a more fortunate event, frequently, as he thus escapes the additional mischief which is to be apprehended on the part of the ignorant pretender. The old story of experience is frequently invoked in favor of these practitioners - in forgetfulness, that if their minds be unprepared, either from ignorance or prejudice, to profit by experience time can only confirm and multiply the erroneous views under which they acted at their first outset in practice.

The writer, however, goes on to offer "some general remarks on the Pathology of internal diseases - the most important which fall under the care of the veterinary surgeon, and which are but little understood by the public in general" - all this for the readers of a literary magazine.

On the matter of the ignorance of many farriers and cow-leeches, and their willingness to follow directions rather than give them, the American Farmer for 1829 offers some enlightening testimony. A man whose horse had fallen sick 
sent for a neighbor who practised among sick cattle, to whom such business properly belongs. He examined the case, and declared his ignorance of the disease and method of cure, but thought his pulse a little accelerated. I told the man to take blood freely; and this was done, but without any apparent effect.

And finding a cow with the same symptoms the next day:

Again the neighbor was called. He made his examination, and again confessed his ignorance of the cause, disease, and mode of cure. I advised to the same remedy, blood letting; and it was done without any apparent benefit.

I then sent some distance for a farrier, who was highly approved in his profession. He examined both cases with attention, and declared that they were unknown to him. . . I apprehended a partial stoppage in the intestines . . . therefore I directed him to make use of his laxative medicines, which he did.

A post-mortem examination of the cow proved to the satisfaction of the owner, but not the farrier, that it died of poisoning - a fact which, according to the owner, he later proved by obtaining a confession from the guilty party.

\section{Friend of the Farmer}

In considering the status of the American Farmer as a medium for dissemination of veterinary information during the first decade of its existence, there are several aspects of the journal worth noting. Although it was antedated by the short-lived Agricultural Museum (1810-1812), the American Farmer was the first sustained effort in America to inform farmers on matters of primary concern to them. Animal disease, of course, was one of these problems. In this sphere, perhaps, Skinner was somewhat less astute than on matters relating to soil conservation, crop rotation, fertilization, and other matters more closely allied to the land. Stock owners, however, did have a medium for exchange of information on the problems which beset them. While some of the material supplied might better have been consigned to the wastebasket - for some of the practices advocated could only lead to disaster - we at least are supplied with what is probably a fairly accurate picture of conditions as they actually existed. In this respect, the Farmer is more valuable as a source of historical data than if the editor had been more judicious in his selection of material. It is in the reporting of "new" diseases in particular that we get some insight into the web of increasing complexity that began to entrap the stock raiser during the early nineteenth century.

John Stuart Skinner, therefore, as the first leader of what was to become a powerful agricultural press in America, deserves mention as one of the early friends of veterinary medicine. Without the modern appendages to an editorial office - or even with them - it seems incredible that what was essentially a one-man enterprise could have been carried on with such dispatch. From the outset, the Farmer, a weekly of eight folio pages in fine print, was the equivalent of more than 1,000 pages a year for one of our present-day journals - and much of the material was written by Skinner himself. In addition to publishing the Farmer, however, Skinner was postmaster of Baltimore, he corresponded extensively with leading agriculturalists in Europe and America, was an ardent sportsman, the most active leader of the Maryland Agricultural Society in the 1820 's, and the owner of a 200-acre farm near Baltimore, where he experimented with many of the innovations he promoted in his journal.

\section{THE TURF REGISTER}

In 1830 Skinner sold the American Farmer, possibly to devote more attention to his American Turf Register and Sporting Magazine, which he had established in 1829. He also edited the Farmer's Library and Monthly Journal of Agriculture, and the Plough, Loom and the Anvil, the latter from 1848 until his death in 1851. In addition, he edited a number of British veterinary works which he published.

During Skinner's editorship of the American Turf Register - to 1835 - this journal contained perhaps more of veterinary interest than most of the several agricultural 
journals which had been established in the wake of the American Farmer. The Register, also the first publication of its kind in this country, quickly established itself as a magazine for sportsmen - the horseracing and foxhunting fraternity in particular - and the early volumes had to be reprinted to supply the demand. While Skinner had published a fair amount of material on the diseases of dogs in the Farmer, it is evident that farmers were less concerned about dogs - other than those which killed sheep - than were sportsmen. Thus the Register was the first publication in America - and the only one for many years - to give sustained attention to the diseases of dogs; these animals, Skinner says, "are worthy objects of veterinary investigation."

On the matter of equine practice, however, it would appear by comparison of the Turf Register with the American Farmer, that among the sporting fraternity in particular, there were more horses' hind ends than there were horses, i.e., the Register is full of retrograde practices.

\section{Dog Diseases in 1830}

Except for the depredations of sheepkilling dogs, and the recognition of packs of ownerless curs which roamed the cities and towns as the primary reservoir of rabies, little overt thought appears to have been given to dogs to this time. Nor had much thought been given to the breeding of good dogs; except for the hunting dogs of a few ardent sportsmen, most were a heterogeneous lot. The Turf Register published articles on the natural history of various dog breeds, and correspondents provided a lively exchange of ideas on the treatment of the diseases which were taking their toll. Distemper appears to have been the major concern of dog owners, if the numerous contributions on this subject are any criteria.

With the emphasis being placed principally upon cures - especially those for diseases which hindsight shows that no real cure could have been anticipated-one contribution might be expected to have about the same value as another. A major exception to the general tenor of writing on dog diseases is an editorial feature on "Canine Hygina" in which it is stressed that "Dogs ... are worthy objects of veterinary investigation. ... We begin by laying down a few short rules on the means of keeping them in health." These include frequent cleaning of kennels and supplying fresh straw, and providing clean water and good food. The dog should be washed, or made to swim twice a week, and should not be fed on carrion; items recommended include barley meal and milk, sheep feet, and boiled flesh. On the matter of dogs seeking out a particular species of "dog-grass," it is claimed:

The efficiency of this herb, in respect to dogs, as a preventive to many disorders, is such, that it should be encouraged to grow in some proper place, where they may be turned to feed freely on it, by which practice they would be kept in health and many dreadful distempers avoided.

Among the many cures offered for distemper during the five year period from 1829-1834 are the following: One lump daily of sulfur and antimony in lard has "saved many valuable dogs," and antimonial wine "will cure in one day." A "strong dose" of tartar emetic, followed by a "good dose" of calomel - each repeated in 7-8 hours if results are not obtained given in nine cases resulted in nine cures. Calomel in 3-4 grain doses will also cure worms - which "often cause distemper." An army physician states that many dogs are lost with distemper through carelessness or indifference to early symptoms when a dose of tartar emetic would be effective, and "My observations condemn the general practice of bloodletting and every form of antimony." The best remedy, he says, is the "turbeth mineral" - sub-oxy-sulphate of mercury.

Commenting on the turbeth mineral treatment, a physician correspondent states that in the absence of specific directions, this will kill more dogs than it will cure. 
On the matter of nervous symptoms in the late stages of the disease - in which the army physician has advised knocking the dog on the head - he says, "I believe I have discovered a remedy for this last stage of distemper. It is the Dover Powder." With its content of opium, this powder might be expected to have some effect - but something short of a cure.

\section{Doubtful for Distemper}

Vaccination for distemper, in the manner essayed by Edward Jenner of smallpox fame, was tried by inoculation with nasal discharges. Sites for inoculation include the inside of the ear - to avoid physical irritation of the vaccinated area - and the inside of the fore leg. By rubbing the virus into a wound in the skin, inoculated dogs will "never take the distemper." Distemper had appeared, seemingly spontaneously, for the first time in America about 1760 and in Europe in 1761-1764. The disease spread like wildfire, and whole packs of dogs clied before some degree of immunity was established. French veterinarians had found as early as 1768 that scrupulous cleanliness was the only dependable prophylaxis. After Jenner had made his epochal disclosures on vaccination for smallpox in 1798, he turned his attention to vaccination for distemper in the dog by inoculation with the virus of cow pox. As might be expected, his results were disappointing - undoubtedly because neither he nor anyone else realized that he was dealing with a complex quite different from smallpox. It seems probable that this abortive effort, coming from one whose fame had been established in another field, did some harm in leading others to believe they were obtaining positive results with distemper discharges when this simply was not the case.

Most correspondents were liberal with their prescriptions. One assures good results by:

following a recipe which no bribe could tempt the vendor to part with; but, by means of some very clever chemist, I have ascertained it to be simply: Jalap powder [a cathartic] 25 grains, Calomel 5 grains.

Hardly in the same category is another individual who states:

The distemper $I$ can cure at any time, unless the $\operatorname{dog}$ is in a dying state. I cannot afford to send you the recipe gratis; but what will you give me for it?

To this the editor replies: "A volume of the Sporting Magazine - the thanks of all true and benevolent sportsmen, and of the whole canine family." Evidently this was not adequate compensation, for the recipe was not forthcoming.

In answer to the same query, another correspondent advises the liberal use of salt, saying: "If my recommending of this remedy shall save the life of one good foxhound, I will be amply repaid for the trouble." Another states he has "never lost a dog in 15 years" by giving a tablespoonful of salt on three successive mornings at the outset of the disease.

Elsewhere it was noted, however, that these "dog-doctors . . . so frequently experience the inefficacy of their own receipt, as to place its infallibility out of the question." Despite these, and numerous other recommendations, distemper continued to play havoc with the dog population. Thus a note in 1834: "Distemper is making great ravages amongst the foxhounds in the Northern Neck of Virginia." Another communication records the unusual death of all but seven of twenty-six hounds with symptoms simulating, but different from, distemper some time after chasing a fox. In 1826, Skinner had editorialized in the American Farmer:

To the person who should discover a certain remedy for the distemper in dogs-society at large and sportsmen in particular, would be very deeply indebted - to the canine race it is as fatal as ever was the smallpox to the human race, when taken in the natural way. We would award high honours and ample rewards to him who should discover in our day, a pre. ventive of the distemper - we would call him a second Jenner, prevention being always better than cure. 
Skinner devotes several pages in successive issues of the American Farmer (vol. 8) to the diseases of dogs - taken directly from a British work, Johnson's Shooters' Companion. Many of the "cures" for distemper given by correspondents to the Turf Register appear in this work; of particular interest is his statement on the value of inoculation:

It is very advisable to inoculate for the distemper. If you can meet with a dog already afflicted, take a little mucous from his nose, and insert it up the nostrils of your whelp. . . . By inoculating for the distemper, the disease will be as much less severe, as the inoculated small pox, compared to what is called the natural mode of taking it. . .

A notion became prevalent a few years back, that by inoculating a dog with the cow-pock, the distemper would be prevented. Dr. Jenner has asserted that, by inoculating dogs for the cow-pock, a disease similar to that which is called the dog's distemper is produced, but in a very slight degree. What is most remarkable, this inoculation renders them afterwards unsusceptible of that infection.

On the basis of personal experimentation, Johnson refutes the idea that immunity will be produced, or that a disease of any sort will be manifested.

Contrary to these findings, a correspondent to the American Farmer in 1830 states he was induced six years previously to try vaccination on the recommendation of a physician:

To my great astonishment and delight, the three dogs took the cow-pox effectually, and never had the distemper afterwards, although I carried my experiment so far as to place them in the hospital, where nine young hounds were suffering in that disorder.... I have continued ever since to vaccinate the young dogs; and though I must admit that some of them have had the distemper after vaccination, it has attacked them in a very mild degree, and they have in nearly every case recovered.

Perhaps the item of most real interest is his reference to a "hospital" for hounds; this would seem more likely a "sick ward" in his kennel than a hospital in the present sense, but it is evident that the need for isolation was recognized.
An extensive listing of the diseases of dogs and their treatment, such as that taken from the British source mentioned, of course, has little bearing upon the nature of canine problems in America. It is worth noting, however, that certain diseases had been called to the attention of the American public - which was all too ignorant of the diseases of any animal, and the dog in particular. Many of the treatments supposedly devised locally undoubtedly came from such sources. In addition to distemper, the diseases described in the series of articles in the American Farmer include: worms, convulsions, cough, scab, canker, sprains, inflammation, sore feet, fleas and lice, foul stomach, red mange, common mange, and an article on bloodletting. Additional diseases mentioned in the Turf Register for the period under consideration include: ticks and mange, for which sulfur, turpentine, oil and soap are recommended; worms - treated with calomel, or a mixture of powder of tin, savin, and wormwood in butter and flour; and a fatal case of dropsy, in which "the dog being tapped, she discharged more than a gallon of clear water at a time."

\section{Horse Diseases in 1830}

As editor of the American Farmer and later the American Turf Register, Skinner was in a position to reach a large segment of the animal-owning population in the eastern United States. As noted above, the Farmer in 1819 was at first devoid of articles of veterinary interest, but these soon made an appearance, and later a "Veterinary" column was begun as the prototype of similar columns or "departments" in practically every other agricultural journal in America. The Turf Register carried a veterinary column for several years from its inception in 1829. In both journals, Skinner had the advice of John Haslam, one of the few graduate veterinarians in America at the time, to rely upon, and it seems likely that Skinner's advocacy of a higher status for veterinary medicine was prompted in part by Haslam. 
In the absence of a professional medium, these journals served to bring various aspects of the problems of animal disease to the public. Some of the information presented undoubtedly was dangerous in untrained hands, and these "veterinary departments" outlived their usefulness; those of this early period, however, are especially valuable in determining what the problems of the time were.

Occasional letters calling for a system of veterinary education were published in the Register, and Skinner more than once alludes to the subject himself, but he apparently realized that the time was not ripe for this development. Commenting in 1833 on the untimely death of a famous racehorse, Skinner urges:

Comparative anatomy and the principles of the veterinary art ought to be taught in all our medical schools. A great proportion of those who are instructed in them are destined to be country practitioners, with very numerous opportunities of being useful in saving the life of valuable a nimals: whilst the inducements held out are not sufficient to insure the presence and service of professional veterinarians.

Considerable numbers of medical men, but probably few of them regularly graduated physicians, did practice veterinary medicine to some extent, and a few turned exclusively to veterinary practice. Whether Skinner's philosophy actually had any influence in this seemingly inevitable aspect of the evolution of veterinary medicine in America may be a moot point. It is doubtful that a strenuous campaign for veterinary schools at this time would have borne fruit. But unlike countless other editors of agricultural journals, who advocated veterinary training as such for farmers, Skinner at least rarely wavered in his urging that this service be performed by those with a professional education.

All too many communications from correspondents whose contributions were lacking in astuteness - or even common horse sense-appear in these columns without comment. The articles chosen by the editor, however, generally can be counted on as having some merit, as have the professional opinions of John Haslam. Furthermore, it seems likely that many of the numerous articles appearing over various pseudonyms are actually editorial contributions; the private citizen at this time was not yet indoctrinated as a contributor to the still new journals.

\section{Destined for Death}

As examples of barbarisms printed without comment, the following stand in silent witness to the preference of some segments of the public for the ignorance of the past. One correspondent relates a treatment for distemper in colts, for which:

I poured nearly a pint of vinegar ... in which two eggs had been beaten . . . into his nostrils, which caused a coughing and ... a discharge from the nostrils.

Several days later the breath had become highly offensive, whereupon he "injected suds of castile soap into each nostril three times a day." The horse died. Another, in giving a cure for fistula, directed that boiling turpentine be poured in the wound every other day. "The operation," he says, "is severe. The horse must be well twitched and held by two or three able hands." In keeping with his rough and ready treatment, the correspondent signs himself "A Yeoman."

The timelessness of certain fantastic remedies may be appreciated from the following "cure" for lockjaw in a horse belonging to a friend of the correspondent, who relates:

After using various remedies, none of which gave any relief, I suggested to him the idea of cutting the cord, which runs between the nostrils, as it seemed to be much swollen, and as he supposed the horse would die, he consented; when, much to his astonishment, the horse experienced immediate relief, and in ten minutes went to eating. I have since tried it two or three times, and always with the same effect.

This is the ancient "cutting of the cords" advocated by de Gray in The Compleat Horseman (1639), not for a "sawhorse attitude," but as a cure for stumbling! 

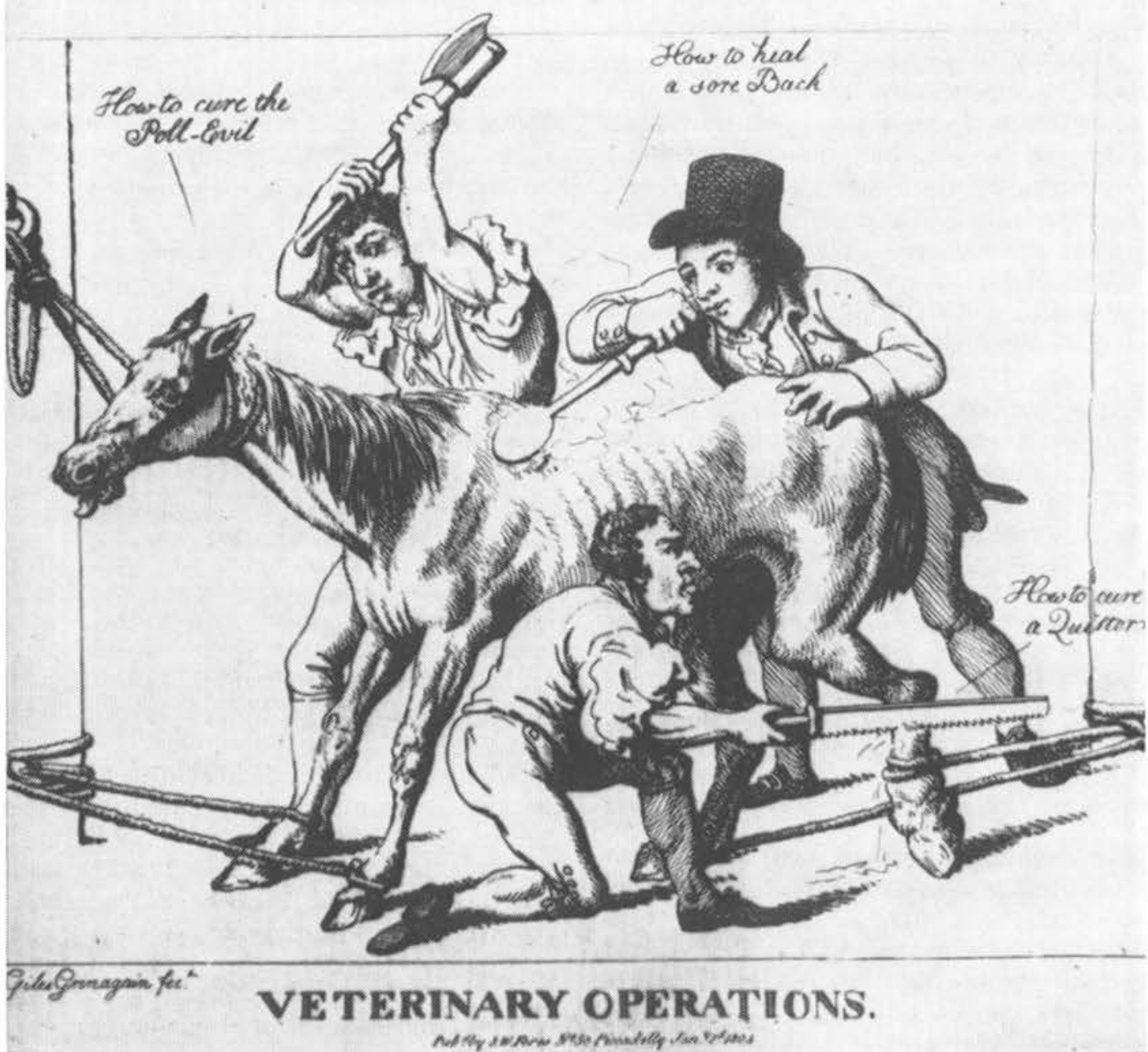

A lithographed broadside cartoon lampooning the veterinary profession (but more appropriately directed at the unschooled farrier). These appear to have been sold during the nineteenth century much as cartoon postcards are today. R. R. Shomer collection.

Elsewhere the editor states: "There are but few veterinary practitioners, probably, who can boast of having been very successful in the treatment of locked jaw." Undaunted, one horseman avers that a sure cure is the administration of five pounds of salt, together with copious bleeding!

The equally ancient practice of placing medicines in the ears of horses had not fallen into the discard; to cure a film in the eye of a horse: "Turn into the opposite ear a great-spoonful of hogslard, and in twenty-four hours, this simple remedy has been known to restore sight." Probably more than a few who read this can attest to the fact that one need not go far into the hinterland to find examples of the aural administration of medicines for a variety of ailments in this enlightened age. One barbarism identified as such by the Register is mentioned in connection with "shoulder strain," for which bleeding, laxatives, and the use of hot fomentations and camphor on the shoulder, together with the insertion of rowels, are suggested, "but the old system of previously boring and blowing and laying on a charge is exploded as barbarous and inutile." In "boring the 
shoulder," a long knife blade was inserted between the shoulder and the ribs, and a "candle" of cloth inserted to cause suppuration. A "charge" of moistened meal - or, often enough, dung - was held in place by elaborate bandages. The fact that it seemed necessary to mention the practice suggests it was still being used.

The theory of "laudable pus," in this pre-Listerian era, was still very much alive. Thus for "attaint," a sore on the fetlock, we are directed to bring this to suppuration, for "there is no such thing as curing wounds in horses by the first intention ... as in the human subject." (But pus was still "laudable" in medical practice.) On the subject of "lampas," however, the idea that the swelling of the palatal mucosa is a disease "is exploded by all veterinary surgeons." The ages-old practice of cautery of the palate is decried as "barbarous," and of bleeding as "dangerous." We are directed to leave it alone.

\section{Doctoring Animals}

The veterinary practices of medical men are of some interest, although it should be realized that not all those who affixed the "M.D." to their names were graduate physicians - some, undoubtedly, were outright charlatans. In general, however, it may be said that these men possessed considerably more ability than the nongraduate farrier, but less than the better qualified veterinarian - so far as treatment of animals was concerned. One contribution in 1834 relates a successful case of radical surgery for hernia. The horse presented a large ventral hernia which prevented normal locomotion. After an unsuccessful attempt to reduce it by bandaging, the doctor relates:

the horse was thrown, his hind legs pulled back and secured. I proceded to the operation, by making a longitudinal incision through the external integuments, down to the protruded vis-
The truss probably was not a particularly effective device, but the "clams" were used both for castration and hernia from colonial times (and still are for hernia). Clater-Armatage: Cattle Doctor
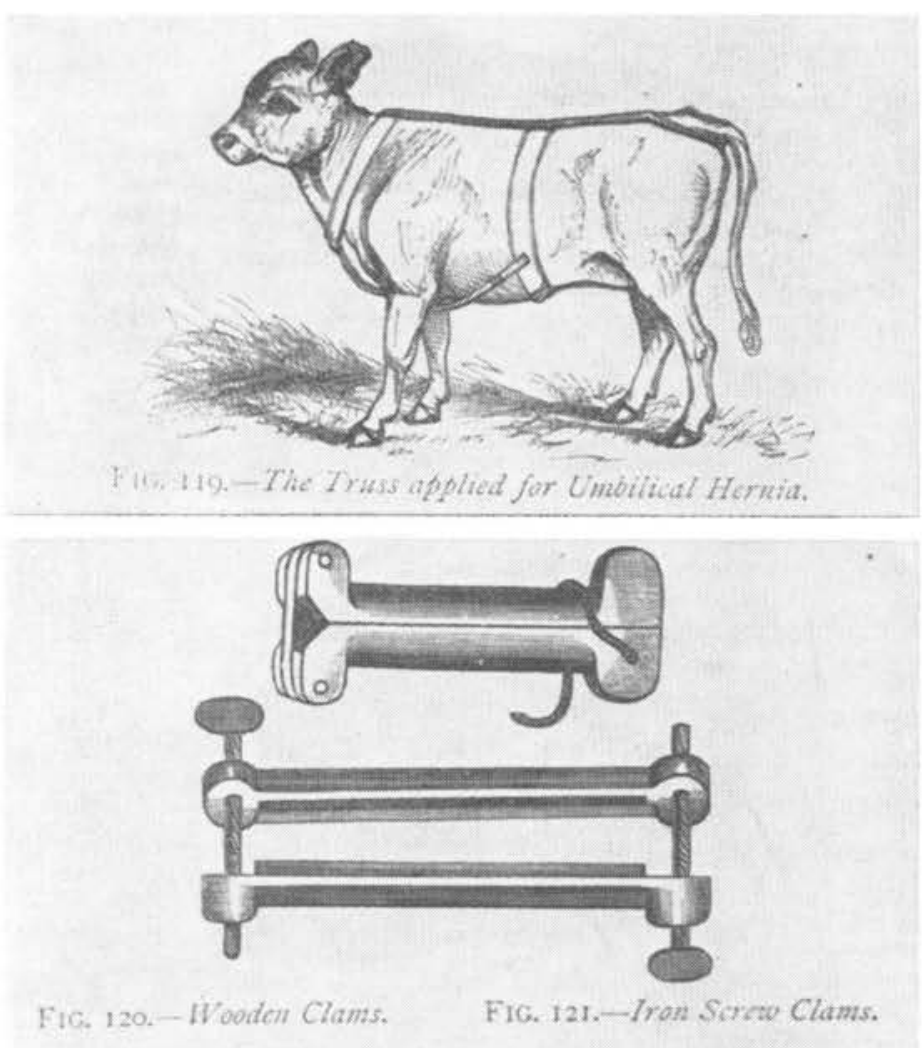
cera, when I discovered that a large portion of the intestines were out, and to my surprise, also the stomach.

He enlarged the hernial ring to facilitate replacement of the viscera, sutured and bandaged it, and "in five or six weeks the horse was as well as it ever was."

Another doctor reports on a radical cure of bone spavin on a horse which was so lame that the owner had given him permission to "experiment." Concerning the method, he says:

The remedy adopted is condemned by some of the highest authorities we have. High authorities are not always infallible, and if we depend upon them too implicitly, knowledge can never advance. . . . I provided myself with a chisel, mallet, and bolt of iron, rounded at the extremity - intending to chisel off the lump, and then to fire it, for the double purpose of stopping the bleeding and establishing a running sore.

The spavin proved to be cartilaginous, so he only fired it; the wound healed in two months, but the lameness returned. Thus:

I determined then to try a second operation, and to combine the chiseling with the firing. I had the horse bound as before, and made two incisions in the same manner. I then took a chisel, an inch wide, and cut off a chip the size of a dollar, and about an eighth of an inch in thickness. I next, with a white hot iron, seared the bone and wound over the whole surface, and turned the horse loose.

According to the good doctor, the horse recovered in three months, and was still drawing a mail coach a year later. He concludes by commenting:

You will perceive that I have scrupulously avoided all the technicalities of the veterinary art, both surgical and anatomical. Comparatively few would understand technical terms.

The latter may not have been entirely amiss, for a year later a "plain farmer" is found asking for "plain words" on the nature of disease and treatment - "language that I may comprehend."

A Delaware physician reports on a pneumonia of horses and mules which was prevalent in 1832 :
Many noble animals - horses and mules died almost without a warning; others lingered with alarming symptoms several days. So great was the general loss, that in consideration for my fellows as well as myself, I concluded to investigate the matter, and resorted to post mortem examinations.... as the most certain means of success. . . . I accordingly procured the services of several persons, and dissected ten animals. ... I was fully satisfied that in all the cases the lungs were the seat of the af fection, and comparing with different authors, I believe it to be equivalent to the Pneumonia of man.

The disease was not reported until 1860 , when a presumed resemblance to the pleuropneumonia of cattle then raging in Massachusetts led him to go back to "notes made at the time."

A nonmedical correspondent on the subject of horse distemper states that a medical friend had assured him that in its early stages it was curable with calomel. $\mathrm{He}$ tried this - apparently in liberal doses whereupon the horse swelled in the legs and became lame:

I tried everything I could hear of, and finally blistered, but without success. I should like to try firing, but have never seen the operation performed, and no person, in this part of the country, knows anything about it. . . He now passes for a spavined horse ... and I have regretted listening to the advice of the physician. ... Five or six months after giving the calomel, I had occasion to bleed this horse; and the operation was followed with a most dreadfully inflamed neck, and the creature would have suffocated, but for the timely application of a blister to the inflamed part.

There were those at this time who still believed that distemper (influenza) in horses was not contagious, although nearly all recognized the disease as inevitable. This same man (above) states, however, "I believe this disease to be contagious, and that the horse will have it more than once." In twenty years he had never raised a colt without its having the disease, and each time the older horses would be mildly affected. He had never lost a colt, and had never bled one for the disease - except for one badly affected, for which a drover assured him if he would "cut off a joint from his long and beautiful tail, and permit it 
to bleed half an hour, he would soon be entirely well." It worked - or at least the horse lived.

Despite an occasional voice crying out against the practically universal practice of bloodletting, the fleam and lancet were the first resort in every illness - and remained so another half century. In 1832 the Register claimed:

Bleeding . . . is the essential remedy in all the diseases of the horse, depending on inflammation, and in these cases the earlier and more freely it is employed, the more beneficial will it be in its effect.

This was followed by a lengthy article on the indications and technic for phlebotomy.

A request for information on blind staggers from a correspondent in Florida, who says the disease was very destructive there, brought forth two pages of directions from a book on farriery which could have been reduced to two words - bleed and blister:

Should the disease continue and its violence resist this treatment, we may open the two carotid arteries, which operation I have performed myself with success, after every other means have failed.

According to the farrier, sleepy staggers results from a stagnation of blood in the ves- sels of the brain; mad staggers from an inflammation of the dura and pia mater.

A correspondent in Louisiana who had lost all his blooded stock from staggers (encephalomyelitis?) says that among numerous remedies tried was one which called for letting six quarts of blood, boring the skull, using pokeroot setons in the skin, and giving large doses of salts. Of particular interest is his statement concerning one of the attendants, who "died on the same day, of influenza, which terminated in inflammation of the brain and delerium."

\section{The Old Turfman}

One of the better features of the early volumes of the Register is a series of lengthy "Thoughts on Blood Horses," by "An old Turfman," who claims that mismanagement is the cause of 90 per cent of the diseases of horses. On the requisites of the medical attendant, he says: "It is not to be expected that an uneducated man, ignorant of the relative powers and effect of medicines, can be a good farrier." On the proclivity for purging horses, whatever their illness, or semiannually if well, the question is raised:

Why three doses of physic, as is the too general practice, are to be given indiscriminately to every horse, I have yet to learn. . . . The

Blisters were the first resort in digestive disorders until the late nineteenth century; the farrier's favorite was a hot shovel. Manning: Stock Doctor

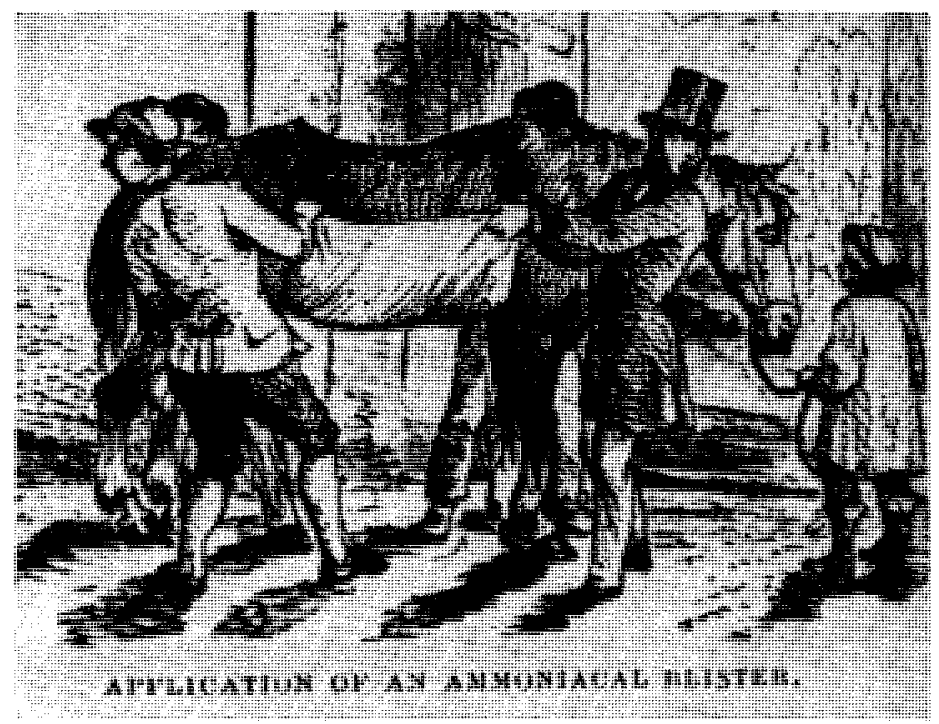



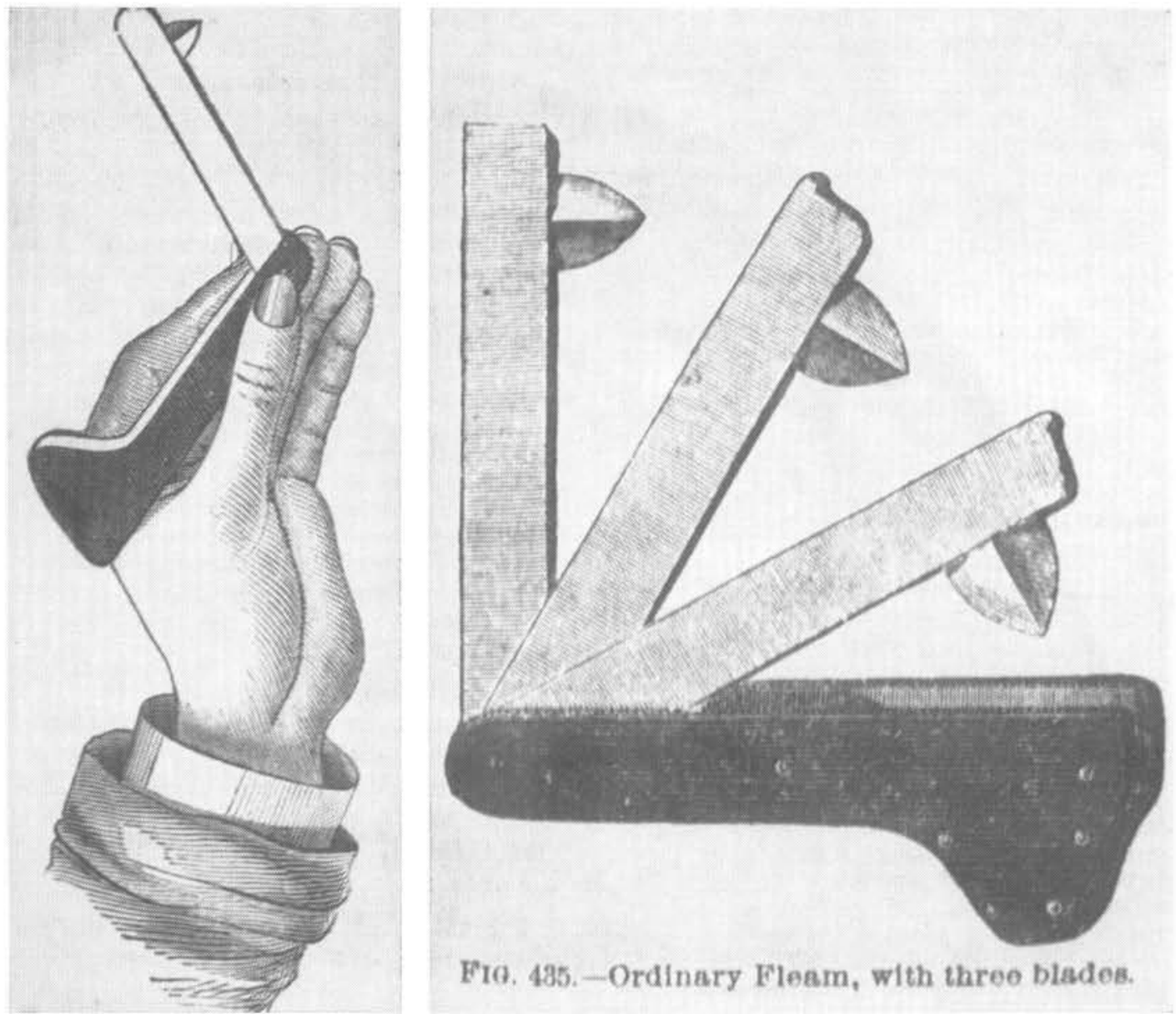

Fia. 435.-Ordinary Fleam, with three blades.

The common three-bladed fleam used for phlebotomy, which was practiced both in human and veterinary medicine for many ailments. The blade was placed against a vein and struck with a "blood stick," akin to blackjack. Liautard: Surgery

effect of medicines in horses has only of late years been thoroughly understood, and when we look back into some old writers on farriery, and examine some of the cathartic drenches, we are astonished that more horses were not killed than cured by them. ...

I am no friend of quackery, in either horses or men, when they are well. I remember the speech of the dying man: "I was well - I would be better - I took physic - and here I am."

$\mathrm{He}$ admits, however, that race horses must have mild purgatives or they will suffer from plethora and stocking of the legs.

In another installment we are offered a long dissertation on the evils of indiscriminate blistering and cauterizing, which: are remedies frequently practised, or at least recommended by grooms ... the person thinks himself of no small importance in proposing remedies, as he imagines it shews him to be a great adept in his profession. Farriers, frequently as ignorant as the grooms, find an interest in being on good terms with them, and therefore seldom oppose their opinions; so that if a consultation is held between master. groom and farrier, two to one are certain to carry the proposition, and the horse is sometimes needlessly tortured.

Frequent references are made to the incompetency of farriers, and occasionally of veterinarians. On the difficulty of diagnosing curb, one writer makes the accusation: "both the horseman and the veterinary 
surgeon have overlooked it." A correspondent in Virginia writes asking about a condition resembling stringhalt: "of which our farriers here seem to know nothing," to which the editor replies, "our respectable veterinary surgeon Haslam .... pronounces it a case of cramp," but is unable to give a remedy. In a detailed article on nicking and setting the tail, it is stated:

Among farriers and horse dealers, some difference of opinion has existed relative to the propriety of exercising a horse during the use of the pulley, and also as to how long the pulley should be used, but these matters can never puzzle the veterinarian, being easily solved by a knowledge of the animal economy, which alone ought to guide him.

A horseman who had made an experimental study on the horse bot is critical of the opinion of Edward Coleman, head of the London Veterinary College-and through him held by his graduates - that bots did no harm:

The professor thinks all horses have botts, and that they assist digestion by aiding trituration; he supposed that seldom or never do they kill the horse, but I think the professor goes too far.

John Haslam, himself a London graduate, also held that bots did not harm the horse, and claimed that in several hundred postmortem examinations he had found no evidence to the contrary.

The teachings of Coleman on the noncommunicability of glanders - which he believed to be spontaneously generated - may in large part be the basis for the accusation of one censor that:

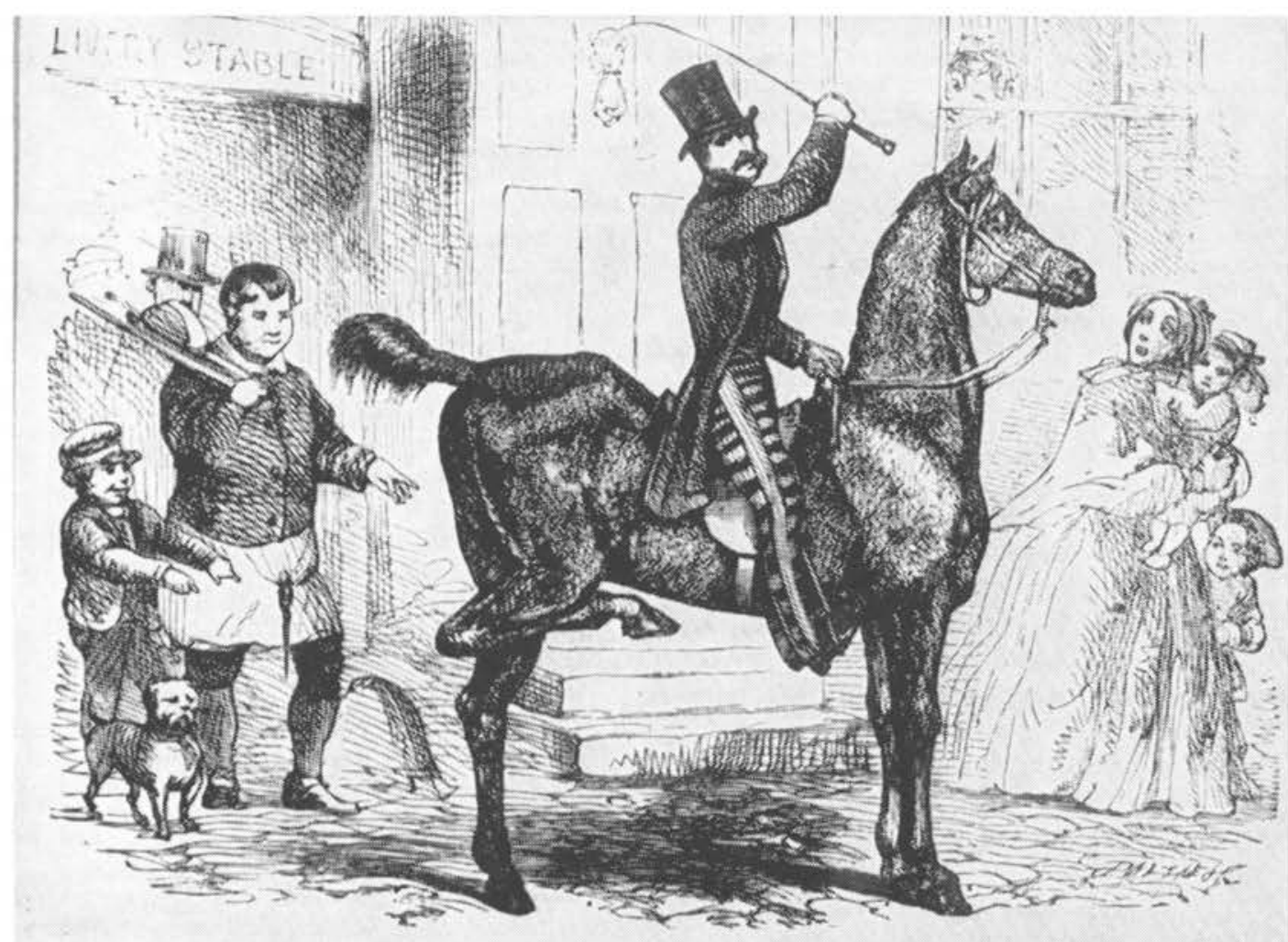

A HORBE HAVING STRING HALT.

Descriptions of the characteristic attitude in stringhalt have not changed, although treatment today - via tenotomy - is somewhat more successful than methods of a century ago. Mayhew: 


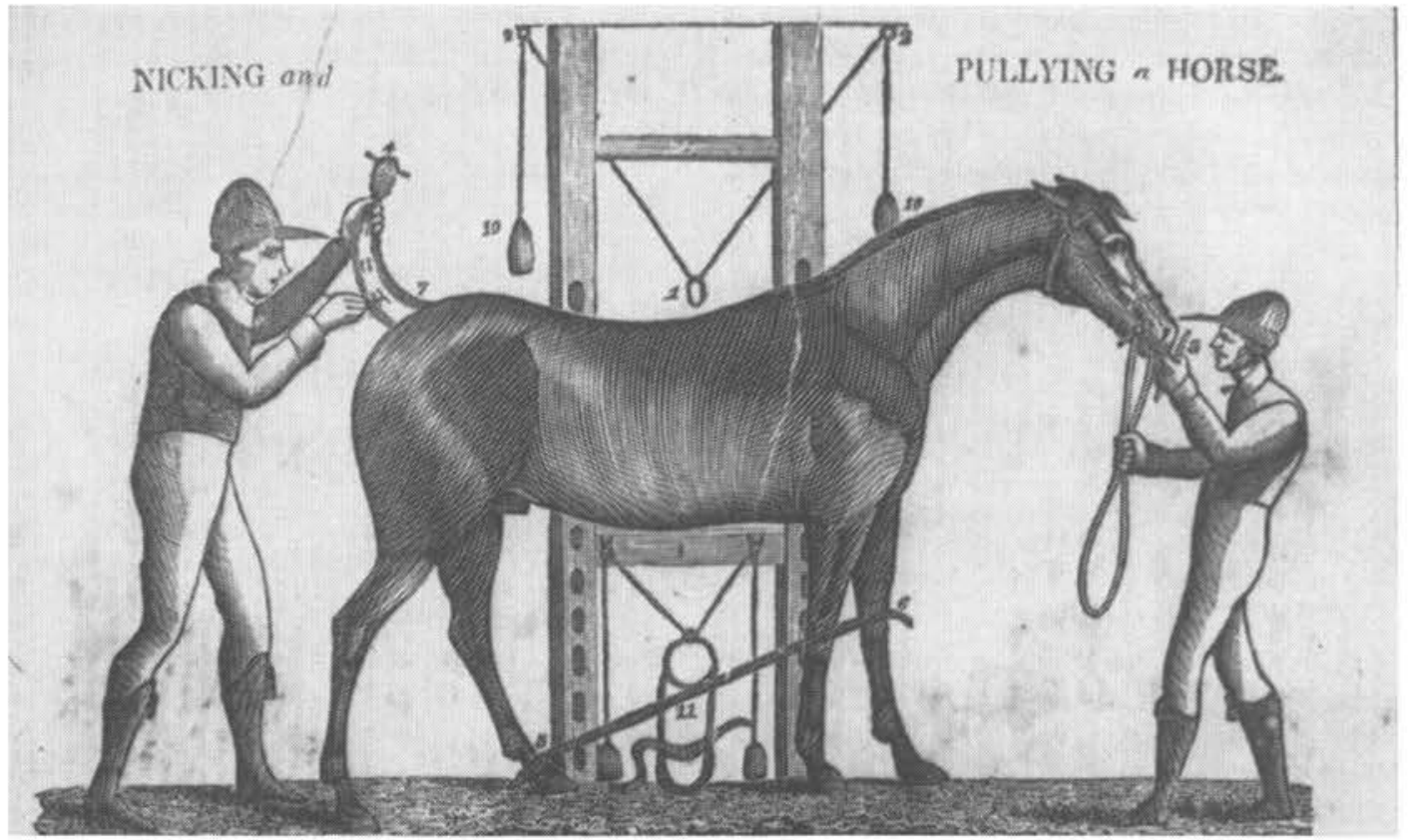

\begin{abstract}
"Nicking," or caudal myotomy, was practiced since colonial times to produce the fashionable tail carriage popular with horse fanciers. The system of pulleys used to maintain an erect tail carriage during the healing process was superseded by a simpler "tail set," or harness. Mason's Farrier, 1820
\end{abstract}

The glanders is a disorder that may be properly called the reproach of the veterinary art, the moderns as well as the ancients; for the disorder was well known even before the times of Columella, and others of the most ancient veterinary writers; and yet no rational method of cure has been discovered for it, and indeed the number of receipts which are found in their books, afford us a strong proof of their deficiency.

Our critic states that one horse can give the disease to a hundred others, "but 9 in 10 times it arises from the poisonous effluvia of the lungs, dung, or urine, impure air, etc." He convicts himself by giving his own version of an "infallible" treatment.

The blacksmith who applied horseshoes hot came in for his share. One Southern gentleman instructed his groom to tell the smith if he ever dared apply a hot shoe again: "I will apply one to his - - !" The smith did apply another hot shoe, whereupon the Southern gentleman, with the aid of two servants, "stamped him $a$ posteriori with the insignia of his profes- sion." And the horse dealer is characterized as claiming: "a nag, proper only for dog meat," is "fit to go to any hounds"; and "roaring," he calls "sound." Also, if his "knees be fractured," he is "well broke."

\section{Grim Farriery}

The editor of the Register accords special mention to to review of a work by a John Grimm, Farrier, in a Winchester, Virginia, paper, and asks if witchcraft has reared its ugly head in that part of the country. The items quoted speak for themselves:

To stop blood - take one piece of wood and make three little wedges of the same. Make them a little bloody from the wound, and stick them in a crack of a $\log$ on the sunrise side of a house or barn, two or three inches apart, and strike on each wedge three strokes with a hammer or stone.

For ringbone:

Go where some horse has died, and take the bone, if you can find it, from the knee down to 
the fetlock. Take this bone on the first Friday after the full moon, and before sunrise rub the ringbone well with the bone, and then rub the ringbone crossways three times. Then return the bone to the same place upside down, and put a stone on the top so that it may not be disturbed.

For the spavin but little can be done:

Take your horse on a meadow of good grass. When standing still, mark out with a stick exactly the size of his foot in the grass, remove the horse and dig up the same and turn the grass upside down in the same spot. This is to be done the first Friday after the full moon.

Such doings, of course, have never been restricted to one place or one time, as the folklore of any region, past or present, will attest.

A correspondent from North Carolina in 1834 reports on:

a new and safe method of castration now practiced in the upper part of this state. . . A man in Guilford county, is in the habit of castrating all horses standing, confined in no way except held by a bridle ... on horses from one to ten years old, and in every instance with the most complete success. . . . If a sufficient inducement were held out, he would attend at any place himself to operate, or teach others - the subject of a more free use of the knife. This gentleman's art may be an important acquisition, indeed, I am persuaded that many gentlemen are induced to let their colts remain entire, from the supposed risk in altering.

That a freer use of the knife was indicated, may be adduced from the statement: "If the knife was oftener used, our stock would improve much."

In the same vein is a comment on the tax on stallions in Virginia. The tax twice the stud fee-says this correspondent:

is not high enough on the low priced stallions. ... But we are a just people, and besides have always been in favor of free trade in everything, and hence have an abundance of quacks who hardly know the bilious fever from the consumption, and a flood of ricketty spindle shanked stallions that would hardly be thought fit for teazers to third rate horses.

A letter to the editor urging that the amateur "extend his knowledge to every thing that can possibly alleviate distress," and requesting directions for balling a horse, states that "few have any practical knowledge in the administration of medicines to the animal." In a two page article in reply, John Haslam states that there are three methods: the balling iron, by hand, and the balling probang. The latter, which he describes as being similar to the modern balling gun, is "an instrument I never saw. But my son tells me that at the veterinary college, in London, they have one; yet he is of the opinion it will never come into general use." Haslam obviously prefers administering balls by hand, and gives full details of the procedure. However, he recommends that the amateur not attempt balling a horse, and he is opposed to the use of drenches, as "the remedy is sometimes worse than the disease." In a diplomatic way, it is evident that Haslam was in favor of having veterinarians admin. ister medicines.

\section{THE AMERICAN AGRICULTURALIST}

In 1842 the American Agriculturalist was added to the growing list of agricultural journals. Edited by A. B. and R. L. Allen, this publication became one of the most respected and influential in its field. R. L. Allen in particular was interested in livestock, and wrote several books, including the extensively circulated Farm Animals (1847), which purported to treat of animal disease as well as animal husbandry in general. Much of the information on disease in this work-like others of its genre - is an ill-considered assortment of material taken from the pages of agricultural journals. In fact, the journals themselves reflect a higher caliber of writing on animal disease inasmuch as they frequently included pleas for more attention to veterinary medicine. This in itself might suggest that the reader should use the remedies recommended with some degree of caution, whereas the books gave their remedies in too authoritative a fashion. Allen, like other writers of the period who appear to have had a sincere interest in the advancement of the veterinary art, might better 
have employed a veterinarian to do this part of his book. But not only were there too few veterinarians - Dadd says 15 in 1847 - some of those who later did write books did little to advance the profession.

The early volumes of the Agriculturalist contain relatively few references to animal disease, but it is of some interest to note the number that were authored by physicians. While the practice advocated by some of these men is deplorable - even by the standards of the times - most of them did express the need for better information on the treatment of animals. Thus in the first volume there is a communication from Dr. Andrew Campbell of Ohio, who describes his experiences with hog cholera in which the affected animals:

resemble precisely the cases of cholera that I often witnessed here in 1833 and 4. They lose the use of their limbs, become as cold as a mass of ice, the tongue and mouth turn purple, and they die in from six to ten hours.

This is perhaps the most clear-cut evidence we have to prove that hog cholera did originate (or was discovered first) in Ohio in 1833; few references to the disease are to be found prior to 1850 , and writers in the 1880's disputed the date of origin. Campbell's treatment - bleeding, plus the administration of linseed oil, pepper, and turpentine - as might be expected, was of little avail. The good doctor apparently had some reservations about the propriety of his attending swine, for he adds:

I hope you will consider it no descent from professional dignity for an M.D., backed by some half dozen diplomas from distinguished Medical Societies, to doctor a pig.

\section{To this Allen replied:}

Dr. C. need not fear that the dignity or laurels of his profession will suffer in this or any other quarter, by attending to, and describing the disease of any of the animal creation, however humble.

\section{The Virtue of Humanity}

In a lengthy communication on "Inflamed Eyes of the Horse" the following year, Dr. Campbell mentions that while he is overly busy:

attempting to cure or palliate the "ills that flesh is heir to" in the human species, my sympathies have been occasionally enlisted in behalf of that noble animal upon which we are so much dependent for many of the leasures and comforts, and derive so much important service - the horse, in consequence of the empyric and barbarous treatment frequently practised upon him. If the animal who claims for himself the image of his Maker, is willing to indulge in "Brandreth's Pills, Lobelia Magnetic Ether," ... [etc.], and write for his epitaph, "I was well, took physic and died," let his curiosity be gratified; but while we assume to ourselves the guardianship of the manner that shall at least entitle us to the virtue of humanity.

Campbell states that the common treatment for spots on the cornea of the horse's eye is to blow powdered glass, burnt alum, or powdered bluestone into the eye, and "by just such treatment many a noble roadster has been prematurely consigned to a cart or the treadmill." Campbell gives his treatment in great detail; essentially it consists of a complicated regimen of bleeding, purging, and keeping the animal in the dark: "Thus," he says, "I have given you, as our Buckeyes term the science, a chapter on "horse-doctoring." "

As suggested by Dr. Campbell, the human species had long had the advantages of physicking themselves with any of a number of patent remedies. While occasional advertisements of the vendors of veterinary remedies appear in the early volumes of the agricultural journals, it was not until well toward 1850 that these entrepreneurs became well established. In 1834 and later, the New England Farmer carried the advertisement of Thomas Hollis, Druggist and Chemist of Boston, for his "Celebrated Horse Liniment . . . decidedly the best and certainly the most convenient article in use." In 1848, "Seabury's Oleaginous Opodeldoc" was advertised in American Agriculturalist as being a suitable liniment for both man and beast. The formula for opodeldoc (camphorated soap liniment) had been given in the New England Farmer fifteen years ear- 
The stomach pump was advocated by Youatt both for lavage and administration of medicines, but despite the popularity of his works in this country, the stomach tube was little used until well into the twentieth century. Youatt: Cattle (1836)

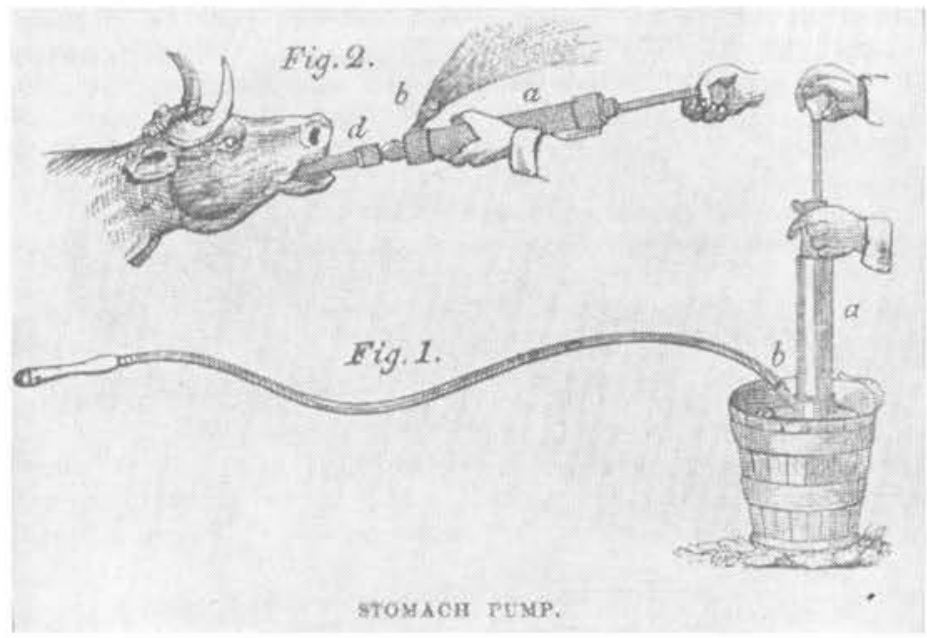

lier: two quarts whiskey, warmed, add all the soft soap it will dissolve, one ounce camphor, and half an ounce of ammonia. And "some gentle physic should be given at the same time. The opodeldoc will scatter the humors if recent, and the physic will clear them out of the system."

When the writers of the minute "medical melodramas" with which we are assailed from every channel today turn their attention from heartburn to heaves, the following script, from the American Agriculturalist for 1850, is offered for what it is worth:

Is your horse in the habit of coughing when he leaves the stable in the morning? Is he less inclined than usual to pull alertly? Does the poor wretch heave and pant for that breath which is perfectly indispensable to healthy organization? Is he thus an object of pity and annoyance to his driver? In short, has he that dreadful scourge, the heaves? You can cure him most certainly, in nine cases out of ten, by the Tattersalls Heave Powders.

In 1832, the New England Farmer advertised:

Maw's Improved Veterinary Pump, for administering clysters to Horses, Cattle, Dogs, \&cc ... the length and flexibility of the Elastic Tubeing affords great facility and security, as the operator may stand at a considerable distance, or even in an adjoining stall.

In 1844 a farmer-correspondent who had trouble with "gravel" (urinary calculi) in a number of his animals, relates that he had "applied to a regular physician" who instituted a complex system of treatment that apparently had some effect. The farmer concludes: "I think by having a record of all such circumstances to refer to when cases of the kind occur, there would be a great advantage in it." In commenting on the treatment of animals by physicians, the editor notes:

In the absence of well-educated Veterinary Surgeons, physicians may do great good, and save many a poor animal much pain, and severe loss at times to the farmer; and in thus acting, they need not fear either degrading themselves or their profession, for in Europe nearly as accomplished an education is demanded of the Veterinary Surgeon, as those practising among their own species.

\section{Unqualified Quacks}

Some appreciation of why veterinary medicine had made but a poor beginning as late as 1845 may be had from a communication from an Ohioan, apparently a stockman, who explains at length:

There is perhaps no subject less understood by the farmers in this country, than the nature and cure of diseases among their stock. The veterinary art is practised, with very few exceptions, by persons wholly unqualified, either by education or experience, for the vocation; hence, the reluctance that many have to entering it. I had occasion a few days since to call on a man who had studied at a Veterinarian 
School in Edinburgh, Scotland, and had practised the art for several years before coming to the United States. He brought with him here a diploma and good recommendations. On asking him why he had given up the practice, he replied, because there are so many quacks in the business in this country, mostly from Europe, it has become very disreputable, and nearly every one who employs me suspects equally my capacity and honesty. Books on this subject are extremely scarce among farmers, and many of them worthless.

There ought and must be a remedy for all this. If every farmer would note down the history of any uncommon occurrence which takes place among cattle, horses, sheep, swine, or lowls; describing, as near as possible, the nature of the disease; its origin and cause; together with the manner and means made use of to effect a cure, and the final result of this practice in so doing, together with his own remarks and observations, as well as those of other men of sense and experience, where a cure has been effected in similar cases, it would throw much light upon subjects where darkness and obscurity now pervade.

There follows a description of a puzzling disease among horses in which the tongue and mouth were blistered, the legs swollen, and the hoof had "a fester at the crown." Three hooves from thirteen horses were lost. This man evidently was not only able to describe the condition with great fidelity, but was something of an experimentalist as well. He relates having tried chloride of lime, corrosive sublimate, arsenic, or copperas, "each of these on different feet, to test their respective virtue," and each apparently being effective. He had no idea of what caused the condition - which apparently was ergotism. The editor states, "Our correspondent has here met a frequent disease. It is caused by poisonous weeds." But what weeds, he does not know.

In a series of articles on "Diseases of Animals," beginning in 1846, Andrew Stone, M.D., of Indiana, states:

There are so many diseases in animals that assimilate to those of the human species, and the treatment of such appears so well adapted to each other, that medical men generally are turning their attention to animal medicine and to agriculture, as sciences intimately connected with their own profession. In fact, the nature and diseases of animals, especially those of sheep, have been too long neglected, and the remedies that are generally prescribed, are by those who know not the why, not the wherefore - who are entirely unacquainted with the true nature of anatomy, physiology and pathology of animal medicine, and, under such circumstances, are as much liable to do injury as good.

Humanity, therefore, justly prompts a more special attention to animals - to ameliorate their diseases and sufferings, and render more scientific and systematic attention to their history. We may justly consider, that a malpractice in regard to brutes, that shall occasion an undue suffering and sacrifice of life, is attended with a degree of moral responsibility at least proportionate to human life itself. The way, then, must be opened by medical men; they alone, at present, as a general thing, can give system, order, and science to the study, and I am happy to see that animal medicine and agriculture are no longer beneath their notice, and begin to assume a standing and attention that they so justly deserve.

\section{No Stone Unturned}

Stone, obviously, was no ordinary man - and perhaps considerably more than an ordinary physician, and for the good that he may have been able to do, either personally or by influencing others, we have reason to be grateful. In saying that medical men at present are the only individuals capable of practicing animal medicine, he was likely correct; by inference, however, he seems to envision the day when men trained in animal medicine as such would be available. Coincidentally, but most appropriately, the article following Stone's concerns unfair competition among stockbreeders in which the writer says, "If another man has what is really better than anything I possess, let my tongue be palsied when it refuses to say it."

In writing on animal disease, Dr. Stone apparently knew whereof he spoke, for he says:

A personal examination ... is always my practice when any of my stock dies from disease, or any unknown cause, which I hope will give additional worth to the cases I shall report, as every examination has been made by myself. 


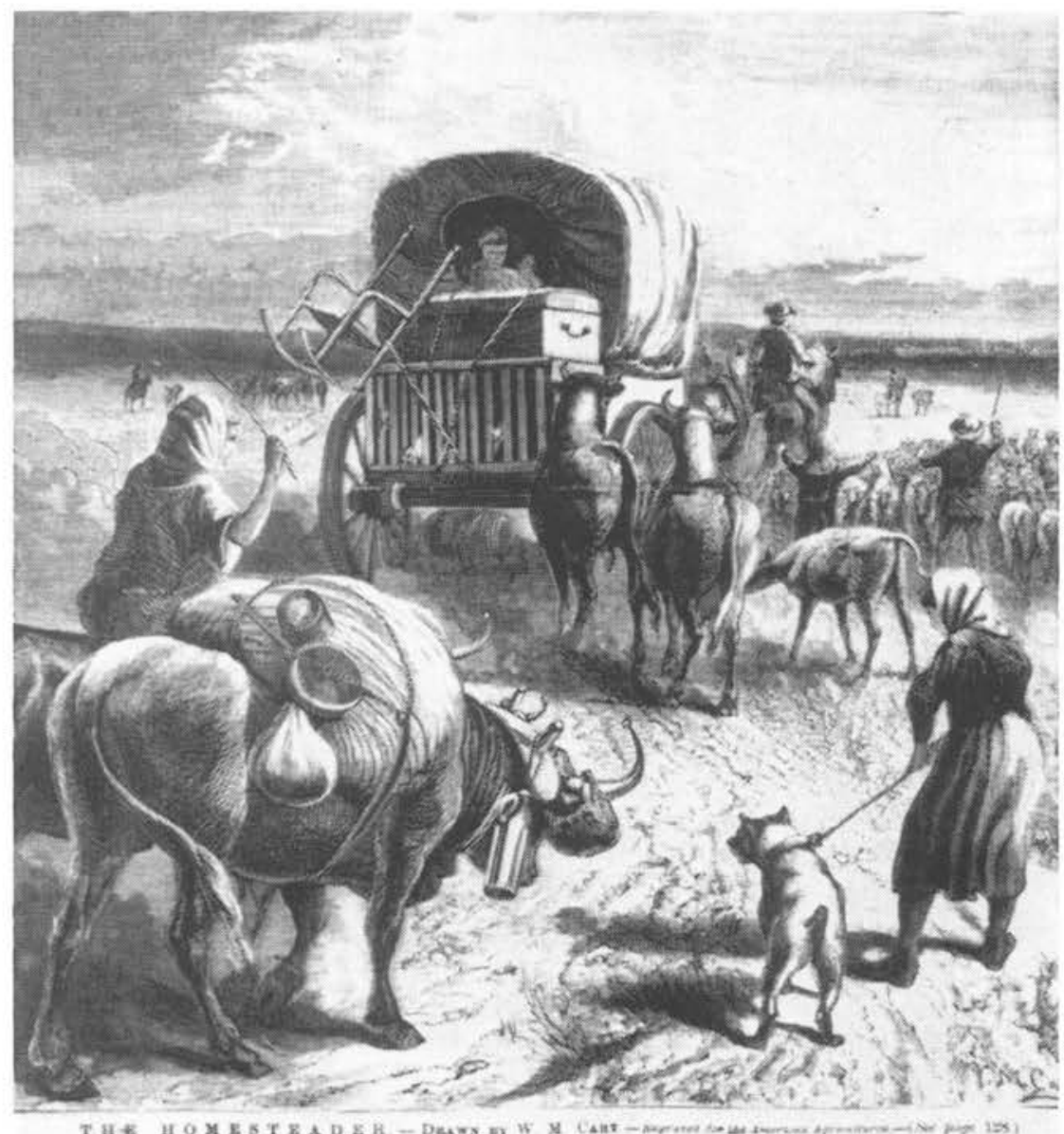

Few contemporary prints gave an adequate conception of the amount of livestock that accompanied the trek westward. The "Pioneer Handbooks" gave directions for treating sick animals as well as human beings. American Agriculturalist

His reports, he hopes, will "cause additional attention to be paid to the diseases of animals, and search for causes of death in every animal that dies in any mysterious or uncertain manner."

The good doctor may be forgiven if in the first case he reports, one of a ewe that died in parturition, he demonstrates his ignorance of comparative anatomy. The thorax and abdomen presented such a healthy appearance that:

I imagined I should be baffled to account for the cause of its death; but on opening the womb, I readily discovered extensive disease; the whole internal surface was studded with a kind of tumor, called in human medicine the cauliflower excrescence.

Possibly later he found that he had discovered the normal uterine cotyledons. We might recall that a number of British farriers - at least one a surgeon-had earlier described the gall bladder of the horse-discovered, undoubtedly, from the confines of a comfortable armchair.

In a later communication, Stone makes a valuable contribution to what might be termed the geography of animal disease, and the effects of constitution upon the incidence of disease. About this time, as the tide of immigration moved westward, 
numbers of reports began to appear in the eastern papers to the effect that in "the West" as a whole, or in particular localities, the country was unfit for stockraising. Stone writes in rebuttal to these prophets of doom:

I have noticed since my residence in the West [Indiana], at times nearly whole flocks of sheep extensively diseased, and the owner, or shepherd, hardly seemed to have any idea what was the nature of the disease, or what the cause; and so for want of a little proper study and reflection, hundreds of these useful animals die annually. As regards sheep husbandry in this section of the country, an important consideration presents itself. To supply the want and demand occasioned by the immense tide of immigration that is constantly rolling to the west, millions of sheep must be brought in. These, like ourselves, who have been raised and accustomed to a healthy climate and soil previous to our arrival here, but poorly bear the change; hence sheep and other animals become subject to new diseases, the result of new causes and influences. It is in this way that the intelligence has gone forth that sheep will not do well on the western prairies ... [but] this is a sweeping conclusion drawn from isolated circumstances.

A major predisposing cause of disease, Stone says, is the periodic innundation of the flat prairies, alternating with seasons of drought-something unfamiliar to residents newly from the East. This keeping of sheep on wet pastures, he relates to the finding of extensive liver damage in sheep dying with various symptoms. He adds: "It was long ago noticed by Professor Drake, of Cincinnati, that hardly a hog was slaughtered at that market that had not a diseased liver." Another factor mentioned by Stone is that immigrants, with an eye on price rather than quality and condition, bring mostly old and infirm sheep: "which generally die off the first winter in this country." Many which survive the first winter, the flooded pastures in the spring, and drinking from the stagnant pools left in the wake of the rains, finally die from lack of water in the summer, when at small expense a windmill would supply ample water.

Of some interest is Stone's statement:
A diseased or affected sheep never should be allowed to remain with the healthy ... [but] should be instantly removed to its proper place - the hospital.

Probably few farmers maintained hospital quarters for diseased animals, but the editor of the Cultivator in 1841 advised: "A division or hospital for weak or diseased sheep is indispensable, and not to be overlooked by the sheep farmer." In 1866 the editor of the American Agriculturalist, in speaking of "A Horse Hospital," states:

Every one who keeps only two horses should be able to separate them if one is sick, and it is hardly fair to turn the well one into the yard.

Morrell's American Shepherd (1846) advises maintaining a "hospital flock" for, despite adequate care:

Disease will make its way to some individuals, which, in that event, require removal from their strong and healthy comrades, and treated accordingly. ... When a sheep is seen declining in flesh, let it be removed forthwith to the hospital.

That a number of the pessimistic reports concerning the midwest as an area for livestock raising were of a local nature is suggested by the enthusiasm of others. Thus in 1842 a man in Illinois reported he had bought 1,770 sheep in Ohio for a dollar a head, and lost only six the first year, and these from rattlesnakes rather than disease. He says he uses "one barrel of salt per month, and the sheep have ever been perfectly healthy." They were folded at night to protect them from the wolves, but had no protection from the elements. Not to be outdone by his neighbor, an Iowan soon responded with the alleged fact that his own state was "the best region of the United States for sheep," for among other advantages:

Disease is unknown among the flocks here, although the farmers as yet have very imperfect fixings for their sheep. Indeed, as yet all the sheep here are kept during the winter without any shelter. 


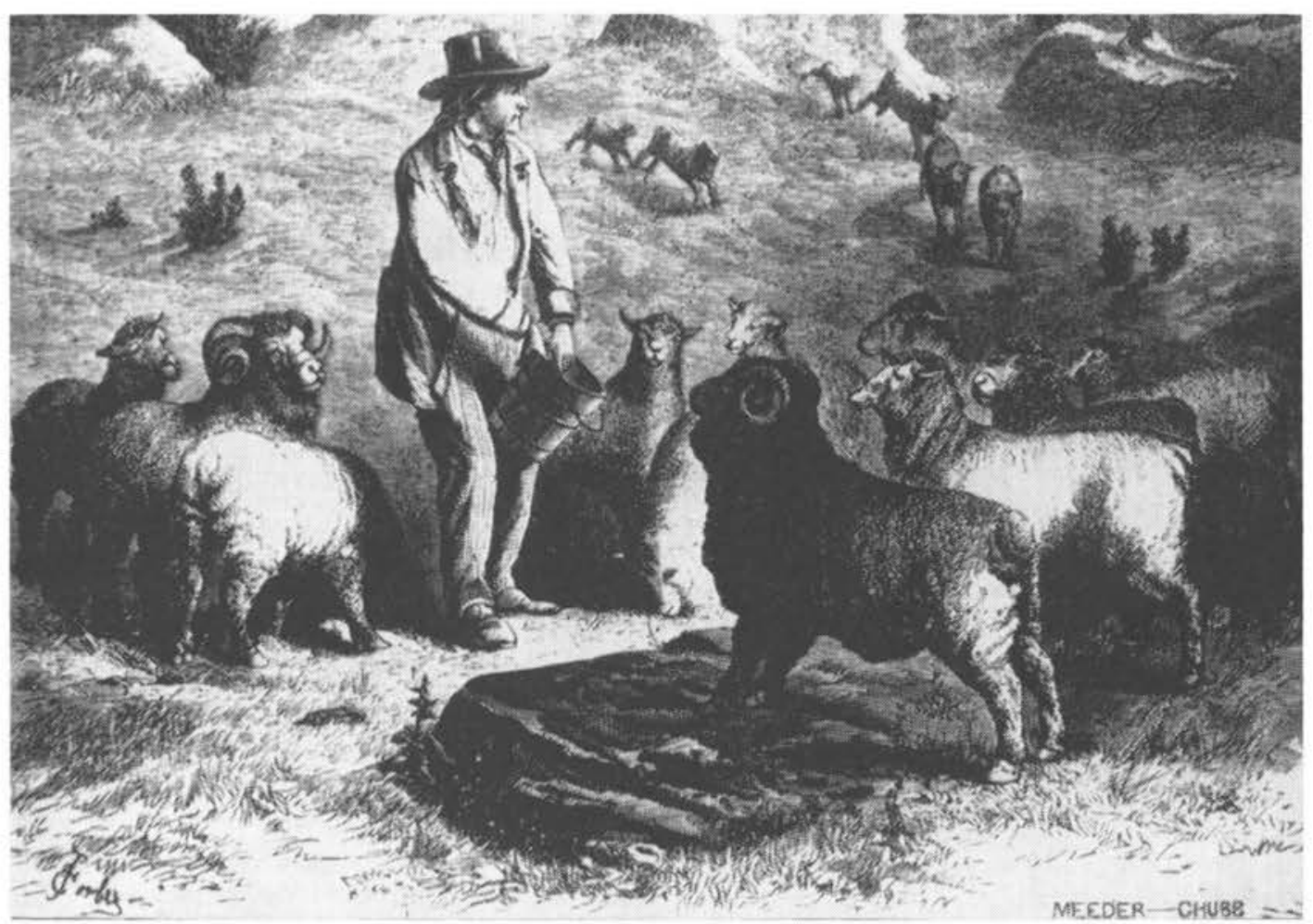

Before the nutritional value of salt was well recognized, "salting" was a common method for rounding up the flock. The method was also used - then, as even now - by meat hunters posing as sportsmen. American Agriculturalist

Patriotic sons of other states soon challenged Iowa, most of them also claiming immunity to disease.

\section{Dog Physicians and Cow Doctors}

On a number of matters, it was suggested that readers who inquired about specific diseases consult with medical men. Thus in 1849 , in response to an inquiry on $\operatorname{dog}$ distemper, editor Allen replied, "We advise our correspondent to consult his physician, or some reliable work on the diseases of dogs." Doubly unfortunate, however, was the fact that he had no such work to suggest, nor did he have the discrimination to weed out the less valuable offerings from his correspondents. In answer to this request, one reader wrote:

As you politely refer the gentleman to some dog physician, I am only too happy to assume the honor.... Take a handful of fine table salt; hold open the dog's mouth, pour it down his throat, and hold his jaws together until the salt is all dissolved and swallowed.

Another, in offering a prescription of about the same value, says, "if it don't cure the dog, I give him the liberty of sending me the hind leg of the next one he loses." This may have been said with tongue in cheek, but if all who read it complied, it seems likely he would have had ample opportunity to put more than one foot in his mouth.

A correspondent from Mississippi in 1844 states that he has lost all of his cats and dogs over a period of years from convulsive fits. Having been told that bleeding would remedy the situation:

I am now trying it . . . by cutting off a piece of the tail each time they have a fit . . . economizing the tail as much as possible, that it may get a fair trial. . . Some other cure would be preferable, as a bobtailed cat is rather 
an unsightly object. Still, better even a bobtailed one than none.

The editor thought that overeating of rats might be a cause, and suggests milk and a variety of table foods.

Concerning the lack of professional assistance, a man writes in 1849 regarding a cow with an inflamed udder:

I could not send for a cattle doctor nor for medicine, without much inconvenience. I therefore proceeded to my library to consult several works I had on farriery, but was disappointed in finding that there was not a single course pointed out that I could follow; for all the remedies used were such as no person could easily get in an emergency. I was, therefore, obliged to follow my own feeble judgment in such matters.

He bathed it with water and lard, and the cow recovered. A second case attended by this same individual concerned a sow with a prolapse of the vagina and bladder after parturition. He replaced the mass and sutured the opening but the prolapse recurred:

I, therefore, concluded to let her alone; but she seemed to suffer so much . . . besides, maggots were revelling in the parts, that I concluded to make short work of it. I enclosed the whole mass in a ligature, and then cut it off. I found I had the bladder, ureterus, \&c., and of course, expected my patient must die; but she improved, became able to go around, eat well, and the color of her snout and ears were as natural as ever. She was able, too, to nurse her pigs, but I was very sorry to find, one day, that she was injured by a cow, which caused her death, which, for my reputation's sake, as a pig doctor, I hope was the case.[!]

A demonstration of the abilities of certain of the fraternity of cow doctors may be had from the expert testimony of a Dr. [!] Stoddard in a court case to recover damages for loss of a cow:

I am a cow doctor. I have followed the business these forty years. I doctor sheep, hogs, and horned critters. I set broken bones, jints, \&c. I never read no books on critters. I took the business up kind ' ' nat'ral. . . About the cow ... I went down to see her the day before she died. . . . I thought if I could start her idees up a little, and kind o' jog natur, she might get along. . . . I went down agin Sunday mornin' and found her dead as a herrin'. I was mightily struck up. We skun her, and snaked her out upon the snow. I then cut her open, and examined her. She had what I call the overflow of the gall. ... I took some sperits down with me, Sunday mornin'. The cow having no further use for any, I took a dose myself.

\section{Life Assured}

Practitioners such as this may have been a compelling reason for the short life of such organizations as "The American Livestock Insurance Company," of Vincennes, Indiana, chartered in 1850: "For the Insurance of Horses, Mules, Prize Bulls, Sheep, and Cattle, of every description, against the combined risks of Fire, Water, Accidents, and Disease." Being capitalized at a mere $\$ 50,000$ would have been practically a guarantee of its early demise. The company went out of business, or at least stopped advertising the following year. The month following its demise, Easterners enjoyed the short-lived benefits of "The New England Live-stock Company."

Apparently undismayed by the experience of its predecessors, the Northern New York Live Stock Insurance Company was incorporated at Plattsburgh in 1851 in the belief:

owners of valuable animals will avail themselves of the advantages offered by this mode of protection. If fire, life and marine insurances are proper and expedient, so is livestock insurance. ... The company have adopted such rates as, they believe, will furnish the means of paying ordinary losses, without resort to an assessment. But to guard against extraordinary losses, which may arise from contagious diseases or epidemics, it becomes necessary to require premium notes.

The company appears to have existed for something over one year, and in response to an inquiry in 1857 , the editor of the Country Gentleman notes: "Several companies have been incorporated in this country for this purpose, but we are not aware that any of them are now doing business. 


\section{Life Not Assured}

The better farmers, of course, were well aware of the inroads made upon livestock by quacks and empirics who pretended to a knowledge of animal disease, and many would prefer letting nature take its course to allowing these charlatans to speed the demise of their stock. Such a farmer was one Sanford Howard of Ohio, writing in the Cultivator in 1843:

There is no subject connected with husbandry, on which light is more needed, than on the treatment of diseases of domestic animals. Many die annually from neglect and inattention, and many more from improper management of their diseases. If an animal is sick, and it is thought advisable to make an attempt to cure him, the course frequently taken is to give him all the nostrums of all the bystanders, each prescription being a "perfect cure," though in its nature and composition as opposite to all the rest as are the poles to each other, and though, perhaps, not one of the advisers has any correct idea of the disorder. I have often been amused at the various specimens of quackery which farmers will suffer to be played off upon them by ignorant cow leeches.

Another correspondent denounces a custom of common swine castrators:

As to the practice of applying salt and ashes to the fresh wound, it is not only useless, but injurious and outrageous, and the man who is guilty of such conduct, deserves the like treatment.[!]

That the few skilled veterinarians available were appreciated is evident from the remarks of a farmer who reported "a terrible distemper or epidemic" among the cattle at Troy, New York. From his description, this appears to have been at outbreak of dysentery confined to two adjacent herds, but:

On post mortem examinations no traces of the disease has been discovered, but they were not made by competent and experienced persons ... should any more cases occur I would advise the owner to call on Dr. Wright, a veterinary surgeon of great skill ... in Albany.

Few other references to veterinarians by name appear in the first ten volumes of the Cultivator (to 1843). One appears in a letter to a farmer "from Prof. Grice, veterinary surgeon, of New-York," in which the opinion was given that abortions occurring in the farmer's herd were caused by ergot poisoning. Another is a mention of Wm. H. Smith, a London graduate, who advocated homeopathic treatment of animals. In 1844 Dr. Wright, who identifies himself as M.R.V.C. - and thus perhaps incriminates himself as having appropriated the British title (M.R.C.V.S.) - responds to a request for information on splints in a horse.

Asking: "Wherein is a man better than a horse, if he does not know more than a horse?" a correspondent relates an anecdote of a man in his community, who:

with great self-confidence and pride, told how he could cure a horse of the bots. . . He took a tea-kettle full of boiling water to pour down his throat. His father interrupted him, so that he succeeded in pouring down the horse's throat only half the tea-kettle of boiling water. In truth, the horse was immediately dead - he opened him, and found just half the bots were scalded to death, when he exulted, by saying, that if his father had not interrupted lim, he should have succeeded in destroying all the bots, and proved the usefulness of his discovery. We remarked to him, that it was an unprofitable mode to kill his horse in order to destroy the bots. Oh, he said, he could easily have saved the horse, by pouring down his throat and equal quantity of oil, to heal the injury of the scald, if he had not been interrupted.

\section{THE ENLARGING SPHERE OF REPORTING ANIMAL DISEASE}

The animal disease situation in Michigan is fairly well documented in the pages of the Michigan Farmer, beginning in 1843. As mentioned earlier, one object of the editor was to secure from farmers the modes of treatment which they had found successful but, as may be surmised, it is more often the identification of the problem, rather than the treatment, which is of most value - at least to the historian of today. More or less in this category is the remedy for calf scours "never known to fail ... in thirty years' use." This 


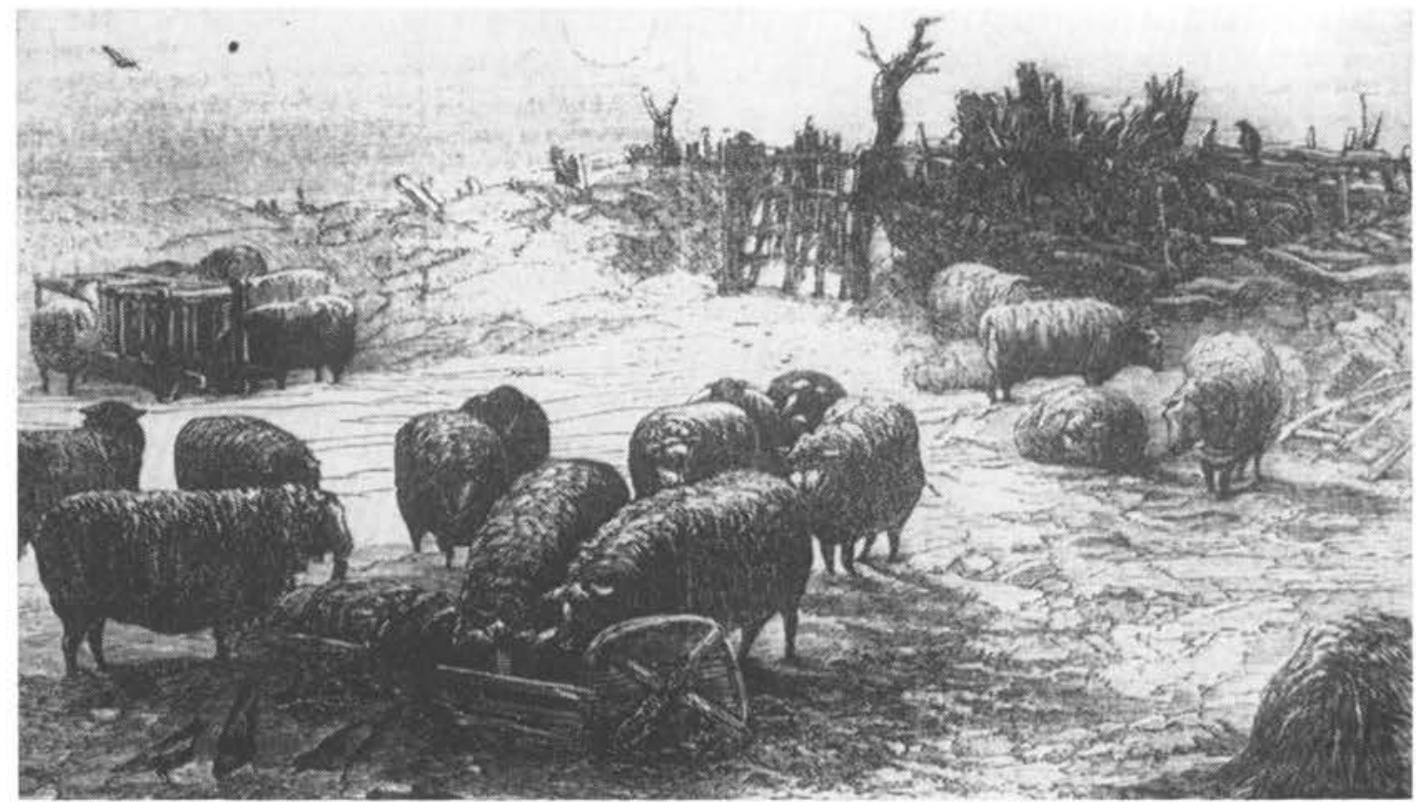

Agricultural editors who urged better care for livestock had to contend with the majority opinion that sheep in particular would thrive better if not sheltered during the winter. There are reports of sheep being buried under twenty feet of snow, with some surviving after being found a month later. American Agriculturalist

required putting half a pint of good cider into a bottle:

Then open a vein in the neck of the calf, and let into the bottle about the same quantity of blood. Shake it well together quickly, and before it has time to coagulate, put it down the calf's throat.

It might be remarked that this undoubtedly salubrious draught would have been all the more effective if another blood donor had been used.

In 1845 a correspondent states that ticks on lambs is "so common" a problem that he gives a formula for a tobacco dip based on 100 animals. The expense of the 12 pounds of tobacco required "is merely nominal ... if the farmer raises his own tobacco as economy dictates ... compared with the loss of life and fodder inevitably incurred by neglecting to attend to it." For scab: "a contagious disease among sheep, now raging in some of the large flocks in the western part of the state, double the quantity of tobacco will be required," and the sheep should receive sulfur in their salt "to drive out the disease." From the numerous entries concerning sheep scab, it is evident that this was a common problem over a long period.

Another correspondent perhaps anticipating the advent of systemic pesticides, concludes:

Nothing is effectual as a cure, except it work through the whole system in the blood. There are many things which, if they can be so applied as to reach the insect which causes the disease, will effect a cure. But the difficulty is in thus thoroughly applying it.

He mentions the length of the wool, or the crust formed, as interfering with local treatment.

Throughout the 1840 's a rumning controversy raged over the merits of sheltering versus not sheltering sheep in the winter. A correspondent who states he had wintered 120 yearling lambs "in a field without water or shelter" argues:

Experience teaches us that disease and distempers are far more frequent in warm than in cold weather; and reason teaches that the 
natural fire of life and their abundant supply of clothing are sufficient to protect the sheep in extremes of cold in a temperate climate.... In Michigan, we are not subject to sudden and heavy snows, as in New England, where hundreds of sheep have been smothered in a night.

Proponents of shelter were equally persuasive, and the editor sees "little prospect that their views will be reconciled":

In most matters in which men differ widely in opinion, it commonly happens that truth lies between. ... If we had sheep to keep, we should neither adopt the continued close confinement... nor the absence of protection. ... Snow, we should deem inadequate to supply the natural demands of thirst. . . . The fact that they will do well without water, is not proof that they will not do better and be more comfortable with it. . . To leave any domestic animal exposed to the storms, and abrupt vicissitudes of our climate, without shelter is, we must think, to say the least, not good husbandry.

In reply to a request in 1846 for a remedy for the "dry murrain," presumably cornstalk disease, or mad itch, the editor responds with a recipe obtained "by consulting with an old cattle doctor." This was to give a bottle of oil and to keep the cow moving. He also mentions that the Emigrant's Hand Book recommends two ounces of gamboge: "This is a powerful physic; and it is very necessary to get something to pass the animal." It is of some interest to note how thoroughly the emigrant was prepared for the exigencies of frontier existence. Cornstalk disease was mentioned elsewhere as killing "a great many" cattle in Michigan during this period.

\section{Dog Days}

In 1849 it was reported that in Detroit: "Mad dogs have been at large in our streets for some days, and many dogs have been bitten, and, it is said, one man." The problem apparently extended beyond the metropolitan area, for a correspondent this same year in urging a law to protect sheep from the depredations of dogs, adds:

I have said nothing of the horrible deaths resulting from the bite of the rabid animal, as such deaths are comparatively of rare occurrence. Some of your subscribers in Oakland county, might tell you something however, re-

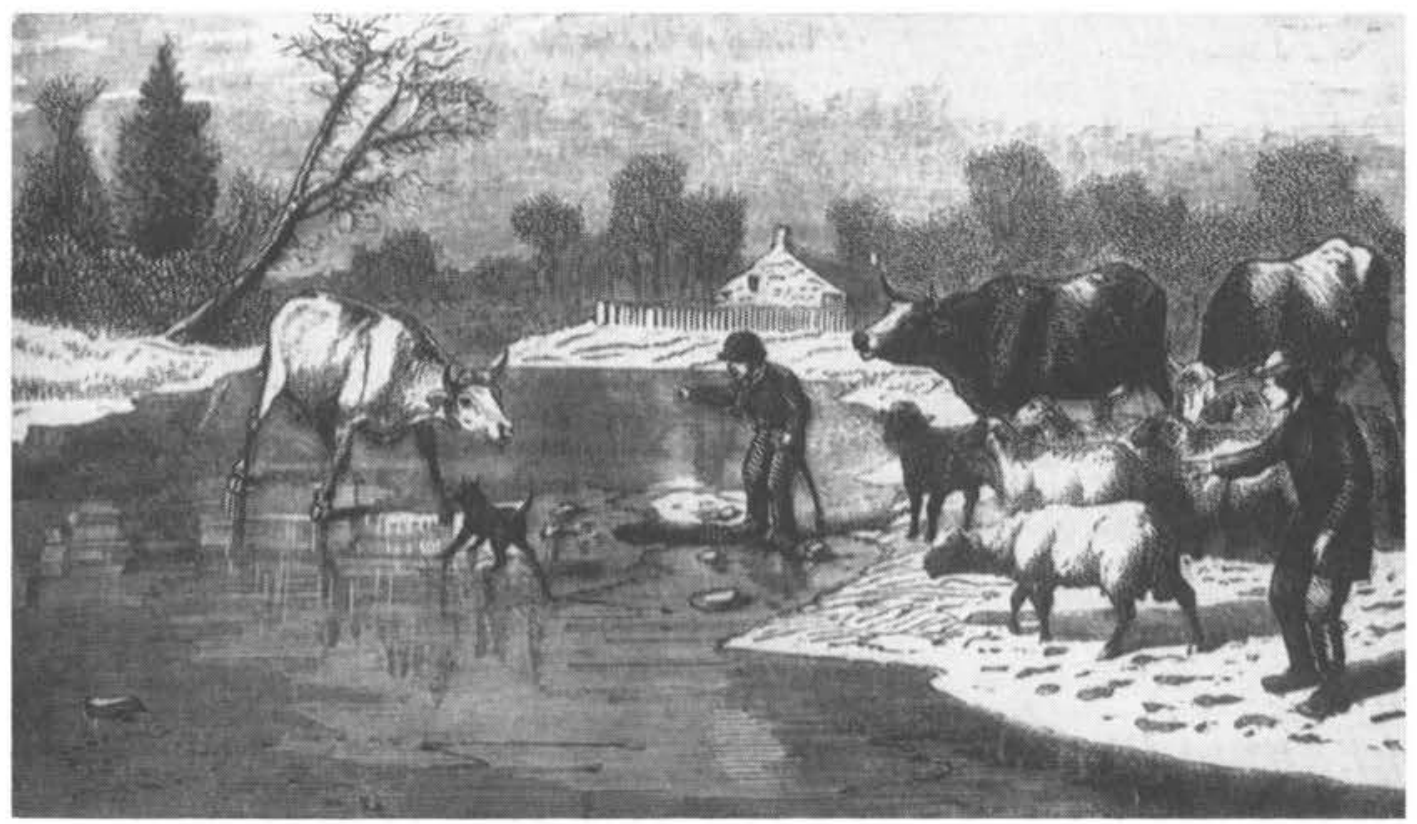

The agricultural papers waged a long campaign on behalf of better care for animals in winter, but tradition died hard - along with countless animals. American Agriculturalist 
specting the cows and hogs they have been compelled to put to death, on account of bites by mad dogs.

On the subject of sheep-killing dogs, he says that Michigan has a "dead letter statute" which makes owners liable for damages, but that it was inoperable. A number of sheep owners, he says, have been driven out of business by these dogs. Instead of farmers having to pen their sheep for protection, he urges a state-wide licensing law to replace the current one which leaves the matter up to townships. And "Let every man who conceives he has $d o g$ work to be done, be compelled to keep his dog at home, or do it himself." Then, if any dog, peaceable or otherwise, be found loose, "let him be shot; or, what would perhaps be better, add infamy to his punishment, and let him be hanged."

Some farmers were reported to have lost half their sheep from "stretches" or colic in 1849, and "great losses" were attributed to "the grub in the head." One man tarred the muzzles of his sheep as a preventive of the sheep bot: "but they would not learn, and still went on losing their sheep in the good old way.",

\section{Cow Leeches and Bloody Murrain}

The so-called "bloody murrain," apparently due to flukes, was present in Michigan from the time of the early settlements of the nineteenth century, having been imported with cattle brought by the settlers. However, because the state was at one side of the stream of migration westward, and off the beaten track of the cattle drives to the large markets, the disease did not reach the proportions it did in other parts of the midwest. The following account is quoted at length more or less as a vignette of frontier conditions in Michigan:

In the early settlement of Washtenaw county [southeast Michigan], as long ago as the year 1828, I lost two or three good working oxen, with a disease at that time new and unfamilar, but which has since become known as the Bloody Murrain. Droves of working oxen and cows were brought from the state of Ohio in those early times, and the farmer beginning on a new farm was compelled to let his cattle run in the woods during most of the summer season. ... This disease was more common and fatal in those early days than at the present. ... After having lost two or three of my cattle, I opened them, and upon examination found leeches in their stomachs. The leeches were much distended by the blood they had evidently extracted. . . A large marsh at which my cattle were accustomed to drink ... was found to contain leeches in abundance. I immediately put my cattle into a good enclosure supplied with pure water, and have never since been troubled with any loss by leeches. This seems to show very conclusively that leeches are the sole cause of this disease. Yet, being a common man, I confine myself to practical facts and leave this subject to be investigated by educated and scientific men.

This communication elicited a response from a farmer who doubted that leeches could be the cause of bloody murrain, because:

In Vermont, where I lived most of my life till the fall of 1830 , I never saw or heard of a case of bloody murrain, though leeches are much more plenty there than here.

He mentions having seen many cattle in Michigan die of the disease, and few being cured.

More often than not, perhaps, these "leeches" were flukes, as attested to by a series of articles in the Ohio Cultivator. In 1859, the editor states:

The return of the grazing season is sure to bring us reports of the fatal effects of the disease known as Bloody Murrain. . . . This disease is most common and fatal in wet and woody regions, and though we believe it is not in any sense epidemic, yet, like the mysterious cholera, the cause and cure seem to be involved in a veil of uncertainty.

The most likely cause, he says, is that mentioned in the Ohio Agricultural Report for 1856:

It is caused by an animal bearing a tolerable resemblence to a leech in shape, and which is the exact color of the liver. . . The parasite is known to naturalists as the Fasciola Hepatica of Linnaeus, or Distoma Hepaticum of modern naturalists. . . When an animal dies from bloody murrain, as a general thing, it dies for 
the same cause as if its throat had been cut; that is, it bleeds to death.

The most common "cures" included salt, alum, ashes, saltpetre, and sulfur. One correspondent states he paid $\$ 20$ for a recipe, which consisted of " $11 / 2$ oz. pearlash, dissolved in two quarts of iron-water from the blacksmith's trough," and which he had never known to fail.

Others were less optimistic: one says, "Nineteen in twenty at least, die that are attacked." A physician writes:

As to a cure for the disease, it may be said to be uncertain, but if they will keep their stock from the places where they get their leeches, they will have no more trouble with Murrain.

\section{And a butcher states:}

Often cattle have Murrain slightly, and recover; the owner gives them something, and is confident he has a remedy for Murrain. There is no cure, but there is a preventive. If your cattle have good running water always, they will not get Murrain.

He states that eight of ten cattle bought in the hills have healthy livers, but the reverse is true of cattle from the lowlands. Also noted is the fact that young cattle are rarely affected. A farmer found that "salt has a tendency to produce Murrain," and that spring watered cattle were affected. A man recently from New York states he had not seen the disease there in thirty-six years, and asks:

If the liver only is affected, and that by leeches, how is it that the urine becomes affected, which is the first symptom that the animal gives to detect the disease, and from which, I presume, the disease has its name? [It was also called "red water."]

An "old cattle king," perhaps with tongue in cheek, claims priority for discovery of the cause of murrain:

More than twenty years ago ... we decided to give the disease a thorough investigation. We first discovered it was caused by leeches in the liver, and afterwards found we were mis- taken. We then found the disease commenced in the kidney, and afterwards discovered it was not always the case; and after a long and patient investigation, we came to the conclusion the more we examined into the disease the less we were sure about it.

As to a cure, he says, "If the animal is not dead when you discover it, give calomel 2 oz., arsenic 2 grs. . . . and then when the animal dies, you can say you have done all that could be done to save it."

A doubter in the "case of Murrain vs. Leeches," wishing to appear "in behalf of the leech, who has been charged with willful and premeditated murder," asks a number of pointed questions, including:

Why the red blood in the urine and feces? Why are the kidneys pulpy? Why the offensive smell of animals that die? Why are the hides worth less than those of normal animals?

\section{The Veterinary Art for Farmers}

Interest in veterinary education was shown in Michigan in the early 1850 's, as in other states, as an adjunct to agricultural education. In 1849 the Michigan State Agricultural Society had expressed the need for an agricultural department in connection with the University of Michigan at Ann Arbor, and recommended that instruction be given on the "anatomy and diseases of animals," among other subjects. In 1853 the University announced a free course of lectures on "agricultural science," three or four daily for eight weeks in the spring, to include: "A description of the different varieties of domestic animals, their diseases, modes of breeding, improving, \&c., \&c.," by the Rev. Charles Fox, who was also a prominent agriculturalist; and "comparative anatomy and physiology of animals," by Professor A. Sager.

Via an advertisement in the Michigan Farmer, it was announced that the agricultural department of the university would open on December 1 of that year with a course of lectures on chemistry and on "Practical Agriculture and Veterinary Surgery." Students would have the option of attending one other class in the Scien- 
tific School, and: "The agricultural students will have access to the books in Ag. riculture which may be found in the University Library." The latter course was given by Fox, but upon his sudden death the following summer, this instruction appears to have been discontinued.

Instruction in "the veterinary art" was included in the first prospectus of the Michigan Agricultural College, established in 1855 (now Michigan State University), but a number of years elapsed before any such instruction was given.

As noted above, the Michigan State $\mathrm{Ag}$ ricultural Society had expressed a need for instruction in the veterinary art as early as 1849 , and in $1855, \mathrm{~J}$. C. Holmes, secretary of the Society, spoke at length on the subject:

Every farmer is more or less interested in the raising, or use of domestic animals, consequently he should be somewhat conversant with their anatomy, structure, diseases, and the best methods of treatment. Some years since, the farriers, or shoers of horses, and they only, were expected to understand all the ailments the horse is subject to, whether occasioned by unskillful shoeing, hard driving, neglect, or any thing else.

To shoe horses and cattle properly it requires not only mechanical skill, but some knowledge of the anatomy of the feet and legs, for it is often the case that lameness is caused by the animal being carelessly shod. .. . The farrier having made the foot, its diseases, and the remedies his study, he is supposed to understand fully all the diseases of animals, and is called upon for advice and treatment. But as a general thing his knowledge of the diseases of animals is very limited. However the subject has been taken up systematically. Veterinary schools and colleges have been established where the anatomy and physiology of animals, the diseases to which they are subject, and the remedies to be applied, are taught; and if the farmer will study the veterinary art he may in a short time understand the diseases of quadrupeds far better than the farrier ever pretended to.

What appears to be the first reference to a veterinary surgeon in Michigan - hardly likely a graduate veterinarian, however is found in a letter to Professor Copeman of the Boston Veterinary Institute in 1857. The writer states that his horse: has been troubled with cracked heels more or less for the last year, and has what is usually termed scratches. I bought him in Detroit in April, and before I had brought him home . . . I had him bled twice by a veterinary surgeon. ... I presume his system yet wants cleansing.

To his request for help, Copeman responds:

You have fallen into a very common error. The extent and evil of this absurd "humoral theory" is plainly seen in the folly of the Detroit veterinary surgeon. He must have studied the veterinary art as it was practiced during the "dark ages." ... What would any sensible man think of the genius of an M.D., who, in such a simple case [as chapped hands], should gravely inform him that "his blood was corrupt and bad," and he must be put through a thorough course of bleeding, physick, \&c. We know the "simple public" never ask any questions when giving or taking physic. Still we think any sensible man would at least make an odd face, and either laugh at the doctor's stupidity or sneer at his impudence.

\section{Rural Practice}

An interesting commentary on the nature of veterinary practice about 1850 may be had from the account books of $\mathrm{E}$. A. Washburn, a practitioner from Adrian, Michigan. His charge for a visit was usually 50 cents; at night, 75 cents; and for keep of a horse, $\$ 2.00$ per week. For numerous clients it appears that he carried considerable amounts on the books for long periods and frequently took in such items as "7l lbs of Beef" for a bill of $\$ 8.00$; wood at a dollar a cord, and pork at $8 \phi$ or butter at $11 \phi$ a pound. Representative charges for services include:

alter colt $\$ 1.00$, stud $\$ 5.00$

dress rupture on white hoss, $\$ 3.00$

treat colt for distemper \& medicine, $\$ 1.00$

treat cow for garget, $\$ 1.00, \$ 2.00$; milk fever, $\$ 1.00$

treat horse for splints, $\$ 3.00$; for spavin. $\$ 1.50$ 5.00

put seaton in tumor, $50 \phi$; take out seaton, $50 \phi$ pull wolf teeth, $\$ 1.00$; cut lampers, $\$ 1.00$

drench, physic or blister horse, $\$ 1.00$

bleed and physic mare, $\$ 1.00$ [paid for by $2 \mathrm{bu}$. corn]

treat heffer for bull hurt, $\$ 1.00$

treat cow for cast withers, $\$ 2.00$ 
to dres poleval [poll evil], $\$ 1.00$

treat grey $\mathrm{H}$. for sweld rectum, $\$ 5.00$

for stop in water, $\$ 1.00$

founder, ringbone, quittor, $75 \phi-\$ 1.50$

visit grey hoss that died, $50 \phi$

medicine for heaves, $50 \phi$

to clean cow, $\$ 1.00$; cow in labor, $\$ 1.00$

treat cow for horn ail, $50 \phi$

treat cow for murrain, $\$ 1.00$; same for Widow

Mills' cow, $50 \phi$

operate on mares sholder for lameness, $\$ 5.00$

treat ox for stub complaint, $\$ 1.00$

proscribe for farcy, $\$ 1.00$; treat farcy, $\$ 2.00$

treat broken pastern, $\$ 4.00$ [2 later visits @

$\$ 2.00 ; 3$ bottles liniment @ $\$ 1.00]$

visit \& medicine for a dog that was blind, $\$ 1.00$

Apparently only charges are entered in his account books, which are in the form of more or less alphabetized ledgers, and thus there is no way of knowing what proportion of his business was for cash. A compilation of the charges for April, 1851, however, will perhaps give an idea of the general run of cases.

\section{April [1851]}

1 medcin for 2 Horses

$\$ 1.00$

$4 \frac{1}{2}$ pt. Linament

5 treat Barny for founder

6 visit Barny

6 visit $\mathrm{gr} \mathrm{H}$ for cold

7 dres Head (poleval) 2nd time

7 treat Charly for Spr Hoc

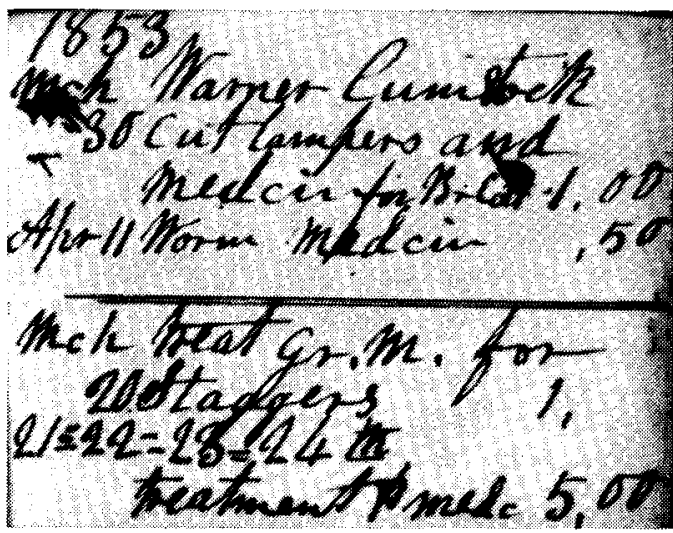

Extract from the ledger of a rural Michigan practitioner for 1852-1853. "Lampers" is a variant of "lampas," or the tumified palatal mucosa of horses, which most farmers and farriers insisted on treating as a disease.
8 care of Charly \& B1. m

8 treat S. M Sweld leg, drench

9 cough medcin for $\mathrm{BH}$

92 wks care \& medcin for farcy

$\mathrm{I} 0.00$

10 foment Charly

10 care of Charly

11 linament

12 care of Charly

12 treat $\mathrm{Br}$. $\mathrm{H}$ for Distemper, bleed and physic

12 dres Head 3rd time

12 medc for $2 \mathrm{H}$ with Distemper

13 visit

17 visit

1.50

17 visit cow \& medcin

I8 visit cow \& medcin

19 [sold?] 1 dog puppy

5.00

20 visit cow \& medcin

23 blistered pony

23 attend Charly, colic

26 dres leg

27 discharge old Charly, 14 days attendance

$28 \mathrm{H}$ with greas hell brot in

28 blister spavin

29 dres spavin

29 oprate on poleval

30 visit $\mathrm{H}$ \& linament

Some of the items reflect bits of unintentional humor or pathos; in one category is "alter 1 bore, 25\%." Another involves a horse that was staked and which died 4 days later, the account reading, " 4 days care \& keep, $\$ 4.00$; for burying, $\$ 1.00$." But on another occasion for a staked horse, "I warant a cure for $\$ 5.00$." A bill for services from July, 1852 to February, 1853 for $\$ 20.50$ appears to have been settled finally in July, 1865 - with $\$ 21.60$ interest. A bill incurred in 1851 was settled in 1854 by credit for 10 bushels of corn and " 28 bus. rutebagy." On another occasion he appears to have sold a client's horse in lieu of 8 weeks' keep. While his books give no indication of how often he performed postmortem examinations, for one case he had been attending (and had given a pint of castor oil and turpentine the day before) he enters the notation, "Open $\mathrm{m}$ died of Bowels. Caus by ulcerated rectum. Parcker [the owner] gave croton oil." 


\section{To Your Good Health}

About this time more attention was being paid to matters that we would today identify as belonging within the sphere of veterinary public health. In 1845 a member of the American Agricultural Association proposed:

There should be enacted sanatory regulations by our public authorities, with a view to prevent the slaughter of unhealthy animals for beef, and the sale of the beef of unhealthy animals. . . Large numbers of the cattle of the West ... [ [ have] diseased livers, [and] vast numbers of these diseased cattle are slaughtered annually. . . Many cattle are scrofulous. The health of all, and of those in large cities, especially, demands that none but the meat of healthy animals should be eaten. But those who purchase have no knowledge by which to be guided. Therefore, persons should be appointed by our public authorities to view all animals before sale to the butchers; and after sale; and the carcass and especially the intestines and viscera after death; with power to prohibit the exposure to sale, and sale of cattle or other animals that show disease before death; and the exposure to sale and the sale of carcasses of diseased cattle after slaughter.

In 1849 the editor of the American Agriculturalist took up the cudgel with some suggestions for "The Improvement of Slaughterhouses":

Under the present system of uncontrolled licensure, as is generally practised here, not only is our sight shocked and our olfactory organs offended by the too frequent occurrence of private slaughtering establishments, but, moreover, a mightier consideration is neglected - the purity of the article vended can with no certainty be determined.

It was noted that in Paris, each animal entering the slaughterhouse was inspected by a veterinarian; if diseased, it was either condemned or sent to a hospital on the premises. Carcasses were inspected by "a good practical physician." The editor of the American Agriculturalist argues:

If a similar system were adopted in this country, not only would these buildings be made a source of revenue to the cities or towns themselves, but, in addition, it would even tend to cleanliness and consequent healthiness, and what is of equal moment, the purity and whol- someness of the articles consumed by the in. habitants.

On the acceptance of the system in France, it is stated:

The butchers of Paris, at first, violently opposed the establishment of the abattoirs; but now they are so convinced of their utility and commodity, that they would almost as vigorously oppose any return to the former system. Indeed, it must evidently be to the interest of the butcher that his meat be killed in the most perfect condition, to ensure its preservation, and to satisfy the public that every precaution is taken to ensure a supply of wholesome meat.

In another particularly vitriolic attack on "the Butcheries of New York," the editor contends:

It is quite time our city fathers proceeded efficiently for the removal of these intolerable nuisances. The stench from these yards is perfectly unsupportable, and has its full share in bringing, augmenting, and continuing the plague of cholera within our city. . . . During the afternoon and evenings, our streets absolutely run with blood, and yet there is enough left, with other offal, to create a pestilence in every neighborhood where they [ these pestilent butcheries ] exist.

The logical remedy - to a New Yorker at least - was the removal of the slaughterhouses

to the Jersey shore [although it might be supposed that the good citizens of New Jersey would have thought differently]. . . . Put salt water between these death-dealing, blood-spilling, stench-creating, pestilence-producing establishments and other civil pursuits. . . Either we proceed with cleansing this Augean stable of ours ... [ or ] we must continue to jog on, like beasts of prey ourselves, surrounded by the decaying offal of our own gluttony.

The citizens of some of our cities today would most likely concur with R. L. Allen's prophecy in $185 \mathrm{I}$ :

The existence of slaughter houses within or even in the neighborhood of cities will soon be classed among the most intolerable nuisances of a barbarous age ... all apology for their continuance, since the era of railroads, has been utterly extinguished. 


\section{Kind Killing}

While few writers appear to have been concerned with humane slaughter, a statement by the editor of the Cultivator in 1843 is a forthright exposition of what undoubtedly was the thinking of many upon the subject. He notes that knocking cattle in the United States and England, and pithing in Italy and Spain are commonly practiced. The latter in particular produced poor quality beef because of poor bleeding, and for the same reason many in this country prefer kosher beef to that killed in the conventional manner. The English practice of bleeding calves daily for some time before slaughter to produce a whiter veal, he reprehends as "a most cruel mode of killing." Also:

Butchers, in killing hogs, frequently perform it in a most barbarous and slovenly manner, mangling the throat. . . Man has a right to take the life of animals when required for food, but humanity requires it should always be performed in such a way as to give as little pain as possible.

A decade earlier, it was noted in the New England Farmer that horses were killed at the Edinburgh Veterinary College by inserting a tube in the jugular vein and causing air embolism:

Three forcible expirations from the mouth are sufficient to cause the animal to die instantly, with apparently no pain. The Association to Promote Rational Humanity should recommend this method for killing cattle, if it should be found expedient.

A similarly inappropriate use of chloroform was suggested in England in 1848 in the thought that the animal would be "not a whit the wiser" for the use of it, and the sweet flavor imparted to the meat might appeal to the taste.

\section{The Pump: Milkman's Friend}

The noted agriculturalist, Henry Colman, in commenting on the milk supply of American cities in 1842, states:

I believe there is no city supplied with better milk, or in a more cleanly condition than Bos- ton. The milkmen are in general a respectable class of men ... and the Bostonians are in general equally particular in requiring good milk for their money. . . In New-York City, it is not so. With the exception of a few milk establishments, where a sacred pledge of pure milk is given, a system of fraud is almost universally practiced. The milk is twice watered; first in the udder of the cow, who is fed upon distiller's swill, of which she has two or three barrels per day, with only enough hay to form a cud for rumination; and next, after it is drawn, it is a very general custom to add one quart of water to every four quarts of milk. ... Indeed, I have been let into the secret, at New-York, of the actual manufacture of milk at a grocery store ... and this compound was sold to the poor and the miserable for three cents a quart. The grocer, though he kept no cow, offered to supply the milkman with what he required, whenever his quantity was insufficient to meet the demands of the day.

With the average cow giving only five to seven quarts daily, it is perhaps understandable that the unscrupulous might take steps to increase the supply. It is quite evident that more milk was sold than could be accounted for by the number of cows kept for the purpose. A joke which went the rounds about this time concerns the wag who woke a farmer with the news that his best cow "had the choke." Upon rushing down to investigate he found a turnip stuck in the throat of his water pump.

In reviewing the disclosures by a John Mullaly on "The Milk Trade in New-York and Vicinity," in 1853, the Country Gentleman states:

Contrary to the generally received opinion, it would seem that milk is not good for babes, for a physician estimates that a large proportion of the eight or nine thousand children, under five years of age, who die annually in New-York, are actually poisoned by the milk which is given them for nourishment. We have never seen so striking an illustration of the dishonest and murderous means which are resorted to in our large cities for purposes of gain, and which have been prosecuted with profit for years, as a legitimate business, without the interference of law.

The number of quarts of pure milk brought into the city daily, on an average, is 91,413 . . . But by an admixture of water, and sometimes 
other ingredients, this quantity is made to measure, on delivery, over $100,000 \mathrm{qts}$. In addition ... there are 13,000 cows kept in the city and its vicinity, furnishing some 180,000 quarts of milk daily, and fed almost exclusively on distillery slops. These cows are kept at as little expense as possible, no straw being allowed them for bedding, very little dry feed, and from the time they enter these Augean stables, they never breathe fresh air again-never go out till they close their life of wretchedness, the victims of a forced intemperance. . . . We are told that all cleanliness is abjured-that the cans are seldom washed, nor the hands of the man who milks them - that these cows die very rapidly; and when ulcers break out on them, their teeth have rotted out of their jaws and their hoofs have become so sore as to render them unable to stand, they are handed over to butchers, who put them through a course of fattening, and retail the meat. . . .

Though the distillery milk, at the best, has less than one-third as much butter as pure milk, and is otherwise less nutricious, it frequently undergoes another process before it is distributed. Small dealers buy from 50 to 200 quarts, and then add to each quart about a pint of water, with divers ingredients, to give the whole consistency and color. By allowing it to stand till it is decomposed, the chalk, magnesia, molasses and all, can be discovered.

Earlier, some of the cheese vendors of Boston appear to have been less scrupulous than the milkmen of that fair city were reputed to be. In 1831 a flurry of articles in the New England Farmer evidenced alarm over the number of cases of food poisoning from eating cheese. Apparently there were few fatalities, but many were made "very sick," and one correspondent states: "For myself, I never knew such a powerful vomit for some hours, which has made me very weak." The vendor was accused of having "sold poisonous cheese a number of times." Two plants eaten by cows were indicted as probable causes:

An eminent physician in Boston, who has frequently, in the course of his practice, taken notice of the effects of this emetic-cheese, attributes them to Lobelia.

Another "learned and skilful physician" was of the opinion, "the poison was caused by the cows eating the Poke weed, instead of the Lobelia . . cows rarely if ever eat the Lobelia." The latter physician had done some field work on the matter, finding an abundance of pokeweed, but little lobelia in the pastures, and the cheese immediately became "healthy" when the cows were removed to a pasture free from poke.

Lobelia, commonly called Indian tobacco, was widely used as an antidote for hydrophobia, and pokeweed, commonly called Garget, was recommended to be fed to cattle to prevent mastitis, or garget, whence the common name for the plant. A frequent practice was to plant poke in one corner of the barnyard so cows, as selfappointed cow doctors, could have free access to it.

The editors of the Country Gentleman in 1868, in urging a reform of the milk industry, state:

That city milk and country milk-the milk of kine and the milk of cans--are two not altogether similar articles, has long been matter of general belief. . . . The measure of dilution of milk with water ... by the Cincinnati milkmen ... is fully twenty-five percent on the averagesome of it more than one-half. . . . The cows are fed mainly on hot distillery slop ... . Iying in manure most of the time . . . and during milking, manure frequently dropping into the pails. It is impossible to describe some of their filthy stables. . . . People are negligent as to the quality of what they received, and, in many of our cities, the supply is really short of the demand, so that the buyer is thankful to get even a wretched article at a high price. . . The agitation of the subject, at least, should go on, and Cincinnati does a good thing in appointing an Inspector to reveal the enormities now too prevalent, even if unable to sweep them away.

\section{There Ought To Be a Law}

Other public health matters also aroused the ire of editors. In 1846, R. L. Allen wrote concerning a problem which had plagued the more genteel folk since the first pig set foot on these shores:

There ought to be a law ... that not a swine in the Union should be allowed to set his foot on other than his owner's premises.

He adds that unless this should be confined to "the quadruped division of the species," 
such restriction of swine "might result in thinning off the population of some of the emporiums of politics ... and other places of frequent resort." Concerning the shambles produced in the streets, he suggests that those "hoggish individuals [who] allow their brother swine to enjoy a free range" should have the garbage they manufacture consumed by their own hogs at home.

In one of the infrequent contributions by female correspondents, a "Dolly Homespun" complained:

Nothing is more disagreeable to us women, than the manner in which the milking is done. Many farmers do not bed their cows at all, and the consequence is, they lie down in their filth, and get up in the morning with bags too shocking to look at ... nine out of ten will not half clean the cow's bag before they commence... and by the time they have finished stripping the cow, the milk is a nasty mess indeed!hardly fit to give a pig. . . Who would drink it if they knew this. ... I wish the men who treated cows, so, had their own faces daubed every morning-I won't add in what.

On the matter of washing udders, the Country Gentleman reported in 1866 that this:

was not the custom or rule in any of the numerous dairies around St. Louis ... they soften the teats with milk from the bucket. . . . On one occasion an Irishman was milking a cow, and the liquid manure was running into his milk bucket. On being reproved for being so filthy, his reply was that it was healthy.

A correspondent offered the advice that a brush was adequate to keep the udder clean, but "once a year it may be necessary to wash a cow's bag."

An incomprehensible custom led to the following animadversion by Allen in 1846 :

At all seasons of the year dead animals are to be seen hung up on fences and trees; and especially is this the case in the spring. On every farm where sheep are kept, dead lambs are suspended in the beautiful, blooming, and fruit-bearing orchards .... to annoy the sight and smell. . . . Dogs and cats too are frequently hoisted into view in the same annoy- ing and disgusting manner. If horses, cattle, sheep, or hogs die, they are drawn out of sight, but not out of smell, and are still sources of disgust.

Allen was primarily concerned with the loss of valuable fertilizer; he does not mention the potential danger to persons or animals inherent in this practice.

Later, a New Jersey farmer explains that the practice of hanging up dead lambs in his area "is to keep the dogs from getting them, as that will learn them to kill sheep. But I think it is a bad sign to have dead lambs, any way." Farmers who tried to get early lambs, he says, frequently lost most of them.

One mode of protecting the public health was commented upon by a correspondent to the Country Gentleman in 1859:

I was entertained one morning at the Charleston, S. C. market by the black headed buzzards, who are there by hundreds to feed upon the offal. Being protected by law - five dollars fine for killing a buzzard - they are as tame as pet chickens.

And in the same year an example of the lack of protection of both human and animal health is mentioned. A farmer had removed several layers of wallpaper from his parlor, one "of a beautiful green, and with corresponding verdancy on our part, the entire peeling was thrown into the barnyard." For three of his heifers: "a post mortem revealed ... the arseniate of copper had performed its legitimate work." During the time that Paris green was used as a paper pigment, numbers of persons were poisoned merely by living in the rooms papered with this poisonous product.

\section{Purveyors to the Populace}

'The publishers of the Agriculturalist, Saxton and Miles, conducted a "Cheap Cash Book Store," the first advertisement for which appeared in March, 1845. Those of veterinary interest are:

American Poulterer's Companion, $\$ 1.25$

Clater and Youatt's Catt!e Doctor, $50 \phi$ 


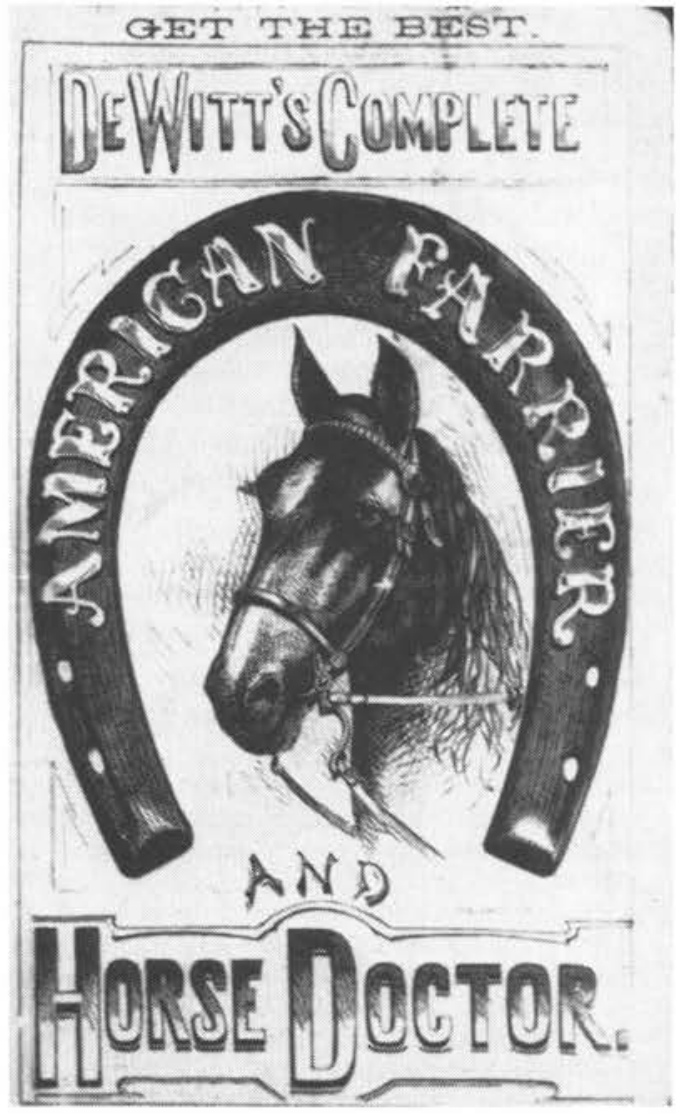

One of the extensively circulated "Horse Doctors" of the latter part of the nineteenth century - no better or worse than innumerable other examples of its genre. Michigan State University Library.

Youatt's The Horse, $\$ 2.00$

Blacklock's Treatise on Sheep, 50 c

The following year saw the addition of:

The American Shepherd, $\$ 1.00$

Stock Raiser's Manual, $\$ 3.00$

Treatise on Cattle, $\$ 3.00$

Knowlson's Cattle Doctor, $25 \mathrm{c}$

Mason's Farriery, $\$ 1.00$

Hind's Farriery, $75 c$

The Horse, its Habits and Management, $121 / 2 \mathrm{c}$

Stewart's Stable Economy, $\$ 1.00$

Treatise on Milch Cows, $38 c$

This list is fairly representative of what was easily available at the time. Some were British reprints, which were cheaper than the imported article; a few imported books at this time sold for as little as $\$ 2.00$, but
Loudon's Encyclopedia of Agriculture sold for $\$ 10.00$, and Stephens' Book of the Farm (3 volumes) for $\$ 27.00$. The market price for bacon in 1845 was $3 \phi$, and butter $15 c$ a pound, which would suggest that few farmers were interested in Stephen' Book of the Farm. It is also of some interest that the editor of the Agriculturalist ran an Agricultural Warehouse; plows sold for as little as $\$ 2.00$. The only item of veterinary interest was the fleam, price not stated.

By 1850 the list of works on the husbandry of various animals, which almost invariably included sections on disease, had been extended considerably. And in addition to the perennial Farriers of Mason and of Hinds, farmers had their choice of the Complete Farrier, 25 ; American Farrier, $75 \xi$, and Every Man His Own Farrier, $50 c$. A relatively unfamiliar entry into the field was Cole's American Veterinarian, 50 c. The fact that many of these can still be had for a dollar or two suggests that they had a considerable circulation, or at least considerable numbers were printed. Not so with veterinary items of a decade or so earlier; for example, the Gentleman's Pocket Farrier, by F. Tuffnell, Veterinary Surgeon, which sold for $15 \mathrm{c}$ in 1834 , now commands a price a hundred times the original.

\section{Yeoman Youatt}

To 1850, and for some time later, the best veterinary works to be had were the several by the eminent British veterinarian, William Youatt, on each of the domestic animals, either in the form of reprints of the British editions, or with additions by American editors. The first was a pirated printing of his work on The Horse, published in Washington in 1834; 3 years after this, the first of his series of works, had appeared in England. Authorized reprints of his works on Cattle (1836), the Horse (1843), and the Pig (1847) appeared in this order; an edited version of the $\operatorname{Dog}$ (1846), and numerous edited versions of the Horse, Sheep, and Cattle were produced until late in the century. Although Youatt's books were more advanced than anything that 


\title{
THE \\ NEW-ENGLAND POCKET FARRIER,
}

on

\section{FARMERS' RECEIP'T BOOK;}

\author{
A SELECTION OF RECEIPTS \\ YOH THE eere OT DISKASE IX
}

HORSES, CATTLE, SHEEP, AND SWINE.

With directions to Farmern fur choosing Good Stock. Also, a variety of Agricuitural and Miscellaneous Receipts.

Following several editions of Jewett's New-England Pocket Farrier, first published in 1795, this title was appropriated for works by several later authors, usually anonymous.

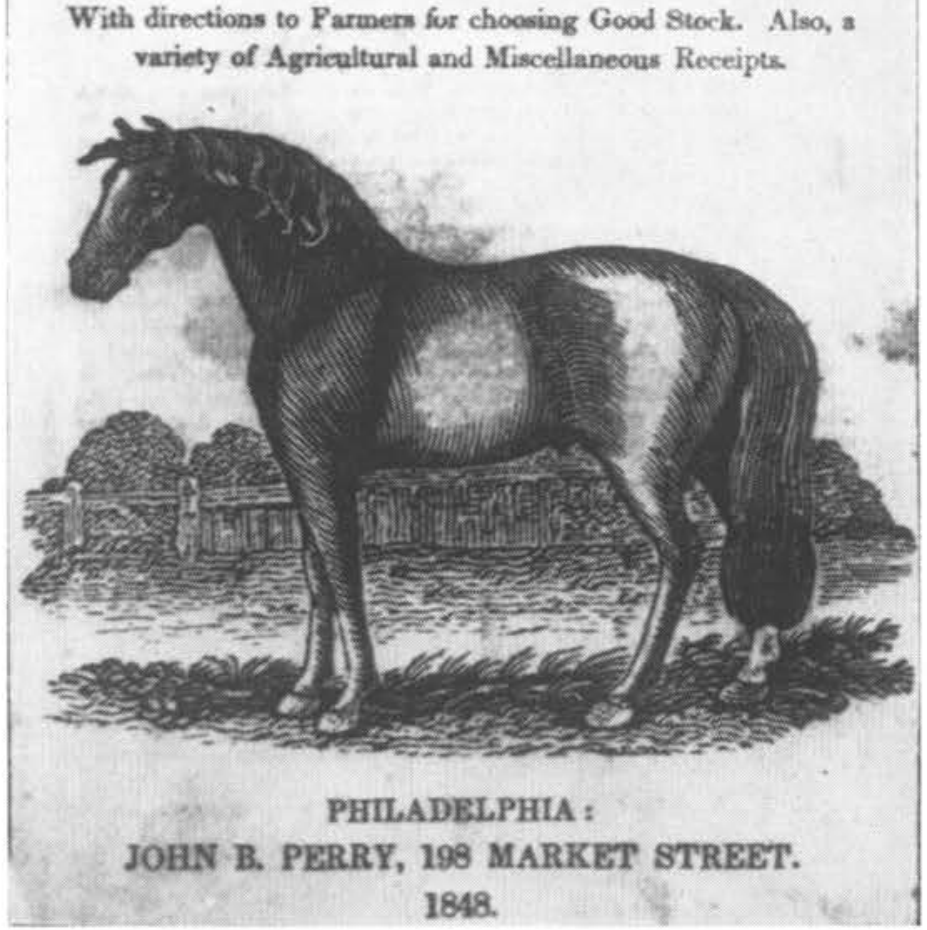

had been produced by an American author prior to 1850 , in many respects his regimen for the treatment of disease was only a moderation of the harsh practices then extant in Britain. Perhaps it was due largely to this fact - that they were not radical departures from accepted practice-that they became the backbone of veterinary medicine in America for half a century or more.

In spite of the fact that Youatt advocated humane treatment of animals, and had written a book on the subject, many of the modes of treatment he gives can be considered as only somewhat less harsh than those of other practitioners. Moreover, he was fully conversant by experience only with the dog; much of his information on other species was gained by reading or correspondence. His medical acumen was such that he could make a judicious selection of the material available to him, and in several respects his concepts of disease were in advance of the medical profession. Thus he was one of the first to champion the specific nature of the rabies virus at a time 
A

\section{HISTORY OF THE HORSE,}

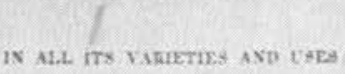

roceruma

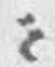

WITH COMPLETE DIRECTIONS FOR THE BRFIDIXC, REIRIVG, AND MANAGEMENT;

Axo ron

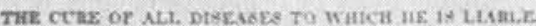

ALa:

A
Wirt a coptoto IXDEX ro TIK W HULE.

W.SSHTSGTON:

PURLISHED AND STEREOTYPED BY DUFF GRERY.

?.+.

1834.
Title page of a pirated edition of Youatt's work on The Horse (London, 1831), an authorized American version of which did not appear until 1843. Youatt's books in American editions were perhaps the most authoritative works on the several domestic animals for nearly a half-century. when medical men preferred to believe in spontaneous generation, atmospheric agencies, and a host of other generalities. A common opinion, as expressed by a Kentuckian in 1855 , was that:

Youatt, in this country and in Britain, is esteemed good authority in veterinary medicine. His observations seem to have been carefully made, and his deductions generally correct-consequently his opinions are entitled even upon abstract questions, to the fullest consideration.
While many conditions undoubtedly were the same on both sides of the Atlantic, others were not, and American farmers and practitioners searched in vain for descriptions of a number of diseases that were peculiar to America. It was to remedy this situation, that the edited versions of Youatt's works were produced by Skinner (Horse), Stephens (Cattle), Randall (Sheep), and Lewis (Dog), each being something of an authority on that particular species. However as pointed out by the Cultivator: 
It strikes us as a great objection ... . that there is no rule by which the reader can know what portions belong to the respective English authors, or what alterations or additions have been made by the American editor.

Not infrequently, ideas were introduced, either by Britishers who revised Youatt's works after his death in 1847 or by American editors, which were in opposition to Youatt's views. Nor could these later additions be considered improvements in every case. There might be some question as to how much of Youatt was left in "Spooner's Youatt on Sheep, edited by Randall."
The American edition of Youatt's work on the dog was the first comprehensive book on this species published here, but additions by American editors did not always improve the text.

\section{T H E I) O (i, \\ BY WILLIAU YOLAIT.}

W I TH I L L USTRATIOYS

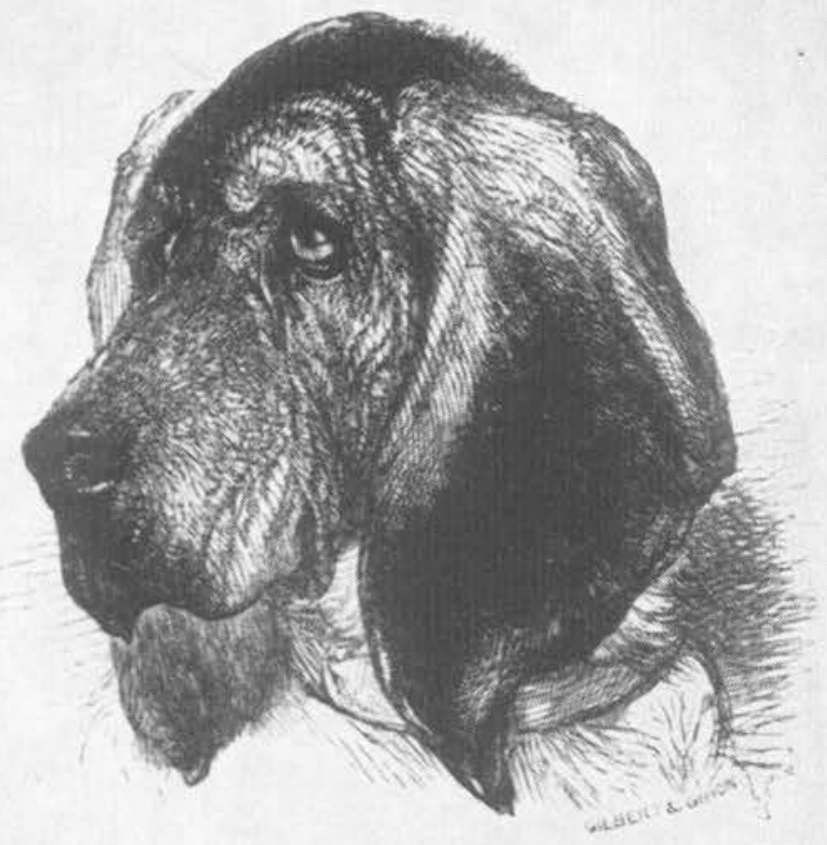

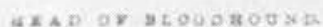

EDITED, WITH A D DTION

BY E. J. LEWIS, M.D.

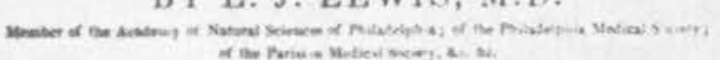

PHILADEI,PHIA:

LEA A N D B L A NCHARD. 1848. 
In many of the American works on animal husbandry, the inevitable section on disease was more often than not taken from Youatt. One such example is Evans' Dairyman's Manual (1851), of which a reviewer in the Cultivator says:

Eight chapters of the book are devoted to the diseases of cattle, and their cures, taken from Youatt, and just enough of them to make it of very little value to any one who needs a work of the kind. Better to apply to Youatt at once, than to resort to the emasculated text of a competent authority at the hands of one who confessedly does not understand the subject which he is attempting to handle. We confess, in all candor, that the book is little, if any better, with this medical addition to its pages.

In rebuttal, Evans states:

The extracts from Youatt on diseases, our reviewer would prefer to leave in the English book. So would the book-maker [himself], if it were accessible to the American dairymen generally; but as it is not, except at an exhorbitant price, it was thought advisable by dairymen and others to devote a little space to diseases.

Evans apparently was more self-righteous than right, for another publisher listed Youatt and Martin on Cattle for \$1.25, and Youatt and Clater for 50 cents.

\section{Mad Medicine}

During 1849 and 1850, the American Agriculturalist ran an extensive series of well-written articles on the diseases of the cow - by an anonymous author, but identified by the editor as being based "on twenty-five years' successful practice of one of the most enlightened veterinary surgeons of the age." In his writing on rabies, for example, this veterinarian demonstrates that he is a notch above most contemporary writers on animal disease. The disease, he says, arises only "from the bite of a dog, or other animal affected by madness, or rabies. Although it is regarded as incurable, it is proper to know its symptoms." A host of other writers continued to give certain cures for rabies until well into the present century. In commenting on a cure for hydrophobia printed in the Agriculturalist in 1850 , an apparently cynical reader says:
There is also a plant growing in this country that is said to cure this disease sure. Some person in Ohio once wrote to me about it, and sent me some seed; but when one of my old out-houses burnt, I lost both seed and name of the plant and writer.

In offering ". . . a better remedy for the cure of wounds by goring," this same cynic suggests:

First, let the gored animal die. Now take off its skin and take it to the tanner and sell it. Take the money and buy as many balls for cattle horns, as you have horns in the herd, and put them on, and bid the said horns to go and $\sin$ no more. It is always better to have one cow gored to death first, before putting on the balls, because "a burnt child dreads the fire."

Again, "a better remedy" for dog distemper is:

Take two grains of strychnine, and give it in a little milk or any food the dog will eat. . . . For nine tenths of the canine race, it is the best medicine in the world.

And on the administration of gunpowder for choked cattle, commonly recommended at the time, another correspondent suggests:

Make a cartridge large enough for a musket and thrust it down the throat ... if the choking is so bad that this will not relieve it, you may use fire with the powder with the next charge.

\section{Education for All}

The editor himself frequently used biting satire to put across some points, but on others he reported facts or opinions in a straightforward manner. A frequent topic throughout the 1840's is the need for agricultural education, including training in veterinary medicine. Thus in 1849 he gives in detail the plan of Professor J. P. Norton of Yale for a state agricultural school in New York, which was to include "a Veterinary Department, where the diseases of animals can find proper treatment."

In the same year he admonishes farmers:

Keep a watchful eye over all your domestic animals. and see that they are not diseased. If 
One of numerous editions of Youatt's The Horse, with additions by American editors. The book today is a valuable reference on the natural history of the horse, if not for its veterinary aspects.

\section{T H E H O R S E,}

BY WILLIAY YOLITT.

A XEW EDITIOX. WITH SEMEgOCB ILLLSTEATIONS

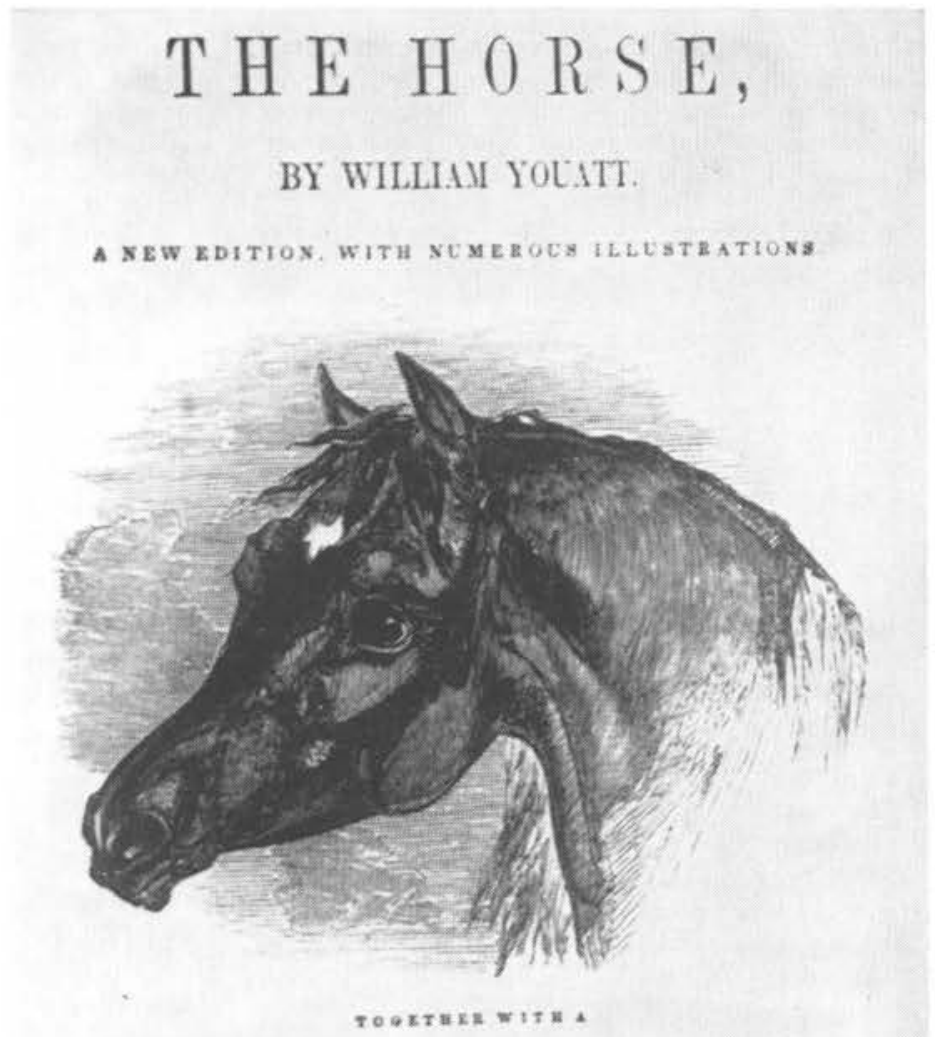

GENERAL HISTORY OF THE HORSE;

a sisecxitatiox ox

THE AMERICAN TROTTING HORSE. HOW TRAINED AND JOCKEYED.

AN ACCOUNT OF HIS REMARKABLE PERFORMANCES; $4 \times 0$

AN ESSAY ON THE ASS AND THE MULE. BY J. S. SKINNER,

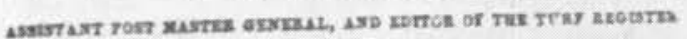

NEW YOR K :

PUBLISHED BY LEAVITT $\&$ ALLEN 379 BBOADWAY. they have a full and frequent pulse, a loss of appetite, a dejected head, and a languid, or watery eye ... depend on it, they are ill, and require the immediate attention of the doctor. or veterinarian.
A later correspondent, however, says:

The farmer should have a knowledge of medicine and of the elements of surgery; for though, in this respect, when applied to human ail- 
ments, it may prove that "a little knowledge is a dangerous thing," yet many a fine animal is allowed to become dog's meat, because its owner could not distinguish between a fever and an inflammation, set a bone, nor bandage a wound.

And another writer on the diseases of the cow insists:

Every person having the direction of the management of cows should be able to perform the operation of bleeding, as circumstances are liable to occur when the life of the animal may be saved by its timely application, where proper assistance cannot be immediately procured ... the fleam will be found the best instrument for those who are not acquainted with this process.

From the outset, the agricultural journals took care not to neglect the farmer's wife and daughters. Thus the Ladies' Department in 1847 carries an article on "Treatment of Ganary Birds under Disease." Overeating, we are told, is:

The most common cause of disease . . moulting . . . is frequently fatal. . . The Canary bird is also subject to epilepsy ... [ [for which] the cure is doubtful. . . In addition to these evils, the Canary is infested by a small insect.

Other diseases described in a later article include rupture, gall in the head, sweating, sneezing, constipation, and overgrown claws or beaks.

\section{Chloroform Castigated}

Among newer developments in 1850 , there is a report on "The Use of Chloroform During Castration of Horses," taken from the Veterinary Record (Veterinarian, London). The author reports that in one of two horses operated upon:
I am of opinion the struggles were more violent than if the chloroform had not been used. I, therefore, am of opinion that there is no certainty in its action, and scarcely any advantage, on the score of humanity, to the patient... we cannot rely upon it as calculated to supplant the hobbles and ropes usually employed during the performance of operations to ensure safety to the horse, operator, and attendents.

As later events proved, general anesthesia for animals did not become a reliable technic for another half century or more; even if the few contemporary reports in American papers had proclaimed it an unqualified success, there would have been all too few qualified persons to capitalize on it. George Dadd is known to have used chloroform and ether as early as 1852, and Jackson's account of the experimental use of anesthesia on animals, recorded in the Report of the Commissioner of Patents for 1852 , is summarized in the Country Gentleman in 1855. This the editor considers "a very interesting article," but he does not enlarge upon its possibilities.

One of the potential uses of chloroform, not likely envisioned by its discoverers, is recorded in the American Agriculturalist for 1858:

It is reported that in Taunton, Mass., several fat logs have been stolen by first administering chloroform, and then taking them from the pens, without so much as raising a squeal.

And the Country Gentleman for 1856 reports:

The latest educational improvement is to administer chloroform to children, while the parent is obeying Solomon's injunction not to "spare the rod." 


\section{Every Man His Own Horse Doctor}

WITH THE DEVELOPMENT of sophisticated and aggressive methods of marketing patent medicines and the appearance of more and more of them, the public found itself able, as it thought, to take care of every animal disease.

\section{PATENT MEDICINES FOR MAN AND BEAST}

Relatively few advertisements for patent stock remedies were carried by the agricultural papers prior to 1850 . In fact, during the decade ending in 1850, the New England Farmer, and the Cultivator between them carried only half a dozen such advertisements. In 1841, the Farmer gave free space to a correspondent who had discovered "an effectual cure for the fouls in cattle" (foot rot), and for which he "wishes to give notice to the public, that he makes ... a salve and prepares it in boxes for delivery at 50 cents per box." That the salve was effective was attested to by nine citizens whose names are given. A postscript suggests the motive in giving free space: the remedy was obtainable at the warehouse run by the publisher of the journal. Also carried in several issues was a notice that Dr. Charles M. Wood, Veterinary Surgeon, had removed his offices to another address in Boston, adding: "All diseases of Horses, Cattle or Swine, are attended to. Also, castrating and spaying," together with the names of fourteen clients "who have employed him for a number of years past." Wood was later an associate of George Dadd in an unfruitful venture in veterinary education, the Boston Veterinary Institute, and was an early president of the United States Veterinary Medical Association.

The Cultivator for 1848 carries an unsolicited testimonial for:

the cattle medicines prepared by Dr. C. S. Toms. His "Russian liniment" for bruises and strains, is said to be not only valuable for horses and cattle, but for the cure of rheumatism, \&c., in the human race. His "condition powders" are highly spoken of. . . The above medicines, coming as they do from a good farrier, I much prefer to trusting animals in the hands of ignorant and conceited quacks.

The same year saw the first of a seemingly endless series of advertisements for the horse and cattle medicines prepared by $\mathrm{G}$. H. Dadd, M.D., later V.S. In urging the public: "Don't permit your Horses or Cattle to die, when the means of cure are within the reach of all," Dadd admits he has:

spent several years in the study of Veterinary practice in London and Edinboro. ... The principles of our practice consist in the rejection of general bleeding, and the total rejection of all medicines that experience has shown to be of a dangerous tendency. . . . These remedies act in harmony with the vital principle... hence are safe in the hands of every one. 


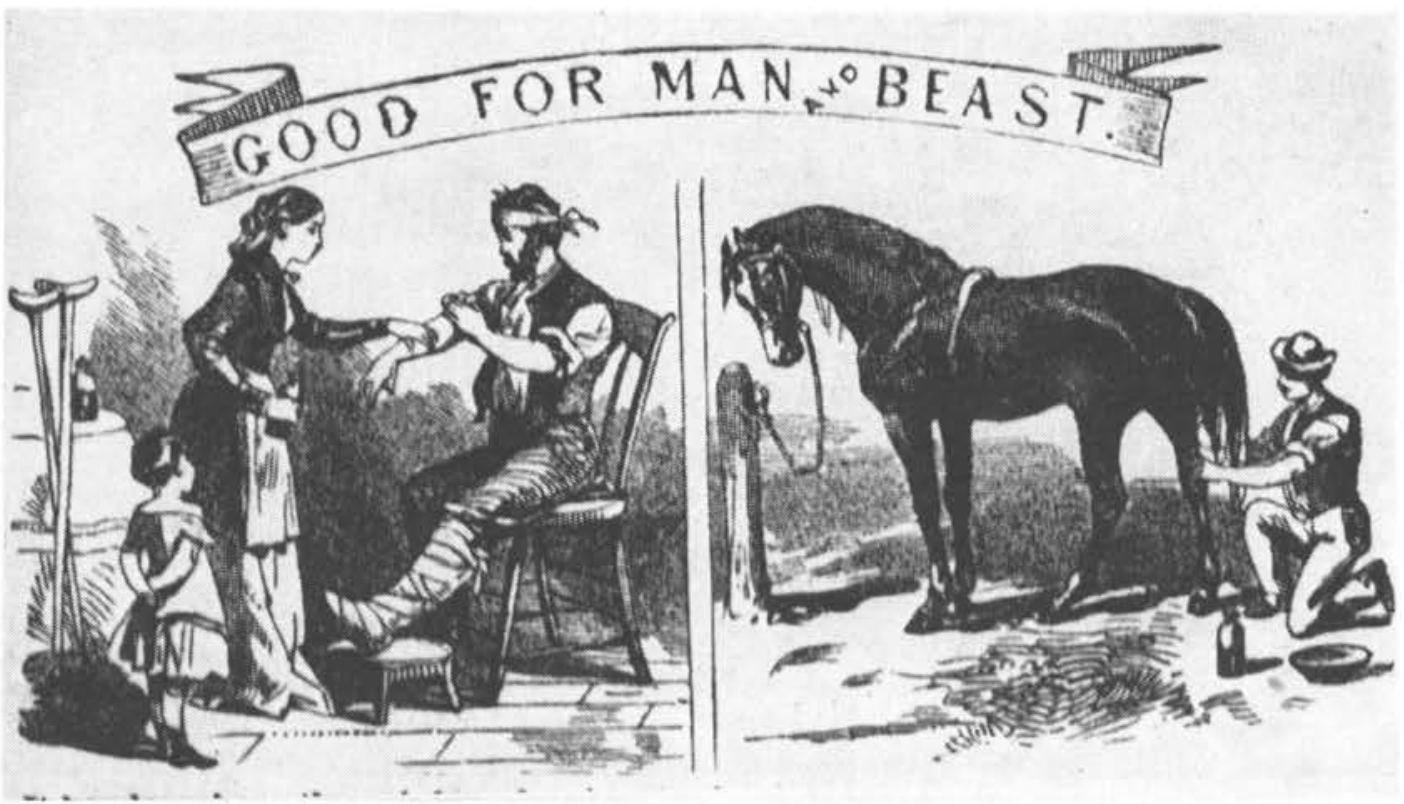

Patent medicines "good for man and beast" were favorites with those who depended on dual purpose books on home doctoring.

The list of remedies, selling for 50 cents to a dollar, includes: physic balls, heave powder, urine powder, tonic powder "for bad condition glanders," liquid blister, healing balsam, mange ointment, hoof ointment, distemper powder, and worm powders, among others.

An advertisement for Merchant's Celebrated Gargling Oil in 1849, directed to the Farrier, Farmer, and Stage Proprietor, claims this preparation is:

Unparalled in the history of Medicine, as the most remarkable External Application ever discovered for Horse's and Human flesh. Fourteen year's experience proves this will cure most cases of spavin, sweeny, ringbone, windgalls, poll evil, callous, wounds, bruises, sprains, fistula, lameness, foundered feet, grease, mange, rheumatism, bites of animals, external poisons, nervous affections, frost bites, corns, burns, chillblains, chapped hands, cramps, caked breasts, \&c, \&c. . . A man who has the care of 193 horses... says it works like a charm.

By the 1860 's, the patent medicine men had become less reticent about the qualities of their products. Thus:

Farmers and Stock Breeders all hail the triumph that Fickhardt's Cattle Powder hath achieved!! Thousands are testifying to its efficacy! The merciful Man is kind to his Beast. ... Knowing this Powder to possess all the curative properties here set forth, we deem a fulsome tirade of words unnecessary. . . . It strengthens the digestion, purifies the blood, regulates the urinary organs, removes all obstructions from the milk tubes, \&.c., \&.c.

Included were testimonials from J. P. Turner, Veterinary Surgeon for the United States Government, and the Assistant Veterinary Surgeon, Hiram Wright, as well as the superintendent of the Mule Corral, the superintendent of the Quartermaster's Office, and other lesser lights.

And while these testimonials would suggest that this cattle powder was equally good for the equine species, army horses apparently were not convinced. The same issue carrying this advertisement states: "The animals die at the rate of about fifty per day, at the lowest calculation." This, of course, did not include losses in combat, but related to the remount depot near Washington. In the winter of the same year Merillat and Campbell state:

Thirty thousand cavalry horses perished in the Federal armies in Tennessee during the 
winter of 1863-1864. The horses killed or wounded in action were few. They died of neglect.

Referring to these 50 or more horses a day which died:

A contract for the purchase of the dead horses in the Army of the Potomac for the ensuing year, was let a few days ago, to the highest bidder, at $\$ 1.75$ per head, delivered at the factory of the contractor. Last year $\$ 60,000$ were cleared on the contract, and this year it is thought $\$ 100,000$ can be made on it.

The contractor could realize from $\$ 20$ to $\$ 40$ a head, the hoofs alone being worth $\$ 2.00$, or more than the delivered carcass. The set of shoes and the tail were worth 50 cents each, and the shinbones "are valuable, being convertible into a variety of articles that many believe to be composed of pure ivory." And in a commentary on the condition of army horses:

Then [there is] the tallow, if it be possible to extract tallow from the army horses, which I think extremely doubtful, unless they die immediately after entering the service.

An all too infrequent type of editorial notice appeared in the Cultivator in 1853 under the heading of Veterinary Surgeon:

A young gentleman who has thoroughly studied his profession as a veterinary surgeon having graduated at Edinburgh in 1851, and since been in active practice, wishes to find a favorable location for the practice of his prolession in this country.

\section{Zenith to Nadir}

Some idea of the nature of veterinary practice in the 1840's, and the types of men who engaged in it, may be gleaned from the agricultural press. Near, if not at, the zenith is a communication of Charles Wood, V.S., to the New England Farmer in 1841 on "The Operation of Bronchotomy Successfully Performed on the Horse." Wood opened the trachea of a horse with strangles, in immediate danger of suffocation, and inserted a small tube with instantaneous relief. Later five quarts of "unhealthy matter" was let out of the abcesses. The tube was left in for twelve days; after removal and cleansing the wound, he "left nature to complete the cure." In a note appended, the owners of the horse "cordially recommend him [Wood] to the public as an attentive and skilful practitioner of veterinary science."

More or less at the opposite end of the scale is a contributor to the same issue, who states he has "for several years practiced more or less as a farrier," and offers a cure for spavin in horses:

for the efficacy of which, not only myself but many of my townsmen can vouch. . . . Take

\begin{abstract}
"Business card" of Charles $M$. Wood, V.S., a prominent practitioner of Boston and an early president of the United States Veterinary Medical Association. New England Farmer, 1841
\end{abstract}

\section{whrte poutu.}

In. Gllatiks M. WooD. Vetrimury Surwon,

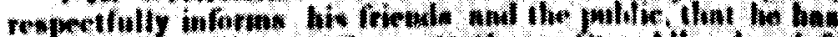

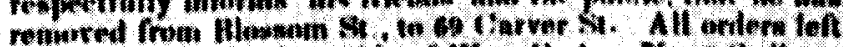

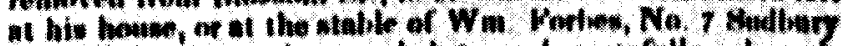

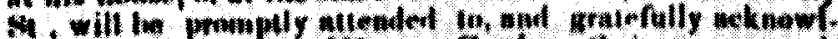

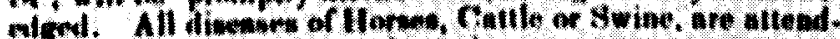

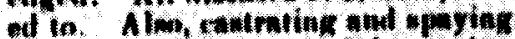

For the infurengtion of thue the moy have eceobles for

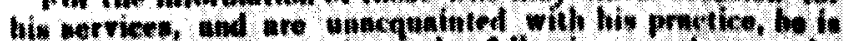

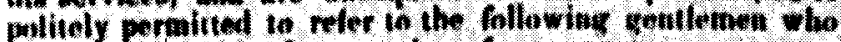
heve enployed him bor suruler of years pai.

Wm. Wantw

Whe J. Nile:

Johua worat.

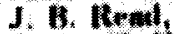

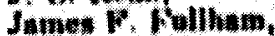

Wn T. LAIII

Jownh C. Pray.

motar, Aprt 0
W WIImms a Tarwer, G, Menthm.

W. lkyleg.

1. Wa Wwari,

later boutro

Aronas Who.

Grond ownot 


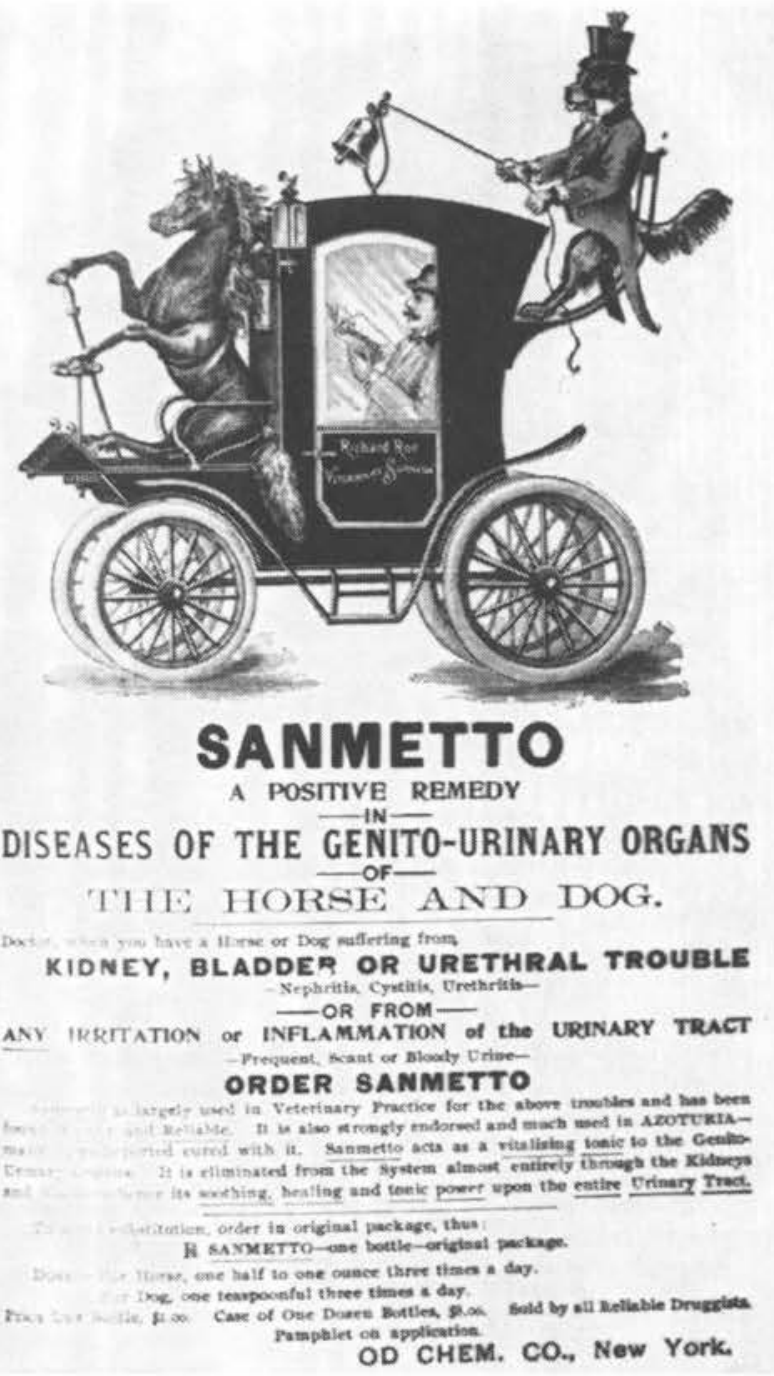

A pre-Madison Avenue concept of the "ultimate" in advertising virtue, ca. 1890 . American Vet. erinary Review

about a pailful of urine into which throw a quantity of old rusty iron; put the vessel near a fire, and let it stand 3 or 4 days. . . Apply this mixture twice a day - and in all cases it will soon effect a radical cure, or at least prove highly beneficial.

As a sidelight on the use of urea, a correspondent to Veterinary Medicine in 1937 observes:

The value of urea as a healing agent has been empiric knowledge among farmers, teamsters and others for many years. Not in its pure crystalline form it is true, but in its crude form, i.e., urine. I recall very vividly, way back about 1890 having a severe case of chapped hands. . . I was insistently advised by the old farmer with whom I lived to urinate on my hands several times daily. Believe it or not, my hands healed quickly after several applications.

On another occasion I observed the use of urine as a wound application to a large indolent ulcer on the leg of a draft horse. The owner urinated on this ulcer several times daily, and no other treatment was used. . . That old ulcer healed promptly.

\section{Noble and Lucrative}

In commenting on "the importance of the veterinary art," the editor of the New England Farmer states: 
We constantly lament that the term cattle doctor should be considered degrading, though we cannot feel surprise at it, when we know the miserable and contemptible quackery which is continually practised by the stupid and ignorant jackasses who undertake to practice in this line. We want a veterinary school, in which the science of comparative anatomy and the diseases of the brute creation shall be as thoroughly studied as those relating to the human frame and system. It would open a noble field for science. It might be made a highly lucrative profession on a level with other liberal professions, and the actual gain to humanity would be immense.

On the veterinary art of another sort, the editor of the Cultivator in 1844, in commenting on the recommendation of "the Thompsonian medicines for the diseases of animals," by a correspondent, states:

Those disposed to try them, can obtain them from any Botannic physician. We are not disposed to entertain a discussion as to the comparative merits of the "life-destroying lancet," and the "glorious system" of Dr. Thompson.

In 1859 an editorial feature in the Country Gentleman (borrowed from the Cultivator, 1853) states:

We have seen a great deal of doctoring for sick animals - some successful, and a great deal of it unsuccessful. . . . Our own observations lead to the opinion that in at least nine cases out of ten, as commonly administered, medicine does more harm than good.

An eminent New-York physician said that taking medicine was always a choice of evils that being poisons in nearly all instances they necessarily did harm to the system. . . . It may be laid down as a general rule, that it is much safer to give too little than too much medicine; and that none should be given unless we know distinctly how it is to operate and what it is for. . . The majority of sick horses get well; every owner tries some remedy; and that particular medicine that he happened to be using at the time, gets all the credit-although as a general thing it retarded more or less his recovery.

This elicited a letter from a reader who had:

been weekly expecting to find in your columns a notice by some of the veterinarians of this country, of the article which you pub- lished .. . so utterly subversive to the first principles of all generally adopted practice in treating the diseases of animals, and destructive of all confidence in horse doctors and cattle doctors, if not also in veterinary practitioners. . . . I hope they will yet be noticed and discussed by some of our ardent veterinary practitioners, or any others who may be ardent advocates of the administration of drugs to sick animals. ... It is certainly of great importance that all owners of stock should have some knowledge of what is truth and what is error.

\section{AMATEURS VS. PROFESSIONALS}

The history of animal disease and attempts to alleviate it in the late 1840's does not differ materially from that of a decade or two earlier. The increasingly abundant agricultural press made more information more readily available, but there is little indication that much of this was of any better quality than that published earlier. Additional books on the diseases of animals were printed, some of which achieved a wide circulation. In 1847, Cole's American Veterinarian, or Diseases of Domestic Animals was advertised:

to be sold at the low price of $50 \mathrm{cts}$, in order to bring it within the means of every man. No pains or expense have been spared ... to produce a work worthy a place in every Farmer's library.

And while perhaps the publisher's claims should be accepted with some reservations, it was stated that 8,000 were sold in six weeks, and double this number in one year. Testimonials at this time claimed it to be "just what farmers want"; "worth its weight in gold"; and "Many times its price to almost any farmer, may be saved by its purchase." Thirty thousand were said to have been sold in four years.

By this time, Cole had a competitor in the form of Allen's Illustrated Treatise on Domestic Animals, which included "their diseases and remedies." It sold for 75 cents, and one review states "it is worth three times that amount." Another of the nearly 30 testimonials states: "Its greatest worth is, 


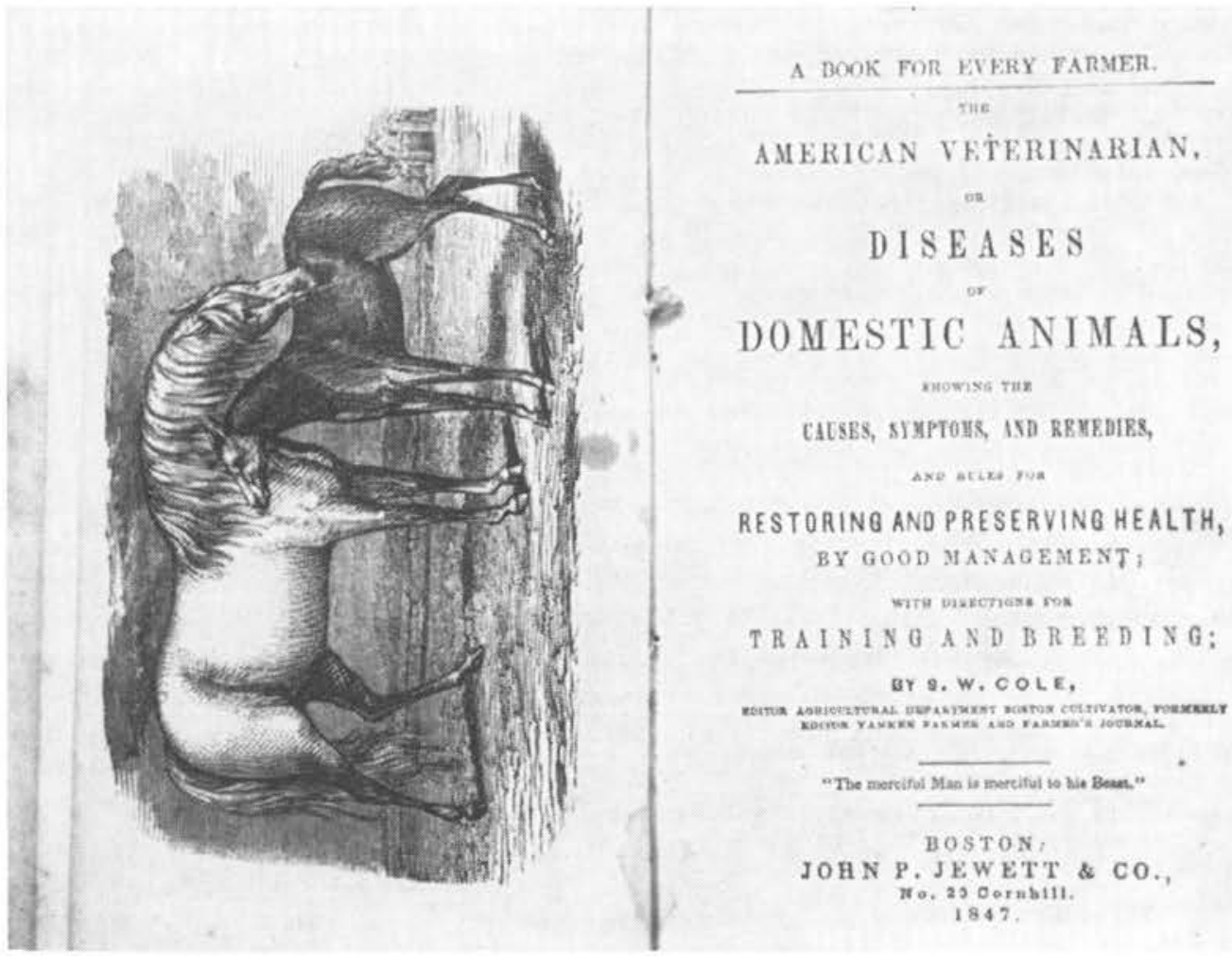

Cole's American Veterinarian (1847), although superior to Dadd's Horse Doctor and Cattle Doctor only in title, was a strong competitor and probably outsold either of the latter works.

as a complete Farrier, showing the disease of animals, their treatment and care." It was claimed that 5,000 copies were sold in four months. Both books, however, were by agricultural editors, the information on disease being abstracted largely from the pages of their journals. A review of the contents of either would provide little new information; thus Allen suggests that hollow-horn is in reality hollow-belly, but he adds a dozen of the common remedies including horn-boring, for those who would prefer to believe otherwise.

While the number of veterinarians who had communications in the agricultural journals at this time was relatively small, the quality of their contributions was generally superior to even the better writing of agriculturalists on animal disease. The appending of "V.S." after a name, of course, does not prove much in itself, but the fact that many of those who did were also well educated is apparent, and coupled with intelligent professional observations, we may assume that the individual was a degree or two above the common herdwhether the V.S. "degree" was awarded or assumed.

\section{The Coming of Age}

In 1854, M. A. Cuming, V.S., of St. John, New Brunswick, in writing on "Bone-Sickness in Cattle," chose to differ with Professor J. A. Nash of Amherst on the nature of the disease. Nash had earlier stated, in response to an inquirer whose cattle "have a hankering for bones, boards, chips and old leather," that this was "bone-sickness" due to a deficiency of soil calcium and phosphorus:

manifested by an unnatural, and, in some cases, an almost rabid craving for bones, so that cows 
afflicted with it, as $\mathrm{Mr}$. T. says, will run for a bone, as if a dog were after them.

\section{Cuming agrees with:}

the practical conclusions of Professor Nash ... while at the same time I dissent from the reasoning by which he arrives at them. . . Science requires our reasoning to be legitimate, as well as our conclusions applicable.

He says the disease was common in Scotland some 20 or 30 years earlier, but that it had disappeared with improved management practices. He considers the disease to be more in the nature of a rheumatic affliction, and concerning Nash's statement that the bones are deficient in salts, he asks:

Where is the proof that in this disease the bones are actually affected? Or if they be, that it is by a deficiency of their earthy constituents? ... in Scotland... the deficiency seemed rather to be in the organic part.

In retrospect, it would seem that Nash's explanation was perhaps the better of the two, but Cuming's logic is not to be denied.

In 1858, Cuming comments on the apparently antagonistic views of two correspondents to the Cultivator on the cause of hoof ail, one attributing it to exposure to severe cold, the other to ergot poisoning. In stating his opinion that either, acting alone or together, might be causes, he says:

We are all too apt in pathological investigations, especially those not conversant with the phenomena of animal physiology, to look for a cause, and to rest satisfied when we think we have discovered that, instead of keeping constantly before us all the causes by which the condition we are investigating can be produced. And hence we often, while removing one source of evil, leave others of nearly equal magnitude in operation, and the benefits we anticipated, being for this reason not forthcoming, we at once discredit instead of praise, because we have discovered only a part instead of the whole. The soundest hygenic wisdom is, when disease is apprehended, to remove all the causes that tend to the production of the disease we would obviate.

An article on "Shoeing Horses," taken from the New York Spirit of the Times by the Michigan Farmer for 1856, is attribu.ted to M. A. Cummings, V.S., but this undoubtedly should be Cuming. In speaking of the natural mechanism of the foot, he states:

Wherever Veterinary Schools exist, and scientific attention is given to shoeing, this natural form of the foot is more or less followed in the shape of the shoe. . . Why it is not so here is perhaps partially due to the use of the buttris for cleaning out the foot when it is shod, as it is impossible with this antiquated instrument to bring the hoof to the proper shape in all its parts; but it is more so to the want of study on the part of those who shoe, of the structure of the foot, its uses, and the relation existing between it and the other motive organs, the bones, tendons, and ligaments of the limbs.

Cuming was also an occasional contributor to the Country Gentleman, and on the appearance of his second article in 1856, the editors remarked: "we should be greatly pleased if he would become a more frequent contributor to the veterinary department of our paper." The "veterinary department," however, was entitled "The Grazier." This communication was in response to an inquiry by a farmer who had lost a cow with obvious symtoms of gastric distress. Cuming, who mentions having made "many hundred postmortem examinations," recognizes impaction as contributing to the death of the animal, but believes it probably was caused by poisoning. On the matter of the treatment described, Cuming says:

At the time the pepper, ginger, soot, milk and molasses hotch potch was given twenty minutes before death, it was a matter of indifference no doubt what was prescribed-unless the death was produced, as it sometimes is suddenly in such cases, by a portion of the medicine getting into the lungs. ... When the vital powers are so nearly exhausted before anything can be done, the better policy is to let doctoring alone.... I trust the time is close at hand when intelligent men will know better than to give any animal, over which Providence has given them power, such a nauseous seasoning to whatever else they may exhibit as "three tablespoonfuls of soot." 


\section{Barbarism and lgnorance}

In a previous communication, in reply to an inqury on hoof ail in cattle, Cuming recoils from the harsh treatment recommended "which those who have had exper. ience have found effectual." These included removing "a round substance of flesh of the size of a common hazel nut," found between the dewclaws and the hoof, and filling it with verdigris, alum, and salt; or, making the same incision:

You will discover a bladder that will puff up; take a hook made of a strong wire and pull it out; then fill it up with boiling hot tar; or apply a mixture of turpentine, nitric acid and oils: observe great caution in mixing the above articles or they will produce an explosion.

Cuming suggests a powder of alum and zinc carbonate, which he says, "I have tried in hundreds of cases and found it to answer every end needed in the treatment of this disease." Concerning the remedies recommended earlier, he says:

I need hardly say that I disagree. . . . Such cruel treatment by whoever first proposed, could only originate in gross barbarity, and as barbarism and ignorance are ever hand in hand, it will not surprise you to learn, that there is no fleshy substance in the position indicated, nor bladder or bag of any kind, except the bursa mucosa, or sheath, in which the flexor tendons of the toes play, the cutting of which would be fatal to the further usefulness of the foot, not to speak of the destruction that would arise from the contact of "boiling tar" or other such fiery agents. ... Such communications reveal the fruitful regions of veterinary research that lie yet uncultivated on the vast American continent, they at the same time can hardly miss to draw a sigh from the lover of the science, over the little that is yet being done to explore them.

In 1856 Cuming writes concerning "Inquiries about Bots":

It is not about the bots, however, I would now speak, but about the cause of the death of the mare ... which I have no doubt arose from the effects of the cure. . . A quart of fish brine was certainly a most outrageous dose to give to any horse or mare, and so long as such barbarous methods are had recourse to, such losses will be certain from time to time to occur... it is more than likely that a portion of [the brine] got into the air passages. ... The only answer veterinary science can furnish, is that the animal died, not of Bots, but of fish brine . . . a case of mare slaughter. . . A homily might be written in in behalf of the introduction and cultivation of veterinary science ... in these districts.

In another instance, Cuming concludes that a correspondent's cow has "some structural or organic disease of the rumen," and recommends fattening for slaughter:

In cases such as I understand this to be, the best and honestest advice the veterinary surgeon can give, is to avoid doctoring as much as possible.

In 1858 he comments upon the humanitarian instincts of a correspondent writing on hoof ail, and hopes:

they will promote the cause of humanity they are so well adapted to serve, by leading farmers to devote more attention than is usually given to the comfort and warmth of their stock during the severe cold of the North American winter. .. . It has always seemed to me that one of the greatest and most ruinous errors of American farming is the little attention given to providing for the feeding and warmth of the cattle. . . No farmer has the right to allow himself the enjoyments of a warm fireside and comfortable bed, till he has first measurably provided for the wants in these respects of his domestic animals.

\section{Cuming's Going}

In August, 1859, Cuming's death is noted in the Country Gentleman:

We notice the recent death of this able and experienced Veterinary Surgeon at St. Johns, N.B. He has contributed many valuable papers to various agricultural publications, and his loss will be severely felt in his own vicinity, and to the agricultural community. The Secretary of the Maine Board of Agriculture ... says: "I consider his death a public loss, having rarely ever met a man of such extensive and thorough acquirement in his profession, and all matters kindred to it. He was an accurate chemist, and was thoroughly at home in all matters pertaining to the theory and practice of Agriculture, and at the same time the plainest and most unassuming of men." 
As something of a valedictory, Cuming had ended his last communication to the Country Gentleman with:

Now is the time when winter is setting in, for farmers to show that they belong to that merciful class that regardeth the life of their beasts, and if they do, so they may rest with full assurance on the immutable laws of nature, that as they sow they will reap, and that even in this life they will have their reward.

Cuming, we should like to think, has long since been enjoying the green pastures of those Elysian fields he might have wished to confer upon all creation.

In a lengthy notice of the death of M. A. Cuming, V.S., the American Stock Journal states that he came from a poor family and:

at the age of thirty-three, his wealth consisting of a wife and five children, he entered the Royal Veterinary College of Edinburgh as a student. ... At his last examination before graduating, he received three out of four medals awarded that year to the class. Having grad. uated with distinguished honors, Dr. Cuming established himself in a successful practice. ... In 1852, the St. John Co. Agricultural Society extended Dr. Cuming an invitation to move to New Brunswick in the hope of securing a large field of usefulness where veterinary science was comparatively unknown, and where he could obtain a competent support.

In many respects this was a failure. Pupils did not come to him for instruction, as he had been led to expect would be the case. He bore high testimonials, but the people did not appreciate his scientific skill.

\section{Cuming's Colleagues}

Another veterinarian, lately of St. John, New Brunswick, R. Rutherford, V.S., writes a lengthy piece on contagious pleuropneumonia and another on choke in cattle in the Cultivator for 1862. Although he uses the plain "V.S.," he apparently was an Edinburgh graduate, or at least he mentions having been a student there.

Rutherford also recommended ligature of the spermatic artery in castrating colts: "From my own observation, I cannot but consider that it offers less risk with greater advantages than any other mode." In 1862 he reported a cesarean operation in a Shetland pony mare with dystocia and suffering from a large ventral hernia of recent origin. Although he considered her a hopeless case, the operation was performed in full; she lived only thirty hours. He says:

It is but very seldom indeed that this operation is resorted to. Many veterinarians think that, on the score of humanity alone, it is unjustifiable, while at the same time they admit that there are exceptional cases in which it may be resorted to as a last resource. Now while partly endorsing this opinion, I would differ with the latter clause. If the operation is determined on, let it be proceeded with before the mare has been exhausted by her own and our efforts to complete delivery.

In May of 1862 Rutherford apparently had returned to Scotland. Earlier, Robert McClure, V.S., of Philadelphia had written on hoven (bloat) and hoose (lungworm) of cattle. Incidental mention is made of a Dr. H. Moore, "a thoroughly qualified and experienced English veterinarian, of Poughkeepsie [New York], who has been for some years practicing in this country." An article by another practitioner, Wm. Somerville, V.S., originally written for the American Veterinary Journal, appears in the American Agriculturalist for 1856. In writing on "Sweeney in Horses - Is it a Disease?" Somerville states, "Of the many diseases to which horses are subject in the western country, there is none more common, nor any which receives such varied treatment." Western horses evidently were used to break new ground, and Somerville mentions sudden pulling on heavy loads as a cause, but thinks that too often additional seats of lameness of the limb are overlooked: "Sweeney first came into existence and is practiced on at present by men who think there is no other disease in these parts."

\section{Tap Roots of Poll Evil}

In quite another category from the communications by veterinarians were those 
from the type of man who would: "warrant a perfect cure of Fistula or Poll Evil for $\$ 8$, having done it repeatedly and never failed of a perfect cure." The method was to take a large goose quill fitted with a "piston-rod" of wood as a plunger to make a crude syringe, fill it with arsenic, and deposit it deep in the fistula, after which:

Leave the horse to his fate for from 10 days to 3 weeks ... probably in 4 days, he will begin to swell about the tumor, which will increase and frighten you; but never fear, it is the best symptom.

The wound may be kept clean with a mixture of urine and copperas, "but do not attempt to extract the tumor by the least force as you will break off the tap-root by which the cure will not be perfect." After the dead mass sloughs out, "one and perhaps two of the fin bones may protrude. If they appear black and dead, cut them off carefully."

On the matter of the value correspondents placed upon their cures, one who suggests blue vitriol for foot rot in response to an inquiry, adds, "If the above makes a cure, will J. R. please send me a three-cent postage stamp - if no cure, no pay." And a simpler regimen for poll evil was given in 1862 by a correspondent who says:

Five dollars was paid a V.S. for this recipe. I have known several cases perfectly cured by it, and never knew it to fail . . . Dissolve as much common salt in urine as it will dissove when hot, and apply quite warm two or three times a day until a cure is effected.

A correspondent in 1861, who asks if there is a sound work on "botanic medicine" for horses, says:

I am not a "thorough-bred" V.S., but I have paid a sufficient attention to the subject ... and I hope to learn more yet .... I have been utterly disgusted at the treatment I have seen animals receive, being drenched with all sorts of nauseous things, simply because some one or other said it was good .... "The Pocket Farrier," and such other small works published to sell, are sadly mischievous; the recipes they contain generally overrate the doses that are suitable for animals, and fre- quently combine a lot of trash that is far more suitable for the manure heap than for an animal's stomach.

The obvious answer was to recommend Dadd's works, and the editor adds:

It is a safe general rule, that unless the owner of a sick animal knows what is the matter, and also just what to do, to give nothing; but attend to every thing that appears to alleviate suffering, or in other words attend to good nursing. More animals have been doctored out of existence by the old fashioned dosing and purging, cut and slashing, kill or cure system, than from a want of medicine.

That the good editor did not always practice what he preached is evident from his suggestion concerning "wolf teeth" of horses. About this time the subject of wolf teeth was fashionable among correspondents; their wisdom being distilled by the editor, he was able to state with assurance in 1859: "They should be extracted, as there is no doubt that they frequently cause blindness." And despite the urging of men like Cuming and other enlightened souls, all too many contributions like the following continued to creep into the pages of the agricultural journals:

Having myself arrived at the age commonly alloted to man, and having seen some of the good effects of experiments, and feeling it a duty to do as much good as possible when I have an opportunity, I send you a number of recipes. Cure of Hollow-Horn in Cattle: Take a tea-kettleful of boiling water.... To Prevent Hollow-Horn: Cut off the end of the tail .... For Cattle that have Eat too much Corn: Take one quart of good yeast, mix a half-pint of human excrements, and pour it from a bottle down the creature's throat, and I think you will soon hear from it. [!]

\section{Generation of Vipers}

Despite the generally good intentions of agricultural editors, the printing of such trash undoubtedly helped perpetuate the conditions they railed against. Moreover, while protests directed to the editor himself were usually graciously received, some editors were less charitable about criticism from the outside. Thus in relating some 
"Further Experiences with Wolf Teeth," in 1857, a correspondent to the Country Gentleman, who had a horse with a film on its eye, states: "A person informed me of the cause, which he attributed to wolf teeth." Upon finding one on the side opposite to the affected eye:

this was removed by placing the end of a piece of iron against the wolf tooth and striking the other end with a hammer, which, of course, cured the eye ... [for a few months, whereupon:] I resolved to take her to a man who was skilled in cases of all kinds pertaining to horse-flesh. He pronounced the difficulty to be a "hook" in the eye. . . After the hook was removed the eye soon recovered, but another hook grew. . . The operation has been performed three times ... yet I am of the opinion that one thorough operation would have been sufficient .. . there has been no indication of a renewal.

Later, the editor notes that C. M. Wood made scathing mention of this particular piece of surgery in the American Veterinary Journal; claiming Wood had distorted the facts, he retorts:

Mr. Cooke gave a plain statement of his treatment of a case of partial blindness in one of his horses. We may venture to presume that there was no scientific veterinarian within his reach ... and he acted as any man of sense would. . . Though that treatment was not, perhaps, the most scientific . . . yet we are by no means certain that he did not accomplish his object as successfully as it would have been done by one of the "profession." It will be a long time before veterinary surgeons will be within the call of many of our farmers. In the meantime we think the agricultural papers are doing much good by the publication of such statements as Prof. Wood attempts so severely to ridicule. The treatment generally recommended is harmless, and frequently requires no more skill than is every day exhibited by the sensible housewife in the management of the ailing members of her family.

While the editor invites Wood to correct such errors instead of ridiculing them, this particular specimen of logic would appear to be the granddaddy of the differences of opinion which were to crop up between the agricultural papers and the veterinary press - yet unborn, except for
Dadd's abortive efforts. Unfortunately, the matter does not end here, and while it might seem unkind to rake up old controversies, there would seem to be some merit in understanding the basis for what in some cases became an almost hereditary antipathy. Wood replies to this editorial in a manner not calculated to make friends, even if he were completely correct - which he was not:

Sir, I disdain to destroy the meaning of any writer, if I am able to understand it. . . I treated that writer fairly and more leniently than he deserved. . . We trust he has learned a lesson which may be of great service to him ... not to consider whatever is first noticed by him as something before unknown and unseen. . . We intended no offence ... but when an error was so absurd and ridiculous, we could not help laughing at it.

Wood, however, errs in stating, "The editor says - 'the treatment recommended by Mr. Cooke is harmless," " to which the editor replies, "We said no such thing." $\mathrm{He}$ might have added, however, "except by inference."

Mr. Cooke gets into the act, saying:

Prof. Wood thinks he has learned me a useful lesson. . . I I have learned a lesson .. . viz: that professional men are very prone to scoff at every effort of others to act for themselves. . . . It is evident that wisdom will not die with Prof. Wood; but the farmer will continue, aided by generous scientific men, to think, act and improve.

It would appear that it might have been better had Wood been less caustic, but if he had not been the one to initiate the larger controversy, it is inevitable that someone else would have.

On a related matter, a physician had earlier written concerning an article on dysentery in animals:

In reading several agricultural papers, I frequently find articles from correspondents, as well as editorials, of the same general tenor, to wit: recipes for the cure of diseases, by name, in animals. Just so long as Agricultural papers give countenance and currency to the treatment of diseases in animals or man, by name 


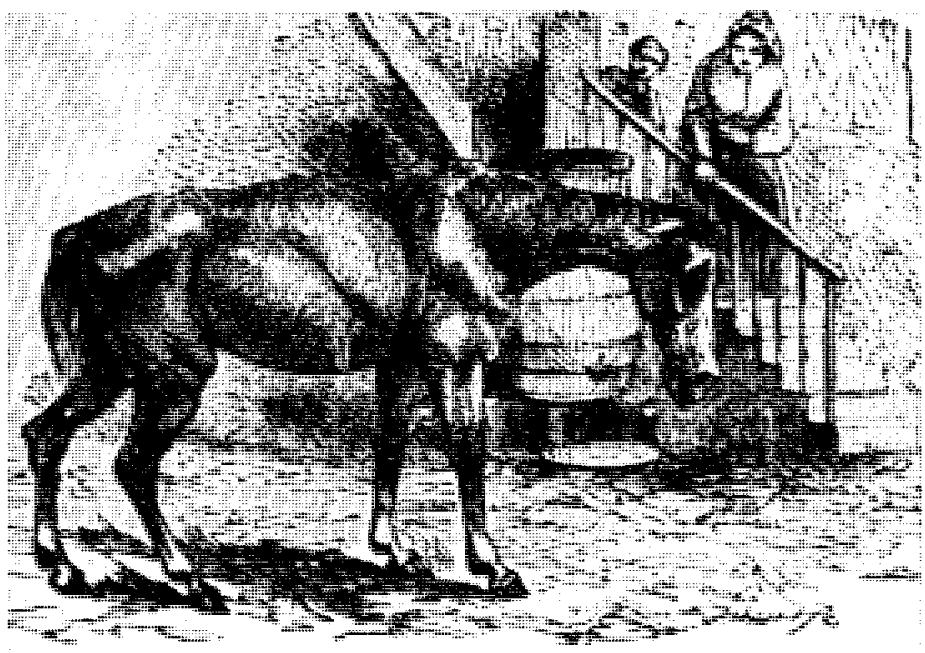

Colic was perhaps the most common complaint of horses when most of them were over- or underfed - and their demise was not infrequently hastened by harsh treatment, especially at the hands of farmers and com. mon farriers. Manning: Stock Doctor and recipes, just so long will their readers be kept in ignorance of any knowledge based upon scientific or philosophic truth. . . . Disease in animals as well as in man, if treated successfully, must be treated according to its true pathology or symptoms and their causes. . . . Only in this way, may we hope to arrive at any satisfactory results, in diffusing through our agricultural press knowledge in reference to the treatment of diseases in the lower animals, which can have any claims to safety or utility.

By a curious coincidence, perhaps, the two communications placed on either side of Wood's letter of rebuttal offer too stark a contrast to pass unnoticed. One is entitled "Cure for Colic in Horses," the history of the case being that the horse in jeopardy:

manifested all the symptoms of a severe colic. I gave him a dose of ginger, whiskey, oil, laudanum, spirits turpentine, altogether a pint, but it had not the desired effect. . . I determined if there was virtue in drugs, to give him a kill or cure dose. Accordingly, I doubled the quantities . . . [and] poured them down his throat. . . To may surprise, in the morning I found him alive... but very weak.

The other entitled "Horn-ail and Hornboring," states:

The one of these is a disease wholly imaginary, and the other is a relic handed down to us from dark and barbarous ages, and it is no small pleasure, (being a sign of better days to come for poor suffering animals) to see that they are both undergoing very severe treatment under the hands of V. S. George H. Dadd. ... Fortunate will it be both for cattle and their owners, when this deep rooted error about horn-ail shall be cast out, and its place supplied by more correct ideas of disease.

The equivocal position of the agricultural editor could, perhaps, have been minimized if some of the retrograde contributions, which were contrary to the stated objectives of the journals, had simply been printed, even without protest. But some of these atrocities were reprinted as editorial contributions. Thus in 1859: "From the letters of our correspondents we condense several valuable recipes, and present them in a single article." Included in this "condensed cow cure" is the boiling water for hollow horn originally printed in 1856. And while this had evoked no protests earlier, a second printing apparently was too much for one subscriber who wishes "to enter his protest against the ignorance and barbarity exhibited in the 'Cure for Horn Ail, or Hollow Horn,", and deplores:

the authority of the usually correct County Gentleman, for such a barbarous treatment.... I know that in the hurry of making up a paper, many things will be published that should have been thrown into the waste basket, but I was surprised to see the "Gentleman" Iending its 
voice and influence to extend and perpetuate such thorough-bred quackery and cruelty.

There is no intent here to single out any one paper for censure; the editors of other agricultural journals were equally guilty, but in this particular case the editor had expressed resentment over another journal saying about the same thing concerning the removal of wolf teeth. As noted elsewhere, however, the Country Gentleman was less an offencler in the matter of publishing these barbarisms on animal disease than were a number of other journals.

Among items of some interest in the late 1840 's is the mention of use of a tarred rope to relieve choke in cattle. A Maine farmer "has used it for thirty years, both for himself and neighbors, and has in no instance failed in relieving the animal without occasioning the least injury." Other cattle problems included a disease of milk cows in Massachusetts in which they: "had a propensity to eat bones - they became weak and their bones would sometimes break in trying to rise." The disease was attributed to a mineral deficiency, and was cured by feeding bone meal. A more mysterious malady, designated as a "new disease" by a physician, is stated to have occurred in 1838 and again in 1846 . Upon post-mortem examination, it was found:

Nearly all the blood in the body, by some unknown process, had been suddenly transferred from its natural receptacles into the intestinal tube. . . Many deaths of the same kind occured in the town of Rye [New York].

The farmers suspected deliberate poisoning, but the physician thought this: "a suspicion far more harassing and vexatious to generous and worthy minds than the loss of property itself." And to "dissipate this delusion, so fraught with mischief to society," the physician assured them, "no human agency could have had any share in the matter."

\section{Christian Cattle}

A native son of Kentucky assures us in 1849:
Our climate is favorable for breeding and rearing cattle. They are free from any marked disease. I have never known an epidemic among them. . . Cattle of Ohio and Indiana are not so healthy. . . . I was told by a Cincinnati butcher, who supplies with beef a portion of the Jews of that city, that he was compelled to procure his cattle for those people from Kentucky. The Priest sticks the animal, which is dressed in his presence by the butcher. Upon opening the animal, if any imperfection of the intestines is visible, such as blisters on the liver, \&c., the Priest remarks, "this one may do for the Christians, but will not do for the Jews you must bring up another." The cattle of Kentucky have no blemish: the intestines are in a perfectly healthy condition; so we, only, can supply the Cincinnati Jews with beef.

The writer, Lewis Sanders, had introduced improved cattle in Kentucky in 1817, and he gives a fascinating history of the Kentucky cattle industry dating from Revolutionary times.

Sheep, as well as cattle, suffered from the more common diseases as much as ever. In 1845 , a Kentucky "grazier" in contesting with another writer, claims in regard to "Foot-rot (so called) in Sheep":

there is no such disease of itself. . . . It is invariably the result of the neglect of another disease, simple and easy to cure. ... It is not contagious, neither can it be communicated by inoculation.

This in turn stimulated a number of writers to contradict this observation. One correspondent states that foot rot was introduced into Vermont about 1826 with some imported sheep, which were added to a native flock, whereupon:

The foot-rot spread with great rapidity through the whole flock. This was the first time I ever saw the disease, or heard of its being in this country. Nor did this infectious disorder stop with this flock; several others became infected with it by being driven along the road where the lame ones had previously been driven, much to the annoyance of their owners, who at that time knew nothing of the disease or its remedy; consequently great losses were sustained before they could get rid of the detestable plague.

A solution of iron sulfate, copper sulfate, and alum in strong tobacco water applied 
after carefully cleaning the feet was found to be a dependable remedy.

It seems unlikely that the infectious nature of foot rot would escape notice, and our Kentucky grazier may have been troubled only with injuries, or stoppage of the secretory duct between the claws. On sheep scab, he states:

That it is infectious there is no question, and consequently every shepherd should be very careful to remove the infected sheep from the rest of the flock the moment he is discovered. In its incipient stage it is easily subdued, but if allowed to take root without applying a cure, it is very difficult to get rid of. There is no excuse for a shepherd who understands his business, allowing it to make any headway, because the symptoms are so evident, that they cannot pass unnoticed, except from palpable and unpardonable neglect, or from ignorance.

Strong tobacco water and brine, vigorously scratched in to the fleece, he says, is an effective cure; mercury ointments recommended by many writers in the journals, can be:

certain death to the animals ... such ointment will cure the disease, yet the remedy is as bad as the disease itself, for it renders such portion of the fleece worthless.

\section{Encephalomyelitis}

In July and August of 1846:

more than 500 horses died on Long Island . . . from an epidemic, which seems to have been of a malignant character. No satisfactory cause has yet [October] been ascertained for the disease, nor any successful mode of treatment discovered.

The Michigan Farmer for December, 1846 gives more details of this outbreak, and states that some parts of New England were also affected:

Within 10 miles of the Union Course, Long Island, not less than 300 horses died in three weeks! The disease affects particularly the brain, the horse becomes stupid, rests his head against something or leans to the side of the stable, or against a fence or tree for support; in a few hours he falls, and dies after a day or two, apparently exhausted. A similar epi- demic prevailed upon the same ground in the fall of 1828, which was equally fatal.

This description suggests that the disease was encephalomyelitis, or "sleeping sickness."

An outbreak of "horse plague" in Kansas and Nebraska in 1912 was identified as forage poisoning, or "so-called" cerebro-spinal meningitis, but has been since identified as encephalomyelitis. In September of that year, A. Bostrom, State Veterinarian of Nebraska reports:

The epizootic disease among horses in $\mathrm{Ne}$ braska extends over two-thirds of the state. . . We know absolutely nothing concerning the nature, cause, treatment or prevention of this disease. The disease is very fatal, not more than $5 \%$ recover.

Investigation by the Bureau of Animal Industry showed that mouldy or damaged feeds, as a result of an excessively damp summer, were the exciting causes.

A. T. Kinsley reports seeing 400 cases and autopsying 40 . He notes:

The extent of the losses from this disease has been exaggerated. In the territory where the disease was most prevalent it appears that less than 40 percent of the horse population died. ... The press apparently did injustice by their startling statements. . . The people in Kansas particularly were almost panic stricken, due largely to the press notices.

Without depreciating the importance of the disease, J. R. Mohler of the Bureau of Animal Industry observes:

Its appearance in America is by no means of recent occurrence, for the affection was reported by Large in 1847 and by Liautard in 1869 as appearing in both sporadic and enzootic form in several of the eastern states. . . It is prevalent with more or less severity every year in certain parts of the United States ... in 1882 as well as in 1897 the horses of southwestern Texas were reported to have died by the thousand, and in the following year the horses of Iowa were said to have "died like rats." However, Kansas seems to have had more than her share of this trouble, as a severe outbreak that extended over almost the entire 
state occurred in 1891, while in 1902 and again in 1906 the disease recurred with equal severity in various portions of the state.

As has so often been the case, hordes of quacks descended upon the hapless horse owners, promising to cure they knew not what with whatever they may have had at hand. Mohler observes:

One of the most unpleasant developments at the outbreak this year was the great amount of "faking" which seemed to be the only contagious feature connected with the disease. All kinds of drug specifics, serums and vaccines developed like mushrooms and were exploited in almost every commuiity devastated by the disease. Many tainted dollars were obtained from the suffering horse owners who grasped at every newly advanced treatment like drowning men clutching at straws. ... In Nebraska, blackleg vaccine was reported to have been used as a preventive on at least 1,600 horses and nearly 1,500 of them are said to have died as a direct result of the vaccine.

In 1846, in Clinton County, New York:

a disease that many horses were troubled with the past winter in this and the adjoining counties ... did not prove fatal, but produced abortions in mares in every case.

Horses as well as mares were affected, the symptoms being stiffness of the legs, running of the eyes, inappetence, and loss of flesh. Abortions frequently did not occur until some time after recovery.

\section{Horse Doctors vs. Horse Diseases}

That the equine population suffered as much from horse doctors as from horse disease is suggested by the rash of itinerant neurotomists which appears to have hit Ohio in 1848. In expounding on the value of agricultural papers, the editor of the Albany Cultivator says:

A correspondent of the Ohio Cultivator, states the case of a farmer who lost $\$ 150$ by neglecting to take that paper. He had taken it formerly, but concluded that he could do without it. After he had discontinued it, certain practitioners of Neurotomy on horses were traversing that State, and the paper cautioned the farming public repeatedly against the practice. But this farmer did not see these cau- tionary remarks, and suffered two fine horses to be operated upon, paying him ten dollars, which resulted in the entire ruin of his two horses.

The obvious moral was: "Farmers must not expect to be guarded against impositions, unless they inform themselves."

The following year an Ohioan states:

The operation of Neurotomy, as described in Skinner's Youatt, has in every instance, in this part of the country, proved fatal. Thousands of dollars worth of horses, operated on, have been lost. ... In June, the hoofs of some of the horses operated on, literally rotted off, while the animal, insensible to pain, continued to stamp the lacerated and denuded stumps on the ground, to drive away the flies, which bit it above the point operated on.

More or less as a defense of Youatt, the editor quotes him to the effect that the most strenuous defenders of the operation:

cannot deny that the horse will batter and bruise that foot, when he has lost sensation in it, which should have been tenderly used; that even the hoof will sometimes be lost, after operations performed with the greatest judgement; that the lameness will sometimes return after the animal has gone sound, one, two, or three years ... [and] that the horse is more liable to accidents.

Many animals during this period received no veterinary attention of any sort. The editor of the Cultivator states:

Perhaps there is not a greater loss of cattle in this country, from any one cause, than from the complaint known as hoove or blown. ... As to remedies, many of our farmers never use any - the animal is often left to itself - if it recovers, the owner is satisfied; if it dies, he has the hide.

\section{And as might be expected:}

The diseases of poultry have seldom received attention in this country, from persons qualified to treat them judiciously. The management of this interesting and useful description of farm stock, both in sickness and health, is usually entrusted to children, or persons who are incapacitated for other business. The consequence is a general ignorance of their peculiar natural habits, as well as their diseases. 


\section{Piercing Inquiry}

Ohio appears to have attracted a number of veterinary practitioners by the late 1850 's, if the number of contributors to the Ohio Cultivator affixing the "V.S." after their names is a criterion. How many of these may have been graduate veterinarians is a moot point; in general, their writings speak for their qualifications. In one of a number of items communicated by him in 1857 , W. Pierce, V.S., states:

We have been called to witness a singular disease among the cattle in this county - a disease that never appeared here before. It is called the black leg by some authors. . . . I think it might be called the black foot, as the toe of the foot appears to be the first part affected, and the end of the tail is affected in proportion to the progress of the disease. . . The affection appears to work back along the sole of the foot, and cracks at the heel. . . . The disease has prevailed in certain sections of the States for several years... [but] no one as yet has been found who knows anything about it, or any remedy for it. . . I I think it high time to investigate the matter, when a good farmer must lose his stock of cattle, without being able to get any information with regard to the disease or its remedy. It is highly important, and should engage the attention of every Veterinary Surgeon in the United States.

\section{The editor states:}

Wherever this disease has occurred, the animals were known to have fed on hay that was spurred, and this has always been assumed as a cause of the malady.

Two months later, Pierce writes:

The cause appears to be settled among us, and all who have thoroughly investigated, now agree with friend [editor] Harris's remarks on our first article. We have examined most of the cases in Portage county, and find without exception the ergot or spur, where we find the disease.

He mentions having made a postmortem examination:

assisted by P. C. Bennett, M.D. . . W We have purchased five head of those diseased cattle, for the purpose of experiment ... [to] enquire if this ergot affects the animal, and how ... [and to] discover an antidote and a correct treatment in the several stages of the disease.
Evidently some farmers in the area had a good concept of contagion, if not of the cause of this particular disease, for Pierce relates:

Where this disease exists among cattle, some consider it an epidemic, and highly contagious. They refuse to drive cattle along the road where it is known to exist. Some will wash their boots if they tread on the yard of the sick, before entering their own yard.

Pierce traced the source of "contagion" in two herds eight miles apart. One farmer had bought half the other's hay, and "the ergot or spur was abundant in said hay. .. . All the cattle that eat of that mow of hay are either dead or badly diseased."

Later, Pierce reports on his experimental animals:

three head were hopeless ... two ... not so bad. . . . I commenced treating them all with diuretics and alteratives, medicines internally, and applying antiseptics to the lame feet. ... The cattle all soon exhibited a favorable change ... after treating them ten days. ... Nearly all lost one, and some both shells of the hoof off one foot, but not until a new one had nearly grown out.

It has been stated ... that the ergot is the cause of cows casting untimely calves. - This is not my experience; on the contrary, all the calves of such diseased cows appear healthy although not strong, and have taken the milk up to the time of the death of the mother. ... Many new ideas have suggested themselves to me while treating the above cases.... Some of us, if not all, are certainly behind the times. This matter should have been settled years ago.

In an attempt to catch up on things, Pierce evidently read many medical texts, and in a later communication he presents an elaborate theory of the mechanism of ergot poisoning; despite some flights of fancy, he does, however, quite correctly attribute the gangrene of the extremities to a "stagnant circulation."

\section{Pox Prevalent}

The following year Pierce writes on "Cow-pox and Scrofula in Dairies," and says: 
It is seldom in a large dairy that these diseases do not exist to a greater or less degree; and if one or more is affected, the virus by the hand of the milker is conveyed to all the rest. The practice of milking with a hand wet in the milk is much followed, and by this practice, inoculation is almost certain.

By "scrofula" Pierce means "hard tumors under the skin of the legs, neck, belly and bag," but does not elaborate on the matter. He adds:

Dairymen also suffer loss from an unhealthy condition of cows in the winter. If they become debilitated, hidebound, bleary-eyed, cold horns, cough, shake the head, grind the teeth, do not ruminate, and become constipated, they are said to have the hollow horn and tail; their horns are bored, the tail cut off, and some application made, and called cured. . . . The cows poor and scabby, sore teats, ugly and cross, the owner wonders why he can't make more butter and cheese, and says it is all in the season ... but perhaps the fault is, he does not understand making good milk. . . . The fault was in the milk, and the cause in the cows.

The American Agriculturalist for 1856 reprints an article by Pierce on milk fever in cows, from the American Veterinary Journal. In this, Pierce says:

This clisease appears to increase both in prevalence and fatality. A few years ago its occurrence was so rare, that it was not investigated, neither was it then so fatal. It is now so common on the Western Reserve, or Northern Ohio, that the dairy men begin to fear sad havoc amongst their cows.

Noting that it is most common in high yielding cows, some now giving 25-35 quarts daily, he states:

This enormous flow of milk overtaxes the system at a time when the animal is under the influence of reproductive excitement. . . . I have never known a poor milker... die of milk fever.

A cow that recovers "is seldom worth keeping, as she would be liable to have it again next year. All such cows should be fattened immediately, and disposed of."

\section{Shadow and Substance}

Another practitioner who makes numerous contributions to the Ohio Cultivator at this time is T. Webb, V.S., of Zanesville. A note on "Lampas in Horses" was occasioned:

by passing a blacksmith shop, and seeing a horse refuse to submit to the barbarous operation of having the lampas, as it is termed, burned out. . . The practice of burning out lampas has received the seal of the ancients, but, I trust, in this age of progression, such ancient barbarities will be superceded by practical science.

He suggests that astringent mouthwashes will be adequate to reduce the tumified palatal mucosa.

In writing on the "Treatment of Disease in Horses," Webb makes a plea for more enlightened attention to this matter:

Most works on farriery pretend to the idea that any person reading them may undertake

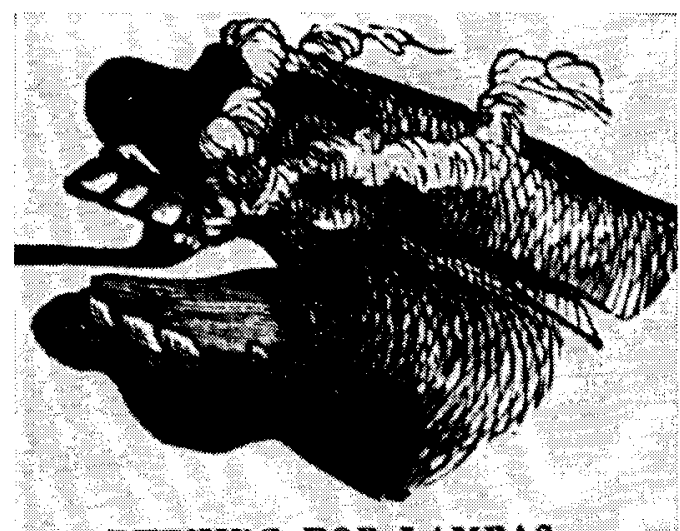

BURKMA FOR LAMP 48 .

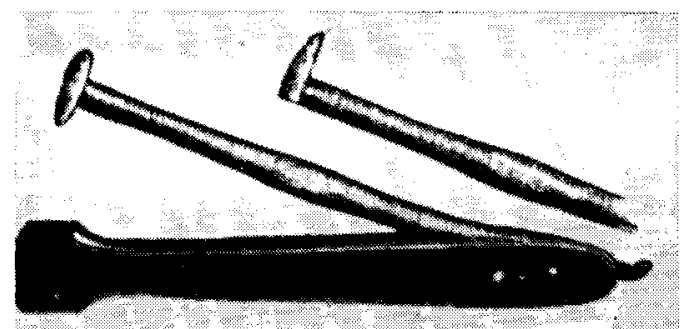

Fo, 41 - -Lancet to Whem at the Palate

Lampas (tumified palatal mucosa), long an imaginary "disease" of horses, was "cured" by bleeding or cautery, both of which methods had their strong adherents. The condition, still seen in young horses, is a physiologic engorgement of the palate. Manning: Stock Doctor 
the treatment of any of the serious diseases the horse is subject to. This is a grevious error ... the lives of our superior horses are frequently sacrificed by such false illusions. . . . To scientifically treat disease, the practitioner must be skilled in anatomy and physiology; without that, we exhibit the shadow, but hold not the substance of pre-eminence.

In speaking of the differential diagnosis of abdominal complaints of the horse, he says:

How frequently have the owners of stock witnessed the above symptoms, while every looker-on, without any medical knowledge, and merely by a cursory view pretends to understand the disease, and prescribes accordingly. Will those would-be oracles prescribe for their families while laboring under the same disease? I think not.

And in a lengthy article on "Lung Fever," he concludes by saying: "Enough has been said to satisfy the owner of valuable stock, that none but scientific practitioners should interfere with it."

Wolf teeth and "hooks" in horses were as much a problem in Ohio as elsewhere, and the Cultivator for 1857 carries an article on these by C. M. Wood, V.S., which had appeared in the American Veterinary Journal. In this he states:

The Editors of certain newspapers in various parts of the country, are accustomed to publish occasionally, recipes in their papers for the cure of diseases in animals. In almost every case, such publications tend to do more harm than good; for diseases are liable to be mistaken, and a remedy for one disease may prove the reverse for another. But supposing the disease to be accurately ascertained, in too many instances the remedy proposed is worse than the disease.

Wood goes on to deplore the practice of knocking out wolf teeth and cutting out the "hook," which, he says, should be spelled hoax. The editor apparently was broad minded, for in an earlier issue he had printed an article on wolf teeth in which the correspondent states:

I have had occasion to examine some 20 or 30 horses that had the Wolf Tooth, or more properly the blind tooth, and have always saved the eyes of the horse, if the tooth was knocked out in time.
The editor, however, on being asked for a cure for hollow horn, recognizes this as "a collateral development of some other disease," and quotes from Dr. Robert Wood's article in the American Veterinary Journal, to the effect that the problem is usually one of catarrh. In deprecating the usual practices associated with hollow horn, Wood says:

It is a too common practice of owners of neat cattle, to dose them when sick, regardless of what the disease may be, with heterogenous compounds, the virtues of which they know but little. Ancl it is not unfrequently the case, that the animal becoming worse instead of better, uncler the treatment, that a veterinary surgeon is called, who upon examining his patient, finds it difficult between the signs of the disease and those produced by the remedies that have been employed, to form a correct diagnosis of the case.

Unsatisfied, however, the editor adds:

Mr. Wood does not tell us how this disease is to be treated, but hints that a regular practitioner should be consulted; which is all well enough where there is a Veterinarian fit to be trusted. But unfortunately, we have in this Western world but few such, and those who make pretensions to skill in such matters, are, with a few honorable exceptions, for the most part, a set of butchering quacks of the most abominable kind.

To save the farmer from these, Dadd's treatment of catarrh is given. Robert Wood was a brother of Charles M. Wood, and like his brother, also served as an early president of the United States Veterinary Medical Association after it was organized in I863.

\section{THE NEED FOR VETERINARY EDUCATION}

Some interest in the possibility of establishing a veterinary school continued to be demonstrated throughout the 1840's, but the thinking of one writer in 1847 suggests a reason for talk not being translated into action. In describing a visit to the Royal Veterinary School at Alfort, France, this "practical man" mentioned the low rate of tuition, the low charges for services to clients, the "practising [ of ] occasional ex- 


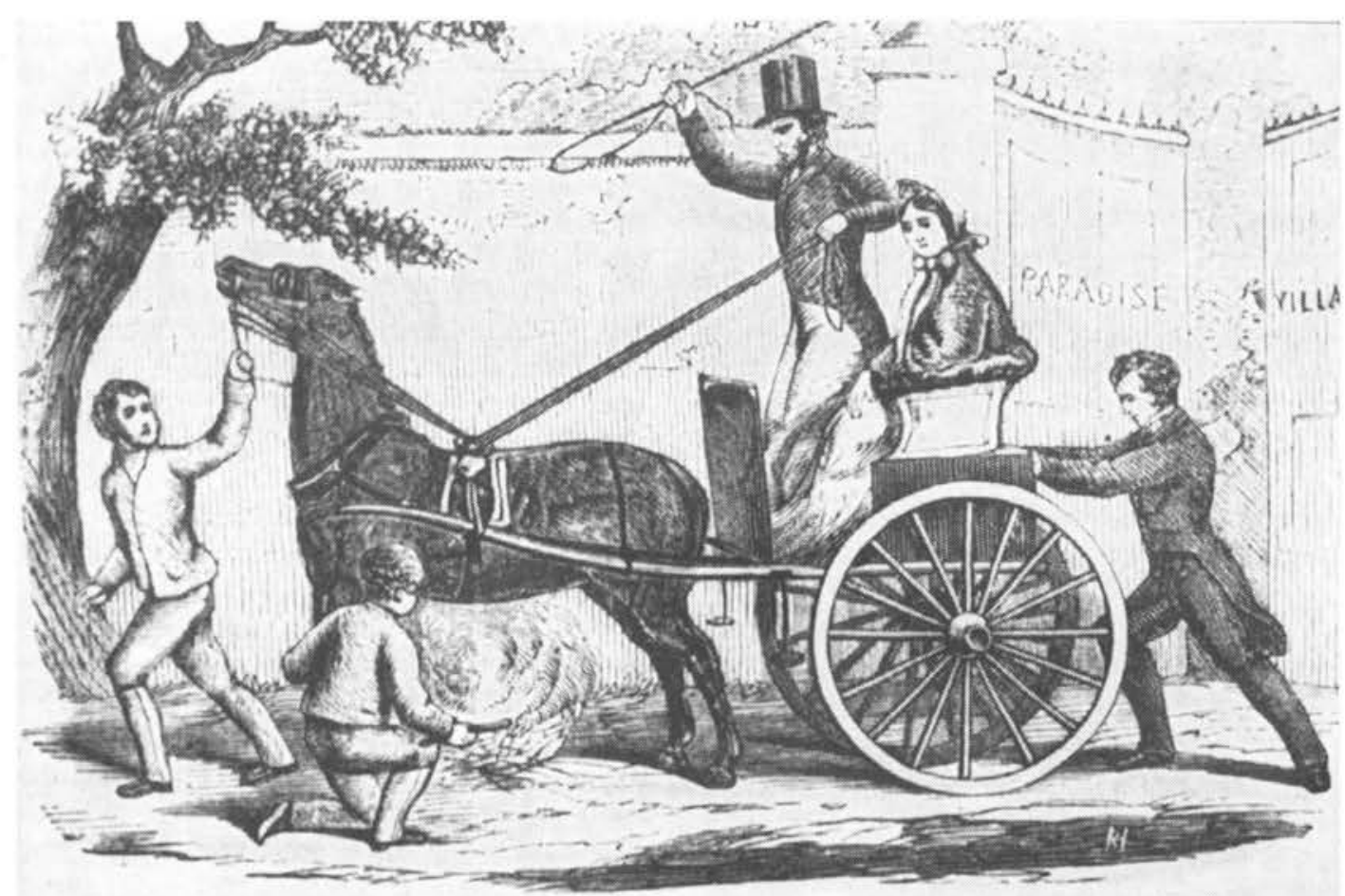

A reputedly common problem, "jibbing," cured in this way undoubtedly gave rise to the ageless story of the balky animal who, after having a fire started under it, moved just far enough forward to allow the carriage to burn up. Mayhew: Horse Doctor

periments," and "a miniature park for the recreation of the pupils," (who literally led an intramural existence). He says:

These things together make up an institution, which is an honor to the country, and which, for the present, at least, we must content ourselves with admiring, without imitating. For if tried by the test, to which every thing of a public nature must be submitted in our country, it will be found that the veterinary school, like the garden of the Tuilleries, and the fountains of Versailles does not pay. That is to say, receipts in money do not balance the outlay of money. Whether increased inquiry. and stimulus to inquiry, do not more than make up the deficit on the balance sheets, is a way of considering the question, too heretical to be for a moment indulged in.

One scheme, designed to keep the cost of instruction at a minimum, was advocated by the prominent agriculturalist, Henry Colman, in 1845. For a proposed agricultural school in New York, he thought:
One or two instructors should be employed constantly for teaching the main branches of education, and a competent farmer should be employed to manage the agricultural department, and to give the necessary practical instruction. Beyond this, no resident instructors would be required,- but regular and full courses of lectures and experiments in geology ... comparative anatomy, the veterinary art, [etc.], by competent professors of these sciences, who might be employed for these objects annually, without the necessity and expense of constant residence, - as is now frequently done at our medical schools.

The latter, of course, is currently done at medical and veterinary schools, but not as a substitute for a regular faculty.

In an apparently extravagant vein, the trustees of a proposed "Peoples' College" in western New York proposed in 1859: "the endowment of nineteen Professorships; among which are: Anatomy, Physiology and Veterinary: Natural History; Chemistry." 
It would appear that this specious mode of "Practical" thinking was the real barrier to the establishment of publicly supported veterinary schools. Men like this could envision an agricultural institution as a "labor school" which could be conducted with little outlay of hard cash. It is perhaps just as well that these individuals did not envision an apprentice type of veterinary training such as was suggested in the proposal for an agricultural school in New York. But as later experience was to demonstrate, the establishment of corporate veterinary schools, where a primary desideratum was that it perforce be conducted at a profit to the proprietors, was an equally poor substitute for schools sufficiently well supported to provide for experimental inquiry and at least a modicum of the niceties of living. Schools conducted for profit may have fitted their students for communion with the sick animal, but could not hope to fit them equally well for coping with the scientific and cultural adjuncts to professional life.

The efforts of well-intended persons at this time, however, should not be clisparaged, for there were those who undoubtedly saw the need for the kind of instruction which experience has dictated as being essential. Particular credit is due the State Agricultural Society of Massachusetts, which appears to have been the first body to have taken overt action on this matter since the short-lived attempts of the Philadelphia Society for Promoting Agriculture early in the nineteenth century. As reported in the Cultitator, the Massachusetts Society in 1846:

has taken active measures for the promotion of knowledge in reference to the anatomy and diseases of animals. They have purchased in Paris, at a cost of $\$ 800$, a figure of a horse of full size, so constructed that it may be taken to pieces, and will accurately represent the muscles, blood-vessels, heart, lungs and other organs, of their natural size and appearance. They have also directed the preparation of fullsized skeletons of the horse and ox. They have engaged Dr. Brooks to give a course of lectures on the diseases of the horse which it is expected will be given next winter.
The legislature of Massachusetts also gave some thought to the need for veterinary education at this time, but as a discipline in a school of agriculture rather than as a separate institution. A lengthy report of European schools, and a plan for a school in Massachusetts, drawn up by President Hitchcock of Amherst College, is given in the Cultivator for 1851. Certain of his general observations might well have been noted by those who were later to be concerned with establishing the system of veterinary education in this country. Thus the validity of his first conclusion: "That these schools usually fail, if they do not receive efficient aid from the government," was to be amply demonstrated later by the wide-scale failure of private veterinary schools, both academically and financially.

Secondly: "Agricultural professorships, in colleges and universities, are not suffcient"; they would attract too few students, and those they did would not fit in - one group or the other "would feel no pride in the institution." Inasmuch as Hitchcock envisioned veterinary professorships in an agricultural school, it is obvious that it did not occur to him that exactly this same thinking would apply. Those who advocated veterinary teaching as a minor adjunct to medical or agricultural schooling little realized what species of step-child they would have created. Hitchcock's plan included:

lectures and recitations in ... Anatomy and physiology, human and comparative ... Veterinary medicine and surgery ... A museum of human and comparative anatomy, including a manikin ... [and] a scientific and agricultural library.

A professor of "Anatomy, physiology, and veterinary medicine, and surgery" was to be one of the six instructors necessary.

In urging the establishment of an agricultural college the editor of the Cultivator, in 1853, states, concerning Veterinary Surgery and Pathology:

The importance of instruction in this department is too much a matter of every-day experience to demand explanation. Lectures on 
animal physiology and anatomy, illustrated by skeletons of the domestic animals, and giving a synopsis of the diseases to which they are subject, with the best modes of treatment, are quite indispensable to such an institution.

Ample gratification, presumably, was afforded by inclusion of the following courses in the first prospectus of the New York State Agricultural College in 1860: "Outline of Comparative Anatomy, Principles of Veterinary Practice, [ and in the last term ], Veterinary Practice."

\section{More Harm Than Good}

Until we have competent veterinarians, says the editor of the Cultivator:

Having seen a great deal of doctoring for sick animals ... . we have long since come to the conclusion that the most skillful physician we have ever met is Doctor Nurse. If an animal it not carefully taken care of - nursed all the medicine in the world can do but little good. And, on the other hand, with good nursing, medicine is generally unnecessary. ... In at least nine cases out of ten, as commonly administered, medicine does more harm than good. . . The majority of sick horses get well; every owner tries some remedy; and that particular medicine that he happened to be using at the time, gets all the credit - although as a general thing it retarded more or less his recovery.

What he fails to mention, however, is that he - along with the rest of his fraternity printed all sorts of "infallible cures" from correspondents without comment, and - as he says - many did more harm than good.

In 1855, the Ohio Agricultural College at Cleveland announced its second season, with "instruction given in lectures, as in Medical Colleges," to include: "Comparative Anatomy and Physiology ... [ and ] Veterinary Medicine."

The Country Gentleman in 1853 offers a plan for an agricultural college, for which:

The course of study may be divided into four departments, as follows:- Practical Agriculture ... Natural Science ... Mathematics ... Veterinary Surgery and Pathology.

The year following, however, the editor thought a veterinary school as such was needed:

In some respects we must acknowledge that ... we are still behind some of our European brethren. For example, almost every European State has its School of Veterinary Medicine and Surgery. . . America has been even slower than England in this respect, and, except that a school has been lately opened at Montreal there is not one, (save perhaps a private one superintended by Dr. Dadd of Boston,) in the whole Western world. Some are yet in doubt of their utility. When Americans become thoroughly convinced of their utility and of the fact that they will pay, there will be no want of them any longer. And we think a great amount of advantage might justly be claimed as due to them....

They have so enlightened the community as to have swept ruthlessly and for ever away, as medicaments, the whole heap of "compound powders" that have been so long employed by farriers and which to druggists and other vendors constituted so profitable an article of commerce. . . They consisted of about one part of the genuine root or seeds, mixed with four or six parts of bean or pea meal or ground linseed cake, colored and scented secundum artem. The banishment of such impositions is one of the benefits derived from veterinary study, and schools. . . .

The lancet, also, is less used than formerly, and only when absolutely necessary. It is well established that it is folly to waste, and wisdom to husband the powers of an animal. Periodical bleedings, once so customary, are now shown by a better knowledge of animal physiology to be utter folly and injury. Violent purging, too, is discarded, and cathartics are now rarely administered, as formerly, at stated periods. The rowel has given place to the seton, and less irritating agents are resorted to for blistering. In short, science and common sense are beginning to banish the ignorance and quackery of old farriery.

This concept being novel to most Americans at this time, the editor might be forgiven for having, two weeks eariler, advised a correspondent who asked for a remedy for the blindness caused by wolf teeth: "The teeth should be removed as soon as they, or their effect on the eyes, is discovered, when the blindness will cease to increase." In all fairness to the editor, Luther Tucker, it should be stated that this 
item is something of an anomaly among his offerings on animal disease.

In a feature article on "Diseases of Animals often caused by Mismanagement," it is stated:

One can hardly spend a few hours on a well traveled road, or in a village thronged with teams, without witnessing such treatment or rather mis-treatment of animals as must result in producing great discomfort and suffering, if not actual disease. For want of judgement or want of consideration and proper feelings, there is everywhere to be seen quite a painful amount of negligent, improper and cruel treatment of domestic animals. Perhaps veterinary practitioners more frequently see cases of disease from such treatment than from all other causes combined.

\section{HUMANITY AND HOMEOPATHY}

The subject of cruelty to animals was occasionally referred to in the agricultural journals, and it may be supposed that these papers had some effect in bringing about a general elevation of public attitudes on the matter. A correspondent in the New England Farmer for 1839 states:

The way to overcome ... [ the ] propensity to inflict cruelty upon domestic animals, is to enact no laws upon the subject, but to spread abroad a salutary influence in the community by persuasive means.

\section{In 1840 the Farmer states:}

For mercy's sake, in this hot weather, deal gently with your oxen. ... There is nothing lost in being reasonably merciful to the brute. On the contrary this is true policy, as well as a dictate of genuine humanity. He who would overtax or abuse a faithful ox or horse, deserves to do his own pulling and trotting, without the aid of these noble servants.

And in a lengthy editorial on "Mercy to Cattle," the editor, Henry Colman, suggests that the farmer's dreams:

should not be disturbed with the ghosts of half-starved cattle tied to their stanchions, so near to a mow of good hay that they can just touch it with their tongues but not extract a lock; and with the images of barn-floors, through the cracks of which the wind blows a gale; and poor shivering cows and horses lying down in their own ordure, which has not been cleaned out for a week, and with piles of snow around and over them in such abundance as to give the stable little preference over the open yard. We pity such a man because he is destitute of the best feelings of a man; but we pity his cattle still more. . . The better care you take of them, the better care they will take of you.

Apparently the "fashionable operations" on horses had been done with decreasing. frequency in the 1830's, but in 1841:

We are sorry to percieve that the barbarous, cruel, and injurious practice of docking and nicking horses is again beginning to be looked upon with favor, after some years of merited disuse. - We wish to enter a decided protest against the system, as injurious to the horse and offensive to good taste. . . None but a narrow-minded, ignorant man, would have in the first place ventured on such a violation of vested rights; and none but blockheads or jockeys, destitute of the better human feelings, could have perpetrated or tolerated the invention.

\section{Barbarism Bared}

On seeing a docked horse tormented by flies, he admits:

We have almost wished that the perpetrator of the outrage, in a state of nudity and his hands tied, could be placed in some of our swamps, for half an hour.

And on the neglect of swine, a correspondent states that despite some of their less than noble traits: "I certainly would not have them excluded from the pale of humanity simply because they are hogs," and suggests that there should be in each town a "Society for ameliorating the conditions of Swine in winter."

In a more specific vein, in an article in 1840 upon "The Treatment of Sick Animals," it is stated that many "unnatural and injurious practices" are perpetrated upon sick animals:

who, if they had tongues to speak, would tell sad tales of the wrongs to which they have been, and still are, subjected. . . . We would insist, that when an animal is well he never requires any medicine... and when he is sick . . always mistrust the man and the remedy, when your friend declares that an article is always good or a certain cure for a disease, without reference to its symptoms - prescribing for the name of the disease, rather than the disease itself: this is the very essence of quack- 


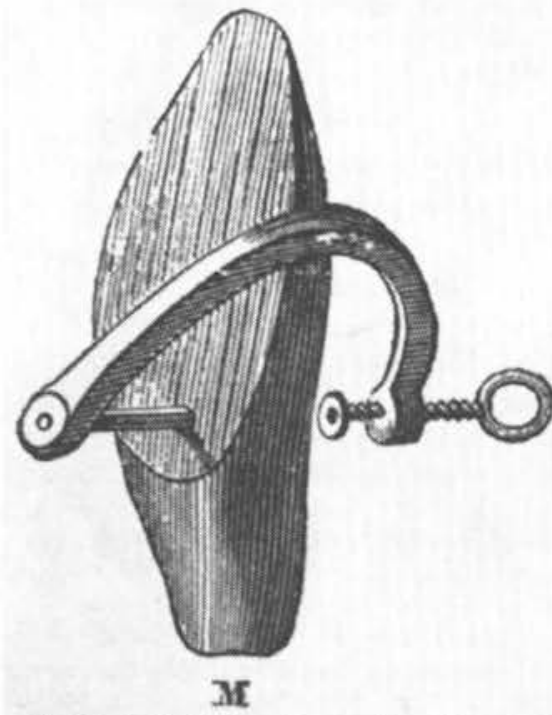

Fras. 562, 568. -Brognlez Apparatus for Amputation of the Ear.

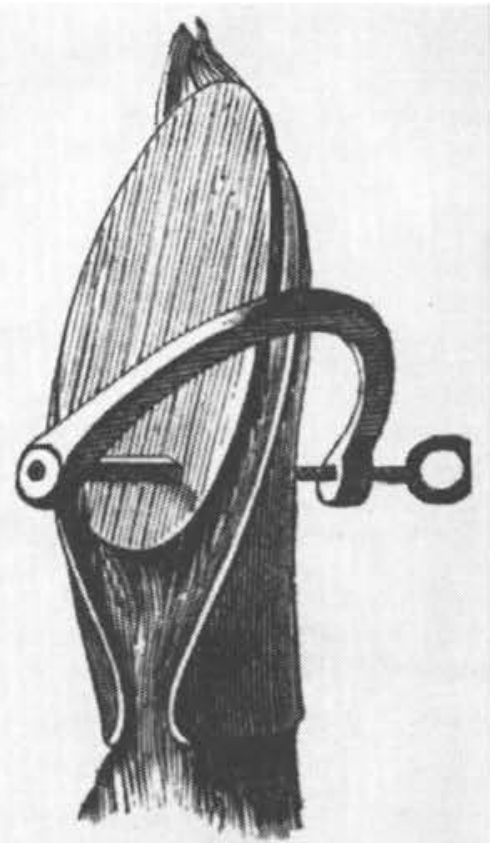

Fra. 554.-Apparatus of Brognlez in Position.

Ear cropping, along with tail bobbing, was a common cosmetic operation on horses in some areas during the nineteenth century. Liautard: Surgery

ery, in man or beast. .. There is never occasion for the administration of the disgusting combinations which the poor animal is made to swallow, from the whim of an ignorant horse or cow doctor. Many a fine beast has been lost by its owner trusting to such prescriptions. . . . [We] have a powerful assistant in nature, if she is fairly used ... specifics, as they are called, are much fewer and less to be trusted than their proprietors would have us believe.

Later editors, who accepted advertising for all sorts of miraculous medicines for either man or beast - or both - had either not read this bit of philosophy, or chose to disregard it. In fact, this editor, along with his fraternity for more than a century, chose to disregard it in printing contributions from people unqualified to give advice.

And a correspondent to the Michigan Farmer, who identifies himself as "Farrier and Blacksmith," in decrying the use of blinders on horses, says:

Art never invented a more fatal thing to the eyes of horses than when she devised this plan of depriving the horse of what nature intended he should enjoy. . . . They gather dirt and heat around the eyes. Dirt irritates the eye and heat produces inflammation ... overexertion of the nerve soon brings on disease. . . B Blind bridles and disease are inseparably connected. Custom hoodwinks the senses of men, as much as blind bridles do the vision of horses.

In 1858, the editor of the American Agriculturalist protested:

Docking horses is bad enough, but docking cattle is worse. . . . The advocates of docking maintain that cattle need bloodletting every Spring. They say that the end of the tail becomes soft, and in connection with this, joints of the legs swell and become weak and tremulous, and that the only remedy is a cutting of the tail. ... Cutting off a cow's tail, to cure the Spring sickness! Why not as well cut off a man's leg to cure his chilblains? The practice is nonsensical and barbarous. . . We half suspect that one reason why hired men are so fond of doctoring cows in this way, is that the treatment saves them from many a brush of the tail during milking-time. 
A writer in one of our foreign exchanges speaks of this docking-mania as prevalent in England, and as mixed up with more superstition than here.... In some districts, farmers think there is witchcraft in the business, and practice "charms," as well as docking. They bind a twig of the rowan tree on the end of the cow's tail, and compel a black cat to pass three times around the cow, and over her back and under her belly, which so enrages pussy that she mews and scratches with great fury until she breaks away from the necromancers and runs off with flying tail, convincing all beholders that surely the devil has got into the cát.

\section{Homeopathy for Horses}

In the Cultivator for 1841 , a correspondent notes that his earlier statement "of the cure of dysentery and diarrheas, \&c. by homeopathic medicines":

was received, but could not be published, lest it might lead to controversy; that nothing should be admitted into the Cultivator, not strictly agricultural.

The following year, another correspondent joins with the former in regretting that the subject of homeopathic medicine for man should be excluded as foreign to the objects of the journal, but, perhaps believing in joining forces with those you cannot beat, he offers a brief for homeopathic treatment of domestic animals:

Deplorable as has been the condition of the healing art in relation to the human family, it has been still more wretched as applied to horses. The leading canon of the veterinary schools has been, that all the disorders of the horse tend to inflammation; hence inflammation must be checked by depletion; then, for all disorders of every name, copious bleedings, drenching, cathartics, and powerful diuretics, are indiscriminately recommended. In nine cases out of ten, the horse dies under the treatment, and the owner has the pleasure of paying a long farrier's bill, and the consolation of knowing that the horse died secundem artem. The great work of Youat is unquestionably the most scientific treatise that we possess on farriery; yet even in this, one cannot read three pages without becoming sensible that the writer knows little of the subject on which he is treating, and that the chance of saving the horse is as good, if left to the unaided powers of nature, as when treated on the most approved principles of the veterinary art. But Homeopathia offers to the proprietors of horses and cattle unfailing sources of relief and cure .... A homeopathic physician will think it no disgrace to exhibit the triumphs of his art even on a horse ... homeopathia is no humbug.

As proof of the efficacy of homeopathic treatment, the writer offers a case attended by Dr. Humphreys of Philadelphia: "at the request of $\mathrm{Wm}$. $\mathrm{H}$. Smith of that city, a graduate of the veterinary college of London." Humphreys states he had been called to see a horse:

laboring under a disease vulgarly called staggers (Phrenitis) for ten days.... I found the animal lying on the ground ... [ with ] every appearance of a speedy dissolution. Dr. Smith feeling assured that any means in his power would be unavailing, determined as a mere experiment, to try homeopathia, not dreaming of the least success.

One dose of belladonna, twelfth dilution, was administered, and the horse was on his feet in two hours. A total of ten doses at twelve-hour intervals "perfected the cure"; thus "a new and brilliant light has dawned on the paths of [veterinary] medicine." The twelfth dilution would contain about one part of the active ingredient in a trillion parts of water. Human beings at least had the advantage of being able to read the label so they would know what the medicine was supposed to do.

\section{The Humane Homeopathists}

Veterinary homeopathy enjoyed a brief period of popularity during the last half of the nineteenth century - being taken up belatedly and dropped with alacrity, by comparison with human practice - more or less as a protest against the harsh practice of the "regular" school. That the bleeding, blistering, and purging of the so-called (by homeopathists) allopathic school frequently did more harm than good can hardly be denied. But it may be doubted that the frequent doses of next-to-nothing of the homeopathists did much more good than 
nothing, and may have done some harm by depriving the patient of specific treatment when this might have been of some avail.

Dr. Humphreys' Homeopathic Remedies, already famous in the human field, entered the lists of veterinary medicine in 1860 with ten Veterinary Homeopathic Specifics with which all the affections of the animal kingdom could be treated. In the preface to the first edition of his Veterinary Manual (1860), Humphreys observes:

Ignorance and cruelty seem to have controlled this branch of medicine - not that men are of necessity careless in regard to the lives of their animals, or designedly cruel as to the measures used to restore then when sick; but so little real knowledge prevails concerning their diseases, and so much error as to the proper methods of cure, that the most absurd and cruel measures almost of necessity prevail, with corresponding results.

Some stock owners, he says:

have more humanely, if not more wisely, abandoned all treatment, preferring to let nature contend with disease alone, rather than with disease and drugs united. But, thanks to Homeopathy, there is a better way.

That the system had not yet found acceptance in the United States, Humphreys attributes to "the inherent intricacies of the system," which - of course - his manual was designed to obviate.

In the second edition of his Manual (1872), Humphreys notes that upon the introduction of his veterinary specifics, "there was a considerable degree of hesitancy and embarrassment in their use ... [ which ] has happily passed away." Perhaps this was because:

The doses have been rendered more uniform, and ten drops has been fixed as the standard for horses. . . . And such has been the demand for them that our Books have run out and the entire energies of the establishment have been taxed to keep up with the demand.

\section{By 1877:}

a demand for a yet more complete and comprehensive work has been created. The general treatment of the diseases noted in the previous editions has been preserved, only that the doses of medicine have been somewhat increased, to conform to more popular usage and the practice of many veterinary surgeons.

It may be presumed that this also resulted in the sale of more medicine.

In the fourth edition (1886), Humphreys reminds us that twenty-five years ago, when he had introduced his ten veterinary specifics:

Veterinary physicians in general were as crude as the people, giving the most abominable and deadly doses . . a legacy of the castoff and obsolete measures once resorted to in treating people by the physicians of a past age. All this has been overcome by the good sense of the people, and the success of HUMPHREYS' HOMEOPATHIC SPECIFICS.

It is perhaps significant that Humphreys attributes none of this improvement to the establishment of veterinary schools. The horse owner, he says, should be able to recognize and treat disease, but there is no need for him to be (or to call) a veterinary surgeon when homeopathy is "so simple that any intelligent person may readily cure a very large proportion, nay, almost every disease to which his animals are exposed."

These intelligent people, judging by the testimonials included in the book, include farmers, stock breeders, livery stable men, horse-railroad men, mining, brewery, manufacturing and express company men, and the Quartermaster General of the United States, who in consultation with a group of cavalry officers had recommended the adoption of Humphreys' medicines by the Army. Veterinarians are conspicuous by their absence, and for good reason; Humphreys himself says, in effect, that it matters not how much or how little of what one or more of his "specifics" was used, and thus one man could fool himself as easily as the next if he so chose.

In essence, homeopathic philosophy taught that minute and frequent doses of a drug, which in large doses would produce symptoms of the disease being treated, would create a "curative impulse." Thus a little of any "specific" medicine, like a 


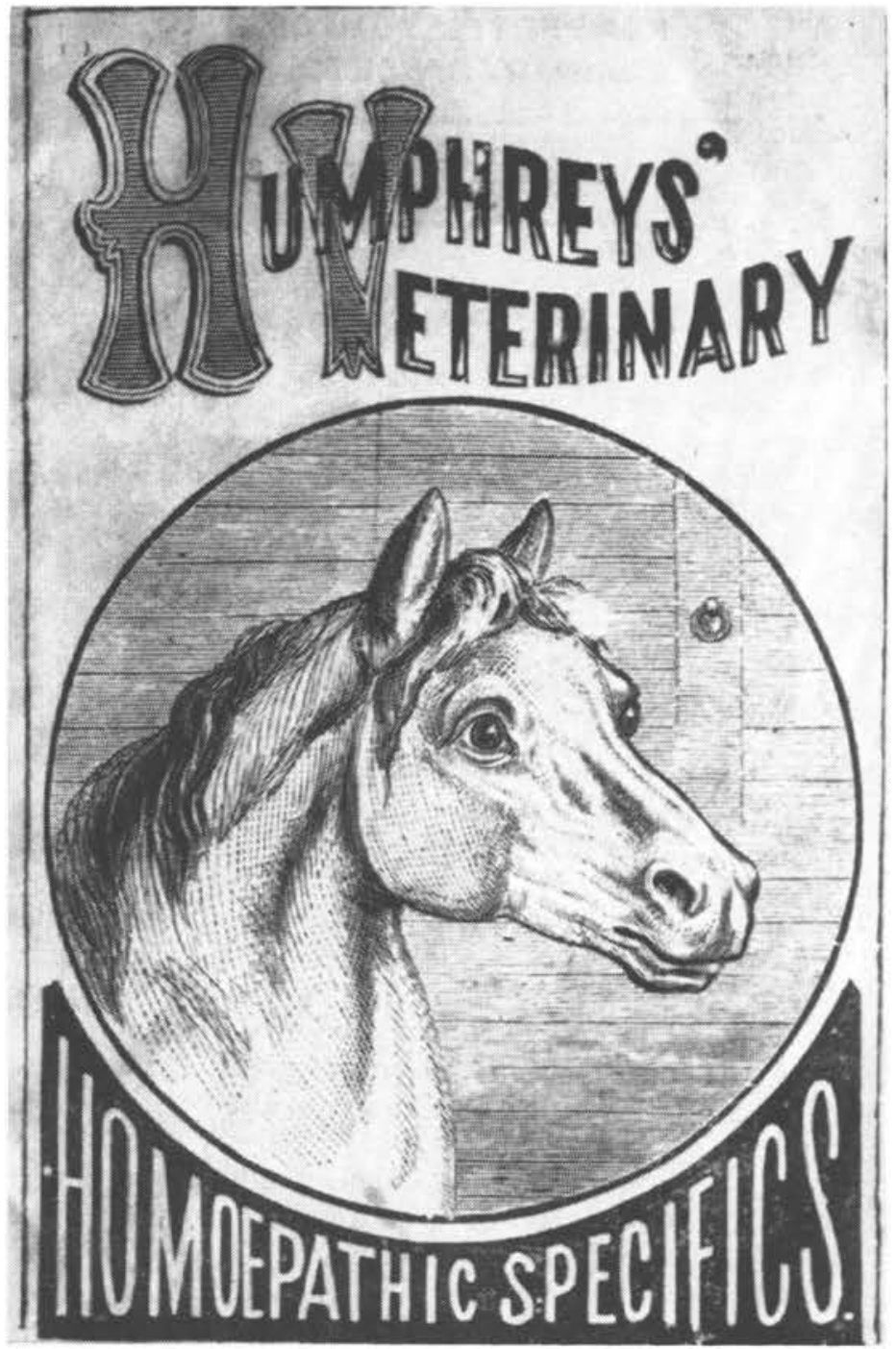

Homeopathic veterinary remedies were popular-more so with owners than with veteri. narians - during the latter part of the nineteenth century, but their use waned before their popularity in human medicine fell into the discard.

catalyst, was as good or better than a lot. In some respects, however, it seems like fighting a forest fire, using a dead match to start a series of backfires. At any rate, with the supposedly active principle diluted sometimes to one part in a billion or more, it would seem that rubbing the bottle on the animal would be about as effective as giving it a few drops.

At a time when magic played a large part in healing, various systems of numbers were followed religiously; thus the four humors, four phases of the moon, four sea- sons, etc., were considered, as was a system of threes based upon the Holy Trinity. Humphreys' Manual of Veterinary Specific Homeopathy placed complete dependence upon ten "specifics" with a standard dose of ten drops:

yet to give two or five drops more in any given case would probably not be hurtful, while to give a few drops less would not endanger the curative action for want of the requisite quantity.

Like pregnancy, perhaps, either you were or you weren't. 


\section{Therapeutic Travesty}

With Humphreys' system, all the diseases of all animals could be treated with one or more of his ten "specific" remedies. Like most patent medicines, no indication of their contents was given, and considering the small amounts of active ingredients, this probably was of little consequence.

Thus, Specific A.A. was for fever, inflammations, and congestion and would take care of moist eruptions, fistula, swelled legs, tumors, contused wounds, incised wounds, staking, founder, synovitis, c a t a r a c t, ophthalmia, pericarditis, endocarditis, anemic palpitation, phlebitis, milk fever, hog cholera, burns, goiter, flukes, etc., etc. Reasonably good directions are given for differential diagnoses of endocarditis vs. pericarditis; atrophy vs. hypertrophy of the heart; so-called spasm (palpitation) of the diaphragm vs. true spasm of the diaphragm (hiccough); and the like, but the treatment is essentially the same for each, i.e., ten drops of A.A.

Each condition was treated symptomatically; thus if a cough accompanied one of the above, the "specific" for coughs, bronchitis, and inflamed lungs should be given also (in alternating doses). Other remedies were for strains, injuries and lameness; influenza, quinzy, and nasal gleet; bots, and grubs or worms; colic, belly-ache, wind-blown, and diarrhea; miscarriage, imperfect cleansing, and hemorrhage; urinary and kidney diseases, and dropsy; ulcers, mange, farcy, abscesses, etc.; indigestion, bad condition, paralysis, and stomach staggers. These were all internal medications; in addition, four external applications were used: sulfur ointment, calendula lotion, tincture of arnica, and "the Marvel of Healing," which could be used internally as well.

\section{SPECIAL VeterinaRY \$PECIFICS.}

\author{
NOT IN THE CSCAL CASE. \\ Put up only in $4 \mathrm{oz}$ and 8 oz Botules.

\section{L.I. Masturbation or Self-Abuse in Colts} \\ or Stallions.
}

M.M. Sterility or Fallure to Breed in Cows, Mares or other Animals.

N,N. Sexual Weakness, Loss of Vigor, or Impotenco in Stallions.

\section{A.A.X Cures f}

R.R. $\times$ Cures

Pneumonia or Lnng Fever after La Grippe; Ifeares or Broken Wind.

$\underset{\text { P.P. }}{\text { Cures }}\}$ Diarrbea, or Scouring in Colts or Calves.

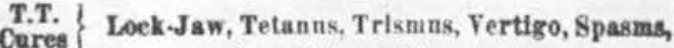 Conrnlsions, Staggers.}

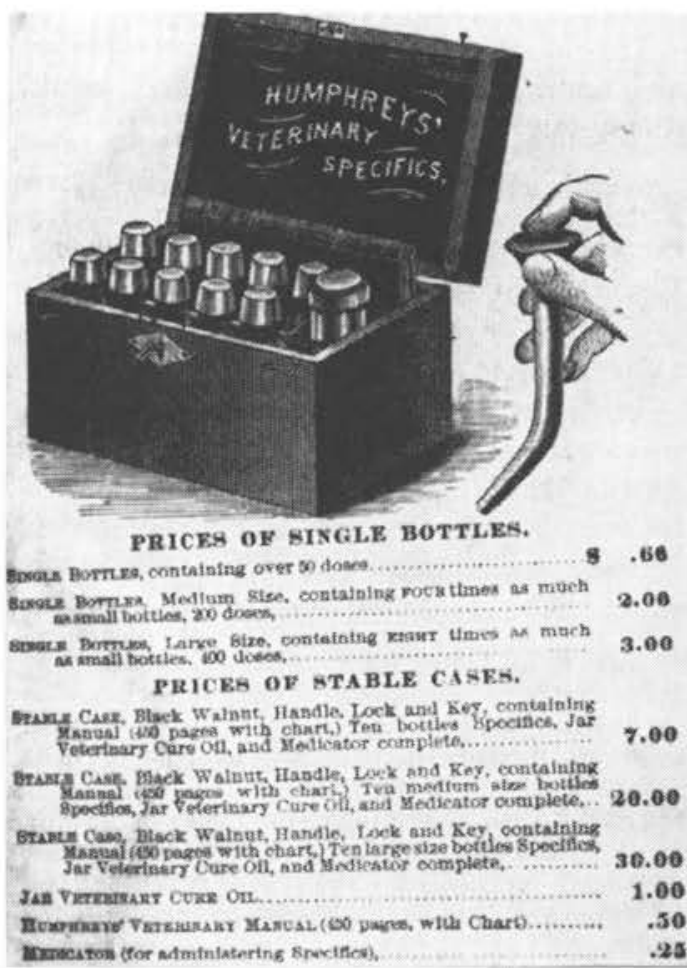

Homeopathic remedies were based on the concept that frequent minute doses of a "specific" drug, which in large doses would produce symptoms of the disease, acted as a "catalyst" in curing that disease. 
The only remedy for which any indication of the active ingredient is given is this latter "Marvel of Healing," which was "a pure distillation of Hamamelis," and was good for such problems as: hemorrhage, toothache, neuralgia, piles, varicose veins, gravel (urinary calculi), burns, diarrhea, catarrh, and as "a toilet article for shaving, bathing, etc." And why not? For a dollar a quart, who could go wrong?

Perhaps because Humphreys' remedies cost only about one cent a dose, thousands willingly bought his medicine chests $(10 \mathrm{x}$ 200 doses in walnut case for $\$ 20.00$ ), together with his veterinary Manual for diagnosis (which "any sensible, faithful man of ordinary intelligence can master without difficulty"). It may be presumed that this class of people was not particularly interested in the active ingredients or principles of treatment employed, and none are given. And, of course, the dilutions employed in homeopathic medicine were such that their action, if any, was rather dubious.

For bloat in cattle, which presumably any man "of ordinary intelligence" could diagnose:

Specific F.F. is sovereign, and may be given a dose every quarter or half hour; it cures every time. We give the method of puncturing, which, however, need never be resorted to if the Specific F.F. be administered.

\section{$O$, ye of little faith!}

With the only requirement being that a proper diagnosis be made so the proper specific could be employed, attention to differential diagnosis of colic and enteritis is stressed "to avoid error in the treatment." The treatment for colic consists of:

Specific for Colic, F.F., a remedy which rarely fails to arrest this disease. Give fifteen drops on the tongue, and repeat the doses every half, or even quarter hour until relieved. ... If fever should also exist, then alternate the Fever Specific, A.A., with that for Colic, F.F. . . If the attack has clearly been occasioned by an over-feed, it will be best to alternate the Specific for Indigestion, J.K., with that for Colic, F.F.
So much for colic. For enteritis:

As early as possible, give the Specific for Inflammation (Fever), A.A., fifteen drops, and repeat the doses every half hour. . . . If not better in two hours, the Specific for Colic, F.F., may be alternated with that for Inflammation. ... After the inflammatory symptoms have subsided, a dose or two of the Specific J.K., for Indigestion, will complete the cure.

Success, apparently, depends upon "who's on first."

Abortion in cattle a ccording to Humphreys' Manual may be caused by atmospheric conditions, trauma, severe illnesses, iron in drinking water, intercourse with the bull during pregnancy, etc., "and when it occurs in a herd, it is very likely to extend to others." The treatment consists of

fifteen drops of the Specific for Miscarriage, G.G., every six hours. . . This interval should elapse between doses, as too rapid ones may even defeat the object, by over-excitement of the system, while a single dose often arrests a miscarriage at once. . . . If slinking prevails in a herd or neighborhood, a dose of the Specific for Miscarriage, G.G., given say twice per week, will arrest its progress and prevent miscarriage, a result that can only be achieved by this benign and scientific treatment.

Like other do-it-yourself systems, Humphreys found it necessary to include a section on "How to Choose the Remedy" and states:

you will have some idea of the nature of the disease, and will at once turn to the Index and page in the Manual describing that and similar diseases and continue the search until the true description is found, and the proper treatment will be pointed out. . . In case a wrong medicine is selected or given, no injury will be done. ... And when a sufficient length of time has passed to clearly show that no good has resulted, the case should be looked over again, and a more appropriate Specific selected.

How unfortunate that penicillin had not yet been discovered! So much for veterinary homeopathy. 


\section{George Dadd and Veterinary Journalism}

\begin{abstract}
ONE OF THE MOST CONTROVERSIAL FIGURES on the American veterinary scene about the mid-nineteenth century was George $\mathrm{H}$. Dadd. While his work attracted little attention from the regular veterinary profession of his time - and even today opinion is divided concerning his contribution to veterinary medicine - he may truly be said to have been a pivotal figure in American veterinary history. During his relatively brief professional life-spanning only about twenty years - he was largely ignored by those outside his immediate sphere, and historians have tencled to judge him by their own set of standards rather than by evaluating his work in its own setting. Also, it is likely that few attempts have been made to bring together any large mass of information about him beyond what may be adduced from his books.
\end{abstract}

\section{A MAVERICK IN VETERINARY HISTORY}

The facts of Dadd's professional life, when interpreted in the light of more modern medical historiography, i.e., interpretations based upon the contemporary situation rather than in the light of what might be considered good or bad today, give us an adequate picture of his contributions to veterinary medicine. Perhaps largely because he worked outside the realm of what was accepted as the veterinary profession of his time, the treatment he has been accorded by later observers is generally in- adequate and unjust. About the best that has been said of him is that:

he condemned in unmeasured terms the cruel practices of the unqualified veterinary practitioners of the day. In this he lived up to the best traditions of the veterinary profession.

Another characterizes him as "a man completely dedicated to veterinary medicine . . . far in advance of his time." But another credits him with being little more than "an interesting and colorful character."

To some extent it is true that he was "thoroughly disliked by the qualified veterinarians of the ' 60 's and later, and execrated for his unethical practices." These latter included the advertising of proprietary remedies, a practice which was contrary to the Code of Ethics of the United States Veterinary Medical Association in the 1860 's, but which nevertheless was engaged in to some extent by some members of the Association and more or less condoned by others. Dadd also wrote extensively for laymen, both books and in the agricultural press, but so did a number of notable members of the USVMA. Being outside the official family, Dadd, of course, was fair game for criticism. It should not be inferred, however, that the USVMA did not police its own ranks during the early days-had Dadd been a member, it is likely that he might have been dropped as 


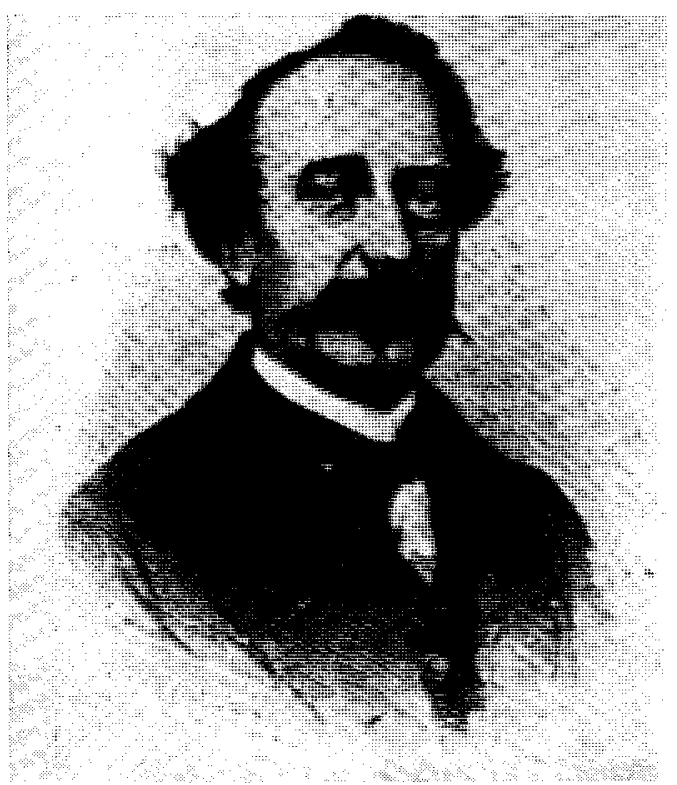

George H. Dadd, M.D., V.S. (1813-1868), pioneer veterinary practitioner, journalist, and educator. Except that he was largely ignored by the "regular" veterinary profession, his more moderate approach to therapeutics might have had a considerable impact on veterinary medicine. Merillat and Campbell: Veterinary Military History

a number were for what were considered breaches of the Code of Ethics. But there is more than a suggestion that censorship of the activities of various practitioners member or nonmember - was not always measured by the same yardstick. By any standard, Dadd was not immune to criticism, but it would seem that an evaluation of his activities based upon a fuller understanding of his motives and methods would result in some mellowing of opinion concerning him.

George Dadd was born in England in 1813 , but virtually nothing is known of his early life other than his admitting to having studied both human and veterinary medicine. It is quite certain, however, that he did not have a graduate veterinary degree, nor is it likely that he studied medicine by other than the apprenticeship route. His own writings place him in Boston as early as 1845 , but it is not likely that he had turned to full-time veterinary practice at this time. In his Cattle Doctor
(1850) he appends a note of appreciation from passengers of a ship on which he was the surgeon, "[we] would here bear testimony to the valuable medical services and advice rendered by him." In his first writings he identifies himself as "M.D.," adding, "Veterinary Practitioner." Later it was "M.D., V.S.," and still later he dropped the M.D. on occasions. At any rate, both from internal and external evidence, it is quite evident that he had but little experience with animals when he began writing on animal disease in 1848.

\section{Veterinary Volumes}

Beginning in 1848 he produced in rapid succession a series of veterinary books in addition to his voluminous writings in the agricultural press. While his early works inevitably reflect his inexperience with animal medicine, his medical training places even these a notch or two higher than most of the veterinary books produced in this country at the time. His later works show him to be what he truly was: a gifted and facile writer on all aspects of veterinary practice. His books include:

Chart of Veterinary Reformed Practice, Boston, 1848

The American Cattle Doctor, New York, 1850 Advocate of Veterinary Reform, Boston, 1850

Anatomy and Physiology of the Horse, Boston, 1851,1857

The Modern Horse Doctor, New York, 1854

Every Man His Own Cattle Doctor, New York, 1856

Diseases and Lameness of Horses, New York, 1858

Nature and Treatment of Diseases of Cattle, Boston, 1859

Lameness, Boston, 1863

Theory and Practice of Veterinary Medicine and Surgery, Boston, 1866

Dadd also edited and published (and largely supplied the material for) his American Veterinary Journal, 1851-1852 and 1855-1859, but its ultimate failure might have been predicted from its meager subscription list. Dadd himself states that there were only 15 graduate practitioners in the United States in 1847. Following the demise of his journal, Dadd served as 
veterinary editor of several agricultural journals in succession from 1862 to 1865 , contributing many hundred pages of generally sound veterinary advice to farmers. Dadd's efforts in this area filled a distinct need at the time, and he may be considered the first influential veterinary journalist in the American agricultural press. Later, James Law and other prominent veterinarians wrote extensively for the laity; in some cases, however, this was not an unmixed blessing so far as the development of professional veterinary medicine was concerned.

In addition to his extensive practice and other activities, Dadd became associated with the Boston Veterinary Institute in 1855. The idea of veterinary education, however, was too new in this country, and the school never enjoyed the patronage that it may have deserved during its brief existence. While the Boston school ran at best - a desultory course until 1859 , the names of several of its graduates are at least a matter of record, and four of Dadd's associates in the enterprise became presidents of the United States Veterinary Medical Association after its founding in 1863. After Dadd assumed the veterinary editorship of the Prairie Farmer in 1863, he conducted a Veterinary Institute of Chicago for several years, but this venture must be considered little more than an outright failure.

Dadd's activities after 1865 are something of an enigma. In 1868 his name appears on a list of nonresident professors at the Iowa Agricultural College (now Iowa State University) as Professor of Veterinary Medicine and Surgery, but he died in Baltimore in September of that year. His sudden drop into obscurity is manifest from the fact that his death elicited only a few lines in the Prairie Farmer - the medium through which he practically established veterinary journalism as a tour de force in the American agricultural press. Curiously, he is credited (erroneously, of course) with having turned to other fields after this date. Merillat and Campbell state: on into the '80's, Dadd devoted a portion of his time to lecturing on temperance and was one of those who laid the foundation for the organization of the W.C.T.U. . . The date of his death is unknown, but occurred sometime prior to 1890 .

Inasmuch as he identified himself as $\mathbf{G}$. $\mathbf{H}$. Dadd, Sr., during his years in Chicago, it is evident that it must have been his son that is referred to on the temperance matter.

Not of least importance is the fact that Dadd was the first American veterinary surgeon to use general anesthesia as a regular adjunct to practice. In his writings he advocates a mixture of ether and chloroform for all painful operations, and he describes its use in a number of cases. He is also credited with being the first here to spay a mare successfully and to perform cesarean section in swine-at least with any regularity and success. His penchant for advertising and his often caustic pen undoubtedly robbed him of professional recognition, but in these matters a number of prominent practitioners of the time were not above reproach.

With this much as an introduction, we can turn to a full consideration of Dadd's activities in vetexinary medicine. The amount of space required for this is necessarily out of proportion to his recognized importance in the history of American veterinary medicine. But it is as much with the idea of establishing what veterinary medicine might have become earlier than it did, that this extensive account is given, as it is - in a sense - to give Dadd his longneglected and just due. It seems logical to presume that had the body of writings he amassed during this time been attributed to a number of the leaders of the then-nascent veterinary profession, this would have long since been recognized as the pivotal period in American veterinary history.

\section{The Vital Principle}

An account in the Cultivator for 1848 of the death of 300 cows in Virginia from redwater elicited what may be Dadd's first communication to the agricultural press. 


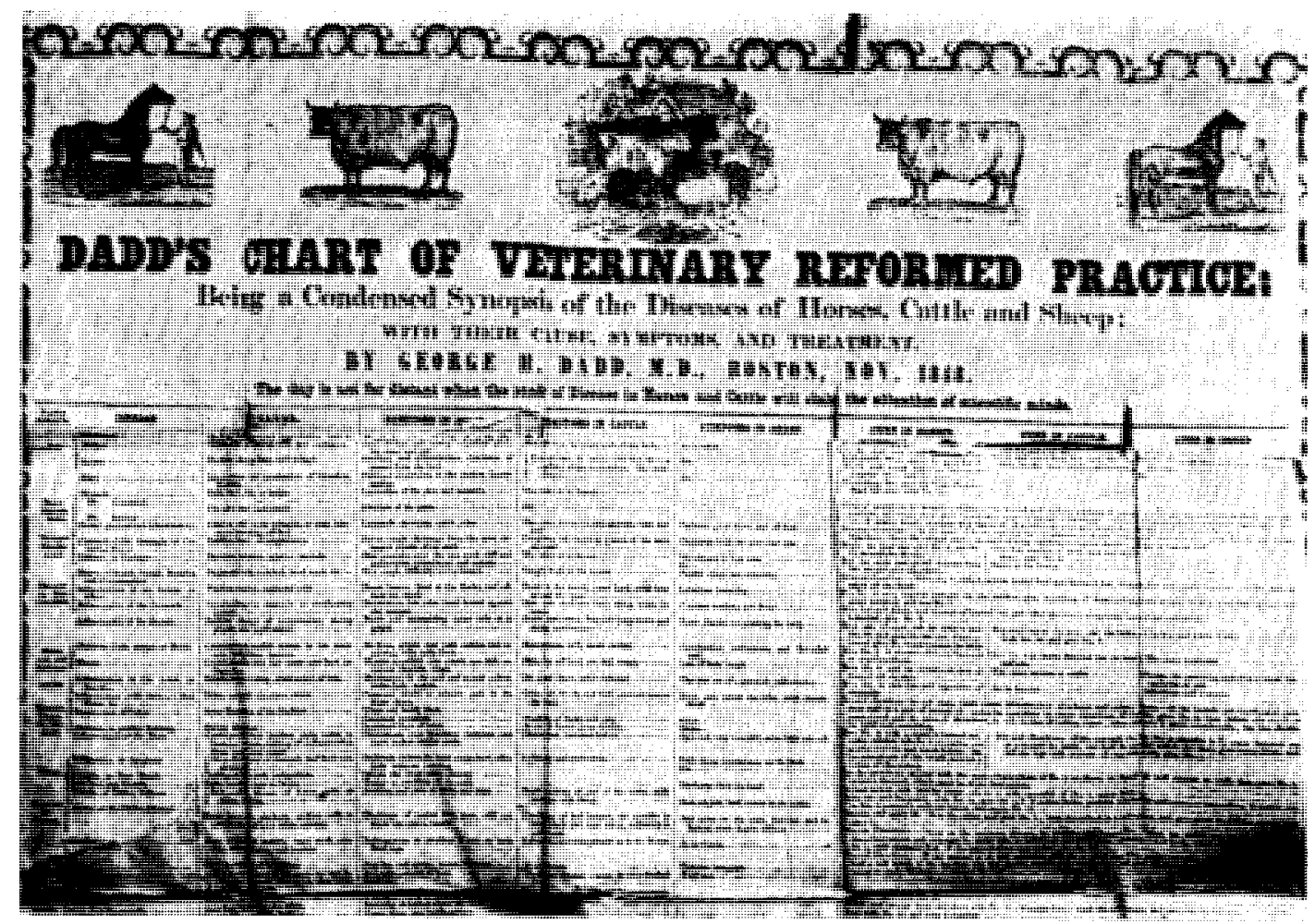

Dadd's "Chart of Veterinary Reformed Practice" was designed to tack up in the barn, or fold into a pocket case, and was intended as a guide to the use of remedies he manufactured and sold. Michigan State University Library

He identifies himself as George Dadd, M.D., and objects most strenuously to the recommended dosing with nitre as "opposed to the vital principle." Rather: "we must open the sluices of the body," with linseed oil and soapsuds clysters containing ginger, to be followed with the "distemper powder," in which he had a proprietary interest. And in response to a request for information on an undiagnosed disease of sheep, apparently a fatal catarrh, the regimen should aim to: "equalize the circulation, remove the irritating causes from the organs affected, and restore the tone of the system." For this purpose a decoction of horehound, marshmallow, elecampane, licorice, cayenne, molasses and vinegar was prescribed.

The following year he has one entry in which he objects to giving opiates for stretches, or colic, in sheep as "not only unjustifiable, but should be esteemed unpar- donable." Dadd's Chart of Veterinary Reformed Practice was mentioned by the editor, who was "inclined to think it useful to the farmer, and all others who keep animals." In 1850 the editors had received a request for information on blackleg, and

Not being practically acquainted with the disease, we submitted the request to Dr. Dadd, of Boston. . . . Dr. D's system is in some respects new to us, and is probably so to some of our readers. We are not prepared to offer an opinion in regard to his peculiar views, but leave them to fair consideration.

Perhaps it did not occur to the editors that they had already passed judgement upon Dadd's system in referring to his "peculiar views." Undoubtedly there were others who had the same opinion.

Dadd prefaces his reply to the query with an outline of "our physiological or reformed practice and theory of disease": 
We contemplate the animal system as a perfect piece of mechanism, subject to life and death; that while the vital power has free and unobstructed action, the animal is in a physiological or healthy state; but when by any means the vital power is obstructed, by over leeding, exposure, \&.c., it is in a diseased or pathological state.

We recognize a conservative or healing power in the animal economy, whose unerring indications we endeavor to follow. Our system proposes, under all circumstances, to restore the diseased organs to a healthy state, by co-operating with the vitality remaining in the organs, by the exhibition of sanative means; and under all circumstances, to assist and not oppose nature in her curative process.

Poisonous drugs, blood-letting, and processes of cure that contemplate destruction of parts, or in other words, act pathologically, cannot be used by us. The laws of animal being are physiological; they never were or ever will be pathological, hence we co-operate with nature and nature's laws. ... The indications of cure, are to relax spasm ... to contract and strengthen weak and relaxed organs ... to stimulate inactive parts .. . to equalize the circulation, and distribute the blood to the external surface and extremities ... . to furnish the animal with sufficient nutriment to build up the waste that is continually going on. . . No matter what the nature of the disease, the treatment should be conducted on these principles.

Dadd's readers may have been surprised, and not a little disappointed, that he had "no particular treatment for blackleg," other than as much of the regimen outlined would apply. He ends his piece with some "advice to farmers":

Let your animals have their meals at regular hours, in sufficient quantity . . . let them have good beds of straw... keep them clean, and avoid undue exposure. Finally, govern them in a spirit of kindness and mercy, and there will be little foothold for disease.

The editors of the Cultivator appear to have had some faith in Dadd's system, for shortly they requested him to write on ringbone, a subject upon which much misinformation was readily available. Dadd describes the condition well, and gives a currently acceptable theory concerning its formation, in contradiction of the commonly accepted idea of a "bladder" which "feeds the ringbone," and which required extraction. The latter was recommended by Cole in his American Veterinarian. Dadd recommends a counterirritant, and states that while surgical interference is sometimes successful: "where there is no lameness, and the only object is to get rid of an eyesore, it had better not be attempted."

\section{M.D. vs. V.S.}

A matter of some interest is the fact that Dadd included the M.D. after his name in his first communications, then became just plain George Dadd, and then added V.S. to his name in the latter communication on ringbone. It would appear that this period, from 1848 to 1850 , was the time during which he had made the decision to identify himself as a veterinary surgeon. In so doing, he became one of the most controversial figures in the history of American veterinary medicine, but whatever his faults may have been, it is immediately apparent that he brought to the veterinary scene an entirely fresh approach. In addition, he possessed more medical acumen than many of his medical confreres, with whom he disputed as strongly as with his newly adopted colleagues.

A contemporary evaluation of Dadd's system appears in a review by the editors of the Cultivator in 1850 of his Advocate of Veterinary Reform, and Outlines of Anatomy and Physiology of the Horse; containing also a Veterinary Dictionary:

This reform is to consist, mainly, in the abandonment of "destructive agents," so called - in other words, blood-letting, and poisonous substances. As a substitute for this, the work under consideration advocates a system which seems to contemplate rather the prevention than the cure of disease. The directions in reference to this point are, in the main, such as would be approved by persons acquainted with the subject. We agree to the old adage that "an ounce of prevention is worth a pound of cure;" still, with the strictest observance of this rule, we apprehend animals will sometimes be sick, and in such cases it will be necessary to adopt the best means for relief and cure. It is impossible to say what these are, under all 
circumstances; but the propriety of restricting the catalogue of medicines to those wholly of a "botanic" origin, (whether poisonous or harmless,) will probably be doubted by many successful practitioners, whose opportunities for observation and the acquirement of knowledge in the veterinary art, have been neither few nor small. The same remark may be made in reference to the rejection of the lancet, in the treatment of disease. It is not our present purpose, however, to make decisions where "doctors disagree." Dr. Dadd's book contains much that is valuable beyond controversy.

The editors appear not to have requested any more information directly from Dadd, nor do any unsolicited contributions from Dadd appear in succeeding volumes of the Cultivator. Dadd's books, however, are frequently referred to as the reference of choice in answering the queries of correspondents, or in recommending works on animal disease. His books were reviewed, and advertised, as they appeared. Notice also was given to his American Veterinary Journal; at its inception (1851):

The Journal will be the medium of disseminating much useful information. . . . A work of this kind has long been needed, and this publication is issued under auspices that will ensure its success. The editor is a practitioner of Veterinary Surgery, and writes to considerable extent of his own experiences and observations. The want of anything like knowledge of the diseases of domestic animals and their remedies, results in an immense loss to the farmer every year, much of which might be saved by subscribing to this journal.

All too few, however, were willing to pay a dollar a year for the Journal, and it was published erratically. In 1859, the Cultivator expressed regrets over its discontinuance "for want of competent support."

On receiving a "Prospectus and Regulations of the Boston Veterinary Institute," in 1855, the editors of the Cultivator state they: "rejoice exceedingly that there is at last some prospect of an institution in this country where young men can prepare themselves for the practice of veterinary medicine and surgery." Obviously, no question was raised as to whether the fourmonth course (two sessions) offered was adequate; at the same time, the Cultivator carried advertisements for the University of Albany, which offered a 16-week term of study in the Department of Law, with degrees ". . . conferred at the close of the term." The Albany Medical College offered two terms of 16 weeks each, and: "Degrees are conferred at the close of each term."

\section{Moon Swine}

In the Michigan Farmer for 1854, a correspondent asks: "Is it luck and chance in raising pigs? or must they come in a par. ticular time of the Moon? . . . or ... is beech shack [mast] bad food for pregnant sows?" His five sows had farrowed 40 pigs, of which only eight lived, "and two of that number at present appear undecided about staying." This occasioned "A few Thoughts on Hogs" from Dadd, who replies:

If a man by chance or otherwise, is lucky enough to have studied physiology . . . the information obtained may enable him to become a successful raiser of this description of livestock - otherwise luck or chance has nothing to do with the matter. . . . There are two circumstances necessary for the development of disease: 1st, Predisposition existing in the individual. 2nd, The Application of a specific cause.

On the matter of feeding beech mast:

If the sow had a grist mill within her stomach, and it were capable of comminuting beechnuts, so that they could be manufactured into chyme and chyle, without overtasking the stomach, I should not object to giving the animal a few.

Noting that it is theoretically possible for one pair of pigs in 16 generations to equal the world's population, he adds: "There are no fears, however, of such a host taking possession of this globe, nature regulates these things; your correspondent's pigs are an example."

\section{THE AMERICAN CATTLE DOCTOR}

Dadd's Chart of Veterinary Reformed Practice (1848) probably sold but few copies; its title must have sounded formidable to farmers, and there were all too few professional men who might have been interested. The first major vehicle for his re- 


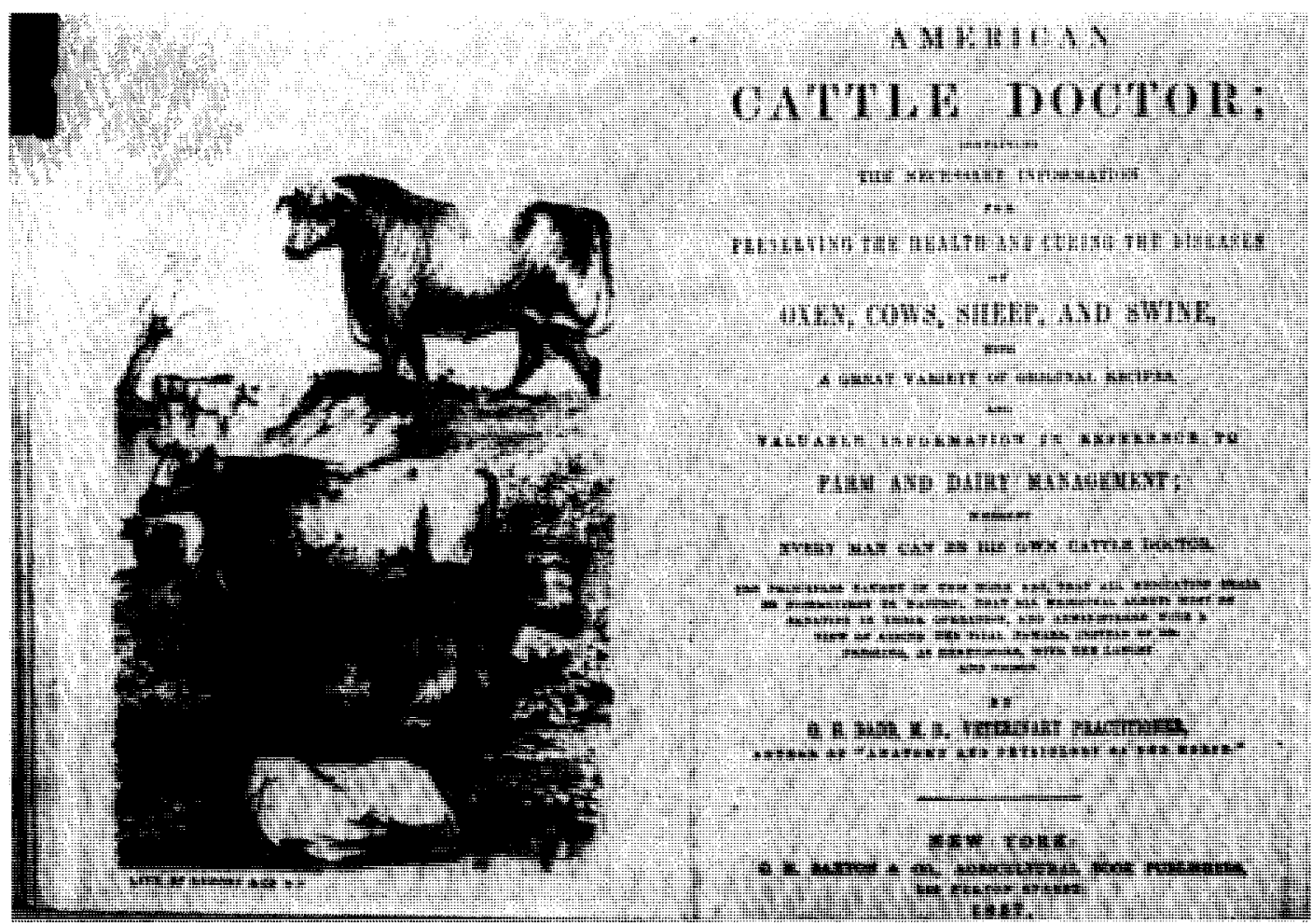

Dadd's American Cattle Doctor (1850), although based on little experience, was his first claim to lasting fame; the book was reprinted without alteration for more than fifty years.

forming zeal, therefore, was his American Cattle Doctor, published in 1850. In his introduction he states:

That many thousands of our most valuable cattle die under the treatment, which consists of little else than blood-letting, purging, and blistering, no one will deny; and these dangerous and destructive agents are frequently administered by men who are totally unacquainted with the nature of the agents they prescribe. But a better day is dawning; veterinary information is loudly called for-demanded; and the farmers will have it; but it must be a safer and a more efficient system than that heretofore practised.

In a vein which sounds much like John Hunter, early champion of the London Veterinary College, Dadd declares:

The object of the veterinary art is not only congenial with human medicine, but the very same paths that lead to a knowledge of the diseases of man lead also to a knowledge of those of brutes. Our domestic animals deserve consideration at our hands. We have tried all manner of experiments on them for the benefit of science; and science and scientific men should do something to repay the debt, by alleviating their sufferings and improving their condition. ... . We advocate the establishment of veterinary schools, and the cultivation of our reformed system of veterinary medicine, on the broad principles of humanity. . . .

When the author first commenced a warfare against the lancet and other destructive agents, his only hopes of success were based on the cooperation of this mighty host of husbandmen; he well knew that there were many prejudices to be overcome, and none greater than those existing among his brethren of the same profession. The farmers have just begun to see the absurdity of bleeding an animal to death, with a view of saving life; or pouring down their throats powerful and destructive agents, with a view of making one disease to cure another! If the cattle doctors, then, will not reform, they must be reformed through the giant influence of popular opinion. Already the cry is, and it emanates from some of the most influential agriculturalists in the country, - "No more blood-letting. Use your poisons on yourselves." 


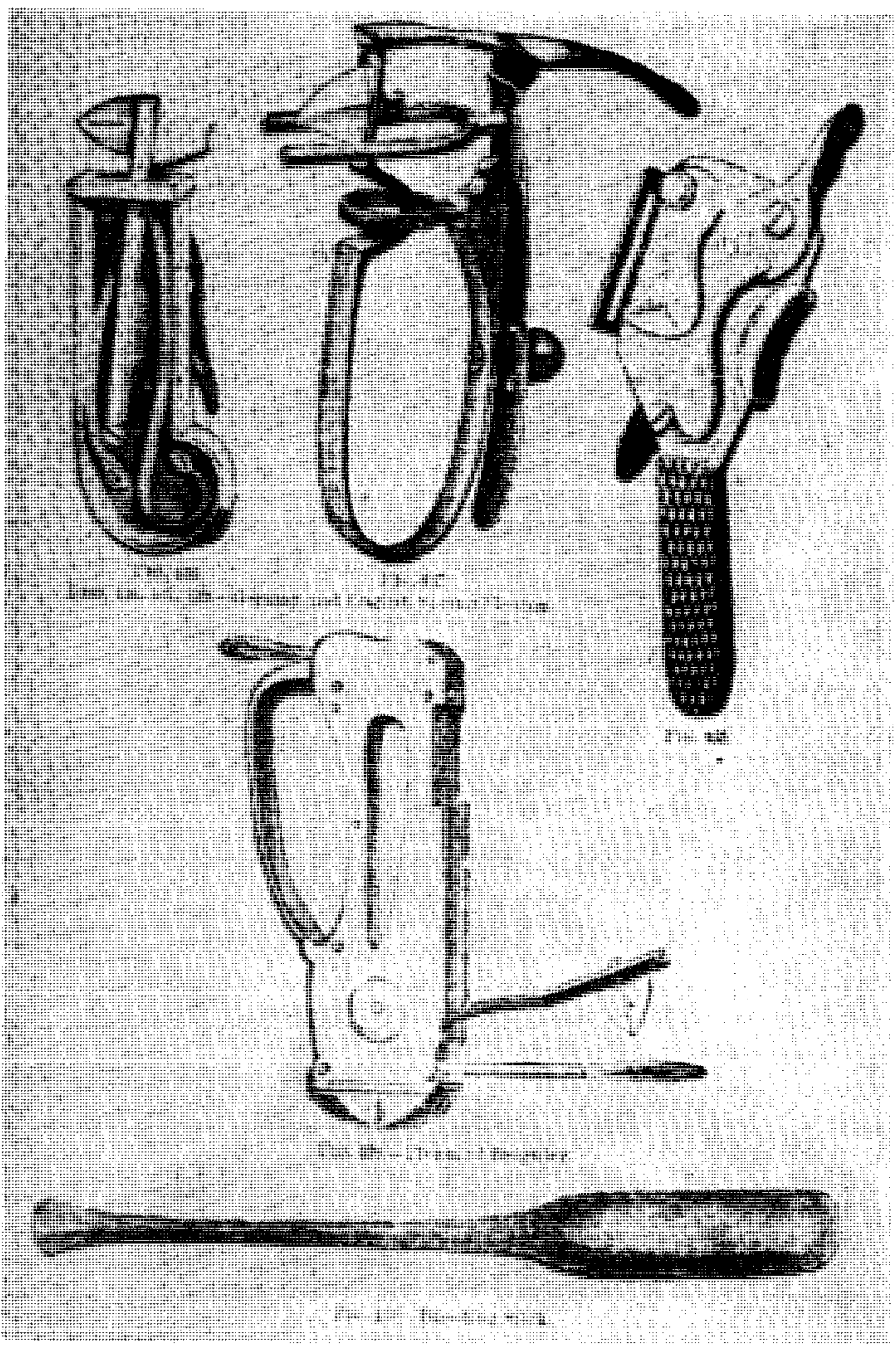

Although Dadd decried the practice of bleeding, practitioners of the mid-nineteenth century found the spring lancet a convenient substitute for the thumb fleam and bloodstick. In inexperienced hands, however, the lancet was considered relatively dangerous. Liautard: Surgery

We contemplate the animal system as a complicated piece of mechanism, subject to the uncompromising and immutable laws of nature. . . We have termed our system a physiological one, though it is sometimes termed botanic, in allusion to the fact that most of our remedial agents are derived from the vegetable kingdom. We recognize a conservative or healing power in the animal economy, whose unerring indications we endeavor to follow; considering nature the physician, and the doctor her servant. Our system proposes, under all circumstances, to restore the diseased organs to a healthy state, by cooperating with the vitality remaining in those organs. . . . Poisonous substances, bloodletting, or processes of cure that act pathologically, cannot be used by us. The laws of animal life are physiological: they never were, nor ever will be, pathological.

\section{Rivers of Blood}

In "Remarks on Blood-letting," Dadd states that the general practice, by custom supposed to be infallible, was such that:

Men and animals were bled; rivers of blood have been drawn from their systems; yet they often got well, and men looked upon the lancet as one of the blessings of the age, when, in fact, it is the greatest curse that ever afficted this country; it has produced greater losses to owners of domestic animals than did ever pestilence or disease. 
He states that a few of "the blood-letting gentry" do so only "to please their employers," but dismisses the lot, saying:

But we are not writing for doctors. Our business is with the farmers - the lords of creation. The former are mere lords of pukes and purges.... they are hidebound.

Reformers, of course, are always unpopular with those who do not care to be reformed, and his characterization of regular practitioners as "lords of pukes and purges" probably did not help his cause - except, perhaps, with "the lords of creation."

Observing that "confession is good for the soul," Dadd admits:

We plead guilty to bleeding, blistering, calomelizing, narcotizing, antimonializing, a great number of patients of the human kind. We did it in our verdant days, because it was so scientific and popular, and because we had been taught to reverence the stereotyped practice of the allopaths [regular medical practitioners ]. . . . On the other hand, we are free from the charge of bleeding or poisoning domestic animals, and can say, with a clear conscience, that we have never drawn a drop of blood from a four-footed creature.

On the matter of dissemination of veterinary knowledge in the United States, he says:

We hear a great deal about sending young men from this country to Europe to acquire the principles of the veterinary art, with a view to public teaching. Now, it appears to us that the United States can boast of as great a number of talented physicians, as well qualified to soon learn and understand the fundamental principles of the veterinary art, as their brethren of the old world. . . . Just send a few to us, for example, and if we do not impart to them a better system of medication than that practiced in Europe, by which they will be enabled to treat disease with more success and less deaths, then we will agree to "throw physic to the dogs," and abandon our profession.

Specifically, he charges:

Veterinary science, as taught at the present day, is a matter for reproach. The melancholy triumph of disease over its victims shows that the science is mere moonshine; that, in regard to its most important object, the cure of disease, it is mere speculation, rich in theory, but poverty-stricken in its results.

It must be admitted that there was some truth in what he said, but it is also obvious that throwing the baby out with the bathwater is rarely the logical solution. As a stopgap measure, it is probably true that given a number of pupils, the country would have benefited more than from an investment of the same time and money on education in Europe. Today, of course, we would be most suspicious of anyone who had the opinions about himself that Dadd entertained, and it would be folly to assume that any one practitioner could give an adequate education to apprenticed students-despite the fact that some might be made into reasonable facsimiles of professional men. But we are dealing with the customs and circumstances of another time-something which is perhaps not given adequate consideration by those who damn Dadd with the greatest vehemence. While Dadd's estimate of only 15 graduate veterinarians in America in 1847 may be open to question, and foreign graduates continued to trickle in, these were not always the best representatives of the profession. Moreover, the fact is that very few Americans went to Europe for veterinary education; some training at the hands of one like Dadd might have been preferable to maintaining the status quo.

\section{Cattle Practice}

Dadd devotes over a hundred pages to general remarks on the nature of disease, the management of cattle, and the need for reform - somewhat more than he devotes to the diseases of cattle as such. On the latter, he demonstrates a lack of familiarity with many of the conditions he prescribes for - which under the circumstances is not surprising. Thus he describes "spasmodic colic" in cattle, but fails to mention scours in calves. $\mathrm{He}$ is vague on symptoms, and in some instances gives none. Thus on bloat, all he says is that: "cattle ... turned into luxurient pasture, after being poorly fed ... are apt to be 
hoven, blown, or blasted." $\mathrm{He}$ recommends the stomach tube for temporary relief, but puts main faith in a "stimulant and carminitive drink." He did not recommend puncture of the rumen:

Some practitioners recommend puncturing the rumen or paunch; but there is always great danger attending it, and at best it is only a palliative; the process of fermentation will continue while the materials still remain in the paunch. Some cattle doctors make a large incision into the paunch, and shovel out the contents with the hand; but the remedy is quite as bad as the disease.

On the other hand, his avoidance of bleeding and harsh purgatives, and his prescribing of simple vegetable remedies at least gave the farmer something to do. If this was of little help, at least it was relatively harmless, for which it can be supposed that the cow might well have been thankful. Undoubtedly the chief merit of Dadd's Cattle Doctor was his insistence on good nursing care; all too many works of the day prescribed a batch of drugs, frequently drastic in action, and left the animal to its own devices.

A section on the spaying of cows is of some interest; he quotes the English veterinarian, William Percivall, to the effect that the operation was "discovered" in the United States about 1832, from where it was taken back to Europe. Dadd recommends the operation for improving the quantity and quality of milk, and for producing superior beef:

The English - those ardent admirers of beefsteaks and roast beef - profited by the new procedure, as they know how to turn every thing to account, and at once castrated their heifers, in order to obtain a more juicy meat.

Dadd also recommends the spaying of cows not fit for breeding: "for then one of the first causes of degeneracy in livestock will have been removed." In performing the operation he mentions that chloroform can be used with benefit - an early reference to the use of anesthesia in veterinary practice. In the 1851 edition of the Cattle Doctor, Dadd describes an opera- tion he had performed that year using chloroform.

On sheep, Dadd gives a tedious dissertation on "the rot," in which he quotes Professor Simonds of the London School to the effect that the flukes in the liver are the effect, rather than the cause, of the disease, but rightly incriminates wet pastures as the predisposing feature. Evidently Dadd knew less about sheep than he did about cattle at this time; he fails to mention the sheep bot ("grub in the head"), and does not recognize the contagious nature of foot rot, saying only: "it is generally considered a local disease." On hogs he has even less to say, and makes no mention of hog cholera. He gives a few remedies for diseases of dogs, including one for rabies.

What, then, is to be our evaluation of the Cattle Doctor? Obviously, it is not the result of a mature experience in the treatment of the diseases of cattle. Nor, from the medical standpoint, does it offer much in the way of specific treatment. But judging it in the light of its own time, rather than that of this enlightened antibiotic age, it would seem to have been a step in the right direction. If cattle were seldom saved by the prescriptions of the Cattle Doctor, at least they were saved from the heroic practices of the horn-boring, tail-slitting, blood-letting fraternity of common cattle doctors. And it might be added that doubts concerning the efficacy of Dadd's remedies are, for the most part, not based upon experimental proof of their inadequacy. On the positive side, his avoidance of harsh methods, and his urging of good nursing care and general management should be cited. His methods for calling attention to the need for better veterinary education, and for the dissemination of veterinary knowledge, would appear distasteful today, but were not out of bounds for the ethical mores of the times. Some inkling of whether Dadd did have something to offer should be found in his Modern Horse Doctor, published four years later, at which time he was able to write more 


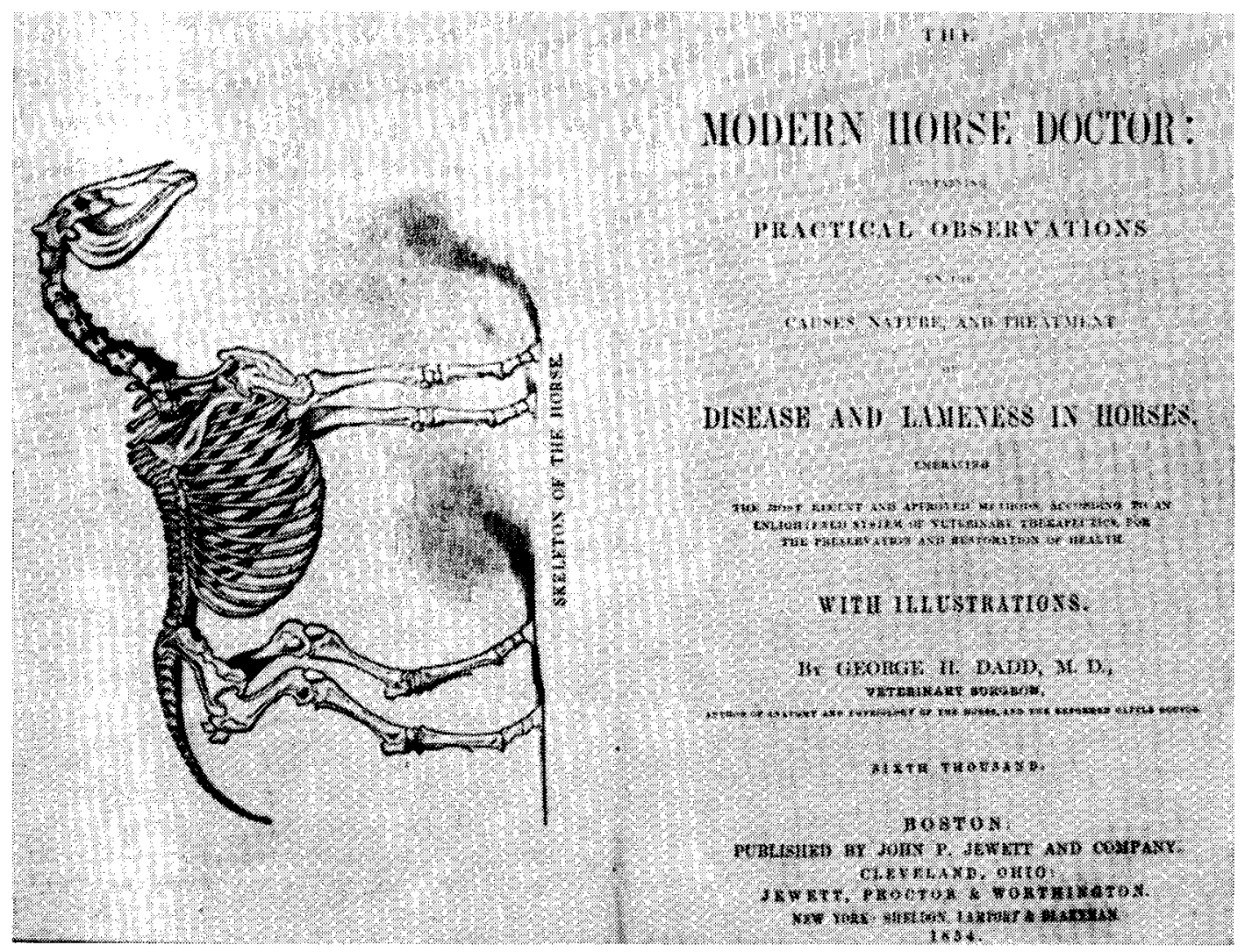

Dadd's Modern Horse Doctor (1854), despite the opprobrious title, was far ahead of contemporary writings, but - except that the title provided an unfortunate precedent - it was superseded by countless works of others who had less to offer.

from experience, and upon which much of his reputation was based.

\section{MODERN HORSE DOCTOR}

The work for which Dadd is best known is the Modern Horse Doctor (1854), which despite its now-opprobrious title, deserves consideration at some length, for it marks a new departure in the field of horse practice. Contemporary reviewers characterized it - in variations of a single theme as:

a manual of genuine science, and ought to be owned and studied on the score of humanity, as well as interest, by every man who owns a horse. ... As a handbook for practical use, we know of nothing to compare with it. ... To many a man would it be worth hundreds of dollars every year. . . B By far the most learned and copious work on the horse and his diseases we have ever seen... . This book supplies a great desideratum which Skinner's admirable treatise on the Horse did not fill. Every man may be his own veterinary surgeon, and with much greater safety to this noble animal, than by trusting him to the treatment of the empirical itinerants who infest the country. . . One of the greatest and most commendable qualities of this work, is, it is practical and plain to the comprehension of those farmers and others for whom it is mainly designed. The course of treatment favors generally a more sanative and rational system of medication than recommended in any previously existing works on farriery. ... It will be of more service than the counsel of a score of ordinary doctors.

While all this may seem a bit fulsome, Merillat and Campbell state that Dadd's book, "despite the opprobrious title," and those of Youatt, "were valuable scientific treatises."

Nor were reviewers any less ecstatic over the qualifications of Dadd: 


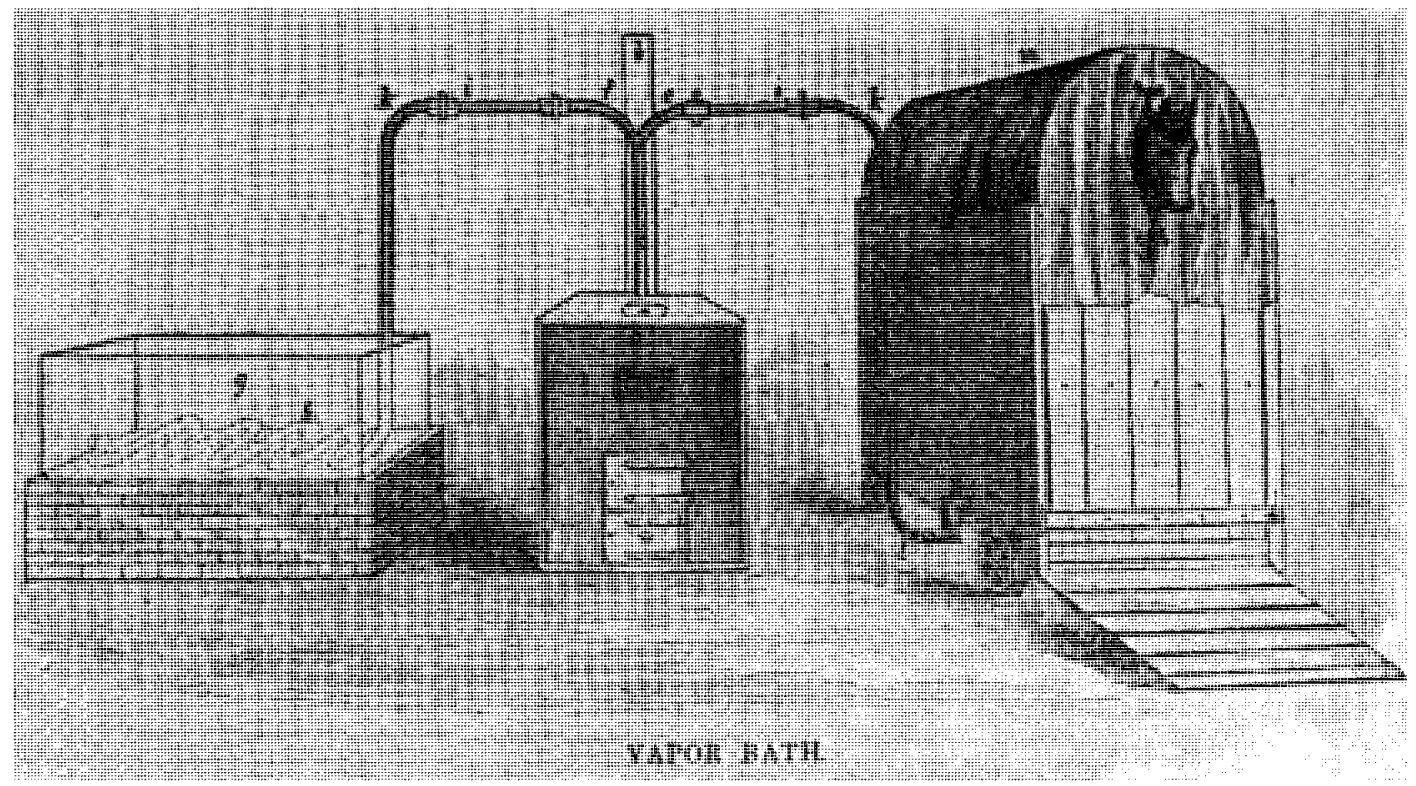

Vapor baths were advocated as therapy for a number of conditions by Dadd in his Modern
Horse Doctor. A similar device was promoted by Carver in his Farrier's Magazine (1818), and
one was exhibited at USVMA meeting in the 1890's. Dadd: Modern Horse Doctor

The author of this work is well known as a most skillful veterinary surgeon. . . . We know Dr. Dadd well, and are satisfied that he possessses most important qualifications for preparing such a book. ... Dr. Dadd has had great experience in the cure of sick horses, and explains the secret of his success in this volume.

Such paeans of praise left little for the publisher, who states only that the book:

is from the pen of a celebrated English Vet erinary Surgeon, Dr. Geo. H. Dadd, well known for many years in this Country, as one of the most successful, scientific and popular writers and lecturers in this branch of medical and surgical science. The book he now offers to the public, is the result of many year's study and practical experience which few have had.

In 1856 the publishers announced printing of the eleventh thousand copies of this work, considerably less than the number claimed for Cole's American Veterinarian in the same length of time. Cole's quite ordinary work had received testimonials almost equal to those accorded Dadd; thus the latter probably should be viewed with some reservations. Editorial comment concerning a later work, however, may be considered a fair characterization of all of Dadd's writings:
Those who know Dr. Dadd are aware that he declares uncompromising hostility to the old cut-and-slash, scour-and-burn, blister-and-bleed system, and in some instances he may carry his assaults too far. But if he errs, it is a pretty safe kind of error on the side of gentle treatment and humanity, and can appeal to nature's restorative power. We have seen enough of diseases in animals to learn that much that is ascribed to medicine, takes place often as well or better under good nursing without medicine; and also, that sometimes remedies are of the utmost importance. We know of no writer on the subject who has discriminated better, if as well, between the two courses of treatment, than Dr. Dadd.

\section{Of his Modern Horse Doctor, the Prairie} Farmer says:

It is the result of study and cxamination by competent hands, being neither a mere compilation like Cole's Veterinarian, nor a mere re-hashing of somebody else's either. It is original, practical; ... it is greatly in advance of Youatt, whose medical practice belongs to a past generation, and a European one at that.

The first edition of Dadd's Modern Horse Doctor was published in 1854, and was based on "his own experience, during a professional career of nine years in the vicinity of Boston." It seems a little 
strange that Dadd, who was such a staunch advocate of veterinary education, should have used so commonplace a title for his work. But the opprobrium is greater today than it was then, and Dadd states that the book:

is intended for that class of agriculturalists and horsemen ... who are in favor of a more sanative and rational system of medication than that recommended in many works of farriery. Such individuals, in consequence of the scarcity of competent veterinary surgeons, are compelled to treat their own horses.

\section{Throw Physic to the Dogs}

Dadd repeats his philosophy of medicine:

The more a man knows of physiology, the less faith has he in medicine. .. Health must not be supposed to exist in drugs and physic balls... [but] in a strict system of hygiene, and without which medicine may as well be thrown to the dogs as given to a sick horse. . . . The author... still adheres to those opinions promulgated in former works regarding the vile practice of bloodletting, and the use of agents that are known to depress the vital prin-

Illustration from Dadd's Modern Horse Doctor, from Snape's Anatomy of an Horse (1683), in turn from Ruini's classic work (1598).

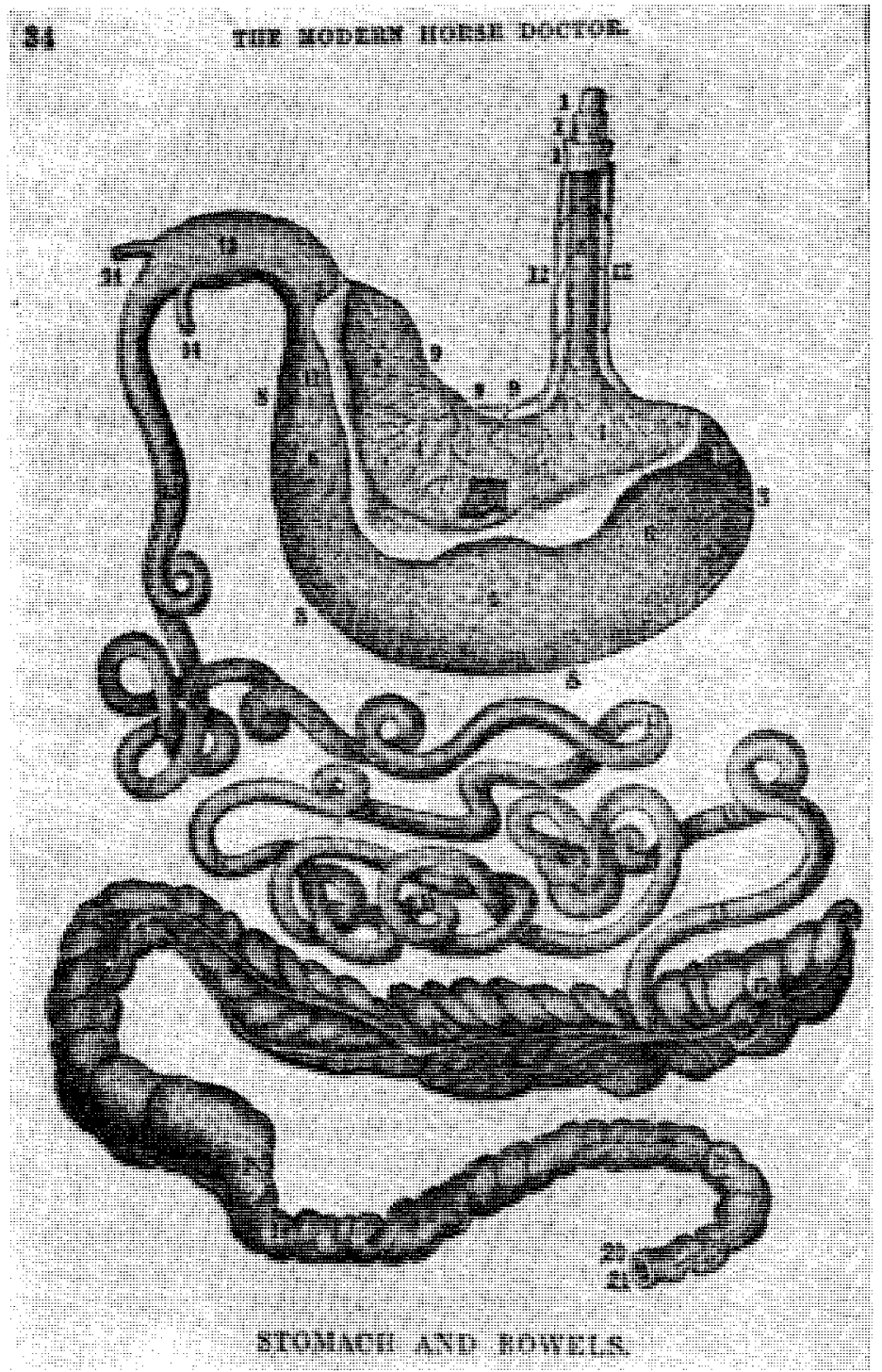


ciple. .. Some change has, however, taken place in the author's views regarding the several medical sects. He was formerly somewhat of a specialist, wedded to one particular system of practice; he now practices without regard to sect, - ecclectically, - selecting from the various systems those means and agents best calculated to aid, foster, and perpetuate the physiological state.

Dadd also changed his mind on the utility of the study of pathology and the other basic sciences in acquiring an adequate knowledge of the veterinary art. He lists the qualifications for human practice and states:

there is a greater need of preliminary education and tact on the part of those who undertake to prescribe for brutes. . . . It is useless, therefore, to suppose that the veterinary art can be acquired at the forge, plough, or in the stable . . . every one to his own trade.

While this work has all the faults necessarily inherent in the "do-it-yourself" type of offering, Dadd at least does not pretend that it is a substitute for a qualified veterinarian if one is available. The obvious fact is, of course, that very few such were available.

From the very beginning, Dadd's Horse Doctor shows that it is written as a "native" production, and from experience. The first condition mentioned, that of "stomach staggers," he says, "is a disease very prevalent in this section of the United States," and he gives reports of cases occurring in Boston. His descriptions are replete with such phrases as, "We have seen some benefit derived from the daily use of an antispásmodic draught," (for "vertigo," but the symptoms given are those of "sleeping sickness"). On "concussion of the brain," he says, "a very few cases have come to our knowledge during nine years' residence in Massachusetts."

"Pink eye and Horse ail," he says should be termed influenza, and he accurately differentiates this from catarrh and strangles. Concerning influenza, he states:

It is a notorious fact that there is no disease to which horses in this country are subject that has opened so wide a field for empiricism as this. Every man has his favorite remedy, and often applies it to his own loss, because he thinks it beneath his dignity to employ a physician to treat what horse dealers consider a simple disease.

Segregation of animals with contagious diseases was not mentioned in the Cattle Doctor; on strangles in horses Dadd says:

The disease is set down by authorities as noncontagious. . . . We always take the precaution to separate the patient from healthy animals, and would recommend this as a general rule in all catarrhal affections.

\section{The Benefit of Veterinary Skill}

On "bleeding from the nose," Dadd states:

When the blood appears frothy and of a dirty color, issuing from one nostril only, the breath being fetid ... the owner had better consult a veterinary suregon, for the horse is probably, or will be, the subject of glanders ... [but] it is a notorious fact, that many valuable horses in this country, are yearly sacrificed at the shrine of ignorance; having been pronounced by their owners as glandered, simply because they have a discharge from the nostrils. . . A horse should not be condemned until he has had the benefit of veterinary skill.

The latter statement, taken out of context, could be taken as derogatory to the veter. inary profession, but presumably Dadd means that the horse should be condemned only after diagnosis of glanders by a veterinarian. However, he does suggest that treatment might be of some avail, and he does not mention the communicability of glanders to man.

Dadd frequently alludes to the necessity of professional veterinary attention; for example: "urinary calculi can only be removed by a skilful veterinary surgeon." And while:

thick urine is at times an evil that only exists in the imagination of the groom ... it may be proper, in all cases where the horse passes, for any length of time, urine that appears to be albuminous, for the owner to consult a veterinary surgeon. 
On "profuse staling," so-called diabetes of horses, Dadd says he "has long since, and continues, to discountenance any unnecessary medication, believing it is the duty of physician to know when to do nothing." But for "suppression" of urine, "the safest plan will be to consult a veterinary surgeon."

\section{Indigestion, Dadd says:}

is the great national disease of the United States; both men and horses alike its victims, it lies at the bottom of almost every disease to which both are subject. ... In nine cases out of ten, colic is the result of impaired digestive organs.

Concerning "lampas," he says that so long as horse owners believe it to be a disease:

and men can be found to "burn it out," as it is sometimes termed, just so long will the error exist, and the barbarism continue... . The most that we would ever do .... is to wash the mouth with a weak solution of alum.

On this matter of burning the engorged palatal ridges, Dadd quotes Percivall, who states:

The horse continues to be persecuted for it, even by some professional men, as well as farriers. The practice is a stigma upon our national character, and a disgrace to the professors of veterinary science.

"Bishoping" a horse's teeth to make him appear younger, Dadd terms "a species of imposition so reprehensible that all honest horse dealers have set their faces against it, and we are not aware that it is to any extent practised here." He states that the operation is so called "from the name of the scoundrel who invented it."

The section on lamenesses shows that Dadd had some practical acquaintance with these problems. He is harsh on the group of quacks who performed neurotomies for every species of lameness, and who gave the operation a bad reputation:

the fault of those who a few years ago went about from one place to another, operating without the requisite skill necessary ... . some of the animals thus operated on were the sub- jects of acute laminitis - a form of disease that no regular veterinarian would ever think of relieving by neurotomy.

Dadd preferred to operate only as a last resort - for incurable lameness.

\section{Etherization for Animals}

\section{Concerning neurotomy, Dadd states:}

We recommend that, in all operations of this kind, the subject be etherized, not only in view of preventing pain, but that we may, in the absence of all struggling on the part of our

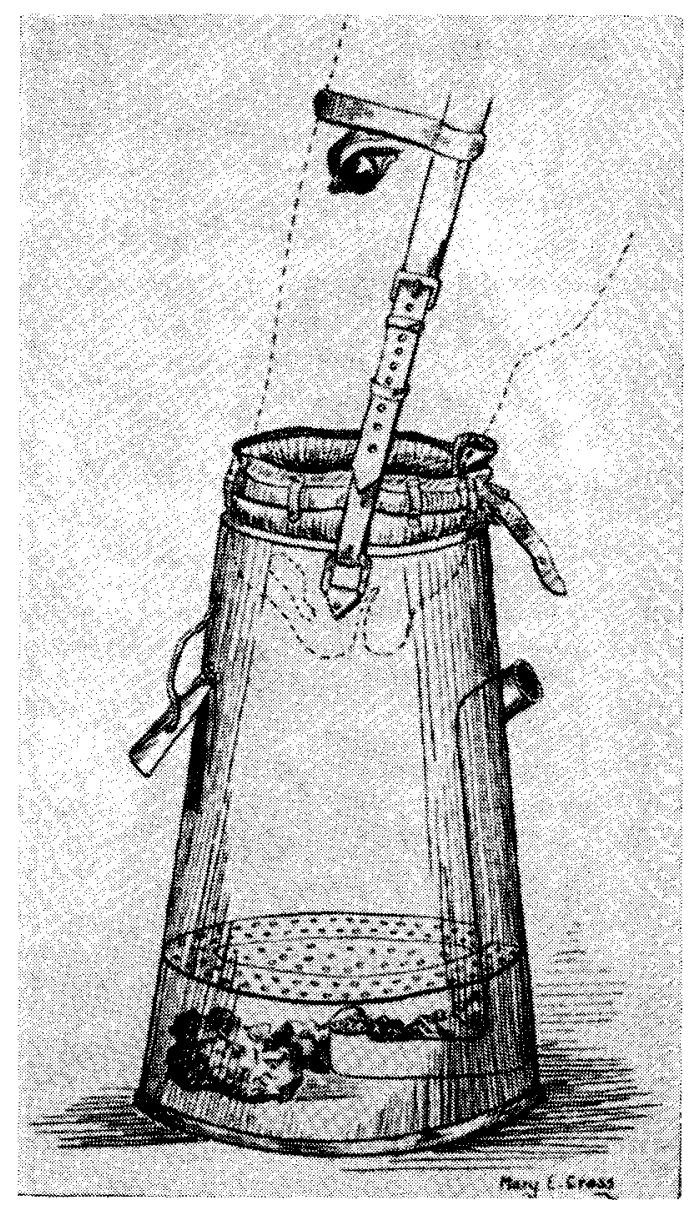

A number of devices for administering ether or chloroform to horses were designed after 1850 , but Dadd and the few other American practitioners who used anesthesia preferred a simple sponge. Drawn from contemporary descriptions by $M$ ary Ellen Haggerty. 
patient, perform the operation satisfactorily, and in much less time after etherization has taken place than otherwise. So soon as the patient is under the influence of that valuable agent, we have nothing to fear from his struggles, provided we have the assistance of one experienced to administer it. We generally use a mixture of chloroform and chloric ether in our operations, and consider it far preferable so far as the life of the patient is concerned, to pure chloroform.

Dadd used a large sponge, and states: “In all cases of etherization at the Massachusetts Hospital, a simple sponge is used. The complicated and expensive breathing machines are dispensed with."

Dadd's proximity to the birthplace of surgical anesthesia probably was a factor in his adopting the practice, although it would have appealed to him had he had only a remote acquaintance with it. From his statement it would appear that he used anesthesia in all major operations - probably the first to do so in veterinary practice in this country. In 1853 Dadd describes an operation for the removal of two melanotic tumors from below the shoulders of a horse, in which chloroform anesthesia was used, the anesthetic being administered by a physician.

Spavin, says Dadd:

has got to be so common a disease of late, that if a purchaser finds a horse free from blemish of this description, he considers himself fortunate. . . Some people have an idea that nothing short of firing or blistering can be of any benefit; yet experience has shown that the practice is unsatisfactory. ... We have succeeded in rendering horses as free from lameness by mild means, as, we think, can ever be accomplished by the scientific, yet barbarous mode of fire and blister. . . . The practice of firing ... is a barbarism that should have long since been discontinued. We never performed the operation but once, and have ever since been sorry for it. As to blisters, we regard them in the light of a last resort; yet, when applied understandingly, we are not sure that it would be good policy to oppose their use.

\section{The Barbarian}

Ringbone, Dadd avers, is torment enough for the horse:

but he must, in addition, be compelled to submit to atrocities unheard of in the history of human medicine, and for which the veterinary science of the present day furnishes no authority, but, on the other hand, one of universal disapprobation. It has been our painful duty, occasionally, to take in charge subjects that have been most shamefully maltreated for the cure of ringbone. One case, which we can never obliterate from memory, happenend to a poor aged animal, that for a long period had been a faithful slave to his master. For many years he had been the subject of this disease. and his owner had long since given up all hopes of cure, till, at length, one of those exotic, pestiferous specimens of inhumanity, termed horse doctors, - but who have no more claim to the title than a maniac or a wild Indian, - undertook, for the sum of five dollars, to cure an hereditary incurable disease.

The owner, through the deceptive arguments of the barbarian, consented to an operation, which for cruelty would have outdone an inquisitor. It consisted in cutting through the integuments down to the bones, - for both hind legs were operated on; a red-hot iron was then freely used over the exposed surfaces; some oil of turpentine then being poured into the horrid wounds, it was set on fire; and thus the brutal operation terminated. What a pity the horse had not the power to make his tormentor exchange places with him, and pay him in his own coin! The disease was not benefitted by the operation, as any veteninary surgeon, had he seen it, would have foretold; the case being one, not only of common ringbone, but also anchylosis of the pastern and coronet joint.

Sons of these barbarians were still operating two or three decades later: Horseman's Friend (!) in 1871 directs for founder: "Bleed four or five gallons from the neck, or until the horse falls . . . and pour boiling lard over the feet."

\section{First in the Field}

The Country Gentleman for 1857 notes Dadd's Anatomy and Physiology of the Horse as "a textbook of the whole subject for use in Agricultural institutions. . . In this respect it is the first in the field." Later, in a fuller review, it is stated:

Its object is to enable the educated physicians of this country to give advice in the management of horses, and is intended for the use of veterinary surgeons, teachers and students; but we think it will be sought and prove especially valuable to all inquiring and scientific farmers, who feel interested in the study of the horse, but who may not be within reach of good vet- 


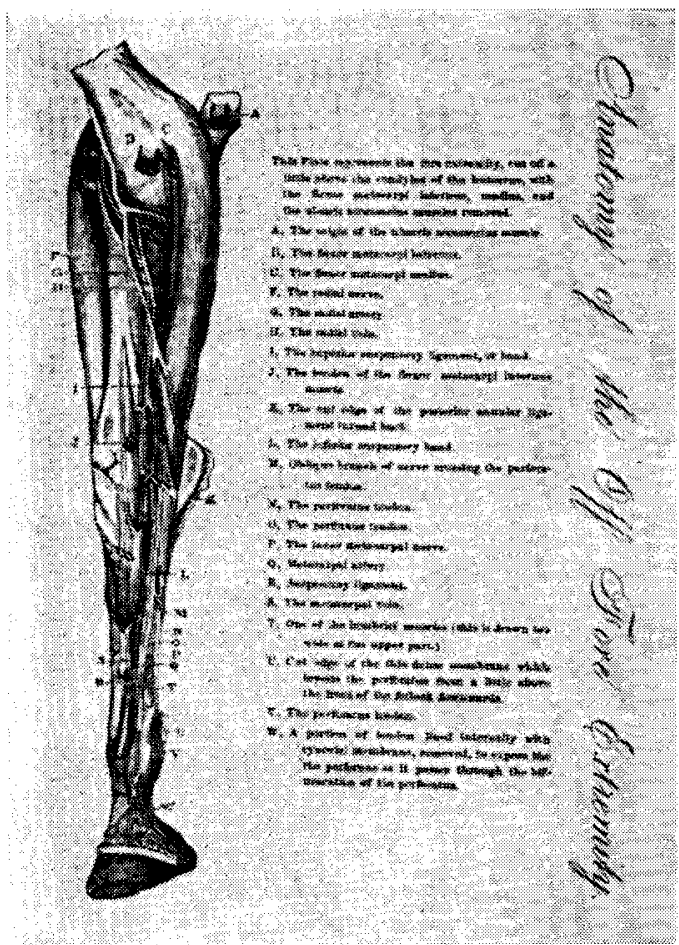

Dadd's Anatomy and Physiology of the Horse (1851), perhaps the most scientific veterinary work produced in America to its time, apparently sold poorly; farriers were not interested, and there was but a handful of educated veterinarians. $R$. $R$. Shomer collection

erinary practitioners. Perhaps everyone of our readers may know one or more "horse doctors," as they are commonly termed, and may be aware that in many instances their best guide in the management of sick animals is only blundering guess-work. ...

Those who are acquainted with the writings of Dr. Dadd, are aware that he takes a very strong ground against some of the older practices... and although in some cases he may carry his points rather far. . . We are quite willing that his mild, cautious and humane treatment may displace some of the former bold and headlong practices.

The book included "a very useful dictionary of veterinary science, of more than sixty pages, worth of itself the whole price of the volume." ( $\$ 4.00$ with colored plates; $\$ 2.00$ uncolored.)

\section{AMERICAN VETERINARY JOURNAL}

The American Veterinary Journal, with Dadd as editor and publisher, began pub- lication in September, 1851, and ran until October, 1852, when Dadd stated:

All that prevented the journal's continuing its monthly visit was - lack of time; our professional engagements being such as to preclude the possibility of performing any longer the double duty of editor and publisher. Hence the journal was laid on the shelf.

Publication was resumed in October, 1855 , with Dadd as editor and proprietor, and S. N. Thompson as publisher. This venture lasted until March, 1859, when publication ceased for very practical reasons; Dadd says:

The only explanation I have to offer is, that in consequence of remissness on the part of subscribers for the past two years, my pocketbook is the seat of a very severe attack of dyspepsia, which threatens to confine me and my family to a diet of shorts.

Dadd's announced objective was a circulation of 20,000 copies, later raised to 50,000 , but it appears doubtful that it ever much exceeded 1,000, and perhaps not all these paid for.

As the first venture of its kind in America-Carver's ill-fated Farriers' Magazine of 1818 hardly qualifying as a contender Dadd's journal is worthy of notice at considerable length. What is surprising is that the venture lasted as long as it did, for it seems unlikely that it ever paid its own way. The principal mode of obtaining subscriptions was the hope that veterinarians and other subscribers would promote it personally - a common practice with agricultural journals, but these had a much larger field to draw from. And being written for both lay and professional readers, it was in some respects "neither flesh nor fowl," but it is evident that a purely professional journal would not have lasted even this long. In 1856 Dadd states:

At this early period in the history of American Veterinary Science it is a matter of impossibility to secure sufficient patronage for the support of a purely veterinary periodical. The fact is, that out of the whole of the subscribers now on our list there are only about fifty! 

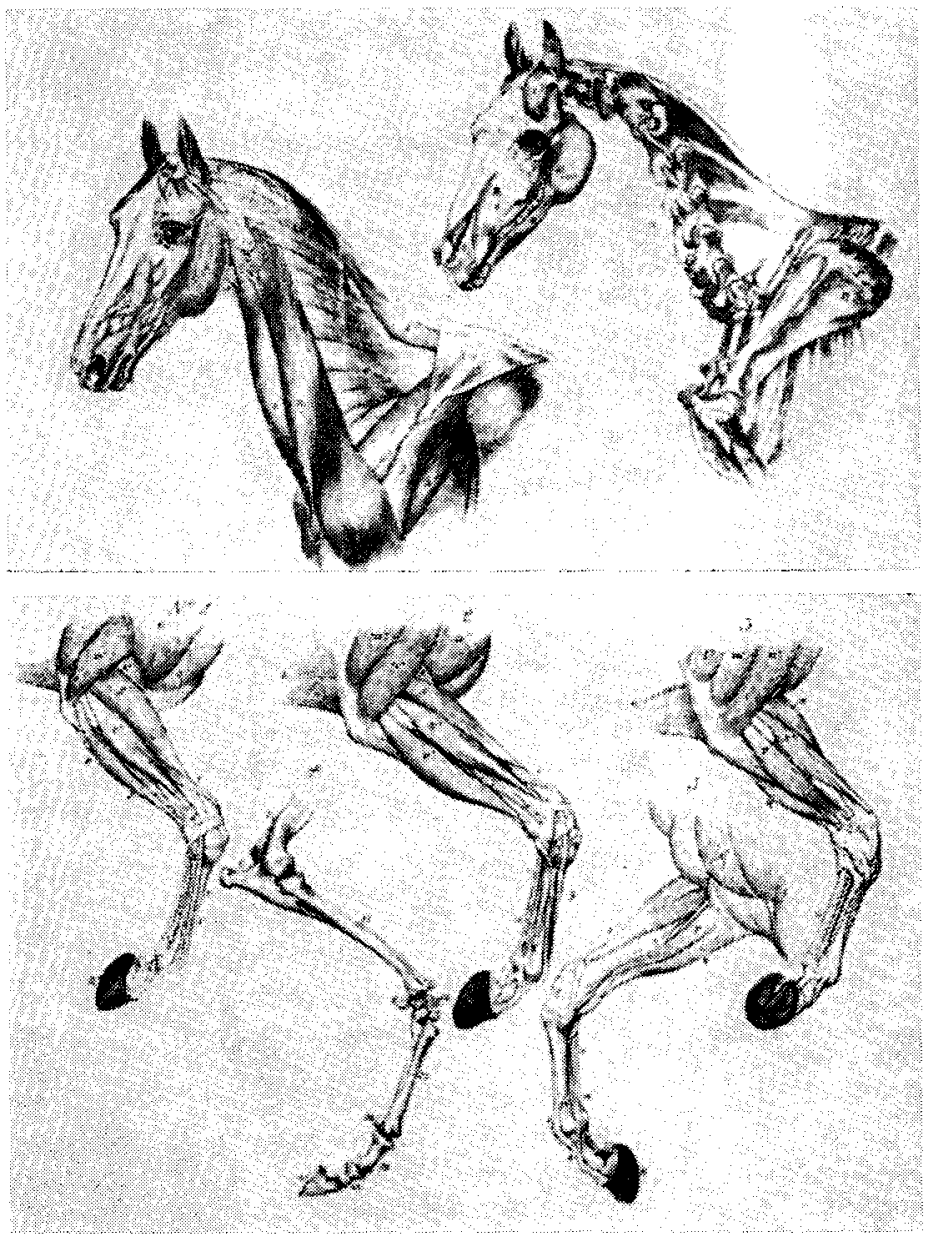

By comparison with those from other American works of the time, the illustrations from Dadd's Anatomy (from Blaine's Outlines of the Veterinary Art [London, 1802]), were both technically and artistically excellent. R. R. Shomer collection directly interested in the promulgation of the principles of veterinary science.

Except for Dadd and his faithful coterie of veterinarians who did write for the Journal, much of the material was taken from other papers - a common practice of practically all periodicals of the time. A close examination of the Journal suggests that it could have served its intended purpose; that it did not is evidence that it was ahead of its time.

\section{Veterinary Education}

One use of the Journal was as an ancy to promote veterinary education, especially in view of the fact that the Boston Veterinary Institute was in operation during the later period of publication. However, one might wish more concerning this school had been put in the journal. In January, 1856, the address of D. D. Slade, M. D., president, "delivered on the occasion of the commencement of the Boston Veterinary Institute," is given in full.

After giving a concise history of the veterinary art from the earliest times, Slade continues:

It is quite time to put veterinary medicine upon the basis which it so justly merits. We have thus far depended upon those who have come to us from foreign lands for all the science and skill which we could command; let us now do all in our power to build up a school for ourselves, whereby we may supply the country which offers such an abundant harvest both for fame and pecuniary remuneration to 
the young man of enterprise and education, as the practice of veterinary medicine upon scientific principles. ... It is needless to suppose that any one may do without thorough education, veterinary medicine requires diligent preparation and long study, and so far from its being beneath the notice of an educated and refined man, it is a study worthy of the best and highest talents.

Slade states that to prepare himself for his position: "a few months were spent by myself at Alfort."

In March, 1856, there appears an extract from the "President's Message," presum- ably that of Dr. D. D. Slade on the need for veterinary education:

No citizen of our country should permit himself to forget, that the inferior orders of creation are entitled to consideration and mercy; they constitute a part of the wealth of the nation, they are subject to the same skill in treatment of their maladies that apply to their "lord and master." Therefore, in view of the ignorance which now prevails in all that pertains to the fundamental principles of Veterinary science, I conjure you to aid and foster it. The emergency appeals to the citizens of every State, and I consider it an imperative duty to
Dadd's American Veterinary Journal (185I-1852; 1855-1859) was the first serious attempt at veterinary journalism in this country, but it probably never paid its own way, and its publication was suspended when Dadd moved westward. $R$. $R$. Shomer collection

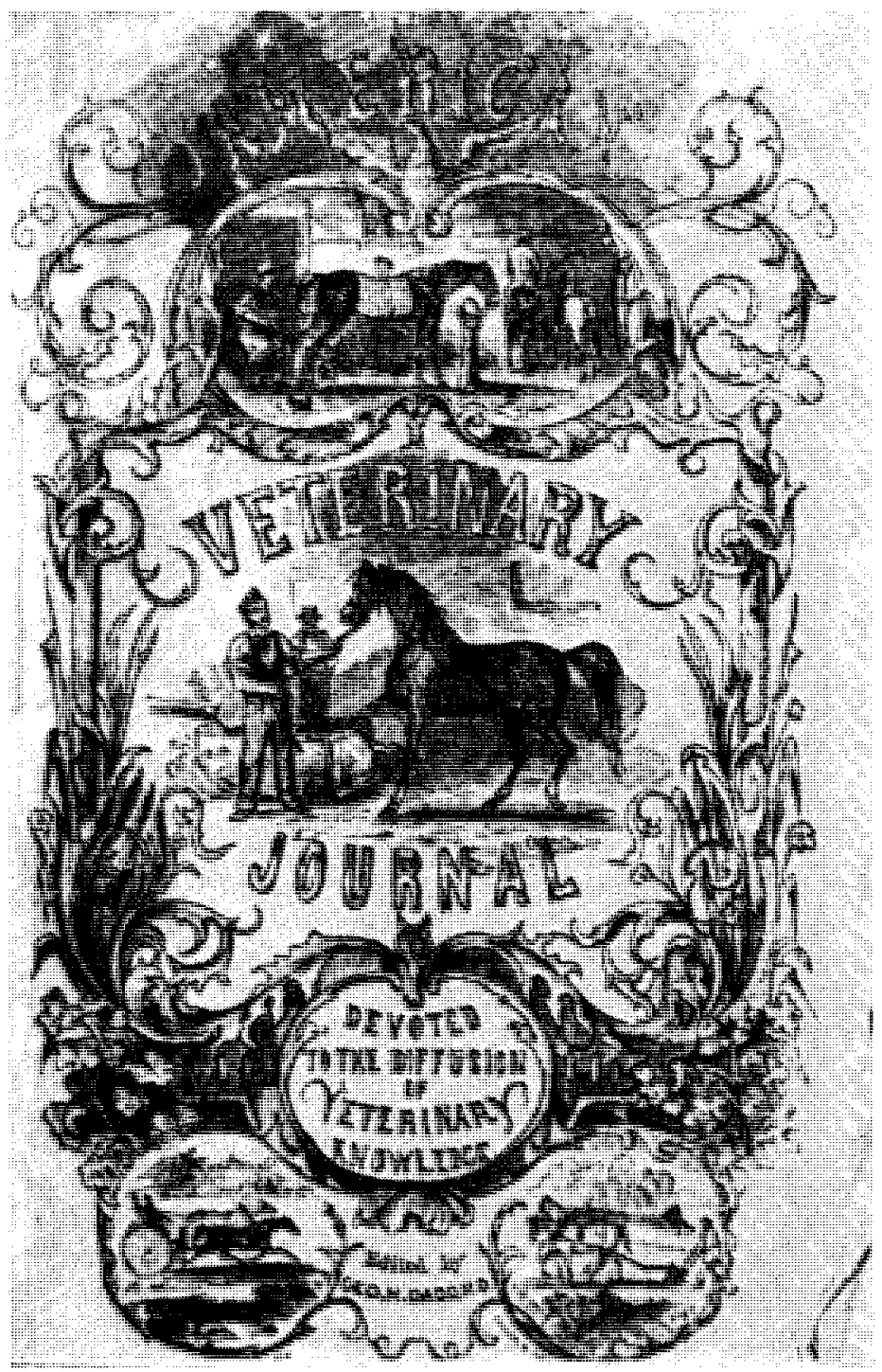


recommend Congress to establish a National Veterinary College, and appropriate, from the National funds, a sufficient sum of money to endow an Institution where the principles of Veterinary Science shall be taught.

In May, 1856, Dadd acknowledges receipt of "A Plea for the establishment of Veterinary Colleges in the United States," a lecture delivered before the State Agricultural Society of Pennsylvania by James Bryan, M. D., Professor of Surgery in the Philadelphia College of Medicine. Dadd states:

It is refreshing to know that amidst the darkness that at present prevails on Veterinary Science, there are a few choice spirits laboring for its advancement; and still more gratifying is it to know that the members of our sister science - the noblest calling that ever man embarked in - are raising their voices and using their influence to arouse the community to a sense of duty which they owe to the inferior orders of Creation.

Dr. Bryan comes to the rescue, as an advocate for those "bereft of speech," and in so doing he has broken the spell, which, with a few exceptions, has hitherto operated to deter his professional brethren from lending their powerful aid and influence for the advancement of veterinary science. We sincerely hope that the members of a liberal profession will no longer stand aloof, nor give our science the cold shoulder; but, like Dr. B., and others that we might name, engage and interest themselves in that which has contributed greatly to advance a knowledge of human surgery.

\section{Horse Influenza}

Much of the American Veterinary Journal for 1856 is occupied with items of more general agricultural interest than strictly veterinary reports. This is in accord with Dadd's stated policy of catering to the farmer as well as the veterinarian. Undoubtedly the material of greatest veterinary interest - then as well as now - is a series of articles on "distemper" in horses. The outbreak of 1872 is frequently considered the first major occurrence of this epizootic, but the Journal leaves no doubt that the outbreak of 1855-1856 was of epizootic proportions. In January, 1856, Dadd states:
There is a disease now prevailing among horses in this State, which in stable language passes under the familiar terms, horse-ail, pinkeye, distemper, \&c. ... In some localities it spreads after the manner of epizootic, or sporadic affection; appearing here and there in certain localities, with greater or less intensity; sometimes singling out half a dozen horses, out of a stable of twenty; at other times ... it runs through a whole stable. ... At the present time there are a great number of truck horses laid up with this affection.

Dadd gives a detailed account of the disease, which he prefers to call influenza, or in its last stages, typhus.

In February, M. A. Cuming reports the disease from St. John, New Brunswick, and says it has:

for some time been prevailing here, and . . . I have every reason to think it is of an epidemic form . . . one of the most insidious, if not the most dangerous, to which animal life is subject.

\section{Dadd states:}

I am informed that in the State of New York, the disease has assumed a most malignant type, and the subjects die in the course of a few hours, notwithstanding the efforts of the most experienced surgeons ... [ [ and later] the veterinary surgeons of England have hitherto maintained a remarkable silence on the subject ... and so late as the year $1850 \ldots$ in London very little is known about such disease.

In the March issue he reprinted a long article on the disease translated from the French by William Percival, and in April, Dadd acknowledges a letter from Isaiah Michener, of Bucks County, Pennsylvania, to the effect that:

influenza has prevailed in his locality since the first of September, and up to the present period; and that he has been remarkably successful in the treatment of the same.

\section{Who's Who}

An analysis of the contributors of original articles to the American Veterinary Journal shows that a fair number of practitioners actually did write for the Journal. Admittedly a large part of the 
space was occupied by material taken from other journals, and Dadd, Copeman, and the two Woods supplied much of the original material. The professional contributors to this volume included three identified as graduate veterinarians: M. A. Cuming, M.R.C.V.S. of St. John, New Brunswick; John C. Ralston, M.R.C.V.S. of New York; and Albert Borcherdt, of Chicago, a graduate of the Dresden school. Those identified as "V.S.," in addition to Dadd, are:

Wm. Somerville, Buffalo, New York

Isaiah Michener, Bucks Co., Pennsylvania

Arthur S. Copeman, Utica, New York

Robert Jennings, Cleveland, Ohio

Wm. H. Rose, New York, New York

Jas. Harkness, St. Louis, Missouri

G. W. Bowler, Cincinnati, Ohio

Elisha F. Thayer, West Newton, Massachusetts

Ebenezer T. Wood, Northampton, Massachusetts

Charles M. Wood, Boston, Massachusetts

Robert Wood, Lowell, Massachusetts

W. Pierce, Ravenna, Ohio

Charles Scrutton, New Bedford, Massachusetts

In another category are Dr. Jewett, of Palmyra, Maine; Dr. B. Way, of Seymour, Connecticut; and C. D. Bent. Three identified as physicians also contributed: D. D. Slade, M. D., president of the Boston Veterinary Institute; Thomas W. Gordon, M. D., of Georgetown, Ohio; and Ben Munroe, M. D., Woodford, Kentucky.

Other practitioners mentioned by name are the officers of the American Veterinary Association of Philadelphia: John Scott, M.R.C.V.S.; W. W. Fraley, V. S.; R. Evans, V. S.; and A. Tegtmeier, V. S.; all of Philadelphia; and E. Coots, V. S., of West Chester, Pennsylvania. C. M. Wood states that the following practitioners in New York were all graduates of the London school: Grice, Curtis, Copeman(?), Lockhart, Wills, and Pilgrim.

Some inkling of the impending fate of the American Veterinary Journal can be gathered from the list of contributors to volume three in 1858 , and the three issues of volume four in 1859. Of the group ap- pearing in volume one, only Copeman, C. M. Wood, R. Wood, Jennings, Michener, Pierce, and Gordon contributed in 18581859. Additional contributors, apparently all V.S., are: A. T. Wilson, Milwaukee, Wisconsin; J. L. Seely, Janesville, Wisconsin; S. B. Stowell, Northampton, Illinois; John Byrne, Antigua, West Indies; and Wm. Beers, Milan, Ohio; as well as a physician, L. S. Nicholson, of Iowa. Also mentioned by name are Dr. F. Hackenberger of Philadelphia, Dr. A. Ferguson of Ohio, Mr. Barton of Antigua, West Indies, and the officers of the Boston Veterinary Association: C. M. Wood, R. Wood, Thayer, Copeman, and Wm. Sanders of Salem, Massachusetts. Several students of the school, listed elsewhere, were also contributors.

The last issue of the Journal, March, 1859 , is conspicuous for its lack of original articles. Dadd's major contribution is a lecture on the "Anatomy and Physiology of the Eye"; other than case reports, the balance of the issue is made up from borrowings from other journals. It is evident that the sands were running out, and Dadd states: "It may be expedient, ere long, to suspend the publication," and mentions "negotiations now pending" with several Agricultural Colleges, his own students, and his books as reasons:

And to be candid about the matter, this Journal does not command the liberal support which it ought to enjoy. . . . Our opinion is, that a Journal of this kind might be made to pay, only by connecting it with some Agricultural paper.

If any of his readers thought differently, and wished to try it, the Journal was for sale. No one thought differently.

\section{One Veterinary Hercules}

It is obvious that the American Veterinary Journal never had the support, either from contributors or subscribers, that it needed. But, considering the circumstances, Dadd carried the Journal along on a surprisingly high level. He has been accused of letting certain unprofessional traits de- 
tract from its quality, but it should be kept in mind that professional ethics then and now were not the same. Thus in 1856 , the London Veterinarian had noted Dadd's Journal as a "good omen," but was distressed to receive, from a Boston practitioner, a packet of handbills touting Dadd's patent medicines.

Dadd calls the informer "a contemptible coward" for not disclosing his identity, and hastens to explain:

Public opinion in this country differs very much from that of the Old World in relation to the preparation of horse medicines. Here, it is needed, there, you need it not.

He states he had begun the manufacture of these medicines in 1847 at the behest of prominent husbandmen, and that they were still prepared under his advice, but:

So soon as a respectable number of legitimate practitioners make their appearance, or my own convictions assure me that I am doing wrong, I will immediately abandon the business. . . . The composition of these medicines has never been kept a secret from the profession. ... In a country where veterinary science hardly has an existence, I am not practising empiricism.

He likens the situation to London having only one graduate veterinarian, for in the United States in 1847:

According to the most reliable authority, there were but fifteen certified surgeons in the whole country! One veterinary Hercules to every two millions of inhabitants!

To assure his English friends "there is not a more ardent laborer in this country in the cause of veterinary science," Dadd states:

I have written over three thousand pages of manuscript for our agricultural periodicals, without receiving one cent remuneration; and have delivered a great number of free lectures ... and have always urged ... the importance of establishing veterinary colleges in this republic.... I submit ... that I am not the vile empiric the sender of these handbills would have you suppose.

On the subject of professional advertising, Dadd later says:
We recommend our subscribers whom expect to get a living in the practice of the veterinary art, to advertise. It pays to advertise. There are a number of veterinary surgeons now practicing in these United States whose fame does not extend beyond the smoke of their own chimneys, simply because they neglect to advertise, and thus fail to inform the public of their whereabouts.

\section{Good Wood}

In 1858 , C. M. Wood, in writing on "Veterinary Medical Knowledge," deplores the apathy:

So generally manifested, by the certified Veterinary Surgeons of this country, in regard to the diffusion of Veterinary knowledge.... They claim the right to remain silent on the subject, unless in the stable, or bar-room. . . . How many of them have ever contributed a single line to a medical journal?

He continues in this vein, and accuses his fellow practitioners of preferring to keep veterinary medicine shrouded in "mystery and ambiguity" in the mistaken belief that they are promoting their selfish ends. While there undoubtedly was some truth in his allegations, this sort of attack could hardly be calculated to win friends, and probably did more harm than good. In arguing for an increasing diffusion of veterinary knowledge, he states:

While the people at large are unadvised of the better practice which science introduces, they will resort to ignorant dabblers as the best practitioners for their animal's diseases. The people must be properly instructed as well as the Veterinarians. And I hold that it is our duty to condemn any practice which is clearly injurious. If the truth is not told, people will suppose that error is truth; and go on inflicting misery, instead of ministering relief. All of us should attend to this matter, and never let a known error appear in print without putting a mark upon it.

Robert Wood, brother of Charles, in writing on "Catarrh in Neat Cattle, alias Horn Ail," comments on the usual absurdities connected with this disease, but adds:

I must confess, however, this is not as frequently the case, now as heretofore, the people generally appreciating more and more the value of our art. ... Where one animal dies in this 


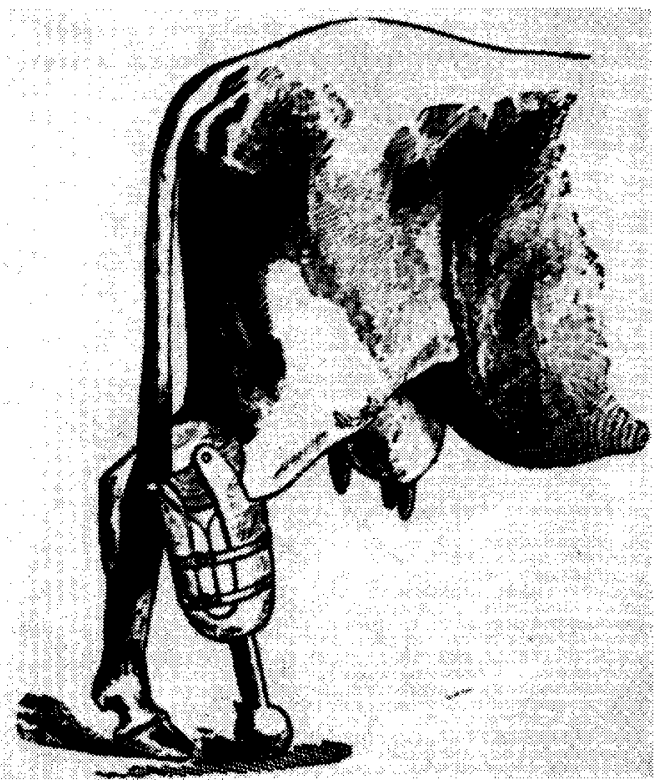

Several apparently successful instances of prosthetic devices being used after amputations were reported from the 1830's, one of the first being for a pig. The operation was most commonly an alternative to fracture reduction. Liautard: Surgery

city and vicinity, at this time, there were ten, twelve or fifteen years ago.

Wood obviously was a progressive practitioner; he mentions using ether anesthesia to castrate several pigs with scrotal hernia, the operations being "perfectly successful, the parts healing by the first intention." Robert Wood, along with C. M. Wood and A. S. Copeman, were listed as "Regular Contributors" to the Journal until December, 1858, and all three were members of the faculty of the Boston Veterinary Institute. The last communication by Robert Wood, however, appears in the March issue. In the April issue there is a report of a case of colic by E. F. Ripley, "Student with Dr. Robert Wood," which in the absence of his mentor the student apparently treated successfully.

C. M. Wood, despite his protestations over the failure of veterinarians to write, lasted only a little longer as a contributor to the Journal. In a report of several cases of fractures in horses, he mentions that a Boston paper had asked, "Is there no de- vice in modern surgery to prevent a horse being killed because he has a broken limb?" and suggests the same means are applicable to man and horses. Wood states: "To this last remark I cannot assent ... in no case have I ever been successful." He reports three cases of tibial fracture, one each of the ulna and humerus, two of the spine and one of the femur, all obviously beyond aid.

In May he writes a letter to the editor of the Journal asking for simpler terminology in veterinary writing:

I always use scientific terms with reluctance; and I truly wish that all writers would abandon them altogether. .. . Some of my contributions to your Journal, have given offence to some of my "professional brethren". ... Why do they not fill a page of the Veterinary Journal?"

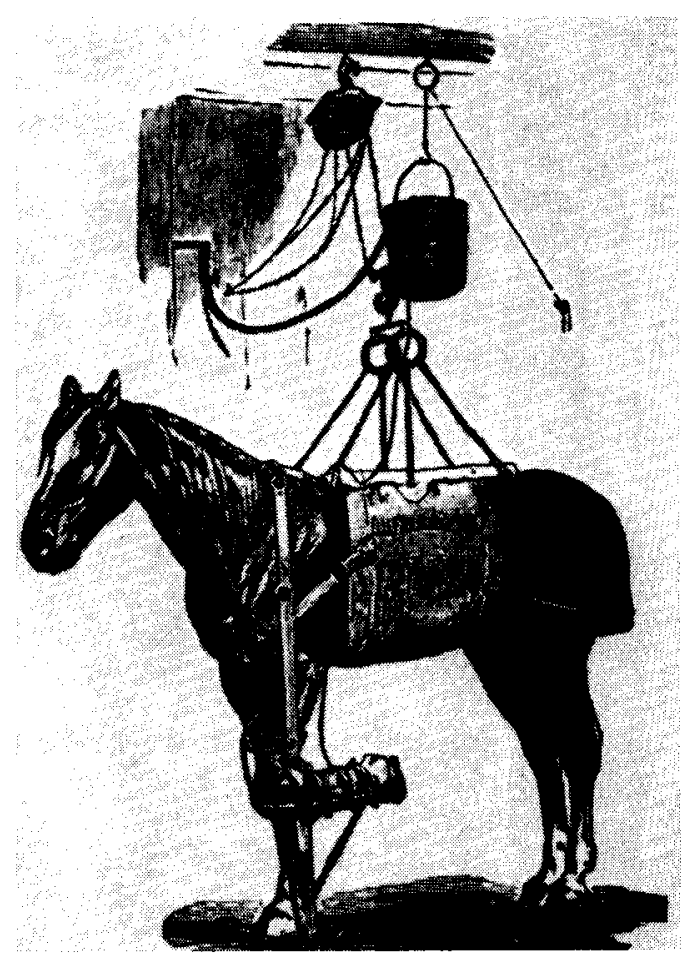

With the use of an apparatus with limb support and slings for fractures below the knee, the prognosis for many metacarpal fractures so handled was considered favorable. Dadd reported a number of successes with simple splints and casts. Liautard: Surgery 
This is his last communication. Curiously enough, he had earlier identified himself as "V.S.", or as "Veterinary Surgeon," but in his two articles on fractures he adds "M.D."

Concerning C. M. Wood, Dadd had stated in 1856:

Dr. Wood ... is one of the Pilgrim pioneers of veterinary science in Massachusetts; he has buffetted the rude shock of popular prejudice in regard to all that pertains to what is commonly denominated "horse doctoring," until reason and science have triumphed over ignorance and quackery; and now, through his own industry and perservance, stands at the head of our profession.

Dadd added a footnote on Horse Doctoring, saying: "Vulgar epithets of this character should never be used to designate the science of veterinary medicine." Yet, Dadd's most widely circulated work was his Modern Horse Doctor, and in this work he had spoken slurringly of veterinarians as the "lords of pukes and purges."

Arthur S. Copeman, Professor of Chemistry and Pharmacy in the Boston Veterinary Institute, was a faithful contributor up to the time his name was dropped; thirteen of his articles appear in 1858, most of them on the actions of drugs. In writing on colic he states, "There is much dogmatism and quackery both within and beyond the profession concerning this disease." In speaking of those who prescribe "hen's dung or chicken's guts," he says their faith is just as strong as that of "the regular Vet's." C. M. Wood takes a misstep farther by speaking of certified "Vets" (i.e., instead of Vet's) in his articles on "Veterinary Medical Knowledge."

The September issue carries an address on "History of Veterinary Science," made by Copeman before the Medical Association of Utica, which had given him an "honorary seat" in that society. In comparing human and animal medicine, he says:

If ... we have greater difficulties to contend with and overcome, a more difficult master to please, and are expected to be perfect in all these duties, I contend that in a scientific, a meritorious and useful point of view, the veterinary profession per se is not unworthy to take its stand along side that of the human.

His last communication to the Journal is also an address given before the Utica Medical Club on "Animal Heat and Motion." Of principal interest is his statement that he had personally "neurotomized more than fifty horses."

\section{Advocate of Anesthesia}

Among references to the use of anesthesia in the American Veterinary Journal in 1856, Dadd states: "Ether is a very excellent remedy in spasmodic colic . . . it will generally mitigate abdominal pain, and tranquilize the nervous system." (The latter phrase has a modern ring!) For colic Dadd employed an ether and chloroform mixture, administered by an inhaler composed of "an old sheet and a sponge," to the point of complete anesthesia. In addlition to making the patient more manageable, and reducing the likelihood of the animal's damaging itself, Dadd considered that the anesthesia had a direct beneficial effect upon the course of the disease. In 1858 he used ether "to diminish the reflex excitability of the nervous system," in a case of puerpural convulsions in a cow.

In the same year Robert Jennings reports on "Experiments with Chloroform and Chloric Ether in Veterinary Surgery." He mentions several cases in the practices of John Scott and W. W. Fraley in which chloroform was used to anesthetize horses with fractured limbs, whereupon some experimental surgery was performed, and the horses destroyed. In another instance he assisted G. W. Bowler in an operation for umbilical hernia, and one for removal of a tumor, both under chloroform. In his own practice he had used chloroform anesthesia in removing a tumor, and ether for neurotomy, noting: "Not having an assistant in this case, I found it extremely difficult to administer the anesthetic, and operate myself." This article indicates that a number of practitioners, not necessarily 
under the influence of Dadd, were using anesthesia at this early date.

In writing on the "Caesarean Operation on Sows," in 1858, Dadd states:

Humanity would suggest that the subject be etherized, when performing so formidable an operation, yet our experience in the use of anesthesial agents on swine, will not warrant us in recommending its universal application.

In the same year, Robert Wood used ether in operating for scrotal hernia in pigs, noting: "Of all the animals $I$ have etherized, the pig is the most susceptible and the quickest brought under its influence."

In 1859 Dadd reports using equal parts of chloroform and ether, which "rendered the animal completely insensible to pain," in removing a tumor from the penis of a horse. As a matter of passing interest, Jennings, in his book on The Horse and His Diseases (1860), states that for amputation of the penis all that is required is "one swift bold stroke of a sharp knife." This in spite of his opinion that "In severe operations, humanity dictates the use of some anesthetic agent to render the animal insensible to pain." At best, Jennings' amputation would seem calculated to leave a bloody stump. Dadd ligated the arteries.

In 1860, the editor of the American $A g$ riculturalist states:

Dr. Dadd, V.S., just informs us that he has recently performed the novel operation of spaying a mare.... We believe this is the first case of the kind in this country, if indeed it is not the first one ever tried ... it has been generally supposed that an operation of the kind would prove fatal. The animal was under the influence of sulphuric ether, and the operation proves entirely successful, ten days having elapsed since it was performed. The object to be attained in this particular case, was to render the mare more docile, as she had heretofore been nearly unmanageable during her periods of heat. Physiologists are of opinion that removing the ovaries, if successfully performed, will render the animal gentle and mild.

Another innovation, that of blood transfusion in the horse, is reported in the 1858 Journal, in an article taken from the Dublin Quarterly Journal of Medical Science. In this, James Farrell, V. S., records several successful cases of direct transfusion from healthy to diseased horses, with improvement in the latter. He states:

Whatever obstacles and objections there may be to its performance in the human subject, there are none to prevent its becoming a most valuable agent in Veterinary science.

In commenting on this, Dadd mentions the unfavorable results of transfusion shortly after Harvey's work on the circulation of the blood, but states:

We can conceive, however, of cases which might occur, when, for example, a horse has lost a large quantity of blood accidentally, to warrant us in resorting to transfusion; and if any of our Veterinary friends are disposed to make experiments of this kind, we urge them to do so.

However, it does not appear that Dadd, or many of his "veterinary friends" attempted the experiment. Robert McClure apparently did use blood from healthy horses in treating influenza in 1863.

In 1856 Dadd noted the action of the New York Legislature on "A bill to protect the people of the City of New York against frauds by the adulteration of milk, and to provide for the inspection of milk." This provided for the appointment of six milk inspectors:

whose duty it shall be to keep a list of all dealers in milk, and examine the quality, and report to the City Inspector all cases of adulteration or selling milk of diseased cows.

And in reprinting an extract from "our enterprising contemporary, Frank Leslie," on the "swill-milk business" in New York City, Dadd states in 1858:

By the vigorous efforts which Mr. Leslie has made to exhibit this pernicious business in all its revolting features, and to utterly annihilate it in the future, he has drawn upon himself and his employees the malevolent rage of all the swill-milk dealers. ... Our city children, who are brought up or largely fed on purchased milk, are poisoned and put to death.

\section{Items of Interest}

Among some of the items of interest reported by Dadd from his own practice in 
1858 are the use of potassium iodide, both internally and externally, for indurated udders of cattle, and the use of imported milking tubes for teat obstructions; a prescription of beef steak and strychnine ". . . to protect sheep from the ravages of the canine species"; iodine ointment to reduce the size of enlarged thyroid glands; a flexor tenotomy for "sprung knee"; successful reduction of a fractured radius in a heifer, and of the first phalanx of a horse; and relief of colic by enterotomy. Of incidental interest is his statement: "The term bloat has long been discarded by Veterinarians." And in response to the request of a Texan, who says, "Many large stock owners could each amply support a surgeon on the profits of the animals saved in the course of a year," Dadd replies:

We cannot spare a single qualified practitioner from this region, for all find ample employment, and there is plenty of room for more.

Also of interest is a note appended to a communication on hog cholera by Thomas W. Gordon, M.D., of Ohio, who states:

We have men among us who think paying any attention to the lower animals, decidedly out of taste, and perhaps out of caste, for a physician . . . but my motive in life has been, and is, to do all I can to ameliorate the condition of my fellow men, and when I can save their property, never to neglect what is to me a duty.

The prescription of copperas, saltpetre and ginger:

Has undoubtedly been the means of saving very many hogs in this section of the country, but I do not suppose it, or any other remedy, will save all that are affected.

\section{The Journal in Retrospect}

Despite the generally unfavorable appraisal of Dadd and his American Veterinary Journal given by Merillat and Campbell, Dadd is admitted to be:

the most facile American veterinary writer of the nineteenth century. His grammar was good, his diction splendid and the range of subjects upon which he wrote, extensive. ... His books were well written and authoritative.

And concerning the Journal:

This publication derives its historical importance, which is considerable, solely from the fact that it was the only one in its field at the time. . . . His [Dadd's] articles in the American Veterinary Journal seldom dealt with strictly veterinary matters. . . . Seldom indeed did he deal with practical subjects of the veterinary clinic. ... No cause for the discontinuance of the publication of this journal is given in its pages.... [but] from all the evidence, one can say the American Veterinary Journal died because it had the wrong editor and did not deserve to live.

The latter estimate apparently is based in part on the statement of C. M. Wood in the Veterinarian (London) for September, 1859.

Its publication [the Journal] was recently suspended for want of patronage. The editor has often stated to some of us its contents were too scientific for this country and that he had to substitute matter of a more simple kind as being he more acceptable to his readers. Thus we think he has aided in the dissemination of error rather than truth, and very soon after what he called the "too scientific contributions" were discontinued, the journal itself collapsed. [ But Wood himself had used scientific terms "with reluctance."]

Merillat and Campbell, however, appear to have been unaware of the three issues of the Journal that appeared in 1859; in the last issue (March), Dadd explains:

in consequence of remissiveness on the part of subscribers for the past two years, my pocketbook is the seat of a very severe dyspepsia. . . . It may be expedient, ere long, to suspend the publication. . . . To be candid about the matter, this Journal does not command the liberal support which it ought to enjoy.

Although he was given to hyperbole, Dadd's statement that fewer than 50 of his subscribers were veterinary practitioners is probably close to the facts. Two decades later, Alexandre Liautard, in reporting on the status of the American Veterinary $R e$ view, states that in March, 1877 there was a deficit of $\$ 90$ on the first issue (January, 1877): 183 copies had been distributed, 105 
paid for. In 1880 the circulation appears to have been under 250 , at which time production costs were barely being met. By this time there were probably some 1,500 or more practitioners in the United States. Thus it might be argued that Dadd was closer to being a realist than his critic and colleague, Wood. The same argument, that there was little of clinical veterinary medicine in the early volumes, could be leveled against the American Veterinary Review; many of its pages, in fact, were reprinted from foreign journals. As Dadd himself stated, concerning his Journal:

At this early period in the history of American Veterinary Science it is a matter of impossibility to secure sufficient patronage for the support of a purely veterinary periodical.

That his hybrid production survived as long as it did is primarily a tribute to Dadd's tenacity.

\section{GEORGE DADD, VETERINARY EDUCATOR}

Dadd's interest in veterinary education spans his entire career, but it might be said that he labored in this field largely to little avail. His efforts on behalf of the Boston Veterinary Institute and his several private enterprises, however, should be considered in some detail inasmuch as they were truly pioneering moves toward a veterinary educational system in America. Those who have been most disparaging of Dadd as an educator have, perhaps, not been as fully acquainted with his work as the scattered data would permit, once assembled.

Little, other than what can be gleaned from the American Veterinary Journal, seems to be a matter of record concerning the Boston Veterinary Institute, including Dadd's connection with it. One thing is certain: Dadd's interest, if not actual engagement, in veterinary education antedates the Institute by several years. His Advocate of Veterinary Reform (1850) contains a letter, in response to an inquiry from Dadd, written by Henry Clay in 1849:

There is no department in the medical world in which there is such a lamentable want of knowledge as that of the proper treatment of horses and cattle. Whoever shall supply this deficiency ought to be regarded as a great benefactor, and I shall be very glad if your exertions entitle you to that merit.

In November, 1851, Dadd notified readers of the American Veterinary Journal:

The undersigned is now prepared to receive a limited number of pupils, with a view of instructing them to practice, on scientific principles, the veterinary art. . . . Let a number of high minded, honorable and temperate men be qualified to practice this art, and they will not only insure themselves a handsome income, but also rescue our domestic animals from a barbarous system of medication. Applications must be made to George H. Dadd, M.D. No. 26 N. Bennett Street, Boston, Mass.

Evidently the response was not overwhelming, for in the Journal for August, 1852, he proposed petitioning the Massachusetts legislature for a charter incorporating:

The Boston Veterinary College of Surgeons . . . for the instruction of young men in all that pertains to the veterinary science, that they may be qualified both theoretically and practically, for the practice of a benevolent profession.

In 1854 the editor of the Michigan Farmer published some remarks on veterinary education contained in a private letter from Dadd, urging some public benefactor:

to use his influence and purse for the purpose of endowing veterinary schools, so that our domestic animals may have the benefits of scientific, veterinary medication.

\section{Dadd continues:}

If you happen to know of an individual desirous of qualifying himself for a successful campaign against ignorance and quackery, send him on this way, I have just commenced a veterinary school, which I hope may be the means of enabling some of our young men to tilt a lance with our elders of the Old World.

While some sources give 1854 as the year the Boston Veterinary Institute was founded, the American Farmer for August, 1855 , states that its charter was obtained in 
May of that year. The Prairie Farmer in 1855 notes:

The Massachusetts Legislature has just incorporated the Boston Veterinary Institute, investing it with University powers, to confer degrees, etc., and to hold property to the amount of $\$ 25,000$. Dr. Dadd is undoubtedly at the bottom of this movement.

While it is Dadd whose name is irrevocably linked to the school, the charter was obtained by D. D. Slade, a Boston physician, who served as president of the new institution, with Dadd and the two Woods as faculty.

\section{The Boston Veterinary Institute}

With regard to the Boston school, Merillat and Campbell state:

In some way the impression has come about that Dadd established and conducted the Boston Veterinary Institute. He tells us himself that he had nothing to do with its management. Wood [C. M.] was, apparently, the real power behind it. He appears to have wearied of refusing the importunities of Dadd and others to admit uneducated students and to give advanced standing to practitioners because of long practice. At any rate he withdrew, and thereupon the school failed.

It is also stated: "Wood was a profound scholar, self-taught as far as veterinary science was concerned." His scholarliness however, would seem open to question in light of his attitude toward scientific terminology: "I always use scientific terms with reluctance." Moreover, the facts concerning the failure of the school seem to be more elusive than suggested above. While it is true that two terms appear to have been insisted upon to the end, Dadd obtained several students for himself - perhaps with the lure of a single term - after the school had closed for lack of students. And while Dadd may not have been the prime mover for the Boston Veterinary Institute, it would appear that he had supplied much of the momentum to keep it going as long as it did.

It is evident from Slade's "commencement" address (at the opening of the Boston Veterinary Institute) that the school opened in the fall of 1855; Slade resigned in 1857 and was replaced by the Hon. Moses Newell, who died in April, 1858. At this time Dadd was listed as Dean and Professor of Anatomy and Physiology; C. M. Wood as Professor of Theory and Practice; Robert Wood as Professor of Cattle Pathology; and A. S. Copeman as Professor of Chemistry and Pharmacy.

Slade's opening address was given in full in the January, 1856 issue of the American Veterinary Journal; he states:

This day witnesses with us the commencement of a new era in the cause of science and humanity - the foundation of a Veterinary College. ... It is difficult to understand, neither shall I attempt to explain, why we, as a people, have so long shown such apathy in regard to veterinary science. ... All that we can offer in justification of this long neglect, is, that we have but followed in the footsteps of older, and perhaps, wiser nations. In Great Britain, for example, it is only at a comparatively recent period, that veterinary medicine has been recognized among the liberal arts, and the profession and practice regarded as by no means incompatible with the dignity of a man of education. We ourselves have, however, now awakened to a sense of the importance of a proper diffusion of a knowledge on this subject, and we should earnestly hope that the establishment of this College may be speedily followed by others in our sister States, which may every year send forth men who will add dignity and importance to the art .

\section{Star of Veterinary Science}

Among the articles written by Dadd for his Journal are a number of lectures given at the Boston Veterinary Institute, or later at his own school. These show evidence of Dadd's being an interesting lecturer, tolerant of the opinions of others - unless they differed with him on the matter of humane and rational treatment. As in his other writings, these demonstrate a broad and varied experience, and an ability for incisive expression. In terminating what he terms "a practical lecture on the eye," he expounds at some length on his philosophy of veterinary education:

I prefer to deal in practice . . you may go about it like competent workmen in any other 


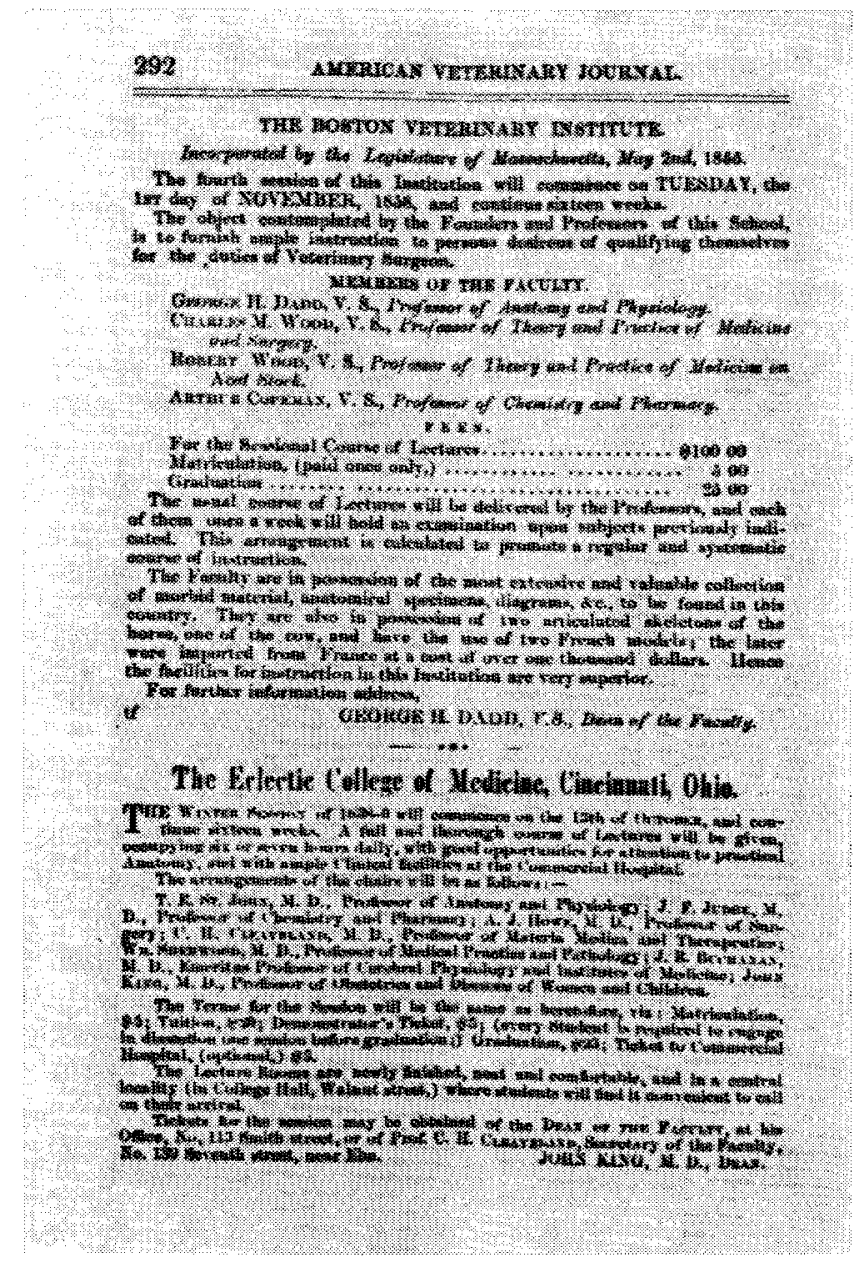

Advertisements for the Boston Veterinary Institute and the Eclectic College of Medicine indicate that the caliber of medical instruction at some schools was about on a par with that offered by the one existing veterinary school. R. R. Shomer collection have hitherto estimated the value of veterinary science in exact ratio to the talents of the $u n$ educated representatives of our art, who have, in many instances, palmed themselves on their patrons as the lights of science. But a brighter day is dawning; the star of veterinary science is in the ascendant-practical knowledge assumes her empire - improvements tread on the heels of improvement - and the dark pages of veterinary science are illumed by her present refulgent progression. It remains for us to show, and carry conviction to the understanding of our employers, not by rhetoric, but by stubborn facts, that we are trustworthy practitioners, have spent our time and money in endeavoring to solve the problems of physiology and pathology, and we must demonstrate these facts in the presence of our employers, on and within the bodies of the ailing and diseased animal; and we can do it in all curable cases. 


\section{Special Privilege}

In a series of answers to inquiries concerning the school in 1856 , a practitioner asks if his long experience ". . . will not entitle him to some special privilege in obtaining a Diploma." Dadd answers: "Every man desirous of graduating must attend two full courses of Lectures." To another who writes that he "is too old to think of commencing a new medical career," Dadd states: "This is only a matter of false opinion, for so long as a man be in possession of sound reason, age interposes no barrier against the acquirement of knowledge." To one who complains that he "cannot spare time to attend lectures," the retort is: "This we consider a very lame excuse, coming as it does from a man, now engaged, and intending to continue in, the practice of veterinary medicine."And to one who fears he "does not know enough to study science," Dadd states:

It is not necessary that a student should be in possession of extraordinary mental talents . . . [while] a classical education will aid him immensely in the pursuit of veterinary knowledge . . . let none despair - the faculty of our infant institution will be glad to welcome such into their ranks.

From these it is evident that the school had sent individual invitations to practitioners and others to attend the institution. The scanty records available would indicate that few availed themselves of the opportunity. According to Dadd, by December, 1857 , the school had only six graduates.

The identity of some students and graduates of the Boston Veterinary Institute (possibly some of them Dadd's private pupils) can be determined from various articles in the American Veterinary Journal; these include:

Dr. Jarvis Gay, South Dedham, Mass. - "a student of ours" [Dadd's?]

Elias F. Ripley, B.V.I. student, [ later ] "Veterinary Practitioner"

Lewis Putnam, B.V.I. student, [later] "resident physician at B.V.I. infirmary"

Wm. Gibb, student, [ later ] "Passed Student"

R. C. Fuller, student, "formerly many years in practice," [later] V.S.
J. E. Smith, George Parry, Jacob Dilts, Mr. Flagg: students.

The American Veterinary Review in 1908 reported the death of William S. Kooker, V.S., who had "attended Dadd's Veterinary School in Boston."

\section{Notice to Students}

It would appear that Dadd in 1858 seemingly became a competitor of the Boston school. In the Journal for January 1858 he inserted on the last page, a short "Notice to Students":

The undersigned is prepared to receive, as private pupils, any number of persons who may desire preparatory education in the principles of Veterinary science. ... Young men who contemplate a regular collegiate qualification, either in the Massachusetts "Veterinary College," or in any other, abroad, will find this an excellent arrangement to put them in the way of accomplishing their object.

Dadd was Dean of the Faculty of the Boston Veterinary Institute at this time, and it may be that the president of the institution, Col. Moses Newell at this time, objected to this competition; at any rate, this notice was dropped. But beginning in July, 1858 (Newell died in April, a similar advertisement appeared regularly in the Country Gentleman, running until March, 1859.

That the Boston Veterinary Institute was still in business is evident - but barely so. In August the Journal announced: "The fourth session of this Institution will commence on Tuesday, the lst day of September, 1858, and continue sixteen weeks." In the September issue the date was advanced to November 1 , and in November the opening was delayed to the $17 \mathrm{th}$. On each occasion it was stated that each of the professors Dadd, Copeman, and the two Woods:

once a week will hold an examination upon subjects previously indicated ... to promote a regular and systematic course of instruction. . . . The Faculty are in possession of the most extensive and valuable collection of morbid material, anatomical specimens... two articulated skeletons of the horse, one of the cow, and have the use of two French models 
[ of the horse]; the latter were imported from France at a cost of over one thousand dollars.

The latter apparently belonged to the Massachusetts Agricultural Society.

Evidently a quorum was not obtained, for the November notice is the last one on behalf of the Boston Veterinary Institute, and in the December issue one appears for the: "SCHOOL OF VETERINARY MEDICINE AND SURGERY, Established in Boston in 1849, by GEORGE H. DADD, M.D., V. S." The school was to be conducted at his place of business. One session of "three to four months," at a tuition fee of $\$ 100$, or two sessions: ". . . occupying a period of from eight to twelve months," for $\$ 200$ were offered; the diploma fee was dropped, and anyone with ten years' experience could qualify in one term instead of requiring two for everyone as the old Institute did. Each student was to be provided with free tickets to "lectures on Chemistry, and Pathological Anatomy, in the Medical Department of Harvard University," and each had "the privilege of attending all cases, which occur in the practice of the Principal and to attend the Infirmary at North Cambridge, free of extra charge." Below this notice is another for the "Infirmary of the Boston Veterinary School:

The Infirmary of our school is now located in North Cambridge; we have a temporary building, for present use, but will shortly erect one that shall be a credit to our profession . . . we have a forge .... also every facility for dissection and have made arrangements with a party at North Cambridge, to dispose of all "offal;" so that we shall not be liable to indictment under the nuisance law.

The advertisement for his school blossomed into a full page in the three issues published in 1859 and more details are offered in an advertisement appearing in the American Stock Journal in 1859:

School of Veterinary Medicine and Surgery

Established in Boston in 1849

by George H. Dadd, M.D., V.S.

The Study of Veterinary Medicine \& Surgery

The undersigned is prepared to receive, as pupils, any number of persons desirous of ac- quiring knowledge in the PRINCIPLES AND PRACTICE of Veterinary Science. Unusual facilities for dissection, demonstration and infirmary practice are furnished, and the pupils can join a class at any season of the year.

\section{REGULATIONS:}

1st. The regular sessional term occupies a period of four months, each student is entitled, at the end of the first session, to a document certifying to his faithful attendance, qualifications, etc.

2d. Each student must, ere he presents himself for examination, have attended two full sessions, and then, provided he pass a satisfactory examination, before a committee of medical men, he receives a certificate bearing their signatures, and that of the principal, and seal of the School.

3d. Any person who may have practiced Veterinary Medicine for a period, of not less than ten years, and can produce documentary evidence of the fact, accompanied by testimonials of good moral character, he can after studying one session, present himself for examination; failing to satisfy the Board of Examiners of his proficiency, he must then qualify himself in whatever branch he appears deficient, and then he is entitled to a re-examination.

4th. During the period of the first or second session, (at the option of the student) he will be furnished with two tickets, which will admit him to attend lectures on Chemistry, and Pathological Anatomy, in the Medical Department of Harvard University.

TERMS: Tickets for a full course.... $\$ 100.00$ Examination fee, (paid once only) $\ldots \ldots \ldots \ldots \ldots \ldots \ldots \quad 4.00$

The student has the privilege of attending all cases which occur in the practice of the Principal, and to attend the Infirmary at North Cambridge, free of extra charge.

The school of Veterinary Medicine and Surgery is located at No. 55 Salem street, Boston, Mass. Good board can be obtained in the city, for the sum of $\$ 3.50$ per week.

\section{GEORGE H. DADD, Principal}

In January, 1859 the Journal carries an account of 25 cases "treated, and prescribed for, at the Boston School of Veterinary Medicine and Surgery." Dadd identifies himself as "Lecturer on Veterinary Science." Two of these cases were reported in full by R. C. Fuller, V.S., a former stu- 
dent. Also reported by Fuller is one of his cases which:

was evidently incurable at the late date his owner sought to obtain medical aid. . . . He was removed to the demonstrating-room of the "Boston Veterinary School," North Cambridge, where the principal proceeded with an autopsy, operations, and demonstrations, the pupils being in attendance.

The operations performed on the clead subject were: paracentesis, tenotomy, tracheotomy, suturing, and nicking. These were followed by an autopsy and anatomical demonstration, "which closed the operations for the day, subsequently followed by an entertaining and lucidly instructive lecture in the evening."

In February, 1859, George Parry, scribe, reports: "Doings at the Dissecting Room of the Boston Veterinary School." A horse "purchased by Dr. Lewis Putnam, resident physician at our infirmary," for five dollars, "which was contributed by the students," was anesthetized and then pithed: "Our instructor, Dr. Dadd, then performed as before; the ante-mortem diagnosis of 'disease of the heart' . . . made by Dr. Putnam, was evidently correct." Another horse which:

a person ... had bled ... to the amount of "half a bucket full," and had administered "lots of medicine," was visited by the principal of our school, who then pronounced sentence of death on the sufferer. . . The autopsy revealed... the animal died secundum ignoramum.

\section{Peripatetic Professor}

How much longer Dadd maintained his school appears not to be a matter of record; mention is made of students accompanying him on a case in April, 1860, but his professorial duties may have been more in the nature of a preceptorship at this time. In 1860, he began a term as Veterinary Editor of the American Stock Journal, continuing with his practice in Boston for some time, but by January, 1861, he had moved to Cincinnati and set up in practice there.

Beginning in April, 1861, Dadd ran nearly a full page advertisement for the: "Academy of Veterinary Medicine and
Surgery, of Cincinnati, Ohio. Incorporated, February 27, 1861." The object was stated to be:

to educate persons by practical and clinical teaching, for the practice of Veterinary Medicine and Surgery. . . . Hitherto, the means for education, in Veterinary art and science, has been very limited, and a vast number of the finest stock in the country die prematurely; many of them of unnecessary diseases, which might be prevented, by proper attention to the law of physiology, and in the rational practice of Veterinary science.

The "Departments of Tuition" were given as Anatomy and Physiology, Chemistry, and Theory and Practice of Veterinary Medicine - including both lectures and "the practice of the Principal." Chemistry was to be given through the medium of tickets to a lecture course "at one of the Medical Colleges of this city."

Two sessions of four months each were required, but one would suffice for "any student having attended one course of Lectures on Human Practice, at any School or College in this, or any other country." The expenses were listed as $\$ 100$ for the first session; $\$ 50$ for the second; diploma free of charge. There is no indication that he secured any students and in March, 1862, the Prairie Farmer announced he had taken up "permanent quarters" in St. Louis.

\section{The Chicago Veterinary Institute}

Dadd's "permanent quarters" in St. Louis were hardly that, for in September, 1862, under the heading: "Veterinary School in Chicago," the Praivie Farmer notes:

Dr. Geo. H. Dadd is now in this city with the object of making arrangements for a permanent location here for the practice of Veterinary Surgery, etc., and probably will open a school of instruction similar to the one he estabilshed in St. Louis. Dr. Dadd has a reputation which has gone before him, and the Northwest will no doubt be glad to know of his location in this city, where he can at all times be consulted by letter or personally.

Not one to let the grass grow under his feet, two weeks later Dadd's business card appears: 


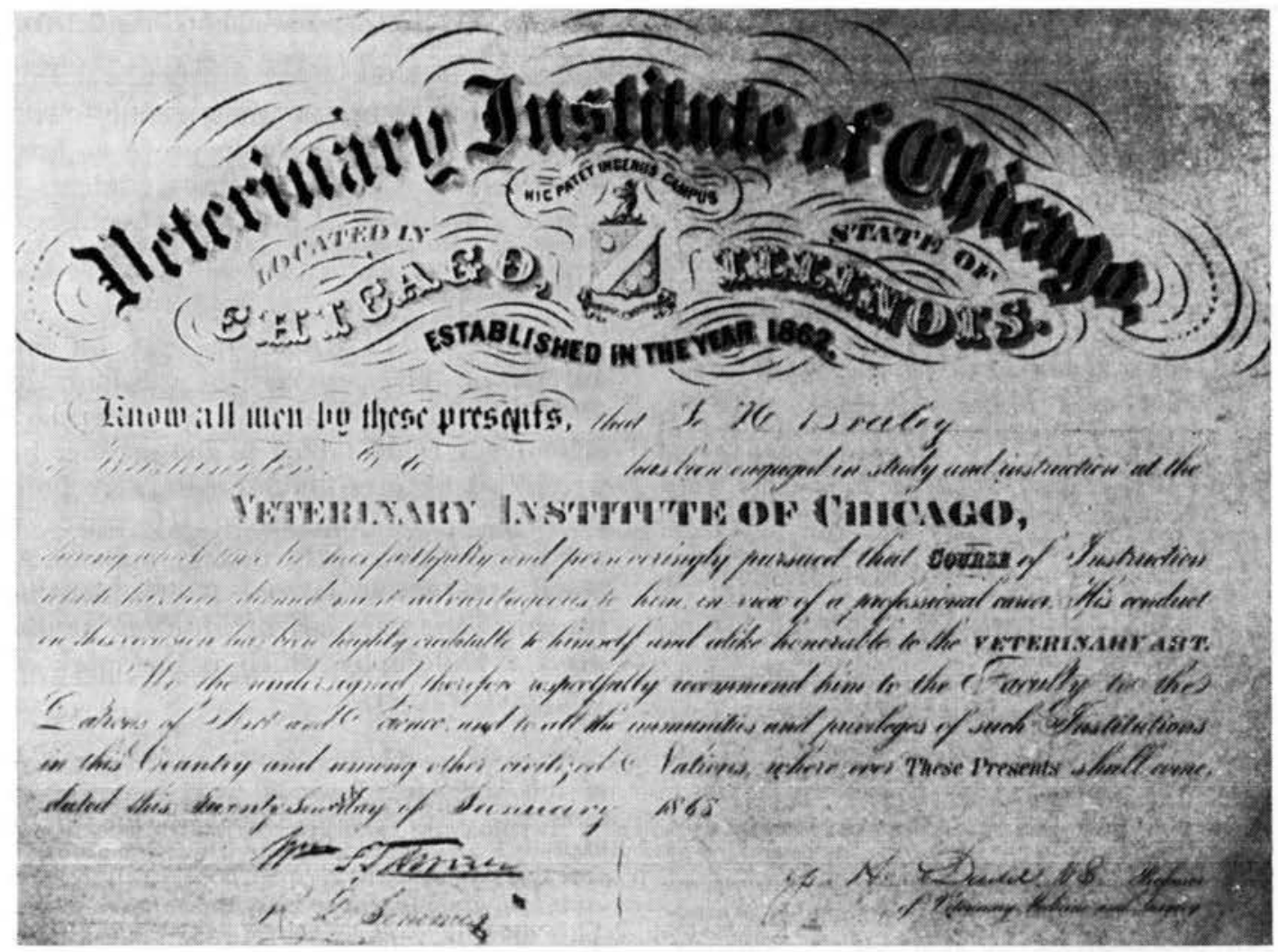

Diploma of graduate from Dadd's short-lived Veterinary Institute of Chicago. Probably more truthful than some similar "sheepskins," this merely states that the recipient "has been engaged in study and instruction." Veterinary Medicine

VETERINARY MEDICINE \& SURGERY. GEO. H. DADD, Veterinary Surgeon, Late Professor of Anatomy and Physiology in the Boston Veterinary Institute. . . . Respectfully announces that he has just removed to the City of Chicago, for the purpose of practicing his Profession, and is prepared to treat all forms of Disease and Lameness incidental to every description of Domestic Animals. Dr. Dadd is prepared and qualified, as a Public Teacher, to receive Students in view of qualifying them as practitioners. Also, to give Practical Instructions, and render competent all persons desirous of serving as Army Veterinary Surgeons. Particular attention given to the operation of Spaying Milch Cows. G. H. Dadd, Veterinary Surgeon, Office, Phoenix Stables, corner State and Adams Sts.

While Dadd's "business card" had about the same degree of frankness as those of some physicians and dentists of the time, it is of some interest that as a "removal notice," it ran for 13 months, appearing for the last time in October, 1863. This was replaced in the issue immediately following by an advertisement for:

VETERINARY INSTITUTE OF CHICAGO. (Incorporated) The regular tuition fee for qualifying students for the practice of Veterinary Medicine and Surgery is one hundred dollars. Diploma, twenty-five dollars. G. H. Dadd, M.D., V.S., Principal.

In November we are provided with further details:

First session, 1863-1864. The perpetual tuition fee, for instruction and qualification One Hundred Dollars. Diploma - TwentyFive Dollars. Single Session ticket, without Diploma - Fifty Dollars. Single class ticket for amateurs, four months - Twenty-Five Dollars. Theory and Practice of Medicine-Anatomy and Physiology, Professor G. H. Dadd; Surgery and Surgical Anatomy, Prof. McDonnell; Principles and Practice of Shoeing, Professor G. H. 
Dadd; Clinical Instruction, Professor McDonnell.

The latter notice was discontinued in January, 1864, and a year later was expanded as a "Circular" detailing the "Departments of Tuition" as follows:

Anatomy and Physiology. - The Lectures on Anatomy and Physiology will be demonstrated and illustrated by Dissection, and by means of Diagrams, Skeletons, and prepared Anatomical Specimens.

Theory and Practice of Veterinary Medicine and Surgery.-Ample means for acquiring a thorough knowledge . . . occurs in the practice of the Principal of the Institute, and the same is also taught through the medium of daily Lectures and Recitations.

The Text Books used in the Institute are as follows:

Anatomy and Physiology - Percivall, Blaine, Dadd, Carpenter.

Chemistry and Pharmacology-Morton's

Manual of Pharmacy, and the ordinary Text Books of the Schools of Medicine.

Materia Medica - Finlay Dun, and the United States Dispensatory.

Theory and Practice-Blaine's Outlines of the Veterinary Art, on the Treatment of Diseases of Horses and Cattle, Youat on the same Subjects, and Percivall's Hippopathology.

Veterinary Jurisprudence-Oliphant, and the Revised Statutes of the State of Illinois.

Regulations - The Sessions of this Institution are perpetual; so that when a Student considers himself competent as a candidate for a Diploma, he can present himself before the Board of Examiners. Students can commence their studies at any time.

This notice ran until August, 1865. How many students, and whether or not there were any "graduates," beyond the record of one diploma which was issued, does not appear to be a matter of record. In 1865 there is a "Case of Mal-Presentation ... Reported for the Prairie Farmer by a Student of the Veterinary Institute." A cow belonging to a man on West Madison Street had been in labor several hours when:

Finally, the services of Dr. McDonnell and Dadd were secured, and, by invitation, the students of the Veterinary Institute of Chicago, were present. . . . Dr. Dadd operated . . . students Carey and Chamberlain employed traction ... and in a few minutes the delivery was effected.

The writer identifies himself only "Student." This would seem to prove at least the existence of two or three students and of cows on West Madison Street.

\section{Lucid Lectures}

One of Dadd's articles in 1863, on amaurosis, or "glass eye," is the substance of a "Clinical Lecture at Chicago Veterinary School." If Dadd talked in the manner he writes, his lectures undoubtedly were both instructive and interesting. He gives a good description of the disease, apparently based upon an actual case with which his students were familiar. In addition, he displays a philosophy which is the mark of the good teacher:

When your attention shall be called to a case of this character, I would have you bear in mind .... that this condition ... as well as many other diseases . . . are often self limited, and the subjects will recover if carefully nursed and left unembarrassed by poisonous drugs. This opinion is endorsed by some of the most distinguished surgeons of the present day. I have no desire to try to saddle you with any peculiar notions of medication emanating from my own fancy. .. Excessive medication is a quicksand which you must try to avoid; thousands of well meaning medical aspirants have actually committed professional suicide, by clinging to the absurd theory of medication as practiced in bygone days.

\section{Having obtained the history:}

which you must endeavor to elicit from the owner... the cause ... you must endeavor to decide on by careful examination, then frame your plan of treatment in accordance with the indications to be fulfilled. . . . Should you consult authorities on amaurosis, you will find much diversity of opinion exists. . . . Don't place too much confidence in mere book authority, no matter how high the source, unless your experience and intelligence endorses the theory or facts in the case... you who propose to do your own thinking, have the ability to judge between right and wrong. Read your textbooks carefully, commit to memory all matters which appear to you as facts, and forget the rest. 


\section{VETERINARY SCIENCE AND AGRICULTURE}

The American Stock Journal advertised that among its improvements for 1860 :

THE VETERINARY DEPARTMENT will be under the editorial direction of Dr. Geo. H. Dadd, the distinguished Veterinary Surgeon, and late Editor and Proprietor of the American Veterinary Journal.

That Dadd's services were needed may be appreciated from advice for founder appearing in this journal in 1859 :

Raise the foot so as to be level - pour spirits of turpentine, a sufficient quantity, so as not to run over the hoof; then set the turpentine on fire, and let it be entirely consumed. If the above does not cure a foundered horse, as soon as the operation is over, then your readers may doubt all further recipes from Veritas. [!]

\section{The Only Remedy}

The American Stock Journal was published in New York; Dadd conducted its Veterinary Department from Boston. In his first column for 1860, Dadd writes:

The history of veterinary science in the "old world," shows that it cannot possibly flourish, unless immediately connected with its sister science-agriculture; in fact, it is a branch of the science of husbandry, and no farmer can be expected to raise healthy stock unless he is somewhat acquainted with its principles and practice... There never was a period like the present, when the services of veterinary practitioners were so much needed . . . and as veterinary surgeons in this country are so few and widely scattered, the only remedy for the emergency, as I understand the subject, is to render the science popular, by endeavoring to instruct the stock raisers. . . . This shall be my sole object, in this new field of labor.

Dadd's experience with professional education obviously had altered his outlook, and in this he undoubtedly had some justification; whether his new approach was the proper answer is, perhaps, open to suspicion.

Dadd apparently gave up the professorial platform with some reluctance; in his first column he discusses "Gut Tie, or Strangulation of the Bowels," and after explaining it in plain terms, he adds: "The operation is rather a formidable one, there- fore the animal should be brought under the influence of concentrated ether." Just what his farmer friends were to make of this is something he does not enlarge upon. The American Stock Journal had run a veterinary column from its inception in 1859; under Dadd the column was considerably enlarged and improved - at least to the extent that Dadd's appointment was a virtual guarantee that no outright barbarities would appear. The Veterinary Department for 1860 occupied an aggregate of 73 large pages of small print-practically book length in itself. Dadd also wrote extensively on contagious pleuropneumonia which had been introduced into Massachusetts in 1859. His investigations of the disease are considered under that heading.

\section{Cattle Problems}

Among other items of interest in Dadd's veterinary column for 1860 is his answer to an inquiry on the spaying of cows:

The operation of spaying cows was known in remote antiquity; in modern practice it dates back about thirty years. ... [ [ In] my own experience ... the milk of spayed cows gives more cream than ordinary milk, and the butter extracted is more delicious in taste. . . There is no danger in performing the operation, provided a suitable animal be selected, and the operation is performed in a skillful manner, the animal being under the influence of sulphuric ether.

A correspondent mentions, "Dr. Dadd, accompanied by three of his students," spayed a number of cows. This occurred in April, 1860 , and would appear to be evidence that Dadd still had a few students.

On the question: "Can diseased food be eaten with impunity?" Dadd states:

It depends upon the nature of the disease; for example milk sickness . . . is not endemic as regards man, but only affects those who partake of the flesh [of affected cattle], their milk and its products ... yet with regard to the flesh, \&c. of cattle, the subjects of Pleuro-pneumonia ... no one single proof can be adduced of any direct injurious effects resulting from the consumption of such objectionable carrion. 
He at least leaves little doubt as to his opinion of the esthetics of the matter.

Up to this time, mastitis, or garget as it was more commonly known, is little mentioned in the agricultural papers. Earlier, when the great majority of cows were such that they gave but little milk, perhaps the disease was not a problem. Later it would seem that under the conditions prevalent in most dairies, it must have been common - perhaps so common as to be accepted as one of the incidental hazards of dairying. In 1860 Dadd states:

This is a very common complaint among cows. . . A great proportion of the cases of garget that have come under my observation, were clearly traceable to errors in dietetics. It is a fact, however, worthy of consideration, that some cows inherit a peculiarity of organism and predispostion to this disease.

He considers that too heavy feeding is the principal cause, notes inflammatory, suppurative, and indurated types, and states that he has not seen gangrenous mastitis in the United States - something not uncommon in Europe. He recommends thorough milking, bathing the udder with cool water, a light diet, and lancing any abcesses that may appear.

In response to an inquiry, Dadd prescribes for spavin, adding: "Dr. Sawbones, however, contends that the easiest way to cure Spavin, is to 'trade off' the spavined horse." And to this same man, who "would like to see a cure for spring-halt," Dadd replies:

So would I - it is an incurable affection. The French people are very fond of horses having a spring-halt gait; they consider the unnatural movements of the hind limbs as somewhat graceful, resembling the gyrations of a French dancing master; hence in view of curing - getting rid of - a faulty animal, send him to France.

\section{Advertising Editor}

Dadd continued to be an inveterate advertiser during this period; beginning with the first issue, the American Stock Journal carried the promotion for his "School of Veterinary Medicine and Surgery." In the early issues he states it was established in 1849; in October and running through November, 1860, he states that the school was established in 1848. At intervals he advertises his books, and an extensive list of some 40 veterinary instruments for sale, including such items as suture wire at 25 cents an ounce, to slings for horses at $\$ 25$. Other items: fleams, catheters, hernia knives, balling irons, castrating clamps, spaying knives, embryotomy knives, nerving knives, probangs, milk tubes, etc., etc., suggest the range of operations some farmers may have been attempting. Just what the farmer was to do with an "instrument for removing the piece of cartilage when performing tracheotomy," or "instrument for reducing an inverted womb," is perhaps in doubt.

In 1860 he advertised:

Compound Fluid Extracts, and Chlorinated Soda, Prepared expressly for the cure of the different forms of Rot which affect Sheep: .. . Fluke Rot ... Water Rot ... Foot Rot ... and Liver Rot.

He also had "Alcoholic Extract of Plantain and Scullcap... for the Treatment of Hydrophobia, Lockjaw, \&c." This was to be taken internally, and the bitten part bathed with it. It should be added that a number of physicians also advertised remedies for rabies which contained the same ingredients - not that this renders Dadd any the less culpable.

\section{Itinerent Advisor}

In November, 1860, the Stock Journal notes:

Dr. G. H. Dadd, Veterinary Surgeon, will on the first of March next remove, with his family, to Louisville, Ky., where he will practice his profession and establish a Veterinary School.

From this it would appear that the pickings around Boston must have been no longer to Dadd's liking. In January, 1861, however, it was noted:

he has changed his mind, and has removed to Cincinnati, Ohio, where he will establish a Veterinary School, and practice his profession. 
Dadd continued his editorship of the Veterinary Department of the American Stock Journal until late 1862. Many of his columns continued to be abstracted from other, principally foreign, journals, but he also contributed a good deal of original material, both in the form of case reports and answers to inquiries, and in academic discussions on such topics as the "Anatomy and Function of the Heart of the Horse."

In August, 1861, there appeared the business card of:

Dadd and Livezey, Veterinary Surgeons, Dealers in all kinds of Surgical Instruments, Books, Fluid Extracts, and all Medicines used by Veterinary Surgeons.

This and his school advertisement ran until March, 1862. Both Dadd and Livezey appear to have had a considerable practice; the latter also contributed a number of case reports to the Stock Journal.

An article on the loss of army horses in 1862 states:

It appears to us that educated veterinary surgeons are as necessary for the army as human surgeons, and it is about time that the General Government call in the aid of science to minister to the wants, aches and the pains of the inferior order of creation. . . . We are glad to know that Gen. Mitchel ... has furnished several companies of artillery with a small medicine chest, containing a few useful articles for obvious diseases and injuries, which may possibly do much good, and be the means of turning the attention of others in the command to the importance of providing for the welfare of horses. Gen. Mitchel has also secured the services of Dr. Geo. H. Dadd, the well known veterinary author and surgeon, and should the General take the field, Dr. Dadd accompanies him.

To this item - apparently written by the editors - a note is appended, stating:

We understand that Gen. Mitchel has resigned, and Dr. Dadd has been appointed Veterinary Surgeon to the Second Ohio Regiment of Cavalry, now encamped at Camp Corwin, and commanded by Col. Taylor.

Dadd apparently saw little - if any - military service, for in May, 1862, the editors of the Stock Journal note that Dadd "has removed from Cincinnati to St. Louis, where we trust his science and skill will be appreciated, as they have been wherever he has been known." Dadd's attempt to form a school in Cincinnati apparently was a complete failure, or at least there appears to be no record concerning any activities of the "Academy." In April, Dadd's new business card had appeared, stating his office to be "at the stable of Glasgow \& Harkness." The latter apparently was James Harkness, a self-educated veterinary surgeon, whose practice was limited to the 125 horses maintained by the firm. Earlier, Harkness had written for the American Veterinary Journal. Dadd's card appears until October, 1862.

Under the heading: "Veterinary Surgeon for Illinois," it is noted in the Prairie Farmer for March, 1862:

Those acquainted with Dr. Geo. H. Dadd, formerly of Boston and late of Cincinnati, will be glad to learn that he is to take up permanent quarters in St. Louis, where he can be more easily consulted by Illinoisians.

Dadd's first "consultation," via correspondence in the Prairie Farmer, appears six weeks later in a diagnosis of ascites as the cause of death of a pig: "From whose porcine corporosity you extracted a bucket and a half of water." In the same communication he identifies a "distemper" in the Nebraska Territory as anthrax "a disease over which medicine has but little control."

In a second article, Dadd gives a lengthy discussion on sweeny of horses, which he says:

prevails very extensively among western horses . . . yet very little of a reliable character has ever been written on the subject, hence as a professed teacher of veterinary science, and not being willing to carry my knowledge to the grave, it becomes my pleasant duty to give the public the benefit of my experience. . . .

\section{To Popularize the Science}

In January, 1863, a Veterinary Department, conducted by Geo. H. Dadd, V.S., 
appeared in the Prairie Farmer. Concerning this venture, Dadd says:

Through the liberality of the proprietors of the Prairie Farmer I am engaged as a regular contributor for the year 1863; during which period I shall endeavor to furnish a series of practical articles on the causes, nature, and treatment of some of the most obvious diseases, incidental to horses and cattle. I shall try, as I have always done, to popularize the science of Veterinary Medicine and Surgery, and in this way exalt it in the estimation of those who may have failed to realize its value.

One of his first articles concerned: "Remarks on Veterinary Science, and the relation it bears to social science," in which he states:

The necessity which now exists for the services of educated Veterinary Surgeons in cavalry regiments of the United States army, is evident to every thinking man; yet prior to the advent of our present national trouble, it was found almost impossible to interest the right kind of men, so that they might use their influence for the purpose of directing attention of the general Government to the value and importance of Veterinary Science; but the probability is . . before long, we may expect to hear of the appointment of a Veterinary Surgeon and Assistant Surgeon to each cavalry regiment. . . .

The great losses which are continually occurring among army horses, is a monstrous and growing evil, and in view of preventing unnecessary diseases and premature deaths the Government must organize a Veterinary corps. It is, also, very important that our science should attract the notice of Legislators, for it bears a very intimate relation to social science; inasmuch as men, and animals are subject to similar diseases, which are communicable one to the other. ... .

Let the husbandmen and stock raisers of this country, put their shoulders to the wheel, in view of estabilshing veterinary schools and colleges throughout the length and breadth of our immense agricultural domain. ... I am not disposed to find fault, nor scold about the itinerant veterinary practice which prevails in this locality ... the fault is not with the practitioners, but with the people who have failed to furnish the means for education.

In response to an inquiry on the spaying of cows, Dadd states:

The operation is performed on heifers at two dollars per head; on milch cows, three dol- lars. A veterinary surgeon, located in this city, cannot afford to leave his business, go in to the country, and perform such operations for any thing less than the above sum. Hence I would advise all those who wish to perform this operation on their own, and neighbors animals, to attend a course of Lectures at the Chicago Veterinary School.

In stating that milk "obtained from diseased animals is not fit to drink," Dadd reveals:

There are thousands of cows kept in large cities, located in down cellar "black holes," or unventilated and filthy barns or stables, that in consequence of such treatment are never in the enjoyment of good health; hence their lacteal secretion cannot be of a healthy character, and when drank ... it must have pernicious effects.

In a half-humorous vein, he gives space to a correspondent with a lame horse which a "celebrated farrier" had diagnosed as:

Twitter bones, and he would be cured in two weeks ... for a certain fee ... with a hot iron, he burned on each side of the joint just above the hoof, and left some liniment to heal it up. . . . I could find nothing (concerning "Twitter bones") in Youatt, and thought perhaps I was "sold" in the matter.

Dadd agrees: "You have probably been 'sold.',"

\section{The Law on Glanders}

In commenting on the sale of glandered horses by the army, it was noted that Illinois had a law which should have covered the matter, but apparently it was not being enforced:

If any person shall suffer to run at large, or keep in any place where other creatures can have access to, and become infected, any horse, mare, gelding, mule or ass, that is known to the owner or the person having the same in his care and possession, affected with glanders, distempers or any other infectious disease, he shall be fined in the sum of twenty dollars, and shall be liable to pay all the damage that may result from such running at large.

Among the numerous items in Dadd's columns for the latter part of 1863 are sev- 
eral on glanders, which apparently was being spread by the sale of condemned army horses. On one occasion Dadd was called to see a colicky horse, and finding it also had glanders, advised destruction of the animal. This horse being an ex-army steed, Dadd advised readers "to be careful how they purchase condemned horses." And noting that many army horses being sold had farcy, he states:

I think it is an outrageous shame that officers in the employ of the government should be permitted to dispose of stock that are not only worthless, but in the eyes of the law are unsaleable. The evil is a monstrous and growing one, and demands the serious attention of our husbandmen. Should a horse dealer in this city dispose of a farcied or glandered horse, and either one of the diseases be communicated to other stock the seller would be held responsible for the conseqeunces. As I understand the subject, the law is no respector of persons, and a Quartermaster has no more right to sell a farcied or glandered horse than a common dealer. .. . It is a notorious fact that the Government of the U.S., under the auspices of its agents - the Quartermasters - are, (as fast as a lot of condemned equines can be got together) authorized to sell or palm off that which is worthless and consequently unsaleable.

Dadd quotes several instances of communication of glanders to man to strengthen his case.

Dadd was still about the only proponent of veterinary anesthesia at this time a decade after he had used it in Boston. In response to a query on how to shoe a vicious horse, he says:

I have seen chloroform used with great success. . . It is only necessary to administer by means of a sponge to the nostrils a sufficient quantity to stupify the horse, or there may be danger of the animal falling on the blacksmith.

And in visiting a colicky horse:

There seemed to be little hope for the animal, and fearing that he might either kill himself by violence or injure those in attendance, I concluded to chloroform him, and thus put a stop to his dangerous performances; he had the best of us about long enough, and now it was for me to show what science had in store for such otherwise unmanageable cases. . . . It was an encouraging sight to behold the once powerful and furious animal, now lying free from pain and deprived of the power to injure himself or those in attendance. . . . At the end of an hour... he was allowed to rise.

The horse was given nitre and lobelia, and except for self-inflicted injuries, was well in a few hours.

\section{With Charity Toward Blacksmiths}

On the subject of veterinary education, Dadd mentions:

The government of Russia expends, per annum, for the support of three veterinary schools, the sum of 754,000 francs. It is about time that the government of this country made a move in a similar enterprise.

And stating that a knowledge of the anatomy and physiology of the foot is required for proper shoeing, he asks:

How is this knowledge to be obtained? Can it be furnished at the forge - in the blacksmith's shop? . . . The fact is, the husbandmen of this country have failed to put their shoulders to the wheel for the purpose of establishing veterinary schools in this country, and if blacksmiths and "vets" do not understand the anatomy of horse's feet, the former whom have vast interests at stake, must come in for a share of the blame.... I for one, am disposed to be charitable towards blacksmiths.

In an article on: "The Present Condition of Veterinary Medicine," the charge is made:

The records of the past and present demonstrate that a total disregard for the feelings of the brute creation is compatible with a high state of civilization. . . Bad as is the effect of quackery in human medicine, it is at least exempt from much of the barbarism that still clings to brute surgery; the man does not live who dares tie a fellow-creature to the table, and hack at him till he finds what he seeks for. But who considers the beast under the same conditions? "It is only a horse," is a sufficient cover for any amount of mal-practice and barbarity.

Among the barbarities railed against are giving a live fish for constipation, pretended reduction of "gut-tie" via laparotomy, wolf-in-the-tail, burning for lampas, 
chiseling off spavins, boiling pitch for fistula, and tearing off the sole; the latter three:

Are only tolerated among the few who are not included in the sphere of civilization ... [and] would stain the reputation of a wild Indian. . . The improvement of veterinary medicine, especially in relation to agriculture, is dependent upon the agriculturalist himself; let but the demand for educated practitioners exist, and the supply will more than keep pace with it.

This lengthy, but acutely phrased article is taken from another journal, and apparently is not written by Dadd, but it is obvious that these thoughts coincide precisely with his own. The effect, if any, on subscribers to the Prairie Farmer would have been the same either way.

\section{No Cure for Cancer}

An article summarizing the known information on cancer in animals is taken from European sources. It might be a little surprising for some today to realize that this much was known a century ago:

With the microscope [and other means] diagnosis of cancer has become relatively certain. ... Cancerous tumors have been found in all body regions and tissues. Cancer is probably incurable; even when a tumor does not reappear after excision, one cannot affirm that the animal is cured. The causes of cancer are unknown. . . Cancer does not disappear under the influence of remedies. . . Carnivores are more susceptible to cancer than herbivores, and females than males... . Cancer is hereditary, or at least it has been observed to be so in the dog; it is not transmissable either from animals to man, or from one animal to another. . . . Cancerous tumors should be excised as soon as possible; when removed from carnivores, a vegetable diet renders relapse less certain... Many tumors have improperly been named cancers.

In two Iong articles on bighead (osteoporosis) of horses in 1863, Dadd indicates:

The evil is one of alarming proportions, and should the disease multiply in a ratio equal to that of the few past years, it will be a terrible blow ... the disease itself is incurable...
Our services as physicians, are only secured ... so that the animal may be enabled to perform the ordinary equine duties; this is what some persons please to term a cure. ... I have often been told that horses, after having all sorts of barbarities practiced on them, have recovered; this, so far as the treatment is concerned, is in accordance with the spirit of the old error, "He got well after taking my medicine; therefore, in consequence of taking it." . . . The disease has extensive ramifications in various parts of the bony fabric, and therefore the local treatment must fail in curing the malady.

Dadd suspected the disease was of nutritional origin, and prescribed cod liver oil, among other remedies. He doubted it was transmissible, but thought heredity was a predisposing factor.

In December, 1863:

The disease known as Influenza, is now quite prevalent in Chicago; it first made it appearance about three months ago, and exhibits all the phenomena of an enzootic affection, appearing here and there in isolated spots within, and around the city. ... It does not differ . . from similar visitations in this country in former years. . . We must neither bleed nor purge, for by so doing we augment the prostration of the system, and to my certain knowledge many animals in this city, that have been thus treated, have died, victims of a misguided notion of medication.

\section{Pecuniarily Professional}

The problem of how much information can or should be given through the medium of a veterinary column has always been a sticky one. This is true of the "What is the matter with my horse?" type of inquiry, especially so when it is obvious that it is only a single animal that is affected. Some of the agricultural journals of the late nineteenth century advertised: "A free horse doctor with every subscription," and attempted to make good the promise. Dadd, however, takes quite a different stand on the matter:

I am willing, and it gives me much pleasure, to answer, through the columns of the Prairie Farmer, communications of a general character, calculated to benefit the community of stock owners, but I cannot spare the time, nor neglect my practice, to answer without pay, letters 
through this paper, which should be addressed to me professionally, and which are only calculated to benefit the writer pecuniarily.

Citing one such instance of a farmer who asked how to remove a "warty-like excresence" from the coronet of a horse which had been fired for ringbone, Dadd replies:

The case you describe would require the attention and services of an educated veterinary surgeon. In order to give you anything like the necessary information, I should have to write a lengthy article. . . The subject is, no doub', of great importance to you, but not to the generality of readers, and in all such cases it is usual to consult a professional man professionally, and inclose the usual fee of two dollars, which will secure an answer by mail.

This would perhaps suggest that Dadd was not overly well paid for his veterinary column, although he makes this stipulation but once. And more than once he does answer items similar to the one he refused in this instance. Like anyone else, Dadd had to make a living, and it may be surmised that his short residence in St. Louis was occasioned by inadequate revenues from practice and his ill-fated school. There are those who would castigate Dadd for his promotion of stock remedies, and this undoubtedly did, even then, lower his professional standing to some degree. And although medical ethics a century ago were not what they are today, an advertisement for "Hostetter's celebrated Stomach Bitters" charges:

Advertising has been pronounced "undignified" by the medical faculty. A physician who advertises a valuable remedy to fifty people in his private practice, would receive the cold shoulder from his professional brethren should he make its merits known to millions through the business columns of a newspaper press. This may be "dignified," but is it benevolent, lumane, or just? Whoever is fortunate enough to discover or invent anything that will prevent, or cure or alleviate human suffering, is bound to make it known.

While his pocketbook presumably was a consideration, Dadd may have promoted some of his remedies with the same motives in mind. Whatever the case, it is likely that any remedies he would manufacture or approve would be an improvement on the general run of remedies that were available. Shortly after his removal to Chicago, Dadd's testimonial appears in an advertisement for: "The American Magnetic Equine Powders ... Liniment ... [and] Lotion." These, Dadd says, he has tested in his practice, and would:

Cordially recommend them as being far more efficacious for the treatment of the various diseases for which they are designed, than any remedies of which I have knowledge.

And advertised by the maker was:

Dr. Dadd's Fluid Extract of Resin Weed Root... for the treatment of all affections of the lungs and throat . . . whether occurring in man or domestic animals.

He seems, however, to have given up promotion of the extensive line of remedies he had manufactured in Boston.

Dadd continued to write for the Prairie Farmer until August, 1865, when his column suddenly stops without explanation. Whatever one chooses to think of his veterinary journalism, this much would seem to be a fact: during the several years he wrote for the Prairie Farmer, the treatment of animals - at least those belonging to owners who followed Dadd - was suddenly elevated to something nearly what we should like to have seen much sooner.

What subscribers did for information on animal disease for some time following is not evident; for the balance of the year, the only articles to appear are several on the danger of glanders in horses purchased from the army, and several on the cattle plague in England. Included among the latter is: "A Prayer for the Removal of the Cattle Plague... drawn up by the primate of England." The "grevious murrain among our herds and flocks," was recognized as deserved chastisement for the erring populace. How much application this may have had to the American scene is, perhaps, a moot point, but American farmers undoubtedly would have approved of the request for protection "from the pesti- 
lence with which many foreign lands have been smitten."

\section{Dadd's Demise}

The first notice in the Prairie Farmer concerning Dadd since his defection from the post of veterinary editor is a review by his successor, N. H. Paaren, of a new work by Dadd in 1867: "Dadd's Theory and Practice of Veterinary Medicine and Surgery ... embracing the latest information on the Rinderpest and the Trichina." The new veterinary editor is rather fulsome in his praise of this work:

We have come to the conclusion that this book is deserving of the highest commendation. In the present state of Veterinary Science in this country, this work was demanded.

In two dozen lines, he uses the following adjectives for the book or its author:

celebrated, disciplined, valuable, appropriate, instructive, entertaining, easily comprehended, satisfying, copious, complete, original, ingenious.... On the whole, we consider this work a valuable contribution both to science and to literature generally.

\section{What more could any author want?}

The next mention of Dadd appears in a notice of the staffing of the Iowa Agricultural College in 1868; among the faculty were a number of nonresident professors, including: "Professor of Veterinary Medicine and Surgery, Dr. Dadd, Baltimore." It is evident, however, that Dadd missed this last chance to return to the lecture platform, for he died about the first of September, 1868. As reported in the Prairie Farmer for September $\mathbf{5}$ of that year:

Death of Dr. Dadd: This well known veterinary surgeon, died last week, in the city of Baltimore, from a disease resulting, it is thought, from a cold contracted during the recent freshet in that city. Scarcely past the prime of life, Dr. Dadd was a hale, hearty man, and his death came unexpectedly to his family and friends. The Dr. has written more pertaining to his profession than any man in this country, and his books, some of which have passed through several editions, are to be found on the shelves of most farmers' libraries. Several years ago he commenced the publication of the Veterinary Journal, which for want of adequate support, was soon discontinued. After this he became a frequent contributor to the Agricultural Journals of the Country, and was for some time Veterinary Editor of Prairie Farmer. He was well known as a practitioner, in Boston, Cincinnati, St. Louis, Chicago and Baltimore, in each of which cities, he at different times resided. His remains were brought to this city [Chicago] for interment, the funeral ceremonies taking place at the residence of his daughter, on Jackson St., on Sunday last.

This would suggest that he had moved to Baltimore after terminating his connection with the Prairie Farmer; evidently after severing his ties in Boston he had not yet found the situation that suited him.

In 1875 the American Agriculturalist advertised Dadd's American Reformed Horse Book:

The result of a lifetime of labor and research on the part of one of the foremost Veterinarians of the age.... Such was Dadd's success that he became widely known, and it was no unusual thing for him to be sent for, hundreds of miles, to attend valuable horses. His career as a practicing Veterinary Surgeon has been one of rare success.

And in promoting his American Cattle. Doctor, it is stated that Dadd was for "Twenty-five years a leading Veterinary Surgeon in England and the United States." The only intimation that he was dead is his identification as "late Professor of Anatomy and Physiology in the Veterinary Institute of Chicago."

Although the above is obviously in the vein of the usual bookseller's blurb, it is not an unfitting epitaph. Few veterinarians before or since have written so voluminously or so well - but to so little avail so far as their influence upon the veterinary profession itself is concerned. Had Dadd chosen to be somewhat less dogmatic in stating his opposition to prevailing practice and insinuated himself into the "regular" veterinary profession, it seems likely that he might have become a stalwart of the budding profession. With New York 
City as the only contender, Boston early became the center of the organized veterinary profession in America, and several of Dadd's associates: the two Woods, Large, Thayer, and Copeman, became presidents of the United States Veterinary Medical Association after its founding in 1863 .

Some insight into Dadd's philosophy may be found in his reply to a letter from Robert Jennings requesting support for a national veterinary organization in 1860:

In regard to the National Veterinary Association I am afraid that you could not get enough "vets" together to make it an object. Jealousies and prejudices are very strong among the members of the craft, mainly graduates from the other side of the water look with supreme contempt on all who will not endorse the creed of dogmatical diction of the autocratic schools. Then, again, you are aware that you, as well as myself, have enemies within and around our fields of practice, that mere feelings of jealousy they will not give countenance nor support. Still if you deem it proper to form a N.V.M.A. you may count on my assistance and support.

Dadd, however, was soon to sever his connections with the Boston scene, and by 1863 , when the next summons for organization of a national association was issued, he had long since been in Chicago. Only one veterinarian west of the Alleghenies, G. W. Bowler of Ohio, an associate of Jennings in his ill-fated veterinary school of
Philadelphia, was invited to the organization meeting. Had Dadd been closer at hand, however, it seems unlikely that he would have been invited.

In retrospect, it would seem that Dadd's activities on behalf of the budding veterinary profession - little appreciated by those who organized it and barely held it together for several decades - had little direct influence upon the development of professional veterinary medicine in America. Even from a most conservative viewpoint, however, it would seem that his philosophy and practice of veterinary medicine was far in advance of the times. Thus it was not until about forty years after Dadd had demonstrated the practicability of general anesthesia that its use was recognized as one of the strongest measures for elevating the status of veterinary medicine. It should not be supposed that he was the only humanitarian among veterinarians of his time, but he was the only one who spoke so forcefully and continually on the need for drastic changes in the rough and ready approach to the administration of drugs and the handling of animals.

Obviously, there is little point in speculating on "what might have been." However, there is nothing to prevent recognition of merit where it is due-even if it comes a century late. 


\section{Dissatisfaction With the Status Quo}

IN THE YEARS following the demise of Dadd, many individuals wrote propounding their thoughts of veterinary science in the periodicals that existed at the time. And the Prairie Farmer continued offering advice and answers to inquiries.

\section{VETERINARY JOURNALISM AFTER DADD}

Dadd's successor as veterinary editor of the Prairie Farmer was N. H. Paaren, M.D., V.S. His first connection with the paper appears to be as a correspondent in answer to an inquiry in 1866 about a cure for cataract in a horse. He states:

Truth compels me to say that as far as I am aware, there is no medicine that can clear away cataract; consequently, the prospects for poor "Charley" will remain rather dark.

His next communication is a lengthy statement about hog cholera, in which the best advice he can offer is:

Never forget that hog cholera is a contagious disease; therefore keep your animals away from flocks amongst which the disease exists, also from particular ground or locality where the malady is of frequent occurence. If the disease is discovered in your own flock, separate immediately the apparently sound ones.

Paaren remained anonymous at first, later he used his initials, but it was not until a year later, that the editors state:
We have ample testimony that the Veterinary department of the Prairie Farmer has been considered one of the most valuable and interesting features of the paper since conducted by N.H.P. Heretofore his full name has been withheld at his own request. We now take pleasure in introducing the gentleman, Dr. N. H. Paaren, more fully to our readers. Highly educated for his position abroad, and also a student and practitioner in the West, he has for nearly two years past been chief Veterinary Surgeon of the cavalry depot at Washington. ... His practice in all the diseases to which equine flesh is heir, must have been more extensive than usually falls the lot of any single individual.

Later, the editors state:

We employ Dr. Paaren to answer questions and prepare articles on the subjects of general interest. His prescriptions and advice are given in the paper and no charges made for the insertion. But when subscribers need immediate attention and desire a written reply, often requiring much time and research, from the Doctor, they should accompany such request with a reasonable fee.

And again in 1867:

Dr. N. H. Paaren, our Veterinary Editor, has taken the fine brick stable at 302 South Clark Street, where he will be able to give the best of treatment and care to sick and disabled stock. Those needing the services of a reliable Veterinarian cannot do better than place their stock under his care.

Paaren's department, however, soon lost 
the charm of Dadd's writing as veterinary editor. While a number of articles, as promised by the editors, are on topics of general interest, most are the run of the mill "question and answer" type of thing, all too frequently without the question. Thus such a telegraphic item as "J.S.: A seton, properly adjusted and attended to, would probably be the best thing you could apply," smacks of the "free horsedoctor with every subscription." And while Paaren apparently did not advertise proprietary remedies, he was not overly subtle in announcing his professional prowess.

Of his competency there is no question, and he appears to have had a wide and varied experience. In addition to his army duty, he mentions, "a very extensive practice in the Eastern and Western States of this country, in South America, in the West Indies, and in Europe." For the first several months, he apparently conducted the Veterinary Department of the Prairie Farmer from the cavalry depot at Washington. Some time before the depot was disbanded in August, 1866, he wrote concerning bighead:

It seems that this disease is far more prevalent in the Western than it is in the Eastern States. According to records there were among thirteen thousand patients treated here in the last year under our supervision, only three cases of "bighead," and they were disposed of as incurable.

Yet he writes most intelligently on the disease for having seen so few cases. The Washington army depot was stated to be "the largest cavalry depot in the United States; has capacity for fifty thousand horses, and a hospital for two thousand five hundred diseased and disabled animals." Thus Paaren's mention of 13,000 patients in one year would seem not to be a gross exaggeration.

\section{A Most Deplorable Lack}

The lack of an adequate number of competent veterinarians in the late 1860 's was a frequent subject of concern to farmers, editors, and veterinarians themselves.

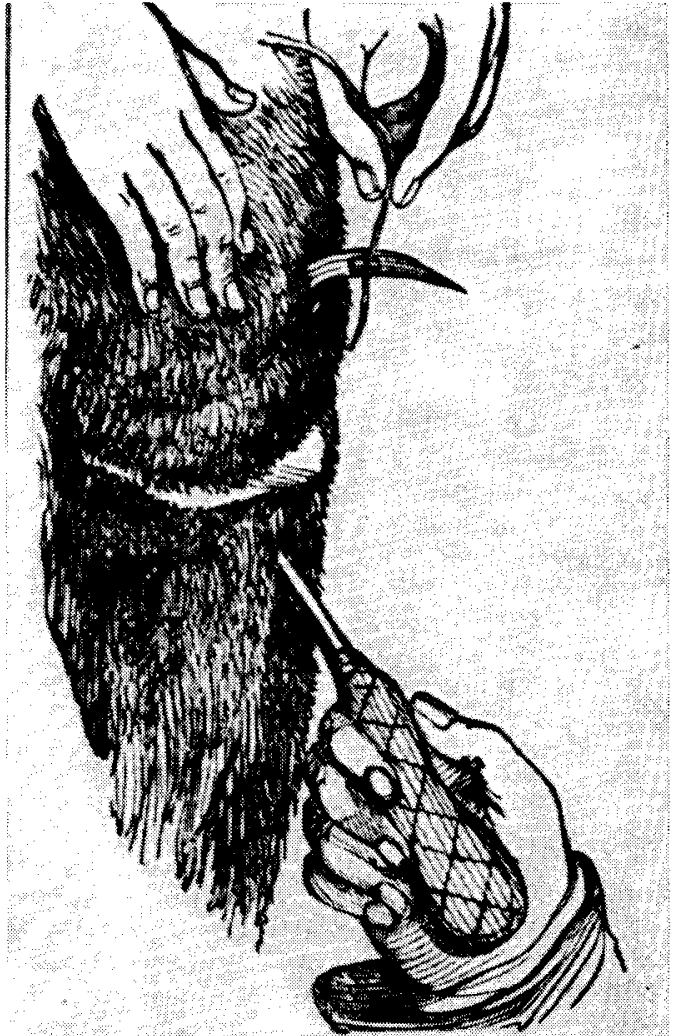

HANXER OF U-UNG SKTON NEEDLE.

Setons, usually of porous materials such as rawhide or cloth, were used since ancient times to promote drainage of wounds - which were almost universally infected. Manning: Stock Doctor

Thus to an inquiry about "lung fever" in horses, the veterinary editor of the Prairie Farmer replies:

Perhaps the best advice I could give ... would be, to procure the aid of a good veterinarian ... the right kind are few and far between. . . . It is better to pay a fee of a few dollars that to trust your animal to a novice or quack or run the risk of losing him. If you delay, even a skillful veterinarian may not be able to do any good. If in consequence of distance or other causes, the doctor.. is not immediately obtainable, ... . [and] one deems it necessary to do something before the arrival of the doctor, give injections of warm water, which never do any harm.

A correspondent writes warning of a quack operating in Illinois, who pretends 
to "remove ringbones, spavins, splints and curbs in from one to three days without breaking the skin." His own horse, suffering from ringbone, was pronounced cured "but in the course of a few days the whole flesh from the hoof to the fetlock joint came off." Paaren adds: "Readers who hear of these men will do well to give them a wide berth. Such villainy should be punished severely."

This was a subject on which Paaren spoke directly to the point. In response to an intended contributor, he states:

As we have some regard for the interests of our readers, you will excuse us for not complying with your desire of inserting your treatise on the various ailments, presumed to be caused from the presence of wolf's teeth in horses. Your correspondence, besides being utterly deficient of reason and sound sense, exposes a most deplorable lack of knowledge in the anatomy of the horse; and you will excuse us if we were mistaken when we regarded your communication as an invitation to put forth some remarks on quack horse doctors generally. . . . This country abounds with men who have taken to themselves the title of Veterinary Surgeons - a kind of fraud for which the law has provided no remedy.

There follows a lengthy diatribe against this clan, most of which had been said by others before him, but perhaps without all the exquisite detail. On the subject of wolf teeth, Paaren says:

Various prejudices prevail regarding their evil effects. It is very commonly asserted, not by veterinary surgeons, but by that positive pest - the common soidisant "horse doctor," that unless they be removed the animal will go blind. Now, as most all colts have these teeth, why do not all these go blind? . . . We need only add that those so-called wolf's teeth have no anatomical relation whatever with the organs of vision. The assertion that wolf's teeth will cause blindness is founded only in ignorance.

In reprinting a statement from the Irish Farmers' Gazette for 1867: "There are not two score of properly qualified veterinary surgeons in the whole country" (Ireland), the editors of the Prairie Farmer add:

We probably, have less than a score of men, pretending to follow this profession, who are not the most arrant quacks and humbugs. By all means let one of the prominent chairs at the new [ Illinois ] University be the chair of Veterinary Medicine and Surgery.

On the matter of the indiscriminate use of drugs, Paaren states:

Continual dosing of animals is just as useless and injurious to them, as is constant swallowing drugs and poisonous compounds to the human system. It is all folly to allow your stables to become hospitals, and to smell and appear like an apothecary's shop. It is much more humane to shoot a horse, or knock an animal on the head at once, than to force down its throat doses of drugs whose quality or action you know little about, having the effect to create disease when it did not exist, and prolong suffering much beyond the time in which nature herself would effect a cure.

\section{Glanders, Government Issue}

As early as 186I, the editors of the Prairie Farmer had commented at length on the sale of diseased government horses:

A large number of contraband horses and mules, and many cavalry and team animals that were unfit for service... were sent into this State... and placed upon the farm of the Brothers Dole, where a veterinary surgeon had the care of them. Of about 2500 received there, some 500 were condemned as not suitable to put back into the service, and were advertised for sale. . . The animals were, as a general thing, in the very worst condition we have ever seen horse flesh, and many had the appearance of disease, such as glanders, fevers, \&\&c., \&cc. . . . It was perfectly surprising to see how anxiously the crowd were to become possessed of horse flesh. . . .

Very many of the animals sold can never be wintered through, and others that may be, will be of little account. However, the government realizes a handsome sum from the sale (\$24 average this sale), which is alright so far as that goes. But there may be some drawbacks to the propriety of introducing this stock upon our prairies. If they, or any considerable number of them, are affected with glanders and are scattered broadcast over our prairie farms, it will be a sorry job for the purchasers and their neighbors. ... If the government needs the funds, the farmers had better make a liberal donation, than to allow a large lot of diseased stock to be scattered over the State, and paying such liberal prices for it. 
The first instance reported in the Prairie Farmer of glanders breaking out in animals sold by the government occurred in 1865. An Iowa farmer, who states: "I have been victimized," bought sixteen mules at Chicago; six days later glanders broke out:

I shall kill and bury every mule I bought. I beg you to caution all purchasers at these sales to isolate their animals at once. ... These mules had access across a fence to my blooded horses, and if I do not lose everyone of them I shall be lucky.

\section{The editors state:}

The government ... should take into consideration whether or not the loss to the country would not be less if a rigid examination of its horses and mules were instituted, and all animals diseased with glanders at once destroyed. All along we have advocated better veterinary surveillance, believing that by the spread of this disease we should pay dearly for the government's parsimonious course in this respect.

In the meantime, they suggest the farmer "let these sales alone."

A correspondent notes that this individual:

is not the only one who has been bitten by buying cheap army mules. A gentleman near here invested in 125, and his neighbors said that his fortune was made, but in a few days the glanders showed itself, and he was obliged to take his drove to some point west of here and sell them for what he could get. Perhaps the transaction was not strictly honest, but it tends to lighten the loss, as it is spread on several individuals instead of one.

This in turn brought a prompt rejoinder from the first correspondent, who asks for the name of this individual who "divided his loss":

He deserves to be held up to universal infamy. No honest man will sell a glandered animal. After I discovered it upon mine, I was offered cost for the apparently sound ones, and I refused it. . . . I have no right to "divide" my loss with my neighbor.

The responsibility of private citizens in this matter had already been tested in some courts. The Prairie Farmer in 1864 reported the upholding of a judgement for $\$ 5,000$ against a defendent who had allowed his glandered horses to occupy a field adjoining that of the plaintiff, who had lost many of his horses.

The editor of the American Agriculturalist had warned in 1865 :

This terrible disease is fearfully prevalent in some of the Government Horse Hospitals. We have feared that it would spread.

And a communication from J. C. Meyer, V.S. of Cincinnati "asserts that it has spread most alarmingly." Meyer writes:

Since the Government has been selling its unserviceable army horses, the glanders have made their appearance in my practice, and are extending to such a degree, that I fear, if the sale of such sick horses is not stopped, not only an immense loss will be sustained by the State, but also, that in a short time we may be unable to obtain the necessary horses for war purposes.

Later under the heading: "Glanders! Too Late," the editor states:

We have heretofore repeatedly warned our readers and the public against the danger of getting glandered horses from the Government. . . . Among the horses sold in this city at the Government sales, those well known to have this most malignant and terrible disease, (affecting men as well as horses) have been repeatedly, and we presume constantly, sold. . . . The Government might better have shot every horse, than to have them spread contagion and death (for the disease is utterly incurable) among the stables of the country, far and near. Besides, we shall very likely hear of men dying in unutterable agonies from this malady.

Shortly afterward an accurate account of the disease and its mode of spread is given to enable farmers to detect its presence and prevent its spread. But "no person should carelessly examine a horse for the glanders. Any handling of the nostril ... may easily inoculate a person with the virus."

Cures continued to be propagated, but in areas where the disease had been known for some time, slaughter was more com- 
monly recognized as the only remedy. Thus, an "old Doctor, whose sands have almost run out," in offering a sure cure for glanders, says:

We have investigated the disease of Glanders in horses and men. And after much experience, we have long since settled down on the grand Panacea. It is one powder and one blue pill. Take one tablespoonful of Dupont's best riffe powder, and put it into the mouth of a good musket, and ram down the paper on the top of it, then take one blue pill of lead of an ounce or less in weight, and ram home on top of that, and then go to the patient, in the stable, and go through the military manual of firing; but be sure to kill the horse, and burn him and the stable, bridles and every thing that has come in contact with him.

If the stable is not too contaminated, and is worth saving, he suggests that it might be disinfected.

Dr. Paaren, in 1866 , offers the following advice to a correspondent who had bought a glandered mare: "First and foremost we advise you to destroy the mare and bury her deep in the ground at a remote place." After thorough disinfection with chloride of lime:

When the stable is dry, place your horned cattle therein - no fear of catching the glanders - and arrange to keep your horses in the cow barn, if possible, from four to six weeks. . . Bridle, bit, halter, blanket and harness, that have been used on the glandered mare, should be scrupulously cleaned in boiling hot water, or if of little value burn them.

\section{A Dose of Nothing}

A correspondent to the American Agriculturalist in 1861 notes that this paper:

contains very few recipes for the cure of diseased animals, and some of my neighbors think the paper is lacking on that account. One of them takes a journal that gives almost a column every week, telling how to cure every thing from a flea bite to a fistula. ... In reading them I am reminded of the sweepings of an apothecaries' shop. ... I have no doubt that a regularly educated veterinary surgeon can often prescribe good remedies, but I don't believe it safe for every body to dose animals according to their own fancy. ... If I have a sick cow, and can get no reliable medical man to prescribe, I generally let Nature have her own way. ... In most cases I find that something else besides the animal needs doctoring. ... Foot rot in sheep is best treated by digging trenches in the pasture, and putting in drain-tiles. A few "plasters" of clapboards on the old stable will cure a good many diseases in horses.

To this the editor replies:

There are a few epidemical diseases which require a general treatment, and rules for such treatment may well be published; but for nineteen-twentieths of the ailments of man or beast, the best possible medicine is a very large, long continued dose of nothing at all.

The editor, Orange Judd, apparently followed his own advice, for his paper in the 1860 's carried very few articles on the specific treatment of animal diseases. While his directions for the use of chloroform by farmers at least made them aware of the potential uses of anesthesia, it may be doubted that in the hands of curious farmers this was much of a blessing to animals. After stating, "this enables the surgeon or veterinarian to perform very difficult and even dangerous operations with comparative ease," and giving the mode of administration in detail, he says:

Besides the use of these agents in effecting insensibility in cases of surgical operations upon injured or diseased animals, by their means a fractious horse may be made manageable while being shod; colts may be gelt, cows spayed, and many other similar operations performed which any ingenious farmer may do himself after a proper investigation.

In quite a different vein is an editorial on pleuropneumonia in 1864, of which: "No doubt we shall hear more. It is acclimated, the seeds are sown from Maine to Minnesota, and they will bear fruit." Noting the extensive system of veterinary sanitary police in Europe, Judd says:

In this country if a man suspects that the disease is in his herd, and knows the danger nothing hinders him from selling out his entire stock ... thus the disease is scattered, surely to break out in distant localities. The man who does this is guilty of inflicting upon nu- 
merous farming communities the greatest possible scourge - the most insidious and terrible malady which can befall their herds.

The need in this country of educated veterinary physicians and surgeons, is very great, and will continue so long as the quackish horseleeches and cow-doctors are encouraged in their quackery by reading farmers, and until young men of character devote themselves to the study of the diseases of animals.

What the editor is arguing for in the case of pleuropneumonia, however, is professional recognition of inoculation to ameliorate the disease:

Indiscriminate immediate slaughter is not to be recommended. Isolation of the herd and inoculation with the virus from the lungs of a slaughtered animal, in the tails of all will enable the farmers to save most of their animals.

In a note of warning "which farmers and all who eat meat should heed," the editor comments upon the "reckless traffic in diseased meat" in Great Britain, noting:

Livestock insurance companies have nearly all failed on account of the ravages of this disease ... [ which] has so increased the price of meat that the meat-consuming public is annually paying $\$ 50,000,000$ more now for the same amount of meat.

A measure which should be acted upon with dispatch is:

the immediate establishment of Veterinary schools or departments in our colleges, and, perhaps, by the employment on part of the State of the best Veterinary surgeons who can be induced to come to this country from Europe, for we now have few, if any, who understand the disease.

And sounding another warning in 1864 , Judd states:

In the neighborhood of this city [New York ], deaths are constantly occurring; the disease is perfectly well recognized and known by the milkmen, and by the authorities, for if an animal dies by disease or accident, the owner is obliged under heavy penalties to notify the sanitary police. . . . There is very great danger that cattle bought in this market and taken into the country to feed, will carry the seeds of disaster which can hardly be estimated. Almost every "cow-leech" is sure he can cure this disease, and farmers who trust them may do so to their cost.

This same year, the editor urged investigation of abortion in cattle:

In Herkimer Co., N.Y., great complaint has been made of the prevalence of this disorder, hundreds of calves having been lost in this manner last year. . . . It appears probable that there is danger in allowing an affected cow to remain with the herd, as other cases are pretty sure to follow apparently from sympathy.

\section{The Pigs Perish}

In Illinois, the Prairic Farmer for 1862 reports:

The loss of livestock in this state alone is immense, by disease and other causes, and is a matter that deserves and should claim the attention and investigation of those in power. ... The loss annually, which we believe could be prevented, would nearly, if not quite, pay the Illinois proportion of the $\mathrm{Na}$ tional tax. In many counties, we are authentically informed, not more than one-fifth of the increase in swine ever mature for the butcher or packer, and the loss of cattle by murrain and black leg is very large.

Hog cholera, which seems not to have become a major problem in Illinois for some two decades after it was first reported in Ohio in 1833, apparently had driven many swine farmers out of business; a correspondent from Coles County states in 1862:

It remains the same loathsome malady, but not as fatal as when it first appeared, and the farmers here are beginning to raise hogs again. There are swine now running over the farms where the cholera was very bad last summer, that appear healthy now.

\section{Another reports:}

A disease new to me and my neighbors, has been prevailing among my hogs, twenty dying out of a lot of sixty. The seat of the disease is in the throat; they appear stupid, and breathe with difficulty ... till they die ... in about twenty-four hours. . . . They seem to suffocate to death; turn purple around throat before 
death, which extends over the lower part of the body in a few hours.

The editors add: "The disease ... is much the same as that of many other sections, and that is enveloped in so much mystery."

Some idea of the measures taken by a community of farmers to combat a disease as baffling as hog cholera may be had from the report of a farmer's meeting, "for the purpose of considering the subject of $\mathrm{Hog}$ Cholera." Ten farmers reported using the following as remedies or preventives with varying results: lard, ashes, soft soap ("had to catch them and pour it down"), salt, charcoal, sulfur, assafetida, copperas, bleeding in the mouth, "Thompson's No. 6 ," tar, lye, and "cut open his scalp, put in salt, and pepper." One states:

I had a large fat one die. I built a fire over it and completely roasted it, and burnt most of the fat off. The hogs ate the remains. . . The disease at once stopped; eight that were sick got well.

\section{But another states:}

I have no faith in burning hogs to prevent the disease as here stated. A neighbor of mine burnt some eight in the manner stated, and they were eaten by the hogs, but with no perceptible benefit.

This happened to be in Iowa, but the story elsewhere was the same.

The vendors of hog cholera cures were censured by a correspondent in 1865, who identifies himself as "Berkshire":

Every few days I see some new specific, recipe or secret advertised as a certain cure for hog cholera. Not satisfied with this alone, the vender usually proclaims that his medicine will make well hogs better, make them fatten faster, \&c., thinking this will certainly be bait sufficient to catch a fine lot of greenbacks; and I presume there are greenhorns enough to nibble all these finely baited hooks, as I have lived long enough to learn that men love to be humbugged. It is my opinion that all these cholera cures are humbugs.

Trichinosis in hogs began to cause some concern in the $1860^{\prime} \mathrm{s}$, and in 1866 the editors of the Prairie Farmer state:
That it occurs in this country is undoubted, notwithstanding the bold assertions of some to the contrary, for out of many hundred specimens of pork which have been examined by scientific men of this city, one in every fifty has been found more or less infected. Let this however cause no alarm, for it only proves pretty conclusively that with the same thorough investigation they would have been found years ago, and there is no reason to suppose that there are more now than there have ever been. Some of the deaths in the army may have been caused by eating raw pork ... but in a country where meat is as thoroughly cooked as it is in ours, there is little to be feared from this scourge.

The later report "Great excitement prevails just at present in and around Cedar Rapids, Iowa, from the fact that three persons have recently died there of the Trichinae disease," failed to generate any excitement in the editorial offices of the Prairie Farmer, except to "exhort everyone to have a care that his pork be well cooked."

In 1866 a correspondent to the Country Gentleman states that disclosures of the "horrid devastations" of trichinosis in Germany:

Have struck the community with a panic; and the market quotations in New-York ... show a falling off in that city of one-half, in the consumption of this oleaginous comestible.

He urges proper cooking of pork, and, "Eat no sausages of unknown genealogy." In particular, he urges people to eat less pork, for:

If it is true, as has been affirmed, that man partakes of the nature of the animal of which he eats, we shall be the gainers in the long run by the substitution of the flesh of the more intelligent beeves and docile sheep for that of the more brutish, uncleanly, voracious, and even grunting swine.

Following a visit with a family near Springfield which owned some 30,000 sheep, the editors state:

Sheep in Central Illinois are subject to few diseases. The foot rot is never known on the prairies. . . . Sheep brought from the east have it very badly, but it entirely disappears the second season. The scab prevails in some flocks. . . . Ticks are not as prevalent as at the 


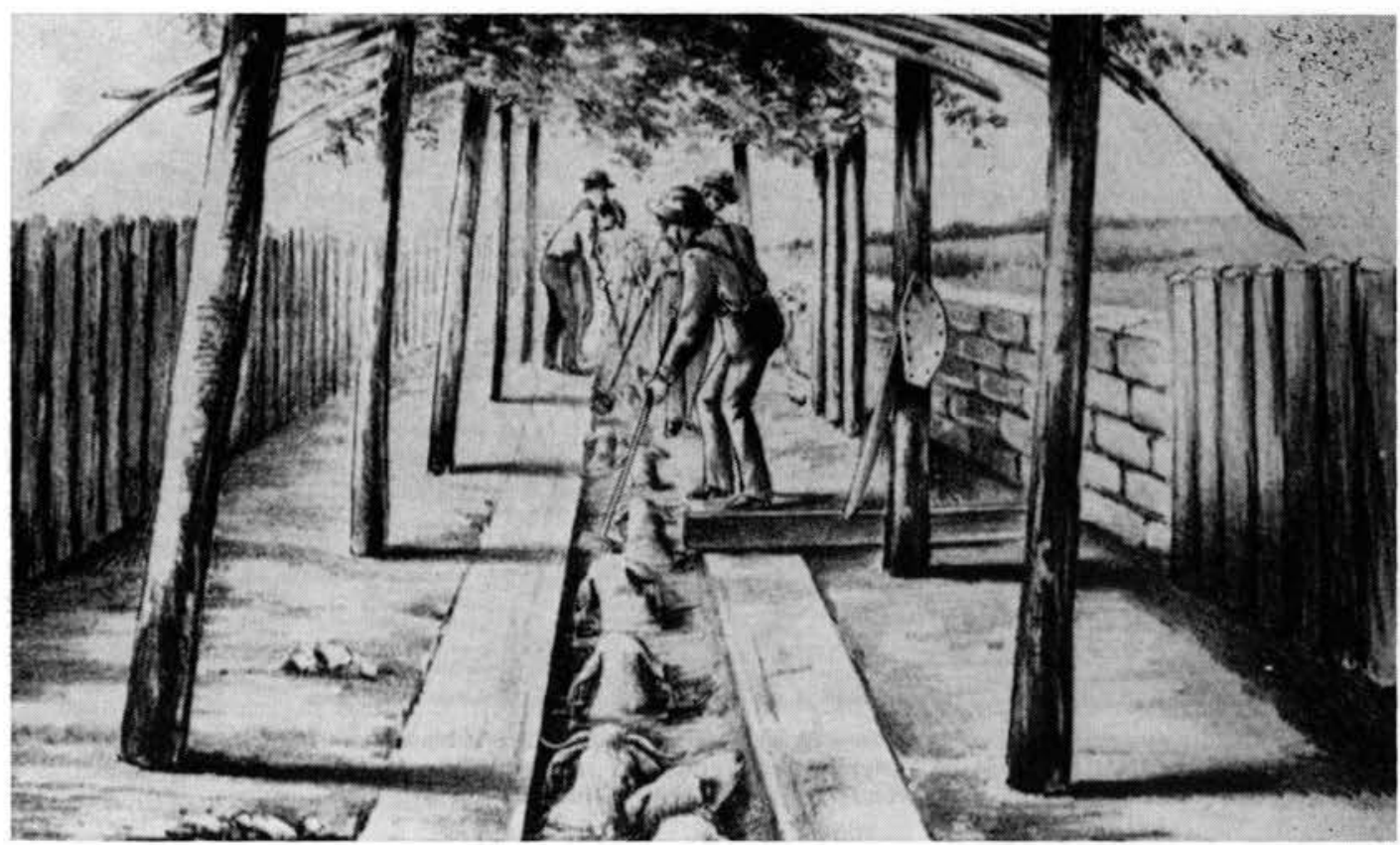

Scabies (mange) of sheep became a major problem which was largely uncontrolled until effective means - dipping in creolin solutions - were developed in the late nineteenth century.

east, yet no flocks are entirely free from them. ... [With] watchfulness during the herding season, but few sheep are killed by dogs... [but] the loss in the small flocks throughout the country when they are left to a free range without a shepherd during the summer, is immense.

With good management, more sheep were lost from rattlesnake bites than from dogs; including some inevitable thievery, on the best farms the annual loss from all causes was estimated at 10 per cent; a flock of 1,000 ewes was expected to produce 800 yearling lambs.

\section{Texans in a Tizzy}

The state of Texas appears to have had its share of troubles about this time, despite reports to the contrary. A letter in the American Veterinary Journal for 1858 states:

Here, above all places is the field for veterinary surgeons. Many large stock owners could each amply support a surgeon on the profits of the animals saved in the course of a year. But here we are shamefully imposed upon by quacks, more so than in any place I know of. Even those who have attained any reputation, in the majority of cases, upon examination, prove to be uneducated and sorry apologies of the skilful surgeon. . . The disease we most fear, in this region, is what is commonly known as Spanish fever.

In 1859 a correspondent to the American Stock Journal, writing "from the interior of the state," reports:

Many sheep are lost from the ravages of a disease called "fatty liver," which attacks the healthiest and most thrifty looking animals, and proves rapidly fatal. In some instances, flocks of several hundred have been almost entirely swept away in the course of two or three months by this terrible disease. It seems to be confined chiefly to the interior portions of the state, and is but little known along the coast.

The Journal considers this to be "liver rot," but attributes it to:

The effect of the miasma produced by the decay of vegetable matter in low, wet grounds, although some writers attribute it to the formation of tubercles in the liver, caused by exposure to cold and wet, and to healthy food.

In 1861 another Texan writes: 


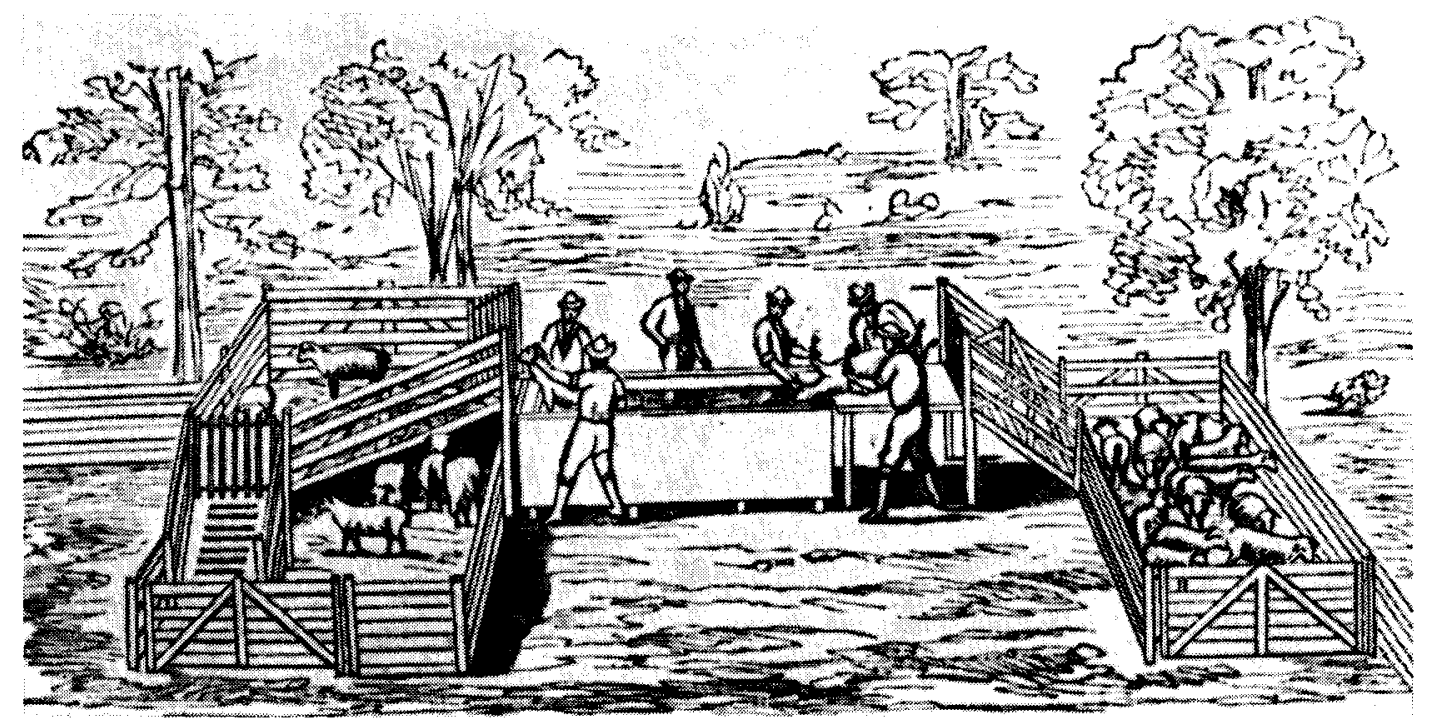

The European system of dipping in aboveground vats had the advantage of portability, but was little used on the western ranges where land (for sunken vats) was more plentiful than wood. American Agriculturalist

We have a disease that is proving very fatal among the horses in our country, which seems to be confined to brood mares and studs . . . which causes some to think it is a venereal disease. ... The animal stands with his hinder legs wide apart, straddles as he walks, and hinder legs apparently very stiff . . . appetite good, though they appear to lose flesh very fast. They generally live from ten to eighteen months after taking the disease.

Texans appear to have favored the American Stock Journal; in 1868 one writes:

Our flocks in Texas are well-nigh ruined with $s c a b$. Thousands have died and thousands more will die, if not treated properly in the way of cure and preventative. Plenty of Sulphur and of Tobacco will cure it. But, first, the remedy is a severe one; and then, they won't stay cured! The insect, in this climate, is to be found on every tree and post against which the poor sheep rub themselves. Few animals are so liable as sheep to the attack of parasitic insects, not only the scab insect, but lice, ticks, and the grub in the head. .. . Pigs are more infested with insects than casual observers would believe, until they examine the skin under a glass. Indeed all animals, even horses ... a are thus infested, and in summer especially, flies torment cows and horses kept in stables to a degree that is most injurious to them; in some instance ruinous. It is found that a washing once or twice a week with . . . crysylic soap prevents flies alighting on the animals at all.

We have in Texas, a terrible pest amongst livestock; known as the screw-worm. When from any accident fresh blood is drawn from an animal, even following the mere bite of a mosquito or the crushing of a tick, it is instantly blown with living maggots, by a large grey fly. The maggots eat their way at once into the flesh, and form a large sack. . . In forty-eight hours a cavity, in an ox for instance, is made large enough to hold a pint, and is one mass of living maggots, tormenting the poor brute beyond conception ... an infested animal can be smelt at a distance of a hundred yards to windward! . . These crysylic compounds... destroy the worms, cleanse the wound and effect a cure.

\section{The American Stock Journal (Pennsyl-} vania) at this time advertised various crysylic compounds, including Black Bar Soap, Sheep-dip, Foot-rot Ointment, and "Death to Screw-worm Ointment." By using the latter:

The altering or marking of young stock may be done with safety, even in the extreme South, at any season of the year.... To that pest of the Southern Stock-breeder, the screw-worm, it is certain death. 


\section{Cattle in California}

In 1769 an expeclition of less than 100 Franciscans, with horses, mules, and 160 head of cattle, arrived in Santiago, and formed the first mission in California. This is the only lot of cattle recorded as having been brought from Mexico to California for many years. The first overland settlers from the East found many large herds. But in 1871 a Californian states:

Stock owners are becoming disgusted and discouraged. Many cattle are dying for want of food. . . . Cattle and horses are roaming about in the valleys and table-lands with no visible means of support. Their next movement will be their hides brought to market. . . The number of cattle in Southern California, at this time, is not one-tenth of what it was ten years ago; and this decrease is owing to want of feed in dry seasons, many of the cattle starving to death. ... At the present time the State does not raise its own meat.

In 1861, a German veterinary surgeon from San Francisco, H. H. Claussen, writes:

An epidemic horse disease in California has been prevalent in different counties in this State, for some months, to a very great extent, whereby horse owners have lost some twentyfive per cent of their stock. The press calls it the "Salinas Horse Disease." In veterinary literature it is known by the name of Influenza. . . The farmers, and most of their socalled veterinary surgeons - in name only, but not in knowledge of the calling - treat the disease wrong, and use for its cure, useless and often contrary treatment. Some try to cure by bleeding... the main cause of such great mortality is wrong treatment and lack of care. In Europe... the mortality has never been so great.

\section{Sympathetic Slinking}

Abortion in cattle had become a major problem by the 1860 's; Paaren notes, "it is of no infrequent occurrence in certain sections of the country," and quotes at length from Robert McClure, "Principal of the Merchants' Veterinary College, of Philadelphia," on the subject. At this time, and until much later, the theory of "sympathy" as a cause of epizootic abor- tion was widely believed in, largely through the influence of Youatt, who literally states that one cow will "slink" her calf out of sympathy for another who has lost hers. On the basis of good evidence, McClure protests:

The theory of sympathy, which some authors and farmers favor as a cause of abortion, is not to be entertained for a moment by any one having any pretention whatever to a knowledge of physiology and the pathological anatomy of cattle.

The major cause of epizootic and the disease can be prevented "by maintaining a high standard of general good health." On the same page of the Prairie Farmer, a correspondent mentions having paid $\$ 10$ for "a secret remedy for the disease in cows of abortion," which was simply to feed "for each one about a teaspoonful of bone, pounded or ground to dust."

Earlier, it was stated:

The dairymen of Herkimer, Oneida, and other dairying districts on N.Y., are losing very heavily from this disease or habit. Entire herds of cows have aborted. The scourge increases every year. No one has yet determined the cause of it.

Abortion in cattle caused much concern in upper New York State in the 1860's. In 1863 a committee appointed to investigate the conditions reported in the Conntry Gentleman:

This habit in the cows... seens to be spreading rapidly, and is justly the cause of alarm to our dairymen; more especially as no satisfactory reason can as yet be given as to its cause, and as no practical, or at least economical means yet adopted, have operated as a cure or mitigation of the evil.

The first appearance of the disease around Little Falls was in 1852, when one farmer lost 13 calves, and 17 the following spring:

That fall he sold off his entire dairy, and removed from under his stables about 100 loads. of manure. . . In the spring of ' 54 he again stocked his farm with cows, and had no trouble until the spring of ' 61 . 
Among the innumerable theories as to the cause of abortion at this time, including the use of stanchions, and the inevitable "sympathy," few were as prescient as that proposed by D. B. Hinman, President of the Chester County (Pennsylvania) Agricultural Society:

We think that when the first case has occurred, and the disease has spread among the herd .... it is continued to the next year and perpetuated through the agency of the bull.

As proof he cites a case of several family cows owned separately, but all served by the "town bull," and all of which aborted. In another instance, a man who did not subscribe to the bull theory bought a bull from an infected herd:

The next season nearly every cow served by the bull aborted. No abortion had taken place on this farm previous to this, and nearly every cow from adjoining farms served by this bull also aborted.

In another perceptive article on abortion in cattle in 1866, a Canadian farmer summarizes the best information to date on the mode of infection. For this he gives credit to John Barlow, the brilliant veterinarian at the Edinburgh school. He states that abortion is of rare occurrence in lower Canada, thus it would appear that most of his information was borrowed. The frequent occurrence of abortions in a herd following the first case, he says:

does not absolutely prove that it is contagious. . . To prove that the disease is contagious, it must be shown ... that upon the introduction of an infected animal among those that are healthy, the disease is communicated to the healthy animals within a period of time sufficiently short to justify the supposition of contagion. That upon the separation of the diseased from the healthy animals, the spread of the disease is stopped.

The follow-up of these and other premises, however, is disappointing. The odor theory was still too strong to be displaced, especially by those who had a firm conviction on the matter. As treatment, bleeding and laxatives are recommended, but:
When abortion prevails to a great extent for years ... a thorough change of herd, however great the temporary sacrifice, will be found the best policy. ... The materia medica of the veterinarian is not richer in specific remedies for deep seated and mysterious diseases than that of the physician. . . Both, as yet, are working at the rudiments of their respective sciences, and are groping with equal success, I suppose, since they grope alike in darkness.

Henry S. Randall, the writer on sheep husbandry, reported from western New York:

The spring of 1862 was distinguished by a peculiar mortality among lambs.... The lambs affected by the epizootic had the appearance of a general want of physical development at the time of their birth. ... The resemblance to a prematurely born animal was striking. ... Congenital goitre in some instances accompanied the preceding symptoms.... The average loss ... varying from 10 to 90 per cent... was about 50 per cent in the larger infected flocks.

\section{Scientific Surgery}

In 1866, N. Cressy, M.D., of Canaan, New York, reported on a "Capital Operation in Veterinary Surgery." This involved a ventral hernia "the size of a four quart measure," in a colt:

I examined the case with Albert Brainard, Esq., a well known and reliable farrier... [and ] decided, as a last resort, to use the knife. The colt was placed on his right side, and $\mathrm{Mr}$. Brainard administered chloroform from the sponge, using about an ounce and a half, which produced complete anesthesia in about five minutes.

He clescribes the classic hernia operation in detail, and states: "We got union in the internal wound, by first intention, and the skin was now nearly closed up by granulation." Cressy was also a veterinarian, but apparently chose to obscure the fact.

Later, G. W. Wetmore, M.D., reports on an operation for scrotal hernia in a colt, in which he assisted Dr. Cressy:

I casually examined the case some time ago, and thought it beyond help, as did Mr. Joseph Marsh, a practical farrier. ... Dr. Cressy was 
called, and after a very careful examination ... decided that the scalpel offered one chance for the restoration of this otherwise worthless creature. I gave the colt the chloroform, and Dr. Cressy . . . castrated the animal on the left side... These operations have excited much interest in the profession ... and we regard them as reflecting much honor and credit upon Dr. Cressy as a comparative anatomist and veterinary surgeon.

In response to the inquiry of a correspondent in the Country Gentleman for 1866 concerning a lump on the jaw of a horse, Cressy gives a learned discussion of the probable nature of the case, and states, "I believe this tumor can be removed very safely with care, but it requires skill to extirpate it, inasmuch as it is in a delicate situation, involving, no doubt, arteries and nerves." Having noted Cressy's operations, another correspondent inquires, "if there are books to be had so that a farmer's son can learn the art both of [veterinary] medicine and surgery?" The editor replies:

No man can become a good horse doctor from books alone - he must have intelligent and well directed practice as a part of his instruction.

But for the most part the situation remained what it was represented to be by a correspondent to the Country Gentleman in 1862 who states:

I cannot for the life of me, perceive the necessity, in pursuing the study of Veterinary Science, of depreciating it to the value it bore in barbarous ages, when the firing-irons and blisters, and other such diabolical resources, were the chief remedies. I cannot see why a member of the veterinary profession should not be, and conduct himself as a gentleman. The act itself has nothing about it that should make people think that because they study and practice it for a livelihood, they must therefore combine it with a low, mean manner of living, or be compelled to associate with blacklegs. This is too much the opinion of the present day, and it is quite time respectable, energetic young men should take hold and lift the business out of the slough into which it has fallen, and make it what it ought to be, a respectable profession.

The establishment of veterinary schools, however, did not immediately make skill- ful surgeons of all aspirants. Writing on castration of the stallion and cryptorchid in 1884, G. Bailey, D.V.S., states that while castration is one of the safest and simplest of operations: "I know of many instances of graduates of veterinary schools whose 'courage fail them' when called upon for the first time." Regarding the many fatalities resulting from the work of certain types of men, he mentions the all too frequently excessive use of the hot iron, stuffing the sac with alum or other materials, and:

I also know of an old and experienced practitioner, who was habitually complaining of his bad luck in castration, who always used a pocket-knife with which he cut his tobacco; and in addition to the blade being always "gummed up" with the "fascinating weed," it was always rusty.

All that is required, he says, is a thorough knowledge of the anatomy of the region, strict cleanliness, and reasonable self-confidence. Most intelligent operators were now using the ecraseur; but:

One of the most ancient modes of operating, and one considerably in vogue at the present day, is that of compression by wooden clams. . . Cauterization, at the present time is mostly confined to country gelders and others whose knowledge of more scientific methods is extremely limited. . . There is another method I have seen employed upon horses and other animals, a barbarous one at best, by charlatans and quacks, that of stretching or tearing out the "spermatic cord," until it breaks somewhere, which of course it will do if sufficient "main strength and stupidness" are applied to it.

\section{On castration of cryptorchids, Bailey} states:

Now that the noted specialist, Farmer Miles, has discovered a safe and humane method of operating upon ridglings. ... I believe the veterinary profession cannot do less than to acknowledge their indebtedness to an ingenious and skilful man for a valuable contribution to veterinary surgery.

Miles, of course, was not the first to use the method he employed, but none less than George Fleming had been prompted to write: 


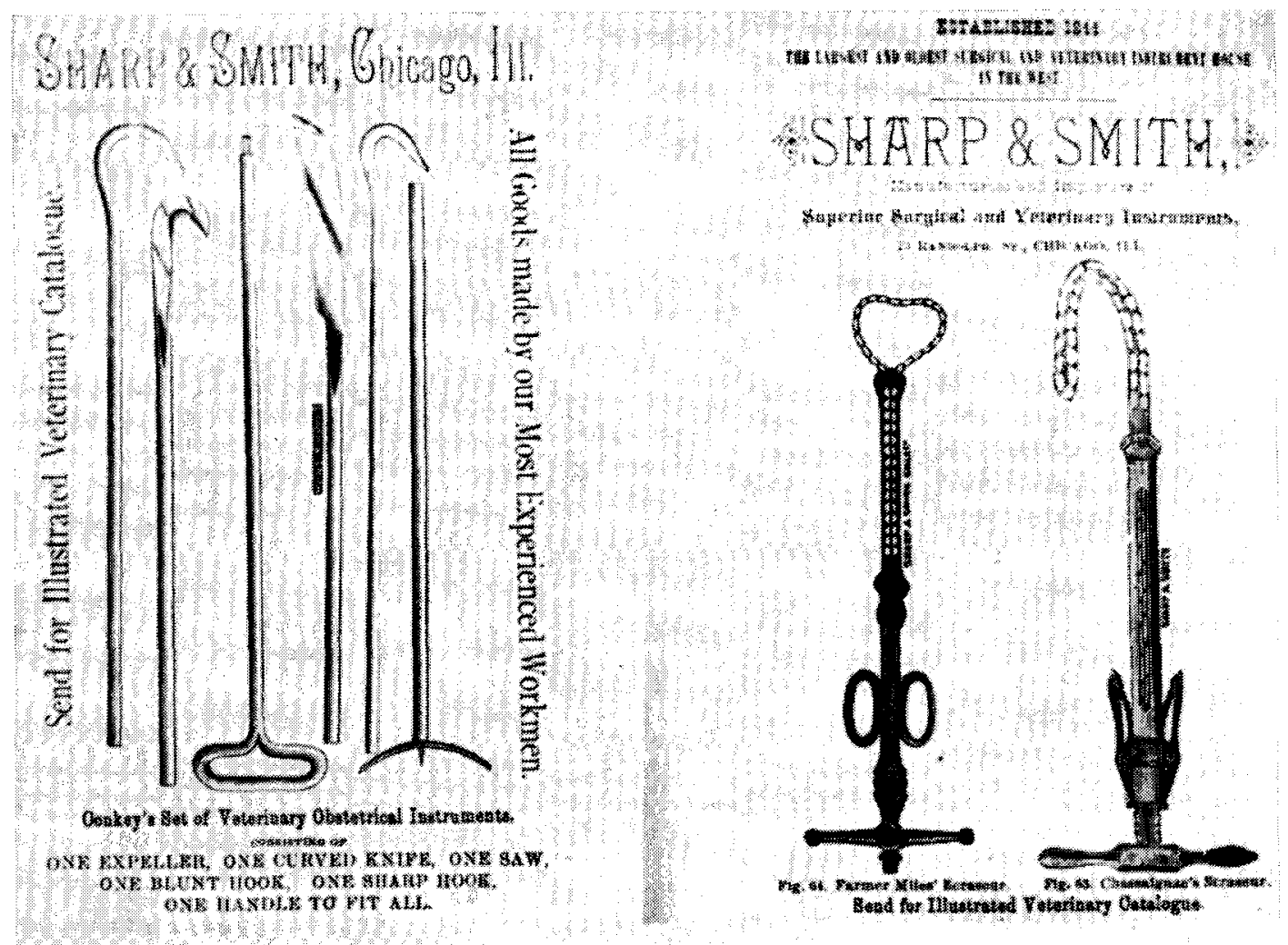

The spaying ecraseur was used in the 1860's by Robert Jennings, but did not gain wide acceptance until Farmer Miles' improved model was manufactured two decades later. American Veterinary Review

It had remained for an "American farmer" to visit England and publicly demonstrate to British veterinary surgeons, what they had never dreamed of being successfully accomplished.

That veterinarians might have needed additional instruction in the art of castration is evident from R. S. Huidekoper's review of Liautard's book on Animal Castration (1884):

This concise and complete little book is a veritable godsend to the veterinary surgeon and to the rural economist, in these days of superstition, when animals are still gelded at the wane of the moon, and educated veterinary surgeons $b u y$ "secrets" of "difficult operations" from self educated gelders, whose long practice has simply made them expert in performing what any good anatomist should do.

Concerning the "secrets" of cryptorchid castration bought by veterinarians from
Farmer Miles, Thomas Rodgers, D.V.S., writes in 1893:

It has been reserved for a layman ("Farmer Miles") to make a greater reputation, and accumulate more wealth, in the practice of this specialty than any professional man in this country. I have seen him operate and should be unjust to deny him great natural aptitude for his vocation, entire coolness, great manual dexterity acquired by much practice, and an excellent, though rather slow, method of casting and preparing for the operation. It has also been my fortune to have the acquaintance of some veterinarians who have received "sealed instructions" from him; and they one and all throw a cloud of mystery round the operation, as though there was some secret about it not known to our teachers. I believe that I have solved their cipher, and that their mountain of quackery having conceived has brought forth just this little mouse - i.e.; Ninety per cent of so-called ridgling horses are nothing but close colts, having the testicle and cord, or some part 
of them, somewhere between the upper and lower ring.

\section{THE LIVESTOCK JOURNALS}

The stock journals, by comparison with the more general agricultural papers, quite naturally carried considerably more information on animal clisease, and thus are valuable sources in this respect. The American Stock Journal, published beginning in 1859 in New York has been noted in connection with George Dadd. Another American Stock Journal began publication in Pennsylvania in 1866, and in 1870 the National Live-Stock Journal, a first-class publication, began in Chicago. Later (1881) the Breeders' Gazette was added to the list, and immediately entered the fight for a national agency to control animal clisease. The short-Iived (1882-1884) U.S. Veterinary and Livestock Journal can be considered in this class. There can be no doubt, despite several of their shortcomings from a veterinary viewpoint, that these journals served an important function in creating an awareness of the increasingly dangerous animal disease situation, and in calling for adequate measures for control.

The National Live-Stock Journal carried many articles on animal disease. At first these were mostly in the form of reprints from other papers, but in March, 1871, $\mathrm{H}$. J. Detmers, V.S., was installed as editor of the Veterinary Department. During his short tenure Detmers provided a number of lengthy and excellent articles on a variety of diseases, but he apparently severed his connections with the Journal the same year. Following this the Veterinary Department as such was dropped, but inquiries of a veterinary nature were answered, apparently by a veterinarian, and the Journal continued to keep its readers informed on the animal disease situation. In 1874 a correspondent asks: "Why is The Journal without a regular Veterinary Department, in which the diseases of stock are treated" The editors state that these have been considered in the other columns, and:
The inquiries of correspondents in relation to the diseases of animals are referred to Dr. N. H. Paaren, whom we regard as one of the most competent veterinary surgeons in the United States.

The following year Paaren's contributions were identified; later James Law was added as an associate editor, but Paaren continued to answer veterinary inquiries.

The Journal carried a report of an outbreak of anthrax in Massachussetts in 1869, and again in 1870 , saying:

The disease which is destroying so many valuable animals in Berkshire county, is the same as that described to the students of Amherst College as Charbon, by Prof. Law, in his recent course of lectures upon Veterinary Science.

A good description of its epizootiology, especially in relation to flooding, is given, and the danger to man is stressed. The same issue (January, 1871) carried an extensive notice of the outbreak of foot-andmouth disease in New York in 1870; the editors state:

Our readers feel a natural desire to ascertain as much as possible of this disease . . but at this distance from the scene of operations, we are compelled to rely greatly upon our exchanges for a description of its manifestations, and the modes of preventing and curing it.

In February: "We have heard of no wellauthenticated case of this disease in the West, as yet, but it is not unreasonable to expect its appearance on the great prairies at any time." And in reprinting a lengthy article on the disease by James Law, the editors state:

It will repay careful perusal; and while at present of immediate interest to Eastern breeders and dairymen, those farther West may need to refer to it an early day.

\section{To Contribute My Mite}

At the time Detmers was made Veterinary Editor of the National Live-Stock Journal he was Professor of Veterinary 
Surgery at the Illinois Industrial University at Champaign. Apparently he sought the connection with the Journal, considering it:

My duty to contribute my mite. . . . If you look through your agricultural exchanges, you will find that, with rare exceptions, the veterinary department is the poorest one of all; that it contains a good deal of nonsense, and is frequently made up entirely of quack prescriptions. . . As veterinary science is so closely allied to animal husbandry, or rather a constituent part of the same, I think The Journal should have, also, a veterinary department in keeping with its other departments. Then the friends and readers of The National Live-Stock Journal may learn to appreciate the value of true veterinary science, and may be induced to promote its cultivation.

The several columns provided by Detmers during his short tenure as Veterinary Editor represent a new high in veterinary journalism in the agricultural press. On periodic ophthalmia:

At the present day ... its true causes are better known, the moon's innocence has been established, and that old dame, charged with so many sins, has been honorably acquitted... [and ] Accusing so-called "wolf's teeth," or "blind teeth," of producing moonblindness, or, indeed, of affecting the eyes at all, is simply old-fogeyism.

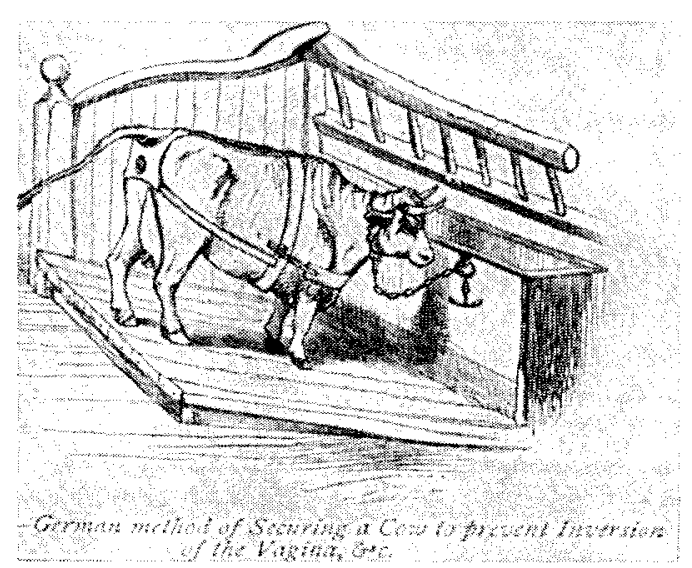

The inclined platform for prolapse of the uterus or vagina has been used for a century or more, but the elaborate harness has been largely superseded by suturing technics. Clater-Armatage: Cattle Doctor
Except for "a good bleeding," his handling of the condition is quite acceptable.

Spaying of cows, he says, has not been widely practiced because of the frequency of peritonitis as a sequel to the common operation through the flank or belly. He advocates spaying through the vagina, a method which: "as far as I am aware, has never been practiced in this country," as a means of obviating the dangers of an abdominal operation. It also results in "less suffering to the animal, and is easily performed." In succeeding issues he discusses dysentery, articular lameness, sheep scab, milk fever, and strangles. On the latter, he mentions its contagious nature, but strangely enough fails to stipulate segregation of the diseased animal. He says, "We will treat of the complications of distemper in a future number," but this is his last column. Evidently he had anticipated continuing his editorship, and no explanation is offered for dropping it. It would seem likely that his articles were too erudite for his audience; Paaren later returned the Journal to the more commonly accepted practice of "answers to inquiries."

It would appear that despite the avowed intentions of the agricultural journals of espousing veterinary science in its broadest sense, it was difficult to strike a balance with demands of readers for free veterinary service on individual problems. At one extreme, in an address to the Ohio Agricultural Convention, Dr. N. S. Townshend stressed:

the necessity of a thorough course of veterinary instruction in the Agricultural and Mechanical College of the State... . The end of veterinary knowledge is not the cure of disease, but the maintenance of stock in the highest conditions of health and profit.... The treatment of disease is only incident to this.

At the opposite extreme the Journal invited subscribers to send inquiries on disease for Dr. Paaren to answer, and Paaren also advertised his services as:

A Qualified Surgeon, of nearly 20 years practical experience, known as the Veterinary Edi- 
tor of the National Live-Stock Journal, and of The Prairie Farmer, will go any distance to perform Surgical Operations, or examine into epidemic or other Diseases of Domestic Animals. Veterinary Advice given by return mail on receipt of $\$ 1$. Will also contract with breeders by the year, to visit once every month or two, at a reasonable rate...

An advertisement which caused much interest was that of a Jas. McKeighan of Illinois, who claimed:

Barren Cows made Fertile. ... [ Having] discovered the means of restoring barren cows to fertility, persons having such animals as they desire to have operated upon, will please communicate . . .

\section{The editors state:}

We depart from our usual custom to direct attention to the advertisement to Mr. James Mckeighan . . . who claims to have discovered a means of restoring barren cows to fertility.... We learned that he relies upon the efficacy of a surgical operation, which, if it does no good, can certainly do no harm, and is not attended by any danger. . . . We advise those who have barren cows to confer with him at least, and submit this matter to a test.

One correspondent writes of one apparently successful case of a four-year-old cow that had never bred. In October: "She is in calf since last May - at least has not bulled since then." Later, however, in response to an inquiry for a cure for barrenness, the editors state: "Have never heard of a permanent cure, or a certain cure." In the meantime, apparently, another quack had bit the dust, for McKeighan had stopped advertising.

\section{Farmer Miles}

The Journal also carried the business card of T. C. "Farmer" Miles, V.S.: "Ridgling Horses Successfully Castrated by the right method. No cutting, only through the skin at the bottom of the scrotum." One of the more remarkable phenomena of the veterinary scene during the latter part of the nineteenth century, Miles, by his own admission was: "The best castrator in the world." This, and his penchant for other superlatives in his voluminous advertising of his prowess, undoubtedly was the cause for many veterinarians labelling him a quack - particularly if they did not know the man. During the 1870's and '80's, however, it was not uncommon for prominent practitioners to announce their abilities in no uncertain terms. And while the USVMA made an effort to lay a restraining hand upon such activities by its members, relatively few veterinarians were members of the Association.

Miles, whose methods savored of the then rampant quackery, however, was no quack. By definition, a quack is "an ignorant or fraudulent pretender to medical skill." Miles, on the other hand, was an unusually talented individual who could back up his most extravagant claims. It is perhaps significant that his standing offer of $\$ 500$ to anyone who could best him in the cryptorchid operation on horses was rarely contested, and never claimed. Moreover, despite his flagrant advertising, he practiced a higher standard of ethics than was to be observed in the conduct of perhaps the majority of veterinarians of the time.

During the 1870's Miles conducted a "college of inguinal surgery" at Charleston, Illinois, at which he taught a method of cryptorchid castration that has not since been improved upon. Although others had practiced the same operation earlier, Miles apparently devised his technic independently, and was sincere in his claims of originality. He travelled the length and breadth of the country performing the operation, at the same time demonstrating his now classic method of restraint. He also published an excellent manual on the anatomy of the inguinal region. Thus it is obvious that he had no secrets to hide; in fact, realizing that he could not personally fill the demand for his services, he openly professed to prefer teaching others his methods to merely performing the operation - which he did so rapidly that it is doubtful that many could have learned it merely by observation. 
Concerning his ethics, Merillat and Campbell state:

He taught the doctrine of Hippocrates and practiced it. He opened his class work with prayer. He was not a hypocrite. He taught his students to act like gentlemen, dress like gentlemen, be gentlemen and had no use for fakirs and fakes. . . Had the veterinary quacks of his day and their descendents followed his concepts of what a veterinarian should be and should do in the matter of conduct and skill, the coming graduates would have found it far harder to replace them. The quack's Waterloo was the field of conduct. The ethics of Farmer Miles would have postponed the supplanting of the American non-graduate by the young, inexperienced graduate, just as our ethics now must save the veterinary profession from public censure.

\section{Calumny From Critics}

Despite an undoubted first-hand knowledge of Miles's prowess, Alexandre Liautard repeatedly criticized what he termed Miles's charlatanry, and was harsh upon veterinarians who wrote testimonials for Miles, which the latter used in his advertisements. Liautard, whose ethics were above reproach, however, was not backward in announcing the merits of the American Veterinary Review and the American Veterinary College, both private institutions in which he had a financial interest.

Miles's story, as related by him in the $U$. S. Veterinary Journal for 1884, reveals him as a more reticent individual than his advertising would suggest. His uniquely straightforward style of writing, to say the least, is refreshing; but more important, it reveals him as an intensely human individual with a genteel humility hardly suggested by his flamboyant advertising.

In recalling "some of the hardships of my wanderings and ups and downs in the world as a castrator," Miles recollects:

I was born May 1, 1825 in Kentucky - "down thar." In 1847 I migrated to Charleston, Ills. Moved to Texas in 1858, and back in 1860 . Farmed as a business; but for pastime gelded horses free of charge, and soon got the name of being a good hand at it. When my practice increased so as to interfere with my farming I gave away my ropes and quit the business several times, but an increased demand for my services and a fondness for such things seemed to compel me to turn my entire attention to castrating and spaying, and traveling in answer to calls for my services until I had crossed the continent from ocean to ocean and from Texas to Canada. In the mean time I had taken the prize at our Centennial Exhibition as the best castrator there, and was complimented by an article in The Spirit of the Times, of New York City, Aug. 22, 1877, which said: "There is no man on the continent of America who is worthy of being compared to Mr. Miles in this respect" - [ ridgling castration ]; and in the same article nicknamed me "Farmer Miles," which stuck to me all over England, Ireland and Scotland, and of which I am not ashamed for I think a good farmer ought to have more sense than I ever had, and in my rambling I find a great many such farmers and like them, and still like my nickname.

How long he had dabbled with castration as a "pastime" Miles does not state, but he was nearly 50 years of age when he turned to this as a full-time enterprise. His success at the Centennial Exposition led friends of his to advise him to demonstrate his prowess in England, which he did, but not without considerable tribulations at first.

Until Farmer Miles practiced and made public his method for the cryptorchid operation in horses, the few veterinarians who were bold enough to attempt it used the flank approach, but the heavy mortality caused all but a few to eschew the operation. The inguinal approach devised by Miles had been reported independently by several European veterinarians as early as 1840 , and had been performed by James Law in this country in 1870 , four years before Miles is known to have engaged extensively in his practice. Law stated to a friend that he had conceived of the approach independently; thus it is quite likely that Miles knew nothing of the work of Law or of the European veterinarians. Miles states that his method was original with him, and his other writings mark him as an honest man despite his predilection for superlatives concerning his prowess. 
Characteristic of the castigation of Miles by veterinarians is a communication by Ezra Mink - a nongraduate of the highest caliber - to the American Veterinary Review for 1877 Mink writes:

The wonder and originality, which is attached and attributed to his operations, indicates a considerable lack of veterinary knowledge, as well as a humiliating concession that the veterinary profession lacks operators of originality and boldness - which in fact is not the case, and is an injustice to the veterinary profession. ... I have no disposition to withhold from Mr. Miles any credit that may be due him for originality, if he never heard of the method before he commenced the practice of it. I gladly concede, that much credit is due him for putting the system alluded to in extensive practice, and by so doing, contributing his share of proof, that it is not so dangerous to castrate cryptorchids in the manner described, as in other methods.

And referring to the endorsement of Miles's method by veterinarians: "from the principal of a college and from an editor of one of the best veterinary journals known," Mink considers:

One effect of such fulsome praise is to increase the egotism, vanity and conceit, of which he was nearly full to repletion, before he received it. Here is a man so filled with charlatanism, that he sings his own praises whereever he goes. He is loud in proclaiming at all times, on all occasions, and in all places, that he can spay cows, and castrate ridglings better than any other man in America can do it. . . .

Is this the kind of man for regularly educated Veterinarians to indorse and cover with certificates? Is this the kind of man for any one who professes to be guided by a proper code of Veterinary ethics to indorse? . . . Did ever a charlatan before get a greater send-off than this Mr. Miles has received from members of high standing in the Veterinary profession? We think not.

\section{Battle of Britain}

Laboring under the misconception that he had been invited to Britain by George Fleming, Miles met with a cool reception upon his visit there in 1877. After several misadventures, including an open feud with Fleming, he struck up a friendship with Professor Wm. Pritchard of the London Veterinary College, and had finally turned his running feud with George Fleming to good account by obtaining a testimonial from the latter under circumstances which gave Fleming little choice. Fleming himself admits that no English veterinarian had attempted the inguinal approach in cryptorchid castration, and he evidently did not wish to subject a horse belonging to the Queen to the risky flank operation - which had been prohibited by law in France since 1717 because of the high mortality. Farmer Miles's operation on this animal, therefore, amounted to something of a "command performance," and may have been the deciding factor in securing for him a coveted opportunity to publicly demonstrate his prowess at the Royal Veterinary College of London. Concerning his entrance into the hallowed walls of the college, Miles relates:

On November 27 th, the day set, I went, and met Prof. Pritchard, who asked me, "Have you met Professor Simonds yet?" I answered, "No, sir." "Well, he is the oldest [born 1810] professor here; better come with me to his office, and let me introduce you to him." [But Simonds outlived Miles by two years. ] I did so. Professor Simonds seemed to me a very crusty old gentleman. I enjoyed his company so little that I soon took my hat and walked back to Professor Pritchard's office, and asked him if he would furnish me with five young men and a horse so we could practice my methods of casting.

Miles's appraisal of Simonds, although somewhat hastily drawn, coincides with that of General Sir Frederick Smith, who knew Simonds as principal of the College: "He was aloof and distinctly unapproachable; he was slow and possessed several mannerisms ... which were as lifeless and uninspiring as his manner. He never failed, however, to command respect." Miles continues:

I soon found myself off in a back stable (with an old gray mare) lecturing my pupils. I also discovered that our stable was surrounded with students outside listening to my talk. About this time Professor Simonds came and rapt on the 
door, boldy saying, "Open this door." I did so. Then he said, "What are you doing in here?" I explained to him that I was preparing five young men to help me at my public exhibit this afternoon at 2 P.M. He very bluntly said, "This is no place to cast a horse. Come out of here. Come up to the casting shed where there is plenty of room." We went, but I felt rather sulky in being ordered around so dictatorially, even if I was in the veterinary college. Professor Simonds said, "There is a suitable place, now cast your horse."

I then said, "Young gentlemen, go on without me," and they did; they cast that old gray mare, and recast her; tied her, and rolled her around so as to show they were experts in the American methods, until Prof. Simonds kindly stepped to my side and asked, "Would you like to see how I cast a horse?" My sulky mood had vanished. I took my hat off to him, and answered politely: "Professor Simonds, I would be pleased to see any veterinary cast a horse in the Royal College, but much more to see the Old Professor himself." He replied, "You shall," and ordered his ropes and a fresh horse. A fine large bay gelding, that looked a little wildish, was led in and roped according to his orders. In the meantime Prof. Simonds was advising and instructing me how to do when casting a horse so as not to get kicked or hurt while putting on the ropes. I thought it the nearest to mockery that $I$ had ever been guilty of to stand there and thank him for instructions that I would never need. But how else could I do? Finally, with ten helpers, the horse was roped, and orders were given to "pull." That horse flounced and bounced, and got off fifteen feet from where he was standing, and fell against the wall, and kept on struggling until his ropes slipped over his head, and he got up before they tied him, and Prof. Simonds gave his help- ers a scolding for not putting on the blinkers, and the crupper, and the circingle; and the way he scolded, I saw that the students were afraid, and jumped around lively and got what he wanted and put them on again, and again he said "pull." Tis true, the horse went down this time, and they held him and tied him, but it was very awkward work, I thought. By this time a large crowd of spectators had collected around us, and up in the galleries. I walked up and thanked Prof. Simonds for the trouble he had put himself to on my account as politely as I knew how.

The crowd, many of them students, apparently sensing Simonds' discomfiture, insisted on Miles repeating his demonstration. Miles, of course, sensed what was afoot, and refused, but the clamor continued, and he finally acceded to their wishes. Miles's five helpers quickly dropped the same horse on the spot, whereupon the crowd cheered, but Miles quickly stopped them, feeling that they were deliberately insulting Simonds. Concerning the two methods of casting, Merillat and Campbell state:

The English hopples were the popular method of casting horses in the '70's and were regarded as the best means until Farmer Miles demonstrated the "rope method" upon which all casting harness employed at this time are but improvements of dubious merit.

\section{Put to the Test(es)}

Having clearly demonstrated the superiority of his method of casting, Farmer

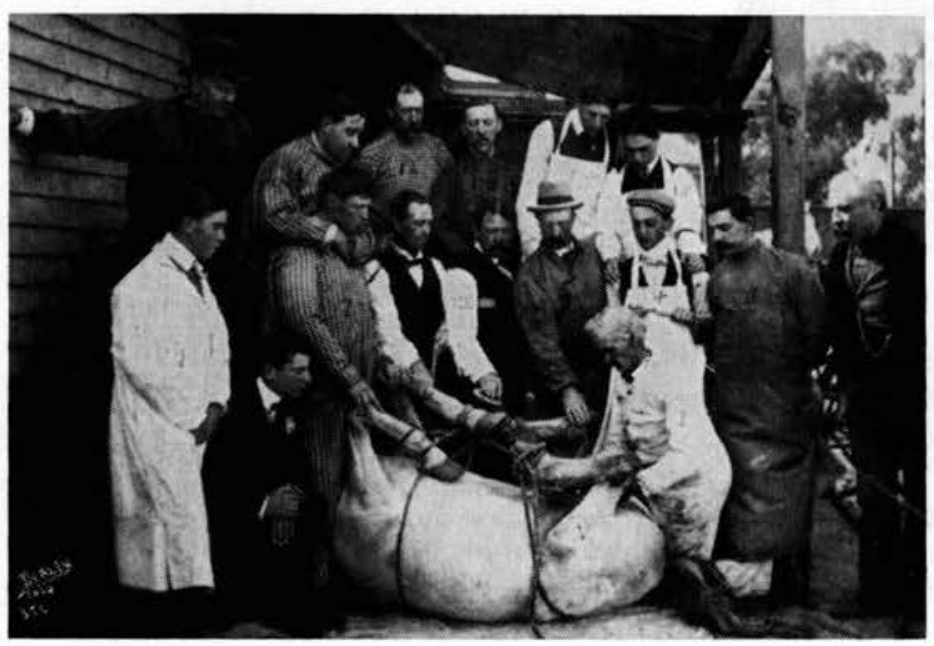

Farmer Miles performing his famous cryptorchid operation on General Shafter's horse before a group of veterinarians at Fort Mason, California about 1900. The man at the far right is General Shafter's coachman. Courtesy Dr. E. G. LeDonne, Sr. 
Miles undloubtedly was anxious to get on with the object of his visit. He did not have long to wait, for at this juncture Professor Pritchard entered the arena with a Mr. Case, whose horse Miles was to operate upon. As related by Farmer Miles, Mr. Case warned him:

My horse is the most vicious animal I ever saw; please be careful, and don't let him hurt you, for he will kick, bite or strike, either or all; he is very vicious.

The horse was standing in a large stall, with his head outward. (This writer, as a student, recalls such a horse, which had to be backed into the stall, and of which everyone - at least those who were honest - admitted they were mortally afraid; I soon learned why he was cross-tied in the stall with his head out - needless to say, this was one horse that did not get groomed, by me, at least.)

Concerning his prospective subject, Miles recalls:

He had a strong halter on, and tied to one side; a good bridle on, and it tied to the other side, and a large iron basket on his nose and face. The crowd now amounted to four or five hundred strong, and nearly all veterinary surgeons. Some had come a hundred miles to see this American farmer tackle a rig horse. When they saw this brute of a horse, as they called him, led in, the crowd fell back and gave me plenty of room in the shed. I am sorry now that I cannot express to my own countrymen, properly, my own thoughts and feelings at this point in my trials. . . . I was a stranger there; yes, a foreigner, besides I was not a professional, yet now in "The College." There stood the most vicious horse I had ever met with as my subject. I was alone. I was lame besides. I was surrounded by hundreds of critics too willing to say, "ha! I told you so." I had my own reputation at stake. I had a small part of my country's shame or honor to bear down on me just now. I felt all this, and that many friends, both home and abroad, would feel pained if I failed to do my work right, and should have to leave England in disgrace as a fool farmer.

With feelings of this kind I dared to put on a bold face, and tried to give what they called a lecture on castration. I said: "As an American farmer, and not a veterinarian, gentlemen, please permit me to express my ideas in my own way;" and I did so the best I could. I acknowledged $I$ did not know much on this subject, but I claimed that the English knew less, for I had seen English veterinarians castrate just as their grandfathers did, but Americans had quit that method for more improved ones.

I tried to direct my remarks mainly to the two hundred and twenty students who expected soon to graduate, and would need to castrate stock. I advised them first to go slow, and never get nervous and tremble as I had seen old vets do about common castration, and never to etherize a horse for such operation; and, furthermore, please never use the English nose twitch as I have seen it used here frequently, almost twisting the upper lip off, and in the meantime saying bad words to the poor horse because he would not stand still, and let it twist off. I here showed them an American nose twitch, a small stick one foot long, with a string at each end, which I claimed, if reasonably applied, was better than ether, chloroform, or the Englishman's ten-foot pole.

I talked about twenty minutes, and then walked up and put my hand on the horse, who seemed surprised at my impudence, and made such peculiar gestures that I felt forced to retire to a place of more safety, and to say to my audience, "We have been wanting a bad subject, but I think this one is worse than we bargained for." They laughed as though it was funny. You might imagine how I felt, or shall I tell you? I felt that I had burned all bridges behind me. It was success or death, now and here. My audience seemed as still as dead people. Two stout men, one on each side at full length of the halter and bridle, stood wide apart holding this vicious horse with an iron muzzle on. My talking stopped to give place to serious thought. I at once decided, and made my attack on the front end, and grasped his left ear in my right hand, and shall always feel that I had supernatural strength to make that horse succumb by my grip, while with my left hand I unbuckled his muzzle and threw it to one side. Just then a number cried out, "Don't do that, he will bite you!" This so frightened the two grooms as to cause them to let go of both the halter and bridle, and run. My little twitch was hanging on my left wrist. Slowly and carefully I applied it on the nose, and, one of my five young men assisting me, we twitched him just right, and then he stood as still as a table, while we adjusted every rope, and took our several positions preparatory to casting him.

All danger was now past, for the horse could not kick or move without falling down. I enjoyed the proudest moment of my life when holding that vicious horse by the tail with my left hand, I laid my right arm upon his back, and said, "Now, gentlemen, you see a practical demonstration of the American nose twitch." 
All danger forgotten, my mouth got the rattles again, and while thus standing I concluded my first lecture, downed the horse, and successfully operated on my first ridgling in the Royal Veterinary College in London, England; and, after some other operations and some caponing of fowls, I felt well; yes more, I felt happy; yes, I felt that I liked everybody, and that everybody liked me.

Concerning Farmer Miles's introduction of the cryptorchid operation in England, Alexandre Liautard graciously conceded:

The farmer's visit had for results, I believe, that European veterinarians became more daring and by degrees began to perform castration oftener.

\section{So much for Farmer Miles.}

\section{The Journal on Colleges}

In discussing hog cholera in the National Live-Stock Journal in 1875, Paaren states:

Almost all the diseases of swine seem to be popularly resolved into "hog cholera." Of all diseases of domestic animals, those of this genus are evidently less thoroughly understood than those of any other species. ... Agricultural stock suffers serious neglect. We venture to assert that ninety per cent of the domestic animals of the farm which suffer from disease throughout the United States annually, are never seen by Veterinary Surgeons. It is most singular that the Americans, who have manifested the greatest activity in the promotion of science and the useful arts, have never been able to found a thoroughly efficient Veterinary College. We number among ourselves but few Veterinarians. . . . Is it to be wondered at that our live stock are cut down by disease in a most disastrous manner?

In the same year, the Hon. T. C. Jones, an associate editor of the Live-Stock Journal, in writing on "The Need of Better Instruction in Veterinary Science," states:

We... have long insisted that full provision should be made for such instruction in our agricultural colleges in all the States. But in reference to the epizootic diseases .... it is obvious that we cannot wait until we have educated a supply of surgeons to answer the calls of all our breeders. . . . The immediate and pressing need is ... that qualified men shall be set at work to investigate and treat these diseases, and that they publish the results, when they have something to communicate; and that their reports be of such moderate length that ordinary people can take time to read them ... and in such form as to be of practical use to the mass of intelligent farmers.

Where these qualified men were to be obtained is not stated.

In response to the above call for State veterinary schools, a "Stock Breeder" writes:

Other colleges ... are organized and sustained by private enterprise, and why should not veterinary colleges be left to the same interest? If there is a demand or occasion for them they will be started, and liberally sustained. . . . But our people, as a mass, do not appreciate their importance, and never will ... until some great calamity overtakes them and the country. Hence the demand for them does not exist. . . . If there were no socalled veterinarians scattered through the country, it would at once be demonstrated that there is a demand for veterinarians. But in almost every neighborhood there are to be found one or more quacks, men destitute of all information and education, who pretend to be veterinarians. The ignorant public fancies that in these they have veterinarians, when they are required; and their practice is so irrational and unsuccessful, that farmers and others have become disgusted with it, and come to believe that veterinary science is a humbug. . . . For myself, I have an utter contempt for the quacks ... if one of my animals is sick, and I do not know how to treat it, I consult my family physician.... I often get but little satisfaction .. . but his advice is much better than that of these quacks.

Under the circumstances he concludes that government schools are the only answer; their products would be the means of teaching the people "to appreciate the importance and necessity of this science."

Some appreciation of the situation of a community without an adequate veterinary service may be gained from the history of "a terrible disease among horses at New York," in 1871. New York City had several dozen practitioners at the time, but only a few were graduate veterinarians; nevertheless this city undoubtedly had a greater veterinary potential than any other in the United States. Within a few weeks 
between 700 and 800 horses, most of them belonging to street railway companies, were stricken with a paralysis, and about 10 per cent died. The New York newspapers offer more than adequate testimony on the inadequacy of knowledge concerning the disease. Thus the New York Sun for June 14 states:

By some it is pronounced to be that terrible disease known as cerebro-spinal meningitis ... although many eminent veterinary surgeons say that it differs from that disease in some essential requisites. ... There is no effectual remedy for the frightful malady yet discovered.

The Times of the same date says:

It still baffles the most eminent and experienced veterinary surgical skill of the city. . . . The veterinary surgeons make the very equivocal statement that they do not understand exactly the real nature of the disease, but add, that it is not contagious.

The Telegram adds:

There is a diversity of opinion among the leading veterinary surgeons as to the character of the disease. Some contend that it is contagious; others claim that it is merely the result of injudicious feeding.

Extracts of these articles appear in the Live-Stock Journal for July, 1871, along with Detmers' comments that these demonstrate:

The want of an institution in which veterinary science is cultivated, and from whence veterinary knowledge may be diffused. If we had in this country a single Veterinary school worthy of the name, the above described dis-

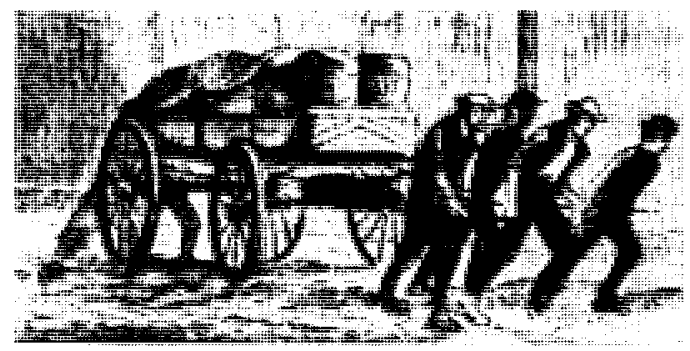

Much of the freight that did get moved in New York City during the 1871 outbreak of horse influenza was drawn by men instead of horses. American Agriculturalist ease ... would be quietly investigated, and brought to light by competent men. ... The disease in question is neither new nor uncommon; we have observed cases every year in the State of Illinois.

While he does not name the disease, he leaves little doubt that he considers it to be azoturia. If this were the case, however, it would seem that the New York outbreak was somewhat atypical of the disease. It reached a peak in June rather than early spring; instead of being confined to work horses, a number of trotting horses were reportedly stricken, and the appetite "seems to increase rather than diminish as the disease advances." Whatever the case, the circumstances were such as to give the public a poor impression of the veterinary profession.

\section{Inroads of Influenza}

A similar situation obtained with the outbreak of equine influenza in 1871-1872, concerning which the Live-Stock Journal accused:

The "doctors disagree," as usual, concerning its treatment; and the uncertainty concerning it is so great, that we hesitate about giving our readers any positive advice concerning its management. ... [however] All authorities concur in declaring that clean, well-ventilated stables must be provided, in order to insure the recovery of affected animals, and prevent the spread of the malady. . . . Its serious character may be inferred from the fact that in many places it has proved so general as to cause a suspension of street cars, omnibuses and express wagons, and blocked the wheels of commerce by preventing the transfer of freight from one locality to another. In New York over 30,000 horses were affected; the piers were piled with baggage and merchandise which could not be moved, and the railroad and express depots with freight which could not be delivered. In New York it was not an uncommon sight to see men in the streets drawing loaded wagons; and most of the street-car and omnibus lines have ceased operations. The same condition of affairs prevails elsewhere.

A Dr. J. C. McKenzie, writing in the Chicago Tribune, states:

The present horse-epidemic is no new disease. ... In the United States, it first made 


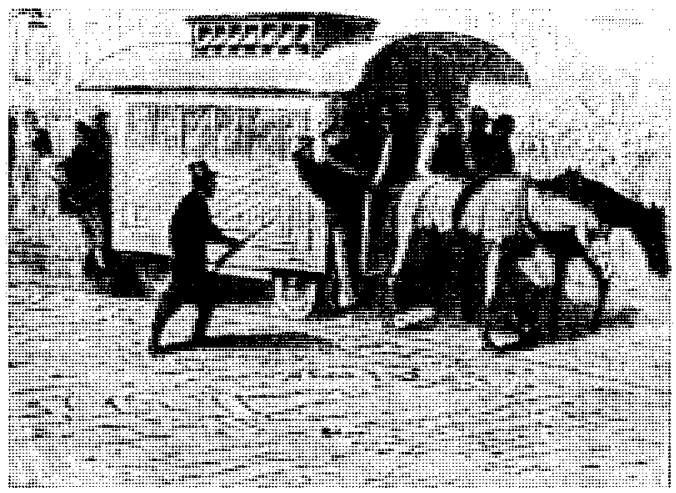

During the great outbreak of horse influenza (1871) in New York, the few horsecars still operating were continuously overloaded, and patrons frequently had to help push the cars upgrade. American Agriculturalist

its appearance in 1856, and is still seen every spring and fall. ... The cause of this, as well as all epizootic diseases, is involved in not a little obscurity . . . all belong to the unsolved problems of veterinary science.

\section{The Tribune also reported:}

The epizootic first made its appearance in Toronto and neighborhood about the lst of October [ 1871$]$, and within a few days nearly every horse in the district was attacked, when it created a good deal of alarm, and among a certain class of owners, a general resort to quack treatment and remedies. The disease . . . is evidently the result of some atmospheric influence. Although a very alarming complaint, it is not attended, if rationally treated, with any great fatality. . . We have it on the authority of Dr. A. Smith, Veterinary Surgeon of the Ontario Veterinary College, whose diagnosis and treatment have been entirely successful, that the disease has nearly disappeared from the city.

Dr. J. J. Withers, veterinarian to the Chicago City Railway Company, stated: "I saw several cases . . . early last fall [1871 ] . . . very mild in form. In December following, it was of a more malignant form.... In all, I have treated 450 cases." This was reported in November, 1872; in December the Journal states:

The epidemic among horses is spreading all over the country, and no portion of it can hope to escape the visitation. Fortunately but few cases prove fatal. . . A new disease, the dropsy, seems to follow this influenza, attacking chiefly those that have been put to work before fully recovered; and it is said that fully one-half thus attacked have died.

In January, 1873:

The disease seems to have spent its force, but is still working westward and southward, in a mild form. It reached the Pacific coast about the middle of December, dropping down among the saints at Salt Lake on its course.

However, in June:

The epizootic seems to have been remarkably fatal among the mules and asses of the West and South. In many counties thirty to seventy percent have fallen victims to the disease. It is still raging on the Pacific coast, but in a mild form.

Concerning this epizootic, Merillat and Campbell state:

No visitation of record equal in kind, scope, or virulence has ever occurred since in this country. While it has been said often that veterinarians could not have helped much anyway, nothing could be farther from the bounds of sound reasoning. There was no veterinary service in the country districts, nor at the horse markets, where such contagions originate, and only a few competent practitioners in the cities. The present [1935] veterinary service or the veterinary service of any period during the past forty years would have prevented such an epizootic from taking a large toll. Moreover, there were three quacks in Chicago who won great reputations in the treatment of horses during this outbreak ... had there been more of the capable type of veterinarians available they too might have built up lasting reputa. tions for work well done.

Obviously, the type of practitioner mentioned by Merillat and Campbell was on the order of J. C. Higgins, V.S., who in writing on influenza in 1863, states:

Where bleeding, purging, and sedative remedies are heroically practiced, the mortality is great; but where rational medical treatment and good nursing are pursued, the loss should not exceed one per cent. . . In cases of prostration when other remedies seemed fruitless, Dr. McClure (one of the professors of the 
Veterinary College of Philadelphia) has obtained the best results by transfusing slowly into the jugular vein about three quarts of blood from a healthy horse.

Thus it is that much of the criticism leveled at the veterinary profession during the latter part of the nineteenth century should have been attributed to the lack of an adequate veterinary service. However, it would seem illogical to attribute the situation arising from the lack of adequate numbers of competent veterinarians to the few qualified men that did exist. Unlike quack practitioners, who seemingly arose by spontaneous generation, educated veterinarians, in the face of public apathy, had no adequate means of increasing their numbers. The failure of attempts to establish veterinary schools prior to 1870 must in large part be charged to the willingness of the public to accept something less than what these schools had to offer. Lacking adequate subsidies, such schools could not turn out a sufficient number of better equipped men to dispel the popular notion that anyone with a few inherited receipts could cure animals. And so the vicious circle continued until the ravages of disease made it apparent that these self-appointed practitioners were not adequate, and certainly not representative of the veterinary profession.

Concerning the great outbreak of influenza of 1872, the American Agriculturalist notes:

If, two months ago, any one had predicted that the streets of New York, Boston, and other cities were to echo to the cry of the ox-driver, and that horses would be for a time removed from the streets, he would have been received with contempt. But nevertheless, in 1872 the unwonted sound has been heard, and the strange sight has been exhibited of express and other wagons slowly moving behind ox-teams, which were urged along by the usual noisy epithets and maledictions of their drivers. . . . Street-cars have been overloaded until car and horses have both broken down under the excessive loads, and occasionally a poor horse died, not from the disease, but from overwork when feeble and sick. On one occasion a horse- car has been drawn by men at increased rates of fare, and loaded wagons have also been thus drawn along.

Apparently there is nothing so bad that some good might not be drawn from it, for:

The recently prevalent horse-disease has done at least some good, as it has called the attention of the public to the need of educated veterinary surgeons.

The editor of the American Agriculturalist, however, long a staunch proponent of the New York College of Veterinary Surgeons, was surprised to read in the New York Tribune:

There ought to be an Academy of Veterinary Science, and all that concerns the treatment of that inestimable animal in sickness and in health should be the subject of study as methodical, as patient, and as accurate as that which is exacted by the College of Surgeons or the medical schools of France and Germany.

In extolling the virtues of the New York College of Veterinary Surgeons, the editor states:

It is not too much to say that the prompt and constant labors of Drs. Liautard, Large, and others of the college did much to abate the fatality attending the recent horse epidemic.

\section{Law and Laws}

With the addition of James Law to the editorial staff of the National Live-Stock Journal, a "Hygenic and Veterinary" column became a regular feature. In 1877 extensive articles on such subjects as the stomachs and food of the ox, watering of horses, rinderpest, anthrax, the hygiene of parturient animals, regular exercise for work horses, sex determination, Texas fever, and pure air for animals - a total of nearly seventy columns, equal to as many pages of a journal of today.

The Live-Stock Journal maintained an attitude toward sheep-killing dogs that was manifested by other agricultural papers. Losses in 1874 for 500 counties in 37 states were reported to be just under 
80,000 killed out of $81 / 2$ million sheep in these counties. On the matter of dog laws, it was noted: "The per-centage of loss is vastly greater in States where no efficient laws exist ... annual losses in Florida amount to 11 per cent. ... Ohio, fourtenths of one per cent." The editors stated in 1873:

A charmed atmosphere seems to surround the kennel, which the average legislator seems fearful to invade ... "dog laws" are annually smothered beneath piles of special legislation, or killed by the ridicule of men who care little, and know nothing, of what such a policy is costing the country. ... The National LiveStock Journal does not ask, nor desire, to have all dogs exterminated; but it does greatly desire to have their numbers considerably reduced, and the survivors required to live and move within the limits of equitable and just police regulations. ... It seems a trifle ridiculous for the legislature . . . to prohibit sheep from running at large, while imposing no restraint upon dogs.

This, at least, was a more moderate solution to the problem than one proposed by a correspondent to the Country Gentleman in 1860. As a good manure, he sug. gests composting:

Ten loads of muck, five dogs, one barrel of lime, and ten bushels of ashes. . . Induce the farmers of the country to practice largely on these principles, and there will be a better prospect for profitable Sheep Husbandry among us, as well as for good crops.

\section{Stock Writers}

The American Stock Journal, published in Pennsylvania beginning in 1866, is notable for the number of medical and veterinary practitioners who wrote for it. H. C. Wheeler, V.S., gives "the whole art of treating poll-evil":

The opening into the tumor must be so contrived that all the matter shall run out, and continue afterwards to run out as quickly as it is formed, and not collect at the bottom of the ulcer, irritating and corroding it.

\section{G. H. Van Doren, V.S., writes:}

In performing severe surgical operations on our different domestic animals, we have often wondered why chloroform is not more fre- quently used. ... This enables the surgeon or veterinarian to perform very difficult and even dangerous operations with comparative ease.

In writing on shoeing, H. C. Renand, V.S., states, "The methods of shoeing adopted by many blacksmiths to prevent lameness, in the opinion of the writer, only increase the evil." And on the internal disease of horses, Renand writes:

There is no symptom which affords such full and trustworthy an account of the general condition of the animal body as the pulse. It is, however, a symptom for the right understanding and interpretations of which some experience is required.

\section{H. V. Gardner, M.D., V.S., writes:}

The symptoms, or indications of phenomena of disease constitute an important branch of medical study. When intelligently read and properly grouped, symptoms form invaluable signs which in various ways guide the practitioner; they usually afford information regarding the seat and nature of the malady, or what is called the diagnosis; they fortell the probable result, or the prognosis; they likewise indicate the direction in which appropriate remedies must be looked for. The symptoms of disease require to be even more carefully studiednature must be even more diligently and ac. curately interrogated by the veterinary than by the human practitioner ... the veterinarian must exercise great tact and patience.

Geo. S. Otis, M.D., V.S., in urging better ventilation for stables, states:

Some physiological writers have said that glanders are often produced by bad air. That it is rendered contagious through the medium of the air is certain. Glanders and all diseases are rendered in a measure contagious, by the diseased animal vapors from the lungs and pores of horses affected with them.

Concerning the "Health of Dairy Cows in Winter," C. H. Rutger, M.D., urges:

As comparative misery and discomfort accompany disease, it is humane as well as economical to see that the animals under our care enjoy as far as possible their creature comforts. We keep often too much stock for the quantity of good and nutritious food which we have for it; and the consequence is cows are. in nine cases out of ten, poorly wintered, and come out in the spring weakened, if not, in- 
deed, positively diseased. ... Cows that are kept in poor condition through the winter are more liable to abortion or slinking their calves. Some attribute this disease to eating ergot of rye found in their feed, but we do not think so. ... Cows having aborted from weakness and general debility of the system can be prevented from aborting again by maintaining a high standard of good general health.

This journal ran a higher proportion of material on animal disease than most agricultural papers, and its veterinary department appears to have been conducted by an experienced professional practitioner. However, he is not identified. In an editorial on "Prevention of Diseases in Animals," it is stated:

Our interests are suffering... for want of statistical and geographical knowledge in relation to the diseases of animals. ... We propose ... to aid in reducing this enormous loss, by collecting information and statistics concerning the diseases of animals; by affording advice and assistance to stock-owners, whenever general outbreaks of disease occur; by ascertaining periodically the health of stock in the countries from which foreign animals are derived; by stimulating inquiry as to the most advantageous means of disposing of diseased animals ... and by adopting all possible means to check such a traffic in diseased animals as tends to the spread of plagues, or to the sale of diseased stock to the public. ...

The knowledge of veterinary science is of great importance to the stock breeders of the United States. The importation of cattle and sheep to the United States is yearly increasing, and already we have had pleuro-pneumonia excitement. . . . If the cattle plague should happen to be introduced into our country it would find us almost totally unprepared, having very few reliable veterinary surgeons. Why cannot many of our young men adopt it as their profession, and go through the course of study requisite to make them skillful reliable surgeons? Veterinary science deserves more consideration than it has heretofore received in this country. A chair in our Universities could be established, filled by a competent Professor and we doubt not, this deserved recognition of the importance of this branch of education would be received with gratification by all intelligent persons. It is only by having a sufficient number of thoroughly instructed surgeons to meet the necessities of our people that we can get rid of the tribe of shallow ignorant pretenders who have no more idea of the pathology of an animal than they have of the origin of comets.

Whether this was written by the editor, N. P. Boyer, or by the veterinarian on his staff, this journal deserves credit for having made as forthright a statement of the situation as had been made to this time. Few papers had such a comprehensive philosophy regarding animal disease in relation to the role the paper expected to play; here, obviously, was not merely a "free horse doctor with every subscription," as others had blatantly proclaimed. Admittedly, all too few of the contributors to this journal were in a position to advance veterinary science, but as has been noted, it seems to have attracted more than its share of professional men.

It has been noted that the provincial character of many of the reports of losses from disease or accident, as communicated to the agricultural journals, is hardly of more than local interest. Perhaps more than other papers, this journal did give some statistics on a national level:

The value of sheep killed by dogs in the United States for 1866 is estimated by the Commissioner of Agriculture at two millions of dollars. The subsistence of the whole number of dogs in all the States is estimated by him to cost annually fifty millions of dollars. These are startling figures to an overtaxed community. . . . Fifty-two millions per annum lost by dogs, to say nothing of the frightful deaths from hydrophobia which they occasion! . . Not five in a hundred [dogs] are of any value. The efficiency of the watchdog is rendered of little avail against professional burglars, who use chloroform or strychnine when a regular job presents itself. . . . Five hundred thousand sheep are annually killed . . . and the number annually injured is three hundred thousand.

On another occasion it is estimated:

Our losses by disease in cattle must amount at least to thirty million dollars per annum ... [and] the aggregate losses of farm animals of all kinds for the past twelve months could not be covered by fifty millions of dollars.

\section{END OF AN EPOCH: ROBERT JENNINGS}

Probably no more suitable character could be found to ring down the curtain 
on this epoch in American veterinary history than Robert Jennings, for it is he, perhaps more than any other one individual, who serves as a connecting link between this period and the one to follow. Whether in the long run he deserved this distinction is perhaps a moot point; that he was fairly astride two major epochs in American veterinary history can hardly be doubted.

Robert Jennings was a native of Philadelphia who in 1846 matriculated at the Pennsylvania Medical College (of Philadelphia), but apparently without the intention of qualifying in medicine. In the winter months of 1846 to 1850 he gave a course of lectures on veterinary medicine to classes of medical students from the several medical colleges of the city, and in 1850 - at the age of 26 - began promoting the idea of organizing a veterinary college in Philadelphia. With the help of two medical professors, James Bryan and Wm. Gibson, he secured a subscription of $\$ 40,000$ for this purpose from a group of Philadelphians, including a number of prominent medical men.

The state granted the group a charter for "The Veterinary College of Philadelphia" on April 15, 1852, and Jennings was placed at the head of the paper institution. Announcements of a course of lectures to begin in the fall of 1853 were circulated, and numbers of inquiries apparently were received, but no students materialized. It is likely that the rather tenuous semiexistence of Jenning's ill-fated college will never be known in full, but his own account in the Journal of Comparative Medicine and Surgery in 1883 appears to agree for the most part with what is known to be the case.

\section{"I Was the First"}

In writing on "The Early History of Veterinary Medicine and Surgery in the United States," Jennings does not hesitate to admit in 1883, concerning his ill-fated venture:
I was the first in the country to move in this arduous undertaking, at the time when the practice of veterinary medicine and surgery was in a low and degraded condition, confined mainly to the hands of a very illiterate and intemperate class of men, whose treatment of the sick animal was characterized by ignorance, absurdity, barbarity and superstition. . . . The necessity for a radical change, and the diffusion of correct veterinary knowledge throughout the agricultural districts was the incentive which prompted my efforts in this direction. As there were no veterinary colleges in this country at that time ... I entered the office of the late T. J. Corbyn, then the leading veterinary surgeon in the City of Philadelphia, as a student, and to assist me further I matriculated at the Pennsylvania Medical College, Philadelphia. During the winter months of 1846 to 1850 I conceived the idea of organizing a veterinary college, to be located in the City of Philadelphia, and for that purpose made known my plans to my medical preceptor, Prof. James Bryan ... and through him to Prof. Wm. Gibson, of the Pennsylvania Medical University - the oldest Medical College in the United States [University of Pennsylvania]. Through their influence . . . [a number of prominent citizens ] readily subscribed to the contemplated veterinary college, and made up a list of $\$ 40,000$. An application was now made to the State Legislature, for a charter which was granted on the 15th day of April, 1852.

This, the pioneer Veterinary College of America, was destined to meet with many disappointments, and much opposition from those who should have extended a helping hand. The graduates of European schools, with few exceptions, gave the movement the cold shoulder, regarding the effort as premature, resorting to various, and sometimes disreputable means to discourage those most active in its success. The only recognized members of the profession in the city, who were coworkers in the cause ... were Thos. J. Corbyn, W. W. Fraley, John Scott, and the writer, who constituted the faculty. An announcement was issued for a regular course of veterinary lectures ... to commence the first Monday in November, 1853, continuing daily for sixteen consecutive weeks, which announcements freely distributed, bringing letters of inquiry in return, but no students; young men of education and respectability, would not engage in a profession of so low a standing.

\section{American Veterinary Association}

Jennings continues:

Failing to secure a class, T. J. Corbyn, W. W. Fraley, and John Scott tendered their resig- 
nations as professors of the college, leaving the writer alone to fight its battles. Nothing daunted, young and ambitious, I sought to harmonize the discordant spirits by bringing the members of the profession in friendly counsel, and urging them to unity of action. A meeting of the veterinary surgeons in the city was called and the subject discussed in all its bearings. After several meetings were held a permanent organization was effected the 7 th day of May, 1854, under the title of the American Veterinary Association, and the following officers were elected to serve one year. President, T. J. Corbyn, V.S.; Vice-Presidents, James Bryan, M.D.; and W. W. Fraley, V.S.; Secretary, M. Roberts, V.S.: Corresponding Secretary, John Scott, V. S.; Treasurer, R. Jennings, V. S.; Librarian, A. Tegtmeier, V. S.; Counseller, Marcellus Munday, Esq.; Patrons, James Bryan, M.D., Wm. Gibson, M.D.

As stated in the by-laws, the objects of the Association:

shall be the cultivation of fraternal feelings among veterinary practitioners; the elevation of the veterinary art to an equal rank with other scientific branches of medicine, the mutual improvement of its members ... the establishment of a Museum of Anatomical and Pathological Specimens; and the formation of a Library . . . and in general, the defence of the rights, and privileges and immunities of the veterinary practitioners in the United States.

Nothing appears to have been stated concerning what undoubtedly remained Jennings' primary concern, the resuscitation of the college. Despite the fact that the American Veterinary Association was - and remained - local in its scope and influence, it is apparent that it did not disclaim national pretentions.

Upon the arrival of George W. Bowler from England in 1854, Jennings continues:

I found in Dr. Bowler an able and energetic co-worker. The Trustees of the college pleased with this new acquisition, at once accepted him as a member of the new faculty, consisting of only Dr. Bowler and myself. . . . We started on a mission in the interest of the new school, making a tour through the states of New York, Pennsylvania, and Ohio, meeting with many sympathizing friends in our travels, but no material encouragement to the new venture. Failing in our mission, Dr. Bowler settled down in Cincinnati, where he still remains. At the same time I accepted the position of Veterinary Lecturer in the Ohio State Agricultural College; then located on the Heights, Ohio City, now West Cleveland, retaining that position until the suspension of the college in the year 1857 . I then returned to Philadelphia, and again renewed my efforts in behalf of the veterinary college.

A faculty consisting of Fraley (Materia Medica and Therapeutics), Corbyn (Pathology and Surgery), Tegtmeier (Chemistry and Pharmacy), and Jennings (Anatomy and Physiology) was approved, and a temporary building was fitted for use. Also: "A dissecting room was built upon the Knackers grounds, where material was always at hand." Plans were approved for a building consisting of:

two lecture rooms, a dissecting room, museum, laboratory, hospital accomodations for thirty patients including twelve box stalls, shoeing forge and operating room, with an operating table so constructed as to secure the patient in a standing position, or by means of a crank to lay him upon the side at a proper elevation.

Dissentions arose, however, and caused the plan to be abandoned: "Had harmony prevailed, Philadelphia today could boast of her Veterinary College."

In reporting a meeting of the American Veterinary Association of Philadelphia, the American .Veterinary Journal for September, 1858, states that this particular assemblage was "for the purpose of forming a veterinary college." James Bryan, M.D., addressed the group and stated:

at least one-tenth of the horses and livestock of this city die annually . . . A large number of contagious diseases originate from diseased animals. Even chickens generate disease to the human body .... The Association have already dissecting room, and are in a fair way to have a large museum.

In November, 1858, the Journal carried a report from a Philadelphia paper of the annual dinner of the Association:

where gentlemen of science and skill interchanged thoughts on the ultimate purposes of the association, which is the establishment in 
this city of a Veterinary College, for which a charter was obtained some years ago, and which the friends of the measure have only awaited a favorable opportunity to bring before the public. Among the guests we noticed several distinguished gentlemen, some of whom were of the medical faculty ... . A representative of the Inquirer ... viewed with deep interest the efforts of the Association to establish a Veterinary College in Philadelphia, which being the natural centre of the United States, would be the best position for such an institution.

\section{In 1859 the Country Gentleman noted:}

The first annual circular of this institution has just been issued, setting forth the claims of the college upon the people of our country. It was chartered by the State Legislature in 1852 , and already contains a large collection for the formation of a museum; and the library embraces some of the most valuable works upon veterinary science to be found in this country and Europe. The faculty consists of four professorships, of which R. Jennings, V.S., is Dean. The regular course of lectures for the season will commence the first Monday in November, and continue daily for sixteen weeks. The lectures embrace all the departments of Veterinary Medical Science, as taught in the regular institutions of Europe.

Because of the expense of maintaining the College quarters - which fell upon the trustees and faculty - an appeal was made to the Philadelphia Society for Promoting Agriculture, which made available its rooms for lectures, where "The College continued to hold its sessions in the Agricultural Hall, until its suspension in 1866."

Upon Jennings' appeal, the Philadelphia Society sent a committee to inspect the library and museum of the veterinary college, which was housed in a temporary building. The committee was sufficiently impressed that at the next meeting it was resolved:

That the use of the rooms of the Agricultural Society be granted to the Veterinary College of Philadelphia, for holding their lectures during the winter session.

The Society also agreed to invite the faculty of the College to deliver a series of lectures on hippology, under the auspices of the Society: Robert Jennings, Jr., quotes Dr. A. L. Elwyn, who "spoke earnestly in favor of inviting the faculty of the college to deliver their course of lectures upon horseology" [sic!]. We have only Jennings' statement indicating that college sessions were held until 1866; at the time of organization of the USVMA in 1863 his address was given as Bordentown, New Jersey.

\section{Jennings, Jr.}

Further light is shed on the matter in 1880 by Robert Jennings, Jr., who gives an extensive narration of his father's activities on behalf of the Veterinary College of Philadelphia. The account is obviously biased in favor of his father, and inasmuch as some of the events occurred 30 years previously, certain facts may be unintentionally distorted. For the most part, however, the account seems fairly accurate, and while it is mostly a repetition of the story of Jennings, Sr., it gives a few details which would have otherwise remained obscure.

In a paper on the history of veterinary medicine in the United States, presented at the meeting of the United States Veterinary Medical Association in 1876, Alexandre Liautard had stated that the New York College of Veterinary Surgeons was the first "truly organized school." This was published in the American Veterinary $R C$ view in 1877, and in 1880 the Veterinarian (London) used this material as the basis for a similar article. The latter aroused the ire of Robert Jennings, Jr., who in a letter to the editors of the Veterinarian, claimed for his father the honor of founding the first veterinary college in America, the Veterinary College of Philadelphia, in 1852. Moreover, he claimed his father was also the "father" of the USVMA, for which Liautard had given the Philadelphia group credit for the initative; Jennings, Sr., acting as secretary, did conduct the initial correspondence, but this presumably was on behalf of the Philaclelphia association. 
Just why Jennings, Jr., (or Jennings, Sr., for that matter) did not attempt a direct refutation of Liautard's earlier article may be surmised. Liautard, however, corrected this omission by reprinting the letter of Jennings, Jr., to the editor of the Veterinarian. In this the son states, "My father, Robert Jennings, was the first to publicly advocate the cause of veterinary science in this country," a statement which should cast doubt on the rest of his "impartial" presentation. His story of events relating to the Philadelphia school, however, appears to be substantially correct, but as such, proves little more than the fact that the College was chartered in 1852. While the number of bona fide graduates of the school, if any, seems in doubt, Jennings, Jr., quotes the Edinburgh Veterinary Review for 1863 concerning "the faculty and graduates at the commencement of the Philadelphia Veterinary College." At this time, however, the "course of instruction" appears to have been free lectures given in the rooms of the Philadelphia Society for Promoting Agriculture. Jennings, Jr., indicates this, and states in addition, "Free clinics were held at the infirmary every Wednesday and Saturday."

\section{More Professors than Pupils}

Jennings, Sr., continues:

Failing to secure a class of students for its proposed sessions, of $1857-58$ and also for 1858 -'59 it renewed its efforts for the session of 1859-60; which efforts were awarded by the application of two students, viz. - Jacob Dilts, of Lambertsville, New Jersey, a graduate of the Boston Veterinary Institute, and W. Wisdom, of Wilmington, Delaware, who had been practicing Veterinary Medicine and Surgery for nearly thirty years. ... With these two students the first session of the Veterinary College of Philadelphia commenced. Unfortunately for the new institution the course of lectures had scarcely begun, when, from some cause not explained, W. W. Fraley, T. J. Corbyn, and Aug. Tegtmeier tendered their resignation as professors in the College. By direction of the Trustees, I at once wrote for Dr. G. W. Bowler who responded to the call.

Bowler, however, resigned after the 1859-
1860 term, returning to practice in Cincinnati, and Robert McClure was appointed to fill the vacancy.

In 1860 Jennings wrote to the Director of the Alfort School, and received a reply thanking him "for the honor that you are well pleased to do us in proposing us to be members of the Veterinary College of Philadelphia." Thus the College gained several distinguished professors - at a distance, to be sure, but including the director, Renault, together with Bouley, Delafond, and Groubaux.

Jennings, Jr., continues:

The college enjoyed the privileges extended to it by the Philadelphia Agricultural Society until 1866, when it suspended further operations, retiring from active service without a stain upon its character, the graduates of which hold legal diplomas, which are protected by law, as are those legally issued by other medical institutions.

Despite the mention of graduates several times, it may be doubted that the school had but very few that should be characterized as such, although a number of diplomas may have been issued.

\section{The Efforts of My Father}

Concerning the commencement exercises of the College in 1863, the Edinburgh Veterinary Review states, "Mr. Jennings suggested that this college, with its graduates during the last five years, should establish a national veterinary association, and ultimately establish a veterinary journal." Jennings, Jr., however, takes liberty with fact in stating: "The United States Veterinary Medical Association was also planned and organized through the efforts of my father." The efforts of Jennings, Sr., on behalf of the USVMA are a matter of record, as are those on his own behalf which led to his expulsion from the Association in 1866 , the year, also, of the demise of the Veterinary College of Philadelphia.

Whether McClure remained with the Philadelphia college until it closed is not stated, but by this time he appears already to have become persona non grata. Jennings, Jr., continues: 


\section{teteriuary College of Zzhiladelphia.}

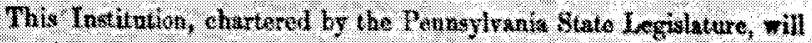
be putin to speration the present year, $(1866)$ at Phitadelphis, where it will be perrianeaty lonted.

Philadelphis, the great enporina of andical stiesce on this continent,

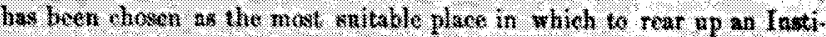
fation for her promolgation of a anter seienes. The reputation of her Medied Arbouk extends over the whole civilized woth The facilitios for Anatowical Investigatinn, Wivieal Inetruction, Ke, Re, are at least as great as hose of any other dity its the Uaion. The Nasean of the Col lege already embraces a collection of Pathological Specizens, in point of excellente far surpuseing thowe of anany Gutropean Velerinary Collegas of wany years standing: The lectrre Roow in converiently and wonbortably fithed up. The Jiswsting Rooms are sufficienty large, and afford every feclity for purating Anutomical Investipations. Material in abundance alroys at haid, without extra diarte The Library contains a number of tho wewt valwable Teterinary works poblwhed in this cownery and in Rurope.

In extablwhing Veterinary Colleges in this country, a new field is opened to the rotary of Velorinsty science for extonsire investigation, sherein $\omega$ build up fame and fortane.

A wasn with but ordman sbilitios, with proper energ can distinguish hiresesf in the roth by nubracing thit profession, while in most others he would ouly arive at medioerity; bere is an anbeuten path for him to parsue, which if faikhfolly and honowly followed, will lead to thefulnews and honor.

\section{Thuntioes:}

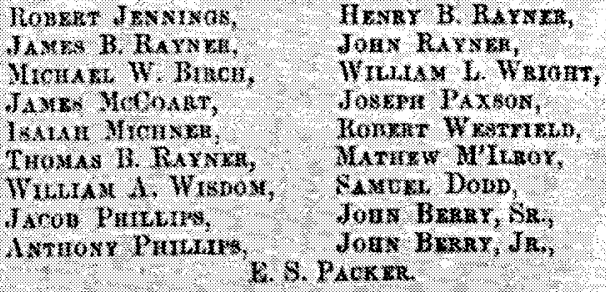

Although the prospectus of the Pennsylvania College of Veterinary Surgeons (nee Veterinary College of Philadelphia) suggests it was an operating institution, it apparently functioned only as an apprentice system with the trustees as preceptors. Michigan State University $\mathbf{L i}$. brary
The Pennsylvania College of Veterinary Surgeons, chartered in 1866 to take the place of the old school, was in the interest of and under the exclusive control of veterinary surgeons. The name of McClure does not appear among the corporators, neither will it be found associated with the faculty of the college. . . These facts should prove his unpopularity among the veterinary profession in the City of Philadelphia.

The new institution gave two courses of lectures in a rented hall, whereupon it moved to another location, where two more courses of lectures were given. The treasury exhausted: "the doors were closed in 1870, since which time [to 1880?] quarterly meetings have been held in Diligent Hall. No effort as yet has been made to reorganize the college."

The year 1866 was a black one for Jennings; not only was he forced to admit final 
defeat in his perennial attempts to get his school on a firm footing, but in this year he was also expelled from the USVMA. Some time after this he moved to Detroit where he conducted a veterinary practice, sold patent medicines, and wrote on veterinary medicine. He died in Detroit on January 5 , 1893, at the age of 78 . As is the custom in obituaries, his omits the more stormy parts of his career and emphasizes his role in organization of the USVMA and his part in the Veterinary College of Philadelphia. Concerning the latter the obituary reads as follows: "A number of students were graduated and received diplomas."

\section{Diploma Mill}

More or less as a postscript, for Jennings can in no way be associated with the Pennsylvania College of Veterinary Surgeons after its supposed demise in 1870 , the activities of Robert McClure form an interesting - if somewhat distressing - bit of American veterinariana. Apparently after the P.C.V.S. officially closed its doors, it was reopened, under surreptitious circumstances, by McClure as the "Merchants' Veterinary College," better known to the profession as the "Philadelphia Diploma Mill." The faculty consisted of McClure, and the course of instruction, if any, a few

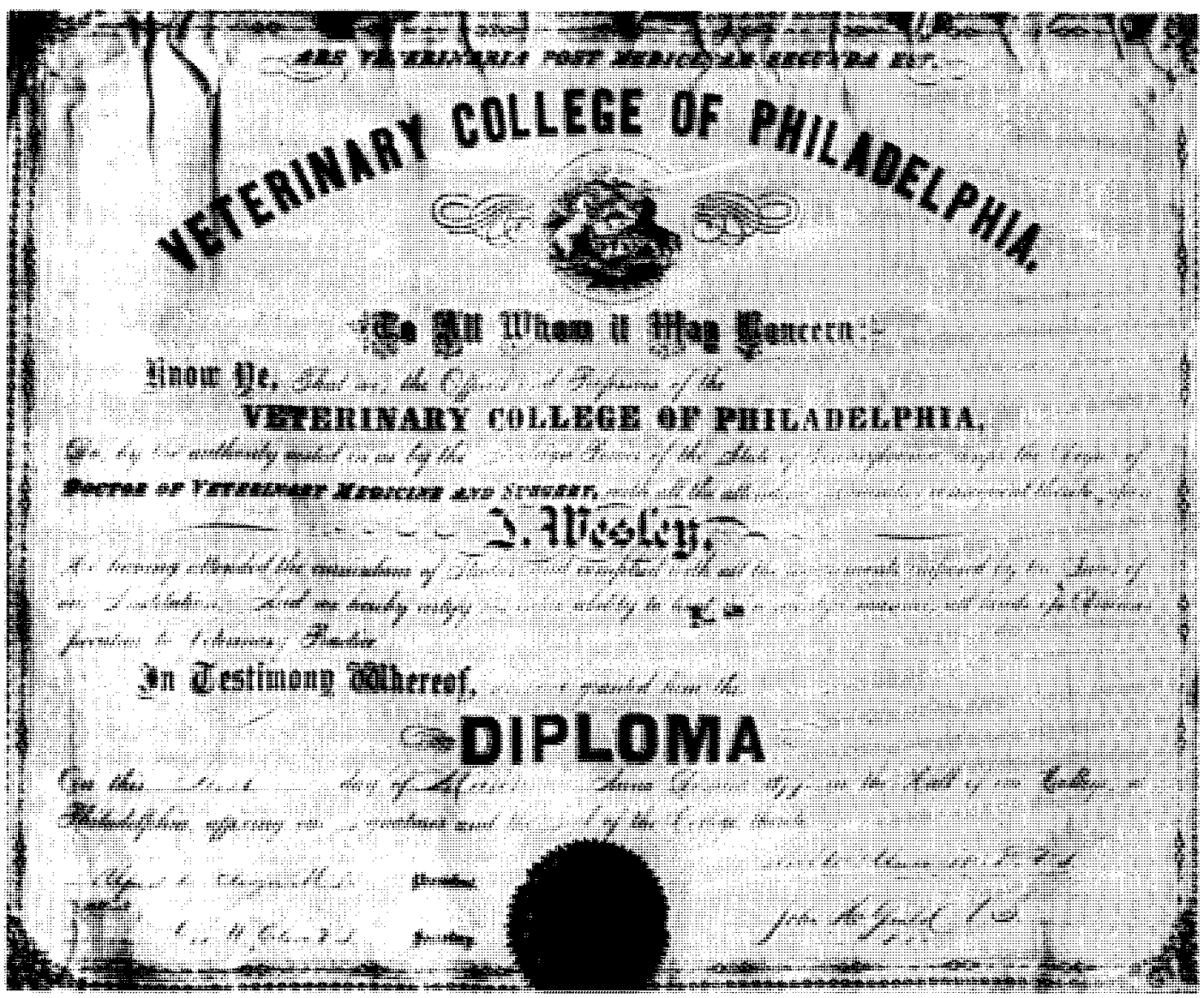

Diploma seized as evidence which led to the conviction of Robert McClure for forgery (Dr. Elwyn's signature) and the demise of his diploma mill in 1877 . McClure had no connection with the Pennsylvania College of Veterinary Surgeons, diplomas of which were valid. Courtesy B. W. Bierer 


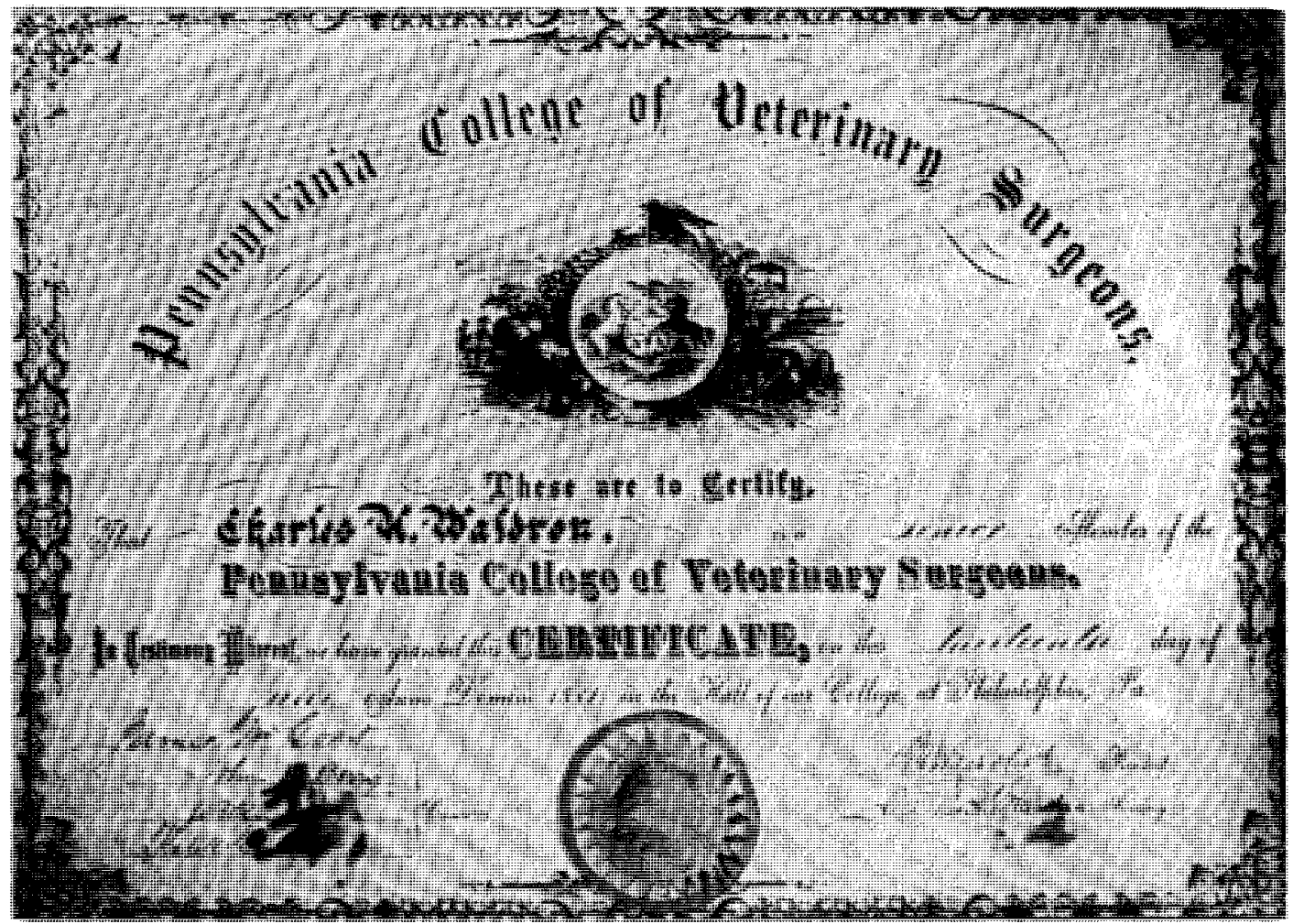

Diploma issued in 1881 by the Pennsylvania College of Veterinary Surgeons, successor to the ill-fated Veterinary College of Philadelphia.

weeks of reading a few books, most likely his own Diseases of the American Horse, Cattle and Sheep (1870) and others from his own pen. His diplomas conferred the degree of Doctor of Veterinary Medicine and Surgery, and apparently were designed to resemble those of the defunct P.C.V.S., with a superimposed seal of the Merchants' Veterinary College.

Under the heading of "Veterinary Colleges," in his book on Diseases ... (etc.), McClure writes:

These do not seem to flourish in this country; the one at Boston has long ago closed its doors. In Philadelphia, the 'Merchants' Veterinary College," bids fair, however, to be quite a success. It is under the guidance of Prof. Robert McClure, to whom all inquiries, in regard to the college, should be addressed. Diplomas are issued on the first of March, each year, to students, and honorary members.

It is perhaps significant that nothing is said of the course of instruction. McClure's book appeared in various forms as late as 1917, when it was stated, concerning veterinary colleges:

These do not seem to flourish in this country; many have been started, but most of them have closed for a want of patronage; Prof. McClure in his earlier years conducted very successfully in Philadelphia, the "Merchants' Veterinary College."

Just how successful this institution may have been, in terms of numbers of $\mathrm{di}$ plomas issued, probably will never be known. The facts concerning its clemise, however, are well documented. 
Following a bit of detective work involving a subtly "planted" offer to buy a diploma in 1877, McClure was arrested for the illegal sale of diplomas, several of which were found in his office bearing the names of intended recipients. He was convicted of forging signatures of medical men (having had the bad judgement of hiring a penman), and was jailed for nine months and fined $\$ 2,000$. While in jail he unsuccessfully attempted to $\mathrm{comm} \mathrm{i} \mathrm{t}$ suicide. From correspondence seized at the time of his arrest, it is apparent that McClure had conducted a lucrative business, the asking price for a diploma being $\$ 100$ or more. At the hearing of the charges against McClure, Alfred L. Elwyn, M.D.:

testified that his signatures to the diplomas was a forgery. He said that about seventeen or eighteen years ago he was President of the Philadelphia Veterinary College, but has had nothing to do with it since 1862, and did not know if it was still in operation. . . . J. H. Warren, professor and teacher of penmanship ... testified that he had written the signature on the diplomas by McClure's authority.

On April 9, 1877, McClure was sent a letter from a J. Wesley asking:

if I pass a good examination before you in veterinary surgery and medicine, will you give me a diploma if I pay you $\$ 100$ at once. I know all about the business, but I want a Philadelphia or Pennsylvania diploma. . . .

To this McClure promptly replied:

if you say that you know all about the business and that you have a copy of my book entitled "Diseases of the American Horse, Cattle and Sheep," by myself, then a diploma will be granted you without examination... .

And in a letter dated April 18 from Dyersville, Iowa, a Daniel Underwood writes:

I understand ... that you grant diplomas from a Philadelphia Veterinary College to men who know their business. . . . Will you let me know how much money I am to send you for one, and how many veterinary surgeons' names will be signed to it; also, if they will be well known men as veterinary surgeons. As Dyersville contains a great many English people, well off, could you get a member of the English Veterinary College to sign it; that would make it worth more money to me.

\section{On April 20, McClure replied:}

three well known vets. sign; one, Mr. Gould, is an Englishman; one gentleman, the President, is an M.D. besides myself, who is known all over the world, being the author of 4 vols on the great subjects of veterinary science. Three of these books will be sent to you along with the diploma, by express, in 3 days after receipt of . . . post-office order for $\$ 135$, fees for matriculation and graduation for the session of 1876-7, in the Veterinary College of Philadelphia. This entitles you to the degree, Dr. Daniel Underwood, M.P.C.V.S. These letters differ from the English by R., from Edinburg by E., Glasgow by G., from Dublin by a $\mathrm{D}$.

This is one diploma that was not issued, for two days later McClure was in jail on the complaint of a Francis Standen, who, as reported in the Philadelphia papers, had collaborated with police authorities "on the plan of Dr. Buchanan, of the Pine Street Medical College." Alexandre Liautard, however, credits a veterinarian with having done the spadework:

To Mr. Gadsden, of Philadelphia, the profession owes a tribute of thanks for his untiring efforts in bringing the culprit to justice, and it is a high credit to him that his whole work in this matter has been only for love of the profession to which he belongs.

Liautard indicates that both Wesley and Underwood were willing agents in bringing about McClure's apprehension. Wesley's diploma remains as mute testimony to the sordid business.

The Pennsylvania College of Veterinary Surgeons continued for some time as a diploma-granting body. A diploma issued in 1881 certified the holder to be a "Senior Member of the Pennsylvania College of Veterinary Surgeons." This bears the signatures of Drs. Raynor and Gladfelter, both reputable veterinarians. Instruction 
at this time apparently was based upon a preceptor system, with a number of veterinarians taking apprentices.

The demise of McClure's diploma mill marks the belated ending of an era in veterinary medicine. True, the line of demarcation between this long period of painfully slow progress and the more satisfying one to follow is not sharp. The United States Veterinary Medical Association had been founded in 1863, but it had barely begun to assert itself as a national institution by 1877 , the year in which the American Veterinary Review was established as the official organ of the
USVMA. Succeeded by the AVMA and its Journal, these institutions have jointly served the veterinary profession continuously since 1877. And while the New York College of Veterinary Surgeons had issued bona fide diplomas a decade earlier, it was not until the American Veterinary College was established in 1875 by secession from the N.Y.C.V.S. that the United States could boast of the beginnings of an adequate system of veterinary education. While it should not be supposed that from this point on the story is one of unremitting success, it is one of continuing progress. 


\section{Development of the American Veterinary Profession}





\section{USVMA-The First Quarter Century}

A COMPREHENSIVE HISTORY of the American Veterinary Medical Association, founded in 1863 as the United States Veterinary Medical Association, would require a booklength volume in itself. As the largest organization of its kind in the world, its record is the history of the rise of the American veterinary profession from utter obscurity to world-wide recognition. Its humble conception and birth during a period of national peril could hardly have presaged, even to its most enthusiastic supporters, the position of strength the Association occupies today. Except for the fact that a majority of its founders were members of the Philadelphia and Boston associations, it is doubtful that a national association could have been formed at this time, much less kept from falling apart. Even this experience, which appears to have been rather more than less of a provincial nature, would not have been calculated to lead to the formation a strong national association.

\section{ORGANIZATION: 1863}

The deceptively titled American Veterinary Association had existed for hardly more than the one overpowering object of of its principal promoter, Robert Jennings - that of establishing a functional veterinary college in Philadephia. The Boston association undoubtedly served more of the functions of a local association today, but it was more metropolitan than cosmopolitan in its membership and philosophy. The influence of the Boston group may be seen in the fact that five of the first six presidents of the United States Veterinary Medical Association were, or had been, members of the Boston association.

Perhaps the fullest account of the events leading to the formation of the USVMA is given by Jennings in 1884. Although by his own hand he places himself at the head of this movement, his account is sufficiently well documented to lend some credence to it. In response to a letter from Jennings in 1859, C. M. Wood of Boston stated:

as to the "National Association": I fully agree with you, and both myself and friends here will hold ourselves in readiness to attend a meeting in New York city for the purpose of such an organization at any time that will best suit the convenience of parties desirous to unite with us in the cause.

How ready Wood and his colleagues were may be open to speculation, but it is apparent that they did not, at this early date, start packing their bags.

Some suggestion of the reason for nothing transpiring at this time may be found in a letter from George Dadd to Jennings in 1860 :

In regard to the National Veterinary Medical Association I am afraid that you could not get enough "vets" together to make it an ob- 
ject. Jealousies and prejudices are very strong among the members of the craft, mainly graduates from the other side of the water look with supreme contempt on all who will not endorse the creed or dogmatical diction of the autocratic schools. Then again, you are aware that you, as well as myself, have enemies within and around our fields of practice, that from mere feelings of jealousy they will not give countenance nor support. Still if you deem it proper to form a N.V.M.A. you may count on my assistance and support.

This appears to be Dadd's last concern with the Association; he was soon to sever his connections with the Boston scene, and by 1863 he had been in Chicago for some time. There is no record of his having made any contribution to the USVMA prior to his death in 1868 , nor is it likely that he was consulted.

\section{Preliminaries in Philadelphia}

The next mention of a national association is in March 1863, when at a meeting of the AVA in Philadelphia, Jennings: "suggested the propriety of calling a national convention of veterinary surgeons for the purpose of advancing the standard of veterinary medicine and surgery in the United States." It was resolved:

That the formation of a National Veterinary Association not having been previously anticipated, the President be and he is hereby authorized to call, at an early day, a meeting of the veterinary profession in the United States for the purpose of permanent organization ... to meet in the city of New York or Philadelphia some time during the coming summer ... [ and] that the Secretary be, and he is hereby requested to communicate with members of the profession in the several States, requesting their attendance at the convention when called.

Of some interest is the fact that veterinarians from five states were present at this meeting.

Jennings apparently obtained a good response to this resolution. John Busteed, M.D., who had been unsuccessful in organizing the New York College of Veterinary Surgeons in 1857, wrote:
Although not a veterinary surgeon, I am deeply interested in all that pertains to that much (in this country) neglected and important science. I have been for the last sixteen or eighteen years trying to elevate that branch of comparative anatomy to a more eminent position than it occupies at present. It will afford me much pleasure if I can in any manner assist you or your associates in perfecting the object purposed. That such an association is much needed there can be no doubt, that it will not only be beneficial to the profession, but to the country at large, and the government in particular. I think with you, that the time has arrived for veterinary surgeons and others practicing or interested in the art to claim for themselves a status to which they are, when properly educated, entitled.

Busteed, who later studied at Alfort, and was more successful in a second attempt to organize the N.Y.C.V.S. in 1865, suggested New York as the proper place for the meeting, and that: "Agassiz would be the most suitable person to deliver the introductory lecture." The noted Swiss-American naturalist, Jean Louis Agassiz, had founded the Museum of Comparative Zoology at Harvard University, and was greatly interested in the anatomy of domestic animals. Busteed's suggestion, however, fell by the wayside.

Wm. T. McCoun of New York, who had been present at the framing of the resolution by the Philadephia society, wrote:

Mr. Chas. Stetson, of the Astor House... is a great admirer of the profession, and is willing to lend us all the assistance that may lay in his power. He offered to me gratuitously the use of a large parlor. . . . To give the thing tone and repectability we must go to a respectable place, and the Astor House has a wide-spread reputation as such.

It is of some interest that the first veterinary association in England was formed, and met, in a tavern. Fortunately, this course was not taken in the United States, but then the inns of old England were of a different sort from the saloons of the states.

A. S. Copeman, then a practitioner of Utica, New York, but who had been associated with Dadd at the Boston Veterinary 
Institute, wrote concerning "the propriety of making some alteration in the name or title of the 'National Veterinary Association' ":

You too well know the bitter enmity, strong prejudice, and mean, petty jealousy, now existing among veterinary surgeons in the United States. . . . If the gentlemen would consent to a change of title, say to the National Society for the Advancement of Veterinary Science, or Knowledge, a door would be opened for the admission of all competent and honorable workmen, all true patrons of the art, as well as those who admire knowledge simply for its real worth and power. By adopting such a name all party-feeling and strife may be prevented. Doctors know the value of this term. Proper rules would exclude all unworthy persons. . . . Let a liberal code be adopted that will bring together a large portion of the "working class" of our profession.

Some of the self-made practitioners, he says, "in many respects are better qualified to practice than some of the two session graduates from abroad."

Others also apparently were concerned that adoption of too rigorous a qualification for membership would result in the fledgling association falling into the control of European graduates. But with Jennings, whose only "degree" was from his own nonfunctional institution, as a chief promotor, it does not seem likely that there was any intent to foster such a program. Others were primarily concerned over the possible admission of quacks. C. M. Wood, who, like Copeman, had only what amounted to an "honorary" degree from the Boston Veterinary Institute, makes a strong issue of this point:

I am aware of the necessity of the cooperation of all the veterinary practitioners to give strength and efficiency to the order. But permit me to say that I beg to be informed as to what are the qualifications required in such as may form the proposed convention. There are many persons who have taken up the practice of veterinary medicine and surgery who have had no proper instructions in those subjects and are entirely ignorant of the principles on which they are founded. They have assumed the title and duties of professional men only for the name and living which may be derived from it. ... The quacks of our profession have never had any respite (from me).... I have stood almost alone in this city espousing the cause of legitimate science, and my efforts have not been unavailing. ... At a meeting of our "vets." here last evening it was voted for several to come, but we must wait your reply to this for information asked for.

Alexandre Liautard, who had come from France only three years earlier, wrote:

My acquaintance with my professional brethren is exceedingly limited, having been myself but a short time in America. I will, however, be most happy to confer with them upon any subject pertaining to the advancement of veterinary education and science.

The above, and other letters were read at a meeting of the Philadelphia society in April, 1863, whereupon the following preamble and resolutions were adopted unanimously:

Whereas, Veterinary science in this country has been kept in comparative obscurity in consequence of its practice having been confined mainly to the hands of men uneducated in the anatomical and pathological relations of the various diseases to which our domestic animals are subject, as well also as to therapeutic action of the remedies used in combating disease. This deplorable condition of the veterinary profession has been the means of excluding the qualified practitioner from the army in the United States. The losses to the national government in consequence from the purchase of large numbers of horses unfit for the duties required of them, having amounted to millions of dollars, therefore,

Resolved, That the friends of veterinary science favorable to forming a National Veterinary Association for the advancement and diffusion of veterinary knowledge meet in convention in the city of New York on Tuesday, June 9th, 1863.

Resolved, That veterinary surgeons in all parts of the United States, and all persons favorable to such an organization be invited to attend the convention.

A local (New York) Committee of Arrangements was appointed, consisting of John Busteed, M. D.; W. T. McCoun, V.S.; A. Liautard, V.S.; Chas. Pilgrim, V.S.; G. C. Grice, V.S.; Robt. Curtis, V.S.; and George Wilkes, Esq. 


\section{The Aitw Hork đimes.}

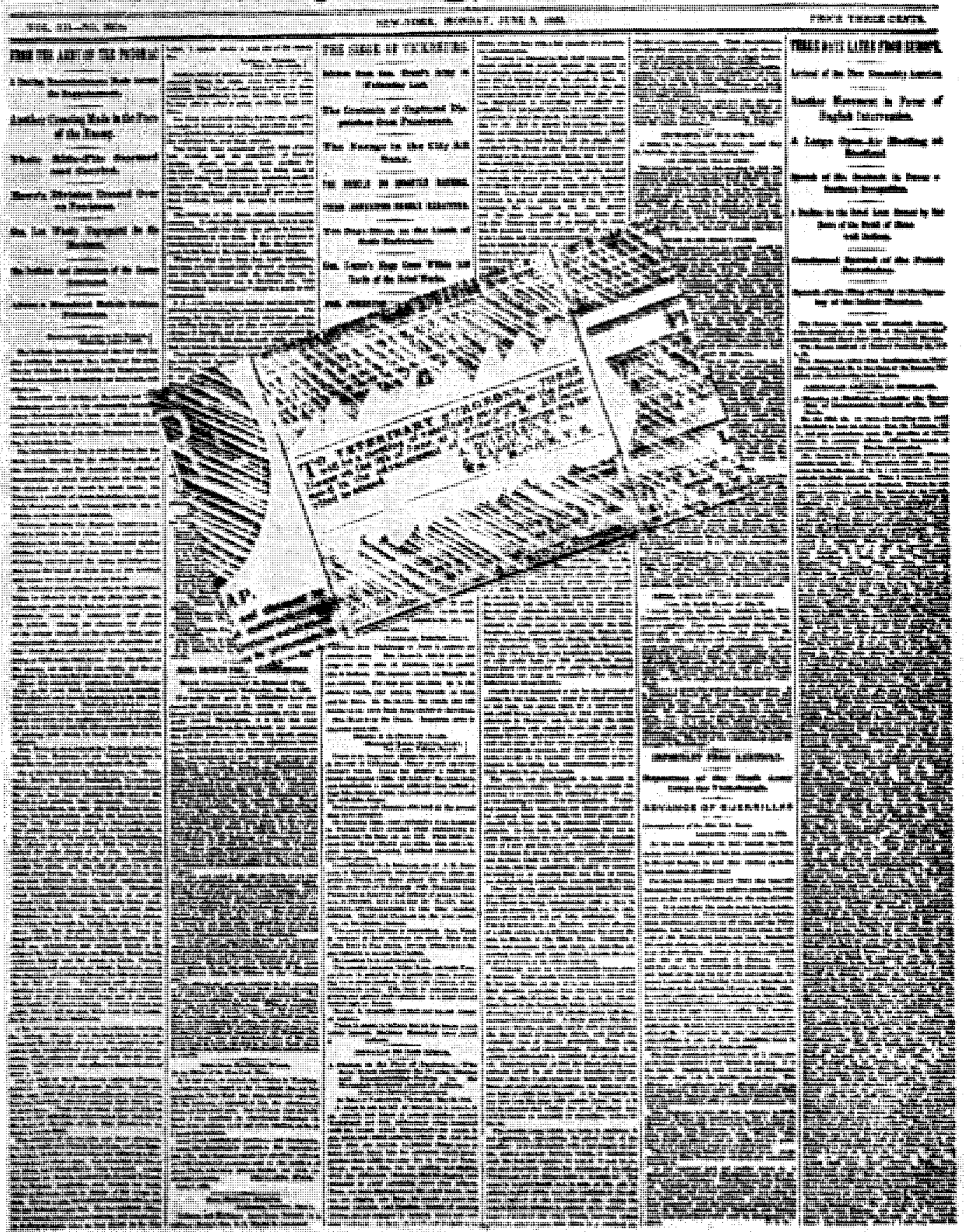

Announcement of organizational meeting of the United States Veterinary Medical Association appearing in the New York Times for June 8, 1863. Courtesy J. M. Arburua 


\section{At the Astor House}

The New York Times for June 7 and 8, 1863 carried the following notice:

To Veterinary Surgeons. There will be a meeting of Veterinary Surgeons at the Astor House on the 9 th of June, at 2 o'clock P.M. All interested in the advancement of veterinary science are invited to attend.

A. Quintard [sic], V.S. A. Large, V.S.

Wm. T. McCoun, V.S.

The convention met as scheduled at the Astor House in New York City on June $9-10,1863$, and was called to order by Wm. A. Wisdom, of Delaware. Busteed was appointed chairman to organize the meeting, and Jennings was named secretary. A committee headed by J. H. Stickney was named to draft a constitution and bylaws, which were read the following morning and adopted. An election of officers resulted in the choice of Josiah H. Stickney of Boston, a London graduate, for president; A. Liautard of New York, a graduate of Toulouse (France), for secretary; and A. S. Copeman of Utica, New York, a nongraduate, for treasurer.

As reported by Jennings:

After considerable discussion the name "United States Veterinary Medical Association" was adopted, by which the organization will be known.

It would be of considerable interest to know something of the nature of this discussion in view of the objections previously made by Copeman. Apparently "United States" was selected in preference to "American" inasmuch as the latter had been pre-empted by the American Veterinary Association. Isaiah Michener of Pennsylvania later stated that it was he who suggested the name that was finally chosen. A major factor may have been that "American" would have included the Confederate States of America.

While the available records of the organization meeting do not mention the Civil War as a factor in choice of a name for the Association, D. M. Campbell states, with regard to the change of designation to AVMA in 1898:

War psychology had determined the selection of the first name, and the influence of another war had considerable to do with the change. When the United States of America was warring with the Confederate States of America, northern veterinarians were naturally particular to have it known that they belonged to the former. With the rapprochement that came when soldiers of the South served with soldiers of the North in the Spanish-American War, about the last of the old prejudices vanished and all North and South alike were proud of the title "American."

It should be noted, however, what while the latter statement undoubtedly is true enough in itself, the change to "American" was proposed in 1897 - nine months before war was declared. Incidentally, this was at the meeting in Nashville, the first to be held in the South. But the name change had originated in recognition of "The professional and economic union between certain parts of the United States and British North America." Thus it would seem that conjecture concerning the original name should be identified as such.

Other activities of the meeting included an address by Robert McClure on "The Origin and Importance of Veterinary Education and Science," and one by C. M. Wood on "Veterinary Education." Jennings reported that he:

exhibited the ecraseur for castrating horses, a French invention, introduced in the United States by him for that purpose in the year 1852 , but it was not favorably received by stock owners. He explained its advantages and working, but it was not at that time appreciated by the members of the convention.

Jennings also exhibited some pathological specimens, and addressed the meeting, as did Copeman and others. Altogether, this was a busy agenda for a two-day meeting of an organization which had not existed before being called to order. What is surprising is that a constitution and bylaws could be drafted in one evening to the sat- 
isfaction of the delegates to the convention. Unfortunately, the records of subsequent meetings do not always indicate such celerity of action or singleness of purpose.

\section{The Founding Forty}

The most complete source of information concerning early Association activities is the Minutes Book, the original handwritten account of the meetings from 1863 to 1893 , but even this contains some obvious inaccuracies. Also, inasmuch as the minutes are only summaries of the meetings, there are obvious instances where the full story is not included, and, possibly, occasional "slanting" of the reporting. Where discrepancies between the minutes and other sources occur, an attempt as been made to rectify these, e.g., Humphrey Sill, as given in the minutes, turns out to be Silliman Humphrey. In other cases, however, it has been necessary to make a decision as to which source of information is probably the most correct, or the conflicting data are presented.

The list of delegates to the organization meeting numbers forty men from seven states, but it is apparent that others were present, who - for various reasons - were not included with the charter members. The founding forty were:
Also listed "from London" - presumably as visitors - were John Arnold and J. K. Quickfall. Other officers elected at the organization meeting were:

Vice presidents: Curtis, Jennings, Saunders, Ripley, Bowler, Wisdom, McClure. Corresponding secretaries: McCoun, Walton, R. Wood, Michener.

Board of Censors: Large, Dilts, Thayer, Essenwein, Palmer.

Of more than passing interest is the fact that in $1946 \mathrm{~L}$. A. Merillat suggested the birthdate of the AVMA should be placed at 1854 - the founding of the American Veterinary Association - rather than 1863. While it is true that in some respects the AVA was about as representative of the veterinary profession as was the USVMA at the time it was founded, it is evident that following the organization meeting, the USVMA clearly disclaimed any connection with the AVA. And while Jennings at first appears to have been a major power in USVMA proceedings, it may well be that his aggressive character was a principal reason for his rapid fall into disfavor.

\section{Minutes of the Meeting}

As recorded in the fine hand of $A$.
New York

John Busteed

Louis Brandt

John F. Budd

Charles Burden

C. H. Birney

W. H. Banister

A. S. Copeman

R. H. Curtis

A. Large

A. Liautard

W. T. McCoun

James Mulligan

E. Nostrand
Massachusetts

O. H. Flagg

James Penniman

$\mathrm{Wm}$. Saunders

J. H. Stickney

E. F. Thayer

C. M. Wood

Robert Wood

R. Farley [?]

Pennsylvania

J. C. Essenwein

R. McClure

G. Mellor

I. Michener

E. H. Palmer
New Jersey

A. C. Budd

Jacob Dilts

T. Cooper

J. C. Higgins

S. Humphrey

R. Jennings

W. R. Mankin

A. Philips

Jacob Philips

J. F. Walton

Maine: E. F. Ripley

Ohio: G. W. Bowler

Delaware: W. A. Wisdom 
Liautard, the minutes of the organization meeting of the USVMA begin:

At 2 o'clock P.M. according to previous arrangements, a large number of Veterinary Surgeons and Practitioners of the Veterinary Art in the United States and also several friends of Veterinary Science met at the Astor House for the purpose of forming an Association for the improvement and advancement of Veterinary Science.

The first order of business was the reading of "the minutes of 2 previous meetings held in the city of Philadelphia." Thus it would appear that these meetings, called by Robert Jennings on behalf of the American Veterinary Association to lay the ground work for the meeting at the Astor House, were considered at the time to be with propriety identified with the object at hand. Jennings was made secretary for the organization meeting, and apparently in this capacity entered the minutes of these two meetings on the first two leaves of what became the USVMA Minutes Book. However, all that remains of these is a notation:

Margin of leaves on which R. Jennings inserted minutes of meetings held in Philadelphia previous to the formation of this Association, and while acting as Secretary.

Just how many more men were present at the organization meeting than are recorded as charter members probably never will be known. From the manuscript of an address by $W$. Horace Hoskins it is apparent that Thomas B. and James B. Raynor, perhaps with several others, were among those of the Pennsylvania delegation who walked out of the first meeting. Possibly this occasioned an article in the Bylaws stipulating: "No member shall withdraw during the session without special permission from the chair."

At the first semiannual meeting in 1864, a letter from Jennings was read, "claiming the right, that Thos. B. Raynor ought to have his name down in the By Laws as a member." C. M. Wood answered, "T. B. Raynor not being present ... had no right to present himself except to the board of Censors." At the annual meeting (1864), T. B. Raynor's credentials were accepted, along with those of P. J. C. Penny, and Jennings moved that "the board of censors examine the candidates":

T. B. Raynor was called before the board, but refused to answer any questions, he claiming the right of membership by virtue of his early associations with the organization of the Association; his claim was refused. P. J. Curran Penny, having been announced, was admitted to the board \& passed his examination before A. Large, on anatomy, E. F. Thayer, on Physiology, C. M. Wood, on Theory and practice of medicine, in a practical manner, and is recommended by the board, to become a fellow [member] of the Association.

Jennings then moved, "that Thos. B. Raynor, and Mr. Farley, of Mass. be accepted as members, they having been active in forming the association." However, after considerable discussion, "it was moved ... and seconded ... that the report of the committee be final." Apparently all that remained was thatagain on the behest of Jennings, "the fee $\$ 5$. - be returned to T. B. Raynor." Thus it is apparent that Raynor and Farley did not become members; Raynor became active in the Association years later, but neither Farley's nor Penny's name seems to be mentioned again. The minutes are not at all clear as to whom was admitted or when. The first clear-cut identification of a new member is the appearance of Henry Lawrence, whose credentials had been discussed on four previous occasions, on the roll of members present at the annual meeting for 1866 .

\section{Thorn in the Side}

Except for adoption of a motion in 1865 that "A. McClure [undoubtedly Robert McClure] be expelled from the Association, for his ungentlemanly conduct at the last meeting, and his expulsion be dated from that meeting," Jennings appears to have become the first major thorn in the side of the Association. There can be little doubt that he was a major power in getting 


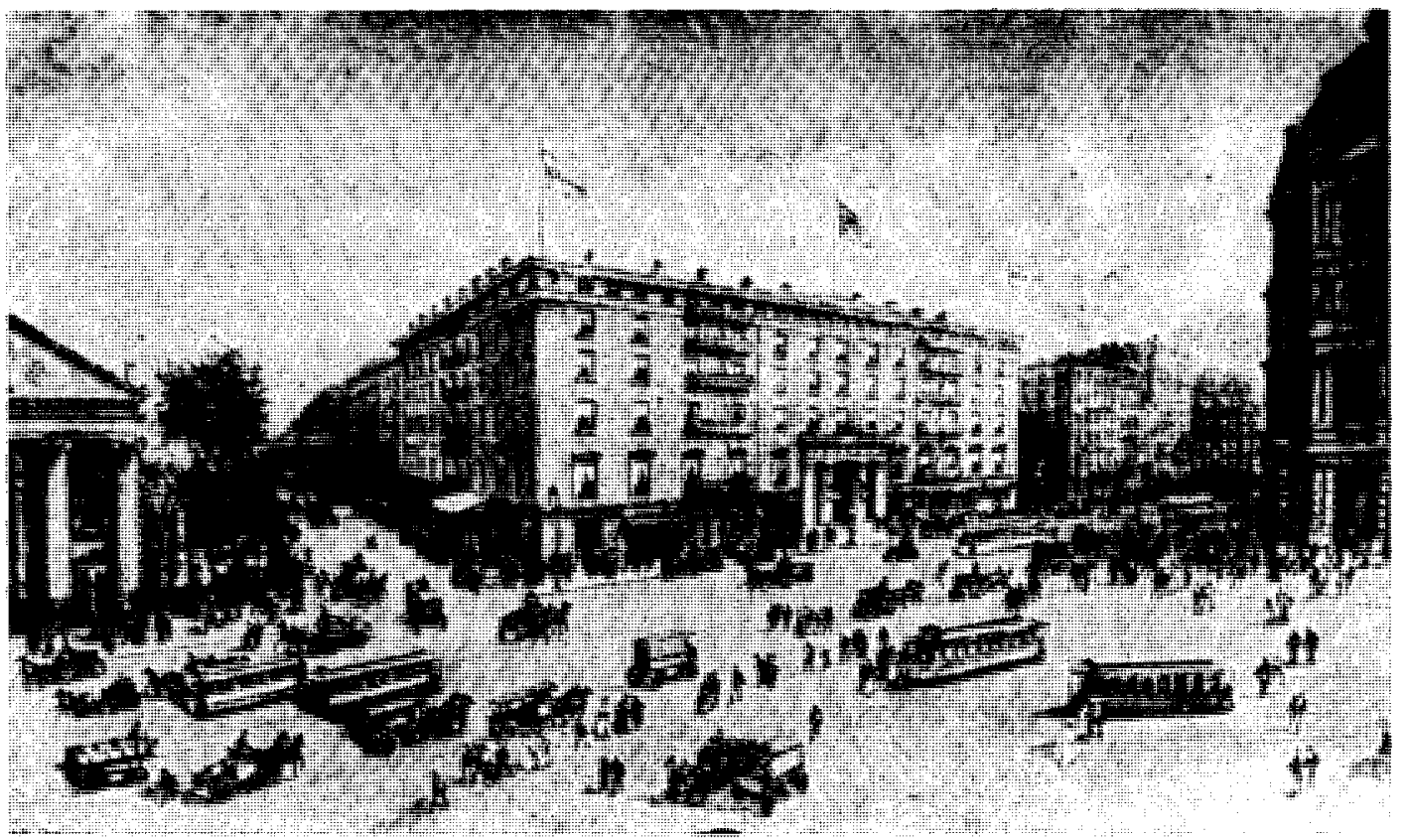

Astor House, site of organization meeting of the USVMA (1863), as it appeared about the time of the fiftieth anniversary of the Association in 1913. American Veterinary Review

the organization meeting called, and for some time he loomed large in the deliberations of the Association. At the organization meeting, C. M. Wood secured, "the thanks of the Association ... due to $\mathrm{R}$. Jennings and R. McClure for their zeal and perseverance in forming the previous meeting of Philadelphia," and both were elected vice presidents (for New Jersey and Pennsylvania respectively).

In 1864 Jennings was nominated for the presidency, but declined in favor of A. S. Copeman (Jennings, Jr., later claimed that this was by "gentleman's agreement"), whereupon Jennings was unanimously elected Secretary. In 1865 Jennings was presented as the nominating committee's choice for President. Nothing appears in the minutes concerning a second nominee, but the tally of votes gave Jennings 8 and C. M. Wood 8; a second balloting gave Jennings 7 and Wood 9.

At the semiannual meeting in 1866 , with Jennings present, it was proposed: "The Secretary shall keep a fair and impartial record of the proceedings of the meet- ings ...," after which it was moved and seconded:

that some action be taken at the annual meeting, in regard to the late Secretary $R$. Jennings, he having introduced into the records, the minutes of two meetings, held in Philadelphia, dated March 1863, and prior to the existence of the USVMA, he claiming the right of insertion, for what he termed preliminary meetings, also of withholding certain papers belonging to the Association.

At the annual meeting, with Jennings absent, a committee appointed:

to investigate the charges brought against $R$. Jennings... of tampering with the records ... considered it a most unwarrantable act on the part of said $\mathrm{R}$. Jennings, and in consequence thereof, they deem it but just to the members of this society, that he be expelled ... his expulsion to date from this meeting, that he be duly notified of the same, and public notice also be taken of it.

This was carried, and it was further moved, "that the minutes inserted by $\mathrm{R}$. Jennings be expunged from the records. (carried)." 
In 1869 William A. Wisdom, one of Jennings' associates in the call for the organization meeting, called attention to the fact that:

Dr. Jennings had complained of the action of the Association in expelling him, as not being in regular order, the Secretary had not notified him regularly, nor was any trial allowed him - he only received notice of his expulsion through Dr. Busteed.

Busteed stated that Jennings had promised to show up at the meeting following his expulsion, but hadn't. Dr. Wisdom "thought the action of the Association in this case might prevent others from joining, as some persons considered Dr. Jennings ill-used." Dr. Michener concurred with the suggestion that Jennings be given a hearing, but Walton urged, "Dr. Jennings ought to let the matter drop for his own sake." Large contended:

the principal cause of his expulsion was his habit of advertising and selling quack medicines . . . that if Mr. Jennings desired to defend himself against the charge of quackery, he should have the opportunity to do so.

In 1870 Busteed noted that Jennings had been requested to appear at three consecutive meetings, but had failed to do so, and "moved that the former action of the Association be confirmed." This was done, and the matter appears to have ended.

It should not be presumed that the Association was preoccupied with such matters, but it is evident that Jennings' associates in particular were not especially happy over the situation. Also, it is evident that - whatever the reason - the USVMA wished to dissociate itself from the Philadelphia group, to the extent of expunging from the minutes a matter which unquestionably had been a part of the proceedings of the organization meeting. How much effect this action might have had in restricting the scope of the USVMA during its early years is hardly amenable to analysis, but it would seem that this tended to divide the loyalties of practitioners in the Philadelphia area. For a number of years after the formation of the Keystone Veterinary Association, which met in Philadelphia, it attracted a larger membership and meeting attendance than did the USVMA.

\section{Busteed "Busted"}

Curiously enough, Busteed, who had presided at the organization meeting and served on the committee which drafted the constitution, was also to fall into disfavor, but for fairly substantial reasons. In 1863, Busteed's chief claim to fame in the veterinary world was as president of the New York College of Veterinary Surgeons which was nonfunctional at the time. In 1864 he was appointed the sole member of the Library Committee; his reports for a number of years were in essence: "No acquisitions." In 1866, upon the urging of Drs. Thayer and Liautard, he was made an honorary member of the Association by acclamation.

In 1871 the Committee on Education, consisting of Drs. Liautard, Large, and Robertson, presented a resolution which was unanimously adopted:

That the United States Veterinary Medical Association request the Trustees of the N.Y. College of Veterinary Surgeons to have an examination of students before admission to the course of lectures, of such a nature as may seem best to them to further the object of a higher grade of education.

This, apparently, did not set too well with Busteed. Although the annual meeting for 1873 was held at the N.Y.C.V.S., Busteed was not present, and he was replaced by $\mathrm{J}$. F. Budd as the Library Committee.

In 1875, after Liautard had formed the American Veterinary College by secession from the N.Y.C.V.S. - with most of the faculty and students - Dr. Large "requested the Sect'y to call at the N.Y.C.V.S. to procure the seal of the Association." Drs. Hopkins and Robertson were appointed to do so but apparently without success. At the semiannual meeting in 1876: "Dr. Wood moved that the Secretary shall obtain the Seal of this Association from Dr. Busteed," 
whereupon it was resolved: "That the President be requested to obtain the Seal from the creditors of the N.Y.C.V.S." In 1877 Dr. Liautard reported having obtained the seal.

That the N.Y.C.V.S. was in disrepute by this time is evident from the response of several schools to a request of the Committee on Education in 1878 for a meeting of representatives of the several schools in America. The American Veterinary College (undoubtedly via Liautard) responded, "she was willing to be present provided her dignity was not insulted by the presence of representatives which the Profession could not recognize." Cornell made it rather more plain, replying:

through Prof. Law that under no circumstances would she be present if the New York College of Veterinary Surgeons was permitted to send a representative - under other circumstances she would take part in the Congress.

By way of enlargement, Liautard explained:

the reply of the American Veterinary College was the decision come to by the Faculty after a due consideration of the subject. ... The representative to be sent by the American Veterinary College could not meet the representative that would be sent by one of the schools that it was contemplated to invite. Further, he believed that the New York College of Veterinary Surgeons would refuse to meet the American Veterinary College in Congress because she does not recognize the existence of the American Veterinary College. ... If the other schools would reconsider their decisions they would come to the conclusion entertained by Cornell University and the American Veterinary College, i.e., "that we cannot recognize the men now connected with the New York College of Veterinary Surgeons."

It was then decided by the Association "that all the Colleges of America except the New York College of Veterinary Surgeons be invited by the Committee to attend the Congress."

\section{Closed Corporation}

The Association appears to have been something of a closed corporation for the first few years of its existence. Evidently only ten new members were admitted through the tenth annual meeting, one of which was elected to office during this time. Of the original 19 officers, three had died, and two were expelled during the first ten years. Nine members of this original slate held a total of 77 offices during this period. Obviously, it is this coterie, principally Liautard, Large, Stickney, Thayer, Robert Wood, and Michener, who were largely responsible for guiding the destinies of the Association during this time. Jennings apparently was anxious to have too large a hand in the proceedings.

At the twenty-sixth annual meeting of the Association in 1889, R. S. Huidekoper, president, and first dean of the School of Veterinary Medicine at the University of Pennsylvania, reviewed the first 25 years of the USVMA. In this, Dr. Huidekoper expressed disappointment over the little that had been accomplished; the Association numbered only 207, and "only about forty come to our meetings." This, of course, was a poor showing. While about 10 per cent of the nation's 400 or more veterinarians in 1863 had participated in formation of the Association, apparently few more than forty were faithful members a quarter-century later. And by this time the veterinarians of the United States numbered some six thousand. Dr. Huidekoper had anticipated that by this time veterinarians would be serving:

not only as practitioners to the individual, but as health officers for the common weal, as economists for the great agricultural community in their dealings in motor and food animals, as experimental pathologists, who verify the work of and offer medical hypotheses for our sister profession, human medicine.

Although the veterinary profession in 1889 could claim but few men of the stature of its retiring president, it should not be thought that other leaders of the profession were satisfied with the status quo. Liautard in particular was equally dissatisfied, and voiced his opinions forcibly and frequently through the American Veterinary Review. 
In likening the progress of the USVMA to that of a turtle, Dr. Huidekoper recognized:

Veterinary medicine, like the turtle, must drag itself from a lowly origin. Its advance must be slow, through the mire of public prejudice, entangled by the reeds of quackery on all sides; when in clear water it must not resent attacks, but draw in for the moment, safe in its own solid usefulness, to come to the surface again and climb to the shore at the proper time.

Having little to report on the accomplishments of the Association under his tenure as president, Huidekoper presented a review of what had been done in the past. Today, of course, this in itself is a valuable piece of work, although if we divest his year-by-year summary of the lists of officers elected and of papers read at the meetings, it is painfully evident that little else indeed appears to have been accomplished. But, under the circumstances of its existence, the important fact emerges that the hard core of the Association was by its own efforts able to keep the USVMA a functioning entity.

In addition to an annual meeting of the Association, a semiannual meeting, at times primarily of officers constituting the Comitia Minora ("Executive Board"), was held from 1864 to 1889 ; nineteen of these twenty-six semiannual meetings were held in Boston, and twenty-two of the annual meetings were in New York. Thus it can hardly be said that the Association displayed a truly national character in this respect during it first quarter-century. It is perhaps more than happenstance that after this date, when the annual meeting was moved about the country (twenty cities in the next twenty-five years), that the Association began to assert itself as a national institution. During the twenty-four years preceding Huidekoper's administration, either Massachusetts or New York had supplied the president in all but two, and the secretary in all but three years, and all of the treasurers of the Association had come from these states. During the following twenty-five years, nine states, the Province of Ontario, and the District of Columbia were represented by the twenty-one men who served as president.

\section{CONSTITUTION AND BYLAWS: 1863}

Appended to the original minutes book is a calligraphic manuscript copy of the Constitution and Bylaws of the USVMA as adopted in 1863, apparently in the hand of the first secretary, Alexandre Liautard. At the AVMA meeting in 1905, Alex. Eger, the veterinary book publisher, presented the editors of the American Veterinary Review with a copy printed in 1863, and acquired by him through purchase of the library of the late J. H. Stickney. Unfortunately, the Review was in private hands at the time, and there would seem to be little likelihood of tracking down this item; its value if found would be obvious - it seems unlikely that another copy exists.

The verbatim transcript is presented in full in the Appendix for those who may be interested in it per se, or for comparison with the present document (which is included in the current AVMA Directory). However, some of the more salient points may be summarized as follows:

\section{OBJECTIVES}

"to contribute to the diffusion of true science and particularly the knowledge of Veterinary Medicine and Surgery." A lengthy set of objectives in 1913 was reduced in 1956: "to advance the science and art of veterinary medicine, including their relationship to the public health." (The dates indicated mean that these provisions were in effect at these times; adoption may have been at a previous time.)

\section{OFFICERS}

In 1863 all officers were elected by the membership, and these constituted the Comitia Minora ("Executive Board"). In 1913 the Executive Committee consisted of the officers (all elected), plus six presidential appointees. By 1956 a presidentelect, editor, and executive secretary had 
been added, the latter two and the treasurer being elected by the Board of Governors (president and president-elect plus chairman of the Executive Board - members of which are elected by districts). The House of Representatives, dating from 1934, with delegates elected by the state and other constituent associations, acts for the membership in conducting business. In 1863 , but not in 1913, provision was made for receiving "such Delegates as the various State or County Veterinary Societies may elect." In 1863: "There shall be one VicePresident elected from each State represented." This was later reduced to one; five were specified in 1913, and by "gentleman's agreement," were elected on a regional basis - as is specified today.

\section{COMMITTEES}

In 1863 - Library, Intelligence and Education, Disease, Finance; in 1913, Library was dropped (as a committee), and Legislation, Publication, Local Arrangements, Necrology, and Resolutions were added. In 1958, seventeen committees were superseded by the creation of six councils: Research, Veterinary Service, Biological and Therapeutic Agents, Public Health, Education, and Judicial.

\section{MEETINGS}

Fifteen members were a quorum in 1863; twenty-five in 1913; 60 per cent of registered delegates at meetings of the House in 1956. In 1863 and 1913 (dropped later): "Every member . . . shall pay due respect to the President and other officers and to his fellows, and [1863] no member shall withdraw during the session, without special permission from the chair." In 1863 and 1913: "No member shall be permitted to speak a second time, until each member who may wish to address the meeting . . . may have had an opportunity of doing so." (At a recent meeting of the House, one delegate reputedly spoke some sixty times at one session.)

\section{ADMISSION OF MEMBERS}

In 1863: "Any Veterinary practitioner or Student of 3 years standing in the profession ... [with] documents and testimonials relating to his professional qualifications," could be admitted after passing an oral examination. In 1913, graduates from a 3-year accredited school: ". . . vouched for in their own handwriting by two active members," were admitted. Initiation fee in 1863 was $\$ 5.00$ (dues not specified); in 1913 , $\$ 3.00$ plus $\$ 5.00$ dues; in $1956, \$ 5.00$ plus $\$ 15.00$ dues.

\section{HONORARY MEMBERS}

In 1863: "the President of the United States, for the time being, shall be ex-officio, an honorary member." This was still the case in 1913, but later honorary membership was limited primarily to "distinguished scientists."

\section{THE FORMATIVE DECADE}

The early meetings of the USVMA are not fully reported, there being no appropriate medium for this purpose, and the meetings appear to have attracted little attention in the agricultural press or the newspapers. The business transactions of the Association are given, although briefly, in the minutes; these are concerned for the most part with details of organizationand resolution of the Jennings squabble. Scientific papers were presented at most meetings, but only the titles and authors are (sometimes) noted. Not until the American Veterinary Review was established in 1877 do we have a clear picture of the proceedings.

In reviewing the meetings during successive years, no distinction will be made between the events which transpired at the annual and semiannual meetings; for many years it was the faithful few who attended both, and in effect were the Association. Although the membership remained fairly static for some time - there appears to have been a net gain of only one member during the first ten years - there was no 


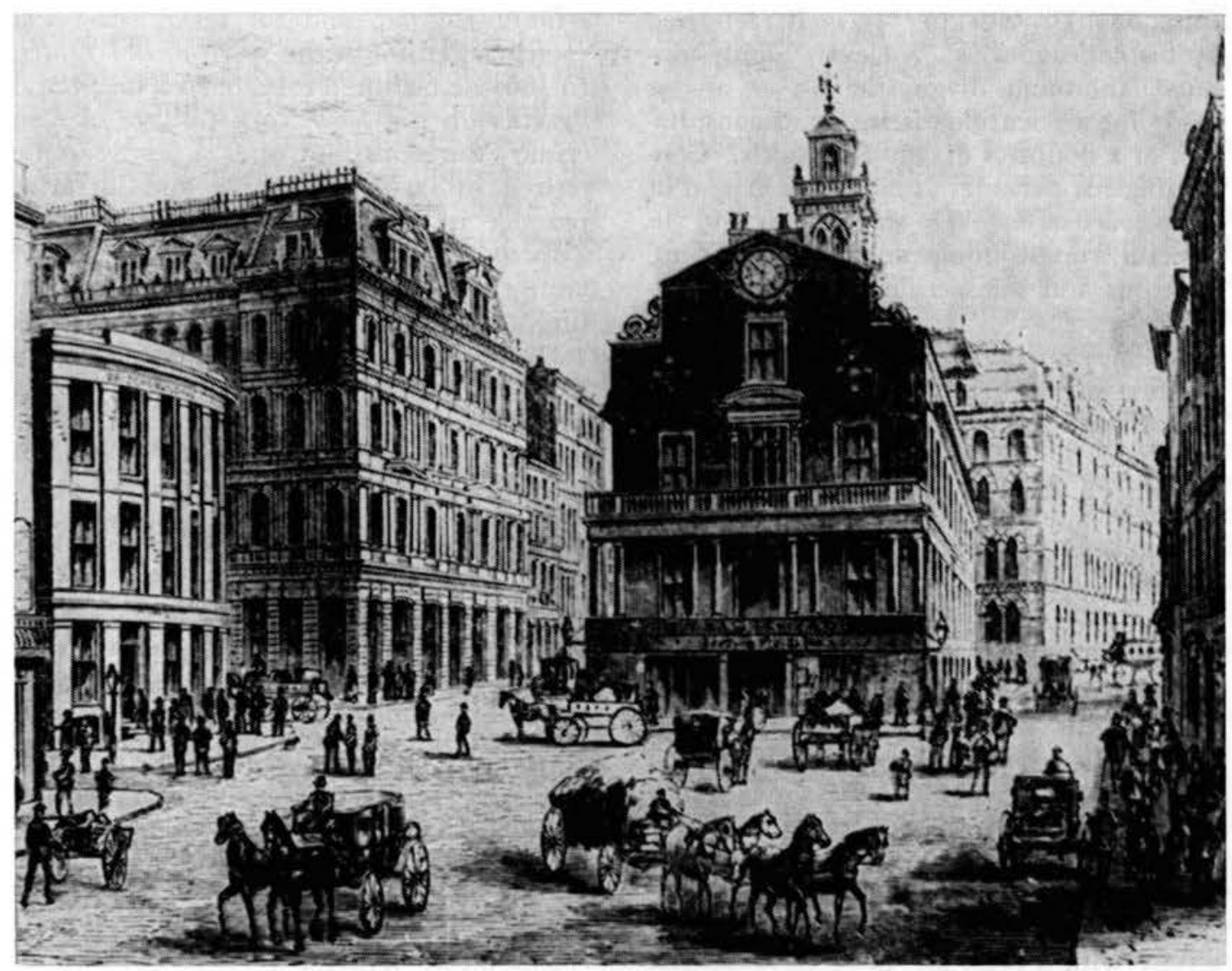

State Street, Boston, in the late 1860's, where semiannual meetings of the USVMA were held for more than 20 years. Boston Guide Book

lack of interest on the part of those who attended the meetings.

\section{4-1865}

Both of the meetings for 1864 were held in New York. Papers were presented by A. S. Copeman on the composition of the tissues of animals; by G. W. Bowler on rabies; by Robert Jennings on suppression of urine in the horse; and by C. W. Wood on the status of veterinary medicine. Committees on Education, Finance, Library, and Diseases were appointed. Election of officers resulted in the choice of A. S. Copeman, president; R. Jennings, secretary; and C. M. Wood, treasurer. The death of Edwin H. Palmer was announced.

At the annual meeting for 1865 in Bos- ton, A. S. Copeman, the retiring president, read a paper on "Philosophy of the Sciences." Henry Lawrence was admitted to membership, and Robert McClure was expelled "for ungentlemanly conduct at the last meeting." C. M. Wood was elected president; Charles Burden replaced Jennings as secretary; and E. F. Thayer was elected treasurer in place of Dr. Wood.

\section{J. H. Stickney}

Josiah H. Stickney, M.D., M.R.C.V.S., first president of the USVMA was born in 1827. Prior to going to London for veterinary training, he had obtained the M.D. degree in Boston. At the time it was unusual for a physician to study veterinary medicine; later the reverse became fairly 
common. Dr. Stickney was characterized by his colleagues as “a clever, highly-educated, thorough diagnostician ... always ready for a scientific discussion, a consultation or a doubtful diagnosis to settle." Concerning his personal attributes, a friend of forty years states: "He was modest and yet forceful, unassuming and yet confident, generous and self-sacrificing beyond measure."

Stickney appears to have been elected as the first president of the Association more or less as a token of the esteem in which he was held by his fellow practitioners. He was also a member of the Committee on Organization which drafted the Constitution, but after his tenure as president, he appears not to have held any major position in the Association. He did not write for the veterinary journals, but did lecture on veterinary science at the Massachusetts Agricultural College. He was, however, faithful in his attendance at Association meetings, and was one of the three founders to see the second quarter-century ushered in. At the following meeting in 1889 - the last he was to attend - he responded to the recognization of his long service with a toast to: "The early days of the Association."

Shortly before he died in 1902, a few days less than 75 years of age, he remarked apparently thinking of his own illness "interesting cases come to us about the time we are ready to die." At the time of his death,"a student and friend to the last moments," writes of him:

Stickney was bitter against opportunism, distrustful of all that were patronizing; he was caustic and quick in his replies, and never given to idle talk. Honest with himself, he commanded the respect of all, even of those who disagreed with him.

\section{A. S. Copeman}

Arthur S. Copeman, V.S., second president of the USVMA, was a self-educated practitioner at Utica, New York, for many years, and in 1855 became Professor of Pharmacy at the Boston. Veterinary Institute. He contributed to the American Vet- erinary Journal, and for seven years was veterinary editor of the Spirit of the Times. In 1864 he became Professor of Theory and Practice in the New York College of Veterinary Surgeons, but after a few years he retired in favor of a large and lucrative practice in New York City. He amassed a fortune, but lost it through a series of family troubles, and in 1876 took his own life.

Dr. Copeman was characterized as "a hard worker, a lover of the microscope, and a fluent writer." In speaking at the opening exercises of the N.Y.C.V.S. in 1865, he stated:

The science of veterinary medicine, as it is now beginning to be understood, is a science that has a far wider application and a far nobler mission than the limited duty of leading the sick animal back to health. . . The great problem of veterinary medicine is not so much how to cure a particular case of fever, but how to prevent the outbreak of pestilence, to discover and to avert all the causes of epizootic and enzootic diseases; in a word, how to preserve the health of domestic animals and thereby increase the wealth of the nation.

\section{M. Wood}

Charles M. Wood, V.S., M.D., third president of the USVMA, came to this country from England in 1835 and started working as a blacksmith, but soon took up veterinary practice. In 1841 he advertised in the New England Farmer: "All diseases of Horses, Cattle or Swine, are attended to. Also, Castrating and spaying." During the 1850's he was associated with George Dadd in the Boston Veterinary Institute, and was a regular contributor to Dadd's shortlived American Veterinary Journal and to the Veterinarian (London). Writing on "Veterinary Medical Knowledge" in 1858 he deplores the apathy:

so generally manifested, by the certified Veterinary Surgeons of this country, in regard to the diffusion of veterinary knowledge ... they claim the right to remain silent on the subject, unless in the stable, or bar-room. . . If the truth is not told, people will suppose that error is truth; and go on inflicting misery, instead of ministering relief. 
Wood is said to have been the brains behind the Boston Veterinary Institute, but this might be subject to question. In 1861 he was employed as a civilian inspector of animals for the Army of the Potomac. An entirely self-educated practitioner, he had an office in a livery stable in Boston on what was later the site of the famed Parker House. While he was characterized as:

proficient in the details of the profession... in treating acute forms of diseases of the internal organs he was a failure. ... He used from ten to forty [cathartic] balls when any one else would have used one.

$\mathrm{He}$ was also characterized as "brusque, antagonistic, and as agressive as one could be." Dadd, however, stated in 1856 that Wood "through his own industry and perseverance, stands at the head of our profession" - a high compliment from Dadd.

Obviously, enough others thought sufficiently well of Wood to elect him successively censor, treasurer, president, and censor three times again before his death in 1869.

\section{6}

The annual meeting for 1866 was held at the New York College of Veterinary Surgeons, of which Alexandre Liautard was the nominal head. Many of the later meetings were held here, or at the American Veterinary College after Liautard became its head in 1875. Also suggestive of the considerable influence he had in Association affairs is his election as its first secretary, later three times as president, his editorship of the American Veterinary $R e$ view, and the fact that he held one or more official positions almost without exception to 1900 .

Few of the early Association meetings appear to have been advertised in the newspapers, nor do accounts of the meetings seem to have attracted the attention of the press during the early years. In 1866 the following "Special Notice" appears in the New York Times for September 3:

The Fourth Anniversary meeting of the United States Veterinary Medical Association will be held in the lectureroom of the New York College of Veterinary Surgeons, No. 179 Lexington Av. on Tuesday, Sept. 4 at 10 A.M. Chas. Burden, Secretary.

A. S. Copeman read a paper on "Diseases of the Chest," followed by a discussion of navicular disease. A committee was appointed to draft a Code of Ethics which was adopted after presentation later the same day. John Busteed was made an honorary member of the Association.

At this meeting a committee was apponted to investigate charges against Robert Jennings "for tampering with the records and withholding other papers belonging to the Association." Upon their report, as noted earlier, Jennings was expelled from the Association. R. H. Curtis was elected president; Charles Burden and E. T. Thayer re-elected secretary and treasurer, respectively.

\section{R. H. Curtis}

R. H. Curtis, M.R.C.V.S., fourth president of the USVMA, was a London graduate who practiced in Brooklyn in the 1860's. He also ran a riding school: "a thing which in those days was peculiar, as horseback riding was only in its infancy in that part of the state." He was characterized as "a kind, genuine gentleman," whose overpowering joy in life was his nephew, Alfred Large, whom he adopted as a son and who later became president of the Association - as close to a father-son combination as ever realized in this office.

Being in his later years at the time of organization meeting, Curtis perhaps had less opportunity to distinguish himself in Association matters than others accorded the presidency. Apparently in ill health, he resigned from the Association in 1868 a year following his tenure - whereupon he was made the first honorary member of the USVMA. He died in 1869 "at quite an old age."

\section{7}

The meeting for 1867 was held at the New York College of Veterinary Surgeons. 
The revision of the constitution was adopted, and Drs. C. M. Wood, Stickney, Thayer, and Large were appointed "to review and revise the transactions of the past and the future." Just how the future transactions were to be revised is not stated, but the purpose in reviewing those of the past appears to have been in anticipation of publishing the transactions of the Association to that date. Whether or not this was done seems not to be on record, but the following year the matter was put in the hands of the committee on Intelligence and Education.

At the meeting, Alfred Large and Alexandre Liautard reported on the horse disease existing on Long Island, which they termed cerebro-spinal meningitis - probably forage poisoning or encephalitis? which later sporadically reached alarming proportions in the Midwest and South as the "horse plague." C. M. Wood read a paper on scrotal hernia.

Elected as the new slate of officers were: president, Robert Wood of Massachusetts; secretary, John F. Budd of New Jersey; and treasurer, E. F. Thayer of Massachusetts. Reversing the earlier practice of having several vice presidents from the several sections of New England and the Middle Atlantic states, William Wisdom, patriarch of the group, was made the sole occupant of this office. Wisdom had been a practitioner in Delaware for nearly thirty years when, in 1859 , he matriculated at the Veterinary College of Philadelphia, along with Jacob Dilts of New Jersey. Dilts was a graduate of the Boston Veterinary Institute and one of the charter members of the USVMA. Shortly after the lectures had begun, however, the faculty - except for the perennial Jennings - defected, leaving Wisdom and Dilts, in effect, private students of Jennings.

\section{Robert Wood}

Robert Wood, V.S., fifth president of the USVMA, had been associated with George Dadd both at the Boston Veterinary Institute as Professor of Cattle Pathology, and as a contributor to the Ameri- can Veterinary Journal. He was characterized as:

a fair student, and had a capacity for the proper gathering and storing of knowledge. He reasoned better than his brother, was deeper and more analytical, while Charles leaned more toward the synthetical. . . He was a good friend, an all-round useful man of far more than excellent ability ... anxious and ready to do all he could in behalf of his profession.

Wood practiced at Lowell, Massachusetts, and apparently took private students about the same time he was associated with the Boston school. Both he and his brother were active in the Boston Veterinary Association from the late 1850 's, and were the only pair of brothers to attain the USVMA presidency.

Robert Wood was perhaps less scholarly than his brother Charles, but evidently was a more progressive practitioner. He mentions using ether anesthesia for castrating pigs with scrotal hernia and for other operations in the 1850 's - when few veterinarians were using anesthesia. In writing on "Catarrh in Neat Cattle, alias Horn Ail," he comments on the usual absurdities connected with the disease, but adds:

I must confess, however, this is not as frequently the case, now as heretofore, the people generally appreciating more and more the value of our art ... where one animal dies in this city and vicinity, at this time, there were ten, twelve or fifteen years ago.

This would suggest he had been in practice since the middle 1840's. He died in 1892.

\section{8}

The semiannual meeting for 1868 in New York was graced by the presence of Professor John Gamgee of Great Britain, who was investigating contagious diseases of animals in this country for the United States government. At this meeting a committee, including Alexandre Liautard, was appointed "to investigate the subject of printing a veterinary journal." The matter apparently was a decade in advance of its time, for the subject appears not to have been discussed again until 1876. It 
was decided to drop from the membership any who were two years in arrears in dues.

At the annual meeting in Boston, I. S. Lombard and James L. Robertson were admitted to membership. Robertson was destined to become secretary and, later, president of the USVMA. The resignation of past-president Curtis was accepted, whereupon he was made an honorary member of the Association. The officers of the previous year were re-elected. The Association adopted a resolution:

That the United States Veterinary Medical Association as a body protest against the appointment by the general government, through the recommendation of General Grant, of Mr. Alexander Dunbar as a clinical lecturer to the army veterinary surgeons and farriers, for an alleged discovery of a mode of treatment of the diseases of horses' feet, the operation being no discovery, but a regeneration of an obsolete idea, and worthy of the attention and patronage of the Society for the Prevention of Cruelty to Animals, it being both an evidence of ignorance and barbarity. Furthermore, Mr. Dunbar has no claim whatever to the title of Veterinary Surgeon, either by education or professional association.

Dunbar was an honest Canadian farmer who had made a small fortune on a method of treating the feet of lame horses; he did not claim to be a veterinarian, but was "elevated" to this status by act of Congress. Except for the objections of one Congress-

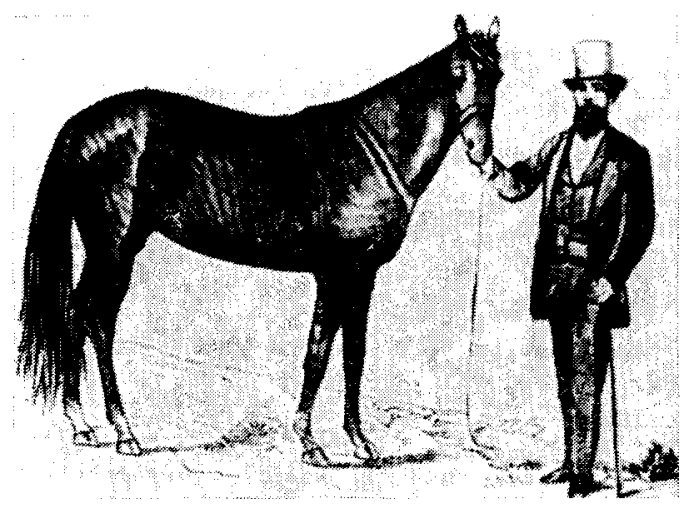

Alexander Dunbar, originator of "Dunbar system" for treating contracted feet which was adopted by the U.S. Army after President Grant had recommended it. Dunbar: Diseases Incident to the Horse, 1871 man, Dunbar would have been paid $\$ 25,000$ for one year's service, but this was reduced to $\$ 10,000$. Although army veterinarians called the system of treatment "foot butchery," Dunbar's method remained in effect for 15 years. Whether the action of the USVMA had any effect or not is not certain, but Drs. Stein, Busteed, and Liautard (N.Y.C.V.S.) are thought to have had a hand in supplying the information which resulted in reduction of Dunbar's honorarium. The resolution of the Association is at least worthy of note as an early attempt to assert influence on a national basis for the betterment of veterinary medicine.

\section{9}

The semiannual meeting for 1869 was again held in Young's Hotel in Boston, and the annual meeting in New York. Having discovered that the diplomas of membership, issued since 1863 , were illegal because the Association was not incorporated, it was recommended that the diplomas already issued be recalled, and only a receipt for the initiation fee be issued hereafter.

It was resolved to study the matter of petitioning Congress for an act of incorporation of the Association, but in 1872 the committee appointed for this purpose reported: "Upon legal advice it was deemed inadvisable to obtain a charter." As a matter of fact, the Association was not incorporated until 1917; Merillat and Campbell state, "For reasons not clearly explained in the records, outstanding figures in the administration of the association objected to incorporating it."

In going back over the records immediately prior to 1916 , the only reason advanced for not incorporating the Association was that it would thus be possible for individuals to sue the Association. Others, however, pointed out that without incorporation individual officers of the Association could be sued (and had been) over matters for which they had not been immediately responsible. Also it was pointed out that another group could incorporate themselves with the same name, and prevent the AVMA from using its own name. 


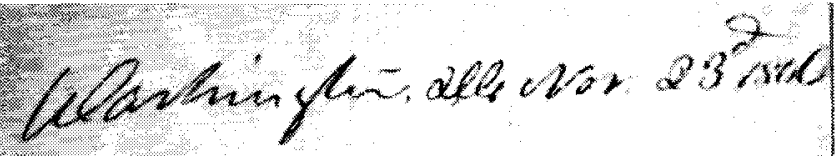
Alexander Denar. the.

Raxplamation. Howe seating of tearing:

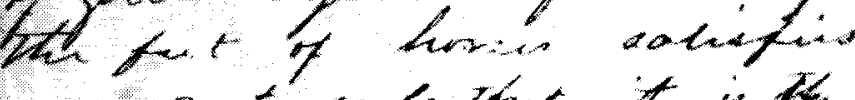
mu not only that it is the hex thatument yet demised

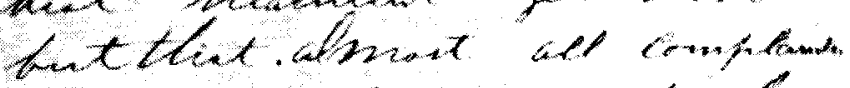
lasing than of the ho..

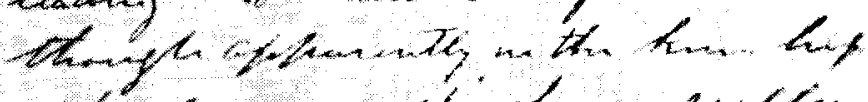

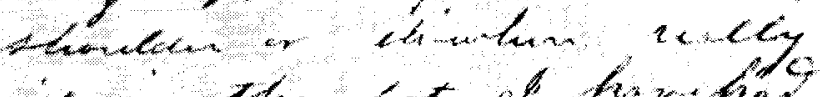

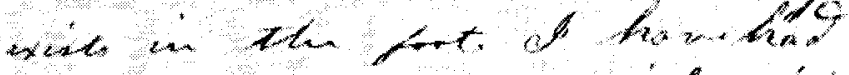

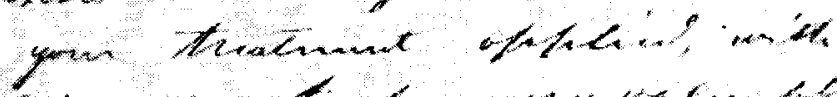

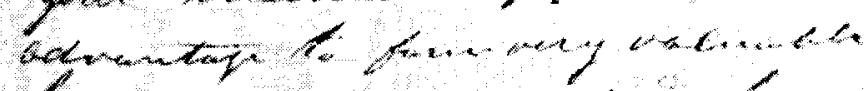

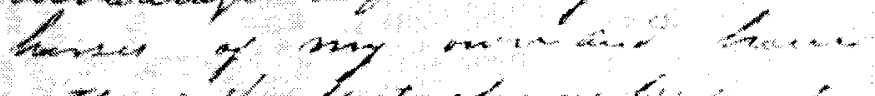

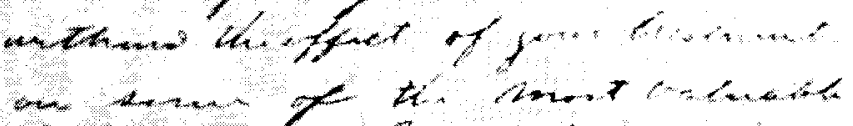

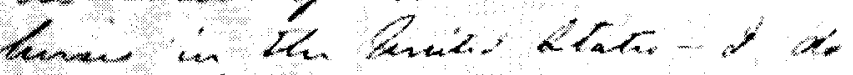

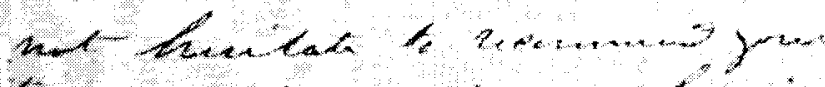

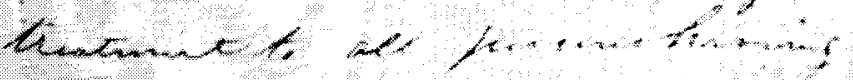

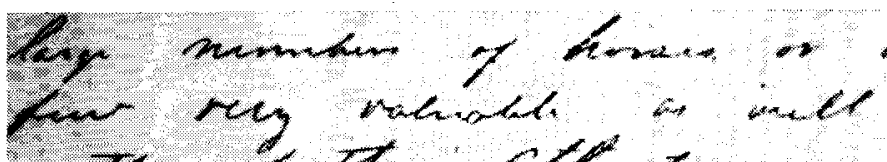
ming of the ot hen.

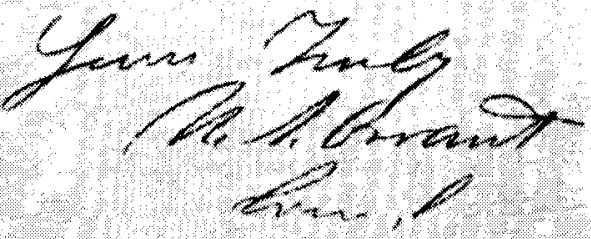

Letter from General Grant to Alexander Dunbar, commend ing the latter for his system of treating the feet of horses. The system of treating the feet of system of treating the feet of it is the best treatment yet de vised but that almost all complaints leading to lameness of the knee, hip, shoulder or elsewhere, really exists in the foot I have had your treatment ap-
plied, with advantage to four very valuable horses of my own your treatment on some of the most valuable horses in the United States- I do not hesitate to recommend your treatment to all persons having large numb-
bess of horses, or few very yaluable, as well worthy of their at
tension. 
Earlier it had been proposed to publish papers presented by members along with the proceedings of the Association meetings, but this year the Committe on Intelligence and Education reported they had received no papers worthy of publication. It was resolved to amend the Constitution to substitute the word "members" for "fellows" of the Association. Resolutions of regret were passed over the loss sustained in the deaths of former presidents, R. H. Curtis and C. M. Wood. Dr. Walter Burnham, apparently a physician, of Lowell, Massachusetts was elected an honorary member - evidently the first "outsider" in this category.

No mention is made of the presentation of papers at the 1869 meeting, but:

An interesting discussion took place at this meeting on "spaying of cows," Dr. Busteed claiming that the operation was first introduced by an American named Thomas Quina [?].

Actually, the operation had been known much earlier, having been practiced with some regularity in northern Europe in the fifteenth and sixteenth centuries, but had been largely dropped until a traveller from Europe found a farmer at Natchez, Mississippi, Thomas Wynn, practicing it successfully. This was in 1831, and although it appears to have become re-popularized in France and England before it was widely practiced in America, most European writers of the nineteenth century credited this "innovation" to America.

Elected as officers for the ensuing year were: president, E. F. Thayer, of Massachusetts; vice president, Isaiah Michener, of Pennsylvania; secretary, James L. Robertson, of New York; and treasurer, Charles Burden, of New York. Robertson, elected to membership the year previous, was the first "new blood" to be admitted to the inner circle; he became a long-time stalwart of the Association, and was accorded the presidency in 1879 . The old faithfuls elected as censors were R. Wood, J. H. Stickney, A. Liautard, W. Saunders, J. C. Walton, and A. Large.

\section{0}

The year 1870 appears to have been one of little activity so far as Association matters were concerned: a quorum was not obtained at the semiannual meeting in Philadelphia, and no papers were presented at the annual meeting at the New York College of Veterinary Surgeons. The officers of the previous year were re-elected, thus apparently establishing securely the precedent set in 1868 on the basis of what was perhaps an expedient. Not until about 1900 was there strong sentiment against a man serving two or more terms as president of the Association, following which time the feeling prevailed that the highest office should not be monopolized. By this time, of course, the membership of the Association was more truly representative of the veterinary profession.

Earlier there had been rumblings of discontent over the apparent fact that the Association was dominated by the New York-Massachusetts group, and in a gesture to break the established pattern of meeting alternately in Boston and New York, the semiannual meeting for 1870 had been scheduled for Philadelphia. The fact that a quorum was not obtained apparently prejudiced sentiment in favor of custom, and for a number of years the old pattern was maintained. The first major break came when the annual meeting for 1884 was held in Cincinnati.

While it could be argued that the Association might have become more representative of the veterinary profession had it moved around, it is perhaps more than likely that the Association would not have gained sufficient support to sustain it, for relatively few veterinarians within its sphere of influence supported the USVMA. With only the meetings to serve as a cohesive force, it is more than a little fortunate that the Association functioned as well as it did.

\section{E. F. Thayer}

Elisha F. Thayer, M.D., V.S., sixth president of the USVMA, was born at Dedham, 
Massachusetts, in December, 1815, and died at West Newton, Massachusetts, July 29,1889 . His father was a physician, but it was some time before the son followed in his father's footsteps. In 1869 the University of Vermont conferred upon him the M.D. degree, but it is not apparent whether this was an earned or an honorary title.

Little is known of his early life, but about 1850 he began to study with Charles M. Wood. He engaged in veterinary practice for some time prior to 1853 when he went abroad to study at London and at Glasgow, where he was a special student of the celebrated John Gamgee. Upon his return he again entered practice, but ill health forced him to give this up for some time. It was undoubtedly his tutelage under Gamgee that so admirably fitted him for his later work with the Massachusetts Cattle Commission in stamping out contagious pleuropneumonia. In 1859, along with George Dadd, he was sent by the state to investigate a new disease in an imported herd of Dutch cattle at Belmont, Massachusetts. Thayer diagnosed the disease as contagious pleuropneumonia, and although his views were in conflict with many physicians and prominent agriculturalists and veterinarians, he was made a member of the Cattle Commission in 1862, and later was its head.

Adopting Thayer's recommendations, the Commission was successful in stamping out the disease in 1865 at a cost of only $\$ 68,000$. As a result of his program being continued - Thayer himself was a member of the Commission for nearly twenty-five years - the disease was kept from appearing again in the state, despite the fact that neighboring states were infected. $\mathrm{He}$ was also a member of the U.S. Treasury Cattle Commission, along with James Law of Cornell University, and J. H. Sanders, the Chicago cattleman. In his report to the U.S. Commissioner of Agriculture in 1869, Dr. Gamgee states that to Dr. Thayer, the people of Massachusetts "owe much for his skill and industry as their veterinary commissioner."
Dr. Thayer was characterized as:

one who ever had an eye single for the advancement of the profession which he loved, and for the health and welfare of the animal. He was a student, ever at work either in his library, the dissecting table or on the subject, working long into the night. .. . Free from any desire for position himself, it was only when fairly thrust upon him that he would accept such places. ... His life is an example for the younger members of the profession to follow.

$\mathrm{He}$ was one of the best informed men of his time in the profession, and undoubtedly was the ablest in veterinary sanitary police matters, as his record attests.

In 1879 he suffered an apoplectic stroke, from which he never fully recovered, yet he continued to work with both the state and national cattle commissions, and engaged to some extent in private practice until his death ten years later at the age of 73.

Merillat and Campbell state that while Thayer was appointed to the Massachusetts Cattle Commission "because of his recognized ability as a veterinarian, he never claimed to be a veterinarian ... [and] hid the fact that he was a veterinarian." But except as this might imply "graduate veterinarian," the facts appear to be otherwise: while not one to assume more credit than was due him, Thayer demonstrated loyalty to his colleagues and pride in his profession; contemporary reports identify him as "the veterinary commissioner."

\section{Charles Burden}

Charles Burden, V.S., was born in London in 1833 and came to America while young, where he entered into veterinary practice with E. Nostrand in New York City. In 1866 both he and Nostrand entered the New York College of Veterinary Surgeons, the latter graduating in 1867 , and Burden in 1868. It is related that during his second year he was the only member of the class. Upon graduation he resumed the practice he had engaged in as a nongraduate, and in 1876 took an addi- 
tional degree from the American Veterinary College.

A charter member of the USVMA, he was truly one of the "old guard," serving as secretary for two years, and treasurer for sixteen, the latter being the longest tenure in any one office to 1935 when M. Jacob completed his seventeenth year as treasurer of the Association. At his death in 1901, Burden was one of but a small handful of surviving charter members of the Association. As censor in 1887 he had been the only charter member to hold office that year.

\section{1}

The meetings for 1871 were held at Young's Hotel in Boston and at the New York College of Veterinary Surgeons. The eligibility of candidates for membership was discussed, and Peter Nostrand was admitted as a member. Drs. Stein, Percy, and Weisse, all physicians and members of the faculty of the N.Y.C.V.S., were elected to honorary membership.

The original Constitution limited membership to "regular practitioners of the Veterinary Profession." At the semiannual meeting in 1871, E. T. Thayer proposed his son, Fred L. Thayer, M. D., for regular membership; this was denied, whereupon A. Large proposed that "Medical" be substituted for "Veterinary" in this article of the Bylaws. After discussion of this amendment at the annual meeting, the motion was withdrawn, and Fred Thayer was admitted as an honorary member. In 1872 Dr. Liautard again opened the matter by re-proposing Thayer for regular membership; Dr. Stickney then proposed that the membership clause be altered to read, "any member either of the Medical or Veterinary Profession." This was carried and, after being laid over for action at the next meeting, was adopted - but not before Dr. Thayer had withdrawn his son's name, whereupon his (the son's) status was confirmed by his being elected again to honorary membership - (at least this seems to be what happened; the minutes are confusing on this matter).
A resolution was adopted and a copy sent to the trustees of the New York College of Veterinary Surgeons:

That the U.S.V.M. Association request the Trustees of the N.Y.C.V.S. to have an examination of students before admission to the course of lectures, of such a nature as may seem to them to further the object of a higher grade of education.

This appears to have been the first of an initially desultory but continuing series of efforts of the Association to improve the caliber of veterinary instruction. In view of the later dissatisfaction that arose concerning the status of the N.Y.C.V.S. it would appear that this resolution had little effect at the time, but there is little doubt that it was the watchful eye of the Association that anticipated and promoted many of the improvements in the system of veterinary education. It is of some significance that at the organization meeting two papers on veterinary education were read, and at the meeting in 1864 a Committee on Education was appointed. This committee appears to be the only one with an unbroken tenure through the years.

Dr. Liautard presented a paper on "Cerebro Spinal Meningitis," which was causing considerable concern on Long Island about this time. As noted above, however, it seems likely that this was a form of forage poisoning - the "horse plague" of the Midwest in later years.

Elected as officers for the coming year were: president, Alfred Large of New York; vice president, William Saunders of Massachusetts; secretary, J. L. Robertson; and treasurer, Charles Burden, both of New York. The incumbent slate of censors was re-elected.

\section{William Saunders}

While it is a fair assumption that only the more progressive practitioners would have been interested in the objectives of the Association, it is also evident that the group exercised good judgement in electing only the more able men to high office. Representative of the group content to fol- 
low rather than lead was William Saunders, V.S., whose father had been a farrier for one of the stage lines in Massachusetts.

The younger Saunders was born in England in 1827, and became a practitioner under the tutelage of his father. A charter member of the USVMA, he was a perennial vice president during the early years, and served several terms as censor. His Association activities, however, appear to have been limited to little more than attending the meetings, and with the influx of new members about 1875, he dropped from notice.

$\mathrm{He}$ was characterized as "nothing of a student," but exuded self-confidence, and had powers of observation which led to generally good judgement, depending largely upon experience to carry him through. He took students; one raised to the dignity of a practitioner was described as "a small, insignificant, and, of course, conceited fellow, more fond of smoking either good or bad cigars than of reading a book."

A colleague states of Saunders:

He was a great favorite with almost everyone he met, and was generous and genial, every day. People employed him who recognized him as a man of no great education, and they made no mistake in doing so, for their interests were safe in his hands and his judgement in general practice was good. ... He was of that class, the unlimited majority who choose the easy roadway . . his dignified manners and appearance carried him along. ... He had commercial faculties largely developed, and always had a large business.

He died in 1884; if he had contributed little to the advancement of veterinary knowledge, he at least brought to the practice of veterinary medicine a certain dignity.

\section{2-1874}

The meetings for 1872-1874 were held in Boston and New York as customary, but little that may have transpired seems to be recorded. The Committee on Charter reported that incorporation of the Association seemed "impracticable." Dr. Thayer presented a case of parotid duct fistula, and cerebro-spinal meningitis was again discussed but, strangely enough, the prevailing epizootic of horse influenza, which undoubtedly caused many of those present to walk to the meeting in New York (1872), seems not to have been mentioned.

New members elected were Theo. K. Very, Robert J. Saunders, J. D. Hopkins, R. W. Finley and Peter Peters. The death of "Dr. Watson" (Walton?) was announced. In 1874 it was proposed to donate $\$ 50$ to aid in the erection of a monument to the memory of Claude Bourgelat at Alfort, France, commemorating his founding of the school in 1765. This would appear to have been the first action of an international character by the Association, and as such is of some significance. The incumbent officers were re-elected in 1872 and 1873. The annual meeting for 1874 was not held owing to an error in the date of the notices sent out, and the semiannual meeting 1875 attracted only the Comitia Minora.

It would thus appear that the period from 1870 to 1875 was a low point in the fortunes of the USVMA. It is evident that only a few new members had been attracted, and a number of the "old guard" had died or had become inactive. Fortunately, a sufficient number of the faithful few remained to keep the Association from dissolution. The fortunes of the Association took an upward turn following this period, however, and with the publication of the American Veterinary Review in 1877 its continued growth seemed assured.

\section{A. Large}

Alfred Large, M.D., M.R.C.V.S., seventh president of the USVMA, was educated at the London Veterinary College, and had returned to the U.S. only a short time before the organization meeting of the USVMA in 1863. Shortly afterward he earned his M.D. degree at the Long Island Medical College, following which he took charge of the practice of his uncle, R. H. Curtis, who had adopted Large as his legal son. 
After A. S. Copeman resigned as Professor of Theory and Practice at the N.Y.C.V.S., Large was appointed his successor, and he continued in this position at the American Veterinary College for several years after the latter was established by secession from the N.Y.C.V.S. in 1875 . $\mathrm{He}$ was one of the first to make the diagnosis of cerebro-spinal menigitis in horses on Long Island, and wrote several articles on the subject for the Veterinarian (London).

\section{A contemporary states:}

Dr. Large was a fluent speaker, a thorough physician, master veterinarian, and superior teacher. . . When he was at the Astor House (1863) and when he held his professorship, Large idolized the veterinary profession. He was very fond of medical studies, and the many sacrifices and concessions that he made to veterinary practice were known only by his most intimate friends. But in later years, for some unknown reason ... he took a great dislike, if not of the profession itself, at least to the connections it imposed on him, and he left Brooklyn for Massachusetts, where ... he retired and established himself into consulting human practice.

\section{Michener}

Isaiah Michener, V.S., was born in 1812 , and for many years was the acknowledged patriarch of the American veterinary profession, but for some unaccountable reason he was never accorded the highest office of the Association. Few, however, were more active for a longer period than he; a member of the Committee on Organization in 1863, it was he who gave the Association its name, and he served variously as vice president, corresponding secretary, censor, and as a member of several committees.

Self-educated, he in turn served as the mentor of a number of prominent veterinarians, among them eight who went on to qualify as graduates, including his own son, Charles, M. R. Trumbower, and A. A. Holcombe, all of whom became important fig-
The requirement that an individual be of age before being recognized as fit to practice as a graduate veterinarian antedates any of the state practice acts. J. C. Meyer, who joined the USVMA in 1875, became the Association's first fifty-year member. AVMA Archives

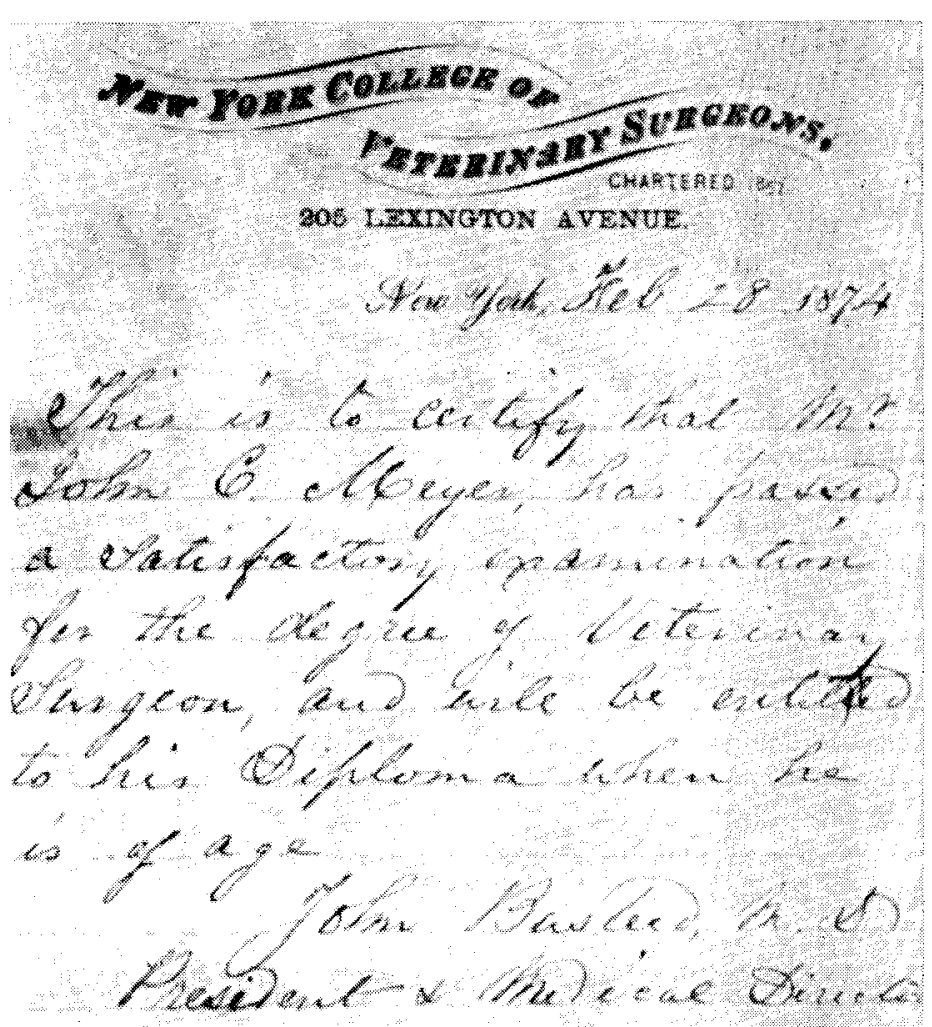




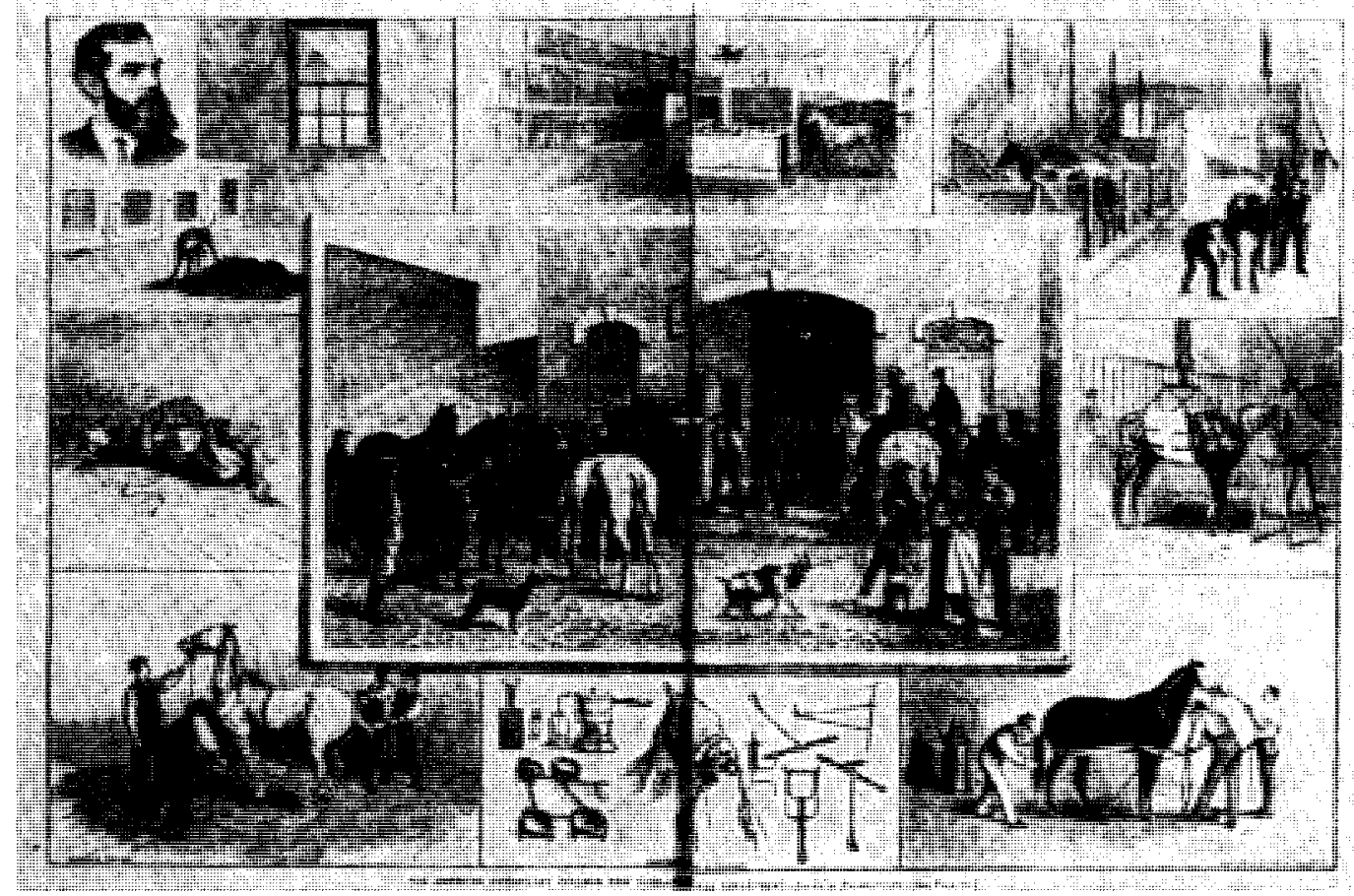

Scene at the American Veterinary College about 1880. Free clinics were held one afternoon a week - despite the fact that the school depended on fees for its operation. Harper's Weekly

ures in the USVMA. For a number of years, I. Michener, as he was invariably known, and his son served side by side as officers in the Association, and he lived to see his son its president. Another son, Curtis, was also a graduate veterinarian, and a third son a physician. It was no idle boast of his that none of the men who had apprenticed under him had failed to make good in practice.

When in his seventies he was honored at the 1891 meeting as:

one having served fifty and more years in the everyday work of the profession, in the hard and laborious duties of a rural practice ... honored and revered by all his profession.

In responding to this accolade, Michener recalls, concerning deliberations over naming of the Association in 1863:

several names were suggested, one of which I remember was "Veterinary Association," which was vigorously opposed, because the vets. of
Philadelphia had a short time before a meeting that a reporter attended and the next day published that he had attended a vegetarian meeting and all their talk was about horses. . . . I then suggested the name of "United States Veterinary Medical Association," which was adopted.

After recounting some of the advances made by the Association, he ruefully admits that in his native state the law provided that:

any one who has ever removed the placenta from a cow or found a soft place in her tail to cut into to let the wolf out, shall be entitled to register [as a veterinarian].

Having outlived his son Charles, he died in June, 1899, after having served more than sixty years in the veterinary profession.

\section{EMERGENCE OF A LEADER}

The meetings for 1875 were held in Boston and at the American Veterinary Col- 
lege-newly formed under Liautard's leadership by secession from the New York College of Veterinary Surgeons. For a considerable period the American Veterinary College - through the influence of Liautard - served as a more or less unofficial headquarters for the Association, with committee and other meetings being held in Dr. Liautard's office.

An appropriation was made for the monument to Claude Bourgelat, and it was ordered that two prizes be given each year for the two best papers on any veterinary subject. Authors of the winning essays were to have their choice of a medal, or books, or instruments, to the value of fifty dollars. The Prize Committee consisted of A. Large, J. H. Stickney, and C. P. Lyman, but it soon became apparent that there was little competition for the prizes.

For the first time in its history, the USVMA admitted a "large" group of new members - numbering 25 per cent of the active membership. The eleven men admitted included two future presidents of the Association: Charles P. Lyman and Charles Michener; also, A. Lockhart, C. H. Stocker and John Meyer, Jr., the latter destined to become the first fifty-year member of the Association. And for the first time a majority of the elected offices (other than the Board of Censors) were filled by other than charter members of the Association: vice president, T. S. Very; recording secretary, J. D. Hopkins; and corresponding secretary, C. P. Lyman. Alexandre Liautard was elected president, and Charles Burden was re-elected treasurer for the seventh time - a position he was to hold for another nine years.

\section{A. Liautard}

Alexandre Francois Liautard, V.M., M.D., eighth and fourteenth president of the USVMA, was born in Paris in 1835 , and graduated from Toulouse in 1856 . Without doubt his coming to America was a signal event for the veterinary profession, for perhaps more than any other one individual it was he who held the USVMA together during its early years. One of the founding fathers, he was the only one of this select group of forty to hold an elective office for more than twenty years in succession. J. H. Stickney was his only contender with seventeen years of consecutive service as an elected officer. In addition, many of the meetings of the Association were held at either the N.Y.C.V.S., or at the American Veterinary College after he became its head - and undoubtedly upon his invitation.

In 1877 he became editor of the American Veterinary Review and, after resigning this post in 1881 , became its proprietor and publisher as well when the Association tendered him the journal. Always strong-willed, he apparently preferred to run the Review without supervision. Moreover, while he continued a staunch friend of the Association, he also became free to criticize it, which he did in no uncertain terms - and continuously - but in a constructive manner. Undoubtedly his biting satire was a major factor in stimulating the Association to perform at an ever increasing tempo. After he severed his financial interest in the Review in 1900 and returned to France, he continued in effect as senior editor for another fifteen years. After purchase of the Review by the Association, he continued a monthly feature until his death in 1918 - a stretch of forty-one years during which he contributed regularly to American veterinary literature.

$\mathrm{His}$ record as an educator was no less outstanding, despite the fact that the American Veterinary Review is his permanent monument to posterity. It was his hand that made the faltering New York College of Veterinary Surgeons a going institution, but when internal affairs became untenable, he withdrew with most of the students to form the American Veterinary College in 1875. This school remained a vital force in veterinary education for the twenty-five years he was its head, a substantial number of the future leaders of the profession coming from the ranks of its graduates. 


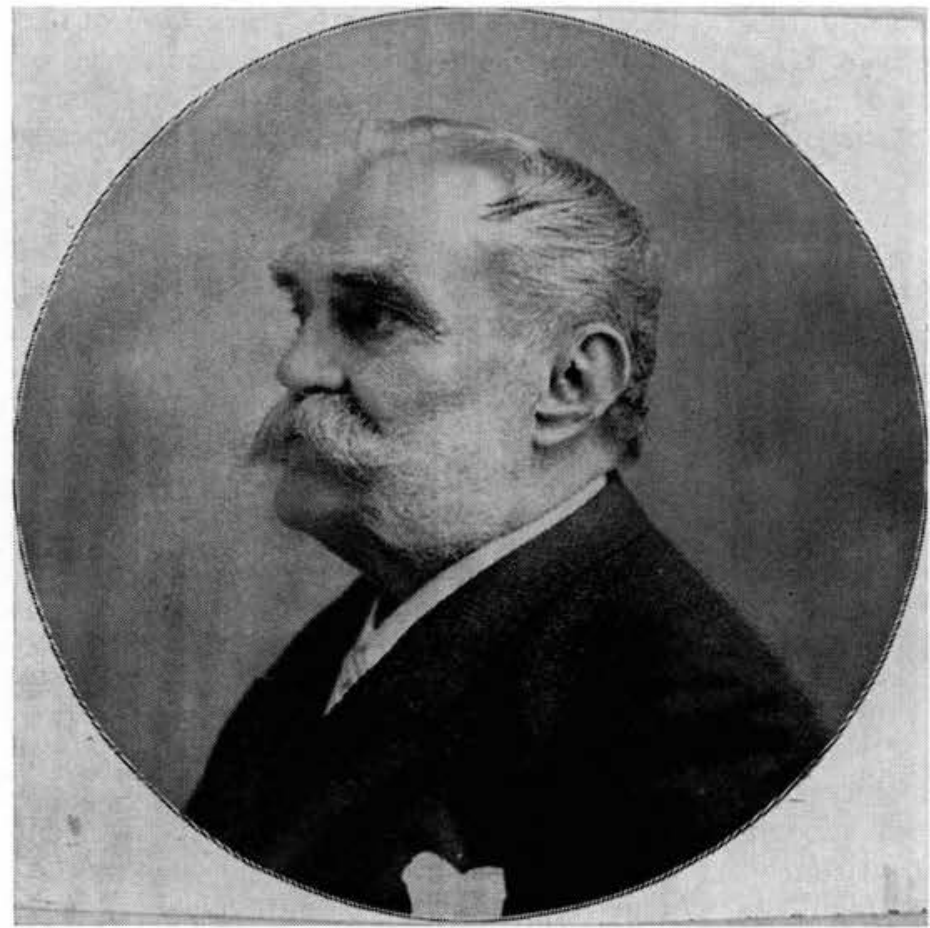

Alexandre Liautard, v.S., M.D. (1835-1918), during his forty years of residence in this country (1860-1900), probably did more to advance the several fields of veterinary medicine practice, education, journalism, and association work - than any other individual. USVMA Proceedings

Like other mortals, of course, Dr. Liautard was not without his faults. While his continuous advocacy of higher standards for veterinary education undoubtedly was a major factor in this becoming a reality, he continued to hold his own school to the old two-year course-possibly at the insistence of a major part of his faculty. Although he lived in the United States for forty years and amassed a small fortune, he never became a citizen. For much of his life here he was referred to affectionately as "Frenchy" by his closest associates - although perhaps not to his face.

He was characterized as:

very fatherly with his students, stern, and yet intimate, without allowing familiarity. Severe and friendly, strict to all and demanding of each the exact performance of his duties, he was very much liked and yet feared more or less by all. His death in 1918 was an occasion for mourning by the veterinary profession in all parts of the world.

One of his students, J. W. Fink, who graduated from New York University in 1900 after this school had taken over the combined A.V.C.-N.Y.C.V.S., recalls sixty years later:

The American Veterinary Review was his last personal tie, and he supervised every line therein. He watched us as we wrapped and addressed them, and it always seemed as if he wanted to write a personal note to every veterinarian who received a copy. No detail was too small to escape his notice, and he regarded all of us as "his boys." When he left, there was a great void at the college.

Few men could hope to live so long in the memory of their students.

\section{6}

In addition to the regular meetings for 1876 in Boston and New York, a special meeting was called in April at Springfield, Massachusetts, at which an effort was made to prepare a veterinary exhibit for the Centennial Exposition to be held in Philadelphia. Nothing, however, seems to have come of this, but there was a department of "farriery," sponsorship uncertain, at the Exposition. This was to comprise: 
a complete and thorough display of all that pertains to Farriery and Veterinary Science. Under these heads will be included, besides horse-shoes and nails, clipping and shearing machines, pads, boots, \&c., surgical implements, bandages and appliances, horse, cattle, and poultry medicines, skeletons, anatomical specimens of diseases, and other illustrations of veterinary science, and also the publications and appliances of the Society for the Prevention of Cruelty to Animals.

Such was the concept of what constitued veterinary science in this enlightened age!

At the Boston meeting $\mathrm{E}$. T. Thayer presented a paper on "Epizootic Aphtha," and C. P. Lyman one on "Internal Disinfection." At the annual meeting held at the American Veterinary College, Henri Bouley of France and George Fleming of England were elected to honorary membership, the first foreign veterinarians to be accorded this honor. The officers of the previous year were re-elected.

It was resolved that a journal be printed semiannually by the Association, to be called the American Veterinary Review, with Drs. Liautard and Lockhart as editors. It was to cost members fifty cents per volume, the deficit to be made up from Association funds.

The meeting was adjourned to meet at the Continental Hotel in Philadelphia ten days later, where papers were presented on the "History and Progress of Veterinary Medicine," by A. Liautard; "Zymotic Diseases, and the Duties of the Veterinary Surgeon," by James Law; "The Effects of Stimulants in Disease," by A. A. Holcombe; "Sanitary Measures in Preventing Diseases in the United States and Canada," by D. M. McEachran; "Chronic Lameness in Horses," by T. S. Very; and "Fistula," by E. T. Thayer. This cross-section of reterinary thought of the time was printed in the first issue of the Review.

\section{History of Veterinary Medicine}

Liautard's history, a paper of 14 pages, is of particular interest as the first significant contribution to American veterinary history. Concerning the exhibits at the
Centennial Exposition, he regretfully notes:

in this great show of the new world, where everything is represented, where every science, art and trade has its place, Veterinary Medicine alone is absent. No matter if it prevents diseases, restores health, improves breeds of animals, regulates sanitary measures, protects trade of animals: no matter, if this immense fortune of $\$ 1,600,000,000$ owes much of its existence to veterinary art, to comparative medicine, in our Centennial buildings, in our exhibition, there is nothing pertaining to it. ...

And why is this? Why is there no provision made in this Country to protect the live stock? With few exceptions there is no one ready to oppose the ravages of an epizootic. All our animals are thus left exposed to all the dangers of disease, and that because with all its importance amongst all professions, the Veterinary is the only one, which has been sadly neglected in America, and which in this year of our Centennial Celebration has made the least progress.

In presenting his history of the profession in America, Liautard expresses the lament of veterinary historians ever since "the lack of documents or records to be looked into," but:

I have carefully looked into periodicals, agricultural, scientific and even sporting papers ... that I [might] lay the foundation for a better history, to be written when our profession will occupy amongst Americans the place where it ought to be-second to none.

Dr. Liautard begins with a cursory survey of veterinary matters in America to about 1850 , and follows this with a rather detailed account of the beginnings of veterinary education in this country. His account of the Dunbar incident in Congress relative to the shoeing of Army horses gives considerably more details of this interesting and - in retrospect - amusing incident in our history.

Of considerable interest is his detailed account of the efforts in 1870 of $\mathrm{A}$. W. Stein, M.D., Professor of Physiology at the N.Y.C.V.S., to secure recognition of the veterinary profession by the American Medical Association. After much discussion, a resolution was adopted by the AMA call- 
ing for its influence to be used in the establishment of veterinary schools, the appointment of veterinarians to boards of health, and their employment by the Army and the Agricultural Department. The latter item, however, was not adopted until a clause calling for "rank and pay of other medical officers" was deleted. In 1872 , Stein was successful in obtaining a resolution by the AMA calling for a committee to study diseases:

transferrable from animals to man ... to prevent the extension of such diseases to man ... and what sanitary measures can be effected to arrest the progress of such diseases in animals.

Little action, however, would appear to have been taken upon the matter.

\section{7}

The meetings for 1877 were again held in Boston and New York. A committee was appointed to petition Congress concerning the enactment of more stringent laws for preventing the introduction of disease by the importation of cattle from foreign countries. And in a paper on "Spinal Meningitis," A. A. Holcombe urged the necessity "for the elevation of the profession that our knowledge of the pathology of certain diseases should be improved . . by careful and exact research."

It was resolved to publish the American Veterinary Review monthly, and that the faculty of the American Veterinary College be added to the editorial staff. Dr. Liautard was given a free hand to spend "an amount of money for advertising said $R e$ view," and a special assessment of the membership was made for unpaid dues and subscriptions to the Review.

Elected as the new slate of officers were C. P. Lyman, president; Williamson Bryden, vice president; A. A. Holcombe, secretary; and Charles Burden, treasurer. Five new members were admitted, including John Meyer, Sr.

The Committee on Intelligence and Education was directed to take steps toward calling a convention of teachers in

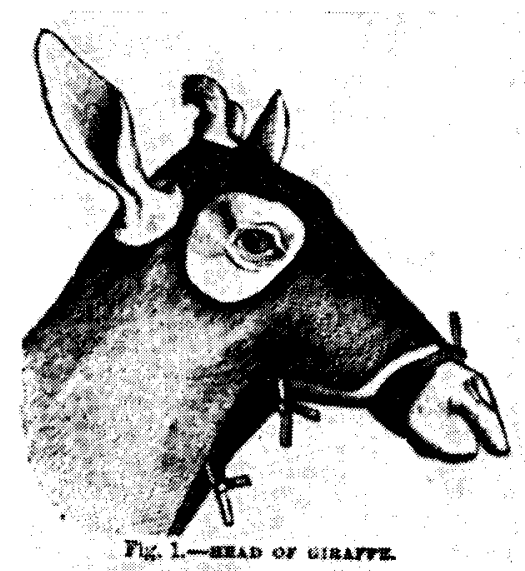

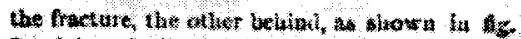

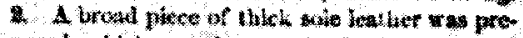

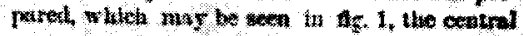

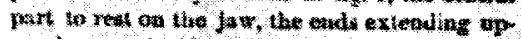

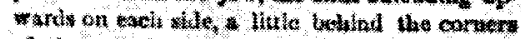

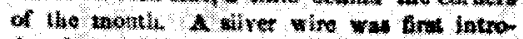

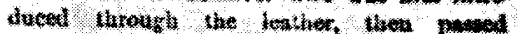

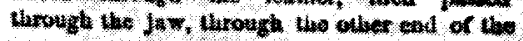

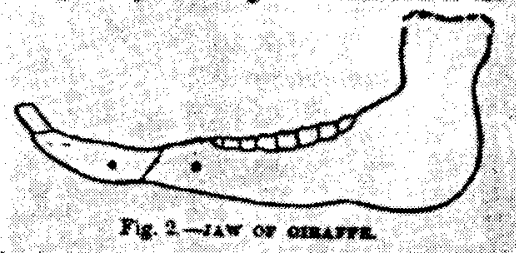

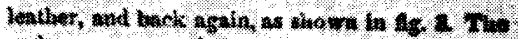

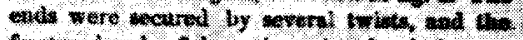

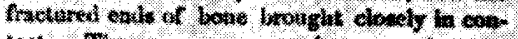

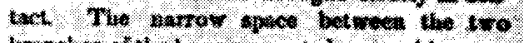

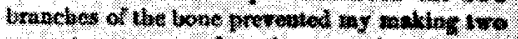

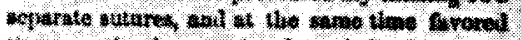

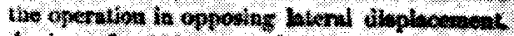
A

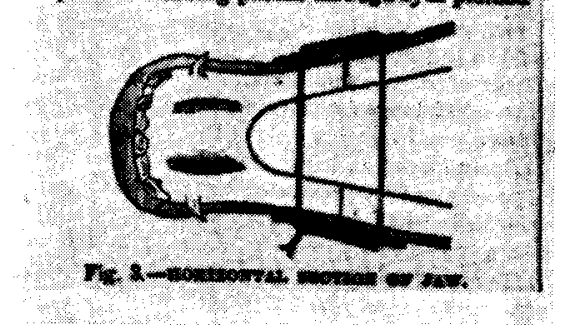

Liautard's repair of a fractured jaw of a giraffe belonging to $P$. T. Barnum attracted a good deal of attention in the 1870 's. Silver wire was used to unite the fractured segments, and a leather hood was devised for immobilization; the animal recovered. American Agriculturalist 
the various veterinary colleges of the country for the purpose of improving the standard of veterinary science and the curriculum of the colleges.

In his address as retiring president, Dr. Liautard called attention to the progress which veterinary medicine and surgery had made, of which "the birth of the American Veterinary Review was the most important of them all."

\section{8}

Boston and New York were again the sites for the meetings in 1878. Communications regarding the proposed Congress of American Veterinary Colleges were received from the American Veterinary College, Cornell, Toronto, Montreal, and the University of Illinois in which each seemed afraid they would be called upon to meet with representatives of some college in disreputable standing. Such a convention being unlikely to succeed under the circumstances, a committee was charged with continuing efforts to effect such a meeting.

At the semiannual meeting, Alexandre Liautard reported on the condition of the American Veterinary Review, and requested the privilege of increasing its size and reducing the subscription price from $\$ 5.00$ to $\$ 4.00$, which was granted. Apparently dissatisfied with the restrictions placed by the Association upon his management of the Review, at the annual meeting Liautard expressed a wish to resign the editorship. Evidently there was no one better qualified to run the publication, and he was unanimously re-elected editor "and instructed to select such assistants as he chose, and to conduct the $R e$ view in whatever manner would in his best judgement conduce to its success."

Reading between the lines, it is apparent that this situation was precisely what Liautard wanted - as a preliminary step toward gaining full control of the Review. In this he can hardly be accused of desiring more than the satisfaction of conducting the Review as he saw fit, for it is probable that the publication never made much money-certainly much less than Liau- tard could have made by devoting the same time to his practice. From the standpoint of sound management, it perhaps did not occur to the membership that with the editor having to depend upon annual re-election to the post, that incentive might be lessened by the knowledge that his position was at the potential mercy of a small group. It seems likely, however, that his fears would have been unfounded.

In his report as chairman of the Committee on Education, Liautard observes:

Our people are ignorant of what constitutes the elements of education of the veterinarian, and that for the public as yet, our profession, the business of a horse doctor, of the cow leech, of the gelders, are all the same. The veterinary education of the people, then, is, I think, a subject which is worthy our attention and deserving some of our efforts. . . The most powerful means of educating the people is the press ... and if the press is the means of educating the people as to the requirements of veterinary surgery . . . what veterinary science means ... veterinary education will have made a powerful go-ahead step . . . but I say it is not the gratuitous advice which may be found filling up column after column in the pages of some of our best papers by which we will educate the people on veterinary science.

Professor D. M. McEachran of Montreal was elected to honorary membership, and eleven new members were admitted, including J. F. Winchester, who later became president of the Association. With the admission of twenty-seven new members in three years, it is evident that the fortunes of the Association were looking up. The officers of the previous year were re-elected.

Papers were presented on "Spavin" by Wm. Bryden; on "Parenchymatous Injections" and on "Melanemia" by A. Liautard; and on "Acute Inflammation of the Air Passages and Pulmonary Emphysema" arising from smoke inhalation, by A. A. Holcombe.

\section{P. Lyman}

Charles Parker Lyman, F.R.C.V.S., ninth president of the USVMA, was born about 


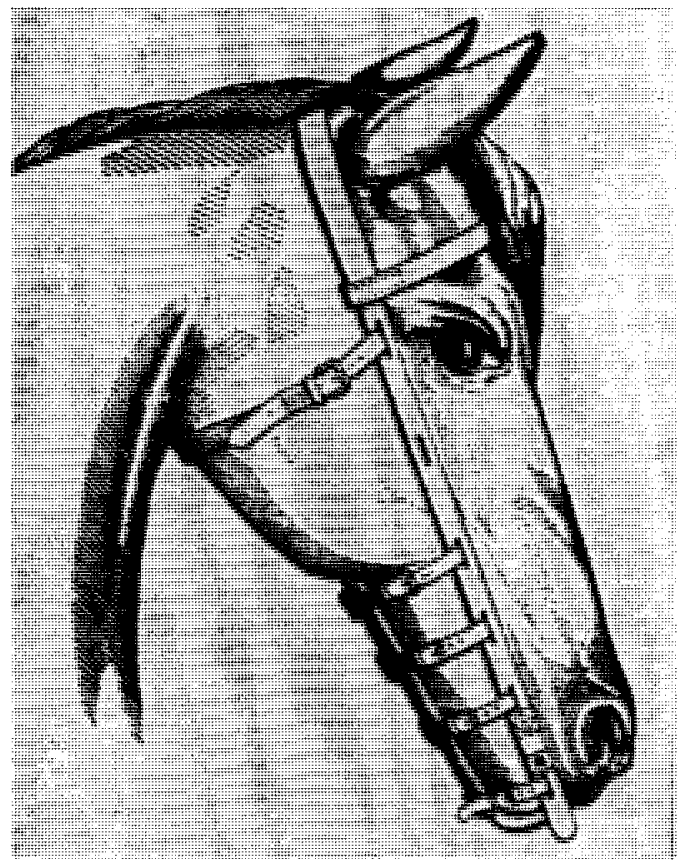

Splint for mandibular fracture. With good nursing care, including feeding via dose syringe, the prognosis was usually considered favorable. Liautard: Surgery

1848 and received his veterinary degree at Edinburgh in 1874, becoming a Fellow of the Royal College of Veterinary Surgeons in 1880. He served as Professor of Veterinary Medicine in the Agricultural College of Massachusetts for a time, and from 1879-1881 investigated pleuropneumonia for the USDA in the United States and England.

In 1882 he became Professor of Veterinary Medicine in the Veterinary Department of Harvard University, and the first dean of this school in 1886, retaining both positions until the school closed in 1901 . In 1895 as a member of the Massachusetts Cattle Commission he is credited with sponsoring compusory tuberculin testing.

Dr. Lyman joined the USVMA in 1875 , and was elected president 1877-1879, the first who was not one of the founding fathers. He seems to have dropped from notice after the school at Harvard closed, and the veterinary journals do not even record his death, which occurred in Cali- fornia, February 1, 1918, at the age of 70 . A son, Richard P. Lyman, was the first Dean of Veterinary Medicine at Michigan State University.

\section{9}

At the meetings for 1879 , held again in Boston and at the American Veterinary College, four new members were admitted, including W. B. E. Miller, who was later president of the Association. It was voted to pay to the secretary an annual honorarium of $\$ 20$. The Committee on Prizes reported that two essays had been submitted, but that neither was worthy of a prize.

A committee was appointed to draw up a set of resolutions to be presented to Congress in relation to the investigation and prevention of contagious diseases of domestic animals. Following two later meetings, a petition was drawn up, and 600 copies were printed and sent to members of Congress, to the heads of departments of the government, and to members of the Association.

Papers were presented on "Contagious Pleuro-Pneumonia," by J. D. Hopkins; "Rupture of the Flexor Metatarsi," by A. Liautard; and on the recurring theme of "Cerebro Spinal Meningitis," by I. Michener. Elected as the new slate of officers were: president, J. L. Robertson; vice president, J. H. Stickney; secretary, A. A. Holcombe; and treasurer, Charles Burden.

As a gentle rebuke to veterinarians who did not support the USVMA, Dr. Liautard added to an announcement of the annual meeting:

This being the only Veterinary Association representing the national interests of veterinarians in the United States, its meetings should command the attention and attendance of every member of the profession. It could and should exercise a potent influence in the advancement of veterinary science ... by seeking to elevate the standard of veterinary education, the development of educational reresources, and the investigation of contagious diseases.

At this time, and for a number of years following, the membership constituted only 
a small proportion of the profession - perhaps .10 per cent - and attendance at meetings rarely exceeded twenty-five or thirty persons - fewer than were present at the organization meeting in 1863 . The available records indicate that perhaps not more than a hundred men had been admitted to membership (including the founding forty), and the years had begun to take their toll - both by death and delinquency - with the result that the Association numbered only about sixty-five members.

In noting the action of the Association to petition for establishment of a National Veterinary Bureau, the Medical Record had observed:

the present status of Veterinary Medicine is so undefined that a National Bureau would not have much more of legitimate professional basis than a National Bureau of Barbers to keep themselves informed upon sycosis.

This, together with other deprecatory statements and misstatements, brought a wrathful reply from "A Veterinarian" (Liautard?), who observed (among other comments in stronger language) "the virtue of the medical profession is not entirely above reproach."

What the USVMA petition had called for was:

a Veterinary Sanitary Bureau, whose duty it shall be to advise Congress as to what measures shall be necessary to control, restrict, or eradicate any contagious or infectious disease affecting the domesticated animals.

Specifically mentioned were lung plague and Texas fever, for which "Congress is ... requested to appropriate a sufficient sum of money to enable the Veterinary Sanitary organization to deal at once and effectually with these important matters." When legislation to this end was introduced, it met initial defeat at the hands of Texas legislators, who, in effect, were successful - temporarily - in legislating Texas fever out of existence.

\section{The McLean Mélange}

The case of Lachlan McLean, a noted practitioner and veterinary sanitarian, pre- sents an interesting commentary on some of the intramural affairs of the USVMA. In considering the qualifications for new members in 1878, the secretary presented "a communication from L. McLain [sic] of Brooklyn declining the honor of becoming a member of the Association," whereupon, "A. Liautard M.D. moved that the name of L. McLain be erased from the roll in accordance with his desire." Robert Wood expressed the opinion: "Mr. McLain ... had intentionally slurred the U.S. Veterinary Medical Association and deserved to be rebuked." This led T. S. Very to move "that before Mr. McLain can again become eligible to membership in this Association he be required in some way to apologize for his action." From remarks of Dr. Wood, it would appear that McLean had objected to the inclusion of nongraduate members; Wood contended, "conferring a diploma did not make a gentleman of the recipient nor necessarily a good practitioner, and ... every man should be respected for his own worth."

In 1879 McLean applied for membership, along with his son, Roderick, whereupon J. L. Robertson suggested that the Association:

recognize his application now, as sufficient apology for anything which he might have said in the past ... we ought out of consideration for Mr. McLean's ability in the Profession, recall the vote of censure.

T. S. Very, who had offered the original motion "took pleasure now in moving that the said motion now be rescinded," which was done unanimously. However:

Before balloting for L. McLean, Dr. Hopkins made a speech in which he objected to the election of the candidate on the ground that he had personally treated the objector in an unprofessional manner. ... On taking a ballot the candidate was rejected by a vote of 14 yeas to 9 nays.

Secretary A. Holcombe then moved a reconsideration of the vote, "claiming that it was unjust to reject a candidate recommended by the Board of Censors and Comitia Minora, because he was objected 
to by one member ... on grounds purely personal." This carried, and another vote resulted in McLean's election. Later during the meeting, Dr. McLean's first participation in Association matters was to move that the price of the Review be reduced from $\$ 4$ to $\$ 3$ for students. Dr. McLean became a faithful member of the Association and was elected president in 1885.

\section{A. A. Holcombe}

Allen Anderson Holcombe, D.V.S., was born in Bucks County, Pennsylvania, August 16, 1850. Earlier a student under I. Michener, he attended the N.Y.C.V.S., and graduated from the American Veterinary College in 1876. In 1877 he was elected secretary of both the New York State Veterinary Society and the USVMA. In 1880 he was appointed inspecting veterinarian at Ft. Leavenworth; he resigned his army position to become successively, State Veterinarian of Kansas in 1884, Territorial Veterinarian for Wyoming in 1890 , and Bureau of Animal Industry inspector at Chicago (1899) and Boston (1918). He died of a heart attack while conducting a tuberculin test on August 13, 1920.

$\mathrm{He}$ was a leading figure at Association meetings for many years, contributed extensively to the Review, and was a staunch champion of higher status for the army veterinarian. He was described by his associates as "a man of great personal charm, a brilliant conversationalist and widely informed on a great variety of subjects - a thinker, always ahead of his time."

\section{0}

The meetings for 1880 were held - as usual - in Boston and New York. Fifteen new members, including the stormy petrel, F. S. Billings, were admitted. Papers were read on chloral hydrate anesthesia, by $\mathrm{C}$. H. Peabody; on veterinary education, and on osteosarcoma, by A. Liautard; on alcohol and belladonna in treatment of tetanus, by T. Outerbridge of Bermuda; Lachlan McLean presented specimens of shoes used in treatment of spavin; and tenotomy, embolism, and soundness were discussed.

Dr. Liautard noted that the Review was free of debt and was increasing in circulation. The propriety of paying an honorarium not to exceed $\$ 25$ for original articles was left to the editor. Liautard tendered his resignation as editor - as he had twice previously-but the matter was tabled.

As chairman of the Committee on Education, Liautard moved that his earlier motion calling for an examination of candidates for membership be rescinded, and:

that the different veterinary schools of the country, through their Board of Trustees and Faculty, be urged to increase their requirements for matriculation, to lengthen the course of studies, and to have a board of examiners, taken from the regular graduates through the country, to act with the Faculty at the examination for graduation.

Under these conditions, the candidate's diploma would serve as a voucher for admission to the Association. Although (according to Liautard) "several of the members ... expressed their hearty approval of the suggestions... the report of the committee was accepted and placed on file," without action being taken.

J. L. Robertson was re-elected president, and Charles Burden, treasurer; $\mathrm{O}$. $\mathrm{H}$. Flagg and C. B. Michener were elected vice president and secretary, respectively.

\section{J. L. Robertson}

James Lindsay Robertson, V.S., M.D., D.V.S., tenth president of the USVMA, was born about 1842, and graduated from the New York College of Veterinary Surgeons in 1867 and from the Medical Department of the University of the City of New York in 1869. After interning he joined the faculty of the N.Y.C.V.S., and in 1876 secured a second veterinary degree from the American Veterinary College, whereupon he became Professor of Theory and Practice at A.V.C., later at the combined N.Y.-A.V.C. After forty years of teaching 
and practice, he had been retired as professor emeritus at the time of his death on November 26, 1913.

Dr. Robertson joined the USVMA in 1868 , and served as its secretary 1869-1874, and as president, 1879-1881. Dr. Liautard called him "my boy," and of him it was said, "His thorough knowledge of his subject and his kindly nature won the hearts of all whose privilege it was to have been his students."

\section{1}

The meetings for 1881 were again held at Young's Hotel and at the American Veterinary College. At the Boston meeting, a lengthy communication from A. A. Holcombe was read in which the status of the Army veterinary service was detailed, "asking the support of the Association in making the veterinarian's position in the army what it should be." As a result, a Committee on Army Legislation was appointed; although it may be doubted that this first committee exercised much influence, it was the beginning of Association efforts on behalf of the Army veterinary service.

The now-perennial matter of Liautard's resignation as editor of the Review was brought up, and as reported by the secretary, C. B. Michener:

In view of the increasing demands made upon the time of the editor of the American Veterinary Review, the society decided to present the journal to Prof. A. Liautard, without any encumbrance, as a slight recognition of the work he has done for the Association and profession at large.

What the real motives of Liautard or the Association may have been in this matter are, perhaps, not amenable to analysis, but it is likely that the Association had little choice in the matter. It is evident that in three years the Review had become a more powerful influence than had the Association in the eighteen years of its existence - something which Liautard well recognized. Moreover, with the Review as a private enterprise, he had no obligation to follow Association policy, and - for the undoubted benefit of the Association - he became one of its strongest critics, but in a constructive manner. Taking everything into consideration, it would seem feasible to postulate that Liautard wanted the prestige and freedom of action this move gave him. Earlier, he had to depend upon annual re-election as editor $-\mathrm{a}$ tenuous position at best.

In one of his first pointed rebukes, Liautard charges:

This association has now been in existence for eighteen years, and what work of any advantage to the profession can it boast of? . . . The profession is said to count about seven or eight hundred members in its ranks, and yet the USVMA counts only sixty-eight members. . . . Are the conditions of admission so rigid that any worthy practitioner cannot be admitted? Why is it that the meetings are so deficient in professional discussions, and so lamentably remarkable for the absence of papers of acknowledged importance?

Liautard's criticism is perhaps a little too harsh. Earlier the USVMA had petitioned for legislation aimed toward the eradication of animal diseases, particularly pleuropneumonia, and while there seems not to have been continuing pressure from the Association itself, a number of its prominent members were active in prosecuting the cause. Certainly, it was the work of these men which in large part laid a substantial framework for the eventual establishment of the Bureau of Animal Industry.

The newly elected officers were president, Williamson Bryden; vice president, Lachlan McLean; secretary, C. B. Michener; and treasurer, Charles Burden.

\section{2}

The affairs of the USVMA reached a low ebb in 1882, when at the Boston meeting it was rather euphemistically reported:

Fully one-third of the members were present [about two dozen], two new members were elected, and the regular committees had no reports to offer.....E. F. Thayer presented 
some remarks on an osseous nasal polypus which he successfully removed in $1867[!] \ldots$. The discussion following on the use of the wire ecraseur [introduced by Jennings in the 1850 's ] was of much interest . . . The meeting then adjourned to dinner, after which the subjects of splenic fever, Texas fever and quittors were discussed.

At the annual meeting - as usual at the American Veterinary College - the officers of the previous year were re-elected - as usual. Whether Liautard's earlier charge that the main fault of the Association was in its officers was directed at Wm. Bryden in particular is a moot point, but it is obvious that little transpired during his tenure as president. However, bowing to custom, his re-election was reassured.

As something in the nature of a rebuke to the regular committees, which had nothing to report, Dr. Liautard, as chairman of the Committee on Diseases, states:

Being unexpectedly called to Europe this summer . . . I was almost tempted to give up the work and follow the example of our friendly predecessors and only report "progress," but at the same time thought that in so doing I would do injustice to our friends and to the Association.

Accordingly, he had distributed one hundred copies of a questionnaire to members in twenty-nine states; thirty replies from fifteen states were returned. In order of frequency of mention, the most common diseases were equine influenza, glanders and farcy, anthrax, Texas fever, hog cholera, chicken cholera, and cerebro-spinal meningitis.

As reported by Secretary Michener:

Dr. Liautard then introduced the subject of inoculation for anthrax. He also presented to the society the different instruments chiefly used in inoculating cattle and sheep. Anthrax blood and virus were shown in hermetically sealed tubes [virus was then used as infective agent ]. Prof. L. suggested the appropriation of society funds for experimental purposes. It was afterward resolved that a committee of three be appointed to make experiments on the value of inoculation by the method of Pasteur, and $\$ 150$ was appropriated for the purchase of some sheep and cows for this purpose. Dr.
Liautard was appointed chairman of the committee, with power to select the other two members.

Although a pre-convention notice had stated: "There is no doubt that besides the reports of the various committees, several interesting papers will be presented," the secretary's report of the meeting states, "There were no reports [by three of four committees], and ... there were no regular papers presented." Drs. Stickney and W. B. E. Miller presented two cases of osteomalacia, but:

other reports of cases were denied the Association owing to the lateness of the hour. The society adjourned to a banquet at Delmonico's, where the evening was passed in the most social and pleasant manner.

Thus it is evident that the Association was in the doldrums at this time; except for Liautard's report on diseases in the United States, and his account of Pasteur's anthrax inoculation, the annual meeting for 1882 would have been something less than productive. And concerning the committee Liautard was to head, no report was made the following year, except that "it seemed almost unnecessary to investigate the Pasteur method, since it is so generally admitted that this is entirely successful." The American Veterinary Review, however, under Liautard's management, continued as the chief external evidence of the developing veterinary profession.

Most of the early original articles in the Review were in the nature of case reports or summaries of existing knowledge of diseases. The first bona fide report of experimental investigation appeared in April, 1882, on "Cestode Tuberculosis. A successful experiment in producing it in the calf," by William Osler, M.D., of McGill University, and a student, A. W. Glement, later president of the USVMA.

\section{Wm. Bryden}

Williamson Bryden, V.S., eleventh president of the USVMA, was born in Scotland and came to this country when a small boy. 
He graduated from the Montreal Veterinary College in 1871 and served as a member of the board of examiners of that school for a number of years. He was a charter member and president of the Massachusets VMA, and served as president of the USVMA, 1881-1883. For many years he was an inspector of cattle at the port of Boston. Upon his death June 28, 1895, he was characterized as "a good friend and ever ready adviser . . . of marked intelligence, and an able student and practitioner."

\section{AN EXPANDED SPHERE OF INFLUENCE}

The meetings for 1883 were held in Boston and at the American Veterinary College. Among the twenty-one new members admitted was W. Horace Hoskins, later secretary, then president, and a longtime stalwart of the Association. Dr. Liautard was appointed to represent the USVMA at the International Veterinary Congress in Brussels. Various case reports were presented, including one by Robert Harrison, house surgeon at the American Veterinary College, on a cesarean section in a cow in which both cow and calf lived. Julius Gerth, Jr., reported on an outbreak of glanders in Newark, New Jersey, "in which he censured the State Board of Health for not taking some steps to eradicate or quarantine the disease." Dr. Gerth, as a member of the Newark Board of Health, is credited with handling the outbreak, an apparent consequence of which was his appointment as State Veterinarian of Nebraska.

Elected as the new slate of officers were president, W. B. E. Miller, of New Jersey; vice president, W. J. Coates; secretary, C. B. Michener; and treasurer, Charles Burden. The election of Dr. Miller was the first major break in the monopoly exercised by a coalition of Massachusetts and New York members with regard to the major offices of the Association. Earlier, J. D. Hopkins of New Jersey had served as secretary (1874-1877), but the real break did not come until 1887. Prior to this date, thirteen of fourteen presidents, seven of eight secretaries, and all five treasurers had been from New York or Massachusetts. During the second twenty-five years this number was reduced to six of thirty-four major offices, and to a scant 10 per cent during the second half century.

In an editorial in the Review for July, 1883, Liautard mentions that a number of the "western" states - Illinois, Wisconsin, Iowa, Michigan, and Ohio - were in the process of calling state veterinary conventions:

to organize and discuss the subject of the advance of veterinary science. This great move cannot be ignored; and it is to be hoped that the West shall not remain alone in it. The Eastern States . . . ought to form their State Associations; and when once each State in the Union has her State Veterinary Medical Association, how easy it will be for all to unite under a grand body, the American Veterinary Association.

While it is probable that Liautard was aware of more than he alludes to, his suggestion concerning an "American Veterinary Association" is more than a little puzzling. He, of course, knew full well that the USVMA did not in fact represent the veterinary profession of the entire country and that "western" veterinarians were dissatisfied with the situation. That he may have suggested this second association primarily as a threat to jar the USVMA into action is intimated by his later statement:

Already a large nucleus for such an organization exists. ... It will be to the United States Veterinary Medical Association that these State societies will naturally attach themselves.

The real facts, however, never did see the full light of day in the Review. In November, 1882, the United States Veterinary Journal, presumably edited by $\mathbf{A}$. $\mathbf{H}$. Baker, co-founder of the Chicago Veterinary College, appeared. The real promoter, however, was T. E. Daniels, a printer, who evidently had conceived the idea of organizing the American veterinary profession 


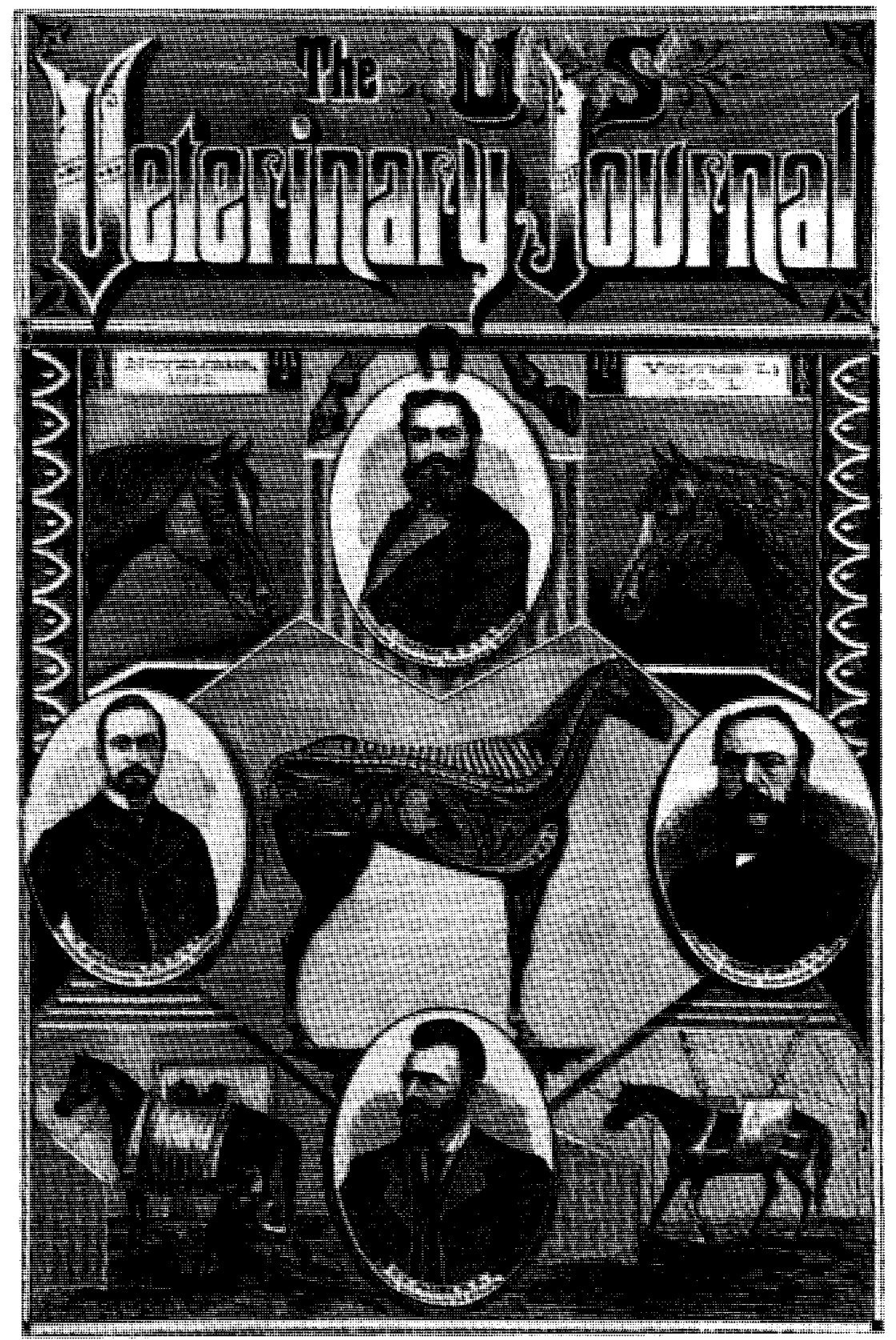

Cover, first issue of U.S. Veterinary Journal. Dr. Liautard strongly objected to the unauthorized use of his picture - which probably implied his endorsement of this rival to his own American Veterinary Review. Library, New York State Veterinary College. 
and publishing its official organ as a profitable enterprise. He was successful in getting state associations organized in Illinois, Indiana, Michigan, Ohio, New York (in competition with the existing state society), and Missouri, for which associations his journal did serve as the official organ until its demise in November, 1884.

A more insidious part of his schemethe tip-off perhaps being the title of his journal - was that this new national group was to be named the United States Veterinary Medical Association. One of the arguments used by those who had urged incorporation of the USVMA soon after its founding was that any group could incorporate under this name and deprive the de facto USVMA of its right to the name. But even with this as a real rather than a merely potential threat, the Association was not incorporated until 1916. Daniels' plan did have one strong point: his national association was to be governed by delegates chosen by the state associations the same plan adopted by the AVMA half a century later.

\section{W. B. E. Miller}

William B. E. Miller, D.V.S., twelfth president of the USVMA, was born in 1840 and claimed Camden, New Jersey, as his home. In 1879 he graduated from the American Veterinary College, following which he rapidly gained a wide reputation. He was among the first to attempt the standing operation for castration, and was well known for his technic with cryptorchid horses; to demonstrate these and other operations he travelled many hundreds of miles. He was a trustee of the American Veterinary College, one of the first inspectors of the Bureau of Animal Industry, president of the New Jersey VMA, and in 1883-1885, president of the USVMA. He died in 1905 .

\section{4}

At the semiannual meeting held in Boston, a major topic of interest was the recent outbreak of foot-and-mouth disease at
Portland, Maine, in cattle imported from England. Following a discussion of the matter, R. S. Huidekoper - who was elected a member at the meeting - offered a resolution:

That it be the opinion of this Association ... that the United States quarantine authorities are, through carelessness and incompetency, responsible for the spread of the infection.

This may seem like harsh judgement for a group of men sitting in Boston to pass upon their colleagues working in Maine, but at least it was made in the presence of G. H. Bailey, Commissioner for Maine on Contagious Diseases. Earlier, Dr. Bailey had reported in the Review:

The herd was inspected on board ship by U.S. Commissioner Thayer, and, being pronounced free from disease, were allowed to land. By some oversight, or misunderstanding between the United States officials here, and the agent of the Grand Trunk road, the animals - instead of being transported by cars - were allowed to be driven over the public highway through Portland and Deering to their destination at quarantine.

After the cattle were placed in quarantine, several mild cases of foot-and-mouth disease - first diagnosed as "foul in the foot" - broke out, and the disease was communicated to a number of cattle which had been driven over the same trail.

Drs. Melvin and Mohler, in recounting the history of foot-and-mouth disease in the U.S., state that this outbreak was "comparatively insignificant ... and restricted to only a few herds, so that the dissemination of the virus was quite easily controlled." This experience, however, did result in the adoption of more stringent regulations and was the last outbreak of foot-and-mouth disease to result from the importation of diseased animals.

For the first time in the history of the Association, the annual meeting was held outside of Boston or New York - at the Grand Hotel, Cincinnati. J. H. Detmers newly elected a member-moved that the 


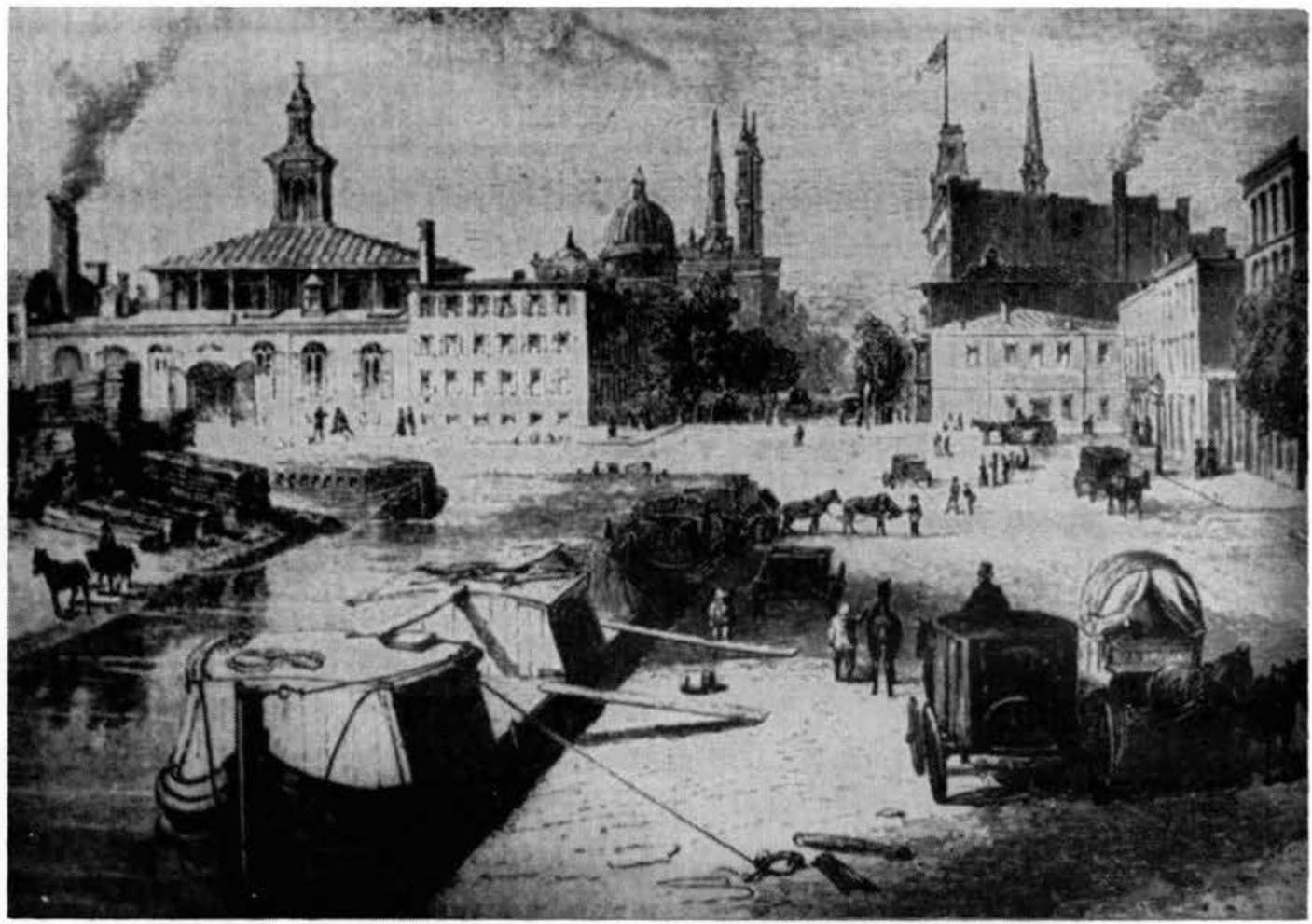

Scene in Cincinnati a short time prior to the USVMA meeting there in 1884, first "western" meeting of the Association. Contemporary print

American Veterinary Review be made the official organ of the Association, but:

secretary C. B. Michener strongly condemned any such action on the part of the Association, and held it to be unwise to make any journal the official organ of an association that knows no special school or set of men. . . This sentiment was heartily endorsed, and Dr. Detmers cheerfully withdrew his motion.

At this time, of course, the Review was closely identified with the American Veterinary College.

Dr. Liautard urged "that veterinarians be compelled to report all cases of contagious diseases," but Detmers objected: "unless the State first recognized the veterinary surgeons." Liautard then offered a resolution - which was carried - that the USVMA:

suggest the obligation on the part of veterinarians and veterinary practitioners to report to the proper authorities every and any case of contagious disease he may meet in his practice, in the same manner as the human practitioner is obliged to do so in his specialty, under the liability of penalty for punishable offenses.

A committee consisting of Drs. Hoskins (A.V.C.), Howe (Toronto), and Bryden (Montreal) was appointed:

to confer with the faculties of the veterinary colleges and schools of North America as to their willingness for a convention of the same, to discuss the advisability of adopting a mutual standard of excellence on examination.

The officers of the previous year were reelected, except that L. H. Howard of Boston was made vice prsident. About the only concession to "western" veterinarians was the enlargement of the Board of Censors from five to seven - to include John Meyer, Sr., of Cincinnati and W. J. Crowley of St. Louis. The secretary's salary was increased from $\$ 20$ to $\$ 50$ a year. 
In a paper entitled "What we have been - What we may become," D. J. Dixon notes the failure of the Association to double its original membership of forty in twenty years:

in the face of more than a thousand practitioners in the country at the present time. . . . [This] gives ground for the charge that has sometimes been advanced, viz: that while the institution was respectable, and contained many leaders of the profession in this country, it is lethargic and approaching decline.

One solution, he suggests, would be to create eastern and western divisions, each with its own corps of officers, and the USVMA as a "central society," which would call "congresses of the profession" at stated intervals. Perhaps in the knowledge that a competitive society was being talked about, this plan created some interest and a committee was appointed to investigate its possibilities. Nothing, however, seems to have been issued in the way of a report on the matter.

\section{5}

The meetings for 1885 were again held in Boston and at the American Veterinary College. The proposal made at Cincinnati for eastern and western divisions of the USVMA was discussed but any action was held in abeyance. The matter of "time wasted at many of our meetings over trivial points, and also the disposition of some members to occupy the floor to the exclusion of many others," was decided in favor of "short speeches from all members." Later the constitution stipulated a limit of ten minutes for discussion of a point by an individual member.

Frank S. Billings presented a discussion and demonstrated pathological lesions of pneumonia and pleuropneumonia, a number of his contentions being contested by Drs. McLean and Liautard. Dr. Liautard supplemented the prize of $\$ 50$ offered by the Association for the best paper presented with the offer of a gold medal. In so doing he expressed hope that the "usual" report of the Prize Committee: "no paper; no prize; no report," would not be repeated. A committee was appointed to petition for better recognition of Army veterinarians. Among the subjects discussed were intratracheal and intravenous medication, polyuria, castration, euthanasia, nymphomania, tuberculosis, and azoturia. H. T. Yokura of Japan, an A.V.C. graduate, was made a member.

Charles Burden was honored on his retirement as treasurer of the Association, which position he had held for sixteen years. This record for continuous tenure in an elected office was not surpassed until 1935 when M. Jacob completed his seventeenth year as treasurer. The new slate of officers included: president, Lachlan McLean; vice president, J. B. Cosgrove; secretary, C. B. Michener; and treasurer, J. L. Robertson.

In commenting on the east-west schism, Dr. Liautard editorialized in reference to the Cincinnati meeting:

The change in the plan of meeting has no doubt produced amongst veterinarians of the West a more harmonious feeling toward their brother practitioners of the East than before existed, and it is to be hoped that this fraternal sentiment will be strengthened at the coming [New York] meeting. From letters that have reached us we derive abundant evidence that the division that existed on account of the formation of a new so-called "National" body is likely to subside.

However, following the meeting in New York, where "a very harmonious and friendly feeling prevailed," Liautard observed: "Whether it was a great success may be a question difficult to answer. ... This meeting ... . was just like preceding ones."

At the meeting, several papers offered by the Committee on Diseases "were, by vote, ordered to be published," i.e., apparently they'were not read at the meeting. This action evoked a strong letter from James D. Hopkins, Territorial Veterinarian for Wyoming:

I am deeply mortified at the apathy displayed by the Association at the last annual meeting, as well as the lack of interest of vet- 
erinarians, in regard to ... the necessity of wholesome sanitary laws and their enforcement for the protection of domestic animals. ... You can imagine my surprise to know that the Association adjourned without reference to any question whereby the profession might have benefitted, or the public served through a discussion of the sanitary condition of its domestic animals.

\section{McLean}

Lachlan McLean, M.R.C.V.S., thirteenth president of the USVMA (1885-1886), graduated from the Edinburgh Veterinary College in 1854 and qualified as a member of the Royal College of Veterinary Surgeons in 1880. After practicing in Scotland for a time, he came to Canada in the employ of the British Government. Later, he moved to the States, and in 1866 founded the Brooklyn Veterinary Hospital, where he practiced until 1914. At this time the hospital was not only the oldest in continuous operation in the United States, but during McLean's 48-year tenure he kept it open 24 hours a day and was reputed to have never refused a call.

In 1879 he was appointed a special Veterinary Inspector on the Board of Health of Brooklyn, apparently the first such appointment in the country. His efforts in this post were rewarded two-fold, for in 1884 the post of Veterinary and Food Inspector was created, along with the position of Assistant Inspector - which was filled by his son Roderick after a competitive examination conducted by Dr. Liautard and four physicians. The elder McLean outlived his son, with whom he also practiced, by twenty-five years, and died at the ripe old age of 94 about 1920 .

Concerning his work, he urged in 1885:

The practice of some Boards of Health, in employing medical men to do the work of the veterinary sanitarian, is not creditable to either profession. . . Let our profession so advance that we will be considered an indispensable part of every well organized department of health, for not alone local but also national interests depend upon the vigilance and painstaking of the qualified veterinary sanitarian.

\section{6}

Although a quorum was present for the semiannual meeting for 1886 in Boston, it was discovered that proper notification had not been made, and thus while technically there was no meeting, the day was spent in the presentation of cases and papers. The annual meeting was held at the Rossmore Hotel in New York, where about forty members from six states were present. Dr. Liautard, upon whose invitation (or insistence?) the meetings had been held at the American Veterinary College in late years, expressed surprise that:

this selection was made in preference to one of the numerous appropriate halls, where similar scientific bodies are accustomed to find accommodations. ... Why a room was not engaged in the Academy of Medicine . . . or why the lecture rooms of one of the two veterinary colleges of this city were overlooked is not very clear to the minds of all the members. ... In any case it proved to be a fairly interesting meeting ... very much like its last predecessor, the time being almost wholly occupied in discussing the business of the Association.

Seventeen new members were admitted, including $\mathrm{W}$. H. Lowe, a future president of the Association. It was voted to appropriate $\$ 100$ toward erecting a monument in honor of Henri Bouley, the late eminent French veterinarian. The Committee on Education was empowered to spend up to $\$ 150$ for its work; and a $\$ 50$ prize was awarded for an essay by Tait Butler. At this time the treasury of the Association contained about $\$ 700$.

Dr. McLean, on retiring from the chair "regretted that individual members took so little interest in the welfare of the Association, and did so little to advance the profession." On this matter, it is of some interest to note the situation which developed over the awarding of the prize to Dr. Butler, this supposedly being a function of the Prize Committee. Although the two contending papers had earlier been published anonymously in the Review, it was decided to have them read at the meeting: "as the committee... not to be out of 
the fashion ... had failed to report, and ... a number of the members present had not read the articles." After voting on the papers and finding the winning one to be by Tait Butler:

a rather unpleasant surprise was experienced by a portion of the members when the fact was learned that the successful essayist was not an American but a Canadian graduate, nor a member of the Association. There was, however, no alternative - the situation must be accepted.

Fortunately, the rules governing the prize stipulated only that the essayist be a veterinarian, for Butler's paper on "Parturient Apoplexy" was a masterpiece. And it may be surmised that this incident helped lead to a fuller appreciation of the interdependence of the veterinary professions of Canada and the United States. In his paper, Dr. Butler notes: "There is perhaps no disease to which bovine flesh is heir concerning the etiology and pathology of which there is less definite knowledge and greater diversity of opinion." And in presenting an effective rebuttal to the theory of F. S. Billings contending that milk fever in cattle is identical with parturient eclampsia in women, he observes:

the wholesale system of adoption [of human medical theories ] practised by many writers on veterinary medicine has led to grave and unpardonable errors, and has been chiefly instrumental in bringing about a lack of independence of thought and original investigation.

It is perhaps not too invidious to note that while Butler, who had graduated from the Ontario school only a year before, later became president of the AVMA, Billings was shortly expelled from membership for, among other things, voicing his untenable opinions in an unbecoming manner.

Dr. Liautard, who had served as president of the Association in 1875-1877, was again elected to this office. Wm. Zuill was elected vice president, and Drs. Robertson and Michener re-elected treasurer and secretary, respectively.

Just what the geographical distribution of the full membership of the USVMA still under the hundred mark - might have been at this time would be difficult to determine. The listing of forty-one officers and committee members (duplications excluded), however, does offer some suggestion. New York with ten and Massachusetts with five still dominated the field. Pennsylvania, Connecticut, and Ohio had three each; New Jersey and Illinois two each; and there was one each from Maine, Maryland, Delaware, Washington, D.C., Rhode Island, Alabama, South Carolina, Indiana, Nebraska, Missouri, Minnesota, Wisconsin, and Wyoming Territory.

The degrees held by this group are of some interest: twenty-five had the D.V.S. and thus were mostly AVC graduates, four having an M. D. as well; ten had a V.S., two with an M.D. also; six were British graduates (M.R.C.V.S.), one of whom (C. P. Lyman) was a Fellow of the Royal College. Liautard was a French graduate; no nongraduates appear to have held office or committee assignments.

\section{7}

By comparison with most of the semiannual meetings, that for 1887 held at the Veterinary Department of the University of Pennsylvania was a beehive of activity. The question of admitting nongraduates to membership was discussed; at the annual meeting it was decided thereafter to admit "only graduates from professional schools." The Association also voted unanimously to recommend a uniform matriculation examination, a minimum of three college terms of six months each, and a common examining board for all graduates. Thomas Bland, the last nongraduate to be admitted (1887), died in 1933.

In response to a discussion of the pleuropneumonia problem by D. E. Salmon, it was noted:

most of the members expressed their belief in the mediate [i.e., indirect] contagiousness of contagious pleuropneumonia, and all condemned inoculation so long as the possibility 


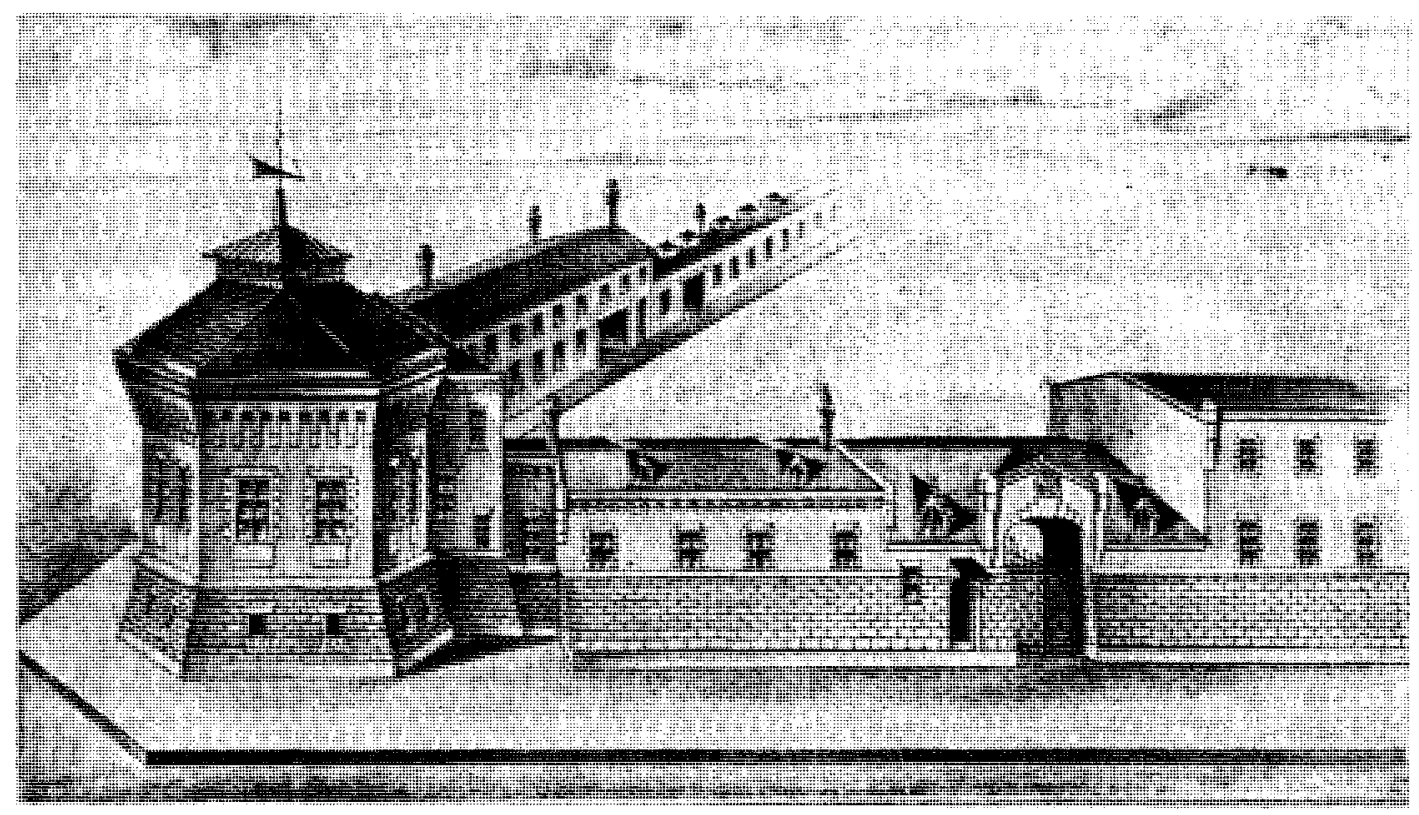

Architect's drawing of original building housing the School of Veterinary Medicine, University of Pennsylvania, 1884. University of Pennsylvania Bulletin

of extermination of this disease exists by means of slaughter of diseased and exposed animals.

Resolutions to this effect were passed, as was one commending the work of the Bureau of Animal Industry.

On the subject of bovine tuberculosis, it was resolved:

That the attention of all Boards of Health throughout the country be called to the necessity of a rigid and competent inspection of all milk dairies and slaughterhouses. . . . [and] That all Boards of Health should have attached to their staff qualified veterinarians to carry on such inspection.

Drs. Huidekoper, Winchester, and Salmon were deputized "to publish this action of the Association in circular form and send it to the different Boards of Health of each State and Territory."

At the annual meeting held at the American Veterinary College, the Committee on Diseases reported on the prevalence of chicken cholera, hog cholera, rabies, anthrax, glanders and farcy, tuberculosis, pleuropneumonia, and cerebro-spinal meningitis.

Elected as the new slate of officers were: president, R. S. Huidekoper; vice president, J. C. Meyer, Jr.; secretary, C. B. Michener; and treasurer, J. L. Robertson. Among new members admitted were Tait Butler and D. E. Salmon.

In editorial comment upon the Philadelphia meeting, Dr. Liautard observed that it:

varied from the custom of former meetings in proving to be an interesting and highly profitable meeting. ... The good that such gatherings might always accomplish . . . if the membership could but be brought to realize their duty to each other and to the community, are well illustrated by this meeting and its results.

Regarding the proposal to admit only graduates:

The time has fully come when the Association should make an effort to establish itself as the representative of the regular profession, and abolish the custom of begging for membership, which has already too long prevailed.

Contrariwise, Liautard realistically criticized the bill presented by the Committee on Army Legislation which urged the rank of Colonel for a veterinarian as "a project 
which can hardly hope to command success."

At the annual meeting, however:

Nothing, absolutely nothing, was done. . . The committees ... failed to report anything of value ... and after an unprofitable and insignificant discussion on the nature of cerebro-spinal meningitis the meeting adjourned.

Much of the time, apparently, had been taken up with what terminated in "an unconstitutional vote" to accept a prize essay which had been rejected by the Committee on Prizes. Earlier, Liautard had suggested that failure of the Association to discharge its obligations might be charged to the officers. As its president for the year just past, how much blame for the 1887 meeting he accepts for himself he does not intimate.

\section{Choleric Controversy}

The great hog cholera controversy between Salmon and Billings was raging at this time. In 1887, the Review purported to publish "communications on the subject ... from the pens of Dr. Billings [70 pages] and Dr. Salmon [4 pages]." And while Liautard deplored "the feelings of hostility which have been generated," he perhaps was smarting a little over Salmon's reproving him for stating that rouget (hemorrahagic septicemia) and hog cholera were identical, and that the means existed for preventing both by inoculation.

On the basis of six months' work, Billings had declared hog cholera "was not contagious ... [but] was a local disease," and asserted, "The time will surely come when either Salmon or I will have to take a back seat ... and the world will know who is right, honest, and consistent." Liautard, whose espousal of Billings' cause was already tending to damage confidence of the profession in the work of Salmon and the BAI, avers: "Dr. B. does good work, and deserves well for his labors on behalf of the profession." But concerning Billings' "diffuse and bombastic writings," Salmon observes: they are the product of a disordered brain. If the edtiorials of the Review are based upon such literature. ... I must occasionally interpose with a mild objection.

Time has proved who was "right, honest, and consistent."

\section{F. S. Billings}

Frank S. Billings, long the gadfly of the American veterinary profession, was born in Massachusetts in 1844, and obtained his veterinary degree with honors at Berlin in 1878. He was well known here through his frequently caustic contributions to the American Veterinary Review before joining the USVMA in 1880. Associated with the American, Chicago, and McGill schools at various times, he achieved his greatest notice and notoriety while at the University of Nebraska, where he claimed to have found the infective agents of hog cholera and Texas fever. In announcing his untenable claims, he vehemently disputed the classic work of the BAI, and forced Dr. Salmon into an extended and needless defense of the Bureau.

In 1890 Billings was expelled from the USVMA for his ungentlemanly attacks upon the veterinary profession in general and Dr. Salmon in particular. He retired to practice in his native Massachusetts in 1892, but continued his warfare with the BAI and the USVMA, practically until his death in 1912. An outspoken advocate of veterinary participation in public health matters, his activities in this area are considered under this heading.

\section{SILVER JUBILEE}

Following on the heels of the highly successful meeting in Philadelphia, the semiannual meeting for 1888 in Baltimore was adjudged "the best and most fruitful in useful results of all that have hitherto been held." Evidently this set the stage for making the Association more truly representative of the veterinary profession by moving the meetings from place to place. At least beginning with the Philadelphia meeting, no two consecutive conventions have been 
held in the same city (except in 1945 when a business meeting only was held in Chicago following the regular meeting there in 1944).

The Baltimore meeting was highlighted by two papers from D. E. Salmon; one on "Hog Cholera" reviewed the work of the Bureau, which, despite the inadequate evidence adduced to that time, had produced several truths which still stand: "that hog cholera was a distinct and very different disease from rouget" (hemorrhagic septicemia); the lesions of hog cholera were faithfully described; and hog cholera "is a strictly contagious disease." And regarding Billings' contention on the latter to the contrary, Salmon states, "such as assertion is supremely ridiculous and shows a lamentable ignorance of the modern classification of disease."

In his paper on "Mediate Contagion in Pleuro-pneumonia," Salmon explodes the theory that the disease could be propagated only by direct contact of infected animals, and charges:

The propagation of these erratic views, which under no circumstances can make the measures adopted against pleuro-pneumonia more thorough or hasten the time when the disease will be eradicated, have done much to cause distrust of veterinary counsel and to impede the progress of the work.

A. W. Clement, later USVMA president and State Veterinarian of Maryland, also spoke on this disease.

At the annual meeting in New York, the subject of tuberculosis received considerable attention, with Dr. Zuill, chairman of the Committee on Diseases, referring "very forcibly to the dire need of legislative action relative to the checking of the progress of [this] disease." Drs. Liautard, McLean, and Clements were named:

to draft a series of resolutions, relative to the rapid increase, the dangers from ingestion of meat and milk from tuberculous animals; [and] the need of properly qualified veterinarians, as inspectors of dairies, markets and slaughter houses.

These resolutions were to be sent to the Medical Congress in session at Washing- ton, D.C., and to all state and national boards of health. Also noted was "the dangerous extent of glanders and farcy in certain localities, particularly parts of Pennsylvania."

Concerning the meeting, Liautard states:

The meeting of 1888 was remarkable for its quietness, its somnolence - in fact, the torpid condition which seemed to prevail... But three members were present of the number of those whose names had been signed on the roll of $1863 . \ldots$ The most important action of the meeting was, we believe, the disposition made of the suggestions of Drs. L. McLean and Liautard, to delegate a committee to the meeting of the American Medical Association in order to call the attention of that body to the prevalence of tuberculosis in the United States, and to suggest means of guarding against its dangers.

Dr. Huidekoper was re-elected president, and Dr. Robertson, treasurer; C. B. Michener retired as secretary and was succeeded by W. Horace Hoskins; D. J. Dixon was made vice president. The matter of ethics appears to have become a live issue; two members were expelled "for violations of the Code of Ethics," and two men were refused admission "on the grounds of unprofessional conduct."

\section{R. S. Huidekoper}

Rush Shippen Huidekoper, M.D., V.S., was born at Meadville, Pennsylvania, May 3,1854 . He graduated from the Medical Department of the University of Pennsylvania in 1877, whereupon he engaged in medical practice. In 1881 he studied veterinary medicine at Alfort, France, and worked in the laboratories of Virchow, Koch, Chaveau, and Pasteur. A descendent of Benjamin Rush, who in 1806 had urged the establishment of a veterinary school at the University of Pennsylvania, Dr. Huidekoper became the founder of this school in 1884 and served as its dean for five years. In 1889 he moved to New York and served on the faculties of the American Veterinary College and the New York College of Veterinary Surgeons.

During the War with Spain, he served as Chief Surgeon of the First Army Corps - 
as a result of which he was abused by the press as a "horse doctor." Afterward he was active in promoting better recognition of the military veterinary service. Of especial significance is the report that he spent many thousands of dollars of his private fortune in promoting legislation for the improvement of the Army veterinary service. It is a matter of record that shortly before his death he not only personally enlisted the support of many army officers, but at his urging, some 6,000 veterinarians wrote their congressmen! The result of this was that a bill calling for commissioned rank passed the House despite disapproval of the administration and the Committee on Military Affairs. Except for an untimely insistence on a separate Veterinary Corps - vigorously opposed by the War Department - it is practically certain that the bill would have passed the Senate. This was a high point in a long struggle for recognition of the Army veterinarian; with the death of Dr. Huidekoper before the next session of Congress, sentiment in favor of improved status was reversed.

Twice elected and re-elected to the presidency of the USVMA (1887-1889, 18901892), Dr. Huidekoper was the only man to be so honored. A man of independent means, he taught and served the veterinary profession for the sheer love of it; he is credited with originating laboratory and practical instruction for veterinary students in the U.S. The author of two books and numerous articles, he also served as editor (and picked up the deficit) of the Journal of Comparative Medicine and Surgery from 1886 to 1901 . He died in Philadelphia on December 17, 1901 following an attack of pneumonia.

W. H. Hoskins relates an incident characteristic of the rich sense of humor displayed by his friend Huidekoper, whose famous mare, Pandora, was not allowed to come to an ignominious end at the rendering plant:

Almost as famous in death as she had been in life, there will ever remain the oft-told story of how he entertained his friends at a sumptu- ous feast at the famous Philadelphia Club. It was known as the Pandora dinner, and given in her honor to many of those who had rejoiced with him at her many triumphs. After the dinner had been served, and the cigars and coffee reached, he told his guests of the several courses in the feast, where the tenderloin and giblets of Pandora's flesh had been so skillfully and tastefully prepared. It was always a source of regret on his part that a flash light picture could not have been taken of the faces of his guests when they realized that they had dined on horse meat.

\section{9}

At the semiannual meeting for 1889 , the last to be held in that favorite mecca, Young's Hotel in Boston, it was recommended - and adopted at the annual meeting "that this Association shall hereafter hold only one meeting yearly." Tuberculosis was the major subject for discussion, with Dr. Liautard calling for:

some means of arousing public sentiment to the importance and grave dangers of this disease. .. . Veterinarians should in their States and respective localities use more freely the channels of the public press, to aid them in at least limiting its progress, and Iessening its evils.

\section{Lachlan McLean suggested:}

If the milk cans from some of the herds infected with tuberculosis were labelled "consumption at eight cents a quart," it would not be putting it too strong, and would probably arouse the people from their state of lethargy.

Concerning a paper by Dr. Liautard on "Recording Clinical Observations," Secretary Hoskins observes:

The advice and suggestions it contained were fraught with great value to the coming generation of veterinarians, if followed by the present, in building up through the channels of records of clinical cases, a literature for the veterinary world that would broaden and increase its value to an inestimable extent.

At the annual meeting in Brooklyn, the forty new members admitted exceeded the attendance of current members. Undoubtedly the most significant matter acted upon was the adoption of a completely revised 
constitution which had been in preparation for some time. A contemporary analysis indicates:

It has placed stronger safeguards around its future list of members, and laid a just responsibility on each of its members' introducing for consideration new candidates for membership. It has changed its meetings from two to one, this . . . to last two or more days, and no step in its history ever promised greater benefit. . . It means better papers, better reports; for the members will be guaranteed a fuller hearing and more deliberate enforcement of plans suggested for the general good of the profession. It promises a wise stimulus for different sections of the United States to compete for its meetings, and this means a greater membership and a more diffuse interest in its work throughout our whole country.

The Board of Censors was made appointive rather than elective as it had been.

Not only would it seem that much of the impetus for a revised constitution had come from President Huidekoper, but, along with Drs. Lyman and Robertson, he was charged with:

the organization of a central legalized body, [which] may prove one of the means of making future meetings of our Association the source of all national movements and work of the profession.

And upon his relinquishing the presidency of the Association, it was said of Dr. Huidekoper: "He leaves its affairs better than he found them." Undoubtedly it was in recognition of this fact that he was later accorded this honor for a second - and unprecedented - two-year term.

Charles B. Michener was elected president, and A. W. Clement vice president, with Drs. Hoskins and Robertson being reelected secretary and treasurer, respectively.

\section{The Quarter Century}

In his address as outgoing president, Dr. Huidekoper reviewed the first twenty-five years' work of the USVMA. Although he notes, "it is to be regretted that we have not a record of many of the transactions," his paper is perhaps the sole remaining readily available source for certain facts pertaining to the early history of the Association. He notes:

Some meetings were replete with papers ... other meetings... have been devoid of any public interest. ... For the future... we should take more accurate notes of cases and prepare papers and present them here... The improvement of the education of our successors is a serious duty we have to perform... The improvement of the position of our colleagues in the army offers a subject of national importance in which we all must aid. .. . We have a great deal to accomplish, but it can be done if we work together and are industrious.

Dr. Hoskins' summary of Huidekoper's address is fairly pointed:

He did not believe that the work of representing the profession in the United States had been as fully performed as the responsibility demanded, neither did he think that the field had been properly covered or the national question of importance to the veterinary world so handled as to make the Association a force and power in the country. His resume bristled with just criticism, and its study and consideration by each member should be weighed, and better results will be brought forth in the next quarter of a century.

If we look at the reverse side of the coin for positive achievements of the USVMA, admittedly these are few up to this point. Perhaps of primary significance is the fact that the organization had survived to celebrate its silver anniversary. It had made its stand on a number of national issues, including the need for a national veterinary sanitary bureau, improved status for the army veterinarian, and higher standards for veterinary education. The American Veterinary Review, although it had since passed into private ownership, undoubtedly was its most substantial contribution to the veterinary profession in terms of concrete accomplishment. 


\section{American Veterinary Review}

With the founding of the American Veterinary Revicw in 1877 a new chapter in the history of veterinary medicine in America was begun. That this was no hastily considered move may be appreciated from the fact that at the fifth semiannual meeting of the USVMA in 1868, a committee consisting of Drs. Liautard, Large, Stickney, Thayer, and C. M. Wood was appointed "to investigate the subject of printing a veterinary journal."

\section{MISSION OF THE REVIEW}

At the thirteenth annual meeting in 1876 it was resolved:

That a Journal be printed by the Association, semiannually, January and July lst, to be called the American Veterinary Review, A. Liautard and A. Lockhart, Editors, to cost each member fifty cents per volume, balance of the expense to be paid from the Association funds.

The reception of the first issue of January, 1877, was such that in March it was resolved: "That the American Veterinary Review should be published monthly and that the faculty of the American Veterinary College be added to the editorial staff." The subscription price was made $\$ 5.00$ a year, and monthly publication began with the April issue, with Liautard as editor, and Drs. Large, Robertson, and Holcombe as assistants.

As stated by Liautard:
It is our intention not to have our periodical limited to the report of cases or discussion of papers; but to embody in it any subject which is connected with veterinary science, and therefore, we will try to furnish our readers with articles of interest to the Veterinarian, to the Agriculturalist, to the Legist, and to the Sanitarian; leaving our columns open to all who may be interested in the elevation of veterinary medicine in America, and with the hope of receiving their kind support and assistance.

The editors of the British Veterinary Journal hailed with "unfeigned pleasure" the advent of the Review, and stated:

From the manner in which the two numbers have been presented to the public, and the excellence and interesting character of their contents, we may safely predict a full measure of success to our young contemporary.

Later, at the fourteenth annual meeting of the Association, retiring president Liautard called attention:

to the progress which Veterinary medicine and surgery had made during that time, and said he believed the birth of the American Veterinary Review was the most important of them all. ... It was born to the Association upon the year of the hundredth anniversary of the birth of the nation .... and is receiving favorable notice at the hands of English, French, and German Veterinarians.

A retrospective view confirms Liautard's opinion. As put by Merillat and Campbell: 


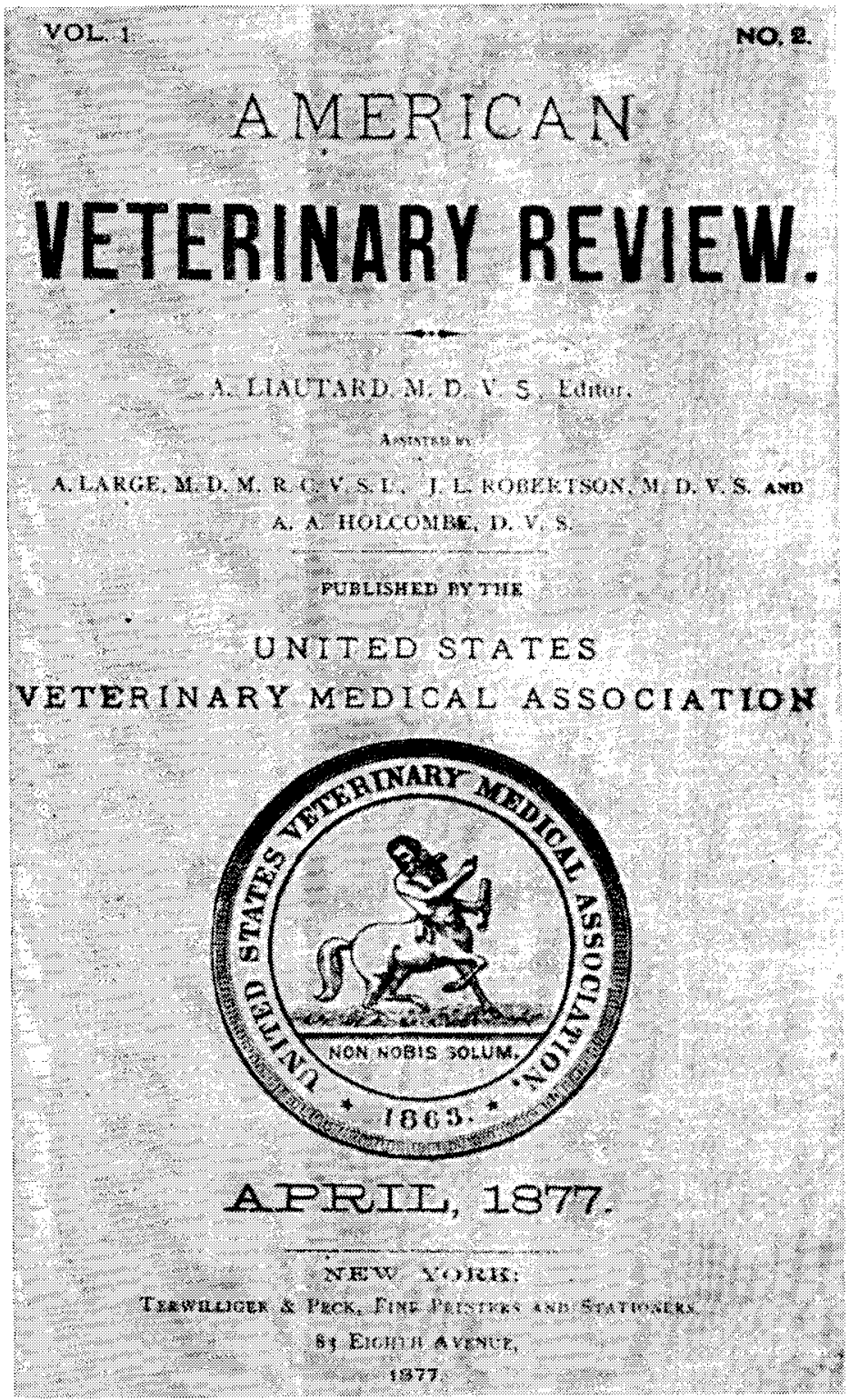

The American Veterinary Review, with Alexandre Liautard as editor, was established in 1877 as the official organ of the USVMA but three years Iater reverted to the editor as a private venture until it was purchased by the AVMA in 1915. Michigan State University Library
Its influence upon the trend and the development of veterinary medicine in this country for 30 years was not equalled by anything else. ... In fact, the Review very largely influenced the policies of the association and to a considerable extent, those of the schools also. The American Veterinary Review constitutes Doctor Liautard's greatest contribution to veterinary medicine in the United States.

Certainly, for the furst ten years or more, the Review was more representative of the
American veterinary profession than any other institution, and it is undoubtedly true that its influence was in large measure responsible for the increasing leadership exercised by the Association. The Review not only was a repository for the history of the American veterinary profession; it created history by bringing to veterinarians in this country a new philosophy and new goals to work toward. Also, it is more than mere conjecture that the lack 
of a public voice had been a major factor in the Association failing to become a major power sooner than it did. A profession without an official journal is like a city without a responsible newspaper; its citizens are deprived of a powerful medium for civic improvement.

In March, 1877, Dr. Liautard reported on the first issue of the Review, published in January. The first edition of 150 copies had been exhausted, and a second printing of 250 had been made, the total printing cost being $\$ 180$. A total of 183 copies had been distributed, of which 105 had been paid for. With $\$ 45$ being received for aclvertising, this left 217 copies and a deficit of about $\$ 90$. Undaunted, it was recommended that the Review be published monthly. In 1880 the cost of printing the Review was $\$ 706$, and $\$ 724$ was taken in from subscriptions. Considering the fact that the Review had been sustained almost entirely by Liautard - without remuneration - it was perhaps fitting that it should have been tenclered to him "as a slight recognition and respect of the labor he has done for us, and the profession at large."

While it is true that, as charged by Merillat and Campbell "Prof. Liautard evinced little interest in veterinary matters west of Philadelphia," and contrary to Liautard's denial of the matter, he did permit the Review to speak somewhat more plainly for his personal interes̀ts than for some others, a charge of egotism cannot be fully justified. It is perhaps logical that activities of the American Veterinary College should be aired more fully than some others; at least when case reports were needed to fill pages, he had a convenient place to turn. Less clefensible, of course, was his missionary work on behalf of higher educational standards for others while he failed to push for these at home as actively as he might have. But this came somewhat later; for the first few years the Review maintained a surprisingly cosmopolitan attitude toward the veterinary profession as a whole.

The first volume of the Review contained more than a hundred pages of origi- nal feature articles, some of which came from outside the New York City area, from as far away as Montreal, Toronto, Chicago, St. Louis, and Cincinnati. Actually, relatively few feature articles were of local origin. Feature articles and abstracts translated from foreign journals accounted for another hundred or more pages. A dozen or so pages were devoted to several veterinary associations, and some two dozen to various activities at the American Veterinary College. Some 50 pages were devoted to papers read at the 1876 Association meeting. Case reports, news and sundry items, and editorials accounted for most of the balance of the more than 400 pages of professional matter in the first volume. An obvious deficiency is the lack of anything suggesting experimental research being conducted in America; some of the papers show evidence of keen clinical observation, but there was painfully little truly experimental laboratory work to be reported at this time.

Original articles, other than case reports, of American authorship, dealt with cerebrospinal meningitis, veterinary education, effects of cold, osteoporosis, enterotomy, pyogenic cellulitis, periostitis, rinderpest, spavin, Texas fever, formation of the corpus luteum, rabies, and contagious pleuropneumonia. The subjects of papers read at the 1876 meeting of the Association included the history of veterinary medicine in the United States, zymotic diseases, use of stimulants in disease, chronic lameness, erysipelatous cellulitis, and veterinary sanitary measures.

Perhaps as much as a quarter of the material in the first few volumes was contributed by Liautard, mostly in the form of editorials and translations from foreign journals. A substantial amount of material was contributed by men who were, or who were to become, leading men in the veterinary profession. The first volume contains articles by Duncan McEachran, James Law, D. E. Salmon, C. P. Lyman, E. F. Thayer, C. B. Michener, and F. S. Billings, among others. The physician Osler, later Sir William, also was a contributor. 


\section{Editorial Urging}

Some abstracts from Liautard's editorials in the first volume demonstrate the scope of his interests, as well as the general tenor which he intended to establish for the Review. In succession, he wrote: On Sanitary Veterinary Medicine:

It seems to us that the duty of all veterinarians of the country is to rally together to obtain from our government laws to organize a Sanitary Veterinary Board, for the protection of our livestock.

\section{On Veterinary Surgery:}

Amputations of extremities, which occupy such a large place in human surgery, are far from having the same importance in the therapeutics of animals... only on few occasions and in animals of great value [will] owners run the risks of a doubtful result. Still it can be recommended ... [in appropriate cases].

\section{On Preparatory Education:}

Let all schools on the continent establish the requirements already adopted in the United States, and ignorant people will soon learn that before attempting to be honored with the trust of caring for our domestic animals they must take advantage of one of the greatest institutions of our country, viz: free public preliminary education.

\section{On Professional Status:}

We have in view but one object - the advancement of our profession - and if, by the publication and success of the Review, we can reach that object, if we can draw the Veterinary Science in America from the low standing in which it has been for so many years, our labors will have received their full reward.

\section{On Veterinary Colleges:}

This Continent is large enough to support several institutions of Veterinary Science; and there ought not to be between them any other sentiment of rivalry than that, to benefit as well and as much as possible the guardians of our live stock.

\section{On Veterinary Practitioners:}

If we look upon the number of persons who are engaged in the practice of the treatment of domestic animals, we can divide it into two large classes: - lst, those who, regularly educated for the profession, and graduated in Veterinary Schools, are ... the true representatives of the Veterinary profession; and also, those who ... have by their exertions, by their self studies and observations, brought themselves with honor to the same level as the regular graduates. 2nd. Those who, ignorant and vulgar charlatans and unscrupulous empirics, are by cruel and absurd treatment, by exhorbitant charges robbing the people of their money, and the poor beasts of their lives. . . .

It is true, that between the two classes, one might find a third one - a kind of bastard who belongs to both, while he belongs to neither ... the graduate who covering himself of his garment of regular member of the profession does not hesitate, to satisfy his own purpose, to impose upon a credulous public, by using all the means of the charlatan - but this one we may leave to himself. Give him rope enough, and he will unknowingly use it round his own neck.

\section{On Public Appreciation:}

Our people are ignorant of the importance of Veterinary medicine; our science is yet, and will be for years to come, in a low social standing. These are, undoubtedly, the impressions that the ordinary practitioner will put to himself when thinking of the condition of the profession in the United States. That there is much truth in these sad words no one will deny, but we think that they are exaggerated.

No, we do not believe our people entirely ignorant of our usefulness or our importance. No, the science will not for years to come remain at a low social standing... though the improvement has been slow, still there is no doubt an elevation in the estimation of the people of the Veterinary schools. We are certain this is due, and to the sending off of well deserved graduates we attribute much of the improved condition of the profession. In fact the time is fast coming when the necessity of a diploma or of a lawful credential, will be indispensable to one who intends practicing.

\section{On the USVMA:}

Something more than general business of a large society like the United States Veterinary Medical Association ought to be carried on at a yearly or anniversary meeting. ... In this last meeting [ 1877 ] ... we had nothing . . . and unless the special efforts of the officers of the Association can wake up the spirit of labor amongst the members, we fear the United 
States Veterinary Medical Association will never see again a meeting like the one held in 1876 , and that, though its members may increase, the good that it might do towards the interests of the profession will be of little use.

\section{On a National Veterinary Bureau:}

We need a Sanitary Veterinary Department, with its headquarters at Washington, in the rooms of the Agricultural Department. . . We are only few in the United States, but each of us working in our own sphere can do an immense amount of good work. Let us offer our services for the good of the country, gratuitous, if necessary, to fulfill the positions of Sanitary Veterinary Inspectors. We say gratuitous, for we may then ask from the department which will gain so much by, our work, we may ask it to recognize our services, our indispensable value in the wheels of the agriculture of America by urging the establishment of a National Veterinary Institute on the same plan as those of continental Europe.

\section{On Agricultural Education:}

Agricultural students cannot receive in an agricultural school the education that good veterinarians ought to have, and good as the efforts of the teachers may have been, the result cannot but be the same, viz.: the turning out of so many men scarcely better than empirics.

\section{On Veterinary Societies:}

Veterinary societies are few in the United States, but we consider the duty of every member of the profession to belong to them - not a duty to himself, but to veterinary medicine, to which he belongs. The question is not whether he cares or not; nor whether or no his professional standing and connection will not suffer from his ignoring respectable bodies composed of the majority of well recognized practitioners; but in the condition where veterinary medicine is as yet in the United States, we hold that every Veterinarian, no matter where his professional position; and where can he better do it than in the centre of a scientific society?

Editorials in succeeding volumes rerepeated these themes - with variations and other subjects related to the development of veterinary medicine, the contagious diseases of domestic animals - individually and collectively, veterinary legisla- tion, state veterinarians, etc., etc. Dr. Liautard spoke forcefully and to the point, leading the way-but not by the nose. Despite the fact that he did not become a citizen during his forty-year stay in the United States, he spoke as an American as well as a veterinarian. Speaking "with great pride and an uncontrollable joy," in his greetings from France upon the occasion of the fiftieth anniversary celebration in 1913, he says of the Association, "all of us veterinarians can be proud of her."

\section{Chronicle of the Profession}

The journals of a profession are perhaps the most reliable determinant of the status of the progression at any given time. This is especially true the farther back one attempts to probe into the history of the profession. Great teachers, of course, are revered by their students, and their influence lives on through their disciples who have been attracted by them into the teaching profession. For the most part, however, it is only those who have written texts that have been widely used that will be long remembered by more than their own students. The same is true to an even greater extent of a talented clinician; if he does not record his experiences for the benefit of his colleagues - and for posterity - his talent will die with him. Others will - often all too gladly - chronicle our deficiencies, both large and small, and to a lesser extent our more outstanding accomplishments. But the man who murders his bride gets far more publicity than the man and wife who live happily together for fifty years and contribute several good citizens-rather than a crop of juvenile delinquents - to the community.

Concerning the early career of the American Veterinary Review, Merillat and Campbell state:

It is the principal repository of the struggles, the hopes, the aspirations, the achievements and in short, the progress of veterinary medicine on this continent during the last quarter of the nineteenth century. In its pages we trace the development of veterinary associations, the 
enactment of veterinary practice acts, the rise of veterinary bacteriology, the improvements in surgery, the beginning and extension of anesthesia, the publication of veterinary text books, the establishment and growth of veterinary schools, the refinements of veterinary pharmaceutical products, the introduction of veterinary biological products - in a word, the history of veterinary medicine.

While it is true that the Journal of Comparative Medicine and Surgery (under several titles) also spans this period, perhaps its most enduring value was in the stimulus to greater excellence it afforded the American Veterinary Review. Although the more cosmopolitan and erudite editorial approach of the Journal attracted many noted authors, it was, undoubtedly, ahead of its time, and this fact alone perhaps proved to be its undoing. It never paid its own way, even after becoming a purely veterinary journal under Dr. Huidekoper's brilliant but somewhat erratic editorship in 1890. It was during this time that it became more competitive in content with the Review, but with the editors personally able to assume the annual deficit, there was no necessity of competing for survival by truly serving the requirements of the profession. During this time the Journal did, however, make notable contributions to the cause of veterinary education and the army veterinary service. Earlier, however regrettable it may be, it may be doubted that veterinarians were much interested in sixty pages on "The Comparative Anatomy of the Pyramid Tract" (1886), or eighty pages on the osteology of hawks and herons (1888). A number of physicians would undoubtedly have been interested in the former title, but even an avid bird watcher might not care to assimilate the latter.

A major problem in establishing a new journal, in particular, one new in concept, is that of securing adequate material to fill the pages - and fulfill the mission of the journal - until it obtains the support of a widening circle of authors. Admittedly, a large portion of the early volumes of the American Veterinary Review was essentially an American review of foreign veterinary medicine. This, however, gave the veterinarian in America access to a broad cross section of developments in veterinary medicine - then, even as now. Among the items from abroad reported in the first volume were diagnosis of pregnancy in domestic animals; continuous irrigation in surgical treatment; colotomy for removal of calculi in the horse (successful); the use of oxygen at high pressure in physiological investigation ("space medicine" $\dot{a}$ la 1877); histology of the mammary gland of the cow; and castration of cows.

\section{What's New}

Although the early volumes contain little suggesting reports of veterinary investigations in America, the Review is a chronicle of newer developments in clinical veterinary medicine. The concept of general anesthesia in veterinary practice, of course, was not new at this time, but its use was to many practitioners. The use of chloroform and ether in reduction of fractures and in the removal of tumors, as well as the hypodermic use of morphine, is described in the first volume of the Review.

Of some interest is the fact that most of the case reports in the early volumes include temperature records, at a time when thermometry apparently was a new departure in both human and veterinary medicine. Concerning this Liautard editorialized in 1878:

Amongst the progress made for the last few years in the appliances for the diagnosis and prognosis of disease, the application of the thermometer must take a first rank. Indeed, it is only a few years since, that the use of this instrument by physicians first, and afterwards by veterinarians was called into extensive and general practice. American veterinarians were not the last to see the benefits to be derived by the use of this little instrument, and though many old practitioners smiled at the idea of the new toy, as some called it, it soon became in the hands of the conscientious observer, an excellent means of assistance, and it soon was found, that both the practitioner as well as the student, could scarcely do without their thermometer. ... Today it is rare to read a report of a case without careful observation of the temperature. 
To show that matters have not changed much in at least one respect, Liautard concedes that the thermometer has on occasions been misused:

and many young graduates will remember forgetting it in the cavity where it was placed, and when returning to find it in the bedding or amongst feces broken in many pieces.

The Review for 1878 carried a series of articles, translated from the German, on: "Thermometry of the Domesticated Animals, and Its Use in Veterinary Medicine."

\section{For Whom the Bell Wether Toils}

Concerning the proper mission of the American Veterinary Review, C. B. Michener writes in 1881:

There should appear in the columns of the Review some brief notes upon subjects that interest not only the veterinary profession, but also the community at large. Particularly is this true with reference to the relationship exiting between veterinary science, agriculture and commerce. Our little journal finds its way in to the hands of many agriculturalists, men who would appreciate the value of well chosen remarks upon subjects such as the feeding and care of stock, draining, and its influence in preventing diseases ... as well as the best means of preventing outbreaks of enzootic or epizootic diseases.

I expect to meet with some opposition to this proposed course, and to be told that this is a veterinary and not an agricultural paper. This, in a limited sense, is true. It is a veterinary journal essentially. But shall we leave no room for the discussion of those questions that affect alike the veterinarian, the farmer, and the stock-raiser?... I think not. . . There is always a danger that a journal like this will become too exclusively "scientific," deal too much with abstract study, and thus, to a certain extent, lose its interest for the busy practitioner.

Certainly no one would object to the several subjects he suggests: the implication of earthworms in spread of anthrax; particular plants or soils causing certain diseases; the restrictions on trade imposed by livestock diseases, and the like. Moreover, the Review did carry articles of this nature. It seems likely that Michener was protesting against the amount of space devoted to reports and translations of foreign research workers. At a time when very little work of this nature was being carried on in this country, however, the Review undoubtedly performed a worthwhile service, both in making this information available, and in acquainting the practicing veterinarian with the concept of veterinary research.

Later a practitioner, in calling a spade a spade, asks:

Must we not, to have a readable, interesting, and valuable paper, present to our readers other than the writings of the most eminent scientists among us: I do not mean that our pages should be filled with inferior matter. I do think, however, that after reading an article by Pasteur, Colin and many others, we should find reports of interesting cases - reports that embody the history, treatment and the results of the special treatment adopted in each particular instance.

In particular, he urges, a veterinary journal should give "the history of existing diseases, whether 'common' or otherwise."

Presumably there were veterinarians who would have preferred more case reports and the like in the early volumes of the Review. The fourth volume, for example, contains but about forty pages of American and half again this number of foreign case reports. Some sixty-five pages are devoted to the work of Pasteur and other French investigators, including several veterinarians, and seventy pages are occupied by an exhaustive report by the English veterinarian, George Fleming, on human and animal variolae. Another twentyeight pages are given over to the research of Dr. Willems of Holland on the causative agent of contagious pleuropneumonia; this was timely inasmuch as equal space was devoted to outbreaks of the disease in the United States, but Willems was an advocate of inoculation for the disease, and in this respect his work perhaps unduly influenced some veterinarians here. Lengthy consideration is given to the laws of Germany for the supression of epizootic disease. 


\section{Professional Loss, Private Gain}

The fact that the Review was able to keep on a sound financial basis - if only barely so - is evidence in itself that there was not an overwhelming protest concerning its content. Of its reception, Liautard states in 1880 :

Since its birth, the American Veterinary Review has met with a success unequaled by any periodicals of its kind, specially if we consider the conditions under which it was issued.

In that year, however: "A letter of resignation from A. Liautard, begging to be relieved of the editorship of the American Veterinary Review ... was presented to the Association." The result of this was that at the subsequent semiannual meeting of the USVMA in March, 1881:

In view of the increasing demands made upon the time of the editor ... the society decided to present the journal to Prof. A. Liautard, without any encumbrance, as a slight recognition of the work he has done for the Association and profession at large.

Although it is obvious that the Review barely made a profit, the editor in 1879 had "reported the condition of that journal as being at present most flattering, and asked that he be permitted to lower his price of subscription from $\$ 4$ to $\$ 3$ a year," which request was denied, except in the case of students.

The real motives of either Liautard or the Association in this matter are, perhaps, too remote to be susceptible to full delineation, and probably little would be gained from such a recital. It is evident that if, as stated by Liautard, it was the demand on his time that prompted his "resignation," his acceptance of full rights to the journal could not but have increased these demands. However much the Review might have been calculated to add to his personal fortunes, he may very likely have given less consideration than the free hand he would obviously have as its proprietor.

At the meeting in 1878, in suggesting that he might resign, Liautard had stated,
"Give your [new] editor carte blanche for his management of your interests in the paper, and above all, let him make his own choice of assistants." It would seem likely, however, that he surmised there would be no scramble for the post. A. A. Holcombe's report as secretary states:

Dr. Liautard tendered his resignation... [but was ] unanimously re-elected to the editorship, and given the privilege of selecting his own assistants and of conducting the Review in accordance with his own judgement.

The title page of the next volume states that the editor is: "assisted by a number of selected veterinarians."

That the Review apparently was in sound financial condition, as Liautard had repeatedly said it was, is indicated by his request in 1878 to reduce the subscription price from five to four dollars, which was granted; and to three dollars in 1879 , which was not granted, except for students. In 1880 Liautard reported, "Its circulation is not only increasing, it is not only free from debt, but has a small amount of funds to its credit." The Association left the matter of paying an honorarium for original articles, not to exceed $\$ 25$, to the discretion of the editor.

\section{Billets-doux for Billings}

In 1879, the ever-intemperate Billings had lamented:

We long to see the day when "our Review" shall contain contributions worthy of translation and recognition in other countries and among mediciners. Alas, when will the day come? Yet we have no reason to complain, for about all the matter of any scientific value in the Veterinary Journal, Britain's leading review, is like our own, purloined from continental workers. We have had a perfect surfeit of "transverse presentations," regular and irregular strangles and colics, of tetanus which ran out, and all such nonsense.

This appears in the body of one of many articles translated from the German by Billings, who, therefore, was himself contributing to a continuance of the situation 
he so resoundingly condemned. Unfortunately, Liautard offers neither defense nor apology for this particular item; not so George Fleming, editor of the Veterinary Journal, however, who says his publication "has no need to purloin, neither has it the intention to act dishonestly." Concerning the Review he notes:

At not very infrequent intervals, there have appeared articles in your interesting periodical, in which, in one part or another, indulgence in strong language and undeserved disparagement, either towards myself personally, or the Journal which I edit, is manifested. I have hesitated to notice these attacks hitherto, trusting to the sense of fairness which I know your readers to possess, and also hoping that your editorial influence would be invoked.... . But as these vituperations and unfounded assertions are continued, and appear to have become a permanent feature in certain communications, I think it is high time to notice them, and to ask for your exercise of the editorial privilege.

Fleming quite correctly directs his strictures primarily at Liautard, and dispatches Billings with the curt note: "In the Review for April, just at hand, there is a paper, at page 12 , with a headling in German, and which is a kind of a translation from that language."

Others were equally censorious: an "Amused Graduate of the A.V.C." states:

Mr. Billings will never gain ... stability by trying to lift himself into notoriety by the waist-band of his breeches. ... Before he commences to run everything pertaining to veterinary science in the United States ... let him make a reputation as a man and a practitioner, and place himself above the need of informing the public [through numerous articles in Turf, Field and Farm ] that he is the son of his father and the first American graduate of Berlin in the United States.

Billings, however, continued to needle the American veterinary profession, although not always without cause. Thus upon the transfer of the Review to Liautard, he writes:

In a certain way the Review has changed hands. It has been the organ of the profession through its Association. It is that no longer. . . . He alone must shoulder the whole burden. In this there is no change, for he has always carried this burden too much alone. ... This reflects upon the profession. They are willing to pay for edification, but not willing to mutually contribute to edify and educate one another.

\section{USVMA vs. AVR}

This action taken in 1881, however, is not without significance in assessing the status of the USVMA at this time. It is evident that the Review had in three years become a more powerful influence than had the Association in 18 years. Rather than being purely a gesture of appreciation for Liautard's work, the gift might be considered a realization of the fact that the Association had but little choice in the matter - who was there to assume the responsibilities of editorship? Under the circumstances, the move undoubtedly was a wise one; the Review continued as much as before as the voice of the Association, and perhaps the veterinary profession benefitted more than it realized from the increasing tempo of dissatisfaction with the status quo reflected in the writings of Liautard. In accepting his new status:

The editor fully appreciates the importance of the task before him; . . . he will more than ever endeavor to do full justice to his position... The pages of the Review will always remain open, and never will be allowed to become the representative of any particular society or association, of this college or of that school. The editor will endeavor to remain strictly what the name of the journal should indicate, above all things, American in character.

Liautard had not been silent in the early volumes of the Review concerning the lack of progress made by the Association, and in this he was not alone. In 1881, however, he issued his most outspoken criticism to date:

This association has been in existence for eighteen years, and what work of any advantage to the profession can it boast of? By a recently published register of the veterinarians practicing in the United States, the profession 
is said to count about seven or eight hundred members in its ranks, and yet the United States Veterinary Medical Association counts only sixty-eight members. ... Why is it that the meetings are so deficient in professional discussions, and so lamentably remarkable for the absence of papers of acknowledged importance? ... We have been giving the subject a great deal of thought, and believe that some important reforms ought to be made in our organization at once.

As an effective comparison, Liautard preceded the above with an editorial on the recent London Veterinary Congress, commenting on:

the large attendance, and the enthusiasm and earnestness of those present... as an incentive to original investigation and research in all the branches of veterinary science. . . We sincerely trust that the examples set by our British friends will serve to infuse new life and vigor into the meetings of the United States Veterinary Medical Association.

\section{The Review vs. the Journal}

Liautard's criticism of the USVMA, however, remained constructive, and it may be fairly considered that this was a major factor in bringing about needed reforms. The Review certainly remained a faithful representative of the American veterinary profession. As suggested above, however, it is not quite true that the Review remained aloof from the politics of the veterinary schools. Not only did the editor's position make it likely that the American Veterinary College would receive a considerable share of attention, with, the publication of the Journal of Comparative Medicine and Surgery more or less as a voice of the Columbia Veterinary College, the Review unobtrusively renewed its championship of the editor's school. Liautard, however, carefully refrained from indulging in the carping criticism occasionally found in the Journal, and directed toward his school.

In 1883 the Journal stated editorially that while the USVMA:

has some good members - it is officered and worked, however, chiefly by the faculty of a single veterinary college and in no sense repre- sents the progressive and scientific elements in the profession.

Although it is true that New York and Massachusetts had had a monopoly on Association officerships, it may be doubted that the American Veterinary College had much of an edge, except in that certain members of its faculty were senior members of the profession. At this time the slate of Association officers was completing its second year of tenure, having been reelected in toto in 1882. Williamson Bryden of Massachusetts, a Montreal graduate, was president; Lachlan McLean, M.R.C.V.S., of Brooklyn, vice president; C. B. Michener of Pennsylvania, an A.V.C. graduate, secretary; and Charles Burden, an N.Y.C.V.S.-A.V.C. graduate, treasurer. Like the Review, the Journal claimed to be:

the advocate of no special school, but will try to keep all the schools up to the best standard it can by kind words of criticism and of praise where they can be given.

\section{Later the Journal stated that the USVMA:}

has, through unfortunate and undesired circumstances, become, in reality, almost entirely an association composed of the graduates of the American Veterinary College.

With the sudden demise of the Columbia Veterinary College in 1884, and the absorption of its student body by the American Veterinary College, however, the Journal noted that however unfortunate this might be:

the result in this case cannot be considered as other than a source of satisfaction to the veterinary profession in this country, assuring it, as it does, the possession of a school which bids fair to rival the best establishment of its kind in Europe.

And later, the American Veterinary College was styled as "a school which has been for so many years a great blessing to this country." Advocates of the Columbia Veterinary College could lay a claim to supremacy as the only three-year school in America; under the circumstances, this re- 


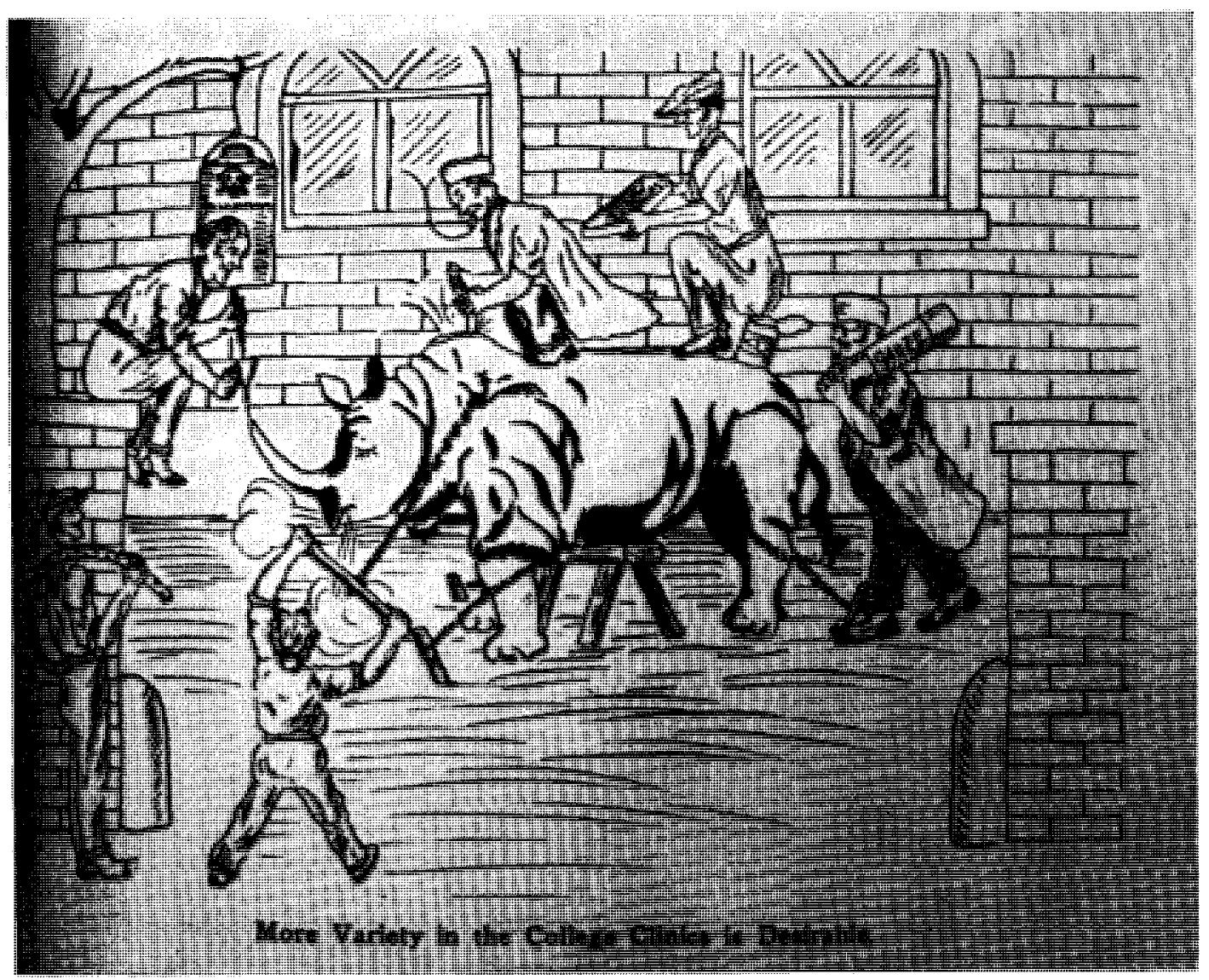

Complaints by practitioners that the colleges were "impractical" are as old as the colleges. Dr. Liautard published this cartoon in the 1880's, apparently as a satire on criticism of his own American Veterinary College. American Veterinary Review

quirement may well have been one reason for its short-lived supremacy.

\section{THE QUEST FOR STATUS}

A major mission of the American Veterinary Review was the establishment of a higher status for veterinary medicine as a science, and of the practitioner as an individual and a member of the veterinary profession. This takes on some semblance of "operation bootstrap," but there can be no doubt of the sincerity of Liautard and others in attempting to frame a new philosophy.

In writing on "Veterinary Education" in 1877, Duncan McEachran, Principal of the Montreal Veterinary College, urged:
We have now reached an era in the history of Veterinary Science in America, which demands that each member of the profession will do his duty to himself, his country, and his profession, by insisting henceforth that this noble science, valuable as noble, for by its proper utilization, millions of dollars which under present circumstances are lost annually, may be saved - must and will be wrenched out of the hands of the imposter, and be practiced only by those qualified by education of a standard, arranged and acknowledged by some recognized authority.

McEachran suggested that minimum standards be adopted, to include a matriculation examination and at least three sessions of six months each, with summer practice or a fourth session in addition, and an exami- 


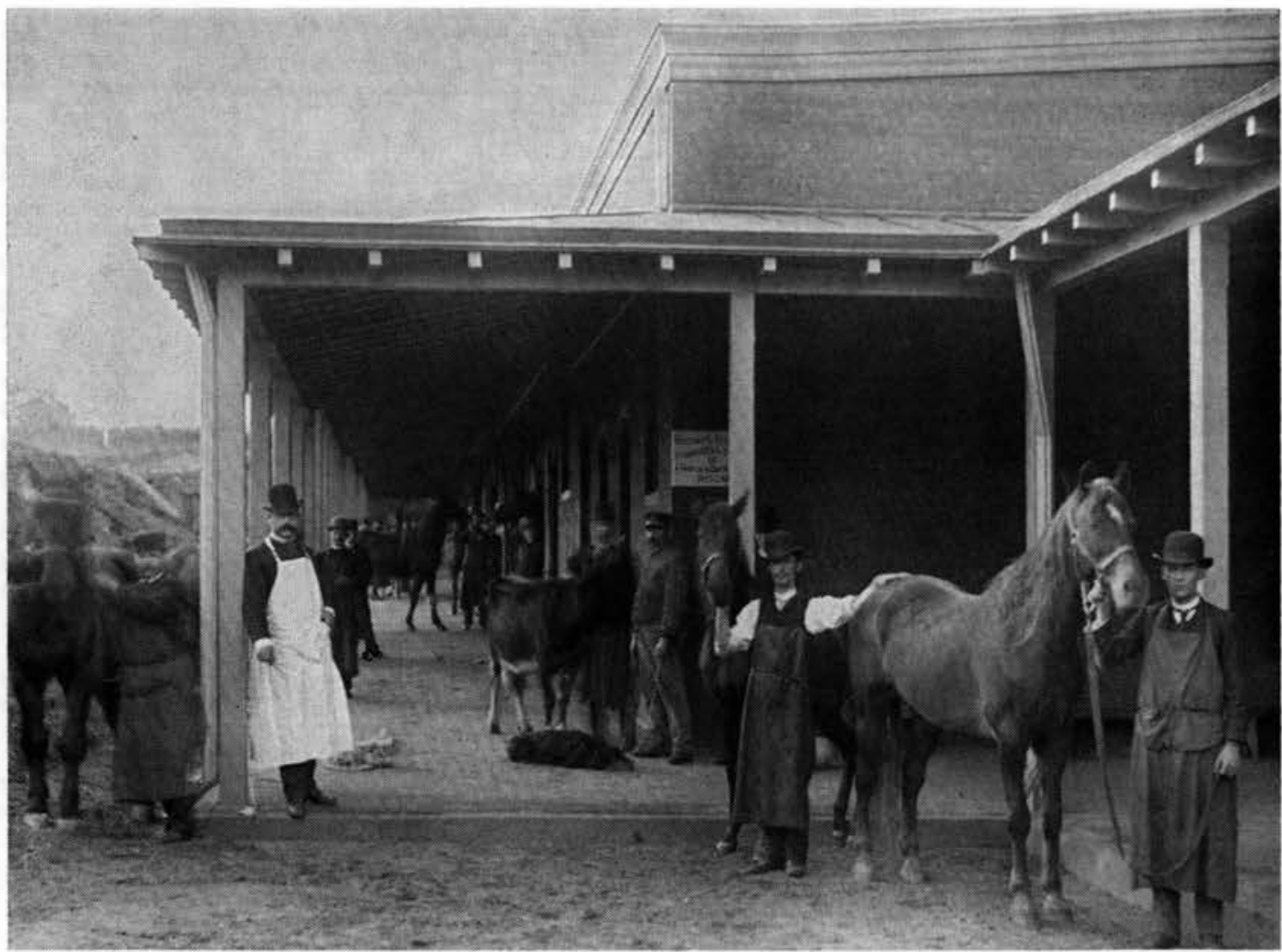

Large animal clinic at the University of Pennsylvania in 1885. The man in the white apron appears to be Rush Shippen Huidekoper, dean of the School of Veterinary Medicine. Michigan State University Library

nation conducted by an outside and impartial board. Further:

This profession has too long been left in private hands and to private enterprise. If any department of education is deserving of Government support and Government supervision, this one is.

Much of McEachran's thesis was directed at the Toronto school and the American Veterinary College. While Liautard fully agreed with McEachran in principle, he steadfastly refused to institute higher requirements so long as Andrew Smith at Toronto failed to; this, of course, was as regrettable as it perhaps was understandable.

Veterinarians worthy of the name were then, as always, proud of their profession, and anxious to see the profession gain the standing it deserved. The disclosures in 1877 resulting in closing the bogus diploma mill that had once been the Philadelphia Veterinary College were hailed by veterinarians as a thorn removed from the side of the profession. Acknowledging this to be a fact, James Law charged, however:

This is healing the wound altogether too slightly; the source of the trouble lies much deeper. All regular graduates of veterinary medicine are not immaculate, and the veterinary profession cannot close its doors effectually against every hypocritical scoundrel who sees in its degree a stepping stone to the acquisition of filthy lucre. Even the regular graduates of the veterinary colleges are found among us laying claim to titles to which they have no right, and acting altogether in the most unprofessional manner.

Law stated that the principal danger of such schools lay in "their private and irre- 
sponsible character." Moreover, the danger would persist so long as private individuals could obtain charters to grant degrees without adequate supervision, for there were still "plenty of unscrupulous men who will seek to work such a machine for their own personal aggrandizement." Like others, Law advocated a National Veterinary School.

\section{Agriculture vs. Veterinary Medicine}

On the basis of Law's remarks, Liautard ineptly stated that Law himself was educating veterinarians in an agricultural school. To this Law responded in most gentlemanly fashion to his colleague's "misapprehension of the facts," saying:

I can confess to no remorse for the sin which I have not committed. . . . Cornell. University does not attempt to make veterinarians of her agricultural students.

Rather, in giving basic instruction in physiology, hygiene, and the like:

Instead of proving inimical to the scientific man, men educated in this way are his best friends. If all our citizens were better instructed in the physiology and pathology of their own bodies, they would no longer support the great army of vampires that now sap their vitals with their blood purifiers, liver regulators, vital elixirs and panaceas in general. The agricultural graduates of Cornell University do not employ the man who cuts out the feeders of ringbones and spavins at a point distant from their seat, who bores the horns and slits the tails of all sick cattle, who finds in blackened teeth a sufficient cause for all the ills that swine are heir to, who corrects watery eyes and a host of other maladies of the horse by extracting apparent or concealed wolf-teeth,

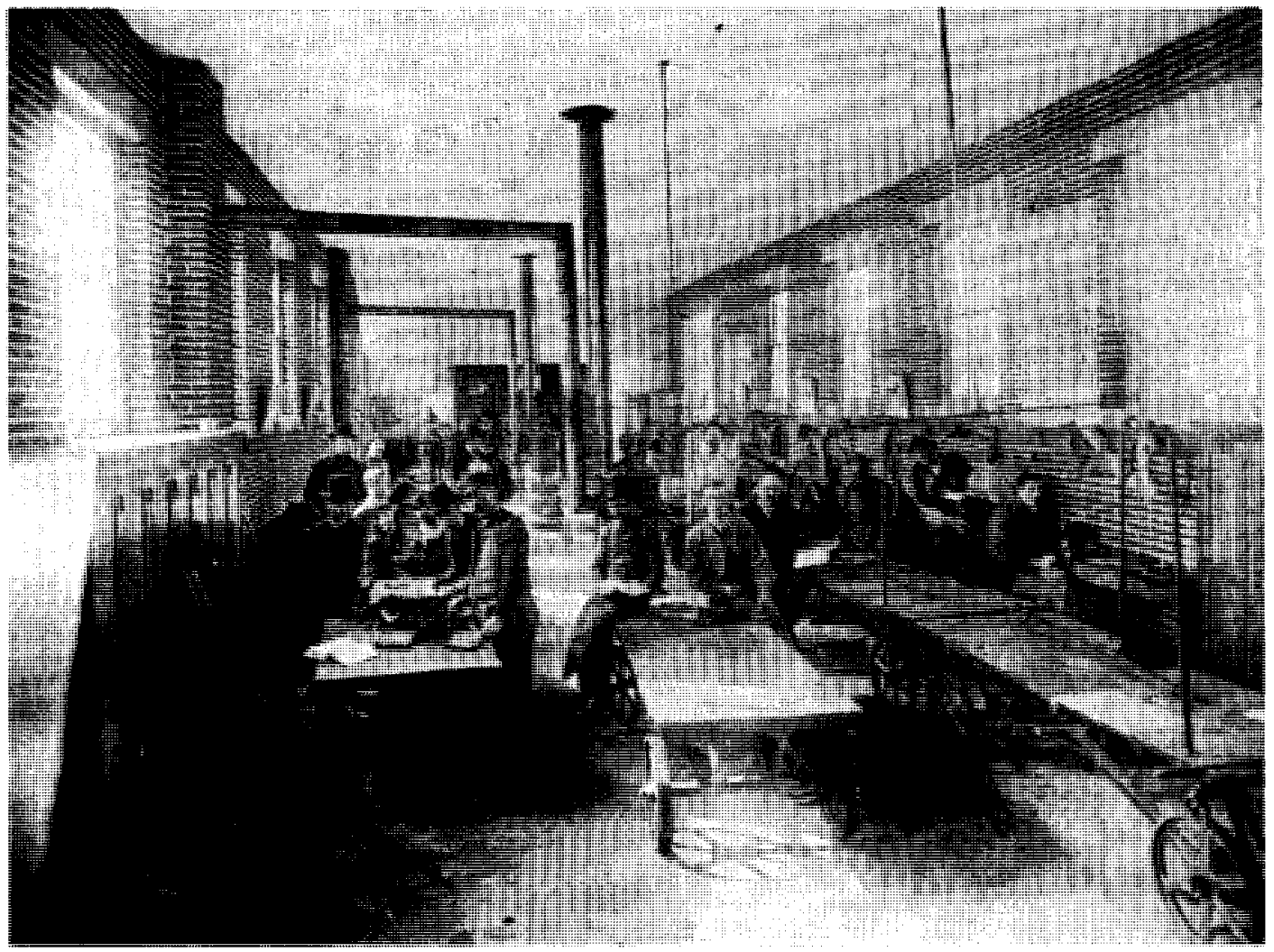

Anatomy laboratory at the University of Pennsylvania in 1885 . The heavy post-mortem - dissection wagons were patterned after those used in European schools and were used to transport horse cadavers at Cornell as late as 1945. Michigan State University Library 
who operates by the planetary signs, who castrates cows and mares by the antiquated flank method, and who sells an infallible remedy for all kinds of worms and in whatever situation - bowels, brain, lungs, liver, spleen, kidneys, peritoneum, etc., etc. They are educated enough to distinguish, appreciate and employ sound and reliable veterinary advice, and to influence their less favored neighbors to a similar course. They are the friends of veterinary progress and of the accomplished veterinarian, and the sworn enemies of the quack and mere pretender...

Agricultural and veterinary education must go hand in hand, and I hail the diffusion of sound knowledge and the capacity of arriving at a just judgement among our farmers, as the precursor of a higher appreciation of veterinary science.

In an address before the National Agricultural Congress in 1878, N. H. Paaren, V.S., later State Veterinarian of Illinois, in speaking of the need for veterinary reform, asks:

Has our government done anything in the way of aiding or encouraging instruction in the only department of knowledge that can be of service in warding off or curing the diseases of domestic animals? Absolutely nothing! . . . No torture was ever so complete as that inflicted on sick domestic animals by the ignorant quacks who pretend to know how to doctor them. Intelligent humanity revolts at the way disease and lameness are treated almost everywhere in our land; and the future historian will allude to some of the practices of our horse doctors to prove that in the year of 1878 we had not yet entirely emerged from the darkness of barbarism, inasmuch as such a state of affairs was sanctioned, nay, indirectly aided, by being tolerated, by what is called the best government the sun ever shone upon.

Paaren called for immediate action to provide:

1. For the establishment and maintenance of a National Sanitary Bureau. 2. For the establishment and perpetual maintenance of a $\mathrm{Na}$ tional Veterinary College.

How well he succeeded in getting his message across may be appreciated from the following resolution adopted by the Agricultural Congress after a discussion of his paper:

Resolved, That veterinary practice in this country is quite too generally unscientific and empirical; that the need of educating skilled veterinarians is imperative, and the attention of agricultural colleges is respectfully and urgently directed to more vigorous efforts in this direction.

\section{Paaren inquires:}

What vigorous efforts can be expected of these institutions who class veterinary science as a third or fourth-rate sub-division, and many of which do not even consider it worth employing a qualified veterinarian as teacher?

\section{D.V.M. vs. M.D.}

At this time a remarkable number of the leaders of the veterinary profession, and more than a few regular practitioners, obtained the M.D. degree. While any additional education would, of course, seem to be desirable, it may be doubted that most veterinarians who did so considered the "post-graduate" training of paramount importance as such. The medical degree was relatively easy to obtain and without the large sacrifice of time and money invested by the "perennial sophomore" of today. Liautard, who had obtained the M.D. degree in 1865, recommended that his students take this step. And in congratulating Prof. F. W. Prentice, M.R.C.V.S., of the Illinois Industrial University, upon his obtaining the M.D. degree, Liautard stated in 1878 that this step is:

one which cannot be too much encouraged in this country as a means of obtaining from the public the respect which is so much due to veterinary science. We believe that there are now in America more veterinarians, graduates of human medicine, than in any other part of the world.

In 1884 the eminent veterinarian and educator, W. H. Hoskins, added the observation that a medical degree would make the veterinarian "a better practitioner as well as allowing him to mingle with the medical profession." The next year, however, Liautard had reversed his earlier stand, asking:

Is this at the present time a title which it is indispensable for men in our calling to possess? Is it for honor of prefixing the M.D. to their D.V.S., or is it their need of a more complete 
medical education which urges our young graduates in veterinary medicine to matriculate at a human medical college?.. . If I am right, it is a step which ought to be discouraged, and if possible, checked, or the veterinary profession must for years to come fail to maintain, as it failed in times past to acquire, the position it ought to occupy, and suffer itself to be thrown back to its old ignoble place in public appreciation. . . .

If more education is what is needed; if more perfect knowledge is desired; if a post-graduate school would be thought useful - and it is, perhaps, always useful - well and good; let us have it. But let us obtain it through the proper channel; which is that in which you have already studied. ... Be a V.S. in the strict sense of the word. Elevate your profession and your title, and yourself by that title . . . without attaching an M.D. to your name.

On the matter of titles, it is a little strange that a number of the veterinary schools awarded the degree, V.S., which was the usual designation adopted by selfdenominated practitioners - many of them able and ethical, but, unfortunately, many more merely quacks and charlatans. According to Bierer, some 3,500 of these degrees were awarded at various times by the Ontario Veterinary College, the New York College of Veterinary Surgeons, the Ohio State University, the Montreal Veterinary Surgeons, and the Indiana Veterinary College.

An interesting commentary on this matter is offered by $\mathbf{E}$. Mink in a letter to the editor of the Review in 1881. He notes that the Review:

directed me to have V.S. appended to my name. In times past I have called myself a veterinary surgeon, and have appended the initials V.S. to my name. I have never considered that the words veterinary surgeon were properly regarded as a title, as they merely designate the name of an occupation, and the letters V.S. are merely an abbreviation of them.

He relates having been challenged on the witness stand regarding his right to use this designation inasmuch as he was not a graduate veterinarian, whereupon the judge had ruled:

Every person has a right to designate the nature and character of his business by respect- able and significant terms, and that he was not obliged to designate his calling by vulgar terms or coarse epithets. . . . If a man were engaged in the calling of dentistry he had a right to call himself a dentist, that he could not be compelled by any individual or legislative body to call himself a rotten-tooth doctor; and so also, you cannot compell a man pursuing the veterinary practice to adopt the vulgar epithets of horse or cow-doctor. So long as he does not falsely assume doctorate or other degrees, he was not censurable.

\section{Mink continues:}

I am not anxious to designate myself a veterinary surgeon. The term veterinarian suits me just as well, it is just as significant, quite as dignified, and I am content to designate my calling by it. I shall carefully avoid appending V.S., or veterinary surgeon, to my name hereafter, as $I$ am anxious to avoid a feeling on the part of veterinary graduates that I am infringing on what they deem their exclusive rights. . . . I will, however, insist upon designating myself a veterinarian, and would, if possible, contest the constitutionality of any law that might be made to prohibit it. . . . There are other things than the lack of ten or fifteen months of college opportunities that unfit men for practice of human or veterinary medicine. Many men who are called qualified because they hold a college certificate, are, in reality, totally unfit to practice successfully.

Some of the continental schools conferred the title "Veterinarian" before they adopted the doctorate; R. S. Huidekoper, who studied at Alfort, but apparently did not graduate, used this title. Bierer styles the use of this title "modest," which it undoubtedly is, but it could be argued that it might be considered the highest title that could be used. Just as "physician" today connotes "M.D.," so perhaps, should "veterinarian" connote a standard of excellence without needing the qualification denoting a doctorate in medical studies.

\section{Prerequisite to Practice}

In 1882 Liautard editorialized on the need for a "College of Veterinary Surgeons of America," with functions similar to those of the Royal College of Veterinary Surgeons of Great Britain. Among the benefits to be derived from such an institution, he argues: 
The various titles and degrees in vogue at the present time would be reduced to a single and common title, whatever that might be.

Other benefits would be a uniform and higher standard of education, and a system of licensing which would rapidly eliminate quackery. While the present National Board of Veterinary Examiners might be thought of as a desirable step in this direction, some seventy years were to pass before this came into being, and it would seem that some additional years will pass before this concept meets with universal approval.

Dr. A. A. Holcombe, the noted Army veterinarian, took issue with Liautard on the matter of a United States College of Veterinary Surgeons, inasmuch as:

It is the inalienable privilege of each State to determine for herself what shall constitute the proper qualifications of her recognized practitioners of a profession.

And while he thought a National Association of Veterinary Schools might do some good in raising standards of the schools:

at present it must be optional with the individual schools.... The majority of students of veterinary medicine have entered upon their studies with the purpose of gaining their degrees in the shortest time possible; and that institution which receives general recognition as being a school in good standing, and which, at the same time, makes it public that the enforcement of the provisions of its curriculum is more apparent than real, is the one to receive the most patronage.

The perennial subject of internship for veterinary students was discussed in the Review as early as 1880. A practitioner writes:

In England and Scotland, office instruction is considered as one of the essential elements of the student's education. There, in many instances, he is indentured to a practitioner for a certain term, with the same care and strictness of detail, as is observed with apprentices sent to learn a trade. . . Perhaps some will interpose the objection, that the student is liable to learn many things which do not accord with the teachings at the college, owing to the busy practitioner getting rusty on many subjects ... [ [but] he obtains much that there is little time and opportunity to teach him at college. ...

When the practising veterinarian accepts a student for instruction he assumes a duty the gravity of which many but imperfectly understand or do not fully appreciate. It is not enough that the student be told to read whenever he finds time, but he should be told what and how much to read, then have his memory tested to see if he retains and comprehends what has been taken in. ... In the pharmacy ... make him a pharmacist, not a mixer of drugs. . . . In the infirmary cultivate habits of observation.... Teach him hygiene in a practical manner. . . . Last, but by no means least, cultivate a disposition to original research by supervising his post-mortem examinations and indicating to him what is healthy tissue and what is diseased, and the significance of the latter.

He admits to some difficulties in putting such a system in practice, however, for "there are but few veterinarians here, and a large percentage of these have not the opportunity not the facilities for such teaching."

\section{Out of the Depths}

The quest of a higher status for veterinary medicine and its practitioners took on a variety of forms, one being the exposure of quackery both without and within the profession. A humorous example, but one nevertheless distressing when it is realized that there were those who would patronize this type of individual, was the "business card" of one of these lesser lights, reprinted from the Prairie Farmer:

HORSE FARRIER. - The under sind lat from chester conty Intends follown Doctern horses \& stock \& flaters him self able to Master Most all deases \& complants among horsis Pleas giv Me a call \& if no cure no pay Except for medison if bought by Me. all orders left at My Residence will be promptly attend to.

Another, apparently anxious to improve his situation, wrote the following to - of all people - the Principal of the Montreal Veterinary College:

Dr Sr. i thought i would drop you a few lines in regards to Vetrinery practis $i$ have Ben doctern horses for the Last To years and would 
like your tearms and know how much it would cost mee To get a dipluma i could come and stay a short time But probley could not stay the Lench of time required byt Probley you could give me some Sadsfactian ... i cane make as much money without one as with it but $i$ would like To go in some large citey and Doe busyness $i$ am red up on the horse purty faire but $i$ ame a maried mane and cant aford to spent much time in College.

Liautard styles this: "knocking on the wrong door;" McEachran was a proponent of higher standards than most of his colleagues in the United States would subscribe to.

A correspondent to the Review in 1878 noted, however, that this form of quackery was not insurmountable; not so:

the very worst form of quackery which besets our profession, quackery in the ranks of the qualified.... When we look to our own ranks, and behold the flagrant violations of principle, preached every day by some of our members, outside quackery sinks into insignificance in quality, if not in quantity, by the comparison, and we no longer wonder that our sister professions are slow to extend the hand of fellowship and wish us success. . . There is too much of this petty jealousy - that detestable remnant of quackery-existing in our ranks to-day, and no matter how high they may stand in public opinion, or in their profession, at the present time, all who stoop to participate in these disgraceful factious controversies, need live but a short time to find their names in the oblivion of their own production, for there are found workers coming into the field, who will win the race in which the older members have so heavily handicapped themselves with the weight of these nauseous dissentions.

... equally as injurious to the true science, is the deprecable practice of editing a "Veterinary column" in a "sporting" or "agricultural" paper. This is nothing more nor less than what might be called aristocratic quackery.

And in speaking of "Veterinary Ethics in Advertising," Liautard states:

Judging from what we daily see, it would seem that the methods employed to "establish a practice," are almost as universal and varied as are the individuals so striving. Many of these methods are highly objectionable, and do not serve to bring aught but reproach upon the institution granting the diploma, and upon the person holding it. . . Have they not been taught the dignity of their profession?...
An advertisement in a paper, that simply states your profession, residence and office hours, cannot reasonably be objected to. Cards bearing only the same, are unobjectionable, and may be presented in person. These are as far as one can go in this direction, between a conscientious physician and a quack. Advertisements of specialties, of secret medicines, the issuing of circulars and posters, or newspaper puffs, cannot be too strongly condemned. . . One had better fail in procuring practice than to obtain it by resorting to the methods employed by patent medicine men and unscrupulous charlatans.

While the classified pages and some hospital signs today offer silent testimony to the fact that a few infractions of the "law" laid down by Liautard still occur, the testimony of a practitioner a century ago offers more than ample evidence concerning what Liautard railed against. Speaking of "Practice in New York and Brooklyn from 1865 to 1923," G. H. Berns (Columbia Veterinary College, 1879), relates:

My personal experience with veterinarians in New York City and Brooklyn dates back to 1865. Engaged in the grocery trade and later on in the milk business, I had occasion to drive horses and came in contact with a few practicing veterinarians. As qualified veterinarians were few in number and ignorant, unscrupulous quacks were plentiful, I met with the latter class most frequently. To show the calibre of some of the men who practiced in Brooklyn, it is necessary only to refer to a few signs that were conspicuously displayed in various parts of the city. On the Jamaica Plank Road near Bushwick Avenue was a large sign, "Dr. Corwin, Veterinary Surgeon." On the door was painted in bold letters, "Horses Doctored Here." Painted on the fence on one side of the building was the picture of a miserable emaciated horse being dragged toward the building by a man, labeled, "Going to the Doctor's." On the other side of the building, painted on the fence, was the picture of a horse in fine condition labeled, "Coming from the Doctor's."

On Flatbush Avenue near Sixth Avenue, displayed in a show window, was a large sign, "Office of Professor Baker, the Common Sense Horse Doctor." On State Street, near Smith, displayed in a show window, was a large sign, reading: "Professor Ricord, Veterinarian. A graduate of the School of Experience. All curable diseases of the horse skillfully treated. Consultation Free." There was a Hans Pilger, with headquarters at Otten's saloon, who 
prided himself upon the fact that he required no office, no cards, no signs of any description. To his German friends he would invariably declare: "Ich bin der doctor ohne schild."

There was Dr. Dellisser, who advertised his wonderful extract of carbon to cure most all the ailments of horse flesh. Another who practiced for years in the vicinity of the city hall, a most profane and vulgar spoken individual, had the reputation of being the greatest liar in Brooklyn. He occupied a small building; one side was filled with skulls of animals, specimens of ringbone, spavins, deformed limbs and feet, and other curiosities. On the other side, arrayed on shelves, were bottles, jars and boxes containing his numerous secret remedies with a bottle of whiskey and a box of cigars completing the outfit. He would display a large section of the lumbar vertebrae of a horse and declare that he took the bone from a horse that was too long in the back, to shorten him up. There were scores of others. The influenza epizootic in '72 and '73 and the enzootic of cerebrospinal meningitis gave the quack element an opportunity to fleece the public more than ever and they joyously hastened, figuratively speaking, to the haymaking while the sun shone, thus driving still lower the standing of the profession.

S. R. Howard, a sort of veterinary Will Rogers, contributed many a pointedly humorous piece to the American veterinary literature of the early twentieth century. Characterizing himself as "somewhat poky and old fashioned" (actually he was a progressive country practitioner), he admits:

Although I know I am not as thoroughly informed along certain lines as I am wont, still I am what might be called an every-day country veterinarian. Therefore, I speak not as the scribes, but as one having authority. . . . Did you ever notice how many popular titles a veterinarian has?

I have been accosted as Dock, Quack, Farrier, Veteran, Cow Leech, Hoss Doctor, Vertinary, Venitianary, Vetenary, Old Honesty and Day Light Robber. . . . Once I was asked by a horse doctor if I had ever studied Dr. Kendall's work on the horse. Astounded at my ignorance, the Dr. (?) further asked if I did not claim to be a Venitian Sergeant. I modestly admitted I was one and told him I had often heard of him and his skill as a surgeon; I was pleased to meet him, etc. I finally asked him confidentially if he had ever performed "aortic regurgitation." "Yes, several times," he replied, "and I can tell you it is an awful bloody operation."

\section{In the Eyes of Others}

Liautard also faithfully recorded notices the veterinary profession received in the medical press, both good and bad. Earlier, physicians writing in the agricultural press had with good reason almost universally condemned the treatment of animals by unqualified practitioners, and had urged the establishment of veterinary schools as the only means of combatting this evil. After schools were established, however, some of this criticism, which actually should still have been leveled at the unqualified, was identified with the graduate veterinarian - or at least no distinction was made between the two groups. Some of this unfavorable climate, unfortunately, was abetted by individuals who passed for members of the veterinary profession. Thus in 1883 as reprinted in the Review, the Medical Record reported:

A person who called himself a veterinary surgeon read a paper recently before the New York Farmers' Club in the Cooper Institute, on the diseases of cattle and their treatment by veterinary doctors, whose methods he condemned.... It is a disgrace to the nation, the orator continued, that there is not one legally chartered, organized, and established veterinary college in the country. Veterinary science here lies deep down in the ditch of ignorance, and the billions of dollars invested in animal property, as well as the animals themselves, are left to the mercies and wantonness of chance. The country is flooded with bogus diploma mills, several of which are in this city and other parts of this State. The speaker went on in the above strain, but failed to mention where the New York diploma mills are. It is understood that parties in this city do practically sell veterinary diplomas, and it is to be regretted that some definite facts were not given.

Liautard printed this without comment, but his inner feelings may be surmised. Obviously, he did not subscribe to the theory: "Let's not notice it, and maybe it will go away."

And in 1880, following the second failure to secure passage of a bill regulating veterinary practice in New York State, the Medical Record had stated: 
With the advent of the germ theory of disease in the late nineteenth century, moist dressings were in vogue as a means of providing continuous antiseptic applications to wounds. Liautard: Surgery

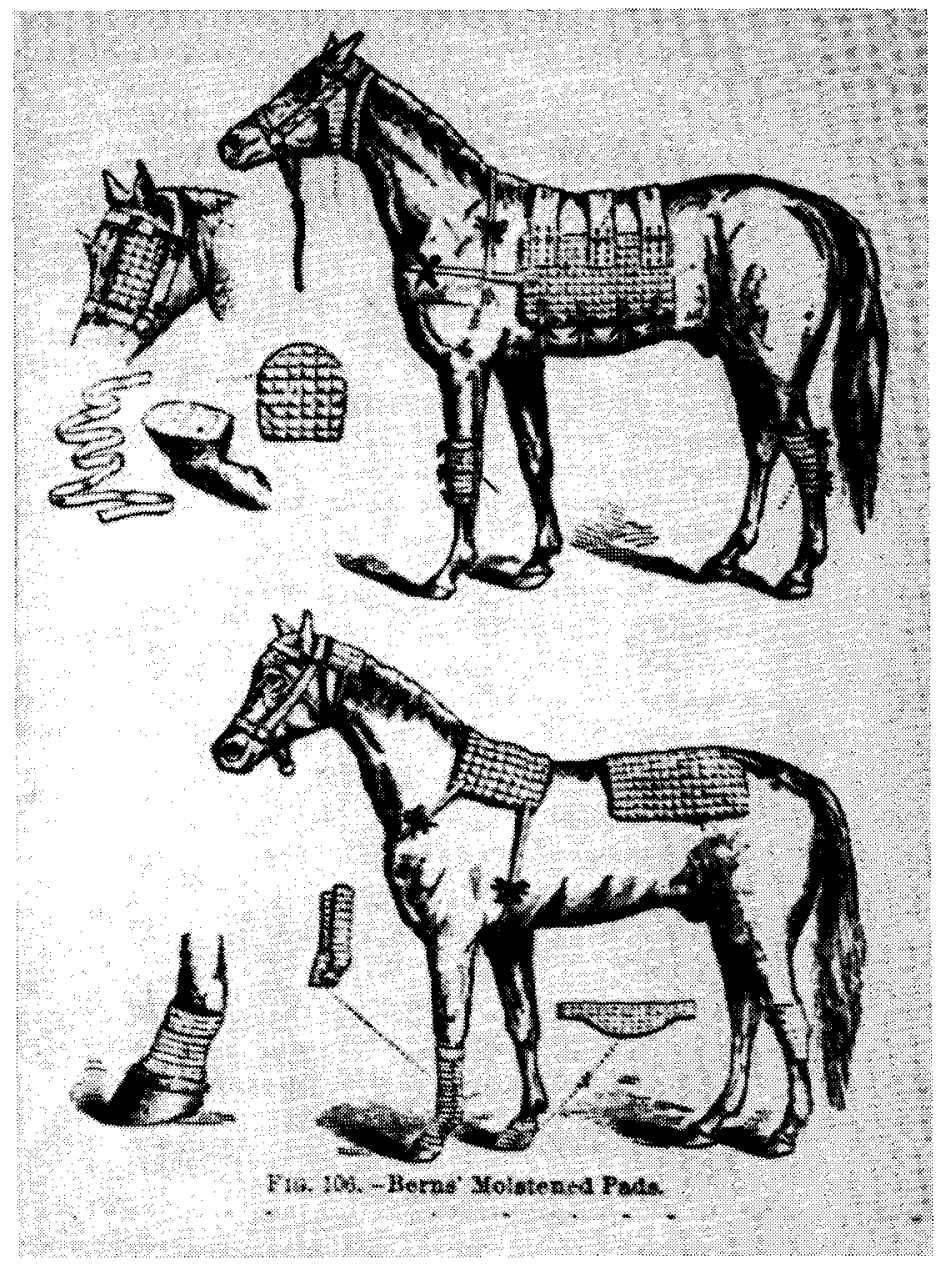

This could hardly be expected otherwise, as it was a somewhat premature measure. It is well to encourage all proper measures for elevating the standard of veterinary medicine, but the practitioners of this art are not yet, as a rule, sufficiently advanced in education or scientific attainments to need the protection of legislation.

\section{In response, Liautard asks:}

Veterinarians of New York, what can you say to this? The Medical Record has told you what it believes to be the truth, and you have no one but yourselves to blame for the allusions made in those few lines. . . We know that many amongst $u$ s are as advanced in education and scientific attainments as many members of our sister profession, but how have we shown it? When have we placed it on record?.. Can we show any scientific work or investigation of which any of us can be proud?

That there was an element of bias in the relentless attack of the Record, may be appreciated from the following exchange: At the seventeenth annual meeting of the USVMA in September, 1879, a committee was appointed to frame "a set of resolutions to be presented to Congress in relation to the investigation and prevention of contagious diseases of domestic animals." Accordingly a well-worded petition including adequate supporting evidence was drawn up on November 25, requesting that the Congress of the United States:

shall establish a Veterinary Sanitary Bureau, whose duty it shall be to advise Congress as 
to what measures shall be necessary to control, restrict, or eradicate any contagious or infectious disease affecting the domesticated animals.

In the meantime, Liautard had editorialized on the matter, and had indicated that while the establishment of such a Bureau "seems to be the general demand," there were differences of opinion as to how it should be established:

With many, and among them ourselves, the National Bureau of Health seems to be the most appropriate department ... when we consider the intimate relationship existing between many of the preventable diseases of man and the lower animals.... But there are a few who advocate the formation of an independent Veterinary Bureau.

Others advocated an affiliation with the Department of Agriculture, but more important than these considerations, Liautard emphasizes "is the urgent necessity for immediate action." There was general agreement on this latter point.

But without waiting to see the nature of the petition, and apparently wishing to capitalize on the seeming differences of opinion within the veterinary profession, the Medical Record on November 7 observed:

the present status of Veterinary Medicine is so undefined that a National Bureau would not have much more of legitimate professional basis than a National Bureau of Barbers to keep themselves informed upon sycosis. There is in this country only one Veterinary College which exists under legislative sanction, and which can grant genuine diplomas. Veterinary practitioners, therefore, are composed of three classes: persons who have graduated from foreign and one regular home school; persons who have graduated from other home schools and have received diplomas which are virtually only certificates; and third, persons who have no regular education whatever.

It is feared that the establishment of a National Bureau out of these elements would produce endless quarrelling, without receiving any valuable results.

Noting that the Record had treated his remarks to "not as kind a reception as past relations had encouraged us to look for," Liautard nevertheless states:
On second consideration ... we are now somewhat inclined to thank ... our friend co-editor ... f for the trouble he has taken in bringing the subject before the medical profession, to which we have accustomed ourselves to look for support, assistance and recognition. Few physicians, we are sure, will consider the subject in the same manner as the Medical Record, and we have every reason to believe that its sarcastic remarks will not be accepted by the large majority amongst the members of the medical profession.

Another "Veterinarian" in writing on the matter was less charitable in his censure of the Record:

When the editor of a scientific journal designedly stoops to malign a sister science, simply because her votaries are, as yet, numerically weak, it exhibits a development of unwarrantable bigotry that is a disgrace to an enlightened country in this period of the nineteenth century. . . . Comparisons are usually the most odious when founded in unpalatable facts, and it was probably owing to his memory of professional forefathers who, as Greek slaves, were keepers of the Roman bath and barbers, that he made reference to their vocation and deficient knowledge of dermatology.... The virtue of the medical profession is not entirely above reproach ... . we need not go beyond the confines of New York city to find practices perpetrated under the wing of the medical profession that would put to the blush the barbers of any age.

As in most cases where a wide divergence of opinion exists, the truth of the matter usually lies somewhere between the two extremes. Admittedly, there was some truth in the charges made by both sides, and it seems that Liautard's gentle chiding was justified. But despite the fact that there was some basis for the fulsome (fivepage) indictment of the medical profession made by the latter writer, it may be doubted that he accomplished much except to further alienate the veterinary profession from its prospective friends.

\section{Worthy Physicians}

In considering the attitude of the medical profession toward veterinary medicine at this time, it must be recalled that many medical practitioners were yet of the nongraduate and noneducated variety, or were 
graduates of schools that were no better qualified to serve the interests of the public than were some of the more poorly equipped veterinary schools. Worthy physicians, however, generally had a good appreciation of the value of veterinary medicine. In 1878 the Medical Society of Harford County, Maryland, adopted the following resolution:

Whereas, In consideration of the fact that there are so few educated Veterinary Physicians in our county, notwithstanding the existence in our midst of such an immense number of domestic animals, so essential to man's use and sustenance, at all times liable to require the physician's aid; therefore be it

Resolved, That we of the Medical Society of Harford county, Maryland, suggest to the American Medical Association .... and respectfully advise it, in the exercise of its weighty and wide-spread influence, to recommend the establishment of Veterinary Colleges, to be conducted by strictly scientific professors; and that the Association also advise many of the young men of the country to enter this new and ungleaned field, instead of increasing the already overcrowded ranks of the regular medical profession.

While this resolution might have been prompted in part by the contention that the medical profession was overcrowdedwhich it was, especially with the more poorly qualified practitioners - there seems to be no doubt concerning the sincerity of this group. Dr. W. S. Forwood, who introduced the resolution, adds:

From the fact that the unskilled have had and still have it in their hands, it has brought the profession into disrepute. Do away with such ignorance and educate the people, or rather a doctor for such cases. As the medical field is crowded, so the field in veterinary surgery is open. The practice would be more lucrative than the regular profession for a time at least. ... Some would object to the respectability of the veterinary, but it is just as respectable to treat lower animals as the higher.

In all fairness, it should be noted that the Medical Record freely criticized the medical profession also, although perhaps in not such direct terms. In commenting on the fact that a sampling of pigs at the Chicago Stock Yard in 1881 failed to re- veal any cases of trichina, it states: "These results, however, are different from any previous one, and the Board of Health contents itself in advising that all pork should be well cooked." In 1882, the Record noted approvingly what amounted to the amalgamation of the New York College of Veterinary Surgeons with the College of Pharmacy, as "a convenient and fortunate one for both parties." And in 1883 it reported that in an address before the Kentucky Medical Society "the practice of veterinary surgery was commended to young men." Also, the recent discovery of actinomycosis in American cattle "should become promptly known to veterinarians and sanitary officials." The American Veterinary Review had been running a series of articles on this subject, written by George Fleming, but the first notice of the disease in America did not appear until a month after it was noted by the Record.

One evidence of the interest of the medical profession in veterinary medicine is the number of physicians who were called upon to address graduating classes. In 1878, J. C. Dalton, of the College of Physicians and Surgeons, in suggesting the value of preventive medicine to graduates of the American Veterinary College, states:

There is a vulgar notion that to prevent disease would be against the interest of the veterinarian, because it would lessen the number of his patients. I need hardly ask you to repudiate this idea, not only because it is degrading, but also because it is false... . There is no danger that the owners of animals will not always need the advice and skill of the veterinarian. . . Beside, the more good veterinary medicine shows itself capable of accomplishing in this respect, the higher will it stand in the estimation of the public.

And J. W. S. Arnold, of the University Medical College, states:

Perhaps I am influenced in your favor, for the reason that so much good physiological work has been done in veterinary schools, by veterinary men. ... And yet, we must, upon critical examination, come to the conclusion that our foundation stones are not rightly placed ... physiology, although beginning to take its place among the foremost departments of medical science, is still an unfinished pillar 
in our edifice. To the advancement of experimental medicine must be looked for the greater perfection of practical medicine. The rehearsal of cases, which crowd our medical journals, do little or no good to the cause; the fashion is to hurry into print an account of the first case which comes into the hands of the young practitioner. To what end? Why, to waste paper and ink in most cases. .. . Those who are in the ranks of medical men, be they horse doctors or man doctors, either take no interest in these higher studies, or being ignorant or indolent, they decry true scientific work because they can see no practical applications. This desire for instantaneous practical results is the damnation of true science. ... You can demonstrate to the commercial mind how necessary it is that Veterinary science should be extended.

\section{Advent of Anesthesia}

One measure of progress of the veterinary profession is the use of surgical anesthesia where indicated. In speaking of the responsibilities of the veterinarian in proper restraining, Liautard states in 1882:

It is in that responsibility that the duties of the veterinary surgeon become equal, if not superior to those of the human surgeon. When the latter has an operation to perform he has his patient brought before him and placed under the influence of chloroform.... The veterinarian, on the contrary, has seldom occasion to have recourse to perfect anesthesia, but very often is obliged to secure his patient in such a manner that by his movements the operation is not rendered more difficult, or the life of the operator or of his assistant endangered.

\section{And later:}

The benefit that the surgeon obtains by the use of anesthesia is undoubtedly of greater importance in human than in veterinary medicine. With the former, besides the relief from pain, there is that of nervous shock or moral influence, which plays so important a part in the recovery of the patient. With the veterinarian this last condition scarcely exists, if it does, and probably for this reason anesthesia is not so commonly used. . . There are, however, peculiar conditions where it becomes a necessity, and in which neglect of employing it might give rise to severe complications. Amongst those are the operations which, at times, rare as they may be, are performed upon the eyes, or in cases of hernia.

The use of anesthesia appears to have been taught at the American Veterinary
College from the beginning, if the number of case reports mentioning its use are a criterion. Among the relatively few surgical cases reported in the first volume of the Review is one in which a mixture of ether and chloroform was used in fracture reduction, and one with chloroform for removal of a tumor. Frequent mention is made of the use of chloral hydrate as a sedative. In 1880, C. H. Peabody, an A.V.C. graduate, read a paper on "Chloral Hydrate as an Anaesthetic for Operations" before the USVMA, stating:

Never having seen any report made of its having been used as such, I take this opportunity to report a few cases in which it has given me satisfactory results.

Among the cases reported were prolapse of the uterus, fetlock injury, scrotal hernia, puncture wound of foot, and ovariotomy. Another veterinarian, J. C. Corlies, reported good results in a case of fracture reduction, and for firing, stating: "We have practiced the use of chloral in a number of cases before, but not with the same degree of success."

The use of anesthesia apparently increased beginning about 1882 , some thirty cases being reported in a period of five years. Mention is made, in the first volume of the Review, of the use of morphine for colic-ending in tetanus, apparently introduced by the hypodermic needle. Both morphine and atropine were used to some extent; in 1885 a layman reportedly gave an aged horse forty grains of morphine:

to get rid of him by as painless a death as possible. . . Having made preparations for the funeral, the grocer proceeded to the stable, where, to his astonishment, he found the horse in excellent spirits.

And a veterinarian in 1886 reported giving sixty grains of morphine to a mare for whom the farmer had already dug a grave: "Next morning she was livelier than she had been for years before," so the owner had her shot.

The first mention of the use of cocaine appears in 1885, when G. C. Faville re- 
ported its use for removing a foreign body from the eye:

The introduction of any preparation into the veterinary pharmacopeia that will aid the operator in performing the minor operations, either by aiding in the control of the animal or by rendering the pain less acute must be hailed with delight. The experiments that have of late been made by members of the sister profession, in the use of muriate of cocaine, have been of great interest and the question must have come to many, why cannot this drug be used as well in veterinary practice. . . The small amount needed for ophthalmic surgery renders its use within the means of anyone; and its perfect action in so far as my experience goes, renders its use desirable.

Veterinarians were quick to seize upon this new adjunct to practice; for removal of a tumor of the eyelid, C. L. Moulton states:

After consulting with an eminent ophthalmist in practice here, I concluded to try the new anesthetic "muriate of cocaine:" and I must say the results exceeded my most sanguine expectation.

And again the same year, C. C. McLean reports its use for neurotomy, with "no manifestation of pain." On the other hand, J. W. Scheibler, A.V.C. house surgeon, reported failure to obtain anesthesia with cocaine in an operation for urethrotomy in a male camel, its struggling rendering the operation impossible.

In writing on "Hydrochlorate of Cocaine in Neurotomy," H. F. James of St. Louis credits C. C. McLean with "introducing cocaine to the profession in connection with the operation of neurotomy." He says:

Neurotomy is acknowledged to be the most painful operation we are called upon to perform, and heretofore, owing to our reluctance to use chloroform on horses, their sufferings were unavoidable. Here we have a drug, cheap in price, easily used, which does away with all this needless suffering, and enables us to do the requisite cutting neatly and quickly; therefore I think I am not speaking too strongly when I say, that the hypodermic injection of cocaine will soon be accepted by advanced veterinarians as an integral part of the operation.

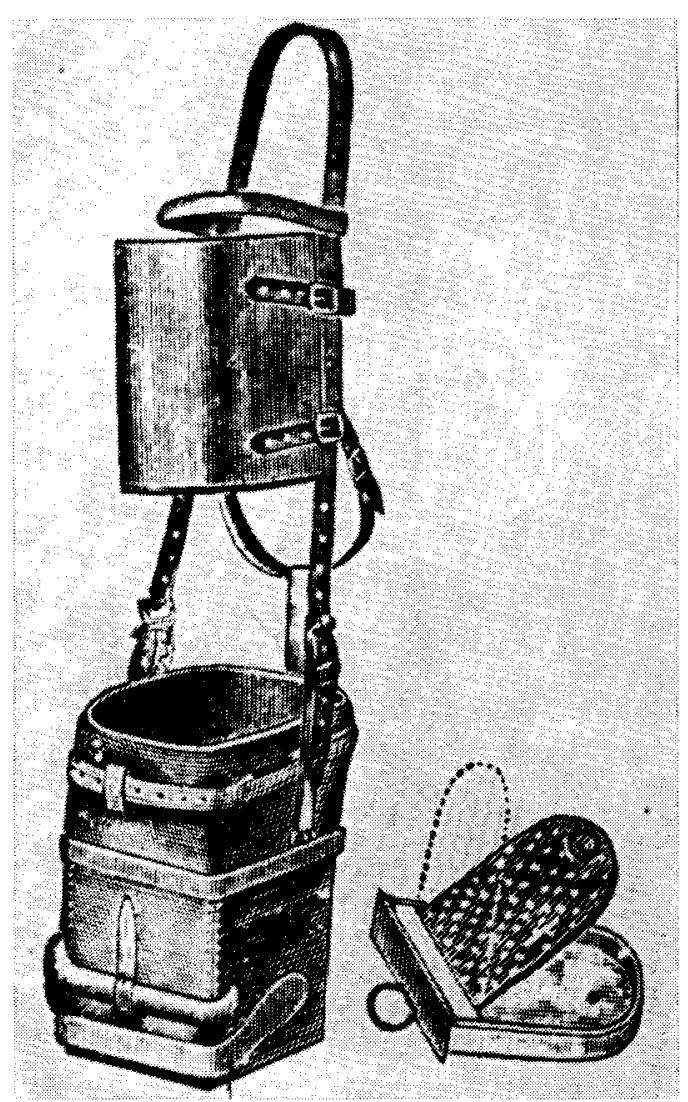

Inhalation apparatus of European design was introduced here during the 1870's and 1880's, but this proved cumbersome for practitioners working alone, and it was not until local anesthetics were introduced about 1890 that this adjunct to surgery was widely used. Liautard: Surgery

\section{Society Affairs}

What appears to have been an extracurricular activity of the American Veterinary College, but one of academic significance as a means of elevating the standards of its graduates, was the College Medical Association. As reported in 1883:

This Association, which has been in existence since the first session of the college, was organized for the purpose of educating the student how to write on veterinary subjects. . . . The subjects are assigned at the close of the session to each of those who are to constitute the next year's senior class. The society meets once a week during the entire session, and at each meeting a paper is read by some one, and discussion or debate follows - the writer to de- 

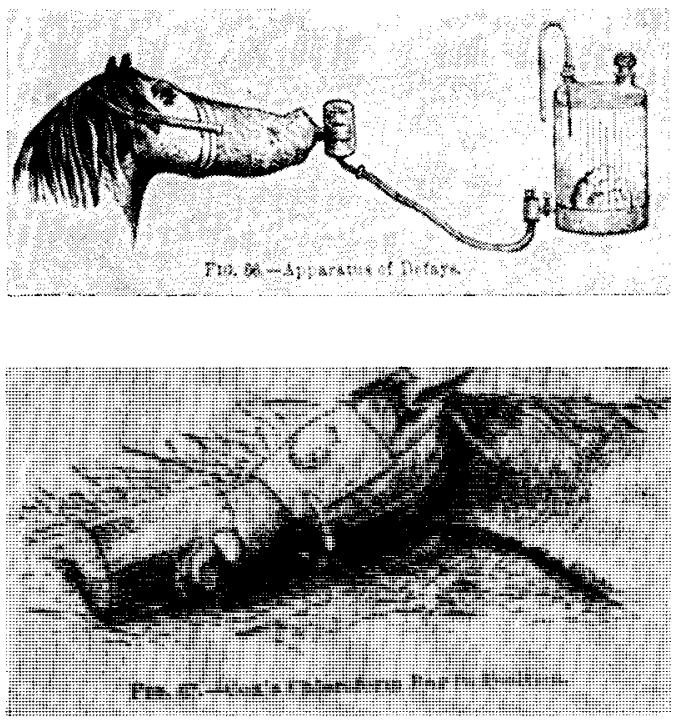

Some anesthetic machines employing principles used today were devised during the late nineteenth century, but without a suitable technic for presedation the excitement stage with chloroform anesthesia rendered all but the simplest devices hazardous. Liautard: Surgery

fend his opinions advanced as best he can. The president, a member of the Faculty, as a rule devotes a few minutes to remarks on the papers and discussion.

The Review gave considerable space to reports of local and state veterinary societies as these were formed. The first such report in 1877 is one of the Montreal association, formed in 1875 , one of the earliest to be established. Also reported is the formation of an association in Rochester, New York, and that of the Alumni of the American Veterinary College. Meetings of the New York State Veterinary Society, founcled in 1876 , were reported in the Review in 1878. With both the New York State Society and the USVMA frequently meeting at the American Veterinary College, together with the College and Alumni Associations, the "comings and goings" at this institution must have been considerable. A number of the stalwarts of the profession were active in all four groups.

The Montreal association appears to have been one of the most active groups from its inception; in 1879 its library contained nearly 300 volumes; that of the USVMA after 15 years, still had practically no books. In 1880 the Montreal Library was "one of the most valuable on this continent, containing all the oldest and most recent works on veterinary and collateral sciences." William Osler, M.D., was vice president and later president of the Montreal association. In 1882 he reported on experimental tapeworm infection in a calf. Appearing later in the Review, this is an early account of laboratory investigation.

By 1885 the Review carried reports of veterinary associations in Masachusetts, Connecticut, Indiana, Pennsylvania, Michigan, Ohio, New Jersey, Wisconsin, Ottawa, and Philadelphia, in addition to those mentioned earlier.

In 1883 Liautard issued a strong blast against the proposal of the United States Veterinary Journal that the various state associations "send delegates to a national convention to be held in Chicago, on December 12, 1883, having in view the object of forming a United States Veterinary Medical Association." Noting that the USVMA was already in its twenty-second year, and had a "large number" of members in twenty states - "all graduate veterinarians" (?) - Liautard states:

It seems to us that the time has indeed come for the veterinary profession of the country to show these gentlemen, well meaning though their intentions may be, that there are enough veterinarians in good standing in the country to manage their own affairs without being interfered with or advised by others whose interests might be interpreted as being more in behalf of their monthly publication than in that of the profession.

Yet, in an apparently equivocal stand, Liautard had stated only a few months earlier in championing the formation of state associations:

and when once each State in the Union has her State Veterinary Medical Association, how easy it will be for all to unite under a grand body, the American Veterinary Association. . . Regular graduates may have, and again try by years of labor to elevate the pro- 
fession from its low standing. Private veterinary schools may by degrees and with time have succeeded in throwing through the country enough educated men to chase the ignorant from the place they now occupy - but how many long years would it have taken? Illinois has done it at her convention - and we believe it can be done all over the country. And the essential factor, in fact the one without which it probably would not have taken place is ... that the majority of these men were self made men.

Thus it would appear that Liautard actually envisioned two Associations: the USVMA, composed only of regular graduates, and an American Veterinary Association, with delegates from state societies for some time perhaps composed principally of nongraduates.

Veterinarians west of the Alleghenies had been dissatisfied with both the USVMA and the American Veterinary Review, feeling-and with justification that these represented only the eastern interests of the profession. Apparently learning of this discontent, T. E. Daniels, a printer, seems to have conceived the idea of supplying this segment of the profession with a journal and an association - even to usurping the name of the established Association. A. H. Baker, of the Chicago Veterinary College, appears to have been editor of the U.S. Veterinary Journal during its brief existence; publication ceased with the first number of the third volume. One thing the Journal was successful in accomplishing was the formation of several state veterinary societies, for which it served as an official organ. This appears to have been a part of the over-all scheme, for the proposal to form a national association called for each state society to send delegates for this purpose. Liautard protested that representation "only by delegates" would result in an organization which "could not have a national character." This, however, is the plan adopted by the AVMA in the 1930's.

Competition, or merely the fear of it, can be a good thing, and as an obvious consequence of this threat, Liautard suggests:
If any good can be derived from the intended convention, all that can be expected is that more veterinarians can be induced to send their names for admission to membership to the old Association, and by thus having a larger number of representatives in the different States, the meetings could be held in places other than those where it has been found necessary to have them, so far, on account of the limited number of members belonging to it that reside outside of the Eastern States.

This was in December, 1883; at the semiannual meeting in March, 1884 "after considerable dispute, the selection of the next place of meeting was left to the Comitia Minora." In July it was decided that the meeting should be held in Cincinnati.

\section{Westward Ho!}

That the current provision for automatic rotation of the general area for the annual meeting is a wise one, may be appreciated by considering the long years of domination by one section. How close the 1884 meeting came to being held in New York instead of Cincinnati is of some interest in demonstrating, if not determination to maintain the status quo, at least the force of inertia. The Comitia Minora, consisting of the officers and Board of Censors of the Association met at the American Veterinary College. Drs. Stickney (Boston), Hoskins (Philadelphia), and Lockhart (New York) were absent. President Miller (New Jersey), Secretary Michener (New York) and Drs. L. McLean (Brooklyn), Burden (New York), and Liautard, Robertson and Coates (A.V.C.) were present, Robertson and Burden proposed Cincinnati; McLean and Michener favored New York, and only after consiclerable discussion was the western location decided upon.

In editorializing on the matter, Liautard states that those who favored keeping the meeting in the East were sure a quorum could not be obtained elsewhere:

If this is to be true remains for the Association to decide. If there is not enough professional ambition amongst the forty or fifty members of the Association who belong to 
the East; if the apathy characteristic of the American veterinarians cannot be shaken enough ... of course there will be no quorum; there will be no meeting; there will be a great failure, a great joy for those who are enemies of the Association - and the next best thing that the U.S.V. Med. Association will have to do will be to die, to cease her labors as unworthy of being a national institution.

Thus it may be seen that this move was one which might make or break the USVMA, and it appears that Liautard was the prime mover in urging that this calculated risk be taken. Perhaps few appreciated, as did Liautard, the full significance of this move. He saw it as the only logical step to put a quietus to those western interests that might have attempted a rival organization. But more than this, he saw it as an opportunity for the USVMA itself to become truly a national organization. Although the attendance at Cincinnati was not large, the meeting was a success, and resulted in the election of the first two western members to the Board of Censors; John Meyer, Sr., of Cincinnati and W. J. Crowley of St. Louis. Liautard characterized the meeting:

as successful as any the Association has ever had. ... It must, however, be conceded that the Western delegation was not as fully represented as was desirable.

The meetings returned to Boston and New York for the next five years, except that semiannual meetings were held in Philadelphia and Baltimore. An inconspicuous notice appeared in the Review for February, 1890, stating that the Comitia Minora would meet that month to determine the place of the September meeting, and: "Those desirous of offering inducements or pleas for the place of meeting will be granted a hearing." Just what inducements were offered and by whom does not appear to be a matter of record, but in April an equally inocuous announcement was made that the meeting would be held in Chicago. As events were to prove, this was a momentous decision, for from this time on the monopoly of the eastern seaboard was broken. The United States Veterinary Medical Association had come of age in its twenty-seventh year.

\section{LEGISLATION AND EDUCATION}

Another important function of the American Veterinary Review was the urging and reporting of legislation to prevent or control the spread of animal clisease; to establish a national veterinary sanitary commission; and to define and protect the status of the veterinarian. In the first volume of the Review, Liautard urged that steps be taken to place the well-qualified, but self-educated, practitioner on the same footing as the graduate, i.e.:

a recognized member of the profession ... we think it could be done in the same way as the human Medical Profession has done for some of its irregular.

If we look amongst many of our States, we will find that each one possesses a number of regular graduates, sufficiently large to organize and form a State Veterinary Society. Could not the same obtain, from the Legislature of their State, acts of incorporation, granting them the power to deliver the Degree of Licentiate to all those who would apply for such degree, providing they would submit themselves to certain rules and regulation as provided by a Board of Censors of said Society.

Such a move, Liautard believed, would be "a great step forward in the advancement of our noble art, and, we believe, a terrible blow to quackery and ignorance."

In commenting on a bill to regulate the practice of veterinary medicine, introduced in the New York State Legislature in $\mathbf{1 8 7 8 ,}$ Liautard states:

It seems to be almost a wonder that at last the veterinary profession should have been sufficiently appreciated by some to induce them to work in behalf of veterinary medicine and present that bill at Albany. To the Society for the Prevention of Cruelty to Animals the veterinary profession of the State of New York is indebted for the step thus taken-and it is but natural that it should come from that honorable body, for both the veterinarian and the officers of that society ought to work together.

As we go to press we are told that a deputation of physicians and horse doctors are to be received... to protest against it. ...W 
doubt if regular physicians, men of education, would dare to speak against this bill ... and if so-named horse doctors join them, we cannot feel afraid of their attempts.

The bill called for a five-man board of examiners: three graduate veterinarians and two physicians, who would grant licenses upon the satisfactory passing of an examination by nongraduate candidates. Graduates of veterinary colleges, or of veterinary departments of agricultural colleges were to be licensed without examination. Practice without a license would constitute a misdemeanor. This did not pass upon its first introduction; later in speaking at the American Veterinary College, the Hon. E. T. Gerry:

strongly recommended united action on the part of veterinarians and of the different schools in the country, saying he had no doubt that the bill would be passed by the next legislature.

In speaking before the same group, Henry Bergh, Society for the Prevention of Cruelty to Animals president, stated:

Owing to the absence of any restraining power on the part of the law, the most densely stupid blockhead may, after a brief experience in a farrier's shop, nail up his "shingle," as the dishonored piece of wood, bearing his name upon it, is called, and henceforth insult science by calling himself a veterinary surgeon! ... Poisons the most active, blistering, firing, purging, along with the knife, the scalpel and the saw, are the barbarous instruments which these merciless ruffians employ to torture the hapless animal with, and astonish the humane and terrified beholder. . . . To put a stop to these inhumanities, as well as their kindred abomination-vivisection, the Society I represent has made repeated and earnest applications for redress to the Legislature, through its counsel, Mr. Gerry.

Speaking of the bill which "through some unknown cause was pigeon-holed, and probably will never again be brought to light," Liautard states in 1879: "The need still exists, and perhaps more than ever is strongly felt by every honest practitioner." As a. substitute measure, he printed the text of a bill "adopted for presentation to the Legislature," by veter- inarians of New York and Brooklyn. This provided for the establishment of a State Veterinary Society with powers to examine candidates and grant the degree of "Licentiate of Veterinary Medicine." This, obviously, was Liautard's original scheme, but there seems to be no record that the bill was ever presented.

In 1881 a bill was introduced in the New Jersey Legislature which would restrict the use of any degree designation to graduates of legally chartered schools, but did not prevent nongraduates from practicing so long as they conformed to this provision. This failed to pass.

\section{The Best We Can Get}

In 1882 Ezra Mink, a nongraduate of Rochester, New York, offered what appears to be his version of a bill which: "I think we can procure the passage of. I think it is the best we can get at present." This called for licensing only graduates of recognized schools, except that any person twenty-five years of age who had been practicing for three years would be exempt from this requirement, provided:

that he can read and write; and that he has in his possession some work or works recognized as authority, that he has read and studied ... that he has knowledge of arithmetic and of pharmacy sufficient to enable him to combine or compound, and to dispense drugs in a practical and intelligent manner and with ordinary safety.

Mink states that medical practice acts so far adopted had all been "prospective and not retroactive," several exempting anyone who had been practicing from two to ten years.

A simpler version of such a bill was read twice and referred to and reported favorably from the Committee on Public Health of the New York Senate in 1882. This provided only that a diploma would be required of those who "shall hereafter practice veterinary medicine and surgery," apparently exempting anyone already in practice. Liautard objected to a bill such as this on the grounds that: 
Far from being an act to regulate the practice of veterinary surgeons, and for the better protection and for the more humane and scientific treatment of dumb animals, if passed, it would prove the most dangerous blow that the advancement of veterinary science could receive, and the clearest recognition of ignorance and quackery. . . . Let us have the power to admit into our ranks good men, but not every one.

While it might be supposed that many nongraduates would have favored a bill with no restrictions on those already in practice, G. H. Kidney, V.S., writes, concerning Mink's bill:

I am not a graduate of any medical school, but have been practicing veterinary medicine for fifteen years, and should the bill become a law, I willingly will give up the practice if I cannot pass the examination required.

It is obvious that at least some of the better qualified nongraduates could have been excluded. Coupled with a provision for admitting graduates without examination, this could have been a grossly unfair practice; it was well known that many nongraduates were far superior to some with diplomas. And while the better class of nongraduates would have had little to fear from an examination, presumably there are veterinarians today who after fifteen years of practice might have trouble with some of the state board examinations.

\section{Problems in Pennsylvania}

In 1883 a bill to regulate the practice of veterinary medicine in Pennsylvania called for licensing without examination any graduate of a legal school, and required that veterinary schools-presumably in Pennsylvania:

shall upon application, without examination, issue a diploma to any person who has studied, or may study for five consecutive years in the office of a practicing veterinary surgeon ... or who has for five years before the passage of this act been continuously engaged in the practice of veterinary surgery and medicine.

Others were entitled to a diploma after examination. As it might be supposed, this monstrosity was opposed by the Keystone Veterinary Medical Association, and in commenting upon its defeat, W. $H$. Hoskins, secretary of the Association stated:

It contained so many vicious features that the Society at a previous meeting determined to oppose and were rewarded by a severe defeat of the bill.

At this time the Pennsylvania College of Veterinary Surgeons employed a preceptor system of instruction. Concerning the College, James T. Ross, V.S., recalls much later in a letter to Dr. G. H. Hart:

it was composed of a number of Doctors all practitioners who took one or two students each. And each had their own way of teaching them. James McCourt was president M. W. Birch \& son Vice President James A. Marchall was secretary. They held meeings once every week. . . . Now I was with M. W. Birch and Son .... as was also Joe Burns of West Chester and also Harry Hahn \& also Chas. Devlin.

Now we studied Strangeways Anatomy did our dissecting at Jacob Meyers place 2 afternoons each week. Jake would give us any portion we would want and put it on the bench for us ... our equipment was not just as nice or up to date as at Penn. But never the less we did pretty well at that, Now we were quizzed one hour every afternoon on what we had dissected previously.... We were taught practical pharmacy every day for we had a lot of that to do, You can imagine when we had to compound all medicines and blisters and ointments and liniments \&ec for all the Car Stables, We had 1300 head at the 2nd and 3rd St. line 800 head at Frankford Road and Lehigh Ave. \& 500 head at Richmond St. \& Allegheny Aven. and many more large Stables. ... And every private stable in that Section. ...

I will never forget when I was going over to Penn. in Oct. 1884. Dr. Glass taught us to make a cantharides blister and we used petrolatum for a base, Well it made a nice looking, ointment but it was not a blister at all, But when I used lard in the same proportion I got an Edenia about 2 in. high I never use petrolatum after that.

Dr. Hoskins apparently had his reasons for protesting the practice act.

A bill introduced in the Illinois Legislature the same year would require that the candidate for licensure hold a diploma from: 
a college authorized to graduate students in veterinary medicine and surgery, or is a recognized member of the Illinois State Veterinary Medical Association or who has passed a satisfactory examination before an appointed board for that purpose.

To be eligible for membership in the Illinois Association, a nongraduate had to have been in practice for two years and present certificates from two physicians as to his standing-as a veterinary practitioner, to be eligible to take the examination of the Board of Censors of the Association.

\section{Legal and Just Legislation}

The problem of what would constitute both legal and just legislation is pointed out by A. J. Murray in 1883 on the occasion of formation of the Michigan State Veterinary Medical Association, which patterned its structure after that of Illinois. Regarding the admission of nongraduates, Mr. Daniels, of the U.S. Veterinary Journal, who had been instrumental in having several state conventions called, urged:

If the lines of the society were drawn too tight, so as to exclude existing non-graduate practitioners, no bill would be obtained from the Legislature to protect the veterinary profession, owing to the small number of members forming the State Veterinary Association.

Although the wording of this seems to carry a veiled threat, Murray recognized that there was some truth in the proposition:

but to overcome this obstacle by adopting into the profession a large number of non graduate practitioners, would be a most ruinous policy. It will be necessary for the veterinarians of each State to wait until they are in position to ask for a protective law, and it would be a very injudicious policy to ask for such a law too soon, as it would be courting certain defeat. The status of the veterinary profession is at present low enough . . . it would become very much lower, by adopting into the profession a large number of veterinary practitioners who have received no professional education, and would also place the State veterinary societies in the position of competitors of the veterinary schools. . . . It is obvious enough that the State veterinary societies may accomplish a great deal of good to the veterinary profession and to the people in general, by using their influence to improve the laws relating to the diseases of animals, but it is well that they should not be too active, and that they should not attempt to accomplish that for which neither the profession nor the people are prepared.

One difficulty-perhaps the major onein getting a bill passed in New York was the lack of unanimity of veterinarians. The New York Veterinary Society, composed chiefly of graduates in and around New York City, apparently would have liked to see only graduates licensed, but proposed a bill which would place the examination of nongraduates in their hands. The New York State Veterinary Medical Association (founded upon Mr. Daniels' uring), composed largely of nongraduates in outstate New York, quite naturally opposed such a proposition, and an apparent compromise, with two examiners from each group and a fifth to be agreed upon by the four, was drawn up for presentation to the Legislature.

After a second look at this bill, however, members of the outstate Association discovered that no provision was made for disposition of the records of the examination. In presenting a substitute bill, the sentiments of the group were:

The New York city societies seem to think that all authority and control over the practice of veterinary medicine and surgery should be placed by law in their hands to be wielded by them as they may see fit. . . . The veterinarians belonging to the State society seem to have two chief objects in view. The first is to exterminate old practitioners ... unless they can pass an examination ... [and] this bill does not guarantee that an impartial practical examination will be given. . . They seem perfectly oblivious of the fact that in the rural districts throughout the State scarcely a single veterinarian who is a graduate of some college can be found. ... The principal leaders in this crusade against old and non-graduated practitioners, are those who are directly interested in the profits and emoluments arising from conducting veterinary colleges. ... We are forced to conclude that their second object is to bring shekels to the coffers of these colleges. 
The bill proposed by the outstate group provided for an examining board appointed by the Regents of the University of the State of New York, and that its reports be made a part of the public record. Although objection to the other bill was made on the grounds that it was "an obnoxious species of class legislation," the substitute bill provided for awarding the degree, Doctor of Veterinary Medicine, to nongraduates who could pass a satisfactory examination. Or nongraduates could merely register "and continue their accustomed practice undisturbed."

Liautard regretted "that so invidious an imputation of partiality and wrong motive should be made," especially in that the author of the tirade against the "big-city interests" was a recent graduate of his school. After evaluating the differences of opinion, Liautard urged:

Let, then, all the clauses requiring an examination be cancelled; let all who are now earning their living by the practice of veterinary medicine be authorized to register. . . But let us have a law which, if of no special advantage to the present generation, will protect the next.

The matter of examination undoubtedly was the stumbling block; when the provision for it was removed, relatively speedy passage of a bill was effected.

\section{Legislation vs. No Legislation}

In noting the passage of the New York bill in 1886 after innumerable delays, Liautard states:

When the various veterinary bodies became willing to forego private feelings in order to organize into one society . . . when the interests of one had become the interests of all, the result was no longer to be doubted.

But concerning the benefits to be derived from its passage, he continues:

Upon a cursory reading, the profession in the State would seem rather to have been lowered than elevated by accepting such legislative regulation. But . . careful consideration ... will bring to the mind the unavoid. able conclusion that it is not only a regulation of our profession, but is a death blow to quackery. ... While the present generation may derive but little benefit from the act, the coming generation will profit by it to such an extent that before many years have passed, no one in the State of New York will be found practicing veterinary medicine without having been regularly educated and graduated.

He notes that New York had the first veterinary schools, the first state veterinary society, and now: "She is the first to give legal recognition to the profession, and to take a decisive step towards the extirpation of quackery in the country."

W. H. Lowe, State Veterinary Inspector for New Jersey, however, took a stand quite different from that of Liautard. Admitting in 1886:

There are a few non-graduates in our State as worthy, and, if you please, more worthy than some graduates, yet I believe we have to draw a line of demarcation somewhere, and where shall we draw it if not between the graduate and the non-graduate? I believe that there are a few self-made veterinarians in the state that a license should be given by the State society. . . But I do not believe that they should be admitted to regular membership in scientific societies... we must have societies of graduates or societies of quacks. . . It is impossible for educated veterinarians to discuss scientific subjects with ignorant "horse doctors."

While Lowe would like to see a "proper" veterinary bill, he did not want one "legalizing the quacks of New Jersey," as New York had just done:

I consider this is not as good as none at all. Before the bill passed a quack was a quack, and a graduate was a graduate, but now all the quacks ... have become legalized practitioners ... [ who ] take special pains to inform the public that they are "registered veterinary surgeons," and display certificates in an unbecoming manner. . . The legislative Act in question, puts the college graduate of the nineteenth century and the illiterate, uneducated "horse doctor" on an equal footing, while it protects a generation of veterinarians yet unborn. In my opinion we are far better off here in New Jersey without any legislation on the subject.

Actually, through defects in the New York bill as passed, the situation was worse 
than suggested by Lowe. Far from being the bill presented to the Legislature, as related by Liautard:

The text of the Act had been garbled, mutilated, emasculated, and the entire essence of the law eliminated. ... Instead of protecting the qualified practitioner by proper conditions and restrictions against the charlatan and pretender, it practically protected the ignorant pretender against the trained scientist, and threw the field open to whosoever might feel a desire to occupy it.

The most objectionable features of the bill, of course, were subject to amelioration by "tincture of time," and some improvements were effected by emendation.

The full story of veterinary practice acts would require a sizeable monograph itself. At this point it will suffice to say that other states had more or less similar troubles, but as in New York, veterinarians made every attempt to secure the best for the profession that could be obtained-although in some cases this came most belatedly. Of some interest is the fact after passage of the New York bill, sixty-five graduates and ninety-nine nongraduates registered in New York City and Brooklyn, one nongraduate by "making his cross." In some outstate counties, nongraduates outnumbered graduates by ten to one.

Concerning the agitation by veterinary societies at the turn of the century for legislation to define and protect the practice of veterinary medicine, J. W. Parker, in adopting a broader concept than many, states:

The concentrated primary aim of veterinarians, relative to needed legislation ... must be to inform the public by precept and example that the profession is one which should be regulated by law - that the demand for legislation in these matters arises from the needs of the public. . . Whatever degree of respect the title "veterinarian" commands is the result of the silent teaching of a very limited number of veterinarians, and in spite of the disrepute resulting from the itinerary practice of hundreds of quacks. . . . As veterinarians we must therefore become practical politicians and lobbyists; must be known as local writers for the secular press, and as speakers on all suitable occasions. We must cooper- ate with mind, money and motive, and above all and including all these must be imbued with professional esprit $d u$ corps, and actuated by altruistic motives.

\section{Upgrading by Examination}

The salutary effect of state examining boards upon the veterinary profession may be surmised by the nature of questions put to candidates at the second examination of the Pennsylvania board in 1896. The examinees were required to answer ten of fifteen questions in each of eleven subjects, and to attain a grade of 65 per cent on the examination, which required two days. From the nature of the questions, it would appear that the veterinary profession in Pennsylvania was in good hands; samples of questions in each subject follow (in abbreviated fashion):

Diagnosis: Give symptoms of spavin, traumatic pericarditis, mange vs. eczema in dog, shoulder vs. foot lameness, navicular arthritis, laminitis, anthrax in cattle. How are tuberculin and mallein administered, and what constitutes a reaction?

Veterinary Practice: Give causes, symptoms and treatment of polyuria, pleurisy, choke, osteoporosis, hog cholera, periodic ophthalmia, milk fever.

Sanitary Medicine: What measures are required to suppress and eradicate contagious pleuro-penumonia, tuberculosis, glanders? How would you demonstrate the contagiousness of rabies? Under what conditions would you condemn meat and milk for human food? Describe the duties of a slaughterhouse inspector.

Surgery: Give symptoms and surgical treatment for: pus in maxillary sinuses and gutteral pouches, roaring, quittor, spavin, paraphimosis, conjunctivitis, stringhalt. Describe operations for tracheotomy, ovariotomy in bitch, impaction of rumen.

Zootechnics: Describe an eight-year old mouth, a Friesan cow, signs of a good milk cow. Define atavism, precocity, hybridization. Give ages of puberty in domestic female animals.

Therapeutics: Give uses, doses and contraindications for camphor, opium, chloral hydrate, belladonna, lobelia, chloroform. Give antidotes for opium, lead and arsenic poisoning. Write a prescription for purpura. How would you disinfect a stable?

Obstetrics: Give causes of sterility, signs of pregnancy, gestation periods, diseases peculiar to pregnancy, accidents of pregnancy, stages 
of parturition. How would you deliver a mare or cow with sterno-abdominal presentation, head retained? Describe hygiene of pregnancy, normal parturition, fetal circulation.

Chemistry: Define chemistry, element, atomic weight. Give tests for sodium, copper, arsenic, albumen and sugar in urine, a case of lead poisoning in a cow from its milk.

Anatomy: Describe the bones of the pelvis, a dorsal vertebra, the flexor pedis perforans, ligaments of the fetlock, plantar nerves, arterial supply of the foot. Give regional anatomy in low neurectomy, difference between lungs of horse and cow.

Physiology: Describe salivary, gastric, intestinal digestion. Give functions of the liver, lungs, testicles. What is the source of bile pigments? What is chyme?

Pathology: Define inflammation, glanders, tuberculosis, malignant tumor, leukemia, anthrax. What is the cause of moist gangrene? What are the terminations of inflammation?

At this point it might be pertinent to ask: "What is your score?"

That the idea of a National Board of Veterinary Examiners had already been conceived is evident from an editorial in 1896 on "Uniformity." The Association of Veterinary Faculties of North America had concluded:

that the State Boards should be organized as far as possible upon the same lines, that the requirements should be similar, and that the action of any single board should be recognized by the others. In this way a license obtained by an applicant would be accepted in any other state of the union having a similar examining body.... [and] would as nearly approach the much-discussed "National Board of Veterinary Examiners" as it is possible to attain.

At this time eight states had similar requirements. Liautard notes that New York, under the Board of Regents, had "obtained more than she needed."

\section{The Continuing Quest for Status}

In writing on "Physicians as Veterinarians" in 1878, a senior medical student states:

You speak of the "false pride of the doctors." That may be the case with some, but the difficulty often lies with public opinion. There are plenty of tender hearted physicians, who possess the requisite knowledge, and would take pleasure in giving relief publicly to suffering animals; but I know of cases where it is thought necessary to treat them on the sly, the owners promising secrecy. I am a medical student in my last College year, having a knowledge of comparative as well as general anatomy, and an understanding of the commoner diseases among domestic animals. This summer I undertook the treatment of several horses and was quite successful. For this I was censured by half the old ladies, as well as a great many men.

As a student in his last year I am allowed to practice, and have had many cases, and some admit having received benefit from my treatment. Yet the influence of their acquaintances was so great, that I was discharged by them because I dared give relief to a suffering brute. In fact many would hurt me all they could, saying, "He's only a horse doctor." Is it any wonder that physicians fight shy of such criticism? I have not the least doubt, if the public would consider it honorable for a physician to relieve suffering anywhere that life exists, that the Medical Colleges would not be slow to take up more of the diseases of the brute and their treatment. It is my intention to, if possible, practice on man or beast, giving relief wherever pain is found, pay or no pay.

To this, the editor of the American Agriculturalist responded:

There are "horse doctors" and horse doctors; or the line is now drawn between "horse doctors" and veterinarians. If a calling is not respected, it is because of the men who fill its ranks, and occupy its offices. We know of veterinarians who are as much respected as any physician in their town or city, and of those who practice upon all kinds of animals, both human and brute, without detriment to their standing. If physicians are thoroughly educated in, and fitted to practice, veterinary medicine, there is little danger that public opinion will be long against them. They have only to persevere in their course, and show their ability and respectability, in order to be respected, and to have all the work they can accomplish.

The editorial opinion is laudable, of course, but it seems as likely as unfortunate that there would have been instances at this time when physicians might have persevered until they starved to death.

Later, in response to an inquiry from a correspondent as to whether he "can be- 
come a veterinarian by studying books on the subject," the editor states:

Our reply to this is the most positive NO! ....We would most earnestly dissuade him from the attempt to become a self-instructed veterinarian, and thus add, however unintentionally, to the number of half-qualified or not at all qualified empirics who all over the country bring the veterinary profession into contempt.

\section{Abundant Harvest}

Like other agricultural journals of its time, the Breeders Gazette, which began publication in 1881, assured its readers: "Inquiries, concerning the proper treatment of diseased animals, will be promptly answered, free of charge," and offered Law's Veterinary Medical Adviser as a subscription premium. N. H. Paaren, State Veterinarian for Illinois, was in charge of the veterinary department of the Gazette. He also wrote ably on some of the more general aspects of health and disease, and in response to an inquiry concerning the desirability of studying veterinary medicine, he states:

The frequency with which we receive inquiries concerning the study of veterinary science, convinces us of an increasing appreciation among the people of the services of thoroughly skilled veterinarians, and of the need that exists in all parts of the country of such men. Even the common "hoss" doctor and the quack begins to see that his days are fast passing away; and among his efforts to retain a foothold, which at best is on very slippery ground, he aims at improvement by inquiring from us what kind of a book it is necessary for him to buy for the purpose of becoming a scientific "vetnerary sargent." However, the reading of one or a few books can no more make a good veterinarian than it can make a good physician. ...

As instances of the encouragement with which educated veterinarians have met during late years in America, and especially the professional recognition which many of them have attained, are their appointments to honorable and responsible positions in some departments of our municipal and State governments. State veterinary inspectors have been appointed in various parts of the country. A Veterinary Bureau has been established in connection with the Agricultural Department in Washington. In the army none but regular graduates are now appointed as regimental veterinarians. In our National Congress matters relating to veterinary sanitary science have received careful attention. The result of all this cannot fail to exalt the status of the veterinarian, while it will extend his sphere of usefulness. ... In veterinary medicine "the harvest is plenty, the laborers few."

That all was not yet sweetness and light is suggested by a communication to the Gazette a few issues later in reference to a lame cow:

The owner, a lady, being ignorant of the fact that the veterinary surgeon who had for years treated the sick and lame horses on the place, was conversant with the diseases of cattle, Dr. K. (a farmer, although he claimed to be a veterinary surgeon) was called, who pronounced the animal to be tail sick. A slit five inches long was made in the tail and filled with salt. The treatment not being satisfactory to the owner a veterinary surgeon was called, who, on examination, found a fracture of the humerus, and advised slaughter as she was suffering intensely. In another case where he [Dr. K.] was called in the absence of the veterinary surgeon, the superintendent being accustomed to see the pulse examined, asked the question: "How is the pulse, Doctor?" The reply was, "I have felt the critters all over and find they hain't got any."

\section{Defense vs. Excuse}

Of particular interest is a series of articles by D. E. Salmon on such topics as: "Why lose fowls by cholera?" "Degeneration of improved animals"; "Acclimatization of cattle in the South"; and "Are the trichinae of salted meats dangerous?" In a biting satire of "Hollow-horn - Absurdities of an Amateur Veterinarian," Dr. Salmon castigates the prominent agriculturalist and physician, Henry Stewart, for using (in another paper):

his influence and reputation to bolster up such barbarous customs by giving them what would be accepted by the masses as a scientific foundation. To the honor of the veterinary profession be it said that its members ... have never failed to discourage both horn-boring and tail-splitting, as well as the belief in such diseases as hollow-horn and hollow-tail, which led to these cruel and useless practices; and if they have not succeeded in entirely preventing such absurdities, they had at least driven their recommendation from the columns 
of the more respectable portion of the agricultural press.

In rebuttal, Stewart claims: "I did not defend the popular error, I only excused it," and continues:

I have heard it charged against Dr. Salmon that he is a young man - a fearful thing to contemplate anyhow-but if the charge is true, let me assure Dr. Salmon as he becomes purged of that crime by advancing years he may, perhaps, find some facts in popular knowledge just as good as the theories and deductions of his science.

\section{Dr. Salmon replies:}

It is comforting at least to know that our friend does not "defend" the barbarous practices which were criticized, - he only excuses them; and though the distinction may be more apparent than the difference, we should be thankful even for this admission. . . . More than a dozen years ago I began a contest against certain cruel and useless forms of treatment for very common diseases of animals treatment which is a disgrace to any civilized people, and I feel it a duty to continue that fight while such practices are either defended or excused.

And in reference to Stewart's charge of guilt by association in claiming that a "D.V.M." of his acquaintance had clefended the theory of spontaneous generation, Salmon counters:

the degree of D.V.M. can only be obtained after six years of special study... it would, consequently, be impossible for any D.V.M. to hold such views as he charges them with; that as a matter of fact no one with this degree has ever held such views, and that Dr. Stewart never was acquainted with nor ever saw a D.V.M.

Salmon, whose D.V.M. was awarded by Cornell in 1876 after he had obtained clinical experience in Europe, was one of only a handful of men in the United States to hold this degree or its equivalent at this time.

\section{Member of Society}

Veterinarians continued to be aware of their responsibilities to the community, and an admirable statement of the duties of "The Veterinarian as a Member of Society" is contained in the Review for 1887. The value of this contribution, however, would have been none the less had the author acknowledged that it consisted of a series of passages taken clirectly from Fleming's Veterinary Sanitary Science and Police. Crediting Fleming with the authorship, therefore, we are assured:

The veterinary surgeon has not only the dictates of humanity to inspire him, and which is the sole incentive of the physician, but he has, in addition, those springing from the importance of his task in a monetary point of view.

The national fortune, as far as animals are concerned, is more or less at stake, and also the comforts, nay, the very necessities of life of large numbers of people may depend upon his exertions; the health of mankind may even be, and frequently is, endangered by the outbreak of an animal plague. It is, therefore, a cluty he owes to himself to cultivate his intelligence and to maintain those moral qualities which alone can enable him to exercise his professional qualifications with credit to himself and advantage to others. His duties toward his prolession are pretty well summed up in his duties toward himself. Its value and status depend entirely upon the intelligence, zeal and proper conduct of its members. When a man practices a profession which gives him an honorable position in society, and to which he owes his means of subsistence, it becomes an imperative duty, as it should likewise be a grateful acknowledgement of these benefits, to devote himself entirely to its advancement in every legitimate way, and to demonstrate its importance and utility. At no other period, perhaps, can this be so well shown as in the matter of contagious diseases. The veterinary surgeon is, in the controlling of these, in a position to testify to its utility and importance to agriculture and the public in general.

\section{Prospects and Possibilities}

In addressing a gathering of Illinois veterinarians in 1888 on "The Veterinary Profession: Its Opportunities and Needs for the Future," W. L. Williams suggests:

In whatever station or pursuit of life, it behooves men to pause occasionally for a time, and make a careful reckoning of their surroundings; to look carefully into the past and consider the forces which have been at work; 
then examine critically their present status, determining what useful or baneful effect this or that force has exerted, and in what essentials their present position differs from that which should have been attained or desired; and then turning to the future, ask what are their prospects and possibilities, and what need they do to attain and secure them.

And in speaking of the days when veterinarians were all too few and all too little appreciated:

The ignorance of the general public seemed so profound that many apparently thought veterinarians were merely born so, and scarcely thought of the existence or need of veterinary colleges for their theoretical and practical education, and from this state of affairs, as well as the character of the men claiming to be veterinary surgeons, developed the idea-which still exists to some extent - that veterinarians cannot and need not be gentlemen, and this feeling has exerted a powerful influence against the adoption of the veterinary profession as a vocation by worthy men. . . .

Later, as the demand for qualified veterinarians became partially recognized, and before there was a sufficient learned force, or a sustaining demand for such institutions, veterinary colleges began to appear, at first proving sort of still-born monstrosities, followed closely by a few premature, sickly, short-lived affairs; not wholly fruitless, however. . . The tottering colleges became settled, and their influence in moulding the then shapeless veterinary profession in America became apparent. . .

Slowly, higher-toned public sentiment brought new and better influences to bear upon veterinary education, some colleges obtaining valuable financial and other encouragement, and also there being established veterinary professorships in many of our agricultural and polytechnical institutions, which exerted a powerful influence for good. ... The honorable position of the lecturer made his profession honorable in the student's eye, bringing worthy young men into such relations as to interest them in veterinary science... and in their turn influencing other capable young men to become qualified veterinarians.

The National and State Governments, through their efforts to extirpate and prevent the spread of contagious disease, have unintentionally done much to advance our profession, by employing almost exclusively well qualified scholarly gentlemen, of honor and integrity, who by their etxensive associations in their official capacity, and undoubted usefulness to the stock owner, have favorably influ- enced the sentiment of the general public. The United States War Department, on the other hand, seems unfriendly to veterinary science, allowing a starving salary and a rank just below a private, all ranks above being filled. ... .

The public press, especially agricultural and live stock journals, has wielded a notable influence, each usually having its veterinary column, generally presided over by competent and gentlemanly veterinarians, their influence for good or evil varying with the men and the times... . Such a column has not been an unmixed good to the profession, or if it has, it is about the only purely good thing, except Christianity, that comes "without money and without price." Many of these columns are now injurious and unprofessional, proving disastrous in various ways.

Concerning the present status of veterinary education, Williams states, "Everywhere there exists a stronger and ever increasing sentiment in favor of a higher standard in veterinary education." This despite his assertion: "A college draws stuclents in proportion to the percentage of students graduated each year, and in inverse ratio to the length of curriculum."

\section{Honor and Wealth}

\section{Dr. Williams continues:}

Turning now to the future, we may safely assert that, to the young man of today, well equipped with integrity, energy and brains, no profession offers a brighter prospect for honor, usefulness, comfortable income and even wealth than that of veterinary medicine. . . The increasing number and value of live stock demands of us, and offers due reward for, higher knowledge and skill in the treatment of their maladies. ... Diseases hitherto unmanageable, or treated only at a loss to the owner, must be studied carefully and rendered more amenable to treatment. . . The ever augmenting menace to national wealth, through the ravages and spread of contagious diseases of animals, must necessarily afford honorable and lucrative employment to a large number of veterinarians. . . Many, if not all, of these diseases, must eventually be referred to the veterinary profession for control or extirpation, affording inexhaustible fields of research....

The veterinarian of the future is destined, also, to be a useful and appreciated guardian of public health. It is generally well known that a large proportion of the meat and milk, 
especially that sold in large cities, is unfit for human food, endangering the health or even the life of the consumer, and the learned veterinarian may render an important service by indicating what is or is not suitable for human food, or by directing such reforms in the care of meat or milk producing animals as would insure healthy products. Highly important, also, are the talents of the skilled veterinarian, when employed to prevent the transmission of serious and fatal contagious diseases from animal to man. . . .

Hereafter, also, the veterinarian can and must be a humanitarian. Closely interwoven in the higher sentiments of every enlightened people, there exists a tender, beautiful, ever extending feeling of humane sympathy for the sufferings of the lower animals, especially of those so inexorably faithful as servants, or true as companions, as are most of our domestic animals. We can and should, when occasion permits, arouse public sentiment in this regard, and in our own work we should study how best to alleviate and avoid suffering, as well as to save money to our patrons. We very much fear that, as a body, we have been habitually far too inhuman in our operations and methods of treatment, sometimes from lack of appliances or the attendant expense, but in too many cases, from a fundamental want of true humanitarian ideas. ...

Here then are vast opportunities for usefulness, for affluence, honor and distinction, abundant work for willing hands, boundless field for enthusiastic research, which must yield rich results to the earnest and conscientious student. . . The future demands a veterinarian who shall be a genuine scholar, with a broad, liberal preparatory and collateral education, to expand the mind and the better enable him to appreciate scientific theories and facts, and give him a standing as a man of learning, and then he should be deeply and thoroughly grounded in veterinary science, not hurriedly crammed for a loose examination, but be truly and ineffaceably learned in every branch of veterinary knowledge.

Probably no more comprehensive nor admirable statement of the situation had been made to this time, and perhaps few since. And although many of the points Williams outlines for the future have long since become reality, his philosophy is just as valid today as it was eight decades ago.

\section{The Spectre of Specialization}

The matter of specialization in veterinary medicine became an issue about 1890 , as it has periodically since. Although the Review commended the development of new fields of veterinary knowledge, the concept that veterinarians should be trained as specialists was condemned. In 1891 Liautard editorialized:

Specialists in veterinary medicine exist, it is true, but their pretensions and the extent of the ground covered by their specialties are without significance or importance. ... A competent practitioner must possess a familiar knowledge of the science as an entirety, even to become exceptionally expert in one or more of its branches.

In 1888 the Review published a series of articles translated from the German, on the diseases of the skin of the domesticated animals, with the notation:

We are quite sure that our readers will recog. nize in this treatise a work of importance and value. . . The subject of dermatology is one which has been comparatively an ignored department of veterinary education. In fact, we know of no veterinary colleges which include this among their regular subjects of study. Like medical ethics ... dermatology is rather than otherwise adjudged to be a fit subject for instruction alone.

\section{In 1891, C. S. Sayre, Professor of Dental} Surgery, Chicago Veterinary College, notes:

Until within the last few years no branch of veterinary science has been so much neglected as veterinary dental surgery. Recently, however, there has been a revulsion among veterinarians, and now about one-half of the cards one sees read "John Smith or Tom Jones, V.S., Dentistry a specialty."

Sayre states that little advancement had occurred in the past two hundred years until the discovery by C. D. House of a method for operating on the teeth without the aid of a speculum. House, a nongraduate:

deserves the respect of the profession, for he certainly taught us a great deal about operative work. With his discovery followed many evils. He immediately started out as a professional veterinary dentist, and made a grand success; and this tempted many poorly qualified men to follow his example, who did more harm than good to the poor brutes subjected 

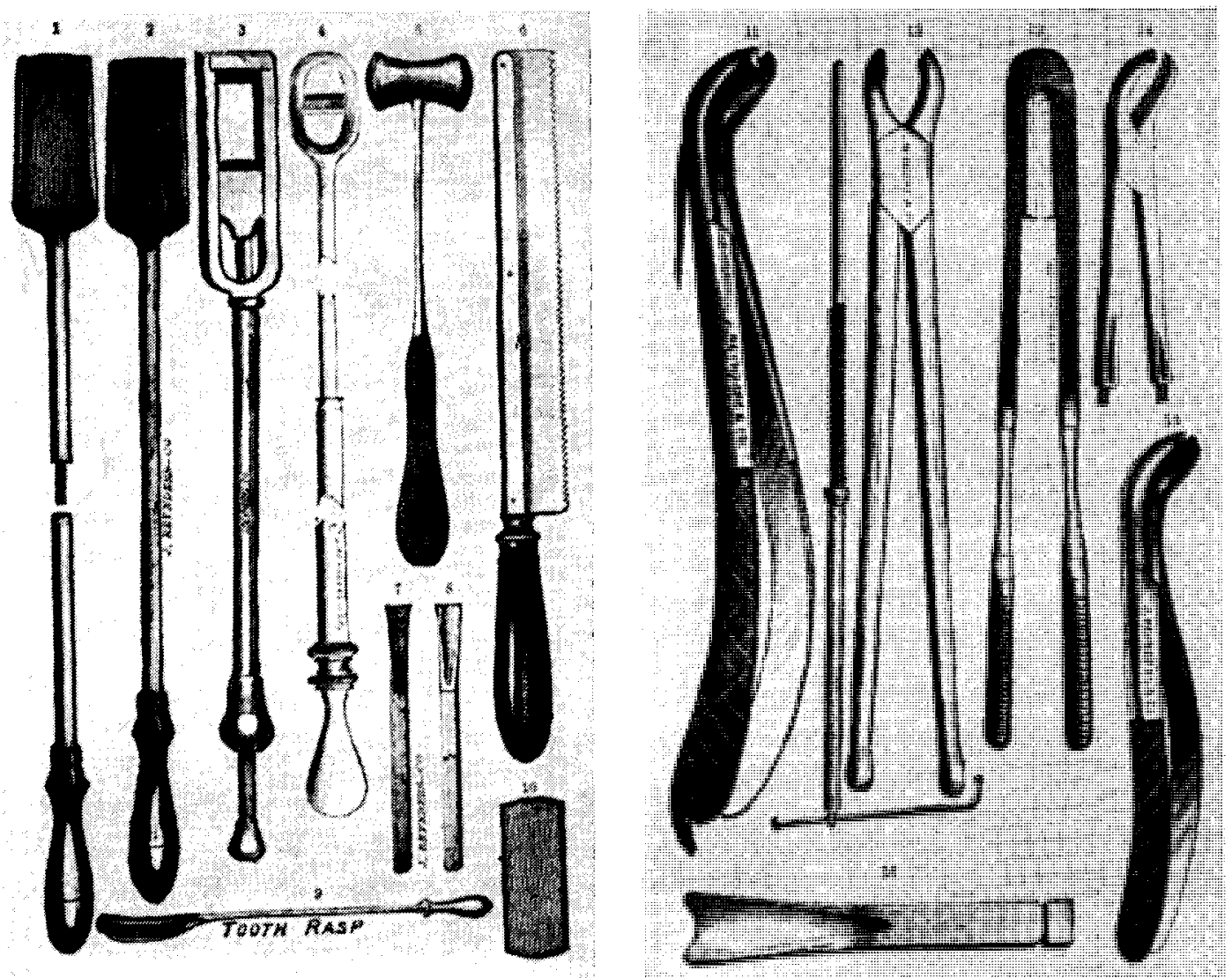

Dental instruments of the late nineteenth century, including forceps, saws, chisels, and elevators, had changed but little from those used a century or two earlier - and some have undergone little change since. Liautard: Surgery

to their treatment, until the veterinary dentist came to be looked upon as a veritable charlatan.

One redeeming merit of this, Sayre claims, is that:

It started the public mind to thinking that our dumb brutes suffered with their teeth as well as ourselves... for after one of these itinerant dentists has visited your towns you have done twice as much dental work as before.

Sayre, however, did not advocate that veterinarians become dental specialists, although:

I am glad that now the profession are giving more attention to this sadly neglected branch of veterinary science. . . We do not want veterinary dentists any more than we want veterinary oculists or veterinary gynecologists. We want veterinarians in the broadest sense of the word: men educated in all branches of veterinary science. At one time I thought we needed veterinary dentists as well as human dentists, but the field of usefulness is too limited.

As is frequently the case with new developments, the pendulum swings farther than their first proponents anticipated. W. L. Williams, who had contributed an extensive study of odontomes in 1891 , recommending the attention of the veterinarian to this subject, in 1906 deplored the fact that:

During the past few decades there has developed in America a conspicuous tendency to 
interfere with the teeth of horses and an attempt has been made to dignify the practice by the appelation of "Veterinary Dentistry."

Not only did veterinarians advertise this as a specialty, but a voluminous literature was produced, and at least two Veterinary Dental Colleges at Detroit and St. Lou is were organized in 1904-1905, the Detroit school advertising a correspondence course in veterinary dentistry. Few today, perhaps, would wish to append "V.D." after their names to indicate their special acquirements, but whether "officially" recognized or not, other areas of specialization have become reality.

\section{A Dark Age Coming?}

As editor of the American Veterinary Review, Dr. Liautard had boundless op- timism concerning his beloved profession, although he could never be accused of viewing it through rose-colored glasses. One of his more pessimistic pieces, entitled: "Is There a Dark Age Coming?" was occasioned, in 1891, by the threat of the establishment of a host of new schools, including a "veterinary dental school," none of which seemed to bode but evil for the veterinary profession. Liautard notes:

The revolution in veterinary practice in America is a success, and all we want now is more of the same kind. Yet there are discouragements. We hear a cry of danger, and we fear there is a severe struggle coming between the true friends of veterinary science and those who are moved by mere mercenary considerations, and who would so combine business objects with the promotion of veterinary science as to inflict irreparable evil upon
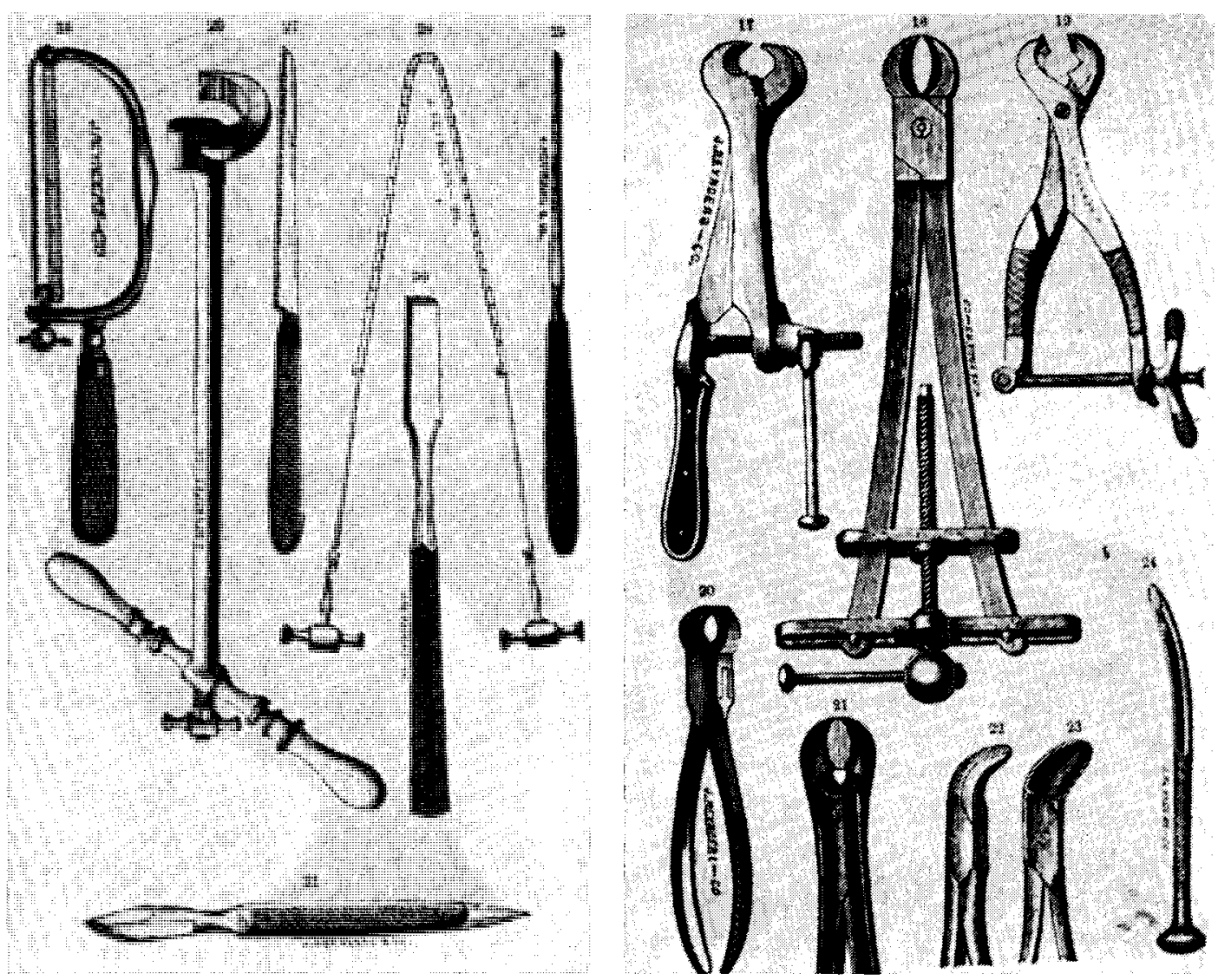

Inadequate leverage was a major handicap with early dental instruments, and vise-action forceps and molar cutters only partially solved the problem until the introduction of double-action instruments toward the end of the nineteenth century. Liautard: Surgery 


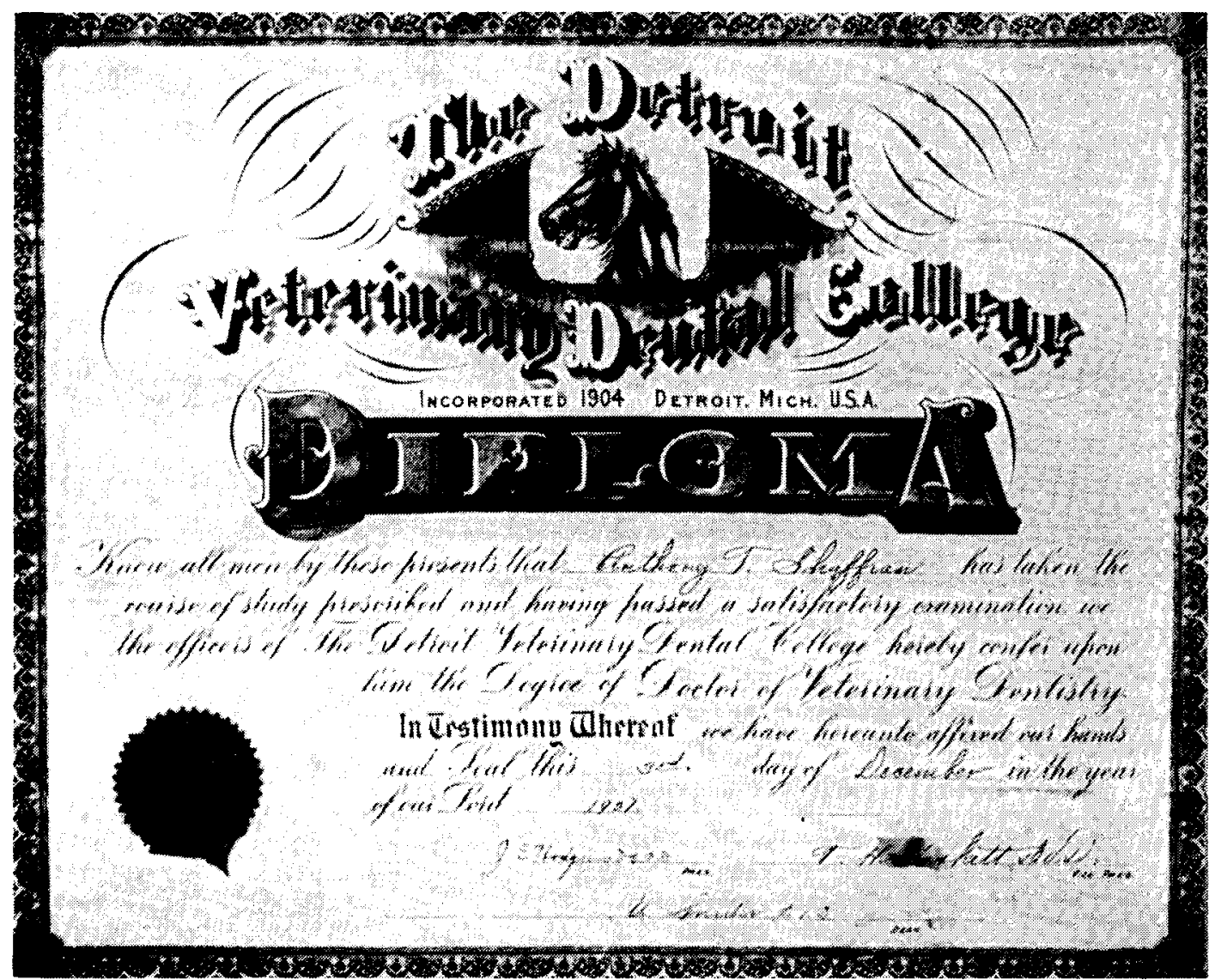

Veterinary dental surgery was an early specialty which spawned several short-lived dental schools, but professional opinion was not favorable to the development of specialties. Michigan State University Library

the latter. We would like to be convinced that the cry of danger is a false alarm, but what are we to think when we hear of the contemplated establishment of new schools, in which the investment of capital for speculative purposes is a leading incident, and a faculty is appointed containing not a single veterinarian of education, and with an empiric at its head to "run the machine"?

Shall we veterinarians who love our profession, and who appreciate our calling and its requirements, stand by silent and inert, and permit a state of affairs so disgraceful to continue, without at least a protest and an effort to put an end to it? ... It is the duty of every veterinarian to watch the work of the parasites who would ruin a noble cause by assuming to identify themselves with its name and its mission. Would that we could inspire every true veterinarian in the land to combine with his fellows in an effort which should never cease until our most honorable profession is established upon foundations which can never be shaken, and then we should never more have occasion for apprehension of the approach of "A Dark Age."

That the established schools were not immune to criticism at the time is indicated by Tait Butler, who in 1890 enumerated the "evils" of veterinary education in America:

that of matriculating men possessing not even the rudiments of a general education ... that of employing men to teach veterinary students who are not themselves veterinarians . . . that of filling (?) two or three chairs by one man. ... [And] eighteen and not eleven months should certainly be the minimum for actual college work.

The report of the USVMA Committee on Intelligence and Education this year, how- 


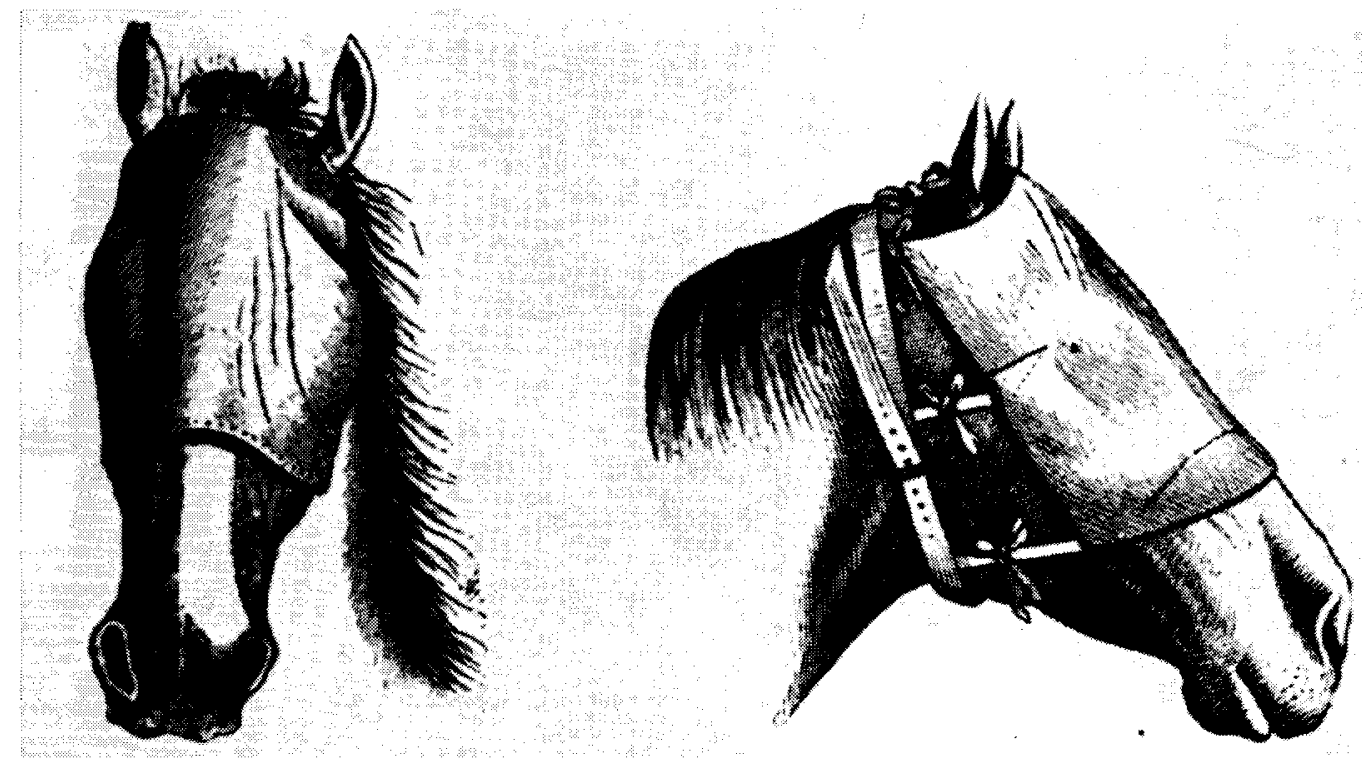

70. 112-Binocular Band (tull tew).

Fo. 114.-Binocular Band slde riew).

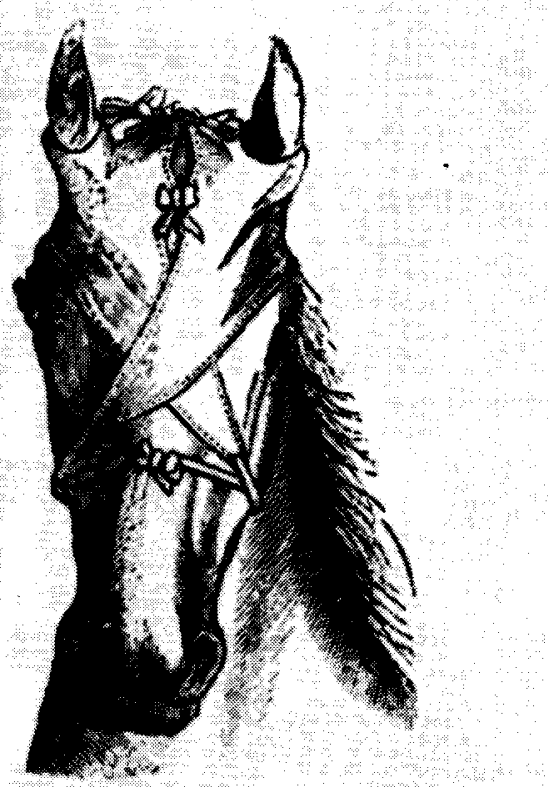

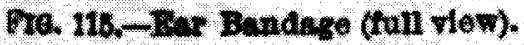

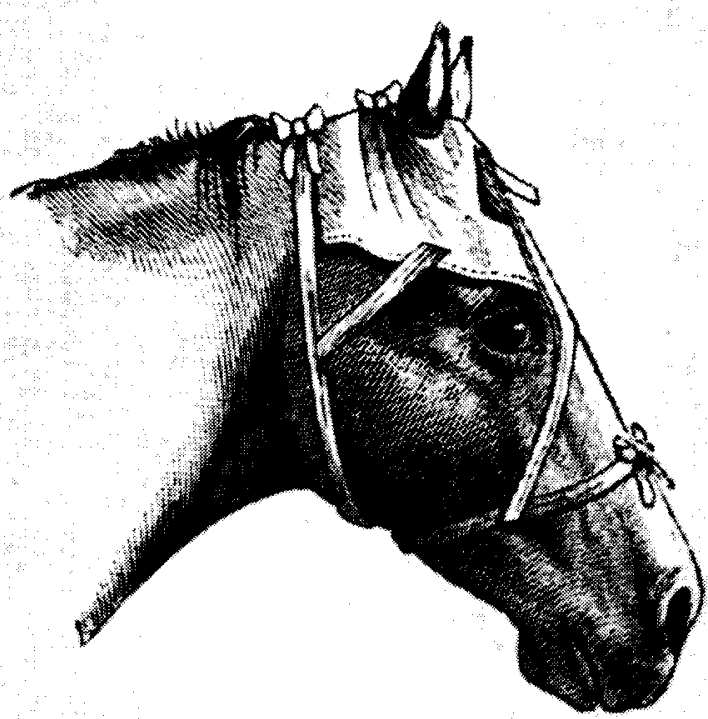

Fra. 116-Ear Bandage (tide viow).

The ability to apply a neat bandage was a major criterion of surgical acumen during the late nineteenth century, when the rationale of wound treatment included the need "to shield it from injurious atmospheric effects, malarious or otherwise." Liautard: Surgery 
ever, concerns itself largely with the need for veterinary legislation as a means of improving the lot of the practitioner, and casting doubt upon the aphorism that "the men of a profession build up their own profession."

The following year, Austin Peters, as the new chairman of the committee, added a "fervent amen" to Butler's sentiments, and proposed "educating the veterinary practitioner," as well as the student, emphasizing in particular, the value of the veterinary journals and societies as agents of "continuing education."

\section{Aptitude and Antisepsis}

A factor to which perhaps too little attention had been given, that of "aptitude for veterinary practice," was discussed in 1891 by W. H. Dalrymple, later presiclent of the Association:

We often have young men drifting into our ranks whose only incentive has been, probably, that some one whom they knew had made a success of it as a veterinarian. . . It seems to us, that to attain to any degree of success whatever as a veterinary practitioner, a man should ... have an innate love for animals, be brought up along with them, study their life and habits, get as perfect a knowledge as possible of them in health; for it is only when we have this knowledge that we can observe the slightest deviation from the normal standard.

Such an individual, he says, "goes about his patients more like a horseman than an old woman, which latter is very prejudicial to a practitioner, in the eyes of horsemen."

In a paper on "Antiseptic Surgery" in 1891 , the first time this title appears in the Review, the author, Roland Lord, notes that those (including "medical authorities") who still oppose the principles of antisepsis fall into three categories:

they have never tried the method ... or having tried, did it bunglingly... or they are of that unfortunate class of people, also too common, who know everything, and amid that knowledge, they know that antiseptic surgery is all bosh. ... An objection is often made to the minuteness of the details in our method; it is the attention to these details which go to make up the complete whole. ... If you carry out this system of surgery you will achieve some glorious results.

Among the several factors leading to an improved status of veterinary medicine, $W$. L. Williams states in 1892, concerning "Veterinary Science in Agricultural Colleges":

It was these instructors of veterinary science, more than any other one agency, which made the phenomenal moral and educational progress of our profession within the past few years possible.

The eminent men holding these positions not only inculcated a respect among their agricultural students for the profession of veterinary medicine, but were the cause of numbers of these students going on to qualify as veterinarians, and to induce promising young men to do likewise. Among the personnel of the Bureau of Animal Industry, the faculties of veterinary colleges, and the USVMA "we find the names of these once agricultural students occupying prominent places."

Liautard had long urged that ethics be made a special subject in the veterinary curriculum, and in 1892 he addressed the Massachusetts Association on: "Ethics as a Means of Elevating the Veterinary Profession." Accepting the fact that the ne plus ultra had not yet been realized, he points to those veterinary colleges which advertise their presumed superior merits as the first offenders. Far too often the graduate used his alma mater as a trademark, inscribing his card with: "Graduate of the Blank Veterinary College," and going still further:

while his shoes are yet covered with the dust of the lecture rooms, he sets out to drum up trade by becoming a specialist! One is a dentist, another chooses lameness for his specialty, a third is great on castration and its various requirements, or perhaps becomes a canine pathologist. 

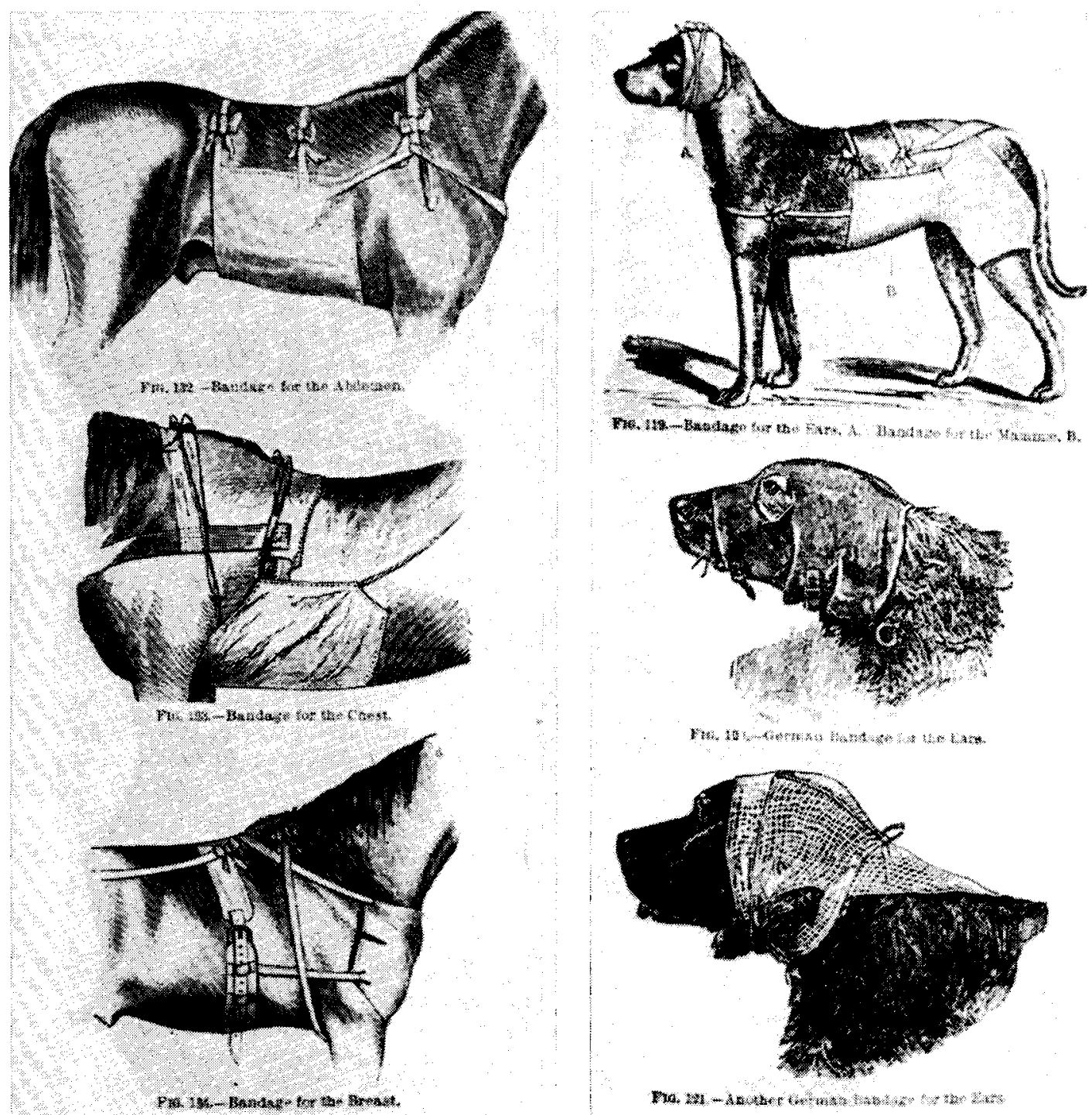

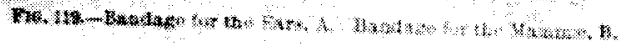

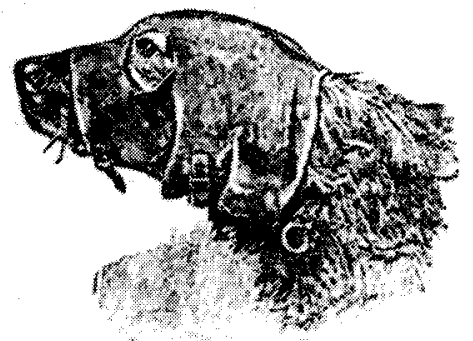

Now a

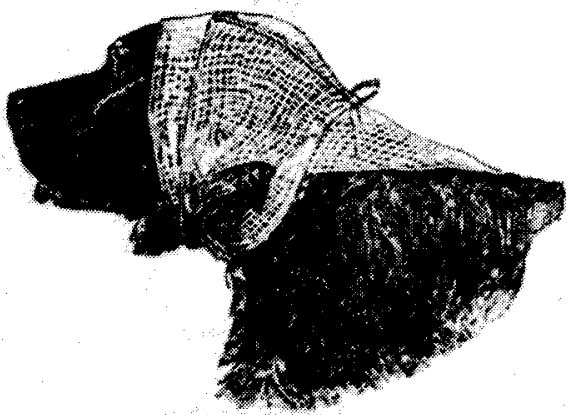

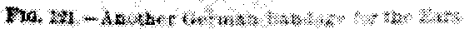

Before antisepsis and aseptic surgery were practiced, many of the elaborate impervious bandages probably did harm by favoring the gowth of anerobic organisms, and some practitioners adopted a mesh bandage as an alternative. Liautard: Surgery

Liautard is particularly censorious of those veterinarians who offer gratuitous advice anonymously in the sporting papers. $A$ Veterinary College of America, similar in function to the Royal College of Veterinary Surgeons, long advocated by Liautard, would, he thinks, be the best means of securing a uniformly high standard of excellence. As a matter of passing interest, it would appear that Liautard's foreign background, after thirty years, had not been entirely suppressed, for in a report of this meeting, the Secretary of the Massachusetts Association affectionately refers to Dr. Liautard as "the Frenchman."

\section{The Old and the New}

Concerning veterinary practice in the 1890 's, G. W. Browning (N.Y.C.V.S., 1892), 
a frequent contributor to Veterinary Medicine in the 1920's recalls:

While I was a senior student of the New York College of Veterinary Surgeons, the house surgeon made the remark: "Give me a good set of firing irons and a bottle of turpentine and I can do almost all it is necessary to do in the successful practice of the veterinary art." After leaving college and settling down to practice in a stock raising community in the black land belt of Illinois in 1892, I hewed strictly to the line of treatment I had been taught while in college. I fired everything. . . . How- ever, in time I began to ask myself why I used such heroic treatment. The result was that except for spavins, I haven't fired a horse in twenty years. .. .

Acute indigestion and the different colics were treated by large draughts out of a long necked bottle. The drenches consisted of a quart of linseed oil, one ounce of turpentine and one ounce of spirits of niter. The horse's head was pulled up by running the halter rope over the limb of an apple tree. It was often pulled so high the animal could not or would not swallow and the drench ran down the trachea causing strangulation. Usually a part of
The first major improvement over the hot poker - other than the simple firing needle, which cooled too quickly - was a pointcautery with a large metallic "heat reservoir" (left), followed by one with its own charcoal burner and two needles, one of which was heating while the other was in use. Liautard: Surgery

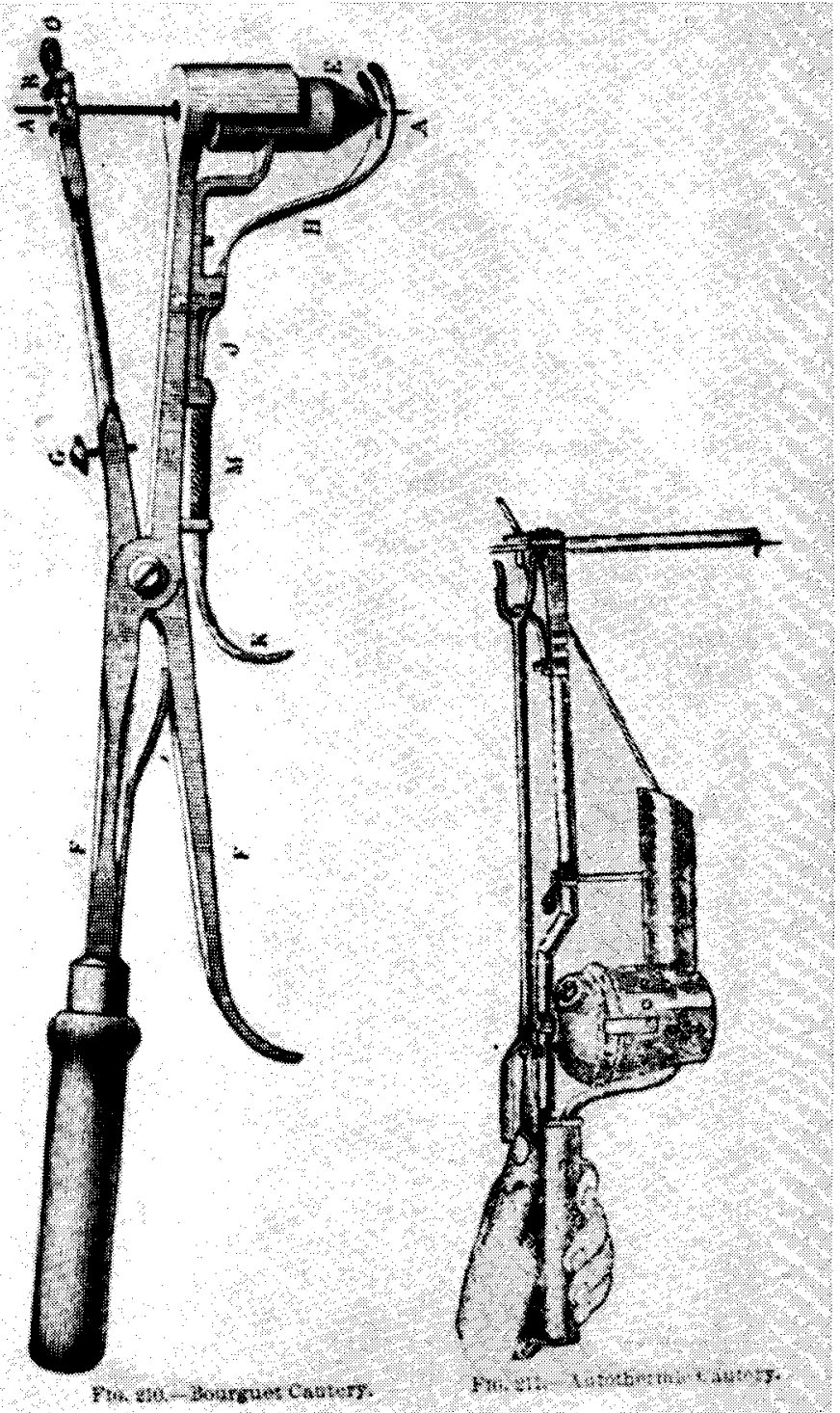




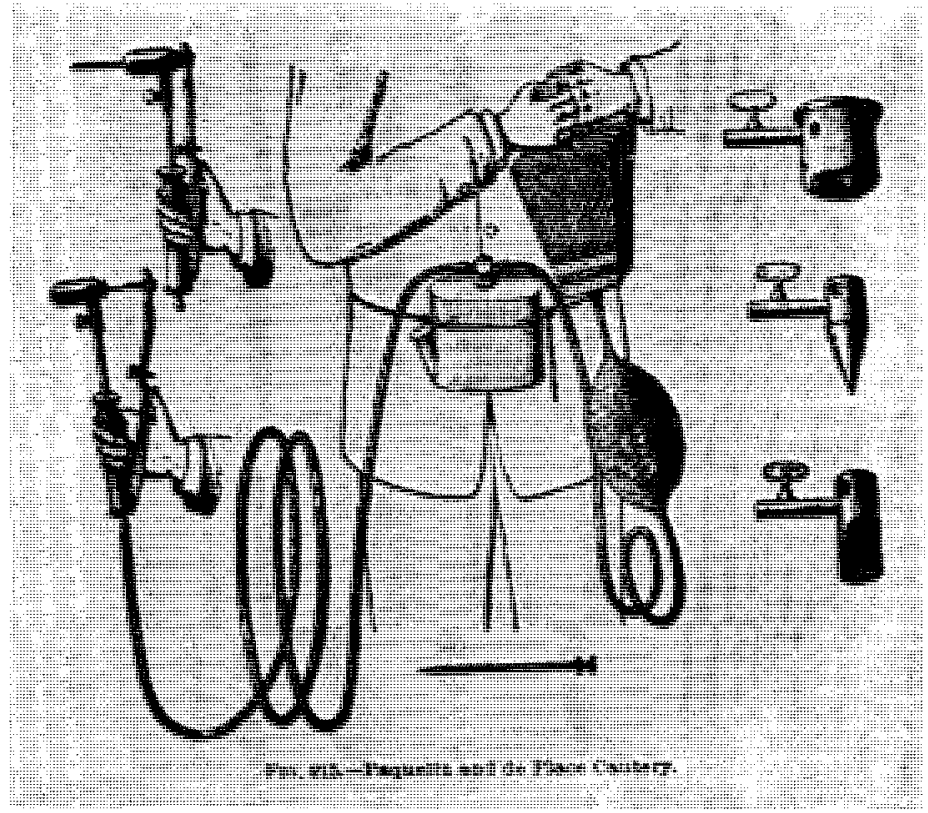

One of the first continuous heat cauteries (ca. 1890) - a considerable improvement over the older type which required a charcoal burner or blacksmith's forge. Liautard: Surgery

the drench ran down the veterinarian's shirt sleeve. ...

Finally the absurdity of it all was too much for further negligence and I began to look around for a more successful line of treatment, and one with less discomfort to the patient. I discarded a great many of the remedies which I was using at that time. However, I never used a new remedy until I freely consulted old medical literature as well as new. I found that a great many drugs valuable for treating the sick and afflicted of olden times had been discarded because they did not know how to use them.

On the subject of anesthesia, Robert Robb, V.S., M.D., writes in 1898:

Owing to surgery in the veterinary profession advancing so rapidly, it is now a question whether or not anesthetics will be carried out successfully as in the medical profession. I cannot see why this neglected branch of veterinary medicine for operations has been so slow in the past; whether it has been due to the lack of experience, or to the valuation of animals or environments, I will not attempt to state. . . . In the past there have been a great many operations neglected or put aside owing to the fact that it was impossible to carry out such a procedure, but at the present day there is such a demand for surgeons that one has to be on the alert, or else he will have his clients seeking new pastures to reap the benefits of more skilled hands.
Robb recognizes an obvious reason for many practitioners - the majority of whom worked alone - not using anesthesia to any great extent:

Many an animal has passed to that other shore on account of the anesthetist, his eyes being centered and his mind so occupied with what was being done with the knife, only to find out when too late that he was kneeling over a cadaver.

\section{His Lot Is Not a Happy One}

\section{In 1896, Turf, Field and Farm notes:}

The lot of the practicing veterinarian is by no means a desirable one. With the diminishing use of the horse, low prices and increasing intelligence of the people, and flooding the country with prepared nostrums, the veterinarian is bound to find his field of future operations a circumscribed one indeed, and he has our sympathy.

\section{To this Liautard retorts:}

The writer of that paragraph is not suffciently acquainted with his subject to know that the veterinarian's future calling is an expanding rather than a contracting one.

The following year, however, E. L. Volgenau, D.V.S., writing in the Review on: 
"The Future of the Veterinary Profession," notes:

some startling figures as to the effect of the bicycle upon business in general and particularly its effect upon the horse and livery business.

A New York paper had put this loss during the last year at some $\$ 45,000,000$; Volgenau states:

To the veterinarian these figures are significant. For the past three years the earnings of veterinarians have been steadily on the decline... [and] the main cause for the diminished earnings throughout the whole country has been the almost universal adoption of the bicycle. The main question is, has the bicycle come to stay? If the answer is in the affirmative, veterinarians will soon have to seek new fields, and other methods of earning a livelihood.

From the four corners of the earth come the reports of veterinarians who are taking up other professions or trades more profitable than the honorable profession to which they have linked their destinies. Salaried positions under the state, municipal and federal governments are in greater demand than ever before, and there is an uneasiness throughout the profession which is ominous. As long as the
The precision of pattern firing was long considered the mark of a competent practitioner - dating from the time when farriers fired in cathedral-window configurations. Liautard: Surgery

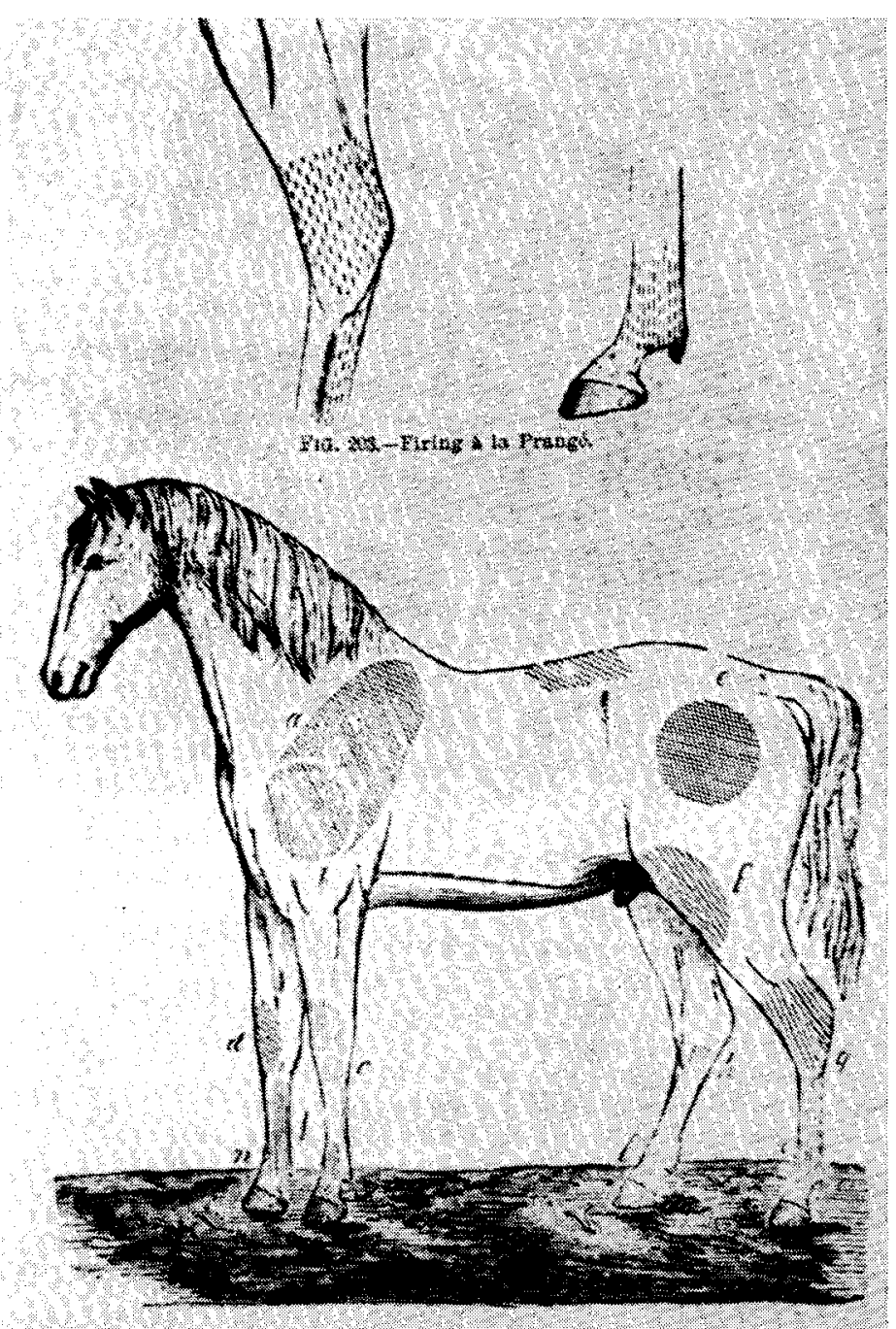

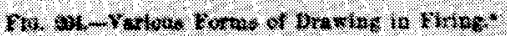


cattle, sheep and hog interests of the country are of such magnitude, there will always be a demand for veterinarians, but the problem in the large cities is a great one. The young man desirious of entering the profession, had better consider well before entering a veterinary college and spending time and money in acquiring an education which will hardly net him interest on the investment. ...

You laugh and say horseless carriages are impracticable, it is visionary, ridiculous to say that this motive power will be applied to delivery wagons, trucks, and the thousand and one purposes for which the horse is now used as the propelling power. Why is it visionary? ... Who would have dreamed fifteen years ago, when the first cumbersome bicycles were built, that to-day millions of wheels could be in use all over the world. . . . The bicycle is no fad ... the motor-cycle and horseless carriage, which at the present time seem bulky and impracticable, will within a short time become so improved that the horse will be supplanted.

Now comes the ultimatum. Granting that the demand for the services of our equine friends is on the decrease, where is the veterinarian to find a market for his professional skill? The municipal, state and federal offices can employ but a limited number of veterinary surgeons. The balance must of necessity be content to earn a scant livelihood by means of the deteriorated general practice, or leave the profession to engage in more remunerative employment.

Having followed the prophet of gloom and doom thus far, it may be hoped that none of his readers stopped here and turned their casting ropes into final instruments of despair, for he continues in a hopeful vein:

There will always be a demand for educated veterinarians, and as their field of usefulness broadens it will devolve upon the colleges to give more attention to the essentially scientific studies embraced in the curriculum... Within these fields lies the work of the future veterinarian, and he will gain his success in life, both social and financial, not so much upon his ability as a skillful surgeon, or by his success in treating colic, fistulous withers or spavin, but upon his scientific knowledge and attainments.

Our fault has been that we have paid too much attention to the practical side of everyday practice, and often at the expense of the theoretical and experimental. We have judged other practitioners and been judged ourselves upon our money-getting powers, the ability to convert our professional skill into dollars and cents. ... The bicycle and horseless vehicle mark the beginning of a new era for the veterinarian. From this time onward the marketable commodity will not be what we can do, but what we know.

Yet, for decades to come many veterinarians continued - in effect - to give diagnosis and other consultations free, depending upon the profits of what they could prescribe to provide their bread and butter.

\section{Auto-destruction}

The veterinary journals had started a running feud with the automobile interests in the 1890's, and took advantage of every occasion to disparage or lampoon the use of the horseless carriage - often with more malice than logic. An early report on the economics of the automobile in practice was offered by Mark White of Colorado in 1909:

For the benefit of my brother colleagues that may be contemplating the purchase of an automobile to displace the horse in their practice, I desire to give them this tip. I have used a machine for the past months in my practice in Denver; I drove a machine 23,000 miles at a cost of $\$ 2,500$. I found the automobile wholly unreliable for my business, and very expensive. If I saved an hour to-day, I would lose two tomorrow. ... I found that when it became necessary to go to the shop for repairs that I fell into the hands of men without any conscience or honesty. They would work on my car one hour and probably charge for two or three, at the rate of 75 cents per hour. . . An automobile will consume the profits of a medium business. . . .

It requires more thought to keep up with the running of the machine and keep it all together than it does to look after one's practice, or study how to make a living therefrom. A doctor, in my judgement, needs to think over his cases and business when he is travelling from one to another during the day, but it is impossible to do so when running a machine, for it must have your entire thoughts.

What Dr. White perhaps failed to realize was that he had driven his machine in several months as far as he would have driven a horse in several years. 
In 1916, however, the irrepressible E. T. Baker reports:

That a car is a trade-getter, one must own a car for awhile to fully realize. To be at a rancher's place, five or ten miles out in the country, twenty or thirty minutes after being called; to relieve a writhing animal of its pain, while chance for recovery is good, is what an auto will accomplish. And even in case of a funeral, the rural verdict will be: "Well, me an' Doc done all we could, fer I got him right away!"

Formerly, upon arriving at a place some hours after being called:

"Well, Doc, yuh don't need to git out; th" mare seems all right now, an' she's eatin'!" used to be a common greeting in the olden days of horse and buggy. The rancher seemed to think that if one did not get out, the bill would be so much less.

On the matter of economics, Baker suggests we forget about cost per mile:

If there is a veterinarian who has kept strict account of all his auto expenses, let him send his photo to Dr. David Roberts for publication. Looking back over old paid bills is as merry an occupation as spending the night in a country cemetery. Outside of horse trading. perhaps more lies have been told about the upkeep of autos than anything else. .... An auto will double one's practice and size of territory; it will decrease one's mortality enough to make him forget repair bills.

One practitioner who appears to have been satisfied with the horse was A. W. Baker, of Brasherfalls, New York, who in 1914 had a horse twenty-four years old that he had driven 78,175 miles, an average of sixteen miles per day: "One day he was driven seventy-nine and four-tenths miles, in twelve hours. Many a day I have driven him fifty miles." The horse, apparently, was a good one, and in good hands.

While a number of prominent veterinarians were still lamenting "the passing of the horse," Dean E. E. Wegner in 1926 observed:

The motor car has trebled or quadrupled the time of the veterinarian as well as every

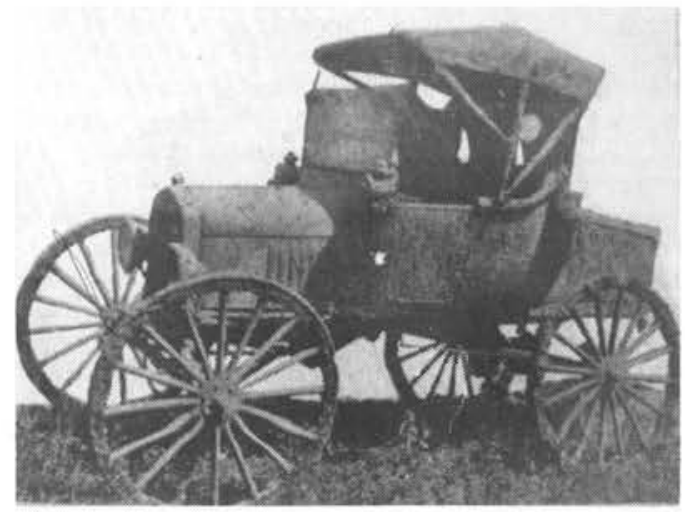

"Mud scow" devised by a rural practitioner to cope with bottomless roads where even the famed Model T Ford was known to occasionally let a man down. Veterinary Medicine

other professional man. He could not today afford to take his lost horse practice back and drive a horse and buggy. Drives that used to require a half day's time can now be made in one hour. The motor car has done more to increase the earning power of the veterinarian than all events together of the past twenty years, and all that it cost him was a small percentage of his horse practice.

To this the editors of North American Veterinarian add:

The motor car has increased the volume of small animal practice by leaps and bounds in cities large and small, as the passing of the horse from the social life of the American family seems to have increased the fondness for dogs and other pets and has not only increased the demand for well-bred dogs but has thus created a better understanding of the value of pets in the family circle.

\section{Consulting the Oracle}

The turn of a century being an appropriate time to take a forward look, W. L. Williams, in outlining: "The Future of the Veterinary Profession” in 1900, states:

We must base it upon our past history and present condition, considering the forces at work, the obstacles in the path, and the progress thus far attained.

With reference to the Mosaic law regulating the use of meat, he continues:

Functions now properly devolving upon our profession have been deemed essential to 
human welfare since the earliest dawn of history. ... . In recent years we have come to see the importance of this law, through bacteriology and pathology, which have demonstrated the close relationship or identity of numerous diseases of animals and man, and have fully shown the importance of wholesome meat and dairy products. . . . The future of our profession in relation to meat and milk inspection is as plain as it is inevitable. The national inspection will be increased and strengthened, and states and municipalities will be compelled to introduce systematic inspection in harmony with the needs of a civilized people.

Concerning the progress made in eradication of animal plagues: "The rude, gross work already done has merely served to uncover deeper, more complex questions." And in reviewing the status of the military veterinarian, Williams says:

The most serious obstacle to a better army veterinary service is the army veterinarians. . . . They have largely assumed the prerogatives of the army mule and expended their energy in "kicking" about their low pay and absence of rank.

He notes, however, that proper rank and pay are essential to a competent service.

Noting that "only a sheet of thin parchment" separates the better self-educated practitioner from the graduate with lesser qualifications, he calls for higher educational standards:

Veterinary education has passed forever from the realm of commercialism and cannot now be conducted in harmony with the needs of civilization except by the philanthrophy of men of wealth or through state support. The laboratory is replacing the lecture room: some other than the veterinary student must pay for the enormous increase in cost. ... In the future the value of a college faculty must be based upon the quality and quantity of teaching done supported by original research and contributions to our store of veterinary knowlledge. . . .

Future veterinary education, reflecting the future of our profession, will be more intensely a part of our university system, the graduates possessing high attainments, a general education in all parts of veterinary science coming first, the general practitioner immeasurably better prepared in surgery, obstetrics, medicine and other essential subjects, and from this well trained body can be drawn all specialists of a high order which exigency may demand.

\section{Pets vs. People}

Speaking on "The Relation of Veterinary Medicine to the Public Health," before the AVMA in 1900, W. H. Lowe states:

People recognize and appreciate much quicker and in a fuller sense what veterinary medicine does for their pet animals and for themselves, in a commercial sense, in protecting the animal wealth than they do for what the science does for the health and lives of the people themselves.

He notes that the creation of the Bureau of Animal Industry came about largely through the inroads of contagious pleuropneumonia, for: "This disease struck the most sensitive thing in all creation - the bank account." On the other hand:

The scandals and sensational reports of bad meat supplied to our soldiers in the SpanishAmerican war must have suggested the importance of an adequate veterinary inspection of animal food and what it would have meant to their health and the lives of the men serving in our army.

Milk inspection, he contends, is set up on the wrong basis in most cities:

Instead of beginning by inspecting the milk, as is often done, they should begin by inspecting the animals, their stables, and the dairy generally.... The public need educating in this matter.

If veterinary medicine had not yet become a major power in public health circles, veterinarians had given these problems serious consideration for some two decades or more, and a voluminous literature on the veterinary aspects of public health already existed by 1900 . 


\section{Veterinary Public Health ca. 1880}

The increased EMPHASis upon the veterinary aspects of public health in recent years might lead one to suppose that veterinarians had given little thought to public health matters in the past. While it is true that veterinary public health as a specifically designated area of endeavor is a relatively late development, it should not be concluded that the founding fathers of the veterinary profession had given little thought to this matter. In fact, the early leaders of the profession had very well-defined concepts of the relation of veterinary medicine to human welfare, and took every opportunity to urge veterinarians to seek ways of serving as sanitarians.

Admittedly practitioners of the 1880's and later were preoccupied with the problems of horse practice, and perhaps all too few took full advantage of opportunities to serve in the area of public health. But to a greater extent it was a failure of public health officials to appreciate the potentialities of the trained veterinarian that resulted in so slow a development of veterinary public health as a basic discipline. More than this, veterinarians simply were not consulted on problems which were primarily of a veterinary nature, but which had public health implications. A few boards of health, notably those of the city of Brooklyn and the state of New Jersey, early recognized the interrelationships of human and veterinary medicine in the interests of public health, and some of these boards have included veterinarians since the early 1880 's.

In addressing the graduating class at the American Veterinary College in 1878, J. W. Arnold, M.D., of the College of Physicians and Surgeons, stated:

Veterinary science is undoubtedly a branch of medical science, and not only does its influence extend to the preservation of the domestic animals used as "beasts of burden," but also to those upon which omnivorous man depends so largely for his food. . . . It is your part to take cognizance of ... every form of disturbance in the lower animals which can be transmitted from one species to another, and from these even to man himself.

Thus it is for you to perform the work of sanitarians. The community at large should then acknowledge the position which you occupy, and it is for you, gentlemen, to gain its full confidence and respect by your own actions - by your own achievements.

\section{ADVOCACY OF THE GERM THEORY}

A knowledge of the coming science of bacteriology was soon to be a prerequisite to an adequate grasp of the public health problem, and the Review appears to have been a major influence in bringing the germ theory of disease to the attention of the veterinary profession in America. 


\section{Germ of the Germ Theory}

Several converging factors are involved: the editor evidently needed material to fill his pages: being French, he turned to the literature of his native country; the work of Pasteur and others in bacteriology was commanding attention in Europe; Liautard apparently had come to the conclusion that Pasteur - and not his critics was correct, and chose to exploit this new controversial field, rather than "playing it safe," and filling his pages with case reports and the like. Liautard not only selected and translated these articles, but in in his editorials he leaves no doubt concerning his beliefs:

The believers in the spontaneity of the development of contagious diseases have found in M. Pasteur a powerful opponent, who slowly, but surely, demonstrates by undeniable proofs that the virulent properties of those affections is due to the presence of microscopical organisms.

The first volume of the Review offered long overdue proof by the French veterinarian, Bouley:

On the Identity of Anthrax in all the Species of Domestic Animals ... that, in fact, the glossanthrax, tongue-evil, black quarter, black leg, splenic apoplexy, constituted but one disease.

The agricultural journals in particular had been the repository of much confusion in the matter of describing one disease under a variety of names. Thus unless symptoms were carefully recorded - and frequently they were not - there would be no way of knowing what was meant by black leg; in some cases this obviously was anthrax, in others it apparently was clostridium infection currently denominated as blackleg. Bouley says:

M. Pasteur, it seems to me, has given a perfectly exact definition of the disease, where he defined it by this agent itself, the bacteridie, which is found in all species identical.

The second volume offers a long article on "The Germ Theory, its Application to
Medicine and Surgery," by Pasteur and others. In some respects this is possibly the most important feature of this particular volume in that it brings to the American veterinary profession of this time, an overt statement of the germ theory of disease at a time when other journals were already attacking it. It would seem that Pasteur's startling message must have made an impression on at least some of his American readers. He says:

All sciences gain by assisting each other. When, after my first communication on fermentations, in 1857-58, one could admit that ferments ... were living beings, that germs of microscopic organisms exist in abundance on the surface of all objects, in the atmosphere, and in waters, that the hypothesis of a spontaneous generation is actually chimerical ... medicine and surgery paid attention to these new lights. A French physician, Dr. Davaine, made the first happy application of these principles to medicine in $1863 \ldots$. .

Our researches of the last year... have rendered as most probable that septicemia results from the presence and multiplication of a microscopic organism, but the rigorous demonstration of this important conclusion remained undone. To affirm experimentally that a microscopic organism is really an agent of disease and of contagion, I see no other way, in the actual state of science, than to submit the microbe ... to the method of successive cultivations. . . Such is, for us, the undisputable proof that anthrax is the disease of the bacteridie. ... .

It is horrid to think that life may be at the mercy of the multiplication of these infinitely small ones. It is also consoling to hope that science will not always remain powerless before such enemies. . . A At the beginning of these researches - for they only begin - and though already a new world is discovered, what is to be looked for in most instances? It is the positive proof that there exist diseases transmissable, contagious, infectious, whose cause resides essentially and uniquely in the presence of microscopic organism. It is the proof that, for a certain number of diseases, we must forever drop all ideas of spontaneous virulency... opinions fatal to medical progress. ...

Scientific novelties often come against prejudices. Well, some will say, what of your bacteridies and vibrios? What are those infinitely small to us? Are they not seen swarming everywhere?... Is there any danger? To these I would ask, of what infinitely small do you speak? We have seen that alongside the 
most dangerous vibrios, there exist very harmless ones.... In the study of microscopic beings, any method is precious, if by it one may succeed in separating from each other numerous species whose association is so common. . .

If I was a surgeon, impressed as I am by the dangers which would rise from the germs of the microbes thus spread upon all objects, particularly in the hospitals, I would not only use instruments of perfect cleanliness, but, after having washed my hands most carefully and exposed them to a rapid singeing. . . I would have... all the bandages, and all the sponges first exposed to a temperature of 130 to 150 degrees, and would only employ water which had been exposed to a heat of 110 to 120 degrees [centigrade?]. All this is practical. In this manner, I would have to fear only the germs in suspension in the air all round the bed of the patient; but observation shows us easily that the number of those is almost insignificant when compared with that of the dust on the surface of most objects . . . and, besides, nothing would prevent the use of the antiseptic manipulations, which, united to those that I indicate, could be considerably simplified. A phenic solution, even very weak and consequently without inconvenience by its action upon the hands of the operator or for his respiration, could be advantageously substituted for strong carbolic solution.

In discussing his research upon the anerobic organisms of purulent infections, Pasteur states that this "is a new confirmation of our principle: fermentation accompanies life without air; a principle which, I am persuaded, will one day predominate all our knowledge upon the physiology of the cell." Of more immediate interest, however, are his closing thoughts, repeated from one of his medical colleagues, who had urged:

The success, as well as the failures, in surgery would find a rational explanation in the principles upon which the germs theory rests, and that this would give birth to a new surgery, already inaugurated by a famous English surgeon - Doctor Lister.

How deeply this penetrated the sensorium of the average practicing veterinarian is, perhaps, a moot point, but from this time on an increasing number of contributors to the American Veterinary Review evidence an understanding of, and a belief in, the germ theory of disease. In the same year (1878), James Law states:

As both the contagious and parasitic diseases are propagated by germs produced in countless numbers in the body of the victim, it follows that the aggregation in a limited area of men and animals, in which they can live and increase enormously, enhances the danger to both kinds of victims.

\section{N. S. Townshend, M.D., writing on hog cholera, states:}

If the disease is typhoid fever, we should expect to find that contaminated water is a principal medium through which the disease germs pass from one animal to another. How far exemption from attack may be secured, when the food and drink are free from all possible contamination, has not, so far as I know, been determined.

\section{Abortion, Anthrax, and Cholera}

At this time, when "sympathy" was still considered a primary factor in producing infectious abortion in cattle, the Review presents a translation from Professor $L$. Frank of Munich, who attempts to answer the question:

What is this suspected infectious matter, and from whence does it generate? and, 2. In what manner does it penetrate into the pregnant animal, and thus produce abortion?

He cites the finding of bacteria in the afterbirth of an aborted fetus, and the experimental production of abortion by introducing mucus from the vagina of an aborting cow into that of a healthy animal: "This fact is a matter of great importance." Also, the finding of bacteria in the amniotic fluid of an aborted fetus with the amnion intact leads Frank to conclude that the bacteria

were already contained in the uterus and penetrated into the foetus through the amnion. . . . These facts tend to show that infectious abortion is due to the action of a contagion.

In writing on anthrax in Canada in 1879, Dr. McEachran states: 
I am not aware of any records of outbreaks of this disease in Canada having been kept, but in conversing with old people who have lived nearly a lifetime in the country, I find that they have no difficulty in recalling to mind repeated instances in which farm stock have died mysteriously, and which then as now was usually attributed to toxic plants, malicious poisoning, "the evil eye," "elfshot," or "a visitation of Providence." . . . The chief source of anthrax is contagion dependent on the existence of a specific poison in the blood.

$\mathrm{He}$ is not quite ready, however, to decide whether the bacteria universally demonstrable in the blood were present "as a cause or product of the disease."

In 1880 Liautard editorialized on Pasteur's work on chicken cholera:

He shows that chicken cholera is not only due to the presence of a microbe, developing itself in the organism of the hen ... but that it can be prevented by inoculation - a fact that goes far into the prophilaxy of the disease, and which cannot escape the attention of our agriculturalists. ... Veterinarians will, no doubt, read with interest, the long papers that M. Pasteur read before the Societe Centrale de Medecine Veterinaire, and which we reprint in full.

In demonstrating infection of chickens by ingestion of the cholera bacteria, Pasteur states:

In this manner one can easily understand the manner of propagation of the disease in chicken yards. Evidently the manure of diseased animals plays the largest part in the contagion.

He logically suggests sanitation as the principal prophylactic measure. And in relating how by attenuation of cultures of the organism he was able to produce immunity to the disease, he states:

Though realizing the propriety of a becoming humility in presence of these mysteries, I hope that the society will see in the facts I have the honor to present, unexpected explanations of the problems presented by the study of virulent diseases. . . . How many mysteries in the history of contagions will one day receive solutions still more simple than the one I am speaking of! Let us throw aside the theories, that we can contradict by positive facts, but not by the vain pretext that some of their applications escape us. The combinations of nature are at all times singular and more varied than those which meet the ordinary conceptions of our minds.

One of these phenomena, beyond "the ordinary conceptions of our minds," was presented by Pasteur in 1881 in an article on "The Attenuation of Viruses and their Return to Virulency." In finding that serial passage of an infectious agent may increase its virulency, and thus account for diseases "which appear spontaneously in all countries," he states:

And now virulency appears before us in a new light, which is not without alarm for humanity.... An inoffensive microscopic organism ... a being [which] cannot develop itself in our body, or in that of ... [ some other ] animal ... could penetrate into another of the thousand species of the creation, invade it and make it sick. Its virulency, then strengthened by successive journeys into the members of that species, might become in condition to invade other animals. ... By this method one may create new virulencies and new contagions.

He states that the opposite is not made improbable by this finding - "the possible diminution of virulency by the journey of a virus through some subject," but he had not yet found any such examples. Perhaps few, other than Pasteur himself, envisioned just how important this concept was to become as a tool in medical research and practice.

\section{More Light}

Pasteur was well aware of the scepticism and outright disparagement of his discoveries by many leading medical investigators and practitioners. In writing on: "The Connection of the Germ Theory with the Etiology of Some Common Diseases," he stated in 1880:

I know that in medical investigations it is difficult to avoid interference with preoccupied ground. Again, I do not forget that medicine and veterinary science are strangers to me. For this I ask the judgement and comment of this illustrious society. Indifferent to frivolous and 
capricious objections, and with just contempt for the vulgar scepticism which adopts doubt as a habit, I look towards the militant scepticism which properly makes doubt a stimulus to inquiry, and whose rule of conduct has for its motto: "more light."

As suggested above, the publication of the researches of Pasteur and other continental workers was perhaps the noblest mission of the American Veterinary Review during its early life. To a greater extent than many medical journals, and the Journal of Comparative Medicine and Surgery, the Review not only reported, but supported the germ theory of disease with a fervor that would have gladdened the heart of Pasteur himself. But this would have had little immediacy of value unless American veterinarians did more than read this passively. It would appear that relatively few veterinarians, unlike some of the more voluble medical writers, were openly critical of Pasteur's work. Of greater importance, however, is how many veterinarians took active steps to apply the findings of Pasteur to teaching and research in America. It would be most instructive if we had transcripts of lectures given at the veterinary colleges at this time, but few of these have been published. Nor was much bona fide experimental investigation being done by veterinarians.

Fortunately, the professional career of D. E. Salmon, following a short period of practice, was channeled into veterinary research. In his early writings in the American Veterinary Review, Salmon demonstrated through his complete understanding of the germ theory of disease the logic of his being chosen in 1883 to head the Bureau of Animal Industry.

In writing on fowl cholera in 1881, Dr. Salmon states:

We are satisfied, after a long series of experiments, that there are points in its. natural history which enable us to control it with comparative ease and with a considerable degree of certainty. .. . The disease germs are seldom, if ever, taken up by the air . . . the virus... is generally, if not always, taken into the body with the food; it is distributed over the grounds, feeding places, etc., in the excrement of affected birds, and the food, drink and gravel are thus contaminated.

He recommends destruction of sick birds, disinfection of the premises, and isolation of healthy birds from any potentially infected, and:

The value of the method of preventive inoculation or vaccination discovered by Pasteur has not yet been decided, but in view of the comparative ease with which the affection may be controlled by the measures detailed above we doubt if it can ever be advantageously adopted as a means of preventing this particular disease.

Pasteur himself had noted that the results of inoculation were still erratic. Salmon's article, incidentally, is one of the first reports of American veterinary research to be presented in the Review, although only his conclusions are given.

The medical editor of the Journal of Comparative Medicine and Surgery in 1880 , leaves some doubt as to the course he expected to take concerning

the over-strained germ-theory of disease. We have no doubt that a careful comparison of the results obtained by different observers will show that molecular movements and microcytes have frequently formed the basis for new "germ-theories" in some cases, and the accidental presence of bacteria ... in others. A judicious study of the finer chemistry of the fluids in infectious diseases would probably lead to more definite and more valuable results.

Salmon, at least, did not humor this diehard proponent of the humoral theory of disease. Nor can his critics be credited with real prescience in anticipating the contributions to microbiology being made with the electron microscope.

\section{The Faith That Is Within Us}

In 1881 an article by Salmon on: "Charbon and the Germ Theory of Disease" appeared in the American Monthly Microscopical Journal, and was reprinted in the 
Review. In this he states that from Koch's investigation of the Bacillus anthracis:

the germ or bacteria theory of contagion received a new impetus. .. . There have always been doubters, however, particularly among English-speaking people, most of whom have been unable to follow the investigations as closely as is necessary to reach sound conclusions. . . It is not uncommon to see such doubts expressed in very strong terms in medical and scientific periodicals. . . . It seems opportune, therefore, to present the evidences for the faith that is within us, so that all may see that we have a foundation clearly and firmly established. [ Italics mine ]

In presenting "a series of facts which show the connection between the virulence of the blood and the presence of the Bacillus anthracis," Salmon asserts:

A single fact of this kind might indeed be called a coincidence... two such facts... a strong probability . . . but when it comes to a set of nine facts, each of which taken alone would be a remarkable confirmation, it seems to me that, as scientific men, we must accept them as a demonstration ... the organism and the virus are one and the same thing, and I believe that any unprejudiced scientific man must accept this conclusion as necessarily following from the above facts.

Continuing his theme, Salmon charges that many "scientists" had either adopted superficial concepts, or rejected sound ones, by "playing fast and loose with the germ theory, in a style not very consistent with the elementary principles of scientific reasoning." These varied opinions, he adds:

are not evidence either for or against the germ theory. In science a fact must be demonstrated before it can be accepted, and when once properly established, it must remain a fact, no matter what results are attained by other lines of investigation. In other words, facts do not contradict each other, and when they appear to do so, it is only because our knowledge of the subject is superficial.

In summarizing the work of Pasteur and others on anthrax, Salmon states:

This being the entering wedge for the germ theory in scientific pathology, it is perfectly right to demand the most conclusive evidence before admitting it; but this evidence has now been furnished - the germ theory has a substantial foundation - and medicine is destined to make its most brilliant triumphs by the discoveries to which it will lead. The progressive pathologist will waste no more time in criticising what is so well established, but will press onward to other and equally important discoveries.

For many years the agricultural press, and the American Veterinary Review since its inception, had pressed for the formation of a National Veterinary Bureau to combat the rising toll of animal disease. In some respects it might be considered fortunate that legislation establishing the Bureau of Animal Industry was sidetracked / until Salmon had achieved sufficient prominence to become the logical choice for its first head. Fortunate, at least, that some considerably less able individual who might have had a long tenure in this position - was not given the nod simply because he was available and earlier Salmon was not - a happenstance perhaps all too frequent, even today.

\section{Who, Except Dr. Salmon?}

Interest in the germ theory of disease did not end with its "discovery" by American veterinary medicine. Admittedly, few veterinarians in America were ready to make experiments to prove it for themselves; and as late as 1890 C. B. Michener asked, "if indeed we except Dr. Salmon, who of us has accomplished any original work?" As editor of the Review, however, Liautard pursued a praiseworthy objective in continuing to present the work of continental veterinarians and research workers which was to lay the foundation for the science of bacteriology and animal disease research in America. D. E. Salmon, of course, was the notable exception; in many respects he was the first American veterinarian to both envision the full scope of the necessary work of the profession and to pursue this vision with relentless and intelligently directed energy.

In 1882, continuing his exposition of 
"Fowl Cholera and the Germ-Theory of Disease," Salmon states:

No longer than a year ago, there were so many criticisms of the germ-theory continually appearing in our medical and scientific periodicals that the writer felt it a duty to place the evidence bearing on the question before the working microscopists of the country in such a connected form that they could scarcely fail to appreciate it. ... After patiently waiting a year to allow those who oppose the germtheory ample time to place their objections to this evidence on record, without any such objection appearing, it may be concluded that up to this time at least, there are no substantial grounds for doubts.

As a working theory, we have seen more light thrown upon contagious fevers by its use for half a dozen years than was gained before in the whole history of medicine; but notwithstanding this, its true friends do not care to press its acceptance in advance of the actual results obtained by scientific investigations.

Upon the basis of Pasteur's work on anthrax, he continues:

We may confidently announce that the first story of the edifice has been reared upon the foundation, and that it is so well finished as to be perfectly safe for use, and to serve as a support for future work.

Not all veterinarians were as willing to accept this new concept, and the writings of some demonstrate a lack of appreciation of the germ theory of disease. But, unlike the medical press, few overt objections to this theory appeared in the veterinary literature. If it were necessary for editors to screen out some contributions of this nature, we can at least be thankful for this much. Salmon mentions that in the medical press:

Still, we occasionally see elaborate articles intended to prove that the bacteria of contagious diseases are nothing more or less than one of the forms assumed by coagulating fibrin.

In support of this statement he mentions an article: "No Bacteria in Diptheria," appearing in the Medical Record for 1882.

In 1883 the Review quoted the Rural New Yorker on Salmon's work on inoculation in which it was noted:
The method adopted by Dr. Salmon for lessening the virulence of the virus so as to fit it for inoculating, or rather vaccinating, purposes, differs considerably from the "attenuating" system of Pasteur, and we are glad to learn that the Doctor is to have an opportunity of thoroughly testing its efficiency.

The same year Salmon reported in the Review: "On the Production of Immunity from Contagious Fevers by Inoculation with Diluted Virus." Working with fowl cholera, Salmon set out to produce a culture of standard virulence, and to use dilutions of this to produce immunity by inoculation. This work demonstrated two important facts as concomitants of all such biological research:

... the individual peculiarities of living animals ... that susceptibility and insusceptibility are only relative and never absolute conditions.

Finding that extreme dilutions fail to produce any result, but that with stronger dilutions "local resistance to the germ fails while the constitutional resistance may still be perfect, and . . . this local multiplication of the virus is sufficient to grant a very complete immunity," he concludes:

The most virulent virus may be diluted to such an extent as to become practically a vaccine, and ... in this conditon it may be used safely for producing insusceptibility.

The advantages of his method over that of Pasteur, Salmon states, lie in the use of a standard virus, of longer activity, and requiring only minutes instead of months for attenuation; in addition, less virus is needed, and less dangerous experiments are required to learn the proper degree of attenuation. On this basis, he suggests:

I should not be surprised if greater advances are made by the investigations of the future, for the prevention of contagious diseases, than have been accomplished in the past, but at present the question is fairly before the medical profession - Shall we vaccinate with a large number of comparatively inactive germs, or with a small number of those which retain their greatest virulence?

In commenting on Salmon's work, Liautard considers this to show that: 
Dr. S. is quite a master of the subject, and that the appointment which he has just received from the Commissioner of Agriculture was well deserved.... It will be gratifying to the veterinary profession of America to learn that, young as she is in the field, she is already making her mark in the most important department of their calling, viz., that of the prophylaxy of contagious diseases.

\section{And concerning his own efforts:}

In accordance with the original programme accompanying the first issue of ou r journal... we have kept our friends informed in reference to the theories and facts of prophylaxy as inaugurated by European practitioners, and applied to the contagious diseases of animals. . . . We cannot but feel persuaded that at least those of our veterinarians who have kept themselves advised through the publications in question, must derive much personal advantage, in various instances, from their advanced knowledge and more enlightened judgement in the course of their professional labors. ... We shall continue to pursue the same course in the future.

\section{Law on Zoonoses}

In 1878 James Law entered a lengthy "Plea for Veterinary Surgery," in which he goes considerably beyond the area sug. gested by the title of his subject. This was printed in the Report of the Pennsylvania Board of Agriculture, and reprinted in the American Veterinary Review, and thus undoubtedly came to the attention of a number of influential persons. In this he explains:

When we enter on the list of contagious and parasitic diseases, we are at once brought face to face with a sanitary question of supreme importance alike to man and to his living possessions. Several of the specific and contagious diseases of animals are communicable to man, with a more or less deadly effect. ... The aggregation in a limited area of men and animals enhances the danger to both kinds of victims. If physicians are left ignorant of the affection in the beast, and veterinarians of the same in man, they each miss the golden link which would reveal the true nature and dangers of the disease, and enable them to contend with it successfully.

In giving specific examples of the relation of veterinary knowledge to human welfare,
Law singles out rabies, glanders, and tuberculosis. On rabies he charges:

Even among the medical profession, we find the most injurious blunders on the subject. How often do we read accounts of hydrophobia in man as the result of a bite from a dog which is known to be alive and well.

And on glanders:

What frightful sufferings and horrible deaths had resulted at all times and in every part of the civilized world, before the discovery that man owed this disease to the domestic animals, can never be revealed, but from the number of cases reported on all sides, as soon as Waldinger's discovery became generally known, a very high mortality can be safely inferred. Here again we have a terrible example of the loss sustained by the disassociation of human and veterinary medicine. The criminal negligence of our State Legislatures to enact laws forbidding the use or exposure of animals suffering from this and other fatal disorders, contagious to man, may be in part charged to the apathy of the medical profession on the subject.

On the subject of tuberculosis, the eradication of which in cattle was to become one of the prime achievements in the entire history of public health, Law urges:

The importance of this discovery of the communicability of tubercle to animals and man, cannot be overestimated, and speaks with trumpet-tongue of the value of comparative pathology to the physician and veterinarian.

With these examples as a basis for his principal argument, Dr. Law goes on to state:

The object of the present paper is to show how much the medical profession may gain from a closer association with comparative pathology and especially from veterinary medicine. Such a connection would accrue even more to the profit of the veterinarian, alike in giving him the status that he ought to possess, and in furnishing him more thoroughly for the practice of his profession. The average veterinarian is, to say the least, no better informed on many of the points referred to than is the average physician, and broader views and sounder practice will come to both from the mutual cultivation of that field which is common to both. 
Law recognizes that many rural areas will not support both a physician and a veterinarian, especially if their fields of work are to overlap. He therefore proposes that the veterinarian secure additional qualifications in the area of public health, perhaps more or less akin to the training afforded by the Master of Public Health degree today, for:

If properly educated, he would prove a sounder guardian of human health, from his acquaintance with the diseases of the dependent animals, and he would be a safter veterinary physician for his extensive acquaintance with the pathology of man. . . For this new field, I propose a new style of practitioner, more comprehensively educated and equipped than either physician or veterinarian-one who has given a longer time to acquire his education ... [ [and] has made himself thoroughly acquainted with the diagnosis and treatment of the maladies of man and beast.

It is in the department of sanitary or preventive medicine that the value of the work of the veterinarian is the highest. . . . With animal plagues, the first case of illness is pregnant with a mighty and ever increasing danger, not only to the other stock of the same owner, but to all the live stock in the nation, and even in some cases to the citizens as well.

The veterinary profession at this time, through Alexandre Liautard and the American Veterinary College, enjoyed cordial relations with the Society for the Prevention of Cruelty to Animals and its New York promoter, Henry Bergh. Speaking more or less in the same vein as Law, but perhaps with some bias toward his own more immediate interests, in 1878 Bergh assures the students of the College:

the "Horse Doctor" has disappeared, to be replaced by the veterinary surgeon, who now takes rank by the side of the human practitioner. And $I$ fail to discover, gentlemen, any essential difference between the principles and purposes which underlie the human and animal medical science. . . The consequences to the public of a better education in the laws of animal medicine, are only beginning to be fully realized.

Not only is the skill of the veterinary practitioner applicable to diseases and accidents of domestic animals, but his learning and experience should be employed by the State in a sanitary point of view. That the national health is greatly deteriorated by the inhuman treatment of animals while in transit upon railroads and otherwise, by which the flesh becomes vitiated so as to be the source of numerous fatal diseases, no sensible physiologist or surgeon will deny. Can there be a more exalted ambition or duty, than to educate young men to stand as sentinels between the unsuspicious public and the diseases and death which the cupidity of corporations engender?

And Liautard, in editorializing on the need for a veterinary sanitary bureau, criticized a proposal in the medical press which urged the addition of several specialists to boards of health, but which did not include a veterinarian. He argues:

The health of our nation cannot be properly protected by sanitary physicians, engineers, and meteorologists alone, for many of the most destructive diseases known depend upon, or orginate in, the lower animals, and it is to those scientists versed in their causes, treatment, and prevention to whom we are to look for protection.

For this reason we would ask that to the $\mathrm{Na}$ tional Board of Health be added a veterinary sanitarian, and also that a Veterinary Sanitary Bureau be formed in Washington, to which all State Boards should report.

\section{And speaking later (1879) of veterinary} sanitarians:

In the cities of New York, Boston, Brooklyn, and perhaps some others, veterinarians have been added to the Health Boards; but the position has been only an honorary one; the services of the consulting surgeon being rarely called in requisition.

In so far as we know, out of the few States which have established State Boards of Health, the State of New Jersey is the only one in which a consulting veterinarian is appointed. ... The public health, and individual prosperity and wealth, demands the presence of the veterinarian in all Health Boards; not as an unpaid official, but with a remumeration proportionate to the services rendered.

The American Public Health Association early recognized the veterinary aspects of public health. At the ninth annual meeting in 1881 one session was devoted entirely to veterinary papers, including: "The Contagious Diseases of Domestic Animals," by 


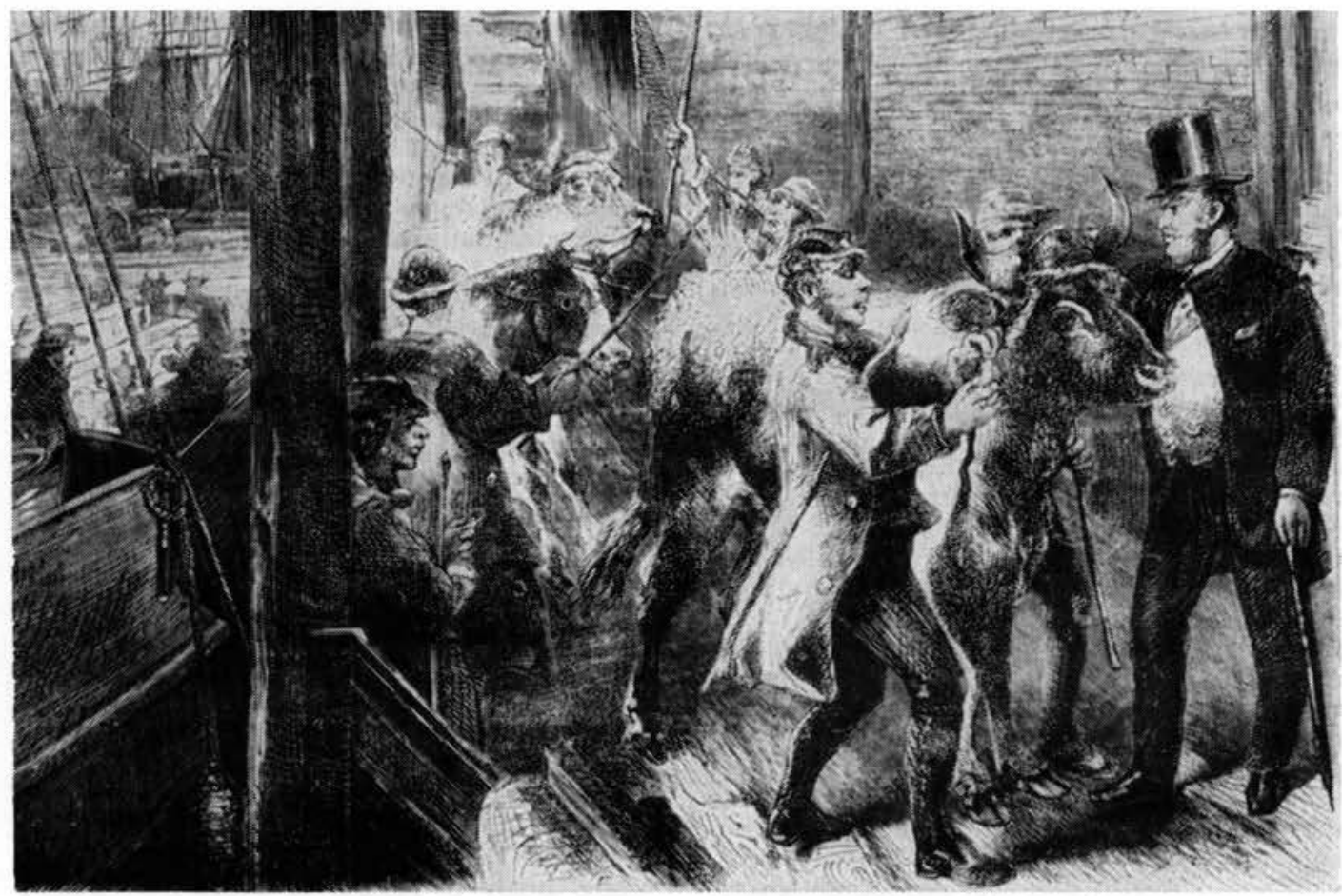

Inspection of American cattle arriving at British markets during the 1860's led to the disclosure that some were diseased, and in 1879 an embargo was placed on stock from the United States. American Agriculturalist

Ezra M. Hunt, M.D.; "Diseases among Texas Cattle," by Dr. J. R. Smith, an army surgeon; "Examination of Hogs at the New Orleans Abattoir," by Dr. J. M. Partridge; and "Trichinae Spiralis in American and German Hogs," by F. S. Billings. While Hunt recognizes that veterinarians should play a distinctive role in certain aspects of the control of animal diseases, he urges:

Medical men and others of this association should feel these investigations to be as worthy of their labor as those directed to some human diseases. The time has come when medical and sanitary experts should recognize the study of the comparative plagues as a part of their work and devote the closest study thereto . . . be it man or beast, it is a common concern in a common welfare.

\section{ANIMAL DISEASE AND MEAT INSPECTION}

In the late 1870 's the federal government began to show some belated concern over the fact that foreign governments were on the verge of prohibiting the importation of animals and animal products unless it was evident that adequate measures were adopted to control the spread of contagious diseases. A circular issued by the Treasury Department in March, 1877, demonstrates just how inadequate was the practically nonexistent system of quarantine:

While the department has no authority under the law to prohibit the importation of horses, sheep and swine, it desires that all measures practicable be taken on the arrival of such animals from the countries named to prevent the possibility of contagious diseases being communicated thereby to stock in the United States.

Great Britain did take action in 1878 , and in commenting on "The Cattle Trade Stoppage Bill," N. H. Paaren, later State Veterinarian of Illinois, reported in the Prairie Farmer:

The British government has especially notified the United States government that, in 
case the latter desires to be exempted from the operations of "The Contagious Diseases (animals) Act, 1878," the lords will require a statement of the laws which regulate the importation of animals into this country, and the method adopted to prevent the spreading of any contagious disease when it exists in any part of the United States.

The reply which the United States Government can give... must certainly be one of a most humiliating nature. ... In the "Revised Statutes of the United States" we fail to find any reference whatever to legislation for the prevention of the spread of infectious and contagious diseases amongst our domestic animals. The few acts that have been passed by some of the states are totally inadequate for the purposes for which they were passed, and most defective also in their operation regarding the prevention of the sale of diseased animals for consumption as food. . .

We do nothing to prevent the spreading of disease, or to exterminate disease, but eat all our diseased cattle. Instead of qualified veterinarians being employed to check the progress of maladies, the butcher's services are in requisition, or the animals are hurried off to the stock yards or slaughter houses of our larger cities. The traffic in diseased swine is on a larger scale than most people would believe... . The state of our meat trade is a disgrace to any civilized country. . . .

One reason .... is the neglect of veterinary science in this country, and consequently the backwardness of that science. The spread of diseases among live stock in the United States is also facilitated by the totally unchecked trade in diseased animals, and by the absence of all proper means to detect and counteract disease. . . Veterinary science is in its infancy among us, and for the want of a sufficently numerous membership of the veterinary profession, the country has not been fortunate in gaining a knowledge of its capabilities. As time wears on the need of educated veterinarians will become an urgent necessity, as veterinary science itself has now become an essential of civilization.

\section{Enter Billings}

Regarding the sale of glandered horses in Massachusetts, F. S. Billings, he of the frequently ill-tempered tongue, charges:

No veterinary police inspection exists at the market in question. Yet the good old commonwealth has a Board of Cattle Commissioners, supposed to exercise control over this and other animal pests. We are not entering into a personal war with these Commissioners. Far from it. The trouble is not so much with them as with the laws and regulations which are entirely inadequate to the business in hand. The Commissioners, only one of whom is active, do not and cannot, single-handed, control these dread ravages. . . .

It is of great public interest and importance to know in how many of our States we have any laws or regulations for the supression of these animal pests. In 1876, Dr. Bowditch, of Boston, published a very interesting and valuable book... entitled, Public Hygiene in America. The same is a most condemning proof of our insufficiency in this regard. With refercnce to laws for the prevention of cattle diseases... we find twenty-one States without any whatever; ten States have some regulations; sixteen States are reported as indefinite, and from one illustrious State no information in this regard could be gained. No national laws or regulations of any importance exist, so far as we know. There is no competent veterinary councilor or head in connection with our national government. In advocating a National Veterinary Police, we are well aware, we touch upon one of the most sensitive points, not only of State, but individual ignorance.

On the question of states' rights vs. moral right, he argues:

One can but ask, What is the use of the State of New York spending thousands of dollars to kill out the disease [pleuropneumonia], while New Jersey is keeping a pestilential hot-box by her side? . . . New Jersey, under such circumstances, becomes a nursery from which pestilence may be dispersed all over the country.

In a more temperate vein, regarding: "The Suppression of Contagious Diseases among our Domestic Animals," Billings later suggests:

Veterinary medicine finds its strength and gains public appreciation, not like human medicine, in the gratitude of the patient or his family, but in its ability to prevent, in a measure, individual or great national losses, and, what is still more important, its ability to prevent many serious diseases or unpleasant disturbances to the human organism. ... What the profession desires, is advancement, as a whole, in public appreciation. In the appointment of Commissions, or, rather, in the manner they have thus far been conducted, this end has been most signally lost sight of. . . . 
As practitioners we are but of interest to the customer. As practitioners alone, we can never get beyond the stable door; the back door which enters to the family, to the legislative halls, to public advancement of our body, is not now, and never will be, open to or opened by the practicing veterinarian. It is only when we manifest our ability to save the community from large losses, from contagio-infectious causes; it is only when we demonstrate our ability to become valuable and faithful guardians of the public health, more valuable in many respects than the M.D., that we can look for public advancement as a profession.

Billings was well known to the American veterinary profession before he became a member of the USVMA in 1880 , for beginning with the first volume of the $R e$ view, he had contributed numerous translations of German articles on a variety of subjects. In welcoming him as a "new member of the profession" in 1877, following his graduation with honors at Berlin, Liautard states:

German entirely as he has proved himself in his writings, we cannot expect from him other than Germanized principles. ... A department for medical and veterinary investigations would give him a great opportunity to apply $h$ is extensive and thoroughly acquired knowledge; but, it appears to us, that at the wheel of advancement of veterinary science proper, is his place. . . We cannot but regret that it may be some years yet before he has joined our ranks.

In a lengthy review of Billings' Relation of Animal Diseases to the Public Health and their Prevention (1884), Liautard states:

The work possesses many excellent points, but would have lost none of its value if the language of the author had been, in many cases, less severe, and in many parts uncompromising.

Billings, some of whose work is considered elsewhere, remained the gadfly of the veterinary profession. Associated at various times with the American Veterinary College, the Chicago Veterinary College, McGill University, and the University of $\mathrm{Ne}$ braska, it was at the latter institution that he gained notoriety with his announcements of untenable claims regarding the cause of hog cholera and Texas fever. In 1885, after a period of study with Virchow in Germany, he was for a time in charge of the pathological department of the New York Polyclinic Medical School, the first such appointment of an American veterinarian.

\section{Exit Billings}

Retiring to practice in his native Massachusetts in 1892, Billings continued his warfare with the Bureau of Animal Industry, and D. E. Salmon in particular. The USVMA and the veterinary profession in general were prime targets after his expulsion from the USVMA in 1890 for unprofessional conduct. Upon his death in 1912, the magnanimous Salmon, whom Billings had most uncompromisingly reviled, wrote:

Dr. Billings was a man of vast knowledge, but his contrary disposition of mind, his great desire for controversy, and possibly a very nervous and irritable character, prevented him reaching in the profession the position to which his education and facilities seem to give him a claim.

Curiously enough, the stand taken by Billings toward Salmon in 1885 belies the enmity which was to develop. In reviewing the first annual report of the Bureau of Animal Industry, Billings states:

Every unbiased mind must become convinced of several things in reading this report: 1st. - That we, as a profession, have a most creditable representative in Dr. D. E. Salmon. Chief of the Bureau. . . . The report, in every way, confirms the views we have been advocating for the past ten years. . . At last we have a veterinarian at Washington who is not afraid to publish the exact condition of things in his report.

An examination of the early writings of Billings demonstrates the promise he exhibited as a prospective member of the veterinary profession. While yet studying at Berlin in 1879 he contributed an article to the Review concerning the proposed 
National Board of Health in which he expressed alarm over the omission of a veterinarian from the roster of personnel. His description of the qualifications requisite for a veterinary member of this board would suggest that he had himself in mind, but this does not alter the merits of his argument. Undoubtedly, he was one of very few veterinarians at the time whose training reflected the breadth of vision and abilities such a position would require.

Such a veterinarian, Billings claims, should be a comparative pathologist in the true sense:

Numerous mistaken writers have spoken of veterinary pathology as comparative. We have veterinary and human pathology. The union of both, and comparison of the results of both forms of investigation is true comparative pathology. . . . We are fully aware of the difficulties the nation would find, in searching for a man equal to the emergency... [but] we will say at once, the man can be found, and a veterinarian at that.

Concerning the qualifications of such an individual:

First, he must be a gentleman; further, he must be well educated in the rise and progress of medical art and science, and of the difficulties which have been overcome. He must be at home in the history of his own profession in every land, and he must be able to exert a healthy judgment over the stand of veterinary medicine in those lands. He must know why it is that his profession has been always in the back-ground, why in most lands it is still holding religiously on to the skirts of the last century. He must be an American in the true sense of the term. He must be impregnated with the scientific spirit of the day, and with fore-seeing ability suiting him to mould things for the future. He must be at home with the various forms of American life, and have power to mould these forms for the good of the whole. He must be a gentleman of culture, a philosopher, as well as a mere technicalist. He must be acquainted with the entire veterinary police laws and systems of the world, and, if possible, have lived more or less in them. He must have an organizative ability of the highest stamp, for he has almost single handed to lay the foundations of a veterinary educational and police system, and woe betide him if he fails.
Such is the irony of fate that Billings probably little realized he was describing, to a greater extent than any other living veterinarian, the man whom he was to make his "arch-enemy," D. E. Salmon, who as first Chief of the BAI initiated and directed many of the functions visualized by Billings.

\section{Meat Inspection}

In editorializing on the matter of veterinarians on boards of health, Liautard states in 1879:

While we are not over sanguine as to the probability of our suggestions being at this time acted upon, there can be no doubt as to the ultimate recognition of the importance of veterinary science in conjunction with this all important subject; and soon or later the veterinarian will find his knowledge in requisition by health boards. Especially needed are veterinarians as meat inspectors, for no other can be so well fitted to detect the presence of disease in the animal intended for slaughter, or the evidence of its previous existence in the meat that is offered for sale... It is a notorious fact that where deficient inspection exists, the avarice of unprincipled dealers imposes upon the unsuspecting public, meats unfit for human food. . . . To fully protect our people ... necessitates the employment of inspectors who possess greater qualifications than are found in the common police officers usually detailed for such duties.

In an editorial on "Veterinary Inspectory of Meat" in 1883, Liautard states:

While considering the question of the regulation of sanitary veterinary medicine, we are brought to the consideration of the relations existing between the veterinarian and the public health in connection with the inspection of meat in reference to its fitness for human consumption as food. . . . How are our Meat Inspectors appointed? What amount of knowledge are they required to possess? With one or two exceptions, outside of New York, are the persons appointed qualified for the position? We reply without hesitation, they are not. Politicians, police officers, and butchers are those who receive the responsible office which empowers them to condemn or approve the meats brought to market for public consumption.

The days are gone when veterinary medicine in the United States consisted only in the treat- 
ment of diseased animals. The days of the oldfashioned "horse doctor," and "cow-leech," are gone by, and within a few years the veterinary profession has taken a foothold amongst us which must become more and more assured every day, and more widely accepted by the public.

In a one-man crusade to warn against the dangers of trichinosis, F. S. Billings published a series of articles on this subject in the Review from 1881 to 1883 , noting that in general the intimate connection between certain human and animal diseases:

is a subject which has been left, until the past few years, too much out of consideration, not only by the public itself, but by those who are especially employed in the study of the question of public hygiene. ... We are living in the day which marks the birth of systematic attempts at the development of preventive medicine.

After noting a number of deaths from trichinosis in the United States, Billings charges:

Neither the law nor the community recognize the existence of any such disease. . . Even our Boards of Health simply recognize the existence of the parasites in pork as a scientific fact, but take no steps to prevent its sale. All the hogs examined by myself were cut up and sold, even though the Massachusetts Board knew that I was continually finding trichinae among them. . . Until the public becomes alive to its own interests, we may be sure no steps toward prevention will be taken by the State.

The subject of meat inspection continued to be discussed, but with little in the way of concrete action resulting until passage of the first meat inspection law in 1891. In 1892, W. L. Williams charged:

During the whole period of human history probably no other vital science has been allowed to drop so far behind its associates nor suffer so seriously from a long and baneful dormancy as the inspection and control of the flesh and milk of animals intended for human food ... [ [but ] we now have abundant promise that meat and milk inspection will soon occupy a highly honorable place in the front rank of the sciences holding a vital relation to human life, health and happiness. ...
In our opinion meat and milk inspection should be carried out primarily in the interests of the intended consumers of the food products, and not, as is too often the case, in the interest of the producer. . . The prime obstacle to effective meat and milk inspection has ever been and will continue to be the ir repressible and unavoidable conflict between the consumer, and upon a scientific and practical adjustment of these interests must meat inspection rest if it is to succeed.

He notes that the recently enacted federal inspection laws "appear to be, in most respects, adequate and beneficent." Experience was to show, however, that this was not the case. The story is resumed under the activities of the Bureau of Animal Industry.

Regarding the restrictions placed by foreign countries upon the importation of American pork products, the Review had noted in 1881:

The widespread prejudice against American meats can be adequately met and overcome only by a rigid system of official inspection by competent experts, appointed by the National or State Government, and empowered to use a seal or other device representing Governmental authority. In the European mind, an official seal is inferior in potency only to the edict of Royalty itself. .. . The European meats with which our own come into competition are nearly all officially inspected, and until American hams and bacon bear the official examination, they will be, in presence of existing prejudices, at a serious disadvantage in the markets of the OId World.

\section{One Nuisance vs. Many}

An inventory of the dead animals received at the New York docks for the year. ending March, 1882, reveals some 8,000 horses, 150 cows, 200 sheep, and 23,000 dogs:

An inquiry might be made, where are the hogs which died in New York, or are found dead in the trucks of the railroads which bring so many of those animals into the metropolis are they turned into hams and sausages? Our Board of Health might enlighten the public in answering the question.

The following year at least a few hogs seem to have been unfit for whatever pur- 
poses they may have been utilized previously, for the inventory lists: horses 6,354, of which 2,118 were killed by the S.P.C.A., cows 187, steers 21 , calves 816 , sheep 531 , cats and dogs 13,367 , mules 24 , goats 128 , hogs 21 , colts 23 , snakes 2 , buffalo 1 , seal 1 , monkeys 2. Also at this time:

The manure nuisance in New York is the most troublesome problem that the Health Board has to solve. The secret of the trouble is that the manure is worth money, and that its price has been raised until its value is fictitious. The owners and keepers of horses are responsible for the nuisance, and they should be compelled to see that the manure that is produced leaves the city. At present the stable owners say that it is better to have one nuisance - the manure mound at the foot of East Forty-fifth street - than to prohibit the cartage of manure to it, and thus make a nuisance of every stable in the city. One thousand loads of manure are produced in New York every day. The Health Commissioners insist that it must not be allowed to accumulate either at the stables or at the dumps.

Of the 10,000 horse stables in New York City in 1880, A. S. Heath, M.D., writes:

Not more than one in a hundred is in perfect sanitary conditon. About one-quarter of the horses are kept in dark, damp stables, or places equally bad. These are the direct sources of most of the mortality of our city horses. As compared with the mortality of stables on the first and second floors, the mortality of the cellar stables is about as ten to one.... Of the two thousand cowstables, there are not ten which are in sanitary respect perfect. ... Many of the city-kept cows sooner or later suffer from tuberculosis, because of the bad sanitary condition of the stables. The average life of the city cow is less than a third of that of the country cow.

\section{Milk Inspection}

The subject of milk inspection also received due notice in the 1880's. Writing on "The Milk We Use and the Source It Comes From" in 1881, Dr. McLean states:

The time is fast approaching when society at large will expect and demand more of the veterinary profession in the way of certifying as to the healthy condition of the animals slaughtered for their use, and particularly that the animals supplying us with so important and extensive an article of diet as milk, be properly fed, housed and of a healthy condition.... There is a great and immediate necessity for a radical reform. ... Doubtless the lactometer will detect the presence of water in the milk. But I have seen cows milked in this city in such a diseased condition, that the mixing of water with their milk would be the reverse of a crime. . .

Nothing but a periodical scientific inspection - without fear or favor - of physical condition of dairy cows can remedy the present deplorable state of matters. . . Had our general public an accurate conception of the diseased condition of the animals in our cities that supply their tables and families with milk, there would be an unanimous and immediate demand for reform.

McLean states that a number of local boards of health had ordinances prohibiting the sale of milk from cows fed on swill, or from diseased animals, but these were "a dead Ietter, for the very good reason that said Boards have no competent officers on their staff to regularly visit and examine these cows as to their physical condition."

In 1856 the first milk law had been passed by Massachusetts prohibiting the adulteration of milk, and in 1859 the first milk inspector was appointed in Boston to enforce a regulation against the feeding of distillery slops to cattle. In 1864 Boston prohibited the use of milk from diseased cattle. Washington, D.C., legislated against insanitary cow yards in 1863 and against adulteration of milk in 1871 , but the first dairy inspector was not appointed until two years later. There is no indication that veterinarians were appointees to any of these positions. The first city to authorize the inspection of dairies appears to have been Newark, New Jersey, in 1882, followed by Washington, D.C., in 1895, New York in 1902, and Chicago in 1904. By 1909 the number of cities having dairy inspection rose to 36 , but five years later this number was reduced to nine. Regular bacteriological examination of milk was first undertaken by Montclair, New Jersey, in 1900. Chicago, in 1908, was the first city to require pasteurization of all milk except that from tuberculin tested cows. 
In 1883, perhaps somewhat prematurely, Liautard noted:

When the first Board of Health in the United States was organized, a few years ago, in New York, and a proposition to appoint veterinarians on the Board was made, it was received with ridicule and sarcasm. The recommendation that "horse doctors" should be employed by the State in connection with an organization having for its object the care of public health, was treated as the wildest of absurdities. How changed is all this to-day; and how different the popular appreciation of the competent and educated veterinarian!

While a few veterinarians had been employed by health boards prior to 1880 , a notable advance was the creation in 1884 of the position of "Veterinary and Food Inspector" by the Department of Health of Brooklyn, "and the filling of such by a regular graduate of veterinary medicine only." Liautard comments:

At last the time has come when educated veterinarians will have their recognition in Boards of Health - no more as a compliment, but as regularly appointed officers.

Later that year it was announced that an examination for the position of Assistant Inspector was held by a board consisting of four physicians and A. Liautard. Of the four applicants, R. A. McLean and W. H. Hornblower, both A.V.C. graduates, were appointed. R. A. McLean was the son of Lachlan McLean, M.R.C.V.S., who was Veterinary Inspector of the Department of Health of Brooklyn, but there would seem to have been no basis for any suspicion of nepotism in either appointment. Like any conscientious mentor, however, it undoubtedly pleased Liautard to see two of his recent charges, one the son of a close associate, get the nod.

It is apparent that Liautard's urging that veterinarians seek employment as sanitarians found fruit in other graduates of his school also. In giving the history of the A.V.C. Alumni Association in 1884, W. H. Hoskins states:

On State and city boards of health five graduates from this school have given efficient service, and their usefulness and worth in this regard has many times shown itself in remarkable proportions. ... The outbreak of glanders in Newark, N.J., that so long existed as a calamitous danger to her people and the noble animals that must ever do man's bidding, was moved upon by one of our number [Julius Gerth ], and to his vigilance and persistency, in that they have placed the disease under the most rigid control, much credit is due. Many such instances could be enumerated, alike the preservation of our infantile population from the dangers of tubercular and otherwise tainted food and milk. Their vast usefulness in this direction is a subject for much deliberation among us, and we should not wait for boards to call us to these positions, but we should constantly agitate among the people their necessity, and thus arouse them to demand such representation for their safety and welfare.

Passing on to a finer subdivision, one from among our number [Thomas Rogers] is now officiating as Milk Inspector for a large district. .. . From his reports I garner a large and varied number of methods of adulterating and doctoring milk. . . A Another fills the position of Meat Inspector, and I am sure but a few years will elapse when the history of this Association will count scores of her men filling similar positions.

In a long article in 1886 on "Milk From a Medico-Sanitary Standpoint," Rogers states:

The pump has been from time immemorial the milkman's best friend. Water is added in all proportions, from the lump of ice placed in the can without dishonest intentions, to the 60 per cent of water and 40 per cent of milk peddled by a dealer in New Jersey who, when caught, was selling 34 quarts off a yield of 14 . How can this fraud be detected? In a limited degree it cannot be detected at all - we must grin and bear it.

On milk as a cause of disease, Rogers says:

Milk may communicate disease to man in several ways: it may undergo alterations, fermentative in character, through the presence of lowly forms of life, and thus acquire poisonous properties; it may be the vehicle by which vegetable or mineral poisons are introduced to the human stomach after having first, so to speak, been filtered through the cow. It may carry to mankind germs of certain diseases having origin in the lower animals; and lastly, it may, after being drawn from the body, act as a carrier, and possibly as a culture liquid, 
for diseases affecting only the human species. It is important that we should bear in mind that the death rate does not depend so much on diseases well known in character, whose origin can easily be traced, as on the pernicious lowering of the vitality of the mass of the people through causes ill ascertained or obscure.

Rogers urges that the commercial dairies, largely swill-feeding establishments, in the cities be abandoned:

These cattle, when sick, are milked as long as milk can be drawn from the udder, are stuffed with grains - and those often in a state of decomposition - to increase the yield, and it is more by good luck than good management if the water supply is not contaminated by human or animal excreta.

If these dairies cannot be suppressed, he contends, at least they should be rigorously regulated, "and every infraction of the sanitary code promptly punished by fine, publication or revocation of the license."

Conditions in the stables of private individuals were often not much -better - if as good. Rogers mentions being called to treat a patient where "on a lot $20 \times 80$ feet, were congregated seven human beings, one horse, one cow, three pigs, one goat, a number of ducks, geese, fowls, and rabbits, and several dogs and cats."

In the same year, 1886, Billings states, concerning bovine tuberculosis in man:

Among the external causes, and certainly among the most important, is the food we eat and milk we drink, especially when the latter is the sole nourishment which we give to so many babes. . . . No part of such [tuberculous ] animals, or any derivates from them, should be sold for human food; yet thousands of them are, and hundreds of quarts of milk from diseased cows dispensed over our cities, or ignorantly consumed by the people themselves.

In 1888, the New York City Health Department recommended what Billings had urged for preventing the spread of tuberculosis: "First, the security of the public against tuberculous meat and milk, attained by a system of rigid official inspection of cattle."

\section{Lachlan McLean, Veterinary Inspector}

In his annual report to the Commissioner of the Department of Health of Brooklyn in 1883, Lachlan McLean states:

In this, my annual report as Veterinary Inspector to your Board, I beg to particularly draw attention to the continued and increasing prevalence of contagious pleuro-pneumonia amongst the milch cows of the city and the immediate surrounding district, with the hope that you may be able to bring some concentrated action to bear to stamp out a disease that is financially ruining those who are locally engaged in the trade, supplying our families with unwholesome milk, and many of our butcher shops with beef, if not directly dangerous, certainly in the highest degree non-nutritious.

He gives an extensive history of the disease and recommends inoculation, saying that while slaughter would be the best method to extirpate the disease, this would ruin industry locally. In this he no doubt was acting with sincere convictions, but it may be doubted that his recommendations were in the best interests of either the veterinary profession or the public.

McLean mentions his "official capacity as Veterinary Inspector ... for a number of years," and that his "active connection" with the commission appointed in 1879 to investigate pleuropneumonia, qualifies him to state: "There is in the Union no other city of the same extent, in which the milkproducing stock is so extensively affected with contagious pleuro-pneumonia." $\mathrm{He}$ claims that 10 per cent of the 5,000 cattle in the 450 stables in Brooklyn, were af. fected, and "at least eighty per cent of the stables are of themselves permanent centers of contagion, and that beyond the control of disinfectants."

Although he recognizes slaughter as the most certain method of eradication, he says this will be too costly: "To stamp out the disease by this process would necessarily entail the entire destruction of the various stables as well as their occupants." He believes, therefore, that an "obligatory and systematic" system of inoculation, as advocated by Fleming in England, would be 
the best procedure. He agrees with Fleming that:

This pitiless and continued slaughter of diseased cows, and the terrible embarrassment to agriculturalists which the present fruitless measures produce, will soon become little short of a crime, in presence of the absolute immunity and humanity which are the attributes of protective inoculation.

Experience was to show, however, that the policy adopted by the Bureau of Animal Industry in ruthless slaughter of affected and exposed animals was the proper answer to the problem in the United States.

In writing on "The Veterinarian as a Sanitarian," McLean urges in 1885:

the communities amongst which we live have a right to expect that we will act actively and intelligently as sanitarians, in protecting them against the dangers of contracting, either by inoculation or ingestion, any of the many contagious or epizootic diseases to which our patients are liable. ...

The practice of some Boards of Health, in employing medical men to do the work of the veterinary sanitarian, is not creditable to either profession. ... Let our profession so advance that we will be considered an indispensable part of every well organized department of health, for not alone local but also national interests depend upon the vigilance and painstaking of the qualified veterinary sanitarian.

In addition to supervision of stables and dairies to prevent the spread of disease, he specifies:

The system of delivering milk in private cans to families should be prohibited; these cans being frequently taken into the sick room and there opened, returned to the dairy to be clẹansed, still retaining a certain portion of the contents, after being exposed to the contaminated atmosphere of the sick chamber, to be handled and cleaned by the hands of the person who takes an active part in the next milking. ... Before milking the teats and udder should be cleaned with a cloth and water kept for that purpose. One has only to see the contents of a milk pail before the milk is strained to appreciate the necessity of this arrangement.

What about the milk of diseased cows? I have no hesitation in saying that the milk of an animal affected with any contagious disease, whether zymotic or septic, should be con- demned. ... As to the advisability of using the flesh of animals affected with a contagious disease as an article of diet: Many of our profession are in favor of rejecting all such animals as being unfit for human consumption, while others advocate the rejection of only certain portions of the carcase ... [ with] the idea that certain parts are good and others bad. Is it not more rational and consistent that all are bad, but certain portions are worse?

\section{In 1884 the New York Medical Journal had reported:}

The inspection of meat in New York is in a fair way to be made much more thorough than it has been heretofore, bills having been introduced into both houses of the Legislature providing for the appointment of five inspectors of meat by the Board of Health, and making it a punishable offense to offer for sale any meat that has not been inspected by them, the inspection to be repeated every second day until the meat is sold.

But this, of course, was not yet law. At a meeting of the New York State Veterinary Society in 1885, where McLean's paper was read, Liautard:

was pleased to pay a just tribute to the city of Brooklyn, and he regretted to say that it was ahead of his own city, that of New York, which had not yet thought proper to recognize the veterinarian as a sanitarian. Brooklyn and Newark, N.J. were the only two cities where the profession were recognized by the Board of Health.

\section{McLean contended:}

the medical gentlemen who were called upon to act as milk inspectors, knew nothing whatever about the diseases of the animal that gave the milk, although they could easily tell if there was much water in it, and that was about all they could tell.

He also stated that he knew of a herd of 90 cows, from which butter was sold at a premium in New York:

that had for the last three or four years been affected with tuberculosis, so that during that time, three or four had died each year from that disease.

The Society adopted a resolution to bring the matter of recognition of the veteri- 
narian as a sanitarian to the attention of the New York Board of Health.

\section{Clement on Consumption}

In $1890 \mathrm{~A}$. W. Clement, a graduate of the Montreal Veterinary College, and a one-time associate of William Osler, addressed the Maryland State Veterinary Medical Society, at which meeting W. H. Welch, M.D., of the Johns Hopkins University was present. Clement claimed:

As members of the veterinary profession, it is our right and privilege to advise the public upon questions of public health which are, beyond doubt, connected with the consumption of meat and milk, and the association of man and animals. . . A disease which costs more lives by far than any other, is tuberculosis, or what is commonly called consumption. One person in every seven born in to the world dies of this disease. . . .

How often, in our own profession, do we see... animals gradually lose in flesh and in the flow of milk, until they finally die, or become so valueless as to pass from the rich man's stable to the shed of one who is, to a great extent, dependent upon his cow to give him milk upon which to rear his family. ... Then, too often, after she has been milked until, from the steady advance of the disease she ceases to produce enough to pay her keeping, the glue factory is cheated, at the expense of the citizens who buy her in small pieces at the stalls in our market places. Of course this is not first class meat, but it forms a very considerable proportion of the meat from which sausages are made.

Clement then goes on to outline the recommendations of the International Veterinary Congress, held at Paris in 1889 , concerning meat inspection. This program is essentially that which later was followed by the federal meat inspection service in this country. He also outlines the resolutions adopted at the twenty-sixth annual meeting of the USVMA, which condemned the use of milk or meat from tuberculous animals, urged the employment only of veterinarians as inspectors, and the periodic inspection of cattle in all dairies supplying municipalities. Although he thinks it improbable that such a system could be adopted immediately, in part because of the division of opinion on the dangers of consuming meat from diseased cattle, he strongly urges:

No such difference of opinion exists as to the milk supply. Tubercle bacilli have been demonstrated in the milk from tuberculous cows, even when there were no lesions in the udder. Such milk is no doubt to blame for much of the tuberculosis seen in young children.

In discussing Clement's paper, Dr. Welch agrees:

We must regard the milk of tuberculous cows as dangerous and to be rejected for food .... [but] the positive statements of veterinary and tuberculosis congresses as to the rejection of the flesh of tuberculous cattle and the views expressed in popular and alarmist articles on this point are not at present warranted by our knowledge of the facts. . . This does not, however, lessen the importance of proper sanitary inspection of slaughtered animals, for there are many other diseases besides tuberculosis that can be conveyed by the use of diseased meat.

There should be no differences of opinion as to the desirability of the measures for inspection of food advocated by Dr. Clement. Public health demands that such sanitary inspection be adopted. It is clear that no efficient inspection of the meat supply can be secured until the law forbids the slaughtering of cattle, swine and sheep in a multitude of private establishments. It is absolutely essential that the reform should begin with the establishment of one or two abattoirs where alone it is permitted to slaughter the animals named. This measure, like many others for the public good, is inimical to certain private interests, and here lies the only opposition to it. As soon as the public is sufficiently informed as to the good which will be accomplished by the sanitary inspection of the meat supply, it is certain that these private interests will not prevail and that this community will adopt the only policy which can commend itself to an enlightened public.

Thus it is evident that the advocates of an adequate food inspection system had a strong ally in Dr. Welch. One of Welch's colleagues, W. T. Councilman, concurs with the sentiments expressed, but is of the opinion:

We are so accustomed to tuberculosis, it is so much with us that we have come to accept 
it as a matter of fate and do not lift our hands in an attempt to mitigate its ravages. While it would, no doubt, be impossible to exclude all the sources of infection, still, many of them can be.

Dr. James Stewart, City Health Commissioner of Baltimore, indicated that he had advocated a law, "creating Inspectors of Food, especially of meat and milk," for the past ten years, and that these inspectors should be veterinarians, "but all in vain up to the present time. I do not despair, however, and shall continue my efforts in this direction in spite of all opposition."

A lawyer who had been invited to discuss the subject from the legal standpoint, states that three boards having jurisdiction in this area had been established: a State and a City Board of Health, and the State Live Stock Sanitary Board, the latter with William H. Wray as Chief Veterinary Inspector. But despite the fact that these boards had considerable arbitrary powers:

our laws are at present wholly inadequate to protect us from the dangers so vividly pointed out by Dr. Clement. ... It would seem that our law-givers never had in contemplation the possibility or the danger of the communication of disease to the human family by infected meat or milk used for food. . . . To be sure, under the head of "Markets," in the City Code, there are two sections, imposing fines of twenty dollars, respectively, for selling unsound meat or milk from diseased cows. The enforcement of this, like the other provisions of the law relating to the markets, is left with the clerk of the market. How far the scientific and professional attainments of that officer enable him to detect and prevent the sale of the meat or milk of an animal with tuberculosis, I leave others to determine. . . One, if not both, of the Boards of Health should include a competent veterinarian, whose duties should be especially directed to the inspection of our meat and milk food supplies.

George C. Faville, of the BAI, adds a point of information: "Of 163 stables supplying milk to this city, containing 2,160 cows... over 10 per cent of them show well-marked evidence of tuberculosis." With this as a basis, he then outlined a resolution to the state legislature and the city council urging centralized slaughtering with adequate inspection, and the periodic inspection of cattle in the dairies.

The subject of this meeting is considered at length not only to demonstrate that veterinarians were aware of the situation and had a program to offer, but that they met with rational and sympathetic treatment, at least in some cases. As a major stumbling block to expediency in adoption of such a program, however, it is evident that most of those present - at this, and presumably other such meetings - recognized the proverbial slowness of legal processes which were utilized by private interests to insure the continuance of their own private advantage. The apathy of the public can perhaps be understood - at this time it was not well informed on the matter; but even after the matter was fairly put to the public, little enough was clone. It required the lurid revelations of The Jungle (1906) to arouse a dormant public spirit.

\section{Public Health Legislation}

The Public Health Law of New York State in 1895 provided for the employment of veterinarians by the State Board of Health as deemed necessary. The board had the power to condemn cattle for tuberculosis:

but no such diseased animal shall be so killed on account of tuberculosis unless first examined by a veterinary practitioner in the employ of the State Board of Health.

After appraisal, "the veterinary practitioner in charge thereof shall forthwith make a post-mortem examination." If affected, half the appraised value (not exceeding $\$ 60$ for a registered animal, or $\$ 25$ for a grade) was to be paid the owner; if no lesions were found, full appraised value was to be paid.

In the case of glanders in horses, however, local boards of health were required to kill every infected animal found:

by employing a competent veterinary surgeon or other person or persons, who, in their judgement, are competent to pronounce upon the nature of the suspected disease. 
Local boards were cautioned against "too hasty judgement, and advised to use every precaution to insure a correct determination as to the nature of the disease." Animals so killed were to be buried three feet cleep, and all infected quarters and equipment clisinfected.

"Sanitary regulations recommencled for adoption by local boards of health" included restrictions against throwing offal, dead animals, and the like:

upon any street, road or public place, and no putrid or decaying animal or vegetable matter shall be kept in any house, cellar or adjoining outbuilding for more than twenty-four hours.

Prohibited for human consumption was "any flesh of any animal which died by disease, or which was at the time of its death in a sickly or unwholesome condition," or the meat of calves under four weeks of age, or of lambs under eight weeks, or of pigs under five weeks. Slaughtering within the limits of the municipality was to be carefully regulated. Also:

No animal affected with an infectious or contagious disease shall be brought or kept within the limits of this municipality, except by the permission of the board of health.

Bodies of such animals were not to be buried within 500 feet of a residence.

The Sanitary Code of the Board of Health of the City of New York, adopted in 1873 and amended to 1896, was considerably more specific in its provisions. Slaughter of animals was prohibited "while in an overheated, feverish, or diseased conclition," as was the offering of:

meagre, cased, blown, plaited, raised, stuffed, putrid, impure, or unhealthy or unwholesome meat or fish, birds, or fowl . . unwholesome, watered or adulterated milk, or milk known as swill milk, or milk from cows or other animals that for the most part lived in stables or that feed on swill, garbage, or other like substances; nor any butter or cheese made from any such milk, nor any unwholesome butter or cheese.

Inasmuch as many of the provisions of such laws are designed to put a stop to specific abuses, it is of some interest to note that the regulations for slaughter included the proviso:

That no cattle [meat animals of any species ] shall be slaughtered, dressed, or hung ... wholly or partly within any street, avenue, or sidewalk, or public alley or place; nor shall any blood or dirty water, or other substance from such cattle ... be allowed to run, fall or be in any such street, etc.

Somewhat less astute were the regulations concerning rabies:

every animal which is mad or has the hydrophobia, or shows symptoms thereof, shall, by the persons owning the same ... be at once killed; and every animal that has been exposed to such disease shall be at once confined.

\section{Contributions not Welcome}

The removal of manure from the horse and cattle stables within the city was quite a problem - as the protestations of resiclents near the river, where much of the manure was taken for the voyage to New Jersey would attest. Daily removal of manure and stable refuse was required, "unless the same are pressed in bales, barrels or boxes...to not more than onethird of the original bulk." Not only was the accumulation of manure in piles prohibited, but, "No person shall contribute to the making of any such accumulation."

Owners with animals having glanders or farcy were required to report the same to the board of health, and removal was under board supervision, whether the animal was dead or alive at the time. And any animal found by an inspector on the streets:

injured or diseased past recovery, for any useful purpose, and not being attended and properly cared for by the owner... or not having been removed to some private premises, or to some place designated by some officer or inspector, within one hour . . . may be deprived of life by such officer or inspector.

The only specific mention of veterinarians is in a provision requiring: 
That every veterinary surgeon who is called to examine or professionally attend any animal within the City of New York having the glanders or farcy, or any contagious disease, shall within twenty-four hours thereafter report in writing to the Board of Health of such city the following facts, viz.: 1 . A statement of the location of such diseased animal; 2. The name and address of the owner thereof; 3 . The type and character of the disease.

\section{Massachusetts Consolidation}

From the early days of the colonies, various towns in Massachusetts - Boston in particular - had had ordinances concerning animal matters as they relate to public health. And from the 1850's the Massachusetts Cattle Commission, long headed by E. F. Thayer, had done yeoman work in the eradication and control of animal disease. By 1895 "an Act codifying and consolidating the laws relating to contagious diseases among domestic animals" appears to have been a necessary and logical step toward uniform regulations throughout the state. The principal personnel called for by the act include "one or more persons to be inspectors of animals and provisions," appointed by the local authorities for each town, and the Board of Cattle Commissioners, appointed by the governor of the state.

In neither case is there any mention of the qualifications of these individuals. The work of Dr. Thayer, of course, had forcibly demonstrated the merits of having a competent veterinarian as head of the Cattle Commission, and the Commission employed a large number of veterinarians in its programs. The scope of its duties makes it obvious that it could function well only under the direction of a veterinarian with broad vision, such as Thayer who began work with the Commission in 1859 and was a member of it for nearly twenty-five years, most of this time as its head.

The Commission was charged with:

power to make from time to time orders and regulations concerning the extirpation, prevention and suppression of contagious diseases among domestic animals, or concerning the destruction, care and treatment of animals af- fected with, or which have been exposed to, any contagious diseases.

In this the Commissioners had the same powers delegated to local boards of health, including:

regulation of inspection of animals and of carcasses, meat and its products; quarantine, killing, burial and disposal of animals or carcasses ... [ [ and ] cleansing and disinfecting of districts, buildings or places.

This was to apply in cases of animals affected or exposed to contagious diseases. Local boards of health were required to "carry out and enforce all lawful regulations, orders and directions of the Board of Cattle Commissioners or any of its members."

How many "inspectors of animals" for local boards of health were veterinarians is unknown, but from the duties of these individuals it may be surmised that those towns were best served which sought a veterinarian for the post. While the remuneration - a maximum of $\$ 500$ annually - may not have been attractive, the opportunities for service were unlimited. Duties required the ability to determine the existence of contagious disease as well as, on a local basis, practically all those delegated to the Cattle Commission. The only specific mention of veterinarians, however, relates to the duties of citizens to report any suspicion of contagious disease among his or his neighbor's livestock, in which case:

such board of health shall forthwith cause such animal to be inspected by an inspector, or by a competent veterinarian appointed by them for that purpose.

And upon consent of the owner, tuberculin could be used as a diagnostic agent "upon any animals condemned as tuberculous upon physical examination by a competent veterinarian."

\section{Livestock Sanitation in Maryland}

The Maryland law of 1888 establishing the State Live Stock Sanitary Board, speci- 
fied that the three Commissioners be "practically engaged in the breeding of live stock." Together with a "Chief Veterinary Inspector," the first appointed being A. $W$. Clement, the duties of the Board were similar to those of the Cattle Commission of Massachusetts. However, Maryland provided but $\$ 3,000$ annually plus $\$ 5$ per cliem and expenses for the Board plus $\$ 1,000$ salary for the veterinary inspector; Massachusetts appropriated $\$ 100,000$ for its Commission in 1895 . Thus it was with some prescience that the Maryland law made specific provision for cooperation with the BAI. A few features of the Maryland law worthy of mention include:

the duty of all persons practicing veterinary medicine in this State to report immediately to said Board all cases of contagious or infectious disease among live stock which may come to their knowledge.

Penalty for failure to report was a fine up to $\$ 50$. Also under penalty of $\$ 100-500$ :

it shall be unlawful for any person to inoculate any animal in this State with the virus of any infectious or contagious disease incident to animals, without the consent of said Live Stock Sanitary Board.

A strong provision of the law was the prohibition against any person disposing of, or maintaining in other than a fenced enclosure, any animal:

which he knows, or has good reason to believe, is affected with any contagious or infectious disease, or has been exposed thereto within ninety days .... [or ] to wilfully expose any animal to others affected with a contagious or infectious disease... on any premises which have been declared to be infected.

Infractions carried a penalty of $\$ 100-500$, and slaughter without indemnity of all exposed animals.

\section{Others in the Act}

At this time, Montana probably had the most detailed laws regarding animal disease and related problems, and provided for a State Veterinarian at a salary of
$\$ 2,500$; he was appointed for two years, and had to post a bond of $\$ 5,000$. Before slaughtering animals only exposed to disease, "the Veterinary Surgeon must call in consultation with him two practicing veterinary surgeons or physicians," and obtain written consent from at least one. Otherwise the duties and authority of the State Veterinarian were similar to those defined in the Massachusetts and Maryland laws. One provision of the Montana law - presumably difficult to enforce - was the prohibition of disposal by any means (including slaughter if any part was consumed by other than the owner) of animals:

affected with, or suspected of being affected with, contagious or infectious disease ... or known to have been affected with or exposed . . . within one year prior to such disposal.

It may be surmised that at times convenient lapses of memory might have been invoked prior to wielding the poleax.

An Alabama law of 1887, "for the prevention and supression of infectious and contagious Diseases of horses and other animals," and consisting of only one paragraph, specifies no mechanism for its enforcement. Apparently it did give private citizens the right to redress "before any court of this State."

The Pennsylvania act of 1895 establishing the State Live Stock Sanitary Board gave the Board, which included the State Veterinarian, broad powers "for the prevention, supression, control or eradication of dangerous, contagious or infectious diseases among the domestic animals." In 1898 breeding cattle imported into the state had to be proved negative to the tuberculin test.

A Virginia act of 1896 invested the Experiment Station of the Virginia A. \& M. College with broad livestock sanitary powers, and specifically charged the Experiment Station veterinarian with the discharge of these. Of some interest is the proviso:

That the disease known as tuberculosis shall be classed as a highly contagious and infectious 
disease, and such measures shall be taken by the Board and its authorized veterinarian as to them may seem necessary to eradicate and prevent the spread of said disease.

\section{Twenty Questions}

The Pennsylvania civil service examination for the position of meat inspector in 1896 included (in abridged form) the following questions:

State the influence of cold storage on quality and preservation of meats. Describe the alimentary canal of a cow. Define myocarditis, exostosis, ascites and septicemia. Give the cellular elements of the blood and their functions. What lesions simulate tuberculosis? Describe the condition of a slaughtered carcass of a healthy animal; of one suffering from an infectious disease; of one that died a natural death. Under the present law what disposition is made of diseased meat?

In the same year the civil service examination for the position of consulting vetterinarian for the city of Philadelphia included the following:

What diseases are directly transmissible from animals to man through consumption of meat? What conditions render meat dangerous as food where disease is not directly transmissible. Describe the causes and lesions of actinomycosis. How may the approximate age of a veal carcass be determined? Give the method of examination for trichina. Mention seats of tubercles in cattle in order of frequency of infection. How may horse meat be distinguished from beef?

Some of the answers may have changed over the years, but the questions would appear to be still valid - at least some of the same ones appear on similar examinations today.

\section{State Veferinarians}

Coincident with efforts to establish a national veterinary bureau, legislation was proposed in several states for the creation of the office of State Veterinarian, such bills having been introduced in 1880 in Illinois, Kansas, and Connecticut. Several states, of course, earlier had appointed Commissioners to investigate and adopt measures to eradicate animal diseases, the first instance being the appointment of $\mathbf{E}$. $\mathbf{T}$. Thayer in the 1850's as Cattle Commissioner of Massachusetts in connection with the outbreak of contagious pleuropneumonia.

Thayer's work had been notably successful; more so than was the case in some other states. In 1881 A. J. Murray, who was appointed one of three state commissioners in Michigan to prevent the spread of contagious diseases among animals, states:

I found that I was unable to prevent the conveyance of Texan cattle into the State, though the State law prohibits this being done, between the first day of March and the first day of November. . . . The laws of this State on this subject have evidently been framed by men who had little if any knowledge of the evils they were intended to remove ... they frequently conflict with the Constitution of the United States.

\section{Illinois to the Fore}

In 1881 Liautard noted "with great satisfaction":

the act passed by the Legislature of Illinois creating such a [veterinary ] bureau. This great breeding State has taken the lead in that direction.... The creation of veterinary bureaus is one that must soon be general all over the country.

This act called for the Governor to appoint:

a competent veterinary surgeon, who shall be known as State Veterinarian or Inspector, and whose duty it shall be to investigate any and all cases of contagious or infectious disease among domestic animals of the bovine species in this State.

Actually, the bill was a measure to suppress pleuropneumonia, rather than one expressly for creating the office of State Veterinarian, and thus the restriction of its scope to the bovine species. This was an unfortunate case of shortsightedness, for a short time later the appointee was placed in an embarrassing position in regard to his attempts to exercise control over glan- 
ders in horses. Pleuropneumonia, however, was the scare-word of the hour, and thus the limited scope of the bill is at least understandable, however unfortunate. The State Veterinarian was empowered to order and enforce quarantine and slaughter of diseased animals, but exposed animals could be slaughtered only after consultation with two "reputable veterinarians or practicing physicians." A sum of $\$ 8,000$ was appropriated for carrying out all provisions of the act, including indemnity for slaughtered cattle.

Later in the year (1881), Liautard mentions:

One of our exchanges brings us the news of the appointment to the position [ of State Veterinarian 1 of one of the assistant editors of the Review, N. H. Paaren, M.D., who has for years been prominent in the State of Illinois by his veterinary works.

Paaren, who more frequently identified himself as M.D., V.S., had been a full-time (nongraduate) veterinary practitioner for 20 years or more, and had edited the Veterinary Department of the Prairie Farmer after George Dadd had left that post.

In April, 1883, Paaren investigated an outbreak of glanders, and ordered that the animals be confined, apparently without the necessary legal authority, for it was not until six weeks later that the pleuropneumonia act was amended to include glanders. Paaren states that he had met with considerable resistance, apparently in the form of doubt as to his authority, and a five-page opinion of the Attorney General was required to clarify his status, which in effect was that the authority of the State Veterinarian with regard to glanders was exactly the same as with pleuropneumonia. The Prairie Farmer at this time notes:

The State Veterinarian of Illinois seems to be vigorously enforcing the glanders act ... he last week had four horses shot and burned.

In 1886, however, the National Live-Stock Journal noted the removal of Paaren as being long overdue: in view of his very evident unfitness for the position of State Veterinarian, the general criticism of his course while holding that office, and the lack of harmony between him and the State Board of Live-Stock Commissioners.

\section{Contention in Connecticut}

Agitation for creation of the position of State Veterinarian in Connecticut evoked strong comment from the New England Homestead in 1882 to the effect that so long as there was a state cattle commission:

There would be about as much sense in asking the Leigslature to appoint a State physician, giving to such person exclusive medical privileges over the mass of practicing physicians. The State does appoint its Board of Health, whose duties may be said to be similar to those of the cattle commission. . . . Why not appoint a skillful physician of the soul to look after the moral diseases of the people?

Without disparaging the work of the cattle commissions, Liautard urges the greater utility of State Veterinarians, for:

their labors would not only touch this or that peculiar form of diseases ... [ [but] glanders, farcy, anthrax, hog cholera, foot and mouth disease, \&cc., \&c. And besides that, they could also exert their professional influence in one direction of our general laws of health, in the inspection of abattoirs, or markets, of meat, which we all know are yet in the hands of men entirely ignorant of the first principles they ought to possess.

The western states took the lead in establishing the office of State Veterinarian; in 1882 the position of Territorial Veterinarian of Wyoming was tendered Liautard, who declined, and J. D. Hopkins was appointed. In 1883, A. A. Holcombe, Veterinary Inspector, U.S. Army, noted the failure of such a bill in Kansas two years earlier:

With $\$ 60,000,000$ worth of live stock in the State, we have, I am informed, but one graduated veterinarian in civil practice, and yet $I$ am aware of large yearly losses from glanders, farcy, anthrax, hog cholera, tuberculosis, cerebro spinal meningitis, scab, Texas fever, contagious opththalmia, and - so report says hydrophobia. Of course, the veterinarian who 
must depend on private practice for a living can do but little for the sanitary policing of the State. . . Practically there are no reliable statistics in the State of the losses from the various diseases, nor will there be until educated veterinary suregons have the opportunity to investigate their frequency, extent and mortality.

Dr. Holcombe was appointed State Veterinarian of Kansas in 1884, and his first report indicated that glanders, Texas fever, hog cholera, and blackleg were the major problems. There were 162 deaths of animals from rabies. Earlier an outbreak of what was feared might be foot-and-mouth disease was investigated by D. E. Salmon and James Law, who determined it to be ergotism.

By the end of 1885 the list of State Veterinarians had grown to 15 , five of whom were located on the eastern seaboard: J. F. Winchester, Massachusetts; F. E. Rice, Connecticut; James Law, New York; Francis Bridge, Pennsylvania; and Robert Ward, Maryland. Those in the more western states included: V. T. Atkinson, Wisconsin; J. S. Butler, Ohio; G. C. Faville, Colorado; Julius Gerth, Jr., Nebraska; A. A. Holcombe, Kansas; J. D. Hopkins, Wyoming; G. Keefer, Montana; N. H. Paaren, Illinois; Paul Paquin, Missouri; and $\mathbf{M}$. Stalker, Iowa. Other states had State Veterinary Inspectors who served many of the functions of a State Veterinarian.

Many of this group, of course, had been prominent in the veterinary profession for some years; others were to become important through their new official positions. Concerning Julius Gerth, Jr., formerly a private practitioner of Newark, New Jersey, Liautard notes that he was the first veterinarian ever appointed by a City Board of Health (Newark) as a meat inspector. Moreover: "His appointment then was followed by a regulation of the Board, making it obligatory for candidates for the said position to be veterinarians." Gerth was perhaps better known for his successful control of an outbreak of glanders in Newark - probably a factor in his securing the appointment as State Veterinarian of Nebraska. He was also the first Secretary of the Veterinary Medical Association of New Jersey.

Five of this group were graduates of the American Veterinary College, four were Canadian and three were British graduates, one (Faville) from Iowa State College, and two (Paaren and Bridge) were nongraduates. In conjunction with the national convention of the Cattle Growers of the United States, to be held in Chicago in 1885, Hopkins addressed a letter "To State Veterinarians and Members of Sanitary Boards," inviting them to meet with this group inasmuch as:

the most important subject for consideration will be Contagious Diseases of Domestic Animals. . . The expressions of these gentlemen will have great weight in shaping future legislation in this matter.

\section{Empathy vs. Apathy}

Earlier, Hopkins had submitted a report to the Committee on Diseases of the USVMA, in which he had noted:

The application of sanitary science, as applied to the prevention of disease among domestic animals, has made an immense advance in this country within the past five years.

He attributes this advance to the numbers of graduates of veterinary colleges becoming widely distributed throughout the country, but urges that continued progress can be hoped for only by the creation of veterinary bureaus "with competent veterinarians in charge, with full authority for the investigation and control of all outbreaks of clisease." Further, he considered:

It is proper that at this time this Association should take an active part in shaping legislation for the control of contagious cliseases of domestic animals ... instead of allowing a few veterinarians to represent themselves in legislative halls.

His report apparently stirred up little discussion at the meeting of the USVMA, like a number of other reports the only action taken was that it was "ordered to be published." This occasioned a letter to Liautarl, in which Hopkins states: 
I am deeply mortified at the apathy displayed by the Association ... when the whole country is becoming sensible of the necessity of wholesome sanitary laws and their enforcement for the protection of domestic animals. ... Had the Association considered the questions and given expression to their conclusions, then the hands of the few veterinarians engaged in official work would have been strengthened, and the public enlightened as to the exact status of the different plagues which afflict our domestic animals.

As reported by C. B. Michener, the Cattle Grower's Convention stressed the necessity of national legislation, "as States have in almost every instance failed to eradicate or even control outbreaks of communicable diseases, without aid from the general government." Apparently some of the veterinarians present did the profession a disservice, for Michener states:

It is a matter of regret that a few veterinarians present advocated the practice of inoculation for contagious pleuro-pneumonia.... Inoculation is not to be seriously thought of in any country where exterimination is possible. ... In dealing with purely exotic plagues, veterinarians who are influenced by such opinions are certainly not those to be trusted during the present crisis.

The official report of the Veterinary Committee of the National Cattle Growers' Association, however, puts the veterinary profession in proper perspective. This comes as no surprise, considering the makeup of the committee: J. D. Hopkins, C. B. Michener, L. McLean, D. E. Salmon, R. S. Huidekoper, and J. L. Brush, the latter being president of the Sanitary Board of Colorado. Noting the alarming spread of contagious diseases, for most of which no cure was known:

It behooves us to urge the necessity for immediate, prompt and forcible action to suppress the existing causes of disease, and to prevent their future spread. State laws are excellent, but insufficient. ... It is necessary that we should have uniform and general laws, rigidly enforced, which will protect all alike. This can only be done through the general government of the United States, and while costly, will prove the most economical in the end... Other countries have procrastinated as we now are doing, and have paid for it in immense losses, and the ruin of their cattle trade.

This was in 1885. The Bureau of Animal Industry had been founded a year earlier, but had not yet had the opportunity to assert itself on a national scalethrough lack of funds, personnel, and authority. Once these were provided, the advantages of a centralized frontal attack upon animal plagues was evident, and the accomplishments of the BAI in two decades stand in stark relief from the futility of the two centuries or more preceding. 


\section{The Animal Disease Problem and the Bureau of Animal Industry}

The animal disease problem in the United States became increasingly well defined after 1850, and undoubtedy was compounded by conditions which prevailed during and after the Civil War. In the following account, some representative aspects of various problems will be considered in the light of contemporary attitudes toward them, together with some of the measures - or lack thereof - taken at the time for their control. It is manifestly impossible to include a complete detailing of each disease considered, and many problems have been left untouched.

\section{DISEASE CONTROL}

Probably the primary problem until well after 1870 was the indifference of the public - officials, private citizens, and livestock owners alike - to the need for an organized attack upon the problem of increasing animal disease, which threatened ruin of the livestock industry. Without veterinary schools or a veterinary periodical press, problems relating to animal disease were principally in the hands of the editors of agricultural journals. How these were handled may have been good, bad, or indifferent, depending upon the particular editor - or his viewpoint, which frequently was subject to change or contradiction.

Many of the agricultural editors pressed for the establishment of veterinary schools and organized attacks upon the disease problem by governmental agencies; others professed to do so while advertising, "a free horse doctor with every subscription." Nowhere was there a sustained campaign for support of veterinary medicine, with the result that the few veterinary schools which had been established to 1880 had hard sledding. Except for local successes, as in Massachusetts, it was not until the Bureau of Animal Industry was established in 1884 - after several unsuccessful attempts - that anything approaching a unified effort toward disease eradication or control appeared on the American scene.

During a visit to the United States in 1868, John Gamgee estimated (apparently conservatively) the losses from disease in this country to vary from 5 to 10 per cent of the valuation of the several species of livestock, the total loss being nearly $\$ 150,000,000$ annually. In 1869 Gamgee wrote a series of articles on the diseases of animals for the American Agriculturalist, in the first of which he urged the establishment of veterinary colleges with government support:

The States of the general Government must take this matter in hand, for without pecuniary aid such efforts as those to which Dr. John Busteed, of New York, has devoted his life and means must prove abortive. 
In recommending the New York College of Veterinary Surgeons (Busteed's school) to an inquirer, the editor of the American Agriculturalist in 1869 states that the school has:

good facilities for instruction, and as instructors, veterinary surgeons not only highly educated in their profession, but high-toned scientific men and physicians, who, though ministering to the wants of animals, eschew quackery in all its forms, secret remedies, nostrums, ointments, and the like, from which most persons, who claim to be veterinary surgeons, and write V.S. after their names, derive a good part of their incomes.... With a thorough education, the veterinarian is in a position to interpose his skill and his counsels to prevent those terrible plagues which often sweep away national and private wealth, and bring disease and death to both animals and mankind. We believe that the time will soon come when people will wonder that it could ever have been a reproach to be a "horse doctor."

At the same time, however, and for much later, agricultural journals carried myriads of advertisements inviting farmers to circumvent the few reputable veterinarians available, along with the "business cards" - unblushing or otherwise - of a number of veterinarians themselves.

\section{A Doctor for the Horse}

Advertisements of veterinary interest in the Prairie Farmer in the late 1860's include that of its veterinary editor:

VETERINARY SURGEON. The undersigned, a regularly and scientifically educated Veterinary surgeon, well known to the public as the editor of the Veterinary Department of the Prairie Farmer, hereby informs stock owners and breeders, located withip one hundred miles' distance from Chicago, that his services can be secured by ... enclosing fare for the round trip. . . . Charge for treatment and advice very moderate ....N. H. Paaren, Late Chief Veterinary Surgeon Cavalry Bureau U. S. Army.

\section{And for hog cholera:}

Tousley's System of Hog Cholera Antidotes, consisting of a preventive Swine Condition Powder to be given in the food, and of a
Powerful Curative Compound ... to be thrown upon the animal's tongue when it refuses to eat. A warranted general cure for Hog Cholera in all its forms. Recipes for the above, also recipes for the cure of Blind Staggers, Quinsey, Inflammation of the Lungs ... for $\$ 10$.

Also:

VETERINARY HOSPITAL. Sandwich, Ill. Dr. J. P. Klensch, graduate from Paris and Germany, lately employed at the U.S. Cavalry Hospital at Washington, has opened a Veterinary Hospital, as above, and invites the attention of the public.

In quite a different vein, in an advertisement for the New York Spirit of the Times, the editor offers:

to those of his readers and subscribers who own horses, a horse-doctor free. ... He has regularly engaged upon his paper, one of the ablest and most experienced professional veterinarians in the United States.

Not to be outdone, the American Stock Journal announced:

a Veterinary Department ... under the charge of a distinguished Veterinary Professor, whose ... prescriptions are given gratis, and thus every subscriber to the Journal has always at his command a Veterinary Surgeon, free of charge.

For those who preferred more immediate aid, the Prairie Farmer offered a choice of some twenty veterinary works, ranging in price from 30 cents to $\$ 3.50$.

\section{Anthrax}

Despite numerous case reports in the agricultural press of the United States from early in the nineteenth century describing what undoubtedly was anthrax, Billings, in 1881, stated: "We do not know that an authentic case of anthrax has ever been recorded in this country." The disease, however, is notoriously no respecter of boundaries, and in 1879 Duncan McEachran had reported:

Although anthrax has never at any time during the last sixteen years ... occurred to any alarming extent, yet every year sporadic 


\section{DR.DANIELS' EMERGENCY CASE SPECIFIC MEDICINES HOME TPETMENT OF SICK ANMLS}

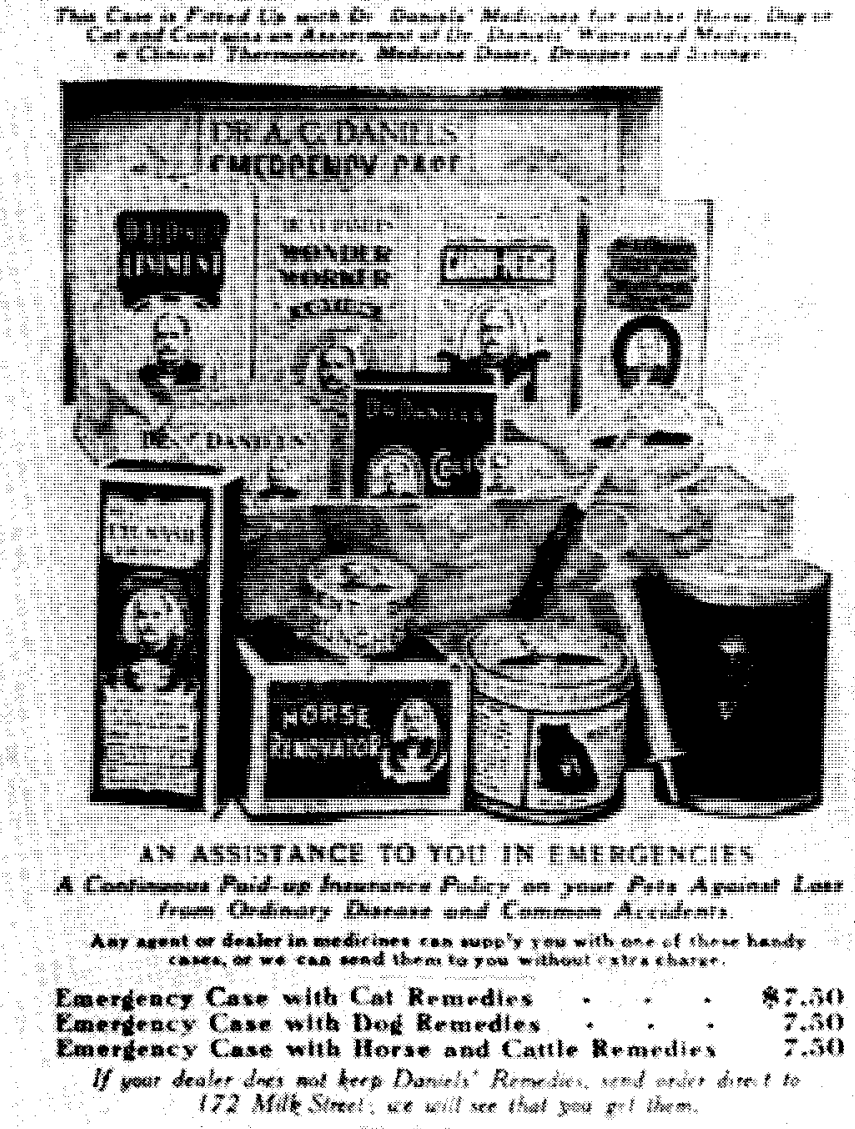

DR. A. C. DANIELS, INC., 172 MILK ST. BOSTON, MASS, U.S.
Dr. Daniels, who admitted to being "the world's greatest animal life saver," distributed innumerable copies of his remedy guides in drugstores and other emporia which vended his wares. cases, or at least a few animals on isolated farms have been reported, and several outbreaks of it have been investigated by me more especially in the Province of Quebec, and recently in western Ontario.

In his lengthy report, he summarizes the history and existing state of knowledge of the disease, stating:

We have it now in our power, by adopting proper means, to cause its disappearance altogether, whereas neglect of such measures will unquestionably lead in time to its becoming a source of very serious loss annually to the country.
In 1879 also, C. B. Michener reported several cases he had seen recently and in the previous year in Pennsylvania and New Jersey, with symptoms and epidemiology which "simulate very closely, if indeed they are not identical with, those of anthrax." And in an editorial on "Anthrax in the West," in 1881, Liautard states that a Dr. Foote (probably H. T. Foote, D.V.S.), upon being called to investigate pleuropneumonia in Nebraska and Iowa, found:

that anthrax was destroying herds at a great rate.... Attributing it to local caluses, pre- 
ventive measures were, at the suggestion of the doctor, instituted at once. The municipal authorities were found ready to promulgate all necessary orders to prohibit the use of milk and the utilizing of the dead carcasses.

On the latter point, Liautard suggests that recent researches of Pasteur indicating that earthworms were capable of carrying the germs of the disease, should be sufficient basis for cremation of the carcasses instead of the more common burial inasmuch as:

anthrax has been prevailing in the west for years; cattle have in some cases been buried, and probably, in others, have been allowed to decompose on the surface without being placed into graves at all, it may be assumed that the soil is saturated with germs, and sudden outbreaks may be expected at any time.

Later the same year, the Country Gentleman reported, "Anthrax has broken out among the cattle near Lincoln, Nebr. Vaccination is being tried as a preventive of the spread of the disease." The outbreak, as reported by W. A. Thomas, B.V.M., occurred in "bottom land which is sometimes inundated," and carried off thirty of forty cows in one herd, as well as several in adjacent herds. Examination of the blood revealed an abundance of anthrax bacilli. The disease was reported in New York, Iowa, and Louisiana the same year, and in North Dakota and Montreal the year following, the latter in a pasture where animals dead of anthrax had been buried some time before.

With the eventual widespread use of anthrax vaccine, first demonstrated by Pasteur in 1881, control of the disease - if not its eradication - became possible. However "anthrax districts" still exist in many areas, and few states appear to be permanently free of the disease.

\section{Glanders}

The existence of glanders, and its danger to human beings, had been recognized by American veterinarians and livestock men at least since the Givil War, but neither its veterinary nor its public health significance was fully appreciated for another two decades or more. Despite the warnings of men like George Dadd in the 1860's, glanders continued to exact its toll. In 1883, M. R. Trumbower, V.S., reported on "two human lives sacrificed on the altar of ignorance," relating the cases of father and son who died of glanders in Illinois. The son died with typical symptoms of glanders, which, however, went unrecognized. The day following the son's death, the father took sick:

Four physicians examined each case when the pustules began to appear, and diagnosed it

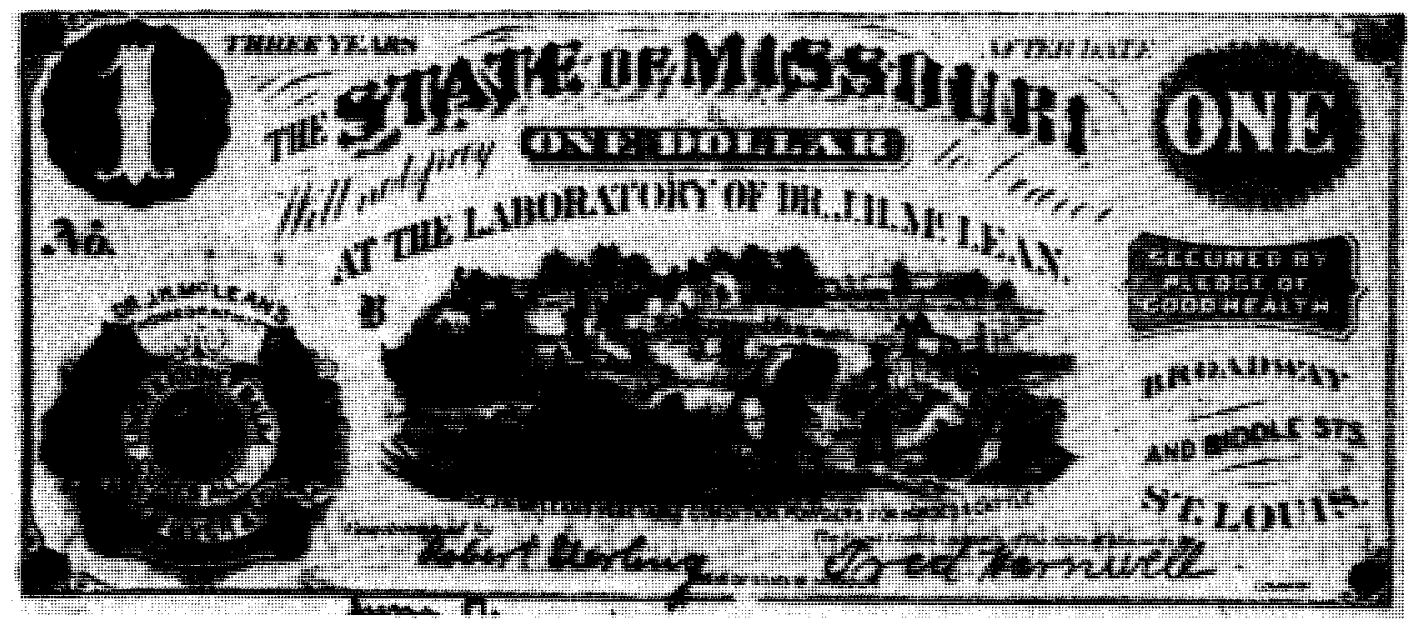

An early "gimmick" promoting homeopathic veterinary remedies in the 1880 's - in a sheaf of bills, this might occasionally have been passed as legal tender. 


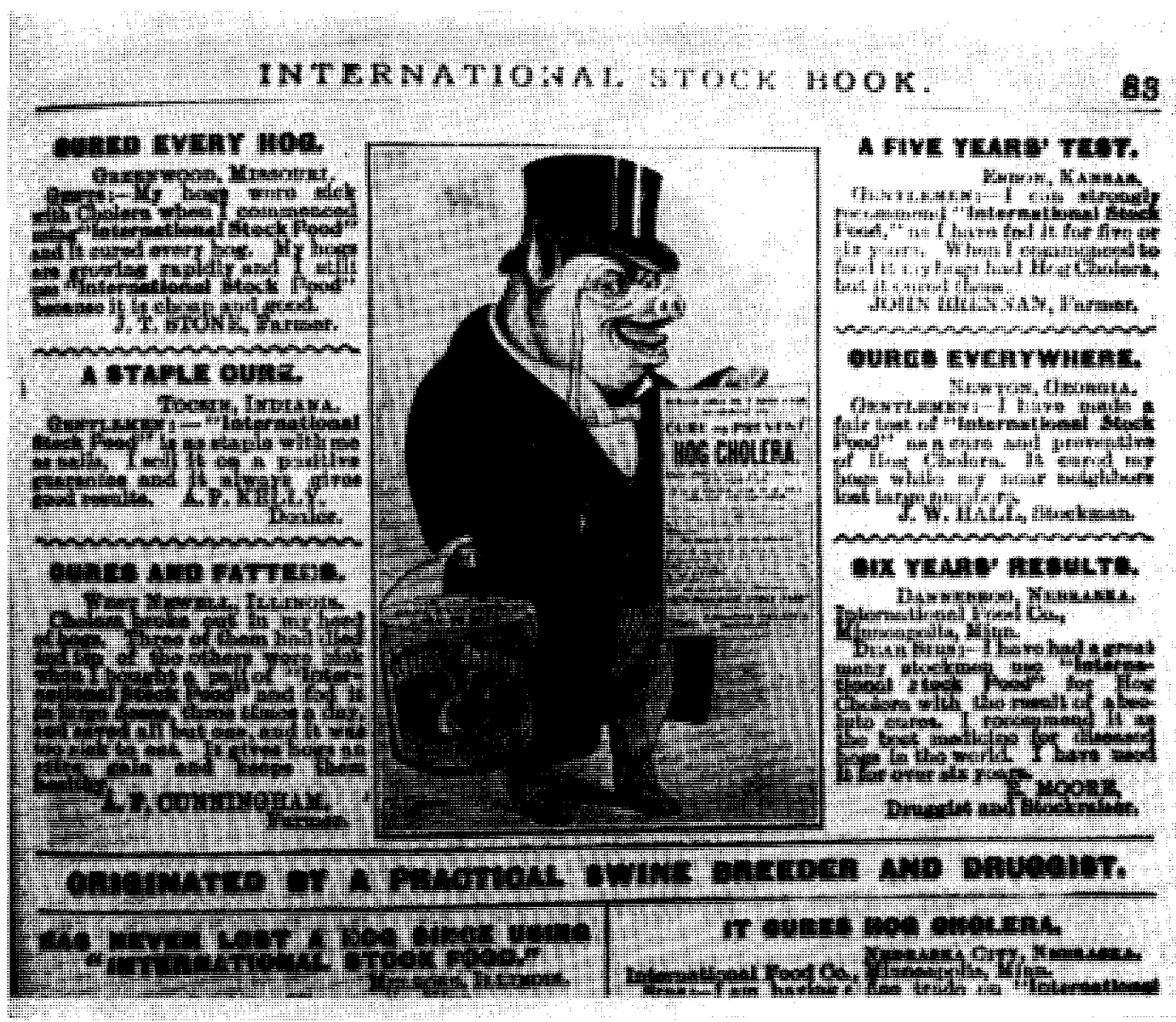

As soon as a new disease was named, there were patent medicine makers who had sure cures for it - soon backed by testimonials from those who all too often had deluded themselves into thinking these so-called remedies were indeed cures.

malignant erysipelas. On the Ist of April five physicians met in consultation, and then agreed to call it "equinia" [glanders].

April 1 was perhaps an unfortunate day for consultation, for the patient died on April 2. Trumbower states:

I had notified one of the physicians on the 13th of March, two days after the boy had taken sick, of the existence of glanders among Mr. Conaway's horses, putting him on his guard in reference to the probable ailment of the son.

Despite the fact that "the statutes of our State do not contain the word glanders," Trumbower condemned six of fifteen horses. Concerning the father, he says:
Mr. Conaway ... was a so-called "hoss doctor;" he cured all cases of nasal gleet; his library consisted of Dr. Stewart's book; his knowledge of materia medica did not extend beyond an infusion of tobacco and stramonium. $\mathrm{He}$ was totally unable to distinguish glanders from nasal gleet, consequently had one or two horses die each year of the former disease.

N. H. Paaren, State Veterinarian in reporting "a widespread outbreak of glanders," gives further details of the Conaway case. The dwelling had a cellar underneath:

full of putrid and decaying animal and vegetable matter, skeletons of hogs, dogs, etc., evidently the accumulation of years. A strong, 
penetrating, indescribable odor pervaded the dingy and filthy rooms of the house.

Five horses in the rude stable were found to have glanders; an order was obtained to have them shot, and the stable and accoutrements burned. All horses known to have had contact with the premises, some seventeen in number, were placed under surveillance. And

I also advised that all the hitching-posts and railings in the [village] streets... be removed forthwith and destroyed. On the evening of the 14th of April there was, consequently, great scarcity of places where to hitch a horse.

As a result of this incident, the pleuropneumonia law of Illinois was amended to include glanders.

In 1883, John H. Rauch, M.D., outlined the functions of the Illinois State
Board of Health with regard to the diseases of animals:

The existence of any contagious disease among food-producing animals would make it competent for the State Board, in its discretion, to investigate the facts - as to cause, extent, etc. - and to make the rules and regulations necessary for its suppression. Such measures may involve condemnation and slaughter of diseased animals; the isolation of the suspected or compromised; the disinfection, or-where disinfection may be insufficient - the destruction, of infected buildings and articles; and all other action necessary to eradicate the contagion. If requisite, quarantine or exclusion may be declared for the protection of threatened localities.

In connection with the recent glanders incident, Rauch states:

It should be borne in mind that the State Veterinarian had no authority to act under the

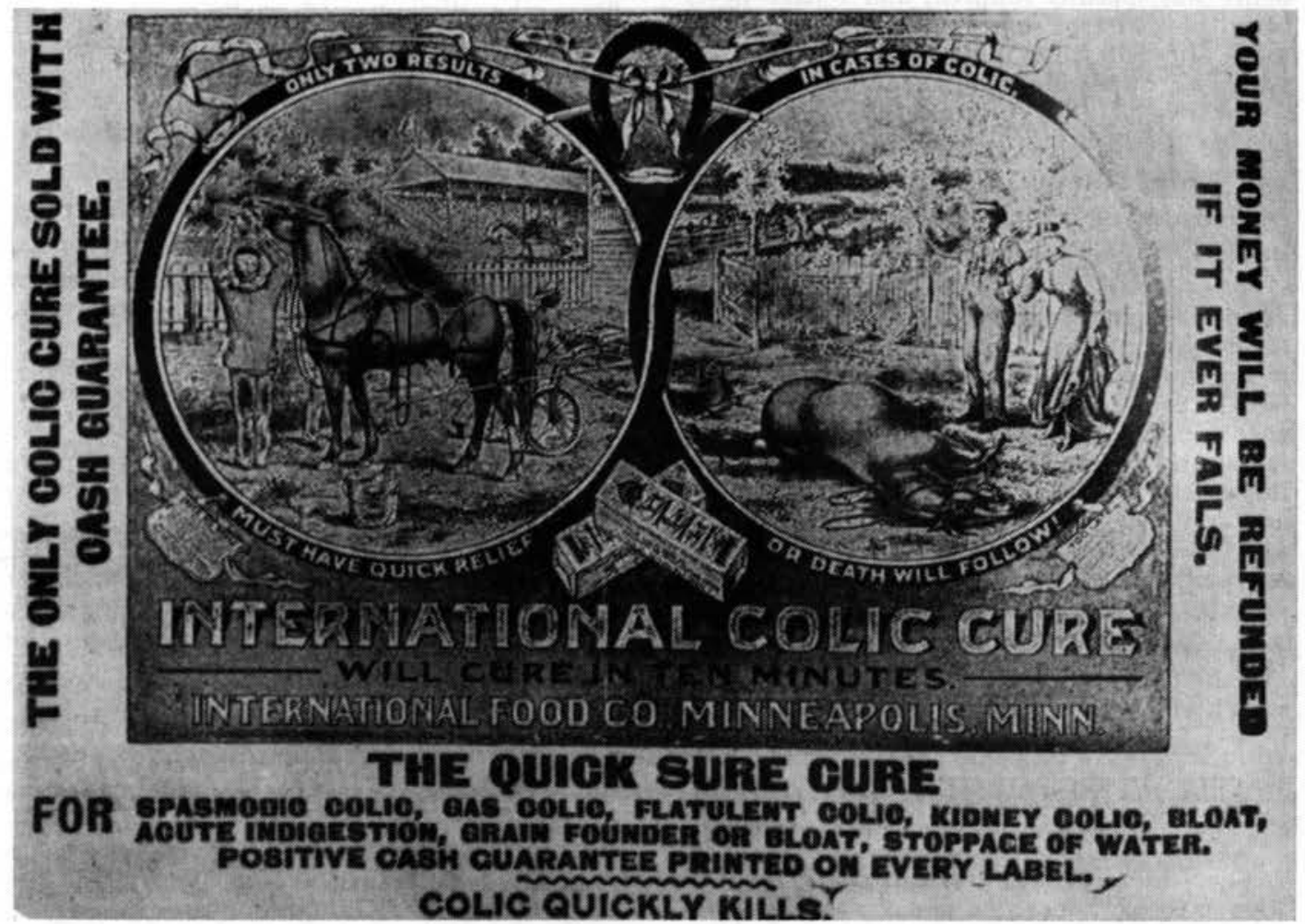

The fcrte of most patent nostrum peddlers was a "guaranteed colic cure," frequently good for many other ills, and perhaps little different from other remedies made up under other labels, but coming from the same mixing vat. 
law, which confines him to animals of the bovine species; nor was the public health threatened by an infected food supply. The disease, however, being one capable of affecting the human family - having, in fact, caused two deaths in one locality, the State Board of Health . . had ample warrant; and Dr. Paaren was at once dispatched to the infected region.

He states, however, that under more normal circumstances the State Board was largely an advisory body, stepping in only when local authorities requested help or lacked authority. As city officer for Chicago in 1868 , at the time of an outbreak of Texas fever in the stockyards, he had instituted a program of inspection and quarantine:

and in a few days the entire beef-supply of the city and the cattle trade were under the complete control of the Chicago Board of Health; the spread of the disease was arrested; confidence was speedily restored, and I have never heard of a case of the disease being caused by cattle shipped from the Stock-Yards after the system of inspection was inaugurated.

The death of a young army veterinarian, James Humphries, from glanders contracted during a post-mortem examination in 1885 , caused Liautard to editorialize:

And how many more shall we have to report? Glanders is all over our continent. . . . There is not one of the agricultural papers, which, weekly or monthly, does not report its existence. .. . Is it not time for our sanitary veterinarians to give their attention to the alarming extent to which the disease is prevailing, and is it not time for the public to be once and for all educated to the fact that the diseases is equally incurable and contagious in all its stages?

He mentions an agricultural paper, in which the editor of the veterinary column had assured an inquirer: "Glanders can be cured in the first stages and. sometimes in the second." Liautard remonstrates:

The editors of such columns ought to be at least men of education, men who know the subject they are discussing, and opinions like the one referred to ought not to be allowed to be put before the public.
Despite the destruction of individual foci of the disease - in the form of frankly glandered animals - the difficulty of diagnosing latent glanders resulted in continuing infection, of men as well as horses. Speaking on the problems of diagnosis at a meeting of the United States Live Stock Sanitary Association in 1913, Drs. Mohler and Eichhorn urged:

It is no longer doubted that in the work of controlling glanders the destruction of the infected animals should be given prompt consideration, and if possible the infection should be traced to its origin. Unfortunately, the nature of the disease is such that only a comparatively small proportion of the cases can be recognized by the ordinary clinical examination, and as long as we limit our efforts to the destruction of these cases, the disease will continue to spread. An effective control can be accomplished only by the elimination of all centres of infection of glanders, Therefore it is essential primarily to have means of diagnosing accurately all forms of the disease.... Since the discovery of mallein ... we are reasonably sure of diagnosing practically all cases of glanders. ... The ophthalmic test should be recognized by State and Federal authorities, since its reliability can no longer be doubted.

With the continued use of mallein, introduced as a diagnostic agent and distributed by the BAI in 1893, and its general use by 1899, glanders had been practically suppressed by the early 1920's.

\section{Actinomycosis}

The Review had carried an extensive description of actinomycosis in a series of articles by George Fleming in 1883, the disease having been recognized in Germany some six years before. In January, 1884, the Review published an extract from the Medical Record, reporting that Dr. W. T. Belfield of Chicago:

has made the important discovery that actinomycosis exists in American cattle. $\mathrm{He}$ was asked by the Commissioner of Health of Chicago to investigate a disease in cattle which has generally been known as "swell-head," and has been called by veterinarians cancer, sarcoma, etc. . . . Dr. Belfield's discovery is an important one, and should become promptly known to veterinarians and sanitary officials. 
Again, perhaps as a result of the acquaintance with the disease afforded earlier by the Review, at a meeting of the Ontario Veterinary Association in December, 1883, J. T. Duncan described a case of actinomycosis sent to him by an Ontario veterinarian:

This is, so far as reported, the first case in America in which the vegetable parasite has been found in the tongue. . . Actinomycosis of the jaws, however is common. . . . It probably is transmissible from animals to man.

Like a number of other diseases, supposed to be "new," but to which little more than a new name had been given, actinomycosis - under a variety of names - had been described in the American agricultural press years before.

\section{Dourine}

In 1883, Charles F. Ring, M. D., wrote on "The new venereal disease of solipeds," i.e., dourine, the first mention of this disease in the Review. He notes that it was seen first in Russia in 1796, and at the time of writing had invaded most of Europe and parts of Africa. He does not use the term dourine, however, but identifies it by the equally familiar name, maladie $d u$ coit, and states:

Its identity with syphilis is complete in every particular, so far as the constitutional difference of the horse will permit, and any one who studies the two diseases carefully must come to the same pathological conclusion.

With all due respect to his convincing and seemingly logical arguments - for the time at least - in the light of present knowledge we are forced to agree that his was a "pathological conclusion." The veterinary profession, however, can be duly appreciative of this timely introduction to the subject, for the disease - soon to be imported - did not catch the profession completely unprepared, as might have been the case had the disease been totally unfamiliar.

Following the series of articles by Ring in 1883, dourine attracted little attention in the veterinary press until 1887 . Those who read only the American Veterinary Review were not aware of the importation of this disease until so informed editorially in July, 1887:

The presence of one more contagious disease ... is at length officially reported. Dourine, or maladie du coit, has made its appearance in the West [Illinois].

Apparently prompted by this disclosure, the Review ran a series of articles translated from the German, which provided an adequate basis for an understanding of the disease.

The subject was naturally one of great concern to the horse breeding interests in Illinois. At a citizens' meeting in DeWitt County in 1887 it was declared:

The existence of the disease can be traced to the year 1885. Its origin has not been satisfactorily determined. There are from twelve to twenty stallions... [ and ] forty to fifty mares in the county afflicted with the disease.

Recommended was the quarantine of all diseased and exposed horses, and the branding of diseased animals with the letters "VD." Veterinarians proposed stronger measures, including castration or the slaughter of all affected animals, and a prohibition against further importation of stallions or mares without "a perfect and clean bill of health," from the point of origin, and "rigid veterinary inspection at the place of landing, and, if necessary, a subsequent quarantine."

\section{Williams to the Fore}

An extensive history of the Illinois outbreak is given in 1888 by W. L. Williams, the Assistant State Veterinarian, to whom credit for recognition of the disease and the measures for its control are due. He states that the outbreak in DeWitt County was the first recognized in any Englishspeaking country, that it probably had been imported with an infected stallion in 1882 , and while not recognized "the malady continued to spread, unobserved in 1884 , suspected in the autumn of 1885 , and asserting itself positively in 1886." A stal- 
lion imported from France in 1882, and put into service in the spring of 1883 , served a large number of mares, which dropped healthy foals. In 1884 the stallion developed lesions of genital disease, and was removed from service early in the season. It was noted, apparently at this time, that he bore on his neck:

a very plain brand, of the letters DN, which I am reliably informed by Prof. Law and Dr. P. Paquin, unmistakably indicates that this horse had been condemned by the French veterinary authorities for maladie du coit.

The horse was sold, treated for his malady, and continued to serve a few mares:

Nothing particularly farther was thought of the matter until the disease broke out in alarming proportions and inquiry was instituted to determine its origin.

Thus it was found that one or both of two mares bred to this animal in 1883 undoubtedly infected the stallion Utopia in 1884 , whereupon his hardly utopian role in dissemination of the disease began. The first deaths of mares bred to him, however, did not occur until the fall of 1885 . According to Williams' story, he was not apprised of the situation nor consulted until April, 1886, "when the disease had assumed such alarming proportions":

Not being fully aware of the extremely insidious, misleading and serious nature of the disease with which I had to cope, and hoping that the disease could be successfully confined to its then apparent narrow scope, I advised that Utopia should be withdrawn from the stud until all symptoms of the disease should disappear. . . . My second visit in April, 1886, brought me to a more full realization of the dangers to our horse breeding interests.

An official report was made to the State Livestock Commissioner on the first of May, thus constituting the first official recognition of the disease in the United States.

\section{Easy Entry}

While it would seem that with foreign interests deliberately pawning off affected stallions, the disease might have been im- ported again at a later date, the incredible truth of the matter is that this particular outbreak could have been averted by a single veterinary inspector at the port of entry. Certainly anyone with but a passing knowledge of French sanitary regulations would have recognized the incriminating DN on the imported stallion. That such casual inspection would not have prevented the eventual importation of the disease, however, is evident from Williams' statement:

The totally unknown and unsuspected nature of the affection, with its long periods of incubation, latency and want of such pronounced symptoms in its earlier stages as we usually expect in a deadly contagious disease, readily allowed it to gain a disastrous hold unobserved or at least unrecognized.

On the subject of prevention and eradication, Williams states:

We are suddenly awakened to the existence of this, to us, hitherto unknown disease in our midst, and if not dealt with firmly and heroically, it must prove a serious scourge to the horse interests of Illinois and the country at large. ... The work of control and extirpation has surpassed our expectations ... due largely to an unusually hearty cooperation of almost every horsebreeder in the infected district, frequently at no small sacrifice.

He states that every stallion kept for public service was personally inspected by him, and all mares bred by infected stallions placed under quarantine. The fact that the mortality among infected mares exceeded 50 per cent tended to make the disease, under strict quarantine, more or less self-limiting, providing that a mare once infected was never again bred. Concerning the future, Williams urges:

The history of the disease in foreign countries repeats the warning over and over: Never under any consideration allow a mare affected with equine syphilis to be bred again.... Hence, at whatever labor or cost, all affected mares should be either killed or held rigidly in quarantine. ... Killing is certainly preferable, wherever it can be readily done, otherwise years of careful watching and supervision must ensue. 


\section{After Forty Years}

A résumé of "The Illinois Outbreak of Dourine" of 1887 , by W. L. Williams in 1927 , is of particular interest in that, coming forty years afterward, his recollections faithfully reflect the conditions he met at that early time. He notes that his early reports:

Like most reports of that class . . have already disappeared and after the lapse of forty years are not readily available to most members of the profession. It therefore appears desirable that the history of the outbreak be briefly retold at this time because, amongst other considerations, references are now and then made to the occurrence in such a manner as apparently to endanger the historical accuracy of the event....

At the time of the outbreak I was performing the dual function of private practitioner at Bloomington, McLean County, Illinois, and Assistant State Veterinarian. ... I was called to the adjoining county of DeWitt in April 1886 , in my capacity as a private practitioner, to examine some stallions and mares affected with a disease which I recognized as dourine, then better known as maladie du coit. Fortunately Liautard recognized the professional and historical value of the report sufficiently that he copied it entire in the American Veterinary Review, Vol. 12, page 295. The existence of the disease was promptly reported by me in 1886 , but ... so far as any visible reaction to my report was concerned, they [ the live stock commissioners] did not hear of it then.

The disease gradually spread and early in 1887 the breeders of the region involved became decidedly alarmed. I then reported the matter to the Commissioners for a second time. ... Finally the Commissioners authorized me to quarantine any diseased animals but still failed to realize the importance of the situation. . . . [Later] I was granted authority to deal with the disease and had placed upon me an abundance of responsibility.

The community was naturally and justly greatly alarmed. There was no one to whom I could turn for counsel who had had experience with dourine. ... Veterinary authorities were in hopeless confusion regarding the symptoms and diagnosis. . . . There was no great degree of confidence in veterinarians in general and, quite naturally, none too much confidence in the veterinarian in official charge. . . .

Having begun to spread insidiously in 1883 and 1884 , the infection had acquired somewhat extensive and intricate dissemination when finally placed under official control in 1887 . In the interval, an undetermined number of animals which had been exposed had been sold and had gone to unknown destinations. ... It was this group which was apparently responsible for the several outbreaks in the northwestern states and Canada.

Disputing the later alleged fact that a stallion shipped from Illinois in 1888 was responsible for an outbreak of dourine in Nebraska in 1892, Williams defends his official report that no animals under his jurisdiction were responsible for later outbreaks:

Aside from the desirability that official reports of the control of contagious diseases should be accepted as authentic, there is another important reason for establishing, if possible, the historical accuracy of the official reports of the Illinois outbreak of dourine. Beginning not far from the date of that outbreak, there arose a tendency, still conspicuous, to abandon, in part, clinical observation in the diagnosis and control of contagious diseases, and to substitute therefor, instead of adding thereto, bacteriological, serological and other laboratory methods. The Illinois outbreak, occurring before the discovery of the trypanosome of dourine, could be controlled only upon the basis of clinical observation. If, as I claim should be done, the official reports are accepted as true, the disease was brought under control within less than two years. Except for one recrudescence, due to violation of quarantine, and involving but two animals, which were promptly and effectually disposed of, no recurrence of the disease has taken place during the forty years.

Furthermore, if it is granted that the official reports are authentic, no diseased animal escaped or was removed from the affected zone after the official recognition of the disease, in 1887. The control of the disease was prompt, complete and enduring, and stands as a distinct clinical achievement which suffers none by comparison with the efforts at the control of later outbreaks when the officials in charge had at their command the bacteriological, serological and other laboratory methods of diagnosis. No forward-looking clinician has the remotest desire to discard or minimize the value of bacteriological, and other laboratory methods of diagnosis, but there is a not wholly unnatural tendency for some veterinarians to be attracted unduly by the newer standards and to forget that clinical observation is still of very great value - just as valuable now as ever in the history of veterinary science. 


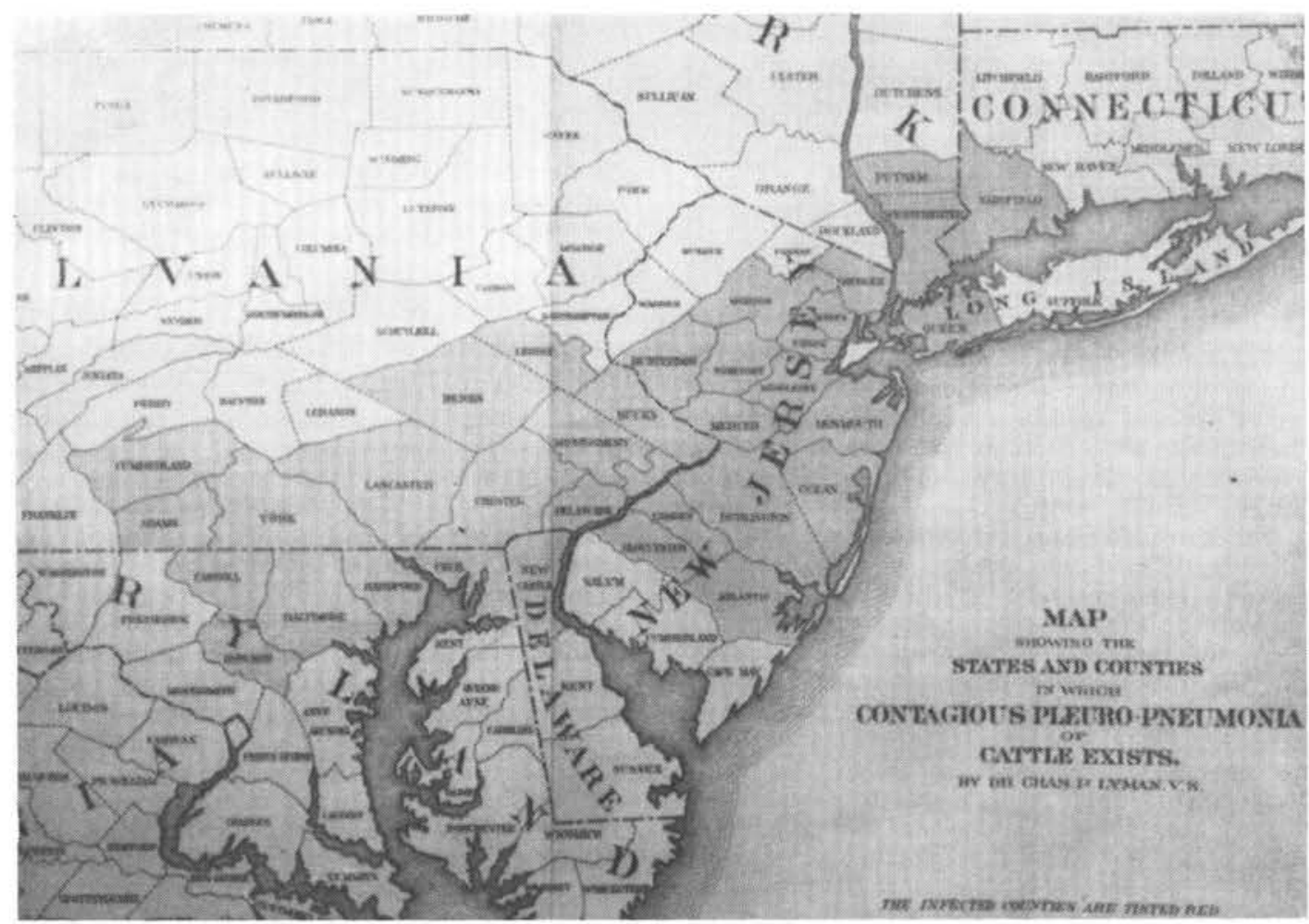

Contagious bovine pleuropneumonia, introduced in an imported cow at Brooklyn, New York, in 1843, had spread to most of New Jersey and eastern Pennsylvania by 1880, and to most of the states east of the Mississippi before it was eradicated in 1892. USDA Report

Later outbreaks, probably originating with animals shipped from Illinois prior to the quarantine imposed by Williams, occurred in several midwestern and western states. With the introduction of the complement-fixation test and destruction of all infected animals, it was believed that the disease had been eradicated by 1920 . However, some infected animals were found in Arizona and California in 1941, presumably through contact with horses owned by Indians. Although undoubtedly unintentional, this might appear to be a case of retribution by the Indians for their harsh treatment in Hollywood horse operas.

\section{CONTAGIOUS PLEUROPNEUMONIA AND THE BAI}

Contagious pleuropneumonia, so-called "lung plague" of cattle, was introduced into Brooklyn, New York, in 1843 through the purchase of a British ship's cow by
Peter Dun, a milkman near South Ferry. The infection spread from his herd to many others in Brooklyn and New York City and vicinity, but appears not to have been recognized as a major threat to the dairy industry. At least this probably was so at first; later there is no question that dairymen, fearing the loss of customers, preferred to keep knowledge of the disease to themselves and strenuously protested both its existence and official efforts to control it.

A second introduction of the disease was made in 1847 in a herd of cattle imported by Thomas Richardson of New Jersey. Rather than allow the disease to spread, $\mathrm{Mr}$. Richardson slaughtered the entire herd, which was valued at $\$ 10,000$, but later, affected cattle were brought into the state from New York. In 1850, another infected cow was imported into Brooklyn from England, and in 1859, the disease 
reached Massachusetts via four cows imported from Holland.

Concerning these four cows, a contemporary account states:

They were shipped in the early part of April, I859, and arrived on the 23d of May, after a voyage of forty-seven days. During the last twenty days one of the cows was unable to stand, and the others were in extremely bad condition. Two of them had to be hauled out to the farm, while two could be driven on foot. The first mentioned cow was killed on the 31st of May, because recovery was hopeless, and the second one died on the $2 \mathrm{~d}$ of June. . . A third cow of this importation did well seemingly until June 20, when she sickened and died in ten days. . . . On the 20th of August another Dutch cow, imported in 1852, took sick, when the idea first obtained that the disease was the same as the "Epizootic Pleuro-pneumonia" of Europe. From this time every possible means was made use of to prevent the spread of the infection, such as separate pastures, stables, and other means of isolation, and the use of disinfecting agents, etc.

The article goes on to state: "At the time of the death of the cows before mentioned, they were examined by veterinary surgeons, who pronounced the disease pleurisy or pleuro-pneumonia." This apparently confirms a report of George Dadd, who says he had been called to see Chernery's cattle. A contemporary report states:

Upon their arrival it appeared that they had been badly treated on the voyage . . . and he [Dadd] testified that he thought their condition was due to want of proper attention. At the time they did not think of any infectious disease. In a short time one of the cattle became so sick, that he recommended Mr. Chernery to kill her, but without apprehending that she was suffering from an infectious disease. In fact, several died before this suspicion was entertained. . . . Mr. Dadd had visited the barns of Messrs. Huntington, Stoddard, Olmstead and Needham. ... In the stock of Mr. Needham he found one clear case of pleuropneumonia, because both the pleura and the lungs were diseased, the latter gangrenous. There was a question as to the disease being infectious, but he was inclined to think it was.

In a subsequent issue of the American Stock Journal, Dadd published a letter from Chernery detailing the origin of the disease in his stock-apparently in re- sponse to a request from Dadd. Later he gives the text of a bill passed by the Massachusetts Legislature "to provide for the extirpation of the Cattle disease, or pleuropneumonia," and an extract from a Spring field paper, which indicates that Dadd had assisted the Cattle Commissioners in some further investigations.

In June, 1860, Dadd gives a first person account of his findings, and reprints several articles he had prepared for the Boston papers concerning "our doings in the infected district." In these, written early in May, he states:

New cases among the suspected herds are constantly occurring, and since yesterday the commissioners have ordered the destruction of one hundred animals. . . . The contagious element of this disease is established beyond the possibility of a doubt. ... It appears to me that this malady is not only a matter of grave importance to the people of North Brookfield; the interests of the husbandmen of the whole of North America are involved, for if this disease should spread beyond its present limits, no one can foretell where it will end. It may prove to be as disastrous here as in the Old World during the years 1844-5.

Your readers in Boston and elsewhere need not feel alarmed lest the diseased meat should be offered for sale in their several localities, for under the stringent precautionary measures enforced by the Commissioners it is almost a matter of impossiblity to get a dead carcass beyond the limits of this town.

I understand that in various parts of this State and elsewhere, considerable alarm is felt in regard to pleuro-pneumonia, and many of the farmers now have their ears wide open whenever an animal coughs, and often suppose the ordinary cow-cough to be the keynote of this affection, when it is well known that almost all cows cough, more or less, during the winter and at this season of the year.

Writing such as this might be considered as representative of the ultimate in what might have been the mission of veterinary columnists in the agricultural press. In addition, a statement made by one of the Boston papers would suggest that Dadd was not one to temporize with such a plague once its nature was known:

Dr. Dadd is of the opinion that every animal in North Brookfield will eventually have to be killed, and could this be done at once the advantage is obvious. 
But in a later issue Dadd writes on the "Treatment and Curability" of the disease. He states that the prevailing censure of the Cattle Commissioners for killing cows with such dispatch is not justified, as they "are not to be blamed for executing the laws." He suggests that as the severity of the disease lessens, as was the experience in Europe:

the isolation of infected and exposed animals; the inoculation of those not diseased yet located near diseased regions; and extirpation in cases of emergency, are the best means of managing this pest.

In December, 1860, the Stock Journal notes: "The Cattle distemper in Massachusetts appears to have died out, or been cured up. Little is heard, and nothing seen of it lately."

\section{To Kill or Not To Kill}

On the subject of pleuropneumonia earlier that year, however, the editor of the American Agriculturalist had stated:

During a dozen years past, we have from time to time heard of single animals, here and there, which, from the descriptions received seemed to be affected similarly to those now diseased in Massachusetts. We are almost daily receiving reports from New-Hampshire, NewYork, New-Jersey, Pennsylvania, Ohio, etc., of local diseases among cattle, which are apparently of a similar character. Whether the disease be the same, or one of the same general type, or whether fear and imagination have aided in making out an analogy, it is not possible yet to decide.

Apparently to aid farmers in making a decision, he gives: "a diagnosis, or description of the symptoms," from the report to the Massachusetts legislature by E. F. Thayer, V.S., and George Bates, M.D.

In printing a letter from a New York farmer on the matter, Editor Judd apparently overlooked the fact that the Cattle Commission had recommended slaughter as the only means of combatting the disease. He says:

The treatment recommended is a good one in any case, for a disease of the lungs, and if it does no good, it can do no harm. The immediate separation of a suspected animal from all contact with other animals, should not be overlooked.

The question of the contagiousness of pleuropneumonia was not at once settled. In the face of what would seem today overwhelming evidence in favor of contagion, medical opinion was elicited pro and con. In testifying before a committee of the Massachusetts legislature, Dr. Jacob Bigelow, an eminent medical practitioner, stated:

As far as I can learn, the question at issue is as to the propriety of slaughtering the infected and suspected individuals. ... I have not made up my mind in favor of the propriety of this measure. No doubt if all the cattle in the State are slaughtered the disease will stop for a time. ... If it should turn out that only half the cattle in the State are slaughtered ... I should not consider, even if the disease should then stop, that it was proved to be contagious. ... In the dark ages, when men were ignorant and credulous, they attempted to arrest epidemics by hanging Jews and burning witches, and if this practice did not prove effectual in stopping the disease, they proceeded to execute more Jews and witches, until it did stop. But I believe it does not follow ... that these two events stood, to each other, in the relation of cause and effect.

The noted agriculturalist, Judge French, giving his opinion on the subject to the Country Gentleman in 1864, quotes another writer whose language is "more decisive perhaps than was becoming a non-professional." This writer states:

A man who with the evidence now before the public, will contend that this disease is not to be treated as contagious, ought to be shut up in quarantine till he recovers of so dangerous a heresy.

French adds that the doubts of men like Bigelow should be proof enough that the disease should be considered contagious, and that all suspected animals should be slaughtered. The very success of the first program of extermination, he thinks, was a factor in the theory of noncontagion gaining ground: 
The danger being passed, men looked wisely at one another, and asked whether after all we had not been more scared than hurt. There was always a strong party opposed to slaughtering, and especially opposed to being taxed to pay for it, part of whom were learned men who had real doubts of the contagiousness of the disease, and part of whom were conservatives like the man in Noah's time, who did not think there was going to be much of a shower, and these advised waiting till the horse was stolen before locking the stable. Some objected to the law, because they said the commissioners carried the disease all over the country in their clothes.

\section{Obvious Epizootology}

It is apparent that Dadd did not immediately grasp the significance of the disease, for he is reputed to have attributed it to "hardships of the voyage." At any rate, it appears that the infectious nature of the disease was not suspected until August. Meanwhile:

On the 29th of June, 1859 , on the same day that Mr. Chernery's third cow died, Mr. Curtis Stoddard, of North Brookfield ... near the center of the State, purchased three Dutch calves from Mr. Chernery. ... On their way from the depot to his house, he observed one of the calves to falter, and, when it got home, appeared to be very sick. Several days afterwards, Leonard Stoddard [ father of Curtis ] removed the calf to his home, thinking he could cure it. He took it to his own barn, where he kept forty head of cattle, but as it grew no better at the end of four days, it returned to the son. On the 23d of August, it died.

And thus begins the sad story. Curtis Stoddard, apparently unaware that his herd was infected, sold 11 cows in November and retained nine, of which he sent some to his father, an uncle, and his father-inlaw:

From his sale, however, the eleven animals went in almost as many directions; and what is very important, without a single exception, wherever they went they scattered the infection, and the disease developed itself. In one case ... more than two hundred cattle... [ were] infected by one which was sold at $\mathrm{Mr}$. Curtis Stoddard's sale.

What follows is probably the most complete detailing of the epizootology of any disease to date - an object lesson of no mean proportions. In part, it may be summarized as follows: Leonard Stoddard swapped a cow with a neighbor, Mr. Needham, who returned it when it proved to be sick: "A fortnight afterwards, the disease appeared in Mr. Needham's herd." Mr. Woodis, of New Braintree, purchased a cow from Stoddard, which "caused him to lose his entire herd." Stoddard also sold a yoke of oxen to Mr. Olmstead, who lost a third of his cattle, and:

Mr. O. sold this yoke to a Mr. Doane, who lent them to be put in with twenty-three yoke of cattle to remove a building to North Brookfield; they were employed a day and a half in this operation, and every one of the twentythree yoke took the disease. They belonged to eleven different herds, and thus scattered the disease through eleven new herds, and each one of these new herds formed a new focus, from which it spread farther.

In similar manner a dozen or more additional contacts, all tracing to the Chernery cattle, via the two Stoddard herds, are given, all with the same result.

The Massachusetts Cattle Commission was established in April, 1860, to deal with the disease; under E. T. Thayer, veterinary commissioner, "the last remnants of the plague were extinguished in 1864, and it did not reappear in that state." Massachusetts was fortunate in having one with the vision and zeal of Dr. Thayer, who remained adamant in his refusal to compromise with those who would temporize with the disease by inoculation or mere segregation of exposed cattle, although the latter measure could have been used at the commissioners' discretion. Dr. Thayer, of course, was fortunate in having a legislature generous enough to provide the funds for indemnity for slaughtered cattle; over a million dollars was appropriated for control of the disease.

Other states, however, were less fortunate; the disease was carried into Connecticut early during the Massachusetts outbreak, and reached Pennsylvania in 1860, Delaware in 1861, and as far as Virginia by 1868. Connecticut was the only other state to be successful in controlling the disease, 
but her proximity to other infected states resulted in a series of outbreaks. It was not until 1879 that national attention was aroused to the danger.

\section{The Evils of Inoculation}

Meanwhile the proponents of inoculation, mainly dairymen who believed they were acting in their own interest - but abetted by a few veterinarians - had rather effectively stalled action upon total eradication of the disease. Frank Leslie, the crusading journalist, exposed "the unhealthy conditions of the swill stables" of New York City in 1858, and stimulated an investigation of conditions by the board of health. In many of the stables, the committee found cows with sores on their tails, or without tails, and reported:

these sores were produced by the inoculation, which is practiced extensively .... [ and which ] consists in the insertion in the tails of the living animals, as the virus, matter from the lungs of a cow which had died of the disease. The cows are inoculated when first brought into the stables, and it generally requires two or three weeks to heal, and sometimes it is thought better to cut the tail off. This is one of the reasons why short tailed cows were found in the stables.

The British veterinarian, John Gamgee, who investigated pleuropneumonia for the U.S. Commissioner of Agriculture, reported favorably on inoculation in 1871 on the basis of European researches. He notes, however, that as practiced in Brooklyn, an objection was "the sloughing of the tail and the animals splashing blood and matter from their sore tails into the milk-cans."

The folly of inoculation in an exotic disease, for which there was every reason to believe eradication would be successful (and had been in Massachusetts), was clearly recognized by men like James Law. Along with other leaders of the veterinary profession and the livestock industry, Law had urged federal legislation to combat this evil, but to no avail. Fortunately, Dr. Law had a generally sympathetic and cooperative agricultural press at his disposal, and so he took his case to the public.

\section{Law on Legislation}

Dr. Law, in one of a number of lengthy articles in the Breeders' Gazette, urges:

It is a matter of the highest moment that citizens, and especially the owners of live-stock, should impress upon their representatives the imperative necessity for the extinction of this crushing incubus upon the cattle traffic.... With a pestilence which is well-known to have been an importation from the Old World, which now bans our cattle because we allow it to occupy but a narrow strip of our sea coast, it seems like madness to delay those measures which would so speedily, and at a single blow, rid us of the destructive invader, and secure for us an untrammelled market for our beef.

In pungent phrases Dr. Law epitomizes the history of pleuropneumonia in this country, and charges:

For a long time the United States have been oblivious to their danger. The city milkmen, suffering from the presence of the pestilence in their herds, dared not acknowledge it lest it should hinder the sale of milk. The city cow dealers found it a most convenient means of increasing the demand for cows, so that they had little reason to complain, while the great body of the stockowners were kept in profound ignorance of its existence.

The fancied security was rudely broken in 1878, when Great Britain issued the order that all United States cattle should be slaughtered at the port of landing. . . The country became excited over the occurrence; newspapers and agricultural clubs denied the existence of the disease, but investigation only revealed the truth of its presence, and we had to face the inevitable. Many can hardly forgive England for her action in the matter, yet, if properly improved, it was the most beneficent act she could have done for us. It brought us the first twinges of pain from the cancer which had been growing unseen and unsuspected beneath the surface. . . . In the case of a purely local cancer the surgeon is criminal who counsels delay; so in the face of such an infected contagion as that now under consideration, the sanitarian is an enemy of the country who would advise temporizing measures, as is also the statesman who enacts them....

The great need of prompt action was pressed on the last Congress, but they found it easier to appropriate money for investigations and reports, than for the real work of "stamping out" the plague. The present Congress, therefore, must begin as did the last, and unless a strong and persistent pressure to action is 
placed upon it, it, too, may shift its responsibility on the shoulders of its successor and give the pestilence one more opportunity to spread and to devastate the entire continent.

Dr. Law, who had investigated the disease as a member of the Treasury Cattle Commission, probably appreciated the local nature of the disease better than anyone else at the time; had his counsel been acted upon with dispatch, it undoubtedly would have taken less than another decade to effect eradication of pleuropneumonia. A gifted writer, as well as a competent sanitarian, Dr. Law's appeal is well worth reading in its entirety for its poetic prose:

Had this dread plague been like Texas fever or milk-sickness, a product of our own soil ... if, after a strenuous but successful struggle, we still had to fear that the vanquished monster would again and again rise up like the smoke of a temporarily extinct volcano .... if the plague already gained a footing on our Western plains-the source of our cattle traffic ... if it had poisoned that mighty stream at its fountain and infected its entire channel ... or if it had cast its withering spell on the wild herds of buffaloes, sanitarians and statesmen might well have paused ere they attempted to grapple with the danger.

\section{The Un-Hatched Bill}

In criticizing the Hatch Bill of 1882, which would have established a Bureau of Animal Industry, the Gazette points out:

so far as the lung plague of cattle is concerned, it is merely a pretense at legislation ... as a measure for preventing the spread of the disease stamping it out or enabling us to give a clean bill of health to western cattle for export, it is not worth a rush.

Regarding the prohibition against shippers receiving cattle: "knowing them to be affected with any contagious or infectious disease," the Gazette urges:

The spread of the disease can only be prevented by a positive interdiction of all cattle traffic between the infected and non-infected regions, except after rigid and careful quarantine.

Nor does the section creating the BAI: make any provision for hedging in or stamping out the lung plague... . The foregoing bill will prove of no earthly use so far as lung plague is concerned, except to further advise the government as to what may be done.

And concerning the appropriation of $\$ 50,000$ for the work of the proposed $\mathrm{Bu}$ reau:

The presence of this disease is now costing our farmers more than $\$ 1,500,000$ annually. Let an appropriation of that amount be made at once, and we can rid the country of it promptly, and furnish a system of quarantine that will hereafter protect us from further invasion.

Later, the Gazette printed a letter from a Canadian correspondent who observes:

It is a marvel to us in Canada that your Congress, which as a rule is so keenly alive to all that pertains to the welfare of any of your valuable industries, should not have grappled vigorously with this scourge, and have taken such decisive measures as would ultimately lead to its total extermination.

And in response to a criticism of the $G a$ zette as an "hysterical publication" for printing the facts concerning pleuropneumonia, the editor gives the assurance:

The Gazette will continue to make efforts to secure the eradication of this disease from the country, even if it be necessary to again and again call attention publicly to the unpleasant fact of its existence.

Obviously, the faith which had been placed in the integrity of Editor J. H. Sanders in his appointment as a member of the Treasury Cattle Commission was not in jeopardy.

Failure of passage of the Hatch Bill evoked an acrimonious letter from the president of the Iowa Improved Stock Breeders Association charging Congress with, "A cool, deliberate, insulting neglect, or an actual betrayal of all these great interests!" In rebuttal, D. E. Salmon expresses no surprise at failure of the bill:

Beginning with a section well calculated to antagonize railroad and other transportation interests, a second section was added to destroy 
any practical benefit that might possibly be derived from the first, by making it apply only to those persons who knowingly violate its provisions.

Dr. Salmon also objected to placing the veterinary activities of the proposed $\mathrm{Bu}$ reau, in effect, under control of the Board of Health (but this provision was struck from bill before its defeat), and notes: "In the whole bill it is impossible to find a clause which gives the chief of the bureau of animal industry any authority." Salmon further suggests:

there is no occasion for great grief, or for serious charges against anyone because of the failure of this bill. Would it not be better... to discuss the matter calmly and see if a bill cannot be framed which will still confer the necessary power for eradicating the plague? In the meantime it certainly cannot be to the interest of the cattle owners that every rumor of the existence of contagious pleuropneumonia west of the Alleghenies should be published to the world. . . I am not in favor of any policy of concealment, but I do think that we should wait for some tangible evidence before giving credence to such assertions.

While agreeing "no false alarms should be given to the injury of any locality," the editor asserts:

The Gazette can not agree with Dr. Salmon as to the policy of silence, or rather of concealment. . . . It is only by continual agitation of the subject that we can hope to succeed in procuring such State and Congressional action as will result in stamping out this dangerous and insidious enemy to our live-stock interests. ... Far better let us have a hundred false alarms than that one new infected center should be suffered to extend itself through ignorance of the fact of its existence.

In response to a protest by Salmon, however, the editor admits, "We unintentionally did him an injustice in our comments," and agrees that the Gazette's policy was essentially the same as Salmon's.

\section{Urgent Necessity}

Veterinarians had given thought to the need for a sanitary bureau long before action was taken to establish the Bureau of Animal Industry. Admittedly, opinion was less than unanimous on how such a bureau should be set up. Some called for a separate veterinary organization, some for affiliation with the National Board of Health, and others with the Agricultural Department. In editorializing on the matter in 1879, Liautard recognized the relationship of veterinary medicine to agriculture, but considered:

the scientific investigation of the cause and means of prevention of animal diseases is a matter entirely independent of agricultural pursuits. . . The National Board of Health seems to be the most appropriate department of our Government with which to organize a special bureau such as is contemplated. When we consider the intimate relationship existing between many of the preventable diseases of man and the lower animals; when we recall the fact that disease-producing causes operate similarly in the different species, and that many of the special diseases of the brute creation offer questions of unequalled importance to the investigator of human ailments by virtue of the susceptibility of their transmission, we must admit the propriety of being associated with a department whose object is in exact consonance with our own.

The important consideration, however, "is the urgent necessity for immediate action."

Later that year the USVMA framed a petition for presentation to the Congress, calling for:

a Veterinary Sanitary Bureau, whose duty it shall be to advise Congress as to what measures shall be necessary to control, restrict, or eradicate any contagious or infectious disease affecting the domesticated animals.

This drew pointed criticism from the Medical Record, noted elsewhere, primarily to the effect that there were not enough educated veterinarians to man such a bureau. To this Liautard retorted, "We are to learn yet that a large number is essentially necessary for the work to be done."

In 1880 James Law submitted a comprehensive report on the "Diseases of Domestic Animals" in response to a request concerning "how far in my opinion the functions of the National Board of Health must embrace a superintendence of the sanitary 
condition of the domestic animals." He undoubtedly would express amazement at the list of zoonoses today, for in presenting what he terms a "formidable" list of diseases, it is of some interest that only ten "contagia common to man and animals" are given: glanders and farcy, rabies, anthrax, tuberculosis, Asiatic cholera, milksickness, fowl-pox, and (now) of dubious significance: eczematous fever, typhoid fever, and diptheria. Also listed are 22 parasites common to man and animals, many of them still of common occurrence.

The contagious diseases of animals only he gives as: Texas fever, hog cholera, pleuropneumonia, rinderpest, pox of several species, foot rot, strangles, influenza, and mastitis, together with fifteen common parasites (including seventeen varieties of scabies and six of lungworm).

While Law makes apparent the obvious impossibility of dealing with all these diseases at once, an effective bureau would be one that "must be prepared to meet and successfully deal with any one of the above affections... when it attains to dangerous proportions," whether it be one common to man and animals, or of animals only. He devotes more attention to tuberculosis than any other disease, giving a full and accurate picture of its nature and epidemiology, stating, "The proper supervision of this affection will demand the most careful consideration of the soundest and most enlightened minds." Had it been possible to put into effect only the recommendations he offers for this and the other diseases he discusses, it seems safe to venture that most of them could have been wiped out, or effectively controlled, long before what actually proved to be the case. Because of the immediacy of the problem of several of the animal diseases, he urges that these be put in the hands of a purely veterinary committee of the National Board of Health.

\section{A Dissenter in the Midst}

The Journal of Comparative Medicine and Surgery, however, with regard to the critical comment of the Medical Record, states:

The propositions in it merit our full endorsement. . . The American Veterinary Association [ sic! ] is not a body analogous to our $\mathrm{Na}$ tional Medical Association; it is not composed of such elements as can claim the reverence due to scientific authority, and its dicta may be readily disposed of as possessing but a slight, if any intrinsic value. . . . All the work laid out for such a "Board" can be accomplished far more thoroughly by our already existing medical boards. .. There is no cause for apprehending that the scheme of the American Veterinary Association has the remotest chance of becoming realized; we refer to it only in order to give the profession an idea of the projects which a certain circle would carry out if they had the power.

The editor at this time was E. C. Spitzka, M.D., president of the Columbia Veterinary College; it may be that he had not made a clear distinction between the American Veterinary College and the American Veterinary Association (USVMA).

In 1881 there was introduced in the Senate "A bill to prevent the introduction or dissemination of infectious diseases among domestic animals in the United States." This bill would have empowered the National Board of Health to regulate importation of animals, to establish quarantines when indicated, and to "investigate and report on diseases of animals." The board of health was also authorized to appoint veterinary surgeons "who shall be ex-offcio members of the Board, together with other veterinary surgeons to act as inspectors."

About the same time a bill was introduced in the Senate which would authorize the Commissioner of Agriculture to establish a "Bureau of Animal Industry, and appoint as its chief some competent veterinary surgeon, approved by the National Board of Helath." This bill would have made the Bureau of Animal Industry, the Department of Agriculture, the National Board of Health and the Treasury Department interdependent agencies, in some instances, without obvious indication as to which had primary responsibility. Of some 
interest is the fact that the first bill provided for $\$ 1,000,000$, the latter for only $\$ 200,000$ to implement it provisions.

Even with the championship of a $\mathrm{Na}$ tional Veterinary Bureau by the American Veterinary Review, and the urging of action by the agricultural press, the divergent views of veterinarians themselves concerning the scope and mechanics of such an organization did little at first to crystallize thinking in the minds of legislators. Together with ignorance of - or indifference to - the problem in Washington, the unthinking efforts of those back home to protect selfish interests rather than to promote enlightened self-interest were successful in stalling action.

\section{Eradication by Legislation}

The bill creating the Bureau of Animal Industry originally contained a provision empowering the President to declare a quarantine of any state or territory which refused to cooperate with the Commissioner of Agriculture in stamping out animal disease within its boundaries. As signed by President Arthur in 1884, however, the bill had been shorn of this provision by the House, the only remaining power delegated to the Commissioner in this respect being the prohibition of interstate transportation of animals which were actually diseased. Furthermore, in the Senate, Texas statesmen, in effect, succeeded in legislating their nemesis out of existence by insisting "the so-called splenetic or Texas fever shall not be considered a contagious, infectious, or communicable disease." It should be added that this proviso was to apply only to cattle shipped by rail to slaughter and which would be unloaded en route only for feeding and watering, but there were no doubts in the minds of Texans that the disease existed only in the minds of veterinarians and northern stock growers.

\section{Bill Emasculated}

Between assertions of the nonexistence of pleuropneumonia - characterized by the
Gazette as "ignorance, stupidity or deliberate falsehood" - and the legislating out of existence of Texas fever by Texas legislators, it is understandable that response to the Hatch Bill should have been somewhat less than enthusiastic in some circles. Congressmen Hatch, himself a Democrat, is quoted as saying, "the good of the Democratic party demanded a few first-class funerals within the party itself."

In commenting on the final passage of the bill, the Chicago Tribune protests:

The bill has not been amended, but emasculated. Everything but the offices has been taken out. ... The officials who are constituted into a bureau by this emasculated bill are to do everything with regard to infectious diseases among cattle except to meddle with or stamp them out. . . They have no power to take any action whatever, and the report which they make to Congress months after the disease has spread beyond arrest will be of as much interest and importance as last year's almanac.

Experience proved that the bill as passed was unworkable so far as the eradication of disease was concerned. Only the Secretary of the Treasury, with regard to exported cattle, and the Secretary of Agriculture within the United States - provided his plans were acceptable to an individual state concerned - had the vested power to expend money for actual disease control. However, the Gazette rejoiced:

the Animal Industry bill has escaped the Philistines of the Senate. It comes out maimed and bruised, sore, lame, halt, and blind almost; but it has come out nevertheless. We can accept and rejoice over it, even in the sorry plight in which it comes, because it is the augury and promise of better things for the future.

That this was the case, future events including amending of the bill, and the appointment of D. E. Salmon as first chief of the BAI - were to prove.

\section{Battle Stations}

While it was pleuropneumonia that had been the primary stimulus which led to the efforts culminating in the establishment of the Bureau of Animal Industry, 
the establishment of the BAI was not an immediate answer to the problem. Hampered by lack of funds and authority, and limited to a staff of 20, there was little that Salmon could do at first except make investigations and recommendations. At this time the eastern seaboard from Connecticut to Virginia was infected. The fact that the normal movement of cattle was from west to east naturally limited the spread of the disease westward, but in 1884-1885 it was found in Illinois, Ohio, Kentucky, and Missouri. BAI inspectors moved into the newly infected territory, but were largely helpless without wholehearted cooperation of the states involved. Thus in Kentucky, despite "the plan so forcibly outlined by the Governor," cattle from infected premises were. shipped to Texas, where-despite the fact that 30 of the 125 cows had died - they were dispersed at public sale.

In 1886 the Kentucky legislature authorized slaughter of infected herds and appropriated money to compensate owners. As reported by U. G. Houck in his history of the BAI:

The slaughter began on March 15, and on March 27 the last infected animals in the State were destroyed and the disease did not reappear in Kentucky. This was our first demonstration of promptly eradicating a contagious disease by the slaughter and disinfection method.

Even considering the fact that few premises were infected, the dispatch with which the problem was handled once the necessary ammunition was provided seems something like a minor miracle and augured well for the fledgling Bureau.

\section{Confidence in the Bureau}

Contrary to the experience in Kentucky, good cooperation was obtained at the outset from the state in the 1884 outbreak of pleuropneumonia in Illinois. By the end of 1885 it was believed that the disease had been eradicated, but it was discovered again in dairy herds near the stockyards in the fall of 1886. Milkmen of the distillery herds involved at first denied the existence of the disease, but later admitted they had been inoculating the cattle to lessen mortality.

In March of 1887, the appropriation for the BAI was raised from $\$ 100,000$ to $\$ 500,000$, and authority was given to purchase and destroy both infected and exposed cattle. In April, James Law was placed in charge of eradication work in Illinois on behalf of the Bureau. By July the last diseased cow had been destroyed; the total cost to the government was just under $\$ 80,000$. This, Houck observes:

was a sufficient achievement to establish confidence in the efficiency of the new Bureau of Animal Industry. ... The success attained in eradicating the outbreaks in the West had a beneficial effect in stimulating a desire for a more vigorous prosecution of the work in the East.

Few of the Eastern states, however, were as ready to cooperate as fully as had Illinois; outright procrastination, evasion and overt opposition - including some $\mathrm{v}$ i o l e $\mathrm{n} \mathrm{c} \mathrm{e} \mathrm{-}$ was met with, and it was not until 1892 that the country was declared free of pleuropneumonia. As noted by Houck:

It cost the National Government $\$ 1,509$,100.72 to eradicate the disease in the United States and required about five years. If the States had been prepared with laws and funds as they are now prepared, probably it could have been accomplished within one year. . . [Nevertheless] the favorable outcome must be regarded as a great achievement for the new Bureau of Animal Industry.

\section{TEXAS FEVER}

Our knowledge of yellow fever would in all likelihood have been delayed if the work of the Bureau of Animal Industry of the U.S. Department of Agriculture on Texas fever had not been done.

This statement in 1920 by Simon Flexner, M.D., of the Rockefeller Institute of Medical Research, added support to the now generally accepted opinion that the discovery of the role of the cattle tick in the propagation of southern cattle fever rates 
as one of the most notable medical achievements of the nineteenth century. As pointed out in 1913 by John R. Mohler, later Chief of the BAI:

It has made possible such triumphs of sanitary science as have been accomplished on the Isthmus of Panama and without which the great canal could not have been constructed so expeditiously and with so little loss of human life.

What later came to be known popularly (or unpopularly in Texas) as Texas fever first became a problem in the Southern colonies during the eighteenth century. According to letters written by St. John de Crevecoeur between 1769 and 1779:

Some years ago a Spanish vessel was cast on the coast of Carolina. The hides it contained communicated an infection which had been hitherto unknown. Now and then it broke out in those provinces. I have heard it asserted that they have begun to inoculate the cattle for this disorder with what success I know not.

He states that the disease was called the "Spanish staggers," and while formerly there had been a considerable trade in cattle driven to Pennsylvania, "the severe losses which the northern people upon the road met with in consequence of the infection made them rise up in arms and oppose their passage."

This early recognition of the fact that apparently healthy cattle could transmit a fatal infection to native stock is suggestive of the "Winchester quarantine" imposed on cattle driven from Texas to the midwestern markets a century later. While the means of infection was unknown, at least the mode of transmission was recognized in laws promulgated by the state of North Carolina as early as 1766:

To prevent the inhabitants of South Carolina from driving cattle to range and feed in this province . . . without having a certificate, \&c., that the cattle were sound.

As might have been anticipated, in 1795 it was found necessary to amend this act:

Whereas it is found by experience that such certificate is insufficient... no person who- ever shall hereafter drive any cattle into North Carolina between April 1 and November 1 from either South Carolina or Georgia.

Also restricted was the movement of cattle within the state from the lowlands to the highlands or vice versa. That the act was biologically sound is evident from the fact that the tick would be most infective during the warm weather.

What appears to be the first scientific investigation of the disease was made by the eminent Philadelphia physician, James Mease, in 1796. Mease writes in 1826:

In the middle of August in the year 1796 ... having called at Anderson's ferry on the Susquehanna, I found the people of the house in great concern on account of the death of some of the cattle, and sickness of others, which had occurred in a few days after a drove from the south had left the place. Upon inquiry I am informed, they communicated diseases to the stock with which they mixed. The admission of a single head was enough to give rise to it. As the drove of cattle exhibited no mark of illness, the mystery of the cause was inexplicable, and is so to this day.

Mease traced the course of the southern herd and found that deaths of native cattle had occurred elsewhere along its route. $\mathrm{He}$ performed a number of post-mortem examinations and tried various treatments to no avail, except for recommending "the obvious expedient of an entire separation of the old stock from the strangers."

The work of Mease on Texas fever is considered at greater length under his contributions to veterinary medicine, but there is little to suggest that his early work was recognized by those who became interested in the disease during the late nineteenth century. In fact, after Mease's contributions, except for occasional references to "bloody murrain" the disease appears to have attracted little attention again until the late 1850's. About this time it became an exceedingly live topic - both for speculation and impulsive action - for the three decades prior to discovery of the cause. In 1854 a large drove of Texas cattle was sold in Illinois at a handsome profit, and in succeeding years additional such drives were made. But within a few years: 
it was found that the southern or Spanish cattle were subject to an epidemic or contagious disease somewhat resembling the yellow fever of the human race, and so contagious did it prove that all along the track those cattle were driven the farmers lost large numbers of their cattle from that disease, many losing almost their entire stock within a few days. So serious was the loss occasioned by each drove of Texas cattle passing through, that the inhabitants of southwestern Missouri held conventions in divers places, and resolved that no more Texas cattle should pass through the country, and by order of these conventions, armed bands of patrols were appointed, whose duty it was to turn back all Texas cattle that might attempt to pass, which they did effectually. Thus ended what was at one time a promising trade.

\section{The Tick Theory Attacked}

Some responsible cattlemen apparently had sounded warnings against the cattle tick about 1860 or earlier, but these were generally scoffed at. Moreover, the tick theory was effectively laid low by the honest conclusions of the eminent British veterinarian, John Gamgee, who investigated the disease at the request of the United States government in 1868. Gamgee listed a dozen possible causes, none of which approached the truth, and dismissed the real cause:

The "tick theory" has acquired a renown during the past summer; but a little thought should have satisfied anyone of the absurdity of the idea.

In his Diseases of the American Horse, Cattle and Sheep (1870) Robert McClure, later jailed for forgery in connection with the sale of veterinary diplomas, neatly solves the problem of Texas fever:

This is ... nothing more than the Fardle Bound of the European writers - impaction of the manyplus [omasum] with withered and dried grass. . . . Texan Fever is a misnomer, and it is not known in Texas or amongst the cattle of Texas, but amongst those of other States. It is even supposed by many persons, well informed, that Texan cattle give disease to other cattle that subsequently graze on pastures trodden by them. How ridiculous and unreasonable is this theory when viewed in the light of science and common sense. How can healthy oxen, and from a healthy country, give or impart a disease they never had?
Obviously, McClure's writing was as spurious as his diplomas.

A Kansas correspondent to the American Stock Journal in 1859 states:

The great drawback we have is, what we call the Spanish fever, among our cattle, caused by driving the Texas cattle through here. There have been about 15,000 head driven up the military road .... on to Kansas City and Fort Leavenworth, during the past spring and summer. ... This disease follows wherever these cattle go, and is seen nowhere else. It has ruined hundreds of men here. ... We can't keep as much as a milch cow on this road. . . . We have tried most every remedy, without much benefit.

An outbreak of Texas fever in Kentucky in 1866 was thought by many to be rinderpest, but, as pointed out by the Country Gentleman, there was no similarity between the two diseases. A correspondent noting that the Kentucky disease appeared only in the wake of a drove of Texas cattle, states: "It is a remarkable fact that the disease has broken out nowhere in a malignant form save where these imported cattle have been." In response to this, a Missourian writes:

Owing to the difficulty of getting Texas cattle through Missouri, some of these drovers have, undoubtedly, taken them through Kentucky, and have thus introduced there what is so well known in Southwest Missouri as the "Texas Fever," or "Spanish Fever," indifferently.

Texans, quite naturally, objected both to the disease being called "Texas" fever, and to the inference that Texas cattle were diseased. A Texan, having:

inquired of stock men and drovers ... their united testimony is, that Texas cattle, when in Texas are free from any contagious disease. The cattle of Western Texas are as healthy as any in the world. ... The truth of the matter is, that some of the cattle become diseased on their route north, beyond the limits of this State. ... Northern sheep, when driven to Texas on the overland western route, often arrive in this State diseased. Some have the scab, which is contagious - the spread of which has caused the death of many native Texas sheep. 


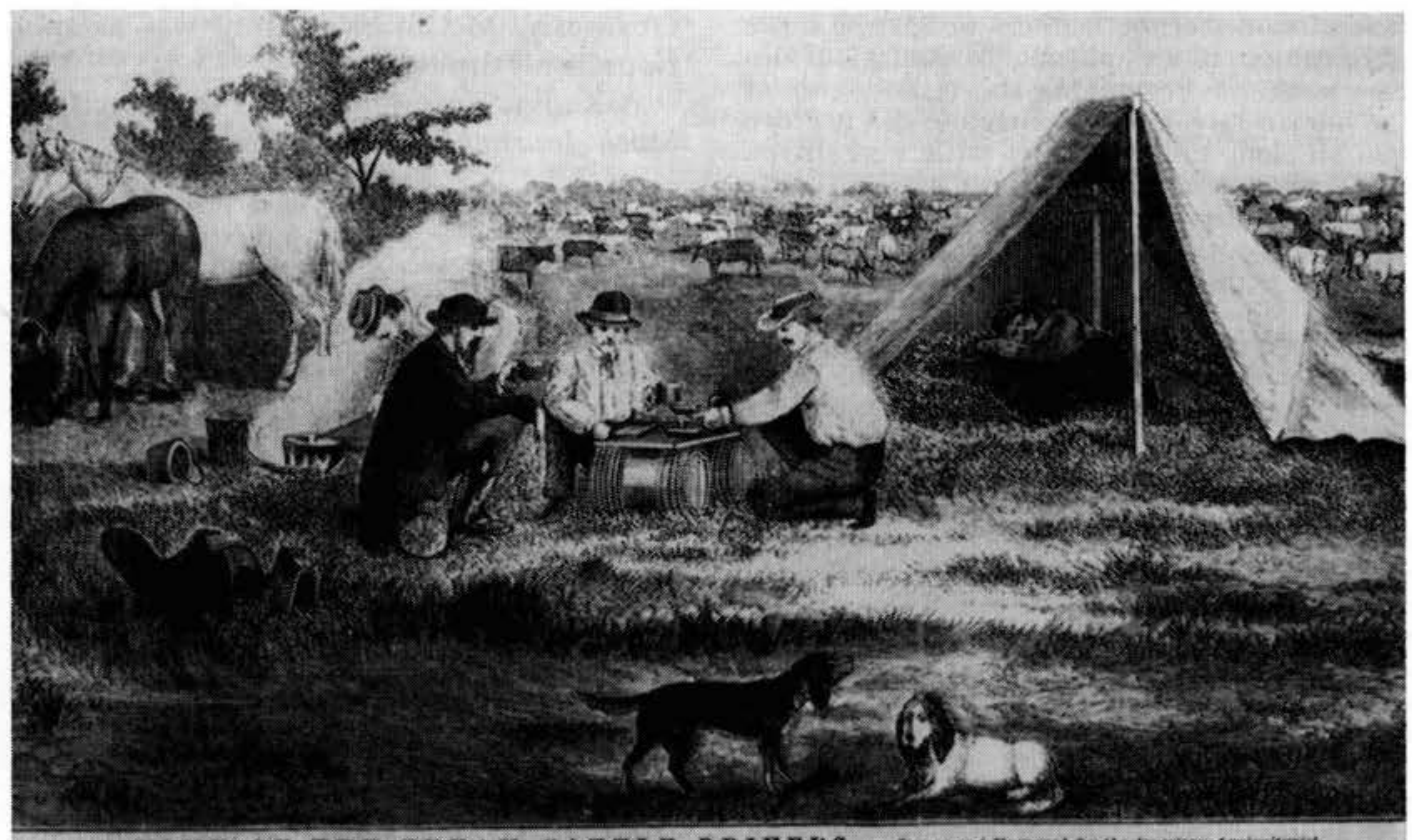

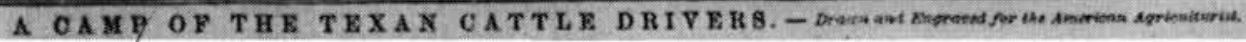

After the Civil War, vast herds of Texas cattle were driven to markets in Kansas City and as far as Chicago until an aroused citizenry - with or without legal sanction - prevented passage of these cattle which spread Texas fever in their wake. American Agriculturalist

\section{No Alternative}

\section{In 1866 a Kansan writes:}

The most exciting topic with us at present is whether Texas cattle can be allowed to be driven through our country. Thus far speculators have been unsuccessful in their attempts. A short time ago a herd was stopped at the head of Mill Creek and 40 of them killed by the citizens of Bourbon county - the remainder, about 1000 head, were driven back to the neutral land and the drovers prosecuted according to law. These cattle by passing through the country introduce a disease called Spanish Fever. This malady is fatal in nearly every instance. In 1859 and 1860 many lost their cattle by it. . . The law we have is insufficient for our protection and although the killing of the cattle mentioned was a rash act, there was no other alternative if we would do justice to ourselves and our neighbors.

This evoked a strong dissent from a man who says:

I have known many droves come to Illinois, but never knew any bad results from them in any respect. ... I have travelled all through
Texas but never saw or heard of Spanish fever. . . The truth is, very few cattle have been driven from Texas in the last eight years, for it would not pay. But we have been furnishing beef for the army and all the eastern markets until it has become scarce and high, and Kansas and Missouri set up that we shall not replenish our stock of beef and work cattle. . . Does any one believe that Texas cattle would introduce Spanish fever without having it themselves?

\section{To this "the Kansan" replies:}

We know that Texas cattle introduce this disease whether they are healthy or not; and I also know of their introducing it in Macoupin county, Illinois, in the summer of 1859. . . The people south of us are more vigilant since the disease has developed itself, and but few of the "longhorns" get this far north. They have within the last month killed one hundred head on the neutral land south of here.

$\mathrm{He}$ notes that cattle held on this "neutral land" until winter were relatively harmless. An Illinois farmer who bought some poor Texas cattle in 1866 and added them to his herd in April, states: 
By the tenth of July they were fit for good beef. About this time my original herd began to die. In two days I lost twenty-seven head and within two or three weeks I lost the whole sixty head. During all this time the Texas cattle did well and not one of them showed any symptoms of disease... . The Texas cattle were examined over and over again but no disease could be detected.

By sad experience, he also found that the pastures were infected, losing his dozen good milk cows in the process.

\section{Legislation vs. Inspection}

\section{The Prairie Farmer for 1867 notes:}

The losses in Kansas have been very large, and the legislature has prohibited the importation of Texas cattle from April to November. Our own state [Illinois] has suffered at times quite severely. . . . [ [Later ]: our stockmen who have been justly alarmed at the prospect of the wholesale introduction of the Texas or Spanish fever amongst the herds of this state, will breathe more easily when assured that a law has been enacted entitled "An act to prevent the importation of Texas cattle into the state."

In 1868 , noting widespread concern over the matter, the editors suggest:

If the States interested would appoint a competent veterinary commission to give this matter of Texas or Spanish fever a thorough examination, they would be doing the people quite as much service, as by these acts. No one seems to know anything about the disease, its cause, treatment or cure; and there are a great many who even doubt that the disease is brought by the long horned bovines of Texas.

How effective the Illinois law was might be open to question, for in June, 1868:

Immense numbers of these cattle are coming up the river from Texas, since the difficulty of driving through Missouri and Kansas, and being distributed over the State. ... If there is anything in the Texas or Spanish Cattle fevers, the State will be pretty sure to find it out in the present season.

\section{And a Kansas correspondent notes:}

There are many thousand Texas cattle on the borders of Missouri and Kansas, ready for being sent forward when opportunity offers.
By keeping quiet the owners hope to escape detention by the citizens of these states.

The first legislation against the movement of Texas cattle had been an act by the Kansas Territory in 1859 prohibiting the driving of cattle from Texas or Arkansas through the four eastern counties between June and November. As farmers moved westward in Kansas, the law was applied to any areas where native cattle required protection. This had the effect of cutting down the area where trail cattle could be held in quarantine pending lifting of the restrictions each fall. Missouri, Colorado, Nebraska, and the Dakota Territory soon passed similar laws; Wyoming and Montana did not at this early date, apparently feeling that the intervening time and space, together with the quarantine imposed by their neighbors was adequate protection.

The philosophy of these legislative acts was challenged in 1877, and the United States Supreme Court ruled them unconstitutional on the grounds that they discriminated against all Texas cattle, and thus constituted a restraint of trade, i.e., only the Federal government could regulate interstate commerce. Further, the court ruled that to be constitutional, such an act would have to be based upon an inspection of the cattle to permit the exclusion of only those animals which were cliseased or suspected of disease. As stated by Osgood in The Day of the Cattleman:

The practical result of this decision was to force the local governments to provide some sort of veterinary service if they were to protect themselves from infected cattle arriving from without.... As a result, laws were passed providing for an inspection system by veterinarians employed by the local governments in Kansas 1882-1884, Wyoming 1882 , Nebraska 1885, Colorado 1885, Montana 1885.

How effective such inspection might have been in the absence of knowledge of the relation of the tick to the disease is perhaps questionable; at least it is a measure of recognition of the necessity for some action. Thus the $W$ yoming law resulted from an outbreak in a trail herd of 
some 5,000 Texas cattle infected with Texas fever, which was losing 30 to 100 head daily on the drive, and, of course, was posing a real threat to the areas through which it was driven. The governors of both Wyoming and Montana issued quarantine proclamations against all Texas cattle until they could be inspected and declared free of the disease by veterinarians employed by the states.

\section{Mind Over Matter}

By the early 1880's contagious pleuropneumonia was also recognized as a threat to western cattle, and in 1883 a National Convention of Stock Growers assembled in Chicago to consider how best to handle the problems posed by these two diseases. This resulted in the formation of a committee to work with the Treasury Cattle Commission in formulating legislation to prevent the spread of infectious disease. Cattlemen of the Southwest, however, feared that any federal quarantine would result in the exclusion of their cattle from northern markets. As put by Osgood:

The southerners were perfectly willing to act against pleuropneumonia, but as to the Texas fever, if it existed at all, it was only in the mind of the northern stock grower.

Texans, who quite naturally denied the existence of "Texas" fever, did admit that "splenetic fever," whatever its cause, did exist in the north. Thus a Texas correspondent to the Breeder's Gazette in 1884 asks:

Why can't we that are interested in the meat production of the United States all work together to get Congress to destroy the pleuropneumonia in this country and prevent the possiblity of its being introduced, without trying to protect breeders in Wyoming from the competition of a portion of the country more favored by nature? Let each State decide for itself whether it will pay them best to handle the healthy Texas-born cattle or the more expensively raised animals that are liable to splenetic fever.

It was not only southern cattlemen who objected to a possible quarantine of south- ern cattle; Chicago brokers and packers feared such a situation would place them at the mercy of the northern cattleman, i.e., they considered it profitable to foster a healthy competition between the two sections of the country. Thus a petition to Congress from Chicago in 1883 urged against such legislation, claiming:

We know of no such disease as contagious lung plague or pleuro-pneumonia among the millions of cattle received at these yards. . . . We believe American cattle generally to be the healthiest in the world ... and there is nothing in their present condition to justify or call for the army of office-seekers to tax the Government with large sums of money.

Termed by the Breeder's Gazette as "illtimed, unwarranted and injudicious":

This whole protest bears evidence of having been written by one who knew nothing of the provisions of the bill protested against, and the signatures were evidently procured by false representations. ... We discern a hidden hand, a power behind the throne, which inspired this movement. .. The great transportation companies - the giant monopolies that, with their hands upon the throat of the people, have well-nigh taken possession of every branch of our Government. . . . The principal stockyards of the country are controlled by these monopolies ... [ [which ] think they see in this bill features which will form the entering wedge to governmental control over railways and interstate commerce.

Concerning the authority of the federal government over cattle which had not actually entered interstate commerce, the $G a$ zette further argues:

The right to "regulate" commerce certainly would carry with it the right to protect that commerce, to take whatever steps may be necessary to prevent that commerce from being destroyed. ... If the Federal Government has no power to reach into the State of New York and extirpate a disease which promises to spread infection to all the surrounding States, and to disease and destroy the value of cattle passing through that State from Illinois, then it has no right, with its strong arm, to break down a barricade which might be erected across the railroads at Buffalo.

The Gazette went further in naming names: 
For instance, a great paper like the Tribune of New York pronounces this effort to be one dictated by self-interest on the part of a few persons wanting official place, and seeks to leave the impression that there is no pleuropneumonia in the country! . . Its position can be accounted for, however, when one understands that the New York Tribune is the organ and mouthpiece of Jay Gould, and that it adopts, as its authority for denying the existence of pleuro-pneumonia in this country, the statements of the man who, a couple of years ago, wrote several elaborate articles to prove that the cattle of his State were dying off from "hollow-horn" and "tail-ail!"

The Tribune's interest in the matter is, perhaps, open to speculation; it was the World which was owned by Jay Gould, the robber-baron railroad tycoon who for some time controlled over half of the railroad mileage in the Southwest.

\section{The Tick a Suspect}

Concerning cattle ticks, a correspondent to the Country Gentleman in 1868 states:

They are believed to have nothing to do with the Spanish fever. All Southern cattle have these or a similar parasite on them, at certain seasons of the year.... These or a similar tick, are to be found on cattle in Southern Illinois.

At the same time Kansans lamented the fact that the Supreme Court had declared unconstitutional their law against driving Texas cattle through their state, as "a terrible blow... Texas cattle can be driven anywhere." A Georgian, "having been acquainted with it [ Texas fever] for nearly thirty years," states:

The disease is involved in great mystery, and there is not the least doubt but it is communicated by the cattle from Texas.... In Georgia, we have a law prohibiting the driving of any cattle, either in winter or summer, from the lower or the middle portion of this State to the upper or mountain portion, under a heavy penalty. The effect of bringing cattle from those sections of country is to give the distemper to our cattle in the months of July, August and September, while the cattle brought in always remain in a healthy condition.
A “Texas Cattle Convention" meeting in Illinois in 1868 reported:

Ticks are found on all cattle with this disease, and on at least a very large proportion of the healthy Texas cattle. Scientific men, perhaps without exception, discard the theory that the ticks cause or communicate the disease.

In 1869 a Kentuckian reported losses from Texas fever after a herd had been driven through; and was inclined to:

think that lice had much to do with the death of the cows ... the cow's udders were covered with them. ... I have never noticed in any account of the disease, any mention of lice.

In the same year a Tennessean in reporting an outbreak, notes: "Many of these animals were covered with ticks, which is believed by some to be the cause of the disease." In 1869 a correspondent to the Country Gentleman states:

Since the "Texas cattle disease" appeared in New York, early last August ... carbolic acid ... is almost the sole agent that has been employed in preventing the spread of the disease in this State.... As the active agent in the Texas disease is now well known ... the action of carbolic acid upon this parasite has been thoroughly investigated. In very weak solutions even, carbolic acid destroys this parasite, which is found in the blood and fluids of all diseased animals. . . That infection "goes in the air" may be doubted, as the parasite that conveys it can with difficulty be separated from the fluids of the animal; but as it is found in all the excrements, in the froth from the nose and mouth, in the ticks that gorge themselves with the blood ... there are a thousand ways in which it may spread.

He states that Professor R. C. Stiles of Brooklyn had discovered the parasite in the blood of affected cattle, but does not indicate how the carbolic acid was used as a preventive of the disease. This early incrimination of the tick, and discovery of the protozoan in the blood, however, went unnoticed. In 1889, Theobald Smith gave full credit to Stiles for his unheralded discovery.

In response to the suggestion that: "Texas Cattle Fever might be communicated to human beings, and become a ma- 
lignant epidemic," the Country Gentleman in 1869, urges:

if there is the least reason to believe that this cattle fever may be communicated to human beings by the use of Texas beef as food ... the public should be informed of it at once.... It would seem that those cattle which are so unsafe company for other bovines, and simply by passing through a country leave such a terribly infectious disease behind them, are not suitable for human food.

In 1872, James Harkness, a self-educated veterinary practitioner of St. Louis, Missouri, writes: "I am convinced that I have found the cause; whether I am right remains to be seen." He relates having found horses which used the same pasture as some cattle which had died of Texas fever covered with ticks:

I then examined the milch cows and calves that were driven through the yard, and found them covered in the same manner as the horses. . . My opinion is this. The Texas cattle deposited the ticks, and the native cattle got them by eating ragweeds and other plants that the Texas cattle rejected.

In 1874 it was noted that cows dying of Texas fever in Pennsylvania were infested with cattle ticks, and a Connecticut correspondent states:

The "Texas cattle disease" has appeared the present season in a number of places in Connecticut, as well as other eastern States, mostly affecting western cattle. A considerable number have died, and doubtless many more affected animals have gone directly to the slaughter. In all cases examined by me I have found this "Texan cattle tick" on every diseased herd. While we have no evidence that the tick is the cause of the disease, yet the fact that it has been found in every diseased herd, and is otherwise unknown here, shows that these cattle have had recent contact with "through Texans," i.e., with those that have been brought directly from Texas and consequently liable to communicate the disease to our northern cattle.

In 1873, however, the American Agriculturalist advised:

The tick does not convey or cause the disease; it is contact with the Texan cattle in the pastures by which it is communicated. A very simple means of prevention is to keep the western cattle completely isolated.

The editor evidently had read Gamgee's report. And in an article on "Texas Fever" in the first volume of the American Veterinary Review (1877), John Meyer, Sr., V.S., of Cincinnati, makes no mention of the tick in discussing the etiology:

Some individuals claim that this is a mystery; others assert that it is orginated by direct contagion. ... We are obliged to pay its tribute to miasmatic influences. The evidences we have persuade us to believe that the system of the Southern stock must be impregnated with the effluvial atmosphere prevailing in that climate.

\section{The Tick Indicted}

A correspondent from Pennsylvania to the National Live-Stock Journal in 1875 states:

We have the Texas fever here, and some thousands of dollars' worth of cattle died during last summer and fall. ... I remember reading somewhere... a letter from somebody ... . who thought he had observed fact to justify him in believing that our Northern cattle were killed by ticks off the Texas cattle. ... I believe he hit the truth exactly. In all the cases that $I$ saw here, the sick cattle had Texas ticks on them. Sometimes they were in great numbers and filled up with blood like dog-ticks. ... These ticks were different from any $I$ ever saw before. ... The Texas cattle all seem to have them. All of our sick cattle had them, and none were sick except those that had been exposed to other cattle that had the ticks. . . If we admit that ticks might poison the blood and start a fatal disease in cattle not used to them, and that other cattle might become hardened to their poisonous influence and not be sick from that cause, then we have a solution of this very remarkable malady. . . .

Some of the cattle that came under my observation had very few ticks on-so few that unskillful observers failed to find any after diligent search. Being a physician, I may claim some skill in such use of my senses as is cultivated by daily practice, without being invidious to others or egotistical, and mention the fact to warn investigators against deciding that no ticks exist in a case before the search has been thoroughly made. . . . Some cattle manifested much greater resistance to the poison than others, and would live until they had thousands of ticks on them - some very large - and 
would be sick for weeks before they died. Others died with only a few small ticks on them, and with only two or three days of sickness. It is reasonable to infer that many cattle might be saved by an early application of some oil that would kill the ticks.

This observing physician, Ellwood Harvey, of Chester, Pennsylvania $-h$ is $n$ a $m$ e should be preserved-obviously hit the nail on the head. Unfortunately, as is so often the case, the bona fide observations of a qualified observer remain lost in the welter of opinions of less well qualified individuals, or of persons whose only qualification is a ready willingness to express an opinion.

In a lengthy article on Texas fever in 1877, James Law summarizes most of the known information concerning the disease, but, except by inference, does not suggest the possibility of the tick being involved. In describing an outbreak in western New York he states:

A farmer bought in Buffalo a herd of steers, purporting to come from Wisconsin, and, a week after their arrival at his farm, a number sickened with Texas fever. The steers in question had clean hides, entirely destitute of ticks; and having taken ill so soon after their arrival, they furnish strong presumptive evidence of having been selected from an infected herd, cleaned of their parasites, and thrown on the market to save further loss to their owner. . . A disease like Texas fever, in which the poison remains latent and unsuspected for several weeks in the system of the already infected animal, affords the most favorable opportunity for perpetrating such unworthy tricks with impunity.

This would suggest that Law gave some credence to the tick theory, but elsewhere in the article he makes it clear that the cause is completely unknown, and states:

In the present state of our knowledge, our safety consists in preventing the introduction of Southern cattle into the Northern States, excepting during the continuance of frost ... but fat cattle may still be imported for immediate slaughter... The virus of Texas fever can be fenced in as easily as the animals themselves.

In the same issue of the Live Stock Journal, the editors in discussing several theories, state that the ticks "are perfectly harmless, unless they can convey a poison from the Southern cattle to others on their perforating appartus."

\section{Intuition vs. Investigation}

That practical stockmen anticipated the tick theory of the transmission of Texas fever is generally conceded-but frequently without documentation. If credible, the following observation places identification of the tick at about 1830 . In 1883, J. O'B. Renick, presumably of the famous cattle breeding family, recalls:

having more than half a century ago witnessed the disease in Pendleton Co., Va. (it was taken from Gulf cattle driven there in the spring season), and having seen it in numerous places since, both East and West, I will say that I never saw a case that was not accompanied by ticks. Most of the Texas cattle brought up here in May or June are covered with large ticks. These drop off and breed innumerable small ticks. In about forty days these ascend the herbage, frequently gathering in knots about the size of a pea. When cattle range over the ground and brush them off, they adhere to the legs, ascend to the belly and flanks, enter into the skin and vaccinate them. If the cattle thus inoculated live they are exempt from the disease as a small-pox patient is exempt from future attacks of that malady. None of the domestic cattle can propagate the disease, as the ticks cannot become impregnated and hatch before cold weather comes on. About the 4 th of July, I think, in 1862 or 1863 , I was in Sangamon and Champaign Counties, Ill., on the trail of Texas cattle, and I found innumerable little ticks. I warned persons not to allow their cattle to range on the trail, but was treated as you will treat this, laughed and jeered at. I had been at home but a few days when I heard, as I expected, that the disease had broken out in the most disastrous manner. The governor of Ohio appointed commissioners to investigate the disease; they went around with their thermometers, but they might as well have used their fingers; and when they reported we knew about as much as we did before. I gave one of them my theory; he said they laughed at it, and would not pay attention to it. ... Now for a preventive: Saturate the cattle, when curried, with petroleum or any other liniment that will kill the ticks.

A year before, D. E. Salmon had informed readers of the Breeder's Gazette: 
The losses are ascribed to ticks, to mushrooms, to peculiar characters of the vegetation, to acid in the soil, to something in the air, and, in fact, to anything and everything but the real cause, which there seems to be an extraordinary determination to overlook.

Salmon, however, could do no better than to attribute outbreaks in the northern and western states "to the introduction of Southern cattle." But along the borderline of the infected district "it is next to impossible to discover exactly how very many of the cases have originated."

The difficulties in appreciation of cause and effect may be seen in Dr. Salmon's repudiation of the idea that the infected area was co-extensive with the malarial district of the South; in this he was correct enough, but he adds, "Texas fever and malaria have nothing in common." Obviously the concept of an arthropod vector of disease still required some embryonating. Concerning Salmon's work on the disease, however, the Gazette observes:

Hitherto but little has been done by men properly qualified to make original investigations in this field. All have been content to follow the track of Gamgee, and to accept his conclusions as final. Dr. Salmon is the first to contest any of Gamgee's theories of the disease.

\section{Texas Fever in Texas}

Captain Richard King, who founded the King Ranch in 1853, conceived the idea of getting the large landowners to buy a strip of land a mile wide from the cattle-producing part of Texas to Kansas City as a hedge against the day when the cattle trails would be fenced. And as reported in the Cattleman:

He also recognized, as did midwestern ranchers who enforced the "Winchester Quarantine," that though the Longhorn cattle from the warm Southern states did not die from outbreaks of Texas fever, it nearly always had a fatal effect on the cattle in the cooler midwest when they came into contact with infected Texas herds.

Although it never came close to fulfillment, Captain King did initiate this visionary plan - conceived on a scale consistent with "Texas-size" thinking. From Kings- ville this would have involved a strip of land nearly equal to the size of Rhode Island, although with only about half of it outside of Texas; it would have, in effect, added less than 0.2 per cent to the total area of Texas.

King's successor, R. J. Kleberg, Sr., although trained in law, was the first large rancher to advocate a program of disease control on the range. Noting from the habits of buzzards that they might be carriers of anthrax, he arranged with the BAI to send scientists to the ranch to study the problem. Finding the buzzard was indeed a carrier, Kleberg, through a friend in the Senate, had a bill passed removing the wildlife protection on the buzzard to enable control of the vulture population. Yet another step was taken by Kleberg toward control of anthrax and other diseases. It had been the practice of ranchers to salvage the carcasses and bones of animals that died on the range. Kleberg, however, instructed his men to burn all carcasses to prevent the spread of communicable disease.

Kleberg's most notable contribution to the livestock industry centers on the Texas fever problem. Not only was he experiencing increasing difficulties in getting his cattle to midwestern markets, but bulls imported from England to improve the native breed were dying of Texas fever. Noting that the bulls always became heavily infested with ticks, he reasoned, "so many insects biting an animal was enough to make it sick." Upon communicating his observations to the Secretary of Agriculture, J. M. Rusk, in 1889, Rusk agreed to furnish BAI scientists to study the problem if Kleberg would furnish the cattle, laboratory, and expenses of the investigation.

Following discovery of the role of the tick in transmitting the causative agent, Kleberg enlisted the aid of Mark Francis of Texas A. and M. College in the task of eliminating the tick. Together they constructed the world's first cattle dipping vat, and developed through trial and error a lime-sulfur dip that would kill ticks but not harm cattle. Later, arsenical dips were 
used. This program had the unexpected effect of eliminating scabies from the herd.

It was found, however, that cattle kept free of ticks for two years lost their immunity and upon re-exposure would become re-infected and die. This led to a program of exposing all calves to ticks at an early age, keeping them free for a time, and then re-exposing them later to keep up their immunity. When J. K. Northway came to the King Ranch in 1916 as the first full-time ranch veterinarian in the country, one of his first tasks was to traw blood from tick-infested older cattle and inject it into tick-free cows to set up a mild infection which conferred immunity.

Realizing, however, that total eradication was the only ultimate solution to the problem, Kleberg was instrumental in organizing the Texas Livestock Sanitary Commission and served as its first head. Quarantine lines were drawn, dipping and inspection procedures instituted, and legislation secured and enforced, with the result that the infected area was gradually reduced until it ceased to exist. It was 39 years after Kleberg had begun working on the problem that the King Ranch was declared entirely free of ticks.

In "Some Veterinary Reminiscences," $\mathrm{N}$. S. Mayo recalls in 1924:

About 1890 the "tick theory" had been announced, but there were a good many "doubting Thomases" in Missouri and adjoining states. Dr. Francis, of Texas, suggested that we try the theory out. He was in a tick-infested region and Kansas was free, so he sent me some tick eggs in a bottle by mail. I hatched them out and placed some of the young ticks on a couple of calves without any serious results. I expressed my disbelief in ticks to Dr. Francis and he suggested that I put the young ticks on an older animal. He sent me another batch of eggs. I was so skeptical that I allowed about forty young ticks to crawl onto my own family Jersey cow. When I hauled her out and performed the last sad autopsical rites I felt that there must be something in the tick theory.

\section{Mark Francis}

The life and work of Mark Francis, adopted son of the great state of Texas, unfortunately, is not known nationally to the extent so richly deserved. Truly the father of veterinary science in Texas - a matter which itself should be of interest to more than Texans - Mark Francis was one of the real pioneers in the fight against piroplasmosis, the tick-propagated southern cattle fever. However, the prominence given to BAI work in this area has tended to obscure his contribution. But this work on behalf of the livestock industry of Texas was not only well known in Texas, but appreciated with typically Texan generosity. In 1918, when, as Dean of the School of Veterinary Medicine (established in 1916), he asked for $\$ 25,000$ for a veterinary building, the result was Francis Hall, costing about four times this figure. And in 1932 , when he requested $\$ 100,000$ for a veterinary hospital, "T. O. Walton, president of A. \& M. College, told the Board of Control that the name of Mark Francis was worth twice this amount."

Veterinarians who read only the American Veterinary Review, and later the AVMA Journal, may well have been completely ignorant of Mark Francis, until U. E. Marney in 1934 presented: "A Sketch of the Life of Mark Francis," from which the following is abstracted. As veterinary historians go back to original sources, instead of depending upon the most convenient résumés of work already at hand, undoubtedly Mark Francis will take his rightful place along with a host of other more or less neglected pioneers.

Mark Francis came to College Station, Texas in August, 1888, having completed his veterinary course as the first graduate of the Ohio State University, whose Dean was Dr. H. J. Detmers. . . At this time Texas, except in area, climate and natural resources, was very much unlike the Texas of today. ... Even though Texas had an unlimited supply of natural vegetation over her great area, where cattle would thrive throughout the entire year without additional feeding, the native animals consisted of the nondescript Longhorn, cat-hammed variety, which could not be improved or bred up because of the fever which attacked all animals that were brought into the State. Also, these bovines, such as they were, could not be taken to northern sections due to the fact that a trail of cattle deaths followed the path of 


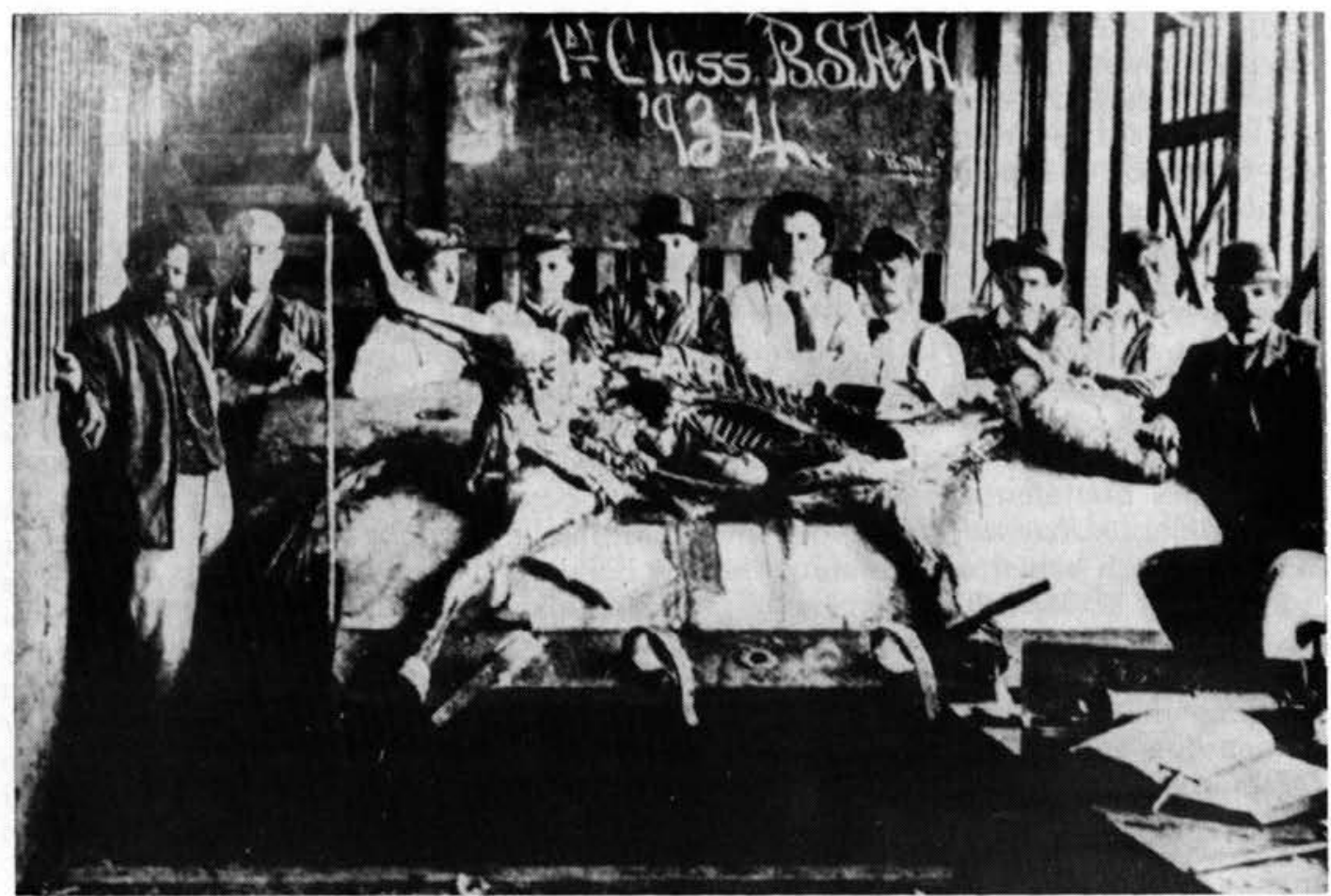

Dr. Mark Francis (right), first veterinary graduate at Ohio State University (1887) and first professor of veterinary science at Texas A. \& M. College (1888), whose work on Texas fever was largely responsible for improvement of the Texas cattle industry. Texas A.\& M. Publication

their transportation. Francis, with his keen analytical mind and ability to pick the most important feature of any proposition, readily saw in the cattle fever the thing that must be conquered and relief obtained therefrom if Texas was to prosper as she should as a live stock state. ...

Francis worked unceasingly to provide methods both for the eradication of the tick from the Texas range and the immunization of breeding cattle imported to improve the low quality of the native animals. This was a long struggle against much opposition and a great amount of experimentation under adverse conditions. ... A room of small dimensions, about 14 by 16 feet, served as office, classroom and laboratory. . . . In this unsuitable place, and with meager equipment, Francis toiled for 15 years ....

In 1897, after nine years of work, Francis drew blood from a native cow in Brazos County, Texas, and sent it to Dr. U. E. Ward, a practicing veterinarian of Wichita, Kansas, for the injection of ten head of young bulls to be used to head native herds of cows on Texas ranges. When these bulls were shipped to tickinfested territory, and all of them, except one, demonstrated a solid immunity and served their purpose well, "Eureka!" was spelled for an important phase of the undertaking in behalf of the cattle industry of Texas. From then on, large numbers of well-bred animals were similarly immunized for use in ticky territories, with resultant steady and constant improvement in the quality of the cattle of the Southland. ...

Francis... continued working on what would appear to have been an utter impossibility - the elimination of the piroplasma-carrying parasite. It is a matter of record how different agents and methods were tried in efforts to find a suitable parasiticide to kill the ticks on the animals.... Francis was prevented from using arsenical solution for this purpose; later this proved to be the preparation par excellence... used in dipping cattle in dippingvats; said vats also having been first introduced by Mark Francis in dipping cattle for tick eradication.

It is unusual for the ideas and innovations of great pioneers to be adopted during their lifetime, but we have an exception in the case of Mark Francis. He has seen the cattle industry of his state grow, from what has already been 
described, to a beef cattle valuation of $\$ 160,500,000$, and the dairy cattle to over $\$ 55,000,000 . . . \mathrm{He}$ has seen baby beef exlibited and first prizes taken in our great live stock shows by Four-H Club members from counties where the ribald population and flagrant press strenuously opposed tick eradication which made all this progress possible. . . Mark Francis will go down in history as the man who dreamed of, and did the major portion of making possible, the great cattle industry of the South.

Mark Francis was born at Shandon, Ohio, March 19, 1863. In 1887 he was the first to be graduated with a D.V.M. from the Ohio State University, following which he took graduate work at the American Veterinary College, the University of Michigan, and in Hanover, Germany. In 1929 he was awarded the LL.D. degree by the University of Miami (Ohio). On the occasion of the seventy-fifth anniversary of the Ohio State University, President W. O. Thompson stated:

If Ohio State University had trained but one man in the 75 years of its existence, and that man was Dr. Mark Francis, of Texas, it had given back to the people more than they had expended upon it in the three-quarters of a century of its existence.

After nearly a half century of service to the state of Texas and the nation, Dr. Francis died in 1936.

\section{M.D. vs. D.V.M.}

In the discussion of the joint efforts of veterinarians and physicians upon problems which are primarily of a veterinary nature, it is perhaps not unusual that medical histories should give pre-eminence to medical men. This is especially true of medical histories published some years ago. Garrison's classic History of Medicine (3rd ed. 1924), in its only reference to Texas fever, states:

Smith's demonstration of the parasite of Texas fever .... and his work (with F. L. Kilborne) ... . was a great advance in the science of protozoan disease.

Thus, while Garrison makes no mention of the veterinary aspects of the problem, he at least does include (parenthetically) the name of Kilborne. Libby (1922), however, merely states: "In 1889 Theobald Smith demonstrated that Texas fever is caused in cattle by a hematozoan parasite."

Such uncritical writing not only deprives deserving individuals of credit due them, but invests others with unsought-for recognition in the writings of other equally uncritical commentators. Thus in some instances, Smith has been given practically full credit for solving the Texas fever problem - something which he never claimed, and undoubtedly would have disowned. One of the better accounts of his work on Texas fever is given in 1936 in an address before the United States Live Stock Sanitary Association, by Irving S. Cutter, M.D., Dean of the School of Medicine, Northwestern University. Speaking on "Theobald Smith and his Contributions to Science," Dr. Cutter notes:

Texas fever was apparently giving the country more concern than any other disease and it was soon to receive the major attention of Smith and his co-worker, F. L. Kilborne. The former approached the task with his usual caution and conservatism; both pursued it relentlessly.

In a preliminary report ... in October, 1889 .. . Smith laid claim to no contribution to the pathology of the condition when he said: "I am fully aware that these facts . . . have been before the public since 1868." ... Smith accorded generous credit to Kilborne ... [ and ] notes that the investigation had been begun in 1888 by Kilborne. He gives credit also to E. C. Schroeder and S. D. Maynard. In his introduction he traces the history of the disease in the United States and cites the earlier papers of Stiles, John Gamgee, John S. Billings, and Cooper Curtice. In addition he mentions the reports of Salmon and $\mathrm{H}$. J. Detmers, Frank S. Billings, Paul Paquin, R. R. Dinwiddie and others. ... At no time did Smith assert that he had originated the segregated pasture experiments but ascribes this suggestion to Kilborne. Whether Kilborne inherited this plan from Curtice is beside the point. It would be the last and most unthinkable act of so generous a soul as Smith to take unto himself merit for the tiniest fraction of a constructive idea made by one of his co-workers. In his investigation of bovine tuberculosis he acknowledges his obligation to Cooper Curtice. 
While there is no need - nor desire - to make a sharp distinction between the contributions of physicians vs. veterinarians to any particular problem, there is some merit in stating the facts with some exactitude. That the more available accounts of the Texas fever story leave out some of the salient facts is indicated by Merillat and Campbell, who state, "In medical literature the connection of Kilborne with the investigation is seldom mentioned: in popular literature almost never." Years later, the Secretary of Agriculture credited a "Mr. Kilgore" with having had a part in the investigations.

Certainly, Dr. Smith himself never claimed credit that was due others; his major contribution was the discovery of the protozoan carried by the tick which is the immediate cause of the disease. And even in this he credits R. C. Stiles of the New York City Board of Health with having seen in 1868 "the microorganism of Texas fever, without, of course, recognizing it." Further, Dr. Smith states:

During the summer of 1889 , Dr. F. L. Kilborne .. . conceived the happy idea of testing this popular theory of the relation of ticks to the disease.

In the long run, the statement by U. G. Houck in his history of The Bureau of Animal Industry is perhaps the most valid that can be made:

Each member of the staff performed his duties well and to each belongs his share of the glory for what he contributed toward the discovery of the cause of Texas fever.

That all concerned were not of the same mind at the outset, however, is suggested by "the unwritten version of contemporary observers" as reported by Merillat and Campbell:

The Southern cattle tick had long been believed by many to be involved in the communication of Texas fever. Few scientific men gave any credence to this. Gamgee had said it was ridiculous; so thought Detmers; so thought Billings. Salmon was inclined to believe "There was something in it." Kilborne, perhaps alone among the scientific men, was wholly commit- ted to the theory and preached it on every occasion. Smith, in keeping with scientific beliefs of the time, regarded it as did Gamgee. Salmon had enough faith in the tick theory to arrange to give Kilborne a chance to prove it. He was skeptical enough about the theory to send Smith along with Kilborne to check on his work, to prevent the latter's preconceived belief from prejudicing his investigation. It is an indication of the broadness and open-mindedness of Theobald Smith that, against his preconceived notions, he was soon convinced by Kilborne, and became the most enthusiastic promoter of the new theory. It was due, however, to Kilborne's insistence in the tick theory that the investigation was made.

\section{The Logical Thing To Do}

It is perhaps natural today to wonder why it should have taken so long for the tick theory to have been tested adequately. The fact appears to be that those most capable of investigating the complexities of this relationship were least likely to consider it plausible. Moreover, it might be pointed out that Texas fever was indigenous to the United States and had only recently become a real problem. The mystery of malaria, which had been of world-wide occurrence since the time of the Romans or before, was not solved until after veterinarians of the BAI proved conclusively the role of arthropods as vectors of disease. It remained for Fred L. Kilborne, the veterinarian who conceived and conducted the first experiments involving the tick theory, to prove the beliefs numbers of stockmen had held for some time. Some forty-five years afterward, Dr. Kilborne recalled:

In view of the fact that western stockmen called the disease "tick fever" and firmly believed the tick was instrumental in spreading it, it is a mystery to me why some of the eastern investigators did not think to plan some tick experiments. To me this seemed the logical thing to do at the outset, to confirm or disprove the tick theory.

Kilborne's proof of the role of the tick in transmitting Texas fever, and Smith's in demonstrating the actual causative agent, were perhaps the most fundamental findings which led to an understanding of 
the nature of the disease. It remained, however, to work out the means for an intelligent attack upon the disease in cattle, a matter in which many veterinarians made substantial contributions. Cooper Curtice had concurrently (1889) worked out the life cycle of the tick and demonstrated that pastures could be freed of ticks by keeping all cattle off them for one year: he is considered to be the "father of tick eradication."

While experiments with carbolic acid dips were begun in 1895 , this agent was frequently more destructive to the cattle than to the ticks, and it was not until Mark Francis of Texas suggested the use of an oil dip in 1897 that the possibility of tick eradication seemed feasible. With the introduction of an arsenical dip in 1906 by Nelson S. Mayo and others, area eradication became a reality, with 127 of the 927 counties under quarantine in 1906 being released by 1911 . With an improved dip the tick-free area was increased to 695 counties by 1923, and in 1938 only 15 counties in two states (Texas and Florida) remained under quarantine.

As in the case of eradication efforts with other diseases before and since, there was much opposition to the program in many areas; at least one BAI inspector was shot and killed in the line of duty; others were shot at, and some were hit. But the work went on, and as early as 1922 the Chicago Daily Drovers' Journal noted:

Tick eradication has already been worth untold millions of dollars to the Southern States, by making possible the development of beef and dairy cattle industries. . . . The work has cost nearly $\$ 23,000,000 \ldots$ probably one of the best investments the people of this country ever made.

But what impresses us most about the tickeradication work is the faith of the men who undertook it, and of their successors who have carried it on.... The veterinary profession of this country is to be credited with many notable achievements, among which the eradication of ticks will take its proper place. Our livestock industry has had good service at the hands of our veterinary friends.

In speaking on "The Veterinary Profession: Its Recognition and Personnel," Ray- mond A. Pearson, president of the University of Maryland, observed in 1927:

Research in the veterinary field made the Panama Canal possible. Very few people know this. It is one of the most thrilling stories in the history of science. Under the direction of Dr. D. E. Salmon, who was chief of the U.S. Bureau of Animal Industry, Smith and Kilborne solved the secret of Texas cattle fever and then - and not until then - it was possible to dig the canal. A monument to these men should be erected by the side of the Panama Canal to tell the world in all the years to come, how the ships of the great oceans were redirected because of veterinary research.

\section{Cooper Curtice}

No account of Texas fever would be complete without a fuller consideration of the work of Cooper Curtice than is usually found. Perhaps no other man in the history of American veterinary medicine has done so much for his profession and his country and received so little credit for it as Cooper Curtice. In 1938 Maurice C. Hall eulogized his long-time friend, and took the occasion to recognize:

the vaunted civilization, progressiveness and culture of . . . this great country [ which ] bestows its decorations and awards only on military men for this or that larger or smaller contribution to the obscene business of war and the destruction of life and property.

By a quirk of fate, Dr. Hall's tribute to Cooper Curtice was published in the same issue of North American Veterinarian that also carried the news of Hall's own untimely death. Curtice died a year later, August 8, 1939, at the age of 83. The following account is, for the most part, in Hall's own words:

Cooper Curtice was born in Stamford, Connecticut, on May 7, 1856. He tells me that he was forced through school by his father. Apparently, the paternal impetus was a strong one, since he continued his studies until he received his B.S. degree from Cornell in 1881, his D.V.S. from Columbian Veterinary College in 1883 , and his M.D. from the National Medical College in 1888.

In 1886, Curtice became an agent in the Federal Bureau of Animal Industry, and began the work in which he was destined, not to become 


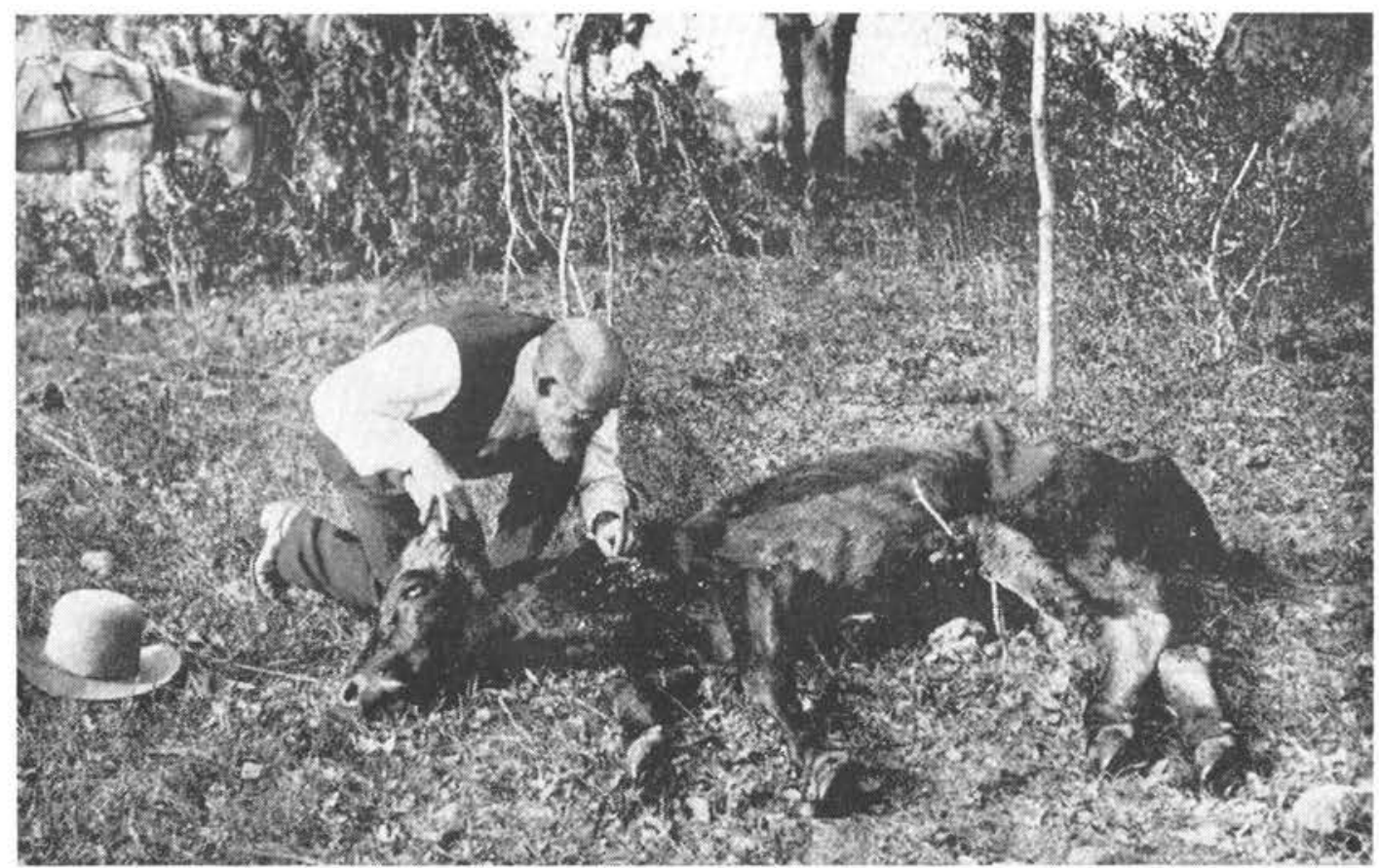

Dr. Cooper Curtice, who in 1891 worked out the life cycle of the tick which transmitted the organism of Texas fever, examining a tick-infested cow dead of the disease. Nation's Business

famous, since he has never sought fame, but to do the unusual and exceptionally valuable work that would have brought fame to a less modest person. During this period he published his classical work on sheep parasites, worked out the life history of the cattle tick, and urged a study of the tick as a carrier of Southern cattle fever. At the time he was rooming with Theobald Smith, and the two men were very good friends. Curtice was a free-lance worker, reporting to the Chief of Bureau, Dr. Daniel E. Salmon. One day the bureau got around to some reorganization procedures, and Dr. Curtice was told to report to Dr. Smith as his chief. He promptly resigned from the bureau, alleging that, although he had a high regard for Dr. Smith as a friend, he did not want him for a chief.

The result of this resignation was the beginning of tuberculosis eradication in New York. Dr. Thomas Newbold, a state senator, had secured the passage of a bill enabling the board of health to investigate tuberculosis. His secretary wrote to Dr. Theobald Smith asking him to name someone who could do this sort of work, and Dr. Smith recommended Dr. Curtice. Soon afterward, he was called to see a herd, and found some clinical cases of tuberculosis. The owner asked him if he would give a certificate of freedom from tuberculosis for the herd if the diseased animals were killed. Dr. Curtice told him that he could tell more about the herd if he gave it the tuberculin test, and the owner agreed to this. More reactors were found on the test. Because of the lack of supervision of the herd, no certificate was issued, but in this way legal tuberculin testing of cattle began in New York State.

Following this, Dr. Curtice was reappointed in the Bureau of Animal Industry, and went on with the work of tuberculin testing and slaughter of reactors. The Secretary of Agriculture, Mr. Morton, then decided to save some money, and Dr. Salmon notified Dr. Curtice that there would be no more work done on tuberculosis. Dr. Curtice returned to field work in New York State, and in 1894 he returned to the Bureau of Animal Industry.

In 1896 he read an epochal paper before the Virginia State Veterinary Medical Association in which he outlined a program of tick eradication, and urged that tick eradication be undertaken. This paper established the right of Dr. Curtice to the title of "The Father of Tick Eradication." He then became Veterinarian at the State College of North Carolina. $\mathrm{He}$ informed the trustees of the college that there would be little to be gained by stirring up the tuberculosis question in North Carolina, but that something could be done with tick eradi- 
cation. That winter he managed to get some regulations governing traffic, and in 1899 , as State Veterinarian of North Carolina, he began the work of tick eradication, clinching his position as "The Father of Tick Eradication."

In 1900 Dr. Curtice went to the Rhode Island Experiment Station. From 1900 to 1906 he conducted studies on blackhead that led him to the very important conclusion that chickens were the hosts of the blackhead organism, that they carried blackhead to turkeys, and that turkeys should be raised away from chickens. Now an established principle, it was Cooper Curtice who first established this segregation principle as a measure of value for the control of poultry disease.

After Dr. Curtice left North Carolina, Dr. Tait Butler took up the work of tick eradication in that State, and by the time the U.S. Department of Agriculture was ready to begin the tick eradication in 1906 , he had cleaned up 16 counties. That same year Dr. Curtice returned to the Bureau of Animal Industry and was out in charge of tick eradication in Virginia and North Carolina. A year later, over 40,000 square miles of territory in the original quarantine area of the South had been released from quarantine, and the war was on!

After so many years of effort and so many important contributions to our knowledge, we now find Dr. Curtice, almost 82 years old, living in his little home in McNeill, Mississippi, on the modest - and the word modest is sheer euphony in his case-retirement pay of the civil service employee of the United States government. It is, perhaps, fitting that in a world in which reward bears no visible relation to merit, Cooper Curtice should live in relative obscurity and with meager rewards, while men of no visible importance should strut in great self-sufficiency, affluent and bedecked with honors.

The special distinction of Cooper Curtice is that this man, who looks like one of the patriarchs, actually is one of the major prophets of this and the preceding century. Standing alone in the past century, he preached the gospel of eradication of southern cattle fever and fever ticks, and of bovine tuberculosis. Unsupported in his opinion by his profession and the live stock industry, he taught that these evils could be done away with. As the voice of one crying in the wilderness, he called upon the stockmen and the veterinarians to purge our land from the sin of live stock diseases. Other men have carried on the work of Curtice until today the "lost batallions" of the ticks fight their last-ditch battles in the swamps of Florida and the chaparral of Texas, but if you follow the trail of our fighting men back to its beginning you will find there the solitary footsteps of the prophet of tick eradi- cation, the Moses who stood alone on the mountain top a half century ago and saw this tick-free South which we duller men see now in fact as he saw it in prophetic vision.

\section{Climate and Disease}

Somewhat as a sidelight, but with obvious relationships to a disease like Texas fever, in 1894, W. L. Williams - a man of many facets - presented an extensive study of "The Influence of Climate and Other Environments on the Distribution and Character of Disease." In this, perhaps the first major contribution to the geography of animal disease, he states:

The influence of climate, housing, food, care, and other surroundings, induce marked changes upon the distribution and character of disease, whether among animals or mankind; and the student of pathology needs to weigh these forces carefully; that he may avoid error by arriving at conclusions based upon observations confined to a limited area....

The study of the various influences controlling the distribution and character of diseases belongs largely to the domain of philosophical medicine, and offers for consideration many highly interesting and instructive problems, but it is no less a part of practical medicine giving new insight into many of those peculiar epizootics, as well as to a large number of extraordinary cases of common affections, which at times so baffle and worry the practitioner. The extraordinary case in one locality, under one class of conditions, frequently constitutes the ordinary disease under wholly different surroundings.

The study enlightens us as to the etiology of many diseases since we not infrequently find the prevalence of a disease in a certain locality attributed to certain we11 marked local environment; when in fact, the same disease and of like character exists in regions where the supposed essential etiological factor of the former locality is wholly absent. So it is that we find our writers attributing a disease at times to some local cause, when a more general knowledge of the distribution of the disease would show them that it existed under conditions requiring some other explanation for its prevalence than that given.

\section{HOG CHOLERA}

Hog cholera, first identified in Ohio in 1833, had become a much-dreaded disease by the early 1850 's, when some ninety separate areas of infection were known to 


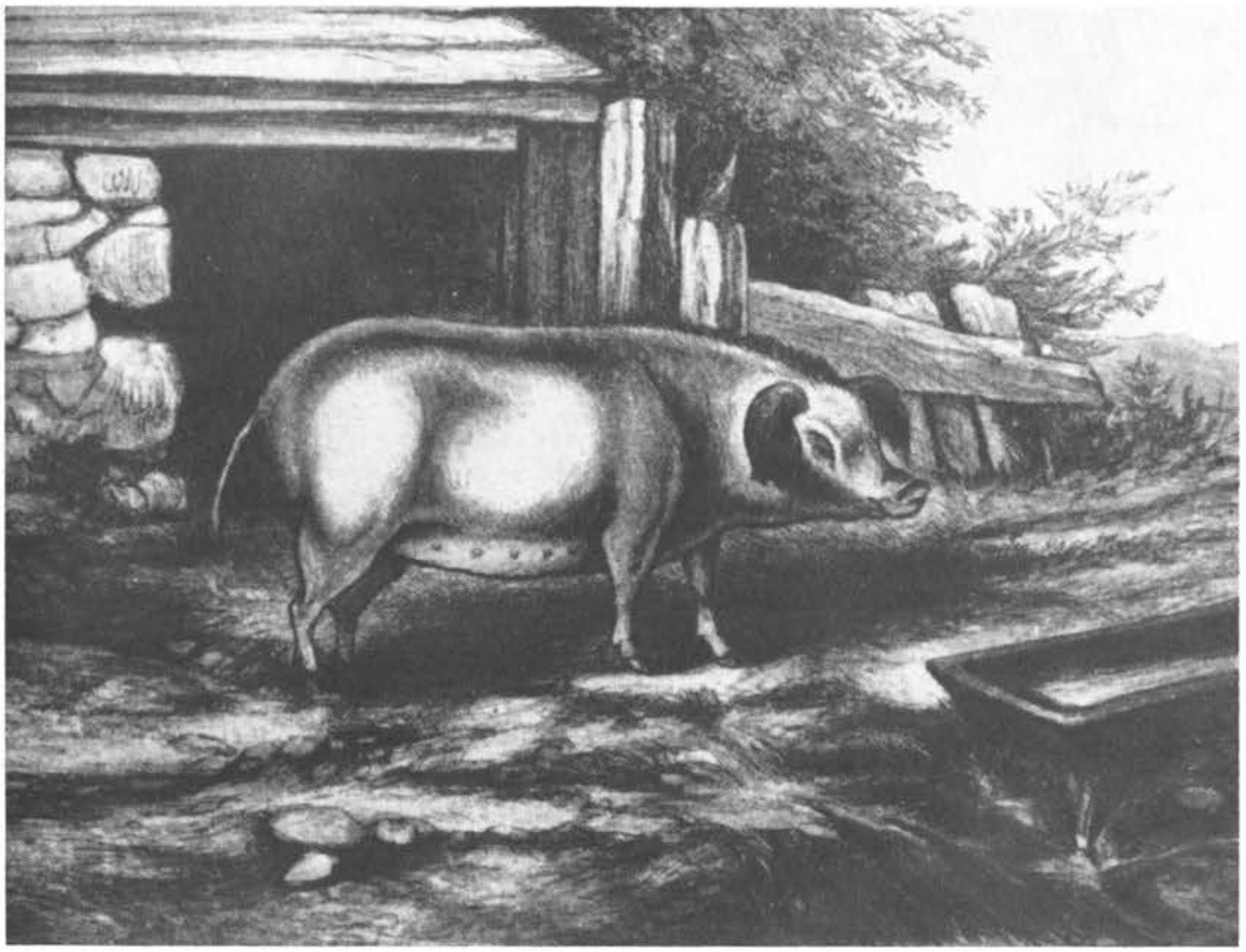

Black and white reproduction of early color plate purporting to show symptoms of hog cholera - a dejected attitude and skin discoloration. Clater-Armatage: Cattle Doctor

exist. By the 1860 's the mortality in infected areas ranged from 15 per cent to 60 per cent or more, and in some sections the swine industry had been all but destroyed. During the 1870's losses from hog cholera accounted for 90 per cent of swine mortality and amounted to some $\$ 20,000,000$ or more annually.

The disease, of course, was badly misnamed, perhaps from familiarity of those who first saw it with a disease of pigs denoted in early British works as "the choler," as an outgrowth of the humoral theory of disease. Descriptions of "choler" in seventeenth-century British works clearly indicate that the two diseases are identical. Thus it seems reasonable to postulate that hog cholera may have been imported unnoticed during the early nineteenth century when American livestock men showed keen interest in improvement of the nondescript American hog. In reporting an outbreak around Cincinnati in 1857, the American Veterinary Journal notes:

The disease is considered incurable, having baffled the most critical investigation into its nature, and has steadily resisted all remedial agents. The malady has been vaguely denominated "cholera," from the failure to discover its true character, and upon that principle which a few years ago prompted mankind to apply the same term to all ills which resemble cholera in the human body and which they did not comprehend.

\section{Stetson on Sty Fever}

The agricultural journals of the day are replete with information, misinformation and speculation on hog cholera, which is not surprising in light of the difficulties experienced by qualified scientists later in 
distinguishing hog cholera from swine plague. One of the more plausible accounts of the disease was written by Ezra Stetson, M.D., who in 1877 contributed a series of articles on "Sty Fever" to the $\mathrm{Na}$ tional Live-Stock Journal. Noting that the swine industry seemed to be making advances despite the ravages of hog cholera, he suggests:

Were it not for disease, there is no good and sufficient reason why Mr. Pig, with his rapid power of multiplication, should not so increase in numbers that they would become a curse rather than a blessing to the whole country.

After describing the first occurrence of the disease in his own pigs some years earlier, Stetson says:

It never entered into my mind at that time that the disease could originate, except the very first time, from spontaneous generation. .... In the good old times, when physicians were unable to account for the origin and spreading of disease, they had a convenient way of getting out of all these difficulties by saying it arose from an atmospheric condition, of which they were entirely ignorant, and Divine Providence was given the credit. The sun, moon and planets came in for their share of the blame; and even in our day and generation, we are not entirely devoid of the superstition once so very common among our ancestors. ... Physicians have long been in the habit of using the word epidemic when they could not satisfactorily account for the origin and spread of the disease, just as though anything could come into being without sufficient cause. . . Each and every specific contagious disease is only produced and propagated by its own specific poison. ... Sty fever is a specific and contagious disease, peculiar to swine. . . That it is a new disease, and only originated a few years ago, I am not ready to admit. It is as old as the cause, and has been guessed at under very many different names, and in America has got the title of hog cholera.

In discussing various possibilities for the origin of hog cholera, Stetson says:

The origin of most contagious diseases has been lost in the mists of antiquity; and, as theories play a very great part in arriving at truth, I shall be compelled to investigate the theory of the origin of this particular disease.

He considers at length: parasites (including bacteria), vitiated atmosphere, and spontaneous generation, admitting that each has some merit. Of some interest is his statement:

As veterinary science is yet in its swaddling clothes, we must look to physicians for testimony, from the fact that they have very much better means of investigation.

Also of interest is his description of what would seem to be atrophic rhinitis in his pigs:

A catarrhal fever ... attacked about all the suckling pigs on my place ... some of them snuffled until the muscles of the face pressed so hard on the bony structure that Mr. Pig's nose got crooked - worse than a pug nose. We have some of this sort on the place now, as witnesses. . . I I have read inquiries about this same thing in various agricultural journals, but no answers.

On the etiology of hog cholera, he states:

So far as my observation extends, this disease has only broken out de novo where there were large numbers of swine ... and this satisfactorily accounts for the immunity from this disease in all countries and localities where but small numbers of swine are reared and fattened. ... It is only when the herd or herds reach into the hundreds, that the disease assumes its most malignant form, and carries death and destruction in its path like a whirlwind.

However, he does not preclude infection of small herds by direct contagion. On diagnosis:

No doubt the thermometer in the early stages would show increased temperature... [However] as the hog is too repulsive an animal to experiment upon, I very much doubt the general use of the thermometer in forming a diagnosis of this disease. [!]

\section{The disease, says Stetson:}

was born in greed, [and] has been propagated in greed.... All the world is striving for something for nothing, and the granger wants to put his corn where it will do the most good.... The rule is, any place is good enough for a hog. The result is, not much more than one-half of last spring's pigs are alive at this writing. . . Prevention is in the power of every owner of swine . . . if proper quarters are given them-always excepting contagion being carried to them. The less hogs in any one 


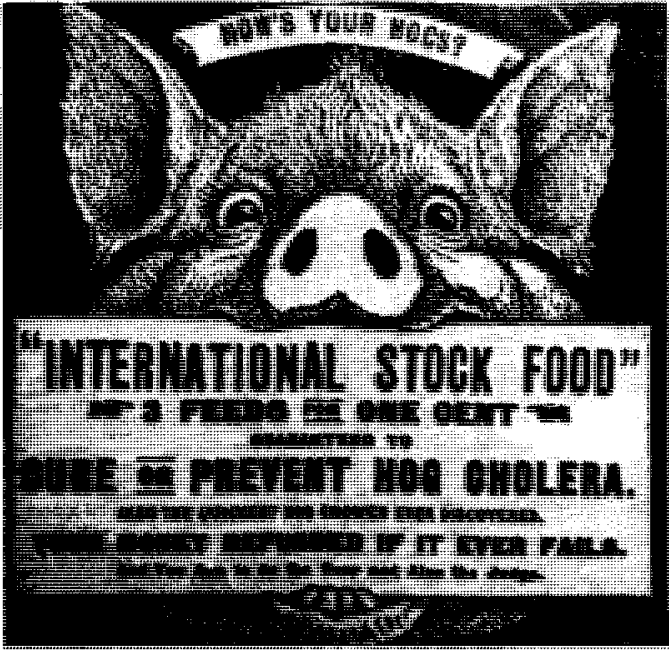

Until the serum and virus method of vaccination for hog cholera was announced in 1908, many worthless preventives and cures were advertised and sold widely - apparently on a caveat emptor basis; none of their failures appear to have been challenged in court.

place, the safest. ... Medicine, as such, should never be given them. This everlasting taking of medicine to keep well is one of the most dangerous of things to men and animals. ... Disinfectants should always be used, to insure safety.

The National Live-Stock Journal at this time carried conspicuous advertisements for Clark's IXL Food for Hogs: "a sure preventive of Cholera." Earlier, the Journal had disavowed any connection with a presumed quack, Dr. E. G. Perry:

who is travelling through this portion of the country selling receipts for the cure of diseases in animals, but more particularly hog cholera ... and who claims to have been engaged in the business of treating diseases of stock for the past thirty-five years.

A suggestion concerning the early history of hog cholera in the United States is found in the Prairie Farmer for 1863. A correspondent from Illinois states:

My observations and experience leads me to believe it to be what was known, forty years ago, as the murrain. Twenty-five years ago I had hogs affected with a disease, the symptoms and appearance of which was the same as it is now seen in this section of the country.
The best evidence for pinpointing 1833 as the date of its first appearance is the statement of Andrew Campbell, M.D., of Ohio in the American Agriculturalist for 1842. In describing the condition at that time, he says the affected animals:

resemble precisely the cases of cholera that I had often witnessed here in 1833 and 4 . They lose the use of their limbs, become as cold as a mass of ice, the tongue and mouth turn purple, and they die in from six to ten hours.

\section{Hog Cholera vs. Swine Plague}

In 1878 the USDA commissioned several veterinarians to make studies of hog cholera; these included H. J. Detmers, James Law, and D. E. Salmon. Detmers used the name swine plague and considered Bacillus suis as the causative agent - which later turned out to be an explanation for part of the story, but at the time did little to clear up the confusion created by the two disease entities concerned. James Law used the term hog fever and incriminated a bacterium, but his lengthy reports must be considered of greater historic interest than of scientific value.

It was not until additional refinements had been made in bacteriological technics that D. E. Salmon was able, in 1887, to announce the existence of:

two diseases of hogs in this country which have heretofore been confounded as one plague. ... These two diseases are sometimes found to exist at the same time in the same herd of swine.

Salmon, however, thought both were bacterial diseases - not surprising in view of the newness of the concept of viral disease and the abundance of secondary invaders in cases of hog cholera.

This initiated the famous controversy between Dr. Salmon and F. S. Billings, the latter claiming for himself the honor of having found the "true" cause of hog cholera to be a single agent causing but one disease, although he did admit the possibility of a second disease - but with poor grace: "In time this question will be 
settled, and the world will know who is right, honest, and consistent between Dr. Salmon and myself." Which, of course, did occur - with the total discrediting of Billings, but not before he had succeeded in casting doubts upon the validity of the work of the Bureau. Much of Salmon's time, unfortunately, was occupied for six years or more in rebuttal of Billings. Bierer states concerning Billings:

His love of investigation . . was surpassed by his greater love of controversy. He poured forth, in an endless flow, a violent barrage of words denouncing any scientist whose researches did not agree with his own. . . Billings was certainly the big, bad man of America's research scientists around 1890. Scientists were afraid to report their findings for fear of what Billings might have to say. . . His failing seemed to be that he visualized his experiments as he wanted them to be, and then set out to prove to the world, by persuasive speech, the accuracy of his vision. . . . When Billings stirred up Salmon, however, he found that he had met his match. Salmon, it soon became evident, was able to defend himself in a verbal encounter.

\section{Billings vs. Salmon}

For a number of years, the agricultural press and the USVMA meetings served as forums for the Billings-Salmon debate. While it may be said that Billings did serve one purpose - that of insuring exactitude of the work conducted by the BAI scientists - it is regrettable that he was not recognized sooner for what he was. For several years, popular opinion, including that of the American Veterinary Review (Liautard), and with it that of many reputable veterinarians, favored Billings. Salmon, in fact, frequently had to defend the work of the Bureau - which should have been supported by the veterinary profession - against doubts and outright attacks by members of the profession. Time, of course, has proved that the Bureau was on the right track.

In a brilliant rebuttal to an attack by Austin Peters, a protagonist of Billings, at the 1892 meeting of the USVMA, Salmon asks:
Does this Association take no pride in the investigations of the Bureau of Animal Industry, or does it propose to stigmatize them as a disgrace to the veterinary profession? Is it willing to brand them as discreditable and the men connected with them as ignorant, incompetent and dishonest on the evidence which has been submitted? Do you forget that Billings villified about every scientist whose reputation might serve him as a stepping stone if he could once get it under his feet?... Why should this Association go out of its way to assist such a man in obstructing the progress of science and in villifying its own members?

The viral nature of hog cholera, in distinction to swine plague, was elicited by E. A. De Schweinitz, a chemist, and Marion Dorset, M.D., of the BAI, who met with moderate success in immunizing hogs against cholera about 1900 , and a virus as the cause of hog cholera was announced shortly before De Schweinitz's death in 1904. Dorset, along with the veterinarians, C. N. McBride and W. B. Niles, perfected a hog cholera serum in field experiments in Iowa in 1908, laying the basis for the common serum-virus method of immunization.

\section{A.V.R. vs. V.M.}

As was the case with many of the "bread and butter" problems of the practitioner, it was through the pages of Veterinary $\mathrm{Medi}$ cine that veterinarians got much of their working information on hog cholera. In 1914, for example, the American Veterinary Review published only six articles on hog cholera; one by D. E. Salmon on the production and use of serum and virus is a good account of what could be expected in practice although it deals largely with laboratory findings. Another is a highly detailed report of laboratory findings on virus. One is an account of the controlby-slaughter method in Canada, a matter then (control by slaughter has now been announced) of purely academic interest to veterinarians in the United States. Another deals with a proposed control program in one state. Papers such as these, of course, have their place. The remaining two can 
be largely discounted; one is a series of anecdotes concerning the reluctance of farmers to pay for prophylactic treatment, the other a condemnation of the simultaneous vaccination and a plug for an intestinal antiseptic - used by the medical profession to disinfect chambers used by typhoid patients.

By comparison, Veterinary Medicine carried twenty-six papers on hog cholera in 1914, including such topics as the basis for serum treatment, care after vaccination, warnings against "cures," environmental complications, preventive measures other than vaccination, time to vaccinate, and "should farmers do the vaccinating?" In addition, several papers deal with the nature and extent of official regulatory programs. Related to the whole problem is a learned discussion of "Contagion by Immunization," by James Law, who, in addition to the hazard of the use of virus as a continuing source of infection, notes the practical problems created by the confusion of terminology. Law argues that vaccination properly means only inoculation with the virus of vaccinia, or variola of the cow (vacca), as employed by Jenner for smallpox:

Its all but universal employment in medical literature at the present time, is the greater reason why we should instantly discard the word as used in this bastard sense and frown upon a misuse so pregnant of loose thought and misleading meaning. If the first violator of linguistic laws and rights in this matter had aimed at introducing a perfect bedlam of confusion in the matter of preventive treatment, he could not have played his game more cunningly.

\section{Senseless Centennial}

In editorializing on "One Hundred Years of Hog Cholera," the AVMA Journal notes:

With the advent of the year 1933, we begin to realize that hog cholera has been with us for a century. Unlike many of the centennials that have been celebrated during recent years, there is no rejoicing in the admission that the swine industry of this country has tolerated the exist- ence of hog cholera for one hundred years. ... Hog cholera probably will continue to menace the swine industry just as long as certain states permit the promiscuous use of anti-hog cholera serum and virus. . . For at least fifteen years the veterinary profession has been in a position to put hog cholera into the category of rare diseases, but has not been given an opportunity to do so. If the use of virus continues to be "wide open," there is no reason to believe that hog cholera will not be just as prevalent in the year 2033 , as it has been in recent years.

As a sidelight, it is of interest to note that the widespread use of hog cholera serum is credited with stimulating the development of a smoothly operating, large capacity veterinary hypodermic syringe. Concerning the development of the serum syringe, Fritz Volkmar credits this to H. J. Detmers, who after severing his connection with Ohio State University, engaged in private practice and continued his researches into hog cholera:

Antedating and anticipating the work of Dorset, Niles and McBryde, Detmers successfully employed anti-hog cholera serum which he manufactured on a fairly large scale for protective vaccination. In 1900, he devised an improvement in the construction of a hypodermic syringe that permitted the instrument to be sterilized without damage to the plunger. . . This syringe, with slight alteration, is still in use today [1933].

In discussing "A Century of Hog Cholera," A. T. Kinsley estimates the cost of hog cholera in 1933 to be about $\$ 20,000,000$ in losses and up to another $\$ 10,000,000$ for vaccination, or about 50 cents per pig in the United States, a cost which had not changed appreciably in the past 15 or 20 years. In 1932 commercial establishments produced over a billion cubic centimeters of serum and 50 million of virus, which required some 300,000 pigs to manufacture. Although 5 times as many swine were vaccinated in 1932 as in 1915:

yet the annual cholera loss, excepting for 1926 , remained practically the same, although it is conceded that there is no other biologic that is as efficient as anti-hog cholera serum. The fact 
that cholera and vaccination have cost the swine industry of the United States over a half billion dollars, in the last eighteen years, should be proof sufficient that there is something basically wrong with the present system. This persistent and continuous cholera loss indicates that at least most of the states in the principal hog-raising section of the United States have either insufficient regulations or laws for the efficient control of cholera or the officials are not enforcing them.

As principal agents in perpetuating the disease, Kinsley indicts lay vaccination and garbage feeding. In commenting on the 1926 outbreak, he states:

Waves or extensive outbreaks of cholera, as in 1926, are prone to occur every ten or fifteen years. . . Sanitary authorities should not be surprised if, under present conditions, one of the most extensive and destructive outbreaks of cholera should occur, regardless of vaccination, unless prompt action is taken to regulate hog traffic effectively, quarantine diseased herds, restrict the distribution and use of virus, and reduce to a minimum the evils of rendering plants and country slaughtering.

This, of course, is not the whole story. Unquestionably, the work of the BAI, which paved the way for large-scale production of serum and virus, was the means of saving the swine industry from virtual extinction. Veterinarians yet in practice can recall the rather abrupt end to the porcine funeral pyres on countless farms throughout the Midwest. It might be argued, however, that the success of this program-despite occasional failures was such that it delayed a more rational approach to the problem of total or near eradication of the disease. Experience has dictated that so long as live virus is used - particularly by unqualified individuals, as has so often been the case - hog cholera will continue to be a problem of some proportions. Gradually, the use of live virus is being outlawed, but those states which continue to permit its use remain a reservoir of the disease. The same has been true of raw garbage feeding which only recently has been outlawed completely - long after Canada had taken both steps.
Another problem has been the complacency over success of the program in the past; in some areas today only a small proportion of pigs are immunized, and thus we are faced with the threat to a large susceptible population with the seeds of the disease still present.

\section{FOOT-AND-MOUTH DISEASE}

For nearly a century, foot-and-mouth disease has been perhaps the most feared epizootic in the United States. As reported by Drs. Melvin and Mohler, the outbreak of 1914 was precipitated:

like a bomb from an aeroplane ... upon the live stock industry of the United States with almost an explosion-like effect. ... The first three outbreaks, in 1870 in western Massachusetts and eastern New York, about 1880 in several lots of imported animals, and in 1884 in the vicinity of the quarantine station at Portland, Maine, were comparatively insignificant; those in 1902 and 1908 were more grave; while the present infection is by far the most serious and extensive of all.

The type of the disease in 1870 appears to have been quite mild, which, together with the restricted movement of both livestock and persons which obtained at that time, accounts for its failure to become more disseminated. The other outbreaks in the 80 's were likewise mild, and restricted to only a few herds, so that the dissemination of the virus was quite easily controlled.

With the establishment and maintenance of adequate quarantine regulations, these were the last outbreaks resulting from imported animals. As a sidelight on the activities of the Quarantine Division of the BAI, it might be noted that a firm policy was adhered to despite unthinking public pressures and, occasionally, political expediency. In editorializing on the disturbance caused by enforcing the quarantine regulations on General Pershing's famed mount, Kedron, Dr. Mohler notes that 6 of the 116 horses returned with their more famous brother, and unlike him, did not "pass" quarantine: one had ulcerative lymphangitis and another had trypansomiasis and were killed; one developed sarcoptic mange, and two others 


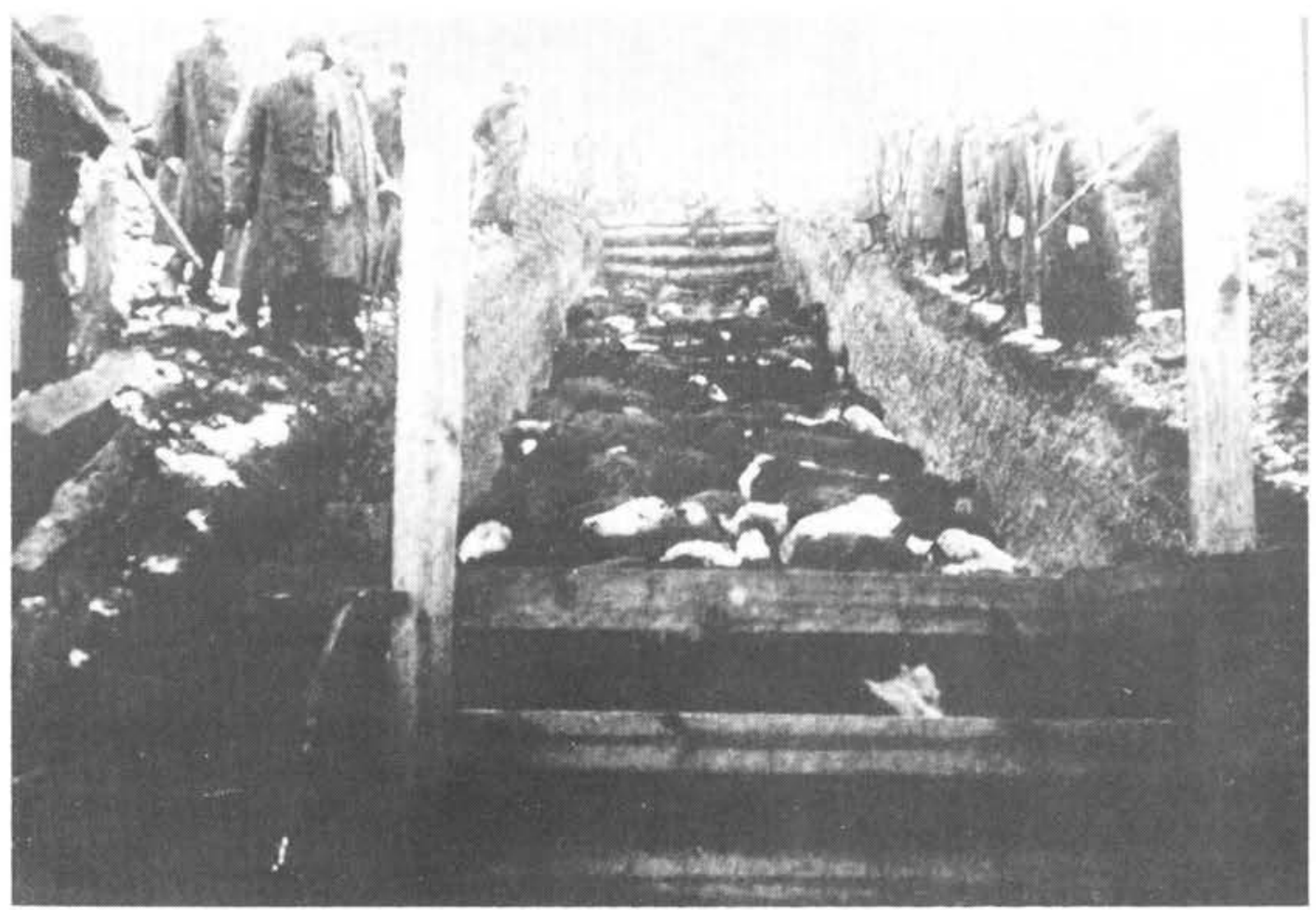

In a few instances during the ruthless eradication-by-slaughter program for the 1924 outbreak of foot-and-mouth disease, BAI inspectors needed firearms for their own protection as well as for carrying out their work. Veterinary Medicine

showed skin lesions; one died from noninfectious causes during the six-month quarantine:

The purpose of care and supervision, of course, is to protect the live-stock industry in the United States from contagion that exists abroad. It will be recalled that notwithstanding vigorous opposition, the quarantine regulations prevented General Pershing's horse from appearing in the various Victory parades. It will also be remembered that following the SpanishAmerican War General Leonard Wood was unable to bring his "charger" from the Phillipines.

The outbreak of 1902 in the New England states, and that of 1908 in the Middle Atlantic states, were traced to imported cowpox vaccine contaminated with footand-mouth virus. Vigorous measures, involving the slaughter of about 4,500 and 3,600 animals respectively, brought about the eradication of each of these outbreaks in six months or less, at a cost of about $\$ 300,000$ in each instance.

The 1914 outbreak, however, is quite a different story. As Melvin and Mohler relate:

It seems probable that the first appearance of the disease in this outbreak was among the hogs of a farmer living two miles west of Niles, Michigan, about the middle of August, 1914. . . How it was introduced, or whence it came remains as deep a mystery today as at the beginning of the outbreak. ... Within two weeks after the first hogs became sick, the disease spread to the cattle on the premises, and simultaneously the cattle belonging to a neighbor developed peculiar symptoms. Each of the farmers called in a different local practitioner, one of whom notified the State authorities of the conditions present, and requested assistance. The first information that reached Washington was a telegram from an assistant inspector at Detroit on September 3, stating he intended to visit Niles, Michigan, to investigate a possible outbreak of aphthous fever at 
the request of the State Veterinarian. The following day a telegram was received stating "No foot-and-mouth disease in Niles, Michigan. Characteristic lesions of necrotic stomatitis present. ..." Had more attention been given to the history of the disease, and less consideration given to pathological phraseology ... some suggestion of the character of the infection would have been implied.

Nothing further was heard from the disease in Michigan until the afternoon of October 10, when a letter arived from the inspector in charge of the Detroit force, to the effect that the disease had spread during the interval from the original two herds to six additional herds in the neighborhood.... The history of the various herds was so completely described that no affection other than foot-and-mouth disease could suggest itself. Therefore, Dr. Eichhorn was sent on the next train to investigate and report. ... On October 12, Dr. Eichhorn wired: "Clinical diagnosis positive. Advisable Mohler leave tonight via Buffalo directly to Niles. . . ."

Dr. Mohler was directed to proceed to Niles to confirm the diagnosis, and took with him Dr. Houck who was to be left in charge of the eradication work, as well as Drs. Gallagher and Smith of Washington. They arrived at Niles at 6:30 p.m. on October 15, and immediately were piloted by Dr. Eichhorn in an automobile to see some of the infected animals. By means of a pocket flashlight, the lesions of the natural cases as well as the calf which Dr. Eichhorn had inoculated in the meantime were examined, and the following night-telegram was immediately sent by Mohler to Washington: "Lesions of inoculated calf slight but typical. Examined tonight number infected cattle. Indisputably European disease. Reports just received indicate 29 Michigan farms infected. Seven in Indiana. Need fifteen additional men." Thus the campaign of eradication was launched.

After an investigation to ascertain the boundaries of the infection, four adjoining counties in southwest Michigan and northwest Indiana were placed under quarantine:

While the quarantined territory was believed at first to circumscribe the centers of infection in that section, the disquieting information was disclosed that a mixed shipment of 28 hogs, 3 cows and 54 sheep had been sent on October 6 from the vicinity of Niles to Chicago. Almost simultaneously it was discovered that the milk from an infected herd had been taken to a creamery daily for the previous two weeks, and the return of the infected skimmed milk to the patrons of this creamery resulted in the rapid spread and almost spontaneous appearance of the disease on thirty-six farms, which increased to over one hundred before the creamery could be closed. The hogs in the Chicago shipment were among the first to receive this contaminated skimmed milk, and their shipment to Chicago before the development of the disease probably infected the cows and sheep in the car as well as the Union Stock Yards of Chicago. From this point infection was carried by various shipments of live stock, especially the classes of cattle known as stockers and feeders from the Chicago stock yards to various parts of the country north, east, south and west.

In addition, one lot of virus produced by a serum company in Chicago and shipped to a number of states, was shown to be contaminated with foot-and-mouth virus. Altogether, twenty-two states and the District of Columbia were found to be infected, and placed under quarantine. The Chicago stockyards were reinfected in January, 1915.

\section{Criticism by Campbell}

In editorializing on the matter in December, 1914, D. M. Campbell states:

The spread of the disease to the Union Stock Yards was very unfortunate, indeed. It looks as if it might have been prevented. For at least two weeks the disease was recognized and known to exist in Indiana before Governor Ralston could be induced to proclaim a quarantine, and during this time many of the farmers in this region, excited by the extravagant stories in the papers telling of the fatalities of the disease, were rushing their hogs into Chicago. . . .

The most unfortunate single outbreak of the disease was undoubtedly that which occurred among the two-million dollar herd of dairy animals exhibited at the National Dairy Show in this city the first week of October. Measures for the control of the disease among these animals and particularly all measures looking toward the destruction of the animals, were accorded violent opposition from the owners which included many influential citizens and politicians in a number of states. These men seemed to have no regard for the live stock interests of the country in general, but were endeavoring only to save themselves an immediate personal loss. It was finally decided to keep these animals under quarantine indefinitely ... but considering the risk that has 
been taken and that must be taken for weeks to come, we cannot believe that the authorities were justified in not destroying these as they did other animals attacked by, or exposed to, the disease. ...

In retrospect, not a few of the mistakes in handling this outbreak can be seen. In the first place it was not recognized in Michigan for many weeks after it should have been, and in the second place the Federal authorities should have taken the matter in hand in Indiana without waiting for the co-operation of the state authorities. . . A third error was made in failing to recognize the disease at the Union Stock Yards on its first appearance. . . The fourth error in handling this outbreak was made by the Illinois live stock authorities in not closing the Union Stock Yards earlier, and when it was closed in not making public the true state of affairs, instead of saying the quarantine was placed on the yards "as a precautionary measure. ..." On the whole, the efforts of the Federal and state authorities, after the disease was recognized, are deserving of the highest praise.

The failure of the Michigan authorities to recognize the disease for forty-eight days was not a mistake; it was worse. . . . A congressional investigation is promised and . . . some official heads may fall.

Early in 1915, however, Dr. Campbell considered:

Fortunately there is another side to the question - a genuine silver lining to the cloud. In many districts where the disease actually appeared and an absolute quarantine was enforced on all farms, the farmers have come to look more kindly upon quarantine regulations and to realize that if foot-and-mouth disease can be controlled and eradicated in this manner, that hog cholera, a far easier disease to manage, can also be eradicated through the same effective measures. .. . In the states afflicted with foot-and-mouth disease and in fact throughout the nation the veterinary profession has gained immensely in prestige and influence as a result of the publicity accruing to it. ... The public has been brought to have a higher appreciation of the veterinary profession than it has ever entertained before. It has taught them to look upon the veterinarians as something more than a class of men more or less skillful in the treatment of sick horses, to look upon them as a class of scientific men trained to guard an important food product and to conserve its supply. It was a great opportunity for the veterinary profession, and to the credit of the profession it must be said that it rose to its responsibility and accepted its opportunity in a truly fitting manner.

\section{California, Here We Come}

From the report of J. R. Mohler on the 1924 outbreak of foot-and-mouth disease in California, it is evident that rapid and efficient action, in contrast to the situation in the Michigan outbreak of 1914, prevented this one from reaching alarming proportions. Word from Rudolph Snyder, agent in charge in California, was received by the Bureau in Washington on February 20, concerning a suspected outbreak near Oakland. On February 23 a decision was reached, and the affected area was immediately quarantined. A local quarantine had been imposed prior to a positive diagnosis being made. Veterinary inspectors having prior experience with foot-and-mouth disease were enroute to California from various sections of the country before nightfall. This was in accord with a carefully conceived plan of attack in the event of such an occurrence. U. G. Houck was put in charge of both state and federal forces. As reported by Mohler:

The policy of promptly slaughtering infected herds, cleaning and disinfecting infected premises and remunerating owners for animals and property destroyed, had proved so successful in previous outbreaks that it was adopted for the handling of this one without a moment's hesitation. The first diseased herd was buried on February 28, and the appraisals and slaughter of infected herds were accomplished so speedily that in many instances the animals were buried within 24 to 48 hours after discovery of the infection. The work ... was pushed so vigorously and effectively that all infected herds were located by March 22, and by March 26 all infected and exposed herds had been killed and buried.

Except for one recurrence, which was quickly stamped out, this would seem to have ended the matter. But on March 22, the disease was discovered in a large range herd in Merced County, southeast of Oakland, from which it quickly spread to the surrounding counties. The initial outbreak apparently resulted from infected material carried by a hunter from the Oakland area. Much of central California be- 
came infected, and the disease reached Los Angeles via animals shipped for slaughter prior to identification of the outbreak. Many of the herds were located in inaccessible mountainous areas, and in some instances it was necessary to slaughter the animals in canyons and blast the hillsides in on them to effect burial. The last diseased herd was found on August 16, but not before 108,000 animals had been slaughtered. A complicating factor was the infection of deer herds in the mountains, eradication of which was strenuously opposed (at gunpoint in some instances) by so-called sportsmen intent on (so they thought) protecting their immediate interests. The logical arguments of the Bureau, however, prevailed.

The disease had barely been eradicated in California when it broke out in Texas in September, 1924. A steam shovel was transported to the infected area by special train, and within two weeks all infected and exposed cattle, numbering some 7,000, were slaughtered and buried. Ellington Airfield, which bordered the infected pastures, was closed by the War Department, and, as noted by Dr. Mohler, "Cooperation on the part of local and state officials, the public and the live stock interests, has been excellent." Without doubt, this was an outstanding example of the efficiency of the Bureau of Animal Industry being aided, rather than impeded, by local authorities.

Another outbreak in California in 1929 was eradicated in two months, with the slaughter of only 3,600 animals, primarily for reasons stated by J. R. Mohler:

The Bureau and the states together have a trained, experienced force of veterinary footand-mouth disease fighters that is not equalled in any other country. Supplies used in eradication work are stored at different points, ready for use in an emergency. The states, with very few exceptions, now have laws which enable them to join the federal government without delay. ... [ However] the prevalence of footand-mouth disease in practically all countries with which we are engaged extensively in commerce, precludes the possibility that we will be exempt from occasional outbreaks.... We are further handicapped by the fact that in spite of the diligent researches of the most resourceful scientists of the world, the causal agent remains elusive.

After a minor outbreak in California in 1932, which was wiped out in about ten days, matters in the foot-and-mouth realm remained tranquil until the 1940's when the disease threatened to invade this country from Mexico. But with concerted action of Mexican and United States veterinarians the outbreak was brought under control. In part to prevent the straying of diseased stock, most of the United StatesMexican border was fenced.

\section{RABIES AND VIVISECTION}

In noting the frequent outbreaks of rabies in England, Alexandre Liautard had editorialized in 1880 :

That no efforts have been taken by the Government to get rid of such a terrible scourge, does not, perhaps, seem so strange to Americans, who are accustomed to see Government ignore all matters relating to veterinary medicine, as it must to veterinarians of continental countries. . . . Fortunately for the United States, rabies is but rarely seen to any considerable extent in this country, never appearing, so far as we are aware, in an enzootic form as it does in England. We have not met a single case in New York for about three years, and we believe but very few cases have occurred here during that time.

The storm clouds apparently were gathering, however, for R. H. Harrison, House Surgeon at the American Veterinary College recorded four cases of rabies in dogs during the summer of 1881. One licked the hand of Dr. Liautard, but then, "without provocation the dog flew at his heels and tried to bite him." A case of rabies in a mule was reported in 1882, and at Reading, Pennsylvania, two butchers were arrested:

charged with selling the meat of three hogs which were bitten by mad dogs, and died of rabies: It is alleged that a number of persons became sick after eating the pork. Similar instances have been reported where the flesh of sheep bitten by rabid dogs have brought on severe symptoms. 
A. A. Holcombe, State Veterinarian of Kansas, reported 162 deaths of animals from rabies in that state in 1884. Beginning about this time the Review contains frequent articles on rabies, stimulated in part by the work of Pasteur. F. S. Billings, however, writing from Nebraska in 1886, states:

It is well enough known to the public, and also to many of my professional colleagues, that I have nourished a most extreme skepticism with regard to the prevalence of rabies among our domestic animals, especially dogs, ever since my connection with the somewhat notorious "Newark boys," which case proved a most ridiculous farce. [Billings had earlier accompanied several boys, bitten by a supposedly rabid dog, to Paris for treatment by Pasteur. ]

After "some four months cautious skepticism" concerning a suspected outbreak in Nebraska, however, he was convinced that several dogs and the cattle they bit died of rabies.

The Journal of Comparative Medicine and Surgery appears to have been alerted to the rabies problem, perhaps sooner than the Review. In 1881, apparently confirming Liautard's earlier assertion, the Journal reported:

For the first time since the establishment of the dog pound in this city [ New York], a case of hydrophobia has been found ... diagnosed at once by Dr. Ennery, veterinary surgeon. . . . The animal was put in the dog cart, where he crept about slowly on his belly. . . . The other dogs, as is usually the case, seemed afraid of him, and tried to keep out of his way, but he bit many of them before reaching the pound. The diseased animal was shot at once, and those bitten were drowned. There is a prevalent error regarding the frequency of hydrophobia. This is the first case that has been found among forty-seven thousand dogs that have been drowned at the dog pound in the past five years.

About the same time, the cause of death of another dog, which earlier had been bitten by a dog in New Jersey, was tentatively diagnosed as rabies at the Columbia Veterinary College.

\section{Dog Destroyer}

Commenting on "The Boston dog destroyer," the Journal states:
During the mad dog scare of 1877 , Dr. Watts was appointed a special policeman with power to arrest all vagrants in the shape of dogs. . . . During that "dog catching" season, the genial doctor captured and killed 846 dogs found about the streets, belonging to nobody, and which no person would care to own. The success of the doctor's crusade against our cur dogs called forth very favorable comments from both officials and citizens, and the next season, 1878, it was considered advisable to continue the work of extermination.

The effectiveness of this crusade is shown by the steady decrease in numbers of dogs caught, only 297 being snared in 1882 .

In 1886, Billings wrote a long review of Fleming's Rabies and Hydrophobia, and of the work of Pasteur, in which he was critical of both authors, but at least he accepted rabies as a reality. At the same time, E. C. Spitzka, M. D., a regular contributor to the Journal, presented a paper on "False Hydrophobia," in which he expresses doubt "whether there really is such a thing as genuine hydrophobia in man, due to transmission from lower animals and to nothing else!" $\mathrm{He}$ states unequivocally, "There is, at present, no proven epidemic of hydrophobia either in New York city or in its vicinity," but a number of deaths from false hydrophobia, an "oft-times fatal imaginary disease," had occurred recently.

It undoubtedly is true that numerous cases of presumed rabies in man have been imaginary, and have been "cured" suddenly by impressing the patient with the significance of the fact that the offending dog itself was alive and healthy. Some cases, however, terminated less favorably, particularly those where the dog was killed "in accordance with the time-honored custom of hanging such criminals first, and trying them afterward."

The "mad dog scares" as reported in the less responsible press, of course, have done great harm in the past. But Spitzka is practically rabid himself on the matter of this persecution of the dog:

Probably the most seriously misunderstood and misrepresented members of our commu- 
nity, at the present moment, are the various representatives of the species canis familiaris. When a journalistic hydrophobia becomes established, these unfortunate beings are not allowed the wretched privileges of falling ill of any disease than the one which it has pleased some magnate of the press to declare epidemic. If a dog does not eat, he has hydrophobia; if he draws his tail between his legs, beware! if his eyes have a strange expression, or, what is the same thing, if you think they have, shoot him on the spot! If he resents your fooling with him, get your doctor to open a subscription for you and start for Pasteur's laboratory by the next steamer, at reduced rates! Hereafter, canine pathology will prove an easy science to master: All symptoms of canine disease are symptoms of hydrophobia; all dogs presenting such symptoms should be destroyed; hence, for all sick dogs there is but the remedy of the bullet or the policeman's club.

Am I exaggerating? Have you followed up the history of the so-called epidemic since the needless, wanton and wicked agitation of the matter was begun a few months ago? Do you remember that for a week after the first flaming announcement was made relative to the Newark epidemic, several scores of cases of hydrophobia were reported from every part of the country?

Dr. Spitzka is especially severe concerning a case that Liautard had been drawn into. As reported in the New York Herald, a dog, which had bitten a woman, was killed and sent to the American Veterinary College for diagnosis. The post-mortem lesions "were considered sufficient evidence, with the history of the case, to justify a diagnosis of rabies." Liautard and the medical consultant of the family advised that the woman be sent to Pasteur for treatment, which was done. A healthy dog was inoculated with brain material from the dead dog, and two weeks later "the patient showed the first symptoms of dumb rabies... in fact, all the wellknown symptoms of rabies were clearly present," and the dog died three days later. The original diagnosis of rabies "was reaffirmed by the post-mortem of the second animal." of some interest is the fact that the Herald quoted Liautard to the effect that he thought it "possible in the future to have a law compelling all owners of dogs to have their animals inoculated for rabies as a preventative."
One of the post-mortem findings on the second dog was "considerable foreign matter in the stomach." On this count, Spitzka states that he had consistently found this in presumably healthy dogs "purchased from street arabs, and not a few of which I had decoyed within the precincts of the laboratory myself." Regarding the symptoms of dumb rabies produced by inoculation of brain matter, he says these "can be produced in healthy dogs, by introducing non-rabic foreign substances into their skull cavities," and had proved this by experiment. The diagnosis of rabies in 1886 may have lacked some of the finesse obtained today, but under the circumstances it would seem that the safe course was the wise one, and Spitzka's arguments must be viewed more or less as "proofs" adduced to substantiate his conclusions.

\section{Smothered to Order}

Dr. Spitzka, however, was justly harsh on physicians who, with inadequate knowledge of rabies, failed to give patients proper assurances in cases of apparently or obviously imaginary "hydrophobia." He further insists that a diagnosis of true hydrophobia should be made only upon a confirming opinion of a veterinarian - presumably on the basis of a diagnosis in the offending animal-although he doubted that such transmission occurred. His faith in the abilities of the veterinarian, however, should not go unnoticed. He relates a number of cases involving faulty medical attention, most of which unnecessarily had terminated fatally: "The following horrible case, I submit in the original language of the report [attributed to the New York Times, February 4, 1886 ]; it requires no comment":

Cohoes, N.Y., February 3d. Sunday night George Waterhouse, aged 14, was taken ill and showed signs of hydrophobia. He grew rapidly worse, and last night was in such a suffering condition, with eyes protruding and mouth frothing, that the physicians saw there was no hope of saving him, and to end his sufferings ordered that he be smothered, which was done. Waterhouse was bitten by a dog six years ago .... and caused no inconvenience until now. 
This may sound incredible, particularly at this late date. Earlier, however, the smothering of rabid persons was at least common enough that the British Parliament passed a law making this specific offense a capital crime. Usually it was a member of the family that administered the coup de grâce; certainly it is likely that the "physicians" in this case were not graduates - perhaps not bona fide medical men at all.

In a clinical lecture on rabies delivered in 1888 at the University of Pennsylvania, R. S. Huidekoper states:

I take this opportunity of making some remarks upon hydrophobia in view of the fact that the disease has existed in an almost epizootic form during the past two months, in view of the importance of the subject, and of the absolutely false ideas which prevail in the popular mind in regard to hydrophobia, which has led to the definite statements and the expressed belief on the part of reputable physicians, that no such disease exists, simply because they have not seen cases, and because the cases are so excessively varied in their symptoms and their course.

As a preliminary, Huidekoper states that he prefers to call the disease rabies. There follows a comprehensive history of the disease from antiquity, and an excellent description of the disease in the several species of domestic animals.

Needless to say, rabies has continued to be a problem, and will continue to be one until adequate means are found for controlling the animal reservoirs of the virus. A primary obstacle has been the perhaps well-intentioned, but certainly misdirected efforts of some humane societies and other would-be friends of man's best friend who impede realistic legislation to curb the population of stray dogs. At the same time they have in some instances rather effectively hampered medical research by having unrealistic limitations placed on the use of dogs and other animals for laboratory purposes. In recent years, rabies in wildlife populations, including foxes, skunks, and bats, and among other species, has become a problem of increasing importance. From the historical standpoint at least, it would appear that sylvatic rabies, originated from contact with rabid dogs during colonial times.

\section{Vivisection}

The subject of vivisection - so-called by its misguided opponents - is one the documentation of which would require a book in itself. Without disparaging the propriety of nonscientific individuals considering that they have a vested interest in the care of animals used for experimental work, it is all too obvious that an all too frequent objective of these groups is to see that animals are not used for experimental investigation at all. Vivisection is - or was made into - an inflammatory term, and manifestos such as the following, addressed to a local S.P.C.A. from the national headquarters, attracted staunch supporters - many of whom undoubtedly were not quite sure what it was that they were supporting:

September 30,1880 . Can you obtain the name of respectable persons - male and female residents of your City to a petition to be presented to the Legislature of this State, asking for the passage of a law to prohibit the dissecting of live animals? An immediate answer is respectfully requested. If in the affirmative the petition for signatures will be sent to you at once. ... Respectfully, Henry Bergh, Pres.

In an address at the Columbia Veterinary College in 1880, the physiologist, Thomas H. Hawkins, in tracing the history of animal experimentation and its relation to medical progress, states:

None have contributed more in this direction than our illustrious friend, Chaveau, who began his experiments, in 1861, upon horses, dogs, and other inferior animals. I may here remind you that veterinarians of the past have contributed much to our medical literature, and we may expect much more from them in the future.

Admitting that a physiologist in his lifetime might cause as much pain to animals as a village butcher or a so-called sportsman in a year's time, Dr. Hawkins suggests: 


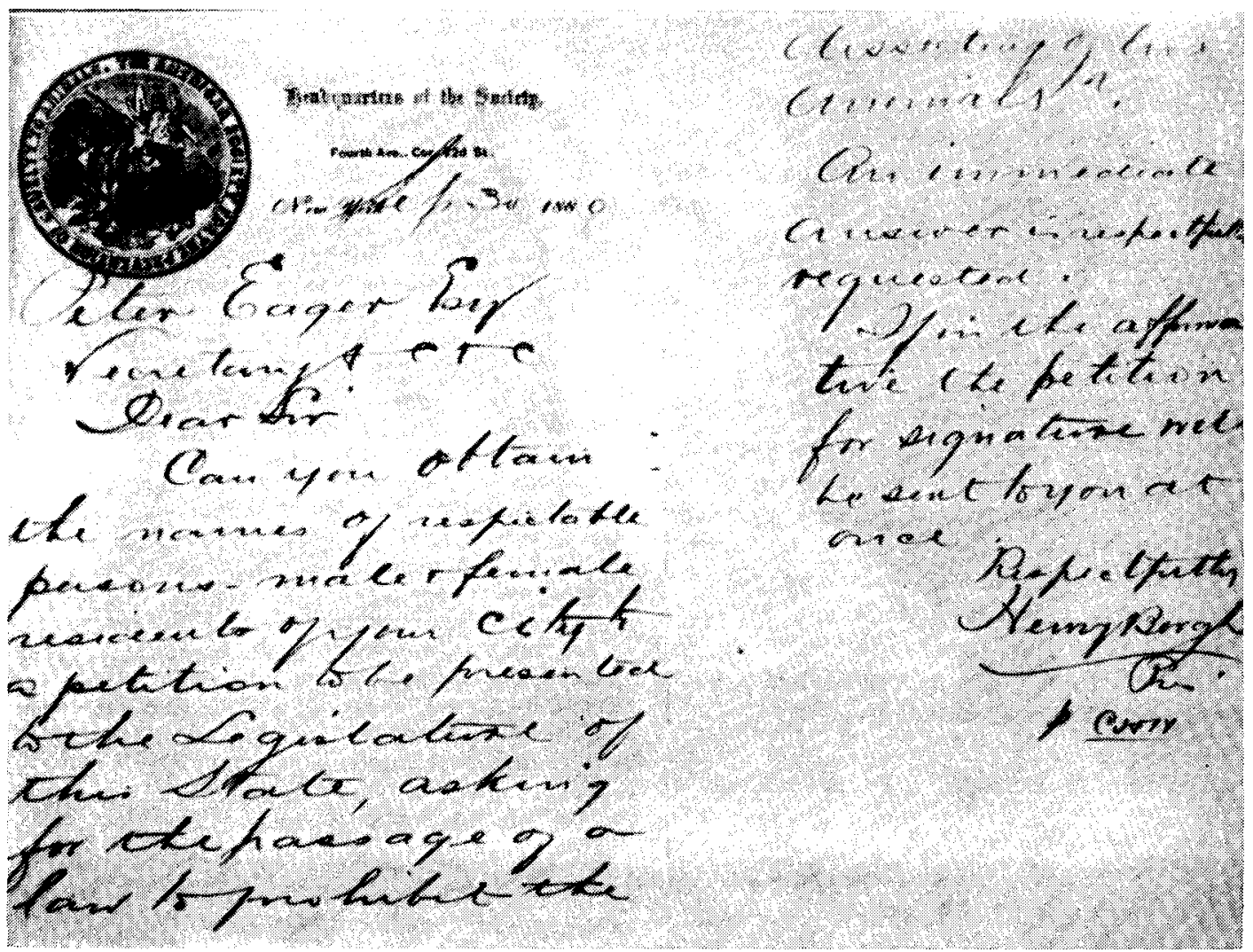

Letter written in 1880 by Henry Bergh, ASPCA founder, asking for "respectable persons - male and female" to support legislation "to prohibit the dissecting of live animals."

Imagine for a moment what would happen if the entire human family were organized into a society for the prevention of the destruction of the canine tribe. ... I fear the dogs would be sufficient in number to vivisect the entire human race. For this very reason it becomes necessary for some to adopt the curious reasoning that summary execution is presumably preferred by dogs who might otherwise enjoy a respite of some days, weeks or months, together with the assurance of an equally painless end.

In numerous instances, however, the S.P.C.A. has been a staunch ally of the veterinary profession. Thus in 1895 a Virginia veterinarian, W. H. Harbaugh, requested a local Society to prosecute a blacksmith for cruelty to animals, specifically "for having burnt a horse's mouth with a heated iron to cure the lampas."
The prosecution had as expert witnesses five veterinarians, three physicians, one dentist, and two horsemen. These were opposed by the owner of the horse in question, three liverymen, and the defendant who testified that he "had burned between 1500 and 2000 and had never seen any bad results." On the strength of the expert testimony for the prosecution, the judge ruled in their favor, but discharged the defendant inasmuch as he had acted according to custom and without malice, "but any other cases brought before him would be tried on their merits." Harbaugh comments:

As this was the first case of the kind ever prosecuted in this State, I consider the decision of the court was fair and just. I also consider it a great victory for the veterinary profession, 
as it will effectually check the barbarous practices of the many pretenders who dupe the ignorant horseowners.

Harbaugh, incidentally, was a collector of old and rare veterinary works; at the time of his death in 1898, his collection included many of the standard eighteenthcentury and early nineteenth-century English works on farriery. Of some interest is the statement, made in the listing of his library, that one item was a manuscript copy of Coleman on the Horse, "written by Thomas Nelson, in his own handwriting, London, 1817." The manuscript, undoubtedly a set of notes taken at the London Veterinary College, would be of great value, for only one such set is known to exist; it is a principal source of information concerning Coleman's teaching, for Coleman during his tenure as head of the London Veterinary College, published none of his lectures, and forbade his students to - so conscious was he of his shortcomings.

Regarding the relationship that ought to exist between the veterinary profession and the humane movement, W. H. Dalrymple, in a paper read before the American Humane Association in 1897, states:

All graduates of the modern schools are, in virtue of the profession they represent, honorary members of humane societies; if not actually enrolled as such, are tacitly understood to exert their influence in the cause of humanity in its application to the lower animals. . . . The profession is a most potent factor in the education of the people in the interests of humanity. The general practitioner, in his daily routine of professional work, has the opportunity to illustrate and explain to his client the superior advantage to be gained by the use of rational and humane methods of treatment; and to denounce the barbarisms that are perpetrated by the ignorant, illiterate and superstitious.

\section{Incubus of Ignorance}

The legitimate work of the humane societies, of course, has always had the backing of the veterinary profession. Concerning the efforts of District of Columbia branch of the American Humane Associa- tion to secure an antivivisection bill in the late 1890's, Liautard writes:

If ever a sect or association labored under an incubus of fanatical ignorance and prejudice, the American Humane Association is the one of most prominent distinction, and the incubus is its local society located in the District of Columbia, whose recent action should expose it to the ridicule of all men, and result in its gradual but certain disintegration, and its place taken by some other organization with brains and humanity instead of a narrowminded, imbecilical, hypocritical conglomeration of long-eared fanatics, who cannot spare sufficient brains from the function of feeding themselves to grapple with an idea larger than a pea. This local society is father and mother of the Antivivisection Bill, which has been before Congress as a menace to scientific progress for a number of sessions, and they regard every living thing which cannot curtail himself within its narrow cloak and become an advocate of that foolish emanation of a lot of cranks, as an enemy of society and one to be looked down upon from their lofty heights of morality.

This outburst (perhaps the most menacing ever penned by Liautard) was occasioned by the fact that the local society had raised hysterical objections to the programming of a paper - requested by the parent organization - by D. E. Salmon on:

Diseases and Abuses of Animals in the United States: what is being done by the Federal Government toward their alleviation and prevention, and what the Humane Societies of the country may do to assist in these efforts.

Embarrassed by the action of the Washington Society, the parent organization tendered an apology to Dr. Salmon. In his even-tempered reply, Salmon noted the efforts of the Washington Society:

to stop experimentation upon animals even for the advancement of medical science. In this I sincerely hope they will never succeed; but they are alienating from cooperation with the humane societies the great humane forces of the country, viz., the medical and veterinary professions, the biologists, the universities, and the Agricultural Department of the Government. . . Under these circumstances is it not time for the liberal and intelligent members of the American Humane Association, who joined that organization to prevent cruelty to animals 
rather than to secure personal notoriety, to stop and consider whether they are called upon to further support and encourage those narrowminded and intolerant people whose efforts are a hindrance rather than an aid to the cause of humanity?

The Philadelphia Medical Journal printed Salmon's paper in full, together with the correspondence relating to the affair, and editorialized:

Kindness to Animals, or Hatred of Science, Which? - In the transfer of a car-load of animals across the continent, or of a ship-load to Europe, there is a hundred times more suffering, more awful torture, than in all the laboratory-experiments of the whole world since science has existed. Laws exist on the statute books, which, if carried into effect, would do away with these atrocities. In entire frankness we ask what is the conclusion logically necessary from the crusade of the antivivisectionists against scientific investigation? Plainly it is not pity for suffering that is the dominant motive with them, but the old medieval hatred of science. . . The old superstition that persecuted "heretics," Galileos, and Quakers, is by no means dead.

In 1920 Dr. Mohler editorialized on the defeat of a "vicious antivivisection measure" in California, which:

under the deceptive guise of humanitarianism, had for its ultimate object the prevention of all practical experimentation with animals . . . [and] which would render illegal the surgical or medical treatment of any animals that are not physically injured, deformed or sick, and which would prohibit such common operations as castration, dehorning, the docking of lambs, mallein and tuberculin testing, and immunization against infectious diseases. .... Fortunately this ridiculous measure, which struck at the very heart of our modern system of disease-control, was defeated by a decisive vote. The veterinarians of that State are to be congratulated on the success of their efforts in that direction.

Obviously, the problem has not yet been resolved, for medical research, rabies control and, to a lesser extent, veterinary practice, continue to be harassed by selfrighteous antivivisectionists claiming to be acting on behalf of the animals to whom they actually do a disservice of no small proportions.

\section{Subhuman Guinea Pigs}

Experimental animals were first used in medicine in the United States when John Dalton, M.D., introduced live demonstrations into his physiology course at the College of Physicians and Surgeons (New York) about 1850. Few experimental animals were used in research, however, before 1900 , and facilities for these were woefully inadequate prior to 1920 or later. It was about this time that the fundamental unity of disease processes in man and the lower animals was recognized, and laboratory animal medicine began to forge ahead. Until relatively recently, however, there were few opportunities for veterinarians in this field, nor were laboratory animals used to an appropriate degree in purely veterinary research, primarily because of this failure of both medical and veterinary investigators to appreciate the interrelationships of human and animal disease.

The Mayo Foundation appears to have been the first research organization to employ a veterinarian to direct the management of its animal colonies, with Simon D. Brimhall being appointed to this position in 1915, followed by John G. Hardenbergh in 1922, and Carl F. Schlotthauer in 1927. At present, some 125 or more veterinarians are employed as specialists in laboratory animal medicine, and a considerable potential exists. Currently, some $35,000,000$ laboratory animals are used annually in American research institutions and, as noted recently by Bennett J. Cohen, himself a specialist in this field:

As the concept grows that the laboratory animal specialist is simply another member of the modern research team, progressive research institutions will find it necessary and desirable to employ such personnel. . . . Whether these positions will, in fact, be created and filled by qualified veterinarians within the next ten to 15 years depends on the vigor with which those already in the field demonstrate and dramatize the true value of the laboratory animal specialist.

\section{BOVINE TUBERCULOSIS}

Volumes have been written on the story of bovine tuberculosis and its eradication; 
only a few facets of the matter can be considered here. Early recognition of the problem has been considered under the section on public health, and the contributions of the veterinary profession to control of the disease have been amply detailed in Man's Greatest Victory Over Tuberculosis (1940), by the physician, J. A. Myers. In part through Dr. Myers' gracious tribute to the veterinary profession, and the fact that many veterinarians have been and are connected with state-federal tuberculosis eradication programs, the salient features of the history of this disease are perhaps better known than is the case with many others.

It was only after the discovery of tuberculin by Koch in 1890 that an eradication program became possible, for until then no adequate means for detecting the disease, other than in its later stages, was known. Another vital step was the differentiation of human and bovine tubercle bacilli in 1895 and proof of the infectiveness of bovine tuberculosis in man, primarily by Theobald Smith and D. E. Salmon. Earlier, there had been much controversy over the dangers of bovine tuberculosis, with Koch denying his earlier claim of cross-infectivity, and even later, so that the BAI perhaps wisely chose to base its eradication measures chiefly upon an economic justification. The direct benefits to human health, however, were quite apparent to those who understood the disease, then as now.

About 1900, infection ranged from as low as 4 per cent in 60,000 cattle tested in Vermont to 50 per cent of 25,000 cattle tested in Massachusetts, with 100 per cent infection in many herds. And while spasmodic attempts had been made by livestock sanitary officials of several states and health officers of municipalities to control tuberculosis, little of an enduring nature was accomplished until the Tuberculosis Eradication Division of the BAI was established in 1917. An exception is the work of the Quarantine Division of the Bureau, through which the incidence of re- actors in the District of Columbia was reduced from 18.9 per cent in 1910 to 3.7 per cent in 1911, and to less than 1 per cent by 1917 .

\section{James Law on Tuberculosis}

Writing on "Contagious Diseases of Animals in the United States," James Law declared in 1884:

This subject has been too long neglected, and is liable to continued neglect for the reason that those who suffer pecuniarily from these affections have a deep personal interest in keeping the extent, and even the very fact of their losses, a profound secret. The city milkman who loses from the bovine lung-plague in a single half-year a number of cows equal to the entire herd that he holds at any one time would drive his customers to other dairies and invoke financial ruin if he published the fact of his heavy losses.

In like manner, horsemen refused to report glanders, or sheepmen foot rot or scab, or swine men trichina or swine plague:

Yet we well know that these are only examples of the animal contagia now existing among us, and that threaten the whole of the live-stock industries in this great country. . . . The vital statistics of New York city show that 29 per cent of the mortality of its adult male population is from tuberculosis, and our examination of the herds that supply that city with milk reveals the astounding fact that in certain herds tuberculosis affects 20,30 , and in some cases 50 per cent. ... One stands in wonder that in this conclusion of the nineteenth century the subject should still be comparatively unnoticed and untouched by governments and by their local and national boards of health.

Law, however, felt that not enough was known about tuberculosis yet to justify an all-out attempt at eradication, for a failure would prejudice all future sanitary legislation. Rather, the problem should for a time be left in local hands; ineffectual as this might be, it nevertheless would be the stepping stone to "that national control which, I trust, many now present may live to see, and which should aim at the entire extinction of this bane of civilization."

An early attack upon the problem of tuberculosis in cattle is reported by the 
Newton (Pennsylvania) Enterprise, for June 4, 1887:

Eleven cows and a bull, belonging to $\mathrm{C}$. Sidney Mather, of Middletown township, having been found to be afflicted with tuberculosis were killed in the presence of State Veterinarian [Francis] Bridge, and all buried in a trench on the farm, after the hides and fat were removed. The herd was attacked with the disease about a year previous and was condemned at a meeting of neighbors, who feared the spread of the disease. The value of the cattle was appraised ... at $\$ 250$, to which amount the owner was reimbursed by the community.

\section{Leonard Pearson and Tuberculin}

In speaking in 1921 on "Pioneer Work in Tuberculosis Control," L. A. Klein reviewed the epochal work of Leonard Pearson:

The first tuberculin test made on this continent was applied in 1892 near Villa Nova, twenty miles west of Philadelphia, to a herd of purebred Jersey cattle . . . the test was made by the late Dr. Leonard Pearson. . . There were 79 cattle in the herd, some of them imported and all purebred, and 51 reacted to the test. .. The reactors were valued at $\$ 10,000$.

Pearson was a young man at that time, only 25 years old. . . . Very naturally the results of this new and practically unknown test applied by an apparently inexperienced young man were questioned by many veterinarians and physicians, some of whom held Federal, State and city positions. One physician went to the trouble to interview Mr. Gillingham and tried to induce him not to have the cattle destroyed. But Mr. Gillingham (a trustee of the University) did not question the diagnosis, and as he did not wish to keep or to sell the tuberculous cattle, he decided to have them destroyed.

Six of the reactors were killed here at the Veterinary School and examined postmortem on March 16, 1892. . . Many veterinarians, physicians, scientists and livestock owners were present to see if the postmortem findings would confirm the results of the test. There were not a few skeptics among them, and one can readily imagine what these doubting Thomases said when the first cow that was killed failed to show any very definite lesions of tuberculosis. But the five other cows destroyed on the same day were plainly tuberculous, and microscopic examination of the lesions from the first cow disclosed the presence of tubercle bacilli. The other reactors were destroyed and buried on the farm near Villa Nova.

You will find no report of this test and the postmortem demonstrations in the veterinary journals of that day. The only record to be found is the Philadelphia Public Ledger of March 17, 1892. It was a peculiarity of Dr. Pearson that he rarely took time to write up his work.

During the following three years Pearson used the tuberculin test in his private practice. Some veterinarians and livestock owners were slow to take it up, and several State and Federal officials and some livestock journals even vigorously opposed it. Its efficiency and reliability were recognized by veterinarians, physicians, sanitary officals and the more progressive livestock owners when they became more familiar with it. But the opposition of some of the livestock owners and journals continued for a long time. They claimed that tuberculin would transmit tuberculosis to a healthy animal, that it would produce abortion and sterility, and that animals would react to it which were not tuberculous.

In 1895, when the Pennsylvania State Livestock Sanitary Board was organized and Pearson became its Secretary and State Veterinarian, he introduced another method in connection with the control and eradication of tuberculosis which has had far-reaching results. This is the principle of testing herds on the voluntary application of the owner. A law authorizing compulsory tuberculin testing was passed in Massachusetts a few years before, but when it was put into operation the livestock owners raised such vigorous objections that the next Legislature repealed it. The principle of testing only on voluntary application was the keystone of what became known as the Pennsylvania plan for controlling tuberculosis, and it is also one of the features of the accredited herd plan.

\section{BAI vs. TB}

In a discussion of "Tuberculosis Eradication: Its Aims, Methods and Ultimate Goal" in 1919, John A. Kiernan, Chief of the Tuberculosis Eradication Division, credits A. D. Melvin with the "broadvisioned conception of the idea to launch this campaign before tuberculosis had gained the master hand over the animal industry of America." This plan, of course, was the cooperative eradication program begun in 1917. Noting that prior to this time practically every state had its own 
concept of how to deal with tuberculosis, Kiernan observes:

The outcome of these many regulations created a very strong resentment on the part of the live-stock owners, many of whom were largely responsible for the approaching chaotic condition. . . . The live-stock owner realizes now more than ever that the prospective purchaser of cattle cannot be humbugged: he is seeking animals to augment his herd from herds whose health is known.

Concerning the accredited herd plan adopted in 1917, and which was operating in fourty-five states less than two years later, Kiernan states:

If we cooperate with the same earnestness that the veterinary profession has cooperated in the extermination of other infectious diseases of the United States, the accredited-herd plan will have done more to raise the veterinary profession in the estimation of the livestock world and in the estimation of this nation and the nations of the world than any work it has ever undertaken.

He suggests that within twenty years it may be necessary to have a "discreditedherd list," and credits members of the International Tuberculosis Commission of the AVMA, appointed in 1909, with having done much of the spade work which finally resulted in the frontal attack by the BAI. However:

the campaign is just in its infancy. No person can forecast the date when this great work will be completed, and it is unnecessary to make any estimate of how long it will take. It may be 50 years or a century before the end is in sight; but what is a century if, at the end of that brief space of time as compared with the ages that have passed and the time that is to come, the job is finished?

At his death on December 13, 1927, Dr. Kiernan was eulogized in Veterinary Medicine as:

unswerving in his attack on tuberculosis as an economic problem. There is hardly another leader in this work but has at one time or another shown evidences of being sidetracked onto public health phases of the work. Doctor Kiernan steadfastly maintained that the eradication of tuberculosis from cattle and swine is amply justified on economic grounds and that the advantages to the public health, large as they are, were just so much clear gain. He realized the live stock industry was not convinced of the importance of bovine tuberculosis to public health and was in no frame of mind to make large voluntary sacrifices to that end.

There should be, of course, no disparagement of a purely economic attack upon a public health problem when this is the most feasible approach; however, in the final analysis, the economic, social, and purely medical aspects of most public health problems can hardly be separated into neat compartments.

In the latter connection, John R. Mohler, in an address on "The interrelation between disease control and animal husbandry problems" in 1928, observes:

The medical profession is keenly interested in the aggressive methods used to combat animal diseases and sits in at live stock sanitary meetings. The banker, at one time skeptical about financing the purchase of pure-bred live stock, now lends his support to pure-bred-sire activities. The housewife is coming to recognize that meat, properly inspected, is one of the best, safest, and most wholesome foods for her family.

Such good-will naturally has far-reaching economic importance, but more important, perhaps, is the stimulating effect on those of us who have selected some branch of the industry as our life work. Fortunate, indeed, is the worker who is proud of his calling, and in whatever way each of us may serve, the pride of service adds richly to our lives ... . in helping to better livestock conditions, in increasing our national wealth, in protecting public health, and in adding to the comfort and happiness of rural life.

While Dr. Kiernan chose to wage the war on bovine tuberculosis on purely economic grounds, it is evident that he fully appreciated the public health aspects of the problem. Thus in 1923 he had urged:

When we appear before a local audience, or committee, or state legislature or other legislative body, and lay before them the facts regarding the transmissibility of tuberculosis to man, we do not infringe upon the rights of the medical profession, in my judgement. The veterinarian is familiar with the etiology, the pathology, and mode of dissemination of tuber- 
culosis in livestock, and knows of its relationship and its ability to affect man; therefore, it is his duty to state these facts whenever the occasion requires.

The announced goal of the BAI tuberculosis program was reached in 1940 when the last two counties in California were declared accredited. However, in a sense the success of state-federal tuberculosis eradication programs has been such that in recent years there has been some reluctance to spend sufficient money to continue these programs at the required level. Thus complacency in a belief held by many that bovine tuberculosis is no longer a problem has resulted in a sharp rise in the number of cases in some states. It is perhaps not too invidious a cliché to remind ourselves that continuing vigilance was ever the price of security.

\section{THE FEDERAL MEAT INSPECTION SYSTEM}

No account of the BAI could be complete without some details of the federal meat inspection program. While local efforts at meat inspection had been made since colonial times, the increasing volume and complexity of the meat trade by the 1850 's and later made even the better of these attempts inadequate to protect the meat-consuming public. Most of the meat consumed at home, or produced for export, underwent at best only the most cursory inspection to eliminate that which was $\mathrm{ab}$ solutely unsalable. Probably the only noteworthy exception to this was in large cities where kosher killing was practiced for local Jewish markets.

Bovine pleuropneumonia had been eradicated promptly in Massachusetts through the action of the cattle commission under E. F. Thayer, and strenuous measures were employed to prevent any of the diseased animals from entering market channels. But elsewhere, the disease was allowed to rage unchecked, or at best, efforts to control it were too little and too late. As a consequence, Great Britain in 1878 imposed restrictions on the import of cattle for slaughter, and in 1889 several other countries of Europe excluded American pork, which was alleged to contain trichinae. As reported by Houck:

The existence of contagious pleuropneumonia in cattle and of trichinae in pork could not be denied, and the governments concerned were within their rights in setting up the restrictions which they deemed necessary for their own protection. However, the extent to which the alleged conditions existed in the United States was the subject of exaggeration so gross and of reports so sensational as to work great injustice to the reputation of American meat. . . In response to appeals from meat packers, livestock producers and others, the first Federal meat-inspection law was passed August 30,1890 .

This law, however, other than providing for the inspection of live animals for export, concerned itself only with the inspection of cured meats, and made no provision for determining the status of animals slaughtered here. Foreign governments quickly recognized the inadequacy of this law and refused to honor the certificates issued thereunder. This was corrected by a law of 1891 which provided for both ante-mortem and post-mortem veterinary inspection of animals slaughtered for foreign and interstate trade. Recognizing several inadequacies in this law, Dr. Salmon obtained passage of an additional act in 1895:

to establish more complete control in respect to the condemned carcasses or parts of carcasses of cattle, sheep or swine which had been inspected in accordance with the provisions of the law.

\section{But as noted by Houck:}

The authority conferred by the laws of 1891 and 1895 was not sufficiently broad to control sanitation and to provide that inspection and supervision of the preparation and labeling of products which is essential to a comprehensive or well rounded system of inspection. Nevertheless it was ample to establish and maintain an efficient ante-mortem and post-mortem inspection on a scale sufficient to cover a very considerable per cent of the animals slaughtered for domestic consumption, and also for maintaining a well-guarded export certification for meats and animals exported. Although Federal inspection was primarily established to 
meet economic needs, its hygienic benefits were not limited to the foreign consumer of our products. In fact, the natural and proper development of the service logically made it a national service in hygiene, and this has long been its dominant value, while its importance from the economic viewpoint remains undiminished.

\section{The Jungle}

In 1894, however, only 46 abattoirs in 17 cities were under federal inspection; obviously many consumers did not enjoy the benefits of this service, which already had become the most important and extensive part of the work of the BAI. Seizing upon the obvious abuses of working conditions and gross insanitation in some plants, Upton Sinclair in The Jungle (1906) presented a sensational and misleading exposé of these conditions as being characteristic of the large packing plants which had federal inspection, thus casting unwarranted aspersions upon the Bureau of Animal Industry. As reported in the American Veterinary Review in 1906:

The newspaper hero of the hour, Upton Sinclair ... is a man totally lacking in experience in abattoir methods, with a strong tendency to magnify what he beheld in his visits to packingtown. It would be difficult for an untrained observer, in the presence of blood and offal, to analyze the situation and finely appreciate the presence of lack of sanitation under such circumstances. . . Then the committee sent to Chicago to investigate the sensational accusations of Mr. Sinclair were about as unaccustomed to such sights as he, and were as much horrified at what they saw as the yellow press had been in printing their findings.

While it is true that conditions in many small slaughterhouses not subject to federal inspection were then - and for long afterward - horrible to contemplate, Sinclair perpetrated a gross injustice in accusing the BAI of permitting these conditions to exist. Indirectly, of course, this also reflected unfavorably upon the veterinary profession. Worst of all, public clamor for a scapegoat in the wake of these disclosures resulted in the discrediting and dismissal of Dr. Salmon as Chief of the
Bureau. Broken in spirit, Dr. Salmon never fully recovered from this blow, which can be characterized as a most monumental expression of ingratitude from a public which knew not what they were doing nor cared to know. The Bureau was blameless in the matter, a fact which could have been easily established by any competent and unbiased observer.

The Congress, however, was not without blame; as reported in the American Veterinary Review:

In the few years that the Federal meat inspection has been in operation in the United States, it has performed wonderful service, hampered by lack of funds and men. Its system of supervision has been admired and lauded wherever its methods were known; but Congress has ever acted niggardly in responding to the entreaties of the Bureau for larger appropriations, so that its watchfulness could be extended to all abattoirs having to do with foreign and interstate trade.... The late Chief [Dr. Salmon] persistently sought extension of the work; but Congress has been so parsimonious that it has utterly failed to protect the great interests of meat production.

Not only did the new law provide for needed reforms - and the funds to implement them (except that the salary of veterinary inspectors remained at a miserly $\$ 1,200)$, but the scope of inspection was more than quadrupled within two years. By 1908 there was fecleral inspection in 787 establishments in 211 cities. But in 1906 there had been 300 veterinary inspectors for 163 establishments; in 1908 there were only 620 veterinarians for the 787 plants, although it may be presumed that with the addition of smaller plants some veterinary inspectors were able to serve more than one.

\section{Hughes vs. Sinclair}

Much of the story relating to the disclosure of The Jungle is best told by $\mathrm{D}$. Arthur Hughes, a government inspector at the time, but whose account is an unbiased and dispassionate one. Writing on "The Value of Meat Inspection to the Public Health," Hughes states in 1906: 


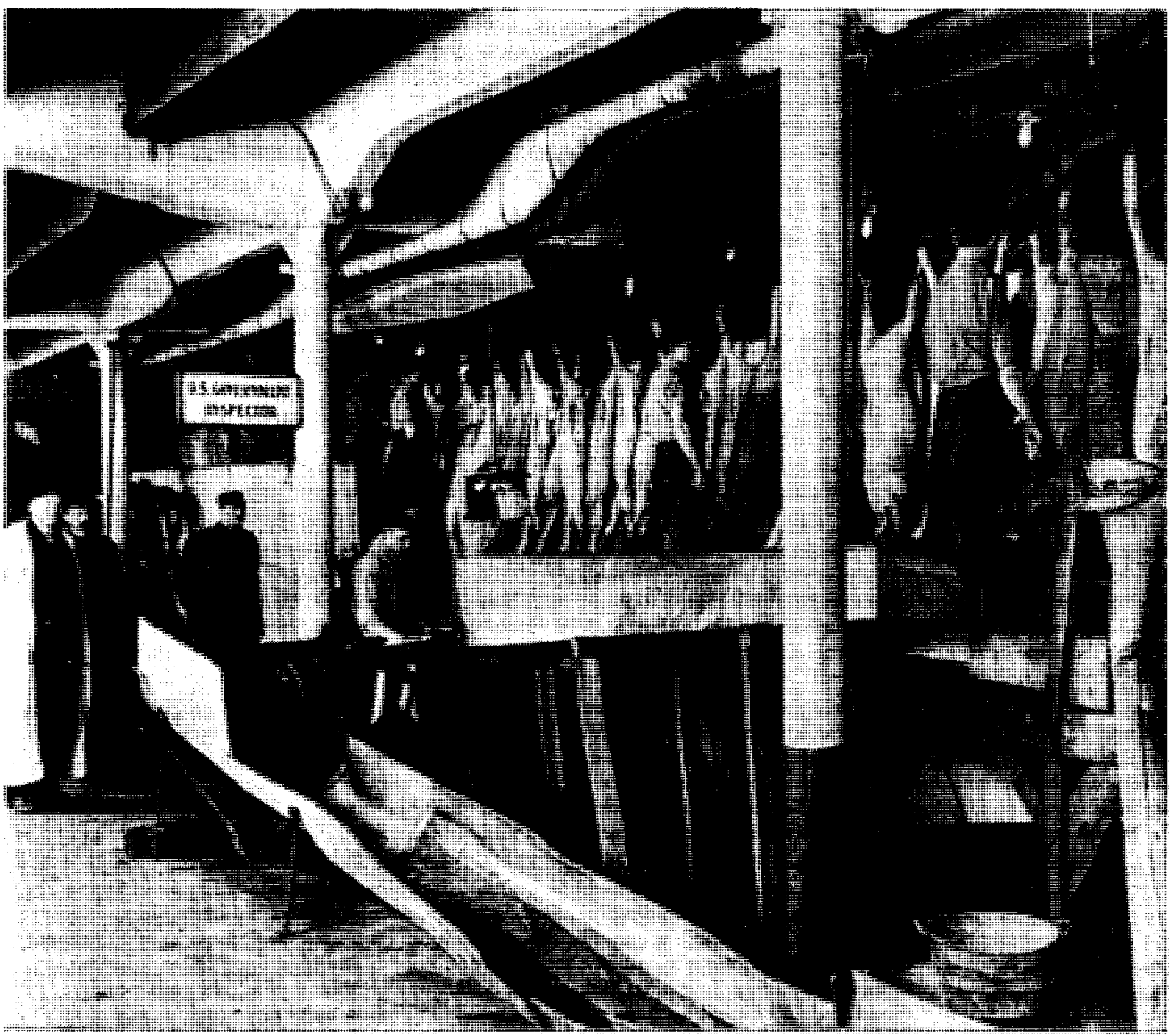

Although by current standards these conditions would not be acceptable, veterinary inspection brought about major improvements in meat processing, especially after 1906 when an exposé of conditions in plants not under federal inspection aroused public interest in the problem. USDA photo

The close relationship of animal diseases to human diseases is well known to the scientist; but the great American public does not know the care and caution which is necessary to prevent the direct transmission to man of diseases common to animals, or to prevent the setting up of diseased conditions in man arising from the consumption of meats from unhealthy animals.

After detailing the accomplishments of the Federal Meat Inspection System to date, he adds:

If the United States government wishes to assure the people that its inspection of meats is indeed valuable to them, it must choose men to inspect, under its order, who are fit for the work by reason of character and intellectual attainments. The government does this.

The Bureau, of course, recognized that the meat inspection law under which it was operating was not the best that could be devised. As Hughes notes:

The inspection regulations, based on the law of $1891 \ldots$ made use of every part of the limited power allowed by the statute. Those regulations were a credit to the men of the Bureau who made them and administered them. 
In 1906, however, the muckraking "exposé" of the meat industry in Chicago by Upton Sinclair in The Jungle, shocked the public with "facts" later found by a federal commission to be "95 per cent false." Moreover, the sensationalism of this "hideous book," as Hughes characterizes it, obscured the full story, and catapulted Sinclair - to this time a writer of cheap pulp fiction into prominence, and a bundle of money, which, being the dyed-in-the-wool socialist he was, he invested in a colony for his fellow-travellers.

Actually, what Sinclair had done was to make capital of a series of articles in the London Lancet in 1905, which while not grossly untruthful, were written by one with a bias favoring the European system of municipal slaughter, and thus casting unfavorable light on the so-called "Beef Trust." The Lancet itself took the occasion to make "a scathing denouncement of conditions said to be found in Chicago." The hue and cry was picked up by the lay press, and:

Shortly that hideous book, "The Jungle," by Upton Sinclair, came from the press. . . . Great credit must be given to the American people for their willingness to wade through the revolting pages of Upton Sinclair. For reckless disregard of the truth; for a form of inanity, which, by its socialistic extravagance, would blind the world to the true idea of a great business; for a story aiming only to fulminate unknowing ones against the manner in which an important industry is conducted, one must turn to "The Jungle." Few so-called realists outside of France or Russia would dare to flaunt on their pages the sickening details and the vulgar description here cast before us. If this is art, we want no more of it. Like Macbeth's physic, we would "cast it to the dogs." It takes brazen effrontery to nauseate us with hateful and disgusting pictures in no way appealing to the sense of beauty nor nobility. If the story were saturated with truth the writing of the work would be pardonable; as everyone who has spent much time in the great abattoirs knows, it is replete with godless exaggeration, the story becomes utterly condemnable.

It is understandable that numbers of nice people would be offended by what necessarily goes on in the best-run abattoir. Also, it is likely that specific instances could be found on most any day in the early 1900 's, which by today's standards would seem to indicate a lack of regard for proper sanitation. And no one would deny that the packers were in the business to make money, and that the small margin of profit per unit characteristic of highly competitive enterprises can lead to what might appear superficially to be "sharp practices." Outright abuses, however, are perhaps more likely to be found in small rather than big business, and it is evident from Sinclair's writing that as an avowed socialist, he was after Armour's hide perhaps more than he was sincerely interested in good meat for the public. It would be most unfortunate if anyone today were to read The Jungle without knowing a little of its background; the passage of time tends to lend authority to writings that may have survived for another reason. The book, of course, is important as a prime example of socialist propaganda. However, the tendency of so many people to think their own times are so much better than any time previous could easily cause them to take The Jungle at face value. Hughes, like others who understood the situation, however, was not misled; only a few months after the storm, he writes:

As a socialist of the school of Karl Marx, if there is one thing more than another which inflames Sinclair's ire it is capital and its owner. Hence the defamation, libel and attempt to arouse class hatred instanced in his abuse of Armour and the Armour interests. It is the purpose of Sinclair to defame the character of Armour, the great capitalist, whom he pillories under the name of "Durham," because he is a capitalist and the Armour capital in the packing interests is an object of horror to him. That a man of Armour's business ability should initiate and organize such a stupendous mass of powerful interests calls not for praise from him but hate. Everything and everybody that Armour touches becomes to Sinclair an object of hatred. Packers are to be hated. Everything they do or attempt to do is to be held up to scorn and derision. United States Government inspectors are in the packing houses. That is enough for Sinclair. To him their duteousness must be only a blind. Covertly they must be working wholly for the interests of the capitalists. 


\section{A Germ of Truth}

What Sinclair failed to recognize, perhaps deliberately, was that many of the conditions he described actually did exist in some of the smaller abattoirs, frequently housed in quarters unfit for stabling cattle, and - it might be added - bordering on the only type Sinclair's socialistic economy would likely afford. Actually, government inspection, perhaps recognized as something of a blessing in disguise at first, could have been instituted only because the large packing interests did exist. Characteristically, the federal government has made no attempt to interfere with purely intrastate commerce, although it might be presumed that countless public health officials in many states have wished it would. A major problem has been the apathy of people toward support of local ordinances requiring adequate inspection, in many cases because of the faith they have in the federal system and the mistaken idea that this applies to all the meat they might purchase.

Hughes himself notes that of necessity there is a germ of truth in Sinclair's charges:

There were no doubt many specific instances of unsanitary acts by individual employees, though at times and in places there was uncleanliness and disorder, nevertheless the great American packing companies have had a set policy forbidding uncleanliness. The own. ers, superintendents and foremen have fought against filth and dirt. Year by year larger and larger sums have heen spent in improvements looking to more cleanliness.

And while he states that many people did not believe the indictments made by the book:

yet their passions were aroused by the horrors which were said to exist ... people did not stop to be judicially minded in such a situation. That there was any truth at all in the statements that had been afloat about the packing houses, lashed popular fury to frenzy.

This fury fell first of all on the packers, and secondarily upon the meat inspection service:
The packers, to him, are monsters; the government inspectors "the laziest, most dishonest, slipshod, careless and indifferent of all the people in the whole packing house."

Both charges, Hughes refutes with unrelenting zeal. If for no other reason, the packer has to think of consumer acceptance: "In all their processes the packers have kept this in mind in no small measure." It is, of course, obvious that a good product is not only good for the producer, but also for the consumer, and pride in a product goes beyond purely pocketbook considerations. And noting that the Department of Agriculture "escaped practically scot-free from serious, vitally hurtful criticism" in the subsequent investigations, Hughes states:

The reason is obvious - the Department had done sufficiently well all that the Meat Inspection law of 1891 permitted it to do.

\section{Blood and Gore}

The type of slaughterhouse Sinclair might well have aluded to - had he been more a sanitarian than a socialist - is described by T. A. Shipley, a special investigator for the USDA in Iowa in 1908, who looked into conditions in local slaughterhouses without federal inspection. He estimated there to be some 1,500 small abattoirs in Iowa, many like the one he describes:

On the bank of a little stream that winds its course through some of the richest farms in Iowa to finally find its way into the Mississippi stands an old rough board shack that is in danger of toppling over on account of the hogs having undermined its supports. It stands in the midst of the feed lot in which there is fed some fifty head of cattle and the same number of hogs. It is innocent of paint or whitewash, either inside or out. The lot is littered with much offal, including the skeletons of two or three horses and the same number of cows whose softer parts have been devoured more or less completely by the hogs, crows and rats. At least they were all in evidence at the time of my visit. It is fair to say there were no flies on the premises at the time of inspection, in December. Looking under this shack - it does not deserve the name of "slaughter house" ... disclosed a leaky floor from which bloody icicles 
projected and a quantity of frozen blood and water under it. . . .

The water for use in this institution, and for the stock around it, is obtained from the above-mentioned stream whose banks show evidence of his hogship having enjoyed many pleasant hours during the previous summer in its moisture, and I am sure the litter on the banks did not add to its purity, although it was being used for the washing of the carcasses and equipment when they were washed. One dirty bucket and one dirty broom, nearly worn out, were all the visible equipment for use in cleaning the place. The proprietor assured me they gave it a thorough cleaning every time they scalded hogs, because they had plenty of hot water left over after they had used it in scalding the hogs. . . .

The proprietor assured me that these carcasses did not hang in this structure to cool, but were hauled to their market immediately after slaughter, and inquiry developed the fact that they had a vehicle which they used to transport the live animals from where they were bought to the place of slaughter, there killed and quartered, the litter brushed out of the vehicle and some dirty burlap stretched along the sides.

Not all conditions were this bad, however, for:

Some butchers have no slaughter houses, but kill in the open, which is preferable, from a sanitary point of view, to the dirty slaughter house, and I have even seen slaughtering operations being carried on in cow stables, pig pens and chicken houses. It would seem that we are in need of devising some way of regulating this business.

Conditions in many of the small houses were as good as would be considered adequate at the time, and it may be surmised that conditions over the state of Iowa as a whole were not very different from those in other states.

\section{An III Wind}

It being an ill wind that blows no good, the furor created by The Jungle did help bring about a more adequate inspection law sooner than might have been the case otherwise. The Bureau was well aware of the deficiencies of the $1891 \mathrm{law}$, and had made numerous overtures toward improved legislation. As noted by Hughes, the prin- cipal faults were first, that federal inspection had to end with examination of the carcasses on the killing floor; no provision was macle for inspection during processing. Secondly, no provision was made for supervision of sanitary conditions of the abattoirs themselves or for personal hygiene of employees, although, as noted, the packers were not entirely unaware of this matter. Nor was any power given inspectors over the possibility of mislabeling of products. And, as was so often the case, appropriations were inadequate and were made on an annual basis; when some of the smaller houses asked for inspection to permit them to engage in export trade, none could be had. In fact, there were occasions when meat for interstate shipment could not be inspected, priority being given by law to meat for export. Thus the situation was somewhat akin to the shoemaker who had no shoes for his children - foreign trade was protected at the expense of domestic consumers.

The old law, Hughes considers, was probably as good as could have been obtained at the time; a better one "must come gradually when the public had become educated to a knowledge of the dangers inherent in meats unfit for consumption." In the new law of 1906: "every weakness in the system discoverable by experience in the operation of the inspection between 1891-1906 has been made good." In addition, the tagging of animals only as "Suspect" at ante-mortem inspection did away with the potential evils inherent in rejection - with the temptation to channel the animals into another market. Moreover, the new law was further strengthened by concomitant passage of a Pure Food and Drug law.

The new law did correct the evils in the previous law, as mentioned by Hughes above. He adds:

According to my thinking there is, however, one fault to be found. . . Sometimes it has been said, rightly or wrongly we know not, that evils arise from the lack of inspection of birds at the large slaughter houses. ... The iniqui- 
ties that are possible when these birds are not subject to ante-mortem and post-mortem inspection at the packing houses cannot be overlooked.

Dr. Hughes undoubtedly would have been distressed to know that another fifty years were to pass before this fault was corrected.

A fortunate provision of the new law was that all existing inspection was in effect abolished, and all packers were required to make new applications for federal inspection. Inasmuch as the new law required a satisfactory level of sanitation in the slaughtering establishment before inspection could begin, this prompted a rapid move in a desirable direction. The one other fault - or rather a circumstance over which the Bureau could have no control, Hughes notes:

In simple justice it should be said that American consumers are marked off by the new legislation into two classes - the unprotected and the protected. ... The unprotected are the people of the country side, the rural villagers, or those in small towns or even cities where meats and meat food supplies are constantly consumed without federal or any other inspection. The nefarious traffic, within state confines, can still go on in diseased, spoiled or uncleanly meat. . . . In such places municipal or state law is imperative.

With increasing centralization of the meat industry, he notes, however:

The protection of the majority of American consumers is now far greater by reason of the superiority of the new inspection and the extent to which it is to be carried.

\section{Army Inspection}

On the subject of meat inspection for the Army, recently assigned to veterinarians, Hughes states that it is not well known that this had become a highly effcient operation:

abetted by the austerity of the staff officers who supervise it, by a hearty desire on the part of the inspectors to serve the people, and by a warm personal loyalty to the soldier in garrison and field. . . The experience of the world shows that more deaths occur from disease than by the bullet.... It may be doubted whether any civilized country in modern times has realized more fully the necessity of a strict supervision of the preparation of meats and meat food products for its soldiers, or made a more complete provision for their inspection ... than has ours.

At this time veterinary inspectors for the Army had no connection with the veterinary arm of the Quartermaster Corps, but were appointed from the ranks of BAI inspectors. Under this arrangement the veterinarian actually served in much the same capacity as before, but was responsible to a staff officer rather than to his superior in the Bureau echelons. Hughes pays tribute both to the War Department veterinarians and staff officers, all of whom: "have had long experience as commissary officers in garrison and field before their assignment as purchasing commissaries takes place." In summing up his lengthy account of the methods employed in army inspection, Hughes states:

A good deal of the best work of the world is done quietly, without much talk, without theatricality. .. . The supervision of the preparation of meats and meat food supplies for the army, under orders from its officers, belongs in that class of work which has hitherto never been mentioned in medical literature. Nevertheless it should be given a high place in the records of preventive medicine because of its protection of human life against ills possible through impure foods.

The Army inspection system soon interested the Navy, and in 1907 Hughes states, "Though belated, the move to establish veterinary inspection for navy meat supplies has been made." At this time Jesse $\mathbf{H}$. White became the first veterinarian to be employed in a professional capacity by the Navy Department; the actual work, however, was done under the supervision of Army officers. Hughes states that the first veterinary inspectors for the Army were C. W. Johnson and Dr. McKinney, appointed in 1902, and G. A. Lytle, G. Loveberry and himself in 1905 .

Noting "provision has been made in the packinghouse law for inspection that inspects," the Breeders Gazette for 1906 sug- 
gested the logic of a veterinary school at the Chicago stockyards to train the numbers of veterinary inspectors required:

Their work is in the stock yards of the country, and it is therefore plain that we should have men trained at the stock yards. . . If the need of a veterinary college at the yards were properly presented to the stock yards officials the result would be a building for a veterinary school greater than any in existence today and a faculty the like of which the world cannot show.

\section{The Inspector and the Public}

As a government inspector, Hughes denies filing a particular brief for this phase of veterinary activity. Objecting to the term, "meat inspector," he notes:

There is nothing more disquieting to the temper nor more deluding to the intelligence than the loose use of a term or phrase. From year to year the veterinary colleges and the students thereof go on speaking of "meat inspection" and "meat inspector" without any clear understanding of the phrases they are using and with confused notions of what inspection, as it is understood by the Department of Agriculture, really means. The truth is, the phrase "meat inspector" had best be abandoned altogether and the longer, but clcar and more inclusive term, Federal veterinary inspector be substituted for it. . . Many forms of the work of a Federal veterinary inspector are in no sense meat inspection.

Hughes outlines the relationship of the inspector to the public; the commercial interests, and the government, noting: "The importance of the office of government inspector has a bearing of which the thoughtless are not aware," i.e., his duty is to protect the interests of all three agencies:

The government looks upon the office of government inspector as a dignified calling. It therefore expects its inspectors to increase their knowledge and make themselves of more value to the people.... The army phrase applies to him: the government inspector's acts should be those becoming an officer and a gentleman.

He notes, however, that the pay scale is not conducive to genteel living.

Additional refinements in the federal meat inspection service, including better pay for inspectors, have increased its efficiency during the years since 1906, of course, but for many years local abattoirs not engaged in interstate commerce operated without adequate safeguards to the health and welfare of the domestic consumer. In most areas this situation has been corrected by the adoption of local ordinances calling for veterinary inspection, including that of home slaughtering, with the result that "distempered" meat is rapidly becoming a thing of the past. This is especially true since the recent inclusion of poultry processing under federal inspection. Total protection of the meat-consuming public, and the assurance of continuation of this protection, will depend upon public support of the concept that no such thing as even "a little disease" in our meat supply can be tolerated.

\section{Filly Filet}

As a now-humorous sidelight on the meat supply of the United States, the advocacy of horseflesh as human food during World War I by W. Horace Hoskins evoked a flurry of comments pro and con. D. M. Campbell urged:

There is no reason, save a sentimental one, why horse flesh should not be used as food in this country, and there are many reasons why it should be used. The horse is less subject to diseases communicable to man than cattle or swine. Its flesh is equally nutritious and palatable, and is eaten and relished by millions of people in many countries. . . In view of the present food shortage the enormous waste of horse flesh is scarcely less than criminal. . . The presentation of these facts by veterinarians will go far in removing the unwise, even ridiculous prejudice against the slaughter of horses for food.

In adclition to having stated the facts as given by Dr. Campbell, Dr. Hoskins had entered an impassioned plea on behalf of his contentions:

Why should we send men to contend with the perils of the deep to secure whales when on our Western plains we have upward of two million of horses, with rich and nutritious flesh, ready for the slaughter pens? ... Shall we continue to encourage every moral wrong that has kept pace with the economic wrongs of our 
land, and allow millions of pounds of wholesome food to go to waste, deny to the animal food raisers of the West, these pastures for sheep and cattle, or deny to our own people and lift our pleas to God for more plentiful and abundant crops, when these horses are roaming over thousands of acres that ought to be tilled and growing grains to save the lives of millions of our brothers and sisters in the war-torn, hunger-stricken allied countries?

On the other side, reaction ranged from the professional: "We as veterinarians should be the last to advocate the killing of horses," to the horse-lover's plaint, "if we can't win out in war without the eating of horse flesh we had better be whipped by the Germans."

\section{The Bureau Lives On}

It is not within the scope of this book to dwell further upon the manifold accomplishments of the Bureau, many of which are ably given by U. G. Houck in his history of The Bureau of Animal Industry (1924). A few of its many achievements, as detailed by Houck, include discovery of the epizootology of Texas fever and a method for eradication of the tick; discovery of the hog cholera virus and development of serum-virus immunization; the speedy eradication of every outbreak of foot-and-mouth disease that has occurred in the United States and the prevention of other plagues from reaching these shores; near-eradication of tuberculosis in cattle in conjunction with improved methods of tuberculin testing; establishment of a meat inspection service which is the envy of other nations; and discovery of control measures for hookworm in man and for roundworms in swine - to name but a handful. Dr. Houck concludes his 390-page history with:

We have aimed to mention only the more important activities, events and achievements which have marked the development and progress of its work . . the Bureau of Animal Industry will continue to grow in importance and usefulness.

It should not be supposed that all was sweetness and light, for that Bureau veterinarians were for many years grossly under- paid is well known. Even more unjust was the marked discrimination against veterinarians by comparison with other USDA employees. Thus the report of the commission on the reclassification of salaries of government employes in 1920 was characterized by J. R. Mohler as a "blow below the belt" to the lay and veterinary inspectors of the BAI. The salary of the Junior Veterinarian, the starting grade, was put at $\$ 1,380$ with increments of $\$ 60$; other junior grade technical positions carried a starting salary of $\$ 1,800$, with $\$ 120$ increments. Veterinary Bacteriologists and Pathologists were accorded the higher figure, and could reach $\$ 5,040$; plain veterinarians, however, could reach only $\$ 3,600$, and were - unlike their supposedly better qualified colleagues - ineligible for the position of Chief of the Bureau. Mohler states:

We are equally confused and chagrined to learn that the veterinary service is evidently considered of less importance to agriculture than any other technical or scientific service in the Department of Agriculture. ... Veterinarians cannot remain satisfied with public service when they are thus discriminated against in the case of both rank and salary, and it is inconceivable how the Federal Bureau can be maintained and recruited as to function properly. . . . And in view of the present high requirements for entering veterinary colleges and the low rating of veterinarians, it could not be expected that many young men confronted with these conditions would be at tracted to the study of veterinary medicine with the intention of entering the public service.

Noting that veterinary college enrollment had fallen to 1,287 students in 19191920, compared with 2,992 in 1915-1916, Dr. Mohler adds:

With the discrimination and lack of appreciation shown the profession by the Reclassification Commission, it is more than probable that a further reaction will be noted in the matriculation at veterinary colleges this fall.

The situation did not improve rapidly, for in discussing "The Veterinary Situation at Washington" in 1928, Dr. Mohler reports:

The veterinary-inspector vacancies are becoming increasingly difficult to fill because of 
the decrease in veterinarians available... partly due to the decreasing number of men studying veterinary medicine.... A further depletion of the forces will have an unfavorable effect on the live stock industry and the public health. ... The incentive to study veterinary medicine would be greatly increased if the Department of Agriculture, the largest single employer of veterinarians in the world, would pay more attractive salaries, thereby increasing the general standard of compensation. ... We have not been able to promote these $\$ 2,400$ men to $\$ 2,500$ until they have had fifteen or more years of service, just because of lack of funds.

He notes with some satisfaction however, a more favorable consideration given by the Congress to recent requests for improvement of the situation.

At the time the BAI had 1,362 veterinarians in its employ; of these only 134 received $\$ 3,000$ or more, the great majority being below $\$ 2,500$. By way of contrast, the department of Public Roads, with 323 employees, had 233 in the $\$ 3,000$ or higher bracket. In the $\$ 5,200-6,000$ bracket the ratio was $16: 1$. Of 215 employees of the Bureau of Plant Industry, I30 were in the $\$ 3,000$ and higher bracket. Today, fortunately, salary scales and working conditions for federal veterinarians are vastly improved, but no one would contend that utopia has been attained.

Dr. Mohler retired in 1943 after 46 years of faithful service with the Bureau, more than half of this time as its chief. He was succeeded by Arthur W. Miller who, like his predecessor, rose from the ranks to become chief during wartime. His quiet dignity belied the high degree of efficiency with which he conducted the Bureau during this troublesome period. Dr. Miller retired in 1945 after 44 years of service with the BAI. His successor was Bennett $T$. Simms, director of the Regional Animal Disease Research Laboratory at Auburn, Alabama, and president-elect of the AVMA at the time.

Without contesting the thinking which resulted in the reorganization of the USDA with the absorption of BAI activities by the Agricultural Research Service by 1953, it is with a note of nostalgia that we acknowledge the passing of the Bureau from the scene. No one doubts that the ARS will continue in the noble tradition, but the old BAI still has a glamor all its own. It will continue to live on in the memory of veterinarians, present and future. As observed by Houck:

Among the workers of the Bureau, past and present, many earnest, energetic, capable men and women have devoted all the useful years of their lives to this branch of the public service. Love for their work has imbued and held them rather than the inadequate remuneration which they received. 


\section{Union of East and West}

The election of $W$. H. Hoskins as secretary in 1888 in the beginning of the second quarter-century apparently boded good for the Association, for in June, 1890, the $R e$ view carried - for the first time - a lengthy "preview" of the annual meeting. This held the promise that the meeting to be held in Chicago - in itself a notable departure from tradition - would be:

the most important meeting held by the Association for many years. .. . It behooves every member ... to consider his duty toward the growing West, and its vast number of earnest, hard working veterinarians, who should to-day be identified with our Association.

\section{REBIRTH IN THE NINETIES}

Another innovation was the publication of an extra number of the Review as a full report (some 120 pages) of the Chicago meeting, which was characterized by W. L. Williams as "the birthday of the true $\mathrm{Na}$ tional Association of the United States." That the move to the West was a wise one is indicated by the fact that no less than five future presidents of the Association not yet members - were present: W. L. Williams, L. A. Merillat, Sesco Stewart, C. A. Cary and S. Brenton.

In his address of welcome, W. L. Williams called for "a strong reciprocal interest between the older and better organized profession of the East, and the younger and now numerically equal body of Western veterinarians." To this, President Michener responded:

We may arrogantly assume, that as of old, the wise men are in the East, but I must insist that the veterinary profession is an exception. ... To-day we place the corner stone - the foundation of our Association has been building since June, 1863 .

The acquisition of some 80 new members was somewhat marred by the dropping of some 40 for nonpayment of dues "and other causes." Those dropped included H. J. Detmers and F. S. Billings, the latter for unprofessional conduct.

The Committee on Education, noting that men still "enter and graduate who can barely write their own names," urged not only standard matriculation requirements, but "a collegiate or academic course of some kind prior to the student's entering upon his veterinary studies." This appears to be the first suggestion that a preprofessional requirement should be exacted. Veterinary textbooks then in use were censured as being behind the times. The need for adequate veterinary legislation was recognized, but this would not be

a universal panacea for every ill. ... The American people-not including politicians who make the laws - are a pretty level-headed lot, and in time will appreciate the distinction between the educated veterinarian and the quack horse doctor. 
The Committee on Diseases reported the work of Theobald Smith on the parasitic organism of the blood in Texas fever, but had little to say concerning the role of ticks in transmission. On hog cholera:

The conclusion has been definitely reached that there are two separate and distinct diseases, the one known as hog cholera and the other known as swine plague.

The government program of slaughter for pleuropneumonia was recognized as so successful "that to-day the disease is thought to exist in only a very limited area around New York City." The fact that tubercle bacilli could be found in milk of cows with no lesions of the udder was emphasized.

Dr. Huidekoper reported having submitted a bill calling for creation of a Veterinary Corps, but was advised this was premature. A substitute bill calling for a veterinary division of the Quartermaster Department was being embarrassed by various other bills promoted "principally by veterinarians now in the employ of the Army."

Papers were read by D. E. Salmon on the work of the BAI, by R. S. Huidekoper on the foot of the horse, by A. Liautard on veterinary jurisprudence, and by Olof Schwartzkopf on meat inspection. Dr. Huidekoper was elected president, W. L. Williams, vice president, and Drs. Hoskins and Robertson were re-elected secretary and treasurer respectively.

Olof Schwartzkopf, a graduate of the Berlin school, came to this country in $\mathbf{1 8 8 5}$ as an assistant to F. S. Billings. Like Billings, he was critical of the American veterinary profession because he advocated the German system of education, military veterinary medicine, and meat inspection. In this he undoubtedly was sincere, but his arguments were ill-timed. In particular, had he not personally insisted on a separate Veterinary Corps, it is probable that a bill giving all Army veterinarians an initial rank of first lieutenant would have passed in 1900 - nearly a half century before this became an accomplished fact.

It may well be that some of the previous meetings would have appeared more productive had they been reported more fully, but it is evident that the Chicago meeting topped any other in a number of respects. Of perhaps the greatest importance was the change in the fortunes of the Association augured by the addition of new blood. So salutary the meeting seemed to have been that at a special meeting of the Comitia Minora in January, 1891 , it was resolved: "That we recommend to the Association that the meeting for 1893 be held at Chicago and that it assumes an international character." This, of course, was in anticipation of the international flavor of the Columbian Exposition to be held there in 1893 .

\section{1}

The meeting at Washington, D. C., in 1891 was something of a disappointment following the success of the Chicago meeting the previous year. Only five "western" veterinarians were present, and only two veterinary colleges and one veterinary science department were represented: "Have our professors of veterinary science the good of their profession at heart? Their reasons for not attending would be interesting." The Special College Committee:

made the time-honored report that most of the colleges favored a three year college curriculum, but were prevented from attaining their desires through the shortcomings of some neighbor.

At the time the feeling was (and probably with some justification) that students would desert colleges that announced a three-year curriculum, and:

American veterinarians, with their deficient education and short college courses, yet manage through inherent enterprise and adaptability to maintain a high rank alongside their colleagues from the long-course colleges of other countries.

Papers were presented by C. C. Lyford on "Barren Mares," by W. L. Williams on "Rachitis," and by R. S. Huidekoper on "Identification of Animals." The Hon. J. 
M. Rusk, Secretary of Agriculture, spoke of:

the mutual interests of agriculture and veterinary science, and of the inestimable and essential value of ... the [veterinary] profession when our national wealth is threatened by contagious and epizootic animal diseases.

In his presidential address, R. S. Huidekoper observed:

The Association has assumed a size and standing which now make the success of its meetings not only of consequence to the personal comfort and satisfaction of those attending, but the larger meetings and the character of the subjects which are brought before them are reflected over the community, who will judge us and our merits and worth by the opinion which we ourselves form of each other.

The committee which had been appointed to investigate the establishment of "a central legalized body of veterinarians" was dissolved without making a report to the dismay of Dr. Liautard, who urged:

Consolidation and union for veterinarians, as for all others, means strength ... elevating our standard and influence, and our usefulness in the general domain of science.

And while he credits a proposition to limit membership to graduates of threeyear schools with having been: "submitted with the best of intentions . . . of elevating our professional standards," he questions its practicability:

The Association has a right to establish rules for its own guidance, and will not the consequence naturally follow that when they find themselves thus excluded from the Association, they will on their part forthwith turn their backs upon the body which ignores them?

Liautard's own school, of course, had a two-year curriculum.

\section{2}

The meeting for 1892 was held in Boston. Once a stronghold of Association activities, this was to be the last meeting there for more than half a century, a fact alluded to by the Governor of Massachusetts in welcoming delegates to the 1946 meeting.

A major step was taken in the unanimous adoption of an amendment requiring that any future applicant for membership:

shall be a graduate of a regularly organized and recognized veterinary school, which shall have a curriculum of at least three years, of six months each, specially devoted to the study of veterinary science, and whose corps of instructors shall contain at least four veterinarians.

Despite Liautard's earlier open opposition to the three-year curriculum, he notes, concerning the Association's stand:

today it has not only become the accepted representative body of the veterinary profession of America, but has acquired such a weight of authority as to enable it to initiate and establish a movement towards which for years many veterinarians have vainly (because singly) worked, to wit: the establishment upon a permanent foundation of an advanced and uniform standard of education for veterinarians in the United States.

The admission of 101 new members marked the largest accession in the history of the Association - more, in fact, than comprised the total active membership less than a decade earlier. Wm. H. Welch, M.D., of the Johns Hopkins University, Prof. Auguste Chaveau, the celebrated French anatomist, and Isaiah Michener were elected to honorary membership. W. L. Williams was elected president, and A. W. Clement, vice president; W. H. Hoskins was re-elected secretary, and J. L. Robertson, treasurer.

Papers were presented by Olof Schwartzkopf and W. L. Williams on food inspection, and by Williams on veterinary science in agricultural colleges. In speaking on the work of the BAI, D. E. Salmon reminds his listeners:

it is one of the objects for which this Association exists, to promote and encourage scientific research .... and that any criticisms will be fair and truthful . . . to bring out points which may have been obscure, or to call atten. tion to conclusions which may be untenable. 
... Our great need is that we should have more original investigations.

Salmon was rankling over a report issued by the Committee on Intelligence and Education, which severely criticized the work of the Bureau as not having "a creditable appearance to other civilized nations," and commended the work of Billings. Salmon characterizes the report as:

misrepresentation ... calculated to bring reproach upon our Department of Agriculture, our scientists, our institutions, and our country... to retard the progress of science.

He then offers an effective rebuttal to the committee report and accurately states the position of the Bureau. In conclusion, he asks:

Does this Association take no pride in the investigations of the Bureau of Animal Industry, or does it propose to stigmatize them as a disgrace to the veterinary profession ... as ignorant, incompetent and dishonest on the evidence which has been submitted?

It would seem fair to state that a majority of the profession sided with Salmon by this time; Billings had been expelled from the Association two years earlier.

\section{A Question of Ethics}

In response to a paper on "Barren Mares" read earlier by C. C. Lyford, in which he recommended the use of a patented cervical dilator, W. H. Hoskins:

was very much interested in the paper... but objected to the right of the essayist to bring in here a patented article. That the Association under their present laws, could not recognize specific plans of treatment, patented articles or proprietary remedies.

Dr. A. H. Baker of the Chicago Veterinary College "did not believe this Association should denounce patented articles," and past-president W. B. E. Miller, in agreeing with Dr. Baker "could not see any comparison between patented impregnators and proprietary medicines," and while he was not in favor of "promiscuous advertis- ing," notes, "We are the only people in existence who do not advertise." To this Dr. Hoskins replied that it was:

an established rule in this Association by usage and by the Constitution and by-laws and code of ethics, from its formation in 1863, that we take no cognizance of patented articles, or in any article that any member of this Association should seek a patent for. Any instruments of value, any plan of treatment, specific in character or of great good, that any member discovered, it was his duty to impart it to us and our right to request it, further that we were not banded together for individual but for mutual advancement.

On another "ethical" matter, the perennial subject of uniform minimum fee schedules for veterinary services is not of purely recent vintage. In 1895 the Maine Veterinary Medical Association adopted the following schedule:

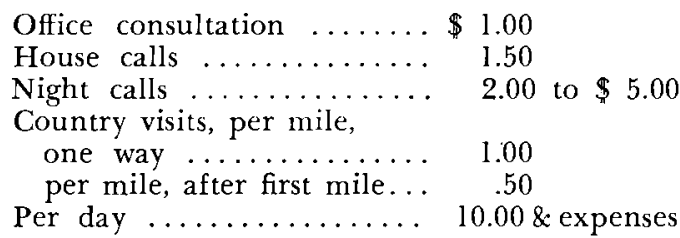

OPERATIONS

\begin{tabular}{|c|c|c|c|}
\hline ing colts & $\$ 3.00$ & & \\
\hline Castrating horses & 5.00 & to & 10.00 \\
\hline Castrating ridglings & 10.00 & to & 15 \\
\hline lastrating small animals & 1.00 & & \\
\hline loating & 1.00 & to & \\
\hline & 5.00 & to & 1 \\
\hline ny & 5.00 & to & \\
\hline Par & 5.00 & to & 10. \\
\hline my & 3.00 & & \\
\hline & 10.00 & to & 15.0 \\
\hline g placen & 3.00 & & 5. \\
\hline g molars & 3.00 & to & \\
\hline & 5.00 & to & 10. \\
\hline $\mathrm{Sp}$ & 3.00 & & \\
\hline Tracheotomy & 3.00 & to & \\
\hline $\begin{array}{l}\text { Minor operations requiring } \\
\text { casting } \ldots \ldots \ldots \ldots \ldots\end{array}$ & 5.00 & & \\
\hline
\end{tabular}

At this time the cost of a veterinary education ranged from as little as $\$ 400$ at some of the two-year schools - for one who lived at home - to as much as $\$ 1,800$ at a three-year school, including room and board. An income of $\$ 1,200$ was considered good for a recent graduate; estab- 
Most of the early fee schedules were adopted as an attempt to eliminate "price-cutting" by suggesting minimum fees; some, however, give the impression of an attempt to rigidly standardize fees on a fixed basis.

\section{The Michigan Capitol Veterinary Medical Association}

This minimum sctuedule of $p$ ings has been adopted by our Association as a guide in making charkes for seterinary services, to be adhered to by our members mo far av local conditions will warrant.

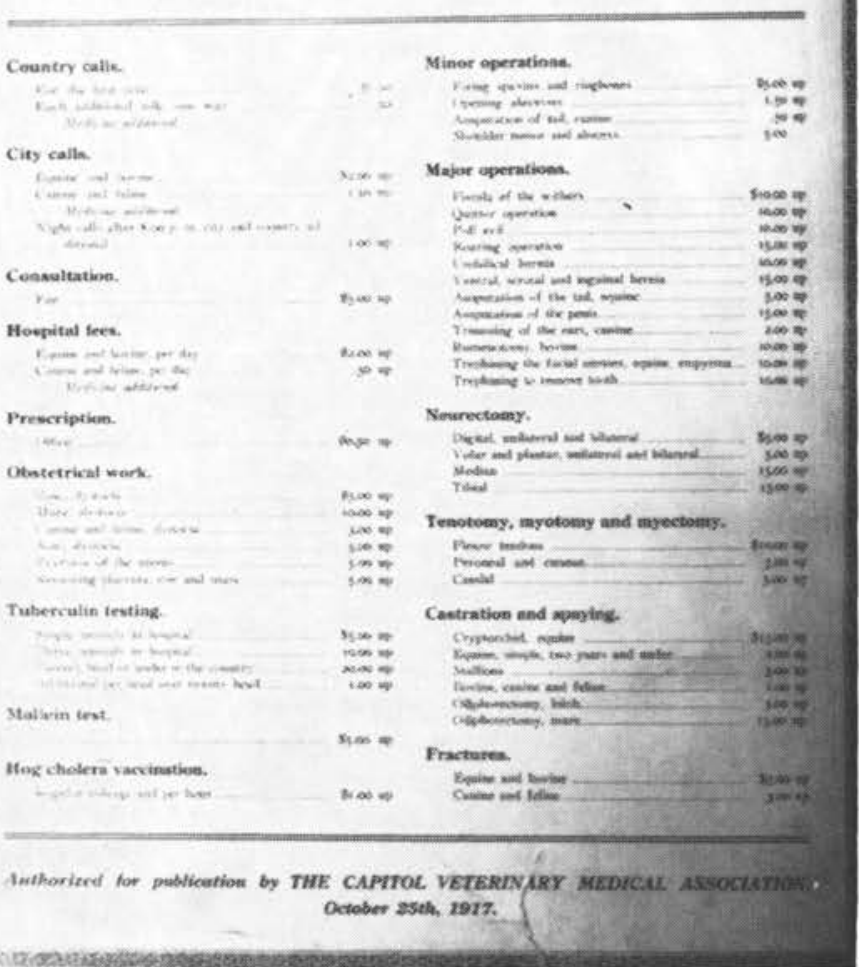

lished practitioners expected to make $\$ 3,000-4,000$, and some made considerably more. Government and institution salaries ranged from $\$ 1,500$ or less for instructors, to $\$ 3,500$ for the Chief of the Bureau of Animal Industry.

\section{W. L. Williams}

Walter Long Williams, V.S., was born in 1856 near Argenta, Illinois. After teaching in a rural school two years, he entered the Illinois Industrial University (now University of Illinois) in 1875. Transferring to the Montreal Veterinary College, his tutelage under William Osler was an inspiration for his later painstaking studies in the problems of reproductive pathology.
In the 1880's he recognized dourine in horses in Illinois and was largely responsible for much of our knowledge of this disease. In 1896 he became Professor of Veterinary Surgery, Obstetrics, Zootechnics, and Jurisprudence at Cornell University, where he was responsible for many innovations in veterinary teaching until his retirement in 1921.

A prolific writer, he contributed many articles to the veterinary journals both here and abroad, and was the author of two classic texts: Veterinary Obstetrics, and Diseases of the Genital Organs of Domestic Animals - long familiar to most veterinarians. Long active in Association affairs, Dr. Williams served as president of the 
Illinois VMA (1889), USVMA (1892-1893) and the New York Veterinary Medical Society $(1906,1907)$.

After his retirement from teaching he remained active in professional affairs and was a familiar figure on the Cornell campus until shortly before his death on October 23,1945 , at the age of 89 . For many years he was affectionately known as "Uncle Billy." In 1944 this writer had the privilege of hearing him address the New York State Veterinary Medical Society on his 65 years in the profession. Much of Dr. William's work is considered at length elsewhere in this book.

\section{3}

The thirtieth annual meeting of the USVMA and "First International Veterinary Congress of America" was held in Chicago at the time of the Columbian Exposition in 1893. The principal evidence of an international character, however, was the election of eleven foreign veterinarians as Honorary Members of the Association, and: "an honorary membership in the Congress was conferred upon some thirty-three members of the profession, covering some twelve countries." There were no foreign veterinarians in attendance.

Extensive consideration was given to the report of the Tuberculosis Committee, which concluded:

That while it may not be practicable at present to undertake the complete eradication of the disease, each State should at least institute a thorough examination of the herds to determine its prevalence. The question of a radical attempt to stamp it out should be agitated; owners of cattle should be apprised of its dangers, all tuberculous cows should be removed from dairies, and all meat should be subjected to a veterinary examination at the time of slaughter.

In speaking of the status of the Association, W. L. Williams notes an increase in membership by 75 per cent in the past few years, and:

Aside from enlarging the scope of the Association and reaching over large territory, the chief change has been in regard to the admission of members. . . For the first time in the history of our Association many applicants have been refused admittance.

The three-year college requirement, he notes:

excludes from possible membership the future graduates of a vast majority of veterinary colleges in America. ... Several of these are anxious to have a cloak of respectability thrown over them through the recognition by us of their graduates... evidence of the growing power of our Association, and of the correctness of our move for a higher standard of education.

It is very clear to you all that we have in this country a number of veterinary colleges which are mere diploma mills, without professional existence or aspiration. ... They admittedly sacrifice professional training to money-making ... [and] are rapidly crowding our professional ranks with incompetent men distinctly in excess of the demand.

On the matter of the size of the Association, a comprehensive - although perhaps not complete - listing (in 1893) of members since 1863 gives a total of 550 in these 30 years, of which 302 were listed as active members for 1893. Many of these had been added in recent years, for it had not been long since the Association had only passed the 100 mark. There were 109 listed as dropped for nonpayment of dues, 21 deceased, 4 resigned, and 7 expelled. There are some obvious discrepancies, however, for only 18 of the 40 founders are listed; a number of those not listed are known to have died. Seven of the founders were still active members: John Busteed, Charles Burden, O. H. Flagg, Alexandre Liautard, Isaiah Michener, J. Penniman, and J. $\mathbf{H}$. Stickney. As a matter of passing interest, Dr. Stickney, first president of the USVMA, was nominated for this post, but his name was withdrawn because he was not present at the meeting.

The Raynor brothers, Joseph and Thomas, deserve mention at this point. Both were present at the organization meeting in 1863, but were among several who withdrew; according to an unpublished manuscript of W. H. Hoskins this was over some question of scruples. Both were known as eminent practitioners of high integrity. In 1864 Robert Jennings attemp- 
ted to have Thomas Raynor listed as a charter member of the USVMA, but neither he nor his brother became active in Association affairs until the 1880 's. For another 20 years or more both were closely identified with veterinary activities in Pennsylvania, and with the USVMA, Thomas becoming a vice president a few years before his death in 1908 . Their father, who had emigrated from England in 1842, was a veterinarian, as were three other sons; the five brothers each practiced for more than 50 years. James, who died in 1905, is stated to have been one of the possibly not more than two or three graduates of the Veterinary College of Philadelphia, headed by Jennings until it closed in 1866.

The Committee on Education reported:

We find that veterinary education is far in advance of what it has been in the past. . . Increasing demands for a higher and a more complete education have led to great improvements in our colleges during recent months ... but we recognize also that there is much room for further improvement.

The committee's recommendations, spelled out in detail, are essentially those that had been advocated for some years, "a uniform matriculation examination, which must be rigidly enforced, a uniform curriculum, and a uniform length of study."

Concerning the veterinary exhibits at the Columbian Exposition, W. L. Williams observes:

It is difficult for some industries or professions to exhibit their triumphs to a body of mixed visitors in such a manner as to interest. and instruct a reasonable number of the passing throng. .... In so far as veterinary science is related to human health it naturally follows the historical antipathy of human medicine to public display of its achievements, because probably of the practical impossibility of making such exhibit without permitting the insinuation of some form of quackery ... but in its relation to economics ... there is certainly scant reason to hesitate making properly designed exhibits.

The BAI had an extensive and splendid exhibit depicting its work in the eradication of animal diseases. While the veter- inary schools of France had large exhibits, those of the United States were not represented. The agricultural colleges, however, had a large and unified presentation consisting of models, skeletons, pathological specimens, and instruments used in teaching and practice. This was under the direction of Dr. E. A. A. Grange of the Michigan Agricultural College; a horse skeleton specially prepared for this exhibit is still in use at Michigan State University.

The matter of incorporation of the Association was again discussed - and tabled, over the objections of F. H. Osgood: "we have been procrastinating and putting it off, not for a day, but years." The seal of the Association was adopted as an official emblem: "One the size of a quarter of a dollar, for bill-heads and letter-heads, and one the size of a dime, which may be used on visiting cards if so desired," but only after incorporation of the Association which was deferred until 1917 (as AVMA - and thus the emblem did not come into use).

Papers were read on millet disease in horses, periodic ophthalmia, fistula, biliary hepatitis in cattle, contagious pleuropneumonia, inspection of southern cattle, swine plague and hog cholera, veterinary education, and the history and prospects of the veterinary profession. Upon satisfactory demonstration that pleuropneumonia no longer existed in either the United States or Canada, a resolution requesting the lifting of the mutual embargoes on the shipment of cattle between these countries and by Great Britain with regard to American cattle was adopted. Another resolution deplored the degrading of the Bureau of Animal Industry "to the shameful basis of the 'infamous spoils system.'”

W. H. Hoskins was elected president; A. W. Clement, vice president; T. J. Turner, secretary; and J. L. Robertson, treasurer.

\section{EMPHASIS ON EDUCATION}

At the 1894 meeting in Philadelphia it was decided to reinstitute the earlier practice of having more than one vice president of the Association, and representatives of 
the eastern, central, and western segments of the profession were elected: J. F. Winchester of Massachusetts, T. J. Turner of Missouri, and W. L. Williams of Montana, respectively.

C. P. Lyman reported that an act of incorporation of the USVMA had been drawn up and presented to Congress through Senator Lodge of Massachusetts. In February, 1893, Senator Lodge had advised:

It is now too late in the session to do anything with any new bill in this Congress, but ... I think there will be no difficulty in getting it through Congress at the next session. These bills are usually passed without objection. [And in December] I will present and introduce your bill, with pleasure.... When it gets to the House it will require more looking after to prevent it from being pigeon-holed.

But in March, 1894:

The bill is in the Committee on Military Affairs [ another "veteran" fiasco? ] . . . J Just now, however, I am so absorbed in the tariff, that it is very difficult for me to give attention to anything, but I will try to do the best I can.

After some months of inaction, Wm. Dougherty, upon his third trip to Washington in the interest of the bill, "after some pretty hard work, located the bill in the Committee on Agriculture and Forestry, where it still remains." Senator Lodge had at least introduced the bill, but the Association was not incorporated until 1917, and then under the laws of Illinois.

C. A. Cary, as Chairman of the Committee on Education, recommended that each veterinary college have a full professor for each of eleven departments (including Physics and Latin). Too many teachers, he felt, were "practical M.Ds. and theoretical veterinarians...n not qualified to become expert professors in Veterinary Medical Colleges."

Speaking for the Committee on Diseases, Leonard Pearson notes:

It is a lamentable fact that we are dependent, almost wholly, for our knowledge of comparative pathology upon the foreign schools
... [ because ] the public has not been brought to see the importance of exact knowledge in regard to the intricacies of comparative pathology, and it has never been willing to pay for work that would lead to these ends.

In response to a letter from a local minister, a resolution was adopted condemning:

the operation of "docking" horses' tails as an operation of fashion ... but so long as it is demanded ... we believe that it should be performed by skilled veterinarians . . . and we cannot unqualifiedly condemn those who perform the operation.

The Virginia State Association protested against this as "a decided straddle of the question," and went on record as unqualifiedly condemning the practice; moreover, "We...pronounce the docking [ of ] tails a cruel and barbarous practice."

W. H. Hoskins was re-elected president, and J. L. Robertson, treasurer; Leonard Pearson was elected secretary.

\section{Association of Veterinary Faculties}

W. H. Hoskins, as Chairman of the Committee on Congress of Colleges, reported the formation of an Association of Veterinary Faculties of North America with C. P. Lyman as permanent president. Dr. Lyman spoke of:

the great encouragement that the movement had met with, and already felt that a great deal had been gained by this commingling of these various representatives, and a better understanding had been accomplished among the schools.

However, Dr. Liautard, who had not been in attendance, later protested in a lengthy letter challenging the constitutionality of the organization: "By what authority does the 'self-named' Association of Faculties exist?" While his school was represented in the group, he objected to the apparent fact that the Association had been rather informally organized by "a few persons engaged in teaching in some of the veterinary colleges." Instead, he urged that the board of trustees of each college appoint a delegate. 
As noted by Merillat and Campbell, from the outset the meetings of the Association:

were battlegrounds for a war between the various schools over entrance requirements, length of the course and the curricula. ... In the beginning the private schools fought one another. ... Eventually the private schools were lined up uniformly against the state schools. ... The desideratum in the imbroglio was students. The state schools did not want the private schools to steal them by means of low entrance requirements and a short term. The private schools did not want to lose them to the prestige of state institutions. . . The fallacy... was probably difficult to see at the time ... there has been no time since 1890 when the reputation for giving a good course did not attract more students than the reputation for low entrance requirements and a "diploma come quick."

\section{5}

There was but meager attendance at the 1895 meeting in Des Moines: only twentyfive members answered roll call the first day. The Association, moreover, was without funds, primarily because the printing of the proceedings of the meetings in two previous years (1892, 1893) had cost more than was taken in from dues. Accordingly, the dues had been raised from three to five dollars - thus creating another problem: despite increased membership, the actual income from dues was decreased by delinquencies.

In his report as Chairman of the Committee on Education, C. A. Cary observes:

The United States is still blessed with a superabundance of veterinary colleges. One in Iowa, one in Illinois, one in Ohio, one in Pennsylvania, one in Massachusetts, two in New York State, and one for the entire South would more than supply the demand. It seems that all the small men in the profession have gone wild on the necessity of having a place in a college .... The faculties of nearly all of the private schools are made up of local men who will work for prestige - a kind of practice prestige.

He suggests that graduates of agricultural colleges with veterinary instruction should receive a year's credit in the recognized three-year veterinary colleges.
In response to objections over the teaching of veterinary science to agricultural students, W. B. Niles counters:

the instruction received does not tend to produce empirics, but ... always tends to a higher appreciation of the science, and impresses the student with his incompetency to deal with all classes of cases.

Most of one day was spent in a discussion of the tuberculosis problem and resulted in a resolution "indorsing the tuberculin test and condemning physical examination only as unreliable, and microscopical examination of dairy milk as deceitful and unwise in the present day."

Some appreciation of the importance attached to the tuberculosis question at this time may be had from the fact that at a subsequent meeting of the Section on Public Health of the New York Academy of Medicine, papers on this subject were read by F. H. Osgood, Leonard Pearson, H. D. Gill, and James Law.

Papers were read by Olof Schwartzkopf on antitoxin production, by Tait Butler on accidents in casting animals, by $\mathrm{S}$. J. J. Harger on roaring, by $M$. H. McKillip on plantar neurectomy, by W. L. Williams on colic, by M. H. Reynolds on hypodermic cathartics, and by J. C. Meyer on anesthetics in horses, which included a practical demonstration - perhaps the forerunner of the clinical demonstrations featured at later meetings.

W. H. Hoskins was re-elected for an unprecedented third consecutive term as president; F. H. Osgood, C. C. Lyford, and R. H. Harrison were elected eastern, central, and western vice presidents, respectively; Sesco Stewart was elected secretary, and J. L. Robertson, treasurer.

\section{W. H. Hoskins}

William Horace Hoskins, D.V.S., was born in Rockdale, Pennsylvania, July 23, 1860. In 1881 he graduated from the American Veterinary College, following which he spent the greater part of his professional life in Philadelphia, in practice, business, politics, and teaching, the latter 
at the University of Pennsylvania where he taught veterinary jurisprudence, ethics, and business methods. During much of this time he also edited the Journal of Comparative Medicine and Veterinary Archives. In 1917 he became Dean of the merged New York-American Veterinary College, where he also taught jurisprudence and clinical medicine.

A strong association man, Dr. Hoskins was closely identified with the AVMA, the Pennsylvania and Keystone Veterinary Associations, and was an honorary member of several other state and regional groups. His record of attendance at 39 consecutive AVMA meetings (from his graduation until his death) probably has never been equalled. In addition to serving on numerous influential committees, he was secretary of the USVMA from 1888 to 1893 , and president from 1893 to 1896 . He served as president and as secretary of the Pennsylvania Board of Veterinary Medical Examiners, and was nominated for mayor of Philadelphia. In addition, he kept up numerous business interests as well as his practice while residing in Philadelphia.

Of him, the Journal states upon his death on August 10, 1921:

As a successful practitioner, Dr. Hoskins ranked among the foremost in the United States, but he was never too busy nor too fatigued to take an active interest in all movements intended to elevate and promote the profession. He was an ardent advocate of a high standard of veterinary education, and his articles in veterinary publications and addresses before public gatherings accomplished much in helping to raise our standard to where it is now. He devoted much energy and time for twenty-five years to secure legislation in the interest of the Army veterinary service, and what has been accomplished was largely through his persistent efforts.

Time has demonstrated that one of his greatest legacies to the veterinary profession was his son, H. Preston Hoskins, longtime editor of the AVMA Journal.

\section{6}

At the 1896 meeting in Buffalo, W. H. Hoskins notes in his presidential address that the depressed economic situation in the past few years:

has shown the way to broader fields of labor and opened full wide a domain of usefulness in sanitary work unlimited in scope, where all mankind may reap the greatest benefits, and which will command for us the highest need of praise and admiration.

In this connection he observes:

training men to minister to the ailments of the lower animals.... is an essential and worthy object, [but] the school has a higher purpose - that of demonstrating the relations in which such diseases stand to the welfare of the human family... The day is not far hence when this must be the aim and purpose of every veterinary school in our land.

In a comprehensive discussion on tuberculosis it was recognized that while:

there exists in some quarters a difference of opinion as to the relation of tuberculosis among cattle to the public health . . . it is the opinion of the United States Veterinary Medical Association that ... tuberculosis of man and cattle is identical.

Not only is the disease transmissible through milk from tuberculous cows, but:

Tuberculin furnishes incomparably the best means of recognizing tuberculosis in the living animal ... [and] is entirely harmless to healthy cattle, and is ... exceedingly accurate.

At the time, tuberculosis eradication was being hampered by claims that the disease in cattle was not a public health problem, and that the use of tuberculin would infect healthy cows.

The Committee on Army Legislation reported that action on a bill calling for the rank of second lieutenant for Army veterinarians had been blocked by a "do-nothing" Congress, and by the QuartermasterGeneral who maintained:

we should be made civilian employees, hired by contract at so much a month . . . the result of which would make about twenty nice political appointments ... so we devoted our entire time toward manufacturing sentiment among 


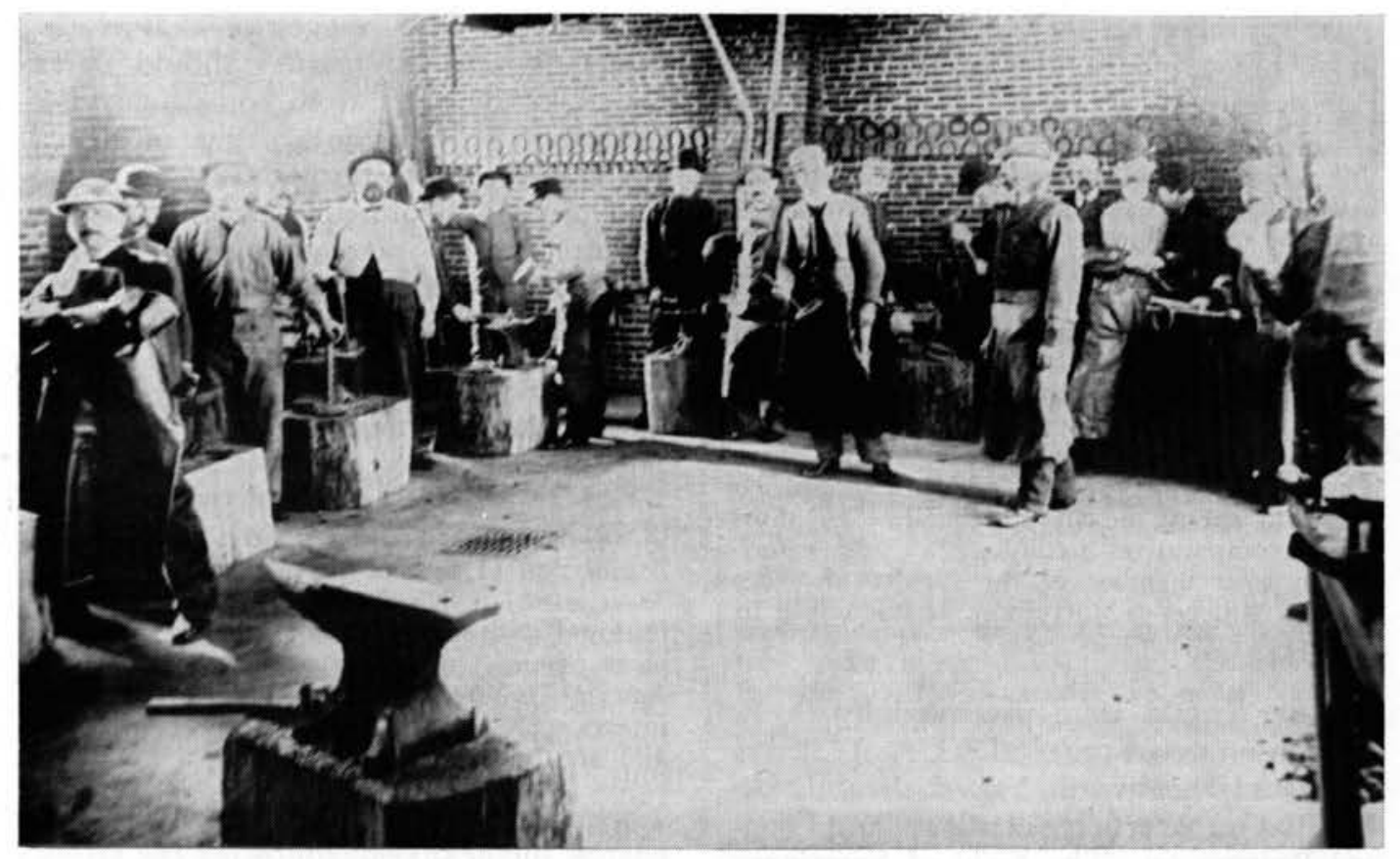

Scene in the forge at the University of Pennsylvania School of Veterinary Medicine in 1885. Michigan State University Library

the members [of Congress] and working with the committees.

The Committee on Education noted:

Of the 17 schools heard from [of 18 ], 14 require a three-years' course of study; 4 of them required this before the question was agitated by this Association, one, just established, voluntarily, leaving nine to the credit - are we not right in saying it? - of the earnest efforts of this Association.

This left the matriculation examination as:

the most important matter that we have to contend with .... While the three New York colleges must submit to the Regents' veterinary student certificate . . . some of them [specify only ] reading, writing and spelling; one ... . while so specifying, allows those who fail to enter upon their professional studies, provided they pass the examination before the beginning of the second year.

In speaking on "Some Experiences in the South," W. H. Dalrymple observes:

Veterinary medicine and surgery, in the more Southern States, are still in their infancy; but through the influence exerted by the reputable graduate the people are beginning to realize the value of intelligent aid in the care and treatment of their animals, in contradistinction to the illiteracy and superstition of the empiric, who is usually in the habit of compounding his mysterious nostrums at certain phases of the moon and performing his so-called operations under similar lunar conditions.

He reports an outbreak of anthrax that spring which "depopulated great herds of cattle, mules, and sheep," and which had exhausted the supply of vaccine - once he had "upset the calculations of the illiterate 'charbon doctor.',

The subject of veterinary instruction for horseshoers in schools of farriery was discussed at length, some siding with the Master Horse-shoers Association in advocating that pathological as well as normal structure of the foot should be taught. The majority, however, apparently agreed with Dr. James McDonough, who had been a practical blacksmith, that the Association should beware of "nursing a viper by making half-educated foot experts." 
In speaking on "The Need for Veterinary Education in Medical Colleges," E. P. Niles notes:

A few years ago it seemed to be a matter of little importance whether a physician knew anything of the infectious diseases of the lower animals or not, but since the researches in bacteriology have opened up a comparatively new field of science we are forced to admit that contagious and infectious diseases are due to a specific micro-organism and that certain micro-organisms are capable of causing disease in both the higher and lower animals. . . The physician of this day and age should, to a certain extent, be an investigator. He must know comparative pathology. ... A veterinarian as a member of the faculty of every medical college, is, therefore, indispensable in this day and age.

Other papers were presented by D. E. Salmon on avian tuberculosis, A. T. Peters on serum therapy in hog cholera, L. A. Merillat on veterinary dentistry, and Leonard Pearson on "The Field of Veterinary Science." F. H. Osgood was elected president; Sesco Stewart, secretary; and J. L. Robertson, treasurer of the Association. As a matter of some interest, this was the first meeting of the Association to be attended by the wives of veterinarians.

\section{7}

At the 1897 meeting in Nashville, president F. H. Osgood called attention to some of the undesirable features of electing the president, i.e., by nomination and a majority vote of those present at the meeting following which the chair was turned over to the new president. Suppose a new president "is opposed to the policy advocated in the annual address of the retiring president. Must a year be lost before the new party have opportunity to declare its policy?" - thus leaving only a day or two for action to be taken on his recommendations before another man is elected. Also:

each member who desires to vote for the Association's officers must pay for that privilege the exact sum which it costs him to leave his business ... to travel ... and support himself while absent.
Dr. Osgood also suggested that voting rights on business matters should be invested in delegates from constituent associations to prevent a miscarriage of the will of the membership through the preponderance of "self-appointed" delegates from the region near the place of meeting. These objections were later recognized as valid by establishment of the House of Representatives in 1934.

Citing "the great help that will come to us all from professional unity," Dr. Osgood suggested:

the desirability of changing the name of this Association to that of the National Veterinary Association of North America. ... The professional and economic union between certain parts of the United States and British North America, is now as close, as far as our mutual interests are concerned as it is between one and another of our States.

This suggestion did result in a name change the next year, following the tabling of a resolution by $\mathrm{A}$. W. Clement in favor of "The American Veterinary Medical Association."

As Chairman of the Committee on Diseases, Theobald Smith notes that the stipulated function of the committee, "to investigate the character and extent of prevalent diseases throughout the United States," was in need of revision:

The need of the present is not diffusiveness ... but concentration ... upon some one theme, to give those who know something about it a chance to impart their knowledge ... and those who do not know, the opportunity to listen.

As a matter of interest, Smith had been proposed for honorary membership some years earlier, but was refused because he was eligible for regular membership as a physician. At the Nashville meeting he resigned his active membership and was elected an honorary member of the Association.

Tuberculosis was again the major topic for discussion. J. M. Parker notes:

there has been too great a tendency, among members of the profession, to look upon every- 
thing as secondary to the question as to whether a cow reacted to tuberculin or not. ... The important question of wholesome milk. . the value of cleanliness and light, ventilation and drainage... should receive greater attention ... [ but] I would not neglect tuberculin.

The ensuing discussion between Drs. Salmon, Pearson, Law, Cary, and Lowe - all future presidents of the Association would be of interest today to anyone engaged in tuberculosis eradication.

D. E. Salmon was elected president; Sesco Stewart, secretary; and W. H. Lowe, treasurer.

\section{EXIT USVMA; ENTER AVMA}

The thirty-fifth annual meeting at Omaha in 1898 was the last to be held as the United States Veterinary Medical Association. Acting upon the recommendation of the Executive Committee, it was unanimously voted to change the name to the American Veterinary Medical Association. On the matter, President Salmon had urged:

This proposition is in line with the growth and development of this body. .. . Some disadvantages ... will probably be more than counterbalanced by the wider range of our vision and the nearer approach to a cosmopolitan character.

Dr. Salmon reviewed the recent progress in animal disease research, noting:

there is nothing more remarkable than the influence which the study of animal diseases has had upon the advancement of human medicine, and the resources which the investigators of this subject have laid at the feet of suffering humanity. The elucidation of the nature of contagion; the establishment of scientific disinfection; the development of aseptic surgery; the introduction of bacterial products, vaccines, animal extracts and antitoxins for the treatment of various diseases are well-known examples.

The work of the Association, he urges:

must be principally of an educational nature. It should begin with its own members, encourage them to study, to think and to write. It should particularly encourage original observation and investigation. ... It should also be active in educating public sentiment.... Convince the people of the various municipalities that we are laboring to save their property and to protect their health, and it will be strange indeed if we meet with opposition.

In particular, he urged more attention to meat and milk inspection, and the eradication or control of hog cholera, tuberculosis, Texas fever, glanders, sheep scab, and rabies.

A proposition to increase the term of the presidential term from one to two years, Dr. Salmon deemed:

ill-advised and undesirable. We have had numerous members of this association who should have been honored with the presidency but for whom the opportunity has never come. If we double the length of the term, we lessen by fifty per cent the chances of every member to gain this distinction, which should be coveted by all.

In the 34 years preceding Salmon's election, there had been but 18 presidents, only seven of whom had served but a single term. Since then, only two presidents have served for two years: C. J. Marshall, because no meeting was held in 1914, and James Farquharson, during World War II.

At the first AVMA clinic, held in a barn on Capital Avenue:

The first operation was upon a ridgling by Dr. George A. Scott, of Independence, Iowa. . . . Dr. L. A. Merillat, of the McKillip College, Chicago, now stepped forward and announced that he would perform on . . . an extremely bad roarer ... his new operation of "arytenoidrraphy," and did so to the delight of all. He is a cool surgeon, and ... his method was very favorably commented upon. At the conclusion of the operation, and while the patient was still under chloroform narcosis, Dr. W. L. Williams, of New York, began the removal of the ovaries from a vicious little old mare.

An exhibit of some interest was an "ingenious" portable "vapor and medicated bath" for horses: "An alcohol stove within this tightly closed room quickly raises the temperature to . . . about $180^{\circ} \mathrm{F}$, when the animal will be thrown into a profuse 


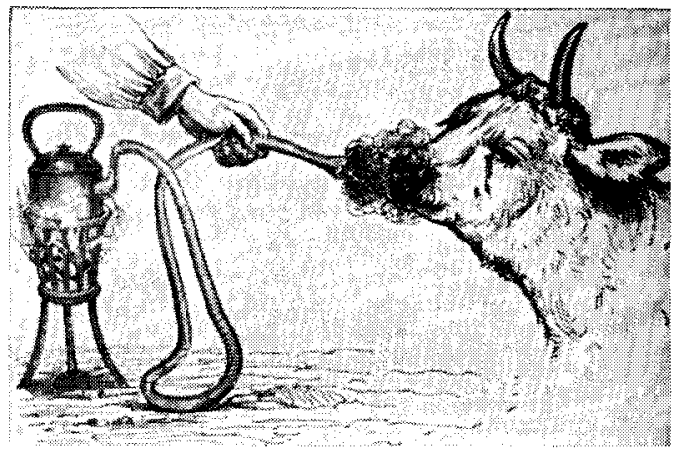

Steam medication, ranging from administration by simple devices to elaborate vapor baths, was popular for respiratory and other ailments during the nineteenth century. Clater-Armatage: Cattle Doctor

perspiration." A similar device had been advocated by George Dadd in his Modern Horse Doctor (1854), and in 1818, James Carver of Philadelphia had advertised his "Patent Universal Veterinary Medical (vapor) Bath" in his ill-fated Farrier's Magazine.

The subject of meat inspection occupied a large part of the program, with presentations by W. H. Hoskins, D. E. Salmon, Leonard Pearson, C. A. Cary, James Law, and Sesco Stewart. This panel is notable for the fact that it consisted of the president, a past-president, and four future presidents of the Association. This was followed by a visit to the Cudahy Packing Company to inspect an exhibit of pathological specimens collected by the local inspectors of the BAI. This proved to be "the most complete and extensive exhibit probably ever held in the world," much credit for which should go to Dr. Don P. Ayer, chief inspector at Omaha.

Dr. A. W. Clement was elected president; Sesco Stewart and W. H. Lowe were reelected secretary and treasurer, respectively.

\section{E. Salmon}

Daniel Elmer Salmon, D.V.M., was born at Mount Olive, New Jersey, July 23, 1850. He graduated with a Bachelor of Veterinary Medicine from Cornell University in 1872, and was awarded the D.V.M. in 1876 after clinical study in France. After investigating contagious diseases of animals for the USDA, he was called to Washington to organize what became the Bureau of Animal Industry in 1884. During the 21 years he served as its chief, pleuropneumonia and several outbreaks of foot-andmouth disease were eradicated, the federal meat inspection system was inaugurated, the mode of transmission and methods for control of Texas fever were worked out, effective quarantine regulations for imported animals were promulgated, and much progress was made upon the control of hog cholera - in spite of the roadblocks imposed by his chief antagonist, F, S. Billings.

Dr. Salmon was never overly popular in his pioneering role, and to defend the many attacks upon the BAI - mostly unwarranted - he felt forced to sacrifice much of the dignity that might have attended his important - but poorly appreciated position. To his credit it can be said that he effectively dispelled doubts from within the veterinary profession concerning the validity of his work and that of other Bureau veterinarians - with the result that he was elected president of the USVMA in 1897. Through no fault of his own, he was in effect "thrown to the lions" in the wake of sensational, but misdirected, charges concerning the meat inspection system, and broken in spirit, Dr. Salmon was removed from office in 1905. After five years in Uruguay, he returned to the United States where he died at Butte, Montana, August 30, 1914.

Various details of Dr. Salmon's work with the BAI are recounted elsewhere, although a full record of his achievements would require a volume in itself. While the Bureau might have been founded without him, it is doubtful that it could have functioned well-certainly not as brilliantly as it did - except for his direction during its crucial years. Except for Salmon's vigorous and pointed defense it is more than probable that the Bureau would have been discredited by the machinations of Billings and others of his ilk over the hog cholera controversy. The same was true regarding the well-meaning but ill- 


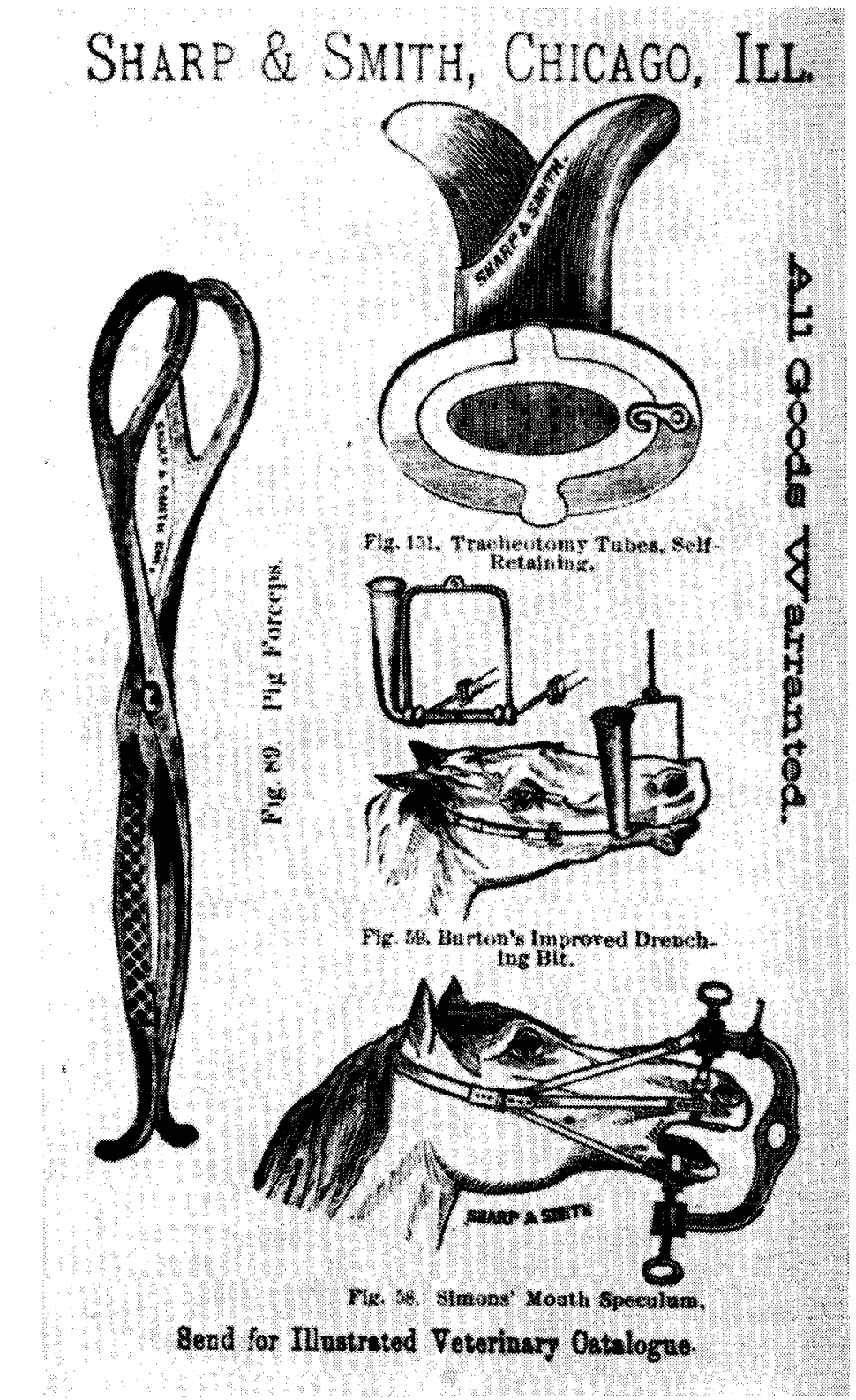

Veterinary instruments, ca. 1890. The drenching bit was a major improvement over the farrier's bottle or drenching pipe, but it was destined to be superseded by the stomach tube. American Veterinary Review

advised attacks on the federal meat inspection system by Olof Schwartzkopf. Obviously, Dr. Salmon did not compile the brilliant record made by the BAI in its early years by himself - although it is evident that he alone was the man who could have conceived and directed its program, and defended it from its enemies. Un. doubtedly one of his chief assets was the ability to attract and hold - at woefully inadequate salaries - the most capable coterie of investigators that could have been assembled at the time - or at any time. W. H. Hoskins characterized Dr. Salmon's life as being: "one of the most complete lives of unselfishness and true public service ever lived by any member of my chosen profession." 


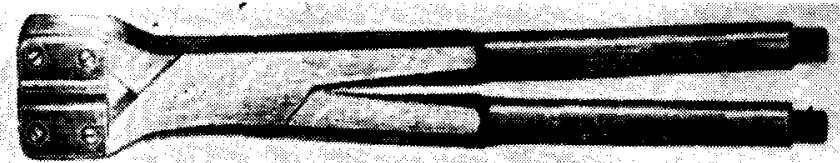

Perfint Molar Cutter, ntralght, $\$ 10.00$.

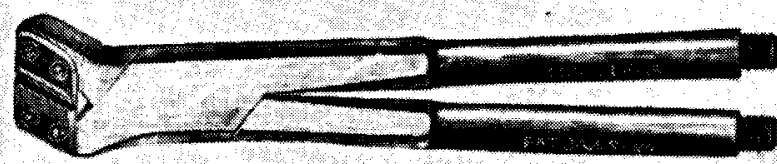

Truncator, 810,00 .

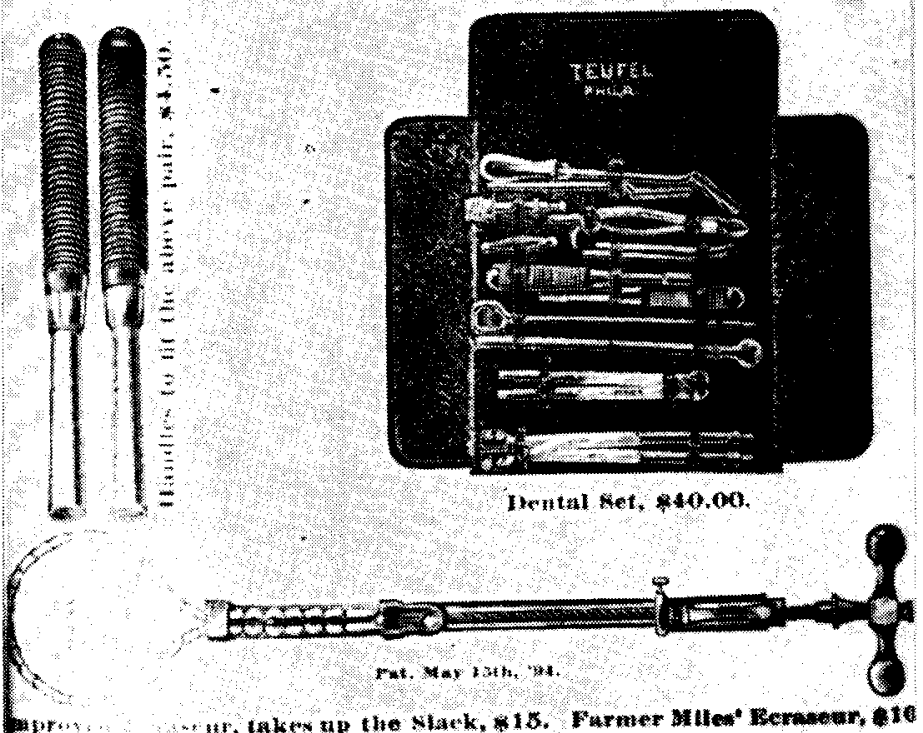

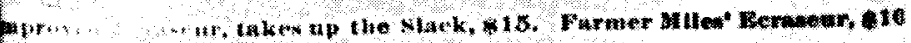

\section{ICOD J, TEUPEL \& BRO,}

Whaturen of Veterinary Instruments,

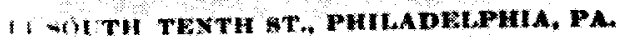

Dental instruments and spaying ecraseur, ca. 1890 . More than a few of these dental sets are still in use. American Veterinary Review

\section{9}

At the meeting for 1899 , held at the Academy of Medicine in New York City, President A. W. Clement observed:

the veterinarian may claim a close brotherhood with the practitioner in human medicine and both professions by working harmoniously can do much to advance the public health.... While we have to thank the practitioner of human medicine for certain new methods of treatment, which we can adapt to our use as circumstances may require, at the same time the field for original work is open for the student of veterinary medicine, and he has it in his power to do much to further our knowledge of disease not only in the lower animals but also in man. Thus, the practitioner in human medicine can also learn from us.

After noting the recent achievements of the veterinary profession, Clement states, concerning what may be done:

We enter the realms of possibilities. ... In all probability in the not-far-distant future we may be so far able to control and cure disease as to render the pole-axe unnecessary except from choice. . . Is it too much to hope that tuberculosis may be cured, that rabies and tetanus may be arrested and their ravages be stopped in much the same way as has been done for diptheria?

In delivering "A Plea for the More Gen- 
eral Use of Anesthesia in Veterinary Surgery," J. P. Turner charges:

we see some veterinary surgeons still pursuing the methods of the ancients ... and the feeling still exists, largely among the laity, that we are a hard-hearted profession.

In a more optimistic note on "The Veterinarian of the Future," N. S. Mayo asks, "who is there to-day who dare pronounce upon the progress in veterinary science that the next fifty years will bring forth?" Dr. Mayo, who lived to see the next fifty years and more (died 1958), states as his credo:

I believe that the veterinarian of the future must choose his profession from high and noble motives, not for the financial interest alone but because he shall love to alleviate the suffering and assuage the pain of those who cannot speak. I believe that the secret of success of the veterinarian of the future will lie in the education he must have. . . The education of the veterinarian of the future should be broad, liberal and scientific.

The program included papers on tuberculosis by Leonard Pearson; dietetics by W. H. Dalrymple; glanders by M. H. Reynolds; asepsis and antisepsis by W. $\mathrm{H}$. Lowe; azoturia by R. P. Lyman; milk hygiene by C. C. McLean; rabies by J. M. Parker; and acetanilid by R. R. Bell. The program of the Association of Veterinary Faculties included papers on state board examinations by A. W. Clement; practical surgery by $W$. L. Williams; clinical lectures by S. J. J. Harger; and the education of the veterinarian by James Law. Of some interest is the fact that of the twentythree papers presented, ten were by past or future presidents or secretaries of the Association.

The clinical program, held at the American Horse Exchange, included a repeat of the vaginal ovariotomy by $W$. L. Williams, who had performed the same operation the previous year; median neurectomy by C. E. Clayton of the New York American Veterinary College; resection of the lateral cartilage for quittor by G. H. Berns; and spaying of a pregnant bitch by W. L. Williams.
Leonard Pearson was elected president of the Association; Sesco Stewart and W. H. Lowe were re-elected secretary and treasurer, respectively.

\section{Milk Fever}

Of the papers programmed for the meeting, one - unfortunately only "read by title" - deserves special mention. This was by Olof Schwartzkopf on "The Schmidt Treatment of Parturient Paresis." The previous year, Liautard had noted in the Review:

Parturient apoplexy is a disease the pathology of which is about as well understood as is that of azoturia, and almost every practitioner has his own ideas as to its therapy. Not a few have settled down to a belief that severe cases die and mild cases recover.

This was in connection with Schmidt's announcement in Denmark of his discovery of udder insufflation, and serial publication of his findings in a translation by the indefatigable W. L. Williams.

In the belief that milk fever was caused by a local infection and absorption of toxins from the udder, Schmidt infused a solution of potassium iodide for its presumably antiseptic effect - which it does not possess. While he apparently did not recognize the benefits from the injection itself, particularly those "interspersed with abundant injections of air," his work laid the foundation for the first successful treatment of this mysterious malady. Unfortunately, it was some time before veterinarians appreciated the significance of Schmidt's statement (which he also failed to appreciate):

The infusion of an iodine salt in the udder, especially when accompanied with the introduction of atmospheric air, gives the promise of a quite typical result and has in a large measure brought about remarkably prompt recovery.

In subsequent volumes of the Review numerous reports on the Schmidt treatment appear, the results being good, bad or indifferent, apparently depending on the volume of fluid and air administered; those who made frequent return calls to 
repeat the treatment enjoyed greater success. One veterinarian, who routinely made three calls at six hour intervals, reports: "What was repulsive to me once is now pleasant. . . Usually I had to hear the same old song - 'She died last night.' Now the tune has changed."

A Michigan veterinarian, W. E. A. Wyman, in 1902, reports a particularly interesting development, the full significance of which, however, was likewise missed. Being caught without his KI on one occasion, he injected two quarts of waterrather than the liter recommended by Schmidt - and found:

This cow was up and doing well on the following morning. This opened the writer's eyes a little. The next cow also got up all right without K.I. in the injection. In fact, almost all cows with parturient paresis will get up after one to three injections of purely boiled water... [ which] upsets the Danish theory as to the cause of the disease and the specific nature of the treatment.

Later this year the Review reported Schmidt's modification of his treatment in which "air is pumped through the iodide of potassium into the mammae until it becomes tense." Earlier, Schmidt had theorized that the smaller quantities of air increased the effectiveness of the iodide, and his modification indicates that he was not ready to relinquish his faith in the efficacy of the drug. Wyman, certainly, should receive some credit for discovering what Schmidt was not ready to admit. At this point it is sufficient to state that it was not long before the true role of udder distention, whether with air or water, was appreciated.

\section{A. W. Clement}

Albert W. Clement, first president of the newly-renamed AVMA, was born in Lawrence, Massachusetts, in 1857. He spent two years at Harvard University, and in 1879 went to $\mathbf{M c G i l l}$ University where he graduated from the veterinary school in 1882. Following graduation he taught at McGill and investigated cattle diseases for the Canadian government. After two years' study in Europe he pursued animal disease investigations at the Johns Hopkins University for six years. He was also connected with the BAI and was active in promoting the veterinary aspects of public health in Baltimore. In 1896 he was appointed State Veterinarian of Maryland, and in 1898 was elected president of the AVMA. His death in Baltimore on March 3, 1901, at the age of only 44 years, was an untimely one for the veterinary profession.

\section{Animal Engineer}

The meeting for 1900 was held in Detroit. In his presidential address, Leonard Pearson dealt with the status of the veterinarian and called for greater attention to: "what might be called the physiologic phases of animal husbandry." Historians have credited Dr. Pearson with the suggestion that the title of veterinarian be relinquished in favor of animal engineer. Thus in 1911, W. H. Hoskins asserted that Pearson "coined the name "Animal Engineer,' and for the field of comparative medical science that of 'animal engineering.'" And in 1935, Merillat and Campbell bluntly claim, "The name 'animal engineer' was suggested as a substitute for 'veterinarian' by Dr. Leonard Pearson ... . in 1900."

As a sidelight on this matter, in speaking on "The Animal Engineer" in 1920, W. H. Lowe urged:

the advisability of bestowing the degree of B.S. or M.S. in animal engineering upon veterinarians who especially distinguish themselves in the study and practical application of scientific principles to the problems of animal husbandry and animal industry.

And in discussing "The Responsibilty Confronting the Veterinary Profession" at the AVMA meeting in 1920, Lowe divides veterinarians into five groups: research workers and teachers, practitioners, sanitarians and official veterinarians, army men, and animal engineers:

those with superior training in the basic sciences and in animal husbandry which fits them to apply this knowledge to the improve- 
ment, development and maintenance of superior livestock.

While it is true that a number of selfstyled "comparative pathologists" were playing down the fact that they were veterinarians - and occasional dissatisfaction with the designation is still met with - this certainly was not the case with Dr. Pearson; in his address he used veterinary (profession) or veterinarian 48 times to twice for animal engineer(ing). What Dr. Pearson said was:

With his knowledge of comparative anatomy, physiology, chemistry, foods and the predisposing and exciting causes of disease, the veterinarian should be the natural expert ... on problems relating to all phases of animal husbandry. Before this can occur largely it will be necessary for the public to relinquish the idea that veterinarians are useful only to patch up decrepit animals or to check the spread of disease, and be educated to regard them as experts in animal husbandry - as animal engineers... each veterinarian [italics mine] should extend his knowledge and his practice, and become an expert in animal engineering.

And while Dr. Pearson recognized the need for precise studies in pathology:

If the veterinary sciences are dominated by comparative pathology, there is danger that the point of view of the veterinarian will become narrow, and that he will not be competent to apply to the best advantage the knowledge of comparative pathology that he possesses.... It is necessary for a veterinarian to be thoroughly familiar with animals in health before he can treat them successfully or economically when they are diseased.

Dr. Pearson's perspective of the entire field of veterinary science is indicated by his endorsement of the eminent German veterinary pathologist, Theodore Kitt, for honorary membership in the AVMA.

In speaking on "The Relation of Veterinary Medicine to the Public Health," W. H. Lowe observes:

A great work is being done by qualified veterinary practitioners all over this broad land in sanitation and preventive medicine, and it is a deplorable fact that the nature and scope of this work is not more fully understood by otherwise intelligent people. Preventive medicine will advance as its value is recognized and demanded by the public generally. ... It seems strange, from the standpoint of the veterinary profession, that the public is so slow in supporting and encouraging what veterinary science is capable of doing for the health and lives of the people themselves.

But with regard to pet dogs and pocketbooks - animal health and wealth - veterinary medicine is "in the great majority of instances, appreciated."

It would appear that Dr. Lowe's request "that the relation of veterinary medicine to the public health shall be discussed as its importance demands," did not go unheeded. M. E. Knowles reported on the transmission of sarcoptic scabies of horses to man; the subject of rabies was discussed by D. E. Salmon and by M. P. Ravenel; and tuberculosis by Austin Peters and R. R. Dinwiddie, "we do have cases of tuberculosis in the human being derived from cattle." In determining what was or was not fit for human consumption, Tait Butler urged greater attention to: "The Relation of the Lymphatics to Meat Inspection."

Tait Butler was elected president of the Association; Sesco Stewart and W. H. Lowe were re-elected secretary and treasurer, respectively.

\section{Leonard Pearson}

Leonard Pearson was born in Evansville, Indiana, August 17, 1868. In 1884 he entered Cornell University and graduated with a B.S. in Agriculture in 1888 . He became interested in veterinary science, and in 1887 was employed by the USDA in the pleuropneumonia eradication campaign near Chicago. He entered the School of Veterinary Medicine at the University of Pennsylvania, graduating in 1890, following which he studied in Germany for a year. On his return to America he became an Assistant Professor of the Theory and Practice of Veterinary Medicine at the University of Pennsylvania; in 1894 he was made Professor, and in 1897 Dean of 
the school, which position he held until his death in 1909. In recognition of his research work, the university in 1908 conferred upon him the honorary degree of Doctor of Medicine. In his student days at Cornell he had been elected to the national honorary scientific society, Sigma Xi.

One of his major interests was tuberculosis. In $\mathbf{1 8 9 2}$ he conducted the first tuberculin test in America, and in 1895 introduced the "Pennsylvania plan" of voluntary testing which gained acceptance - when compulsory plans had failed. $\mathrm{He}$ was a member of several important congresses on hygiene and tuberculosis, and in 1908 was chosen to preside over the section on animal tuberculosis at the International Congress in Washington, D. C.

Dr. Pearson was a prolific writer, and was one of the founders and editors of the Veterinary Magazine. In 1895 he organized the Pennsylvania State Live Stock Sanitary Board, and was appointed its secretary and state veterinarian, holding the latter position under a succession of governors of the state. In 1908 he diag. nosed Johne's disease for the first time in the United States. He served as secretary of the AVMA (1894-1895) and president (1899-1900). It was in his presidential address that he suggested the veterinarian should have the qualifications of an "animal engineer"; it appears that it was his colleagues who attributed to him the suggestion that this title be substituted for "veterinarian." In his obituary in the Review, his biographer states that Dr. Pearson "had justly earned the proud title of the leading 'animal engineer' of America." He served as president of both the Pennsylvania and the Keystone Veterinary Associations, and was a member of the American Public Health Association, State Grange, and the Philadelphia Board of Health, among other organizations.

For two years or more Pearson's family and friends were aware of the fact that his manifold duties and responsibilities were beginning to tell upon him, and after a narrow escape from accidental gas poi- soning, he was prevailed upon to take a vacation. He took a sea voyage to England, returning via Halifax, where an attack of hay fever caused him to go to Newfoundland. It was after he was well enough to consider returning to duty that he suffered a sudden collapse and hemorrhage, and died in a few hours at Spruce Brook, Newfoundland, September 20, 1909.

His biographer in the Review says of him:

He knew how to think, speak and write, was conscientious, far-sighted, honest, possessed good judgement and enjoyed the general esteem of all who knew him. He was a captivating orator, precise, methodical and clear, and possessed to a high degree the gift of analysis, synthesis and generalization. The many abstract and complex problems filtered through his mind as a pure crystal. Speaking or writing he reflected the exceptional qualities of his beautiful intellect. There was exactness and faithfulness to the rules of our language and a perfect fitness of words to express ideas in every sentence he used.

His long-time friend, AVMA President James G. Rutherford, states:

Dr. Pearson was in a class by himself among the veterinarians of this continent, while even in the Old World there are few who rank anywhere near him. He was not only a great veterinarian but a great man in many other ways, and one who, had he been spared, would have made a well-defined mark on the national life of his own as well as that of other countries.

He was only 41 years of age when he died.

In 1935, AVMA President R. S. MacKellar, Sr., said of Leonard Pearson:

$\mathrm{He}$ toiled for humanity, with almost a supreme contempt for worldly gain, but he lived for us, the practitioners, that we might thrive and better serve.... Here ... imbued with a lofty spirit of patriotism in the truest definition of that word, was a veterinarian who thought and motivated wholly and only in terms of national ideals, in terms of national defense, in nation-building terms. . . . Here was a man who looked upon it as his solemn duty, as his sole responsibility, to make his state and his country "veterinary conscious."

\section{1}

At the annual meeting in Atlantic City, President Tait Butler noted, despite urg- 
ings that graduates enter research and sanitary veterinary medicine:

it still remains a fact that nine out of every ten graduates must earn their living as general veterinary practitioners, and therefore fitness for general practice is the standard by which the efficiency of college education should be judged.

And urging greater attention to "the practical business side of veterinary education," Butler was critical of teachers "who never had any experience in general, unaided, independent veterinary practice of any sort."

Concerning the work of the Association, he avers:

This is the age of specialization . . . and the time is near at hand when we must be prepared to so change the machinery of the organization to meet the requirements of modern ideas and methods. . . . Accordingly it appears to me that three sections working concurrently, one considering questions of interest to the general practitioner and including the clinics; one dealing with sanitary questions, including meat and milk inspection, and general State medicine; and one comprising investigators, experiment station workers, etc. [are needed].

M. E. Knowles noted "with extreme regret . . . the closing of the Harvard Veterinary Department . . . when so many illegitimate institutions remain open and prosper." In the same vein, L. Van Es charged:

There are colleges whose only purpose is to educate, and others which are simply commercial enterprises or which serve only to give a certain amount of prominence to their promoters. In regard to the latter class, I beg to suggest that they can do no greater service to the profession than by retiring from business.

Observing that Minnesota, Iowa, and Washington had veterinarians on their state boards of health, S. B. Nelson urged, regarding the relationships of animal and human disease:

the veterinarian by his education is the proper person to represent the state boards of health in this branch of its labors, and ... thus, in theory, a state board of health is not complete in its personnel without a veterinarian.

Papers on meat and milk inspection were presented by C. A. Cary and G. R. White, and on the transmission of tuberculosis through meat and milk by John J. Repp.

In a paper by "the rising young surgeon out of the West," L. A. Merillat observed:

The gain in surgery and the lost confidence in internal medicine, so apparent in human medicine, is not yet apparent in veterinary practice, as inquiry among the veterinarians of this country brings out the confession that many practitioners never operate at all . . and why? First, because of the difficulty of accurately diagnosing surgical diseases; and secondly, because of the lack of ingenuity displayed in securing the diseased patient.... The veterinarian who is a good diagnostician, and who is a mechanic in the art of securing his patients specially for each operation, is a successful surgeon regardless of his deficiencies in other directions.

Among other papers presented were those by Veranus A. Moore on disinfection, and on anthrax by W. H. Dalrymple. Tuberculosis, glanders, and Texas fever were discussed. Clinical demonstrations included neurotomy and cunean tenotomy for spavin, myo-neurotomy for crib-biting, and caudal myotomy for tail-straightening in horses.

On the somber side, the deaths of pastpresidents Clement and Stickney were noted, along with that of former secretary and treasurer, Charles Burden. A member, C. D. Morris, was expelled for having written a letter to the Secretary of War which had been instrumental in securing the defeat of an Army Veterinary Bill after it had passed both houses of Congress. Morris' expulsion was later rescinded.

J. F. Winchester was elected president; Sesco Stewart, secretary; and W. H. Lowe, treasurer.

\section{Tait Butler}

Tait Butler was a native of Ontario, Canada, and graduated with honors from the Ontario Veterinary College in 1885 , after which he began a general practice 


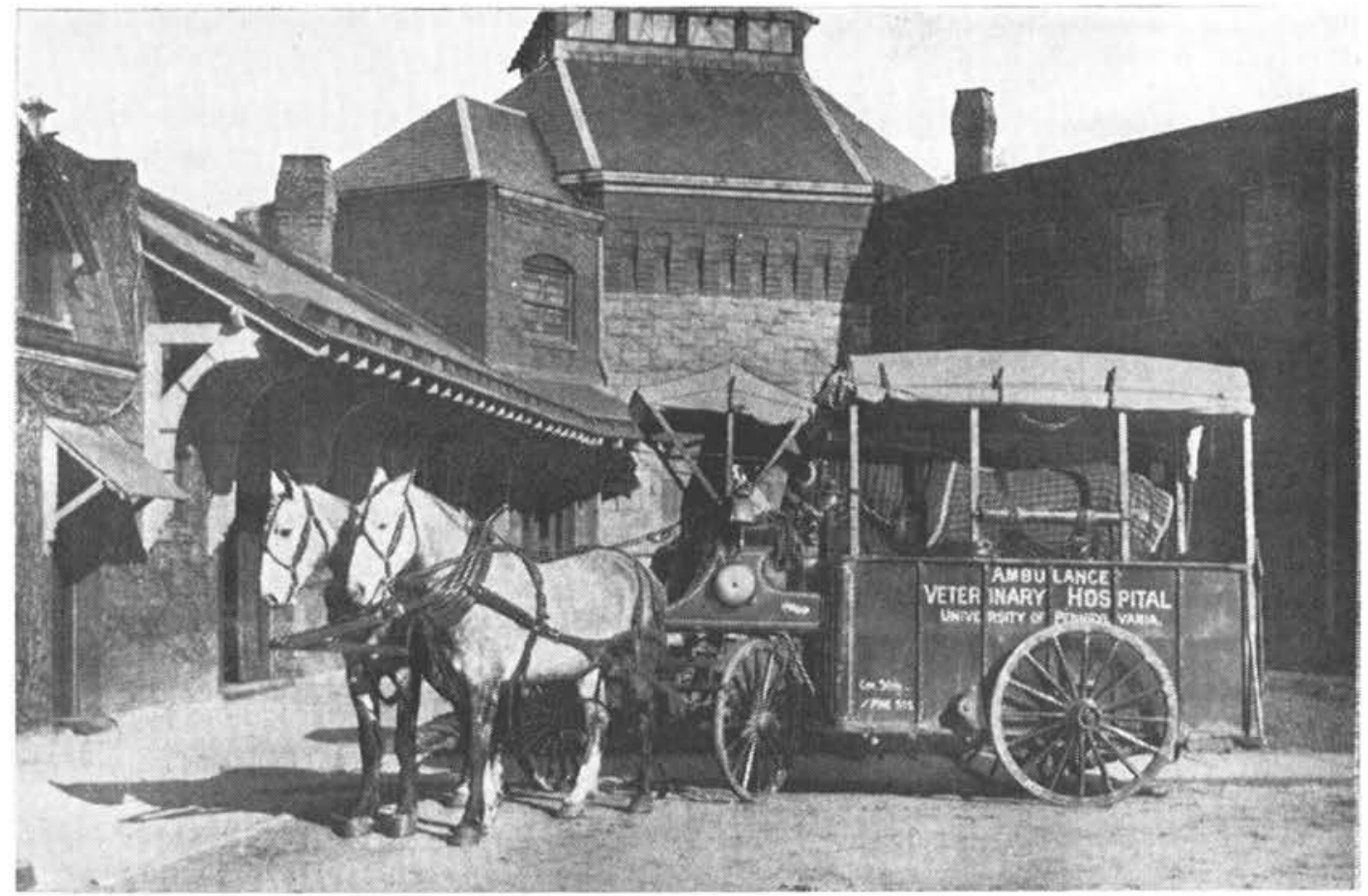

Horse ambulance of the University of Pennsylvania Veterinary Hospital, ca. 1890. Some of these ambulances were real showpieces - painted fire-engine red with brass fittings. University of Pennsylvania Bulletin

in Davenport, Iowa. He was an organizer of the Iowa VMA and served as secretary (1888-1889) and president (1889-1890). From 1891 to 1909 he served as Professor of Veterinary Science at Mississippi, Kansas, and North Carolina successively, retiring from the latter post to become editor of the Progressive Farmer, in which capacity he continued until his death on January 13, 1939. In 1934 he was awarded a medal for distinguished service to agriculture by the American Farm Bureau, and his many friends in the South urged his appointment as Secretary of Agriculture in 1932.

He was but 38 years old when he was elected president of the AVMA in 1900, but it is evident that he had a broad grasp of veterinary problems; he had first come to the attention of Association members in 1886 when he won the USVMA prize essay contest.

\section{Age of Specialization}

Perhaps related to Dr. Butler's cognizance of "the age of specialization," what would seem to have been a new development in veterinary practice was reported by the Review in 1897: "The first canine ambulance, in connection with a veterinary hospital, which we have heard of is that of Dr. Leavy, of New York City." Ambulances for dogs - perhaps more as conveyances for strays - had been used by the S. P. C. A. for some time, and horse ambulances had been in use for a considerable time. A "splendid horse ambulance" was offered for sale in 1897:

Elegantly ornamented with brass railing, brass lamps, etc. Painting the work of an artist. Makes a finer appearance on the street than a fire engine ... lined with steel and the whole is built to last forever.

Commenting on canine practice at this time, R. H. Harrison, who had presented 
some of the first canine cases in the Review, urges:

At the present time, when the price of horses is so low that an owner hesitates to call a veterinarian, on account of the expense of treatment, a surgeon can aid his reputation and pocket by skill in his treatment of dogs, and their owners. Being a lover and owner of dogs myself, I can appreciate a little sympathy for them in some one else, and a surgeon can always gain friends, and legitimate and profitable advertising by his judicious sympathy with the owner and friend of his patient.

Among the several complicated cases he presents is one of cutting the lateral rectus muscle for strabismus.

Earlier, the subject of Comparative Psychology had been investigated in the I880's by T. Wesley Mills, M. D., Professor of Physiology in the McGill Veterinary College. Together with his students, he formed an Association for the Study of Comparative Psychology in 1885 , in the belief that:
Men who had chosen comparative medicine as a career must have some real liking for those animals, at least, which are classed as domestic ... that a knowledge of the mental constitution of anmals must prove invaluable to the veterinary surgeon in the diagnosis and treatment of the diseases of his speechless patients.

\section{Canine Practice}

It is understandable that veterinary practice was primarily horse-centered during the latter part of the nineteenth century, although this, in part, might be considered a heritage from the past, for dogs were plentiful - and some at least well cared for-and even the large cities had large dairies within the city limits. In 1883 , R. H. Harrison, House Surgeon at AVC, had written:

Canine practice is rapidly becoming an important feature in the practice of veterinary medicine and surgery; and to those interested in the study it proves remunerative, and at the same time opens up a field of pathological research very interesting and instructive. Dogs in

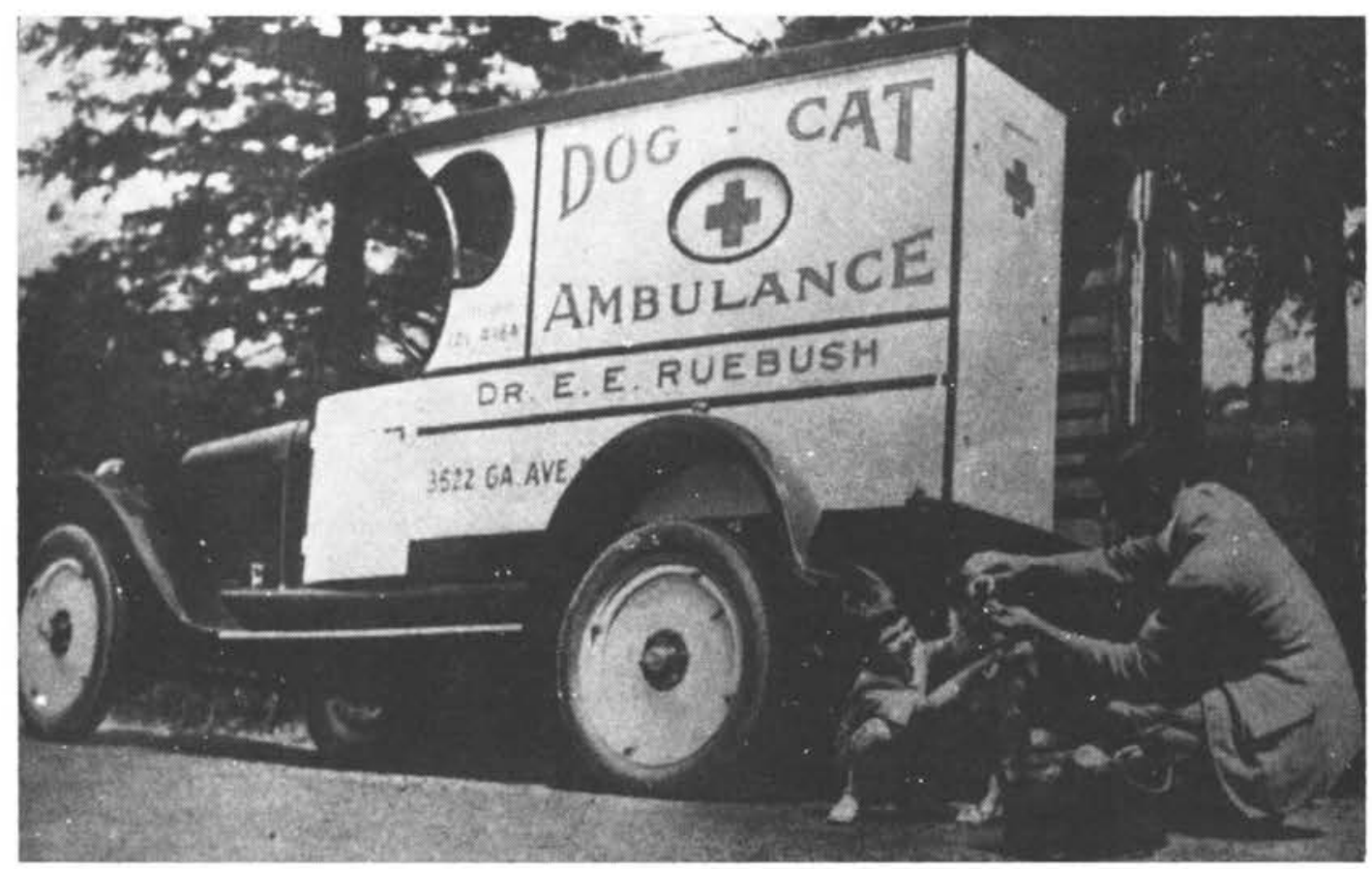

Before it was considered unethical to display one's name on a professional vehicle, both large and small animal ambulances were in vogue - to some extent as a travelling "business card." Veterinary Medicine 


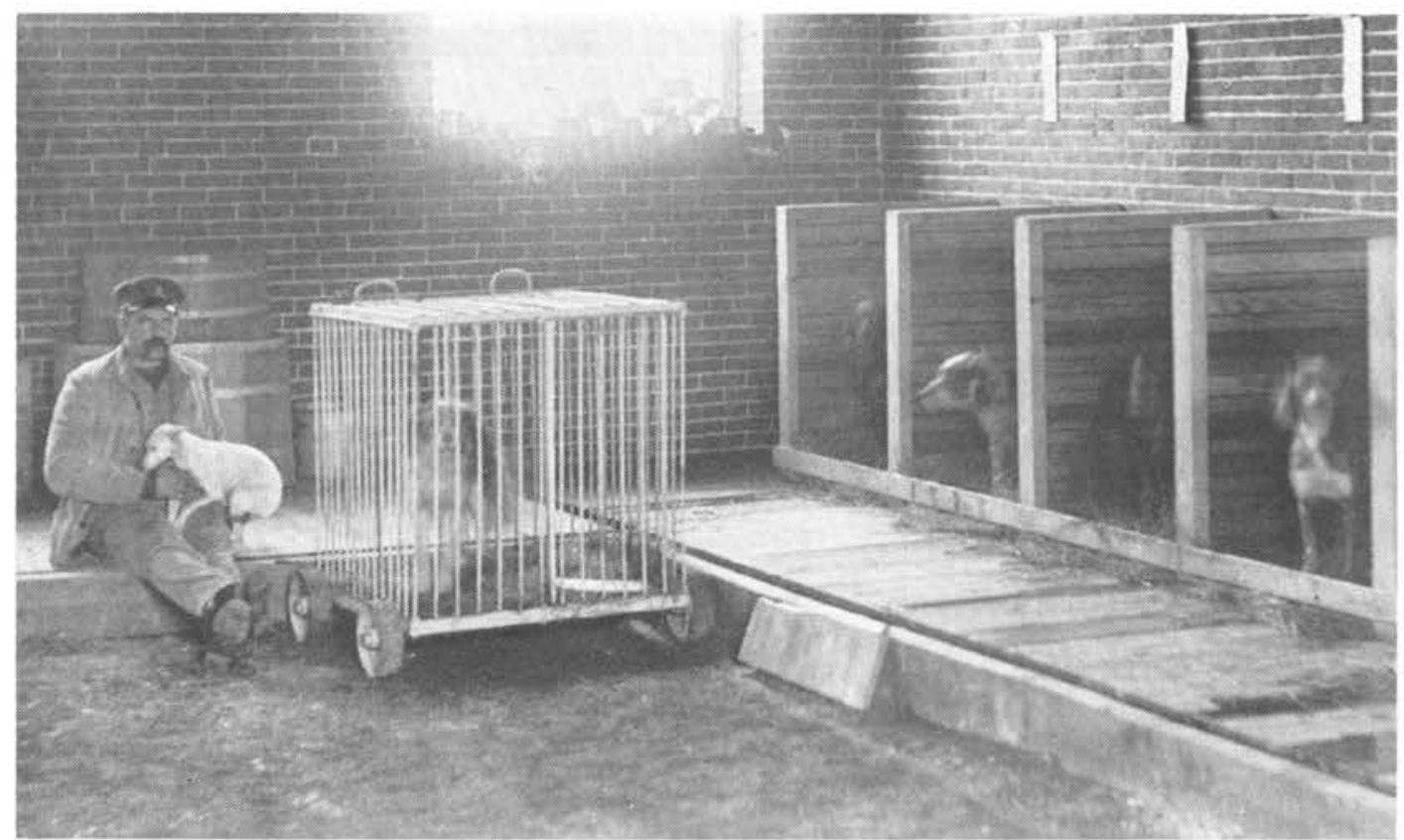

Canine ward, University of Pennsylvania Veterinary Hospital in 1885. Although a few schools taught small animal medicine and surgery this early, the specialty was slow to develop. Michigan State University Library

this country are more highly thought of, are better bred, and are more valuable than formerly. Especially is this the case with sporting and pet dogs.

Harrison had been running a series of reports on "Canine Pathology," in the Review and presents a number of highly instructive cases including: extirpation of the eye, removal of dislocated lens, tinea favosa, renal calculus, tuberculous nephritis, and several cases of rabies. The first paper on canine distemper appeared in the Review in 1885 .

If veterinarians were slow to develop dog practice, others apparently were not. The New York Tribune in an item on "A Dog Home and Hospital," in 1881, states there were several of these institutions in the city. One of the largest:

contains about 300 dogs, only a small part being in the hospital wards. The keeper of the house and his wife have been in the business for thirty five years. The wife herself is a dog doctress, and gets $\$ 3$ for each of her visits.

The proprietor is quoted as saying:

People, somehow or other, will go to any sacrifice to save a pet dog, while they seldom scruple to kill a good horse that has broken its leg or become otherwise injured. . . I have set horses' as well as dogs' limbs in such a manner that no expert would have been able to tell the difference.

In a review of Hill's Management and Diseases of the Dog (1881), it is stated:

The author, in his preface, speaks very truly regarding the little attention that has been paid to the diseases of the dog. Man's best animal friend has been, and still is for the most part, at the mercy of ignorant quacks.... The treatise is not an exhaustive one and does not pretend to go very deeply into pathological matters. We might, indeed, critize it on this account, but it is to be remembered that there is as yet no audience for any profoundly scientific treatise on canine diseases.

In 1884 the editors of the Journal of Comparative Medicine and Surgery, noting "this is a hospital era," for all sorts of human ills, urged:

We need a hospital for dogs, cats, and the small domestic animals. The amount of money in pet dogs, watch-dogs, and house-dogs in this city and suburbs is very great. Yet there is no good place where sick dogs can be well 
taken care of. To be sure there are the veterinary hospitals, but they are no better than stables, and are not suitable for small and delicate dogs.

The spaying of bitches, Hill says:

is now almost unheard of, and I trust the time is not far distant when it will be discontinued on other animals. The operation is both inhuman and useless; I am thankful to say that I have never seen it performed in canine practice.

Billings, however, states:

The operation is humane and useful in that if made obligatory by law, except to breeders, in a special license, it will tend to decrease the number of dogs, especially useless curs, and thus can lead also to a diminution of the chances of hydrophobia in man.

Apparently something of a pioneer in canine practice, Billings (1885) states that the lateral incision, as recommended by Youatt (and by Liautard in his Animal Castration, 1884) is senseless:

the only way to perform this operation is with ether, and by the median line. There is absolutely no danger in it; of 400 bitches of all ages, I have never lost one from the operation, and only one from the careless applica-

\section{DISEASES OF THE DOG INCLUDING THEIR TREATMENT.

\author{
DR. ALEXANDER GLASS'S \\ DAsscanos of TiE wakx of \\ PROF. GEORG MULLER.
}

MERE TMAN 400 PAGES OF REAONG MATTER. MEARLY 100 ILUUSTRATIONS. Sant post-paid on rocaipt of $\$ 5.00$.

\section{READ WHAx Is sAp of $I T$ HY THE.}

\section{AMERICAN VETERINARY REVIEW.}

"It is well illustrated and in every way is admirably adapted to fill a place that has long been but inadeguately occupied $\rightarrow$ no one at all in. terested in the subject can afford to be without a copy in his library."

Advertisement for Muller-Glass's Diseases of the Dog (1897), comment upon which would be superfluous - except, perhaps, that it could have been published only in a veterinary journal. American Veterinary Review

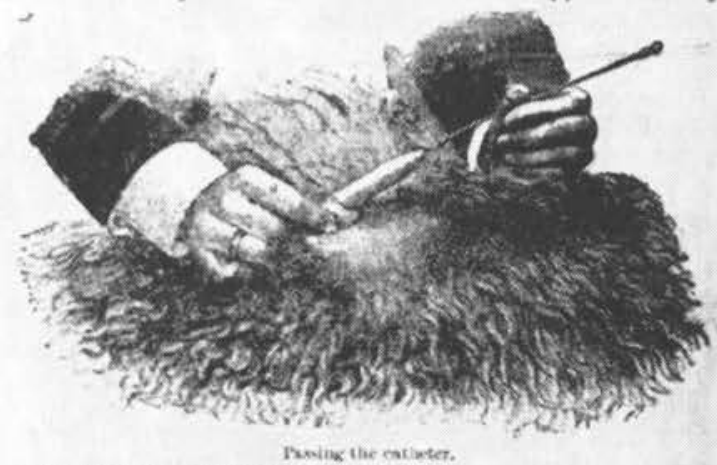

Already adopted as a text-book by the

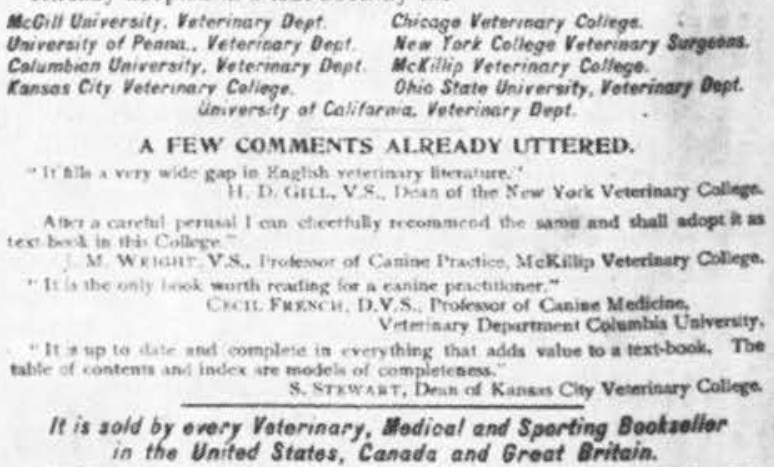




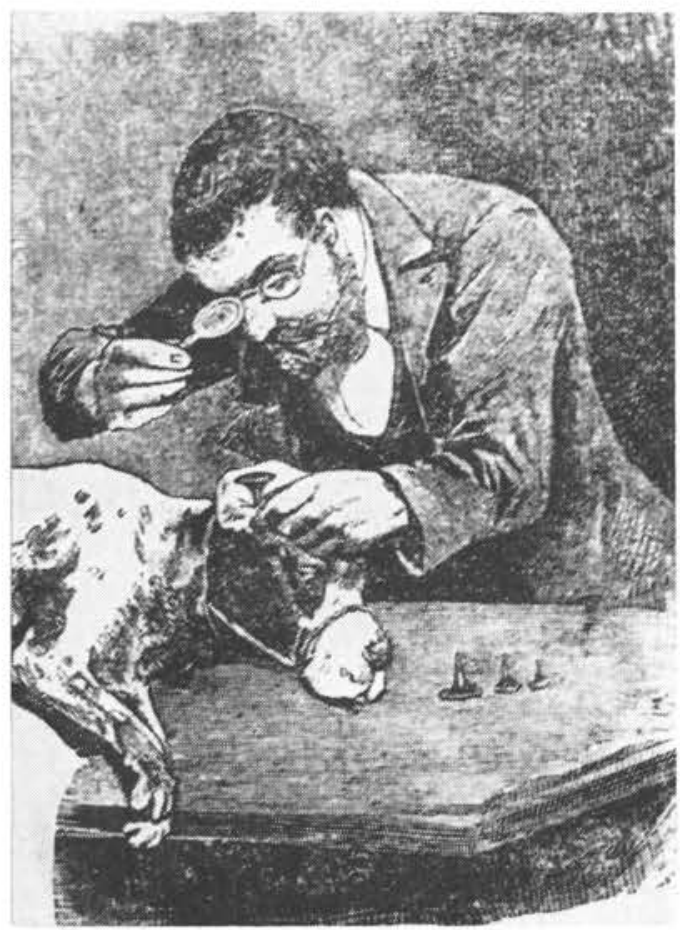

Otologic examination had been practiced in Germany for a considerable period before it was introduced to American veterinarians with the translation by Alexander Glass of Muller's Diseases of the Dog (1897). Muller-Glass

tion of chloroform by an assistant, which caused me to have recourse to ether.

\section{2}

President J. F. Winchester, at the 1902 meeting in Minneapolis, recommended increasing the term for graduation to four years, and for Association membership to three years of schooling. Together with higher matriculation standards and the selection of men of broad and liberal education for the school faculties:

the results will be that in the near future all cities will have a veterinary health officer acting with the medical officers of health in controlling and preventing diseases; the public will cease to look upon the veterinarians as mere animal physicians and surgeons and will grant them the privilege of interpreting and administering laws relating to public health.

Among his recommendations was one for a "Veterinarians' Mutual Aid Society," the function of which would be "to assist members of the veterinary profession, their widows and orphans who might prove to be deserving of professional benevolence." The matter of an insurance program had been discussed earlier in the Review:

It is not infrequent that in a business which is rated by the insurance people as "extrahazardous" that a veterinarian is disabled for weeks and even months by an accident which incapacitates him for any duty; or by disease. the result of infection from a patient, or through the natural penalities of human existence; or in case such accident or disease is sufficiently severe to terminate his life, then the question of the means for immediate necessities imposes itself upon him or those whom he may leave helpless behind him.

The AVMA Group Insurance Trust, established in 1957, might be thought of as growing - after a long, latent period out of this recommendation by President Winchester.

\section{Cheap Protaction}

Group insurance for veterinarians had been available before 1957, and professional liability insurance dates back to 1926. In 1932 it was noted that liability insurance had been available to veterinarians for six years, and during that time 56 suits had been brought against the 220 practitioners holding this insurance. Nine cases went to trial, and in two instances verdicts were returned against the defendants. Noting "the amount of damages claimed or sued for has been quite large in some instances," the Journal editor suggests:

It is not our intention to frighten veterinarians unnecessarily, but the figures speak for themselves. The number of members who have found it necessary to fall back upon their liability insurance for protection against actions started against them is larger than anyone expected when this form of insurance policy was first written. . . Considering that the insurance costs less than five cents a day, it would appear to be a rather cheap form of protection.

In $1903, \mathrm{Wm}$. Dougherty had presented a plan for a "Mutual Benefit Society for 
Veterinarians ... to afford pecuniary aid to sick or injured members, and also aid to their widows and orphans or legal heirs." Sick benefits of $\$ 15$ per week for up to eight weeks were to be taken from a fund supported by annual assessments of $\$ 6$ per member, or "extra assessments ... when necessary." A death benefit fund was to be supported by an initial assessment of $\$ 1.00$ plus ten cents per year for each year over age 25 . Each time a member died, the entire membership was to be assessed at the initial rate, and "A sum of money equal to one assessment call of the entire membership, less $15 \%$, shall be paid to the heirs." After considerable discussion, it was decided to poll the entire membership (some 470) in writing. At the following meeting Dr. Dougherty reported having discussed the matter with $W$. $H$. Hoskins:

He has grave doubts as to the success of the assessment plan. After giving it a close study, I have personally come to the conclusion that the assessment plan is not practicable.

On the matter of insurance of another sort, in 1898 a Veterinary Service Association was incorporated in New York City "to furnish medical attendance to horses and cattle by competent and licensed veterinary surgeons," under the supervision of Mark L. Frey, a graduate veterinarian. For a registration fee of fifty cents plus fifteen cents a week per animal, unlimited medical attendance was to be provided by a corps of veterinarians located throughout the city. For this service the veterinarian was to receive two dollars an animal per year; surgery would be performed on the usual practitioner-client basis.

Noting that the scheme had a decidedly unethical taint, and that the only veterinarians who could be induced to fall for it would be those who had no practice, the editors of the Review ask:

How can a man be such an ass as to give his clients into the hands of such a concern, allowing them to collect the money for his work and paying him wages, as the mill owner does his laborers.

\section{Straight and Narrow}

Returning to the meeting (1902), in a paper on "The Legitimate Field of the A.V.M.A.," Roscoe R. Bell noted the opposition of the Pennsylvania VMA to the clinics and "discussions of questions of purely local and narrow interest" at the AVMA meetings, the contention being that these were outside the scope of the AVMA. W. Horace Hoskins had urged elimination of both the clinics and of clinical papers from AVMA programs, with the substitution of "broader association work along truly national lines."

As Dr. Bell points out, this would leave little more than "the reading and discussion of papers on state medicine and national legislation." Also, this would require expunging of Article II of the Constitution:

The purpose and object of the association are to contribute to the diffusion of true science, and particularly the knowledge of veterinary medicine and surgery.

Not only would this be "a grievous wrong to the great body of practitioners," Dr. Bell contends, but:

it is an impertinence beyond parallel and a presumption without precedence for a number of members so short of a majority to suggest that the sections of the program which interest the majority shall be totally eliminated.

As a matter of passing interest, C. J. Marshall had reported some 1,700 registered veterinary practitioners in Pennsylvania at this time, but "about 1,000 names on our registration list were placed there improperly." Fewer than 300 were graduate veterinarians; about 200 belonged to the state association, and 27 to the AVMA.

The deaths of John Faust, the last nongraduate to be admitted (1884); R. J. Saunders, one of the founders; and past-president R. S. Huidekoper were noted. Sesco Stewart, secretary for seven years, was elected president; John J. Repp was elected secretary, and W. H. Lowe reelected treasurer. 


\section{THE ASSOCIATION IN CANADA}

The fortieth annual meeting of the AVMA was held in Ottawa, Ontario, in 1903, the first meeting of the Association on Canadian soil. "This," Sesco Stewart claimed in his presidential address, "should remove any doubts which Canadian veterinarians may have entertained as to the breadth of purpose of this organization."

That A. W. Clement, in his presidential address in 1899 had perhaps envisioned a broader scope of the newly-renamed Association than was intended is suggested by his concept of its "embracing in its field the United States, Canada and Mexico, nay, even more, the whole Pan-American Continent." While there is considerable latitude in the connotation of "American," it is evident that this broad concept of the interrelationship of the veterinary professions of the Western Hemisphere did not become a reality until the establishment of the Pan-American Congress of Veterinary Medicine in 1951. De facto recognition of Canada as a full partner, however, was long overdue. The following year (1900) six Canadians were elected to membership more than were members at the time - and Fred Torrance of Winnipeg was elected a vice president of the Association; in 1917 he was elected president. Of the 48 new members in 1900,18 were from the Ontario and McGill schools. In 1908, J. G. Rutherford, Veterinary Director General for the Dominion, was elected president of the AVMA, and in 1911 the provinces of Ontario, Manitoba, and British Columbia each had more AVMA members than had 20 of the states.

On the subject of education, Dr. Stewart notes that as a result of the AVMA's raising its standards for membership:

A number of veterinary colleges raised their standard so that graduates would be eligible to membership, and this achieved a great gain for our profession. In 1897 the United States Bureau of Animal Industry established a like standard for eligibility to enter the veterinary service in the Department of Agriculture. So potent was the combined influence of these two regulations that practically all of the veterinary colleges of the continent have announced the three-year standard.

The "sensation of the meeting" was D. E. Salmon's paper on "Bovine and Human Tuberculosis," in which the results of $\mathrm{Bu}$ reau efforts to disprove Koch's contention that tuberculosis was nontransmissible between cattle and man were given:

The effect of Dr. Salmon's paper was electrical; every one seemed to realize that they had been particularly fortunate in being present to listen to the reading of a paper that effectually settled an important question of world-wide interest; that a new chapter in the history of medicine had been completed; that an international bomb had been exploded; and that they had been present when the lucifer was applied. ... Cheer after cheer leaped from the throats of the guests, and the essayist was applauded to the echo. ... There was no discussion - just praise.

As a matter of some interest, Salmon's paper was part of the program which was conducted in the magnificent barn on the farm of the Hon. W. C. Edwards, who spoke on the Bang system for eradication of tuberculosis that he had been pursuing on his farm. The Hon. Sidney Fisher, Minister of Agriculture for Canada, extolled "the importance of veterinary science to agriculture," and J. G. Rutherford, Chief Veterinary Inspector for the Dominion, spoke on glanders. Together with papers by J. Desmond, government veterinarian of South Australia, on tumors in domestic animals; and epizootic aphtha by Prof. Edoardo Perroncito of Italy (read by title), the meeting took on a distinctly international aspect. Also presented were papers on avian tuberculosis, by V. A. Moore and A. R. Ward; bovine tubercuIosis, by J. J. Repp; cardiovascular drugs, by P. A. Fish; and meat and milk inspection, by M. E. Knowles.

Roscoe R. Bell was elected president; J. J. Repp and W. H. Lowe were re-elected secretary and treasurer respectively.

\section{Sesco Stewart}

Sesco Stewart, D.V.M., was born in Ontario, March 23, 1855, but moved to the 
United States while quite young, and considered Pennsylvania as his home state. In 1878 he obtained the M.D. degree from Wooster University and entered medical practice in Iowa. In 1885 he graduated from Iowa State in the same class with G. H. Glover, later dean at Colorado and AVMA president, and W. B. Niles, co-discoverer of hog cholera serum. Dr. Stewart engaged in veterinary practice until 1892 when he entered meat inspection at Kansas City. Here he became interested in the Kansas City Veterinary College, and was the moving spirit in its reorganization in 1895, becoming its president in that year. A year later he became secretary-trcasurer of the college, which position he held until his death on February 7, 1918, at which time he was also dean of the faculty.

Dr. Stewart was presiclent of the Iowa VMA in 1886 and secretary, 1887-1892. He was a charter member of the Missouri Valley Veterinary Association and twice served as its president. He served as secretary of the AVMA, 1895-1902, and was elected president, 1902-1903. Upon his death, W. H. Hoskins said of him, "He seemed to have died too soon. His work was not finished."

\section{4}

The annual meeting for 1904 was held in St. Louis at the time of the World's Exposition. In his presidential address, Roscoe R. Bell noted that the prosperity being experienced by the veterinary profession was not due to "boom times," but to:

the quality of the practitioner himself, which has inspired the owner of livestock with greater confidence in his ability to render valuable services, not only in the treatment of the diseases from which animals suffer, but the advice of the veterinarian of the modern school is sought upon questions of sanitation, particularly for the eradication and prevention of those animal scourges which destroy the herds and flocks of livestock breeders and owners.

In taking up the perennial subject of veterinary education, Dr. Bell suggests that perhaps the recently de-activated Associa- tion of Veterinary Faculties was a more logical agency than the AVMA to be concerned with details of "censorship over the schools of the country ... to see to it that they live up to the statements in their announcements."

In a provocative discussion on "When to Operate," L. A. Merillat notes the dearth of so-called "popular papers" presented at the meetings, and observes:

The capable writer finding it distasteful to present a paper here that does not compare favorably, from a scientific standpoint, with those which delve deeply into the realms of mystery and are adorned throughout with high-sounding technical terms, leaves the task alone and comes to the meetings year after year to hear only the year's revelations of the field and laboratory. He goes home proud enough of the progress of his profession, but without additional knowledge as to his daily vocation.

Dr. Merillat concludes his lengthy argument with a condemnation of the AVMA clinics as being:

not a fair presentation of the highest standard of American veterinary surgery ... they should be abandoned or conducted on entirely different lines. ... The member of this Association who is incapable of performing this or that operation will add nothing to his deficiency by occupying a seat at these exercises. They excite the greatest curiosity, but they do not instruct the unlearned.

At the clinical session, 14 cases were presented (none by Dr. Merillat); of these, one at least should have been exempted from Merillat's wrath - a demonstration of the passing of the stomach tube by G. R. White. This was something which undoubtedly most of those present had not seen done; the reporter, E. M. Ranck, states, "There is no reason to believe that it will not soon come into universal use by veterinary practitioners." But considering the facilities for a crowd of perhaps 200, some doubt may be cast upon the educational value of certain other demonstrations. These included quittor operation (40 minutes); two standing castrations (15 seconds and 8 seconds); roaring operation (30 minutes); vaginal ovariotomy; intestinal anastomosis (dog); and 6 lame horses 
which were diagnosed and prescribed for. Yet, "It was generally conceded that this was altogether the most satisfactory clinic held."

It is perhaps not too invidious to note that at the 1906 clinic there were no less than 6 roaring operations and 2 quittors. As in previous years, this also was "the best clinic that had yet been staged," and perhaps it was, but it might be doubted that six roaring operations could be considered as more than an opportunity for six men to prove their prowess - with little opportunity for its being proved otherwise. And while "practical" papers had been, and continued to be, presented, surgeons had to be contented with mostly other than surgical papers until the meetings were sectioned beginning in 1910 .

M. E. Knowles was elected president; J. J. Repp and W. H. Lowe were re-elected secretary and treasurer, respectively.

\section{R. R. BeII}

Roscoe R. Bell, D.V.S., was born in Virginia, August 16, 1858. After graduating from Norwood College he became a staff member of the Spirit of the Times (New York) until he entered the American Veterinary College, from which he graduated with honors in 1887. The following year he became Professor of Materia Medica at A.V.C., retaining this position until failing health forced him to relinquish it in 1907. He died of Bright's disease on February 8, 1908.

In 1896 Dr. Bell purchased an interest in the American Veterinary Review and became one of its editors, and sole editor and presumably proprietor - upon Dr. Liautard's return to France in 1900. Merillat and Campbell note upon Dr. Bell's assumption of the junior editorship of the Review, "there was immediate improvement in the publication. He supplied a technique and finesse that the senior editor did not possess." The local, state, and national veterinary associations each honored Dr. Bell with their highest office; he was elected AVMA president in 1903.

\section{5}

At the 1905 meeting in Cleveland, President M. E. Knowles noted:

The usefulness of the veterinarian is increasing rapidly as the lay public more fully recognize the value of the educated veterinarian's services, not merely as a practitioner alleviating the suffering of our domestic animals, but in the still higher sphere of the sanitarian. . . While his mission as a practitioner is a most noble one, the part he plays in preserving human life is far more important.

And congratulating Pennsylvania for having made Leonard Pearson a member of the state board of health, Knowles urged, "It is largely within our power to see to it that every State in the Union has upon its board of health a capable veterinarian."

Both the papers and the clinic would appear to have been more to the liking of Dr. Merillat; papers were presented by $W$. L. Williams on spavin, R. C. Moore on neurectomy, M. H. Reynolds on stable ventilation, and $\mathrm{L}$. A. Klein on scours. The clinic was described as:

very near to being a perfect one: in fact, so near, that we heard a prominent opponent of this section of the annual meeting's programme acknowledge that he was mistaken; that properly conducted he believed they were a valuable addition, educational and interesting.

An evening session included a paper by Dr. Merillat on "Accidents and sequellae of Surgical Operations," which required an hour of rapid reading, during which:

Not a sound could be heard save the author's voice, so intent were his auditors to catch every word, and when he had concluded there ensued a discussion which has probably rever been equalled in this country.

Other papers were presented by Leonard Pearson on immunization of cattle against tuberculosis; S. H. Burnett and Jacob Traum on blood examination in the dog; J. R. Mohler on cultivation of trypanosomes; and by E. L. Quitman on the U.S. Pharmacopoeia. In a paper on "The Profession and the Advancement of Science," D. A. Hughes inquired: 
Is the eagerness to receive knowledge on the part of our membership commensurate with the eagerness to give knowledge?... Our books are in sharp contrast with the great modern books on human medicine ... [ [ and ] many of the articles on veterinary topics ... are commonly very faulty. ... They are apt to be either a mouthing of old material or repetition of the commonest things in textbooks. . . . We do not prize enough the opportunities we have to perform post-mortem examinations... pathological material is, through carelessness or indifference, constantly being thrown away and the knowledge lost to science. ... Not until men of the requisite capacity bestir themselves will there be produced bodies of scientific papers equal in scientific import and content to papers on similar subjects in human medicine.

In accordance with the 1904 revision of the bylaws, the Honor Roll of members for 25 consecutive years was established with three men qualifying: Will i a m Dougherty of Baltimore, and past-presidents John F. Winchester of Massachusetts and James L. Robertson of New York. The death of past-president William B. E. Miller was noted. William Herbert Lowe was elected president, with George R. White of Tennessee being elected treasurer to fill the post vacated by Dr. Lowe, John J. Repp was re-elected secretary.

The clinic included several operations for spavin, stringhalt, lameness, roaring, quittor, and tendonitis in horses by L. A. Merillat, W. H. Hoskins, J. W. Adams, M. H. McKillip, W. L. Williams, and others. Chloroform anesthesia was demonstrated by Dr. Merillat, and passing of the Phillips stomach tube by G. R. White and J. M. Phillips. A diagnosis of rheumatism in a dog was made by R. R. Bell, and R. P. Lyman demonstrated flank and vaginal ovariectomy on a cow.

\section{E. Knowles}

Morton Edmund Knowles, D.V.S., was born at Clinton, Iowa, on April 24, 1862. After graduating from De Pauw University, he entered the American Veterinary College and graduated in 1884. He was State Veterinarian of Indiana, 1886-1892, and of Montana from 1892 to 1913. Commissioned a second lieutenant in the Veterinary Corps in 1917, he rose to the rank of major, and served as Chief Veterinarian on the staff of General Pershing. Merillat and Campbell state, "but for the efficiency of Major Knowles at the evacuation stations ... the operation of the Veterinary Corps ... would have broken down completely."

Dr. Knowles joined the Association in 1891, was a vice president 1900-1904, and was elected president in 1904. He also served as president of the Montana VMA, and as state veterinarian is credited with providing his adopted state with "a splendid system of animal disease control, under conditions that made such work extremely difficult, and at times most discouraging." He died June 16, 1923.

\section{The Stomach Tube}

As with other questions involving priority there is an aura of uncertainty concerning use of the stomach tube in America.

Although the stomach tube apparently had been known to the veterinarians of ancient India, it was forgotten for centuries until the celebrated British anatomist, Alexander Monro, secundus, mentioned it in his lectures, dating at least to 1779. A communication by Monro, appearing in Rowlin's Complete Cow-Doctor (1799), occasioned widespread use of the tube for a number of years for bloat, but this also seems to have been largely forgotten. In 1847, Edward Mayhew, lately of the London school, discovered the expedient of passing a tube via the nostril of the horse, and although his discovery was published, it was largely disregarded for half a century.

Probably the first mention of the stomach tube in the veterinary literature of America is to be found in several of the numerous editions of William Youatt's books published here beginning in the 1830's. Although Monro had suggested the tube as a convenient means for administering medicines, for many years it was advocated almost solely for relief of bloat in 


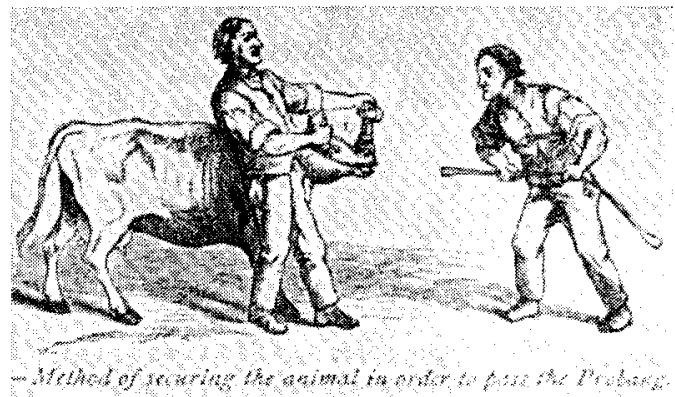

The probang-sometimes in the form of a stiff rope - was used for relieving choke throughout most of the nineteenth century; although the stomach tube was known, it was little used until well into the twentieth century. Clater-Armatage: Cattle Doctor

cattle, and for administration of nutritive gruel in tetanus in the horse.

The first article in the American Veterinary Review on the use of the stomach tube did not appear until 1904. In this, J. M. Phillips states that he had conceived the idea of using the tube for a variety of conditions from having recalled seeing as a boy, a cut in a book showing the tube used in tetanus in the horse. However, he did not act upon his idea until:

In 1895 I heard of Dr. H. B. Piatt's having employed a tube in cases of stomach derangement with success. ... I purchased a tube similar to his, and used it . . . in my practice whenever it was indicated.... I can assure the profession that it is one of the most practical operations in veterinary surgery. . . The use of the tube is idicated in acute indigestion, engorgement of the stomach, gastritis following acute indigestion, toxic gastritis and ordinary chokes.

He states that while taking a postgraduate course at the Chicago Veterinary College in 1903, he met practitioners from nearly every veterinary college in the United States and Canada: "I learned from them that none had practiced this operation, and none of their alma maters had taught any form of siphoning the stomach of the horse."

Phillips put his modification of Piatt's tube on the market, and in $1905 \mathrm{~F}$. J. Bliss stated that he had exhibited a Phillips Stomach Tube at the 1903 AVMA meet. ing, but:

I recollect it did not appeal very strongly to those present, and was commented on, if at all, adversely. . . I I want to be understood as claiming that more can be done in five minutes to relieve a case of colic than you can do with the whole gamut of remedies that we have been using for the past fifty years.

An indication of the amount of interest stirred up by Bliss's demonstration may be gathered from the fact that no mention was made of it in a lengthy report of the meeting as published in the Review. Later in 1905, however, the "Publishers' Department" of the Review, which regularly called attention to the products of advertisers, states: "Dr. Phillip's Stomach Tube is endorsed by veteriarians everywhere."

In 1906 the Review notes:

Dr. D. O. Knisely, of Topeka, Kansas, is the inventor of a new design of stomach tube for use in the horse. It differs from other tubes in being double to permit the injection of fluid through a lesser and thinner walled compartment, and thereby thin the stomach contents that it may flow more freely out through the larger, and more rigid walled compartment.

At the time of Knisely's death in 1917, it was stated that he was best known among veterinarians for his advocacy of the use of the stomach tube. But:

Dr. Knisely was not the first to use the stomach tube on animals. That distinction probably rests with Dr. E. L. Quitman of Chicago, who first used this contrivance for the relief of gastric flatulence more than twentyfive years ago, but to Dr. Knisely is due the credit for popularizing the stomach tube. . . He designed the one that bears his name - a double current tube, that permits a simultaneous inflow and outflow and is widely used in this country... . There are now few practitioners who do not possess one.

Later, in response to a question on the matter, D. M. Campbell notes that Alexander Monro, the Edinburgh anatomist, should receive credit for introduction of the tube, and that Quitman was the first man in America to use it - but only briefly 
about 1892. However, George Dadd advertised a stomach tube for $\$ 5.00$ in 1859 , and Leonard Pearson mentioned its use in the USDA publication on Diseases of Cattle in 1892. Dr. Campbell correctly notes, however, "For some time . . . Dr. Knisely was the leader and almost the only exponent of the use of the stomach tube. ... In this advocacy he was early joined by L. A. Merillat."

In 1934, J. M. Hurd notes: "The use of the stomach tube in veterinary medicine is essentially an art of American veterinarians," and while "leading practitioners everywhere use the stomach tube daily," he feels that many still do not realize its full value. In particular, he suggests, "its use also tends to minimize doctoring by the owner, as few laymen will attempt to pass a stomach tube."

Regarding another technic which had not yet gained universal acclaim, in 1904 W. F. Sykes notes that the prejudice against intravenous medication $\mathrm{u} n \mathrm{doubted} \mathrm{ly}$ stemmed from its association with blood transfusion and the unsatisfactory experiences many physicians had had with the latter technic generations ago. He mentions that intravenous injections had been employed as far back as the eighteenth century, but that frequent infection, and the ungrounded fear of admitting air into the veins, had served as powerful deterrents to its widespread use. In giving the technic in detail, Sykes states, "The opportunities for intravenous injections will become more numerous the less they are feared and the better they are known."

On the subject of "Immunization and its Practical Application," L. Van Es writes in 1904:

While processes of immunization are coming more and more into use in medicine, they have nowhere reached a higher degree of usefulness, or are employed more extensively and successfully than by the veterinary branch of the profession.

As a matter of considerable interest, he offers a warning, the full implications of which have, perhaps, recently only been fully appreciated:
Immunization by the inoculation with an active virus, perhaps, will never be seriously considered in practice as it is not free from danger and is always accompanied by a certain element of risk.

\section{6}

In his presidential address at the 1906 meeting in New Haven, Connecticut, W. $H$. Lowe expressed regret over the resignation of D. E. Salmon as Chief of the BAI, but delight that A. D. Melvin had been appointed in his place. Earlier, the Executive Committee of the AVMA had nominated Leonard Pearson as its first choice after Secretary of Agriculture Wilson had asked for "an expression from this association as to the qualifications of the man to be appointed." A resolution was adopted giving "full and hearty" endorsement to Dr. Melvin, as was one commending the BAI upon its being found blameless in the alleged meat inspection scandal which had forced the resignation of Dr. Salmon.

Contrary to those apostles of doom who, having viewed the bicycle as the agent of extinction of the veterinarian a decade or so earlier, now eyed the automobile with the same misgivings, Dr. Lowe avers:

The future of the veterinary profession does not depend upon "the coming of the automobile" or "the passing of the horse," but it does depend, and always will depend, upon the ability, adaptability, character and purpose of the young man who knocks at the college door for matriculation.

Among his recommendations was one that a category of "Fellow of the AVMA" be created to honor those:

who have rendered some conspicuous service for the benefit and advancement of veterinary science and art, and who have been recommended for such conspicuous service by a majority of the living past presidents of the A.V.M.A.

This was occasioned by the recent adoption of an Honor Roll for twenty-five-year members, Lowe contending: "I would have had the condition of enrollment on the 
Honor Roll achievement rather than the length of membership. ... It is the men who do things that should be honored." Little fault, however, could be found with the first Honor Roll members: this year the name of $W$. Horace Hoskins was added to those of past-presidents Winchester and Robertson, and Wm. Dougherty, who had labored on behalf of Army legislation.

Following the adoption of a motion the previous year by C. J. Marshall, a nominating committee consisting of the pastpresidents (Bell, Butler, Hoskins, Robertson, Stewart, and Winchester) presented a slate of candidates, with three names for president and two for each of the other offices. In many of the preceding years there had been "no contest" for most of the offices. James Law was elected president; R. P. Lyman, secretary; and George $\mathrm{R}$. White, treasurer.

Papers were presented on glanders by V. A. Moore, Ward Giltner, J. G. Rutherford, G. H. Berns, and Cassius Way. Other topics included roaring, by W. L. Williams; insect pests, by W. H. Dalrymple; tick eradication, by Tait Butler; mange, by A. T. Peters; arecoline, by P. A. Fish; and the Army Veterinary Service, by $\mathbf{C}$. $\mathbf{H}$. Jewell.

At "the ideal clinic which we have all been hoping for," 25 horses and one dog were operated on, with W. L. Williams, L. A. Merillat and G. R. White dominating the field. The proceedings were interrupted by a humane society officer who claimed:

he had been informed that unnecessary operations were being performed, or that animals were being caused to suffer pain simply to demonstrate surgical methods ... but when shown what was being done he changed his mind, and remained to witness many of the procedures.

\section{7}

Attendance at the Kansas City meeting in 1907 , nearly 800 , was almost twice that of any previous meeting, but only 180 of these were members (total membership, 734). There had been 175 members (of
592) present at the meeting in St. Louis in 1904, and more than 200 nonmember veterinarians from Missouri and Kansas were at the Kansas City meeting.

Speaking on "Old and New Science," president James Law notes:

Miserable failures constantly follow the lack of the new scientific knowledge. ... On the other hand our modern, improved, laboratory methods of diagnosis have been allowed to crowd out the older approved systems, and to leave a case in doubt which could have been quickly and accurately determined by such older methods. . . [ However] I stand for the new diagnosis quite as strongly as I do for the old ... each is essential in its own proper place... both should be availed of when circumstances permit.

The "burning question" of veterinary education, Dr. Law avers:

cannot be settled until we advance the requirements for admission to the profession approximately to those exacted in the sister profession of human medicine. .. . The increasing demands exacted of aspirants to public veterinary service mark an epoch in which veterinary education must respond to such demands, or be relegated to neglect. . . The veterinarian is the only logical or safe officer to be charged with the control of animal diseases that are dangerous to man, yet, if the public is to entrust him with this duty, it must be first assured that the veterinarian in question is equally accomplished in all that pertains to these diseases in the lower animals as the physician is in regard to the same affections as seen in man. . . . Stagnation in the veterinary profession means death.

Continuing Dr. Law's theme, W. L. Williams, in speaking before the recently reactivated Association of Veterinary Faculties, called for more and better preparatory education of veterinary students, stressing:

the needs for efficiently studying veterinary science and the recognition of the veterinarian as an educated gentleman.... Invasion of fields logically belonging to the veterinarian are now and then threatened by the agriculturalist because of his higher and better education, consisting of four years each of high school and college or university work.... The veterinary service in America is everywhere defective and fragmentary.... There 
is scarcely an area which would not to-day afford abundant room for the addition of an equal number of veterinarians. ... But the men for this task must be of a higher type than those now existing and must be prepared to take up the work now left undone by existing veterinarians.

As chairman of the Committee on Intelligence and Education, Leonard Pearson called attention to the fact that veterinary education was deficient in such areas as milk, meat, and dairy inspection, nutrition, animal disease research, and animal husbandry:

In the long run, veterinarians will find themselves occupying the fields that they are better fitted to occupy than are men trained in other lines and in other schools. . . . So long as men must go to institutions other than veterinary colleges to obtain the best attainable training in many of the fundamental subjects that enter in to the veterinary sciences, the veterinary profession cannot be said to have a very secure hold on its field, and it cannot advance as it should.

Among papers presented were those on tuberculosis by A. D. Melvin, J. F. Winchester, and J. R. Mohler; milk inspection by C. A. Cary and Ward Giltner; infectious ulceration in sheep by M. E. Knowles; and the perennial subject of roaring by W. L. Williams.

W. H. Dalrymple was elected president; R. P. Lyman and G. R. White were reelected secretary and treasurer, respectively.

The Honor Roll of twenty-five-year members, established in 1905, was enlarged to include past members who would have qualified earlier. These were the founders: Charles Burden, O. H. Flagg, Alexandre Liautard, Isaiah Michener, J. Penniman, Josiah H. Stickney, Elisha F. Thayer, and Robert Wood. Others, with dates of election, were: James L. Robertson (1868); R. J. Saunders (1871); T. K. Very (1872); J. D. Hopkins (1873); Wm. Dougherty (1874); C. P. Lyman, J. C. Meyers (1875); Benjamin McInnes, C. W. Crowley (1876); W. J. Coates (1877); J. F. Wincester, W. H. Wray (1878); D. J. Dixon, R. H. Harrison, F. H. Osgood (1881); W.
Horace Hoskins, L. H. Howard, F. W. McLellan, and W. A. Sherman (1882). Nine of the twenty-seven men were deceased; only one of the founders, A. Liautard, was still living - in France since 1900. This left James Robertson, with forty years of service, the senior active member of the Association, along with Drs. Hoskins, Dougherty, and Winchester as active members of the "official family."

\section{James Law}

James Law, F.R.C.V.S., was born in Scotland, February 13, 1838, and entered the Edinburgh Veterinary College at 16, graduating in 1857. He became Demonstrator of Anatomy at his alma mater, and coauthored a text on anatomy with his preceptor, John Gamgee. Later he was Professor of Anatomy at Gamgee's ill-fated college in London. In 1868 he was picked by Andrew White, president of Cornell University, to be Professor of Veterinary Science in the newly established institution, in which capacity (from 1896 as dean of the New York State Veterinary College) he was to serve for 40 years, until his retirement in 1908.

His many accomplishments include his monumental five-volume work on Veterinary Medicine, published about the turn of the century, and countless articles in the veterinary and agricultural publications over many years. As a leading authority on epizootic disease, he was a member of the Treasury Cattle Commission, and was a special investigator for the BAI. He was a leading proponent of higher standards for veterinary education, a position not incompatible with his Farmers' Veterinary Advisor or his veterinary editorial departments in the New York Tribune and the Livestock Journal.

It was in recognition of his manifold contributions to veterinary medicine, rather than as a long-time Association worker, that he was accorded the presidency of the AVMA in 1906. His death on May 10, 1921, terminated one of the longest and most distinguished careers of service to veterinary medicine in America and evoked the 
following tribute from his successor, Veranus A. Moore:

Dr. Law was an inspiring and thorough teacher. In his earlier years at Cornell he was not only a teacher of unusual distinction but also the leading comparative anatomist and pathologist; the most skilled in veterinary surgery; the keenest in physical diagnosis; and the most scientific and successful livestock sanitarian in America. It was at his feet that Daniel Elmer Salmon and Leonard Pearson received their inspiration for the valuable work they accomplished. Occasionally in those earlier years, with a prophetic vision, he would refer to the coming of veterinary colleges that would be worthy of the cause they were to serve. . . . And now the mantle of this great scholar and teacher has fallen on the veterinary educators of the land. No one of them is capable of wearing it alone.

\section{8}

In his presidential address at the meeting in Philadelphia in 1908, W. H. Dalrymple called attention to the fact that the American Medical Association was urging "rational reciprocity" based upon uniform standards of education and legislation among the states, and observes:

The trend of professional opion, both medical and veterinary medical, I think, seems evidently to be in this direction of reciprocity among the states; and which, I believe is a prospective condition, concerning our profession, worthy of the best thought of this association. If I mistake not, one of the first steps in the accomplishment of this end, would be uniformity in the educational requirements, both for matriculation and graduation, in the different veterinary institutions throughout the country.

The report of the Committee on Education, read by Leonard Pearson, evoked much discussion. It dealt mainly with criticisms of the report issued by the USDA, which recommended certain minimum standards for matriculation and graduation-modified from a similar report made by the committee, but which had failed to obtain the approval of the Association. The USDA report, based on visits of a committee to the schools, listed eleven of the nineteen schools as Class A, i.e., meeting their recommendations; four Class
B, whose graduates were no longer to be recommended as eligible to take the Civil Service examination; and four Class C, new schools which did not yet have any graduates. While it was recognized that some action had to be taken with regard to some of the schools with lesser requirements, the committee objected to the rigid curricular requirements and educational standards for teachers imposed upon the schools:

This recommendation shows complete disregard for sound principles of teaching. ... To say that a professor of anatomy must give at least 200 lectures and 300 hours of laboratory work is to interfere with a detail of pedagogy with regard to which the Secretary of Agriculture has positively no right to interfere. . . Anatomy is a subject difficult to teach by lectures.

In rebuttal, Tait Butler, a member of the USDA committee, was of the opinion:

the Committee was as competent to say how anatomy should be taught as Dr. Pearson is to judge of the competency of the Committee.... If it is within the province of the Secretary of Agriculture to say that anatomy shall be taught his employees, then it is within his province to say how it shall be taught and how much shall be taught.

In speaking on "The Important Relation of the Veterinarian to Public Health," Fred J. Mayer, M.D., noted, "This newly recognized responsibility raises the veterinarian to full fellowship with his medical brother," and urged the AVMA to:

take the initiative in establishing a postgraduate school or Institute of Comparative Medicine ... where medical men and veterinarians may take a course which neither should neglect.

Tuberculosis was discussed by V. A. Moore, J. R. Mohler, O. E. Dyson, H. J. Milks, and Burton Rogers, and members were urged to participate in the International Congress on Tuberculosis to be convened shortly in Washington, D.C., and of which Leonard Pearson was chairman of the section on tuberculosis in animals. Among other papers presented were those 
on hog cholera immunization by A. D. Melvin; livestock transportation by N. S. Mayo, and shipping fever by C. H. Jewell; opsonic therapy by R. A. Archibald; and veterinary history by $D$. Arthur Hughes.

By unanimous consent it was resolved that the AVMA:

extend the privilege of membership to veterinarians of the new world, and that veterinary associations in other countries of North, Central and South America be invited to send representatives to our annual meetings.

John G. Rutherford of Canada was elected president; R. P. Lyman and G. R. White were re-elected secretary and treasurer, respectively.

\section{W. H. Dalrymple}

William Haddock Da $1 \mathrm{rymple}$, M.R.C.V.S., was born in Scotland, April 23, 1856, and was educated at Glasgow. In the 1890's he became Professor of Veterinary Science at Louisiana State University, where through his work and writings he became known as the "father of veterinary medicine" in the deep South. In 1915 it was said of him:

Indeed the name Dalrymple in Louisiana and adjacent states has signified a new attitude of the professional men towards the public. $\mathrm{He}$ early grasped ... . the lofty principle that the highest form of medical practice consists in disease prevention, and that it is the duty of the public health officer to sacrifice monetary advantage to that end.

A Fellow of the American Association for the Advancement of Science, and of the American Medical Association, Dr. Dalrymple was long a stalwart of the AVMA and was elected to its highest office in 1907. Upon his death on July 17, 1925, the governor of Louisiana stated, "The state and nation has indeed suffered a great loss."

\section{9}

In his presidential address at the 1909 meeting in Chicago, J. G. Rutherford expressed his regrets:

that the influence of this association was not earlier brought to bear on the profession in
Canada. . . The conditions under which the practice of comparative medicine is carried on are practically identical in both countries, and nothing but good can result from the maintenance of the most friendly relations between members of our profession on both sides of the international boundary. . . . In both countries we are slowly gaining ground in the control and eradication of animal diseases, and, as a consequence, are year by year improving our position with the general public and even with the live stock men themselves, who, in the very nature of things, are the last to be convinced of the benefits which they are the first to derive from our efforts. . . . [ But ] we are still a long way from being in the position of Alexander the Great, who wept because he had not more worlds to conquer.

Concerning "the vanishing art of diagnosis," Dr. Rutherford observes:

Too many of our young practitioners to-day depend almost entirely on the microscope, either in their own hands or, more frequently, in those of some pathologist, who, with all his knowledge, may be devoid of practical experience or even of common sense. . . . It is well to maintain a reasonable balance between science and practice, with perhaps a friendly leaning to the latter, in recognition of the old and well-established principle that in the ordinary work of life the practical man may get on fairly well without theory while the theoretical man without practice is almost certain to come to grief.

Dr. Rutherford was of the opinion that it would be profitable to divide the program into sections "so that each member may elect to listen to such papers as deal with the special lines of professional work in which he is most interested." Tait Butler had made the same suggestion in 1901, proposing sections on general practice, sanitary medicine, and research. The first sectioned meeting was held in 1910 .

Secretary Lyman's report called attention to a number of inadequacies;

our present requirements for admission are inadequate ... there is no ruling on the present method of electing officers ... the ruling in relation to unethical practices is at present dilatory.

Dr. Lyman also suggested that "the position the Association has attained" war- 


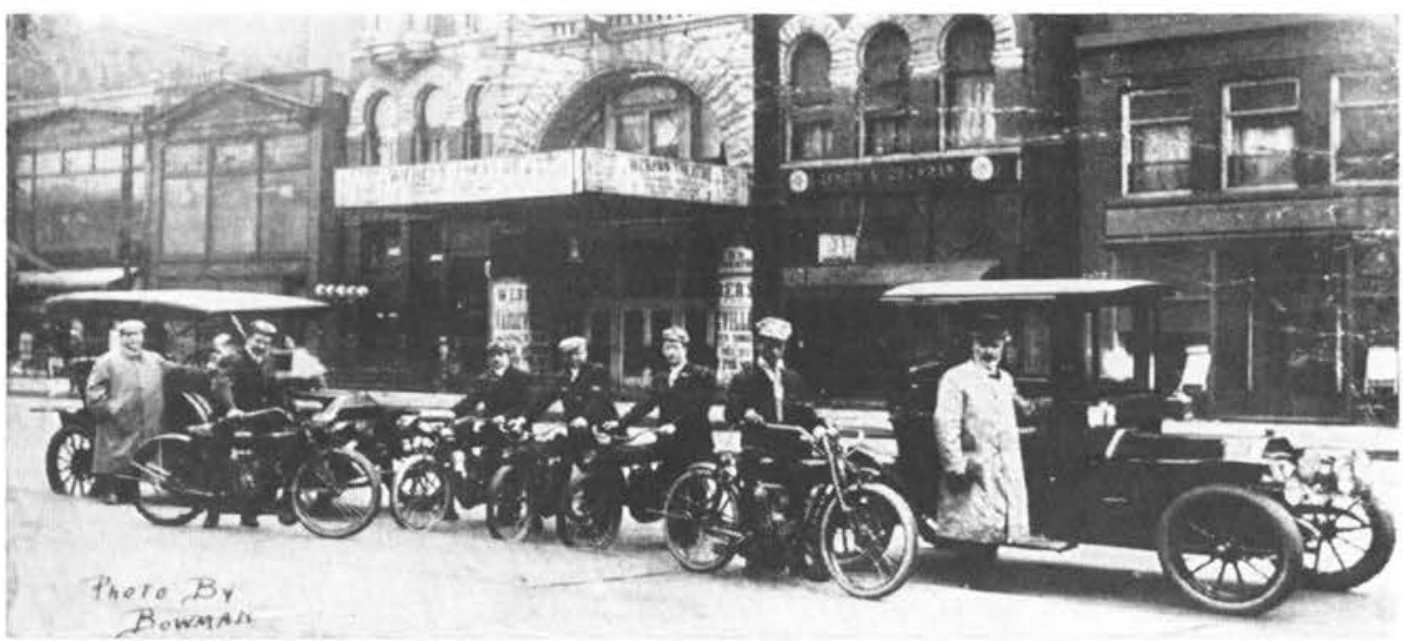

Members of the Chicago firm of Wright and Merillat in 1908. Dr. J. M. Wright (right) was State Veterinarian of Illinois; Dr. L. A. Merillat (left) was at various times practitioner, educator, author, military veterinarian, AVMA president, journal editor and historian, among other activities. Easten Iowa VMA Publication

ranted purchase of a typewriter for use by the secretary. At this time the Association had a total income of about $\$ 4,500$ and expenses of about $\$ 2,500$, of which $\$ 1,500$ was for printing the annual proceedings.

Following the practice established the previous year, the Committee on Diseases augmented its report, with papers being presented on rabies by J. R. Mohler, V. A. Moore, and C. H. Higgins. Rabies was selected, "As this disease, because of its wide prevalence, great economic and sanitary importance, and easy elimination, should not exist in this country." Papers were presented by C. M. Haring on tuberculosis, A. T. Kinsley and W. B. Mack on swamp fever, and Fred Torrance on internal secretions, the first paper on the new subject of endocrinology to be presented at an AVMA meeting.

A joint evening session was held with the Chicago Medical Society, the program being devoted to a consideration of milk and milk hygiene. The speakers included W. A. Evans, M.D., Health Commissioner for Chicago, M. H. Reynolds, and ex-Governor Hoard of Wisconsin, who made his famous remark concerning clean vs. "cleaned-up" milk: "I would not marry a woman that had been made clean."
With the admission of 177 new members, membership in the AVMA passed the 1,000 mark. A. D. Melvin was elected president; Drs. Lyman and White were reelected secretary and treasurer, respectively.

\section{J. G. Rutherford}

John Gunion Rutherford was born in Scotland, December 25, 1857, and came to Canada in 1875. He graduated first in his class from the Ontario Veterinary College in 1879, following which he practiced at various places in the United States, Mexico, and Canada. In 1884 he moved to Manitoba and became Veterinary Inspector for the province until 1892, when he resigned to enter politics, being elected to the Manitoba legislature, and in 1897 to the Dominion Parliament. In 1902 he was appointed Chief Veterinary Inspector, and in 1904, Veterinary Director General for the Dominion. It was primarily through his efforts that the Ontario school was made a provincial institution affiliated with the University of Toronto, which conferred upon him the degree of Doctor of Veterinary Science in 1920.

Dr. Rutherford joined the AVMA in 1902, was five times elected a vice-president, 
and was elected president in 1908. This same year he was honored by being the first American graduate elected as an Honorary Associate of the Royal College of Veterinary Surgeons. Among other qualifications, it may be said that he was one of the few truly great statesmen which the American veterinary profession has produced. Death came after a protracted illness, at Ottawa, July 24, 1923.

\section{CROSSING THE CONTINENT}

The first meeting of the Association in the far West was that of 1910 in San Francisco. President A. D. Melvin noted this fact in speaking of "the gratifying growth of our association, a growth not only in numbers and in territory represented, but in standing and prestige and in things accomplished." Regarding legislation before Congress which would have created a Department of Public Health, Dr. Melvin spoke favorably, except for a provision that would have transferred the Bureau of Animal Industry to this new agency:

The Bureau of Animal Industry is essentially an agricultural organization ... . even though some branches of its work have an important bearing on the public health.... The production and conservation of the public food supply are of the highest importance to human health, but the measures by which such production and conservation are accomplished are mainly agricultural. ... The government's veterinary work should by all means remain under veterinary direction, even if regarded solely from the standpoint of efficiency without any regard to professional pride.

\section{The Committee on Diseases noted:}

During the past year our country has not been visited by any new or unusual epizootic disease ... [ nor ] any severe outbreak of diseases indigenous to our country .... [ which ] emphasizes the efficiency of the Federal Veterinary departments in both the United States and Canada.

Tuberculosis continued to hold the spotlight, with papers being presented by Drs. Mohler, Rutherford, V. A. Moore, Reynolds, Ward, and Haring.
Following a preliminary meeting of the Association of Veterinary Faculties and Examining Boards, the program for the first time was distinctly sectioned, with sessions on Medicine, Pathology, Milk Hygiene, and Surgery. A feature of the latter section was an address, reputedly extemporaneous, by L. A. Merillat on: "The Present Status of Animal Surgery in America." Never one to mince words, Dr. Merillat charges:

Veterinarians have much less to be proud of as surgeons than they have as workers in some of the other departments of the profession. ... We have continued year after year to disobey the commonest laws which govern scientific surgical manipulations. . . . We have not attracted the greatest minds of the profes. sion into the surgical ranks.

And on the subject of anesthesia, he asks:

To what extent have the veterinarians availed themselves of this great victory over surgical pain? ... In the large colleges and in the larger hospitals, the spirit of compassion seems to prevail, but in the general practice there are still too many torturing operations performed without due and sufficient regard for the sufferings we inflict.

And on asepsis and hemostasis in surgery:

For twenty years the veterinary profession entirely ignored asepsis ... [ [and] we are today knowingly guilty of practicing faulty methods. . . . . We have been prone to wade through long bloody dissections, leaving the matter of hemostasis for the last step. . . The surgical wound held free from blood by modern methods of hemostasis, held free of microbian contamination by modern methods of asepsis and inflicted without pain by modern anesthesia is our only path to that high level now occupied by the art of human surgery.

Dr. Merillat notes, however, that the profession had come a long way since "the institution of an almost shameful clinic at Omaha in I898."

An unexpected "feature" of the trip west was the wreck of the "American Veterinary Special" train in the badlands of Montana. Several cars were derailed, but no one was hurt, and the affair took on something of the aspect of a picnic. 
G. H. Glover was elected president; C. J. Marshall, secretary; and G. R. White reelected treasurer.

\section{A. D. Melvin}

Alonzo Dorus Melvin, D.V.S., was born in Illinois in 1862, was educated in business, and graduated from the Chicago Veterinary College in 1886 . He entered the Bureau of Animal Industry, and became noted almost immediately for his work in suppression of contagious pleuropneumonia in Illinois and Maryland - marking him as a man to be picked for greater responsibilities. $\mathrm{He}$ was successively Veterinary Inspector in Chicago and at Liverpool, England; in charge of Bureau work at the Union Stock Yards; Assistant Chief of the Bureau; and, upon the retirement of Dr. Salmon in 1905, he served as Chief of the Bureau of Animal Industry until his death on December 7, 1917. During his tenure as chief, he was largely responsible for major improvements in the fecleral meat inspection system, and for eradication or control measures against foot-andmouth disease, Texas fever, sheep scab, dourine, hog cholera, and tuberculosis.

\section{1}

In his presidential address at the $191 \mathrm{l}$ meeting in Toronto, G. H. Glover spoke of many things relating to the general theme:

We are proud of our chosen profession and the progress that it has made. . . Harmony is the prime essential to strength in any institution, and to this factor must be attributed, more than to any other, the rare interest and splendid growth of the American Veterinary Medical Association.

The growth of the Association, while overdue, had been little short of remarkable. Membership $(1,189)$ was twice that of five years before, and triple that of ten years earlier. California, which had the grand total of five members in 1905, added 36 at the meeting in San Francisco in 1910, and 32 more in 1911. Altogether, 435 new members were added to the roll these two years-more than the total membership a decade before. Some of this increased interest in the AVMA, as in the case of California, undoubtedly can be attributed to that generated by moving the meeting site to new sections of the country.

The Surgical Section featured a paper on the roaring operation by W. L. Williams, and one on: "The Merits of Williams' Operation for Roaring," by Prof. Frederick Hobday of London. In the Section on Practice, $\mathrm{H}$. Preston Hoskins made his debut with a paper on pneumonia, and K. F. Meyer, recently graduated from the veterinary school at Zurich, spoke on nephritis. Papers on various aspects of veterinary biologics were presented by $P$. A. Fish, E. L. Quitman, Adolph Eichhorn, A. T. Kinsley and R. A. Archibald; equine anemia was discussed by W. B. Mack; and bovine hematuria by Seymour Hadwen. The Sanitary Section featured papers by W. H. Dalrymple on anthrax and tick fever; C. D. McGilvray on glanders; and Cassius Way on milk sanitation. John $\mathbf{R}$. Mohler, J. G. Rutherford and S. H. Gilliland discussed various aspects of the tuberculosis problem.

At the meeting of the Association of Veterinary Faculties and Examining Boards, Dr. Glover, president of this group also, charged that this body:

has not fulfilled the mission for which it was created. ... We seem to have been lacking in the initiative, uncertain of our authority, and luke-warm as to the vital problems which affect our institutions.

Unlike the situation in past years, however, a vigorous program included papers by $R$. A. Archibald on suppression of correspondence schools; Sesco Stewart on uniform state board examinations; fundamental education by R. P. Lyman; anatomical teaching and nomenclature by Septimus Sisson and I. E. Newsom: and physiology and pathology in the curriculum by P. A. Fish and S. H. Burnett.

The surgical clinic, held at the Ontario Veterinary College, featured three roaring operations by Prof. Hobday, who also oper- 
ated on two dogs. By comparison with the clinics of 1906 and 1907, when 36 of 40 operations were on horses, among the 47 animals in the 1910-1911 clinics were 12 dogs, 5 cows, and one pig.

As a matter of passing interest, the ladies, who had attended the meetings for the first time only 15 years earlier, outnumbered members of the Association (but not veterinarians) in attendance at the Toronto meeting.

In considering what the future might have in store, Dr. Glover notes:

In the face of past achievements and in the light of our present knowledge, it certainly is no idle dream to predict that the time is coming when it will be possible to build up the body defenses against any and all bacterial diseases. Our work must go forward by three parallel and seemingly important lines; first, combatting disease wherever found and by every known agency; second, fortifying the body by its natural defenses and other agencies; third, waging a relentless warfare against pathogenic microorganisms.

Samuel Brenton was elected president; C. J. Marshall and G. R. White re-elected secretary and treasurer, respectively.

\section{One Profession, One Title}

For many years Alexandre Liautard had advocated a uniform veterinary degree, preferably administered by a central body equivalent to the Royal College of Veterinary Surgeons of Great Britain. Perhaps as an aftermath of his continual hammering on the subject, the matter became widely discussed about 1910. At the AVMA meeting that year, Dr. Glover, in considering the variety of titles extant, considered:

The crux of the whole matter is that there seems to be no serious objection to any one of these degrees, but the public are woefully ignorant as to their import because there are so many of them, and honestly believe in many cases that they stand for different vocations or different degrees of educational attainment in veterinary art, or something they scarcely know what. It is confusing to the public, engenders discord in the ranks, casts unfavorable reflec- tions upon the profession, and no doubt has an economic significance.

D. Arthur Hughes, in speaking of the historical aspects of the degree dilemma in America, states:

The variety of titles conferred was due, in many instances, to the rivalry of the colleges. ... From the beginning of veterinary education in this country this rivalry has existed, and it has, sad to relate, intensified and become, I fear, more vulgar as time has gone on - or at least it has, in many degrees and shades, cheapened the profession, and has the flaw of vulgarization in this matter of variegation of veterinary titles. . . The consequence is that an evil has been done which cannot be effaced in our own or the next generation. Thousands of titles have been given which cannot now be expunged - only the agonizingly slow processes of time can wear away the large, funny titles from sign boards and door fronts.

Both Hughes (Cornell) and Glover (Iowa) had D.V.M. degrees, but neither overtly suggested that this form be given preference over some other.

The German-educated Olof Schwartzkopf, who signed his articles as "Veterinarian," gives an extensive history of the veterinary degree in Europe and America, stating, "Our colleagues in Europe consider our numerous degrees a mystery, if they express themselves politely." At the time (1911) 9 schools granted a Doctor of Veterinary Medicine (5 D.V.M.; 2 V.M.D.; l D.M.V.; I M.D.V.); 3 Doctor of Veterinary Surgery (D.V.S.); 4 Doctor of Veterinary Science (3 D.V.S.; 1 D.V.Sc.); and one each: Veterinary Surgeon (V.S.); Doctor of Comparative Medicine (M.D.C.), and Bachelor of Veterinary Science (B.V.Sc.).

With convincing logic, Schwartzkopf demonstrates:

By elimination of the degrees having no fixed or permanent standard, we have left for a choice the old V.S. and the more modern D.V.M. ... [ But] to fall back on the V.S. would be too great a reaction after we have allowed the veterinary doctor degrees to permeate the country. . . . Thus . . . let us choose the D.V.M. which is correct by precedent and tradition ... and understood every where. ... If we take the well-established M.D. as a 
guide, the V.M.D. would perhaps be the best imitation. But as our degrees of doctor of veterinary medicine are now all written in English with the exception of one, the most proper American abbreviation is that of D.V.M.

Having read these discussions, a veterinarian sent in a card used by a nongraduate, which read: "Late Acting Veterinary and Chief Ferrier, Dep't of the Phillipines." While the title undoubtedly was assumed without profound thought, "Veterinary" was - and is - acceptable British usage, and "Ferrier" is historically more correct than "Farrier."

\section{G. H. Glover}

George H. Glover was born in 1864 and received a B.S. in agriculture from Colorado in 1884, and the D.V.M. from Iowa State in 1885, along with Sesco Stewart and W. B. Niles. Dr. Glover spent twelve years as an inspector in Colorado and Montana after graduation, following which he practiced for seven years in Denver, during which time he was also an instructor in the College of Agriculture for a short period. In 1907 he was instrumental in the establishment of the present College of Veterinary Medicine at Colorado State University, and served as dean until his retirement in 1932.

In 1910 he was elected president of the AVMA, the Colorado VMA, and the Association of Veterinary Faculties. He was said to have a ready pen and a ready tongue, and could write and speak for lay and professional audiences with equal facility - not only on veterinary topics, but on temperance, politics, or theology as well. Dr. Glover died at a ripe old age on January II, 1950.

\section{2}

At the 1912 meeting in Indianapolis, President Samuel Brenton acknowledged some discontent with the system of nomination of officers by a committee composed of past-presidents:

Our Association had a period when an unseemly struggle for official places, both elective and appointive, characterized our annual meeting. ... Many of the newer members ... do not realize the beneficient influence of the present plan of nomination. It is very apparent to those who have long acquaintance with association affairs that our nominating committee has without prejudice endeavored to serve the very best interests of the Association.

The section on sanitary science featured a symposium on hog cholera; that on medicine a symposium on glanders, which included papers by R. S. Mackellar, K. F. Meyer and C. J. Marshall. As something of a new departure, the three sessions of the section on surgery were devoted to the clinic at the Indiana Veterinary College. The roaring operation was of paramount importance, with performances by W. L. Williams, J. N. Frost, L. A. Merillat, J. W. Adams and J. H. Blattenberg. In a paper on "The Surgical Relief of Roaring," Drs. Williams and Frost reported their work aimed at denudation of the lateral ventricles of the larynx, using the burr devised by Dr. Blattenberg - with poor results until Frost hit upon the "trivial" idea of adding a few wisps of cotton. They note:

Few operations in the history of veterinary surgery have undergone so rapid development as has that for roaring since our first communication to this society six years ago. During this brief interval the operation has been adopted practically wherever veterinary science is known.

Other papers included those on biologics by C. A. Cary; infectious abortion by Ward Giltner; communicable diseases by V. A. Moore; tuberculosis eradication by John F. DeVine; and clinical instruction by $\mathrm{A}$. T. Kinsley.

It was decided to appoint a committee to assist the editors of farm journals "to purge their advertising columns of fake and misleading advertisements concerning proprietary preparations put out for the use of veterinarians and the public." While this committee was to act only upon request of a journal, the resolution creating it was adopted only after strong protests that failure to condemn an advertisement for a product of possibly doubtful merit would automatically constitute an endorse- 


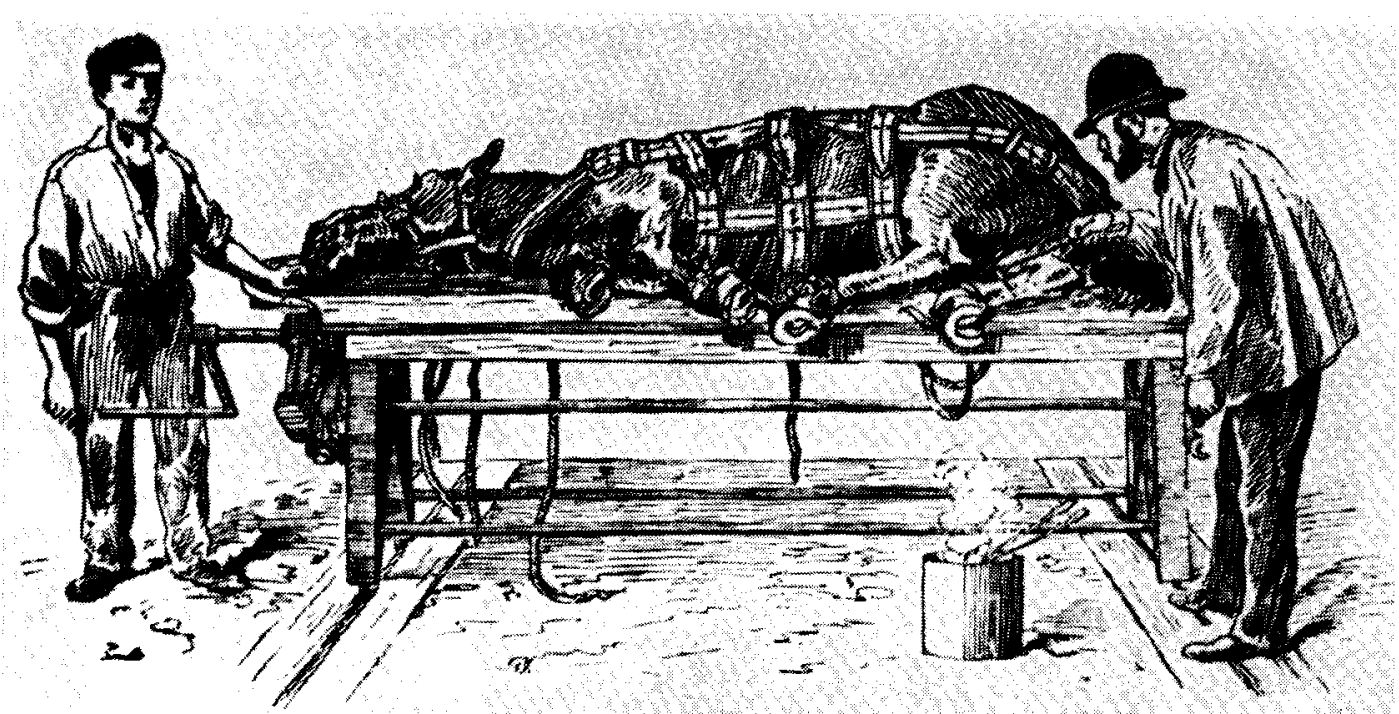

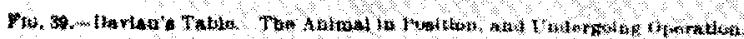

Large animal operating tables were in use at most of the colleges by 1900 and were an important factor in the development of improved surgical technics as well as a great boon to teaching. Liautard: Surgery

ment of that product. Nelson S. Mayo, who had championed the proposal, was made chairman of the committee, and C. A. Cary and S. B. Nelson were members. The following year they reported considerable progress, notably in having advertising for the London (Ontario) Veterinary Correspondence School completely eliminated from all periodicals. Some journals, as the Progressive Farmer, edited by Tait Butler, eliminated all questionable advertising - at a considerable cost in loss of revenue, but "Others, and among them some of the most influential papers of the continent, paid no attention to our letters."

John R. Mohler was elected president; C. J. Marshall and G. R. White were reelected secretary and treasurer, respectively. After a long tenure as librarian, W. L. Williams relinquished this post in favor of S. H. Burnett.

\section{Clinical Curiosities}

The clinic at the Indiana Veterinary College may have afforded some members their first acquaintance with the large animal operating table. Opinions concerning its merits were divided, for on the subject of "The Veterinary Operating Table," W. L. Williams had noted in 1906: "The operating table for the horse has been enthusiastically championed and unsparingly condemned by veterinarians of high and low degree." Some, he says, object to the table because it is not portable:

The same objection could be urged against an office, pharmacy or hospital. ... Others have attributed their want of success in surgery to the lack of an operating table, and when they have tried the machine only to find that it can neither perform operations nor heal wounds they are very naturally disappointed. Others cling to the operating table, as a magnificent advertisement and use each opportunity to display the machine even for cases which could be better handled without confinement at all or in the stocks. ... We could not consistently continue the use of the table in daily work for a period of 9 years, side by side with various kinds of casting harness . . . except it had for us some points of superiority. . . . Our study and experience leads us to assert that the operating table has a highly important place in the surgery of our domestic animals, and 


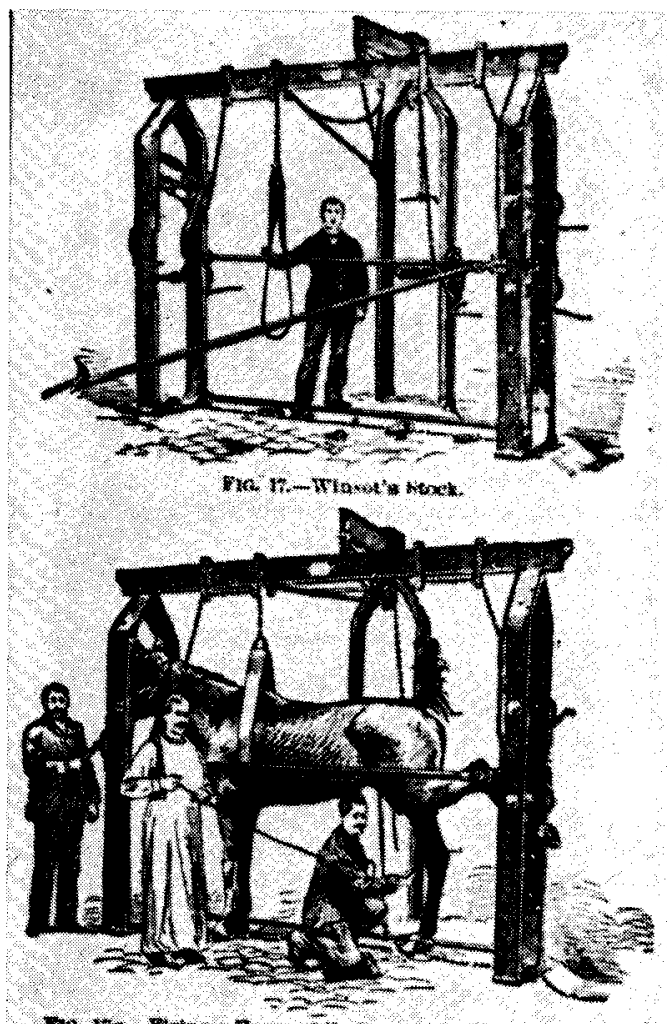

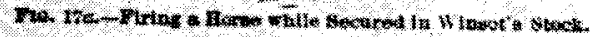

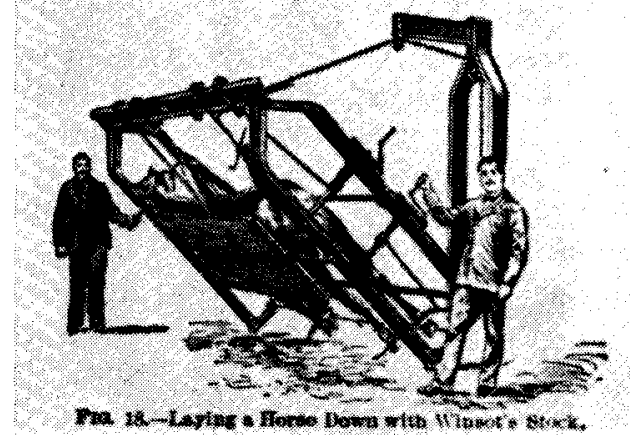

The merits of various types of operating tables were loudly proclaimed by some veterinarians usually those who had them - and decried equally vigorously by others, who claimed they were impractical. Liautard: Surgery

that its use must constantly increase as surgery advances.

As major advantages of the table for certain types of surgery, Williams stresses the safety, comfort, and convenience of both surgeon and patient, and the greater possibilities of asepsis in operating.
The properties of the $x$-ray, discovered by Roentgen in 1895, were the subject of a lecture and demonstration to the students of the Ontario Veterinary College early in 1896. In noting this, the Review states, "The 'X ray' is, without doubt, destined to be of inestimable benefit to science in the near future." And in 1897: "The application of this comparatively recent discovery in photography has received more attention, we believe, at the hands of English veterinarians than with other practitioners."

In commenting on a report of the use of the x-ray to diagnose a case of persistent lameness in a trotting stallion - which was taken to the University of Kentucky Medical School for the purpose - the editors of the Review in 1910 note:

The clinical application of the $\mathrm{X}$-ray, on account of expense and other reasons, certainly is not general; but we had the pleasure about two years ago of seeing, by the aid of the X-ray, an iron rivet in the digestive tract of a puppy, at one of the meetings of the Veterinary Association of New York City.

Writing on "The Use of X-ray in Veterinary Medicine" in 1915, H. E. Kingman, Sr., then Professor of Surgery at Colorado, mentions, "The literature in regard to the use of the $x$-ray in veterinary practice is incleed limited." He presents a number of cases in which the x-ray had been used to advantage in diagnosis:

We cannot deny that many of the diagnoses of lameness made by veterinarians are arrived at through symptoms that are not always as plain as one might wish. . . By being able to definitely diagnose one becomes more astute. By being certain of a diagnosis the practitioner becomes sure of himself and gains the confidence of his client. In our profession we are in need of more accurate means of diagnosis, and I firmly believe that the $\mathrm{x}$-ray can be made to occupy a great field in the diagnosis of disease in the large animals.

\section{Small Animal Medicine}

Speaking on "Canine Practice" in 1912, J. C. Flynn accuses:

A great many times I have been told by my client that he had called in some certain doctor 
During the I920's a few veterinarians employed radiography extensively-but usually without adequate safeguards - and many suffered serious $x$-ray burns. Veterinary Medicine

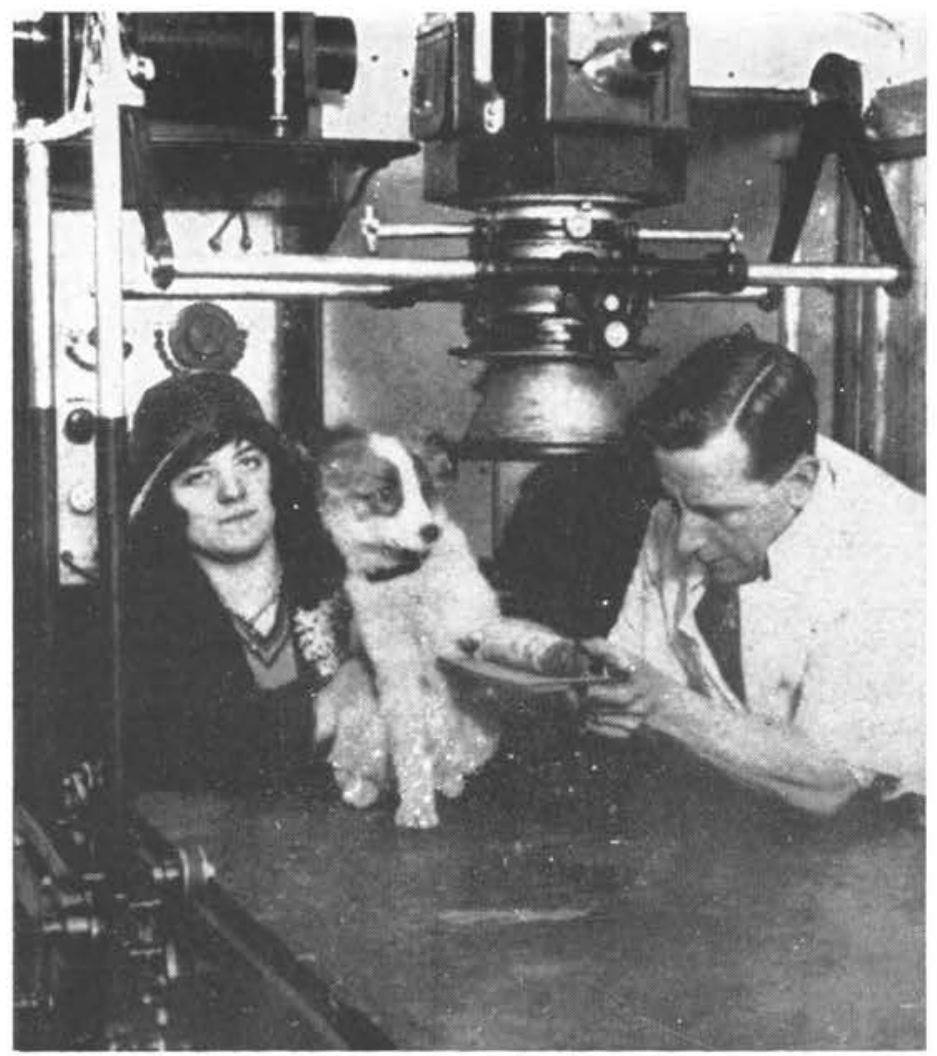

on a number of cases and that each time the latter's advice was, "Oh, give it a close of castor oil." To take it for granted that the laity knows nothing of disease and medicine, and that their pet stock can be handled in a careless manner, is a grave mistake. We lower ourselves and our profession in the eyes of the public when we fail to treat the dog in the same scientific manner in which we treat the other domestic animals. . . The owner can only infer that one of two conditions exists. The reterinarian either does not care for his dog practice or he does not know how to intelligently treat the dog....

The veterinarian is not alone to blame for the lack of proper care of the sick dog. Our schools and colleges have failed to grasp the true situation and have not impressed upon the minds of the student body the necessity of a thorough training in canine practice... . In this day and age, when canine breeding has reached a condition which we may well call an art, it behooves us as veterinarians to give this important branch of veterinary science a close study. . . . "The dog is his own doctor" is a phrase you hear every day, and a number of our profession agree to it. The dog is his own doctor, it is true in a measure, because conditions have made him such. He is not so by his own choice any more than you or I."

Referring to what he terms the first period of small animal practice-prior to 1920 - J. V. Lacroix states:

Only a small number of veterinarians gave any considerable portion of their time to smallanimal practice and few of these hospitalized dogs and cats. In fact, many well qualified veterinary practitioners, during much of this period, did not feel complimented when their horse-owning clients requested them to give attention to ailing dogs. In such instances, attention given to a dog or a cat was usually gratuitous.

Dr. Lacroix credits Flynn with having had more influence on the development of small animal practice than the sum total of all other factors in the 1920's:

Dr. J. C. Flynn gave the better part of two years of his time, without compensation, in 


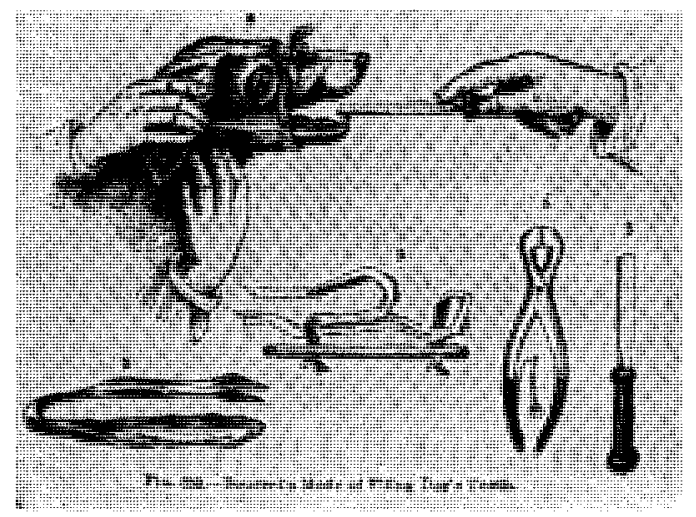

Canine dentistry, as practiced in Europe, was advocated in this country during the era when equine dental operations were popular - long before small animal practice had developed to any appreciable extent. Liautard: Surgery

criss-crossing the country by automobile accompanied by Mrs. Flynn, in response to invitations extended by the secretaries of veterinary organizations, small and large. Doctor Flynn was a successful practitioner in the treatment and hospitalization of small animals at Kansas City, Mo. He was a capable and versatile exponent of demonstrational methods, and whenever he gave clinical demonstrations, attendance was good and interest high. His sutureless technic for spaying puppies, created of economic necessity in his practice, was something of a sensation as he executed this operation. . . With an unusual background of experience in small animal practice, a good speaking voice, and a ready wit, Doctor Flynn quite naturally encouraged hundreds of veterinarians to engage in small-animal practice.

On the construction of small-animal hospitals, Dr. Lacroix states that Duncan McEachran, at Montreal in the 1880's, was one of the first to provide hospitalization for dogs and cats. And:

in subsequent years veterinarians here and there provided modest facilities for the treatment of small animals, chiefly dogs. But, it was Flynn who set an example by offering hospital facilities in a good building especially designed and constructed for the purpose before World War I. ... It was not until the late twenties and early thirties that many well constructed hospitals... were available.

The first extensive reporting of topics in small animal medicine was a monthly Department of Cynology, conducted by $\mathrm{C}$.
G. Saunders in Veterinary Medicine. This began in 1913, and ran through 1914, during which time what amounted to a textbook in serial form was published. Veterinary Medicine was a leader in presenting departmentalized veterinary topics, a number of which were in the nature of pioneering in these fields: poultry practice (B. F. Kaupp), swine practice (A. T. Kinsley), laboratory diagnosis (C. F. Lynch), plant poisoning (L. H. Pammel), parasitology (M. C. Hall), zootechnics (E. Merillat), and cattle practice (J. F. DeVine). Departments of Surgery (L. A. Merillat) and Foreign Abstracts (A. Eichhorn) had been pioneered in the American Veterinary Review by Merillat and Liautard, respectively.

On the subject of canine pathology in 1916, Veterinary Medicine editorialized:

A lack of interest on the part of students, amounting to a positive hindrance, and not incompetency of lecturers on this subject, is the chief difficulty to giving more efficient instruction in canine pathology in this country. The average veterinary student reared in the country is not a cliampion of the dog, does not look upon canine practice as being worth while and is not at present an enthusiastic supporter of this part of the veterinary college curriculum.

\section{Botany and Biologics}

In writing on "The Veterinarian and Poisonous Plants" in 1912, D. A. Hughes states:

We know that poisonings from eating noxious plants are common; yet the records of them are not made, at least not published. . . . Undoubtedly poisonous plants should be made a branch to be taught as a part of every veterinary college curriculum. ... [ The teaching ] must be the work of a veterinarian rather than a botanist; for it is the veterinary aspect of the case which rightly appeals to the veterinary student. . . The path of the student of plant toxicology is beset with many difficulties, as many plants only in part are toxic; or only in certain periods of their growth; or under conditions of decay; or because of alterations in their substance produced by seasonal conditions. ... The chemistry of plant poisons is in its infancy.... Manufacturing chemists have exhibited a fearful neglect of plants now called poisonous, which will prove to be medicinal plants with many virtues in the alleviation of disease when their merits have been 


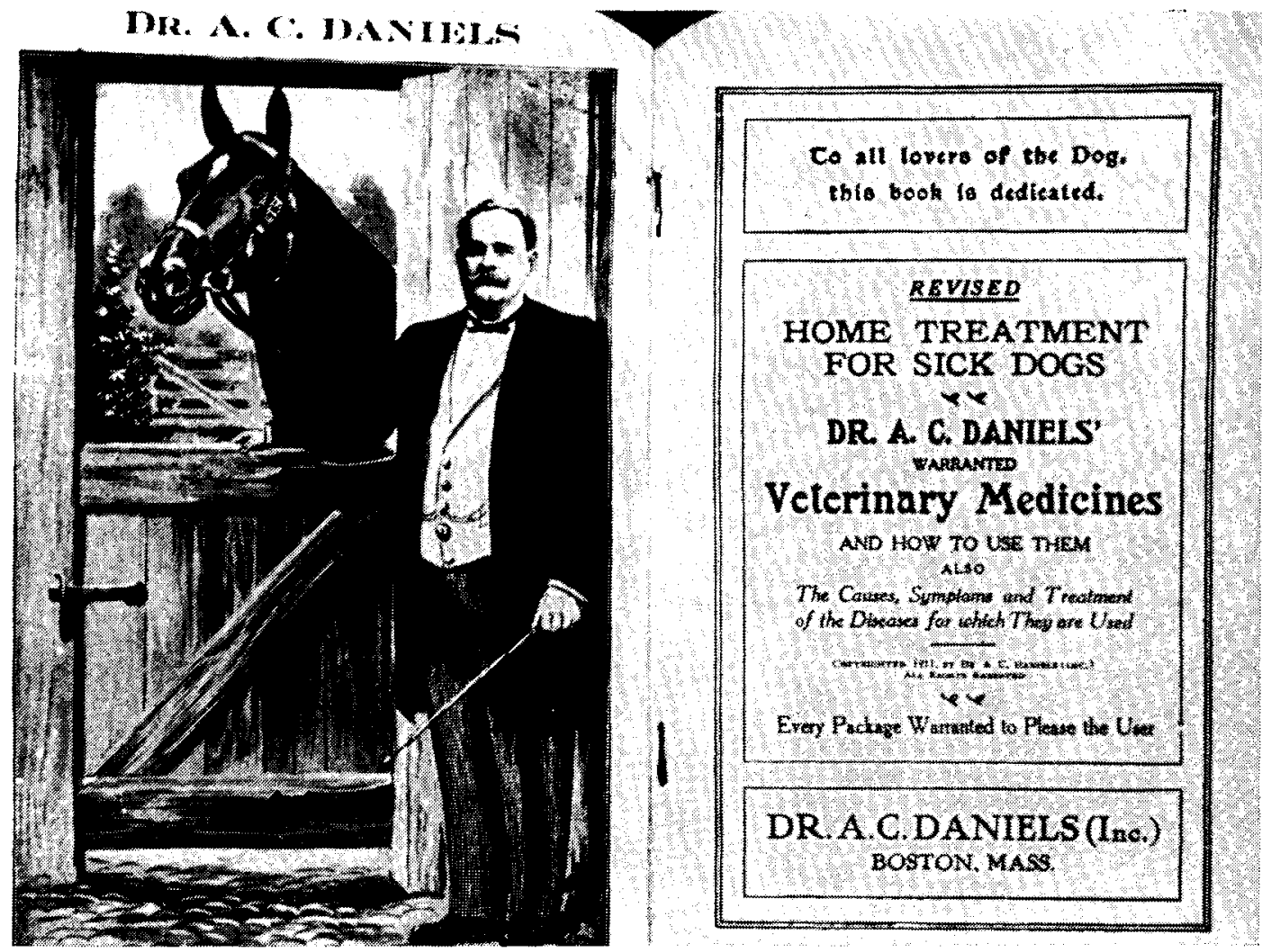

Daniels' Dog Doctor was one of few such advertising pieces during the early twentieth century to be devoted entirely to the canine species.

studied. ... There are a few forms of poisonings of which we know something - such as locoism, delphinosis, hemlock poisoning, lupinosis, ergotism, mountain laurel poisoning.

The development and relatively successful use of anthrax vaccination in the 1880's paved the way for the introduction of other biological products: tetanus antitoxin, tuberculin, hog cholera serum, and autogenous bacterins, among others. A number of these were used with good, bad, or indifferent results by some veterinarians, or not at all by others. Obviously many of the poor results attributed to their use stemmed directly from faulty standardization; a practitioner who had good results with the product of one manufacturer would lose a distressing number of cases with another product. This led the Review in 1910 to editorialize:
The result of the investigation recently made by the United States Department of Agriculture through its Bureau of Animal Industry, on the standardization of tetanus antitoxin, demonstrates clearly the advisability of federal supervision over its manufacture, and over all biological products used in veterinary medicine.

Writing on "Biological Therapeütics in Veterinary Practice," in 1910, T. F. Krey states:

Not many years ago serum therapy in the treatment of disease was considered skeptically. Even the most progressive veterinarians looked upon its use as an expensive experiment only to be considered as a last resort, and then, only in extreme cases where the life of a valuable animal was threatened. To-day we find a vast majority of veterinarians fully alive to the importance of serum therapy and ever ready on all occasions to administer serums, antitoxins or vaccines, whenever their use is indicated. 


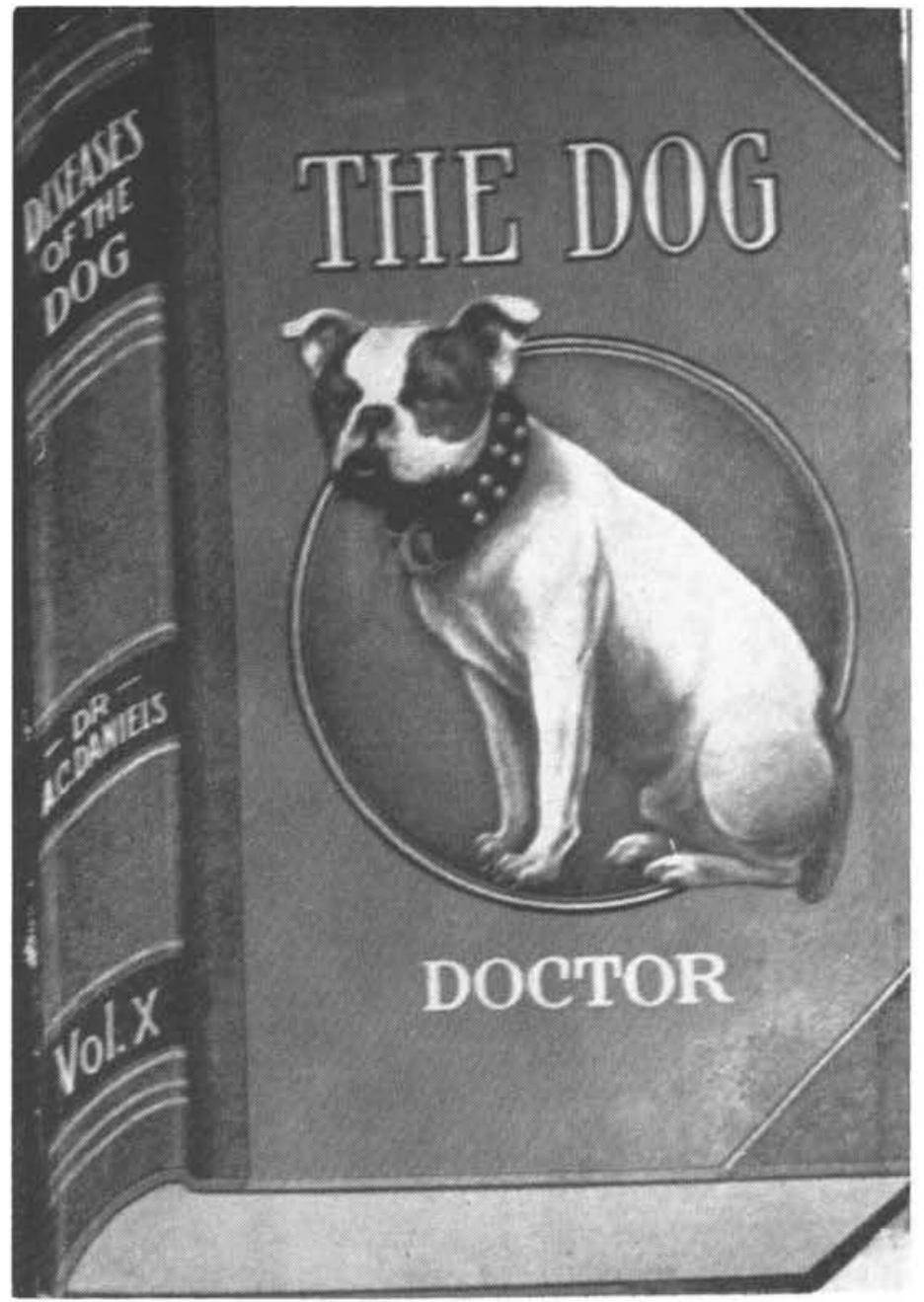

The proprietary medicine fraternity was ever alert to means for subtle as well as overt promotion - this seemingly massive volume is only a cover illustration for a small booklet on remedies for dog diseases.

As a special form of biological therapeutics, a fashionable practice in the early 1900 's was that of "autotherapy." As elucidated by C. H. Duncan, M.D., in an address before the New York City VMA in 1912:

Specific antibodies are developed in healthy tissues by auto-inoculation . . . that is, by the introduction of the toxic substances developed during the course of the disease in healthy tissues. The process tends to bring about a natural cure .... Rule I. In extra-alimentary and extra-pulmonary diseases if the toxic product of the disease is placed in the mouth it will tend to develop specific antibodies. . . . Rule II. In intra-alimentary and intra-pulmonary diseases if the toxic product of the disease be placed in healthy tissues outside of these systems, it will tend to develop specific antibodies. . . The therapeutic value of autogenous pus, given in this manner, is greater than the autogenous vaccine prepared from a pure culture of the offending micro-organism by the method now in vogue.

Thus for infected wounds, Duncan prescribes for his human patients, "a drop or two of pus every hour for three hours," and for puerperal septicemia, "a weak dilution of the lochia in the mouth. . . . It is only going one step farther, to place a part of the menstrual discharge in the mouth to cure some forms of pelvic disorders." (!)

This appears in the Review without comment from the editors; in 1914 it carried 
a report of a homeopathic medical society on the efficacy of autotherapy, in particular, that advocated by Duncan. Veterinary autotherapy was held in high esteem by a number of noted veterinarians, among them D. J. Mangan, Chief Veterinarian of the New York City Department of Street Cleaning, who had 4,000 horses in his charge:

He has used Dr. Duncan's autotherapy for four years in all forms of sepsis, and endorses it highly. In some disorders of the horse, as in ozena or nasal gleet, acute infections of the hoof and fistula of the dorsum, autotherapy is by far the best treatment and in some cases the only successful treatment. He believes that he probably cured one case of glanders.

Veterinary Medicine also took note of autotherapy. And although the editor, D. M. Campbell, apparently gives tacit approval to certain aspects of the practice, he characterizes as "rotten therapy" the administration of pus per os in the treatment of fistula:

Similia similibus curantur with a vengeance. Next someone will give teaspoonful doses of crushed bone for fractures and phonograph records of coughing for tuberculosis. . . To my mind the oral administration of suppurative discharges from fistulous tracts, gonorrheal lesions, or other chronic suppurating conditions, is the very antithesis of scientific treatment and cannot by any possibility have any beneficial therapeutic effect.

At the same time Mart R. Steffen, a regular contributor to Veterinary Medicine, writes concerning Duncan's claim that milk from a fresh cow injected subcutaneously into one in declining lactation will stimulate milk flow:

While it looks rather fishy, we will not laugh until we have tried it out. If the news, for such it is to us, came from anyone but Dr. Duncan we might have a little more faith in it. But we happen to know that the doctor seems to have a mania for this "like cures like" method of therapeutics. For the past seven or eight years he has been in convulsions over it.

It was about this time that L. A. Merillat recommended the radical operation for fistula as the best hope of permanent cure.

\section{Price and Prejudice}

In a good summary of the status of veterinary biological products in 1912, R. H. Wilson states:

It is only within the past few years that biological products have been employed extensively in veterinary medicine. There has existed more or less prejudice against them on account of their expense and apparent ineffciency in some cases. But this prejudice has been practically eliminated, and the demand for the products would indicate that their practical value in most instances has been proven without a doubt.... If medical research is as fruitful in the future as it has been in the past, it would seem that the time is not far distant when practically every form of infection can be successfully combated with a biological specific.

The preparations he notes as being in demand include anthrax vaccine, either as an attenuated living virus, or a killed vaccine, the latter having the advantage of not being able to cause the disease; the former, "by its promiscuous and reckless use it may be the means of spreading the disease instead of curbing it." Also blackleg vaccine, in the one or two inoculation form; and rabies vaccine, which

owing to the complicated nature of the treatment, it has not been employed in veterinary medicine until quite recently. ... Reports indicate that the method is attended with the same degree of success as in dealing with rabies in man.

Concerning the tuberculosis vaccine on the market: "The practical value of this product is rather doubtful."

On the use of bacterins - a more scientific form of autotherapy - he says:

The results obtained by the use of bacterial vaccines, properly prepared and administered, are indeed gratifying. Many stubborn suppurative conditions, such as fistulous withers, poll evil and quittor, which do not yield to ordinary surgical and medicinal treatment, are benefited and completely cured by bacterial vaccines. Febrile disorders due to bacterial infections, in many cases respond to bacterial therapy and make rapid recoveries.

On tetanus antitoxin: 
As a prophylactic agent against the disease this product is now generally recognized as a specific. .. Many operators will not undertake an operation of any consequence without first administering tetanus antitoxin.

And on hog cholera serum: "This product devised by Dorset and Niles is at present probably the most reliable biological product for combating hog cholera." Other antisera of use are: influenza antitoxin, antistreptococcic serum, and antianthrax serum. Biological diagnostics in use include tuberculin:

the most extensively used biological diagnostic agent in veterinary practice ... of great value in detecting tuberculosis and if it is honestly and intelligently applied can be considered sufficiently reliable to be depended upon in every case.

Mallein is characterized as "a fairly efficient agent in dealing with glanders. If the operator is familiar with all the details of the test and capable of interpreting the results, its usefulness cannot be doubted." During World War I it was claimed that many horses were needlessly destroyed because of faulty readings of the mallein test.

Speaking on the need for standardization of biological products, C. A. Cary charges in 1912:

The multiplicity of biological products that may be found on the market causes the public to open its mouth, buy, devour, suffer, get relief, or get no action, paying the price regardless of results. ... All that is required is a little pressure of the hypodermic syringe, and the mysterious biological product will do the rest.

Lack of standardization, he emphasizes, has been the cause of tuberculin's having for some twenty years' a "variable and checkered" history; and on anthrax vaccine:

Doubtless the indiscriminate sale of anthrax vaccines to the laymen, and possibly to professional men, has been the means of disseminating anthrax, especially where the germs were not properly attenuated.
The alternatives suggested by Cary are government manufacture and distribution, or government supervision of commercial production:

I do not wish to imply or to assert that much good has not been done by the manufacturers of biological products. In fact, they have done a great deal that could not have been accomplished without their work.

\section{High on the Hog}

Speaking on "The Highway of Service" in 1925 , D. I. Skidmore, Chief of the Division of Virus-Serum Control of the BAI, notes the existence of 91 establishments operating under government license, of which 57 produced hog cholera serum and virus only. More than 760 million cc. of serum and 34 million cc. of virus were produced in 1924; cost of inspection was about $\$ 150,000$. In one year 9 million cc. of serum had been condemned: "The value in hogs conserved by denial of the use of this rejected serum is estimated as approximately $\$ 4,000,000$." The stimulus to production due to the fact that potent serum and virus were available was estimated at another four million dollars per year.

Noting that some thoughtless persons had complained that the goverment took greater interest "in the protection of our livestock than of people," Dr. Skidmore asks:

Is it for the comfort and welfare of the hog that we immunize it against hog cholera? ... We serve and promote the welfare of men, women, and children and contribute to the happiness of humanity by providing a way for the accomplishment of the things which aid in conserving the live stock industry. ... The producer of biologic products of proven value may well feel a personal pride in the part which he takes in this service.

\section{GOLDEN JUBILEE}

The fiftieth anniversary meeting in 1913, held in New York City, was to have been graced by the presence of its honorary president, Alexandre Liautard, who since 1900 had been living in France. Illness of his wife, however, prevented Dr. Liautard, the 
only living founder of the Association, from attending. In his address, read at his request by his former partner, R. W. Ellis, Dr. Liautard recounts the early days of the Association and notes that with the change of name:

Her history is but the continuation of her former life, and her membership is larger than that of any other similar body in the world. Her word is known, recognized and appreciated in every scientific veterinary center, for she will forever remain the solid representative of our profession in the new world. She has stretched her roots in every specialty of our branch of medicine ... everywhere $t$ h e A.V.M.A. finds many of her worthy members.... The Association has proved and will always remain true to her original motto, Non Nobis Solum - "Not for us Alone."

John R. Mohler, president of the Association, in doing honor to the founding fathers, recalls:

At a time when everything seemed in an irrevocable turmoil, there were found some indomitable veterinarians sufficiently resolute to brave the existing storm. It was reserved for these men to be the first to conceive in wisdom and establish in strength an association qualified to meet successfully the purpose of the founders and to serve triumphantly as one of the pioneers of veterinary societies. Undeterred by the lack of numbers and unyielding to the clamor of radicalism, it has held fast consistently to a sane equilibrium and has demonstrated its merits by its survival.

Dr. Mohler dwells at length on the achievements of the veterinary profession, noting:

The acquirement of knowledge in the domain of animal diseases during the last five decades has been constant and amazing and compares favorably with the progress in other branches of science which has attracted the admiration of the world. As chemistry and physics have advanced from alchemy, and astronomy from astrology, so has veterinary medicine progressed from empiricism and become scientific.

\section{In summary, he urges:}

From the history of veterinary medicine let veterinarians draw confidence in the invincible strength of their science which though at one time despised even by the well-informed, has during the last five decades attained such great importance and such wide influence in the life of this and other countries. And let them take fresh courage and make new resolutions to rival all the other professions in useful work to be accomplished in the fifty years to come.... Gentlemen, I have no fear for the future of veterinary medicine.

Several changes in the structure and operation of the Association were discussed following recommendations of the committee on reorganization, with D. E. Salmon as chairman and James Law, D. M. Campbell, George H. Hart, and C. J. Marshall as members. The most sweeping change was one calling for creation of a House of Delegates which:

should represent the delegated power of the members of the A.V.M.A. and be the national representative body of the constituent Associations. It should elect the general officers of the Association and a board of nine trustees, and should transact all the general business of the Association.

This, however, failed of adoption; another two decades was to pass before the present House of Representatives became a reality.

In offering a dissenting opinion to the majority report of the committee on reorganization, D. M. Campbell proposed that nominations for elected offices be made by the membership at large via a mailed form; the Executive Board would tally the votes and place in nomination for each office the names of the two men from each of five districts who had received the greatest number of votes, whereupon the entire membership would be eligible to vote via mail ballot. Dr. Campbell perhaps objected less to the majority recommendation on this point than to the current method of nomination by the past-presidents. This, he felt, was lacking in democratic principle inasmuch as a small group of men - who, in effect, determined the makeup of the committee-could wield power for long periods. As a matter of passing interest, under this arrangement $\mathbf{W}$. L. Williams could have been a member of the nominating committee for 52 years, Tait Butler and G. H. Glover for 40 years. 
Dr. Campbell's plan, however, might have created some difficulties in that it would have been possible for one man to be nominated for several offices. He did win a partial victory in that the nominating committee was dropped and the previous plan of nominations from the floor reinstituted. The Executive Board continued as an appointive body.

Dr. H. S. Murphey called for action "to provide for an outline of the history of veterinary progress in this country during the past fifty years." As a result, the first committee on History was appointed, with D. Arthur Hughes, chairman, and H. S. Murphey, Tait Butler, W. L. Williams and F. H. Osgood as members.

A number of the men who participated in the program helped frame the accomplishments for the second 50 years to the Centennial: J. V. Lacroix presented a paper on abdominal wounds; H. D. Bergman one on therapeutics; H. E. Kingman, Sr., on anesthesia; K. F. Meyer on paratuberculosis; and B. A. Beach (with F. B. Hadley) on chickenpox. Others present at the meeting included R. S. Mackellar, Sr. and Jr., Evan Stubbs, H. L. Gilman, E. C. Deubler, J. E. Weinman, and J. P. Hutton.

Reports on the "Kansas horse plague" - encephalomyelitis - of 1912 were presented by A. T. Kinsley and B. F. Kaupp; on dourine and glanders by J. R. Mohler, Adolph Eichhorn, and B. T. Woodward; on tuberculosis by C. M. Haring, S. H. Gilliland and C. J. Marshall; Texas fever by John Kiernan and G. R. White; colic by L. A. Merillat; mastitis by L. A. Klein; and infectious abortion by W. L. Williams, J. N. Frost, W. E. Cotton, K. F. Meyer and E. C. Schroeder. Various aspects of therapeutics were presented by $\mathbf{P}$. A. Fish, H. Jensen and R. A. Archibald. The scope of abdominal surgery was discussed by Frederick Hobday of England and by J. H. Blattenberg; other surgical topics included roaring by $\mathbf{L}$. A. and E. Merillat; lameness by John W. Adams and Joseph Hughes; and firing by George B. McKillip. Other notables on the program included Cassius Way, L. Enos Day, Carl W. Gay and J. F.
DeVine. Sesco Stewart, president of the Association of Veterinary Faculties and Examining Boards, addressed that body on the need for a standard examination for licensure. Few programs, perhaps, have included so liberal a representation of notable men - already so, or who were to make their mark in the veterinary profession.

C. J. Marshall was elevated from secretary to president, and Nelson S. Mayo elected secretary; G. R. White was re-elected treasurer.

\section{The Association at the Half Century}

Dr. Mohler's address at the fiftieth anniversary meeting stands in stark contrast to that by R. S. Huidekoper at the quartercentury mark. In reviewing the accomplishments of 25 years, Dr. Huidekoper had observed:

The meetings were always pleasant affairs socially ... . and we learned to know each other and to fill the want of professional friendship which is felt by many who stand alone in new localities. Some meetings were replete with papers.... Other meetings, and there were unfortunately many of them, have been devoid of any public interest.

In 1888 the Association numbered 207 members, of whom 42 attended the meeting-one more than in 1863. Dr. Liautard had charged: "The meeting of 1888 was remarkable for its quietness, its somnolence - in fact the torpid condition which seemed to prevail." By comparison: "In 1863 all was activity, movement, discussion, anticipation and hope."

In 1913 the Association numbered some 1,650 members, and some 260 new members were added at the meeting. At this time there were 31 Honor Roll (twenty-five-year) members, of whom 17 were present; 4 of these lived to become fifty-year members: J. C. Meyer (1925), Benjamin McInnes (1926), L. H. Howard (1932), and G. H. Berns (1934). Alexandre Liautard, although an honorary member since 1900 , was the first to complete 50 years of active identification with the Association (1913).

During the first 25 years the Association had been dominated by a New York - Mas- 
sachusetts axis; only one annual meeting was held elsewhere, and 13 of 15 presidents had been from these states. During the second 25 years only two meetings were held in New York, one in Boston, and 16 of 21 presidents were from other states. Concerning the Association in 1888, D. M. Campbell observed:

It was national in name only. ... Its importance in veterinary medicine was already on the wane. ... National leaders thought the Appalachian Mountains were the dividing line between domestic animals and the buffalo.

But in 1913:

It was a different veterinary science, a different veterinary art, and a different veterinary service that the A.V.M.A. surveyed on its 50th anniversary. . . I It was a very different meeting of the association that President Mohler called to order on September 1, 1913.

If the reports of the state secretaries are an accurate reflection of the status of the veterinary profession at this time, a sampling indicates:

California is in a prosperous and very satisfactory condition generally. ... Colorado has made steady advance. . . . In Connecticut ... interest in the profession is keen.... In Georgia, opportunities for practitioners, very good.... In Maine, much has been accomplished.... In Maryland, our veterinarians look prosperous and happy. ... In Mississippi, veterinary matters a $\mathrm{re}$ making progress. ... The profession in Missouri is in a prosperous and healthful state... In Nevada, conditions for practice are growing better. . . . Conditions in New York have been steadily improving.... In North Dakota, practice has become quite lucrative. ... In Ontario, practice has been good. ... Tennessee has been marked by continued improvement.... In Wyoming, conditions are the very best that could be expected.

\section{J. R. Mohler}

John Robbins Mohler was born May 9, 1875, and was educated in Philadelphia, receiving an M.A. from Temple University in 1893 and the V.M.D. from the University of Pennsylvania in 1896. Then he did advanced work at Marquette University and at Alfort. In 1897 he entered the Bureau of Animal Industry as a field inspector in the Quarantine Division. Later he was transferred to the Meat Inspection Division, and in 1899 to the Pathological Division, becoming its chief in 1902. In 1914 he became assistant chief of the BAI, and chief in 1917 upon the death of A. D. Melvin.

By the time he was elevated to chief of the Bureau, Dr. Mohler had already authored, co-authored, or translated some 5,000 pages of veterinary literature; he had been vice president of the U.S. Livestock Sanitary Association (1910), member of the International Tuberculosis Commission (1910), and vice president (1911-1912) and president (1912-1913) of the AVMA, among numerous other activities. At 37, he had been the youngest AVMA president since 1900; the twelve men preceding him averaged more than 50 years of age at the time of election. In 1915 it was said of him:

He has been found fit in all the trials of high public office ... and, as he rose in favor, at every step has merited his promotions by scientific activity and productiveness.

In 1939 he was awarded the Twelfth International Veterinary Congress prize, and in 1943, upon his retirement as chief of the BAI, he became the first recipient of the AVMA award. His death on February 12,1952 , terminated one of the most productive careers in the history of veterinary medicine.

\section{DEBUT OF THE JOURNAL}

Through the good offices of W. H. Dalrymple, past-president of the Association, and long the outstanding exponent of veterinary medicine in the South, the 1914 meeting was scheduled for New Orleans in December. Shortly before convention time, however, C. J. Marshall - undoubtedly acting in what he thought was the best interest of the profession-decided the meeting could not be held as scheduled. A postcard ballot was sent to the membership asking for a vote on postponement, 
accompanied by the following statement from Dr. Marshall:

As you know aphthous fever exists in sixteen states. All Federal agents, all state agents in these states and many private practitioners, many of them members of the Association, are engaged in exterminating the disease. For this reason it will be impossible for these members to attend the meeting scheduled for the last week of December in New Orleans.

This, of course, was tantamount to a directed vote, and the cards were sent so late that no other action was logical, or even possible. In commenting on this action, D. M. Campbell names it:

a calamitous thing, absolutely uncalled for. ... Illinois was hit as hard as any state by footand-mouth disease... yet during the first week in December, Illinois veterinarians held the greatest meeting in the history of their association. . . Even before the announcement of the postponement word came from Washington that the epizootic is completely under control. . . . I believe that he [ Dr. Marshall ] . . . has let slip the greatest opportunity that the A.V.M.A. has ever had to impress its usefulness upon the public.

As predicted by Dr. Campbell, the meeting for 1914 was not held.

This void in the proceedings of the Association makes it convenient to discuss an action taken at the meeting of 1915, the spadework for which, of course, had been initiated much earlier. This action was the re-acquiring of the American $V e t$ erinary Review as the official organ of the AVMA. In accordance with the expressed opinion of the Executive Board, it had been resolved, "to take such measures as may be necessary to establish an official organ of the association as The Journal of the American Veterinary Medical Association." While there appears to have been no preconceived idea of purchasing back the Review, the feeling developed that this would be preferable to starting a new journal. A prime factor in having a journal was the expense of printing the Proceedings each year; these cost about a dollar a copy to print and mail, and members received them free so long as their dues
(\$3.00) were paid. Moreover, this was a most inefficient arrangement, for most of the papers were printed in the Review anyway, frequently in advance of publication of the Proceedings.

When Dr. Liautard returned to France in 1900 , he presumably sold his remaining interest in the Review to R. R. Bell (already a co-owner), who along with $R$. W. Ellis continued to edit and publish it. With Dr. Bell at the helm (associate editor since 1896), the Review steadily improved in quality, and at his death in 1900 his interest was bought by Dr. Ellis, reputedly for $\$ 2,500$, the same amount paid by the AVMA for the rights to the journal in 1915. By this time, however, the Review - as stated by Merillat and Campbell"was moribund," and, without generous support by the veterinary book publishers and the colleges (most ran half or full page advertisements), "the publication must have had a large deficit and one concludes, would have failed as so many American veterinary publications have clone."

Dr. P. A. Fish of the New York State Veterinary College was appointed editor, a position he held until 1918 when he entered military service. He was succeeded by W. H. Dalrymple, who because of failing health relinquished the post to John R. Mohler in 1919. In 1923 the offices of secretary and editor were combined, with H. Preston Hoskins filling this position until 1939.

\section{Egg Farmers and Endocrinologists}

In writing on "What Veterinarians Should Know About Diseases of Poultry," B. F. Kaupp in 1914 states:

The poultry industry is being heralded as a billion dollar business. ... It is high time the veterinarian was awakening to the possibilities of poultry practice. It is charged that the average poultryman is a "tight wad." But the fact remains that he is no tighter than many of us can remember he was in being "chary" about employing a veterinarian to treat his ill horse or cow twenty years ago. If the veterinarian really become proficient and shows his proficiency he will be in demand. 
With about 3 per cent of veterinary income in the 1950 's being from poultry practice, perhaps much the same might yet be said.

In 1916 P. A. Fish editorialized:

Veterinarians have been inclined to ignore poultry practice and this in due time may arise to trouble them.... If they are derelict in their duty then we may expect the matter will be taken care of by others. ... Not many years ago small animal practice, as a specialty, was a rarity; now it is common and profitable. Time is demonstrating that the veterinary is a comprehensive profession and that more opportunities for specialization exist than in the past. The veterinarian is the logical one to develop these opportunities and as they develop the profession becomes more attractive and more important in the minds of the general public.

In writing on "Hormones and the Ductless Glands" in 1915, when the science of endocrinology was in its infancy, P. A. Fish notes:

It is an interesting fact that some of the ancient ideas, based largely upon superstition, and wholly theoretical in character, have, in the light of later scientific research, possessed, in a far-fetched way, some germs of truth in them.

In reviewing the knowledge of the times on the few hormones that had been studied, he predicts a great future for adrenalin:

Therapeutically it is often used on an empirical basis, but with our increasing knowledge of its physiologic action rational explanations for its use may be looked for in the future.

The then-extraordinary finding that pregnancy in one member of a pair of Siamese twins resulted in lactation in both, with subsequent laboratory confirmation in rabbits, led him to predict:

A beginning has been made in the laboratory which when properly worked up and followed out may influence our relations with the milch cow. The day may not be exceedingly remote when the hormone of an extract from fetal calves may be utilized economically and found to be as generally efficient as the service of the bull.
In this, of course, he had reference to the artificial stimulation of milk secretion not of conceiving calves - but, then, who knows?

\section{P. A. Fish}

Pierre Augustine Fish was born at Chatham, New York, February 17, 1865. After graduation from Hartwick Seminary in 1885, he received the B.S. in 1890 and the D.Sc. from Cornell in 1894, D.V.S. from the National Veterinary College in Washington, D.C., in 1896, and the D.V.M. from Cornell in 1899. Having worked under V. A. Moore while the latter was with the BAI, Dr. Fish returned to Cornell with Dr. Moore as a member of the first faculty in 1896, becoming a full professor of physiology in 1902. Upon retirement of Dr. Moore as dean, Dr. Fish was appointed his successor.

Earlier editor of the Cornell Veterinarian, Dr. Fish was appointed first editor of the newly acquired Journal of the American Veterinary Medical Association. In 1918 he relinquished his post to become a major in the Veterinary Corps. He was the author of several works on veterinary physiology and therapeutics, and was a frequent contributor to the Journal. He was a vice president of the AVMA (1908) and president of the New York State Veterinary Medical Society (1915). Dr. Fish died at Ithaca, February 19, 1931, only a week after Dr. Moore.

\section{5}

In his presidential address at the 1915 meeting in Oakland, California, C. J. Marshall dealt largely with the foot-and-mouth disease outbreak which had been the cause for postponing the meeting of 1914. With praise for the work of the BAI, but with something less for that of the states, he charges:

Even a slight study of the diversified legislation scattered through the forty-eight states discloses the great inaptitude with which the problems have been approached. Powers grudgingly given, jealously curtailed, ignorantly 
divided and weakened, spell a pall through the years of futility, ignorance and sordid greed. . . . Let us urge upon the lawmakers in all of our States to recognize disease as a common foe to be fought with might and main - not singly, but in a hearty cooperation, if the years to come are to note any advance in the struggle.

The matter of incorporation of the Association, first broached in 1869 and dropped in 1872, was brought before the Association by a recommendation of the Executive Board. An objection to incorporation was raised by W. H. Hoskins, who although a good business man himself, thought this would make the Association vulnerable to being sued. R. P. Lyman, however, stated he had been sued as an individual on an Association matter, and felt this was an unfair obligation. N. S. Mayo pointed out, "The establishment of a journal is a business proposition requiring a definite business organization," and noted that incorporation would be necessary to collect outstanding bills and the like. The Association voted for incorporation, and this was accomplished under the laws of Illinois in 1917.

The report of the Committee on Diseases featured a symposium on hog cholera, with presentations on the history of the disease by V. A. Moore; diagnosis by W. W. Dimock; etiology and control by $\mathrm{C}$. M. Haring; dissemination and prevention by A. T. Kinsley; and preparation and use of serum by S. H. Gilliland. An extensive report of the foot-and-mouth disease outbreak of 1914-1915 and a paper on shipping fever of horses were presented by John R. Mohler. Abortion in cattle was discussed by Ward Giltner and E. T. Hallman.

In his report as chairman of the first Committee on History, D. Arthur Hughes noted:

At present the necessary historical materials are incomplete, scattered, inaccessible to the historical worker. The sense of importance of its historical materials has not been aroused in the profession. The profession knows that it is making progress; but very few persons know how great this progress is. The reason for this is that no short history of veterinary progress has ever been written. Nor can it be until the sources of information can be reached. The inaccessibility of data is due to the fact that no provision has been made for assembling it in accredited archives.

It might be noted that at this time the Association had no library; although it had had a librarian for fifty years, the only function of this officer in late years had been as custodian of surplus copies of the Proceedings.

Dr. Hughes, who except for his untimely death the year following undoubtedly would have become the profession's first historian, recommended "that the office of historiographer and veterinary archivist be established by the association." And in urging that veterinary history be taught in the schools, he avers:

Men who, veterinarians though they may be, know nothing of veterinary history have not that constant manly pride in their profession begotten of an ever-present knowledge of its past accomplishments.

In speaking on "A Publicity Policy for the Profession," F. F. Sheets urged establishment of a bureau for:

placing fundamental veterinary truths before the public persistently, precluding the possibility of indifferent unprogressive men continuing to delude even part of the people as to what in reality constitutes the worth of modern veterinary services.

The present practice of the farm press, collecting annually twenty-five cents from Farmer Dupe of Squedunk Corners for the privilege of sending him innumerable pages of high priced advertising matter ... is apparently inspired with the most philanthropic motives to supply the public with all kinds of commodities free. The paper cooperates by a free veterinary advice column sometimes venturing so far as to indorse the nostrums further guaranteed in the advertising section. ... The resultant injury is twofold, the owner becomes the prey of the nostrum purveyer and the profession is afforded no ethical opportunity to justify itself.

R. A. Archibald was elected president; C. M. Haring, secretary; and F. H. Schneider, treasurer. Since 1865, one or both of 
the latter posts had been filled by an incumbent.

On the matter of veterinarians being poor business men, in writing on "The Commercial Side of Veterinary Practice" in 1914, W. J. Martin states, "The man who is engaged in seeking a livelihood in this profession and does not give his full attention to his financial affairs is doomed to failure." He notes that while veterinarians are giving better and more rapid service than earlier, they were getting no more for their calls despite the fact that: "The actual purchasing price or value of an American dollar is just about one-half what it was 20 years ago." (A familiar note!) Martin is perhaps one of the first to openly admit that there is more to veterinary practice than the love of the profession:

Our profession is largely a commercial proposition, regardless of any other theory to the contrary. If an animal is not worth the expense of medical treatment, the owner will not spend any money therefore. Sentiment scarcely enters into the question. It is not so in human practice. ... When the price of domestic animals falls below a point that they cease to be valuable to their owners, our compensation likewise falls.

It should not be supposed that Martin consiclered veterinary practice a purely commercial venture, however:

Every profession has its commercial as well as its ethical side to consider. . . . We cannot be ethical without being commercial, because it is the latter that largely supplies us with the common necessaries of life. . . . It is high time that the old fee-bill or price-scale was revised, so that young men just entering the profession ... might have some idea what to charge for their services.

Martin, undoubtedly, had in mind the common failing of recent graduates to charge fees on the college clinic basis, either unaware of economics - or in some cases, in a deliberate attempt to "corner the market."

\section{J. Marshall}

Clarence James Marshall was born near Rome, Pennsylvania, March 13, 1864, and graduated from the University of Pennsylvania in 1894, whereupon he became house surgeon, later an assistant to Leonard Pearson, and in 1909 Professor of Theory and Practice of his alma mater. Shortly after Dr. Pearson's death that year Dr. Marshall succeeded his late friend as State Veterinarian. Active in local, state, and national association work, he served as AVMA secretary (1910-1913), and in 1913 was elected AVMA president - the last man (except for one during World War II) to serve two terms in this office.

In 1916 he went to Europe to study the organization of the military veterinary service of the French and British armies, and in 1917 was charged with drawing plans for the newly established Veterinary Corps. Commissioned a major, he was appointed assistant director of the Corps, promoted to lieutenant colonel, and served to 1919 . At the time of his death on October 29, 1938, he had been a member of the teaching staff of the University of Pennsylvania for 42 years.

\section{The Fair Sex}

\section{In 1915 D. M. Campbell noted:}

Women may be said to have invaded the veterinary profession, there being now in the United States four women who are graduate veterinary practitioners. ... In at least one veterinary college (McKillip) four women have enrolled this year in the freshman class with the expressed intention of qualifying for municipal food inspection and perhaps other sanitary work. . . Because of the novelty of the enrollment of girls at a veterinary college, at least three magazine writers have already interviewed these students with the intention of writing up the opportunity the veterinary profession offers to women. . . May we soon expect to see the advertisements of a number of our veterinary colleges in the ladies' magazines? . . . We withhold predictions as to the success that women may achieve in veterinary work or to the effect that they may have on the male members of the profession or the colleges they attend.

On the subject of women in veterinary medicine, Dr. Helen Richt (Kansas State, 1932) observed that in 1932 more than 25 
per cent of students at the Royal Veterinary College of London were women:

a post-war development in England, and we judge from comment in British veterinary publications .... an unwelcome one to the veterinary profession in that country.... Although there is a place for women in veterinary medicine [ in the United States], and probably will be an even better field in the future, no woman should take up this profession, unless she is adapted and fitted to surmount the difficulties common to pioneering.

That Dr. Richt (Irwin) found her place in the veterinary profession is indicated by the fact that she served as the first woman veterinarian to hold an official AVMA office, that of secretary of the Section on Small Animals at the 1937 convention.

In 1938, a prominent veterinarian, upon receipt of an inquiry concerning the prospects for women in veterinary medicine from the daughter of a physician, observes:

it is difficult indeed to lend encouragement to any member of the weaker sex that would cause her to aim at admission to any veterinary school. The deans of most of the schools or the admission boards prefer to keep women out of their respective schools because it costs money to send any person through veterinary schools and the chances are not very good that a personable young woman would continue throughout her life in the profession of her choosing. Then too, she might keep some young man from entering who would diligently practice veterinary medicine all his productive life.

\section{6}

At the 1916 meeting in Detroit, President R. A. Archibald noted some of the major achievements of the year: acquisition of the American Veterinary Review as the official organ of the Association; passage of the long-sought-for Army bill; and eradication of the outbreak of foot-andmouth disease. And concerning matters of immediate importance to the Association, "the first problem that strikes us most forcibly is that of reorganization." Among the points to be considered, Dr. Archibald suggested affiliation of state associations with the AVMA, provision for president- elect, a full-time secretary, and a managing editor for the Journal.

As chairman of the Committee on Diseases, John R. Mohler noted an increased prevalence of hemorrhagic septicemia, due in part to the time and effort of the $\mathrm{BAI}$ being diverted to the foot-and-mouth disease outbreak. Swamp fever of horses and infectious abortion of cattle were recognized as problems requiring greater attention. A notable feature of the meeting was a symposium on brucellosis, with papers being presented by W. L. Williams, J. F. DeVine, C. E. Cotton, F. B. Hadley, Ward Giltner, and Adolph Eichhorn. That knowledge of the problem was inadequate was recognized, and sanitation was considered the only universally acceptable practice relative to control of the disease.

Hog cholera was discussèd by R. R. Birch and Robert Graham, shipping fever by J. R. Mohler and G. B. McKillip, local anesthesia in dentistry by $\mathrm{H}$. E. Bemis, tuberculin testing by G. H. Hart and Jacob Traum, experimental physiology by H. D. Bergman, and business methods in veterinary practice by D. M. Campbell. The report of James Law, chairman of the Committee on History, consisted of a seventy page "Recent History of Veterinary Medicine," dealing chiefly with the great animal plagues since 1870 .

A decision to restrict publication of papers and committee reports presented at the meetings to the Journal was deplored by D. M. Campbell; Veterinary Medicine carried a comprehensive report of the Detroit meeting only a week after the meeting ended. A primary purpose in acquiring the Review had been as a vehicle for the proceedings of the meetings, and for several years, Merillat and Campbell note, "it was little more than an installment publication of the proceedlings of the A.V.M.A., in lieu of the annual bound volumes." It might be noted, however, that while the new Journal carried some 600 pages of Association matters and papers its first year (1916), consiclerably more of the remaining 1.100 pages was devoted to scientific subjects than had been 
the case with the Review in its declining years.

A major change in AVMA reorganization was the provision for election of members of the Executive Board by districts; by gentlemen's agreement the five vice presidents had been elected on a regional basis, and voids in representation could be filled by discretion of the president, who appointed six members. But in 1906, for example, there was no one in the official family who resided west of Chicago. Continuity on the board was also provided for by election for five-year terms on a rotating basis. In three successive years (1910-1912), 34 men had served one year each; one secretary served two years; and only the treasurer and librarian served all three years.

In noting that America had about 20, 000 veterinarians, N. S. Mayo suggests:

America is now fairly well supplied with veterinarians. The demand is not for more veterinarians, but for veterinarians with a more thorough training, not only in strictly professional lines, but in related lines, which will make them not only more efficient as professional men but more useful to society at large.

C. E. Cotton was elected president, and L. A. Merillat, secretary. F. H. Schneider was re-elected treasurer.

\section{R. A. Archibald}

Robert A. Archibald was born in Ireland in 1870 , came to the United States in 1887 , and graduated from the Chicago Veterinary College in 1891, following which he is said to have started practice in California on $\$ 20$ borrowed from a colleague. In 1899 he became city veterinarian and assistant bacteriologist for the city of Oakland, Professor of Bacteriology in the Oakland College of Medicine in 1908, and the same concurrently in the San Francisco Veterinary College in 1909.

Active in association work, Dr. Archibald was three times president of the California VMA, member and president of the state examining board, and twice an AVMA vice president before being elected president in 1915 . He is credited with being the first to advocate reorganization of the AVMA along lines that would make it a truly national body. He died on March 14, 1922.

\section{7}

At the meeting for 1917 in Kansas City, President C. E. Cotton noted that despite considerable improvement in recent years, numbers of graduates were being turned down by various examining boards, and observed:

The time of the horse doctor has passed. The old plaintive argument that the country needs practitioners and that we wish to give the poor uneducated country boy a chance to enter the profession in order to meet the crying needs of the farming communities, has become threadbare and stale. All the other professions have closed their doors to this standard of preparation. There is now no reason why this young man cannot obtain the preliminary education, provided he is made of the right kind of stuff. . . The practitioner of veterinary medicine must be a man of broad knowledge and thoroughly trained in his technical subjects. This necessitates his obtaining a general as well as a technical education. . . . The standard of the profession in not judged by the leaders but by the general average of those holding a veterinary degree.

Dr. Cotton noted that while medicine required two years of college preparatory work, the most exacted by any veterinary school was a high school diploma; others had only an entrance examination that "an immature child in the sixth grade" could pass. Impatient with the reluctance of some members of the Association to press for higher standards, he urged early action on a requirement of high school graduation and a four-year course of nine months each year.

In $191 \mathrm{I}$ the Association had approved "matriculation requirements equivalent to those for admission to recognized high schools"; in 1914, one year of high school and three collegiate years of six months each; and in 1915, a four-year veterinary course of at least twenty-eight months. Colleges which had adopted high school graduation as a requirement had experienced a drop in admissions, but in a few years attendance had increased beyond previous levels. 
Tuberculosis was a principal topic for discussion, with papers being presented by S. H. Ward, C. J. Marshall, Jacob Traum, C. H. Higgins and M. H. Reynolds. J. R. Mohler reported on vesicular stomatitis, and on regulation of veterinary biological products. Among other papers were those by C. H. Stange on hog cholera; Adolph Eichhorn on blackleg; Robert Graham on forage poisoning; Joseph Hughes on median neurectomy; and W. L. Williams on abortion. Digestive disorders in cattle were discussed by D. H. Udall, and in horses by J. F. DeVine. One session was devoted to a symposium on animal parasitism with Seymour Hadwen, C. P. Fitch, B. F. Kaupp, and L. Enos Day, among others, participating.

A paper of some novelty was "The Principles of Osteopathy as Applied in the Treatment of Veterinary Patients," by E. A. A. Grange. Apparently with some reservations, he reported:

The literature of the science describes many cases in which the line of treatment had a beneficial effect in small animals, but nothing has been done, as far as I am aware, by way of experiment or treatment in horses or cattle.

The clinic, which along with the meetings was held at the Kansas City Veterinary College, featured the surgical treatment for sterility by W. L. Williams; teat surgery by $\mathrm{T} . \mathrm{H}$. Ferguson; molar extraction under local anesthesia by H. E. Bemis and L. A. Merillat; and operations for roaring by J. W. Adams; hernia by G. B. McKillip; and fistula by $\mathrm{H}$. E. Bemis.

As secretary, L. A. Merillat charged:

fewer than ten per cent of the veterinarians of this country support the organization that created and now maintains a profession for them to exploit and enjoy. . . O Obviously the veterinarian ... having found prosperity without effort, has never thought of drafting plans for self-preservation, and is today the victim of his own indifference.

The first Executive Board, elected under the recently adopted reorganization of the Association, included V. A. Moore, Fred Torrance, W. H. Hoskins, C. H. Stange,
J. R. Mohler, and R. A. Archibald. Dr. Torrance was elected president, L. A. Merillat was re-elected secretary, but resigned shortly to enter military service and was replaced by L. E. Day.

\section{Standard of the Profession}

An inkling of what barred numbers of graduates from practice in some states may be had from a composite of questions from state board examinations for 1916 . The compiler notes:

Very recently the examinations have come to deal more and more with questions pertaining to animals other than the horse and with questions of sanitation, quarantine, the handling of contagious diseases, etc.

\section{Anatomy:}

Describe the humerus, fetlock joint, small mesenteric artery, deep flexor of the phalanges, foramen ovale, thoracic duct, sensitive laminae. Name divisions of digestive tract in horse, pig, ox and describe differences. Describe distribution and function of fifth cranial nerve. Name and locate openings of pharynx.

\section{Theory and practice:}

Give etiology, pathogenesis, symptoms, complications, course, differential diagnosis and treatment of: influenza, pleuritis, hemorrhagic septicemia, hog cholera, tetanus, tuberculosis, pharyngitis. Write a prescription for: general tonic, chorea following distemper, garget in cow. Give action, uses and dose of digitalis for horse, cow, dog. Give indications and antidote for chloral.

\section{Pathology:}

Define: hemorrhage, petechiae, ecchymosis, aneurism, embolus. Describe lesions of: hog cholera, blackleg, glanders. Give diagnosis for: glanders, rabies, anthrax. Describe preparation of tissue specimen for laboratory bacteriological examination. Classify pathogenic bacteria. Name four parasitic diseases of sheep. Give life cycle Taeniae coeneurus, Ascaris megalocephala.

\section{Surgery:}

Describe: amputation of penis, wound healing and treatment, trephining for upper sixth molar, castration of horse, reduction of simple leg fracture in horse, tenotomy for spavin lameness, relief of tympanites in horse and cow. paracentesis thoracis, cryptorchid operation, 
inguinal hernia repair. Give treatment for fistulous tracts, suppurating nail puncture, chronic navicular disease.

\section{Obstetrics:}

Give gestation period for mare, cow, bitch, ewe, sow. Define dystocia, presentation, premature birth, abortion, estrum. Give cause, symptoms and treatment for: nymphomania, parturient apoplexy, mammitis, perforate urachus. Give method of handling for: breech presentation in mare, reduction of prolapsed uterus in cow, dystocia from ascites, hydrocephalus. Give causes and treatment of abortion.

\section{Clinical diagnosis:}

What is diagnosis? What information is required for a diagnosis? What is the tuberculin test, mallein test? Give symptoms of excessive hemorrhage. Distinguish between arterial and venous hemorrhage. Define fever. $G$ ive symptoms and sequellae of influenza.

\section{Physiology:}

Explain: action of heart, ruminent digestion, animal heat, functions of gallbladder in horse [!], physiology of respiration. Name and give location of two nervous systems. [?] Give names and actions of digestive secretions. Give pulse, respiration, temperature of horse, ox, dog, sheep, pig. Distinguish between serum, plasma, lymph. Give normal components, abnormal constituents, tests for urine.

\section{Chemistry:}

Define chemistry, analysis, synthesis, molecule, atom. Give symbol and atomic weight for antimony, calcium, iron, phosphorus, sulphur. Define Avogadro's law in relation to volumes of gases. Describe Marsh test for arsenic. Give specific gravity of horse and ox urine and method for estimation of total solids. Give test for sugar, hemoglobin, albumen in urine. Describe Babcock test, test for formaldehyde in milk.

\section{E. Cotton}

Charles E. Cotton was born in Prescott, Wisconsin, September 18, 1871, and received his veterinary degree from the University of Pennsylvania in 1893. He was one of the pioneers in tuberculosis eradication, and became active in a variety of professional and livestock affairs, being influential in the programs and policies of the livestock sanitary organizations of the country for many years.

Dr. Cotton was elected president of the Minnesota Society (1909), the AVMA (1916), and the USLSA (1936). In World War I, he was commissioned a Major (1917), and served as a general veterinary inspector of the Veterinary Corps until his discharge in 1919. In 1948 he became an Honor Roll member of the Association, and in 1952 was awarded the Twelfth International Veterinary Congress prize for outstanding service to the veterinary profession. He died at the age of 82 on April 21, 1954.

\section{8}

The annual meeting for 1918 was held in Philadelphia. Noting: "The war found our profession in America unprepared," President Fred Torrance observed:

War has demonstrated the value of the veterinary profession to the nation and increased its importance as a necessary $\operatorname{cog}$ in the machinery of modern life. ... The demand for well educated veterinarians, not only for war, but to care for the enormously valuable livestock of the country, now and hereafter, will increase the attendance at our veterinary colleges, will render it easier for these to obtain the financial support necessary to their success, and render possible a high standard of education and efficiency.

The program featured a "war session," with papers by Majors J. P. Turner and L. A. Klein, and by J. R. Mohler and A. H. Baker. A symposium on contagious diseases included papers on various aspects of the abortion problem by C. P. Fitch, J. F. DeVine, Ward Giltner and E. T. Hallman. Swine practice was discussed by C. C. McLean, W. W. Dimock, and T. H. Ferguson. Parasitological problems were presented by M. C. Hall, Seymour Hadwen, and E. L. Quitman.

The deaths of past-presidents A. Liautard, A. D. Melvin, and Sesco Stewart were noted. Dr. Melvin's portrait, along with those of D. E. Salmon, his predecessor, and J. R. Mohler, his successor as BAI chief, were exhibited along with those of James Law and Leonard Pearson. These had 
been painted for the art gallery of the Saddle and Sirloin Club of Chicago. In addition to the well-known achievements of these men, all past-presidents of the AVMA, it is of interest to note their academic relationships: Mohler was a student under Pearson, who in turn had studied under Law, who also was the preceptor of Salmon, whose protégé Melvin was.

Later, in presenting the portraits to the Club, V. A. Moore (successor to Law) noted:

We cannot at this time measure the value to humanity of the work and influence of these truly great and good men. They will stimulate others to greater effort for all time because they possessed the master words of success - character and work. Their labors have extended over a period of fifty years, the most prodigious period of change the world has ever known ... wherein are written our knowledge of animal diseases, the progress in American veterinary education and the history of our animal industry.

These portraits were lost in the disastrous stockyards fire in 1934.

About 1,000 new members were adnitted to the Association, including many from the BAI and the Veterinary Corps. V. A. Moore was elected president; N. S. Mayo, secretary; and M. Jacob, treasurer. P. A. Fish resigned as editor of the AVMA Journal to enter military service, and W. H. Dalrymple was appointed to this post. However, because of failing health, Dr. Dalrymple gave up this position the following year, and J. R. Mohler assumed the editorship.

At a luncheon meeting the previous year, a group of women formed the Women's Auxiliary to the AVMA. The meeting was presided over by Mrs. A. T. Kinsley, and the first officers were as follows: president, Mrs. W. H. Hoskins; corresponding secretary, Mrs. Ashe Lockhart; recording secretary, Mrs. C. E. Cotton; and treasurer, Mrs. Hans Jensen. In 1918 a constitution and by-laws were adopted, which specified the object as:

to give necessary financial assistance to the family of any veterinarian engaged in war work if his life has been forfeited in pursuance of such work, or if he has been temporarily or permanently disabled.

In 1920, the present auxiliary Loan Fund was established, in part from monies collected for the initial objective. In 40 years, the original group of about 55 members increased to more than 6,000 .

\section{F. Torrance}

Fred Torrance was born at Montreal, July 13, 1859, and attended McGill University, where he received the B.A. and D.V.S. degrees, the latter in 1882 . He located in a pioneer practice at Brandon, Manitoba, and in 1892 moved to Winnipeg, where he became well known in the veterinary profession. In 1912 he was appointed Veterinary Director General for the Dominion of Canada, continuing in this capacity until 1923, when he became professor of physiology and hygiene at the Ontario school.

Under his leadership, dourine was eradicated from the western provinces, and glanders was practically eliminated. Other major campaigns were those against mange and tuberculosis in cattle, and hog cholera, the latter by elimination of raw garbage feeding. A man of great personal warmth, it was said of him while at Ontario, "he endeared himself to the students," and to the staff he was "a staunch friend and able colleague."

Dr. Torrance served as president of the Manitoba Association, honorary president of the Ontario Association, twice vice president of the AVMA (1900, 1913), and was elected AVMA president in 1917. He died on June 29, 1924.

\section{The Women}

The following short history of the AVMA Women's Auxiliary was written by Mrs. E. R. Walker, and appeared in the Journal in 1958.

A Short History of the AVMA Women's Auxiliary. - On Aug. 22, 1917, a group of women met for luncheon at the Kansas City Veterinary College, Kansas City, Mo., to organ- 
ize the Women's Auxiliary to the AVMA. Mrs. A. T. Kinsley, Kansas City, Mo., presided at the business meeting. The following officers were elected: Mrs. W. Horace Hoskins, Philadelphia, president; Mrs. Ashe Lockhart, Kansas City, Mo., corresponding secretary; Mrs. Hans Jensen, Kansas City, Mo., treasurer.

The original purpose of the organization was to aid the families of veterinarians whose welfare had been disrupted by World War I.

The 1920 national meeting marked an important development in the auxiliary history because the present-day auxiliary Loan Fund was founded.

A big step in the structural life of our Auxiliary was in 1930, when a move to encourage the state auxiliaries to become chapters of the AVMA Auxiliary was begun. These form our present-day House of Representatives.

A pamphlet, "What the Veterinary Profession Means to the Public," was sponsored by the AVMA Auxiliary in 1945. Through this pamphlet, the public was greatly enlightened and the membership in the auxiliary was doubled.

In 1946, it became possible for any auxiliary to an AVMA student chapter to become an affiliate of the Women's Auxiliary.

The AVMA Auxiliary annual achievement award of $\$ 25$, made to the outstanding senior student in each accredited veterinary school, was originated in 1948.

Since 1952, the Women's Auxiliary has encouraged state and local auxiliaries to contribute to the AVMA Research Fund in support of the AVMA Research Fellowship Program. Under this program, carefully selected young veterinarians with an aptitude for research are awarded fellowships to carry out specific projects at approved educational institutions.

In 1953, charter members were automatically made life members.

The Memorial Fund, made up from contributions given in memory of deceased veterinarians or members of their families, and gift legacies, originated in 1954.

In the period from August, 1917, to July, 1957, the membership of the women's auxiliary of the AVMA has shown tremendous growth, increasing from a small group of 55 members to 6,285 active members.

\section{9}

In his presidential address at the 1919 meeting in New Orleans, V. A. Moore acknowledges:

the existence of a false conception of professional authority... . Numerous appeals have come to defend the rights of veterinarians ... [but] I do not find that practitioners are vested with it [authority] when their professional function is considered alone. ... In the true sense, veterinarians are the servants of animal owners. According to the tenets of our ethics, they can serve only when requested to do so and, by the property rights, they have no other alternative.

There is a delicacy in this situation that members sometimes overlook. The sense of being a servant is often humiliating, but never so when considered in a true, professional spirit. ... I am bold enough in the faith I have in the future possibilities and usefulness of veterinarians, to believe that the time will come soon when they will command sufficiently the confidence of men in other occupations to enable them to perform fully the mission of their calling. It is this principle, rather than vested authority, that gives them the dignity of professional men.

Several of the section meetings were devoted to a single topic: two general sessions were devoted to the Army Veterinary Service, and one to diseases in the South; infectious equine anemia was the topic for one session on sanitary science. C. J. Marshall reported 31 deaths from malignant catarrhal fever on one farm in Pennsylvania, and although this disease was considered something of a rarity:

The disease may be more prevalent than is generally supposed. A diagnosis in this case would have been overlooked if the disease had occurred in a small herd with but few deaths.

As a matter of passing interest, W. $\mathrm{H}$. Hoskins noted:

When the Volstead prohibition bill reached conference it was discovered that a provision permitting the veterinarian to prescribe liquors under like conditions as the physician had been omitted ... [ but ] we were assured ... the omission was not intentional.

Later, in response to an inquiry by N. S. Mayo, the Bureau of Internal Revenue ruled:

you are informed that veterinarians may not prescribe intoxicating liquors for internal use for their animal patients. ... [This] is limited to duly qualified physicians for persons 
only. Not to exceed 6 quarts of alcohol may therefore be obtained by any veterinarian during any calendar year.

With dry humor the Journal notes: "The announcement that the law does not permit the prescribing of alcoholic liquors for animals will be sad news to many stable attendants."

In urging veterinarians to become proficient in sheep practice, the irrepressible E. T. Baker accuses his colleagues, when called to attend sheep, of taking the attitude: “I don't know much about sheep, and I really do not know what is the matter with them." The farmer thereupon calls the county agent, who has read a book on sheep, and:

At last he had found an expert... the county agent has gained his confidence; also, the veterinarian has lost it. . . The veterinarian has lost the sheep practice in that community; not much, to be sure; but ten years ago how many of you ever dreamed that swine practice would be the money-maker of today?

Others had attempted to interest the veterinarian in sheep practice; in 1915 the Cornell Veterinarian had devoted an entire issue to sheep problems.

C. A. Cary was elected president; N. S. Mayo was re-elected secretary, and - as was to be the case until $1943-M$. Jacob was re-elected treasurer.

\section{A. Moore}

Veranus Alva Moore was born in Houndsfield, New York, April 13, 1859, and received his B.S. from Cornell (1887), M.D. from George Washington University (1890), an honorary veterinary degree from the University of Pennsylvania (1911), and a D.Sc. from Syracuse University in 1919. From $1890-1896$ he was with the BAI, succeeding Theobald Smith as chief of the Pathological Division in 1895. In 1896, as Professor of Veterinary Pathology, Bacteriology and Meat Inspection, he became a member of the first faculty in veterinary medicine at Cornell. In 1908 he succeeded James Law as dean, and remained in both capacities until his retirement in 1929.

Dr. Moore joined the AVMA in 190I, was four times a vice president, first chairman of the Executive Board (1916), and was elected president in 1918. He was an authority on tuberculosis, serving on the International Tuberculosis Commission, and co-authored with W. A. Hagan a textbook of General and Pathogenic Bacteriology and Immunity (1925). One of his two sons became a veterinarian, Ervin V. Moore (Cornell, 1917). Dr. Moore died at Ithaca, February 11, 1931. 


\section{Toil in the Twenties}

At the 1920 meeting in Columbus, Ohio, President C. A. Cary urged a reappraisal of teaching methods:

Some teachers stuff the student with too many unimportant, useless facts. ... Too many teachers believe that the whole knowledge of medicine is confined to his special subject, and then proceed to cram it all into the student.

In particular, he called for less time being spent on the anatomy of the horse and more on other species, more and better animal husbandry, and better clinical facilities, together with a requirement that vacation periods be spent in practice. Also, the curriculum should be arranged for the potential general practitioner with specialties reserved for graduate study, and "less time should be wasted on football, other games, holidays and numerous idle periods."

\section{A SEARCH FOR STABILITY}

Regarding the Association, Dr. Cary urged revision of the constitution:

so that every member in good standing may vote on all important subjects and in the election of all important officers. . . . In addition to an all-time Secretary and Editor, we need an all-time home for this double head and heart of the organization.... Our frequent and sudden changes of Secretary and Editor have given us no stability or definitiveness of pur- pose. . . For the good of the Association we are sadly in need of a fixed, permanent home.

The latter suggestion met with approval, and the Executive Board was directed to look into the matter of location and cost of buildings. On the matter of permanency of personnel, it might be noted that since 1915 there had been three editors and four secretaries.

In a discussion of the applications of $\mathrm{R}$. V. Cannon and J. G. Slade, both colored, W. H. Hoskins recalled: "For twenty years we have drawn the color line in this Association. I consider that there have been rejected on that ground several good veterinarians," to which P. A. Fish added: "The Government recognizes these men in their appointments in the Bureau, and if they can qualify in that respect it seems to me that they should be allowed to come in this." Both men were elected by a large majority.

On the subject of "Anesthetics in Veterinary Operations," R. R. Dykstra, in noting the progress in human surgery, charges:

In veterinary surgical operations we have not yet advanced to the same stage of humaneness in the treatment of our patients... Many veterinarians do not realize the unfavorable, or in some instances almost repulsive, impression made on the owner of a pet or valuable animal by the barbaric cruelty of surgery without anesthesia. . . Outside of the difficulties in application, no matter from what 
other angle viewed, there is no excuse for performing veterinary operations without adequate anesthesia.

The section on General Practice and Surgery included papers on veterinary medicine in France by L. A. Merillat, traumatic indigestion by $\mathrm{D} . \mathrm{H}$. Udall, swine diseases by C. H. Stange and Charles Murray, skin diseases in dogs by H. J. Milks, cryptorchidism by E. E. Wegner, and schlerostomiasis in horses by C. E. Covault. The section on Sanitary Science included several papers on brucellosis by C. M. Carpenter, I. F. Huddleson, B. T. Simms, J. P. Turner and R. A. Kelser; on anthrax by Adolph Eichhorn, botulism by Robert Graham, and avian epithelioma by J. R. Beach.

In speaking on "The Relation of the Agricultural Press to the Veterinarian," E. S. Bayard, editor of the National Stockman and Farmer, noted:

The agricultural press has been criticized by veterinarians for two things. . . . First, for giving veterinary advice through its columns. ... In our own case we have tried to make this department a work on animal husbandry rather than a prescription counter. ... Second, the advertisements of veterinary medicines. ... I must here plead not guilty.

He relates his suspicions of a hog cholera remedy, which he had had investigated by "leaders of veterinary research," who found it worthless.

\section{A. Cary}

Charles Allen Cary was born at Millersburg, Iowa, in 1861 and taught school before graduating from Iowa State (B.S. 1885, D.V.M. 1887). After some time in practice, state work in Iowa, teaching in South $\mathrm{Da}$ kota, and study in Europe, in 1893 he became Professor of Veterinary Science at the Auburn Polytechnic Institute (Auburn University). In 1907 he was instrumental in having the first veterinary school in the South established at Auburn and served as its dean until 1935. Through his influence as State Veterinarian and long-time president of the Alabama Live Stock Asso- ciation, Alabama was the first state to require health certificates for interstate shipment of animals. He was an early champion of tick eradication and of municipal food hygiene; his entire professional life was devoted to bettering livestock sanitation in his adopted state.

Dr. Cary joined the AVMA in 1890, was elected president in 1919, and was an active worker for the 45 years of his membership. Probably no other man has served on more committees than he; at the time of his death on April 23, 1935, he was a member of the Executive Board.

\section{1}

In speaking on "the doctrine of unity" at the 1921 meeting in Denver, President D. S. White urged:

I cannot emphasize too much the importance of unity. While admittedly we have made progress in this regard in the last half century, nevertheless I firmly believe it would have been more rapid and fruitful had we been more firmly united through the years which have passed. ... I think sometimes we are too apt to clique off into little, self-interested groups, each with its own leader and each at cross-purposes with the other groups. ... Firmly united the veterinary profession is already weak enough to fight the battles it must fight in order to carry on its legitimate work.

Secretary N. S. Mayo, in noting a drop in membership - mainly through nonpayment of dues - observed:

The general economic depression that prevails has had a marked influence upon our membership, as it has on practically all associations. . . The number of letters expressing financial stress has been much greater than usual.

In the first presentation of a paper by a Mexican veterinarian, Luis Santa Maria urged:

the need of cooperation between the United States and Mexico for the control of epizootics. . . Contrary to what is supposed, the international interchange of livestock ... has not been given its due importance from the sanitary point of view. 
And on the Canadian side of the border, Fred Torrance noted that prior to the law of 1915 requiring the cooking of garbage, 90 per cent of the outbreaks of hog cholera in Canada could be traced to this source. Since then incidence of the disease had declined to the point that "We now have ... so far as I know not a single case of hog cholera in the whole of Canada."

Papers presented at the meeting included those on brucellosis immunization by F. B. Hadley; red water in cattle by Edward Records and L. R. Vawter; surgical technic by H. E. Kingman, Sr.; diagnosis of poultry disease by F. R. Beaudette; tuberculosis eradication by H. R. Smith; municipal food inspection by G. H. Glover; hemorrhagic septicemia by $H$. P. Hoskins, and by I. E. Newsom and Floyd Cross; and control of parasitic diseases by M. C. Hall.

An important paper published in 1921 was one by A. F. Schalk and R. S. Amadon on "Gastric Motility Studies in the Goat and the Horse," in which - the first of a notable series of studies - they note:

In the field of physiological research there exist certain problems the solution of which has received but little attention, and the sum of our knowledge consists in most instances of vague theories possessing no original experimental evidence.

\section{S. White}

David Stuart White was born September 28, 1869, in Staten Island, New York, and received his veterinary degree from Ohio State University in 1890, following which he continued his studies in Europe under such men as Dieckerhoff, Möller, Fröhner, Günther, and Lungwitz. He returned to his alma mater in 1893 and became dean of the College of Veterinary Medicine in 1895, holding this position until 1929.

In October, 1917, he was commissioned a Major in the Veterinary Corps, and became Chief Veterinarian of the A.E.F. in France with the rank of Colonel - the first veterinarian to achieve this rank. He effected a transfer of the Veterinary Corps from the Quartermaster Corps, under which it was operating in France, to the Medical
Corps. He was decorated by the governments of France and England, and was made an Honorary Associate of the Royal College of Veterinary Surgeons.

Long a leader in Association and college circles, Dr. White served as president of the AVMA (1920-1921) and authored a text on The Principle and Practice of Veterinary Medicine. He died January 7, 1944.

\section{EMBLEM OF THE ASSOCIATION}

Some years earlier there had been sentiment expressed toward the desirability of having an official emblem for the Association. While the USVMA had adopted a seal figuring a centaur in 1863 , there is no indication that the AVMA ever considered using this symbol; in fact, it was little used during the later years of the USVMA perhaps because it was too "horsey." D. M. Campbell, appointed chairman of a committee on emblem in 1915, had reported the following year that there was "considerable sentiment for the blue cross," and recommended some design incorporating this symbol be adopted. Already a number of firms manufacturing veterinary supplies had been using this in one form or another.

In 1921 the committee recommended for adoption the caduceus with superimposed $\mathrm{V}$ as used by the Veterinary Corps. The design had been used earlier by the California VMA, and its adoption by the AVMA was urged by $\mathbf{H}$. B. Wintringham of Fresno. This, of course, is the design that was officially adopted. Later, Dr. Wintringham and J. M. Arburua (the latter as late as 1960) pointed out that this was perhaps a less desirable symbol than might have been devised, i.e., the caduceus being the staff of Hermes (Mercury), this has more commercial than medical overtones.

The caduceus, of course, was as inappropriate a symbol for the veterinary profession in 1921 - or anytime - as the medical profession had decided it was earlier. The good record of the Veterinary Corps during World War I, however, undoubtedly had given it special lustre, and it should not be supposed that the decision of the Asso- 
ciation was made without due consideration. However, the founding fathers had - apparently without previous consideration - adopted a classically correct symbol in 1863. Having been a matter of concern - to a few, at least - at intervals for half a century, a full discussion of the problem seems indicated.

The seal of the United States Veterinary Medical Association, adopted in 1863, shows a centaur with scroll in hand, signifying that he is the one who was supposed to have transmitted a knowledge of medicine from Apollo to Aesculapius. Together with the motto: Non Nobis Solum - "Not for us alone," the seal was an appropriate device to suggest the mission of the USVMA in the transmission of knowledge. In his greetings to the Association on its fiftieth anniversary in 1913, Liautard, in recalling the adoption of the seal in 1863 , states that it "for years afterward was applied on the certificates that were delivered to newly elected members." It may be doubted, however, that any of these certificates exist, for in 1869 it was considered that these were illegal, inasmuch as the Association was not chartered or incorporated. It was resolved, therefore, to call in those diplomas already issued (perhaps not more than fifty) and substitute a receipt of the initiation fee.

How extensively the seal was used is not a matter of record. Few pieces of Association literature issued prior to 1900 have been preserved, and but few of these carry any sort of emblem. The "Proceedings Book" for the fiftieth anniversary meeting has a centaur on the spine, but this is a rather juvenile characterization, not nearly so noble in face or form as that on the original seal.

With the reorganization of the Army in 1901, veterinarians of the cavalry and artillery were given insignia as described in the Review for 1903:

A horse's hoof has been selected as the insignia of the corps of veterinarians, the latest addition to the United States Army. ... The prosaic hoof is given a mythological value by the addition of wings, like unto those of Mercury, in order to give the effect of motion. Veterinarians in the cavalry arm will wear the winged horse hoof pendent from the familiar crossed sabers, and those attached to the artillery will display it under the crossed cannons symbolic of that arm.

With the establishment of the Veterinary Corps in 1916, the familiar caduceus with the superimposed $\mathrm{V}$ was adopted-or, rather, prescribed.

It would appear that the seal of the USVMA was never considered to be an emblem of the AVMA. A suggestion was made in 1906 that the AVMA adopt an emblem "which its members may use upon their stationery, in the same manner as Members of the Royal College of Veterinary Surgeons have done for many years." To this the Review replied: "A special committee was appointed by the United States Veterinary Medical Association as long ago as 1892 to consider the subject," which in 1893 reported:

Your committee would suggest the adoption of the seal of this Association, reduced to the following sizes: one of the size of a quarter of a dollar for bill-heads and letter-heads, and one the size of a dime, which may be used on visiting cards, if so desired. Your committee would recommend that the emblem be not given out until such time as a charter of incorporation of the Association be obtained.

Inasmuch as this report was adopted by a large majority at the 1893 meeting, the Review suggested deletion of the last clause - the Association not having been incorporated "thereby making the emblem available, in conformity with our correspondent's suggestion." No action appears to have been taken on this suggestion; in fact it might well have been construed as being in violation of the Code of Ethics, which at the time stated: "advertising through the medium of posters, illustrated stationary, newspaper puffs, etc., will not be countenanced by this Association."

At the 1907 meeting at Kansas City, James Law appointed a special committee on "Association Seal," with E. L. Quitman as chairman. No indication of its purpose seems to have been recorded, and the committee was dropped in 1911, apparently without having reported any action taken. 


\section{Red Cross - Blue Cross}

In 1913 and 1914 a medical supply house advertised: "A Veterinary Red Cross on your auto or buggy will distinguish you from other medical people. It will save you extra driving."

At the AVMA meeting in $1915, \mathrm{D}$. M. Campbell was appointed chairman of a Committee on Emblem, to collect data concerning possible designs for an official emblem for the Association. In response to a request in Veterinary Medicine, several designs were submitted by veterinarians, most of them incorporating the blue cross in one form or another: within a large $\mathrm{V}$; on a circular shield with AVMA superimposed; or within a horseshoe. At the time a number of commercial firms were already using the blue cross in one form or another, and it was also used "by a great many veterinarians throughout the United States and Canada." At the Oakland meeting in 1915 the California Association had distributed:

souvenir lapel buttons of this type, bearing the letters in gold "A.V.M.A." [ which ] so popularized the blue cross that there are now hundreds of veterinarians wearing these buttons and using auto emblems of similar design.

The Illinois State Society and the Illmo VMA had adopted the blue cross as an official emblem. The committee report in 1916 recommended:

the Blue Cross as an insignia for this association, the cross to be the same shape and of the same proportions as the Clara Barton Cross, either plain or set in a gray or white circular background.

By 1916 one serum company was using the blue cross with the inscription Ne plus ultra; another featured a rampant hog "branded" with the message: "We save 'em." One emblem company advertised the blue cross as being endorsed by L. A. Merrillat, D. R. Campbell, Joseph Hughes, D. S. White and others. In the same year, however, N. S. Mayo notes:

At Oakland a communication was received from a prominent army veterinarian, stating that an international conference was to be held at Bern in the near future to adopt an international veterinary emblem for the protection of horses in war. The writer also stated that it was quite certain that the emblem adopted would not be a blue cross, as to most veterinarians the blue cross is the emblem of the British Society of the Prevention of Cruelty to Animals.

Mayo thus considered it advisable to defer action on adoption of an emblem pending a decision of this conference.

In 1916 the New York State Veterinary Medical Society had adopted a resolution:

that the emblem of the A.V.M.A. be a plain enameled cross, color to be the same as that designated by the United States Army Veterinarians and the same to have A.V.M.A. in plain black letters across the front.

\section{Concerning the Caduceus}

In 1921 the AVMA Committee on Emblem recommended for adoption the caduceus and superimposed $\mathrm{V}$ as used by the Veterinary Corps for collar insignia, to be set on a red plate surrounded by concentric white and maroon discs. As adopted, this is identical with the present emblem, except for the substitution of a disc bearing AMERICAN VETERINARY MEDICAL ASSOGIATION in place of the concentric discs. The design earlier had been used by the California VMA, and its adoption by the AVMA was urged by $\mathrm{H}$. B. Wintringham of Fresno.

In 1932 Secretary Hoskins, in discussing the emblem at the annual meeting of the AVMA, notes:

For a time, the caduceus was used as an emblem by members of the American Medical Association, but in 1912, after considerable discussion, a change was made in the emblem and the caduceus was replaced by the true Aesculapian rod, the appearance of which is markedly different from the caduceus, or wand of Mercury. In the June, 1932, issue of the Scientific Monthly, an article by Dr. Stuart L. Tyson, entitled "The Caduceus," appeared, and the author pointed out the incorrectness, or the inappropriateness, of using the symbol of Mercury rather than the symbol of Asclepius in connection with medicine. As so well shown by Dr. Tyson, there is practically no connection between Mercury and the healing art. ... 
This question came up at the recent meeting of the California State Veterinary Medical Association, and the matter was referred officially to the A.V.M.A., through Dr. Joseph M. Arburua, of San Francisco. This matter will receive the attention of the Executive Board. It is quite likely that we will want to study the advisability of making some change in the design of our official emblem.

Dr. Hoskins mentions the recent advertisements of a new brand of gasoline in which:

Mercury was holding his caduceus in one hand, and probably the question arose in the minds of many veterinarians as to just what might be the connection between the official automobile emblem of the American Veterinary Medical Association and the caduceus of Mercury, as displayed in the advertisements of a new brand of gasoline. However, the connection in the latter case is perfectly plain. Mercury, as the messenger of the gods, was gifted with unusal speed.

It might be added that since then the caduceus itself has had prominent display as the symbol of a firm which advertises "mercury-made" motor oil.

The matter was considered by the House of Delegates at the 1960 meeting following a recommendation by the Executive Board that "the caduceus insignia be discontinued." Over objections by military representatives, Dr. Arburua contended:

the insignia of Hermes, or Mercury, who was the messenger of the gods, is associated with many unsavory functions, among them the god of the heavy purse, the function of taking the dead across the River to the nether land; the god of the highways, and, as Apollo once prophesied, he would be known as the lord of sheep robbers.... The caduceus ... has never been associated with medicine, as far as Greek mythology is concerned. . . . It is inappropriate, in spite of the fact that the Army is using it.

The motion to discontinue the caduceus as an emblem (after a new one would be agreed upon) was tabled.

\section{HARD TIMES AHEAD}

In his presidential address at the 1922 meeting in St. Louis, A. T. Kinsley noted:
Until about 1912, practitioners were primarily engaged in the medical or surgical relief of clisease. . . Equine practice constituted the major portion of the practitioner's routine business. ... Diseases of cattle ... were given little consideration ... swine and poultry were rarely given more than a passing thought. ... The veterinarian's services at this time are principally confined to the prevention and control of infective diseases of meat-producing animals in herd units. . . The successful veterinarian of today is an immunologist; the successful veterinarian of twenty years ago was a surgeon. . . . This transition was too sudden and complete for the best interests of all concerned. .. . In some sections surgical operations are so rare that they are a novelty.

In recognizing the retrenchment of the profession as a result of the depression, Dr. Kinsley observes:

The future of our profession is dependent upon our attitude toward and relation with agricultural interests. ... The veterinary profession will survive, because veterinary service alone insures the livestock industry against the ravages of disease and is indispensable in the conservation of the health of nations.

Earlier, N. S. Mayo had observed that the depression:

has affected every one, not only financially but psychologically. I do not think it has hit us harder than it did the farmer and stockman, but certainly hard enough. Quite a few veterinarians gave up their profession and entered other lines of work.

On "The Trend of Veterinary Practice," W. H. WeIch notes:

the graduate of later years . . . is no longer just a "horse doctor," but is the confidential adviser of the livestock owner concerning all the domesticated animals on the farm.... As a sanitarian he is no less valuable than the physician in guarding the health of his client's family. He is the leader in bacteriology, pathology and other fields of original research, while as inspector of foods his services are indispensable.

The development of immunization for hog cholera, Welch continues:

Placing as it did the swine industry on a safe financial basis, its value to the entire world can 
not be estimated, while the hog, hitherto al most entirely ignored by schools and veterinarians alike, strangely enough now becomes one of the profession's greatest assets ... and has been placed there solely by reason of the efforts of the veterinary profession. . . That the county agent or anyone else who imagines himself capable of rendering intelligent service along this line, by exploiting vaccination in the hands of other than the veterinarian, is, in his gross ignorance, perpetrating a great injustice on the hog, the hog owner, the veterinarian, the county which employs him, as well as on the nations at large which his methods will eventually deprive of much pork, is a self-evident fact. ... The farmer himself freely admits the superiority of the veterinarian in vaccination, but because he has been led to believe that he can successfully perform it, only time and experience will teach him the lesson that the veterinarian is the cheaper in the end.

I feel that there is a future belonging to the veterinarian in the position as county livestock adviser. Who more capable than he in advising along all lines of animal husbandry, sanitary problems, and all phases of livestock production: The time is coming when throughout the entire livestock belt such a man will be employed in a majority of the counties, and he will be a wonderful asset in the improvement of livestock in his locality.

And directing an accusing finger at the veterinarian who purchases proprietary drugs instead of compounding his own, Welch points up one possible explanation of what has become an increasingly persistent problem in veterinary medicine:

The practitioner who allows himself to become addicted to this custom is fast losing out on his knowledge of medicine, instead of coming to know a drug more thoroughly in its action. He will in time become merely a mechanical automaton, and the stock owner who is able to diagnose his animals' trouble will fare equally as well by going to the drug store and purchasing over the counter the remedy that has been compounded by some other firm for that particular ailment. . . . The empiric has always treated his patients by just this process.... Our future is what we make it.

On the subject of "Dispensing as an Asset to the Veterinary Practitioner," C. W. Bower claims that a proper system of dispensing can account for a quarter of a veterinarian's income, and serve to increase his clientele by catering to those who would otherwise diagnose their own problems and secure medicines from the drugstore. Further, a service can be rendered to many of these persons inasmuch as many will undoubtedly have made incorrect diagnoses. Also: "It keeps our minds keen on materia medica, and causes us to look up and study medicine and materia medica more than we ever did in college."

In urging that veterinarians adopt a positive program to deal with the problem of lay vaccination of hogs, Clarence Ousley, former Assistant Secretary of Agriculture, observes:

A veterinarian is something of a missionary, and he is warranted in doing something more than sitting on his dignity and awaiting calls from an uninformed populace. . . . A man has an "unalienable right" to let his animals die, provided he does not imperil the lives of his neighbor's animals; but no layman has a right in morals or in sound public policy to "practice" ignorance.... It would be quite as rational to permit laymen generally to vaccinate against smallpox.

For the first time a session was devoted entirely to small animal practice, with papers on gastroenteritis by $O$. V. Brumley, eye diseases by $\mathrm{H}$. J. Milks, intestinal parasites by $M$. C. Hall, mange by R. P. Marsteller, distemper by W. E. Muldoon, and use of $x$-ray by G. P. Frost. In the clinic, the cesarean operation was demonstrated by W. G. Brook, with intratracheal anesthesia administered by J. G. Hardenbergh.

Dr. Hardenbergh also presented a thought-provoking discussion on: "The Value of Animal Experimentation in Vetterinary Medicine," and urged veterinarians to take the lead in educationg the public on this matter. Other papers included several on abortion by R. A. Kelser, Ward Giltner and I. F. Huddleson, and W. E. Cotton; several on swine diseases by Drs. Dorset, McBryde and Niles, R. R. Birch, and A. F. Schalk; sterility by W. L. Boyd; the Veterinary Corps by R. J. Foster; and the veterinary curriculum by V. A. Moore. 


\section{H. P. Hoskins, Secretary-Editor}

A decision of far-reaching importance made at the 1922 meeting was that combining the offices of secretary of the Association and editor of the Journal, and the appointment of $\mathrm{H}$. Preston Hoskins to this post - which he was to hold for sixteen years. Many were loath to dispense with the services of J. R. Mohler - whose name on the masthead was, as put by Dr. Torrance, something like the "U.S. inspected and passed" mark on a piece of meat; but both Mohler and Mayo, who championed the combined post, declined it, inasmuch as it was to be a full-time position. There was some objection to the appointment of Dr. Hoskins, based upon his relative youthfulness and presumed inexperience. But as noted by Dr. Hoskins himself, he had held a variety of secretaryships, had been in editorial work for ten years, and had been raised in a veterinary atmosphere. It would seem as though the Executive Board had given careful thought to the matter.

With the above in mind, it is of some interest to note the tenor of editorials during Dr. Hoskins' first months of service. On "Publicity" he notes that the Association had approved a fund for this purpose enough for one insertion of a half-page advertisement in a leading farm magazine:

Most veterinarians agree that the one thing most sorely needed by the veterinary profession today is publicity. . . Hearty approval is given to the proposal of a leading biological house to inaugurate a nation-wide advertising campaign in favor of the veterinarian.... Each will conclude with: "The livestock industry is the cornerstone of America's agricultural wealth - and the veterinary profession is its greatest safeguard." . . . We are indeed pleased to know that this splendid work has been undertaken.

With respect to the supposed economy of lay vaccination:

Farmers have only been "kidding" themselves in this regard, too many times. ... [ But] so far as the vaccination of hogs is concerned, unless a veterinarian can go out and do a better, cleaner and more satisfactory job than his client can do himself, there is no particular object in the farmer employing the veterinarian to do the work.

Concerning "Our Code of Ethics," and the matter of listing a specialty when a veterinarian's practice is limited to that branch:

Times have changed and are changing, and it would appear that this question should be taken up and discussed now, just as well as later. It has been pointed out that members in our sister profession of medicine do not hesitate to "advertise" (we use the word with reservations) that they confine themselves to the practice of this, that or the other field of medicine or surgery, and without any apparent infraction of the code of ethics of human medicine.

Of course, if we relax, we must do so very cautiously. If some are given the proverbial inch, they will take the proverbial mile. But there is moderation in all things. We can not afford to be too straight-laced.

\section{And on "The Function of Our Journal" Dr. Hoskins stated this is:}

To establish and maintain ethical standards for American veterinary literature. . . To serve as an accurate chronicle for current events in and pertaining to the veterinary profession. ... To direct attention, if and when necessary, to any conditions in our own midst, which need correction. . . To serve as a forum for the discussion, always in a scholarly and dignified way, of the problems with which the members of our profession find themselves continually confronted. . . . To provide a sufficient variety of reading matter, so that there will always be something to attract and hold the interest of every member.

\section{A. T. Kinsley}

Albert Thomas Kinsley was born at Independence, Iowa, February 26, 1877, and received the B.S. (1899) and M.S. (1901) at Kansas State, studied pathology at the University of Chicago, and graduated from the Kansas City Veterinary College in 1904. A successful practitioner, he purchased an interest in that college in 1912, and became its president, and taught pathology, bacteriology, and parasitology. A frequent contributor to the veterinary periodicals, he pioneered a section on swine practice in Veterinary Medicine at a time when this 
specialty was little known outside the Midwest. He was widely known as a skilled diagnostician, a manufacturer of veterinary biologicals, and as an exponent of better veterinary education. He was the author of a book on Swine Practice and a Textbook of Veterinary Pathology.

Dr. Kinsley was active in the Missouri Valley Veterinary Association and the AVMA; he served the latter in numerous capacities, including the presidency (19211922). He died on December 8, 1941.

\section{3}

The meeting for 1923 was held in Montreal. In his presidential address, W. $H$. Welch credited the AVMA with being:

the influential factor in causing the various colleges to keep abreast of the times ... but I wonder if they fully realize the demands that the future will exact of the successful veterinarian and are properly preparing him to meet that emergency?

The practitioner, Dr. Welch notes, was totally unprepared for the sudden decrease in horse practice, and the equally sudden increase of interest in the hog "a hitherto despised animal, unmentioned in any literature, save market reports."

The veterinarian of the future, Dr. Welch continued:

is going to be the most important factor in successful livestock agriculture, and his patients will include everything from the canary bird up. ... There is a relationship between the schools and the practitioner that cannot be ignored, because the success and prosperity of the practitioner is always reflected in the attendance at our colleges. Our schools are empty today, because of the financial conditions that have confronted the practitioner, in common with the live stock agriculturalist.

The extent of the depression in veterinary medicine can be appreciated from figures cited by Dr. Welch. In 1910 there were 11,552 practitioners and 2,717 students; in 1923 there were about 8,500 practitioners and only 531 students enrolled. An estimated 500 were leaving the profession annually from all causes, and only about 180 entering it. However, the valua- tion of farm animals had increased by 50 per cent during this period: "Therefore, be of good cheer regarding the permanency of our profession."

A notable feature was the attendance of ten past-presidents of the AVMA: W. L. Williams (1892-1893); S. Brenton (19111912); J. R. Mohler (1912-1913); C. J. Marshal! (1913-1915); C. E. Cotton (1916-1917); F. Torrance (1917-1918); V. A. Moore (1918-1919); G. A. Cary (1919-1920); D. S. White (1920-1921); and A. T. Kinsley (1921-1922).

\section{A Matter of Policy}

The Executive Board presented a proposed policy for the AVMA, drafted by a committee consisting of Drs. Munce, Welch, Merillat, Udall, Jacob, Mohler, Cotton, and Hoskins. The report, which was adopted in 1924 after approval by numerous local and state assuciations, appears to be the first detailed blueprint of Association policy and philosophy. As stated in the preamble:

The purposes of the American Veterinary Medical Association are to promote and protect the interests of the veterinary profession; to raise the requirements of veterinary education; to procure the enactment of uniform laws and regulations governing the control of animal diseases; to carry out the enforcement of these laws and regulations [?]; to encourage public opinion through various means regarding problems of animal hygiene; and to promote good fellowship in the profession.

\section{On agricultural extension:}

The Association should support every effort of the Agricultural Extension Service to increase the production of a better class of live stock. . . Veterinarians affiliated with agricultural colleges and agricultural extension services should confine the instruction and advice given to agricultural students and live stock owners on veterinary subjects to: (a) The fundamental principles of live stock sanitation; (b) First aid, and (c) The value of employing competent veterinary services in the diagnosis, prevention and treatment of animal diseases.

\section{On veterinary education:}

preliminary education in subjects directly allied to veterinary medicine must be stressed, 
while membership in the various veterinary medical associations and post-graduate work for keeping up-to-date are essential. . . . Undergraduate veterinary education should be conducted only at institutions approved by the AVMA.

\section{On legislation:}

All ills cannot be cured by legislation; much still depends on individual effort through the rendering of efficient service, whether private or public. ... The Association should render assistance in the enactment of all legislation affecting the public's interests.

\section{On regulatory service:}

This Association recognizes the right of the states and provinces to employ veterinarians for the purpose of giving free professional service for the control of communicable diseases. ... The general use of special county, state, federal or provincial employees for the performance of routine work ... is not a wise permanent policy.

The policy on public health was perhaps not as strong as might have been desirable:

The veterinarian should continue to render every possible service to health officials by supplying information with reference to animal diseases. . . . The veterinary profession should commit itself to the policy of promoting the use of healthy animals and healthful animal products.

\section{On allied organizations:}

The veterinary profession through its membership should be identified with those organizations and participate in their deliberations whenever possible ... in an endeavor to harmonize policies and activities that may be of mutual interest and benefit.

On publicity:

The policy of this Association should be to promote and carry on ethical publicity, calculated to improve the service of the veterinary profession.

\section{On humane measures:}

This Association should support humane measures and assist in teaching and guiding the public mind in correct methods of handling animals humanely.

\section{On veterinary biologics:}

It appears desirable that this Association establish, in cooperation with the Federal Bureau of Animal Industry and producers of veterinary biological products, a classification of veterinary biologics, whereby the veterinary practitioner may be guided and the live stock industry protected. ... This Association cannot endorse any biological product until its efficacy is definitely proven.

\section{On preventive medicine:}

Recognizing that prevention is the essential factor in the control and eradication of disease, this Association is committed to a policy of more general use of every established prophylactic measure.

\section{Up and Down the Spine}

In commenting on the fact that one veterinary journal in 1923 had carried an advertisement of a chiropractic school appealing to "veterinarians who are desirous of retiring from veterinary practice," $\mathrm{J}$. V. Lacroix observes:

It is to be doubted whether a successful veterinarian who had the means and the mood to retire, would care to top off his career by bursting forth as a chiropractor. ... The intention may be to address primarily the veterinarian who simply wants to quit and seek another way of making a living. ... If he had been an able and conscientious practitioner of veterinary medicine, he would be too strongly imbued with the more thorough principles of his science ever to feel at ease as an apostle of drugless healing.... His head would falter on the spinal column of his patient, and he would long to administer the forbidden pill.

The American Journal of Clinical Medicine for April, 1923, lampooned these advertisements with cartoons depicting some dire results of the application of chiropractic to veterinary medicine. Dr. Lacroix notes, "It seems to have occurred to the medical profession that possibly there is a sinister plan among the spine manipulators to invade the veterinary field." 


\section{W. H. Welch}

William Henry Welch was born May 7 , 1871, near Bloomington, Illinois, and graduated from Illinois Wesleyan University in 1890, and with honors from the Chicago Veterinary College in 1892, following which he established a lucrative practice at Lexington, Illinois. Active in community affairs, he was mayor of Lexington two years and participated in scouting and masonic activities. He served as president of the Illinois VMA, and as its secretary for a number of years, and in 1930 was appointed chief veterinarian of the Illinois Department of Agriculture.

Dr. Welch joined the AVMA in 1917 and was elected president in 1922. At the time of his death on October 25, 1935, it was said of him:

As a practitioner, he was progressive, alert, clean and ethical.... As an association worker he had no peer, for he believed firmly in organized veterinary medicine. . . His life was emblematic of the profound student, scholar, gentleman and good fellow, always calm and resolute in the defense of the right and the ruthless opponent of wrong.

\section{4}

At the meeting in Des Moines, President C. H. Stange pressed for adoption of the statement of policy outlined the year before:

I cannot too strongly urge this Association ... to focus its attention on our national problems and be less concerned with the details of our internal organization. ... Our big work, opportunities and problems lie outside and not inside of our organization. ... There is a lack of recognition in the profession as well as outside as to the real purpose of the profession. We believe that no country on earth is so safe for animal industry as is this continent, due very largely to the organization and efficiency of the veterinary profession. . . These facts, however, have an economic and sociologic significance not generally understood. We need publicity which will allow these facts to become known.

The statement of policy was adopted by the Association.
Noting that 106 persons in 22 states had died of rabies in the past three years, Adolph Eichhorn urged:

The veterinary profession should now follow a well-defined policy in promoting the control of rabies by the prophylactic vaccination, in preference to any method heretofore devised. ... Opposition against rabies vaccination can be readily met by education and sound arguments and therefore the efforts of the veterinarian should be directed to employ such means to popularize the vaccination of dogs ... [and] to point out the erroneous stand which the anti-vivisectionists are taking in this matter.

In presenting "Some Suggestions for Financing and Promoting Veterinary Education in America," Ward Giltner observes:

Veterinary education must come to stand before the public as education at its best and truest sense, and veterinary practice as a noble and indispensable art firmly grounded in science. . . . Financing a project of advertising veterinary education might be undertaken jointly by the veterinary colleges, the AVMA. and the several state associations. ... The federal government should also make provision for financially assisting veterinary education.

Dr. Giltner suggested reimbursement of $\$ 1,000$ per student from states without veterinary colleges, to be paid by the federal government or the states involved. Several schools have had such a plan in operation for some time.

Also presented were papers on uterine pathology by E. T. Hallman; estrus in domestic animals by H. S. Murphey, G. W. McNutt, B. A. Zupp, and W. A. Aitken; the army veterinary school by $\mathrm{R}$. A. Kelser; goose septicemia by F. R. Beaudette; sheep problems by I. E. Newsom and Floyd Cross, and by E. T. Baker; agricultural extension by T. E. Munce; foot surgery by T. $H$. Ferguson; and bovine abortion by $F$. C. Schroeder and W. E. Cotton.

With the establishment of radio station KSAC at Kansas State College in 1924, a series of regular programs on veterinary medicine was initiated in December of that year. The first programs included "The Services of the Veterinarian to the 
Community" by J. H. Burt, "Animal Diseases Communicable to Man" by R. R. Dykstra, "The Importance of Early Medical Attention in Animal Diseases" by J. F. Bullard, and "Abortion Disease of Cattle" by E. J. Frick.

A similar series broadcast over station WKAR at Michigan State College in 1926 included such topics as "Veterinary Education" by Ward Giltner, "The Development of the Chick Embryo" by F. W. Chamberlain, "The Digestive Tube of Farm Animals" by H. E. Johnson, "Meat Inspection" by E. T. Hallman, "The Udder of the Cow in Health and Disease" by L. B. Sholl, "The Care of the Pleasure Horse" by J. P. Hutton, "Veterinary Practice With Small Animals" by E. K. Sales, and "Vaccination in Veterinary Practice" by I. F. Huddleson.

\section{H. Stange}

Charles Henry Stange was born in Cedar County, Iowa, May 21, 1880. He worked on a farm for several years before deciding upon veterinary medicine as a career, and graduated from Iowa State in 1907 with the highest honors in the entire university. Becoming Assistant Professor of Veterinary Medicine that fall, his administrative abilities were recognized by his appointment to the deanship at Iowa State in 1909, the post he continued in until his death, at which time he was the ranking veterinary dean in the country. During this twentyseven years, 79 per cent of the alumni of the Division of Veterinary Medicine had graduated (the school had been in existence twenty-seven years when Dr. Stange became dean). Already the first school to have a four-year course, under Dr. Stange Iowa State was the first to require high school graduation for matriculation (1911), and a year of pre-veterinary college work (1931).

The idea of organizing student chapters of the AVMA originated with Dr. Stange, and he lived to see chapters in all of the schools in the United States and one in Canada. He joined the AVMA in 1907, was chairman of the Executive Board for three of the nine years he was a member of the board, and in 1923 was elected president of the Association.

At the time of his death on April 26, 1936, it was stated:

Perhaps it would be no exaggeration to say that Dean Stange had a greater influence on veterinary education in this country during the past two decades than did any other member of the veterinary profession.

\section{THE MAN, MERILLAT}

In his presidential address at the 1925 meeting in Portland, Oregon, L. A. Merillat considered the changes "the passing of the horse" had wrought in veterinary practice:

From a business we have taken over the work of a profession. Preventive hygiene and public health problems are diverting our attention away from the mere notion of salvaging so much horsepower. The whole scheme of preventive medicine - the big idea of lessening the sum total of domestic animal and human diseases - did not perturb those of us who were general practitioners until the storm which took away our main-sail came along to jar us into the realization that other responsibilities were awaiting attention. ... .

Veterinary practice is still profitable, many veterinarians are prosperous and the average income of veterinarians in their various activities is increasing, but to the average man, with the outstanding attraction removed, it is an intangible calling and hence not thought of as a life occupation. To make the changed meaning of the word "veterinarian" more fully comprehensive is the big job at the moment.

As chairman of the first section on Small Animal Practice, E. A. Ehmer observed, "more and more men have turned to this field, until now ... it is considered the most acceptable and progressive branch of veterinary medicine." First secretary of the section was J. C. Flynn, one of the real pioneers in small animal practice.

Concerning the nature of veterinary practice, Dean E. E. Wegner observed:

Ethically, we have tried to follow our older sister profession, and in that we have made some mistakes, because veterinary medicine is a commercial proposition and the veterinarian must show the owner a profit if his services are 


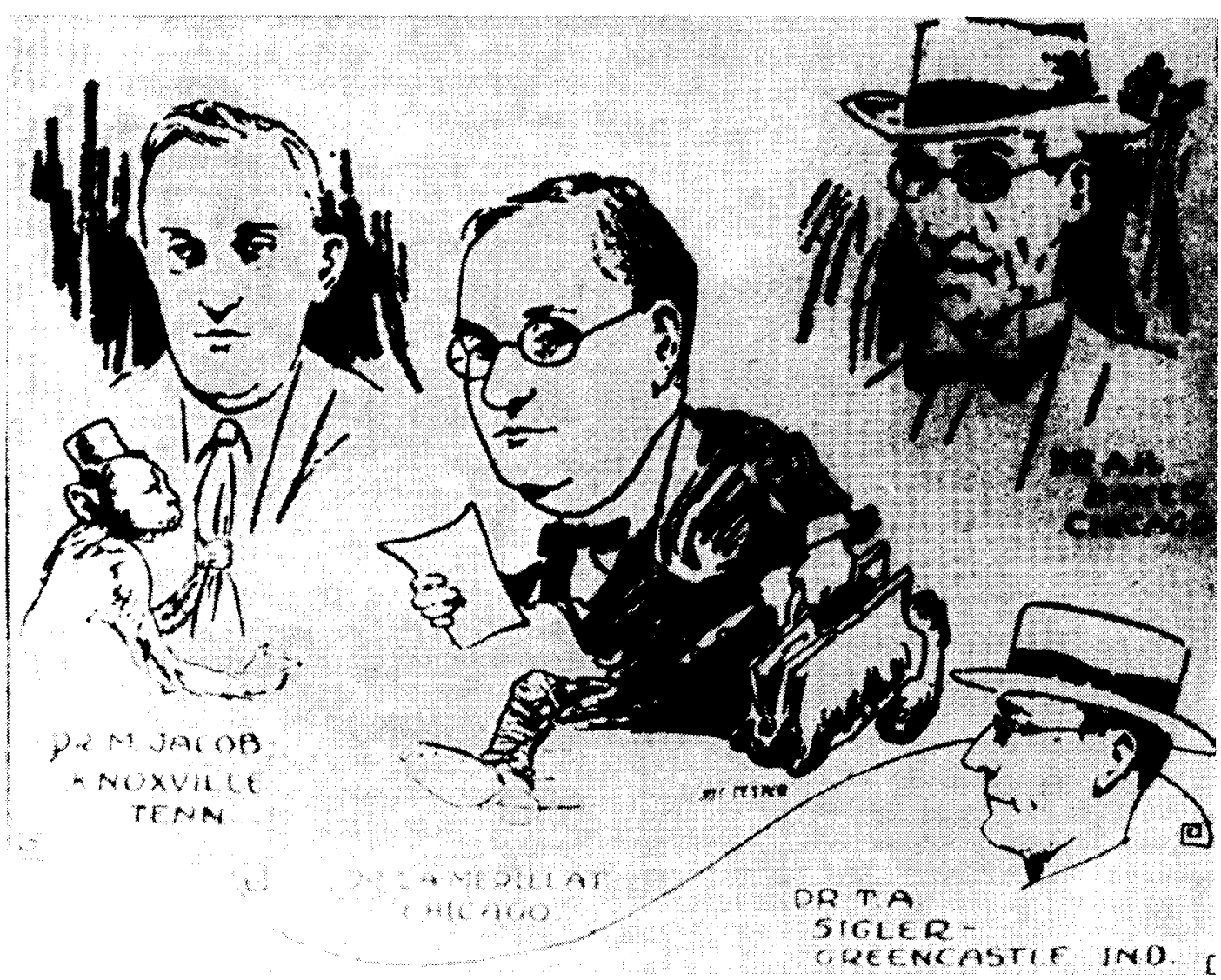

Prominent figures at AVMA meetings in the 1920's included Drs. L. A. Merillat (president 1924-1925), T. A. Sigler (president 1926-1927), M. Jacob (treasurer 1918-1943), and A. H. Baker (Chicago Veterinary College). AVMA Journal

to be used. Why not enlighten the owner directly and show him how he can profitably use this profession to advantage? Certainly such a program of education is not a crime, when the public has such a distorted opinion of us. ... .

What the veterinarian needs is a course in legitimate, commercial salesmanship.... As matters stand at present, it is impossible to interest young men in the veterinary profession because the public generally does not understand or know about the present high educational standards and the many fields of usefulness to which a veterinary education can be put. Education of the public is a slow and tedious process and years will be required to make this change in public sentiment and it will have to come about by observation of the veterinarian himself, his qualifications and his activities.

Among the papers presented were those on anthrax control by Adolph Eichhorn; canine distemper by J. G. Hardenbergh; bovine laparotomy by J. N. Frost; gonad transplantation by C. M. Haring; brucellosis control by B. T. Simms and F. W. Miller; fowl pest by J. R. Mohler, and by Evan Stubbs; diseases of the central nervous system by $\mathrm{O}$. V. Brumley; and arteriosclerosis in domestic animals by $\mathrm{S}$. A. Goldberg.

The elite circle of fifty-year members was initiated with J. C. Meyer, the sole survivor of his "class" of eleven admitted in 1875. To 1874, if the available records are complete, the cumulative membership had been just under fifty, and of these, only Alexandre Liautard had survived $\mathbf{5 0}$ years (but had returned to France after 37 
years). In 1925 only eleven men had records of 40 or more years of continuous membership. In 1955 the Association numbered eighteen living fifty-year members, four of whom had sixty-year records; E. B. Ackerman, Paul Fischer, N. S. Mayo and L. A. Merillat. Two additional members joined the exclusive half-century club in 1926; Benjamin McInnes of Charleston, South Carolina, and C. W. Crowley of St. Louis:

The records show that we will not have the opportunity of marking another similar occasion for at least six years, as not one of the members who joined the Association between the years 1876 and 1882 is any longer with us.

As a matter of further interest, the Association had 201 Life Members in 1930, i.e., with 25 years of continuous membership; in 1958 the number was 210, despite the fact that the total membership was more than triple the figure for 1930. The figure for Life Members in 1958 does not include the 28 Honor Roll members, but, as noted above, the Association could not have had more than 3 fifty-year members in 1930 .

\section{A. Merillat}

Louis A. Merillat was born at Wooster, Ohio, March 22, 1868, and graduated from the Ontario Veterinary College in 1888. Locating in Chicago, he soon built up a large and lucrative practice, in addition to serving as Professor of Anatomy at the McKillip school (1893-1900), and Professor of Surgery at the Chicago Veterinary College (1900-1913), in which capacity he rejoined the McKillip school until it closed in 1919 .

Commissioned a Major in 1917, he was Division Veterinarian of the Forty-first Division, later Executive Officer for the Franco-American Veterinary Liason Mission in Paris, then Chief Veterinarian of the First Army. He was discharged in 1919 as Lieutenant Colonel with the Legion of Honor from the French Government. Few veterinarians in civil life have maintained the intense interest in military affairs as did Dr. Merillat, who with D. M. Campbell wrote the remarkable two-volume Veterinary Military History in 1935.

A prolific writer, he contributed many articles on surgical topics and subjects of general professional interest to the several veterinary journals. A confirmed student of history, he wrote extensively on this sub. ject during his later years, and from 1939 to 1950 was editor-in-chief of the AVMA Journals. His "Memoirs" in the Journal (1946-1947) offer a fascinating and valuable commentary from one who perhaps knew more of the history of the profession than any other individual. $\mathrm{He}$ was also the author of several textbooks on veterinary surgery and dentistry.

Dr. Merillat joined the AVMA in 1893 , and served as vice president in 1896 and secretary in 1916. In 1917 he turned in an unprecedented 556 new members - and was unanimously re-elected, but was called to military service shortly afterward. For a number of years he was chairman of the Section on Surgery, was elected president of the Association in 1924, and at various times was a member of practically every important committee of the Association. Active until his death at the age of 87 , on February 25, 1956, it can truly be said that few men have ever served a cause so faithfully for so long.

\section{L.A.M. on Status}

Writing in Veterinary Medicine in answer to the question: "Is veterinary practice keeping pace with the general progress of veterinary science?" Dr. Merillat had observed in 1921:

The growing impression among practitioners that the sanitary branch is naively and intentionally crowding them in to the background is silly palaver. The fact is sanitary medicine is looking after its own interests and piling up achievement after achievement while general practice is allowing itself to be overshadowed through its own weakness. . . General practice depends for existence upon the treatment of individual animals for individual owners. It is a vocation strictly delimited by its merit as a salvage enterprise on a much smaller scale than sanitary medicine. If it saves property 
below the cost of salvage it will live; if not, it will be deleted by the immutable laws of commerce. To live it must progress; to progress it must become useful, competent, efficient. ..

The fact that human medicine is splitting up into specialities which sometimes deal with only one disease and always in a single species is often made an excuse for the shortcomings of the veterinarian who must handle every disease in so many different classes of animals. . . There could be no greater calamity befall the veterinary profession than to allow its integrity to disintegrate into different branches. Its power will depend upon a unity of effort by all who have received veterinary degrees, the sanitarian, the teacher, the food inspector, the small animal practitioner, the general practilioner, etc.

As the obvious means for progress, Dr. Merillat pointed to the journals: "It is almost deplorable to note how many among us are non-readers"; to graduate study: "More graduate work of just the right kind will do much toward rehabilitation of the practitioner's status in the profession and among those he serves"; to association meetings: "A glance at the programs of veterinary associations, national, state and local, shows that the practitioner is losing a golden opportunity to bring out the clinical details he needs most"; and to books: "A dust-ridden library of a few antiquated volumes is an exhibition that silently announces a non-progressive practitioner." And elaborating upon "our lost orientation":

Once upon a time when the horse was the only form of individual transportation and mobile motor power, the veterinary profession had a fixed orientation - a definite status. It treated the horses of its patrons in accident and disease. In this capacity it was richly rewarded with a high respect and conficlence. ... But since fate diverted our attention from the motor to the food-producing species, these friendly relations have been jeopardized if not in many cases sacrificed. We risked a secure status in animal husbandry for a phantom in the domain of public health and in the shift lost our orientation. We drifted into a policy assuming to protect the consumer who knows us not and cares less instead of remaining faithful to the producer, our friend who pays the bills and who naturally expected our support in times of need. As a consequence we often find ourselves back to the wall fighting against a hostility we ourselves kindled.

For one as history-minded as Dr. Merillat was, this sounds almost as if it were taken out of context - which it is not. He might have pointed out that a period of indecision was perhaps an inevitable aftermath of anything so cataclysmic as the revolution created by the internal combustion engine. Moreover, the qualified horse practitioner earlier had to fight an uphill battle for public recognition - both for his professional competency and social respectability. It was hardly the responsibility of the consumer "who knows us not" to take the initiative.

\section{Public Health Pundit}

That Dr. Merillat did perhaps recognize some need for orientation toward the public health aspects of veterinary medicine may be seen in a subsequent feature on "The Destiny of the Veterinarian":

The fear about our future would warrant consideration if we were any worse off than other professions. ... Veterinary science will never have any good reason to fear its future for... as an insurance against loss to the live stock industry alone, veterinary science will survive and thrive. A profession exploiting a science that assures the stock owner a skillful, sensible and humane handling of his precious property, that insures the nation's greatest industry against wholesale losses, that conserves millions of the national wealth, that proffers assistance when needed to public health movements and that has proven its indispensability to the transport of armies will not die while civilization lasts. It cannot succumb to passing influences. It cannot even decline.

In noting that the horse accounted for 80 per cent of the work of about 8,000 veterinarians in 1900 compared with only 10 per cent of about 14,000 in 1920 , Enos Day refused to admit that this change is due entirely to the "passing of the horse." Rather:

by keeping abreast of the scientific facts brought out by diligent research . . . the veterinary profession [has] a much broader 
knowledge of the diseases of the various other animals. By this increased knowledge and power to combat disease they have gained the confidence of all concerned.

That veterinary contributions to public health were not completely hidden from the public in the early 1920's may be appreciated from an article by J. H. Beard, M. D., in Nation's Health. After itemizing the contributions of domestic animals to the welfare of man, Dr. Beard notes:

Yet these noble animals, when ill, have proved to be the worst enemies of man. They have destroyed him with tuberculosis, killed him with anthrax, cut him off with glanders, filled his muscles with trichinae, racked his body with Malta fever, and loaded his intestines with tapeworms.... That $\mathrm{man}$ should have some of the roses and avoid the thorns, that these best friends should feed and clothe him today and not destroy him tomorrow, is the contribution of the veterinary surgeon to public health. In his efforts to protect and save animals, the veterinarian has conciously and unsuspectedly pointed to hidden paths by which man has been able to attain an average life nearer the normal limit of three score and ten. . . . Discoveries in the field of veterinary science, with rare exceptions, have been helpful in the domain of medicine.

Dr. Merillat, however, continued to preach a restricted concept of what constituted the role of the veterinarian. As editor of Veterinary Medicine in 1923 he passes censure upon the USDA for its nowclassic film on tuberculosis, "Out of the Shadows," and upon veterinarians for:

assuming without proof that it portrays the truth ... we have been trying to show that cows are a menace to mankind. ... We do not believe it is wise for the veterinary profession, in view of its purely agricultural connections, to promulgate propaganda belonging strictly to the public health service. We believe it is as unwise for the veterinarian to proclaim even the cold facts about tuberculous milk as it would be for the milkman to paint them on his milk wagon. ... That duty belongs to someone else. ... We have lost our professional orientation; we do not belong to the public-health service and the livestock interests are kicking us out.

\section{And later upon the same theme:}

Ever since we have turned a great share of our attention to food-producing animals, we have made the monumental blunder of trying to place ourselves in a position of greater importance by proclaiming, sometimes quite loudly, that we are guardians of the public healt $h$. Indirectly we are, directly, we are not, and the sooner we get it into our heads that we are guardians of the public health only to the extent that the agricultural interests want us to be, the sooner veterinary science will be adopted as its faithful ward. ... No veterinarian is a public health officer. . . I It is no part of his work to venture opinions as to the effect food products might have on the public health. . . We should be telling the dairyman that his only hope lies in establishing the reputation of keeping only healthy cows and of producing wholesome milk, instead of "snitching" to the public about the matter of harmfulness. . . . The horse sometimes has glanders, and glanders can be transmitted to humans, but we do not publish the fact.

Merillat's stand undoubtedly was based upon the conviction that the veterinarian did not (and could not?) qualify as an expert on public health matters:

Veterinary science must justify its existence by its worth to agriculture, not by its worth to public health. We know nothing about the diseases of humans. . . . Ours is a knowledge of animal diseases only. . . If we are able to supply the physician with useful information about animal diseases that he can put to good use, so much the better for us, but when we endeavor to tell the physician that certain of his patients have contracted disease from certain of our patients, we are saying something we are not in a position to prove. ... The role of the veterinary profession as it seems to be unfolding in the United States today is that of keeping livestock healthy - the field man's function - and of handing over to the consumer food products that are pure and wholesome - the food inspector's function. Here our mission comes to an abrupt end.

An announcement of the USDA in 1923 that: "Bovine tubercle bacilli ... are responsible for about $10 \%$ of the deaths due to tuberculosis among children under five years old," evoked the comment:

Wouldn't it be better if the promotors of agriculture put it this way: "Of all the tuberculosis among children under five years old only $10 \%$ is believed to be caused by milk from tuberculous cows?. . . [ This] would do just as much good from the standpoint of justifying the eradication of bovine tuberculosis. . . . 
We want to eradicate tuberculosis from animals, and we want to do it badly ... because it's the only sensible thing to do; it pays. ... [ [But] by scaring mothers from giving cow's milk to their babies, by trying to make the people believe that cow's milk is something to fear, by stating point-blank that if they drink milk they will get tuberculosis, we have actually stopped progress in many instances. . . . It is thought today that a certain amount of tuberculosis of children is of bovine origin. . . . It is known that the mad-dog gives rabies to a certain small percentage of the persons it bites; it is known that occasionally a man will contract glanders ... anthrax ... mange . . . [but] these dangers now, in their full aggregate, are not, nor ever have been, a great menace to mankind under ordinary conditions.

Criticism of the film, "Out of the Shadows," evoked an argument for: "A broader conception of the veterinary profession," by L. B. Ernest, of the USDA Tuberculosis Eradication Division. This criticism, Dr. Ernest contends:

is the first unfavorable comment of this film that has come to our attention. This picture was produced for the purpose of furthering the tuberculosis-eradication campaign. Before production it was submitted to and approved by the United States public health service. ... It appears that the writer of these articles believes that any injection of veterinary service into any phase of public health is going outside of the realm of veterinary practice. . . . The editor's conception of the functions of the veterinary profession impresses many of us as being entirely too narrow and selfish and as ignoring the public spirit and the desire to serve humanity that should characterize any body of men who aspire to the dignity of being classed as a profession. ... .

The writer believes that nothing is to be gained by the profession as a whole by attempting to conceal the ill effects of unwholesome milk and the lack of proper sanitation upon the farms, or the danger from milk infected with bovine tuberculosis. The frank and open recognition of such things will become a part of veterinary practice when the best of service is being rendered. ...

The writer takes issue with the editor's statements to the effect that the veterinarian's work in food inspection is purely for the benefit of the agricultural interests and not for the benefit of the public health. Such a conception is not justified by the facts. It is a matter of history that the principal motive back of the pas- sage of the present Federal meat inspection law was the protection of the consumer's health. . . . The editor's philosophy, if applied to government functions generally, would mean that the public health service is designed for the advancement of the selfish interests of physicians and druggists rather than for safeguarding human health. . . Agriculture itself, in fact, does not exist merely for the purpose of bringing profit to the farmer, but has its highest justification in providing food and comfort for the human race....

And so, while the veterinarian is concerned primarily with the health of animals, his concern goes beyond the welfare of the animals themselves and the profits of their owners, and extends to the real objects for which the animals are raised - the service of mankind. $\therefore$. If the veterinary profession is to attain its highest ideals its members must not confine their knowledge or activity to the simple dispensation of drugs or the application of surgery or the control of a few animal diseases. . . . The veterinarian of the future will be the principal sanitarian of the future. This can not be avoided except through a total lack of preparedness and a refusal to assume responsibility.

In rebuttal, Dr. Merillat reiterates his contentions that the veterinarian "is an expert on the health of animals only," and the USDA film: "does not tell the truth." On the other hand:

The charge that we are narrow and selfish we take good naturedly because these are such common human faults; as common as broadmindedness is rare. And besides, we take solace in the words of a great philosopher who said "To avoid unkind criticism, say nothing, do nothing, be nothing."

Dr. Merillat undoubtedly was sincere in his convictions; he made no pretense of disguising his philosophy; "the practitioner, right or wrong will be our motto." To what extent his editorial policies shaped the thinking of veterinarians may be a moot point; it would seem a logical surmise that more might have been attracted to the public health aspects of practice, or public health work per se had he campaigned as vigorously for this as he did against it. It is also evident that the philosophy of many of his prominent predecessors, who had advocated the cause 
of public health beginning in the 1870's has long since been vindicated.

Not all practitioners in the 1920's, of course, believed that direct service to the livestock interests was the only justification for the veterinarian's existence. Thus A. J. Magrane, Sanitary Officer of Mishawaka, Indiana, writes in 1924:

I think more veterinarians should try to get connected with boards of health in towns and cities. ... I have lots of work; for instance, take care of all milk, meat, water and food inspection. . . . I look up all garbage, rubbish, dirty home and outhouse complaints; hang up all infectious disease signs, feed the families if necessary, fumigate homes after quarantine, take throat cultures of all diphtheria cases when time to release them, look up any and all complaints coming to the board regarding sanitation or quarantine. . . . I am called upon to trace all social diseases that are reported to the board.

It is now five years since I was appointed, after working hard for it. . . Being a veterinarian, I knew I was better fitted for the position than a layman. I am at the hospital every day, in the laboratory. I meet all the physicians on common ground. They have the same regard for me as for other physicians; so do the Sisters who run the hospital and the nurses. I believe we could elevate our profession a great deal if more veterinarians would try for these positions for which they are fitted.

It might be added that the name of Magrane has long been a household word in Mishawaka.

Dr. D. M. Campbell, who resumed the editorship of Veterinary Medicine in 1924, and who was a member of the American Public Health Association, called attention to the fact that in that year only seventeen veterinarians were members of this group. He urges:

Because of the large number of veterinarians engaged in municipal meat and dairy inspection and in state and county work, having a bearing on public health, it would appear that the profession should be represented by many times this number in the national association.

\section{Give 'em Hell}

A real problem in the 1920's was that of lay encroachment upon veterinary prac- tice, particularly with reference to vaccination for hog cholera. While editor of Veterinary Medicine in 1923, Dr. Merillat waged a continuing battle on this matter, on the behalf of both the practitioner and the farmer whose hogs were ill-protected by ill-advised methods of circumventing the veterinarian. In particular, a sore point was a recent Iowa law which provided for licensing of lay vaccinators after a two-day course, a matter which roused the wrath of Hell (Henry Hell, an Iowa practitioner). Under a lead: "Make the course four days and close the colleges," Dr. Hell observes:

Our state legislature in its infinite wisdom has proclaimed that any farmer who has taken a 48-hour course under a veterinarian deputized by the state college or animal health commission may legitimately compete with the college graduate in $60 \%$ of his earning power. Why not give the farmer another 48-hour course and let him handle the entire veterinary practice of the state.

\section{On this matter, Merillat notes:}

Strange how silent the self-named benefactors of the veterinary practitioner are about a real menace - the menace of training farmers in the technic of hog cholera immunization; the menace of decorating them with a license; the menace of scattering a death-dealing virus to the four winds. The stock of medicine in the farm stable is not likely to harm the veterinary practitioner today any more than it harmed him in the past, but the Iowa idea is something else. It is a dragon, a real, devouring, fire-spitting dragon that does not only fill up the medicine chest, but fills it up with agents for diseases that even the most learned veterinarian knows too little about. .

Here is something that makes the medicine evil sink into the background as a triviality. . . . No state, no nation has the moral right to lure its sons into a vocation and then sacrifice them at such an altar. And then, there is by right not even common sense in turning over the handling of such scourges as swine diseases to unqualified persons and to do so at a time the veterinary profession might reasonably expect some appreciation for its achievements in discovering the means of controlling these very diseases.

The roots of this problem went deeper than a mere desire on the part of organizations which presumably had the best in- 


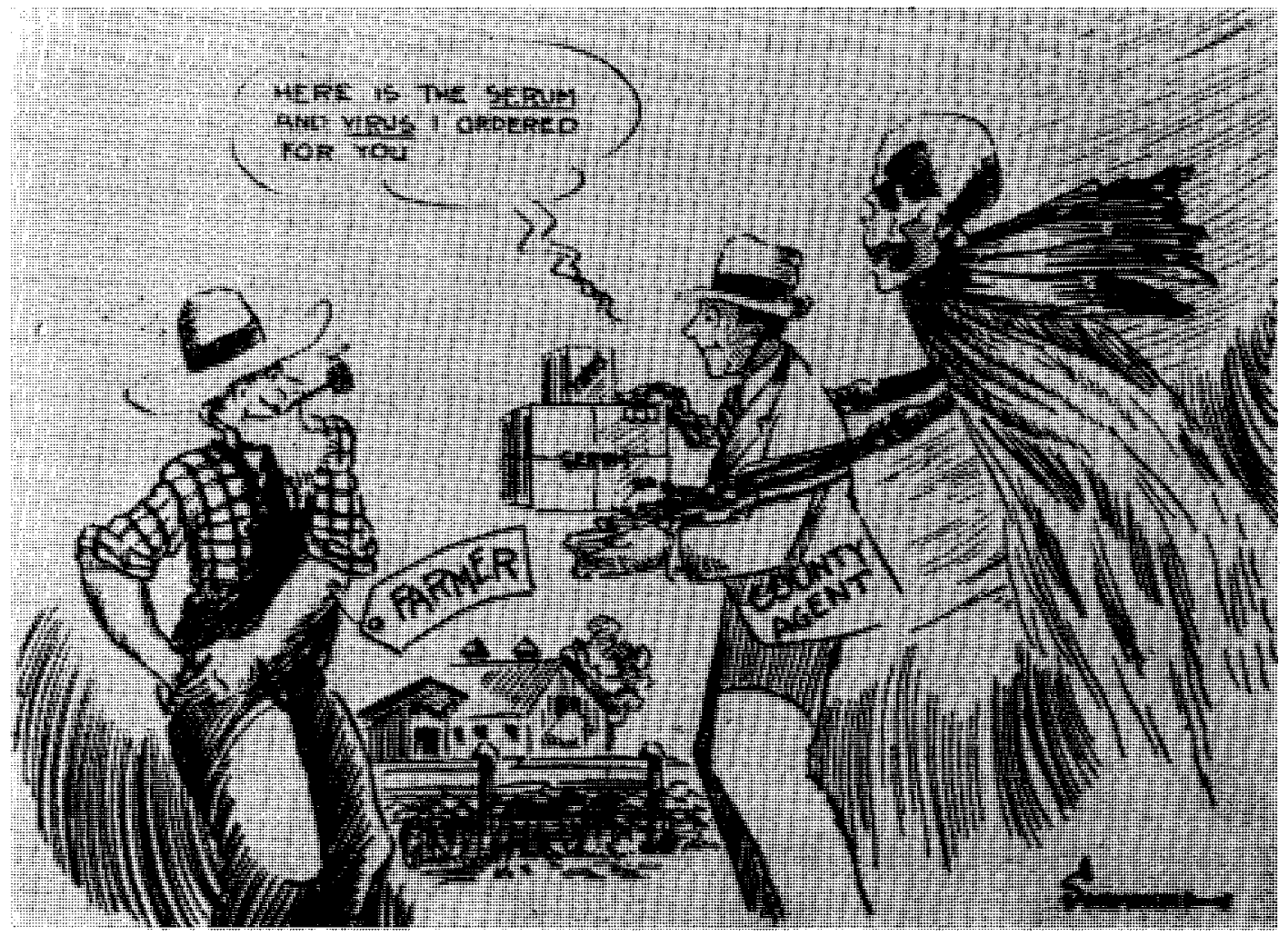

Cartoon by Dr. E. A. Schmoker protesting sales of hog cholera virus to farmers in the 1930's. Veterinary Medicine

terests of the farmer in mind to save him the cost of veterinary service. It is true that in some quarters it was believed that the veterinarian was making a huge profit from vaccination - and undoubtedly there were some instances of overcharging. But it is also true that perhaps a majority of farmers were not as dissatisfied with the situation as some over zealous promotors of the idea of lay vaccination claimed. And economic conditions in the early twenties were such that the prospects of saving a dollar were not to be overlooked. However, it is also a fact that in some areas there were not enough veterinarians - in particular, not enough oriented to swine practice. Vaccination was still relatively new, and the full dangers of live virus had not been adequately realized - and still are not in many areas.

Nor should it be thought that the agri- cultural press was entirely one-sided in the matter. Under a lead: "Farm Bureau and Veterinarians," the Orange Judd. Farmer in 1921 states its position:

The farm bureau is the farmer's organization, created to serve him. It is entirely possible that in some counties there has been inadequate veterinary service, either by reason of lack of skilled men, overcharges or careless work. Not all counties are blessed with expert and conscientious veterinarians.

In such a case, assuming they are sure of the facts, it is manifestly the duty of the farm bureau to take the matter in hand. However, it is our opinion that such vaccinating work should be considered only a temporary recourse, pending the establishment of reliable and expert practicing veterinarians. ... It would be unfortunate ... to force out of business a skilled, hard working, conscientious practitioner.

And would it not react eventually against the farm bureau if cold figures should show that 
the cost of vaccination, performed by the farm bureau, was greater than the cost of the same vaccinating by the practitioner, and that the percentage of unfavorable results was as great or possibly greater?

\section{Lacroix's Lament}

At the same time L. A. Merillat editorialized in Veterinary Medicine against veterinarians serving anything but the agricultural interests, J. V. Lacroix, in North American Veterinarian, was taking quite the opposite stand regarding: "Veterinarians and Public Health." Thus in 1923 he editorializes:

It is regrettable that some veterinarians in this country should advocate a pussyfoot policy in discussing animal diseases that may be transmitted to human beings. Their excuse for such an attitude seems to be a belief that the circulation of knowledge regarding the danger of animal diseases may lead to the curtailment of the use of animal products by the public. This would lessen the quantity of livestock produced and incidentally the need for veterinary services. Therefore, according to this line of reasoning, it is better for the profession to disregard the question of public health, since it is incompatible with the best monetary return from practice. Thus, with malice aforethought, we are to condone the sale of tuberculous milk for human consumption, rather than to apprise the public of the danger from such food and insist upon measures for overcoming this menace to health! . . .

No science worthy of the name can prosper by its adherents dodging the facts. The truth must be faced and recognized as such, if one's science is to have an enduring worth and not be merely an excuse for living off the community. . . . While specifically the aim of the science may be said to serve most immediately the interests of animal industry, yet it is certainly a mistaken zeal that would place such interests above human interests. ... Is it not better for veterinarians to insist that the people's food from animal sources should be free from disease and to interest the public in establishing such conditons? In the long run such a course can lead only to a greater consumption of animal products. ... Furthermore, it will mean a wider recognition of the profession as the agency working for this greater security of life and health. Not only will such service bring to those who render it their need of material reward, but, of higher value, there will be in their minds the comforting sense of helpfulness - the satisfaction of viewing a world made better because of their efforts.
In expanding upon the subject later the same year, Dr. Lacroix observes that the "public" includes the farmer:

And the farmer is interested in his own health and that of his family, even more than he is concerned with the health of his livestock. This being so, silence on the part of those who should know regarding diseases of animals communicable to man, cannot be construed as a friendly act toward the livestock owner. The farmer is interested in public health, and if the veterinarian has nothing to say on the subject, others will step in and say a mouthfulperhaps even to the extent of discrediting the veterinarian as an authority on animal diseases.

There is also the further fact to be considered that no science, no profession, no social activity, can place itself in a watertight compartment and have nothing to do with other sciences, other professions and other activities. ... A hermit-like aloofness from contact with allied branches of thought, spells decay and eventual extinction of those who adopt such an attitude. The medical profession has pointed out that the cooperation of human and veterinary medicine is necessary for the best results in both fields. We may expect to see a greater realization of this ideal in the future. . . The stock owner is not to be likened to Robinson Crusoe, with the veterinarian as his man Friday, all alone on a desert island.

Concerning the desirability of interprofessional cooperation, J. H. Beard, M.D., writing in NAV on "The relation of animal diseases to public health" urges:

The versatility of bacteria in passing the barriers of species, the co-operation of animals and man in the preservation of parasites by mutally contributing to their life cycle, the role of insects in conveying organisms from diseased animal reservoirs to man, and the effect of the nutrition and the poisoning of animals upon their milk and meat are conditions that demand the united efforts of veterinary and human medicine in the comparative study of disease and in the preservation of public health.

\section{Campbell's Coming}

Veterinary Medicine had been practically silent on the subject of public health for nearly two years after D. M. Campbell resumed its editorship - after L. A. Merillat had so strongly discounted the value of veterinary participation in this area. In 
late 1926 this journal reprinted an article by the eminent British veterinarian Frederick Hobday on "the value of the veterinary profession in the preservation of public health." Dr. Hobday, later Sir Frederick, observes that in Britain - as obviously was the case in America:

The general public as a body have no conception of the part played by the members of the veterinary profession in the preservation of public health ... of the diseases for the prevention of which it is necessary, in the interests of the public health, for the medical man to seek the aid of his veterinary confrere.

In 1927 Veterinary Medicine carried one article overtly titled: "Veterinary Science and its Relation to Public Health," in which the state health commissioner of Oklahoma reported that the state had decided to discontinue free Pasteur treatment of humans and concentrate on vaccination of dogs. In a lengthy review of "Veterinary Medicine in 1927," the only mention of public health is the endorsement of pasteurization of milk by "a considerable group of veterinarians engaged in public health work" in this country, and the doubts of "a substantial body of veterinarians in Great Britain" on the same subject.

In a similar review in 1928, however, six pages carry a "Public Health" lead in bold print, although it is noted:

The interest of the veterinary profession in its problems having a bearing on public health cannot be said to have either increased or lagged materially during the year. . . . The discovery that undulant fever in man as a result of infection from milk is more prevalent than was formerly supposed, aroused no particular interest among veterinarians, although it occasioned much discussion among public health officers.

As further evidence for his contention that veterinarians had displayed little interest, Dr. Campbell continues:

In the matter of participation in the annual meeting of the American Public Health Association, reterinarians appear to have been remiss; but few veterinarians attended this great convention and only one, C. M. Carpenter of the New York State Veterinary College, presented a paper, although altogether 17 papers were presented at the meeting on subjects of particular interest to veterinarians, and on which they have special knowledge.

Of eight papers on public health topics reviewed as being of interest to veterinarians, only one came from a veterinary journal. In asking, "Is canine distemper a danger to children?" A. H. Bryan reports four cases in which distemper in dogs was followed by nine cases of colds, influenza, bronchitis, or pneumonia in children who played with the dogs. He concludes:

The human physician or veterinary surgeon upon diagnosing a case of canine distemper where children are liable to infection, is justified in observing prophylatic measures to the extent of insisting that the children be kept away from the dog entirely, and from any portion of the premises that the dog might have infected, until thorough disinfection. . . . The small animal practitioner can do more than any other group of professional men to throw light on this problem ... . and once again place the veterinarian in the role as essential to the health of a community.

Dr. Bryan concedes that his findings may have been pure coincidence, and that more research would be needed to establish a causal relationship.

The fact that claims for a causal relationship between canine distemper and various respiratory infections in man were later refuted is, perhaps, beside the point. In a discussion of reaction to his paper, Dr. Bryan notes:

One well known veterinarian seemed to consider that anything seeking to relate canine distemper to human infection had a tendency to hurt the canine industry, and possibly the canine practitioner.

This attitude, of course, is in the same category as the refusal to publicize the fact that milk from tuberculous cows may spread tuberculosis in man on the basis that this would hurt the dairyman, and thus the cattle practitioner. Dr. Bryan notes: 
Research workers at Johns Hopkins Medical School, who are engaged in a study of cold and influenza problems, confirmed the clinical observations of the writer, stating that organisms present in canine distemper are transmissable to the human.

And after mentioning clinical confirmation by other physicians, he concludes:

The veterinary profession will assume still greater importance from a public servant, in proportion to the service it renders in controlling human, as well as animal diseases. One of the greatest surprises to the veterinarian is the impetus accorded the dairy farm industry, following the war on tuberculosis. The veterinary practitioner has gained prestige, as well as added practice, due to his necessary service in controlling the disease, because he is serving the public from a health standpoint.

Of some interest in connection with the suspected relationship of canine distemper to human respiratory infections is a statement in 1935 by D. J. Davis, Dean of the University of Illinois College of Medicine, concerning the cyclic nature of influenza:

We may be reasonably sure that within the next 10 to 15 years, we will be visited with another pandemic of influenza and for the first time in all history, the prospect contains elements of encouragement owing to the research of Laidlaw and Dunkin on distemper in the dog.

\section{Fowl Play}

The May, 1925, issue of the Journal was devoted entirely to avian diseases "as an indication of the importance we attach to this particular field." Michigan had recently redefined its livestock laws to include poultry, and New Jersey to add "or poultry." And:

The sooner the public at large appreciates the fact that the study, diagnosis, treatment and control of diseases of poultry is a purely veterinary problem, the better off our poultry industry will be. During the past six months we have witnessed just about enough dabbling in the control of a serious poultry disease, by those without any training in animal disease control, to make us thoroughly disgusted.

The situation alluded to was a serious outbreak of European fowl pest. A laboratory investigator had imported some of the virus from the Pasteur Institute in the summer of 1923 :

The introduction of this virus - of a disease which, by the way, had not previously existed in this country - was not only a violation of a federal law, but it was one of the most thoughtless acts upon the part of a supposedly intelligent person that has ever been called to our attention. It is almost beyond belief.

Not only had this investigator used the virus carelessly, and had shipped it to other supposedly qualified investigators, but it was reputed that he permitted an assistant to inoculate some fowls on his father's farm:

It very strongly indicates that this criminal carelessness was the origin of the recent epizootic of fowlpest, which was not brought under control until it had spread to at least eight states.

More than a half million chickens died in the New York City markets during the six months ending in December, 1924:

a loss that was probably the largest ever sustained by the poultry industry of America ... the poultry industry of New York City was in a demoralized state.

Other states reporting outbreaks were New Jersey, Pennsylvania, Michigan, Indiana, Illinois, and Ohio.

\section{CURTAILMENT OF THE COLLEGES}

In speaking of the mission of the veterinary profession at the 1926 meeting in Lexington, Kentucky, President J. W. Adams observes:

The work of the physician has always been held in high esteem, because it deals with man, and human life. This is the popular conception, and it follows that the veterinarian's work is held to be utilitarian and not humanitarian.

I have never accepted this distinction. I cannot bring myself to believe that there is any life that is not sacred. . . An animal is conscious of self as an entity, a free individual. It has sensations, emotions, suffers bodily pain and experiences mental pleasure. We have volun- 


\section{A Prediction}

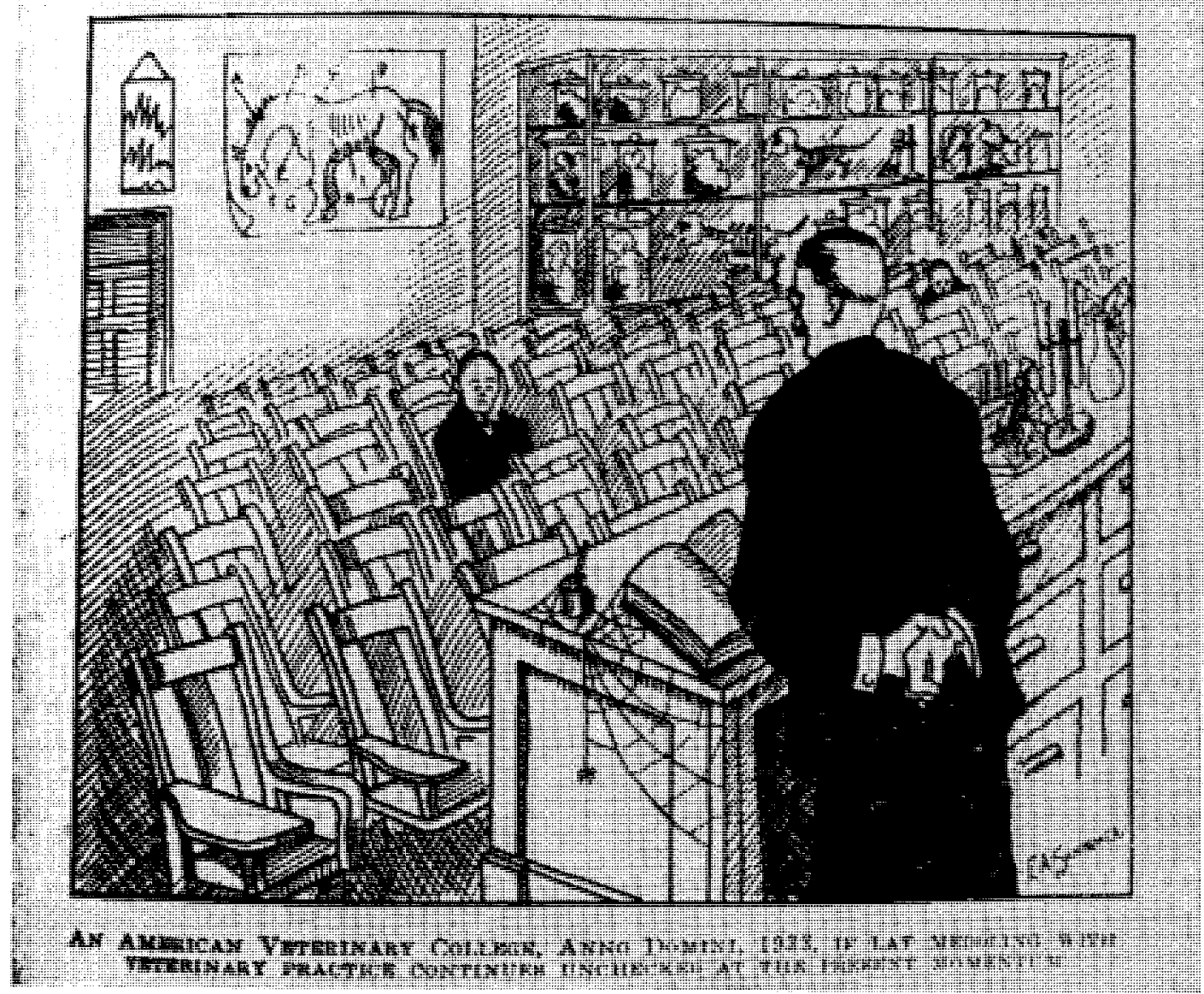

Cartoon by Dr. E. A. Schmoker suggesting what the veterinary colleges would be reduced to if lay meddling in veterinary practice continued unabated. Veterinary Medicine

tarily chosen a course of training which is designed to minister to the ailments of these dumb creatures. It is a noble work. Let us consecrate ourselves to it. ... I love the veterinary profession. It completely fills my being. It satisfies my noblest longings - all my soul's desires.

Concerning a history of the profession, P. A. Fish observes:

Much valuable information has doubtless been lost through the death of the older members; it is obviously necessary, if a history is seriously contemplated, to get as much assistance as possible from the veterans remaining with us. For historical purposes, life is too short for procrastination.
The program included papers on tuberculosis by Evan Stubbs, and by J. A. Kiernan; on brucellosis by C. M. Carpenter, and by I. F. Huddleson; abortion in mares by W. W. Dimock and E. S. Good; the estrous cycle of the mare by W. A. Aitken; inherited defects of stock by F. B. Hadley and B. L. Warwick; canine distemper by Ashe Lockhart; bovine indigestion by M. G. Fincher; blacktongue by C. C. Rife; skin diseases by H. J. Milks; and lameness by R. R. Dykstra.

The curtailed enrollments in veterinary colleges evoked much discussion; thus Dean V. A. Moore notes: 
The suggestion has been offered that ... a longer curriculum or higher entrance requirements would result promptly in a larger registration and professional preferment. Another has proposed the amalgamation of veterinary with human medicine. On the other hand, the need for veterinarians is so acute that men have had the audacity to appeal for lower requirements to practice. Further, certain agricultural agencies are endeavoring to popularize knowledge of animal diseases and teach farmers how to become their own veterinarians. Certain enthusiasts have hinted at the possible absorption of veterinary medicine by animal husbandry, thereby eliminating the profession.

As the crux of the problem, Dr. Moore states, "I believe the outstanding weakness in the veterinary profession today is to be found in its general, rather than its technical preparation." High school students he says, come:

ill prepared in the classics and not at all prepared in anything else. They have been instructed in many things, but they have not learned how to study or how to think for themselves.

\section{Another fault is that:}

Veterinarians, like physicians, have placed emphasis on their art ... and the art has not been quick to accept the teachings of science. One of the difficulties in veterinary medicine is its failure to recognize that the greater part of the sciences which contribute to make it what it is today, did not originate within the profession. ... There are a few veterinarians ... who have concluded that veterinary medicine has a monopoly on the pure sciences found in the veterinary curriculum. ... Why should not animal morphology, physiology and sanitary science be taught to the future husbandmen of the country? . . It is the art of veterinary medicine that should be safeguarded. . . I believe it is quite unsafe, and professionally a crime, to give the remedy for a disease to a person who cannot make the diagnosis.

\section{Dean Moore favored:}

a five-year course, which, for the present, should be made optional, in which the first year would be devoted to cultural subjects and basic sciences. ... The one condition of success, the sole safeguard of the profession, is "the moral worth and intellectual clearness" of the individuals who enter it. Education alone cannot give these but it may nourish them and bring those who possess them into the front, wherever and whenever they are to be found.

Thus Dr. Moore suggested a year of cultural preveterinary training, but $\mathrm{E}$. T. Hallman countered that the experience in medicine had been, "These high educational requirements have resulted in an enormous growth of poorly educated cults and quackeries, all preying on the public under the guise of doctors." Dean Stange considered it:

unfortunate that, as educational institutions, we have been in the habit of comparing our profession with that of medicine ... but practically there is a very wide difference. Our profession performs, in most of its branches, an essentially economic service.

He suggested a B.S. degree be awarded at the end of the four-year course, and, "The doctor's degree . . . should be offered only after further study, or at least five years of successful experience and a satisfactory thesis or other requirements." And noting an impending calamity when "The bars will be let down so as to enable lay pretenders to enter practice," Dean White urged, "Encouragement rather than discouragement should be given the intending veterinary student."

\section{J. W. Adams}

John William Adams was born at Middleton, Mississippi, November 8, 1862, and spent most of his early life in Minnesota where he received the $B$. $A$. degree in classical studies (University of Minnesota) in 1886. He taught English at a military school for three years before entering veterinary study at the University of Pennsylvania. While an undergraduate he rowed on the crew, and was an all-American center on the football team. After graduation in 1892, he studied at Berlin and Dresden, specializing in horseshoeing under Prof. Lungwitz, whose text he later translated. He returned to the University of Pennsylvania in 1893, was made Profes- 
sor of Surgery and Obstetrics in 1896, and elected to stay at this post rather than accept the deanship which was offered him in 1909 .

Dr. Adams joined the AVMA in 1894 and served in various capacities; he was president of the Pennsylvania VMA (19211922), vice president of the Keystone VMA (1901-1902), and was elected president of the AVMA in 1925. Death came from a heart attack on October 22, 1926, only a month after completing his tenure as AVMA president. He was characterized as "the kind of a man who has earned his sterling reputation by sheer ability and close application."

\section{Sound the Alarm}

The matter of encroachment upon veterinary practice by agricultural interests was noted with alarm by a distinguished Russian veterinarian in 1926, who urged:

The tendency of the American agriculturalists to trespass in the realm of veterinary science, foreign to them, is very unpleasant and dangerous, because the veterinary branch is no less complex than the agricultural one. The public must be made to understand that it is one thing to know how to handle a syringe but quite another thing to realize and foresee the complex problems presented by some diseases and which can only be comprehended by the veterinary practitioner trained on scientific principles. In Russia, long before the revolution there was a moment when the agriculturalists tried to become the masters in the realm of zootechnics and live stock industry, but the veterinarians fought them with determination and not without effect.

In printing this warning, Dr. Lacroix observes, "It seems that we ourselves are the least aware of just what is transpiring around us."

In discussing "the present and future of the veterinary profession" in 1926, A. T. Kinsley notes the probability that from the literature of the preceding few years:

succeeding generations will conclude that the veterinary profession was in a deplorable condition in 1923,1924 and $1925 .$. . The veterinarian, and particularly the practitioner, was prosperous during the period of the war and until about 1920 when the depression of agricultural commodities occurred. Since that time there has been a gradual readjustment although the price of live stock and the income of the practitioner are less than they were during the war.

The agricultural depression, Dr. Kinsley notes, was a major cause of the reduction of income of the midwest practitioner, to a large extent through lay vaccination for hog cholera. This was not solely a matter of supposed outright economy, but was abetted by the suspicion created by an unstable pricing practice of many serum companies. Fluctuations of price by as much as 100 per cent during the year prevented practitioners from establishing standard fees for vaccination; the farmer whose hogs had been given serum at $\$ 1.00$ per hundred cc. might well wonder why he was charged more than his neighbor whose hogs had gotten 49-cent serum.

The entrance of states into the serum production picture further complicated matters, since many of these states not only permitted, but promoted, vaccination by farmers and state employees. "Lay vaccination," Kinsley charges, "is an expensive privilege and the production of serum and virus by a commonwealth for such purpose should be discontinued." And noting an instance where nonprofessional employees of a state with a veterinary school had gone into areas adequately served by veterinarians:

This is a paradoxical situation - a state institution maintaining a veterinary college in which state funds are expended in educating men for veterinary service and simultaneously maintaining a serum plant and sending an employee into the field to do veterinary service.

\section{Hiatus in Higher Education}

In 1927 a press announcement by the USDA in calling attention to the fact that the BAI was short of veterinarians, notes:

The number of last year's graduates (132) from all veterinary colleges in the United States and in Canada was... scarcely up to 
the replacement needs of this one branch of public service.

At this time the BAI alone employed about 1,350 veterinarians, with a turnover of about 10 per cent annually, a figure perhaps surprisingly low in view of the entrance salary of $\$ 1,860$ - and the prospects of $\$ 2,400$ after ten or more years of service. In the hope of attracting more applicants for Bureau positions, it was urged, "veterinary medicine is worthy of consideration by young men about to prepare for their life work."

Concerning this, D. M. Campbell observes:

All the solicitude and all the urging of the civil service commission will continue unavailing in increasing the number of the matriculants at veterinary colleges unless its efforts be supplemented by a little encouragement by that same department of agriculture that employs each year a group of veterinarians equivalent in numbers to the entire graduating class of all the veterinary colleges in North America. ... It lies within the discretion of the chief of the Bureau of Animal Industry to set the entrance salary for a veterinary inspector at any amount up to $\$ 2,400$ a year if he can not get acceptable applicants at a lower figure. It follows if the entrance salary were set at $\$ 2,400$, some provision would soon be made for higher pay for lengthened service. The increase in pay would soon be reflected in the salaries of veterinarians in state, city and commercial employment. Veterinary practitioners, too, would be benefitted and veterinary courses would at once become more popular with highschool graduates intending to enter one of the professions.

It is probably no secret that for many years starting salaries for instructors in veterinary schools, and perhaps other institutions hiring veterinarians, were pegged to the BAI entrance salary.

In the same year M. H. Reynolds reported a study which showed for the years 1919 to 1924 an increase of 40.8 per cent in enrollment in medical schools, and 49.1 per cent in schools of theology, but a decrease of 24.2 per cent in veterinary enrollment. On the basis of these figures and other considerations (e.g., an increase of 30 per cent in pastor's salaries), Reynolds concludes:
Young men will not continue to attend veterinary schools in considerable numbers when they see other young men doing better in other lines, composite investments and receipts considered. . . . If improvement in agricultural prosperity alone brings inviting returns to practicing veterinarians, then our schools will fill up again ... when we compare total veterinarians, with total domestic animals and total valuations, it is difficult to believe that America is over supplied with competent veterinary service. If there is anything wrong, there must be other factors. . . Could the veterinary profession lower cost ... by knowing definitely what lines pay, composite cost and returns considered, and which do not? Could our professional returns be increased by definitely working for public good will like Swift and Standard Oil are doing and by extending the veterinarian's market as they do? ... Could the profession increase its returns socially by dress, manner, general culture and social activity? .. . Our student attendance must rise and fall with the relative net advantages enjoyed by the profession.

\section{7}

In his presidential address at the 1927 meeting in Philadelphia, T. A. Sigler observed:

The veterinary profession has controlled or eradicated every disease the live stock industry has called on it to combat, with the single exception of hog cholera, and this is the only serious disease that the laity has interfered with.

Our greatest problem is selling our profession to the public, who are misinformed concerning the duties of our calling . . . They very frequently ask . . "What do you veterinarians do since the horse is gone?". . . People do not think of the large amount of wealth tied up in other classes of live stock. ... We welcome... the coming of the motor cars that divorced us from the livery stable horse doctor and caused us to cast our lot in other directions.

Speaking on "The Veterinary Profession: Its Recognition and Personnel," Raymond A. Pearson (brother of Leonard), president of the University of Maryland, notes, among many other contributions of the veterinary profession:

Research in the veterinary field made the Panama Canal possible. Very few people know this.... Under the direction of Dr. D. E. Salmon.... Smith and Kilborne solved the 
secret of Texas cattle fever. This quickly and naturally led to the control of yellow fever and then - and not until then - it was possible to dig the canal. A monument to these men should be erected by the side of the Panama Canal to ... atone for the unjust treatment given to Dr. Salmon before and after the close of his great service at the head of our splendid Bureau of Animal Industry.

Concerning the "Grading of Small-Animal Hospitals," J. V. Lacroix suggested a "Hospital Branch" of the AVMA be established - perhaps the first public pronouncement of the concept that achieved substance with the later founding of the American Animal Hospital Association. On specialization in practice, F. H. Miller argued:

true specialism, properly and ethically carried out, does pay the highest dividend in any profession and is of the greatest possible service, when so conducted, in adding to the sum total of human knowledge.

Of particular interest was the presentation of papers by Bernhard Bang of Denmark on abortion and tuberculosis. Also presented were papers on bacterial nomenclature by W. A. Hagan; milk fever by P. A. Fish; bovine genital disease by W. W. Williams; dairy practice by E. R. Cushing; hog cholera by Marion Dorsett; fractures by C. P. Zepp; bovine sterility by Leonard Goss; fowl paralysis by J. R. Mohler; and infectious enteritis by H. E. Biester, publication of which marked the first use of full-color illustration by the Journal.

In a report on epidural anesthesia, W. M. McLeod and E. R. Frank note this had been demonstrated at the previous meeting by Dr. Benesch of Austria, a method "which is rapidly gaining favor among American veterinarians."

On "Bovine Infectious Abortion," Bang notes that it was thirty-two years earlier that he was the first to identify the causative agent, and now:

It is commonly admitted that the bacillus, to which you as a rule give my name, is the chief cause of the bovine infectious abortion. . . . I wish to express my sincere admiration for the numerous excellent researches on infectious abortion which have been made in your country. Your scientists have indeed for many years been in the fore front in this field. In congratulating you with my whole heart I express the hope that the energetic attempts you make to eradicate this disastrous disease may be crowned with success.

Secretary Hoskins reported that the plan for junior membership in the AVMA, announced in 1924, had been put into effect with the organization of student chapters at the state colleges of Michigan, Washington, Iowa, and Kansas, and the University of Pennsylvania.

\section{What's in a Name}

A considerable discussion revolved around the adequacy of the term veterinarian; G. A. Dick urged:

You will all agree that the term "veterinarian" does not adequately describe the functions of our profession as it is today and some of our most eminent men believe that, if we could find another name that would better describe our activities or functions, it would greatly assist the public in understanding our activities and our functions.

To this N. S. Mayo replied:

I do not know whether it is possible for us to coin a new word that will express to the average layman the field that the veterinarian occupies so far as his relation to public health is concerned. If such a name could be coined, I would welcome it, but I believe that within a very few years the public will become more and more impressed with the value of veterinary service so far as public health is concerned ... and when these facts are brought more prominently before the public our position will be realized no matter what you call it.

Dr. L. A. Klein, however, states:

I am not ashamed of the name "veterinarian." On the other hand, I am proud of it. The veterinary profession has an honorable reputation which gives any member of it a right to take pride in it. It has accomplished many things not only of benefit to the animal industry but also for the benefit of public health. At the same time I realize that this name "veterinarian" does not describe our work. . . . I 
want the general public to be able to understand the work of the veterinary profession because this understanding is having a very serious effect, in my opinion, upon the present progress of the veterinary profession and it may exert a very serious effect upon its future because this idea prevails, that the veterinarian does nothing but doctor horses.

Dr. Klein thus anticipated the clamor, thirty years later, for disbanding the Veterinary Corps because "the Army had more veterinarians than it had horses." He further relates an account of a student whose family had offered to pay his way through medical school, but demurred at paying any expenses in veterinary school. The author knows of at least one student who worked his way through veterinary school for this very same reason, and of another whose wife divorced him, apparently on this same account.

Dr. Klein suggests, in keeping with the prestige earned by the BAI, that the degree of "Doctor of Animal Industry" might be offered, but "I have not found a name for the man." To this, J. W. Connaway interjects:

I think what we want is more honest-to-God veterinarians, who are not ashamed of the pigpen and the work that they have to do. . . . The public are beginning to appreciate this and we do not want to confuse the public with some new name. . . . They do not stop to consider that this peculiar name isn't exactly fitting for everything. That is true of hundreds of English words which have come to mean very different things from what they were originally coined to mean. So I stand for the name "veterinarian."

Secretary Hoskins apparently had been holding the trump card, for he neatly terminates the discussion with "a sort of preliminary report" of the Committee on Policy:

It is suggested . . that it is not advisable to make any change in the name of the veterinary profession or its allied organizations. In the interest of the veterinary profession and the public at large, it is urged that a modern and comprehensive definition of the term "veterinarian" be made in keeping with the activities which come under the domain of the profession at the present time.
Noting that the matter of a change of name "has been taken both seriously and otherwise by the public," Dr. Hoskins editorializes:

Even if nothing comes of the proposal, the veterinary profession has certainly been the gainer as the result of the publicity that has been given the subject by the press throughout the country. It is doubtful whether the same amount of publicity could have been obtained in any other way.

In observing that the real motive undoubtedly was a desire to divorce the connotation of "horse doctor" from "veterinarian," he suggests:

It would be easier to give a modern, up-todate definition to the word "Veterinarian" than to adopt a new word and then have to explain its meaning. ..."That is the new name for veterinarian." ... Not so long ago a delegation of morticians - they used to be known as funeral directors - were taken for a group of brick-layers.

A widlely-reprinted newspaper editorial urged:

It is most unfair to a conscientious veterinarian, trained at much expense for a service of great importance, to make him the butt of cheap horse-doctor jokes. His professional value is beyond question. It is entitled to respect . . . but there is a lack of earnestness upon the part of veterinary surgeons to "sell themselves" to those who need their service and the public in general.

On the lighter side, the Cleveland Plain Dealer answers "What Shall We Call 'Em?" with:

Vets do not like the name Vets;

"Hoss Doctors" is passé;

What are we going to call 'em? Let's

Decide it right away. ...

Beastosophist? Livestockopath?

Catleech or Cowropractor?

Dogmatophist? Philhippomath?

Pighealer? Mulofactor?

These hit at specialties - and yet

They ought to, for the fact is

No up-and-coming modern Vet

Would touch a general practice.

On this matter, perhaps the best suggestion comes from John A. Kolmer, M. D., an honorary member of the AVMA, in an 
address on "The Relation Between the Medical and Veterinary Professions." Dr. Kolmer urges:

The time has arrived when there should be a wider and deeper acknowledgement and appreciation of your special qualifications for public health and laboratory careers in human medicine. Indeed if the present plans for abolishing the degree of Doctor of Veterinary Medicine should meet with success because of it inadequacy, I would suggest the degree of Doctor of Medicine in Animal Diseases as a substitute for showing that you are first and foremost doctors of medicine, with special training in the diseases occurring among the lower animals, several of which are transmissible to human beings.

Dr. Kolmer notes his choice of Fred Boerner for an assistant professorship in bacteriology and clinical pathologist in the Graduate School of Medicine of the University of Pennsylvania:

At no time have my students, all graduates from the best medical schools in the United States and some foreign countries, questioned his teaching or the propriety of having as a teacher a V.M.D. man. Nor have the staffs of the hospitals, composed of the leading medical and surgical experts of Philadelphia, ever questioned the propriety of my selection. And when I needed a good research bacteriologist for the Research Institute of Cutaneous Medicine I selected Dr. Malcolm J. Harkins, also a graduate in veterinary medicine. . . Furthermore, the first steps have already been taken for the admission of properly qualified V.M.D. men to associate membership in the American Society of Clinical Pathologists.

\section{T. A. Sigler}

Thomas A. Sigler was born in Clinton Township, Indiana, September 15, 1879, and graduated from the Indiana Veterinary College in 1902. For a time he taught at the Indiana and Terre Haute schools in addition to conducting a general practice, and in 1904 moved his office to Greencastle, Indiana, where he became active in civic affairs in addition to conducting a nationally-known practice for more than half a century. His intensely practical ideas resulted in his being much soughtafter for lectures and demonstrations at association meetings and clinics.
Dr. Sigler served as president of the Indiana VMA (1911-1912), and was elected AVMA president in 1926. He died on June 24, 1957.

\section{PROSPECTS FOR PREVENTIVE MEDICINE}

The 1928 meeting at Minneapolis broke all previous attendance with a registration of over 1,400. In his presidential address, Reuben Hilty urged:

Unless the practicing veterinarians pay more and more attention to so-called preventive medicine, we will be compelled to bow to state medicine. True, we must depend on state medicine in the handling of outbreaks of dangerous diseases, on account of the authority with which its men are clothed, but unless the practicing veterinarian is himself prepared to render the stockman this service in preventing clisease in his herds and flocks, he will clamor for state medicine.

Past-president D. S. White issued a protest against:

the too common habit of thought which seems to link us closely with agriculture. While to be sure the veterinary profession is an aid to agriculture, it is no more so than any other of the professions. If linked up with anything, it should be with medicine.

In part, Dean White related this to the fact that:

85 per cent of the graduating class in medicine hold baccalaureate degrees, while less than 2 per cent of the veterinary graduates .... can boast of any preliminary education beyond the high school. . . . Medicine is forging far ahead of us because she is in a position to use only the best material. . . . We have failed to guard the portals of the profession. ... [ [We] should look forward to an increase in the entrance requirements in order to fill up the schools with a better educated, more mature type of student.

We cannot continue to take the rejects, the culls, the boys who wanted to study something "higher" and failed and with this material build up a great veterinary profession. Medicine is forging far ahead of us because she is in a position to use only the best material out of which to make physicians. . . In our profession, in part due to the lethargy and sometimes hostile spirit manifested toward increasing the standards of education and the development of the schools, we have failed to guard 
adequately the portals of the profession, with the result that too many of the mediocrity and too few of the superiority are filling in the gaps in the profession caused by the ravage of time. ...

The veterinarian, therefore, who desires to see his profession continue to grow in the appreciation of the people, must become more alert to the needs of the school and use his influence as a citizen and voter to further them. Among other things he should look forward to an increase in the entrance requirements in order to fill up the schools with a better educated, more mature type of student, whose intellectual plane is higher than at present and more on a par with the student in the other professions. He should be more careful to recommend prospective students only when he knows them to be fit. More than once some loyal alumnus has introduced to me a prospective student whose only recommendation was that he had made a failure of everything else. . . . Kind deans of other colleges have frequently come to me with similar offerings in the way of faltering students whom they wish off their hands. "This boy likes horses - he ought to make a great veterinarian."

\section{Past-president and Dean G. H. Glover} suggested:

Perhaps our course of instruction is too strictly professional, that training young men for citizenship is more important than training them in a specialized way for the veterinary profession.

In discussion of the papers by Deans White and Glover, W. H. Feldman doubted "if the rank and file of our veterinary students possess a lower mentality than the average for the rest of the college or university." Dr. Feldman recommended extension of the curriculum to five or six years, doubting the propriety of awarding the D.V.M. for what was really only a baccalaureate degree. Also, the veterinary curriculum should be so standardized that it would be recognized anywhere "as fulfilling all the requirements for admission to graduate work and the full candidacy for the Ph.D. degree."

Papers were presented on rabies control by F. H. Brown and by B. J. Killham, state veterinarians of Indiana and Michigan respectively, in which each noted that the disease had not been brought under con- trol; sheep diseases by E. T. Baker and by Hadleigh Marsh; hookworm in dogs by S. W. Haigler; foreign bodies in cattle by E. E. Wegner; pathology of sweet clover poisoning by L. M. Roderick; transmissibility of tuberculosis by A. F. Schalk; equine breeding diseases by $W . W$. Dimock; anatomy of the dog by J. D. Grossman; pullorum disease by B. T. Simms; hog cholera virus by $H$. C. H. Kernkamp; brucellosis by Ward Giltner; diagnosis of paratuberculosis by W. A. Hagan and Alexander Zeissig; and fecal examination in domestic animals by E. A. Benbrook.

It was decided that the Salmon Memorial Fund, which had been accumulating since the death of Dr. Salmon in 1914, and amounted to more than $\$ 6,000$, should be used for awards to outstanding veterinary students. The first award of $\$ 600$ was made to Erle R. Carter, a junior at Iowa State. The funds which had been collected for a memorial to Dr. J. J. Schmidt, of milk fever fame, were expended for a bust and plaque in his honor at Copenhagen.

\section{R. Hilty}

Reuben Hilty was born in Hancock County, Ohio, in 1878 and graduated from Ohio Northern University. After teaching school for two years, he entered the Ohio State University, and obtained his D.V.M. in 1907. For most of his life he practiced in Toledo, where he was also zoo veterinarian and a noted judge at horse shows. He was a founder of the Ohio Board of Examiners, on which he served for 15 years. During World War I he was assistant chief veterinarian of the $A$. E. F. in France and was the recipient of the Legion of Honor from the French government, retiring with the rank of Lieutenant Colonel.

Active in official AVMA circles from 1917 to 1943 , Dr. Hilty served at various times as secretary of the Section on General Practice and of the Section on College Faculties and Examining Boards, and member of the Committee on Education and 
on Legislation. In 1927 he was elected president of the Association. Dr. Hilty died March 4, 1952.

\section{9}

In his presidential address at the 1929 meeting in Detroit, T. E. Munce noted:

The majority of the veterinary practice laws were enacted at a time when the standard of veterinary education maintained by the A.V.M.A. was lower than at the present.

Therefore, he urged that state boards discontinue examining graduates of approved schools and become primarily licensing boards "until such time as the feasibility of a national licensing board could be determined."

On the subject of disease prevention, Dr. Munce proposed:

The veterinary profession should assume the leadership in matters of preventive medicine. Veterinary researches that will continue to discover defenses against disease should be given more sympathetic and substantial support. ... More of the public funds which are being spent for free veterinary service could to advantage be diverted to veterinary research, and training veterinarians in the use of better methods.

As Chairman of the Committee on History, P. A. Fish reported some progress on the proposed history of American veterinary medicine; he had completed an introductory chapter: "relating to veterinary science from ancient times down to a comparatively recent period." Chapter II was to deal with the beginnings of the profession in America; Chapter III "has already been written by the late Major Schwartzkopf ... [ on ] the history of the Army Veterinary Corps." Also "practically finished" was the history of the veterinary schools, including "complete lists of the alumni of the forty-four veterinary schools ... approximately 19,735 names." Unfortunately, it seems doubtful that any of this material exists today.

On "The Veterinarian's Obligation to the Poultry Industry," H. J. Stafseth, chair- man of the first Section on Poultry, observed:

Intelligent and up-to-date poultrymen are desirous of obtaining efficient veterinary service... The veterinary profession must find an effective way to reach the poultryman with a type of service that he can use with profit to himself and adequate remuneration to the veterinarian.

Concerning the problems of veterinary parasitology, M. C. Hall urged:

Parasitic diseases are approximately as important as bacterial diseases.... [but] with the number of men now engaged in the study of veterinary parasitology in this country it would probably be a matter of centuries to secure satisfactory answers to these questions.

Papers were presented on poultry practice by A. D. Goldhaft, and on fowl pox by F. R. Beaudette; milk fever by P. A. Fish; rabies vaccine by $H$. W. Schoening, and rabies control by T. E. Munce; canine distemper immunization by Adolph Eichhorn; hog cholera virus by C. N. McBryde; and infectious enteritis in swine by $\mathrm{H}$. E. Biester and Charles Murray.

The Society of Phi Zeta, with chapters at Cornell (1925) and Pennsylvania (1928), was organized on a national basis, with V. A. Moore as president; L. A. Klein, vice president; and W. R. Hagan, secretary.

\section{T. E. Munce}

Thomas Edward Munce was born in Washington County, Pennsylvania, April 26, 1877. After attending Washington and Jefferson College, he returned to the farm for five years before entering veterinary studies at the University of Pennsylvania, from which he graduated in 1904. After three years of general practice he engaged in livestock regulatory work, becoming Deputy State Veterinarian for Pennsylvania in 1909 and State Veterinarian in 1919. He served as president of the Pennsylvania VMA and of the U.S. Livestock Sanitary Association.

Dr. Munce joined the AVMA in 1904; he served as the first secretary of the Sec- 
tion on Sanitary Science in 1916, and as a member of the Executive Board prior to his election as president of the Association in 1928. In 1934 he presided at the first session of the House of Representatives. At the time of his election to the presidency, L. A. Merillat cited him as "a tireless worker in behalf of the veterinary profession - not one branch, but all." Dr. Munce died at Harrisburg, Pennsylvania, March 17, 1936.

\section{In the Name of Humanity}

Dissatisfied with the increasing encroachment upon private practice by humane society hospitals, a committee headed by R. S. MacKellar, Sr., had met with a group from the A.S.P.C.A., "and immediately cordial relations were established." The combined group drew up a "Proposed Code of Ethics for Humane Societies and Veterinarians," which was adopted by the American Humane Society in 1928 and by the AVMA in 1929. This called for:

Ioyal cooperation between veterinarians and humane societies ... to avoid conflict with the development of the veterinary profession ... [but] in localities where the veterinary profession is unable or neglects to provide the facilities... it logically rests upon the humane societies to undertake the task.

Humane organizations ... [ shall] use their best influence . . to urge the public to avail themselves of the services of qualified veterinarians ... [ [and] the A.V.M.A. shall use its influence to have introduced into the curricula of the veterinary colleges correlated instruction in the humane care and treatment of animals.

. Humane society animal hospitals and clinics ... [should] offer their facilities to all licensed veterinarians on an equitable basis.

In an address on "Existing Relations Between Veterinarians and the Humane Organizations" in 1930, W. A. Young, of the Boston Animal Rescue League, reports the results of a questionnaire sent to about 150 humane societies. Satisfactory relations with local veterinarians were reported by 93: distinctly unsatisfactory relations by 31. Eight had full-time veterinarians; 19 part-time; 86 had veterinarians on call; 14 were provided with free service by local veterinarians. Nearly all said they could use veterinarians more advantageously; 40 stated they needed additional veterinary service. Frequent complaints were a lack of sympathetic understanding of the mission of the humane societies, and of apparent conflict with private practice.

In calling for more universally cordial relations between veterinarians and humane societies, Dr. Young observes that the latter:

have been markedly responsible for the growth and popularity of the veterinary profession. ... They are continually pounding away at the public, demanding that people provide adequate care, shelter, food and medical attention for their animals. .. . Every humane organization issues one or more publication urging better care for the animals and invariably these publications say: "When your animal is sick or injured, consult your veterinarian."

The subject continued to be of interest, and at the 1932 meeting Raymond J. Garbutt, Chief Veterinarian of the New York A.S.P.C.A., discussed "The Relationship of the Veterinary Profession to $\mathrm{Hu}$ mane Organizations." Noting that the A.S.P.C.A. (established in 1866) had opened its first animal hospital in New York in 1912, Dr. Garbutt observes:

Much of the criticism against humane society hospitals has been without justification. There are veterinarians who even have questioned the right of societies to maintain hospitals. . . [ To 1912] the Society maintained no hospital but ... it soon became apparent that it would be better to build a hospital and to centralize control. A survey showed a few modern hospitals in New York City but most of them were insanitary, dark and altogether unfitted for caring for animal patients. . . .

Most humane hospitals have been opened and operated by veterinarians who served gratuitously in the early periods of formation, but as work increased and the lack of control of free employees became more apparent, the humane hospitals centralized control, employed competent men and remunerated them on a weekly or monthly basis. All large organizations have found this to be the better way, and the societies know it is justified. They can point to the United States Army, which abolished its contract veterinarians for regular army officers, 
to the U.S. Bureau of Animal Industry, which employs about 1,300 veterinarians, and to the large dairy companies, railroads, and express companies, which employ their own veterinarians. Humane societies are surely within the law and certainly have the right to employ their own staffs rather than contract for their veterinary work.

He does admit, however, that some humane society hospitals have overstepped their jurisdiction in performing luxury services in direct competition with private practitioners, but on the whole:

Because of the birth of the humane movement the veterinary profession has been made a better profession. ... An advertising campaign has been carried on relentlessly in behalf of the veterinary profession, which has brought to it prestige, publicity and financial reward, paid for by the humane organizations. 


\section{Thinking in the Thirties}

IN HIS PRESIDENTIAL ADDRESS at the 1930 meeting in Los Angeles, T. H. Ferguson observed:

No one can really appreciate to the full just what the American Veterinary Medical Association means to the veterinary profession of this country, unless he has had an opportunity to gain first-hand information concerning the business of the Association, its contacts, and its ramifications. If more veterinarians could have this opportunity, and would take advantage of it, our resident secretaries would not have such a hard time securing new members, and there would be dispelled any doubt that might remain in the minds of any of our members as to the desirability, not to mention the necessity, for increasing our income.

\section{PROFESSIONAL ETHICS AND PUBLIC RELATIONS}

Ward Giltner reported that the American Association for the Advancement of Science had requested the AVMA to prepare the program for the Section on Medicine for the AAAS meeting at Des Moines in 1929. The program, which "favorably presented veterinary medicine to the general public and to science in general," included such notables as J. R. Mohler, M. C. Hall, J. G. Hardenbergh, P. A. Fish, C. H. Stange, W. H. Feldman, A. F. Schalk, I. F. Huddleson, C. P. Fitch, W. L. Boyd, and B. T. Simms. The audience, however, consisted primarily of the speakers and the staff of Iowa State:
There is one thing that is very evident and that is that the medical profession is not particularly interested in our problems. .. . The people to whom these papers should have been directed were not in attendance.

A one-paragraph report of the meeting in Science offers a valid résumé of some of the concepts presented:

Because of the number of animal diseases which may be transmitted to man, veterinary medicine is a necessary factor in the care of the public health. ... For the control of these diseases public health officers and veterinarians must work together. Veterinarians contributed largely to the health of the army during the World War by careful inspection of all meat, milk and their products before consumption. The importance of continued study of the parasites of man and the lower animals was emphasized. . . Veterinary parasitology is daily be coming of greater importance.

Papers presented at the Los Angeles meeting included those on pathology museums by W. H. Feldman; rabies vaccine by R. A. Kelser; fur farm problems by $\mathrm{J}$. E. Shillinger; liver fluke investigations by J. N. Shaw; swine erysipelas by Hadleigh Marsh; bull fertility by C. R. Donham and B. T. Simms; bovine cervicitis by H. E. Kingman, Sr.; and avian coccidiosis by $\mathrm{H}$. J. Stafseth.

\section{The Good Old Days}

Writing in Veterinary Medicine in 1930, the sharp-witted E. T. Baker offered some 
pointed remarks about "the veterinary supply house," for the benefit of those who perhaps still talked longingly of "them good old days":

In those days, the veterinary practitioner had to work out his own salvation. Several of the larger pharmaceutical houses devoted a few pages in their catalogs to veterinary supplies, which they kindly sold to the stockman or layman at the same price charged veterinarians. Blackleg biologics were distributed by the government as freely as garden seeds, and they also compiled several veterinary textbooks on horses and cattle to help obviate the need of the services of the graduate practitioner. In fact, it has been only within the past few years they learned of the existence of the private practitioner.

Proprietary medicines were sold in every country store, and later on, distributed from wagons or autos by agents. County agents, in their endeavors to save the country, jumped in bravely with hypodermic syringes and offered all kinds of free treatment. . . . At the present time the private practitioner has these weapons to fight with: His individual business acumen; his bank account; enough clients with sufficient live stock; veterinary magazines; associations, and supply houses.

We cannot over value the ethical supply house, for it supplies us with the very sinews of practice. It helps us keep a jump or two ahead of the handy stock man who has received a short course at his state college and who is a full-fledged quack. We only wish we had enough business to patronize all the ethical supply houses.

\section{T. H. Ferguson}

Thomas H. Ferguson was born in Linn, Wisconsin, August 18, 1873, near Lake Geneva, the community he served for over 60 years. He graduated from the Ontario Veterinary College in 1896 and returned to Lake Geneva where he established a general practice and became a leader in community affairs. He was a member of the state examining board for many years, president of the Wisconsin VMA in 1911, and in 1929 was elected president of the AVMA, the fiftieth man to hold this position.

Dr. Ferguson's skill in veterinary surgery was internationally recognized; he appeared on programs throughout the United States and Canada-perhaps more times than any other surgeon in history - and for many years no AVMA clinic was considered complete without a demonstration by him. In 1938 he was given the golden key of the AVMA, and in 1946 the Twelfth International Veterinary Congress award. One of his sons was associated with him in practice for 30 years, and another became a physician. Dr. Ferguson died at Lake Geneva on October 12, 1957, at the age of 84 - after a career which few have equalled and none excelled.

\section{1}

In his presidential address at the meeting in Kansas City in 1931, M. C. Hall outlined an aggressive policy for the veterinary profession:

a continuing, comprehensive and constructive policy looking towards the sound development of veterinary medicine in the future ... toward the attainment of the status by the veterinary profession of a learned profession.

Included in his recommendations were a survey of undeveloped areas and activities for veterinary services, increased participation in public health work, civil service status for state veterinarians, a code of ethics "worded in constructive terms of things to be worked for," closer affiliation with groups having mutual interests, adequate financial returns for practitioners, and "an open mind on the subject of state medicine."

For the colleges, Dr. Hall suggested greater flexibility of the curriculum keyed to immediate and forseeable needs of the profession, more emphasis on the conference method of instruction to "assist in developing future leaders," and an enlarged scope of cultural preparatory studies. For the practitioner, he urged, "more cooperation and less competition by the establishment of more partnerships and clinics"; cooperation with county agents in disease prevention; and increased publication of case reports. And "We [ should] give our financial support to commercial houses that conduct an ethical business."

At the governmental level he proposed a general officer for the Veterinary Corps, 
and an entering rank as first lieutenant; a keener interest of the AVMA in federal and dominion veterinary service, with:

steps to develop ... statistical services for providing accurate information as to ... animal diseases in North America ... [and] that closer cooperation be developed ... [ with] the practicing veterinarian.

The AVMA itself, Dr. Hall urged, should admit, not exceeding 20 per cent of the active membership "persons having a doctorate degree in medicine, science, or philosophy." It should also make provisions "for a form of organization under which the business affairs of the Association shall be transacted by a small representative body."

A committee consisting of B. T. Simms, T. H. Ferguson, and O. V. Brumley was appointed to consider Dr. Hall's program; their recommendation, adopted later during the meeting, called for formulating detailed plans for implementing these policies. That Dr. Hall's proposals were sound is evident from the fact that, except for admission of nonveterinarians, practically every point has been adopted in one form or another.

The Executive Board recommended moving the AVMA offices from Detroit to Chicago "using rented quarters in Chicago until such time as it is deemed advisable to build or purchase a home." This move was made in 1932. Regarding a suggestion in 1959 that the still-rented AVMA offices in Chicago be vacated in favor of Kansas City, a dissenter countered: "What about Denver, or Florida, or the West Coast, where visitors to the executive offices can combine a little pleasure with their business?"

Kurt Wagener of Berlin presented papers on foot-and-mouth disease and vesicular stomatitis. Other topics included: dog diets by C. F. Schlothauer; pullorum disease by A. J. Durant, and by H. C. H. Kernkamp; sheep pneumonia by I. E. Newsom and Floyd Cross; anesthesia by E. R. Frank; baby pig anemia by Robert Graham and Frank Thorp, Jr.; anthrax by N. F. Williams; several on brucellosis by C. F. Clark, C. R. Donham, C. P. Fitch, and F. B.
Hadley; lamb diseases by Hadleigh Marsh; salmon poisoning by B. T. Simms; and virus diseases of fowls by C. A. Brandly.

\section{Head Count}

An extensive survey by the Committee on Education shows that in 1931 there were approximately 12,240 veterinarians in the United States, about 1,200 fewer than in 1920. Of these, 76.5 per cent were in practice; 11.6 per cent in federal and 5.3 per cent in state service; teaching, commercial, and municipal work accounted for about 2 per cent each, and Army 1 per cent. At this time only 35 per cent of the total number of veterinarians were graduates of existing schools. The estimated number of nongraduate practitioners was about 2,800 , about 19 per cent of the total. The average age of veterinarians was 43 years, and a conspicuous trend toward fewer very young graduates was noted. It was estimated that 400 new students - of which only 300 would graduate if current figures continued to prevail - would be needed annually if the total number of veterinarians was to be maintained. This would re. quire doubling the average attendance (709) for the decade ending with 1930, or nearly tripling that which prevailed during the mid-twenties.

The distribution of the veterinary population was closely correlated $(.89 \pm 0.02)$ with the value of cattle, less so with horses and swine. A sampling of 608 practitioners in eleven states showed the following percentages of time devoted to the several species: cattle 38 , small animals 24 , horses 19 , swine 14 , poultry 3 , sheep 2 . The amount of time expended on cattle and horses was closely related to the percentage of valuation; the percentage valuation of poultry and sheep, however, was nearly four times the percentage of time devoted to them; conversely the time devoted to swine was three times its percentage valuation. The earnings of 417 practitioners in eleven states ranged from $\$ 600$ to $\$ 25,000$, with a median of just over $\$ 4,000$; the highest quarter averaged just over $\$ 8,000$; the lowest just over $\$ 2,000$. At this time BAI sala- 
ries averaged $\$ 2,800$, teaching salaries $\$ 3,500$.

In an editorial on "State Medicine" in 1931, Dr. Hall notes the objections voiced by the American Medical Association, and observes:

There are various reasons why the veterinary profession as a whole should not take sides in this matter, especially at this time ... a majority vote of the American Veterinary Medical Association could represent only a majority of persons having certain opinions, a sterile procedure unless the Association contemplated a program of active support for or hostility to state medicine.

Noting that the veterinary profession was already considerably involved in state medicine, largely through the BAI, he considers:

By and large our reactions to the advantages and disadvantages of state medicine and private enterprise will be determined by our interest in life, or temperaments, and our training and education. . . . It behooves the veterinary profession to keep an open mind on the matter of state medicine and to avoid committing our profession to a stand on this subject, regardless of our individual opinions.

\section{Hallmark of Ethics}

Writing on "Ethics in Veterinary Medicine," Dr. Hall observes:

We must have a code and ... it presents difficulties in formulation, interpretation and application, [thus ] it is worth while to examine our code from time to time, to refresh our memory as to its provisions, to consider its limitations, and perhaps to modify it.

At the time (1931), the Code of Ethics contained six provisions, to each of which Dr. Hall offers some pointed suggestions:

1. All members are expected to conduct themselves at all times as professional gentlemen: "The word gentleman itself has fallen on hard times and has not the generally accepted meaning it once had. . . Many men feel that there is more honor in being known as a man than as a gentleman."

2. No member shall assume an academic title or degree which has not been conferred upon him by an institution of learning in good standing: "To violate this provision of the code would stamp a man as dumb, rather than unethical."
3. No member shall attempt to undermine or injure the professional standing of another by unfairly or unnecessarily criticizing his professional work: "Where is the borderline between fair and necessary criticism and unfair and unnecessary criticism ... and to what extent is the public entitled to protection against incompetency?" [ These three sections remained essentially unchanged to 1960.]

4. In consultation cases the veterinarian in attendance must give the opinion of the consultant to the client in the presence of all three, or the consultant transmit it in writing to the client through the attending veterinarian, and the consultant must not revisit the patient except by invitation from or by agreement with the attending veterinarian: "The ethical concept here does not seem as lofty as might be wished. . . A sound ethic would contemplate rather specifically the preservation of the rights of all parties concerned, including the veterinarians, the clients and the patients." [ On consultations, the Code of Ethics in force in 1960 was greatly expanded; but the only "protection" offered to clients was "to assure the client's confidence in veterinary medicine." ]

5. [Regarding advertising]: "The provisions of this section are quite habitually violated. . . . The question may be raised as to whether ... the section should be repealed on the theory that dead things should be buried."

6. [Regarding secret remedies]: "There is no doubt but what some veterinarians in practice keep to themselves useful findings.... As far as disciplinary action is concerned, probably little can be done. . . The remedy will lie in the development of a personnel from future veterinary students who appreciate that almost all they have of knowledge they owe to the living and dead who gave it to them."

7. Charges against members for unethical conduct must be presented to the Executive Board: "The code is mostly a statement of things unethical and forbidden. ... It is too negative and lacks the stimulating value of positive and constructive statement. Perhaps it is time to write a new code or in some other way to keep before our veterinary students and the profession the positive and constructive ideas of honesty, integrity, courtesy, courage, tolerance, kindliness, thoughtfulness and good sportsmanship as the summation of ethics. . . In fact the code savors too strongly of the police. ... There is less value in the language of the police court than in these words of Paul: 'Whatsoever things are true, whatsoever things are honorable, whatsoever things are just, whatsoever things are pure, whatsoever things are lovely, whatsoever things are of good report; if there be any virtue, and if there be any praise, think on these things.'" 
While the Code of Ethics had been ammended from time to time since its first adoption in 1866, few changes in fundamental philosophy had been made. However, additions to it - spelling out what constituted violations - had by the late 1950 's converted the relatively simple code of 1866 (about 250 words) into a complex two-page document in fine print. In 1960 a completely restated and compact version of the Code of Ethics was presented, emphasizing that:

exemplary professional conduct not only upholds honor and dignity, but also enlarges our sphere of usefulness, exalts our social standards, and promotes the science we cultivate.

\section{C. Hall}

Maurice Crowther Hall was born at Golden, Colorado, July 15, 1881, and was educated at Colorado College (B.S., 1905), University of Nebraska (M.A., 1906), and George Washington University (Ph.D., 1915; D.V.M., 1916). He worked for the BAI from 1907 to 1916 when he became a research parasitologist at Parke, Davis \& Co. He served in the Veterinary Corps (1918-1919), following which he returned to the BAI, and on the death of B. H. Ransom in 1925, became Chief of the Zoological Division. By 1930 he had published nearly 300 papers, mostly on parasitology and anthelmintics. His discovery of carbon tetrachloride as a remedy for hookworm was a major contribution to public health.

Dr. Hall, who was elected AVMA president in 1930, also wrote in the field of the social and economic aspects of science, some of these papers being recognized as classics of style. He was proficient in nine languages. While he is remembered most widely for his hookworm remedy, perhaps of greater significance is the fact that largely through his efforts, veterinary parasitology was rescued from near oblivion. He died May 1, 1938.

Long an advocate of more attention being given to his specialty, in commenting on "The College Course in Veterinary Parasitology," Dr. Hall had observed in 1922:
It will probably be conceded by most American veterinarians that there is no topic in veterinary medicine concerning which the veterinarian is less informed than the subject of parasitology. ... This is not the fault of the veterinarian or of the veterinary colleges. It is the natural and inevitable historical result of past and present conditions in this country. Since the establishment of the comparatively new science of bacteriology, the engaging study of bacteria and of diseases caused by them had dominated the attention of the veterinarian more or less to the exclusion of the study of animal parasites. The diseases due to bacteria and the filtrable viruses are spectacular and demand attention.... The animal parasites are not so spectacular. . .

For the most part, parasitology in this country has been neglected by the American veterinarian and regarded as a minor and comparatively unimportant topic by our veterinary colleges. ... The sacrificial goat could volunteer or be drafted; someone must teach parasitology, not because of its interest and importance, but to avoid leaving a gap in the curriculum ... anyone who would or must teach parasitology.

On the status of "Veterinary Parasitology in the United States," Dr. Hall claimed in 1929:

Parasitic diseases are approximately as important as bacterial diseases. The bacterial diseases are spectacular, but they are more or less sporadic ... parasites are ubiquitous and most of them are present throughout the year and every year. ... Before the livestock industry can be relieved of many of the losses which it now suffers from parasites, it will be necessary to make extensive surveys to ascertain what parasites are present in this country and where they are prevalent, to work out the life histories of these parasites, to ascertain their habits, to develop effective treatments and to devise satisfactory prophylactic measures to prevent future losses. With the number of men now engaged in the study of veterinary parasitology in this country it would probably be a matter of centuries to secure satisfactory answers to these questions.

\section{2}

At the 1932 meeting in Atlanta, President R. R. Dykstra called for a positive publicity program, observing:

Having had a lowly beginning, the veterinary profession is still made the victim of a type of publicity that is very difficult to contend with. 
He mentions a motion picture which "portrays the veterinarian on a plane far lower than the oldtime illiterate horse doctor," and on protest was told "they had to have a villain, and the veterinarian fitted into their scheme of things."

And in answer to a protest over an insurance company advertisement lauding the medical profession for controlling tuberculosis, but making no mention of the veterinary profession, the president of the company:

stated that he was aware of the services of the veterinarian in the control work in regard to tuberculosis, but the veterinarian still lacked popular appeal, and their advertisements were written with the primary objective of getting the public to read them.

As positive measures for securing deserved recognition, Dr. Dykstra suggests that the USDA identify its veterinarians as "veterinary inspectors" in press releases. Also:

veterinarians in public positions should take every opportunity to appear in a professional capacity before the public. . . Veterinarians in private practice... should not miss an opportunity to present their profession in the various service clubs. ... There are many organizations of women's clubs that are intensely desirous of increasing their knowledge about meat and milk inspection .... [ and] veterinarians have been able to obtain a very high grade of publicity by the publication of carefully worded articles in the agricultural and lay press.

As something of an innovation, he suggests:

The national organization, the state organizations, or possibly our veterinary schools, should at once proceed to obtain phonographic records in which leaders of the veterinary profession would leave an indelible record, in their own words, of some of their activities which, in a measure, have been instrumental in placing the profession in its present more or less enviable, though little known, position. If we had phonographic records by Law, Salmon, Dalrymple, and a large host of others who have passed to the great beyond, how invaluable these would be for the education of our embryonic veterinarians. We should no longer delay obtaining such records from those who are still with us.
In concluding with the admonition: "We should strengthen our morale by a faith in veterinary medicine based upon its high accomplishments." Dr. Dykstra states, "It will do us all good to renew our allegiance to that unofficial code of ethics formulated some time ago by an unknown writer:

To regard my profession as something more than a means of livelihood;

To value character more highly than reputation and truth above popularity;

To be merciful and humane, preventing needless suffering among dumb beasts;

To be faithful and zealous, preventing needless loss to those I am called on to serve;

To guide my conduct by sober judgement and my judgement by a never-sleeping conscience; To be modest and open-minded and thankful for every opportunity to increase my knowledge and usefulness;

To be a co-worker with my fellow practitioners by the mutual interchange of counsel and assistance;

To be true to myself, measuring my own success by the value of the service I render rather than by the fee I receive."

In the first Section on Military Medicine, with D. M. Campbell as chairman, papers were presented by Major R. A. Kelser on improvements in the Army veterinary service; L. A. Merillat on "Reminicscences of the World War"; and N. S. Mayo on "Some Lessons of Peace." In the Section on Small Animal Practice, papers were presented on canine diabetes by $H$. J. Milks; operative care of small animals by C. F. Schlotthauer; canine distemper by A. S. Schlingman; and intravenous therapy by E. J. Frick.

Other presentations included those on acid-fast bacilli by W. A. Hagan and P. P. Levine; erogtism of cattle by J. W. Lumb; agglutination tests for Bang's disease by $\mathrm{C}$. P. Fitch and C. R. Donham; hepatitis of swine by A. H. Quin; foal diseases by W. W. Dimock and P. R. Edwards; acute mastitis by R. B. Little and F. S. Jones; and pathology of Johne's disease by E. T. Hallman and J. F. Witter.

The AVMA offices, which had been moved from Detroit to the Prairie Farmer Building in Chicago, two miles west of the Loop, proved to be inconveniently located and were moved to LaSalle Street. Earlier, 
Secretary Hoskins had noted, "We were not getting the callers we wanted to see, and were getting too many that we did not want to see." He also reported that the AVMA library, which had consisted of one book when he took office in 1922, presently contained some 350 bound volumes. And on the AVMA emblem, the inappropriateness of which had been pointed out by J. M. Arburua: "It is quite likely that we will want to study the advisability of making some change."

\section{R. R. Dykstra}

Ralph R. Dykstra was born at Groningen, Holland, in 1879, and came to the United States at the age of two. He grew up in northwestern Iowa, studied pharmacy, and after several years in the drug business began veterinary studies at Iowa State, graduating in 1905 . He joined the staff at Iowa State becoming Professor of Comparative Anatomy and Obstetrics in 1909. In 1911 he went to Kansas State and became head of the Department of Surgery and Medicine in 1913. In 1917 he was appointed dean at Kansas State, which position he held until his retirement in 1948 . He died May 8, 1962.

Dr. Dykstra joined the AVMA in 1912, and served in numerous capacities prior to his election as president in 1931. Prior to this he had served as president of the Kansas VMA. With the death of T. H. Ferguson in 1957, he became the senior member of the group of past-presidents of the AVMA in terms of longevity since his tenure. Not content with "retirement," Dr. Dykstra remained busy with a variety of professional activities and had long been recognized as one of the leading statesmen of the veterinary profession.

Ever one to be in the forefront of the fight for professional recognition, in speaking in 1925 on "Publicity for the Veterinary Profession," Dr. Dykstra had urged:

The individual veterinarian should be heard more frequently in his own home community than is usually the case. As a class of men, we are too modest. If other professions had to their credit the list of attainments of the veteri- nary profession, it would be constantly dinned into our ears. The individual veterinarian can do no greater good to himself or to his profession than by careful, tactful, judicious statements, at opportune moments, about his profession. It is professionally sinful to be bold or blatant, but being too humble is also to be condemned. . .

Veterinarians in public positions ... must be combatively for the profession. . . . The public veterinarian can stand squarely on his feet when he defends the thought that for the best of the live stock industry it is necessary to employ the trained veterinarian for the control and prevention of animal diseases. It is absurd to admit to the slightest degree that anyone whose training is not along veterinary lines is as qualified to give veterinary service as the graduate veterinarian. . .

The time is fast approaching when our organizations must take a more active part in obtaining desirable publicity for the profession. The profession is not lacking in attainments, but the general public knows little about them. ... It seems to me that our national veterinary organization should look into the matter of disseminating information of a veterinary nature in the same general manner as Hygeia is doing for humans. ... Such a journal, if published, should be sent to all public libraries, high schools, live stock journals, and other fountain-heads of general and live stock information. ... It would give the profession widespread publicity and, in the minds of laymen, place it upon the plane which it justly deserves.

However, a committee to look into the matter of a lay journal had reported at the 1926 meeting:

There are too many journals at the present time... It is an open question whether there is a popular demand for such a journal ... [which ] would have to enter into more or less active competition with numerous other publications already occupying more or less the same field. ... The venture would be a very expensive one ... [and] would have to have an individual editorial staff. ... It is almost impossible to get veterinarians to agree on what kind of information should be supplied to the public. ... Such a journal as is proposed would be doomed to financial failure and . . . it appears to be much better for the present at least to depend upon getting this particular kind of information to the general public through the already existing and established channels of publicity.

Needless to say this ended the matter. 


\section{VETERINARY ECONOMICS}

The depression was the topic of the hour at the 1933 meeting in Chicago. President N. F. Williams observed:

There can be no virtue in attempting to conceal the fact that the veterinary profession is suffering sympathetically the pains of agriculture that languishes in the depths of despair, a victim of the unwise counsel and misdirection of political forces that are no longer manageable.

In reviewing the history of the veterinary profession, Dr. Williams noted that the practitioner has always been the foundation of the profession, and as at various times in the past, veterinary medicine could fall again:

unless the security of its foundation be zealously preserved.... In the present time of stress, the practitioner's most faithful and uncompromising supporters have been the ethical veterinary supply houses and the veterinary journals, which long ago pointed out the danger of temporizing with those whose methods and practices tend to undermine the profession.

In speaking on "Economic Aspects of Veterinary Medicine," J. R. Mohler asserts:

With this and other nations grappling with huge economic problems affecting millions of people, the interests of any group of workers must, of necessity, be a minor part of the entire program.... The value of veterinary work may seem remote to persons who are unemployed, discouraged, and hungry. . . . It is the part of wisdom for veterinarians to adapt themselves and adjust their affairs to the constantly changing order of things. . . . When the value of a normal animal is low, that of a sick animal is naturally still lower. . . Y Yet to cast anchor and wait for recurrence of former conditions invites stagnation.

As new areas to explore, Dr. Mohler suggested poultry practice, and centralized veterinary services - as bot control, and disinfection after outbreaks of disease.

Dr. Mohler explained that many of the activities of the BAI are based upon wellrecognized economic laws. Thus the cost of eradication of foot-and-mouth disease by slaughter is "a very small fraction of what the annual loss from the same disease would be if it were enzootic here." And the risk of introducing foreign diseases by permitting unrestricted importation of animals and their products from infected areas "outweighs the value of such importations."

Urging "It would be questionable economics as well as unsound veterinary procedure to relax any form of preparedness that has proved to be valuable," Dr. Mohler noted that at times it may be expedient to bow to the law of supply and demand. Thus in the hog cholera outbreak of 1926 the demand for serum far exceeded the supply ready for use. The Bureau, therefore, released a quantity of untested serum on the basis of reliable information:

which showed that the risk from untested serum would be much less than the probable loss from cholera if the protective serum was not made and released promptly. . . . It was a case of putting on one side of the balance the risk of distributing untested serum, and on the other side the probable toll of hog cholera that would have resulted from slavish adherence to the regular procedure.

On veterinary education, C. H. Stange observes:

The influence of training on the future interest of the veterinarian is well illustrated by the difficulties in getting some members of our profession, who were educated primarily in diseases of the horse, to interest themselves in diseases of cattle and swine. . . The lack of interest in food hygiene in many sections is undoubtedly due very largely to the fact that the veterinarians as students received little or no instruction in this subject. ... As long as our profession is not crowded there will be no urge for young men with veterinary training to permeate into all the fields which veterinary medicine could best serve.

Not only is the profession uncrowded, but Dean Stange warns of an inevitable decrease in numbers of practitioners unless nearly 50 per cent more students graduated than in the past decade:

At the present time there are very few, if any, graduates from recognized veterinary colleges who are driving taxicabs, attending filling stations or doing any one of a number of other kinds of work not considered even in a remote way as professional. The writer doubts if any of the other professions have a better 
record in this respect than ours. A careful study of the alumni of two of our older and well established veterinary colleges revealed the fact that approximately 96 per cent of the graduates in veterinary medicine followed their profession. This reveals, on the whole, general satisfaction with their chosen profession.

During the depression, small animal practice suffered less than general practice, and numbers of veterinarians gravitated into this area - to an extent that the projected necessary increase in numbers graduated would have to be raised if even only normal service was to be maintained in other than small animal practice.

A feature of the meeting was the presentation of medals to Cooper Curtice and Fred L. Kilborne in recognition of their pioneer work on the role of the tick in cattle fever. In accepting his medal, Dr. Curtice acknowledges:

I am proud to have been the chosen pioneer in your wise policy of recognizing leading accomplishments of members of the veterinary profession, whose labors have been varied and far-reaching, and in so great a volume that there may be many a "forgotten man.". . . I trust that the efforts of this Association will advertise to the world how our veterinarians are benefitting the livestock industry and their part in protecting the food, health and wealth of our country.

Medals had been awarded the previous year to the four fifty-year members, and there was considerable sentiment for continuing this recognition of distinguished service.

\section{Century of Progress}

The World's Fair, featuring "A Century of Progress," was in full swing during the 1933 meeting of the AVMA, and an exhibit of the Pitman-Moore Company and Allied Laboratories, entitled: "A Century of Veterinary Progress," attracted much attention. The exhibit was turned over to the AVMA and was shown in the Hall of Science for the remainder of the season. So successful was this that a major exhibit was planned by the AVMA for the following year. This was to consist of eight dioramas, featuring veterinary education, general practice, small animal practice, sanitary science, research work, food inspection, military medicine, and biological manufacture. These were to be designed with the idea of combatting the criticism:

The general public has no conception of the width and breadth of the field of veterinary medicine, or the scope of the activities which collectively constitute the work of the modern veterinarian.

Speaking on "Progress in the Medical Sciences," C. F. Schlotthauer observes:

As one goes deeply into the history of medicine, one is impressed with the important part that animals have played, and still do, in the transmission of certain infectious diseases to man. . . However, the lower animals did not fail man, for as methods of animal experimentation were developed they were used in combatting many diseases. . . . Continued animal experimentation is essential for the advancement of medicine. However, it is costly. Therefore, it would appear that since man and animal have always been and still are closely associated in health and sickness, physicians and veterinarians could serve mankind better if they were more closely united. . . . Both can profit by observing the other fellow's problems, by exchange of advice and suggestions. . . . It is only by such cooperative work that progress in medicine can go on at reasonable cost and rate of speed.

In discussing "The Business Side of Our Profession," J. C. Flynn cautions:

Many efficient and capable veterinarians fail because they are not good business men, while a quack in the same town may prosper, because he makes up in business acumen that which he lacks in veterinary science. . . The success attained in the conduct of a veterinary practice does not ncessarily depend on one's ability to collect a good fee. He must be able to read and understand the individuals with whom he deals - not only his clients but his employees.

A notable feature of the program was a comprehensive "History of Veterinary Medicine in the United States," by J. M. Arburua, who notes:

The chronicling of historical data seems to be a phase of veterinary literature that has been sadly neglected in this country. It can 
be said, we believe without fear of contradiction, that in no other profession can one be found that knows so little of the history and traditions of his profession as the average veterinarian.

Dr. Arburua's paper can be considered the cornerstone of the present epoch in veterinary historiography.

Papers were presented on oesophagostomiasis by R. E. Rebrassier, and wildlife parasites by J. N. Shaw; Bang's disease by R. R. Birch, and by C. P. Fitch and C. R. Donham; bovine sterility by W. L. Boyd, and endometritis by Otto Stader; swine diseases by Frank Breed, and hog cholera tissue vaccine by $W$. H. Boynton; canine distemper by M. L. Morris, and by A. S. Schlingman; intradermal vaccination by $C$. E. Salsbery; laryngotracheitis by C. A. Brandly; fowl pox by E. L. Burnett; and enterohepatitis of turkeys by L. $H$. Schwarte; abdominal surgery in small animals by C. W. Bower; and gas gangrene in cattle by C. J. Marshall.

The year 1933 marked the death of the last nongraduate member of the AVMA, Thomas Bland, who joined the Association in 1887, and who in 1905 had been instrumental in securing a veterinary practice act in Connecticut.

\section{N. F. Williams}

Nicholas F. Williams was born in Boston, July 27, 1872, although many of his friends considered him Texas born and bred, so closely was he associated with the livestock industry of that state. He graduated from the Kansas City Veterinary College in 1911, following which he practiced in Amarillo for 15 years. In 1926 he was appointed State Veterinarian for Texas, and was reappointed for several successive terms. For a number of years he was a member of the state examining board, and was three times president of the Texas VMA. In 1933 he joined the Jensen-Salsbery Laboratories as manager of the Philadelphia depot of the firm.

Dr. Williams joined the AVMA in 1917, and was a member of the Executive Board prior to his election as president in 1932. He was characterized as being "gifted with a genial personality, is a fluent and forceful speaker, possesses demonstrated executive ability, and is regarded by everybody as a 'square shooter.' "He died in Philadelphia on April 8, 1937.

\section{SMALl ANIMAL PRACTICE AND AAHA}

The American Animal Hospital Association was organized at Chicago, November $9-10,1933$. The first slate of officers included M. L. Morris, president; D. A. Eastman, vice president; and A. R. Theobald, secretary-treasurer. Dr. J. V. Lacroix was director of publicity.

The first meeting was held in Cincinnati, April, 1934, with about 50 veterinarians in attendance. Featured was a five-hour session on the treatment of fractures, introduced by Dr. Robert B. Cofield, a local orthopedic surgeon. Major presentations were made by E. F. Schroeder, of the Angell Memorial Animal Hospital, and by Otto Stader, who introduced "a new feature in the employment of splints and pins for the reduction of femoral and other fractures." The subject of canine distemper was presented by M. L. Morris.

The stated objectives of AAHA were:

To improve the veterinary service and facilities for the hospitalization of small animals;

To protect and promote the professional interests of veterinarians engaged in the hospitalization of small animals;

To improve the standard of instruction for veterinary students in cynology and allied subjects;

To disseminate useful information concerning the health of animal pets among the owners of such animals:

To establish and maintain a high standard of equipment, methods and personnel in the hospitalization of small animals and supply owners of such animals with accurate information as to the availability of such facilities.

In commenting editorially on the organization, D. M. Campbell notes, concerning the dues for animal hospitals, "Sixty dollars yearly is a sizeable fee for a veterinary association and when first enthusiasm wears off, members will ask themselves 
what they are getting for it." Further, some of the standards suggested for hospitals "should afford leeway to the taste of all. . . Will minimum standards be set for animal hospital buildings, equipment and personnel?" These and other questions undoubtedly occurred to others as well. That they have in large part been answered is suggested by W. A. Aitken, who notes a growth in membership from seven hospitals and seven men in 1933 to 370 hospitals and 1,200 men in 1958, the 25 th year of the founding of AAHA. Currently, Association activities include a three or four day annual meeting, and:

approximately $70 \%$ of the member hospitals and at least an equal number of nonmember hospitals are visited annually by an official representative of the association. . . The next quarter century will bring ever greater advancement.

In 1958, however, an anonymous AAHA member asked:

Has the time come to re-examine the whole situation with a view to possible re-orientation? AAHA's growth during the past 25 years has been slow - from 7 charter members to a mere 375 or so at the latest annual meeting. Although the AAHA has fulfilled much of its original purpose, it has had rough going in one of its objectives - the regular inspection of hospitals to encourage maintenance of desired standards of hospital plants, as well as the methods employed. This cannot be done when a majority of the veterinarians who hospitalize small animals are non-members ... because the membership dues are excessively high. . . . Many practitioners are of the opinion that it would be timely to consider dividing the objectives of the founders of AAHA so that the second division could limit its activity to coping with problems relating to hospital plants, whereas the study of materials and methods would be carried out by the original organization. Such a division should result in a potential new membership of 3,000 .

In 1959, Modern Veterinary Practice notes:

It is ironical that the United States, with by far the largest group of small animal practitioners in the world, is today without an association that can represent it in the new International Association of Small Animal Specialists. ... An association open to all veterinarians with an interest in small animal practice is urgently needed. . . Membership in such an organization should quickly reach 7,000 to 8,000 .

Such an American Small Animal Veterinary Association, it is urged, could provide for dissemination of information, legal and legislative counsel, aid in obtaining personnel and in sales of practices, public relations problems, and management counsel, in adclition to other functions. There would be no intent that this organization should encroach upon the established functions of AVMA or AAHA.

\section{Despair Over Dogs}

In 1933, when allegedly a shortage of veterinarians in rural areas compounded the problem of lay vaccination, a committee of the New York City VMA investigated an alleged oversupply of veterinarians in metropolitan areas. The committee report notes that in 1922 there were about 136,000 dogs licensed in metropolitan New York, or about 2,900 for each of the 47 practitioners whose work was at least 75 per cent small animal practice. In 1931 the figures were 291,000 dogs for 126 small animal practitioners, or about 2,300 apiece, a loss of about 600 dogs per practitioner. Thus:

Your Committee feels that with the large number of veterinary students enrolled in the veterinary colleges, many who come from the cities and are planning to enter the small animal field, that a chaotic situation will be brought about unless we take remedial measures. We feel that an influx of these men who will unquestionably enter the small animal field will do a great deal of harm to the practitioners already established and that many of these new men, unable to derive a substantial livelihood from their profession, will of necessity, engage in measures unbecoming to professional men... We believe that there is a great deal of merit in limited enrollment, having in mind the need for the profession and the disadvantages of an oversupply to both the profession and the public.

At the same time, however, Dean C. H. Stange observes:

We have at present approximately 5340 veterinarians from $40-55$ years of age, and by the 
time a high school graduate who decides this year to study veterinary medicine in one of our leading colleges can be prepared and enter the profession, this large group of veterinarians, which is approximately one-half of the profession, will be $45-60$ years of age. From this time on, there will be increasing numbers retiring from active service, and it is readily apparent that the 10 veterinary colleges now in existence will not be able to maintain the present profession, numerically speaking. The next 20 years, therefore, will bring with it a very heavy burden, and it is quite possible that additional veterinary colleges will be established.

It is understandable that urban practitioners would view with alarm any potentional threat to their security, and it may well be that New York City was beginning to suffer from a surfeit of small animal practitioners. It may be doubted, however, that the fullest potential for their services was being realized - and it is likely that some of these same men had earlier chided fellow practitioners for failing to appreciate the possibilities offered by dog and cat practice. Most obvious, of course, is the failure of the above-mentioned committee report to take into account the actual numbers of veterinarians in relation to their age brackets. Also, their reputed "large number of veterinary students" was actually about 1,300, an increase from the 530 enrolled in 1923 , but a far cry from the 2,700 students in 1910 . It may be doubted that veterinarians suffered more than any any other occupational group during the depression years, and perhaps less than most. This appears to have been especially true of small animal medicine.

In commenting in 1935 on the growth of small animal practice, the editors of Veterinary Medicine observe:

While rural practice is floundering to keep its head above water, the small animal branch, unhampered by outside agencies, is developing by leaps and bounds. The small animal group has enlarged its field during the same years and under the same conditions of industrial depression that the large animal group has found it difficult to carry on. While the one was erecting elegant hospitals representing a vast investment, the hospitals of the other have become unoccupied. . . . Rural practice is not a passing occupation, it is simply passing into other hands, the sinister hands of charlatanry. . . The present trend in veterinary medicine is to the place whence it came, and unless thoughtful minds within the profession prevail, the chances of farm animals continuing to receive the ministrations of scientific medicine are not bright. ... For two decades the Agricultural Extension program has fostered quackery in animal medicine. The results are apparent in the decline of veterinary medicine in its field simultaneously with the growth of clinical medicine in a field it has not reached - the petanimal industry.

\section{VETERINARY MEDICINE: AGRICULTURAL OR MEDICAL?}

The inevitable lessening of practice during the depression, however, abetted in rural areas by increasing lay encroachment, led to an investigation of other areas as logical outlets for the services of veterinarians. It is of some interest to note that the journals which earlier had vociferously proclaimed that service to agriculture was the only legitimate objective of veterinary medicine began to question this philosophy.

Thus in 1933, Dean C. H. Stange observes that the circumstances leading to the establishment of the state veterinary colleges:

has led many to feel in the past that we were a part of agriculture, and in some cases we were regarded as an agricultural science, when, as a matter of fact, we are dealing with a medical science and should always have been recognized as a branch of those sicences. This is in no wise a criticism of agriculture; rather it should be considered a criticism of veterinary science in that we have not, to the greatest possible degree, brought medical sciences to bear upon the problems in agriculture. . . . I do not mean, as some have interpreted, that we should divorce ourselves from agriculture or decrease our interest and concern; but I am sure we can be of greater help in the solution of these problems if we develop our fundamentals of education in the field of medicine.

\section{In 1934 Veterinary Medicine editorial-} izes:

The veterinary profession has long been interested in public health, but its employment in this work so far has been only in special fields and somewhat disconnected. . . Every major success that veterinary medicine has 
scored in disease control and eradication has been wrought over the protest and in spite of the violent objection of the agricultural leaders. . .

The most wide-spread disease of swine in this country is hog cholera. Our experience with it dates back 100 years. . . Measures for the control of this disease never have been in the hands of veterinarians. . . In Canada, hog cholera control has always been a strictly veterinary matter. ... The cost of hog cholera to the farmers in the United States is, and has been for 15 or 20 years, $\$ 500,000$ per million animals ... in Canada it has been $\$ 175$ per million animals. In other words, under agricultural control, hog cholera costs American farmers 3,000 times as much per animal as it costs Canadian farmers where the control of the disease is wholly in the hands of veterinarians. ... .

Veterinary medicine is a medical science, not an agricultural science. The handling of animal disease is a medical - a veterinary medical - problem. Agricultural science is outside its field when it attempts to direct it and must inevitably fail.

In "Some Thoughts on Human and Veterinary Medicine," however, L. A. Merillat in 1935 challenges the concept that the two branches have much in common:

The family physician is about as useful in the hog lot as the veterinarian in the bedroom, and as medicine advances, therapeutics becomes too eclectic for the veterinarian to look no farther into his art than the conventional practices and prescriptions of the family physician... Canine medicine is one thing, equine medicine another, and human medicine is foreign to both. . . "Good for man and beast" belongs to the era of quackery. Nutrition alone disqualifies that platitude. . . .

Except for the basic knowledge animals furnish and the etiological role they play in human medicine, the gap separating the one from the other widens rather than closes with the march of medicine. . . . The fundamental generalities of medicine are feeble concepts when one is confronted with a problematic syndrome or puzzling disease, peculiar to a certain species. . . The lesson is that veterinary medicine must develop from its own investigation. If it cannot lead or at least parallel human medicine it does not deserve a place above the rank of second fiddle. . .

Because human and veterinary medicine are coming to a better understanding through the role played by animals in public health it has been proposed that veterinary medicine cultivate a closer study of human medicine by adopting man as the type species. . . The reverse would be more consistent. Human medicine is more obligated to make a study of animal medicine than is veterinary medicine to study the human clinic. . . There can be no gain in burdening the already over-crowded veterinary curriculum.

But in the same year, in asking, "Does the training of the veterinarian fit him peculiarly for protecting the health of the public in rural communities?" Ward Giltner states:

The answer is emphatically and unhesitatingly, yes.... If his community needs his services he cannot afford to refuse a position on the board of health, as health officer, meat or milk inspector, sanitary inspector, or any other position for which he is qualified and the duties of which do not render him less efficient in his practice... If he wishes to take the position of leadership in the public health service he should take post-graduate work in a school of public health. ... However, I do not visualize the veterinarian as the inheritor of the overwhelming control of rural public health work. He should always do those jobs for which he alone is trained and he should offer strong competition for those for which he is well qualified as are the members of other professions... The veterinarian must concern himself not only with the treatment and prevention of animal diseases, but also with the protection of human health when it is menaced by those diseases. He has a duty to inform himself fully as to the relationship of the animal and the human disease and without ever encroaching upon the prerogatives of the physician, to take such steps as will prevent the spread of the disease from animal to man or advise as to the available treatment where man has contracted the disease. ... In a narrow sense a physician is interested in human disease not human health. Certainly a veterinarian has only an academic interest in human disease but a deep and abiding interest in human health.

\section{New Fields To Conquer}

In speaking of "New Opportunities for Veterinarians" in 1933, H. H. Magens observes:

Conservation is emerging from the barbershop and poolroom stage and is about to enter a scientific stage of development. . . The idea of scientific management of wild life is just beginning to seep into public consciousness.... It behooves the veterinary practi- 
tioner to take advantage of this new trend of thought and to familiarize himself with these activities which not only are very interesting from a professional standpoint but may be made very helpful in establishing the value of professional veterinary service amongst sportsmen. . .

Of recent years, our conception of the importance of infectious diseases and parasitisms as destroyers of wild life has undergone revolutionary changes. . . . Ticks last winter killed more moose in Northern Minnesota than did hunters. . . . "Alkali disease," possibly botulinus intoxication, kills more wild duck in the northwest than the migratory birds law preserves. ... Disease is a veterinary problem and the success of the scientific management of this enormously important natural resource of our country awaits its solution.

And in 1936, H. J. LaDue, editor of the American Fur Breeder, in writing on "what fur breeders expect of the veterinarian," observes:

I doubt whether 10 per cent of the 9000 practising veterinarians of the United States have had any contact with the fur breeding industry or are acquainted with its history and development. . . Here is an animal industry that merits the attention of every veterinarian. .. . Some of the most successful fur breeders in the United States are veterinarians.

Mr. LaDue mentions that the first silver fox ranch in the United States was established in 1910; in 1936 some $\$ 50,000,000$ were invested in fur ranches:

There are many unsolved problems in fur farming. The solution of these would be greatly accelerated if veterinarians throughout the country were in closer contact with our industry.

\section{B.S.A. vs. D.V.M.}

Throughout 1933 Veterinary Medicine waged unceasing war on county agents who engaged in veterinary practice. In November, 1932, the AVMA special Committee on Agricultural Extension Service had submitted a comprehensive statement of the situation to a congressional committee, detailing claims that the veterinary profession renders an essential service to agriculture; that the Federal extension service cannot render this service; that county agents sell veterinary medicines and engage in the practice of veterinary medicine in violation of the Smith-Lever Act; that as a result "many veterinarians have abandoned their practices and have sought employment in the Bureau of Animal Industry ... [ or ] in other fields of endeavor"; and that continued activity of the Federal and State extension services in the field of veterinary practice:

will result in depriving agriculture of a veterinary service which is indispensable to its existence on the present scale and on the plan now followed in this country.

Dr. D. M. Campbell notes:

The issue between the veterinary profession ... and the agricultural extension services of numerous states is joined. The veterinary profession has stated its position officially. The outcome is not readily predictable. . . . It is the conviction of the A.V.M.A. Committee that the interference with veterinary practice on the part of the agricultural extension services, bad as it is and extensive as it has been, has only begun in comparison with what it is the settled intention of these services to accomplish. Unquestionably a drive is on to exempt county agents from the provisions of the veterinary practice act in each state of the union. This drive has already succeeded in North Carolina and Nebraska.

In testimony before the same congressional committee, D. F. Luckey, Executive Secretary of the Illinois VMA, amply documented his charge that in the guise of saving the farmer money, the extension service in his state was spreading hog cholera and making a profit on treating the disease. He cites a number of instances in which serum was sold to farmers at markups ranging from 50 per cent to as high as $871 / 2$ per cent. These same farmers had, in effect, paid a share of the county agent's salary and the overhead of the extension service, paid for the serum purchased by the county agent - and then bought it from him at a substantial markup. To be eligible to participate in this scheme, each farmer was charged a fee of $\$ 15.00$. Dr. Luckey concludes:

The farm advisers distribute virus to incompetent vaccinators who spread hog cholera. 
Then the farm adviser sells more serum and virus. This system keeps hog cholera prevalent and the hog raisers in continual danger of hog cholera so that they are pressed to pay $\$ 15.00$ a year each into the farm bureau so that they can buy serum and virus to further spread hog cholera. It is a reasonable estimate that through the farm adviser's activity, hog cholera and the added expense of vaccination is costing the hog raisers of Illinois at least $\$ 300,000$ annually more than is necessary.

Dr. Luckey, whose integrity was above reproach, further testified that one veterinarian had been coerced into joining the farm bureau (at a cost of $\$ 15$ ) by the threat "they would have to recommend his veterinary practice, in a certain section where they controlled, be given to another veterinarian," and that another had joined only to find the county agent a few days later teaching farmers to vaccinate their own hogs.

Not all county agents, of course, were guilty of these practices, nor does it appear that an outright invasion of veterinary practice contemplated as a formal policy by the Federal Extension Service. In fact, at the time of these hearings, $C$. W. Warburton, Director of Agricultural Extension, USDA, made the deposition:

County agents are not trained veterinarians. When they enter the diagnostic and treatment field of animal diseases the farmers are not getting the best service. Yet such service by publicly paid employees may cut into the practice of the professional veterinarian and make it impossible for him to live.

Dr. Campbell's urging that the extension service be "exterminated" evoked this rebuttal from K. L. Hatch of the extension service in Wisconsin:

Whatever may be the grievances between county agents and veterinarians elsewhere it is not so in Wisconsin. . . . I am sure that veterinarians no more care to see the county agent abolished than the county agents desire the destruction of veterinarians.

As proof of his contention he points out the close cooperation of $W$ isconsin veterinarians and county agents in testing for brucellosis. While admitting that the situation was not as bad in some states as in others, Dr. Campbell continued the battle, exposing instances of county agents engaging in veterinary practice, and running a series of provocative cartoons designed to discredit this activity.

For several years the Associated Serum Producers had been doing yeoman service in promoting the veterinary profession among hog farmers through advertisements in the leading farm papers. In "A Study in Contrasts" in 1934, Veterinary Medicine reprints an advertisement of the Associated Serum Producers beside a letter sent to county agents by a nonmember firm. The following excerpts speak for themselves:

You can take the risky short cut of home diagnosis and amateur vaccination - or you can profit by the experience of the most successful farmers and swine owners who have found qualified veterinary service indispensable. . . Be safe call your veterinarian.

Today farmers universally vaccinate and treat their livestock themselves. This eliminates the cost of veterinary service. County extension agents are our dealers. Should you have any condition in your livestock you do not understand, we invite you to write us.

The problems of lay treatment with potentially dangerous medications and the like, of course, have not been solved to the satisfaction of veterinarians - or the safety of the public - but the matter of encroachment upon veterinary practice by county agents and other governmental employees is nothing compared to what it used to be. In many areas, county agents are enthusiastic supporters of adequate veterinary service - by veterinarians - but this traditional antipathy has tended to obscure the situation in some cases.

\section{4}

The program of the 1934 meeting of the AVMA was conducted jointly with sessions of the Twelfth International Veterinary Congress in New York City. Dr. J. R. Mohler was unanimously elected president of the Congress, at which delegates from 61 countries were present. A few of the distinguished scientists from foreign countries were Minett and Hobday of England, 
Wall and Forssell of Sweden, Wagener and Ostertag of Germany, Leclainche, Guerin and Ramon of France, Marek and Manninger of Hungary, Gerlach of Austria, Frei of Switzerland, and Kral of Czechoslovakia. Other countries represented on the program were Italy, Rumania, Brazil, Uruguay, Denmark, The Netherlands, U.S.S.R., Tanganyika, Union of South Africa, Spain, Poland, Bulgaria, Scotland, Egypt, and the Dutch East Indies, in addition to Canada and the United States.

In his address as AVMA president, C. P. Fitch noted:

This year we are inaugurating an entirely new method of legislative procedure. The House of Representatives meets officially for the first time. . . The functioning of this organization will be directly influenced by those whom it seeks to aid. It can no longer be justly said that a few dominant personalities... dictate the policies of this organization.

At the first session of the House, amendments were initiated to provide for a president-elect (approved in 1935) and for election by mail ballot upon nominations by the House (disapproved); a proposal to add a Committee on Public Relations was later approved, one to admit nonveterinarians as active members was not approved.

Papers presented at the joint meeting by American workers included those on encephalomyelitis by R. A. Kelser; mastitis by F. S. Jones and R. B. Little; psittacosis by K. F. Meyer; coryza by J. R. Beach; hog cholera by Marion Dorset; sterility by $W$. L. Boyd; parasitology by M. C. Hall, and by T. W. M. Cameron; abortion by W. E. Cotton; foot-and-mouth disease by Jacob Traum; paratyphoid infections by Charles Murray; deficiency diseases by G. H. Hart; pullorum disease by $\mathrm{H}$. Van Roekel; leukemia by E. L. Stubbs, and lymphomatosis by F. D. Patterson; diseases of young animals by W. L. Williams; and the relationship of veterinary science to animal breeding and public health by J. R. Mohler.

A post-congress clinic was held at Columbia University with demonstrations of epidural anesthesia by E. J. Frick; ocular enucleation by H. C. Stephenson and H.
J. Milks; circulatory pharmacodynamics by H. H. Dukes and Jesse Sampson; hernia reduction by W. M. Mitchell of Edinburgh; intestinal anastomosis by W. F. Guard; cesarean section by E. K. Sales; blood examination by R. E. Nichols; cecotomy by D. A. Eastman; and fracture pinning by A. R. Anderson.

Dean C. H. Stange warned of an inevitable decrease in numbers of practitioners - and practice - unless graduating classes were increased by at least 50 per cent: "As long as our profession is not crowded there will be no urge for young men with veterinary training to permeate into all the fields which veterinary medicine could best serve." Also, the schools would have to place more emphasis on training in these areas; many displaced equine practitioners had shifted to small animal medicine rather than cattle or swine practice, and there was little interest in food hygiene.

Dr. Fitch recommended several changes in policy for the Journal, in particular, "papers ... which are of limited interest or which are unduly lengthy, either be omitted ... or materially reduced"; and a section of abstracts added:

particularly for practitioners of veterinary medicine. . . . It is not always easy for a person trained in the research field to evaluate properly some scientific papers published in our Journal and other scientific publications.

\section{P. Fitch}

Clifford P. Fitch was born in Oneida County, New York, July 1, 1884, and graduated with honors in mathematics and biology from Hamilton College in 1906, following which he taught high school. In 1911 he received the D.V.M. with honors from Cornell, remaining on the staff until 1917, when he became chief of the Division of Veterinary Medicine at the University of Minnesota. In 1921 Iowa State College conferred upon him the degree of Doctor of Science.

Dr. Fitch joined the AVMA in 1912 and served on the Committee on Bang's Disease from 1919 to 1930 , when he was elected to the Executive Board. In 1933 he 
was elected president of the Association. A long-time secretary of the Minnesota VMA and the State Live Stock Sanitary Board, he played a major role in formulating policies for animal disease control in Minnesota. Among other honors, he was a fellow of the American Association for the Advancement of Science, and a member of Sigma Xi and Phi Beta Kappa. Dr. Fitch died on January 12, 1940.

\section{5}

At the 1935 meeting in Oklahoma City, President R. S. MacKellar urged, "Membership in the American Veterinary Medical Association should be dependent upon membership in and the approval of a local or state association." And regarding the problems of redistribution of veterinarians occasioned by the depression:

The necessity has arisen for reciprocity between certain states, whereby veterinarians in stricken areas can be assisted in reestablishing themselves in other states. ... In this connection .... there is no record of a single case of a veterinarian being on public relief.

On the need for better public relations, Dr. MacKellar states:

There remains yet to be taken a concrete step to bring to the effective attention of the profession and the people the whole question of "veterinary consciousness." To make America "veterinary minded". . . this Association should create a Committee on Public Relations.... As long as we defer in getting our story properly before the people, and the drama of our profession in current events, that much longer shall we continue to shroud our careers in ambiguity in the public mind and narrow our national scope.

Speaking on "The Veterinary Service of the United States," L. A. Merillat charges incompetency:

because it is operated without plan or unified direction. . . . Veterinary quackery of 1935 is more deadly than it was in the nineteenth century. ... The self-made, state-made quacks of this period have had a dangerous arsenal thrust into their hands by public sanction. . . . When the veterinary quackery now growing so strong in the United States drags the veterinary service down to its level as it is certain of doing, even the spectacular plagues of known history can return to complete the job of the smouldering panzootics of this hour. Diseases of animals that once destroyed great nations can destroy great nations now. ...

What is the remedy? ... when the American Veterinary Medical Association has formulated a plan for erecting a faultless veterinary service for the American people and all groups use their influence to put the plan into operation, the troubles of the veterinary profession will begin to lessen. . . . The veterinary profession of the United States is confronted with conditions that must first be understood before organized veterinary medicine can fulfill its obligations to its members and to society.

Secretary Hoskins reported that 47 state associations (Idaho and the District of Columbia did not have associations) had affiliated with the AVMA, and the Ontario Association had taken favorable, but not final, action.

Grading of the veterinary schools was urged by Dr. MacKellar, to comply with an Army ruling that candidates for reserve commissions must have graduated from a Class A school. Col. R. J. Foster, however, reported that the stipulation had been changed to "a recognized school," thus taking considerable pressure off both the AVMA and the schools.

In an early report on artificial insemination in cattle, H. E. Kingman, Sr., stated he had been practicing this technic for some time at the Wyoming Hereford Ranch, "but the results are far from satisfactory." Cassius Way, working with dairy herds, reported 40-50 per cent success. E. R. Frank noted that a student at Kansas State had artificially inseminated a dog.

Among the papers presented were those on brucellosis control by A. E. Wight; swine erysipelas by $T$. W. Munce; periodic ophthalmia by Alexander Zeissig; demodectic mange by M. L. Morris; hydrocephalus in dogs by C. F. Schlotthauer; and dextrose therapy by Otto Stader.

Papers on poultry subjects included fowl leukemia by M. W. Emmel, and fowl paralysis by R. Fenstermacher; swine erysipelas in turkeys by F. R. Beaudette and C. B. Hudson; treatment of caged birds by 
Cliff Carpenter; and viral diseases by C. A. Brandly.

\section{R. S. MacKellar, Sr.}

Robert Stuart MacKellar, Sr., was born in Edinburgh, Scotland, July 12, 1875, and came to this country while very young. In 1894 he graduated from the New York College of Veterinary Surgeons and began practice in New York City. Except for two years at Nyack, New York, he has continued in this practice for more than 60 years, the last 30 plus in association with his son, R. S. Mackellar, Jr., (Cornell, 1928).

Dr. Mackellar joined the AVMA in 1910, was elected to the Executive Board in 1927, and was Board Chairman (19311934) prior to his election as president of the Association in 1934. Since then he has maintained an active identification with AVMA affairs. He was secretary of the New York City VMA for nine years, and was three times its president. He also served as vice president and president of the New York State Veterinary Medical Society.

\section{RETROSPECT AND PROSPECT}

In 1932 Fritz Volkmar had called attention to:

the anomaly that veterinary history is not taught at any of the American veterinary colleges; presumably from the mistaken notion that the veterinary profession in this country has no past. While it is true that veterinary history here is still in the making, nevertheless, the veterinary profession of North America has a glorious past of which it justly may be proud. At the present time, when the sentiment is for lengthening the veterinary curriculum to provide for broader cultural training of veterinary students, the inclusion of a lecture course on veterinary history may well be given serious thought by those in charge of veterinary education.

And in an editorial on "A Far-reaching Omission in Veterinary Training," L. A. Merillat in 1935 charges:

It is customary and orthodox to complain that the veterinary profession is not under- stood and not appreciated. Unfortunately this is true, but not more so by the public than by veterinarians themselves. On that account, treating the ills complained of is apt to lack logic. . . The veterinary profession of the United States is building alongside, not upon, the right foundation and continues to do so because too few of its personnel have ever qualified in the history of what it represents. No one on the outside can be expected to know more about our enterprise than we ourselves know about it.

The medical profession has been placing its case intelligently before the people since time out of mind. How it dotes on Hippocrates, Galen, [et al. $]$. . . to emphasize how unfortunate mankind would be but for the blessings these men have brought! The same program is employed for veterinary medicine in all of the important countries except for the United States. Here we reap as we have sown. . . . Our work lacks the background that only a better knowledge of veterinary history can consecrate.

Broadcasting about scientific discoveries and stamping out foreign plagues is helpful propaganda, but what good can that accomplish if the public does not know to whom it is obligated for the achievement? Remaining entirely ignorant of the principles that compel nations to maintain a veterinary service of the highest possible order, that they may not perish from loose attention to a fundamental resource, is a gap to fill. . . Repairing a house can be done better if one knows its make-up.

The years 1933-1935, however, are notable for the number of contributions to the history of American veterinary medicine. Dr. Arburua's initial effort in 1933 is noted elsewhere as the cornerstone of this period of historical endeavor. In 1933 A. T. Kinsley presented "A Century of Hog Cholera," also noted elsewhere, and in 1934 J. P. Foster, "Some Historical Notes on Contagious Pleuro-pneumonia." In 1934 William Moore, L. J. Faulhaber, and J. H. Brown published a 54-page Veterinary History of North Carolina, and in 1935 a 225-page History of the School of Veterinary Medicine of the University of Pennsylvania, 1884-1934 was published on the occasion of its fiftieth anniversary. And in 1935 L. A. Merillat and D. M. Campbell's monumental two-volume Veterinary Military History appeared. This was characterized by Dr. Arburua as: 
the outstanding veterinary contribution of the decade. . . This new work fills a gap in American veterinary literature which, until now, has been incomplete. ... As true historians, they have attempted to present bold, ungarnished facts, with a minimum of bias, and it may truthfully be said that they have succeeded, although facts frequently were embarrassing. . . The title is misleading. Although the work covers the military aspect the more completely, nevertheless it gives us, by far, the best available work on the civil veterinary history of our country. . . . It is hard to conceive of anyone in or out of the profession who would not benefit by its reading.

In $1935 \mathrm{~J}$. R. Mohler presented a paper on "Fifty Fruitful Years in Veterinary Science," in which he lists as the principal fruits of veterinary endeavors:

1. A successful conquest over fear. 2. Contributions to public health. 3. Improved economic stability. 4. Humane treatment of animals. 5. Industrial development. 6. A better international understanding looking toward world peace.

Dr. Merillat however, summarizes the current status of "The Veterinary Service of the United States," amplifying his contentions with historic fact:

Nowhere is there any evidence in American history that a veterinary profession of the orthodox sort was wanted, except by the practitioners. . . When the American Veterinary Medical Association has formulated a plan for erecting a faultless veterinary service for the American people and all groups use their influence to put the plan into operation, the troubles of the veterinary profession will begin to lessen.

Dr. Volkmar's desire to see history taught in the veterinary colleges did not materialize, and in 1935 H. P. Hoskins editorializes:

A student can complete his course at almost any veterinary college without learning very much about the history of his profession, or even the names of more than half a dozen veterinarians prominently identified with the profession. This is not true of medicine. Nor is it true of law. Why should it be true of veterinary medicine?

Concerning "The Value of History," Dr. Merillat observes:
If what has gone before in one's occupation does not amount to much, neither does the diagnosis of disease amount to anything in its treatment. . . . It is plain stupidity for the veterinary profession to trek and stumble along handicapped by public ignorance of its contributions to human welfare as it has done so long in this country because even the leaders are indifferent to: (1) The extent to which veterinarians have made the world a safer place in which to live; (2) the extent to which they have amplified man's food, clothing and pleasure; (3) the extent human diseases have been curtailed through their achievements; (4) to what extent the industries have been promoted under their watchful direction; (5) to what extent human and animal suffering has been attenuated by their scientific discoveries and the utilization of them; (6) to what extent human welfare rests upon their daily work; and (7) to what extent man's present setup was made possible through the progress veterinary medicine has been able to make in spite of a general misunderstanding of its objectives and obligations inside and outside of the profession.

Anyone who has read this far might well consider his interest as silent testimony to the fact that the urgings of these men nearly a generation ago have borne fruit. Certainly the several enthusiasts who have sparked the recent resurgence of interest in history would not claim to have invented the subject. And while there is some merit in editors and publishers printing what should be least be a matter of record, the fact is that veterinarians are reading more history than ever before, and stuclents are having an increasing opportunity to study the subject.

\section{6}

In his presidential address at the 1936 meeting in Columbus, Ohio, J. C. Flynn urges:

If we are to serve the country well, we can do so only by keeping our colleges abreast with the progress of medicine. . . When the American Medical Association was organized in May, 1847, medical education in the United States was a farce ... comparable to that of veterinary medicine, when this Association was formed in 1863. . . However, during the last decade of the 19th century, great progress was made in the educational systems of both professions. . . Today. . . graduates come out of the colleges well trained in medicine and surgery, but with very little conception of how to 
associate their training with the many problems they meet in their chosen field. . . I I believe no student should be given a diploma to practice until he has had at least one year with a good practitioner....

Food inspection is one of the undeveloped fields of American veterinary medicine ... A gigantic system of food inspection would not be costly, and it would pay good dividends to agriculture in consumer confidence and the people in terms of better health. Expanding the veterinary service to that extent would, however, require a larger personnel than we have now. . . . The number required is limited only by the amount of service the profession is resourceful enough to develop.

News items in the Columbus papers at the time of the meeting mention:

The mere fact that this is its seventy-third yearly meeting shows that it has had a long line of progress and an important place in the professions that have to do with the curative and preventive arts. . . These two groups [human and veterinary medicine] have much in common in the fight to prevent the spread of disease, whether it be in our food supplies or in our bodies.

However, in speaking on "The Bridge of Goodwill," Samuel R. Guard, editor of Breeder's Gazette fires a salvo point blank at the veterinary profession:

The charlatan, the deceiver, the herb-doctor, the cheater is in your midst . . another Augean stable that needs a modern Hercules. Animal Husbandry, no less than human kind, has to deal with quacks, fakers, and "medicine men" who would fatten on the diseases that terrorize us.

\section{Thus he notes that Dr. Roberts'}

Uterine Capsule for slow breeding cows consists of sodium bicarbonate, sucrose, starch, cereal tissues and some dried yeast ... [ [and ] I learn that my old friend Frank B. Graham, will teach me, i.e., he will teach anyone "who can read his own writing and has fair hearing," how to treat barren cows and by inference how to conquer Bang's disease. ... In fact, he offers the hope to any owner of aborters that his students will buy such cattle, and he infers that his method will cure them. . . Anyone who condones such a practice is a menace to the animal industry. . . I am dismayed to contemplate the horror and destruction that follow in the wake of this nefarious business.
Those who are not aware of the methods employed by Graham to discredit the veterinary profession will be interested in Mr. Guard's description:

When he holds a school, Mr. Graham surrounds it with the mummery that you would expect after reading his advertisements and his catalog. He makes every student raise his right hand and swear that he is not a veterinarian. Because the vets are trying to close him up! He instructs the boys not to take any notes, because they can't keep up!

"Does everyone here understand that he is not to tell what he heard or saw?" the president of the "Graham Scientific Breeding School" inquires pertinently as he collects the 50 bucks. Then the next day he asks all the boys to stand up who will agree to take this oath: "On the honor of a gentleman, I promise not to teach anyone what I have learned in this school." It is not exactly the oath of Hippocrates, but it serves the purpose. Then he asks you to look around and see that everyone is standing. So he concludes with this benediction: "If you believe in these men you saw standing and in Almighty God you cannot betray. Neither can you betray ten thousand other breeders who have taken this course."

\section{Guard continues:}

I want to build a new bridge of goodwill between the veterinary profession and the live stock industry. . . I could read you letters which you ought to consider with care. They would show you what's wrong with your profession. They would tell you of veterinarians who presume to cure barren cows. Of veterinarians who charge unconscionable fees. Of tightlipped, narrow-minded veterinarians who maintain the supercilious high and mighty attitude of not telling the farmer anything for fear he will do his own veterinary work, not even the simplest principles of sanitation or animal hygiene for fear the live stock won't get sick and make a fat fee for the local veterinarian. ...

Can we get together?... These enrollments in the Graham School, and these uterine capsule sales, and the vivid correspondence from the field defending Mr. Graham's purpose and methods, all indicate what? They indicate a yearning hunger for something that we have not supplied. They show a demand that is very insistent. Let us supply it. . . I myself, as a live stock editor, have suggested and I reiterate it now, that every important live stock county in America should have a live stock agent, who should be a trained veterinarian as well as an animal husbandman. . . . In my layman belief your code of ethics is not a veterinary code, it 
is a medical code, copied from the M.D.'s. You should sell your work to the public. You should build the bridge of goodwill between the veterinary profession and the livestock industry. An American Veterinary Institute - as a free will information service to your brother stockmen - would do it.

Concerning "The General Practitioner," past-president T. A. Sigler notes:

It was through the services of the general practitioner rendered to our beasts of burden, the horse and the ox, that veterinary science had its birth. ... Has the general practitioner been somewhat forgotten in the advance of the profession? ... Has the practitioner neglected his opportunities for pushing the profession forward? The small-animal practitioners. . . . have pushed their business, increased their facilities, modernized their hospitals, until they are quite as efficient as those who handle our human patients. ... It is up to us in general practice to improve our methods in every way we can and try to make capital out of handicap, by seeing to it that every sanitary measure and precaution is taken... Asepsis and anesthetics ... have robbed the handling of large animals of some of its hazards. . . We must not fall into the rut of slipshod fashion of merely getting by and trusting to luck.

After a spirited discussion, a proposal to grade the veterinary colleges as Class $\mathrm{A}, \mathrm{B}$, or $\mathrm{C}$ failed of adoption. However, a report of the Committee on Education outlining criteria for a Class A school was adopted for consideration "in connection with any future classification." This called for "suitable facilities," a staff of 17 veterinarians for a school with 200 students, one preveterinary year, and a four-year curriculum with specified minimum times devoted to each of 12 subject areas. In retrospect on the subject, L. A. Merillat noted that the AVMA:

has often hesitated but never erred in the making of final decisions. . . So, at the present time, when the schools . . . are restricting entrants to comply with the limited accomodations and facilities that state legislatures are supplying, the time is not opportune for placing the struggling schools in an embarrassing position.

Papers were presented on hip injuries in small animals by E. R. Schroeder; crystal violet vaccine by $C$. N. McBryde, in- digestion in dogs by L. W. Goss, ketosis by L. M. Roderick, infectious bronchitis by F. R. Beaudette, mastitis by C. H. Case, prostatic disease in dogs by C. F. Schlotthauer, sheep diseases by F. E. Hull and W. W. Dimock, virus studies by C. A. Brandly, brucella antigen by I. F. Huddleson, enterohepatitis by A. J. Durant, trichomoniasis and anaplasmosis by $\mathrm{Hu}$ bert Schmidt, and streptococcic infections in dogs by H. J. Stafseth.

With the death of George H. Berns at the age of 89 , the list of Honor Roll members was reduced to three, of which C. W. Crowley and Benjamin McInnes became the first sixty-year members. Dr. McInnes died the following year at the age of 85 . The son of a farrier, he had been educated at Edinburgh (M.R.C.V.S., 1874), and soon after his return to South Carolina he was appointed State Veterinarian.

In accordance with a new provision for election of the president a year in advance, O. V. Brumley was made the first president-elect of the Association.

\section{Service and Status}

In editorializing on the status of the profession in 1936, L. A. Merillat notes:

It is amazing how many thoughtful men are becoming wary over the destiny of the veterinary profession. ... A critical survey of the present situation shows that but a small percentage of the service ordinarily delegated to graduates of veterinary colleges has ever been developed and much of that which has been ... is falling into outside hands. . . To argue that there is a sufficient number of graduates in the United States is not to know how little of the total veterinary service is done by the college-trained group, not to understand how much of it remains to be developed, and not to realize how fast the clinical, investigational, educational and administrative functions are passing out of the hands and councils of the personnel constituting the veterinary profession. ...

Judging from the sound doctrines which or ganized veterinary medicine in this country has always defended and the progress it has made during the short 73 years of its life, it is inconceivable that it would not mobilize its influence for the public good when an issue as important as the one now perturbing the majority of its membership has crystallized. 
In a radio address on "What Veterinarians Are Doing Todlay," Presidlent Flynn states:

It is the intention of the members of the American Veterinary Medical Association to put forth our best efforts to bring about better health regulations throughout the United States and to bring the standard of health in the small towns and rural districts up to that of the large cities. . . A Another thing that we plan to do is to try and eliminate from the racetracks of this country the unscrupulous individuals who dope race horses, thereby putting into disrepute one of the great American sports, to say nothing of the inhumane treatment given our good and noble friend, the horse.

Dr. Flynn closes with the suggestion, "If the public will go to the trouble to investigate, they will be surprised at the accomplishments of the veterinary profession," and gives in a general manner several of the major achievements in recent times. It might be questioned, however, just how much of the public would take the trouble to look up the details.

In an address in 1936 on "Planning for the Future in Veterinary Medicine," W. A. Hagan observes:

We have awakened to a consciousness that a straight course cannot be steered unless we have a chart to go by. . . . The profession should take a broader view of its work than has been done in the past. Every member should be made to realize that his function is more than doctoring the ills of live stock. He should be an adviser to the public on animal health. . . . [ Although ] I am for anything that will bring us in closer alliance with medicine, and for anything that will aid in dispelling the notion that veterinary medicine is just a specialized branch of agriculture . . . we should not forget practical considerations which tell us that our natural friends are the live stock men. . . A professional group numbering no more than ten or eleven thousand members cannot hope to get far... unless it has the friendly support of larger, more influential groups. . . .

I believe that the profession has progressed further in the estimation of the public than many of us have realized. . . . The future progress of veterinary medicine in this country, and the improvement of the status of the profession in the public eye, are dependent upon our own efforts to improve the service that we are rendering. ... A full realization that the trend of all medical thought today is toward prevention rather than cure, and that the initiation of programs of lay education leading in this direction is desirable, should be inculcated into the profession.

\section{State Service}

An experiment to provide low cost veterinary service to be conducted by the Resettlement Administration and the Extension Service of Michigan State University was announced in 1936. This plan called for an organization which would provide for a contract veterinarian to make one visit per month to the farm of each member. He would render all necessary veterinary services, including docking, dehorning, vaccinating, castrating, etc., and give advice on feeding, sanitation, and the like, for a membership fee of $\$ 5.00$ and an annual charge of 80 cents per animal unit - a unit consisting of 1 horse, 1 cow, 2 young cattle, 5 hogs, 7 sheep, or 100 poultry. Thus a farmer with 1 horse, 4 cows, 2 heifers, 2 sows, and 100 chickens would pay (to the association) just over $\$ 11$, in monthly installments. In addition, he would be entitled to two emergency calls per year, a charge being made for additional calls. The veterinarian would be on salary (not stated), would spend six days a month, drive 275 miles, and supply all equipment and drugs, except biologicals and expensive pharmaceuticals, which would be supplied him at cost. The Journal editorializes:

Although the proposed plan has many of the earmarks of group medicine ... one decided advantage of the plan is to be found in the fact that the veterinarian will be called upon to render services which ordinarily are not performed by the veterinarian. . . A tremendous advantage ... provides for the veterinarian acting as an advisor in animal husbandry problems. . . There will be no problem of unpaid veterinary bills ... [ and ] the periodic visits of the veterinarian to each farm should prove valuable in preventing the development of disease. . . . The experiment will be watched with considerable interest.

There is no evidence, however, that the proposed experiment ever materialized. 


\section{J. C. Flynn}

J. C. Flynn was born at York, Nebraska, in 1878 and graduated from the Kansas City Veterinary College in 1910. He established one of the first exclusively small animal hospitals in the country, and for many years was the leading exponent of small animal practice, travelling many thousands of miles urging others to enter this specialty and giving demonstrations of his technics. Dr. J. V. Lacroix credits Dr. Flynn with having had more influence on the development of small animal practice during the 1920's than all other factors combined.

Dr. Flynn also wrote on small animal topics and was an associate editor of North American Veterinarian for a time. He was elected AVMA president in 1935 and was instrumental in bringing in about 500 new members. Later he helped organize the American Society of Veterinary Therapy which attracted a sizeable membership for several years. He retired from practice in 1940, but became active again during the war. He died on April 26, 1954, in Kansas City, where he had spent most of his professional life.

\section{7}

Public relations was a dominant theme at the Omaha meeting in 1937. In his presidential address, Colonel R. J. Foster noted:

The veterinary profession's activities in public life are often-times found to be subordinated, not only to its detriment but to that of the work to be accomplished. Public officials and organizations - national, state, and municipal - are prone to utilize the services of veterinarians under descriptive headings, thereby entirely obliterating their professional standing. ... We should use every means at our disposal to keep our professional identity known ... by insisting on proper titles identifying the professional services rendered.

Regarding a growing menace to public health, Colonel Foster urges:

The control and eradication of rabies in animals is certainly a veterinary problem in which all other agencies should cooperate. . .
I know of no other animal disease that is trans mitted to humans where the disease is subject to control and eradication by other professions or organizations than the veterinary profession. Why should an exception be made to rabies?

And on food inspection:

There is still one very serious defect that is most deplorable from the standpoint of protection to human health. There is very little or no inspection or supervision over locally or farm-killed meats. ... [ And ] you cannot have efficient milk inspection in this country unless milk production is under the sanitary supervision of the veterinary profession. . . I I believe that what this country needs is another Upton Sinclair "Jungle" novel setting forth conditions of our meat and milk supply that are not under professional supervision.

Speaking on "Greater Achievement Through Closer Cooperation," J. R. Mohler observes:

with public approval and support, the prestige of the veterinary profession of this country has grown. ... This work has become a dominant influence in agriculture, industry, and human welfare throughout the United States. . . Good business methods have prevailed. Through sound organization the cost of veterinary service is small in proportion to the benefits derived. . . Cooperation within our profession has not only fostered progress, but has done so with economy and businesslike efficiency. . . .

Intellectual pioneers have rarely had an easy time. . . Until rather recently a few individuals, or at least a small minority, have led the majority in scientific thinking and action. In the veterinary profession today we are fortunate in finding a much more advanced situation in this respect. The great majority of veterinarians are conspicuously open-minded and progressive. ... In tuberculosis eradication the support of a large majority has carried this vast campaign to assured success. Yet there have been noticeable examples of doubt, indifference, and even opposition by persons whose hearty cooperation would have been extremely valuable....

In veterinary field work, the type of cooperation that I deem especially desirable has these qualities:

It is intelligent, recognizing the professional soundness of the project.

It is public spirited, subordinating self-interest to the common good.

It is courageous, signifying a willingness to carry on even against odds. 
It is optimistic, having full confidence in ultimate success.

Secretary Hoskins reported on the publication of a new directory: in the five years since the previous one over 900 new members had been added, another 500 reinstated, and about 1,000 dropped for nonpayment of dues, the net membership being in excess of 4,600 , the largest in history. One new name was added to the Honor Roll, that of past-president Tait Butler.

In the decade or so since the private schools had closed, total enrollment (in the state schools) was sharply curtailed - although this undoubtedly was due in part to the depression. An inevitable concomitant of the closing of the private schools was disclosed by the rising death rate of members, increasing from 8.47 per thousand in 1930 to 13.61 in 1936 .

The Journal circulation was in excess of 5,000 copies, the highest in history. The Executive Board recommended a revamping and enlargement of the Journal, with the establishment of topical departments. This was adopted and put into effect the following year. As put by President Foster:

At every meeting that $I$ have attended during the year, the members have almost unanimously favored revamping the Journal and putting a little "it" or personality into the thing.

The "new" Journal made its appearance in 1938, with perhaps the most significant change being the addition of a group of associate editors of specialties. These included: J. R. Beach, Poultry Diseases; E. A. Benbrook, Parasitology; J. B. Bryant, Swine Practice; C. H. Case, Cattle Practice; James Farquharson, Large Animal Medicine; C. P. Fitch, Research; Ward Giltner, Public Health; W. F. Guard, Surgery and Obstetrics; R. A. Kelser, Military Medicine; J. A. S. Millar, Small Animal Practice; J. R. Mohler, Sanitary Science; C. R. Schroeder, Zoo Practice; and J. E. Shillinger, Diseases of Wildlife. Editor Hoskins, however, noted one lamentable fact: "Less than 2 per cent of the entire membership ever contribute anything to the Journal."
What might be thought of as a temporary "hall of fame" consisting of active veterinarians is the list of nominations for representation at the 13 th International Veterinary Congress. As submitted by Adolph Eichhorn, these included (one in each of ten sections): G. B. Schnelle, Internal Medicine and Surgery; J. R. Mohler, Infectious Diseases; T. H. Ferguson, Cattle Diseases; M. C. Hall, Parasitology; R. A. Kelser, Tropical Diseases; E. L. Stubbs, Poultry Diseases; G. H. Hart, Zootechnics; Ward Giltner, Food Hygiene; R. J. Foster, Military Organization; and A. F. Schalk, Veterinary Physiology.

Recipient of the first 12th International Congress Prize was Denny H. Udall, for his achievements in "the development of knowledge basis to pathology and methods of control of bovine mastitis." An innovation in AVMA history was the election of the first woman to an Association office that of Dr. Helen Richt Irwin as secretary of the Section on Small Animals.

Papers were presented on nutrition by G. H. Hart, endocrinology by W. G. Venzke, hernia by E. R. Frank, urolithiasis by I. E. Newsom, and actinomycosis by James Farquharson. On poultry: diagnosis by S. H. McNutt, leukosis by C. D. Lee and by E. L. Stubbs, and laryngotracheitis by F. R. Beaudette. On research: brucellosis by C. M. Haring and by C. P. Fitch, oat hay poisoning by Frank Thorp, Jr., and moldy corn poisoning by L. H. Schwarte. And on small animals: neurology by C. F. Schlotthauer, dermatology by S. W. Haigler, blood transfusion by $C$. W. Bower, and cat diseases by F. F. Parker.

In commenting upon the Omaha meeting, Veterinary Medicine notes some of the changes wrought since the previous meeting there in 1898. Then, of a total membership of 246 , only 114 were members in good standing. Dr. A. T. Peters was the only officer, and Tait Butler, J. P. Turner, W. L. Williams, and W. B. Niles, committee members, were the only surviving members of the official family in 1898. Of the 14 men who presented papers at the 
1898 meeting, only L. A. Merillat, J. W. Connaway, and Charles Ellis had survived, along with two other members of the 43 in attendance (total attendance: 134), G. A. Johnson and W. H. Kelley. Of 24 honorary members in 1898, only one, Sir John M'Fadyean, was living in 1937.

Concerning the general tone of more recent meetings, it is charged:

one notes no improvement in the quality of the papers presented. . . . Leaders in the profession write no better English nor present no higher class scientific papers now than Salmon, Pearson, Stewart, Nelson, Law, Merillat and others wrote in that earlier day, nor is there much difference in the subjects discussed. Rabies, hog cholera and tuberculosis were engaging attention then as now. . . . Filtrable viruses were discussed in the president's address, as was also shipping fever . . . the need for collecting statistics on the loss from animal disease... [and ] the need for informing the public concerning veterinary service.

\section{A Matter of Policy}

In their report, the recently established Committee on Policy, consisting of L. A. Merillat, Cassius Way, M. Jacob, R. J. Foster, and H. P. Hoskins, note:

A favorable change toward the importance of veterinary medicine is taking place. In all parts of the world veterinarians are succeeding in drawing public attention to the obstacles diseases of animals lay in the path of mankind. ... [ However] incalculable harm has been done to the veterinary profession by avoiding the use of the words "veterinary" or "veterinarian" in so many of the important public services which are purely veterinarymedical in character. The result has been that the masses are little aware that a veterinarian actually exists in this country. . . The surveys of this Committee appear to show that the American public, once aware of the purposes of veterinary medicine, will insist upon its fullest utilization.

Reporting for the Committee on Public Relations, D. M. Campbell notes its adoption of two specific directives of the Committee on Policy:

1. Our veterinary service shall be operated with the public welfare uppermost in mind. 2. Human and animal welfare are inseparable and publicity for the veterinary profession must be written around that indisputable fact.
Particular attention was called to the campaign of the Associated Serum Producers to focus the attention of livestock owners on livestock health and to acquaint them with the values of veterinary service.

Speaking as president of the Association later in 1937, O. V. Brumley presented a comprehensive program for "the expansion and improvement of public health education for the future." This included revision of the veterinary curriculum to provide adequate public health orientation, development of a curriculum leading to the degree of Doctor of Public Health, surveys of public health situations by veterinarians in their local communities, an educational program initiated by the AVMA, closer cooperation with the medical and dental professions, a wildlife research program in relation to the zoonoses, and efforts by the veterinary profession to have proper recognition and a part in the federal public health program. In concluding, he states:

The work of public health is so broad and inclusive that no one profession can master all the problems. The veterinary profession has a very definite place in the program and we should recognize that other professions and agencies have theirs also. Consequently, we should accept our part of the responsibility for the promotion of a public health program and cooperate fully with all others interested in the same thing for better health and a happier citizenship for the entire country.

At the same time, A. F. Schalk recognizes public health as the least developed aspect of veterinary medicine, but, noting the salaries of $\$ 1,200$ to $\$ 1,500$ frequently offered for full-time positions in this area:

To express it but mildly, the outlook and prospect is exceedingly dark and discouraging in view of existing conditions. The student can ill prepare himself specifically for such indefinite work and the college officials and instructional forces will hesitate to catalog additional special courses in a field of work that now appears so speculative and holds out so little in encouragement for the future.

\section{The Stader Splint}

A major advance in fracture treatment, and one which found ready application in 
human surgery, was developed by Otto Stader, of Ardmore, Pennsylvania, and demonstrated by him early in 1937. This technic, utilizing the Stader reduction splint, rapidly supplanted the more commonly used technics for several types of fractures, and within a year had been applied in about 300 cases by some 40 veterinarians. During this time Dr. Stader also served as consultant in application to the splint in ten human cases.

As noted by Dr. Stader, a number of the technics used until the twentieth century were not unlike those described by Hippocrates, and until the 1920's, the most common technic was that of splinting with wood or metal strips in conjunction with bandaging impregnated with plaster or some other hardening agent: "Many a practitioner has lost his temper when such a cast had to be applied to a femoral fracture on a male dog." The Thomas traction splint obviated some of these problems, but created others, especially with regard to the regaining of normal joint function. As stated by Dr. Stader:

Our patients are difficult to restrain; are destructive to many of the splints applied; and in many cases are unable to indicate to us when the splints that we have applied are causing pain and discomfort. It is often difficult to apply effective splints to the dog's extremities because of their anatomical structure. We see too often the fouling of the splint by the body excretion. Last, but not least, we are unable in many cases to effectively secure countertraction which is necessary in order to maintain length and alignment of the fragments. To overcome effectively these problems and at the same time afford greater comfort, unrestricted circulation, and free articular functions, new methods different in principle and a new type splint of special design seemed necessary.

\section{R. J. Foster}

Robert Julian Foster was born in Ohio, September 7, 1880, and grew up in Ithaca, New York, where he obtained his D.V.M. at Cornell in 1902. After teaching at Clemson College, the University of Missouri, and Kansas State, he served with the United States Cavalry until 1916 when he was appointed First Lieutenant in the Veterinary Corps. As a Major in 1918 he or- ganized and commanded the Veterinary Section of the Medical Officers' Training Camp at Fort Riley, and as a member of the Surgeon General's staff he directed the reorganization which placed the Veterinary Corps on its present basis. In 19201922 he was Chief Veterinarian, Army of Occupation, at Coblenz, Germany.

Upon his return to the states, he received special commendation for his instruction in the School of Horsemanship at Fort Riley, and served as Department Veterinarian, Canal Zone, from 1926 to 1929. Upon his recommendation, a meat inspection service was established for the Civilian Conservation Corps, the more than 100 veterinarians so employed bringing the Veterinary Corps to its greatest strength since 1920.

Colonel Foster joined the AVMA in 1906 and represented military veterinarians several times since 1908. In 1932 he was elected a vice president, and in 1936 president of the Association.

\section{DIAMOND JUBILEE}

The meeting of 1938 in New York City marked the seventy-fifth anniversary of the Association. In his presidential address, O. V. Brumley recalls:

75 years of achievement. . . Within this period many important achievements have been attained, viz: cooperation with other agencies in the development of an indispensable live stock industry; the establishment of a veterinary educational system; the development of the sanitary sciences on a scientific basis; and the inauguration of many important public health programs. Research has added greatly to the knowledge of the medical sciences. . . Laws and regulations... have been placed on the statute books; veterinary associations have been organized ... and veterinary practice has extended to nearly all sections of the North American Continent. The American Veterinary Medical Association has been, in a great measure, responsible for the successful development of these activities.

Noting "There will be many new problems to ... be solved by a progressive, alert, scientific veterinary profession," Dr. Brumley called for increased public and professional relationships, better distri- 
bution of veterinary services, and "A definite program of public education ... to acquaint the public with the numerous services of the veterinary profession."

Speaking on "Seventy-five Years of Progress in Veterinary Medicine," J. R. Mohler observes: "To the extent that we reflect on events within the last three quarters of a century, to that degree will our mental penetration into the future be aided and strengthened." Twenty-five years earlier, as president of the Association at its fiftieth anniversary meeting, Dr. Mohler had urged:

From the history of veterinary medicine let veterinarians draw confidence in the invincible strength of their science which though at one time despised even by the well-informed, has during the last five decades attained such great importance and such wide influence in the life of this and other countries. And let them take fresh courage and make new resolutions to rival all the other professions in useful work to be accomplished in the fifty years to come. . . Gentlemen, I have no fear for the future of veterinary medicine.

As a reminder of what the veterinary profession had accomplished, Dr. Mohler lists some of its achievements:

Eradication of contagious pleuropneumonia, and of every outbreak of foot-and-mouth disease that has occurred in the United States, and the exclusion of other foreign animal plagues.

Practical eradication of bovine tuberculosis, and material reduction of Bang's disease, together with encouraging benefits from calfhood vaccination.

Discovery of the virus of hog cholera, of serum-virus immunization, and of crystal violet vaccine.

Discovery of the nature of tick fever, and a successful method of tick eradication, together with demonstration of insect vectors of disease.

A federal meat inspection service that has won world-wide recognition, and success in destroying trichinae in pork by refrigeration.

The development of bacterins, aggressins, vaccines, antigens, dips and disinfectants, some of them highly specific and notably successfuI in reducing the incidence of a variety of diseases.

Perfection of a serological test for dourine, and practical eradication of the disease, and widespread eradication of scabies in cattle and sheep.

Discovery of a remedy for hookworm in dogs which has been used successfully on millions of people.

Improvement in the diagnosis and treatment of bovine mastitis, and for diagnosis of pullorum disease in poultry.

Advancement in standards of veterinary education and of private practice, including hospitalization and use of biologics, anesthetics and $\mathrm{x}$-ray.

Papers were presented on liver metabolism by C. E. Hayden, circulatory dynamics by $H$. H. Dukes and H. T. Batt, transfusion therapy by R. S. Amadon, diagnostic hematology by Fred Boerner, parasite diagnosis by R. E. Rebrassier, and bovine trichomoniasis by G. Dikmans. Also equine breeding hygiene by W. W. Dimock, hog cholera tissue vaccine by W. H. Boynton, milk hygiene by G. H. Hopson and by Ward Giltner, brucellosis vaccination by $J$. G. Hardenbergh and by C. M. Haring, kidney pathology by R. F. Langham and E. T. Hallman, and induced traumatic gastritis by $R$. W. Dougherty. And on poultry respiratory anatomy by W. M. McLeod, reproductive physiology by E. A. Hewitt, turkey paratyphoid by B. S. Pomeroy and R. Fenstermacher, epidemic tremor by Henry Van Roekel, and leukemia by M. W. Emmel.

That some things change but slowly is indicated by the fact that Dr. R. S. MacKellar, Sr., a member of the local committee, was then characterized as "one of the oldest general practitioners in New York City." That other things do change - single rooms at the Hotel Pennsylvania were $\$ 3.50$, doubles $\$ 5.00$. Members of the official family, or who presented papers at both the fiftieth and seventy-fifth anniversary meetings included J. G. Hardenbergh, J. R. Mohler, Adolph Eichhorn, M. Jacob, Cassius Way, W. W. Dimock, and Ward Giltner. The International Veterinary Congress prize was awarded to $G$. $H$. Hart.

\section{O. V. Brumley}

Oscar V. Brumley was born at Leipsic, Ohio, March 8, 1876, and graduated from Ohio State in 1897. After graduate work in Berlin he returned to Ohio State, where 
he became professor and director of the clinics in 1910, secretary (1912), and dean of the College of Veterinary Medicine in 1929. His textbook on the diseases of small animals was a standard work for many years. Active in public health and humane work, he had served as president of the Columbus Board of Health in 1931, and had been elected president of the Columbus Humane Society the week before his death. He was president of the Ohio VMA (1910-1912) and secretary (1920). A member of the AVMA Executive Board from 1930 to 1936, Dr. Brumley was elected president of the Association in 1937. Re-elected to the Executive Board in 1939, he served as its chairman, 19401944. During his official tenure there was a major reorganization of the Association and an integration of the national and state associations. Dr. Brumley died January $13,1945$.

\section{Spectre of State Medicine}

On the subject of "Public Health and State Medicine," J. V. Lacroix observes in 1938:

The role of state medicine in veterinary practice is a question of vital importance to the veterinarian of today. No matter what the reaction of the individual practitioner state medicine has arrived. . . Not only is state medicine indicated because of the already proven value of organized efforts in disease control but conditions now exist in the veterinary profession, particularly the lack of trained veterinarians, which are forcing the profession toward state medicine. . . If Eastern Iowa, where 85 per cent of the veterinary practitioners are said to be more than 45 years of age, is a criterion it may eventually be necessary for state medicine to control all veterinary activity in this country. At present there are not enough veterinarians to enlarge the veterinary program and there is no prospect of more becoming available soon. ...

The private practitioner who makes full use of the state medicine facilities available to him need not feel antagonistic toward state medicine. There is a definite important place for progressive men in private practice who will employ modern methods in preventive medicine and who will make use of the facilities offered him by state medicine. Public health is not a problem for the physician alone, but it must also be safeguarded by contributions of the veterinary profession.

On a local basis, however, Dean W. A. Hagan of the New York School viewed with some alarm the numbers of New York residents who desired a veterinary education:

I estimate that there are at least half as many residents of New York now studying veterinary medicine in institutions outside of the state as are enrolled in our own college. The total number will yield an annual crop greater than can easily be absorbed. . . . If these students would stay in the states that have accepted them as students, there would be no cause for complaint, but that is just what these students are not going to do. Within two or three years most of these men will be back in New York, particularly in the metropolitan area, which is their home, ready for practice. . . . Under the circumstances I think the time is ripe for strenghthening our state licensing examination, not with the idea of discriminating in any way against those who have obtained their education outside the state, but to make sure that only the really well qualified will be able to obtain licenses. ...

A number of prominent members of the veterinary profession have been claiming that there is a very great dearth of veterinarians and that as a result much work that veterinarians might be doing was falling into the hands of other groups. Some of these men have criticized the veterinary schools for not devoting more time in their curricula to public health training. ... So far as expanding greatly the public health work in the veterinary curricula is concerned, there simply is not time for it in a well balanced program. I do not think that we should be greatly exercised over the fact that in public health programs the veterinarian usually occupies a subsidiary place. . . . If veterinarians wish to qualify for this work, the same courses that are open to the others are open to them.

Taking note of an apparent trend of the times, Cassius Way, in his address as AVMA president in 1940, observes:

Perhaps we are heading toward a system of state medicine, subsidized practice, county service, or what not. It would seem advisable that the best minds in the profession should get together and take toll, balance the budget, so to speak, study the cause and effect and, if possible, evolve a solution.

Dr. Way did take a strong stand against certain types of "state medicine," including 
encroachment upon veterinary practice by the Farm Bureau, and plans of colleges of agriculture to "organize farmers into an association to deal collectively for veterinary service. This sort of collective bargaining puts professional men on the basis of laborers."

On the matter of the wide radius over which some veterinary college ambulatory clinics were giving essentially free service, Dr. Way contends:

such "State Medicine" is directly contrary to the ideals held by such pioneers of the profession as Law, Liautard, McEachran and Moore. . . The practitioner ... has quite definite priority rights when it comes to the practice of veterinary medicine. . . The practitioners and their clients support the state institutions as taxpayers. When a state institution gives free, or low-cost, medical treatment to the animals of private citizens, the taxpayers pay for it.

W. L. Williams, 84 years of age and still full of fire, takes vigorous objection to Dr. Way's statement concerning:

the ideals of Law, Liautard and McEachran, the three veterinary teachers of their day, with whom I was most intimately concerned and whose ideals in veterinary education I believe I understood fairly well. . . During Law's directorship of the college [Cornell, of which Dr. Way was a graduate ], we were in absolute accord ... . both believing firmly in the value of and necessity for free clinics. . . . Liautard evidently approved of my efforts and ideals. ... After the free clinics had been established under Professor Law and myself, and Liautard had retired to his native land, he caused me to be made an honorary member of the Central Veterinary Medical Society of France. ...

Principal McEachran, from whose college I was graduated 61 years ago, like Liautard ... could not establish such free clinics as those at Cornell and elsewhere without financial ruin, but there are important evidences that he was not violently opposed to them. ... The clinics initiated by Professor Law and myself constitute, in a large measure, an adaptation of Osler's ideals to the teaching of veterinary medicine. As far as I could see, McEachran and Osler held identical ideals regarding the teaching of medicine of man and animals, but neither of them was in a position at that time to put such ideals into effect. . . .
Way makes no allusion to the important fact that free clinics were impossible in private, unendowed veterinary schools, and that the introduction of free clinics in state schools helped sound the death knell of the former. The private veterinary schools had ... required or advised that the student get his clinical insruction during the six-month interval between college sessions. ... It would be extremely interesting if Dr. Way would submit, in tabulated form, outstanding surgical operations ... contributions of economic importance to our current literature ... [ and ] veterinary books largely used at present as texts . . . developed in America. Let him place in one column those developed in free college clinics and in another those introduced otherwise. . . He would probably discover that the men in colleges supporting free clinics make a good showing. ...

State veterinary schools are created and maintained that they may render valuable economic services to the state through the adequate training of students, that they in turn may, after graduation, render commendable professional service - not that they must enter upon lucrative trade activities.

\section{9}

In asking for greater support of the AVMA at the 1939 meeting in Memphis, President H. D. Bergman urges:

Professional organization is the sole protection of every individual veterinarian in this country, regardless of his field of activity. . . . History definitely indicates that the advance of the veterinary profession has been directly related to the growth and development of its societies.

To compare favorably with medicine and dentistry, AVMA membership would have to be increased by about 25 per cent.

On veterinary journals, Dr. Bergman proposes:

our association should dominate the field of veterinary journalism in this country through maintaining facilities for the publication of whatever journals or other periodicals the profession will support.

The Committee on Public Relations proposed a popular veterinary magazine to:

Educate the public to a better appreciation of the significance of veterinary medicine ... heighten appreciation of the A.V.M.A. on the part of members, non-members and the na- 
tion's press ... [ and] help members to combat the encroachments of incompetent intruders and other influences inimical to the veterinary profession and to the best interests of animal husbandry.

Anticipated circulation of 35,000 copies was to be by direct mailing to clients or others designated by members, at the rate of $\$ 3.00$ monthly per 20 subscriptions (minimum) paid for by the AVMA member.

It was voted to institute a Board of Governors, to consist of the Executive Board chairman, the president, and the president-elect. Dr. H. Preston Hoskins, who had been secretary since 1922 and editor of the Journal since 1923, relinquished both posts in favor of L. A. Merillat, who served as executive secretary (1939-1940) and editor-in-chief to 1950. The name of J. W. Connaway was added to the Honor Roll. Dr. John R. Mohler was the recipient of the Twelfth International Veterinary Congress award.

Papers were presented on encephalomyelitis by $\mathrm{H}$. W. Schoening, and by C. F. Schlotthauer; canine coccidiosis by F. X. Gassner, and bovine parasitism by $D$. W. Baker; pig mortality by L. P. Doyle, pig pneumonia by Frank Thorp, Jr., and hog cholera by $\mathrm{H}$. C. H. Kernkamp; various aspects of brucellosis by A. Eichhorn, O. F. Huddleson, H. J. Metzger, and W. E. Cotton; mineral deficiencies by Hubert Schmidt; hemorrhagic septicemia by W. A. Aitken; and pneumonia in the horse by D. L. Proctor.

Rabies was a subject of intense interest because of recent outbreaks in various parts of the country, with discussions by $\mathrm{L}$. $\mathrm{T}$. Webster, M. D., R. A. Kelser, and others. Also enteritis by L. W. Goss; avian tumors by L. J. Goss, and tumors of small animals by Peter Olafson; and vitamins in small animal practice by M. L. Morris (read by C. W. Bower). Dr. J. W. Patton, whose work on so-called "fright disease" had attracted nationwide attention, discussed nervous disturbances due to avitaminosis $\mathrm{B}_{1}$.
Artificial insemination of cattle, recently introduced in this country, was demonstrated at the clinic, following which the Journal editorialized:

the interest of practicing veterinarians in the recent revival of this centuries-old substitute for coitus has not been excited to the same extent as that of breeders of live stock. . . A Artificial insemination has a place in the practice of veterinary medicine only to the extent of our knowledge of its many details.

Later, it was urged, "artificial insemination is a responsibility of our profession."

Prior to the meeting, Dr. Bergman had prepared promotion material on "Veterinary Contributions to Human Health," emphasizing that man is subject to 70 animal diseases; the United States is the safest place in the world for livestock; and that discoveries by veterinarians had greatly decreased the number of hunchbacks from tuberculosis, had made possible the Panama Canal through work on Texas fever, and that hookworm treatment in man had followed discovery of a remedy for dogs.

\section{H. D. Bergman}

Henry Dale Bergman was born in New. ton, Iowa, November 22, 1886, and graduated from Iowa State in 1910, following which he joined the staff as an assistant in veterinary medicine. After graduate work at the University of Chicago, he returned to the Department of Physiology and Pharmacology, becoming head of the department in 1916, and dean of the Veterinary Division at Iowa State in 1943, retiring in 1952.

Among other activities, Dr. Bergman was president of the Iowa VMA, chairman of the veterinary division of the Association of Land Grant Colleges, representative to the National Research Council, AAAS fellow, contributor to several revisions of the National Formulary, delegate to the International Veterinary Congress in 1930 and 1934, and AVMA president 1938-1939. 


\section{Changing Times: The Forties and Fifties}

ONE MEASURE of the vitality of a profession is the support it gives its associations. During the twenties, the total number of veterinarians had dropped from about 13,500 to under 12,000, and AVMA membership had increased by only 426. During the thirties, when the number of veterinarians was barely maintained because of reduced school enrollments, the Association picked up an additional 1,611 members.

\section{LIFE BEGINS AT FORTY}

By 1940 about half of the approximately 12,500 American veterinarians belonged to the AVMA, and about an equal number belonged to state associations, although for individual states AVMA membership varied by as much as 50 per cent above or below that of the state association. A proposal to link national with state membership was defeated in 1940 , as was one to increase AVMA dues from $\$ 5.00$ to $\$ 7.50$. Ten states (including California and Pennsylvania) had dues of $\$ 2.00$ or less; the others, except for New York and Iowa with $\$ 10.00$, ranged from $\$ 3.00$ to $\$ 5.00$ a year. The five states with the largest number of veterinarians were New York (921), Iowa (804), Illinois (790), California (726), and Ohio (713). In order of AVMA membership the lineup was: California, New York, Iowa, Ohio, and Pennsylvania.

At this time only one state (California) had more than 450 AVMA members, and thus had 5 votes in the House of Representatives, and 4 states had 4 votes each (300-450 members). This formula for voting strength was still in effect in 1958, when California had 1,300 members, and New York, Illinois, Iowa, and Ohio each had more than 700. In 1960 these states had 7 votes; Texas, with just under 700 members, had 6 , and six other states had qualified for 5 votes; six top states, with about 36 per cent of the membership had about 21 per cent of the voting strength, roughly equal to the six top states in 1940 , which with about 40 per cent of the membership, had about 25 per cent of the votes. In 1958 the six top states, with 35 per cent of the membership, had only about 16 per cent of the voting strength.

\section{0}

In his presidential address at the 1940 meeting in Washington, D.C., Cassius Way, noting that Pennsylvania had instituted a two-year preveterinary requirement, suggests:

we will not reach the goal of having the most nearly perfect veterinary educational standards until all veterinary colleges require a sevenyear course for a college degree either in agriculture, science or arts and a professional or doctorate degree.

And on the recent increases in enrollment: "we are now graduating more veterinarians than will be needed to replace 
those who are dropping out of the ranks."

In refuting charges of "profiteering" and alleged sale of seals of approval in the AAHA - AVMA program of dog food testing, Dr. Way explains:

seals are not sold; they are awarded to manufacturers whose products have been submitted, tested and found to meet requirements. . . The total cost to each manufacturer is approximately $\$ 950$, of which $\$ 500$ is to cover the expense of the test . . \$450 ... to cover the cost of supervision, promotion, publicity, etc.

Dr. I. F. Huddleson, who presented a paper on progress in the study of brucellosis, was awarded the International Veterinary Congress prize. Brucellosis was also a major topic in the Section on Research, with papers being presented by C. F. Clark, W. S. Stone, H. J. Metzger, H. S. Cameron, and C. M. Haring.

Other papers included those on bovine kidney pathology by R. F. Langham; blood typing in cattle by L. C. Ferguson; nutritional diseases of swine by H. C. H. Kernkamp; bloat by R. W. Dougherty; sheep parasites by R. E. Rebrassier; equine abdominal surgery by James Farquharson; genetic aspects of poultry disease by C. A. Brandly; iritis of fowls by C. D. Lee; X-ray diagnosis by G. H. Schnelle; hospital economics by C. C. Rife; and vitamin deficiencies by M. L. Morris.

Dr. J. G. Hardenbergh was made Executive Secretary of the Association, with L. A. Merillat continuing as editor-in-chief of publications, including the newly established American Journal of Veterinary $R e$ search. Concerning the perennially-proposed "Reorientation of Veterinary Medicine," Dr. Merillat counters:

conserving property for farmers is the principal function of veterinary science. Public health is but incidental thereto. . . Transforming our entire educational system from the agricultural to the medical domain would be an undertaking that is entirely out of proportion to the benefits in sight.

October, 1940, marked a milestone in tuberculosis eradication when the last two counties in California were declared accredited. In 1917, when the program of eradication was conceived by J. R. Mohler, an incidence of 10 per cent or more ( 50 per cent in some areas) had been reduced over the intervening years, under the direction of J. A. Kiernan and A. E. Wight, to 0.5 per cent. An outbreak of encephalomyelitis resulted in some 4,000 deaths of horses and mules among some 17,000 affected, primarily west of the Mississippi River.

In taking note of Bert W. Bierer's multigraphed work on American Veterinary $\mathrm{H}$ istory, the Journal observes:

Much of the difficulty veterinarians meet is hard to overcome because the events of the past are not taken into account. Only a carefully compiled history can provide the means of placing veterinary science where it properly belongs in the affairs of our country.

\section{Cassius Way}

Cassius Way was born at Gilead, Connecticut, August 28, 1881, and graduated from Cornell University in 1907, following which he became a pioneer in milk sanitation in the Chicago milkshed. His educational work among farmers there is considered a major factor in establishing the concept of clean stables and healthy herds in the production of quality milk. Returning to New York City about 1914, he continued to figure prominently in certified milk production, but became best known as an equine practitioner among the racing stables and breeding farms along the eastern seaboard.

A member of the official family of the AVMA for more than thirty years, Dr. Way served on a number of committees, of ten as chairman, and was chairman of the Executive Board for nine years. He was president of the Association in 1939-1940. His untimely death on August 5, 1948, at the age of 67 , occurred following an injury sustained while treating a horse.

\section{1}

At the meeting for 1941 in Indianapolis, President A. E. Wight reported that prompt action by the Association, in conjunction with representatives of allied professions, had been successful in securing the 
same deferment from military service accorded medical and dental students and practitioners. No mention of the veterinary profession had been made in the original bill.

Concerning tuberculosis eradication, in which he had played a major part, Dr. Wight emphasized:

All cattle must now be regarded as highly susceptible to the disease; permanent eradication depends entirely upon the vigilance of the veterinary profession and upon continuance of federal and state appropriations sufficient to maintain adequate control.

Having reached the initial goal in tuberculosis eradication, a start had been made on brucellosis, with 391 counties in 23 states being declared modified accredited brucellosis-free areas during the past year.

The Executive Board recommended formation of a research council and the establishment of a number of $\$ 1,000$ fellowships by creation of a research fund through contributions from industry. This, J. C. Flynn thought, "seems to be rather a gigantic proposition," and action was deferred, "to give us a little time to sift it." The proposal was later adopted without demur, but the AVMA Research Fund did not come into being until 1945 .

With membership reaching 6,657 , the Association for the first time in its history represented a clear majority of the veterinary profession. Journal subscriptions exceeded 7,000, and the American Journal of Veterinary Research was already approaching 2,000. A primary consideration in publication of the research journal had been the backlog of technical articles awaiting publication. But the new journal had attracted "more and more papers from veterinary scientists and others who formerly sought publication elsewhere," and bimonthly publication was under consideration to reduce its backlog.

The International Veterinary Congress prize was awarded to Adolph Eichhorn. The addition of N. S. Mayo, E. B. Ackerman, and J. P. Turner to the Honor Roll brought the number of fifty-year members to nine.
Papers presented included several on mastitis by O. W. Schalm, W. D. Pounden, and E. N. Moore; bovine pneumonia by W. T. S. Thorp, and by R. F. Langham; retained placenta by $M$. G. Fincher; cesarean section in cattle by E. R. Frank, and embryotomy in mares by $W$. R. Krill; the Army remount system by $W$. E. Jennings; equine nutrition by Cassius Way; plastic surgery by J. C. Flynn; distemper inclusion bodies by Walter Wisnicky; fowl leukosis by C. D. Lee, and by C. A. Brandly; and avian encephalomyelitis by Erwin Jungherr, and by H. Van Roekel.

In speaking on "Veterinarians in $\mathrm{Na}$ tional Economics" earlier in the year, L. A. Merillat had observed:

The reason that veterinary science as an economic question remains so obscure in this country is that we have done the impossible thing of trying to separate animal health from animal disease - two sciences which are inseparably dove-tailed. ... Things wh ich should have been done 75 years ago, when associating animal diseases with human welfare was too vague to be an issue in statesmanship, are now here for the veterinary service to act upon. . . . That it is necessary to write an essay on "the veterinarian in national economics" at this late day is unfortunate.

With regard to the criticism that too few AVMA presidents had come from the ranks of practitioners, an analysis showed that 15 men from 4 states had served during the first 25 years; of these, 4 had been primarily college men and the others practitioners, some of whom had engaged more or less in livestock sanitation. During the next half-century, 48 men from 20 states, Canada, and Washington, D.C. served; of these, the colleges accounted for 14, practice 13 , state livestock sanitation 11 , the BAI 5, Canadian livestock sanitation 2, commercial laboratories 2, and the Army one.

\section{A. E. Wight}

Alexander E. Wight was born in Medfield, Massachusetts, April 14, 1876, and graduated from Harvard University in 1897. He joined the BAI in 1898, and was assigned to the Tuberculosis Eradication 
Division under J. A. Kiernan in 1917 when the modified accredited program was started. In 1928 he became head of the division and by the time he retired in 1946 every state was accredited. In addition to the tuberculosis program, he was in charge of brucellosis eradication.

Dr. Wight had been an officer of the United States Live Stock Association and the District of Columbia VMA, and in 1940-1941 served as AVMA president. He died in Washington, D.C., on March 11, 1957.

\section{THE WAR YEARS}

In his presidential address at the 1942 meeting in Chicago - the first "war session" - H. W. Jakeman reviewed the history of the veterinary profession and noted:

History reveals the futility of efforts to accelerate the production of gregarious animals without a comparable increase in disease supervision. . . . In these days of increased hazards, the profession must prove equal to its intensified responsibility.

And while extolling the work of the BAI and livestock sanitary boards, he observes, "Had the adjective 'veterinary' ... been used more constantly and persistently through the years the achievements of the profession would be much more widely and favorably known." In urging greater attention to veterinary economics, Dr. Jakeman contends:

Our advancement is dependent to a great extent on the type of service we render to agriculture and to medical science. . . Our concept of the profession should not be limited to problems connected with the prevention and treatment of animal diseases. . . A solid foundation in the science of medicine with greater emphasis on such basic subjects as physiology, pathology, genetics, nutrition, physiochemistry, sanitary science and others will enable the graduate to become proficient . . . in any specialized field.

To a large extent, the program was in keeping with the tenor of the times: papers were presented by J. R. Mohler on "Veterinary Resources as Aids to Victory"; by A. E. Cameron on "The Veterinary Profes- sion in Canada and Its Trend in Wartime"; and by R. A. Kelser, recently raised to the rank of Brigadier General, on "The Veterinary Profession and Its Present Responsibilities." General Kelser was also awarded the International Veterinary Congress prize. Dr. H. E. Kingman, Jr., discussed the role of the veterinarian in the war program of the meat industry; the civil defense work of a county veterinary association was presented by W. F. Guard; and M. L. Morris discussed pet feeding problems resulting from wartime restrictions.

Speaking on the procurement and assignment service, Lieutenant Colonel S. F. Seeley, M. C., reported a shortage of physicians in the Medical Corps at the time of the Pearl Harbor disaster, but, "In the veterinary corps, fortunately, there was an adequate number of personnel ... and a reserve corps equal to the number on active duty." And on returns of the manpower questionnaire:

of the somewhat less than 13,000 veterinarians of the United States, fewer than 400 have failed to answer the questionnaire - the best percentage of any profession .... [and ] the most accurate and the most complete survey of any profession in the United States.

The civilian veterinary service, however, was less well prepared for the emergency, particularly in face of an impending increase in military requirements. Mark Welsh, in speaking on "Modern War and Farm-Animal Diseases," notes, "for the job we have to do in conserving our food supplies and protecting the public health ... we are definitely deficient in critically needed services, if not materials." In particular, he mentions the need for more diagnostic laboratories, better mortality and morbidity statistics, and more adequate laws governing use of drugs especially "that proven dangerous products be confined to those qualified to use them."

Concerning this latter problem, the Journal notes with alarm the urging of the American Druggist that pharmacists wield 
a "big stick" in promoting veterinary medicines among "agricultural graduates who know their animals and poultry," now that veterinarians "many who were available to the farmers are now in the Army."

On a brighter note, Otto Stader reported on the adoption of his reduction splint by the armed forces:

Some five years ago we first started using splints in New York City on fractures in man but only during the past 10 months, has it received recognition, due to the war emergency. ... A great deal of recognition by the medical profession has been given to the veterinary profession as a result thereof. . . . This instrument is being considered as a definite and distinct contribution by the veterinary profession to human surgery.

Among other papers presented were those on the bovine uterus by H. E. Kingman, Sr.; hernia by T. A. Sigler; neoplasms of the bovine eye by E. R. Frank; avian neoplasia by K. L. Bullis; salmonella infection in turkeys by B. S. Pomeroy, and pullorum disease in chickens by C. H. Cunningham; schistosomiasis in man and animals by $\mathrm{J}$. H. Steele; equine influenza by T. C. Jones and Fred Maurer; X-ray therapy by M. A. Emmerson; experimental neuropathology by C. F. Schlotthauer; and hospital economics by C. C. Rife.

As chairman of the Committee on History, L. A. Merillat urged publication of Bert W. Bierer's monographs on veterinary history; this project, however, apparently became a wartime casualty. At this time the total assets of the AVMA were about $\$ 42,000$; annual income was about $\$ 75,000$, but with 50 per cent of the dues being assigned to the Journal Fund for a number of years, the AVMA Fund proper was overdrawn some $\$ 90,000$ while the Journal Fund was $\$ 101,000$ in the black.

\section{H. W. Jakeman}

Harry W. Jakeman was born in Halifax, Nova Scotia, in 1885, and graduated from the University of Pennsylvania in 1909, following which he did graduate work in Europe. He engaged in general practice in British Columbia for five years, and then became associated with the Pitman-Moore Laboratories. His father and a brother were veterinarians, and during his younger days he was something of an athlete and a musician.

Dr. Jakeman served as secretary of the British Columbia VMA for 5 years, secretary-treasurer of the Massachusetts VMA 12 years, and was founder and served as as secretary-treasurer of the New England VMA for 13 years. A member of the AVMA Executive Board 8 years, and of the Board of Governors 5 years, he served as president of the Association, 1941-1942. Dr. Jakeman died December 23, 1946.

\section{3}

The meeting for 1943 was a two-day "war conference" in St. Louis devoted largely to the impact of the war upon the veterinary profession. President $W$. W. Dimock called upon veterinarians to utilize the "limitless number of things we already know how to do to prevent the loss of domestic animals." And regarding veterinary service in marginal areas, Dr. Dimock predicted:

Within a very few years, we are going to have county or area veterinarians who will receive remuneration from federal, state, or county funds sufficient to enable them to live in those isolated sections having a limited livestock population where a veterinarian otherwise would not be willing to live.

In speaking on "Postwar Trends in Veterinary Practice and Research," G. H. Hart notes that with stress in veterinary education being placed on anatomy as:

the great mental discipline . . the curriculum could be criticized for not giving the student a broad enough viewpoint regarding factors affecting the well being of our domestic animals in the light of new bodies of knowledge that are being rapidly developed.

$\mathrm{He}$ mentions genetics and nutrition as being of paramount importance. With broader training in the basic and applied sciences, Dr. Hart feels, regarding the fears of encroachment in certain areas, "We should not be jealous of demands upon us 
for endless repetition of simple routines which the layman can learn to do equally well under supervision."

On "Veterinary Education in the Postwar World," W. A. Hagan contends:

the time will be at hand for all veterinary schools to improve methods, and ... increasing the time devoted to the professional education.... We still fail, in large measure, to carry over into our clinical teaching much of the basic scientific knowledge which the student spends most of his first two years in acquiring.

On additional training, Dean Hagan considered the merits of a second preveterinary year to be less than those of a fiveyear veterinary curriculum, with more work in nutrition, virus diseases, parasitology, and the case method of clinical teaching.

With regard to the transfer of the meat inspection division of the BAI to the food distribution division of the USDA, a resolution was passed "expressing the hope that as soon as is practicable the meat-inspection service be reestablished as a division of the Bureau of Animal Industry."

The AVMA award, established in 1931, was activated with the nomination of retiring BAI chief John R. Mohler as the first recipient of this honor, but presentation of the award was not made until 1946. Arthur W. Miller was appointed the new chief of the Bureau. The IVC prize was awarded to Otto Stader.

Dr. J. V. Lacroix was elected treasurer of the Association, succeeding $M$. Jacob who had died during his twenty-fifth year in this office, the longest tenure of any officer of the Association.

\section{Jacob}

Moses Jacob was born January 6, 1879, in Pennsylvania, and graduated at the head of his class from the University of Pennsylvania in 1899. Associated with the University of Tennessee from 1900, he was professor of veterinary science (1905), head of animal husbandry (1921), and dean of agriculture (1937), in which capacity he was serving at the time of his death on March 22, 1943. From 1915 to 1921 he also served as state veterinarian. Dr. Jacob had been president of the U.S.L.S.A. and of the Southern States VMA, and had served as AVMA treasurer from 1918.

\section{W. W. Dimock}

William Wallace Dimock was born at Tolland, Connecticut, February 20, 1880, and graduated with a B.S. in agriculture from the University of Connecticut (1901) and D.V.M. from Cornell in 1905, following which he spent four years in Cuba investigating animal diseases. After ten years at Iowa State College as professor of pathology, he became head of the Department of Animal Pathology at the University of Kentucky in 1919. It was here that he gained fame for his work on infectious abortion, sterility in mares, and diseases of foals, being author or co-author of more than 150 publications.

A member of several veterinary and livestock groups, Dr. Dimock served as president of the Kentucky VMA, and as AVMA president, 1942-1943. Not content with retirement, at the time of his death at Lexington on July 23, 1953, he was veterinarian emeritus and professor of veterinary science on special assignment at the University of Kentucky.

\section{4}

Despite wartime travel restrictions, attendance at the 1944 meeting in Chicago - the third "war conference" - exceeded 1,500, of which 998 were veterinarians. In his presidential address, C. W. Bower reported on the expanded public relations program, which included inauguration of a series of radio programs for local broadcasting:

Obviously, the time has arrived when veterinary medicine should not "hide its light under a bushel." ... We have yet to bring about a general realization of what this country would be, if diseases of domestic animals were not kept under a reasonable degree of control.

A major achievement had been the success of the AVMA-sponsored campaign 
to upgrade the status of federal veterinarians.

Concerning the type of service the profession should be rendering, Dr. Bower urges:

Veterinarians of the more useful type "sell" more animal health and fewer animal cures. They write prescriptions in terms of management, sanitation, nutrition, and breeding; while they regard chemo- and biological therapy important, there are other factors considered and corrected in obtaining maximum benefits and enduring respect.

And on the numbers of veterinarians needed:

I contend that the country must have more graduates than the colleges are providing, particularly in the face of the proposed expansion of the veterinary service. Expanding the service and supplying men to fill the new places must go hand in hand. Nothing could lead deeper and deeper into incompetent veterinary service-quackery-than to create openings for nonexisting graduates.

Not everyone agreed that more veterinarians were required, despite the urging of leaders of the profession. Dr. Merillat editorialized in the Journal:

It seems that the veterinary profession, here and elsewhere, has to chose between growing in numbers and affluence and staying small and mediocre or, perhaps, expendable... The number of veterinarians a country needs will be governed a great deal by which one of these two schools wins.

And in his inimitable style, he concludes, "Perhaps one should embalm this piece until 1965 - the time it generally takes for imperfections of the veterinary service to become conspicuous." As chairman of the AVMA Postwar Planning Committee, $\mathrm{H}$. L. Foust had pointed out that in 1942 about 46 per cent of veterinarians in the United States were past 50 years of age, and 17 per cent were past 60 .

In acknowledging the existence of areas deficient or lacking in veterinary service, president-elect James Farquharson observes:

To improve the lot of these unfortunate areas, we are beginning to hear much about socialized veterinary medicine. Free enterprise, thought, expression, and initiative would become shackled under the bureaucratic regimentation of socialized veterinary medicine. We stand for continued development and expansion of private practice. But, we realize that we must meet the challenge to provide veterinary service where needed.

A feature of the meeting was a series of panel discussions, including obstetrics, moderated by T. H. Ferguson; swine diseases, by Frank Breed; brucellosis, by W. L. Boyd; and poultry diseases, by Cliff Carpenter. Papers were presented on swine enteritis by H. C. H. Kernkamp; skin diseases by C. P. Zepp; canine nutrition by $M$. L. Morris; sulfonamides by W. T. S. Thorp; avian coccidiosis by P. P. Levine; and avian respiratory diseases by J. P. Delaplane.

Dr. D. F. Luckey received the IVC prize, and I. F. Huddleson was the first recipient of the Borden award in veterinary medicine.

\section{W. Bower}

Charles W. Bower was born at Perry, Kansas, November 26, 1896, and graduated from Kansas State in 1918. He established a practice at Topeka in 1919, his being the first small animal hospital in Kansas. Active in AVMA affairs, he was president of the Association, 1943-1944, was nine times president of the National Board of Veterinary Examiners, chairman of the Judicial Council, and recipient of the AVMA award in 1955 for "selfless devotion to the profession."

Dr. Bower also served as president of the Missouri and Kansas Veterinary Medical Associations, president of the American Animal Hospital Association, and secretary of the Kansas Board of Examiners. He died at Topeka on November 22, 1960.

\section{5}

The 1945 AVMA meeting was cancelled in accordance with a governmental request that all organizations abandon convention plans to relieve the critical transportation problem. Thus it was decided to hold only a meeting of the House of Representatives, 
and that the present group of officers should hold over for the coming year.

In his presidential address, James Farquharson dealt with criticisms that were frequently voiced. In answer to "What has the AVMA ever done for me?" he notes that even many members "have the idea that our central office does nothing more than operate a printing press of the Journal!" After reviewing activities of the AVMA in seeking an elevated status for veterinary education, military, and federal veterinarians, and of the profession through an increased program of public relations and information, he notes, "these stands have benefited every member, as well as nonmember."

And concerning practitioner charges that the AVMA was "ultraconservative" in its policies, Dr. Farquharson observes:

Practitioners constitute, by far, the majority of its membership. .. Practitioner members can, if they choose, have a clear majority in every governing body of the Association. . . A majority of the Executive Board are from the fields of education, regulatory work, and research. By training and environment, they naturally acquire conservative viewpoints. . . The House, in recent years, seems to have failed as the deliberative body in conducting the business of the Association and is prone to be a "rubber stamp" for the recommendations of the Executive Board.

Among the recommendations made by Dr. Farquharson were these: closer integration of the national and constituent associations, and induction of the new president at the first business session; at present, "He is denied the opportunity of presenting his program to the general membership. A year later, he gives his swan song and any worthy recommendations are apt to be wasted effort." Also recommended was a combination of the Executive Board and Board of Governors to avoid "duplication and complications regarding matters of policy that result in unnecessary red tape, delay in action, and inefficiency."

Other recommendations included a fulltime man in the central office for public relations work, a magazine for national distribution to livestock owners, consideration of an increase in dues, and:

Our educational institutions need some stimulating force for certain reforms. ... The demand for internship is convincing evidence that the undergraduate is receiving insufficient training in the art of clinical veterinary medicine. Curricular changes have not kept pace with new fields of veterinary endeavor.

\section{The Committee on History reported:}

Much of the history of veterinary medicine in America has been recorded in the journals as "on the spot" news, but has not been assembled as a history because that would be difficult, discouraging, baffling, and time-consuming [true enough!], while the payoff would be nil because a book, if published, would not sell for enough money to make the project worthwhile.

On this latter count it might be argued that much depends on what is taken as a basis for a project being "worthwhile." In 1944-1945 the budget (out-of-pocket cost) for the American Journal of Veterinary $R e$ search (excluding any allowance for editorial expense) exceeded income by 50 per cent. And with the customary 50 per cent of total AVMA office expense (excluding paper and printing costs) being charged against the AVMA Journal, it did not quite break even. In 1942, L. A. Merillat had urged publication of Bert W. Bierer's monographs on American Veterinary History, but with 50 per cent of the dues being assigned to the Journal, the AVMA Fund proper was overdrawn.

The IVC prize was awarded to $\mathrm{L}$. A. Merillat, and the Borden award to W. L. Boyd.

\section{James Farquharson}

James Farquharson was born in Aberdeenshire, Scotland, January 19, 1897, and moved to Colorado in 1906 . His veterinary training, interrupted by two years' service with the Canadian Cavalry during World War I, was completed at Colorado State A. \& M. in 1921, following which he pursued graduate work at Iowa State and the Mayo Foundation. He taught anatomy at Colorado from 1922 to 1933 , meanwhile con- 
ducting a private practice, and was director of the clinics from 1934 to 1952, during which time he became an acknowledged leader of the profession in the field of large animal surgery.

Dr. Farquharson served on the AVMA Executive Board, Council on Education, and Research Council, and as president during 1944-1946, the only man since 1915 to serve two terms. He died on March 11, 1954.

\section{Postwar Promise}

In his presidential address at the 1946 meeting in Boston, James Farquharson dealt largely with education as the basis for veterinary practice. In particular, he wonders, "if the educators have not lost sight of the art that should follow the science of veterinary medicine. . . There is not one veterinary college that is built around clinical medicine." Also, more attention should be paid to virology, nutrition, poultry, and public health, and to "rural background, personality, and psychological attitude of the applicant in relation to the true objectives of organized veterinary medicine."

In calling attention to the need for more adequate college salaries, Dr. Farquharson observes: "It is not unusual for a veterinary graduate in his first year of practice to make more than a dean of a college." The decision of two states to open new schools "is a most regrettable and unfortunate situation ... the rush of applicants will continue for another year or two at the most." And to staff these schools, "The natural recourse of raiding faculties of established institutions decidedly weakens and undermines our professional and educational standards." In the field of research in the medical sciences:

veterinary medicine should be the leader. . . . We need to encourage the desire for research on the part of the graduate veterinarian. Rela. tively few are willing to sacrifice the time for doing advanced work. . . . Research awakens and promotes exhaustive reading and stimulates active thinking in workers with progressive ideas. . . There must be a closer rela- tionship between the research worker and the clinician... Too often graduate work is done through the microscope to the exclusion of the varied clinical picture ... for the sole purpose of entree to a better position and an increase in salary.

Reporting for the Committee on Postwar Planning, H. L. Foust notes that with an already high average age of practitioners, and greatly decreased numbers of graduates during the latter war years:

a great need for veterinarians has existed, and will continue to exist. The critical factor is that during such periods many possible veterinary needs may be unfilled, many may learn to get along without veterinary service, substitutes for veterinary service may be found, proprietary remedies and drug store and feed store competition cannot be met. Substitutes in the form of legislation may appear. ... All these factors deserve our serious attention.

Features of the meeting were symposia on poultry practice, moderated by Cliff Carpenter; Newcastle disease, by F. R. Beaudette; canine distemper, by C. P. Zepp; penicillin in small animal practice, by $H$. C. Stephenson; artificial insemination, by R. E. Klussendorf; and brucellosis, summarized by A. B. Crawford. Among other presentations were papers on rinderpest by R. E. Shope, M.D.; rabies control by Alexander Zeissig; cattle scabies by $\mathrm{D}$. W. Baker; swine brucellosis by $\mathrm{L}$. $M$. Hutchings; veterinary problems of air transport by B. D. Blood; udder infusion with penicillin by W. T. S. Thorp, and genesis of udder infections by J. M. Murphy; geriatrics in small animal practice by G. B. Schnelle; mammary gland surgery by W. D. Riser; and lameness by J. N. Frost.

The IVC prize was awarded to T. H. Ferguson on the occasion of his fiftieth year of service to the veterinary profession and his seventy-third birthday. Dr. J. R. Mohler received the first AVMA award, for which he had been nominated upon his retirement as BAI chief in 1943, but presentation of which had been deferred. Dr. W. E. Cotton received the Borden award for his research on brucellosis. 


\section{J. V. Lacroix}

John V. Lacroix was born near Hiawatha, Kansas, July 31, 1882, of parents of French nativity, and received his preliminary education from French tutors. He graduated from the Kansas City Veterinary College in 1906, following which he engaged in general practice at Hiawatha. He was on the KCVC staff, 1910-1917, and served as Captain in the Veterinary Corps during World War I, following which he engaged in practice at Evanston, Illinois, from 1919 to 1949 . Perhaps best known as founder (1920) and editor of North American Veterinarian, he continued with his journal and book publishing interests until 1957. Since then he has maintained an active affiliation with a group dedicated to the preservation of American freedom.

Active in association affairs, Dr. Lacroix was one of the founders and guiding spirits of the American Animal Hospital Association, and served as AVMA treasurer 19431947. He was recently elected a Fellow of the New York Academy of Sciences.

\section{7}

At the 1947 meeting in Cincinnati, President B. T. Simms, noting that all veterinary colleges in the United States and Canada were publicly supported, urged:

Unless we are to be branded as ingrates we must pay this debt; pay the people as a whole rather than just the livestock owners and producers . . . by contributing to the health, the wealth, and the happiness of all our people. .. The permanency of the wealth of our people is inextricably associated with our profession. . . As we contribute to the health and wealth we set the stage for happiness.

While the animal disease picture was reasonably bright, Dr. Simms warns:

some developments give us reason for real concern. The gravest of these is the appearance of foot-and-mouth disease in Mexico. Before the Mexican livestock sanitary authorities could get an effective organization to fight it, the disease had obtained the greatest foothold it has ever had on the North American Continent.

Through cooperation of the United States with the Mexican government, however, it appeared that the tide had turned. And rabies:

the disease concerning which we know so much and accomplish so little, was probably more serious in the United States during 1946 than in any other year in history. . . . Losses among baby pigs were probably greater this year than ever before... X disease... seems to be established in several states and ... the brown dog tick is apparently continuing its invasion of new territory.

On the numbers of veterinarians needed, Dr. Simms notes:

Developments in the last few years may cause us to revise upward our estimates as to the number of veterinarians we need. ... Instead of being alarmed at the number of new veterinary colleges which are being developed we can well doubt that even these additions to our colleges will give use a sufficient number of veterinary graduates.

A symposium on foot-and-mouth disease featured the Hon. George W. Gillie, who for some years had been the only veterinarian to be a member of Congress, and who had sponsored the bill authorizing the United States to cooperate with Mexican authorities in the recent outbreak. Papers presented included those on socalled equine encephalomyelitis in pheasants by F. R. Beaudette; the Army veterinary service by Col. J. A. McCallam; the proposed national examining board by W. R. Krill; developments in nutritional research by M. L. Morris; hormone therapy by C. A. Cairy; baby pig disease by G. A. Young; the bovine placenta by H. E. Kingman, Sr.; infertility in cows by J. W. Cunkelman, in bulls by G. R. Moore, and in swine by L. M. Hutchings. Also intravenous gelatin in shock by Mark Allam; rabies by E. S. Tierkel; and veterinary public health by Martin D. Baum. Several papers and a panel discussion were presented on Newcastle disease, which had been a problem of increasing importance in recent years.

The IVC prize went to W. J. Butler for his work as a livestock sanitarian; Jacob Traum received the Borden award for his distinguished career in epizootology. Dr. 
J. W. Lacroix retired as treasurer of the Association and was succeeded by W. A. Young.

In an early Journal report on the potential misuse of penicillin in mastitis, F. W. Schoefield and D. A. Barnum warn: "In current veterinary practice, it is evident that penicillin has limitations which at first were not recognized.... Its indiscriminate use will bring a valuable agent into disrepute." Some contemporary reports were rather more optimistic.

\section{B. T. Simms}

Bennett T. Simms was born at Emelle, Alabama, January 25, 1888, and graduated from Auburn University in 1911. After doing graduate work at the University of Chicago, in 1913 he became head of the Department of Veterinary Science at Oregon State College where he was widely known for his work on brucellosis, salmon poisoning in dogs, and in parasitology. $\mathrm{He}$ was secretary-treasurer of the Oregon VMA (1915-1938) and member of the state examining board, AVMA delegate, and member of the AVMA Committee on Education (1919-1928). In 1944 he became presidentelect of the Association, but because a regular meeting was not held in 1945, he served as president, 1946-1947.

In 1945 Dr. Simms was appointed Chief of the Bureau of Animal Industry and served in this capacity until the BAI was absorbed by the Agricultural Research Service, whereupon he became chief of the animal disease and parasite branch of ARS. Upon his retirement in 1957 he accepted a teaching and research position with the veterinary college at Ankara, Turkey.

\section{Fundamental Philosophy}

In his presidential address at the 1948 meeting in San Francisco, W. A. Hagan stressed education as the basis for professional advancement:

It is the function of professional schools to implant basic ideas, concepts, and habits of thought ... [and] an understanding of the processes by which new facts are discovered, for if the graduate is to be a worthy representative of his profession he must constantly, throughout his life, be a student.

And with an obvious need for more veterinarians, and a surplus of applicants with advanced standing, this was an opportune time to increase admission requirements, particularly with a view to obtaining students with more liberal backgrounds.

Dean Hagan called for better clinical training as a more desirable alternative to the perennial proposals for internships, and for continuing consideration of a national examining board with the hope that many states would eventually accept such an examination in lieu of their own. And while he acknowledged the part played by organized public relations:

Every member of our profession is playing a part in enhancing or degrading its reputation with the public, for public opinion is only the composite of many private opinions each of which is formed through contacts with one member, or at best, a few members of the profession.

In speaking on "Veterinary Education in Great Britain," W. M. Mitchell, M.R.G.V.S., affirmed Dean Hagan's stand: "The most fundamental problem of veterinary life is education, and if progress is to be maintained, we can never be content with things as they are."

On "Preventive Veterinary Medicine," K. F. Meyer asserted:

The ideal of medicine is the prevention of disease, and the necessity for curative treatment is a tacit admission of its failure. . . An appreciation of the function of prevention in maintaining animal health and, consequently, of proper values can in time be created by good education. ... The veterinarian must have suitable training in preventive veterinary medicine. As an educated man, he should be familiar with the philosophy of a national health program. ... He should be imbued with the idea of preventive action as an integral part of clinical veterinary medicine. ... A well-informed veterinary profession is an essential keystone in a sound, well-balanced, effective public health program and a very important pacemaker in the future policies to be adopted by animal husbandry and the livestock interests. 
A panel discussion on veterinary pediatrics was moderated by J. W. Britton; on large animal hospital practice by E. J. Frick; veterinary public health by $\mathrm{J}$. $\mathrm{H}$. Steele; and Newcastle disease by J. P. Delaplane. Papers were presented on mastitis epizootology by R. W. Ormsbee and O. W. Schalm; diagnosis of urinary diseases by D. L. Coffin; treatment for filariasis by $F$. J. Kingma; reproductive endocrinology by G. H. Hart; Army horse breeding operations by Col. W. E. Jennings; and control of periodic ophthalmia by $\mathrm{T}$. C. Jones.

The IVC prize was awarded to $\mathrm{A}$. E. Cameron, former Veterinary Director General for the Dominion; and the Borden award to A. F. Schalk for his work on ruminant digestion. Additions to the Honor Roll included past-presidents J. R. Mohler and C. E. Cotton.

For the second year in a row the Association had operated at a deficit, primarily because of rapidly rising material costs and a fixed income. Raising the dues from $\$ 7.00$ to $\$ 10.00$ was expected to relieve the situation, at least temporarily.

\section{W. A. Hagan}

William Arthur Hagan was born at Fort Scott, Kansas, October 14, 1893, and graduated from Kansas State in 1915. He joined the staff there before going to Cornell in 1916 as instructor in pathology and bacteriology. In 1926 he became head of the department, and in 1932 dean of the school of veterinary medicine. During his tenure at Cornell, he earned the M.S. degree, was an assistant at the Rockefeller Institute, studied in Europe, served as consultant to the $\mathrm{BAI}$, and surveyed veterinary educational and livestock disease-control problems in postwar Germany, among other activities. In 1938 he was awarded a Doctor of Science degree by Kansas State University. In addition to numerous contributions to the periodical literature, he authored a text on The Infectious Diseases of Domestic Animals (1943).

Dean Hagan served on the AVMA Executive Board, as a member of numerous committees, and as president of the Association, 1947-1948. He retired as dean at Cornell in 1959, at which time he had been the senior member of the group of veterinary deans for some years. In 1960 he was appointed director of the ARS Animal Disease Laboratory at Ames, Iowa. He died February 1, 1963 while enroute to London.

\section{9}

At the 1949 meeting in Detroit, President L. M. Hurt noted:

The veterinarian's connection with the livestock industry has become increasingly apparent and important. .. The members of that great segment of American agriculture have a great deal to do with the success of the institutions of veterinary medical education, and they are directly responsible for the livelihood of every general practitioner. We work for them - not they for us - except that they are important in promoting favorable legislation both at national and state levels, and especially legislation which appropriates funds.

Among particular problems, Dr. Hurt mentions losses among young animals, indiscriminate use of vaccines and drugs, brucellosis as "No. I Public Enemy," and rabies - of which he writes:

The continued presence of this disease constitutes a national disgrace. . . We should stress the necessity of dog control and mass vaccination as disease-control measures of major importance. There is no longer any logical excuse for the recurrent outbreaks.

A resolution was adopted calling for establishment of "a line of demarcation between the services the lay inseminator is qualified to render and those requiring the graduate, licensed veterinarian." With regard to brucellosis eradication, a resolution "to study the possibility of the employment of lay technicians by the federal government ... under the direct supervision of a full-time federal or state veterinarian" was tabled - in spite of the fact that the BAI already was empowered to use lay inspectors. This resolution had been reworded from an initial proposal to investigate: 
the need for employing lay assistants when conditions are such that practicing veterinarians are able to participate to the maximum of their abilities ... without reducing the service rendered through their regular practice.

Objectors pointed out:

a good part of the practitioners in our part of the country exist because they are able to participate in whatever brucellosis program is carried on ... this question is purely a matter of States' rights ... it looks like the AVMA is backing the idea that they should use lay technicians... with the present tendency for getting medicine into government control, so that anybody can practice it, we do not want, as veterinarians, to encourage any work by laymen.

A revised form of the resolution was adopted later; this specified that a committee:

investigate the possible need for employing lay assistants in any area. If the use of lay assistants is found to be necessary, the committee should recommend in what capacity and under what supervision they can be used.

An innovation was the telecast of a presentation on fracture fixation over a local television station as an integral part of the session on Small Animals - presaging the extensive use of closed-circuit television in subsequent years.

In a symposium on "As Others See Us," Sam R. Guard, editor of Breeder's Gazette, presented a medicine case used by $\mathrm{T}$. J. Stearns of Louisville, and estimated that well over a million animals worth some $\$ 80$ million had been immunized, tested, or treated from its contents. He notes:

Livestock owners have learned to appreciate this service rendered by practicing veterinarians, and are anxious to have the veterinarians themselves realize the important position they occupy in the successful management and healthy maintenance of farm animals.

The IVC prize was awarded to Gerard Dikmans for his research in parasitology, and the Borden award to R. R. Birch for work on brucellosis.

Papers were presented on advances in veterinary therapy by A. H. Quin, in avian viral diseases by F. R. Beaudette, and in poultry pathology by $H$. J. Stafseth; on rabies control by $A$. Zeissig; veterinary aid in Europe by F. A. Todd; swine erysipelas by W. A. Aitken, and brucellosis by L. M. Hutchings; X-ray therapy by M. A. Emmerson; and ophthalmology by W. G. Magrane.

\section{M. Hurt}

Leslie M. Hurt was born near Kellogg, Iowa, November 5, 1880, and graduated from Iowa State in 1904, following which he joined the BAI for a short time. He was a member of the staffs at Iowa State and Michigan State, and in 1912 became city veterinarian for Pasadena, California, shortly thereafter assuming the duties of livestock inspector for Los Angeles County. In 1924 he organized a department of livestock disease control, meat inspection, and related activities, with a large force including a number of veterinarians, the work of which gained him a national reputation in livestock sanitary circles.

Dr. Hurt served as president of the Southern California and the state VMA, on the U.S.L.S.A. Executive Committee and the AVMA Executive Board, and as president of the AVMA in 1948-1949.

\section{TELEVISION AND THE FIFTIES}

The meeting for 1950 was held at Miami Beach, with Florida becoming the twentyfifth state or province to be host to the AVMA. In his presidential address, C. P. Zepp, Sr., noted several trends which would affect the veterinary profession of the future, including:

the rapid development of preventive medicine . . . the rapid development of therapeutic agents and their distribution to laymen ... the increased practice of veterinary medicine by humane organizations under the guise of preventing cruelty ... [ and ] the socialistic trend of society.

On the place of the veterinarian in the economy, Dr. Zepp observes:

First, we are the guardians of health of the animals of the nation, and second, we are the first line of defense in preventing the spread of communicable diseases from animal to man. These obligations make us indispensable for the defense of our nation. 
And on the function of the practitioner:

The scientific administration of drugs and biological products to animals to save their lives and to restore them to health for food and efficient production, is the basis of a veterinary profession. . . . The practitioner cannot delay and depend on the laboratory or records and textbooks when rendering service. ...

So far, here in the United States, our profession has met the needs for veterinary service quite well. However, I can see signs of trouble developing ... agitation to train lay help ... controversy between the practitioners and the regulatory men over the brucellosis program ... the socialistic trend of our federal and state regulations. ... The government can, by its directions and regulations, take over our work. . . . We need to forewarn our government and regulatory men, who can influence this trend, that dictatorial veterinary medicine will be a failure.

On education, Dr. Zepp urged a closer association with medicine as an institution more fundamentally allied with the veterinary profession than is the case with agriculture, and: "The biggest advantage I can visualize for the veterinary profession is that it would advance the standing of its members as medical men." And feeling that the schools had swung too far toward research emphasis:

the policy of selection and education of our future veterinary profession deserves serious consideration by a balanced group of our profession. ... The majority of the applicants for entrance are students . . . who can easily assimilate book knowledge. The selecting boards, composed primarily of educators, few of whom have ever practiced, select this type of man because they want him to be able to carry the veterinary course prescribed by them.

A National Board of Veterinary Examiners was established "to elevate the standard of qualification for the practice of veterinary medicine," by administering a written examination which states could accept in lieu of their own. Decision to use the national examination, and other requirements, including practical examinations, would be left to the individual states. Dean W. R. Krill, chairman of the committee which formulated plans for the board, was elected its first president, and J. G. Hardenbergh the first secretary-treasurer.
Dr. L. A. Merillat retired as editor-inchief of AVMA publications and was succeeded by R. C. Klussendorf, who had been associate editor and assistant executive secretary of the Association since 1945. Dr. Klussendorf resigned the following year, however, and was succeeded temporarily by C. R. Donham, until W. A. Aitken was appointed editor-in-chief in 1952. The Association passed the 10,000 mark in membership.

The IVC prize was awarded to N. S. Mayo for his long record of contributions to the veterinary profession; the Borden award to James Farquharson for his contributions to surgery and medicine; and the AVMA award to L. A. Merillat "in recognition of fifty-seven years of service." Dr. L. Van Es was added to the Honor Roll, which numbered one sixty-year member, H. P. Eves.

Papers were presented on "National Defense and the Veterinary Profession," by Brigadier General J. A. McCallam; and on the USAF Veterinary Service by Colonel W. O. Kester. Panel discussions were held on veterinary public health, rabies, distemper, heartworms, and infertility. Papers were presented on antihistamine therapy by A. H. Quin and C. M. Cooper; brucellosis by C. A. Manthei, and by L. M. Hutchings; canine hepatitis by J. A. Baker; the dog psychologist by C. E. Harbison; radioisotopes in poultry research by C. L. Comar; umbilical hernia by D. L. Proctor; and socialistic trends in medicine by E. R. Annis, M. D.

\section{P. Zepp}

Clarence P. Zepp, Sr., was born near Gettysburg, Pennsylvania, March 10, 1892, and taught school three years prior to entering Cornell, where he graduated in 1919. A championship wrestler, he was also a member of the football team and the honor society. During World War I he served as an artillery officer. A practitioner in New York City since graduation, Dr. Zepp has been active in association affairs, and served as an executive board member of the New York City and State societies. 
He was president of the American Animal Hospital Association in 1944-1946, and AVMA president in 1949-1950. A son, C. P. Zepp, Jr. (Cornell '43), has been associated with him in practice for some years.

\section{1}

At the 1951 meeting in Milwaukee, President W. M. Coffee recognized a demand for specialization in veterinary practice and a need for more training in nutrition. In calling upon all veterinarians to become AVMA members, he urges:

We need a strong organization because our number is small, especially compared with the large amount of diversified services we are called upon to perform, and compared with the size of the groups we sometimes oppose. . . We need a strong organization to protect our profession against encroachment by unqualified competitive services.

The Milwaukee meeting marked the first use of closed-circuit television at an AVMA meeting, with the first telecast being a demonstration of anesthesia narrated by James Farquharson; others were on canine surgery with C. F. Schlotthauer; poultry diagnosis with C. H. Cunningham; and large animal surgery with E. J. Frick. Symposia were held on brucellosis, fractures, bacterial diseases of poultry, avian respiratory diseases, aids in dystocia, reduced fertility in cows, fertility in bulls, and veterinary public health practice.

In addition to a symposium on veterinary public health in civil defense, a special conference was held on military requirements and civil defense. On the possibilities of biological warfare, W. A. Hagan warns:

in the present state of "cold war," it is wholly conceivable that enemies may not wait for the outbreak of actual warfare to begin biological attacks. So far as animal diseases are concerned, it is important that all veterinarians be alert now for the appearance of unusual diseases. . . Local veterinary practitioners are the key men in our defense against biological warfare directed against animals. ... No practitioner should think that he is unlikely to be the first to see such diseases.
From another angle, W. T. S. Thorp notes:

It is certain that the veterinary research worker will be involved directly or indirectly in the defense of this country. ... We are well equipped for this task. The veterinary research worker is familiar with many of the disease agents which could be used against us.

And in an atomic attack, C. A. Brandly observes:

Responsibility demands that the veterinary profession so organize and mobilize its manpower and facilities that in event of atomic disaster its resources may be utilized fully and effectively through the agency of the director of civil defense... The veterinarian can contribute valuably in the treatment of casualties during the critical two- to four-day period following an atomic attack ... [ and ] veterinary hospitals . . may qualify as first-aid stations.

And in addition to handling animal casualties, "the veterinarian must deal also with problems created by exposure of food to the elements and to contamination."

In presenting some of the broader aspects of the problem, Asa Winter suggests:

We think we are busy now, and we are, in serving to protect the health of a livestock population which regularly contributes between 55 and 60 percent of the total agricultural income of this nation. We must think seriously on the effects of disruption of this industry, such as could occur at any time through carefully planned sabotage.

The IVG prize was awarded to $R$. S. Sugg for his manifold contributions to the veterinary profession; the Borden award to L. A. Klein for his work on dairy cattle disease control; and the AVMA award to A. H. Quin for his leadership in public relations work. Adolph Eichhorn became an Honor Roll member; N. S. Mayo and E. B. Ackerman joined the elite sixty-year circle.

\section{W. M. Coffee}

William M. Coffee was born near $\mathrm{Pa}$ ducah, Kentucky, February 25, 1899, and graduated from the Indiana Veterinary College in 1918. The son of a veterinarian, and owner of a stock farm, Dr. Coffee has 
been associated with livestock all his life. After a year of practice in Louisiana, he returned to LaCenter, Kentucky, where he established a general practice and clinic which grew large enough to require several professional assistants.

Dr. Coffee served as president of the Kentucky VMA and the Southern VMA, trustee of the University of Kentucky, delegate to the AVMA House of Representatives for nine years, and was president of the Association in 1950-1951.

\section{2}

Following meetings in new locations Miami Beach and Milwaukee - the two previous years, the meeting for 1952 returned to Atlantic City - after a lapse of 51 years. Of those present in 1952, S. E. Hersey, R. S. Mackellar, Sr., and H. Preston Hoskins (as a young "visitor") had been present at the meeting in 1901. President J. R. Wells urged:

With no remaining vast frontiers to settle and put into production, we must do a more efficient job of conserving what we produce. . . . Reduction of [ disease] losses and the adequate feeding of our people present a tremendous challenge to the profession. ... $A$ better understanding between all the medical professions will be beneficial to everyone.

Concerning "two controversial matters," Dr. Wells notes with alarm:

the recommendation of the Council on Education to scrap the traditional requirement that the head of a veterinary college be specified as a veterinarian. ... Only a veterinarian thoroughly understands all phases of veterinary education.

This was in reference to Minnesota where the veterinary school was under the jurisdiction of the agricultural college. Following an extended discussion in the House (requiring ten pages of fine print), it was decided to withhold action on the matter. And:

The other controversial subject is a proposed nominating committee to select candidates for the president-elect. ... One of the proposed safeguards is always the inherent right to nominate from the floor, but ... the universal tendency is for a majority of the voting members of any organization to automatically accept the recommendations of such a committee.

From 1906 to 1913 a nominating committee composed of the past-presidents had presented such candidates as James Law, W. H. Dalrymple, J. G. Rutherford, A. D. Melvin, G. H. Glover, and J. R. Mohler. But sentiment for the traditional method of nomination at the meeting had prevailed in the reorganization of the Association effected in 1913.

After several years of operating in the red, the most serious consequence being a reduction of accumulated surplus, the Association had operated in the black to the extent of nearly $\$ 8,000$ the past year, but there had been a deficit of $\$ 12,000$ in operation of the Research Fund. The latter had been nearly depleted by withdrawals of principal to support fellowships, of which 21 had been granted, with 11 graduates completing 14 advanced degrees in the 7 years the fund had operated. In making a plea for increased support of the fund, A. H. Quin emphasizes:

Research .... is the only road that we can travel toward solution of the countless unsolved problems involved in the diseases of animals and their relation to the health of mankind.

The IVC prize was awarded to C. E. Cotton for his work in livestock sanitary matters; the Borden award to R. B. Little, whose work on mastitis had included the first report of the use of antibiotics in treatment; and the AVMA award to A. A. Husman, long active in BAI disease eradication work. The Honor Roll lost J. R. Mohler, who died during the year, but gained A. W. Miller, retired BAI chief. Dr. H. E. Kingman, Jr., who had been appointed to fill the unexpired term of W. A. Young as treasurer, continued in this post to 1958 when he became Executive Secretary of the Association.

Television was used extensively at the sessions, with a total of fifteen separate presentations, including: intravenous medication, bovine claw amputation, rumen sampling, equine endoscopy, swine bleed- 
ing, bone pinning, intestinal anastomosis, anal sac extirpation, ear drainage, hernia repair and bovine cesarean section. Symposia were presented on canine hepatitis, bovine vibriosis, antibiotic therapy, swine and human health, and rabies. Several sessions of a joint conference on illegal practice were held; some of the recommendations included improved public relations, more attention to ethics within the profession, more exact definition of illegal practice, and "a high standard of veterinary medical practice is the best defense against quackery and illegal practice."

\section{Dollar-wise}

A survey of about 2,000 veterinarians conducted by the AVMA indicated that the average gross income of practitioners was about $\$ 17,700(\$ 8,200-29,800)$, with a net of $\$ 7,400 \quad(\$ 4,500-13,500)$. Percentage of time devoted to large animal practice (income) ranged from 88-92 per cent in Iowa, the Dakotas, Nebraska, Wyoming, and Vermont to under 30 per cent in Florida, Massachusetts, and New Jersey. An index purporting to show the adequacy of large animal service available indicated that Delaware, with one veterinarian for each $\$ 500,000$ worth of stock was best supplied. Montana, with one veterinarian per $\$ 5,000,000$ worth was least well supplied. States with a median supply were Alabama, North Carolina, and Iowa.

About 44 per cent of veterinarians (replying to the questionnaire) participated in regulatory work, with annual earnings of about $\$ 200$ to $\$ 1,400$, and 68 per cent indicated they had a source of income in addition to practice. Gross income from large animal practice tended to be related to the number and value of livestock (excluding poultry); the total number of veterinarians was more closely related to value than to numbers of livestock. There was little correlation between numbers of veterinarians and gross income.

While this survey (reported in 1954) indicated that practitioners in 22 states obtained 40 per cent or more of their income from small animal practice, and less than 10 per cent in but 4 states, only 10 per cent of the veterinarians listed in the 1954 directory classified themselves as small animal practitioners.

A survey in 1956 indicated an average net income of $\$ 10,694 \quad(\$ 5,600-13,700)$, about 45 per cent higher than in 1952 . Practice accounted for the sole source of income for 74 per cent (but 68 per cent had "other sources" in 1952), and 78 per cent of veterinarians practiced alone; 72 per cent worked 60 hours, and 41 per cent worked 70 or more hours per week. Small animal practice accounted for 45 per cent of gross income, and net income tended to be related to the proportion of the gross derived from small animals. While 47 per cent of large animal practitioners who charged relatively low fees were in the highest net income bracket, the opposite tended to be true of small animal practitioners.

\section{J. R. Wells}

John R. Wells was born in Falls Church, Virginia, February 23, 1894, and graduated from the University of Pennsylvania in 1922. He served on the staff of the Angell Memorial Hospital two years, and in 1925 established a general practice in Palm Beach, Florida, serving also as municipal meat inspector for Palm Beach and West Palm Beach. In 1935 he began specializing in small animal practice in West Palm Beach.

Dr. Wells was president of the Florida VMA in 1935, and served several terms on the state examining board. He was a delegate to the AVMA House of Representatives (1937-1939), and served as president of the Association in 1951-1952.

\section{3}

In his presidential address at the 1953 meeting in Toronto, W. L. Boyd emphasized the role of research in the development of veterinary medicine:

Through research, the veterinarian will discover and devise new and improved methods of diagnosis and treatment, both preventive and therapeutic. The successful control of dis- 
eases of newborn animals, which are at present responsible for tremendous losses, will be of untold value in meeting new food-production goals. . . The degree to which veterinary medicine will continue to advance will be measured by the extent or degree to which we support, prosecute, and utilize the developments of our research programs.

Among recent developments cited by Dr. Boyd were: solution of the hyperkeratosis problem; a method for diagnosing atrophic rhinitis; and vaccines for leptospirosis, keratoconjunctivitis, hog cholera, Newcastle disease, canine distemper, and hepatitis. Some of the lethargy regarding civil defense in general, and the threat of bacterial warfare in particular, he contended, should have been dissipated by the sudden and inexplicable outbreaks of foot-andmouth disease in Canada, and of anthrax and vesicular exanthema in the United States in 1952; "It is high time that the veterinary profession should play a more active role in matters of civil defense."

In an early report on "a new philosophy" in swine disease eradication, G. A. Young noted:

Swine diseases may be effectively eradicated by preparturient removal of baby pigs by hysterectomy, early isolation of the pigs, and adaptation for raising on the farm with reasonable precautions to prevent exposure to disease.

This technic has since been widely applied in the production of specific pathogen-free pigs, particularly with regard to control of atrophic rhinitis and transmissible gastroenteritis.

Television demonstrations included use of magnets in "hardware disease" of cattle, bloodless tonsillectomy, cataract extraction, perineal herniorrhaphy, curarization in dogs, bone grafting, skunk de-scenting, hip repair, abomasotomy, and pudendal nerve block. Symposia were held on enteric diseases of swine, hog cholera eradication, leptospirosis, radiology, canine distemper, hospital management, skin diseases, bovine infertility, and state veterinary health programs. Papers were presented on antibiotics in poultry feeds, frozen semen, veterinary public health education, and a number on Newcastle disease.
The IVC prize was awarded to Leunis Van Es, long associated with animal disease research at the University of Nebraska; the Borden award to G. H. Hart for his work in infectious, nutritional and endocrine diseases; and the AVMA award to G. W. Gillie, who as a member of Congress had been instrumental in securing legislation upgrading federal and military veterinarians.

\section{W. L. Boyd}

Williard Lee Boyd was born at Batavia, Iowa, September 27, 1883, and graduated from the Kansas City Veterinary College in 1909, where he instructed for two years before going to the University of Minnesota in 1911. Associated with C. P. Fitch in brucellosis research, he moved through the ranks to become director of the School of Veterinary Medicine in 1947 , retiring in 1952 after 41 years of service to the University.

At various times Dr. Boyd served as president of the Minnesota State Livestock Sanitary Board, the Research Workers in Animal Diseases in North America, the Minnesota Veterinary Medical Society, and the AVMA (1952-1953). In 1945 he received the Borden award for his work in cattle pathology.

\section{The Ethical Question}

In his presidential address at the 1954 meeting in Seattle, Brig. Gen. J. A. McCallam urged establishment of "an official and adequate reporting system of communicable diseases of animals in the United States." And in calling for action toward obtaining increased grants from Congress for animal disease research, he observes:

The present administration ... has appropriated millions for research in various fields of medicine and for dental research. . . . Is is not time . . . to bring to the attention of Congress the need for increased funds for research in animal diseases to combat the tremendous losses among food-producing animals? Also, the effect these losses have on the economy of this country and the public welfare.

As a matter of "concern and vital importance," General McCallam pointed to "the 
active campaign conducted by some druggists, and at least one state pharmaceutical association, to encourage and advocate the development or expansion of an animal health department in drugstores."

Speaking on the problem of dispensing vs. vending, at a joint conference on Public Relations and Ethics, J. M. Arburua notes:

We have no clear-cut line of demarcation where one ends and the other starts... But the time has come when an answer must be found. ... We must overhaul our present code of ethics in regard to dispensing and formulate a new veterinary code, and not follow too closely our old ideas which we took from the practitioner of human medicine.

And on dispensing vs. diagnosis, F. B. Young urges:

We have gotten into more or less of a rut ... not charging for our true veterinary service. . . Our best... means of fighting lay treatment of livestock is to stress diag. nosis. ... . We should not dispense on owner diagnosis except in very obvious cases. . . . If you depend upon the sale of drugs for your principal income, you can expect competition. Veterinarians don't have any God-given rights to sell drugs for animals. . . Veterinarians should stay more in the field where they have a monopoly, that is with diagnosis and service.

Regarding national advertising and local promotion of pet remedies, A. G. Misener contends:

the small animal practitioner is not rendering a complete veterinary service to his clients unless he is prepared to dispense those medications that are required after a proper diagnosis is made. If he does not have the service available ... the next time the pet is afflicted with an ailment ... the druggist or pet shop proprietor may consult his diagnosis chart and sell medication which may do no good, or may even harm the pet.

On the broader aspects of the problem, W. R. Krill emphasizes:

Somewhere along the line in our public relations we have failed to impress our clients with the importance of a diagnosis and that medication should be based on a careful physical examination of the patient. It is the responsibility of every practitioner to educate his clients as to the dangers of indiscriminate medication; that early diagnosis is essential to good livestock disease control; and that drugs are no better than the care and professional knowledge which has been used in making the examination in order to determine the course of treatment to be followed. ... These are the positive things our profession has to offer the public. If these are fully carried out by every veterinarian, I doubt that we need worry about the merchandising of drugs.

Apropos to the discussion on ethics, a Veterinarian's Oath, promulgated by A. H. Quin, was adopted by the House with the idea that it would be administered to graduating seniors by college faculties:

Being admitted to the profession of veterinary medicine, I solemnly dedicate myself and the knowledge I possess to the benefit of society, to the conservation of our livestock resources and to the relief of suffering of dumb animals. I will practice my profession conscientiously and with dignity. The health of my patients, the best interest of their owners, and the welfare of my fellow man, will be my primary considerations.

I will, at all times, be humane and temper pain with anesthesia where indicated. I will not use my knowledge contrary to the laws of humanity, nor in contravention to the ethical code of my profession. I will uphold and strive to advance the honor and noble traditions of the veterinary profession.

These pledges I make freely in the eyes of God and upon my honor.

The IVC prize was awarded to F. W. Schoefield for his work in veterinary bacteriology and pathology; the Borden award to M. G. Fincher for his work on the diseases of dairy cattle; and the AVMA award to N. J. Miller who, as a Colorado legislator, had been a prime force in revamping the state public health service to include a veterinary division. The year had taken more than its share of prominent men, including past-presidents Cotton, Dimock, Farquharson, and Flynn; also, H. J. Milks of Cornell, R. P. Marsteller of Texas, and I. E. Newsom of Colorado.

In addition to a broad program of televised clinical demonstrations, symposia were held on anaplasmosis, hepatitis and distemper, hospital management, poultry disease control, and veterinary public health. Papers were presented on blue- 
tongue, ketosis, swine erysipelas, Johne's disease, mucosal disease, leptospirosis, hip displasia, enzymatic debridement, bat rabies, trichinosis, and cortisone therapy.

\section{J. A. McCallam}

James A. McCallam was born in Philadelphia, May 13, 1894, and graduated from the University of Pennsylvania in 1917, following which he was appointed a Second Lieutenant, Veterinary Corps, in the Regular Army. A graduate of the Army Veterinary School and Medical Field Service School, he served in a wide range of capacities, was promoted to Colonel in 1943 and served in the South Pacific, where he was awarded the Legion of Merit and the Bronze Star. In 1946 he was recalled from Japan to become director of the Veterinary Division, Office of the Surgeon General. In 1948 he was promoted to Brigadier General and remained as head of the Veterinary Corps until 1953.

A member of the AVMA since 1918, General McCallam represented the Corps as clelegate in the House, and the AVMA as delegate to the Fourteenth International Veterinary Congress, as vice president, associate editor of the Journal, and as president of the Association in 1953-1954, following which he has headed the Washington, D.C., office of the AVMA.

\section{5}

The meeting in Minneapolis in 1955 shattered previous attendance records with 2,057 veterinarians and a total of 3,715 present. In his presidential address, A. H. Quin urged action:

to adequately and properly evaluate the projected need for veterinary personnel over the next 25 years. . . The greatest tragedy that could possibly befall our profession is that we might fail in meeting this responsibility. . . . Our most skilled economists predict a necessary 35 per cent minimum increase of animal protein foods to feed a continental population of $225,000,000$ within the next 20 years. . . [Yet] there are still approximately 1,000 counties in the United States and Canada that are entirely devoid of service by graduate veterinarians.
In speaking on "Veterinary Medicine and World Peace," Charles W. Mayo, M. D., contends:

It is safe to predict that the future may see an increasingly important role played by the veterinary profession in the achievement of world peace. ... You must be called on and depended on to train teachers who, in turn, will instruct others of their own nationalities so that, by the gradual growth of education and its practical application, the practice of veterinary medicine will be initiated where it does not now exist and will continue to improve and progress where it is present.

Telecast presentations were coordinated by L. E. Fisher (whose finesse earned him a regular job in this department), and included uses of radioisotopes in veterinary research, procuring baby pigs by hysterectomy, canine prostatectomy, glaucoma repair, bone plating in fractures, plastic lens prosthesis, and televised symposia on bovine infertility and on anesthesia.

Other symposia were held on regulatory agencies, brucellosis control, leptospirosis, Newcastle disease vaccines, avian hemorrhagic diseases, and on veterinary public health education. Papers were presented on the downer cow syndrome, inherited defects in cattle, parakeratosis in swine, neurological factors in sexual behavior, bovine fluorosis, osteomyelitis, bone marrow biopsy, fungus infections, ornithosis, and displaced abomasum, among other topics.

The IVC prize was awarded to $B$. T. Simms, past-president of the AVMA and former BAI chief; the Borden award to H. E. Kingman, Sr., for his work on bovine reproduction; and the AVMA award to C. W. Bower for his service to veterinary education and the profession.

A resolution was adopted condemning a proposed prepaid pet health insurance program, or any other such program which would:

restrict the freedom of pet owners to select the veterinarian of his or her choice ... restrict the freedom of the attending veterinarian to elect to consult or to select the consultant of his choice ... interfere with the normal opportunities of the veterinarians to achieve recognition according to their individual professional abilities... or interfere with the 
conduct of veterinary practice on a direct relationship basis between the client and the veterinarian.

\section{A. H. Quin}

Abner H. Quin was born at Crystal, Iowa, in 1895, of a veterinary family; his father and two uncles were veterinarians. Following a period of military service during the Mexican border dispute, he graduated from the Chicago Veterinary College in 1920. After practicing a while in his home town, he joined the Fort Dodge Company as a field veterinarian, where he remained - except for two years of practice with J. V. Lacroix - until 1942. Since then he has been with the Jensen-Salsbery Laboratories, much of the time as director of professional services and vice president of the company.

An active association worker, Dr. Quin was president of the Iowa and the Central Iowa VMA, and a member of the Public Relations Committee of the Kansas City VMA and of the AVMA. In 1951 he received the AVMA award for his leadership in public relations work, and he served as AVMA president in 1954-1955.

\section{6}

At the 1956 meeting in San Antonio, President Floyd Cross called for increased attention to public relations:

For far too long, our profession has been far too modest in letting the public know of its education, abilities, capabilities, attainments, and its rightful place in the medical service of our country.... We have a twofold task; first - the responsibility for keeping the membership informed and abreast of developments of the profession; second - to interest and inform nonveterinary groups concerning the services that we, as veterinarians, are capable of rendering and the extent of our training.

Dr. Cross recommended that more emphasis be placed on animal disease reporting, poultry practice, artificial insemination, genetics, public health, graduate training for veterinarians, and staffing veterinary schools with veterinarians trained in the needed specialties:

are we willing to concede, that veterinary students in certain areas of study can receive from well-trained, nonveterinary instructors the high quality of teaching which we require? Do we also consider that research in certain fields of animal physiology and pathology can be done effectively by individuals who are without a complete and thorough training in the medical field?

Symposia were presented on medical uses of atomic energy, control of zoonoses, wildlife rabies, viral immunology, infectious bronchitis immunization, poultry inspection, ornithosis, and mucosal disease complex. Papers were presented on the California mastitis test, chlortetracycline feeding, prednisolone in ketosis, public health significance of antibiotics in foods, tissue culture, toxicity of organic phosphorus insecticides, production and use of germ-free animals, fluorescent antibody technic, tranquilizing agents, fluid therapy, cat scratch fever, and coxofemoral luxation in cattle, among other topics.

The IVC prize was awarded to Hadleigh Marsh for his work on sheep diseases; the Borden award to H. L. Gilman for his work on cattle diseases; and the AVMA award to past-president Colonel R. J. Foster, former director of the Veterinary Corps. First recipient of the Practitioner Research award was W. H. Riser. Colonel Foster's name was added to the Honor Roll; a major loss occurred with the death of L. A. Merillat.

Among events at the national level affecting the veterinary profession, it was noted, "The proposal of the Secretary of Defense to eliminate the Veterinary Corps of the Army and the Air Force... created a furor within and without the profession." Opposition to the proposal by the AVMA and allied groups finally resulted in the order being rescinded in 1958. Opposition to the compulsory inclusion of veterinarians under social security, however, was unsuccessful.

A survey which attempted to assess the real value of veterinary services to the livestock owner, in terms of actual dollar values of animals conserved, indicated that for every dollar spent on veterinary service, the owner received $\$ 5.78$ return on his in- 
vestment. Regarding veterinary services, it was observed:

there is a definite trend among practitioners to make their charges on the basis of adequacy of professional services rendered instead of net earnings accrued through dispensing of drugs.

\section{H. E. Kingman, Jr.}

Harry E. Kingman, Jr., was born September 4, 1911, at Fort Collins, Colorado, and graduated from Colorado State Univ. in 1933. He engaged in general practice, tuberculosis eradication, and meat inspection to 1940 , when he became assistant director of research for Wilson and Co. In 1951 he was elected treasurer, and in 1953 assistant executive secretary of the AVMA, continuing in both posts until 1958 when he succeeded J. G. Hardenbergh as executive secretary. The son of a noted veterinarian - sometimes a difficult situation - Dr. Kingman has established himself in the tradition of a number of noted father-son combinations in the veterinary profession.

\section{Floyd Cross}

Floyd Cross was born in Berthoud, Colorado, August 10, 1891, and graduated from Colorado State Univ. in 1914. He joined the faculty at Colorado in 1915 and became head of the Department of Veterinary Medicine in 1934, dean of men (1936), head of the Department of Bacteriology and Pathology (1942), and dean of the School of Veterinary Medicine in 1947, retiring in 1957. An accomplished athlete in his undergraduate days, Dr. Cross coached the freshman football team for twenty years.

During World War I he served as an artillery officer on the Mexican border, and in France with the Veterinary Corps. His work as an extension veterinarian during World War II resulted in the establishment by the Colorado Cattleman's Association of a generously supported "Floyd Cross Foundation." In addition, he has been recognized as a leading authority on sheep diseases. Active in the Colorado and the Intermountain VMA, and the AVMA since 1920, Dr. Cross was president of the Association in 1955-1956.

\section{7}

In his presidential address at the 1957 meeting in Cleveland, Brigadier General W. O. Kester presented a twenty-ninepoint program for consideration. Concerning the status of the general practitioner, he emphasizes:

We have a developing problem in how to make the lot to the general practitioner, especially the large animal practitioner, economically more favorably competitive with other newer and developing areas of veterinary medicine. . . . Perhaps our present concept of large animal practice is too restrictive to fit in with modern economics. . . . Many splendid opportunities go undeveloped simply because the local veterinarian is unaware that they exist. Some of these pertain to services which the public demands and will have whether or not we provide them.

A number of General Kester's recommendations have since been adopted, including augmentation of the AVMA public relations personnel, bimonthly publication of the research journal, establishment of a trust to administer the Research Fund, and raising the dues to $\$ 25$.

In discussing "Unanswered Public Health Problems," L. E. Burney, M.D., Surgeon General, U.S.P.H.S., notes:

It was just a decade ago . . . that the veterinarian became an integral member of the modern public health team. The control of animal-borne diseases which are transmissible to man [ has] depended upon the special skills and competencies of the veterinary profession. Today . . . in addition [veterinarians ] are applying valuable insights to many other fields - such as the chronic diseases and environmental health. .. But these tasks are far from finished. .. Sanitary conditions on many farms and in many small towns, for example, are even today below the standards we accept as a nation.

The IVC prize was awarded to Edward Records, veterinary bacteriologist of Nevada; the Borden award to S. H. McNutt for his work in veterinary pathology; the AVMA award to O. H. Person for his 
legislative and public relations work; and the Practitioner Research award to W. G. Magrane for his work in canine ophthalmology.

Television presentations included demonstrations of cardiac resuscitation, immobilizing darts for capture of wild animals, space medicine research, and intraarticular injection of corticosteroids. Symposia were held on canine hipdysplasia, pancreatic disorders, avian chronic respiratory diseases, veterinary public health administration, kennel-borne diseases, parenteral enzyme therapy, and skin diseases.

Papers were presented on preparation of frozen semen, cultivation of viruses in leukocytes, scrapie in sheep, chemical residues in meats, transmission of avian lymphomatosis, intracranial pathology of the dog, human infections of vesicular stomatitis, and physiological responses to radiation, among other topics.

Association membership had increased 55 per cent during the past decade, from about 9,400 in 1948 to 14,600 , with increases in all states, and ranging from minor gains to over 100 per cent increases in Florida, Georgia, Maryland, Mississippi, Montana, Tennessee, Utah, and Canada. The AVMA budget had tripled during this period, and passed the half-million dollar mark. The AVMA Group Insurance Trust, established in late 1956, had enrolled about 2,600 members in 31 states, the District of Columbia, Hawaii, and Canada.

A major revision of the Constitution and Bylaws was adopted by the House of Representatives (which body thereupon became the House of Delegates). Among the changes were provision for more equitable districting and voting power of constituent associations, and replacement of numerous committees by six councils.

\section{W. O. Kester}

Wayne O. Kester was born at Cambridge, Nebraska, August 27, 1906, and graduated with honors at Kansas State in 1931, following which he engaged in practice. In 1933 he was commissioned a Sec- ond Lieutenant in the Veterinary Corps, his first assignment being as district veterinarian with the Civilian Conservation Corps. He witnessed the attack on Pearl Harbor, and served as Chief Veterinarian in the Pacific Theater during World War II, which duty earned him the Legion of Merit. Promoted to Colonel in 1943, he served as chief of the Meat and Dairy Hygiene Branch from 1945 to 1949 , when he was transferred to the Air Force as director of the USAF Veterinary Service. In 1953 he was promoted to Brigadier General, and in 1957 he retired from active duty. General Kester served as AVMA president in 1956-1957, and has been a leading figure in the American Association of Equine Practitioners.

\section{The Old Order Changeth}

The meeting for 1958 was held at Philadelphia, where in accordance with the revised constitution, the presidential address was given at a pre-convention meeting of the newly designated House of Delegates. President W. W. Armistead reported on progress toward implementation of the extensive program outlined the year before by General Kester, and presented a number of:

profound problems which will be successfully met only by a broad revision of our whole professional philosophy. ... We cannot afford to ignore the developing vertical integration $o^{t}$ agriculture, the consolidation of small farms into large ones, and the fast dwindling farnx population. ... There will be increasing demand for the highly efficient specialist, less need for the traditional general practitioner. ... We shall need many more large animal practitioners, but they will no longer be competing with each other for the same kinds of practice.

On the need to increase public awareness of the veterinary profession, Dr. Armistead observes:

So far as the average citizen is concerned, "doctoring" sick animals is all there is to veterinary medicine. As a result, the number of youngsters who want to study veterinary medicine has not kept pace with the general increase in college enrollment. And nearly all ... 
want to enter private practice. ... We need to develop the more accurate idea that the veterinarian is an educated, well-rounded, medical scientist whose services in some way touch the life of every man, woman, and child, and who is able and willing to assume a responsible role in society outside the narrow confines of his professional interests.

Dr. Armistead also called for strengthening of local and state associations with the AVMA serving as a coordinating agency for a federation of local societies, and for greater support for research and education. He concludes:

Let us design our association efforts for the most capable, the most ethical, the most optimistic among us. Let us build a profession which will serve with increasing distinction and will rely on merit, not uncertain legal protection, to assure us of an expanding place in the sun.

The IVC prize was awarded to $\mathrm{H}$. W. Schoening; the Borden award to C. A. Manthei; the AVMA award to J. A. MCCallam; and the Gaines award to Frank Kral. Dr. J. G. Hardenbergh retired as Executive Secretary after eighteen years of service, and was succeeded by $\mathrm{H}$. E. Kingman, Jr. The Association lost its two oldest Honor Roll members, E. B. Ackerman and N. S. Mayo, both admitted in 1891, and added L. M. Hurt and Jacob Traum to this category. Also lost by death since the previous meeting were past-president T. H. Ferguson, Dean R. S. Sugg of Auburn University, and R. L. Anderes, editor of Veterinary Medicine.

\section{J. G. Hardenbergh}

John G. Hardenbergh was born in Berkshire, New York, April 14, 1892, and graduated from the University of Pennsylvania in 1916. He served with the Veterinary Corps 1917-1920, was a member of the reserve to 1936 , and served as an advisor to the War Manpower Commission during World War II. In 1921 he joined the Mayo Foundation in the division of experimental surgery and pathology as one of the first veterinarians in the country to be engaged full time in laboratory animal medicine. In 1927 he became associated with the Walker-Gordon Laboratory at Plainsboro, New Jersey, and taught part time at the University of Pennsylvania.

A member of numerous livestock and public health associations, Dr. Hardenbergh served as secretary of the New Jersey VMA several years, and in 1941 became Executive Secretary of the AVMA. Upon his retirement in 1958, he was cited for having had a major responsibility for the orderly growth of the Association and the veterinary profession; during his eighteen years of service, AVMA membership had doubled, and the budget increased from under $\$ 100,000$ to more than $\$ 500,000$. He died on February 11, 1963.

\section{W. W. Armistead}

Willis W. Armistead was born in Detroit, October 20, 1916, and graduated from Texas A. \& M. College in 1938 (D.V.M.), Ohio State University (M. S., 1950), and the University of Minnesota (Ph.D., 1955). Following a period of practice, he joined the clinical staff at Texas A. \& M. in 1940, and entered the Veterinary Corps in 1942, with service in North Africa and Italy. In 1946 he became clinician and professor, and in 1953, dean, at Texas A. \& M. Since 1957 he has been dean of the College of Veterinary Medicine at Michigan State University.

An author of numerous scientific and general articles on veterinary subjects, Dr. Armistead was consulting editor of North American Veterinarian and contributor to several books. He was president of the Texas VMA in 1947-1948, and of the AVMA in 1957-1958.

\section{9}

The meeting for 1959 was held in Kansas City in conjunction with the Third PanAmerican Veterinary Congress. In his presidential address, R. E. Rebrassier asserted:

We have accepted the new position of leadership to which our profession is called by society. If veterinary medicine is to assume this leadership, it must accept a broad view of the nation's needs and the profession's role. 
And on the challenge of vertical integration in agriculture: "we are approaching this problem in a sound professional manner, without misgivings, and the profession will assume its merited role in the new order."

Concerning "The Veterinarian and the National Welfare," J. A. McCain, president of Kansas State University, observes:

The public image of the veterinarian is more condescending than unfriendly. ... People generally haven't accepted the fact that veterinary medicine is a profession, with intellectual and educational qualifications as demanding as those of other learned occupations. . . . The veterinarian who takes justifiable pride in his profession should be zealous in his determination to correct such erroneous public impressions. Far more important than pride, however, is the fact that a vigorous and progressive veterinary profession is vital to the nation, and whether the profession fulfills its mission adequately depends upon a chain of events starting with public understanding and appreciation.

The IVC prize was awarded to $\mathrm{W}$. $\mathrm{H}$. Feldman for his contributions to comparative pathology; the Borden award to Peter Olafson for his pioneering work on several cattle diseases; and the AVMA award to J. G. Hardenbergh for his eighteen years of distinguished service as Executive Secretary. The Practitioner Research award went to E. A. Churchill for his investigations in large animal surgery; and the Gaines award to W. O. Brinker for his contributions to small animal surgery. The name of H. E. Kingman, Sr., was added to the Honor Roll; W. A. Aitken retired as editor-in-chief and was succeeded by $\mathrm{D}$. A. Price.

Symposia were presented on poultry vaccines, radiology, artificial insemination, canine filariasis, leptospirosis, and respiratory virus infections of cats. Papers were given on mucosal disease, rhinotracheitis, bluetongue, ovine virus abortion, electrocardiography, canine congestive heart failure, feed medication, surgery of the canine stifle joint, avian mycoplasma, avian encephalomyelitis, tuberculosis eradication, radioactive fallout in feed and milk, animal disease control in Great Britain, and bovine rabies in Mexico.

A comprehensive survey of veterinary medicine in the United States and Canada was proposed:

to evaluate the achievements, resources, and potentialities of the veterinary medical profession ... with a view to determining the desirable areas of growth ... and recommending improved approaches. techniques, and methods for the provision of a healthier livestock population.

The areas to be surveyed were education, practice, research, public health, and trends in livestock agriculture. It was anticipated that the survey would require two years and cost about $\$ 400,000$.

As a matter of passing interest, it was at the Kansas City meeting in 1931 that the decision to move the AVMA offices from Detroit to Chicago was announced. This move had been in line with the obvious need for a permanent home, but in 1959 considerable sentiment was expressed for moving from still-rented quarters (third location in Chicago) to AVMAowned quarters elsewhere.

\section{R. E. Rebrassier}

Russell E. Rebrassier was born at Louisville, Ohio, July 27, 1890, and earned the D. V. M. (1914) and M.Sc. (1925) from the Ohio State University. After working for the Ohio Agricultural Commission and Lederle Antitoxin Laboratories, he joined his Alma Mater in 1916, becoming chairman of the Department of Veterinary Parasitology, from which position he retired in 1959. Active in association work, he was secretary (1929-1946) and president (1949), and since 1959 executive secretary of the Ohio VMA.

A member of the AVMA Council on Education, Dr. Rebrassier was presiclent of the Association in 1958-1959, and representative to the International Veterinary Congress at Madrid in 1959. He has also served as president of the Columbus Board 
of Health, president of the Alpha Psi national council, and is a member of Sigma $\mathrm{Xi}$ and Phi Zeta.

\section{INTO THE SIXTIES}

Registration at the 1960 annual meeting in Denver topped 5,000, an all-time high. In his presidential address, S. F. Scheidy called attention to the need for increasing emphasis being placed on career recruitment, and on public and professional relations. President-elect E. E. Leasure, in riscussing the impact of vertical integration in agriculture on veterinary medicine, was of the opinion "that the versatility, the alertness, the aggressiveness, and the educational background of our professional people will enable us to meet the challenge."

Recipient of the AVMA award for meritorious service was C. E. DeCamp; of the Twelfth International Veterinary Congress prize, Dean Emeritus W. A. Hagan, who became director of the newly established National Animal Disease Laboratory at Ames, Iowa, in January, 1960. Dr. D. K. Detweiler received the Gaines award for his work in cardiology, and Professor Emeritus H. H. Dukes, the Borden award for his lifetime contributions in veterinary physiology. Dr. G. T. Easley was given the Practitioner Research award for his work in bovine reproduction.

A signal honor was accorded Jacob Traum with his selection as an Honorary Associate of the Royal College of Veterinary Surgeons.

At the 1961 meeting in Detroit, President-elect Mark L. Morris presented a "Blueprint for Action," calling for increased awareness of the role of veterinary medicine through improved intra-, inter-, and extraprofessional relations, with em- phasis on intensified recruitment and improvements in the educational system. To make the D.V.M. degree have the stature it rightly deserves, he urged commitment to "dedication that builds a tradition for veterinary medicine."

The AVMA award went to Frank B. Young; the IVC prize to Frank Kral for eminence in dermatology; and the Gaines award to J. T. McGrath for his work in neurology. Dr. H. S. Cameron received the Borden award for his multiple contributions to veterinary medicine; and the Practitioner Research award went to J. L. McAuliff for his work in cattle diseases. Dr. Dan J. Anderson moved from the Executive Board to the position of Presidlent-elect.

Among the major problems being given continuing consideration by members and leaders of the veterinary profession during the early sixties were those related to the changing face of large animal practice occasioned by de facto and impending alterations in the patterns of animal production. A noteworthy event was enactment of legislation aimed at eradication of hog cholera. Small animal practitioners in particular were giving increasing attention to the possibilities of incorporation of practice; and a problem affecting all veterinarians was the role of the profession and the individual practitioner in Civil Defense. None of these problems - or a number of lesser ones - will be resolved fully very soon, but it can be said that this was a period of greater awareness of the tasks facing veterinary medicine. In particular, there was a greater determination for accelerated progress as the organized veterinary profession looked toward its centennial year - and beyond it to the beginning of a second century of progress. 


\section{What's Past Is Prologue}

As the American veterinary profession stands upon the threshold of its second century of service, it might well cast a glance in two directions: to view prospects for the future, and to pay due homage to the past. As in any other pursuit of mankind, our veterinary heritage comprises moments of greatness interspersed among a greater profusion of more ordinary events - some so commonplace they seem not to have been events at all. But not only does the past illuminate the present, in a sense it is the present - for the present is not created daily with the sunrise, but is a distillation of the past. And that "what's past is prologue" should come as no surprise, for whether by overt action or by default, we are shaping our tomorrow day by day, and in the accelerated pace of the present, what is today soon becomes another fact of history.

It would augur well, then, to give occasional pause to view our prospects for tomorrow by the reflected - and sometimes flickering - light of what has gone before. More than this, it would be well to cast the searching light of careful inquiry backward as well as forward, not fearful of finding the skeleton of a horse doctor in the medicine chest, for it is only by a full awareness of yesterday's shortcomings as well as successes that we can avoid repeating our mistakes tomorrow.
The founding forty of the United States Veterinary Medical Association had no assurance that the foundling they endowed with pride of ancestry would become a power outside its then-narrow confinesor even survive. But even a superficial reading of the document formalizing their action would indicate that this was no hastily-conceived instrumentality, for many of the concepts stated or implied in the original Constitution and Bylaws are as valid today as they were a century ago. But while their action gives us a convenient means for dating the organized profession of this country, it is evident that they did not create the American veterinary profession de novo - nor would any of the USVMA founders have claimed they had.

What is surprising, considering the obstacles to effective action imposed by both external and internal forces, is that the organized veterinary profession - which was barely able to sustain its own numbers for a long period-did survive. From the vantage point of temporal distance it should be possible to assess some of the factors responsible for the vicissitudes as well as the vitality of the budding profession. That so few individuals have given serious attention to the chronicling of American veterinary history may be considered as mute evidence that all too little 
thought has been given to our heritage. And without an adequate backlog of historical publications based on careful research, it would be presumptuous for one person to draw sweeping conclusions, especially from his own work. In the long run it is up to each individual to determine for himself what significance a recital of fact may have.

\section{AXIOMS OF HISTORY}

In the course of several years of research and writing, however, there have emerged a number of truisms relating to our earlier history which subsequent events have proved significant, so significant that they may be considered axiomatic. The most inescapable of these are: that whenever man and animals coexist there will be problems of a veterinary nature; that if these needs do not receive professional attention they foster unprofessional attendance; and that a prolonged period of neglect cannot be atoned for solely by the issuing of diplomas or edicts, however well backedl they may be by good intentions.

That the veterinary art should have been so long neglected, and that its full potential for benefit to the public is not yet realized, should not be particularly surprising. Of the several medical sciences, it is quite logical that human medicine should have been the first to be developed to a high degree. Yet many people continue to spend more money for fake cancer cures and the like than for the best medicine has to offer, despite an adequate indoctrination based on the observable and publicized accomplishments of the medical profession. And although some aspects of veterinary medicine - in most cases the least evident have more impact upon society than some facets of medicine, the veterinary art by its very nature lacks the immediacy of relationship to persons that medicineby its nature - has, i.e., obvious self-interest.

What has not been made sufficiently apparent is the nature and scope of the stake the ordinary citizen has in veterinary medicine. It is not too far-fetched to suggest that the physician Osler, whose name is still most revered in clinical medicine, probably saved fewer lives than did countless veterinary inspectors of his time who made our meat and milk supply fit for human consumption. Nor is it unreasonable to expect that an individual would be personally grateful to the physician who saves his life, even though principal credit should at times go to the frequently nameless researcher who put the necessary tools in the physician's hand. Medical historians, however, have fairly adequately chronicled these discoveries, along with their applications by clinicians.

\section{IMAGE OF THE PROFESSION}

From a review of our veterinary heritage it is evident that there have been many men whose names have been household words within the veterinary profession-for a time - but whose contributions have been allowed to escape from notice. The same is true of the many discoveries by men who achieved but lesser notice during their lifetimes and have been all but forgotten. And equally apparent is the fact that the work of the practitioner - always the backbone of the profession - in preserving our animal industry from utter destruction, both by his performance of day-to-day routine duties and in times of imminent disaster, is little appreciated. Nor has much been said about the sociologic impact of small animal medicine.

All these-and more - redound to the credit of the veterinary profession, and to the benefit of society. These are matters in which we can and should take justifiable pride and satisfaction. Except as our accumulated experience can be demonstrated to have a direct bearing upon the economy of livestock operations, however, the individual practitioner is constrained by the same mores concerning his abilities as is the physician. A major difference, during the past half century at least, has been that the physician has had a silent part- 
ner - the medical historian - who, by making the achievements of medicine public domain, has contributed immeasurably to the image of the physician.

In considering the image of the veterinary profession during the past century, it is evident that without adequate documentation of our achievements, all too often it has been the sensational and unfavorable notices that have reached public consciousness via the newspapers and farm journals. Without the broader picture only the historian can provide in easily assimilated form, it has been this succession of inadequately refuted exaggerations and half truths that has been accepted as fact. The public - all too many of whom still equate the veterinarian of today with the horse doctor of the late nineteenth century - are completely unaware of the fact that it was during this very same period that veterinarians of the Bureau of Animal Industry wrote a chapter of veterinary and medical achievement unmatched in the history of mankind. It is something of a paradox that the public has forgotten that the general run of physicians of that same time was hardly - if at all - better qualified to practice than was the general run of veterinarians. Still more paradoxical is the fact that perhaps most veterinarians have been as unaware of this golden age of veterinary medicine as the unsuspecting public.

Obviously, then, if our own history teaches us anything, it is that we should learn more of our history - that our heritage has significance not only to ourselves but to everyone. In particular, it is essential we appreciate that what we do not learn we are destined to repeat without realizing it. Perhaps the principal lesson is that the veterinary profession is best served when it renders maximum service to an informed public.

\section{A LOOK AT THE RECORD}

It behooves us, therefore, to take stock of our accomplishments, to keep a record of them before us, and to use this record as one basis for professional development. An adequately documented history might be thought of more or less in the same light as the pedigree of a fine animal: having a certificate of ancestry in hand does not alter one's background, but it does open the record for all to see. And although at any given moment, present performance is of primary importance, being able to point to a record of past achievement gives added assurance of continued productivity.

What, then, have been some of the more significant developments within the veterinary profession during the past century? And of equal importance - perhaps more so in utilizing the record of the past as a guide to future growth - what were the basic factors responsible for these developments? Undoubtedly the prime factor has been the men of veterinary medicine, idealistic men dedicated to the rendering of selfless public service in matters related to the health of domestic animals.

A century ago, when the entire veterinary profession of the country could have assembled in one room - and a considerable part of it did on that fateful day in June, 1863 - there were three of this small band already marked for greatness: Alexandre Liautard in education and journalism; E. T. Thayer in regulatory veterinary medicine; and I. Michener as the epitome of the progressive practitioner. Not long afterward, James Law of Cornell entered the scene, to be followed before the turn of the century by such men as R. S. Huidekoper, W. H. Hoskins, and Leonard Pearson of Pennsylvania, and - a man for the ages $\rightarrow$ D E E. Salmon, first Chief of the Bureau of Animal Industry. Add to these $W$. L. Williams of Indiana and Cornell, and two other stalwarts of the BAI, Fred L. Kilborne and Cooper Curtice, and we have an even dozen of the men who played major roles in establishing the veterinary profession as a vital force prior to 1900. There were others, of course.

If we were to name but one change more responsible than any other in securing for the enlarging veterinary profession its rightful place in the affairs of man, it could hardly be doubted that this has been in the area of education. Beginning with Smith and McEachrean in Canada, and 
Law and Liautard in the United States, the aggregate activities of all those men engaged in teaching and research have been the foundation of all permanent improvements in the veterinary domain. But education, nurtured by research, would avail but little unless the preparation of mind and hand were employed in the service of man. In the long run it has been the combined labors of the well trained and hard working - but little recognized - body of practitioners whose efforts have brought the fruits of veterinary medicine to the people. As with the other professions, it would be difficult to measure the achievements of the practitioner whose work may frequently be significant but is rarely spectacular.

There is one group of veterinarians the men of the BAI - deserving of more than passing tribute. From the beginnings of the Bureau in 1884, it was this small band of dedicated men who in two short decades under their remarkable chief, D. E. Salmon, literally saved the American livestock industry from virtual extinction. Underpaid, overworked, little recognized, and facing formidable odds ranging at times from mere public apathy to overt opposition, these men compiled an amazing record of solid achievement never before, and - under such circumstances - not since duplicated. As detailed elsewhere, the record left by veterinarians of the Bureau, including those who labored under the leadership of A. D. Melvin, J. R. Mohler, and their successors, is worthy of continuing study and broader appreciation. The tradition they established is being carried on under the aegis of the Agricultural Research Service.

Military veterinary medicine, with a heritage extending back to pre-Revolutionary times, came of age only belatedly during World War I, but rapidly established itself as an essential force in national security, both present and future. During two major wars it is probably no exaggeration to say that few groups so small in numbers had responsibilities approaching the scope of those delegated to the Veterinary Corps. Always at the forefront in peace as well as war, Army and Air Force veterinarians presently are engaged in space medicine and radiation biology in addition to other activities, not the least important of which is their basic function in food hygiene.

Small animal medicine, also a late comer, has become synonymous with all that is progressive in the application of advanced medical and surgical technics to pet animals, and - without laying claim to it has indirectly become a socio-economic force of considerable magnitude. With medical research becoming more animaloriented, laboratory animal medicine has developed rapidly as an outlet for specialized service by veterinarians. Coupled with expansion of animal disease research, the demand for veterinarians with either broad or specialized training in the entire spectrum of the medical sciences has continued to outstrip the supply.

Public health work, which as such has been recognized as an outlet for a limited number of veterinarians since the late nineteenth century, has in recent years become an expanded sphere, especially for the veterinarian with graduate level training in public health. Much of the daily work of practitioners in all fields of the profession, however, has always had a closer identification with the public health than has been generally recognized. It should be recalled that it was the BAI veterinarians Kilborne and Curtice, along with others such as Mark Francis of Texas, who did much to elucidate the problem of arthropod vectors of disease through their work on Texas fever, and who thus laid the groundwork for the conquest of yellow fever and the building of the Panama Canal. Maurice Hall discovered a remedy for hookworm, and the Stader splint revolutionized fracture repair. But while these contributions are among the more spectacular which are directly related to human welfare, they are but a few of many. When it is considered that there are some 200 diseases communicable between man and animals, control measures for many of which have resulted from veterinary research - and which are carried out daily by veterinarians - the relationship of veterinary medicine to public 
health becomes obvious. Unconsidered, however, the relationship may tend to be obscured.

\section{A GLIMPSE OF THE FUTURE}

What portents are there for the future? The safest estimate would be that the status of veterinary medicine can be - indeed will be - what we determine it shall be. How far we shall go and how fast is largely up to us, although it would be unrealistic to speculate over the exact shape of things to come in the far distant future. The basis for predicting the present state of the veterinary profession existed twentyfive years ago, but it may be doubted that many, even of the most optimistic prognosticators, would have envisioned the present state of the veterinary profession as a fait accompli. Today we are in a better position than ever before to believe and make use of the truism that "what's past is prologue." To a greater extent than ever before, thinking men are giving careful consideration - based to a degree on the immediate past - to the future, your future and mine. What is most encouraging is the fact that more and more attention is being given, not to "what's in it for me," but to "how can we best serve mankind."

We need establish but one qualification if we are to make a reasonable estimate of the status of the veterinary profession, say twenty-five years from now. It is as simple as this: that we make our plans on the basis of rendering the maximum of service to man. We have the means today - manpower, money, and the mind to do it for accomplishing goals undreamed of twenty-five years ago. The most fundamental of these will be to insure an adequate food supply for the ill-fed millions all over the globe, not excluding those within our own boundaries. Almost everywhere there is a protein shortage that can be alleviated best through optimal attention to animal husbandry, and this end can be served best only by proper attention to the veterinary aspects of animal production. From the lessons of the past it is evident that if we do not serve in this capacity, others will. The enviable record already made by numbers of veterinarians, both civilian and military, in this area would seem to be a fair guarantee that we will do more.

To accomplish this - as only one of a number of tasks ahead of us - will require not merely greater numbers of veterinarians, but more men trained in more skills, educated in broader concepts, oriented to more efficient use of that most precious of commodities-time. A number of the schools have already indicated an awareness of these essentials by executing or laying the groundwork for sweeping revisions of the traditional concept of professional education. Most of the schools have the physical plants to implement these changes of concept; the problem of attracting adequate numbers of competent staff and students is receiving attention long overdue.

With the rapidly increasing emphasis upon promoting public awareness of the role of veterinary medicine in the affairs of man, it seems likely that the problem of recruitment of more and better qualified students will have been solved within a relatively short time. And within a few more years, many of these students - attracted by the increasingly favorable climate for the teacher and investigator will be ready to wipe out the present shortage of qualified educators and researchers.

The upsurge in construction of hospital facilities equal in many respects to those in human medicine is one of the more hopeful signs that the status of the veterinary profession will continue to rise in the public estimation. This is not a superficial development, but one based upon the sound foundation of increased technical excellence and the experience of those who - not so long ago-pioneered in small animal practice. In fact, many of the benefits of advanced hospitalization technics have been extended to large animal medicine, e.g., equine practice, where the in- 
dividual animal has considerable value. To a large extent, the rapid development of small animal medicine has also accelerated the emergence of laboratory animal medicine as a specialty, for it has been the demonstration of technics comparable to those of medical practice that has called favorable attention to the contributions veterinary medicine can make in practically all areas of medical research. Nor should the veterinary aspects of research in animal production be underestimated, something which the lunatic fringe of antivivisectionists conveniently forget if , indeed, they have had it called to their attention. Incredible as it may seem in this supposedly enlightened society, the antivivisection problem will probably become worse before it becomes better.

Large animal practice undoubtedly will become keyed more and more - as it already has in many areas - to the involvement of the veterinarian in management. Not that the practitioner will discard his boots and obstetrical sleeve altogether for a business suit, but that as the exponent of herd health, he will become increasingly involved as a partner in profits to the producer. His primary service will be in furthering productivity by preventing trouble, but fire engine practice as such will not be entirely a thing of the past. In particular, with the increasing value of individual animals, there will still be emergencies to make demands upon his hands - hands even more skilful than today. But it seems unlikely that the same hands that pull calves valued in four or five figures, or repair injured teats on cows with a potential lifetime production of a quarter million pounds of milk, will also be doing much castrating and dehorning, or even much routine vaccinating.

\section{CONTINUUM}

A major change, one of increasing tempo rather than purely an innovation, will be more adequate provision for lifetime education of the practitioner. Today's short courses, conferences, conventions, text- books, and journals are, by comparison with what future promise holds, horribly inefficient both in terms of time and money spent for value received. With the ready availability of films, slides, taped lectures, teaching machines, televised demonstrations, and the like, these technics will probably supplant most of the meetings of today - which differ from those of yesterday in little more than size and number. Meetings will continue to be held, but these will become more and more restricted to intimate conferences and those of specialty groups for informal discussion of matters of mutual interest, with the purely instructional matter being relegated to more convenient and continuous scheduling at home. The social value of such meetings should not be lost sight of and, if anything, should be enhanced by the common interests of such groups.

In the past, the most objective and permanent indication of the status of a profession has been its journals, and this will probably continue, but unless there is a major revamping of format, today's journals will lose out to other media. The journals covering the entire profession will become broader in scope, with more emphasis on what everyone needs to know: news, socio-economic developments, intraprofessional "politics" - in the broad sense, interprofessional relationships, and cultural features of particular interest to the veterinary population. In addition, with a new approach to content, journal advertising - which will continue to be an essential supporting arm-will evolve to a considerable extent into "technical exhibits." Scientific material will be restricted to specialty journals or - perhaps more likely - subscribed to on a topical basis in condensed form, with individual entire articles being made available through largely automated distribution means.

By comparison with today, the practitioner of tomorrow will be better educated, better trained, more skilful in one particular line-but more aware of what is 
going on in other areas of the veterinary profession, in medicine, the animal sciences, and the world at large. He will have a relatively better income and standard of living, including more time for pleasure as well as self-development, and will occupy a more prominent place in the affairs of man. As we have indicated, how far and how fast we will go is not susceptible to precise determination. But on the basis of past performance - history if you will - we can and will go farther and faster than ever before, and those who believe otherwise would do well to look for another means of livelihood.

With due homage to the past, and with proper respect for the lessons it has to offer, the future can be one of unparalleled progress, limited only by the vision of those who dare to dream - and who have the courage and know-how to translate dreams into reality. 


\section{Veterinary Medical Education}

\section{A Rapid Revolution}

THE HISTORY of veterinary medical education in the United States and Canada formally begins with the sincere but unsuccessful attempts of men like George Dadd to establish the Boston Veterinary Institute, and of Robert Jennings to initiate the Philadephia Veterinary College in the 1850 's. The ideas of these men, previously clescribed in this volume, fomented and grew in the minds of scientists, Europeaneducated veterinarians, and legislators until veterinary schools were established in rapid succession from New York to California and from Texas to Montreal.

Compared with the standards achieved by the schools and colleges of the 1960's, the schools of a century ago were primitive and located in livery stables or similar structures in the larger cities. In light of the lack of trained educators, there is little wonder that the schools of the last century were substandard. That the early leaders of the profession were able to influence legislators, and to convince the public of the need for scientific veterinary institutions is no little accomplishment.

Although the French and German influence was present to some degree in the philosophies expounded by the early schools, the greatest influence upon veterinary education in the United States was exerted by the graduates of British schools. As Dr. James Law, a product of Scotland and the first Dean of The New York State

\section{bY GEORGE C. CHRISTENSEN}

Dean, College of Veterinary Medicine lowa State University

Veterinary College at Cornell University, said in 1896:

As an English speaking people, we have been especially influenced by English example in shaping many of our institutions, and in none more so than in those to which veterinary education has been committed. It has been a crowning glory of the Anglo-Saxon race that they have suspected and frowned upon a too paternal government. In Europe and America, South Africa, Australia, and New Zealand, a prominent aim has been to restrict the functions of government to the protection of the citizen in his personal rights of property and conscience, his lawful business enterprises, and his pursuit of pleasure. Education, it is true, came in for a constantly increasing share of national control and support, but this was mainly along classic lines, and was a legacy which came down to us from the early monastic and ecclesiastical schools. For purely secular education, money was slowly and grudgingly allowed, with a wholesome dread of the evils to be apprehended from class legislation. ... It is only in recent years that manifest value to the nation, in its competition with other nations, of the highest knowledge and skill in science and arts, has led to the founding and support of technical and professional schools of all kinds, to keep the country in the front of the race of civilization and progress.

In the United States, as in Great Britain, the veterinary schools were private ventures and consequently largely dominated by financial interests. The founders of each of these schools had to answer these crucial questions: Will the venture pay? Can fees be secured to sustain it? Will the name of 
the college bring the faculty members greater and more remunerative practice? Will the prospective fees, fame, and practice warrant the investment?

Answers to these questions were necessarily dominated by the question of money. The temptation must have been great to subordinate educational consideration. Pressure was heavy to shorten the curriculum to admit ill-prepared candidates, to graduate large numbers regardless of fitness, and as a final degradation, to sell diplomas.

After the ill-fated attempts to establish veterinary colleges in Boston and in Philadelphia, The New York College of Veterinary Surgeons was chartered in 1857 in New York City by John Busteed, M. D. Although the school was hampered by internal strife, it did a remarkable job for its time, operating almost continuously until 1899. Despite its stormy years and final demise before the beginning of the twentieth century, it is generally regarded as the true progenitor of veterinary education in the United States. According to his contemporaries, Dr. Busteed was entitled to be called "the father of veterinary medicine in this country," since he did more than any other to agitate, popularize, and bring the subject of veterinary medicine before the people and government.

The earliest schools had courses that consisted of two sessions of four months each. Frequently, the work of the second year was a repetition of the first. Students also accompanied the professors on calls in private practices.

Matriculation requirements in the early schools were very flexible. An elementary or grade school diploma was supposed to be required for admission, but maturity and practical experience was usually accepted in lieu of formal scholastic requirements. A prematriculation examination of prospective students was occasionally given.

During the period between 1852 and 1948, thirty-four of the veterinary schools established in the United States and Canada were closed down. Some of these were affliated with universities which merely discontinued the veterinary curriculum. The former veterinary schools, in order of their establishment, are as follows:

\section{School Name and Location}

Veterinary College of Philadelphia

Boston Veterinary Institute

New York College of Veterinary Surgeons,

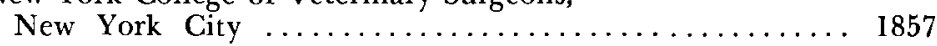

Montreal Veterinary College

(Later at McGill University

Montreal, Canada)

American Veterinary College,

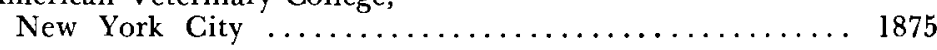

Columbia Veterinary College,

New York City ..................... 1877

Northwestern Veterinary College,

Minneapolis .......................... 1881

Harvard University,

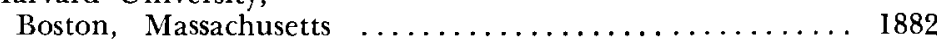

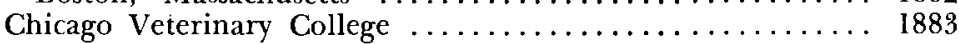

University of South Carolina .................. 1888

Baltimore Veterinary College ................. 1889

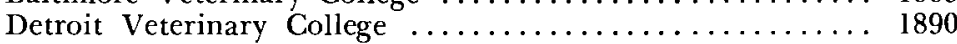

Iowa Veterinary College,

Des Moines ........................... 1890

Kansas City Veterinary College ...................... 1891

Kentucky State Veterinary College,

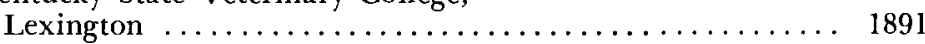

Ohio Veterinary College,

Cincinnati

$\begin{array}{cc}\text { Closed } & \text { Graduates } \\ 1870 & 0[?] \\ 1860 & 0[?] \\ 1899 & 291 \\ & \\ 1903 & 268 \\ 1898 & 628 \\ & \\ 1884 & 80 \\ 1890 & 3 \\ 1902 & 128 \\ 1920 & 2387 \\ 1891 & 1 \\ 1891 & 1 \\ 1899 & 35 \\ 1894 & 13 \\ 1918 & 1789 \\ 1895 & 1\end{array}$

1896 
Indiana Veterinary College,

Indianapolis ............................ 1892

1924

McKillip Veterinary College,

Chicago ............................... 1892

1920

1212

National Veterinary College,

1898

United States College of Veterinary

1892

Surgeons, Washington, D.C. ................. 1894

1927

Queens University,

Kingston, Ontario

Grand Rapids Veterinary College,

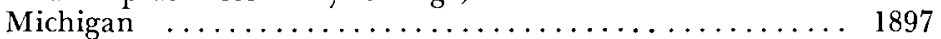

1899

Western Veterinary College,

Kansas City, Missouri .......................... 1897

New York American Veterinary College ............... 1899

San Francisco Veterinary College ................ 1899

$1918 \quad 572$

1908

1922

1918

Cincinnati Veterinary College .................. 1900

1920

University Veterinary College,

Kansas City, Missouri ...................... 1902

1906

St. Joseph Veterinary College,

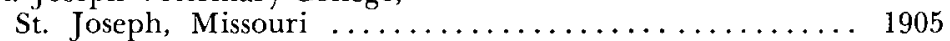

1923

Western Virginia University,

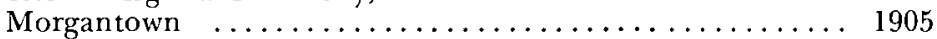

George Washington University,

Washington, D.C. ..................... 1908

1912

1918

Terre Haute Veterinary College,

Terre Haute, Indiana ...................... 1909

Southwestern Veterinary College,

Dallas, Texas .......................... 1909

Arkansas Veterinary College,

Fayetteville ......................... 1913

1916

1920

Middlesex University

Waltham, Massachusetts

1938

1947

Of the current schools, the School of Agriculture and Veterinary Science of Mexico established the first course leading to a D.V.M. degree on the North American continent, in 1853. The National School of Veterinary Medicine became an independent facility in 1916. This was followed by the Ontario Veterinary College in Toronto, Canada, in 1862.

During the latter part of the nineteenth century, the private schools flourished. Why then did they become extinct? Whatever had been accomplished in the field of veterinary medicine was the result of personal and individual effort. The government, which in England, France, and Germany was liberal and generous in the support of veterinary science, had done nothing at first for such schools in the United States. Veterinary Science was languish. ing, not from want of interest but from the lack of funds to conduct experimental re- search. Bogus diplomas were a problem, as was the lack of entrance requirements, standardized curricula, and licensing examinations. Governmental support of veterinary education was the topic of constant discussion in the veterinary journals.

According to Dr. D. McEachran (1877):

This profession had too long been left in private hands and private enterprise. If any department of education is deserving of government support and government supervision, this one is. Were it possible to estimate the annual loss to either country [the United States or Canada], owing to the neglect of so valuable an auxiliary to the agriculturist, or the damage done by uneducated quacks, or even by imperfectly educated men holding diplomas, it would arouse the most apathetic, and waken up our governing bodies to an active sense of their negligence.

It may not be known either to the public or profession, but it is a fact, that so far as the teaching is concerned, it is anything but profitable, and in too many instances, not only do those on whom the greatest responsibility re- 
volves receive no remuneration, but if they are not out of pocket they are fortunate; and too often, instead of being encouraged in their good work, are exposed to the jealousy and ill-will of those whose best interests such institutions must serve most.

Some of the larger universities saw the need for colleges of veterinary medicine just following the Civil War.

In 1868, President Andrew D. White of Cornell University recruited Dr. James Law of Edinburgh, Scotland, to initiate instruction in veterinary medicine. According to Carl F. Becker, in his historical account of the founding of Cornell University (1943):

While in England, President White triumphantly gobbled up Professor Goldwin Smith and Dr. James Law, a highly recommended young man in the veterinary science. And so he returned, flushed with success and pleased more than a little when it was jocosely said that he had brought back, as a part of his European spoils, an Oxford professor and a Scotch horse doctor.

According to President Andrew D. White's diary, James Law was brought over for a salary of $\$ 2,000$ until such time that his independent or outside income totaled $\$ 500$, when his Cornell salary would be reduced in proportion. Dr. Law was educated in the schools of Edinburgh and France. Prior to his coming to Cornell in 1868, he was Professor of Anatomy and Materia Medica in Edinburgh, and Professor of Anatomy in London. Dr. Law established a four-year course leading to the degree of Bachelor of Veterinary Science. Two post-graduate years, followed by a satisfactory examination and thesis were required before the degree of D.V.M. was granted by Cornell University. Although he was highly acclaimed by editorials in the veterinary journals of that time (because of his professional training and his reputation as an author and editor), Dr. Law and Cornell were openly criticized for establishing a veterinary department in Ithaca, rather than in New York City.

As early as 1877 , Dr. Law wrote a letter to the Country Gentleman regarding the requisites of a veterinary school:
A veterinary college requires a body of trustees whose position shall be a guarantee of good faith, such an oversight in fact as is now given to our best State and agricultural colleges. It requires a faculty whose attainments are guaranteed not only by public confidence, but by the possession of a degree of one of the best existing veterinary colleges, and if possible by repute for original investigation. It requires that all candidates for admission shall submit to an entrance examination to test their possession of an education sufficient to enable them to pursue their professional studies to advantage. It requires that a very full course of study shall be pursued within its walls before a candidate can present himself for examination in order to the obtaining of a degree. It requires that the degree shall only be awarded after a satisfactory examination at a designated time and place, by a board of examiners apart from the faculty of the college. It requires, finally, a sufficient endowment, so that it may be fully furnished with all the necessary appliances for rendering the instruction lucid and thorough, and to guard against the constant temptation in medical schools to crowd in numbers, irrespective of fitness, and to graduate them at the earliest possible moment, in order to increase the salaries of the teachers.

Although professorships of veterinary medicine were being established in many universities in the United States, Iowa * State College was the first to establish a state supported veterinary college (1879). Up until that time, veterinarians were often self-taught or learned what they knew from older practitioners. This paralleled the procedure practiced by physicians. The idlea of a truly scientific veterinary college in Ames was conceived by Dr. Milliken Stalker, who had graduated in agriculture in 1873 and had attended the New York College of Veterinary Surgeons and the Toronto Veterinary College. Dr. Stalker became the first dean of a school which shared quarters with the department of botany in the college president's old house. A small bedroom served as laboratory and the front parlor as a lecture room. The president's barn served as the first animal clinic. The course of instruction was two years of nine months each. In light of present requirements and scope of subject material, this seems woefully inadequate. However, at that time, medical schools 
generally required two school years of four to six months each.

Dr. Stalker and a physician, Dr. D. S. Fairchild, carried the burden of responsibility for the Division of Veterinary Medicine at Iowa State College from its beginning in 1879 until 1893. House surgeons and nonresident lecturers were changed frequently, but actually did little to relieve the professors of any major responsibility for teaching or research.

\section{NEED FOR RESEARCH RECOGNIZED}

The private schools of the era were interested in applied research, but some crusaders visualized the need for basic investigations. In 1878 Dr. J. Arnold of the University Medical College of New York City wrote:

And now, what can be said of what is being done here in our own land to further scientific medicine or offer inducement to those who are willing to devote their energies to such a noble enterprise? A truthful answer would be of no flattering character, for we shall find that not only the community at large, be they horse doctors or man doctors, either take no interest in these higher studies or being ignorant or indolent, they decry true scientific work because they can see no practical application. This desire for instantancous, practical results is the damnation of true science; the telegraph, the steam engine were not developed by men of commercial minds, but by those who, seeking diligently for knowledge, which is truth, found the precious treasure, and being pure of heart, gave to their fellow men the results of their labors.

According to Williams (1888), the need for veterinary education at that time was demonstrated by several factors. The American institutions were not producing enough veterinarians to fulfill the needs of the nation. British veterinarians were coming to this country in fairly large numbers. All over the country "scoundrels" were assuming the title of Doctor of Veterinary Science. Stockmen were beginning to realize the need for competent veterinarians. The state and national governments were also realizing the need of qualified veterinarians to fill the ranks of the profession.
In 1888, horses, mules, milk cows, oxen, and other cattle, sheep and swine were valued roughly at $\$ 2,236,000,000$. This was a very substantial part of the, nation's total wealth, and uneducated practitioners could not be trusted with such a responsibility. The leaders of the profession began to look objectively at the country's veterinary colleges. During the late 1800 's, it was becoming more and more apparent that increased knowledge of veterinary medicine, improved facilities, and improved methods of teaching were becoming more and more important. The Association of Veterinary Faculties predicted in 1894 that the following things would soon be required universally: entrance examinations, a three-year curriculum, constant use of the microscope, and laboratory knowledge.

Between the years of 1880 and 1900 the number of veterinary schools in the United States increased from three to twenty-five. Most of these schools, however, were of short duration. Of this group, only five are still in existence. The majority of the schools founded around the turn of the century were proprietary in nature. Their primary concern was to produce as many graduates as possible and their standards were not always the best.

During this time, a few leaders were crying out that it was a national disgrace that original research found no home in this country where money could be made. Wealthy men or corporations were willing to find a means for applying the results obtained by scientists in their laboratories. It was also frequently pointed out that the nationality of these scientists was not American. They were generally Europeans.

According to Dr. James Law in 1895, the most accomplished teacher cannot keep fully abreast of the times, unless he is constantly in contact with the "burning questions of the hour," and, therefore:

it is not enough that we secure the best men as teachers, but we must provide them with the means of maintaining their pre-eminence. The veterinary faculty, therefore, and the laboratory workers should be placed in the closest relation 
with every department of sanitary work in the field . . . the ability of teachers in the state college should be constantly stimulated and kept up-to-date, and that students should be provided with the most advanced teaching and the best ocular demonstration.

The eminent scientist is not willing to bury himself where he cannot have the best opportunity for advancement in his specialty. He may decline a chair where this opportunity is restricted, while he would grasp at a position which offered abundant opportunity for investigation and advancement.

The increased recognition of the need for original research to go hand in hand with teaching and practice proved to be the beginning of the end of private schools. Fees could not be raised to a sufficient level to maintain both teaching and research programs.

\section{THE TURN OF THE CENTURY}

During the last five years of the nineteenth century, it became evident to many that the short-term private schools were on their way to oblivion. The low national economy at that time, coupled with inadequate preparation of their graduates, helped spell their doom.

Individual veterinarians and their organizations criticized colleges offering D.V.M. degrees in less than three years. A resolution was passed by the Veterinary Medical Association of New Jersey, disapproving the two-year course offered at the $\mathrm{Na}$ tional Veterinary College at Washington, D.C. An editor of the Journal of Comparative Medicine and Veterinary Archives said that he was certain that those schools which did not come up to the standard demanded by all fair-minded practitioners as absolutely necessary would become extinct. The Iowa Veterinary College, Des Moines, closed five months later.

According to C. A. Cary (1896), it was the duty of every member of the United States Veterinary Medical Association to encourage his respective state to build and equip a state veterinary college and grant no charters to private schools, unless they equal state colleges in faculty, equipment, and course of study. Dr. Cary added that only about one-half of the faculty of the different colleges are fitted to hold the positions which they are in. He disapproved of the common procedure of instructing in a veterinary college, and at the same time maintaining a private practice.

The Journal of Comparative Medicine and Veterinary Archives thus editorialized about the closing of the Ohio Veterinary College in 1896:

There can be but one outcome for a long period in the future of such schools, erected on the basis of a money winning investment. They will go into the wall, for the time today required in properly equipping a veterinary practitioner is very different from ten years ago.

Born of no scientific parental love, devoted to no aspects of educational advancement than a business undertaking could create, it dies unlamented and will soon be forgotten with the hope that it will never be resuscitated under such auspices.

Agricultural colleges began playing an important role in the teaching of veterinary science in the late nineteenth century. Twenty-three out of forty-seven agricultural schools had professors of veterinary science who lectured on anatomy, physiology, diseases of farm animals and materia medica. Students were taught how to properly care for animals and how to treat some of the more common ailments. Although some veterinarians thought these departments and their students would be a menace to the profession, time has proved their value, not only in performing the above functions but in carrying on vital research concerned with diseases and the well-being of the nation's livestock.

During the first quarter of the twentieth century, veterinary education was greatly improved. Nearly all the schools adopted three-year programs shortly after the turn of the century. In 1903, a four-year course was initiated at Iowa State College. By the end of World War I, all the schools had converted to the four-year curriculum. Matriculation requirements had changed from a grade school education to a high school education twenty-five years later. 
The private schools found it increasingly difficult to compete with tax-supported schools. They began closing one by one, until in 1927 they had completely passed from the American scene. Later one private school, associated with Middlesex University in Massachusetts, operated from 1938 until 1947. It was forced to discontinue operations for many of the same reasons as its predecessors. According to a prediction by Williams in 1900 , future veterinary education, reflecting the future of our profession, would be more intensely a part of the university systems, the graduates possessing high attainments, a general education as well as specialized training in surgery, obstetrics, medicine, and other essential subjects.

According to Hagan (1951), the old, private schools were not abandoned without a struggle. They were forced out of existence by advancing educational standards established by state and national gov. ernments and by the profession itself. Another fact in the situation was the rapid decline in the number of horses in cities where all of these schools were located, a circumstance which sharply reduced the incomes from private practice. In spite of their shortcomings, these schools generally served a good purpose. They supplied veterinary practitioners, at a time when they were greatly needed, and when no other source of supply was at hand.

During this period, new schools associated with land-grant universities were begun. In addition to those already at Toronto (Ontario), Iowa State College, the University of Pennsylvania, Ohio State University, University of Montreal, Cornell University, and Washington State University, schools were founded in Alabama, Arkansas, Colorado, Georgia, Kansas, Michigan, and Texas. The schools in Arkansas and Georgia remained open for only a few years, but the other five have been in continuous operation. And Georgia was re-established in 1946.

During this period, numerous discrepancies existed among colleges with regard to requirements for a clegree. The pres- ident of the AVMA stated at the fortythird annual meeting:

There is no work more important than this Association has taken part in than that of veterinary education - uniform matriculation requirements, uniform curricula, uniform degrees at graduation, uniform state requirements, a license to practice and other problems must be met with suitable solutions.

Realizing the need for standardized education, the AVMA organized the association of faculty and examining boards. It was agreed that little could be done to unify standards except on mutual agreement of all schools concerned. Thus, faculty members from all schools were included.

Attempts were being made during the first decade of the twentieth century to increase entrance requirements, to increase graduation requirements, to increase licensing requirements by examination boards and, as previously mentioned, to standardize all educational requirements. Progress made during this period can be attributed in large part to work by the AVMA, by professional publications such as the American Veterinary Review, by local and state professional societies, and by the USDA.

In working with the AVMA and by writing articles in the professional journals, the professional educator greatly influenced the upgrading of the profession. Also, the influence of the BAI of the USDA was felt through published circulars such as: "Report and Recommendations Regarding Veterinary Colleges" and "Regulations Governing Entrance to the Veterinary Inspector Examination." The latter included a list of accredited colleges. This classification of colleges almost immediately became a standard of comparison. Schools not listed were compelled to achieve early accreditation or face extinction. Although some requirements were considered unfair, resulting controversies stimulated introspective examination of veterinary medical education.

One problem of the period was concerned with standardization of degrees of- 
fered by veterinary colleges. Although the degree of D.V.M. (Doctor of Veterinary Medicine) was the most common, various schools offered the V.M.D., M.D.V., D.V.S., M.D.C., V.S., Sc.D.V., S.C., and M. V. It was generally felt that the D.V.M. was most appropriate. Although most educators agreed that the title or degree was not as important as the knowledge of veterinary medicine and the ability to use it, uniformity of degrees was still considered a desirable goal.

During the second decade of the century, the necessity for emphasizing science as well as practice in the veterinary curriculum was recognized. Leaders of the profession publicly proclaimed that the best method for raising the profession to a higher plane was by upgrading the educational institutions. The responsibility of the schools for teaching their students how to prevent the annual multimillion dollar livestock losses was recognized by the public. Legislators appropriated funds for pharmacy and physiological laboratories (new subjects in the curricula), isolation wards, and large hospitals.

Although longer courses and more subjects were popular topics of the time, T. B. Rogers (1914) complained that all student energy was concentrated on receiving passing marks. After comparing the photographic mind with the creative brain, he stated, "Unless enough time is added to the curriculum to allow a more leisurely absorption of knowledge, I do not see that the education of today will give any better results than the education of 40 years ago."

There was a temporary decrease in applications after the standards were raised and the matriculation requirements were made stiffer, but applications increased during the next couple of years. The students who had not been accepted before had gone back to school to pick up the requirements so that they could reapply as soon as possible.

\section{AN ILL WIND}

In 1914 an unexpected calamity was largely instrumental for increased interest in the improvement of standards in veterinary education in the United States. The tragic foot-and-mouth disease plague which struck the United States in the summer of that year had a beneficial effect upon the status of veterinary medicine and veterinary education. The first appearance of the disease was among the hogs of a farmer living outside of Niles, Michigan, in August, 1914. By February, 1915, 2,245 premises and 223 counties of 20 states and the District of Columbia had become infected. Since wholesale slaughter of both diseased and exposed animals was considered the best means of controlling contagious diseases, this was carried out on a large scale. Very rapidly, 68,776 cattle, 68,235 hogs, and 9,087 sheep and goats were either slaughtered or died of the disease.

In a presidential address, delivered at the annual meeting of the Ohio State Veterinary Medical Association in January of 1915, Dr. Septimus Sisson declared:

One of our greatest citizens said not long ago that the American people did not learn so much by experience as by calamities. It is probably true that the recent outbreak of foot and mouth disease, with the attended serious financial losses and dislocation of trade, has done more to bring our profession before the public in a few weeks than all the previous half century of patient and unassuming service.

Several months Iater Dr. L. C. Kigin, Acting State Veterinarian of Nebraska, realized that:

The psychological moment is here and if we do not take advantage of the existing opportunity and inform the rank and file and start our march upward, there is one thing sure, we will certainly go on the decline.

Dr. Kigin stressed the need for raising the entrance requirements for veterinary colleges and added:

I daresay that if the standard of entrance is not given more consideration by veterinary colleges in this country in the very near future it will be a greater hindrance to our advancement and uplift than anything else I know.

A sidle effect of the increase in interest in veterinary education at this time was 
an introduction of short courses for practitioners during the summer by the universities of Minnesota and Pennsylvania and by Iowa State College. These were usually five- to seven-day courses given to help the practitioners keep up with the latest developments in veterinary medicine.

\section{WORLD WAR I}

During World War I many veterinarians were employed in the Armed Forces. The number of freshmen enrolled in all veterinary colleges in the country for the year 1917-1918 was 338 against 637 in the preceding year. Due to the scarcity of instructors, as a result of wartime and the excessive work of the veterinarian at home during this period, there was a natural letdown of the educational staff in the veterinary profession.

According to T. P. White, speaking in 1918:

The graduate of the future must be a trained educator as well as a practitioner; he must be qualified to address public gatherings and have a knowledge of sanitary buildings in public health matters. The profession must expand with balance of world powers and as it appropriates its rightful function in a sphere of science we must look to the individual member to assimilate the necessary knowledge to keep the veterinary problems and ethics abreast of other professions engaged and concerned in making this habitation of man a better place in which to dwell.

Committees were formed in the AVMA pertaining to various phases of professional training. Questionnaires were sent to all veterinary schools in the country requesting detailed information on training programs. Results indicated the lack of competent instructors. There was also a need for uniformity in teaching methods to improve the quality of the final products. An AVMA committee report in 1919 stated that each veterinary college was under profound obligation to furnish education of a high orcler:

It must first have capable teachers, adequate equipment and abundant clinical material. If a given college cannot offer such education, it should provide some means whereby students may procure it at another institution, either as undergraduate or postgraduate work.

One of the trends of state institutions was that they invariably were located in small, inland towns and were associated with agricultural schools in relatively isolated communities. In order to get instructors away from the cities, the salaries had to be larger than any state was willing to pay. Another apparent disadvantage of state schools at that time was that the relationship of man and animal diseases was closer in larger cities. Although there were many critics of the establishment of veterinary schools in the country towns, Dr. C. H. Stange went on record saying:

As far as educating men at state colleges in small cities, I believe we can educate veterinarians for these rural provinces to handle the question - aside from preventing disease among livestock - to more advantage when we have them under those conditions than in any city in which I have been. I want to say the big problems in disease control work in this country are in the agricultural districts and we can train them better in those districts than in any big city.

\section{POSTWAR PERIOD}

The period immediately following World War I saw a rebirth of the veterinary profession and the educational process needed to keep it going. According to Dean Eugene Davenport of the University of Illinois, nothing was clearer than that a new era was at hand in respect to education and research within the field of veterinary science. Dr. Davenport said:

Recent discoveries have thrown new light on the causes of diseases in animals and man, and while they have made treatment more rational than heretofore, they have vastly complicated the subject as a whole. Because of this, the oldtime methods and materials of instruction have rapidly become antiquated, and any college which now undertakes to prepare practitioners in this field must be equipped with the best of apparatus and the most skilled of instructors if it is to meet the demands which the public rightfully makes.

The early 1920's saw a decrease in enrollment in the veterinary schools throughout the United States. Although there was 
some clamor for lowering of standards, it was generally recognized that if good standards were to be maintained, the better elements would be attracted, as every young man entering the profession would act as a force to attract or repel others. The educational institutions began de-emphasizing the study of the horse and cooperated in more complete studies of all domestic animals and factors related to health and disease. They broadened the curriculum in order to better meet the needs of the times.

By trying to instill a greater awareness and appreciation of the areas relating to animal husbandry, the schools better prepared the future practitioners to be conversant and sympathetic with the problems of the clientele. With such a change on the part of the attitude of the schools, the farmer was less reluctant to seek help from a veterinarian as a specialist in livestock matters.

Dr. J. R. Mohler (1921) saw some of the needs of the future when he said:

The veterinary schools have the evolution of the medical schools before them as a guide to their own evolution. The medical schools have dropped preparatory courses and now devote their time to professional work. Substantially what has happened in their case will happen in ours.

Postgraduate short courses were organized for many schools and were popular with practitioners. The need for continuing education was becoming more apparent. Veterinary education entered into the realm of service, the beginnings of true professional status. Schools learned to meet the needs of a better education for more qualified students. The instructional needs of the faculty were geared to meet an ever greater obligation. Veterinarians were considered essential to the livelihood of man.

The dependence of man upon animals existed before the beginning of civilization. With the passage of time this dependence was intensified, rather than weakened. There was now definite progress towards the production of better animals and the training of more highly qualified veterinarians to safeguard their health.

It was generally recognized in the early 1920's that one of the most important duties of the profession was to provide adequate teachers for the maintenance and advancement of the profession. Future progress of the profession was realized to be dependent upon the efficiency of the veterinary colleges. Educators promoted research and investigation, resulting in the establishment of experiment stations in every state. Now, one goal of the colleges was to turn out efficient investigators who had the capacity of determining facts resulting from the deductions of carefully planned and accurately executed experiments.

One of the biggest problems facing the educators in the 1920's was the decrease of graduates from veterinary schools, coupled with the decrease of practitioners. The number of graduates from accredited veterinary schools in the United States over a span of years was as follows:

$\begin{array}{lll}\text { 1908: } 469 & \text { 1909: } 569 & \text { 1910: } 748 \\ \text { 1911: } 806 & 1912: 735 & 1913: 644 \\ \text { 1914: } 684 & \text { 1915: } 698 & \text { 1916: } 734 \\ \text { 1917: } 774 & \text { 1918: } 867 & \text { 1919: } 214 \\ \text { 1920: } 375 & \text { 1921: } 267 & \text { 1922: } 153\end{array}$

On the average, there were 400 veterinarians retiring every year. There were about 125 to take their places. There were many reasons for the drop in graduates. World War I had been fought, and many men had been drawn from the colleges to go to war. These men would normally have been graduated about 1920, 1921, and 1922. The replacement of the horse by the automobile was certainly a second factor. With job opportunities apparently looking dim, it was not surprising that many young men looked to other professions. But, at the same time, the increasing milk market was raising the rural economic level. Veterinary efficiency was getting higher. Livestock numbers and general economic prosperity were tied together. Little by little, the popularity of veterinary medicine as a career was again taking hold. 
The president of the AVMA, Dr. C. H. Stange, addressed the Association in 1924 with the comment that research and education must be depended upon to keep the veterinary profession from lagging behind its sister professions. Other leaders of the profession were saying that no more schools were needed at the time, but the ones that were being established would have to be improved in order to meet the demands of the future. Professors and practitioners alike came to realize that "learning" was a term connected to education outside the college, as well as the time spent in veterinary school.

Although 1924 saw the closing of the last nonuniversity affiliated veterinary institution in the United States, the Indiana Veterinary College, it was also apparent that enrollment in most of the state institutions was low. There was an average of 45 students per college, with Iowa, Michigan, Pennsylvania, New York, Ohio, Colorado, and Kansas having 55 per cent of the 695 veterinary students in the United States.

Educators began to establish publicity programs to interest the public in veterinary medicine. Writing in the Journal of the American Veterinary Medical Association in 1924, Dr. R. A. Pearson said, "All veterinarians should be thinking about how they can help interest young men of the very finest type to enter the veterinary profession to fill the depleted ranks." Practitioners also started to put up exhibits at local fairs and gatherings to interest the general public in the profession and in animal diseases.

Dr. Ward Giltner, dean of the veterinary school at Michigan Agricultural College, saw the vital need for research in the veterinary schools (1923) when he said.

Steps should be taken to provide liberally for further research on the nature of disease. Veterinary education should adequately appraise its responsibility in the matter of training men in curriculo and extracurriculo to serve animal husbandry and, thus, mankind.

More and more veterinarians were beginning to extol the importance of re- search as the foundation in science. As Dr. S. M. Hayes wrote in the Journal of the American Veterinary Medical Association in 1925:

Research in medicine is the fountain from which the knowledge of etiology, pathology, prevention and treatment of diseases must flow. It is the very foundation of the science. No matter what field a veterinary graduate may follow, he must depend upon the results of research. Progress in every branch of veterinary medicine is dependent upon it, and by it, the profession will reach its height of practical usefulness and its highest recognition as a learned profession.

Also, Dr. Hayes pointed out in the same year:

Education in veterinary medicine has, and of necessity must continue, to undergo evolution if we mean by this term growth and development. Knowledge in the field of veterinary medicine has increased faster than it has been possible to change curricula to meet the newer needs of the graduate. It has been necessary to add subjects, and to lay less or greater emphasis upon some that have long been in the curriculum. Our institutions have done well to keep pace, and no censure of inefficiency is here implied. The need for revision of the curriculum is a constant problem.

During the 1925-1926 period there were 13 veterinary colleges in the United States and Canada. These schools maintained a faculty of 130 members at a cost of $\$ 871,591$. Six of these schools had funds for conducting research programs; other schools were involved in research but had no separate funds established for this purpose.

The problem of a decline in the enrollment in the colleges of veterinary medicine in the United States from approximately 1,300 in 1917 to 500 in 1925 was a major one. The number of men being graduated each year was still less than the number of men lost in the profession by death alone. The problem of insufficient academic material was also great. Most of the veterinary colleges had average enrollments too small to make class work either effective or economic. The very best of them did not boast of being adequately supplied in material, equipment, or staff. 
In addition, knowledge in the field of veterinary medicine had increased faster than it was possible to change the curricula and meet the newer powers of the graduate.

\section{THE LOW POINT}

Bright young men were not encouraged by practitioners to enter the veterinary profession. The practitioners were pessimistic of the future of their profession because of relatively low incomes, because of the alleged encroachment of municipal, state, and federal veterinarians upon the field of private practice, and because of the unethical activities of some county agricultural agents and high school agricultural teachers. Thus, in the middle 1920's came one of the lowest ebbs in the history of veterinary education in the United States. The general public did not favor improvement in the veterinary educational system in order to accommodate the increasing demands being placed upon the profession. People still had the picture of the veterinarian as a "horse doctor." Consequently, the decreased interest in and use of horses at that time convinced people that the veterinarian was no longer necessary.

Many of the professional men and scholars of this period realized the dire need for an improved system of veterinary education. Dr. Raymond A. Pearson, president of the University of Maryland stated (1927):

The veterinary profession is necessary for a successful livestock industry. A successful livestock industry is necessary to a successful agriculture. A successful agriculture is necessary to a prosperous nation. The veterinary profession, therefore, is one of the cornerstones underlying national prosperity.

\section{AN UPWARD TREND}

With the onset of 1928, student enrollment in American veterinary schools increased to 791. Some expressed the belief that with new openings for veterinarians constantly being created, there would be general improvement for the practitioner in nearly all parts of the country. The out- look for the profession was never better. With this change in outlook, veterinary schools began making strides towards improving their educational programs. They began to train men to use their common sense in the understanding of the nature, distribution, and the control of disease, and to help students to think for themselves and not to merely cram themselves with an inexhaustible supply of facts and theories.

With the disappearance of the horse as the dominant animal in the veterinary profession, the time had come for an intelligent appraisal of the place of veterinary education and practice in the development of the American livestock industry, in the maintenance of a successful and permanent agriculture, and in the preservation of a prosperous and healthy people. The United States had finally reached the point where it was ready to respect, promote, and employ trained veterinarians and to give them the professional recognition and merit they were due.

The recognized schools at that time were all land-grant colleges, with one exception. The student enrollment varied from 9 to 114 students. David White, of Ohio State University, felt that there were three functions of a school at that time: teaching, research, and a source of authoritative information. Schools of the time, however, were deficient in these respects. Many were inadequately equipped and the buildings were not large enough to house the animals nor were they large enough for teaching purposes. Educators felt that teaching staffs at the schools were inadequate for properly educating veterinarians. Some even felt that there were enough fully qualified teachers in the United States to man only one good school. There was a clamor for graduates to work for higher degrees, such as the Ph.D. It was thought that the duty of any graduate planning to go into teaching was to better the standards of the profession. The Committee on Education in the annual meeting of the American Veterinary Medical Association also felt that the major cleterring factor in the prog- 
ress of veterinary education was the lack of funds.

\section{THE GREAT DEPRESSION}

Between 1930 and 1940 veterinary medicine experienced the throes of readjusting to two major economic calamities. First, the disappearance of the horse (and poor educational standards) led to the closing of the proprietary schools. Secondly, the great depression resulted in lower incomes by prospective college students. Relatively few students could afford to go to college. Livestock values during the first half of the decade hardly warranted the services of veterinarians. It was frequently more profitable to allow an animal to die than to have the added expense of a veterinary fee. Because of reduced enrollments and sharply diminished support from state budgets, school funds were severely cut.

In spite of this, major educational advancement was made between 1931 and 1936. Entrance requirements of all the schools were raised to include one year of preprofessional college work. This preprofessional year made it possible to allow more time for such new subjects as Virology, Pharmacology, Nutrition, and Food Hygiene.

Dean C. H. Stange of the Division of Veterinary Medicine at Iowa State College stated in 1930 that the recruiting of staff members was one of the most difficult problems for the veterinary colleges. He proposed three solutions: first, that medical men be brought in as instructors; second, that men from foreign veterinary faculties be added; and third, that people from the field of "pure science" be allowed to work in veterinary education.

During the depression, the largest group of veterinary students had an interest in and experience with livestock. Nearly 46 per cent of the entering students in 1931 were from farms. The rest was largely made up of students whose parents had professional or executive backgrounds. In 1932, two methods of screening prospective veterinary students were established. First, a preveterinary year was required by some schools and, secondly, one school was limiting its enrollment to only the "most qualified applicants." Included in the latter was a careful evaluation of the high school work, especially in the scientific field, and a personal interview.

Along with the gradual increase in students came a number of other problems. As a result of these problems, the AVMA set up a Committee on Education, which studied the various aspects of veterinary education at the time. This committee, which made its first report in 1931, was mainly interested in the quality of the instruction that the student was to receive, but noted that a lack of qualified instructors prevented professors from doing research and writing.

\section{POSTDEPRESSION YEARS}

In 1934 , there were 1,643 veterinary students enrolled in the ten veterinary colleges in the United States. There was an increase of over 72 per cent in the number of freshmen enrolled as compared with the previous year. The AVMA Committee on Education noted a marked increase in the number of students entering these colleges with college degrees or credits.

In 1935, there was an increase of 332 veterinary students over the enrollment of the previous year. Students were beginning to benefit from many improvements in facilities and by the increased size of the faculty. Among the new improvements appearing at the veterinary colleges were research laboratories, libraries, increased facilities for meat inspection, added facilities for laboratory courses and diagnosis, and laboratories for study of food hygiene. All schools were adding more full-time professors and instructors. Clinic buildings were being enlarged and large animal wards were being added onto the previously small veterinary hospitals.

Requirements for admission to the veterinary schools were becoming stricter. According to W. A. Hagan, dean at the New York State Veterinary College (1936):

In our system of selected admission, we are considering qualities other than scholastic 
ability, although, of course, scholarship is the first requisite. The background of experience with animals is considered, also mental habits and character, as far as they can be determined. All the candidates that are accepted are interviewed, so that their personalities and personal appearance can be judged. Records of mental ability tests often are available, and all that come to us through the New York State College of Agriculture bring with them a farm practice rating, which gives us a fair idea of how much experience they have had with farm animals.

In 1936, the Council on Education of the AVMA defined the necessary curriculum of a veterinary school. The Council's required curriculum included subjects such as Gross Anatomy, Microscopic Anatomy, General, Special, and Post-mortem Anatomy, Bacteriology and Serum Therapy, Pharmacology and Therapeutics, Comparative Physiology, Parasitology, Clinics, Surgery, Medicine, Hygiene and Obstetrics.

During the academic year of 1936-1937, there were 1,968 veterinary students enrolled in United States and Canada. The average freshman class was composed of fifty students. This was from one-half to one-sixth of the number of students that applied for admission. The students that were admitted were selected on the basis of scholarship, motivation, and adaptability. A large share of the students had more than the minimum one year of preveterinary work before applying to veterinary school. Even with the tremendous increase in the number of students, the number of newly graduated veterinarians was still not keeping pace with the decrease in the total number of veterinarians due to death.

During the late 1930 's, veterinarians were not only doctoring sick animals but were taking on a large role in the area of public health. In addition to using animals for research on diseases which were transmissible to man, they were the principal guardians for the nation's food supply. The state universities were taking great pains to produce better trained, more scientifically-oriented veterinarians. This stress on the improvement of the scientific nature of the profession greatly changed the public image of the veterinarian.

Due to the upgrading of the profession, the D.V.M. degree was being sought by an unprecedented number of highly qualified students. Since the schools of that time were hardly prepared to handle the new influx, many major problems pertaining to veterinary education arose.

The first problem, of course, was simply that of accommodating a large number of students. The physical facilities of the universities were largely inadequate, but members of the profession could not agree upon whether more veterinary colleges were needed. Many felt that the country needed better veterinarians, not more. However, this problem of too many applicants was really a boon to the profession for admission boards could pick those students who were academically superior and had the highest motivation. The increased selectivity of candidates for admission to the veterinary colleges gave the public a more positive impression of the profession, and it elevated the prestige of the field as a whole.

Secondly, there was difficulty in securing enough adequately trained teachers for the large number of students. There was a scarcity of graduate students in all fields of veterinary medicine. Consequently, many of the universities began extensive graduate programs to stimulate the better students to enter into the fields of research and teaching.

Numerous debates were reported in the literature regarding the desirability of increasing the veterinary curriculum by another year. All schools at this time were on the four-year professional plan. Dr. O. V. Brumley thought that careful admis. sions would do more to raise the professional standards than increases in matriculation requirements. Dr. Brumley wrote (1938) that a good education was indispensable but of even greater importance was the more fundamental quality of intelligence.

Finally, there were constant problems regarding the curriculum. Curricula were 
being modified in schools throughout the United States in order to improve the preparation of the student for his role in the total field of veterinary medicine. Due to the increased importance of the veterinarian in public health, there was a great deal of planning for the inclusion of pertinent subjects in that field. As other fields or disciplines became especially important they were added to curricula.

\section{WORLD WAR II}

With the beginning of the fourth decade of the twentieth century, an external force, that of World War II, had an important bearing upon the standards of veterinary education in the United States. Up until that time, scientific research was carried on at a relatively slow pace in the general field of veterinary medicine. With the advent of the war, research in animal diseases turned to methods of prevention. Less emphasis was placed on transportation as this was largely taken over by machinery. How. ever even here, our less mobilized Allies made great use of American veterinarians since they used animal power much more than did the United States. Unlike the situation that prevailed during World War I, the United States Army Veterinary Corps was concerned with communication pigeons, guard dogs, Medical Corps research dogs, and sanitation. Emphasis was placed upon preventive medicine and food hygiene.

Although a portion of the veterinary students dropped out at the beginning of the war to join the Army, the federal government soon realized that veterinarians as well as physicians and dentists were constantly needed to keep up the professional manpower in the United States. Consequently, Army Specialized Training Programs were initiated which allowed veterinary students, as well as those in the other professions, to continue their studies while in uniform. Veterinary students were made aware of the many opportunities existing in the field of veterinary medicine. Careers were opening up in all phases of research, teaching, public health work, and laboratory animal medicine, as well as in specialized practice.

Progress in veterinary medicine during the 1940's was rapid. Public relations had been improved by sound veterinary medical practice, coordination with other professions and service organizations, and the establishment of high standards of veterinary education. The war set up an emergency situation whereby the resources of veterinary education could be tested. The results which were highly favorable, proved to other professions that the education given to veterinary students was on the same level as given to men in other learned professions.

\section{POSTWAR EDUCATIONAL EXPANSION}

After World War II, veterinarians were in great demand throughout the United States. Returning veterans wanted to enter upon a course in veterinary training under the G. I. Bill. Many of these men were handicapped by the lack of veterinary schools within their home states. In response to the increased demand for veterinarians and the demand for veterinary education by the returning veterans, seven veterinary schools were founded between the years 1945 and 1948. These schools were established at Tuskegee Institute, the University of Georgia, the University of Missouri, Oklahoma State University, the University of Minnesota, the University of Illinois, and the University of California. Nine years later a new school was founded in Indiana (at Purdue University), bringing the total number of veterinary schools in the United States and Canada to twenty.

The profession continued to grow in depth as well as breadth during this period. By 1949, all schools had extended the preveterinary requirement to two years. As stated by Hagan (1951), "Professional curriculums, highly specialized as they are, are poor substitutes for general education." The trend throughout the United States had now definitely swung to a need for a general education prior to specialized professional training. 


\section{THE MODERN PERIOD}

Let us take a brief look at the twenty veterinary colleges in operation in the United States and Canada at the beginning of the 1960's.

The first veterinary college to be established in either the United States or Canada was the Ontario Veterinary College, established in 1862 by Andrew Smith. In 1908, D. A. A. Grange was appointed principal, and an optional third year was added to the course for the Bachelor of Veterinary Science degree from the University of Toronto. In 1918, Dr. C. D. McGilvray became principal of the college. Four years later, the college was transferred to Guelph in order to effect closer contact with the university and with the livestock industry. Dr. A. L. MacNabb was appointed principal in 1945, and during the next seven years the degree granted was changed from Bachelor of Veterinary Science to Doctor of Veterinary Medicine. Also, the undergraduate course was lengthened to five years, and forty-six acres of land were acquired for a research station. Following Dr. T. Lloyd Jones's appointment to the principalship in 1952 , facilities of the Experimental Disease Station were developed and new buildings were added to the college.

Although Cornell University was the first school to have a Professor of Veterinary Science, the College of Veterinary Medicine of Iowa State University, established in 1879 , is the oldest college of veterinary medicine in the United States. The first dean, Dr. M. Stalker, presided from 1879 until 1900. Since then, the following administrators have been in charge of the activities of the veterinary college: W. H. Beardshear, J. H. McNeil, C. H. Stange, C. Murray, H. D. Bergman, I. A. Merchant, dean of the college from 1952 who retired in 1963 and was succeeded by G. C. Christensen. The college functions in teaching, research, extension, diagnostic service, and clinical service. Research is conducted in all the departments, and its specific research facilities are maintained a mile from the cam- pus. The National Animal Disease Laboratory is located at Ames and provides an opportunity for undergraduate and graduate students as well as faculty members to become familiar with the latest methods of research and the results of that research. I

The University of Pennsylvania's School of Veterinary Medicine was formally established and opened in 1884. The school traces its orientation and philosophy to Dr. Benjamin Rush, a signer of the Declaration of Independence and a member of the medical faculty at the university. Dr. Rush was the first American physician to hold veterinary medicine as a part of all medicine. It is this concept of "one medicine" which is emphasized today throughout the University's Medical Affairs Division of which the School of Veterinary Medicine is an integral part. Graduate facilities are offered through the school's affiliation with the university's Graduate School of Medicine for advanced study in clinical disciplines and with the Graduate School of Arts and Sciences for continuing education in the basic sciences. In addition to its buildings on the university campus in Philadelphia, the School of Veterinary Medicine owns New Bolton Center, a 320-acre rural medical center in nearby Chester County. The first dean of the school was Dr. Rush S. Huidekoper. He has been followed by John Marshall, Leonard Pearson, Louis Klein, George Dick, Raymond Kelser, and Mark W. Allam.

The School of Veterinary Medicine of the Province of Quebec, affiliated with the University of Montreal, is the only Frenchspeaking veterinary school in the Americas. It was founded in Montreal in 1886 by V. T. Daubigny. In 1929 the school moved from Montreal to Oka, Quebec. It was transferred in 1947 to St. Hyacinthe, Quebec. The first building of the new school was erected in 1953. This included administration areas, offices, classrooms, library, basic science laboratories, student quarters, and the research and diagnostic laboratory of the Provincial Health of Animals Service. The requirements for admission to the school at Quebec are the 
same as for other schools in North America. Dr. Joseph Dufresne, the current dean, was appointed to that position in 1960.

A school of veterinary medicine offering a D.V.M. degree was established at the Ohio State University in 1885. Dr. Henry J. Detmers was appointed Chief. In 1895 , the school name was changed to the College of Veterinary Medicine. Deans of the college have been Drs. D. S. White, O. V. Brumley, W. R. Hobbs, and W. R. Krill. Since 1950 , the college has been gradually relocated to a different area of the Ohio State University campus. New buildings are completed for the teaching of anatomy, bacteriology, preventive medicine, parasitology, physiology, and pharmacology. Adcled buildings for the teaching of pathology and for animal holding facilities for research and clinics are being completed. In addition to the usual course of instruction, the undergraduate program is unique in that it provides on-the-job training in the fields of public health, regulatory medicine and in the broad field of preventive medicine, in cooperation with state and federal agencies.

Although the New York State Veterinary College at Cornell University was established in 1896, veterinary medicine was taught as a subject at Cornell University since its founding in 1868. Dr. James Law, a veterinarian from Scotland, was a member of the very first staff to be gathered at Cornell. He taught the entire veterinary science program from 1868 to 1896. Established in 1894, the College officially began operations in the fall of 1896. Dr. George C. Poppensiek was appointed Dean in 1959. He was preceded in this office by Drs. James Law, Veranus A. Moore, Pierre A. Fish, and William A. Hagan. Because of the growth of the University, the old veterinary campus was vacated in 1957 and the College moved into new quarters.

Courses leading to the professional veterinary degree were first offered at Washington State University in 1899. First known as the School of Veterinary Science, the name was changed to College of Veterinary Medicine in 1923. Dr. S. B. Nelson served as Dean until 1919. His successors have been D. E. Wegner, R. E. Nichols, J. E. McCoy, and E. C. Stone, (since 1952, but who resigned in 1962 to accept a governmental post. Dr. J. A. McCurdy is acting dean). The original college was moved to new quarters in 1942. In 1960 , added clinical space was built.

The School of Veterinary Medicine at Kansas State University was formally established as a department in 1905. In 1919 the department became the School of Veterinary Medicine. In recent years, the school has established the Kansas State University Foundation for Veterinary Medicine, which has as its objective the advancement of veterinary science through education and research. Since Dr. E. E. Leasure became Dean in 1948, many new buildings were added to the basic college. Dean Leasure was preceded in office by Drs. F. S. Schoenleber and R. R. Dykstra.

The School of Veterinary Medicine at Auburn, Alabama, was established at the Alabama Polytechnic Institute (Auburn University) in 1907. In 1949, the school was designated as a regional school by the Board of Trustees in accordance with legislative action taken by Alabama and cooperating states. The first students were admitted uncler the regional program in the fall of 1949. The program has sponsored almost 300 students since that time. Dr. C. A. Cary served as Dean from the establishment of the school until 1935. He has been succeeded by Dr. I. S. McAdory, Dr. R. S. Sugg, and Dr. J. A. Greene (since 1958).

Founded in 1907, the College of Veterinary Medicine, Colorado State University, has been under the leadership of Deans G. H. Glover, I. E. Newson, F. Cross, and R. Jensen. Graduate study toward advanced degrees was initiated in 1925. Physical facilities consist of three academic buildings, an animal reproduction laboratory, and an experimental farm. Off-campus facilities are used primarily in the research program. 
A professional program leading to the D.V.M. degree was authorized by the Michigan state legislature in 1909, and the first students were admitted to the College of Veterinary Medicine at Michigan State University in 1910. Succeeding the first dean, Dr. Richard P. Lyman, have been F. W. Chamberlain, W. Giltner, C. S. Bryan, C. F. Clark, and W. W. Armistead. In addition to its veterinary curriculum, the College also enrolls approximately 130 students annually in its Medical Technology curriculum. During the past years, greater emphasis has been increasingly placed on research and graduate study.

The School of Veterinary Medicine at $A$. of $M$. College of Texas was formally initiated in 1916 under the leadership of Dr. Mark Francis. The school occupied a new physical plant in 1955, located on a 270-acre tract of land, adjacent to the main university campus. Dr. A. A. Price was appointed Dean in 1957. In addition to Dean Francis, he was preceded in office by R. P. Marsteller, R. C. Dunn, I. B. Boughton, and W. W. Armistead.

Established in 1944, and advanced to professional college status in 1957, the College of Veterinary Medicine at the University of Illinois has not only expanded and improved its professional training program, but has expanded and integrated its research and graduate program with the clinical, diagnostic and extension activities directly serving the IIlinois animal industry. With the Illinois Department of Agriculture, it jointly operates the Diagnostic Laboratory, offering students an opportunity for extensive training in diagnostic procedures. The first dean, Dr. Robert Graham, was succeeded in 1956 by Dr. Carl A. Brandly.

Tuskegee Institute's School of Veterinary Medicine (Alabama) was established in 1945 as a direct outgrowth of the shift of emphasis on southern agriculture and the increased need for veterinary services. Dedicated in 1950, the School of Veterinary Medicine is permanently housed in six buildings, which provide facilities for instruction in all phases of veterinary medicine. Since 1949 the school has been a regional service institution, cooperating with the Southern Region Education Board in ten southern states, accepting students from these states on a quota basis. Deans of the School of Veterinary Medicine at Tuskegee Institute have been Dr. F. B. Evans, Dr. F. D. Patterson, and Dr. T. S. Williams.

The University of Georgia School of Veterinary Medicine was established by the University Board of Regents in August, 1946. Dr. Thomas J. Jones became Dean in 1947. The first class of students was graduated in 1950 . The professional curriculum of the School of Veterinary Medicine is slanted toward developing welltrained, competent practitioners with emphasis on high scholastic achievement. All professional veterinary classes are housed in the School of Veterinary Medicine building, completed in 1953.

The study of veterinary medicine at the University of Minnesota began in 1947 with the establishment of a school of veterinary medicine on the St. Paul campus as a part of the Institute of Agriculture. In 1957, the school was designated the College of Veterinary Medicine. Dr. W. L. Boyd was the first Director of the School of Veterinary Medicine. Since 1952 administrators have been Dr. M. H. Roepke, Dr. H. C. H. Kernkamp, and, as of July, 1954, Dean W. T. S. Thorp. The clinic building, the first to be constructed for the College, was completed in 1951. Preclinical quarters were constructed in 1954 , and additional buildings were completed in 1959. New diagnostic and animal isolation quarters were finished in 1960 and additional facilities have been approved as part of a continuing expansion program. Many of the current research programs are conducted in cooperation with members of the College of Medical Sciences and the Institute of Agriculture.

The College of Veterinary Medicine at Oklahoma State University was organized in 1947 from the Department of Veterinary Science. The first class of the College of Veterinary Medicine was graduated in 1951. The College of Veterinary Medicine at Oklahoma is a regional school serving 
Oklahoma and contract states under the Southern Regional Education Board. Dr. Glen G. Holm was appointed Dean in 1956. He was preceded by Dr. C. H. McElroy and Dr. Harry W. Orr.

Dr. C. M. Haring, Head of the Division of Veterinary Science at the University of California for over forty years, was the first dean of the School of Veterinary Medicine established at Davis, California. Dr. George H. Hart succeeded Dr. Haring in 1948, the year the first class was admitted. Following Dr. Hart's retirement in 1954, Dr. Donald E. Jasper was appointed Dean, and he was succeeded in 1962 by Dr. W. R. Pritchard. In addition to the professional program, an extensive graduate training program is carried out in virtually all areas of veterinary medicine. A research farm is maintained about one mile away from the central campus for livestock experiments. Isolation units are available in addition to pastures, corrals, and other barns and buildings.

Although veterinary medicine has been taught at the University of Missouri since 1885, the School of Veterinary Medicine was first established in 1946. Dr. A. J. Durant, the first Dean of the school, was appointed in the same year, and was succeeded in 1949 by Dr. A. H. Groth, who retired in 1963 and was succeeded by Dr. B. W. Kingrey. In addition to new buildings on the campus, a ninety acre farm has facilities for the animal disease research program.

The newest veterinary school in the United States is the School of Veterinary Science and Medicine at Purdue University (Indiana) which was established in 1957. The school admitted its first class of students in the fall of 1959. Dr. L. M. Hutchings, former Head of the Department of Veterinary Science, served as Dean from 1957 until his death in July, 1959. Dr. E. V. Morse was appointed Dean in 1960. The buildings housing the teaching, research, clinical, and service facilities of the new school occupy a 34 -acre plot on the main campus of the university. In addition, the school maintains a 360 -acre research farm. As is the case with many of the older schools, Purdue University not only offers a professional curriculum leading to a D.V.M. degree, but has graduate programs leading to the M.S. and Ph.D. degrees in each of the four academic departments.

The twenty veterinary schools in operation in the United States and Canada had a student enrollment of 4,008 in 1961 . Of the 1,104 first-year veterinary students, 55 had five years, 214 had four years, 301 had three years, and 443 had two years of preprofessional work. A total of 210 first-year students have advanced degrees. In addition, veterinarians engaged in graduate study at veterinary schools total 403 . The increasing demand for veterinary education, as evidenced by the number of professional and graduate students in the veterinary schools during the 1961-1962 academic year, is resulting in a broader but yet more detailed professional curriculum as well as a more comprehensive graduate training program throughout the entire United States and Canada.

The earliest schools of veterinary medicine had unlimited freedom in the scope of their curriculum, the number of professors, and plans of studies. The need for standardization of requirements led to a system of self-government employed by the profession in the form of a Council on Education as part of the AVMA. The aims and purposes of the Council, as stated and approved by the House of Representatives of the American Veterinary Medical Association in 1956, are to promote active progress in veterinary medical education in the various schools and colleges with full accreditation of them as the ultimate goal.

In fulfilling this function the Council encourages and assists schools to meet requirements. Upon request, the Council considers evaluation of newly established schools making accreditation possible at the time of graduation of the first class. The Council outlines means and methods for progressive improvement of veterinary medical education. It requires the correlation of scientific knowledge, clinical experience, procedures, and techniques of 
veterinary medical education and the socioeconomic conditions of the times. It strives to establish and apply criteria for the accreditation of schools and colleges which offer courses leading to a degree in veterinary medicine, including admission requirements, undergraduate curricula, research programs, and graduate training in veterinary medicine. It periodically publishes the accreditation status of the schools and colleges and establishes standards of proficiency by correlating all the activities associated with veterinary medical education. It studies methods of teaching in veterinary medical schools with the objective of progressive improvement and, finally, it constantly studies the needs for establishing courses that will enable veterinarians to meet changing demands.

In light of the present demands for comprehensive instruction on the professional and graduate school level, the Council recommends that members of any veterinary medical faculty should have adequate academic qualifications. These qualifications include general and special training. Research activities and contributions to original knowledge are important criteria in evaluating the faculty and school. It looks for evidence of a balanced program of teaching and research when the faculty is considered as a whole. It recommends that the policy of faculty recruitment recognize the need in professional education to seek personnel specifically qualified for teaching.

With the proper policing of professional veterinary education by members of its own ranks, veterinary medical education has reached the highest point in its history. Specialization on the part of veterinary medical faculties, as well as AVMA requirements, has drastically changed the over-all picture of veterinary education in the United States. Specialty organizations, such as the American Association of Veterinary Anatomists, the American Association of Veterinary Bacteriologists, the American Society of Veterinary Physiologists and Pharmacologists, the American College of Veterinary Toxicologists, the American Veterinary Radiology Society, the American College of Veterinary Pathologists, the American Association of Veterinary Nutritionists, the American Association of Equine Practitioners, and the American Association of Zoo Veterinarians, among others, have been highly effective instruments in encouraging teachers and research workers within specific disciplines to exchange information regarding instructional and investigative techniques. This had not only led to more uniformity in the standards of veterinary medical education throughout the country, but has increased productivity in the ever-enlarging research program.

Cooperative research between scientists in all disciplines of veterinary medicine with scientists in allied disciplines, such as Biochemistry, Pharmacology, Radiology, and in all departments of medical schools, led to an increased awareness on the part of the Doctor of Medicine and the Doctor of Veterinary Medicine about the role that each can play in furthering and advancing knowledge regarding both animal and human health. Research programs sponsored by such agencies as the National Institutes of Health, the National Science Foundation, and the Rockefeller Foundation, to name a few, have been highly productive in the obtaining of knowledge regarding basic information concerning cardiology, neurological diseases, arthritic conditions, digestive disorders, and many other syndromes of animals. This information has, in turn, become invaluable in the hands of physicians who apply this knowledge to the care of the human being.

\section{A LOOK TO THE FUTURE}

Our colleges and universities are faced with exceedingly complex problems in determining the direction that veterinary medical education should take during the next few decades. A century ago, an educator's main concern was to train his students to diagnose and treat ailments of the horse. As rural economy was strengthened, the task of the graduate veterinarian encompassed the care of all farm animals. As urban conditions improved, the vet- 
erinarian became responsible for the health of pet animals.

Although veterinarians worked for governmental agencies such as the Bureau of Animal Industry in the United States Department of Agriculture and the military services, an overwhelming majority of students prior to World War I trained to become private practitioners, usually on their own or occasionally in a partnership. They looked forward to being rugged individualists.

During the 1940's and 1950's, careers opened up to veterinarians in numerous health fields. The increase in educational requirements to include at least six years of university work helped to broaden horizons. The public demand for the knowledge and skills possessed by the Doctor of Veterinary Medicine forced him to respond to the necessity of adapting his practice according to changing agricultural economics. He acquired or renewed skills that enabled him to take his rightful place in all forms of medical research and in public health administration.

Currently, the demand for graduate veterinarians in the United States far exceeds the supply. "Career recruitment" has become recognized as not only necessary, but vital, if the need for veterinarians is to be met. The AVMA and state professional associations are encouraging the establishment of programs to interest well-qualified and highly motivated students to seek veterinary medicine as a career. Guidance counselors in high schools and colleges are helping to direct both rural and urban youth to the potential careers available to people possessing professional veterinary training. Parents are becoming aware of the possibilities for their children in this field. Practitioners and veterinary research workers are striving diligently to interest talented youth to look toward careers in veterinary medicine by visits to high schools, talks before service clubs and civic groups, and by helping with the work of the Boy Scouts, 4-H Clubs, and the Future Farmers of America.

This increased need for veterinarians in the United States cannot be met by merely adding more schools of veterinary medicine or by crowding more students into each of the present schools. Without doubt, new schools will be added in more states. The present programs would suffer if too much crowding were to take place. However, the changing need for veterinary skills must first be assessed and curricula adapted accordingly.

Although a year-round crash program was followed during World War II in all veterinary, medical, and dental schools, it was universally acknowledged as being unsatisfactory. Students had little time for the digestion of facts and data. Professors had no time for research, writing, and evaluation of their course offerings. It is conceivable that well-planned trimester or all-year quarter systems may be utilized to increase the number of veterinary graduates. These will, of course, necessitate larger faculties and staffs in order to permit professors to pursue original investigations, write textbooks and research papers, and have the opportunity to keep their teaching programs ahead of changing needs.

Summer clinical programs are being utilized by a few schools to give students more clinical experience before graduation. Given in the summer between the third and fourth professional years, these programs are proving to be very successful and it is anticipated that more schools will follow suit.

Future concern about veterinary medical education is as much involved with the emphasis placed upon various areas of the curricula as it is with the number of hours a student has in contact with his instructors. Should there be minor or even drastic changes in the traditional pattern of veterinary professional education? Should there be an increase in time needed for preprofessional training? Should specialty training be emphasized or encouraged on a post-doctoral level? Should greater emphasis be placed upon graduate programs leading to Master of Science or Doctor of Philosophy degrees? Are we in danger of allowing interest in research distract from sound teaching? 
These questions must be evaluated and carefully answered if the veterinary profession is to fulfill is mission for the remainder of the twentieth century.

There is little evidence that a three- or four-year preprofessional curriculum is seriously being contemplated by current schools. However, a large number of students in each class have three or more years of college training prior to admission. The opportunity to receive both Bachelor of Science and Doctor of Veterinary Medicine degrees by spending an extra year in college is encouraging some students to voluntarily increase their preveterinary training (in addition to, or in lieu of, the B.S. degree now awarded by most schools at the end of the second professional year).

The four-year professional programs are being examined by universities in light of the current and future demands upon their graduates. In addition to practice, students look forward to careers in research, teaching, the armed forces, commercial activities, laboratory animal care, and government service.

The changing agricultural economy is forcing the farmer to consolidate. The small family farm is rapidly becoming a thing of the past. The gathering together of huge herds or flocks is not only leading to increased problems in disease prevention and control, but is forcing the veterinary schools to train their students in disease prevention, herd management, and economics.

The increased transportation of animals by air from one country to another is requiring more instruction in exotic diseases and in diseases transmissible from animals to man. In the future, the graduate veterinarian will play even more of a vital role in public health matters.

The need for more detailed knowledge in surgery and diagnosis, as well as in the basic disciplines of anatomy, physiology, pathology, microbiology, and nutrition, is responsible for the increased popularity of group practices. Veterinary medical education must adapt to this situation without substantially increasing the length of time required for a person to receive his D.V.M. degree. The current trend is for institutions to offer specialized training on a postgraduate level-in the form of interneships, residencies, specialty training and graduate instruction leading to advanced degrees. This appears to be a significant trend for the future.

The formation of specialty groups or associations has led and will continue to lead to improved standards in veterinary medical education. Most groups meet to work out solutions to mutual problems concerning nomenclature, research, and professional and graduate training (American Association of Veterinary Anatomists, American Society of Veterinary Physiologists and Pharmacologists, American Association of Veterinary Bacteriologists, American College of Veterinary Toxicologists, American Veterinary Radiology Society, American Association of Veterinary Nutritionists). Other groups (American College of Veterinary Pathologists, Animal Care Panel) also require examinations and certification as membership criteria. Certification by the American College of Veterinary Pathologists, for example, indicates that the person is highly qualified to perform a large number of clinical-pathological tests and is experienced in pathological diagnosis. Certification, however, is no indication of research training or ability.

Graduate training (offering research training) leading to the Master of Science or Doctor of Philosophy degrees is offered by departments within many veterinary schools. The scope of this type of program is almost certain to increase rapidly. The close association of teaching and research programs makes graduate training beyond the D.V.M. degree highly desirable in all subject areas, with the possible exception of clinical medicine and surgery. It is anticipated that certification will be established for clinical areas during the coming years and that prospective clinicians will be interning at universities in order to qualify for the examinations.

Cooperative research with medical schools, medical research institutes, and 
agricultural research institutes will continue to broaden and take more of the veterinary professions' time. A recent editorial in the Journal of the American Medical Association (January 13, 1962) emphasizes the similarity between the training and goals of the M.D. and the D.V.M. It is pointed out that:

human and veterinary medicine are being drawn closer and closer together in the basic sciences to gain maximum health for man, pets, and farm animals. There is a peculiar paradox in the fields of research and clinical medicine: the studies undertaken in a small group of animals may save the lives of a million men and, contrarily, a surgical technique developed primarily for man may become applicable for the treatment of many animals. This emphasizes the quandary for those who would question the value of research in fields that seem at first visionary and unproductive.

It appears certain that veterinary medical education of the future will not only be concerned with keeping professional curricula abreast of the times or with postgraduate training, but also with so-called "service" teaching. The veterinary science departments have long been responsible for teaching the fundamentals of anatomy, physiology, and sanitation to agricultural students. Many of the veterinary medical schools have continued this service, with worthwhile results. Present trends indicate that veterinary schools will have more and more responsibility in the organization of medical technology programs; in the teaching of biological subjects to engineers (in preparation for cooperative research programs in bio-engineering); in the teaching of physiology to pharmacy students; in the teaching of comparative anatomy to agricultural and medical students, and in the teaching of neurology to psychologists and bio-electronic engineers. This trend has not diluted professional educational programs nor has it detracted appreciably from research and clinical activities. It has, however, been of decided service to other disciplines and, at the same time, broadened the horizons of veterinary medical education.

The costs of veterinary medical education in the future will be high, both to the student and to the state. In Pennsylvania, for example, the legislature provided $\$ 2,800$ per medical student and $\$ 3,200$ per veterinary student for 1962 . There is no doubt that education involving high expenditures for facilities and equipment as well as high ratios of instructors to students will continue to be expensive. It is more and more apparent that state legislatures are recognizing the need for many more Doctors of Veterinary Medicine in the future and are willing to pay the bill.

A summation of veterinary medical education in the United States, past, present, and future, might best be expressed in the words of an editorial written in the Journal of the American Medical Association (January, 1962):

The schools of medicine and veterinary medicine recognized for many years, long before the ascendancy of medical education and experimental medicine, that their house should be put in order. The problems were deep-rooted and not easily composed. Students were still sitting on hard benches, listening to dry lectures, taking notes on the cuff, and working in dark, dingy laboratories. Those were the days of cram sessions and the medical primer. Then, through successive moves the long, tiresome lectures gave way to demonstrations and clinical clerkships. Laboratories and operating rooms for fundamental investigation are becoming the equivalent of the surgical amphitheatre. Indeed, the facilities for experimental surgery and biological analyses as well as the curriculum of [veterinary] medical education have set a pattern for other academic pursuits, and progress continues day after day.

\section{BIBLIOGRAPHY}

Advertisement: Dr. G. H. Dadd's School of Veterinary Medicine and Surgery. Am. Vet. Jour., 3:388, 1858.

Arnold, J.: Address Delivered at the Annual Exercises of the American Veterinary College. Am. Vet. Rev., 2:13-17, 1878.

AVMA: Essentials of an Acceptable Veterinary Medical School (As Revised by the Council on Education and Approved by the House of Representatives of the AVMA) . AVMA, Chicago, Ill. Oct., 1956. 
AVMA: American Veterinary Medical Association Directory. AVMA, Chicago, 1ll. 1960. Ayres, J. P.: Scope of Veterinary Medicine in the United States. Conf. on Public Health for Veterinarians. N.Y. State Veterinary College at Cornell University, Ithaca, N.Y. Jan., 1961.

Becker, C. L.: Cornell University: Founders and the Founding. Cornell University Press, Ithaca, N.Y. 1943.

Brumley, O. V.: Veterinary Education and Training for Public Health. J.A.V.M.A., 92:366-80, 1938.

Butler, T.: Veterinary Education in America. Am. Vet. Rev., 13:440, 1889.

Cary, C. A.: Report on Committee on Intelligence and Education. J. Comp. Med. and Vet. Arch., 15:382-90, 1894.

Christensen, G. C.: Genesis of Veterinary Education in the United States. J.A.V.M.A.. 128:437-40, 1956 .

- With Honor to the Past. The Iowa State College Veterinarian, 20:79-83, 1958.

Dadd, G. H.: Communication. Am. Vet. Jour., l:438-40, 1856.

Davenport, E.: Keep the Standards Up. J.A.V.M.A., 55:615-17, 1919.

Editorial: What Will Others Do? J. Comp. Med. and Vet. Arch., 17:481, 1896.

: A Costly Experience. J. Comp. Med. and Vet. Arch., 17:778, 1896.

: The Future of Veterinary Education in New York State. Am. Vet. Rev., 21:739-41, 1898.

…: Veterinary Student Enrollment for 1934-1935. J.A.V.M.A., 85:567-72, 1934.

: Rewards of Experimental Medicine. J. Am. M. A., Jan. 13, 1962.

Giltner, W.: The A.V.M.A. and Infectious Abortion of Cattle. J.A.V.M.A., 64:469-74, 1923.

J.A.V.M.A., $67: 8-15,1925$.

Gordon, M. B.: Medicine in Colonial New Jersey and Adjacent Areas. Bull. Hist. Med., $17: 38-61,1945$.

Hagan, W. A.: Planning for the Future in Veterinary Medicine. J.A.V.M.A., 88:503-13, 1936.

-: Veterinary Medical Education - Its Evolution and Present Status. J.A.V.M.A., 118:287-92, 1951.

Hallman, E. T.: Veterinary Education and Research. J.A.V.M.A., 70:9-15, 1926.

Hayes, F. M.: Education and Research in Veterinary Medicine. J.A.V.M.A., 67:773-79, 1925 .

Hoskins, H. W.: The Trend of Veterinary Education. J.A.V.M.A., 55:146-57, 1919.

Huidekoper, R. S.: Introductory Address at the Opening of the Veterinary Department, University of Pennsylvania. Am. Vet. Rev., 7:377-96, 1884.

Kigin, L. C.: Raising the Standards of Entrance. Am. Vet. Rev., 47:90, 1915.

Law, James: [Quoted Letter to Editor of "Country Gentleman."] Am. Vet. Rev., $1: 330-33,1877$.

-_ : Letter to the Editor. Am. Vet. Rev., 1:365-70, 1878.

: State Suppression of Tuberculosis Unwarrantable if not Thorough. Am. Vet. Rev., $18: 813-28,1895$.

- : Inauguration Address of New York State Veterinary College, Am. Vet. Rev., 20:645-52, 1896.

- : A Half Century of Veterinary Medicine in Cornell University. Cornell University Official Publications, 10:1919.

Liautard, A.: History and Progress of Veterinary Medicine in the United States. Am. Vet. Rev., 1:5-19, 1877.

Marshall, C. J.: Veterinary Education. J.A.V.M.A., 65:28-35, 1924.

McEachran, D.: Veterinary Education. Am. Vet. Rev., 1:113-15, 1877.

Melvin, A. D. and Mohler, J. R.: Foot-and-Mouth Disease. Am. Vet. Rev., 47:107, 1915.

Merillat, L. A.: The Grading of Veterinary Colleges. J.A.V.M.A., 90:206-10, 1937.

Mohler, J. R.: Editorial. J.A.V.M.A., 58:1-4, 1920.

- Editorial. J. A. V. M. A., 59:565-71, 1921.

Moore, V. A.: Dr. Law as a Scientific and Professional Man. Second Annual Banquet of the Society of Comparative Medicine of the New York State Veterinary College, Feb. 15, 1905.

- American Veterinary Education and Its Problems. The Cornell Vet., 1:65-75, 1911.

News Item: Animal Census - Turf, Field, and Farm. Am. Vet. Rev., 12:189, 1888. 
Current Veterinary Colleges in the U.S. Am. Vet. Rev., 19:432-35, 1895.

Association of State and Provincial Veterinary Colleges: Committee Report on Entrance Requirements. J.A.V.M.A., 55:234-37, 1919.

-: Teaching Obstetrics and Diseases of the Genitalia. J.A.V.M.A., 55:599-606, 1919.

: Veterinary Education and the War. J.A.V.M.A., 54:678-79, 1919.

Student Enrollment. J.A.V.M.A., 73:885, 1928.

-: Report on the Committee on Education. J.A.V.M.A., 79:669-702, 1931.

: Report of the Committee on Education. J.A.V.M.A., 89:476-83, 1936.

Report of the Committee on Education. J. A. V. M. A., 91:441-42, 1937.

: Veterinary Colleges of North America, Cuba and Mexico. Norden News, Nov:-Dec., 1950.

: Veterinary Colleges of North America. Norden News, Dec., 1960.

—: Veterinary School Enrollment Exceeds 4,000. J.A.V.M.A., 139:1275-76, 1961.

Norwood, W. F.: Medical Education in the United States Before the Civil War. University of Pennsylvania Press, Philadelphia. 1944.

Pearson, R. A.: Address of Welcome. J.A.V.M.A., 65:53-54, 1924.

‥: The Veterinary Profession: Its Recognition and Personnel. J.A.V.M.A., 72:26, 1927.

Rogers, T. B.: Some Thoughts on Veterinary Education. Am. Vet. Rev., 44:709, 1914. Sisson, Septimus: Our Profession. Am. Vet. Rev., 47:260, 1915.

Smithcors, J. F.: Evolution of the Veterinary Art. Vet. Med. Publ. Co., Kansas City, Mo., 1957.

Stafseth, H. J.: Where Our Veterinary Students Come From. J.A.V.M.A., 65:123, 1924.

Stange, C. H.: Some Problems in Veterinary Education. Cornell Vet., 1:75-78, 1911.

- The Address of the President. J.A.V.M.A., 65:689-94, 1924.

: History of Veterinary Medicine at Iowa State College. Iowa State College, Ames, Iowa. 1929.

-

Tyler, D. E. and Christensen, G. C.: Effective Teaching in Schools of Veterinary Medicine. J.A.V.M.A., 137:449-52, 1960.

Udall, D. H.: Education for the Practice of Veterinary Medicine. J.A.V.M.A., 73:409, 1928.

U.S.D.A.: Office of Information Report. Am. Vet. Rev., 47:5, 1915.

White, D. S.: The Only Source of Supply of the Profession. J.A.V.M.A., 74:283-92, 1929.

White, T. P.: The Veterinarian. J.A.V.M.A., 54:30-33, 1918.

Williams, W. L.: The Veterinary Profession: Its Opportunities and Needs for the Future. Am. Vet. Rev, 12:110-19, 1888. 


\title{
Military Veterinary Medicine
}

\author{
by EVERETT B. MILLER
Lieutenant Colonel, Veterinary Corps
United States Army
}

Military veterinary Medicine began with the origin of the U.S. Army and rather closely parallels the development of the profession of veterinary medicine in the United States. Between 14 June 1775 and 3 June 1916, or until congressional legislation created a commissioned officers' corps of veterinarians in the Army, much of the history of military veterinary med. icine must be gleaned from the histories of the mounted combat arms and medical and supply services. These histories in. clude references to veterinary affairs which in chronologic sequence present a fairly clear-cut picture of the development of military veterinary service.

\section{EVOLUTION: 1775-1916}

Cavalry, frequently known by other names, the combat arm formed in 1777 , became the birthplace of military veterinary medicine in 1792. Congressional legislation of 1792 provided that each of the four troops of light dragoons (cavalry) would have one farrier to care for the ailments of horses. The heritage of the Veterinary Corps officer is specifically traced to horseshoers and farriers who acted as animal nurses in the "old, old Army." In fact, the horseshoe-shaped insigne of the farrier was once carried into the design of the veterinarian's distinctive insigne which, for a few years before World War
I, included the unclersurface of a shod horse's foot.

In 1798, the number of farriers had increased from four to a total of ten, and the original pay of $\$ 8$ had been increased to $\$ 10$ per month. Cavalry and farriers were not a part of the Army from 1802 to 1808 , but in the latter year Congress provided for a regiment of cavalry for which eight farriers were authorized. Farriers were first included in horse artillery in 1812. Due to reduction in the horsed combat arms following the War of 1812, the farrier disappeared from the military scene until 1833, when a regiment of cavalry was formed with a complement of ten farriers. Ten additional farriers appeared when a second cavalry regiment was organized in 1836.

The 1834 and 1835 editions of General Regulations for the Army described the annual report of the Inspector General as including a discussion of the "Veterinary Department of Cavalry," noted "whether the Veterinary Surgeon is competent to the duties of his station... whether the farriers are properly instructed and expert in their business." This is likely the first use of the term "veterinary surgeon" in official Army publications, but it is fairly probable that it may have been used interchangeably with "farrier" as it has not been established that there were any veterinarians in the Army at that 


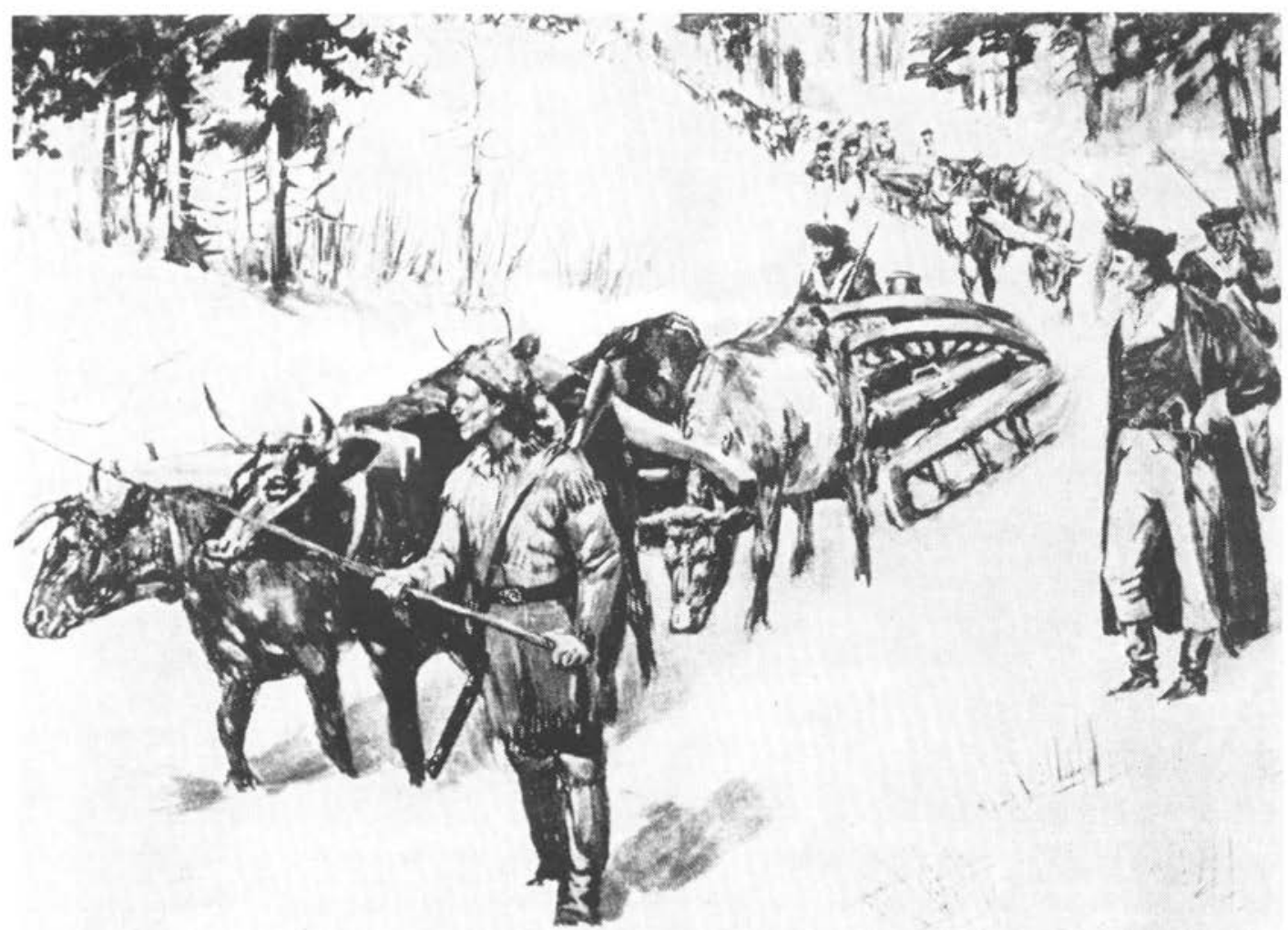

Support for Knox: Ox-drawn sleds guided by soldiers of the Continental Army leave Ticonderoga for siege of Boston (1775). Few horses were used during the Revolutionary War, and many of those that were suffered more at the hands of their users than from enemy action. U.S. Army Photograph

time. Pay tables did not list a veterinary surgeon.

It appears that the Quartermaster's Department may have contemplated the hiring of civilian veterinarians as early as 1837 , but there is no evidence of congressional appropriation for such purpose prior to the appropriation act for the fiscal year 1849. That few veterinarians were hired might be evidenced by the fact that, during the fiscal year that marked the beginning of the Civil War, the Quartermaster's Department expended only $\$ 168.50$ for services of civilian veterinarians.

During the war with Mexico and through the period of Indian fighting before the Civil War, the number of farriers varied with the number of mounted units authorized, but their general status remained more or less unchanged. With the beginning of the Civil War, a veterinary sergeant was authorized for each of the three battalions in a cavalry regiment. It may be presumed that he had the duty of supervising farriers with companies of the battalion. He received $\$ 17$ per month and ranked with a sergeant of cavalry. This grade of veterinary sergeant was dropped in 1862, but under the act of 3 March 1863 each regiment of cavalry was authorized a regimental veterinary surgeon with the rank of regimental sergeant major and pay of $\$ 75$ per month. Appointments were made by the Secretary of War following selection by the chief of the Cavalry Bureau upon nomination by regimental commanders. The increased grade and pay 


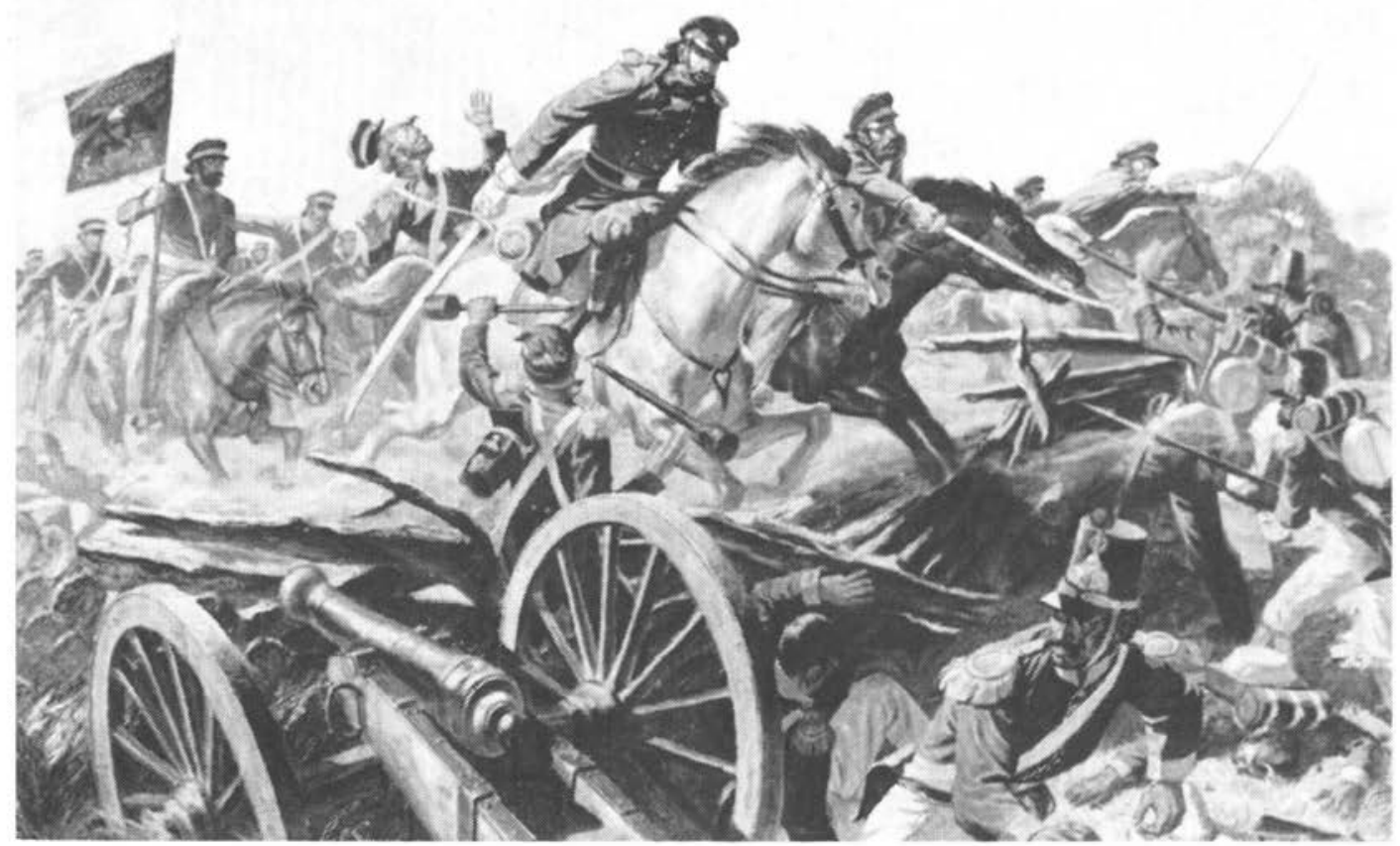

Battle of Resaca de la Palma (Texas - 1846), climaxed the opening campaign of the Mexican War and marked the first outstanding use of Cavalry in a major American war. Army regula. tons recognized the need for veterinary services which, however, were supplied by farriers. U.S. Army Photograph

was likely provided as a result of the Army's terrific animal loss due to disease and in an effort to obtain better qualified personnel to provide veterinary service. There were apparently no fixed standards of education and experience, and it seems probable that not more than a very few graduate veterinarians applied for or received appointment. During the Civil War, the Quartermaster's Department spent $\$ 93,666.47$ for the hire of civilian veterinarians.

After the Civil War, the total of six Regular Army cavalry regiments was augmented by four additional regiments. Unlike each of the six older regiments which were authorized one veterinary surgeon, each of the newly formed regiments was authorized two veterinary surgeons, one of whom was designated "Senior Veterinary Surgeon" and received pay of $\$ 100$ per month. This disparity in personnel authorization persisted until 1899 .
One of the important milestones in the improvement of military veterinary service was the requirement set forth in Army General Orders of 1879 and first included in Army Regulations of 1881 that thereafter all appointed as veterinary surgeons with Cavalry were to be graduates of established and reputable veterinary schools or colleges. The regulations also provided that the veterinary surgeons would have rank and precedence comparable to those of a sergeant major. The 1881 appropriation act provided for fourteen veterinary surgeons with Cavalry, but it appears that there were actually twelve on duty. The Quartermaster's Department was at that time employing one full-time veterinarian for the care of animals, and in the later 1880 's several more were employed for this purpose.

At the beginning of the Spanish-American War, the Cavalry was authorized fourteen veterinary surgeons (four seniors and 
six juniors) for its ten regiments. Artillery reentered the evolution of the Army Veterinary Service where each battery of field artillery was authorized a veterinary sergeant; previously, in 1812, horsed artillery had farriers and after 1861 was provided with artificers who very likely performed the duties of farriers.

The end of the investigation of the "embalmed meats" of the Spanish-American War marked the start of the Army's veterinary food inspection service. In July, 1901, a veterinarian was transferred from the U.S. Department of Agriculture and appointed Meat Inspector, Subsistence Department at Large, U.S. Army, for the purpose of making receipt inspections of meats in addition to inspections made prior to delivery by veterinary inspectors of the U.S. Department of Agriculture. By 1906, the number of Army subsistence veterinary inspectors had been increased to six, and War Department Orders had directed post commanders to use veterinarians to conduct ante-mortem and postmortem inspections of beef purchased locally. Dr. C. W. Johnson was the original appointee, followed by Dr. W. H. McKinney for duty in Kansas City, Mo. Drs. G. A. Lytle, D. A. Hughes, and C. J. Loveberry, in 1906, were stationed at Chi- cago, Illinois, Omaha, Nebraska, and San Francisco, California, respectively.

Congressional legislation in 1899, after the beginning of the Philippine Insurrection, greatly improved the lot of Army veterinarians with Cavalry. It provided that every regiment of cavalry would be authorized two veterinarians, one to have the pay and allowances (not the rank) of a second lieutenant of Cavalry and the other the pay of $\$ 75$ per month and the allowances of a sergeant major. Later, the senior veterinarian was accorded a rank between that of a cadet and second lieutenant, the highest rank achieved by veterinarians prior to the authorization of a corps of commissioned officers in 1916.

The so-called Army Reorganization Act of 1901 made further improvement in the status of the Army veterinarian by providing that all veterinarians (two for each regiment of cavalry and one for each regiment of artillery) would have the pay and allowances of a second lieutenant. The number of such veterinarians was 42 . The act also provided that veterinarians employed as civilians by the Quartermaster should receive pay of $\$ 100$ per month. The Quartermaster's Department became the Army's largest user of veterinarians, and at one time it had more than 60 veterinarians em-

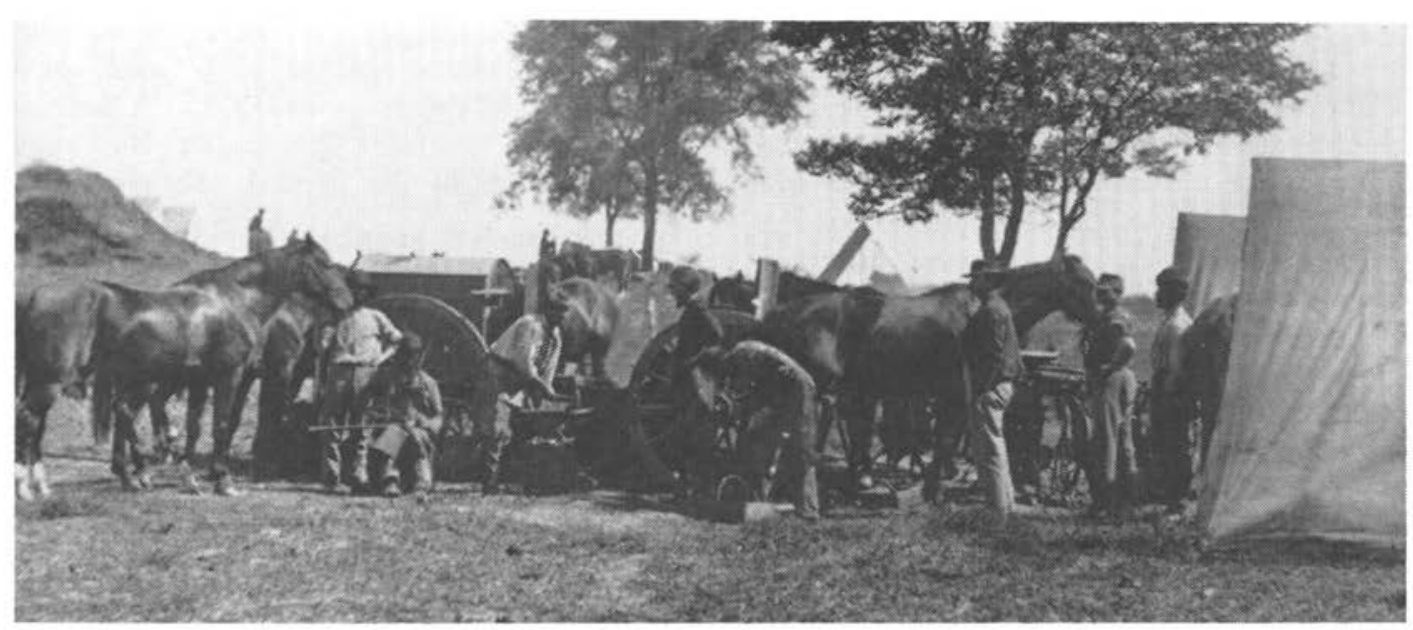

Civil War farriery unit, Army of the Potomac. With inadequate veterinary service there was an appalling wastage of horses in both the Union and Confederate armies. Library of Congress Collection 


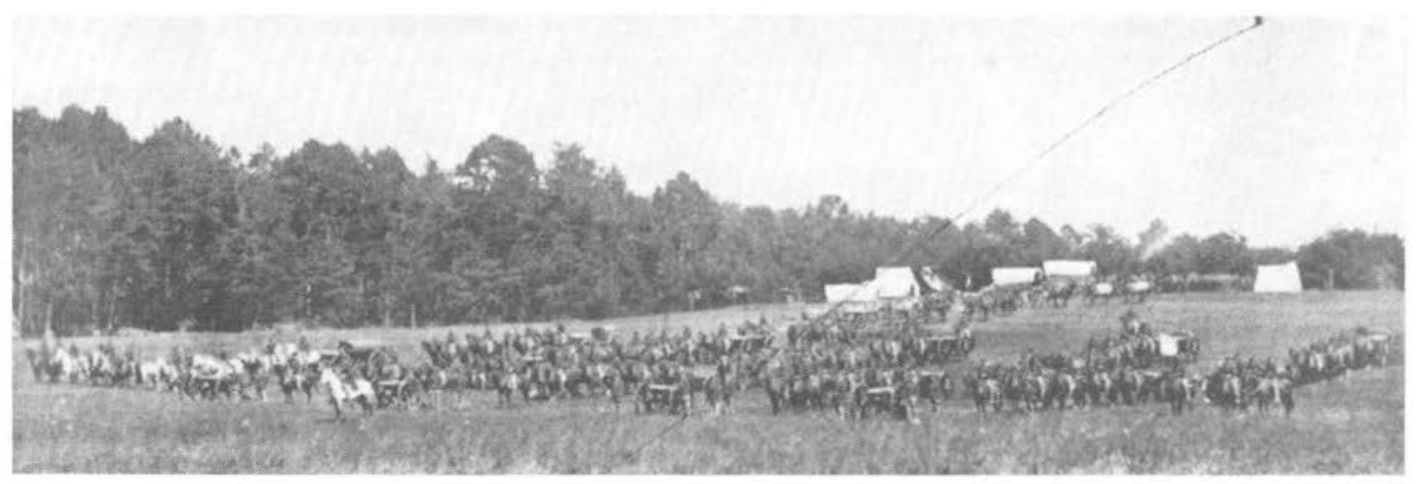

Civil War Quartermaster Supply Company. Procurement of animals, as well as veterinary services, were Quartermaster responsibilities, and the few veterinarians in service were hampered by ill-advised regulations. Library of Congress Collection

ployed as civilians in the Philippine Islands. The pay of veterinarians employed as civilians (contract veterinarians) remained at the $\$ 1,200$ per year level in spite of repeated efforts of The Quartermaster General to obtain a pay status more nearly comparable with that of Army veterinarians with Cavalry and Field Artillery. The pay of veterinarians of Cavalry and Field Artillery was increased in 1908 from the previous $\$ 1,500$ to $\$ 1,700$ per year (pay of second lieutenant, mounted). Retirement of veterinarians with Cavalry and Field Artillery was first authorized under the provisions of the appropriation act of 1911 .

During the 124 years between 1792, when the farrier was first authorized, and 1916, when the commissioned Veterinary Corps was authorized, the military veterinary service moved forward nearly in pace with the progress being made by veterinary medicine in the United States at large. The progressive improvement in military veterinary service was due to (1) increasing appreciation by the military and legislative branches of the real need for such service, (2) the inherent desire of nearly every individual veterinarian in the service to provide better service and to improve his personal status, and (3) the unceasing effort of civilian veterinarians through the American Veterinary Medical Association to improve military veterinary service and the status of their professional brothers in the service of their country. Although much improvement in veterinary service had been effected, there was still much room for improvement. The service was being provided by separate groups of veterinarians - two fully militarized groups, the veterinarians with Cavalry and Field Artillery, and two civilian employee groups, the meat inspection and animal service veterinarians working for The Quartermaster General. Proper coordination in and between groups was lacking, pay rates were not uniform, and the over-all service did not have an Army-wide organization to exercise administrative, functional, and policy control. These shortcomings were overcome when the National Defense Act of 1916 made provision for a Veterinary Corps of commissioned officers and wisely made the corps a component of the Medical Department.

\section{DEVELOPMENT: 1916-1940}

The history of the development of the Army Veterinary Service during the period between 1916 and World War II devolves on such a large number of subjects that it will be considered by major topical subjects and each will be discussed in chronologic order.

\section{Legislation and Major Administrative Directives}

The congressional legislation authorizing the Veterinary Corps was section 16 of 
the National Defense Act, approved 3 June 1916. This important historical document is quoted [in part ]:

Sec. 16. VETERIN.IRIANS. - The President is hereby authorized, by and with the advice and consent of the Senate, to appoint veterinarians and assistant veterinarians in the Army, not to exceed, including veterinarians now in service, two such officers for each regiment of Cavalry, one for every three batteries of Field Artillery, one for each mounted battalion of Engineers, seventeen as inspectors of horses and mules and as veterinarians in the Quartermaster Corps, and seven as inspectors of meats for the Quartermaster Corps; and said veterinarians and assistant veterinarians shall be citizens of the United States and shall constitute the Veterinary Corps and shall be a part of the Medical Department of the Army.

Hereafter a candidate for appointment as assistant veterinarian must be a citizen of the United States, between the ages of twenty-one and twenty-seven years, a graduate of a recognized veterinary college or university, and shall not be appointed until he shall have passed a satisfactory examination as to character, physical condition, general education, and professional qualifications.

An assistant veterinarian appointed under this Act shall, for the first five years of service as such, have the rank, pay, and allowances of second lieutenant; that after five years of service he shall have the rank, pay, and allowances of first lieutenant; that after fifteen years of serv. ice he shall be promoted to be a veterinarian with the rank, pay, and allowances of captain. and that after twenty years' service he shall have the rank, pay, and allowances of a major: Provided, That any assistant veterinarian, in order to be promoted as hereinbefore provided, must first pass a satisfactory examination, under such rules as the President may prescribe, as to professional qualifications and adaptability for the military service; and if such assistant veterinarian shall be found deficient at such examination he shall be discharged from the Army with one year's pay.

Little had been accomplished toward implementation of the provisions of the above-cited act before the entry of the United States in World War I. The Selective Service legislation (Overman Act) of 18 May 1917 gave the President full authority for expanding the Veterinary Corps beyond the provisions of the $\mathrm{Na}$ tional Defense Act. Under this authority, War Department General Orders No. 130 (section III), 4 October 1917, established the Veterinary Corps, National Army, as follows:

1. The President directs that under the authority conferred by section 2 of the act "To authorize the President to increase temporarily the Military Establishment of the United States" approved May 18, 1917, there be organized for the period of the existing emergency a Veterinary Corps, National Army, to consist of the commissioned and enlisted personnel hereinafter specified.

2. The total number of commissioned officers and enlisted men may be approximately equal to, but shall not exceed, 1 commissioned officer and 16 enlisted men for each 400 animals in service; the veterinarians and assistant veterinarians of the Regular Army, National Guard. drafted into the Federal Service, and Officers' Reserve Corps in active service, shall be considered as a part of the total commissioned personnel herein authorized.

3. The commissioned personnel shall consist of veterinarians and assistant veterinarians and the grades and the ratios in grades shall be as follows:

Seven veterinarians with rank of major to 20 veterinarians with rank of captain, to 36 veterinarians with rank of first lieutenant, to 37 assistant veterinarians with rank of second lieutenant.

In no case shall original appointments or promotions be made so as to make the ratio between any of the grades above that of second lieutenant to the grade next below it above the ratio specified.

4. The enlisted personnel shall consist of men of the grades indicated below and the proportions of these men shall not exceed those in. dicated. In each 200 enlisted men there may be 5 sergeants first class, 10 sergeants, 10 corporals, 40 farriers, 2 horseshoers, 1 saddler, 3 cooks, 43 privates first class, 86 privates.

5. The Surgeon General will submit recommendations to the Secretary of War for the commissioned and enlisted personnel now required for the organization authorized above, which, upon approval by the Secretary of War, shall be put into effect. The organization of the Veterinary Corps will be subsequently increased or decreased as the needs of the service require upon recommendations by the Surgeon General after they have been approved by the Secretary of War.

A Veterinary Corps, National Army, having been provided, the principles and policies for its operation were provided in SR (Special Regulations) No. 70, 15 
December 1917, Special Regulations Governing the Army Veterinary Service. This regulation contained the first comprehensive description of the administrative and functional organization of the Army Veterinary Service. Additional implementing instructions were contained in a series of circular letters which were promulgated by the Surgeon General's Office during World War I and thereafter until late in 1920. Special Regulations No. 70, supplemented by the Surgeon General's circular letters, provided administrative and technical guidance until supplanted by 52 numbered Army Regulations which were published in 1921-1922. These Army Regulations, with minor changes from time to time, were in effect at the beginning of World War II.

After World War I, the wartime military establishment was replaced by a more permanent peacetime organization under the provisions of the act of 4 June 1920 which amended the National Defense Act of 1916 to the degree that a new law seemed to emerge. This act, as further amended or modified by the appropriation act of 30 June 1922, the act of 14 July 1932, and the act of 31 July 1935, markedly influenced the development of the Army Veterinary Corps. The effect of these acts will be discussed in their relation to the subject headings which follow.

\section{Administration and Organization}

When the National Defense Act of 1916 came into existence, there was no veterinary service organization above the regimental, camp, and depot level and no professional supervision or coordinating control over the separate local activities. The act did nothing to change this situation as it contained but little above the specific provisions for forming a corps of commissioned officers within the Medical Department. The Surgeon General, in early 1917, invited certain civilian veterinarians to confer with him on planning the organization and expansion of a wartime veterinary service. According to Merillat and Campbell conference mem. bers included Maj. Gen. W. G. Gorgas, The Surgeon General; Maj. C. G. Furbush, MG; Maj. G. E. Griffin, VG; Lt. A. L. Mason, $\mathrm{VC}$; and the following civilian veterinarians: V. A. Moore, dean of the New York State Veterinary College, Cornell University; C. J. Marshall, of the School of Veterinary Medicine, University of Pennsylvania; D. S. White, dean of the College of Veterinary Medicine, Ohio State University; J. R. Mohler, assistant or acting chief of the Bureau of Animal Industry, U. S. Department of Agriculture; and C. E. Cotton, president, American Veterinary Medical Association. Of these, Marshall, White, and Cotton were commissioned into the Veterinary Corps, National Army, on 3 October 1917. A special committee of the American Veterinary Medical Association submitted a recommendation to the Surgeon General's conference group for the organization of a veterinary service patterned after that of the British Army's veterinary service. The conference group accepted this proposal, and a recommendation was submitted to the War Department on I4 July 1917. This recommendation resulted in the publication of General Orders No. 130, 4 October 1917, which established the organization of the Veterinary Corps, National Army. Prior to the issuance of this general order, the Surgeon General, anticipating its publication, had replaced his original conference group with a veterinary advisory board of five prominent civilian veterinarians to formulate plans for the more detailed organization and administration of the veterinary service. The recommendations of this board resulted in the publication of SR 70 which, together with the Surgeon General's circular letters, provided administrative and technical direction until 1921.

After the appointment of a civilian veterinary advisory board, a Veterinary $\mathrm{Di}$. vision was established in the Surgeon General's Office in October 1917 when a number of the original veterinary advisers were commissioned in the Veterinary Corps, National Army, and were assigned to duty 
in the Veterinary Division. Under the directorship of Medical Corps officers from 1917 to 1922 and Veterinary Corps officers thereafter, the Veterinary Division continued through World War I and thereafter as the office at War Department level responsible for the operation of the Army Veterinary Service.

During World War I, practically all of the veterinary officers were assigned to combat divisions, remount depots, and other units within the Zone of Interior which were exempt from control of the six departments within the United States. For this reason, veterinary officers were not assigned to department headquarters. The Surgeon General's Office exercised direct coordination and supervision of the veterinary service at the many exempted installations. This was accomplished through five senior veterinary officer general inspectors who traveled from camp to camp within each of five established geographic areas. These inspectors were of great value in advising the many young and inexperienced veterinary officers and in keeping The Surgeon General informed on all matters pertaining to the newlyorganized service. Various required reports were submitted directly to The Surgeon General from all exempted stations.

After World War I, more and more of the formerly exempted units and installations were placed under the control of the departments in line with a general policy of decentralization. With this change, the need for traveling general inspectors no longer existed, and the assignment of a veterinary officer to the office of each department surgeon to supervise the Veterinary Service within the area became desirable. The first such department veterinarian was assigned in 1919; others were assigned later. The military departments were discontinued in 1920 but were replaced by nine numerically designated corps areas. Thus, the former department veterinarian became a corps area veterinarian. His duties were first completely outlined in Army Regulations in 1920. The number of corps area headquarters to which a vet- erinary officer was assigned varied from year to year. After mid-1938, each corps area had an assigned corps area veterinarian and the onset of World War II saw veterinary activities well coordinated within the corps area commands.

Reference to the responsibilities of the Army Veterinary Service when outside of the Zone of Interior and to the office of chief veterinarian in an expeditionary force was first contained in SR 70. At variance with the more commonly accepted concept of subordination to the chief surgeon, this SR 70 provided that the chief veterinarian report direct to the commander in chief. Under this concept, the Chief Veterinarian, American Expeditionary Forces in France, was assigned to the office of the force's Chief Quartermaster where he became veterinary technical adviser to the theater's remount service rather than a central administrator of the veterinary service. The veterinary service was in fact under the direct control of the Quartermaster Corps instead of the Medical Department. This arrangement was wholly unsatisfactory from every standpoint, but it was not corrected until August, 1918, when the Army Veterinary Service was finally placed under Medical Department control and the Chief Veterinarian was assigned to the Chief Surgeon's Office.

Department veterinarians were assigned to the Hawaiian, Philippine, and Panama Canal departments in 1918. From the office of the department surgeon, they supervised and coordinated the veterinary services in these departments in the same manner as the veterinary service was supervised by department or corps area veterinarians in the Zone of Interior.

\section{Personnel}

\section{REGULAR ARMY OFFICERS}

It was not until the spring of 1917 that anything was materially accomplished to provide a commissioned veterinary corps as authorized by the National Defense Act of 1916. Before that time, a board of officers, composed of three Medical Corps 
TABLE 1

Years of Service Required for Promotion of Veterinary Corps, Regular Army, Officers, As Described by LaW, 1916-40

\begin{tabular}{|c|c|c|c|}
\hline Rank & Act of 3 June 1916 & Act of 4 June 1920 & Act of 31 July 1935 \\
\hline $\begin{array}{l}\text { Second lieutenant . . } \\
\text { To first lieutenant ... } \\
\text { To captain . . . . . . . . . . . . . } \\
\text { To major . . } \\
\text { To lieutenant colonel } \\
\text { To colonel . . . }\end{array}$ & 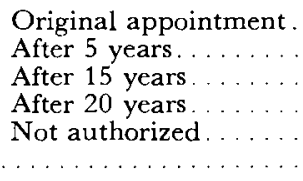 & 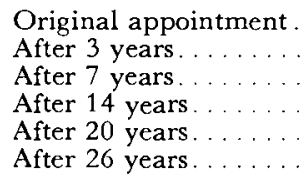 & $\begin{array}{l}\text { Original appointment } \\
\text { After } 3 \text { years } \\
\text { After } 12 \text { years } \\
\text { After } 20 \text { years } \\
\text { After } 26 \text { years }\end{array}$ \\
\hline
\end{tabular}

officers and two veterinarians, was appointed to examine the physical and professional qualifications of veterinarians then in Cavalry, Field Artillery, and Quartermaster Corps for appointment into the Veterinary Corps, Regular Army. Later, the examinations were extended to civilian veterinarians. By 6 April 1917, 58 officers with previous military service had been commissioned. By July, 1918, the corps had been filled to its authorized strength of 118 . The authorization remained at this level until, under the 1920 amendments to the National Defense Act, it was increased to 175 . The vacancies thus created were partially filled (to a total strength of 163 by December 1920) by integration into the Regular Army of selected Veterinary Reserve officers who had seen active military service during World War I. The appropriation act of 30 June 1922 provided that, effective I January 1923, pay would be restricted to 126 regular Veterinary Corps officers. The cutback from the then actual strength of 158 to the authorization of 126 was accomplished in part by normal attrition, but the appointments of 22 officers were forcibly terminated by "pink ticket." The National Defense Act was never amended to reflect the reduced authorization, but the restriction was repeated in successive appropriation acts so that the authorization and actual strength was still 126 at the beginning of World War II. Subsequent to the integration program noted above, vacancies within the authorized strength were filled only in the lowest grade by appointment from an eligible list established after examination of candidates for appointment.

Temporary promotions of Regular Army Veterinary Corps officers were made under authority of the provisions for the National Army during World War I. Permanent promotions were made upon completion of a fixed number of years of service and successful completion of physical and professional examinations (Table 1).

\section{RESERVE OFFICERS}

With the onset of World War I, it was evident that the demand for veterinary officers would have to be met by the appointment of veterinarians in the Veterinary Section, Officers' Reserve Corps, under authority of the Officers' Reserve Corps section of the National Defense Act of 1916. In the spring of 1917, The Surgeon General authorized the deans of veterinary colleges and some few leading practitioners to conduct professional examination of veterinarians who might apply for appointment as second lieutenants, Veterinary Officers' Reserve Corps. After the fall of 1917, candidates for appointment were examined by Medical Department boards of officers at Army camps. During the wartime period, a total of 1,596 veterinarians were commissioned in the Reserve and served on active duty. Like the veterinary officers of the Regular Army and those of the National Guard, Veterinary Corps Reserve officers were integrated into the National Army on 4 October 1917, under the provisions of General Orders No. 130. On 7 August 1918, all officers were transferred into the 
U.S. Army. This latter personnel action was interpreted as one of outright discharge from the Officers' Reserve Corps, so the demobilization of the Army resulted in the unconditional release of all former Reserve Corps veterinary officers from further military obligation. The Veterinary Officers' Reserve Corps then comprised only the few who had not been called to active duty and those who had been clischarged prior to 7 August 1918.

The Veterinary Section of the Officers' Reserve Corps was reestablished on 1 January 1919 and by the end of that year had 92 members. Many former veterinary officers who had rendered satisfactory service during the war were reappointed in the Reserve in the grades held when relieved from active duty. Later, the majority of new appointments were veterinarians who had completed their training under the Reserve Officers' Training Corps program which was started in four veterinary colleges in 1920. The number in the Reserve, which from 1925 to 1938 averaged about 1,000, had increased to over 1,500 in 1940 , providing an adequate source of supply of veterinary officers when needed during World War II. After mid-1930, over 100 Reserve Corps veterinary officers were, on their own applications, ordered to active duty with the CCC (Civilian Conservation Corps) for which certain administrative and supply functions, including the inspection of food by veterinary officers, were being performed by the Army. These officers were relieved from active military duty in late 1939 , but many were reemployed as civilian employees of the CCC to perform meat inspection duties.

\section{NATIONAL GUARD OFFICERS}

During World War I, 74 officers with the National Guard were inducted into federal service. These, like all other veterinary officers, were integrated into the $\mathrm{Na}$ tional Army on 4 October 1917 and into the U.S. Army on 7 August 1918. These were discharged from military service following the war. Later, veterinarians again became a part of the National Guard, and, by 30 June 1941, 34 National Guard veterinary officers were in active Federal service. Also included among the 2,313 veterinary officers who saw active military service during World War I were 17 originally appointed in the National Army, 207 appointed in the U.S. Army after 7 August 1918, and 2 retired Regular Army Veterinary Corps officers. The peak active strength was 2,234; this peak was reached on 30 November 1918. The peak active strength in Europe during World War I was 890 officers on 28 December 1918.

\section{ENLISTED MEN}

The National Defense Act of 1916 did not provide for veterinary enlisted personnel. The first provision for enlisted men was contained in General Orders No. 130, which established a National Army Veterinary Corps consisting of commissioned and enlisted personnel. It provided for a strength not to exceed 16 veterinary enlisted men for each 400 animals in the Army. The number of enlisted men rapidly increased, and a wartime peak of 18,007 men was reached on 31 October 1918. About two of every three enlisted men saw oversea service. Demobilization after World War I saw the rapid release of wartime or Selective Service enlisted men from the Veterinary Service. During the spring of 1919, the War Department authorized enlistment or reenlistment with the Medical Department, Regular Army, for immediate assignment to duty with the Veterinary Corps. War Department General Orders No. 127, 17 November 1919, augmented the Medical Department enlisted strength by 1,500 personnel spaces with the expressed contingency that personnel "will be enlisted in the Medical Department but will be assigned to duty with the Veterinary Corps." By 30 June 1920, there were 965 enlisted men, "Medical Department (Veterinary Service)," on duty. Under the 1920 amendments to the National Defense Act, a reduction in overall Medical Department enlisted personnel authorization was effected, and this was reflected in the decrease of the veterinary 
suballotment to 800 in 1922. Further reduction in authorization followed, and the average authorization through the years to 1940 was approximately 600 , while the average actual strength was very close to this figure. Both the authorized and actual enlisted strengths were generally below that necessary for operation of a fully efficient veterinary service.

\section{Training and Instructional Services}

\section{TRAINING IN WORLD WAR I}

The most discouraging situation in the beginning wartime expansion of the Army Veterinary Service was its inadequate training. Practically all veterinary officers were lacking in military experience, and there was a very serious shortage of trained men to help the untrained, as there was no corps of commissioned officers before 1917. Training of individual officers and enlisted men was necessary as was also the training of units. Many officers were of necessity self-trained. On-the-job training was conducted in unit schools at regimental, depot, division, and camp level wherever possible, but the quality of training was too often poor due to lack of trained instructors. Most of the few experienced officers who were available as instructors were assigned to Medical Department special training facilities or schools.

Only about one-half of the Veterinary Corps officers serving during World War I received military veterinary training in Medical Department or other training installations giving formal instruction. Approximately the same proportion of enlisted men received this type of training. The school at Camp Lee, Virginia, was concerned principally with the organization and unit training of 36 hospital and replacement units for the American Expeditionary Forces in France; 6,500 of its students were sent overseas with organizations. The school at the General Supply Depot in Chicago supplied specialized training in food and forage inspection.

TRAINING AFTER WORLD WAR I

The end of World War I brought the early closing of all of the wartime veteri- nary training schools or facilities other than the Course in Meat and Dairy Hygiene and Forage Inspection in Chicago and the veterinary laboratory course in Philadelphia. The latter was transferred to Washington, D.C., in 1920 and later became a part of the Army Veterinary School.

The course of instruction at the Chicago General Supply Depot was designated as the Veterinary School of Meat and Dairy Hygiene and Forage Inspection in 1920, as an Army special service school under the Medical Department for the training of veterinary officers and enlisted personnel. The school was reorganized in early 1922 and was renamed the Army Veterinary School. Pursuant to War Department authorization of 7 July 1923, the school was transferred to Washington, D.C., where it was integrated into the organization of the Army Medical Center. The school conducted the basic course for Veterinary Corps officers and the technicians' course for enlisted personnel throughout the peacetime period. The Army Veterinary School graduated 162 officers and 196 enlisted men between 1920 and 194I.

In 1920, the Medical Field Service School for the field training of Medical Department personnel was established at Carlisle Barracks, Pa. Groups of Veterinary Corps officers first regularly attended this school in 1923; a total of 113 Veterinary Corps officers had graduated before 1941.

The following tabulation shows the number of Veterinary Corps officers graduating from Army schools, other than Medical Department schools, during the peacetime period.

Army War College ............ I

Command and General Staff School 2

The Cavalry School ........... 12

The Chemical Warfare School .... 8

Quartermaster Corps Subsistence

School $\ldots \ldots \ldots \ldots \ldots \ldots \ldots \ldots \ldots \ldots \ldots \ldots$
Total $\ldots \ldots \ldots \ldots \ldots \ldots \ldots$

During the same period, 15 Veterinary 
Corps officers completed courses in civilian educational institutions.

Some of the most important peacetime training was the training conducted in veterinary ROTG (Reserve Officers' Training Corps) units in four veterinary colleges between 1920 and 1935. During this period, nearly $\mathbf{5 0 0}$ veterinary ROTC students received their professional degrees and were commissioned as second lieutenants in the veterinary section of the Officers' Reserve Corps.

\section{Equipment and Supplies}

Shortly after becoming a part of the Medical Department, the Army Veterinary Service was equipped and supplied in common with the Medical and Dental Corps. However, at the beginning of World War I there was practically no veterinary equipment or supply on hand. The relatively small holding of veterinary supplies in the hands of the Quartermaster Corps was transferred to the Medical Department, and veterinarians who were then entering active military service were asked to bring their equipment with them for purchase by the Army. In addition, the Secretary of War granted authority to civilian animal humane organizations to furnish gift donations so that Army animals would not suffer from the lack of veterinary equipment and supplies.

Donations of considerable amounts of equipment and supplies were made by the Blue Cross Society, sponsored by the American Red Cross, and by the Red Star Animal Relief, organized as a part of the American Humane Association. The appropriations act of 12 May 1917 provided funds for the Medical Department expressly "for the purchase of veterinary supplies," but it was late 1917 before nearly adequate stocks were available in the Medical Supply Depot, St. Louis, Mo. Supply tables revised in early 1918 provided new wallets, chests, and unit assemblies, largely patterned after British Army equipment, for veterinary detachments, hospitals, and other field units. Before 22 April 1918, nearly $\$ 41 / 2$ million had been expended for veterinary equipment and supplies, which by that time were on hand in adequate amounts.

After World War I, the Medical Department supply tables were subjected to various revisions, but the classification of veterinary supplies remained more or less the same after 1928. During the peacetime period, the Medical Field Service School and the Army Veterinary School, working with the Veterinary Division of the Surgeon General's Office and selected test units in the field, did much to improve and develop the veterinary equipment and supply, particularly the various assemblies for field use.

\section{MISSION AND RESPONSIBILITIES}

With an understanding of the beginnings in military veterinary medicine and of developments in the Army Veterinary Service since its formation pursuant to the National Defense Act of 3 June 1916, the objectives and accomplishments of the 2,I16 veterinarians who served in the Veterinary Corps of the Army during World War II became more real. At this point, it must be emphasized that the wartime expansion of the Army Veterinary Service was generally orderly, even showing increasing efficiency in answer, or partial response, to the seemingly imponderable problems and questions which then arose. This was not true during World War I when the newly created Army Veterinary Service was necessarily expanded even before its fundamental principles or nuclei were fully developed. The onset of World War II found the Army Veterinary Service with a tested definition of its mission and responsibilities and with a central administrative agency in operation - two factors which were essential to orderly expansion. Their existence was a credit to the Veterinary Corps which had actively continued and repeatedly reevaluated them once they had been developed in the years past.

The mission and responsibilities of the Army Veterinary Service in World War II were generally no different from those which were defined soon after the Veterinary Corps was created and was made a 
component of the Medical Department. Only the words were changed after World War I, and time had brought about some refinements in these definitions as well as a more firm establishment of the relationship of the corps in Medical Department organization. Special Regulations No. 70, 15 December 1917, described the objects of the Veterinary Corps as follows: "to protect the health and preserve the efficiency of the animals of the Army," and "also provide for the inspection of meat-producing animals before and after slaughter and of dressed carcasses; and for the inspection of dairy herds supplying milk to the Army." Parts of the definition originated with the National Defense Act of 3 June 1916, which had created the Veterinary Corps to include veterinarians, veterinarians with mounted units, veterinary inspectors of horses and mules, and veterinary inspectors of meats. On 25 January 1922, AR (Army Regulations) No. 40-2005, Medical Department-Veterinary Service, General Provisions, provided: "The Veterinary Service as a part of the Medical Department ... is charged in peace and war with duties falling under two definite heads: First, those in connection with the animals of the Army; second, those concerned with the food supplies of troops that are of animal origin." This was restated in the 15 September 1942 edition of the same regulation and was continued throughout the remaining period of World War II.

\section{Animal Health}

With reference to animals, the Army Veterinary Service was responsible for (1) investigating animal hygiene and sanitary conditions and making recommendations with respect thereto; (2) advising on those methods of animal management concerned with animal health and efficiency; (3) instructing military personnel on military animal sanitation and management and on horseshoeing; (4) examining animal feeds and forage when procured, in storage, and at issue; (5) evacuating and caring for sick and wounded animals; (6) physically examining animals; (7) managing and controlling veterinary hospitals and all other veterinary units; (8) investigating and controlling those diseases of animals which were known or suspected to be transmissible to the human being; and (9) controlling, training, instructing, and assigning to duty of the commissioned and enlisted personnel of the Medical Department who belonged to the Veterinary Service. These responsibilities expressly meant that the Army Veterinary Service in World War II-

1. Applied the principles of veterinary sanitary science to maintain animals in a correct environment with regard to their shelter, restraint, handling, feeds and feeding, grooming, work and exercise, shoeing, clothing, and equipment with the purpose of eliminating, so far as practicable, the causes of physical inefficiency.

2. Initiated suitable measures for the control of communicable diseases.

3. Reduced animal losses and inefficiency by the prompt discovery of the sick and wounded, their separation from the well, their evacuation, their segregation in veterinary hospitals, and the application of curative measures.

4. Physically examined animals prior to purchase and at other times with a view to insuring the acquisition of only serviceably sound animals and the prompt and economical disposal of the unsound.

5. Reduced the incidence among military personnel of diseases transmissible by animals by the application of veterinary public health measures applicable to military animals and civilian animals in the vicinity of troop areas.

\section{Food Inspection}

Regarding food supplies, the Army Veterinary Service in World War II was responsible for (1) the procurement and surveillance inspections of meats, meat foods, milk and dairy products used by the Army; (2) the determination, by inspection or other means, of the sanitary condition of 
food establishments, warehouses, and shipping conveyances and of the methods used in manufacturing, storing, shipping, and handling food products; (3) the submission of recommendations with respect to the food supply; and (4) the instruction of veterinary food inspection personnel. These responsibilities meant that the Army Veterinary Service-

1. Applied the principles of sanitary control over the condition and methods used in the production or manufacture, shipping, storage, issue, and other handling of food products, including food establishments, warehouses, freezing plants, refrigerators, railroad cars, ships, and airplanes as well as milk herds and dairies.

2. Reduced or eliminated the hazards to troop health that existed in diseased, contaminated, or deteriorated food supplies, by sanitary inspections and reinspections of food products.

3. Assured that the quantity and the sanitary, nutritive, and grade qualities of food products were delivered by contractors in accordance with the requirements of specifications and purchase instruments.

By the operations listed, the veterinary food inspection service assured that the food supplies of animal origin which were purchased by the Army were produced in establishments maintaining acceptable stanclards of sanitation, that they were: sound and of the required quality when procured, and that the food products at time of issue to troops were wholesome and fit for human consumption. The operations also were important in the conservation of the Army food stockpiles against unnecessary deterioration or outright losses due to spoilage.

\section{Relation With Medical Service}

In the conduct of this service with Army animals and the inspection of the Army food supply, the Veterinary Service was aclministered, under the direction of The Surgeon General, by a Veterinary Corps officer who was selected by The Surgeon General and assigned to duty in his office as chief of the Veterinary Division. Below the level of the Surgeon General's Office in the organizational structure of the Army, these services in a theater of operations, territorial department, corps area (later service command), camp, airbase, or other station, or in a field army, army corps, division, air force, or other unit were the responsibility of, and were conducted by, the senior Veterinary Corps officer, whose official designation was "veterinarian." His basic title was, for example, chief veterinarian, department veterinarian, corps area (or service command) veterinarian, station veterinarian, depot veterinarian, base veterinarian, port veterinarian, army veterinarian, corps veterinarian, division veterinarian, brigade veterinarian, or regimental veterinarian. At these levels of the military organizational structure, the dual nature of responsibilities of the Army Veterinary Service - concerning animals on one hand and troops on the other - involved a close and definite relationship in Medical Department organization and administration. The veterinary service with animals and the general medical service with troops proceeded along parallel lines. Their problems of sanitation, preventive medicine, control of preventable diseases, professional care and treatment of the sick and injured, and the administration of hospitals were precisely analogous, as were the procedures prescribed and the means provided for their solution.

\section{Staff Duties}

While appropriately united in one department and administered under one head - The Surgeon General - the veterinary and medical services were, in a technical sense, separate except as they met on the common ground of an animal disease which might possibly be communicable to man. On the other hand, the veterinary service with troops or operations concerned with the examination of the food supply was a matter of sanitation and, thus, a direct extension of the sanitary service of the Medical Department, which was 
charged with responsibility in all matters concerning the protection of the health of troops. Proper coordination of these activities of this service branch of the Army was assured only when there was but one representative of the Medical Department on the staff of the commanding officer. Since all considerations involving the health of troops were paramount, such staff duty logically devolved upon the senior Medical Corps officer present with the command. This principle, however, was construed as placing the veterinary officer of the command as a subordinate of, or assistant to the surgeon only in a staff capacity. In his staff relations, the veterinarian furnished the surgeon with such technical information as was necessary in properly representing the affairs of the Medical Department. In addition to their staff functions as surgeon and veterinarian, respectively, the medical officer commanded the medical detachment and the veterinary officer commanded the veterinary detachment, and in such command capacity each was directly responsible only to the commanding officer. Accordingly, at posts, camps, and stations, such matters as reports and returns relating exclusively to the veterinary detachment or to veterinary technical operations not involving the health of troops were not transmitted by the veterinarian through the surgeon.

In the absence of a veterinary officer, the ordinary staff duties of the surgeon were expanded to include direct responsibility for the command's veterinary service, including its administration. Where there were no veterinary personnel - officer or enlisted - the surgeon represented the Medical Department in matters pertaining to the Veterinary Service, utilized such facilities as were at his disposal, and kept the commanding officer advised as to the veterinary requirements. To the extent that veterinary personnel were available, these situations were avoided by the assignment of specially trained and selected veterinary noncommissioned officers to the surgeon's offices of commands, by the authorization to employ civilian veteri- narians, or by the naming of an attending veterinarian who performed at such stations the same duties as were required at his regularly assigned station.

\section{Professional Duties}

In addition to the cluties and responsibilities devolving upon him as a doctor of veterinary medicine, the Veterinary Corps officer inherited certain duties and responsibilities which were commensurate with his commissioning as an Army officer and were proper to the performance of the mission assigned to the Army Veterinary Service. These may be classified as professional, advisory, and administrative. The professional duties were typical of those which were performed by the veterinary surgeons and employed veterinarians who saw service with Cavalry, Field Artillery, and the Subsistence and Quartermaster's Department before 1916; they had no advisory duties and no personnel to assist them. The advisory duties may be compared with the activities of professional consultants or civilian experts, but only the Veterinary Corps officer could perform all three classes of duties and be responsible for them, including that of command. The duties and responsibilities, in general, of the veterinary officers when acting in a professional capacity were to -

1. Practice preventive veterinary medicine by recommending suitable measures for the prevention and control of animal diseases and injury, including physical examinations of animals.

2. Provide treatment and hospitalization for animals analogous to that provided to troops by medical and dental officers.

3. Conduct sanitary inspections of establishments producing, storing, issuing, or otherwise handling foods of animal origin which were used by the Army and to conduct procurement and surveillance food products inspections.

\section{Advisory Duties}

When acting in an advisory capacity, or as a staff veterinary officer, his duties were - 
1. To keep informed of existing conditions having any bearing upon the health and physical efficiency of the animals of the command and, especially in a moving command, to anticipate the occurrence of such conditions.

2. To keep informed of conditions affecting foods of animal origin which might have a bearing upon the health of troops.

3. To transmit to the commanding officer such of this information having a bearing upon the military administration and to submit appropriate recommendations.

4. To transmit to the surgeon such of this information having any bearing upon the health of troops.

5. To make prescribed reports and returns and to take appropriate action on reports and returns received from subordinates.

6. To perform such other duties as directed by superior authority.

These advisory duties did not mean that the veterinary officer took corrective action to minimize a defect - that being the direct responsibility of the commanding officer. If, however, the commanding officer expressly authorized the Veterinary Corps officer to give orders in his name for the correction of such defects, then the duties and responsibilities of the latter were correspondingly increased. In advising, it became necessary for the veterinary officer to remember that when any veterinary necessity of the moment conflicted with a purely military necessity, the former was ranked secondary in importance, unless the veterinary officer was convinced that the responsible military authority was not aware of the far-reaching results from a veterinary point of view, in which case, it was necessary to again present the matter to the military authority, who alone possessed all of the facts bearing on the decision of action for which he alone was responsible.

\section{Administrative Duties}

In his administrative duties, the Veterinary Corps officer was directly responsible for the condition and efficiency of the veterinary service of his command - this being comparable to the duties of administrative officers of the line units of the Army. More specifically, the veterinary officer was responsible for -

I. The training, discipline, efficiency, and assignment to duty of the personnel which he commanded and the supervision of the internal economy of the veterinary organization or unit.

2. The maintenance of equipment in proper condition by requisitioning the needed supplies and by properly caring for the property on hand.

3. The keeping of prescribed reports and the making of prescribed reports and returns.

4. The performance of such other duties as were required by superior military authority, such as the conduct of veterinary instructional services in horseshoeing schools.

\section{Changes in Emphasis}

The mission and responsibilities of the Veterinary Service during World War II were not materially different from those of World War I. However, during the war, there were some changes in the emphasis on parts of the mission and responsibilities and in the way that they were fulfilled. For example, World War II saw the definition of Army animals, so far as the Army Veterinary Service was concerned, expanded to mean not only horses and mules but also Army dogs and signal pigeons and even laboratory animals. However, this change in meaning did not add to, or detract from, the mission of the Army Veterinary Service to protect and preserve animal efficiency; nor did changes in animal strength have an influence on this mission. Similarly, the newer threats to troop health which came with leptospirosis and rabies of dogs or with psittacosis and salmonellosis common to pigeons - diseases which are infectious for the human being - had little influence on the basic concept of the mission of veterinary public health and its relationship in the Medical Department. In regard to the Army food supply, which was many times the volume of any past 
TABLE 2

Veterinary Service to Horses and Mules in the U.S. Army, by Year, 1941-46

(Rate expressed as number per annum per 1,000 average strength)

\begin{tabular}{|c|c|c|c|c|c|c|}
\hline \multirow[b]{2}{*}{ Year } & \multirow{2}{*}{$\begin{array}{l}\text { Average } \\
\text { Strength }\end{array}$} & \multicolumn{2}{|c|}{ Admissions } & \multicolumn{2}{|c|}{ Deaths } & \multirow{2}{*}{$\begin{array}{c}\text { Days of } \\
\text { Treatment }\end{array}$} \\
\hline & & Number & Rate & Number & Rate & \\
\hline $\begin{array}{l}1941 \ldots \ldots \\
1942 \ldots \ldots \\
1943 \ldots \ldots \\
1944 \ldots \ldots \\
1945 \ldots \ldots \\
1946 \ldots \ldots\end{array}$ & $\begin{array}{r}46,520 \\
49,701 \\
56,287 \\
43,334 \\
35,200 \\
7,717\end{array}$ & $\begin{array}{r}44,696 \\
33,424 \\
31,784 \\
25,471 \\
19,939 \\
3,119\end{array}$ & $\begin{array}{l}960.8 \\
672.5 \\
564.7 \\
587.8 \\
566.4 \\
404.2\end{array}$ & $\begin{array}{r}2,528 \\
2,181 \\
2,987 \\
2,364 \\
2,856 \\
275\end{array}$ & $\begin{array}{l}54.3 \\
43.9 \\
53.1 \\
54.6 \\
81.1 \\
35.6\end{array}$ & $\begin{array}{r}918,553 \\
706,794 \\
853,481 \\
610,916 \\
486,652 \\
59,210\end{array}$ \\
\hline
\end{tabular}

Source: Reports, Veterinary Division, Surgeon General's Office, for the annual reports of The Surgeon General, 1942-45. (Official record.)

period, the increasing emphasis on centralizing food procurement, on conducting inspections at food establishments, and on conserving Army stockpiles by surveillance inspections involved changes and expansion of the administrative organization of the Army Veterinary Service in the Zone of Interior and theaters overseas in lieu of amendment to the statement of mission and responsibilities.

Table 2 shows the number of animals treated, and Table 3 shows the amounts of foods of animal origin that were inspected. These tables present a picture of the magnitude of the mission and responsibilities of the Veterinary Service during World War II.

\section{ADMINISTRATION}

The Army Veterinary Service was administered as a component of the Medical Department under the direction of The
Surgeon General by a Veterinary Corps officer who was selected by The Surgeon General and assigned to duty as chief of the Veterinary Division of his office. Pursuant to the regulations of the Army, his title was that of chief of the Veterinary $\mathrm{Di}$ vision and not chief of the Veterinary Corps. His recommendations and actions were first subjected to review and approval by The Surgeon General, but on certain matters of primary veterinary concern these recommendations were accepted so regularly that, from a practical viewpoint, the chief exercised a varying degree of direct control over the Veterinary Corps.

In 1939, the chief of the Veterinary Division, then a veterinary officer with the rank of lieutenant colonel, was advis. ing The Surgeon General directly on the administration of the Army Veterinary Service. The Veterinary Division at the time included one other veterinary officer

TABLE 3

Inspections of Foods of Animal Origin, Procured, Handled, and Issued by the U.S. Army Veterinary SERVICE, BY YEAR, 1941-46

(In millions of pounds)

\begin{tabular}{|c|c|c|c|c|c|}
\hline \multirow[b]{2}{*}{ Year } & \multirow[b]{2}{*}{ Grand Total } & \multicolumn{2}{|c|}{ Procurement Inspections } & \multicolumn{2}{|c|}{ Surveillance Inspections } \\
\hline & & Passed & Rejected & Passed & Rejected \\
\hline $\begin{array}{l}1941 . \\
1942 . \\
1943 . \\
1944 . \\
1945 . \\
1946 .\end{array}$ & $\begin{array}{r}2,715.71 \\
11,004.71 \\
25,055.21 \\
47,028.41 \\
55,583.92 \\
9,680.26\end{array}$ & $\begin{array}{r}1,292.38 \\
4,296.24 \\
9,714.47 \\
13,522.40 \\
13,885.78 \\
1,873.11\end{array}$ & $\begin{array}{r}58.41 \\
242.33 \\
307.96 \\
374.20 \\
246.35 \\
42.92\end{array}$ & $\begin{array}{r}1,364.44 \\
6,962.77 \\
15,015.30 \\
33,091.65 \\
41,411.26 \\
7,749.95\end{array}$ & $\begin{array}{r}0.49 \\
3.36 \\
17.49 \\
40.17 \\
40.53 \\
15.17\end{array}$ \\
\hline
\end{tabular}


and four civilian employees. During the pre-World War II emergency period, the veterinary personnel strength was augmented by three officers - the first increase in their numbers since mid-1925. With this change, the peacetime Veterinary Division was reorganized to include, as of 7 December 1941, the chief of the division, the assistant chief, the officers in charge of the animal service and the meat and dairy hygiene subdivisions, and the liaison officer to the U.S. Department of Agriculture and the Quartermaster General's Office. A few months later, this internal arrangement was replaced by one more or less contemplated in the mobilization plans which had been developed in the preceding peacetime years. The Veterinary Division was divided into four subdivisions: (1) Personnel, Statistical and Training; (2) Inspection; (3) Animal Service; and (4) Meat and Dairy Hygiene. Probably the most important part of the change at this time was that mobilization planning had provided for the rank of the chief of the division to be that of brigadier general. Thus, on 17 March 1942, this officer, Col. Raymond A. Kelser, VC, was advised by The Adjutant General of his temporary appointment as brigadier general in the Army of the United States (with date of rank, 9 March 1941). He was the first in the history of the Army Veterinary Service to attain general officer rank. The other parts of the mobilization plans were not as rigidly carried out, though a Veterinary Corps officer was assigned to the Personnel Division (for the period, 9 February 194311 April 1944), and, in lieu of the veterinary subdivision in the planned Inspection Division, the position of traveling veterinary consultants was established.

On 26 March 1942, the Veterinary Division was elevated to the status of a "serv. ice" within the organizational structure of the Surgeon General's Office and was internally organized to include the director of service and three divisions (each with three subdivisions). 



\section{Constitution and By-laws of the United States}

\section{Veterinary Medical Association: 1863}

\author{
(Adopted June 10, 1863)
}

The Committee appointed to draft By-Laws for the United States Veterinary Medical Association respectfully offers the following for the consideration of the Association.

Josiah H. Stickney, Boston, Mass.

George W. Bowler, Cincinnati, Ohio

Arthur S. Copeman, Utica, New York

Isaiah Michener, Bucks Co., Pa.

Jacob Dilts, Mercer, N. Jersey.

Elias F. Ripley, Portland, Maine

R. H. Curtis, Brooklyn, N. Y. [name deleted]

John Busteed, 407-4th Ave., N. York

William A. Wisdom, Wilmington, Del.

CONSTITUTION AND BY-LAWS

Chapter 1

Art. 1. This association shall be known as the United States Veterinary Medical Association. It shall consist of Stated and Honorary Members.

Art. 2. The purposes and objects of the Association are to contribute to the diffusion of true science and particularly the knowledge of Veterinary Medicine and Surgery.

Art. 3. The Officers of this Society shall be a President, Vice-Presidents, a Recording Secretary, a Corresponding Secretary, and a Treasurer, all of whom shall be elected, by ballot, at each anniversary meeting, and a majority of all the votes shall be necessary for a choice. They shall be elected for one year and until their successors are chosen; to whom they shall without delay, deliver and transfer all moneys, books, manuscripts, vouchers and all other property in their possession.

Art. 4. At each anniversary meeting, the Association shall appoint in the manner provided for in the election of officers, six Censors, to continue in office for one year and until others are appointed in their place.

Art. 5. The several officers of the Association, together with the 6 Censors, shall constitute the Comitia Minora.

Art. 6. The Association shall receive such Delegates as the various State or County Veterinary Societies may elect, on proof of due qualifications.

\section{Chapter 2. President}

Art. 1. It shall be the duty of the President to preside at all meetings of the Association, and preserve order and decorum.

Art. 2. He shall appoint all committees, unless otherwise ordered by special resolution.

Art. 3. He shall have no vote, except on questions where the votes are equally divided, and in the election of Officers, Censors and Delegates.

Art. 4. He shall keep on file all documents and certificates in relation to the Association, that may be deposited with him, and these he shall deliver to his successor.

Art. 5. The President shall perform all the duties prescribed by the Laws of the Association and resolutions thereof.

\section{Chapter 3. Vice-Presidents}

Art. 1. There shall be one Vice-President elected from each State represented. 


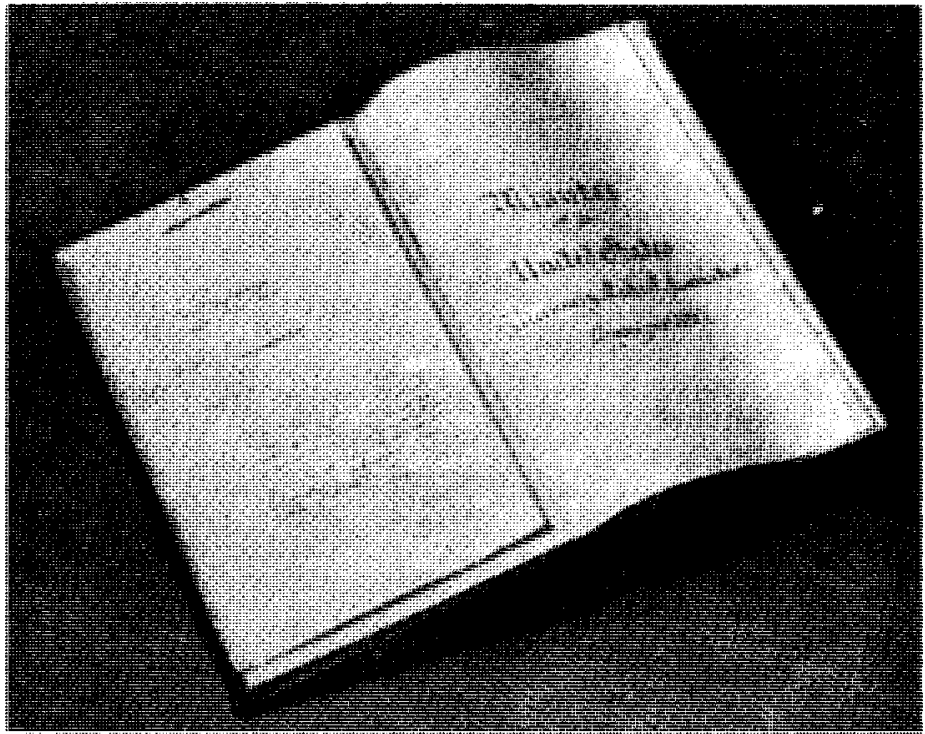

Flyleaf of the first Minutes Book, with manuscript draft of the Constitution and Bylaws of the USVMA adopted at the organization meeting in 1863. AVMA Journal
Art. 2. The Association shall elect one of the Vice-Presidents, in the absence of the President, to perform the duties of that Officer.

\section{Chapter 4. Corresponding Secretaries}

Art. 1. A Corresponding Secretary shall be elected from each State by ballot at the annual meeting.

Art. 2. Their duties shall be to conduct the correspondence of the Association. They shall retain copies of all letters written by them in behalf of the Association, and preserve and file all letters and communications received by them in their official capacity and shall report the same at each meeting.

Art. 3. They shall obey all orders and resolutions appertaining to the duties of their office.

\section{Chapter 5. Secretary}

Art. 1. The Secretary shall perform the duties directed by the laws of the Association and the by-laws and resolutions of the same.

Art. 2. It shall be the duty of the Secretary to notify each person proposed as a member of this Association, that he has been so proposed and transmit him a copy of the first, second, third, fourth, fifth, sixth, articles of the 13th chapter of the by-laws.

\section{Chapter 6. Treasurer}

Art. 1. It shall be the duty of the Treasurer to put all the moneys of the Association into one fund, to be appropriated to the payment of current expenses and for such other purposed as the Association may at its anniversary meetings direct.

Art. 2. He shall pay, by order of the President all bills cluly audited by the Finance Committee.

Art. 3. At every anniversary meeting he shall give a cletailed statement of his receipts and disbursements, duly audited and signed by the Finance Committee.

\section{Chapter 7. Censors}

Art. l. It shall be the duty of the Censors to examine applicants, who may apply for that purpose, provided they present them satisfactory testimonials that they are regular practitioners of the Veterinary Profession, and if on examination they find him qualified, they shall give a certificate thereof in writing to the President of the Association.

Art. 2. The examinations shall be held at the stated meetings of the Comitia Minora or at a special meeting called by the President for the purpose.

\section{Chapter 8. Comitia Minora}

Art. 1. The Comitia Minora shall meet once in 6 months.

Art. 2. The President may call a special meeting of the Comitia Minora whenever he shall deem it necessary.

Art. 3. The President or a Vice-President, together with five Censors, shall constitute a quorum for the examination of candidates for 
fellowship; but any five members may constitute a quorum for the transaction of other business.

Art. 4. The journal of the proceedings of the Comitia Minora shall be kept by the Secretary, and read at each anniversary meeting, together with the names of the attending and absent members; and if it shall appear that any member has been absent from two meetings in succession, without having assigned a satisfactory reason, he shall be ineligible to office for the ensuing year.

Art. 5. All communications, memoirs or essays on medical subjects, after having been read before and accepted by the Association may be submitted to the Comitia Minora for their subsequent examination, by whom they may be ordered to be published.

Art. 6. The Comitia Minora shall make the necessary arrangements for the meetings of the Association and execute such other duties as the Association shall direct.
Art. 7. The Comitia Minora may make rules and regulations for their government not inconsistent with the by-laws of the Association.

Art. 8. It shall be the duty of the Comitia Minora to take cognizance of breaches of the precepts of medical ethics which shall be laid before them, and they may report the results of their proceedings thereon to the Association, if they think proper.

\section{Chapter 9. Permanent Committees}

Art. 1. The following permanent committees shall be appointed by the President, at the anniversary meeting, viz: the Library Committee on Intelligence and Education, Committee on Diseases and a Finance Committee.

Art. 2. The Library Committee shall have the immediate charge of the Library. They shall make and preserve a correct catalogue of the books belonging to the Association; they shall make such purchases of books as the Association may from time to time direct, and they
Seal of the Association and original Minutes Book containing handwritten proceedings of meetings from June 9, 1863 to October 20, 1894. AVMA Jour. nal

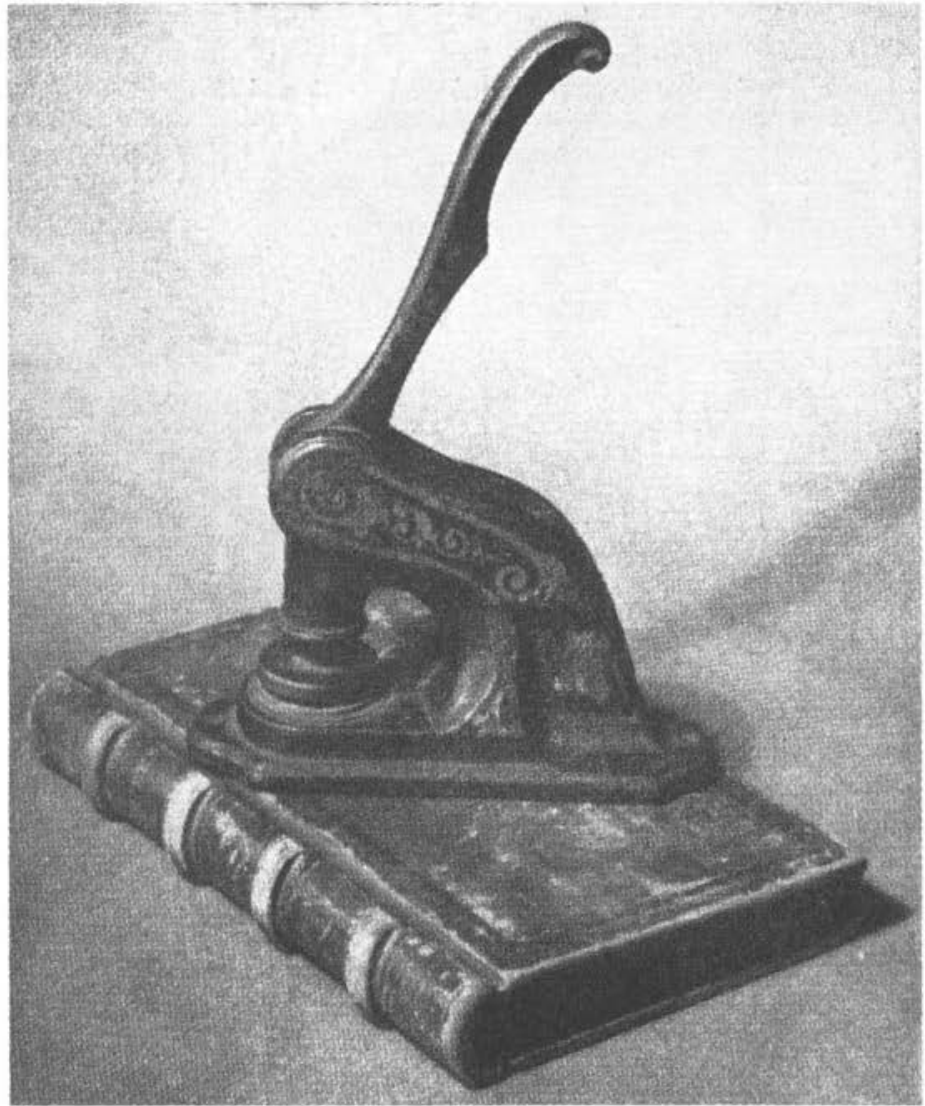




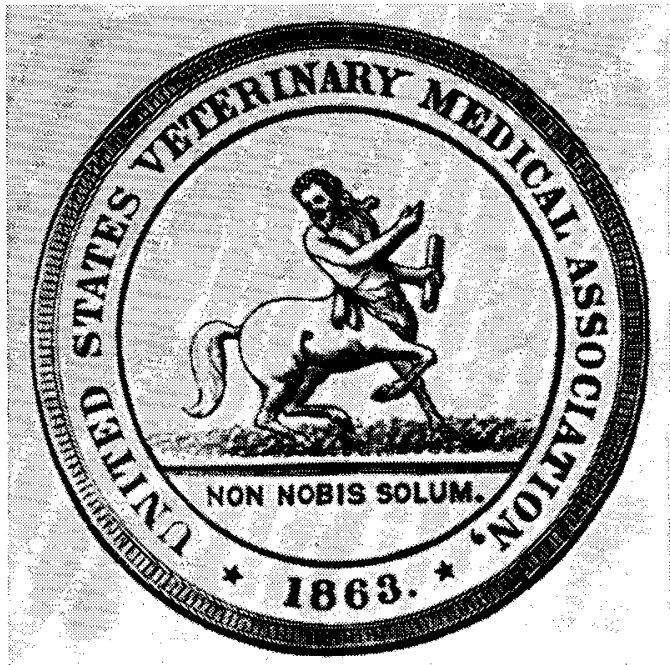

Seal of the USVMA adopted at the organization meeting in 1863 and used until the name was changed to AVMA in 1898. American Veterinary Review

shall report, in writing, at each anniversary meeting, the actual condition of the library, the number of volumes, the number of works added, whether by purchase or presentation, as well as the number, if any, missing.

Art. 3. The Library Committee shall have power, with the consent of the Association, to make such rules and regulations as shall be thought most conducive to the welfare of the library.

Art. 4. The Committee on Intelligence and Education shall collect and report to this Association recent veterinary medical facts and intelligence.

Art. 5. Any member of this Committee may report verbally such articles of intelligence as he may acquire.

Art. 6. This Committee shall keep a book in which they shall record all information given to the Association.

Art. 7. This Committee shall take charge of all models and instruments belonging to this Association.

Art. 8. It shall be the duty of the Committee on Diseases to investigate the character, causes and progress of diseases as they may prevail, with the best means for their prevention and cure and keep a record of the same.

Art. 9. It shall be the duty of the preceding committees to report, whenever ordered by the Association, the records of their proceedings, with such observations as they may think proper.
Art. 10. The Finance Committee shall audit the Treasurer's account and also all other accounts that may be presented to the Association for payment, and they shall also devise ways and means to raise funds when necessary, to meet the expenditures of the Association and report their proceedings at each anniversary.

Art. 11. The President shall be ex-officio a member of the Several Permanent Committees and he shall have power to convene them whenever, in his judgment, it shall be necessary.

\section{Chapter 10. Meetings of the Association}

Art. 1. The Anniversary Meeting of the Association shall be held on the first Tuesday in September in every year, the Comitia Minora shall select the place and hour of meeting, unless otherwise directed by the Association, due notice of which shall be given by the Committee.

Art. 2. Special Meetings shall be called by the President or, in his absence, by a Vice-President, upon the written request of twenty members, specifying the particular objects of such meetings, a notice of which shall be published at least one month before said meeting in such papers as the Secretary shall select. The President is also authorized, at his discretion to call special meetings duly notified as above.

Art. 3. The Anniversary and Stated Meetings may be adjourned from day to day.

Art. 4. Fifteen members shall form a quorum for the transaction of business, and a quorum shall always be presumed present, except at anniversary meetings, unless an actual count be called for.

Art. 5. In the absence of the President and Vice-President, the Association shall elect any member as president pro tempore.

Art. 6. Every member shall observe order and decorum in the Association, shall pay due respect to the President and other officers and to his fellows and no member shall withdraw during the session, without special permission from the chair.

Art. 7. All questions of order, whether in debate or otherwise, not specially provided for, shall be decided by the usual Congressional rules.

\section{Chapter 11. Anniversary Meetings}

Art. 1. At each anniversary meeting, the minutes of the Comitia Minora, the Treasurer's report of the last year and the reports of the various Committees shall be read.

Art. 2. The election of officers for the en- 
suing year, as provided for in Article 3, Chapter 1 , shall be next in order.

Art. 3. Amendments to the By-Laws shall be considered and accounts against the Association shall be acted on.

\section{Stated Meetings}

Art. 4. At each stated meeting, after the presiding officer shall have declared the Association formed, the minutes of the last meeting shall be read.

Art. 5. The motions and other unfinished business of the last meeting shall be considered.

Art. 6. No member shall be permitted to speak a second time, until each member who may wish to address the meeting on the subject under consideration may have had an opportunity of doing so; nor shall any member be allowed to speak more than twice, on any question, without special permission.

Art. 7. Communications on medical subjects may be received and read before the Association, by the members presenting them. The presiding officer may direct the order in which communications shall be read.

\section{Chapter 12. Special Meetings}

At special meetings no other business, except such as shall have been specified in the requisition, and in the published call for the meeting, shall be transacted.

\section{Chapter 13. Admission of Members}

Art. 1. When any Veterinary practitioner or Student of 3 years standing in the profession, applies for admission into this Association, the documents and testimonials relative to his professional qualifications shall be placed in the hands of the Secretary, who shall lay them before the Comitia Minora: whose duty it shall be to examine the same, and if they deem it expedient examine also the candidate and if they approve thereof, they shall grant him a certificate of fellowship.

Art. 2. No person, immigrating from a foreign country, and claiming the right to practice Veterinary Medicine and Surgery shall be admitted a fellow of this Association by the Comitia Minora, unless he shall produce satisfactory testimonials of his professional qualifications.

Art. 3. Every member shall sign the Constitution and the By-Laws.

Art. 4. Every candidate, before signing the By-Laws and receiving his certificate of fellowship, shall be required by the Secretary to pre- sent the Treasurer's receipt for his initiation fee of Five Dollars, which shall be appointed to the use of the Association; whereupon the Secretary shall present him with a copy of the By-Laws.

Art. 5. No person shall be considered a member of this Association, until he has complied with the preceding article.

Art. 6. Every member shall observe the code of medical ethics adopted by this Association and be answerable to the Comitia Minora, for breaches of the same.

Art. 7. The following shall be the form of Certificate of Fellowship.

These are to certify that is

a fellow of the United States Veterinary Medical Association incorporated in the year of our Lord one thousand eight hundred and sixty three.

In testimony whereof, we have affixed our hands and the seal of the Association, this

\section{Censors} day of

\section{Secretary} 18

\section{Chapter 14. Contributions and Arrears}

Art. 1. The Association, at the anniversary meeting, may assess such amount as shall meet the yearly expenses.

Art. 2. The treasurer shall, from time to time, at the cost of the Association, collect the arrears of each member.

\section{Chapter 15. Honorary Members}

Art. 1. Any member may propose a candidate as an honorary member; the medical rank or station held by him shall be furnished in writing by the proposer, at or previous to the time of such proposal; the person so proposed shall be balloted for at a subsequent meeting. A majority of votes shall constitute him an honorary member.

Art. 2. No more than three honorary members shall be annually elected.

Art. 3. The honorary members may take part in debate but shall not be entitled to vote.

Art. 4. The President of the United States, for the time being, shall be ex-officio, an honorary member. The following shall be the form of diploma for honorary member:

This is to certify that we, the President, Vice-Presidents, and Fellows of the United States Veterinary Medical Association have received as an honorary fellow of our Association and the said is hereby authorized to claim 
and enjoy all the rights, privileges and honors belonging to the said fellowship.

In witness whereof, we have caused these presents to be signed by our President and Secretary and sealed by our common Seal, this day,

President: day of Recording Secretary

\section{EMENDATIONS}

In 1866 it was recommended that the article pertaining to qualifications of candidates be amended to read:

the documents and testimonials relative to his professional qualifications, "moral character \& antecedents" shall be placed in the hands of the Secretary.

This was adopted in 1867 , at which time a revised Constitution and By-Laws was presented and adopted. Among the more noteworthy changes made in the Constitution were:

Chap. 4. Art. 1. The Secretary shall keep a fair and impartial record of the proceedings of the meetings of the Association, and shall neither add or erase.

This apparently was occasioned by Jennings having added the minutes of meetings held in Philadelphia prior to the organization meeting. and which by vote were ordered deleted.

Chap. 5. Art. 1. The Treasurer shall give security for the trust reposed in him, whenever the Association shall judge it requisite, and the funds of the Society shall require it.

This raises the interesting question as to whether some members were to be considered more or less trustworthy than others.

The original document did not distinguish between the Constitution and the By-Laws; in the revision, the latter portions dealing with meetings and membership were designated the By-Laws, the major additions being a Code of Ethics and provision for expulsion of members:

\section{Article 4. Code of Ethics}

Sec. 1. No member shall assume a title to which he has not a just claim.

Sec. 2. No member shall endeavour to build up a practice by undercharging his brother member.

Sec. 3. No member shall speak disrespectfully of another, or in any way attempt to lessen his professional reputation, particularly for his individual advancement.

Sec. 4. In all cases of consultation, it shall be the duty of the veterinary surgeon in attendance on the case, to give the opinion of the consulting veterinary surgeon (whether favorable to his own or otherwise) to the owner of the patient in presence of all three.

In case of the absence of the owner, the veterinary surgeon consulted may, after giving his opinion to the attending veterinary surgeon, transmit it also in writing to the owner, through the medical attendant.

It shall be deemed a breach of this code for a consulting veterinary surgeon to revisit a patient, without special invitation or agreement.

Sec. 5. In advertising, the veterinary surgeon shall confine himself to his business address. Advertising specific medicines, specific plans of treatment, advertising through the medium of posters, illuminated bills, newspaper puffs \&cc, will not be countenanced by this society.

Sec. 6. Secret Medicines-Any person who shall advertise, or otherwise offer to the public, any medicines, the composition of which he refuses to disclose, or if he proposes to cure disease, by any such secret medicines he shall be denounced as unworthy member and be expelled from the Association.

Sec. 7. Every member shall observe the Code of Medical Ethics adopted by this Association, and be answerable to the Comitia Minora for a breach of the same.

\section{Article 8. Expulsion of Members}

Sec. 1. The Comitia Minora shall be invested with power to hear, or determine, upon complaints filed before them in writing relative to the improper or immoral conduct of any member, and shall, if thought advisable, report upon such complaint to the Association, at the next annual meeting, the offending member being duly notified of such complaint, and allowed the privilege of defence; and such member if deemed guilty by a vote of two-thirds of the members present, shall cease to be a member of the Association.

Sec. 2. Any member who shall be absent from two anniversary meetings, without a satisfactory excuse, shall have his name dropped from the roll. 


\section{Index}





\section{Index of Subjects}

Abortion, 14, 65, 76, 115, 201, 214, 263, 267, 391

Academy of Veterinary Medicine and Surgery (Cincinnati), 246

Actinomycosis, 361, 422

Advocate of Veterinary Reform, 219

Agricultural journals, 113, 196, 249

Agricultural Museum, 149

Agricultural Research Service, 480

Agricultural schools, 353, 646

Alfort Veterinary School, 204

American Academy of Arts and Sciences, 65, 71

American Agriculturist, 143, 161

American Animal Hospital Association, 571, 587,609

American Cattle Doctor, 216, 220

American Farmer, 114, 149

American Farmer's Horse Book, 45, 50

American Home and Stable Doctor, 51

American Humane Association, 466, 576

American Public Health Association, 562

American Shepherd, 166

American Stock Journal, 245, 249

American Turf Register, 116, 149

American Veterinarian, 191, 219, 226

American Veterinary Association, 235, 284, $295,299,300$

American Veterinary College, 303, 319, 350, 363

American Veterinary History, 609

American Veterinary Journal, 113, 231

American Veterinary Medical Association. See also United States Veterinary Association clinic, 493, 509, 514, 520, 523, 540

emblem, 547

Executive Board, 539

Honor Roll, 511, 513, 515

House of Delegates, 531, 593

income, $518,612,619$

incorporation, $311,316,487,536$

Journal, 456, 593, 601, 610

membership, 520, 532, 601, 608, 630

name, 299

nominating committee, 514, 531, 623

objectives, 553

offices, $580,583,632$

Research Fund, 610

student chapters, 556

Women's Auxiliary, 542

American Veterinary Review, 113, 240, 319, $323,327,340,393,455,509$

Anatomy and Physiology of the Horse, 216, 230
Anesthesia, 217, 229, 237, 253, 346, 362, 384, $497,519,545$

Animal Castration, 270

Animal engineer, 498

Animal Plagues, 66

Animals

disease, 169

huge, 57,123

shelter, $7,14,19,67,170$

Anthrax, 26, 131, 271, 328, 390, 417

Antisepsis, 381

Antivivisection, 464

Artificial insemination, 607

A.S.P.C.A., 367, 403, 464, 576

Associations. See specific names

Association of Veterinary Faculties, 372, 488 , $497,514,520$

Astor House, 296, 299

Auburn University, 657

Automobile, 386

Autotherapy, 528

Azoturia, 279

\section{B}

Barbarism, 153, 194, 208, 230, 253

Bicycle, $\mathbf{3 8 5}$

Big head, 133, 148, 254

Biologics, 527

Blackleg, 191

Blacksmiths, 58, 253

Bloat, 82, 98, 214

Bloodletting, 34, 40, 62, 84, 115, 140, 157, 186, 221

Boards of Health, 22, 397, 406, 408, 501, 510

Boke of Husbandrie, 98

Bolton Center, 147

Book of Knowledge, 60

Books. See specific titles

Boston Veterinary Association, 235

Boston Veterinary Institute, 174, 217, 220, 232, $241,297,310,641$

Bots, 30, 37, 40, 105, 128, 159, 169

Breeder's Gazette, 271, 373, 440

Bureau of Animal Industry, 388, 406, 415, 431, $479,489,494,519,637$

Burnt Tongue, 115

Caduceus, 547, 549

California, University of, 659

California VMA, 547

Canada, veterinary medicine in. See Veterinary medicine, Canada 
Canary birds, 186

Canine practice, 502,524

Cannibalism, 7

Castration, 161, 269, 273

Cattle disease, $9,16,71$

increase, $5,7,11$

Cautery, 158

Centennial Exposition, 320

Cerebro-spinal meningitis, 310, 315, 317

Cesarean operation, 195, 217, 239

Charms, 30

Chart of Veterinary Reformed Practice, 216, 218

Chicago Veterinary College, 365

Chloroform, 186

Citizen and Countryman's Experienced Farrier, 34

Civil defense, 622, 625

Code of Ethics, 215, 338, 548, 552, 576

Colic, 53, 198, 214, 253

Colleges and schools. See specific names

Colonies

New Amsterdam, 13

New England, 12

Pennsylvania, 16, 56

Spanish, 4

Virginia, 6

Colorado State University, 657

Columbia Veterinary College, 350

Compendium of Cattle Medicine, 128

Compendium of Farriery, 47

Complete Horse Doctor Book, 53

Cornell University, 641, 644, 657

Cornell Veterinarian, 544

Country Gentleman, 131

Countryman's Companion, 16

County agents, 591

Cow doctors, 10, 167

Cultivator, 128

Dentistry, 376

Dictionary of the Veterinary Art, 115

Diseases of the American Horse, Catlle and sheep, 290

Distemper

cat, 67

dog, 67, 127, 150, 167

horse. See influenza

Docking, 12, 106, 129, 208

Dog

diseases, 53,150

laws, $13,20,24,84,142,282$

sheep-killing, 142

Domestic Animals, 71

Domestic Medicine, 41

Dourine, 423

\section{E}

Echinococcosis, 142

Edinburgh Veterinary Review, 287

Education, 81, 87, 146, 153, 173, 204, 232, 241, $315,323,375,388,481,487,491,508,514$, $516,539,555,573,585,598,605,608,612$, $616,618,623,636,641,647$

Emigrant's Handbook, 171

Encephalomyelitis, 200

Epizootics, 65

Ergotism, 94, 164, 202
Essay on Sheep, 79

Essays on Field Husbandry, 59

Ethics, 381, 481, 578, 581, 625

\section{F}

Farcy, 37, 60, 103

Farm Animals, 161

Farmers' Almanack, 32

Farriers, 58, 72, 77, 90, 160

Farriers' Dispensatory, 61

Farrier's Magazine, 101, 107, 113, 231

Farriery Improved, 46

Fees, 174, 484

Flies, 6, 56

Folklore, 32

Food hygiene, 8, 22, 69, 88, 136, 175, 199, 239, $249,403,471$

Foot, unsoling, 38

Foot and mouth disease, 271, 331, 457, 531, 617

Foot rot, 142, 194, 199

Founder, 38, 51, 74

Fractures, 53, 73, 237

\section{G}

Gapeworms, 68, 117

Garget (mastitis), 10, 65

Gentleman's Farrier Repository, 46

Gentleman's Pocket Farrier, 45, 46

Geography of disease, 165,451

Gcorgia, University of, 658

Germ theory, 389

German,

Pennsylvania, 17, 30, 48, 57

books in, 45,48

Glanders, 37, 40, 103, 128, 160, 228, 252, 260 , $396,409,419$

Graham's Scientific Breeding School, 597

\section{H}

Harvard University, 324

Hatch Bill, 431, 434

- Haws, 62, 83, 130

Hernia, 155, 268

Hex Book, 29

History of Epidemics and Pestilential Disease, 24,66

Hog cholera, 41, 162, 263, 337, 445, 451, 530, $547,550,591$

Hollow horn, 71, 122, 130, 196, 198

Homeopathic Veterinary Manual, 211

Homeopathy, 208, 211

Horse

discases, 152

doctors, 19

shoeing, 99, 105, 160, 193, 49l

Horseman's Friend, 51

Hospitals, 152, 166

Humane socicties, 514

Husbandman's Guide, 60

\section{I}

Illinois, University of, 658

Indiana Veterinary College, 355

Indians

agriculture, 3,70

veterinary medicine, 4

Influenza (horse), 66, 70, 112, 156, 228, 234, 254,279

Insurance, 506, 627, 630

Iowa State University, $217,644,646,656$ 


\section{J}

Journal of Comparative Medicine and Surgery, 339, 346, 350, 393433,462

Journals. See specific title

Jungle, The, 408, 472

\section{K}

Kansas City Veterinary College, 552

Kansas State IJniversity, 657

Keystone Veterinary Association, 303, 368

King Ranch, 144

\section{L}

l.ameness, 177

Lampas, 130, 155, 203, 229, 465

Iay assistants, 620

Lay encroachment, 562, 568

Lecches (flukes), 172

Livestock insurance, 168, 263

Lockjaw. See Tetanus

London Vetcrinary College, 147, 275, 466

\section{M}

Mad itch, 132

Mallein, 422

Management and Diseases of the Dog, 50.4

Mange, 41, 106

Manure nuisance, 403, 409

Markham's Maister-peece, 34

Maryland Livestock Sanitary Board, 410

Massachusetts Cattle Commission, 410, 429

Massachusetts Society for Promoting Agriculturc, 57

Massachusetts State Agricultural Society, 206

Mastitis, 144, 250

Meat inspection. See Food hygiene

Medical Repository, 85

Merchant's Veterinary College, 289

Merino fever, 79

Michigan Farmer, 116, 169

Michigati, University of, 173

Michigan State Agricultural Society, 173

Michigan State University, 174, 658

Michigan State VMA, 369

Military veterinary medicine, $77,188,251$, $259,666,677$

Civil War, 667

cnlisted men, 675

food inspection, 22, 477, 669

legislation, $327,336,339,490,501,669,672$

mission, 677

National Guard officers, 675

Regular Army officers, 673

Reserve officcrs, 674

Spanish American War, 668

Veterinary Corps, 482, 547, 572, 579, 628, 637,670

veterinary sergcants, 667

veterinary surgeons, 668

War of 1812,660

war with Mexico, 667

World War I, 673, 676

Milk, adulteration of, $177,239,404$

Milk fever, 203, 497

Milk sickness, 136

Milking tubes, 145, 240

Minnesota, University of, 658

Missouri, University of, 659

Modern Horse Doctor, 216, 225

Modern System of Farriery, 97
Montreal Veterinary Association, 364

Montreal Veterinary College, 355

Mules, 75, 118

Murrain, 172

\section{$\mathbf{N}$}

Nachrichters, 45

National Board of Veterinary Examiners, 356, 372,621

National Livestock Journal, 271

National Veterinary Bureau, 325, 345, 354, $359,394,642$

Neurotomy, 201, 229, 363

New England Farmer, 137

New Treatise on the Diseases of the Horse, $34,46,66$

New York Agricultural College, 207

New York College of Veterinary Surgeons, $281,286,296,304,355,361,417$

New York People's College, 205

New York State VMA, 369, 549

New York State Veterinary Society, 364, 369

Nicking, 159

North American Veterinarian, 387, 449, 568

Nursing care, 64

Ohio AgricuItural College, 207

Ohio Cultivator, 138

Ohio State University, 355, 656

Oklahoma State University, 658

Ontario Veterinary College, 280, 355, 643, 656

Operating table, 523

Ophthalmia, 102, 272

Orange Judd Farmer, 563

Oxen, 118

\section{Parasitology, 582}

Patent remedies, 162, 187, 250

Pennsylvania, University of, 87, 147, 656

Pennsylvania College of Medicine, 234

Pennsylvania Medical College, 284

Pennsylvania State Agricultural Society, 234

Pennsylvania State VMA, 507

Pferde-Arzt, 45

Phi Zeta, 575

Philadelphia College of Medicine, 234

Philadelphia Society for Promoting Agriculture, 59, 81, 114, 135, 206, 286

Physicians, 59, 155, 163, 360

Pigs, prolificacy, 517

Pleurisy, 103

Plcuropneumonia, 262, 314, 405, 413, 426, $430,434,471$

Pneumonia, 156

Poll evil, 31, 51, 195

Poor Richard's Almanac, 45

Post-mortem, examination, 83, 164

Poultry diseases, 201, 534, 555, 575

Practical Horse Farrier, 99

Practical Stock Doctor, 72

Practice laws, 358, 366, 575

Prairie Farmer, 217, 252, 258

Preventive medicine, 62, 283, 361, 573

Professional advertising, 236, 253, 357, 417, 522

Prolapse, 98, 168

Public health, 19, 69, 178, 375, 388, 408, 559, $564,589,602,629,637$ 
Public relations, 536, 578, 583, 594, 597, 600, $602,606,626,628,630$

Purdue University, 659

Purging, 157

Quackery, 163, 169, 357, 370, 597, 624

Quebec Veterinary School, 656

\section{$\mathbf{R}$}

Rabies, 24, 53, 68, 70, 90, 92, 115, 126, 143 , $171,184,396,409,461,555$

Ringbone, 160

Rittenhouse College, 94

\section{$\mathbf{S}$}

Salivation of horses, 98,135

Salt, 17,166

School of Veterinary Medicine and Surgery (Boston), 245

Sheep

bots, 96

diseases, 76,166

increase, 13

pox, 142

rot, 141

scab, $79,170,264$

Shooter's Companion, 152

Short History of Veterinary Medicine in America, 94

Shoulder strain, 38

Slaughter, regulation, $8,21,70$

Slaughterhouses, I3, 21, I76, 472, 475

Small animal practice, 587,637

Sore tongue, 136

Spavin, 61, 102, 156, 161, 230

Spaying

cattle, 120, 224, 249, 252, 272, 313

dogs, 505

Specialization, $376,501,571,660$

Splints, 38

Spontaneous generation, 63,97

Staggers, 38, 41, 139, 157

State board examinations, 371,540

State veterinarians, 412

State veterinary medicine, 581, 599, 605, 612

Stomach tube, 163, 224, 509, 511

Strangles, I03

Stringhalt, 159, 250

Superstition, 27, 51, 62, 103, 210

Sweeny, 195, 251

\section{$\mathbf{T}$}

Tetanus, 41, 105, 129, 153

Texas A \& M College, 444, 658

Texas fever, $5,71,93,434,437,439,444,449$

Thumps, 141

Treatise on the Prevention of Diseases of Horses, 40, 62

Trichinosis, 264, 402

Tuberculosis, 339, 396, 405, 407, 467, 486, 490, $508,560,609$

Tuberculin test, 469

Tuskegee Institute, 658

\section{U}

United States Treasury Cattle Commission, 314

United States Veterinary Journal, 274, 329, 364,369

United States Veterinary and Livestock Journal, 271

United States Veterinary Medical Association, $215,286,295$. See also American Veterinary Medical Association

committees, 306

constitution and by-laws, 305

founders, 300

name change, 492, 508

membership, 304, 324, 335

objectives, 305

officers, 305

seal, 303,548

University of California, 659

University of Georgia, 658

University of Illinois, 658

University of Michigan, 173

University of Minnesota, 658

University of Missouri, 659

University of Pennsylvania, 87, 147, 656

Urine, 98, 190, 228

\section{V}

Verminous aneurism, 98

Veterinarian (London), 236, 286

Veterinarians, numbers, 216, 259, 553, 569 , $580,588,614,617,650$

Veterinary

books, 179

chiropractic, 554

colleges, 94, 101, 136, 278, 290, 314, 378, $538,568,642$

degrees (titles) $, 355,571,521,648$

economics, $537,585,610,624,628$

history, 238, 284, 321, 531, 536, 566, 575, $586,595,604,615$

Veterinary College of Philadelphia, 90, 284, $310,352,641$

Veterinary Dental Colleges, 378

Veterinary Institute of Chicago, 217

Veterinary Medicine, 283, 455, 526, 547

Veterinary medicine, Canada, 508 status, $71,107,344,351,354,372,479,539$, $558,598,629$

Veterinary Military History, 558

Vieh-Arzney-Buch, 45

\section{W}

Washington State University, 657

White snake root, 136

Witchcraft, 27, 82, 160

Wolf in the tail, 9, 72

Wolf teeth, 197, 204, 207

\section{$Y$}

Yellow water, 51, 84

$\mathbf{Z}$

Zoonoses, 423 


\section{Index of Names}

Ackerman, E. B., 558, 610, 622

Adams, J. W., $511,522,540,566,568$

Agassiz, J. L., 296

Aitken, W. A., 555, 567, 588, 607, 620, 621, 632

Allam, Mark, 617, 656

Allen, A. B., 161

Allen, Lewis, 71

Allen, R. L., 161, 176, 178

Amadon, R. S., 547, 604

Anderes, R. L., 631

Anderson, A. R., 593

Anderson, D. J., 633

Annis, E. R., 621

Arburua, J. M., 547, 550, 584, 586, 626

Archibald, R. A., 517, 520, 536, 539

Argall, Governor, 8

Armistead, W. W., 631, 658

Arnold, J. W. S., 361, 389, 645

Atkinson, V. T., $4 \mathbf{I} 4$

\section{B}

Bailey, G., 269, 331

Baker, A. H., 329, 365, 484, 541

Baker, A. W., 387

Baker, D. W., 607, 616

Baker, E. T., 387, 544, 555, 574, 578

Baker, J. A., 621

Baltimore, Lord, 12

Bang, Bernhard, 571

Banister, W. H., 300

Barlow, John, 268

Barnum, D. A., 618

Bartlett, J., 46

Bates, George, 428

Batt, H. T., 604

Baum, M. D., 617

Bayard, E. S., 546

Beach, J. R., 546, 593, 601

Beard, J. H., 560,564

Beardshear, W. H., 656

Beaudette, F. R., 547, 555, 575, 594, 598, 601, 616,620

Beer, Wm., 235

Belfield, W. T., 422

Bell, R. R., 497, 507, 508, 510, 534

Bemis, H. E., 538, 540

Benbrook, E. A., 574, 601

Bergh, Henry, 367, 396, 464

Bergman, H. D., 538, 607, 656

Berns, G. H., 357, 497, 514, 532, 598

Bierer, B. W., 94, 355, 609, 612

Biester, H. E., 571, 575

Bigelow, Jacob, 428
Billings, F. S., 326, 333, 335, 337, 343, 348, $398,399,405,447,454,462,481,505$

Birch, R. R., 538, 551, 587, 620

Birney, C. H., 300

Bland, Thomas, 335, 587

Blattenberg, J. H., 522

Bliss, F. J., 513

Blood, B. D., 616

Boerner, Fred, 573, 604

Borcherdt, Albert, 235

Bower, C. W., 551, 587, 601, 614, 627

Bostrom, A., 200

Boughton, I. B., 658

Bouley, Henri, 321, 390

Bourgelat, Claude, 316

Bowler, G. W., 235, 238, 285, 300, 307

Boyd, W. L., 551, 578, 587, 593, 614, 625, 658

Boyer, N. P., 283

Boynton, W. H., 587, 604

Bracken, Henry, 46

Bradford, Wm., 12

Brainard, Albert, 268

Brandly, C. A., 580, 587, 595, 598, 609, 610, 622,658

Brandt, Louis, 300

Breed, Frank, 587, 614

Brenton, S., 481, 521, 522, 553

Bridge, Francis, 414

Brimhall, S. D., 467

Brinker, W. O., 632

Britton, J. W., 619

Brooks, W. G., 551

Brown, F. H., 574

Brown, J. H., 595

Browne, Peter, 94

Browning, G. W., 382

Brumley, O. V., 55I, 557, 580, 598, 602, 604, 654,657

Brush, J. L., 415

Bryan, A. H., 565

Bryan, C. S., 658

Bryan, James, 234, 284

Bryant, J. B., 601

Bryden, Williamson, 322, 327, 328

Buchan, Wm., 41

Budd, A. C., 300

Budd, J. F., 300, 303, 310

Buel, Jesse, 95

Bullard, J. F., 556

Bullis, K. L., 612

Burden, Charles, 300, 307, 309, 313, 314, 315, $319,322,324,327,329,333,486$

Burdon, Wm., 45

Burnett, E. L., 587 
Burnett, S. H., 510, 520, 523

Burney, L. E., 629

Burnham, Walter, 313

Burt, J. H., 556

Busteed, John, 296, 300, 303, 309, 486, 642

Butler, J. S., 414

Butler, Tait, 334, 336, 379, 451, 489, 499, 500, $514,516,523,531,601$

Butler, W. J., 617

Byrne, John, 235

Cairy, C. A., 617

Cameron, A. E., 611, 619

Cameron, H. S., 609, 633

Cameron, T. W. M., 593

Campbell, Andrew, 162, 454

Campbel1, D. M., 299, 459, 478, 512, 529, 531, $534,537,538,547,549,558,562,564,566$, $587,591,602$. See also Merillat and Campbell

Cannon, R. V., 545

Carpenter, C. M., 546, 565, 567, 595, 614, 616

Carter, E. R., 574

Carver, James, 101, 107, 113, 142

Carver, William, 99

Cary, C. A., 481, 488, 501, 515, 522, 530, 544, $545,546,553,646,657$

Case, C. H., 598, 601

Chamberlain, F. W., 556, 658

Chaveau, Auguste, 483

Christensen, G. C., 656

Churchill, E. A., 632

Clark, Bracy, 128

Clark, C. F., 580, 609

Clark, John, 40, 62

Clay, Henry, 241

Clayton, C. E., 497

Clement, A. W., 328, 338, 340, 407, 411, 483, $496,498,508$

Clements, J., 101

Coates, W. J., 329

Cobo, Father, 7

Coffee, W. M., 622

Coffin, D. L., 619

Cofield, R. B., 587

Cohen, B. J., 467

Coleman, Edward, 128, 159

Coleman, Henry, 205

Columbus, Christopher, 4

Comar, C. L., 621

Connaway, J. W., 572, 602, 606

Cooper, C. M., 621

Cooper, T., 300

Coots, E., 235

Copeman, Arthur, 174, 235, 238, 242, 296, 299 , $300,307,308,309$

Corbyn, T. J., 284

Corlies, J. C., 362

Cosgrove, J. B., 333

Cotton, C. E., 538, 539, 541, 553, 619, 623, 672

Cotton, W. E., 551, 555, 593, 603, 616

Councilman, W. T., 407

Covault, C. E., 546

Crawford, A. B., 616

Cressy, N., 268

Crevecoeur, St. John de, 14, 436

Cross, Floyd, 547, 555, 580, 629, 657

Crowley, C. W., 558, 598

Crowley, W. J., 332, 366
Cuming, M. A., 139, 192, 195, 234, 235

Cunkelman, J. W., 617

Cunningham, C. H., 612, 622

Curtice, Cooper, 447, 449, 586, 636

Curtis, Robert, 297, 300, 309, 313

Cushing, E. R., 571

Custis, G. W. P., 142

Cutter, I. S., 447

\section{D}

Dadd, G. H., 113, 187, 198, 215, 295, 427, 641

Dadd, G. H., Jr., 217

Dale, Thomas, 7

Dalrymple, W. H., 466, 491, 497, 501, 514, 516, $517,520,533,542$

Dalton, J. C., 361, 467

Daniels, T. E., 329, 365

Daubigny, V. T., 656

Davenport, Eugene, 649

Davis, D. J., 566

Day, L. E., 540

DeCamp, C. E., 633

Deigendesch, Johann, 45

Delaplane, J. P., 614, 619

De Leon, Ponce, 5

De Schweinitz, E. A., 455

Desmond, J., 508

DeSoto, Hernando, 5

Detmers, H. J., 271, 331, 447, 454, 456, 481, 657

Detweiler, D. K., 633

DeVine, J. F., 522, 526, 538, 540

Dick, Charles, 22

Dick, G. A., 571, 656

Dickens, Charles, 18

Dikmans, Gerard, 620

Dilts, Jacob, 244, 287, 300, 310

Dimock, W. W. 536, 541, 567, 574, 583, 598, 604,613

Dinwiddie, R. R., 447, 449

Dixon, D. J., 333, 338

Donham, C. R., 578, 580, 587, 621

Dorset, Marion, 455, 551, 571, 593

Dougherty, William, 488, 506, 511, 604, 609

Doyle, L. P., 607

Dufresne, Joseph, 657

Dukes, H. H., 593, 604, 633

Dun, Peter, 426

Dunbar, Alexander, 311, 312

Duncan, C. H., 528

Duncan, J. T., 423

Dunn, R. C., 658

Durant, A. J., 580, 598, 659

Dykstra, R. R., 556, 567, 582, 584, 657

Dyson, O. E., 516

\section{E}

Easley, G. T., 633

Eastman, D. A., 587, 593

Edwards, P. R., 583

Edwards, W. C., 508

Eger, Alexander, 305

Ehmer, E. A., 556

Eichhorn, A., 422, 520, 526, 538, 540, 546, 551, $575,604,607,610,622$

Eliot, Jared, 59

Ellis, Charles, 602

Ellis, R. W., 531, 534

Elwyn, A. L., 286, 291

EmmeI, M. W., 594, 604 
Emmerson, M. A., 612, 620

Ernest, L. 13., 561

Erra Pater, 60

Essenwein, J. C., 300

Evans, F. B., 658

Evans, R., 235

Evans, W. A., 518

Eves, H. P., 621

\section{F}

Fairchild, D. S., 645

Farley, R., 300

Farmer Miles, 269, 273

Farquharson, James, 493, 601, 609, 614, 615, 621,622

Farrell, James, 239

Faulhaber, L. J., 595

Faust, John, 507

Faville, G. C., 362, 408, 414

Feldman, W. H., 574, 578, 632

Fenstermacher, R., 594, 604

Ferguson, A., 235

Ferguson, L. C., 609

Ferguson, T. H., 540, 541, 555, 579, 601, 614, 616

Fiehrer, Joseph, 122

Fincher, M. G., 567, 610, 626

Fink, J. W., 320

Finley, R. W., 316

Fischer, Paul, 558

Fish, P. A., 508, 514, 520, 534, 535, 542, 545, $571,575,578,657$

Fisher, L. E., 627

Fisher, Sirlney, 508

Fitch, C. P., 540, 541, 578, 580, 587, 593, 601

Fitzherbert, John, 98

Flagg, O. H., 300, 326, 486

Fleming, Gcorge, 26, 66, 127, 269, 275, 321, 349,422

Flexner, Simon, 435

Flynn, J. C., 524, 556, 586, 596, 600, 610

Foote, H. T., 418

Forwood, W. S., 361

Foster, J. P., 595

Foster, R. J., 551, 594, 600, 602, 603, 628

Foust, H. L., 6I 4, 6 I6

Fox, Charles, 173

Fox, Joseph, 78

Fraley, W. W., 235, 238, 284

Francis, Mark, 444, 445, 637, 658

Frank, E. R., 571, 580, 594, 601, 610, 612

Franklin, Benjamin, 45, 67

Frey, M. L., 507

Frick, E. J., 556, 583, 593, 619, 622

Frost, G. P., 551

Frost, J. N., 522, 556, 616

Fuller, R. C., 244, 245

Furbush, C. G., 672

\section{G}

Gamgee, John, 8, 310, 314, 416, 430, 437, 447

Garbutt, R. I., 576

Gardner, H. V., 282

Gassner, F. X., 607

Gay, Jarvis, 244

Gaylord, Willis, 97

Gerry, E. T., 367

Gerth, Julius, 329, 404, 414

Gibb, William, 244

Gibbons, Walter, 19
Gibson, William, 34, 61, 66, 284

Gilbert, Richard, 6

Gill, H. D., 489

Gillie, G. W., 625

Gilliland, S. H., 520, 536

Gilman, H. L., 628

Giltner, Ward, 514, 522, 536, 538, 55I, 555, $556,574,578,590,601,604,651,658$

Glover, G. H., 509, 520, 522, 531, 547, 574, 657

Good, E. S., 567

Googe, Barnaby, 9

Goldberg, S. A., 557

Goldhaft, A. D., 575

Gordon, Thomas, 235, 240

Gorgas, W. C., 672

Goss, L. J., 607

Goss, L. W., 571, 598, 607

Gould, Jay, 441

Graham, Robert, 538, 540, 546, 580, 658

Grange, E. A. A., 487, 540, 656

Greene, J. A., 657

Grice, C. C., 297

Grossman, J. D., 574

Groth, A. H., 659

Guard, S. R., 597, 619

Guard, W. F., 593, 601, 611

\section{H}

Hackenberger, F., 235

Hadley, F. B., 538, 547, 567, 580

Hadwen, Seymour, 520, 540

Hagan, W. A., 571, 574, 575, 583, 599, 605, $613,619,622,633,653,657$

Haigler, S. W., 574, 601

Hakluyt, Richard, 4

Hall, M. C., 449, 526, 541, 547, 551, 575, 578, $582,593,601,637$

Hallman, E. T., 536, 541, 555, 556, 558, 583, 604

Hanger, George, 116

Harbaugh, W. H., 465

Harbison, C. E., 621

Hardenbergh, J. G., 467, 551, 557, 578, 604, $609,621,631,632$

Harger, S. J. J., 489, 497

Haring, C. M., 518, 536, 556, 601, 604, 609, 659

Harkins, M. J., 573

Harkness, James, 235, 251, 442

Harlan, Richard, 98

Harrison, Robert, 329, 461, 489, 502

Hart, G. H., 368, 531, 538, 593, 601, 604, $612,619,625,659$

Harvey, Elwood, 443

Haslam, John, 115, 128, 130, 147, 159, $16 \mathrm{I}$

Hatch, K. L., 592

Hawkins, T. H., 461

Hayden, C. E., 604

Hays, S. M., 651

Hell, Henry, 562

Hersey, S. E., 623

Hewitt, E. A., 604

Higgins, C. H., 518, 540

Higgins, J. C., 280, 300

Hilty, Reuben, 573, 574

Hinman, D. B., 268

Hoard, Governor, 518

Hobbs, W. R., 657

Hobday, Frederick, 520, 565 
Hodson, Matthew, 34

Hohman, J. G., 30

Holcombe, A. A., 317, 321, 322, 324, 326, 356, $413,414,462$

Holm, G. C., 659

Holmes, J. C., 174

Hopkins, J. D., 316, 324, 333, 413, 414

Hopson, G. H., 604

Hornblower, W. H., 404

Hoskins, H. P., 490, 520, 534, 547, 549, 552, $572,595,601,602,607,623$

Hoskins, W. H., 301, 329, 338, 339, 340, 354 $368,404,478,481,489,507,511,536,543$. 545,636

Houck, U. G., 435, 447, 460, 471, 479

Howard, L. H., 332, 515, 532

Howard, Sanford, 169

Howard, S. R., 358

Huddleson, I. F., 546, 551, 555, 567, 578, 598, $607,609,614$

Hudson, C. B., 594

Hughes, D. A., 472, 510, 517, 521, 526, 532 536,669

Hughes, Joseph, 540, 549

Huidekoper, R. S., 87, 270, 331, 336, 338, 355, $464,482,523,636,656$

Hull, F. E., 598

Humphreys, Dr., 210, 300, 422

Hunt, E. M., 398

Hunter, John, 91, 221

Hurd, J. M., 513

Hurt, L. M., 631

Husman, A. A., 623

Hutchings, L. M., 616, 620, 659

Hutton, J. P., 556

\section{J}

Jacob, M., 315, 333, 542, 544, 602, 604, 613 Jakeman, H. W., 612

James, H. F, 363

Jasper, D. E., 659

Jefferson, George, 79

Jefferson, Thomas, 20, 24, 78

Jeffries, George, 34

Jenner, Edward, 142, 151

Jennings, Robert, 90, 235, 238, 257, 283, 295 . 299, 300, 30I, 307, 641

Jennings, Robert, Jr., 286

Jennings, W. E., 610, 619

Jensen, R., 657

Jewell, C. H., 514, 517

Johnson, C. W., 477, 669

Johnson, G. A., 602

Johnson, H. E., 556

Jones, F. S., 583, 593

Jones, T. C., 612, 619

Jones, T. J., 658

Jones, T. L., 656

Judd, Orange, 143, 262

Jungherr, Erwin, 610

\section{K}

Kaupp, B. F., 526, 534, 540

Keefer, G, 414

Kelley, W. H., 602

Kelser, R. A., 546, 551, 555, 578, 583, 593, 601 $607,611,656,683$

Kernkamp, H. C. H., 574, 580, 607, 609, 614, 658

Kester, W. O., 621, 630
Kidney, G. H., 368

Kiernan, J. A., 469, 567, 609

Kigin, L. C., 648

Kilborne, F. L., 447, 448, 586, 636

Killham, B. J., 74

King, Richard, 444

Kingma, F. J., 619

Kingman, H. E., 524, 547, 578, 594, 612, 617 , 627,632

Kingman, H. E., Jr., 61 1, 623, 629, 631

Kingrey, B. W., 659

Kinsley, A. T., 200, 456, 518, 520, 522, 526 $536,550,552,553,569,595$

Kitt, Theodore, 499

Klein, L. A., 510, 541, 571, 575, 622, 656

Klensch, J. P., 417

Klussendorf, R. E., 616, 621

Knisely, D. O., 512

Knowles, M. E., 499, 508, 511, 515

Kolmer, J. A., 572

Kooker, W. S., 244

Kral, Frank, 631, 633

Krill, W. R., 610, 616, 621, 626, 656

\section{$\mathbf{L}$}

Lacroix J. V., 525, 532, 564, 569, 571, 587, 613, 616

LaDue, H. J., 591

Langham, R. F., 604, 609, 616

Large, A., 300, 301, 310, 313, 315, 316

Law, James, 217, 271, 274, 281, 304, 321, 343, $396,414,430,432,443,454,456,468,489$, $497,514,515,531,538,548,636,641,641$, 657

Lawrence, Henry, 301, 307

Lawrence, John, 39

Leasure, E. E., 633, 657

L.ee, C. D., 601, 609, 610

Leslie, Frank, 239

I evine, P. P., 583, 614

Liautard, Alexandre, 240, 274, 278, 286, 291, $297,299,300,304,309,310,313,319,432$, $461,463,482,486,530,532,548,557,636$

I,ittle, R. B., 583, 593, 623

Livingstone, R. R., 79

Lockhart, A., 319, 567

Lombard, I. S., 311

Loveberry, C., 477, 669

Lowe, W. H., 334, 370, 388, 493, 497, 498, 508, 511,513

Luckey, D. F., 591, 614

Lumb, J. W., 583

Lydford, C. C., 482

Lyman, C. P., 319, 321, 322, 323, 488

Lyman, R. l'., 324, 343, 497, 511, 514, 517, $520,536,658$

Lynch, C. F., 526

Lytle, G. A., 477, 669

\section{$M$}

McAdory, T. S., 657

McAuliff, J. L., 633

McBryde, C. N., 455, 551, 575, 598

McCain, J. A., 632

McCallam, J. A., 617, 621, 627, 633

McClure, Robert, 195, 239, 267, 287, 289, 299 $300,30 \mathrm{I}, 307,437$

McCoun, W. T., 296, 300

McCoy, J. E., 657

McCurdy, J. A., 657 
McEachran, D. M., 321, 322, 343, 351, 391, $417,526,636,643$

McElroy, C. H., 659

M'Faydean, John, 602

McGrath, J. T., 633

McGilvray, C. D., 656

McInnes, Benjamin, 532, 558, 598

MacKellar, R. S., Sr., 500, 522, 576, 604, 623

McKeighan, James 273

McKenzie, J. C., 279

McKillip, G. B., 538, 540

McKillip, M. H., 102, 489, 511

Mckinney, W. H., 669

McLean, C. C., 363, 497, 541

McLean, Lachlan, 325, 327, 333, 334, 403, 405, 415

McLean, R. A., 404

McLellan, F. W., $5 \mathrm{I} 5$

McLeod, W. M., 571, 604

MacNalsb, A. L., 656

McNeil, J. H., 656

McNutt, G. W., 555

McNutt, S. H., 601, 629

Mack, W. B., 518, 520

Magens, H. H., 590

Magnus, Albertus, 31

Magrane, A. J., 562, 620, 630

Mangan, J. 1)., 529

Mankin, W. R., 300

Manthei, C. A., 621, 631

Markham, Gervase, 9, 34, 73

Marney, U. E., 445

Marsh, Hadleigh, $574,578,580,628$

Marsh, Joseph, 268

Marshall, C. J., 493, 507, 521, 522, 532, 537, $540,553,587,672$

Marshall, John, 656

Marstellar, R. P., 551, 658

Martin, W. J., 537

Mascall, Leonard, 39

Mason, A. S., 672

Mather, Cotton, 28

Maurer, Fred, 612

Mayer, F. J., 516

Maynard, S. D., 447

Mayo, C. W., 627

Mayo, N. S., 445, 497, 517, 522, 523, 536, 539, $541,546,549,550,558,571,583,610,621$, 622

Mease, James, 25, 81, 90, 123, 436

Mellor, G., 300

Melvin, A. D., 457, 469, 513, 517, 518, 520, 637

Merchant, I. A., 656

Merillat, E., 526

Merillat, L. A., 300, 481, 492, 493, 501, 509, $510,518,522,526,540,546,549,556,558$, $583,590,594,598,602,606,609,614,621$

Merillat and Campbell, 26, 62, 77, 188, 217, $225,240,242,274,276,280,311,314,341$, $345,448,489,498,534,558,595$

Metzger, H. J., 607, 609

Meyer, J. C., 261, 317, 323, 332, 366, 442, 489, 532,557

Meyer, J. C., Jr., 319, 336

Meyer, K. F., 520, 522, 593, 618

Michener, Charles, 317, 319, 326, 327, 329, 333, $335,336,338,340,3+3,347,394,415,418$, 481

Michener, Isaiah, 234, 235, 299, 300, 303, 313, $317,324,483,486,636$
Miles, Farmer, 269, 273

Milks, H. J., 516, 546, 551, 567, 583, 593

Millar, J. A. S., 601

Miller, A. V., 480

Miller, A. W., 613, 623

Miller, F. H., 571

Miller, F. W., 557

Miller, N. J., 626

Miller, William, 139

Miller, W. B. E., 324, 329, 331, 484, 511

Mills, John, 48

Mills, W. T., 503

Mink, Ezra, 275, 326, 355

Minor, Peter, 20

Misener, A. G., 626

Mitchell, John, 15

Mitchell, W. M., 593, 618

Mohler, J. R., 200, 422, 436, 457, 467, 470, 510 , $515,516,520,523,531,533,534,536,537$, $540,541,552,553,557,571,578,592,596$, $600,601,606,611,613,616,619,637,650$, 672

Moore, E. N., 610

Moore, E. V., 544

Moore, H., 195

Moore, G. R., 617

Moore, R. C., 510

Moore, V. A., 501, 508, 514, 516, 522, 536, 543, $551,553,567,575,657,672$

Moore, William, 595

Morris, Anthony, 147

Morris, C. D., 501

Morris, M. L., 587, 594, 607, 609, 611, 614, 617, 633

Morse, E. V., 659

Moulton, C. L., 363

Mullaly, John, 177

Mulligan, James, 300

Munce, T. E., 555, 575, 594

Munro, Alexander, 88

Munroe, Benjamin 235

Murphey, H. S., 532, 555

Murphy, J. M., 616

Murray, A. J., 369, 412

Murray, Charles, 546, 575, 593, 656

Myers, J. A., 468

\section{$\mathbf{N}$}

Nash, J. A., 192

Nash, Robert, 21

Nelson, S. B., 501, 523, 657

Nelson, Thomas, 466

Newell, Moses, 242

Newsom, I. E., 520, 547, 555, 580, 601, 657

Nichols, R. E., 593, 657

Nicholson, L. S., 235

Niles, E. P., 492

Niles, W. B., 455, 489, 509, 551, 601

Northway, J. F., 445

Norton, J. P., 184

Nostrand, E., 300, 314

Nostrand, Peter, 315

Nufer, Jakob, 121

Olafson, Peter, 607, 632

Ormsbee, R. W., 619

Orr, H. W., 659 
Osgood, F. H., 487, 489, 492

Osler, William, 328, 343, 364

Otis, G. S., 282

Ousley, Clarence, 551

Outerbridge, T., 326

Paaren, N. H., 256, 258, 271, 354, 373, 398, $413,414,417,420$

Palmer, E. H., 300, 307

Pammel, L. H., 526

Paquin, Paul, 414, 447

Parker, F. F., 601

Parker, J. M., 493, 497

Parker, J. W., 371

Parry, George, 244, 246

Partridge, J. M., 398

Pasteur, Louis, 390

Pater, Erra, 60

Patterson, F. D., 593, 658

Patton, J. W., 607

Peabody, C. H., 326, 362

Pearson, Leonard, 469, 488, 492, 497, 498, 499, $510,513,515,516,656$

Pearson, Raymond, 449, 570, 651, 652

Penn, William, 4, I7, 28, 57

Penniman, James, 300,486

Penny, P. J. C., 301

Percivall, William, 224, 229

Perroncito, Edoardo, 508

Perry, E. G., 454

Person, O. H., 629

Peters, Austin, 455, 492, 499, 514

Peters, A. T., 601

Peters, Peter, 316

Peters, Richard, 81

Philips, A., 300

Philips, Jacob, 300

Phillips, J. M., 511, 512

Pierce, W., 202, 235

Pilgrim, Charles, 297

Pomeroy, B. S., 604, 612

Poppensiek, G. C., 657

Pounden, W. D., 610

Pratt, H. B., 512

Prentice, F. W., 354

Price, A. A., 658

Price, D. A., 632

Pritchard, William, 275, 659

Proctor, D. L., 607, 621

Putnam, Lewis, 244, 246

Quin, A. H., 583, 620, 621, 622, 626, 628

Quitman, E. L., 510, 512, 520, 541, 548

\section{$\mathbf{R}$}

Ralston, J. C., 235

Ranck, E. M., 509

Randall, H. S., 268

Rauch, J. H., 421

Ravenel, M. P., 499

Raynor, J. B., 301, 486

Raynor, T. B., 301, 487

Rebrassier, R. E., 587, 604, 609, 632

Records, Edward, 547, 629

Renand, H. C., 282
Renick, J. O'B., 443

Repp, J. J., 501, 508

Reynolds, M. H., 489, 497, 510, 518, 540, 570

Rice, F. E., 414

Richardson, Thomas, 426

Richt, (Irwin), Helen, 537, 601

Rife, C. C., 567, 609, 612

Ring, Charles, 423

Ripley, E. F., 237, 244, 300

Riser, W. D., 6I6, 628

Roberts, M., 285

Robertson, J. L., 311, 313, 315, 324, 325, 326, $333,335,336,338,340,482,511$

Roderick, L. M., 574, 598

Roepke, M. H., 658

Rogers, Burton, 516

Rogers, Thomas, 404, 648

Rohlives, J. N., 53

Rose, W. H., 235

Ross, J. T., 368

Rush, Benjamin, 17, 25, 30, 69, 81, 86, 656

Rusk, J. M., 444, 483

Rutger, C. H., 282

Rutherford, J. G., 508, 514, 517, 518, 520

Rutherford, R., 195, 500

\section{$\mathbf{S}$}

Sales, E. K., 556, 593

Salmon, D. E., 335, 336, 337, 343, 373, 393, $394,400,414,431,434,443,454$, $466,468,472,482,492,494,531,636$

Salsbery, C. E., 587

Sampson, Jesse, 593

Sanders, J. H., 314, 431

Sanders, William, 235

Santa Maria, Luis, 546

Saunders, C. G., 526

Saunders, R. J., 316

Saunders, William, 300, 313, 315

Sayre, C. S., 376

Sayre, F. B., 85

Schalk, A. F., 547, 551, 574, 578, 601, 619

Schalm, O. W., 610, 619

Scheibler, J. W., 363

Scheidy, S. F., 633

Schlingman, A. S., 583,587

Schlotthauer, C. F., 467, 580, 583, 586, 594, $598,601,606,612,622$

Schmidt, Hubert, 598, 607

Schmidt, J. J., 574

Schneider, F. H., 536

Schnelle, G. B., 601, 609, 616

Schoefield, F. W., 618, 626

Schoening, H. W., 575, 607, 629

Schoenleber, F. S., 657

Schroeder, E. C., 447

Schroeder, E. F., 587

Schroeder, E. R., 598

Schroeder, F. C., 555

Schwarte, L. H., 587, 601

Schwartzkopf, Olof, 482, 489, 495, 521

Scott, George, 493

Scott, John, 235, 238, 284

Scrutton, Charles, 235

Seely, J. L., 235

Seeley, S. F., 6I I

Shaw, J. N., 578, 587

Shaw, Nathaniel, 34 
Sheets, F. F., 536

Shelden, Elisha, 78

Sherman, W. A., 515

Shillinger, J. E., 578, 601

Shipley, T. A., 475

Sholl, L. B., 556

Shope, R. E., 616

Sigler, T. A., 570, 573, 598, 612

Simmonds, William, 6,275

Simms, B. T., 480, 546, 556, 574, 578, 580, 618, 627

Sinclair, Upton, 472

Sisson, Septimus, 520, 648

Skidmore, D. I., 530

Skinner, J. S., 89, 114, 146, 149

Slade, D. D., 232, 242

Slade, J. G., 545

Smith, Andrew, 280, 352, 636, 656

Smith, Capt. John, 4, 6, 11

Smith, Frederick, 275

Smith, H. R., 547

Smith, J. E., 244

Smith, J. R., 398

Smith, Theobald, 447, 468, 481, 492

Smith, W. H., 169, 210

Snyder, Rudolph, 460

Somerville, William, 195, 235

Spilman, Thomas, 11

Spitzka, E. C., 433, 462

Stader, Otto, 587, 594, 603, 612, 637

Stafseth, H. J., 575, 578, 598, 620

Stalker, M., 414, 656, 644

Stange, C. H., 540, 546, 555, 556, 558, 578, $593,649,653,656$

Starkey, Marion, 27

Steele, J. H., 512, 519

Steffen, M. R., 529

Stein, A. W., 321

Stephenson, H. C., 593, 616

Stetson, Charles, 296

Stetson, Ezra, 453

Steuben, Baron, 78

Stewart, Henry, 373

Stewart, James, 408

Stewart, Sesco, 481, 489, 508, 520

Stickney, J. H., 299, 300, 305, 307, 313, 324, 486

Stiles, R. C., 441, 448

Stocker, C. H., 319

Stone, Andrew, 164

Stone, F. C., 657

Stone, W. S., 609

Stowell, S. B., 235

Stoy, Henry, 25

Stubbs, Evan, 557, 567, 593, 601

Sugg, R. S., 622, 657

Sykes, W. F., 513

\section{$\mathbf{T}$}

Taplin, William, 47

Tegtmeier, A., 235, 285

Thatcher, James, 140,145

Thayer, E. F., 235, 300, 307, 309, 310, 313, 32I, $343,410,428,636$

Thayer, F. L., 315

Theobald, A. R., 587

Thomas, W. A., 419

Thompson, J., 40
Thompson, W. O., 447

Thorpe, Frank, Jr., 580, 601, 607

Thorp, W. T. S., 610, 614, 616, 622, 658

Tierkel, E. S., 617

Todd, F. A., 620

Toms, C. S., 187

Torrance, Fred, 508, 518, 541, 542, 547, 553

Townshend, N. S., 272, 391

Traum, Jacob, 510, 538, 540, 593, 617, 631, 633

Trumbower, M. R., 317, 419

Tucker, Luther, 97, 207

Tufts, Cotton, 66, 71

Turner, J. P., 188, 497, 541, 546, 601, 610,

Turner, T. J., 487

Tusser, Thomas, 72

\section{U}

Udall, D. H., 540, 546, 601

Underwood, Daniel, 291

\section{V}

Van Doren, G. H., 282

Van Es, L., 50I, 512, 622, 625

Van Roekel, H., 593, 604, 610

Vawter, L. R., 547

Venzke, W. G., 601

Very, T. S., 316, 319, 321, 325

Volgenau, E. L., 384

Volkmar, Fritz, 456, 595

\section{W}

Wagener, Kurt, 580

Walker, E. R., Mrs., 542

Walker, Thomas, 23

Wallington, William, 121

Walton, J. F., 300, 313

Warburton, C. W., 592

Ward, A. R., 508

Ward, Robert, 414

Ward, S. H., 540

Ward, U. E., 446

Warwick, B. L., 567

Washburn, E. A., 174

Washington, George, 22, 24, 40, 56, 72

Way, Cassius, 514, 520, 594, 602, 605, 609, 610

Weaver, Richard, 147

Welbb, T., 203

Webster, L. T., 607

Webster, Noah, 24, 66

Wegner, E. E., 387, 546, 556, 574, 657

WeIch, W. H., 407, 408, 550, 553

Wells, J. R., 624

Welsh, Mark, 611

Wesley, J. 291

Wetmore, G. W., 268

Wheeler, H. C., 282

White, D. S., 546, 547, 549, 553, 568, 573, 652, 657,672

White, G. R., 501, 509, 511, 514, 521

White, James, 115, 128

White, J. H., 477

White, Mark, 386

White, T. P., 649

Wight, A. E., 594, 609, $6 \mathrm{I} 0$

Wilkes, George, 297

Williams, N. F., 580, 585, 587

Williams, T. S., 568 
Williams, W. L., 374, 377, 381, 387, 402, 423, $451,481,485,493,497,510,514,520,522$, $531,537,540,553,593,601,606,636,645$ Williams, W. W., 571

Wilson, A. T., 235

Wilson, R. H., 529

Winchester, J. F., 323, 4I4, 488, 501, 506, $51 \mathrm{I}$ Winslow, Edward, 12

Winter, Asa, 622

Winter, G. S., 45

Winthrop, Governor, 12

Wintringham, H. B., 547, 549

Wisclom, W., 287, 299, 300, 303, 310

Wisnicky, Walter, 610

Withers, J. J., 280

Witter, J. F., 583

Wood, Ebenezer, 235

Wood, C. M., 187, 197, 235, 237, 240, 242, 295, $297,299,300,301,307,308,313$

Wood, Robert, 204, 235, 236, 239, 242, 300, 310,313
Wray, W. H., 408

Wright, George, 128

Wright, Hiram, 188

Wyman, W. E. A., 498

Wynn, Thomas, 313

\section{$\mathbf{Y}$}

Yokura, H. T., 333

Youatt, William, 17, 180

Young, F. B., 626, 633

Young, G. A., 617, 625

Young, W. A., 576, 618, 623

\section{$\mathbf{Z}$}

7eissig, Alexander, 574, 594, 616, 620 Zepp, C. P., 571, 614, 616, 621

Zuill, William, 325

Zupp, B. A., 555 